\title{
EVOLUÇÃO CRUSTAL DA PLATAFORMA SUL AMERICANA, COM BASE NA GEOQUÍMICA ISOTÓPICA Sm-Nd
}

\author{
KEI SATO
}

Orientador: Prof. Dr. Unkerto Giusenpe Cu veri

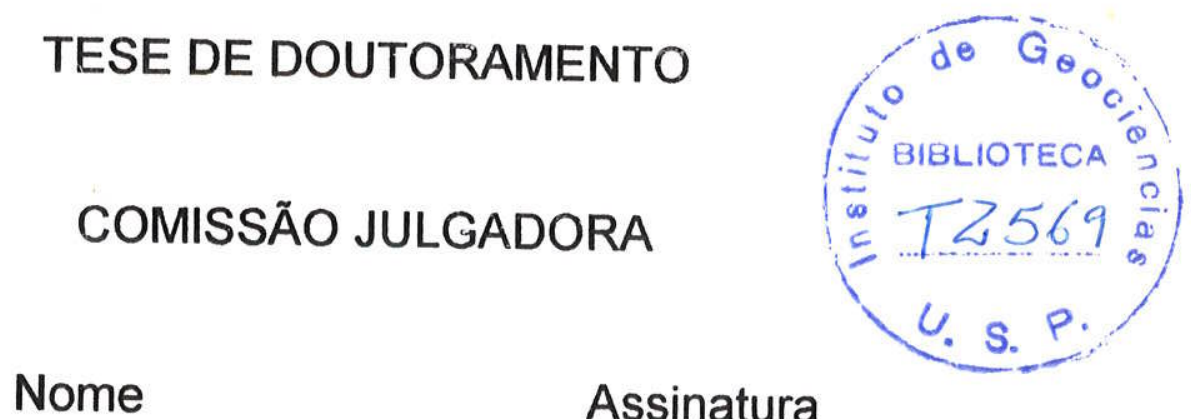

Presidente: Prof. Dr. Umberto Giuseppe Cordani

Examinadores: Prof. Dr. Benjamim Biey de Brito Neves

Prof. Dr. Marcio Martins Pimentel

Prof. Dr. Moacyr Moura Marinho

Prof. Dr. W. Randall Van Schrius

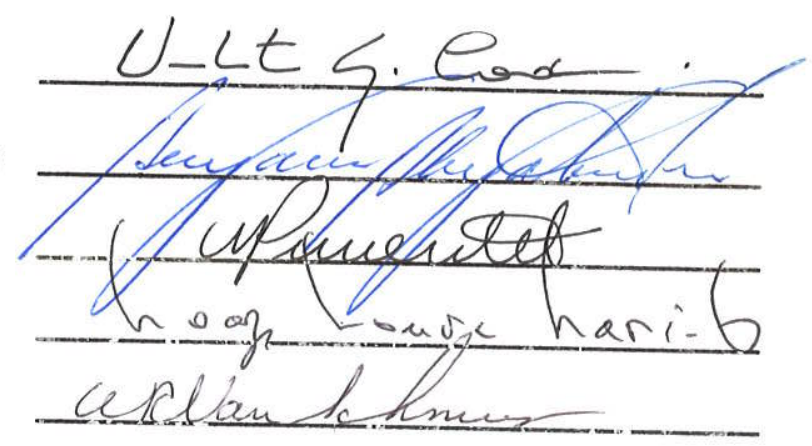

SÃO PAULO

1998 


\section{UNIVERSIDADE DE SĀO PAULO \\ INSTITUTO DE GEOCIENCIAS}

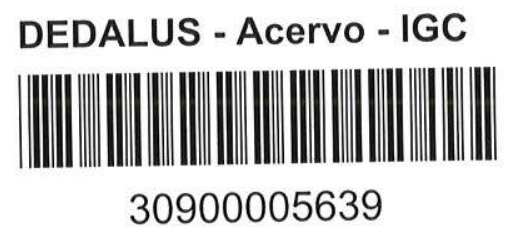

\section{“EVOLUÇĀO CRUSTAL \\ DA PLATAFORMA SUL AMERICANA, \\ COM BASE NA GEOQUIMIICA ISOTÓPICA Sm-Nd".}

Kei Sato

Orientador: Prof.Dr. Umberto Giuseppe Cordani

TESE DE DOUTORAMENTO

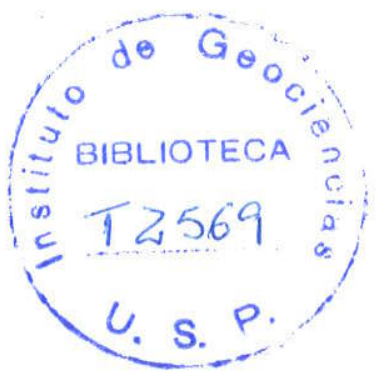

Programa de Pós-Graduação em Geoquímica e Geotectônica 
A minha querida esposa Laura

Tas filhos Eduardo 7. Sato

Mareas M. Sato

Nilson $ᄌ$, Sato

tos meus pais Maki Sato

Torayoshi Sato (in memórian) 


\section{AGRADECIMENTOS}

O autor externa seus mais sinceros agradecimentos a todos colegas que colaboraram direta ou indiretamente na realização deste trabalho.

Inicialmente ao orientador professor, Dr. Umberto G. Cordani pelas inúmeras sugestões e críticas construtivas recebidas durante a execução deste trabalho. Acrescente que o mesmo sempre esteve presente nos momentos mais difíceis da carreira profissional, desde a contratação em 1974 pelo CPGeo, quando era estudante de Física.

Sinceros agradecimentos são devidos também ao professor Dr. Oswaldo Siga. Jr. pela cuidadosa revisão do texto, e pelas inúmeras sugestões recebidas.

Agradecimentos são igualmente extensivos aos (às) professores (as) doutores (as) do Instituto de Geociências - USP e de outros Institutos, Colombo C. G. Tassinari, Enio Soliani Jr., Koji Kawashita, Wilson Teixeira, Benjamim B. de Brito Neves, Mário Campos Neto, Márcio M. Pimentel, lan McReath, Miguel A. S. Basei, Marly Babinski e Maria H. Macedo, pelas proveitosas discussões, e pelas sugestões recebidas de fundamental importância no desenvolvimento deste trabalho.

Os professores Doutores Gunter Lugmair (Univ. Califórnia S. Diego - La Jolla USA), R. W. Carlson (Carnegie Institution of Washington - USA), Riccardo Petrini (Istituto di Geocronologia e Geochimica Isotópica de Pisa - Itália), W. R. Van Schmus (Univ. de Kansas - USA) e Nuno Machado (Universidade de Quebec - Canadá), prestaram inestimável colaboração durante o desenvolvimento nas técnicas analíticas de Sm e Nd no CPGeo, em várias ocasiões, no periodo 1990-1994.

Muito obrigado aos colegas do Centro de Pesquisas Geocrológicas - Liliane A. Petronilho, Ivone K. Sonoki, Solange Lucena de Souza, Valéria Cristina S. R. Santos, Artur T. Onoe, Helen M. Sonoki, Walter M. Sproesser, Décio Duarte, Cláudio dos Santos, Mercedes D. Vergara, Vasco Antônio P. Silva e José Elmano Gouvéia (em memória), pela imensa colaboração recebida.

Gratidão especial é igualmente endereçada aos colegas do Inst. de Geociências - USP: Dalton Machado da Silva, Edmir de Oliveira, Claudionor Barbosa, José G. Neto e Henrique Martins - grafica; Jaime de Souza - fotografia; Claudio Hoppe - laminação; Rita P. Conde, Marcia C. Ponte - informática; e Reynaldo P. Castellon desenho. 


\section{SUMÁRIO}

AGRADECIMENTOS

ÍNDICE DE CAPITULOS

I

INDICE DE FIGURAS

II

ÍNDICE DE TABELAS

IV

RESUMO

$\mathrm{IX}$

ABSTRACT

XII

XIV

\section{CAPÍTULO 1}

INTRODUÇÃO / OBJETIVOS

\section{CAPÍTULO 2}

EVOLUÇÃO DA CROSTA TERRESTRE

2.1 - Nossa origem comum

2.2 - Formação do sistema solar

2.3 - Processos formadores de crosta terrestre, no tempo geológico

2.4 - Evolução da crosta continental

\section{CAPITULO 3}

METODOLOGIA

3.1- Princípios básicos da geocronologia 9

3.2- Geocronologia Sm-Nd 10

3.3 - Técnica de análise 13

3.4 - Cronograma de execução do presente trabalho 15

\section{CAPÍTULO 4}

SISTEMÁTICA INTERPRETATIVA Sm-Nd

4.1 - Generalidades

4.2 - Variação química no manto superior

4.3 - Utilização dos isótopos de Nd em petrogênese

4.4 - Datações geocronológicas pelo método $\mathrm{Sm}-\mathrm{Nd}$

4.5 - Idades modelo $\mathrm{Sm}-\mathrm{Nd}$ em estágio único

4.6 - Problemas na interpretação das idades modelo

4.7 - Cálculos de idades modelo em estágio duplo 


\section{CAPÍTULO 5}

DISCUSSÃO DOS RESULTADOS

5.1 - Antecedentes a respeito da evolução da Plataforma Sul Americana 33

5.2- Craton Amazônico 38

5.3 - Fragmento Cratônico Rio Apa 62

5.4 - Craton São Luis 66

5.5 - Faixas de Dobram. Paraguai-Araguaia / Tocantins / M. Coreau 68

5.6 - Craton São Francisco 76

5.7 - Domínio Borborema 121

5.8 - Dominio Jequitinhonha 151

5.9 - Complexo Goiás Central 171

5.10 - Domínio Uruaçu 189

5.11 - Domínio Brasilia 195

5.12 - Domínio Araxá - Alto Rio Grande 199

5.13 - Fragmentos Cratônicos Luis Alves e Rio de La Plata 214

5.14 - Fragmento Crustal Curitiba 228

5.15 - Domínios Paranaguá e Dom Feliciano 239

CAPÍTULO 6

CONSIDERAÇÕES FINAIS 263

REFERÊNCIAS BIBLIOGRAFICAS 278

\section{APÊNDICES}

Apêndice 1 - Nota explicativa das tabelas utilizadas no capítulo $5 \quad 291$ Apêndice 2 - Legenda das litologias encontradas nos trabalhos prévios. 292 Apêndice 3 - Técnicas de medidas isotópicas de Na no espectrômetro de 293 massa

Apêndice 4 - Espectrômetro de massa 


\section{ÍNDICE DAS FIGURAS}

Fig. Título

pág.

2.1 Taxa de produção de calor da Terra 5

3.1 Espectro de $\mathrm{Nd} \quad 11$

3.2 Espectro de $\mathrm{Sm} \quad 11$

4.1 Exemplo de evolução isotópica de Nd no tempo geológico 19

4.2 Diagrama de evolução isotópica de Nd. Definições de idades $T_{\text {CHUR }}$ e $T_{D M} 23$

4.3 Diagrama $\varepsilon_{\mathrm{Sr}} \times \varepsilon_{\mathrm{N}_{d}}-$ Variação isotópica do manto 26

$\begin{array}{lll}4.4 & \text { Diagrama de mistura } & 28\end{array}$

4.5 Exemplo de evolução isotópica de $\mathrm{Nd}$, segundo modelo de estágio duplo 31

5.1-1 Curva de crescimento da crosta continental no tempo geológico 34

5.1-2 Compartimentação geotectônica da Plataforma Sul Americana 35

5.2-1 Mapa geológico do Craton Amazônico 40

5.2-2 Histograma de idades Rb-Sr das Províncias Ventuari-Tapajós e Rio Negro Juruena 41

5.2-3 Mapa de localização das amostras datadas no Craton Amazônico 43

5.2-4 Diagrama de evolução isotópica de $\varepsilon_{\mathrm{Nd}}$ - Provincia Amazonas Central 44

5.2-5 Diagrama $\varepsilon_{\mathrm{Sr}} \times \varepsilon_{\mathrm{Nd}}$ - Província Amazonas Central 44

5.2-6 Diagrama de evolução isotópica de $\varepsilon_{\mathrm{Nd}}$ - Província Maroni - Itacaiunas 45

5.2-7 Diagrama $\varepsilon_{\mathrm{Sr}} \times \varepsilon_{\mathrm{Nd}}-$ Província Maroni - Itacaiunas 45

5.2-8 Isócrona Sm-Nd - Província Maroni - Itacaiunas 48

5.2-9 Diagrama de evolução isotópica $\varepsilon_{\mathrm{Nd}}$ - Províncias Ventuari-Tapajós e R. Negro Juruena $\quad 48$

5.2-10 Diagrama $\varepsilon_{\mathrm{Sr}} \times \varepsilon_{\mathrm{Nd}}-$ Província Ventuari - Tapajós 49

5.2-11 Diagrama $\varepsilon_{\mathrm{S}} \times \varepsilon_{\mathrm{Nd}}-$ Provincia Rio Negro - Juruena 49

5.2-12 Diagrama de evolução isotópica de $\varepsilon_{\mathrm{Nd}}$ - Provincias Rondonianas -S.
Ignácia e Sunsás

5.2-13 Histograma de idades modelo $\mathrm{Sm}-\mathrm{Nd}\left(\mathrm{T}_{D \mathrm{DM}}\right)$ das areias fluviais do Rio Madre de Dios $\quad 50$

5.2-14 Histograma dos principais eventos de acreção do Craton Amazônico 51

5.3-1 Mapa geológico simplicado do fragmento Cratònico Rio Apa 64

5.3-2 Diagrama de evolução isotópico de $\varepsilon_{\mathrm{Nd}}-$ Rio Apa 65

5.4-1 Mapa geológico simplicado do Craton São Luis 67

5.5-1 Compartimentação tectônica da Provincia Paraguai-Araguai / Tocantins 71

5.5-2 Mapa geológico simplicado da porção setentrional da Faixa de Dobram. Paraguai-Araguai / Tocatins 72

5.5-3 Diagrama de evolução isotópica de $\varepsilon_{\mathrm{Nd}}$ - F. Paraguai-Araguaia/Tocantins 73

5.6-0 Mapa geológico simplicado do Craton São Francisco 78

5.6-1 Craton de S. Francisco - Mapa de localização aproximada das amostras datadas 79

5.6-2 Diagrama de evolução isotópico de $\varepsilon_{\mathrm{Nd}}$ - rochas granitóides do Complexo Contendas-Mirante $\quad 82$

5.6-3 Diagrama $\varepsilon_{\mathrm{Sr}} \times \varepsilon_{\mathrm{Nd}}$ - rochas granitóides do Complexo Contendas-Mirante 82

5.6-4 Diagrama de evolução isotópico de $\varepsilon_{\mathrm{Nd}}$ das rochas vulcano-sedimentares do Complexo Contendas-Mirante 83

5.6-5 Diagrama $\varepsilon_{\mathrm{Sr}} \times \varepsilon_{\mathrm{Nd}}$ - rochas vulcânicas do Compl. Contendas-Mirante 83

5.6-6 Diagrama de evolução isotópico de $\varepsilon_{\mathrm{Nd}}$ das rochas intrusivas do 
5.6-8 Diagrama de evolução isotópico de $\varepsilon_{\text {:d d }}$ das rochas do Bloco Gavião e da região de Jacobina

5.6-9 Diagrama $\varepsilon_{\mathrm{sr}} \times \varepsilon_{\mathrm{Nd}}$ das amostras da região de Jacobina e do Bloco de Gavião

5.6-10 Isócrona de referência $\mathrm{Sm-Nd}$ (rocha total) das rochas granuliticas do Complexo Jequié

5.6-11 Diagrama de evolução isotópico de $\varepsilon_{\mathrm{Nd}}$ das rochas granulíticas do Complexo Jequié

5.6-12 Diagrama $\varepsilon_{\mathrm{Sr}} \times \varepsilon_{\mathrm{Nd}}$ das rochas granuliticas do Complexo Jequié

5.6-13 Diagrama $\varepsilon_{\mathrm{Nd}}$ versus tempo geológico $\mathrm{T}(\mathrm{Ga})$ das amostras da região de Lagoa Real

5.6-14 Diagrama $\varepsilon_{\mathrm{Sr}} \times \varepsilon_{\mathrm{Nd}}$ das rochas grranitóides da região de Lagoa Real

5.6-15 Mapa geológico simplicado da região Sul do Craton do S. Francisco

5.6-16A Diagrama $\varepsilon_{\mathrm{Nd}}$ versus tempo geológico $\mathrm{T}(\mathrm{Ga})$ das rochas granitóides e básicas de Bonfim (Belo Horizonte - MG)

5.6-16B Diagrama $\varepsilon_{\mathrm{Nd}}$ versus tempo geológico $\mathrm{T}(\mathrm{Ga})$ das rochas granitóides e básicas do Complexo Campo Belo (Belo Horizonte - MG)

5.6-16C Diagrama $\varepsilon_{\mathrm{N} d}$ versus tempo geológico $\mathrm{T}(\mathrm{Ga})$ das rochas granitóides do Cinturão Mineiro

5.6-17 Diagrama $\varepsilon_{\mathrm{Sr}} \times \varepsilon_{\mathrm{Nd}}$ das rochas granitóides da região meridional do Craton São Francisco

5.6-18 Diagrama $\varepsilon_{\mathrm{Nd}}$ versus tempo geológico $\mathrm{T}(\mathrm{Ga})$ das rochas granitóides e vulcânicas da região nordeste do Craton $\mathrm{S}$. Francisco

5.6-19 Diagrama $\varepsilon_{\mathrm{Nd}}$ versus tempo geológico $\mathrm{T}(\mathrm{Ga})$ das rochas granulíticas da região de Salvador-Itabuna

5.6-20 Diagrama $\varepsilon_{\mathrm{Sr}} \times \varepsilon_{\mathrm{Nd}}$ das rochas nordeste do Craton $S$. Francisco

5.6-21 Diagrama $\varepsilon_{\mathrm{Nd}}$ versus tempo geológico $\mathrm{T}(\mathrm{Ga})$ das rochas granitóides da região de Correntina - Mansidão.

5.7-1 Mapa geológico simplificado da Provincia Borborema

5.7-2 Mapa de localização aproximada das amostras datadas pelo método Sm$\mathrm{Nd}$ - Provincia Borborema

5.7-3 Diagrama de evolução isotópica $\varepsilon_{\mathrm{Nd}}$ no tempo geológico das rochas granitóides e básicas do Maciço Rio Piranhas

5.7-4 Diagrama de evolução isotópica $\varepsilon_{\mathrm{Nd}}$ no tempo geológico das rochas plutônicas brasilianas do Maciço Rio Piranhas

5.7-5 Diagrama de evolução isotópica $\varepsilon_{\mathrm{Nd}}$ no tempo geológico das rochas granitóides e granuliticas do embasamento do Maciço Caldas Brandão

5.7-6 Diagrama de evolução $\varepsilon_{\mathrm{Sr}}$ versus $\varepsilon_{\mathrm{Nd}}$ das rochas granitóides do Maciço Caldas Brandão

5.7-7 Diagrama de evolução isotópica $\varepsilon_{\mathrm{Nd}}$ no tempo geológico das rochas granitóides e básicas da Faixa Seridó

5.7-8 Diagrama de evolução isotópica $\varepsilon_{\mathrm{Nd}}$ no tempo geológico das rochas granitóides e vulcânicas ácidas da Faixa Seridó

5.7 -9 Diagrama de evolução $\varepsilon_{\mathrm{Sr}}$ versus $\varepsilon_{\mathrm{Nd}}$ - Faixa Seridó

5.7-10 Diagrama de evolução isotópica $\varepsilon_{\mathrm{Nd}}$ no tempo geológico das rochas granitóides do embasamento da Faixa de Dobr. Pajeú-Paraíba

5.7-11 Diagrama de evolução isotópica $\varepsilon_{\mathrm{Nd}}$ no tempo geológico das rochas 
plutônicas brasilianas da Faixa Dobrada Piancó - A. Brígida

5.7-12 Diagrama de evolução isotópica $\varepsilon_{\text {Nd }}$ no tempo geológico das rochas granitóides da Linha Sienitóide (Alto Teixeira)

5.7-13 Diagrama de evolução isotópica $\varepsilon_{\mathfrak{N}}$ no tempo geológico das rochas granitóides do Maciço Pernambuco Alagoas

5.7-14 Diagrama de evolução isotópica $\varepsilon_{\mathrm{Nd}}$ no tempo geológico das rochas granitóides da Faixa de Dobramento Sergipana

5.7-15 Diagrama de evolução isotópica $\varepsilon_{\mathrm{Nd}}$ no tempo geológico das rochas granitóides da Faixa de Dobramento Riacho do Pontal

5.7-16 Diagrama de evolução $\varepsilon_{\mathrm{Si}}$ versus $\varepsilon_{\mathrm{i} d}$. Faixa de Dobram. Riacho do Pontal / Rio Preto

5.7-17 Diagrama de evolução isotópica $\varepsilon_{N d}$ no tempo geológico das rochas granuliticas e granitóides da região Santa Quitéria, Tróia e Jaguaribe

5.7-18 Diagrama de evolução $\varepsilon_{\mathrm{Sr}}$ versus $\varepsilon_{\mathrm{N} d}$. Porção Norte da Prov. Borborema

5.7-19 Principais dominios de acreção manto-crosta continental da Província Borborema

5.8-1 Unidades tectônicas do Domínio Jequitnhonha

5.8-2 Mapa de localização aproximada das amostras datadas pelo método Sm$\mathrm{Nd}$ - Domínio Jequitinhonha

$5.8-3$

Diagrama $\varepsilon_{\aleph_{d}}$ versus tempo geológico - Guanhães.

5.8-4 Diagrama $\varepsilon_{\text {: }}$ versus tempo geológico - Mantiqueira 155

5.8-5 Diagrama $\varepsilon_{\text {. }}$ versus tempo geológico - Juiz de Fora 158

5.8-6 Diagrama $\varepsilon_{\mathrm{id}}$ versus tempo geológico - Embu 158

5.8-7a Diagrama $\varepsilon_{\mathrm{Xd}}$ versus tempo geológico - Costeiro (NE de S. Paulo) 159

5.8-7b Diagrama $\varepsilon_{\Upsilon d}$ versus tempo geológico - Costeiro (região de S. Paulo) 159

5.8-8 Diagrama $\varepsilon_{i d}$ versus tempo geológico - Aracuai 162

5.8-9 Diagrama $\varepsilon_{\mathrm{Sr}}$ versus $\varepsilon_{\mathrm{Nd}}-$ Embu e Costeiro 162

5.8-10 Diagrama $\varepsilon_{\mathrm{Sr}}$ versus $\varepsilon_{\mathrm{N} d}$ - Guanhães, Mantiqueira, Juiz de Fora e Costeiro (NE de S. Paulo) 163

5.8-11 Histograma das idades modelo Sm-Nd $\left(\mathrm{T}_{\mathrm{DM}}\right)$ - Domínio Jequitinhonha 163

5.9-1 Compartimentação tectônica da região Centro-Oeste do Brasil 173

5.9-2 Mapa geológico simplificado da porção Centro-Oeste do Brasil $\quad 174$

5.9-3 Localização aproximada das amostras datadas pelo método Sm-Nd Porção Centro - Oeste do Brasil

5.9-4 Diagrama isocrônico Sm-Nd da região de Crixás - Hidrolina 176

5.9-5 Diagrama $\varepsilon_{\mathrm{Nd}}$ versus tempo geológico - região de Crixas-Hidrolina 176

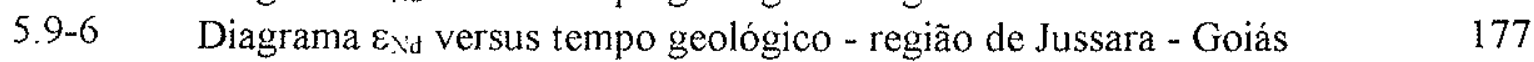

5.9-7 Diagrama $\varepsilon_{\mathrm{Nd}}$ versus tempo geológico - região de Iporá-ArenópolisRibeirão

5.9-8 Histograma das idades modelo $\mathrm{Sm}-\mathrm{Nd}\left(\mathrm{T}_{\mathrm{DM}}\right)$ - região de lporá 180

5.9-9 Diagrama $\varepsilon_{\mathrm{Sr}}$ versus $\varepsilon_{\mathrm{Nd}}$ - Goiás - Central 181

5.10-1 Diagrama $\varepsilon_{: \backslash d}$ versus tempo geológico - complexo Canabrava 191

5.10-2 Isócrona $\mathrm{Sm}-\mathrm{Nd}$ das rochas ultrabásicas e básicas do complexo Canabrava 191

5.10-3 Diagrama $\varepsilon_{\mathrm{Nd}}$ versus tempo geológico - complexo Niquelândia 193

5.11 Diagrama $\varepsilon_{\text {. }}$ versus tempo geológico - Domínio Brasília 196

5.12-1 Mapa geológico simplificado com localização das amostras datadas -

Dominio Araxá

5.12-2 Diagrama isocrônico $\mathrm{Sm} * \mathrm{Nd}$ das rochas granulíticas da região AnápolisGoiânia 
5.12-3 Diagrama $\varepsilon_{\text {Ni versus tempo geológico - Dominio Araxá }} 202$

5.12-4A Mapa geológico simplificado com principais cidades - FARG E NESG 203

$\begin{array}{lll}\text { 5.12-4B } & \text { Mapa de localização aproximada das amostras datadas -Faixa Alto Rio } & \\ \text { Grande / Nappe de Empurrão Socorro - Guaxupé } & 203\end{array}$

5.12-5 Diagrama $\varepsilon_{\backslash \mathrm{Y}}$ versus tempo geológico - Faixa Alto Rio Grande/Nappe de empurrão Socorro-Guaxupé

208

5.12-6 Diagrama $\varepsilon_{\mathrm{Sr}}$ versus $\varepsilon_{\mathrm{Na}}$ - Araxá, NESG e FARG 208

5.13-1 Compartimentação geotectônica da região Sul da Plataforma Sul

5.13-2 Compartimentação geotectônica da porção SE de Paraná e SE de S.

Catarina e localização aproximada das amostras datadas pelo método Sm-

$\mathrm{Nd}$ do Frag. Cratônico Luis Alves

5.13-3A Mapa geológico simplificado do Escudo do Rio Grande do Sul 218

5.13-3B Principais cidades chamadas no texto e localização aproximada das
amostras datadas pelo metodo Sm-Nd. Escudo do Rio G. do Sul

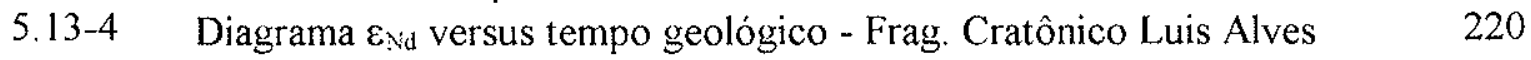

5.13-5 Diagrama $\varepsilon_{\mathrm{Sr}}$ versus - $\varepsilon_{\mathbb{N} d}$ - Fagramento Cratônico Luis Alves 220

5.13-6 Diagrama isocrônico $\mathrm{Sm-Nd}(\mathrm{RT})$ das amostras ultrabásicas localizadas próxima à cidade de Piên

5.13-7 Diagrama $\varepsilon_{\mathrm{Nd}}$ versus tempo geológico - rochas ultramáficas de Piên $\quad 221$

5.13-8 Digrama isocrônico Sm-Nd (minerais) - Domínio Luis Alves 224

5.13-9 Diagrama $\varepsilon_{\mathrm{Nd}}$ versus tempo geológico dos minerais separados da rocha granulitica - Dominio Luis Alves

5.13-10 Diagrama $\varepsilon_{\mathrm{Nd}}$ versus tempo geológico das rochas granitóide do Bloco Taquarembó

5.13-11 Diagrama $\varepsilon_{\mathrm{Nd}}$ versus tempo geológico das rochas granitóides do Bloco São Gabriel

5.13-12 Diagrama $\varepsilon_{\mathrm{Sr}}$ versus - $\varepsilon_{\mathrm{Nd}}$ - Bloco São Gabriel 227

5.14-1 Mapa geológico simplificado e localização aproximada das amostras datadas da Faixa Itaiacoca (Paraná)

5.14-2 Diagrama evolução isotópica $\varepsilon_{\mathbb{N}}$ versus tempo geológico das rachas granitóides das Faixas Itaiacoca e São Roque

5.14-3 Diagrama evolução isotópica $\varepsilon_{\mathrm{Sr}}$ versus $\varepsilon_{\mathrm{Nd}}$ - Granitóides dos Complexos Itaiacoca e Faixa São Roque

5.14-4 Diagrama evolução isotópica $\varepsilon_{\mathrm{Nd}}$ versus tempo geológico - vulcânicas do Grupo Itaiacoca

5.14-5 Diagrama evolução isotópica $\varepsilon_{\mathrm{Sr}}$ versus $\varepsilon_{\mathrm{Nd}}-$ Vulcânicas do Grupo Itaiacoca

5.14-6 Diagrama evolução isotópica $\varepsilon_{\mathrm{Nd}}$ versus tempo geológico das rochas granitóides do Domínio Curitiba

5.14-7 Isócrona mineral Sm-Nd - Domínio Curitiba 235

5.14-8 Diagrama evolução isotópica $\boldsymbol{\varepsilon}_{\mathrm{Nd}}$ (em minerais) versus tempo geológico Dominio Curitiba

5.14-9 Diagrama evolução isotópica $\varepsilon_{\mathrm{Sr}}$ versus $\varepsilon_{\mathrm{Nd}}$ - Domínio Curitiba 236

5.14-10 Localização aproximada das amostras datadas pelo métod Sm-Nd.

Domínios Curitiba e Paranaguá

5.15-1 Diagrama evolução isotópica $\varepsilon_{\mathrm{Nd}}$ versus tempo geológico das rochas granitóides do Dominio Paranaguá

5.15-2 Diagrama evolução isotópica $\varepsilon_{\mathrm{Sr}}$ versus $\varepsilon_{\mathrm{Nd}}-$ Domínio Paranaguá 
5.15-3 Principais cidades e localização aproximada das amostras datadas pelo método $\mathrm{Sm}-\mathrm{Nd}$ no Escudo do Rio Grande do Sul

5.15-4 Mapa geológico simplificado do Domínio Dom Feliciano - Santa Catarina

5.15-5 Diagrama evolução isotópica $\varepsilon_{\backslash \text { id }}$ versus tempo geológico das rochas

5.15-6 Dranitóides do Domínio Dom Feliciano (Faixa Tijuca) - Santa Catarina granitóides do Dominio Dom Feliciano (Faixa Tijuca)- Rio Grande do Sul 244

5.15-7 Diagrama evolução isotópica $\varepsilon_{\aleph_{i d}}$ versus tempo geológico das rochas granitóides do Domínio D. Feliciano - Batólito de Pelotas- Santa Catarina 245

5.15-8 Diagrama evolução isotópica $\varepsilon_{\mathrm{Nd}}$ versus tempo geológico. Batólito de Pelota e Encruzilhada do sul (RS)

5.15-9 Diagrama evolução isotópica $\varepsilon_{\text {Nd }}$ versus tempo geológico. Integração dos dados das figuras 5.15-7 e 5.15-8

5.15-10 Resumo dos principais dominios de acreção manto-crosta continental. Dominio Dom Felciano

6.1 Histograma da acreção de crosta juvenil da Plataforma Sul Americana no tempo geológico

6.2 Curva de crescimente da crosta continental juvenil da Plataforma Sul

Americana

6.3 Principais domínio de acreção manto-crosta continental

6.4 Histograma da acreção de crosta juvenil no tempo geológico relativo a porção NW do Lineamento Transbrasiliano.

6.5 Histograma da acreção de crosta juvenil no tempo geológico relativo a porção SE do Lineamento Transbrasiliano.

6.6 Taxa de crescimento setorial para as crostas continentais separadas pelo lineamento Transbrasiliano.

6.8 Diagrama $\varepsilon_{\mathrm{Nd}} \times \mathrm{T}(\mathrm{Ga})$. Evolução isotópica de $\varepsilon_{\mathrm{Nd}}$ no tempo geológico em rochas granitóides selecionadas (tipo TTGs) da Plataforma Sul Americana 


\section{ÍNDICE DE TABELAS}

TAB. Título

3.1 Medidas das razões isotópicas nos padrões de La-Jolla e BCR-1

3.2 Concentrações de Sm e Nd obtidas por técnica de diluição isotópica - Padrão $\mathrm{BCR} 1$

4.I Concentrações médias de Sm e Nd - (Faure 1988 modificado)

4.2 Valores de $\varepsilon_{\mathrm{Nd}}$ nos diferentes ambientes geoctectônicos

CRATONS AMAZÔNICO - SÃO LUIS - RIO APA E FAIXA PARAGUAIARAGUAIA / TOCANTINS

5.2-1 Dados Sm e Nd das rochas da Província Amazônia Central 53

5.2-2 Dados Sm e Nd das rochas da Provincia Maroni - Itacaiunas 55

5.2-3 Dados Sm e Nd das rochas da Provincia Ventuari - Tapajós 56

5.2-4 Dados Sm e Nd das rochas da Província Rio Negro - Juruena 58

5.2-5 Dados Sm e Nd das rochas da Prov. Rondoniana- S. Ignácia / Sunsás 59

5.2-6 Idades modelo em areias fluviais de Madre Dios - região da Prov. Sunsás 61

5.3 Dados Sm e Nd das rochas do Fragmento Cratônico Rio Apa 63

5.4 Dados Sm e Nd das rochas do Craton São Luis 66

5.5 Dados Sm e Nd das rochas da Faixa de dobram. Paraguai-Araguaia /

Tocantins / Dominio Médio Coreaú $\quad 74$

CRATON SÃO FRANCISCO

5.6-1 Dados Sm e Nd das rochas do Complexo Contendas-Mirante (embasamento) 106

5.6-2 Dados Sm e Nd das rochas do Complexo Contendas-Mirante (sequência vulcano sedimentar)

5.6-3 Dados Sm e Nd das rochas do Complexo Contendas - Mirante (granitóides intrusivos)

5.6-4 Dados Sm e Nd das rochas do Bloco Gavião / Jacobina 110

5.6-5/6 Dados Sm e Nd das rochas do Complexo Jequié (embasamento) 112

5.6-7 Dados Sm e Nd das rochas do Complexo Jequié (supra - crustais) 113

5.6-8 Dados Sm e Nd das rochas da Região de Lagoa Real / Riacho de Santana 114

5.6-9A Dados Sm e Nd das rochas dos Complexos Bonfim, C. Belo e B. Horizonte 115

5.6-9B Dados Sm e Nd das rochas do Grupo Bambuí (Região de Minas Gerais) $\quad 118$

5.6-10A Dados Sm e Nd das rochas da região NE do Craton São Francisco 118

5.6-10B Dados Sm e Nd das rochas da região Salvador - Itabuna 119 
5.6-11 Dados Sm e Nd das rochas da região Oeste de Craton São Francisco PROVÍNCIA BORBOREMA

5.7-1 Dados Sm e Nd das rochas do Maciço Rio Piranhas 139

5.7-2 Dados Sm e Nd das rochas do Maciço Caldas Brandão $\quad 140$

5.7-3 Dados Sm e Nd das rochas da Faixa Seridó $\quad 140$

5.7-4 Dados Sm e Nd das rochas da Faixa Dobrada Pianco-A.Brigida $\quad 142$

5.7-5 Dados Sm e Nd das rochas da Faixa Dobrada Pajeú - Paraiba 143

5.7-6 Dados Sm e Nd das rochas do Maciço Pernambuco-Alagoas 145

5.7-7 Dados Sm e Nd das rochas da Faixa Dobrada Sergipana 146

5.7-8 Dados Sm e Nd das rochas da Faixa Dobrada Riacho do Pontal 147

5.7-9 Dados Sm e Nd das rochas da Faixa Dobrada Rio Preto 147

5.7-10 Dados Sm e Nd das rochas do Domínio Ceará 148 DOMINIO JEQUITINHONHA

5.8-1 Dados Sm e Nd das rochas do Sub-Dominio Guanhães 165

5.8-2 Dados Sm e Nd das rochas do Sub-Dominio Mantiqueira 165

5.8-3 Dados Sm e Nd das rochas do Sub-Dominio Juiz de Fora 166

5.8-4 Dados Sm e Nd das rochas do Sub-Domínio Embu 166

5.8-5 Dados Sm e Nd das rochas do Sub-Domínio Araçuaí 167

5.8-6 Dados Sm e Nd das rochas do Sub-Domínio Costeiro 168

5.8-7 Dados Sm e Nd das rochas do Sub-Domínio Cabo Frio 169 DOMÍNIOS CENTRO-OESTE E LESTE DO BRASIL

5.9-1 Dados Sm e Nd das rochas do Complexo Goiás - Central 183

5.9-10 Dados Sm e Nd das rochas do Domínio Uruaçu 197

5.9-11 Dados Sm e Nd das rochas do Domínio Brasilia 198

5.12-1 Dados Sm e Nd das rochas do Domínio Araxá 210

5.12 2A Dados Sm e Nd das rochas da Faixa Alto Rio Grande 211

5.12-2B Dados Sm e Nd das rochas do Nappe de Empurrão Socorro - Guaxupé $\quad 212$ DOMINIO SUL DO BRASIL

5.13-1 Dados Sm e Nd das rochas do Fragmento Cratônico Luis Alves 250

5.13-2 Dados Sm e Nd das rochas dos Blocos Taquarembó e São Gabriel 252

5.14-1 Dados Sm e Nd das rochas das Faixas Itaiacoca e São Roque 254

5.14-2 Dados Sm e Nd das rochas do Dominio Curitiba 257

5.15-1 Dados Sm e Nd das rochas do Dominio Paranaguá 259 
5.15-2 Dados Sm e Nd das rochas do Dominio Dom Feliciano -(Faixa Tijucas)

5.15-3 Dados Sm e Nd das rochas do Domínio Dom Feliciano -(Batólito de Pelotas) 261

6.1 Tabela de números de datações pelo método Sm-Nd por intervalo de tempo geológico e por dominio geológico.

6.2 Áreas de acreção manto-crosta continental por intervalo geológico da Plataforma Sul Americana

6.3 Tabela de idades modelo TCHUR e TDM das rochas granitóides (TTGs) selecionadas da Plataforma Sul Americana 


\section{RESUMO}

A sistemática Sm-Nd é um dos melhores métodos para a investigação dos processos maiores de evolução relativa a formação da crosta continental no tempo geológico. Idades modelo Sm-Nd podem indicar a época dos eventos de diferenciação mantélica e formação da crosta continental juvenil, e as incertezas interpretativas decorrem da falta de informação adequada sobre a química do manto superior e sobre os processos de fracionamento químico durante diferenciação do magma matélico, bem como sobre os processos secundários que ocorrem em ambiente crustal (mistura de fontes, fracionamento químico entre $\mathrm{Sm}$ e Nd durante refusão de material crustal, etc.).

Metodologias da sistemática $\mathrm{Sm-Nd}$ são apresentadas e aplicadas em rochas da Plataforma Sul Americana.

As principais conclusões indicam acreções juvenis com períodos de intensa atividade entre 3,1 e $3,0 \mathrm{Ga}(\sim 8 \%$ do volume total da crosta continental), 2,8 e $2,7(\sim 20 \%), 2,2$ e 1,9 $(\sim 40 \%)$ e 1.3 e $1,1(\sim 7 \%)$. Tais periodos correspondem aproximadamente aos valores mais frequentes observados em escala mundial.

A curva de crescimento da crosta continental no tempo geológico indica que cerca de $35 \%$ da crosta continental era formada no final do Arqueano $(2,5 \mathrm{Ga})$, mas a maior taxa de acreção de material juvenil ocorreu durante o Paleoproterozóico com $88 \%$ de volume acumulado ao final deste período e atingindo a $98 \%$ no início do Neoproterozóico, restando muito pouco para épocas posteriores. Portanto, o Paleoproterozóico mostra-se claramente como a principal época de formação de crosta continental juvenil da Plataforma Sul Americana, correspondendo a aproximadamente $54 \%$ em volume.

O Lineamento Transbasiliano é uma megasutura, ativa durante o Neoproterozóico, que separa duas grande massas continentais: a porção NW que inclui os Cratons Amazônico, São Luis e Rio Apa e suas regiões marginais e a porção SE, formada por um mosaico de blocos que compreende os Cratons do São Francisco, do Rio de La Plata e de Luiz Alves, bem como as respectivas regiões marginais e outros fragmentos menores.

Em termos de evolução crustal setorial observou-se certa semelhança em ambas as partes das massas continentais durante o período entre 3.0 e $1.7 \mathrm{Ga}$ com concentrações similares (picos) tanto no Arqueano como no Paleoproterozóico. Diferem em relação ao Arqueano precoce, visto que não há dados do lado NW, com valores tão antigos (3.7-3.5Ga) como os do Bloco Gavião, 
Contendas-Mirante e Caldas Brandão, período em que a massa NW (Cratons Amazônico-São Luis) permaneceu virtualmente inafetada pelos eventos tecto-orogênicos, a não ser em suas regiões marginais, enquanto que a massa SE teve uma evolução muito mais complexa, tendo participado da formação de pelo menos dois supercontinentes (Rodínia e Gondwana). 


\begin{abstract}
$\mathrm{Sm}-\mathrm{Nd}$ isotopic systematics is relevant to the topics of origin and evolution the of continental crust, where model ages refer to the time when crustal material was differentiated from the upper mantle. Alternative interpretations are due to a lack of adequate information on crustal processes and the variable composition of the mantle sources.
\end{abstract}

The Sm-Nd methods are presented, and applied on rock materials from the South American Platform

The main conclusions indicate juvenile accretion with higher growth rates (peaks), around 3.7-3.5Ga $(\sim 0.5 \%$ in volume $), 3.1-2.9 \mathrm{Ga}(\sim 16 \%), 2.7-2.6(\sim 9 \%), 2.2-1.9(35 \%)$ and $1.3-1.0$ $(7 \%)$.

The continental growth curve indicates that about $35 \%$ of the crust was formed by $2.5 \mathrm{Ga}$, $88 \%$ by $1.8 \mathrm{Ga}$ and $99 \%$ by $1.0 \mathrm{Ga}$, and the remaining $\sim 1 \%$ was added in the Phanerozoic. Rapid crustal growth occurred between 2.2 and $1.9 \mathrm{Ga}$. The main period of continental crust formation ocurred during the Paleoproterozoic, corresponding to $54 \%$ in volume.

$\mathrm{Sm}-\mathrm{Nd}$ model ages, when compared with the crystallisation ages of granitoid rocks, furnish a rough estimate of juvenile vs. reworked material. Within the South American Platform about $45 \%$ of juvenile continental crust is still preserved within tectonic provinces of different ages. The remainder represents continental crust reworked in younger tectono-thermal events. In particular crustal reworking was predominating over juvenile accretion during Meso-Neoproterozoic.

The Transbrasiliano Lineament is a megasuture, active in the Neoproterozoic, which separates a large northwestern mass, including the Amazonian and São Luis Cratons, from a southeastern mass, formed by a collage of cratonic fragments, of which the São Francisco and Rio de La Plata are the largest. The crustal evolutions of these two large continental masses are considered individually, and can be resumed following form:

1 - Old Archean rocks (>3.4Ga) are found only within the south-eastern part (Gavião Block, Contendas-Mirante Complex (São Francisco Craton) and Caldas Brandão Massif (Borborema Province);

2 - On both continental masses, crustal evolution between 3.0 and $1.7 \mathrm{Ga}$ is very similar;

3 - During Meso and Neoproterozoic times, the northwestern mass (Amazonian and São

Luis Cratons) remained virtually unaffected by tectono-orogenic events, while the southeastern mass is composed of smaller cratonic fragments, which later took part in the formation of two large supercontinents: Rodinia during the Mesoproterozoic, and Gondwana in the Neoproterozoic. 


\section{CAPÍTULO 1}

\section{INTRODUÇÃO / OBJETIVOS}




\section{INTRODUÇÃO/OJETIVOS}

As razões isotópicas ${ }^{143} \mathrm{Nd} /{ }^{144} \mathrm{Nd}$ podem ser utilizadas com grande propriedade para a investigação dos processos maiores de evolução crustal, e em especial o da formação de crosta continental.

É objetivo principal deste trabalho empregar a metodologia isotópica $\mathrm{Sm} / \mathrm{Nd}$ para estudar a evolução geotectônica da América do Sul, no Precambriano, à luz de diversas centenas de determinações geocronológicas obtidas pelo autor, a partir de 1991, no Centro de Pesquisas Geocronológicas da USP (CPGeo-USP). Além dessas análises, foram também compilados, recalculados e utilizados todos os dados que se fizeram disponíveis, obtidos por diversos pesquisadores em laboratórios estrangeiros, de modo que este trabalho pretende ser uma síntese mais ou menos completa e atualizada da evolução crustal da Plataforma Sul Americana.

Como objetivo complementar do trabalho, foi feita a completa implantação da metodologia Sm-Nd nos laboratórios do Centro de Pesquisas Geocronológicas do Instituto de Geociências da Universidade de São Paulo (CPGeo-USP). Este segundo objetivo pode ser considerado como plenamente atingido, uma vez que, desde 1992, já foram realizadas com sucesso cerca de 1000 determinações completas Sm-Nd, em rochas que abrangem todo o território nacional, e partes da Argentina, Uruguai, Portugal e Angola, em trabalhos de geocronologia de interesse de vários dos pesquisadores ligados ao CPGeo. A parte metodológica, acompanhada de alguns exemplos da aplicação do método, foi adequadamente descrita no trabalho de Sato et al. (1995).

Com relação ao assunto principal deste trabalho, o autor balizou suas hipóteses de trabalho pela síntese anterior (Cordani et al., 1988), realizada há cerca de uma década, e baseada essencialmente em análises $\mathrm{Rb}-\mathrm{Sr}$ e nas razões iniciais $87 \mathrm{Sr} / 86 \mathrm{Sr}$ de muitas centenas de rochas granitóides de todas as províncias tectônicas maiores da Plataforma Sul Americana. A sistemática empregada na discussão dos resultados isotópicos $\mathrm{Sm}-\mathrm{Nd}$ (capitulo 5) utiliza, com poucas modificações, as mesmas unidades tectônicas caracterizadas por Cordani et al. (op.cit.). O mencionado capítulo 5 constitui a parte principal, original, do trabalho, onde se interpretam os resultados analíticos $\mathrm{Sm}-\mathrm{Nd}$, quase 
sempre em termos de idades modelo $\mathrm{T}_{\mathrm{DM}}$, o indicador mais empregado em situações similares.

Por outro lado, para que os leitores tenham claras as idéias do presente autor a respeito dos processos de origem e evolução da crosta continental, no tempo geológico, e das potencialidades interpretativas do método $\mathrm{Sm}-\mathrm{Nd}$, foram incluidos dois capítulos específicos a respeito ( capítulos 2 e 4), aos quais é intercalado o capítulo 3 , com a parte metodológica, onde se descrevem as técnicas analíticas empregadas no CPGeo-USP.

Finalmente, as conclusões parciais resultantes das interpretações efetuadas caso a caso, para todas as províncias tectônicas consideradas, foram reunidas no capítulo 6 , onde procura-se elaborar a síntese enunciada pouco acima. A evolução crustal da Plataforma Sul Americana é então descrita a partir da análise da curva de crescimento da crosta continental no tempo geológico, e esta pode ser comparada com curvas análogas de outras partes do globo. 


\section{CAPÍTULO 2}

\section{EVOLUÇÃO DA CROSTA TERRESTRE}




\section{CAPÍtulo 2}

\section{PROCESSOS MAIORES NA EVOLUÇÃO CRUSTAL}

\section{1 - Formação planetária, nossa origem comum}

Conforme nos é ensinado pelos astrofísicos modernos, a origem do Universo é atribuída ao "Big Bang", a grande explosão inicial ocorrida há cerca de 13-15 bilhões de anos, a partir de um volume muito pequeno em que se concentrava toda a matéria, com densidade extrema. Os físicos teóricos, que trabalham com modelos e simulações dos estágios iniciais do Big Bang, nos dizem que foram sendo formados, sucessivamente, e durante o primeiro milhão de anos, fotons, as partículas elementares, e finalmente átomos de hidrogênio. Num Universo inicial constituído apenas de hidrogênio, formaram-SE as primeiras estrelas, integrando as primeiras galáxias, e no interior delas começaram a funcionar as fábricas dos elementos que conhecemos, formados em reações nucleares.

A evolução estelar indica um estágio de estabilidade que leva alguns bilhões de anos, em que o combustível nuclear (hidrogênio) é consumido para formar hélio, e em seguida passa por um estágio de temperatura mais alta em que ocorrem fusões nucleares dos átomos de hélio e de elementos mais pesados (estágio de Gigante vermelha), e finalmente, um estágio terminal, de curta duração (as supernovas), em que são formados os demais elementos pesados.

O ciclo de evolução estelar se repete indefinidamente em todas as partes do Universo, e a produção dos elementos no interior das estrelas obedece a regras bem definidas, que dependem das propriedades fisicas dos nuclídios envolvidos, de modo que a proporção relativa dos elementos resulta similar, qualquer que seja a estrela produtora. Após os primeiros bilhões de anos desde o Big Bang, os processos conduzidos pelas primeiras estrelas condicionaram as proporções relativas em que os diferentes elementos são encontrados, em todas as galáxias. A composição química resultante é denominada "Abundância Cósmica" ou "Abundância Solar" dos elementos. 


\section{2 - Formação e Evolução do Sistema Solar}

Como parte integrante da galáxia denominada "Via Láctea", os elementos que a integram foram formados no interior de pelo menos uma supernova que explodiu há não mais do que $4.8 \mathrm{Ga}$., e foram lançados no espaço para posteriormente serem aglutinados na "nebulosa solar", que viria a dar origem ao nosso Sol, bem como aos corpos planetários que integram o sistema, há cerca de $4.6 \mathrm{Ga}$.

Dessa nebulosa solar, composta por gás e poeira cósmica, com composição química correspondente à abundância solar dos elementos, além do Sol, formaram-se os planetas que conhecemos, durante processo de acreção por atração gravitacional. Maiores informações a respeito podem ser encontradas em Safronov (1972), Anderson (1989), e também em Cordani e Sigolo (1997).

Durante a evolução do Sistema Solar, num estágio inicial de alta temperatura foram perdidos grande parte dos elementos mais voláteis ( $\mathrm{H}, \mathrm{He}, \mathrm{C}, \mathrm{N}, \mathrm{F}, \mathrm{Ne}$, etc.) nos planetas internos em formação (Mercúrio, Venus, Terra e Marte) e também nos corpos parentais dos asteróides (e dos meteoritos) que existiam, naquela época remota, entre as órbitas de Marte e Júpiter. Perda de voláteis ocorreu em muito menos escala nos planetas externos (Júpiter, Saturno, Urano, Netuno) que retiveram seus envoltórios gasosos. A origem comum dos planetas internos e dos corpos parentais dos meteoritos é o que justifica o modelo "condrítico" para a composição química global da Terra.

Após o processo de acreção planetária, os planetas internos, aquecidos pelos impactos de corpos menores relativos ao próprio processo de aglutinação, e também pelo calor interno produzido pelos nuclídios radioativos, passaram por um estágio de diferenciação primária, que levou à formação de um núcleo metálico denso, com composição análoga à dos sideritos, e de um manto silicático, com composição análoga à dos acondritos. Datações efetuadas em numerosos meteoritos indicaram que tais processos de diferenciação ocorreram praticamente em seguida à acreção planetária, há cerca de $4.56 \mathrm{Ga}$.

\section{3 - Processos formadores da crosta terrestre, no tempo geológico}

Durante toda a evolução do planeta Terra, grandes quantidades de material liquido foram extraidos do manto silicático, por fusão parcial. Os magmas assim formados, primários, de natureza basáltica, foram incorporados à assim denominada "crosta oceânica", de espessura pequena $(5-10 \mathrm{Km})$, mas cobrindo grandes áreas da superficie do planeta. Como parte da 


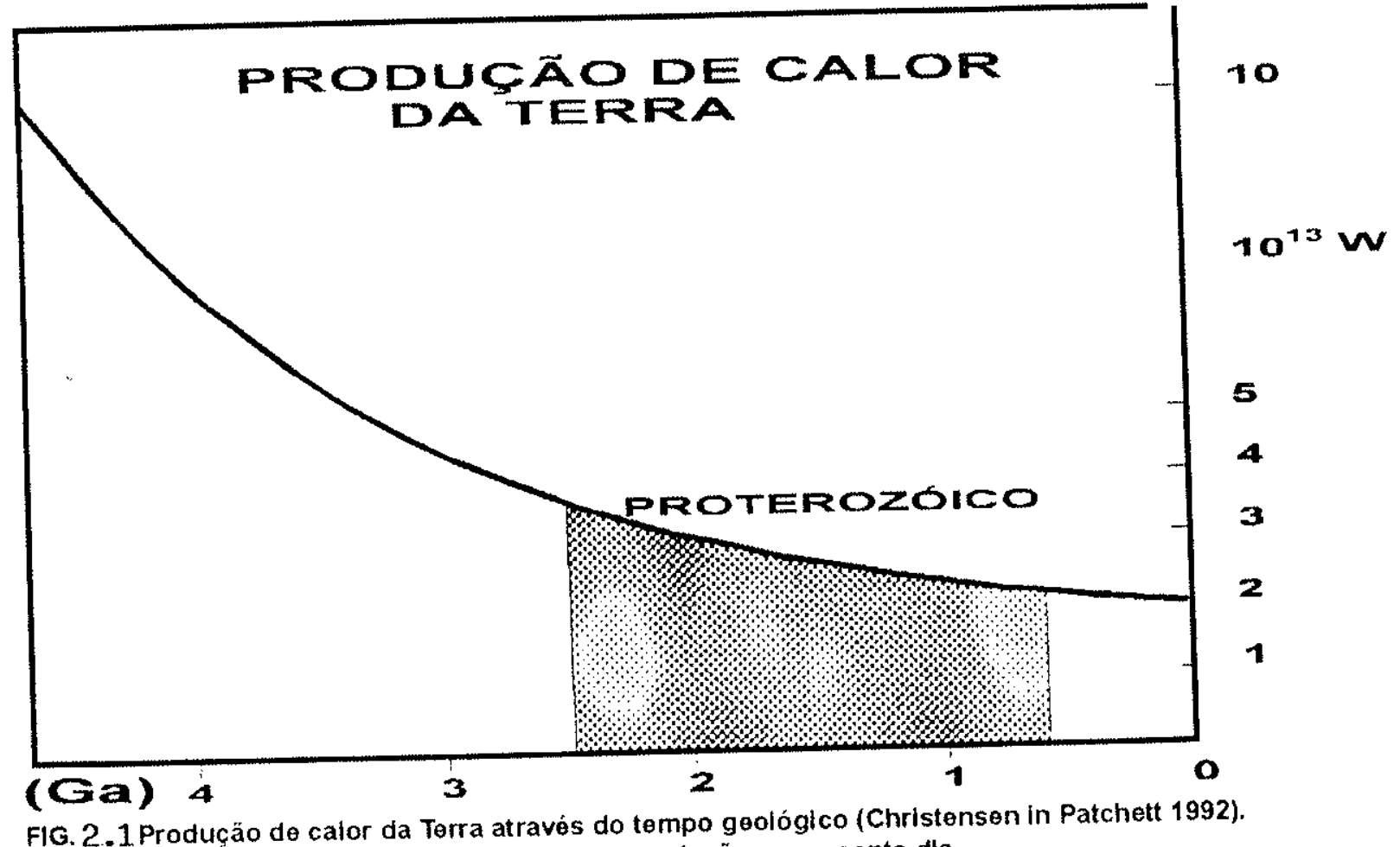

FIG. 2.1 Producäo de calor da Terra através do tempo geológico (Christensen in Patchett 1992) A produção de caior é 2 vezes maior a $2,5 \mathrm{Ga}$ em relação ao presente dla. 
litosfera oceânica, a crosta oceânica tem vida curta na superficie do planeta (dezenas de milhões de anos), sendo reciclada de volta para o manto em processos tectônicos denominados de "subducção", e que ocorrem nos limites convergentes entre placas tectônicas.

Acredita-se que processos similares aos da tectônica de placas do presente (regime tectônico plataformal) tenham ocorrido no passado, pelo menos desde o fim do Arqueano, e acredita-se também que o regime tectônico permóvel, característico do Arqueano, tenha sido de muito maior intensidade, visto que a energia liberada pelos elementos radioativos $(\mathrm{U}, \mathrm{Th}, \mathrm{K}$, e outros elementos de meia-vida curta) era pelo menos três vezes maior do que no presente (fig. 2.1 - James 1989 ).

Se crosta oceânica é apenas transiente, na história da Terra, e seu destino é voltar para o manto, crosta continental pode ser estabilizada na superficie do planeta, como é comprovado, por exemplo, pelos Gnaisses Acasta, de cerca de $4 \mathrm{Ga}$, encontrados no Canadá.

Crosta continental pode crescer por magmatismo intra-placa, por adição de material de caráter normalmente básico, produzido no manto (Rudnick, 1995). Entretanto, o processo mais comum de crescimento da crosta continental é por adição de material nas mesmas margens convergentes de placas onde ocorre subducção de crosta oceânica. Ao voltar para o manto, a placa litosférica descendente pode sofrer fusões parciais, que produzem magmas secundários, já não mais de natureza basáltica. Tais magmas voltam para níveis mais altos, e se incorporam à crosta continental em arcos magmáticos, com componentes vulcânicos ou plutônicos, de caráter básico a ácido, de acordo com o estágio de diferenciação e fracionamento do material. Este processo de crescimento continental, que implica na diferenciação unidirecional manto-crosta em pelo menos dois estágios (crosta oceânica e crosta continental) tem ocorrido desde o Arqueano, com a formação de TTGs (suites de tonalitos trondhjemitos - granodioritos) até o presente, com o magmatismo calcio-alcalino das zonas de subducção.

Segundo Martin (1987), os mecanismos de formação de TTGs podem ser resumidos da seguinte forma : 


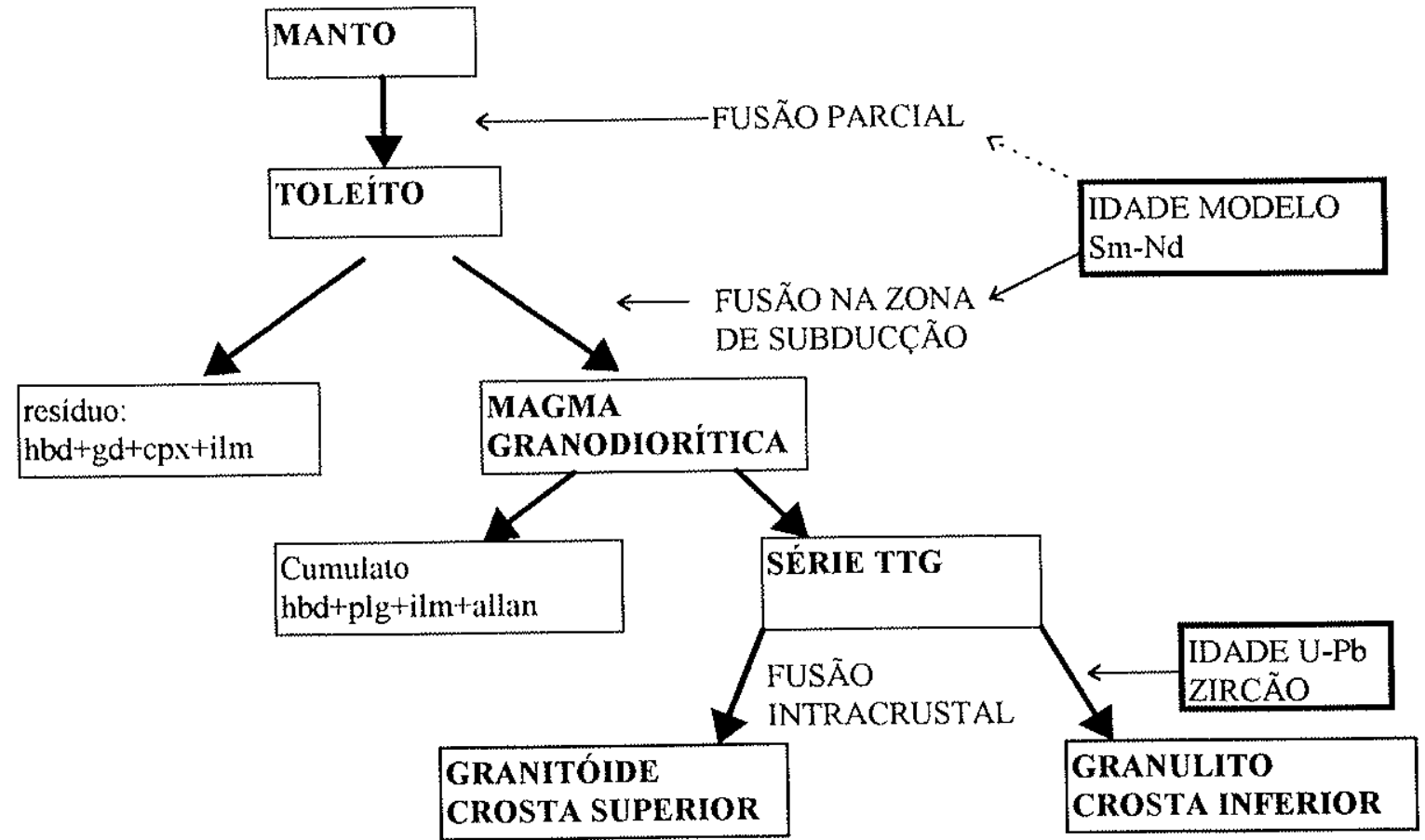

1 - Fusão parcial do manto superior, com produção de magmas toleiíticos. Formação de crosta oceânica

2 - Fusão parcial da crosta oceânica, com produção de magmas granodioríticos, e deixando resíduo de granada anfibolitos na crosta inferior.

3 - Cristalização fracionada dos magmas granodioríticos, produzindo as variedades diferentes de rochas granitóides, instaladas na crosta superior.

Processos análogos à formação dos TTGs ocorrem até o presente, no regime tectônico plataformal, nos arcos magmáticos das margens ativas cordilheiranas. Tais processos indicam crescimento da crosta continental a partir do manto, um dos assuntos mais fascinantes da história da Terra, e que pode ser investigado através das assinatura isotópica de diversos elementos ( $\mathrm{Sr}, \mathrm{Pb}, \mathrm{Nd}, \mathrm{Os}$, e outros) nos sistemas rochosos. Por exemplo, a crosta continental teria sido ela formada mais ou menos continuamente, desde o Arqueano Inferior até o presente? Haveria episódios de maior intensidade de formação de crosta continental ? Em que proporção poderia dar-se a sua reciclagem para o manto (subducção A) ? 


\section{4 - Evolução da Crosta Continental}

A distribuição aparentemente episódica das idades radiométricas, em termos globais, tem sido apontada desde a década de 60. Em histogramas, os registros radiométricos parecem apontar "picos" de valores de idade aparente em torno de $2.7,1,9$ e 1,3 $\mathrm{Ga}$ em todos os continentes, além de cerca 0,6 nos continentes que se originaram da fragmentação do Supercontinente Gondwana (Condie 1997).

Ao que parece, crosta continental "juvenil" (formada a partir do manto da maneira apontada pouco antes) foi formada em grande proporção no Arqueano e início do Proterozóico. Posteriormente prevalecem materiais retrabalhados (por exemplo por refusão a partir de protolitos crustais), embora haja evidências de formação de crosta juvenil no Neoproterozóico e mesmo no Fanerozóico na América do Norte e na Eurásia (p. ex. Sengör et. al, 1993).

Segundo muitos autores, como por exemplo Cordani e Brito Neves (1982), os regimes tectônicos do passado foram condicionados pela evolução termal do planeta, e pela formação de grandes massas continentais, estabilizadas na superficie do planeta a partir do fim do Arqueano. As fases principais teriam sido as seguintes:

1 - Até cerca de $2.8 \mathrm{Ga}$. - Regime permóvel, com grande mobilidade, reciclagem e formação de microcontinentes, os quais por colisão poderiam ter formado uma ou mais grandes massas no final do Arqueano.

2 - Entre 2.8 e 1.3 Ga. Formação de super continentes por aglutinação, e consequente dispersão por fraturamento, com formação relativamente importante de crosta continental juvenil, acompanhada de certo retrabalhamento crustal. $O$ último supercontinente do período foi Rodínia, formado pela aglutinação de massas continentais durante o Ciclo denominado Grenville.

3 - Após 1.3 Ga. Predomina o retrabalhamento crustal, embora continue o processo de adição de crosta continental juvenil nos cinturões orogênicos cordilheiranos. Formação de grandes massas com crosta continental tais como Laurásia, Báltica, Gondwana, etc., atuando como placas tectônicas coerentes durante o Neoproterozóico e todo o Fanerozóico. 


\section{CAPITULO 3}

\section{METODOLOGIA}

Este trabalho está baseado essencialmente em medidas isotópicas de $\mathrm{Sm}$ e $\mathrm{Nd}$ em rochas da Plataforma Sul Americana. Neste capitulo serão resumidas as informações essenciais de geocronologia e de geoquímica isotópica, de caráter metodológico, necessárias para o completo entendimento das interpretações efetuadas, em termos de evolução geológica.

\section{1 - Princípios básicos de geocronologia}

Nuclídios radioativos são os que se encontram na natureza em estado energético metaestável, e que acabam desintegrando-se espontaneamente, emitindo radiações eletromagnéticas, emitindo partículas nucleares ( alfa, betä, beta+), e/ou capturando elétrons da órbita K (captura K). O produto final da(s) transformação(ões) nuclear(es), que atinge o estado fundamental (de energia mínima), é denominado nuclídio radiogênico.

A equação fundamental da geocronologia é baseada no processo físico de decaimento radioativo, definido por uma exponencial negativa, que se apresenta da forma seguinte:

\begin{tabular}{ll} 
& $N=N_{o}$ e- $\lambda T$ ou \\
$T=(1 / \lambda) \ln \left(N_{0} / N\right)$ & \\
se $N_{0}=N+F$ então & equação 1 \\
$T=(1 / \lambda) \ln [1+(F / N)]$ & \\
\hline
\end{tabular}
onde

$\begin{array}{ll}\lambda= & \begin{array}{l}\text { constante de desintegração (esta definida pela } \\ \text { probabilidade de decaimento radioativo) }\end{array} \\ \mathrm{N}= & \begin{array}{l}\text { número de nuclídeos de um determinado elemento } \\ \text { radioativo medido hoje na amostra (pai) }\end{array} \\ \mathrm{N}_{\mathrm{O}}=\quad \begin{array}{l}\text { quantidade inicial do nuclídeo radioativo no momento } \\ \text { do fechamento do sistema. }\end{array} \\ \mathrm{F}=\quad \mathrm{n}^{\mathrm{o}} \text { de átomos transmutados (filho - radiogênico) }\end{array}$


$\mathrm{F}$ = número de átomos do elemento filho que foram transmutados, que na prática é igual à quantidade total de átomos presente (Fp, medida atual) menos a quantidade inicial de átomos $\left(\mathrm{F}_{\mathrm{o}}\right)$, preexistente no sistema no momento de seu fechamento $\left(\mathrm{F}=\mathrm{F}_{\mathrm{p}}-\mathrm{F}_{\mathrm{o}}\right)$.

Para que uma datação geocronológica tenha significação geológica é necessário que a quantidade inicial de átomos do elemento filho (Fo) seja conhecida, ou possa ser calculada, e também que o sistema tenha permanecido fechado com relação a modificações na quantidade de átomos de ambos os isótopos, radioativo (pai) e radiogênico (filho).

Finalmente, os isótopos radioativos naturais de interesse para os estudos de evolução geológica são os que possuem meia vida da mesma ordem de grandeza do tempo geológico (bilhões de anos), e que são suficientemente abundantes na natureza, em diversos tipos de rocha, para permitir medidas com a precisão adequada. Tradicionalmente, os métodos radiométricos utilizados em geocronologia são o $\mathrm{Rb}-\mathrm{Sr}$, o $\mathrm{K}$ - $\mathrm{Ar}$ e sua variante $\mathrm{Ar}$ $\mathrm{Ar}$, os métodos $\mathrm{U}-\mathrm{Th}-\mathrm{Pb}$ e suas variantes $\mathrm{Pb}-\mathrm{Pb}$, o Re-Os, o Lu-Hf e finalmente o que nos interessa neste trabalho, o método $\mathrm{Sm}-\mathrm{Nd}$.

\section{2 - Geocronologia Sm-Nd}

O Sm e o Nd possuem sete isótopos cada um, respectivamente $(144,147,148,149$, 150,152 e 154) e $\left(142,143,144,145,146,148\right.$ e 150), (figs 3.1 e 3.2) onde o isótopo ${ }^{143} \mathrm{Nd}$ é radiogênico e o isótopo ${ }^{147} \mathrm{Sm}$ é radioativo, sendo os demais isótopos estáveis. O método radiométrico $\mathrm{Sm}-\mathrm{Nd}$ baseia-se na desintegração do ${ }^{147} \mathrm{Sm}$ em ${ }^{143} \mathrm{Nd}$, através de uma emissão espontânea de partículas $\alpha$ segundo a constante de desintegração $\lambda_{\mathrm{Sm}}$.

$$
{ }^{147} \mathrm{Sm}_{62} \stackrel{-\cdots}{ }{ }^{-\cdots 3} \mathrm{Nd}_{60} \quad\left(\lambda=6,54 \times 10^{\left.-12 \mathrm{a}^{-1}\right)}\right.
$$

No caso do método Sm-Nd, a equação fundamental da geocronologia (equação 1) toma a forma seguinte:

$$
\mathrm{T}=(1 / \lambda) \ln \left[1+\left({ }^{143} \mathrm{Nd}-143 \mathrm{Nd}_{\mathrm{o}}\right) /{ }^{147} \mathrm{Sm}\right]
$$

onde ${ }^{143} \mathrm{Nd}_{\mathrm{o}}$ é a quantidade inicial, existente antes do fechamento do sistema. Isótopos são medidos em espectrômetros de massa na forma de razões isotópicas. Desta forma, para uma melhor precisão nos cálculos, na expressão acima ambos os membros são divididos por ${ }^{144} \mathrm{Nd}$, resultando:

$$
\mathrm{T}=(1 / \lambda) \ln \left[1+\left({ }^{143} \mathrm{Nd} /{ }^{144} \mathrm{Nd}-{ }^{143} \mathrm{Nd} \mathrm{o} /{ }^{144} \mathrm{Nd}\right) /\left({ }^{147} \mathrm{Sm} /{ }^{144} \mathrm{Nd}\right)\right] \quad \text { equação(2) }
$$




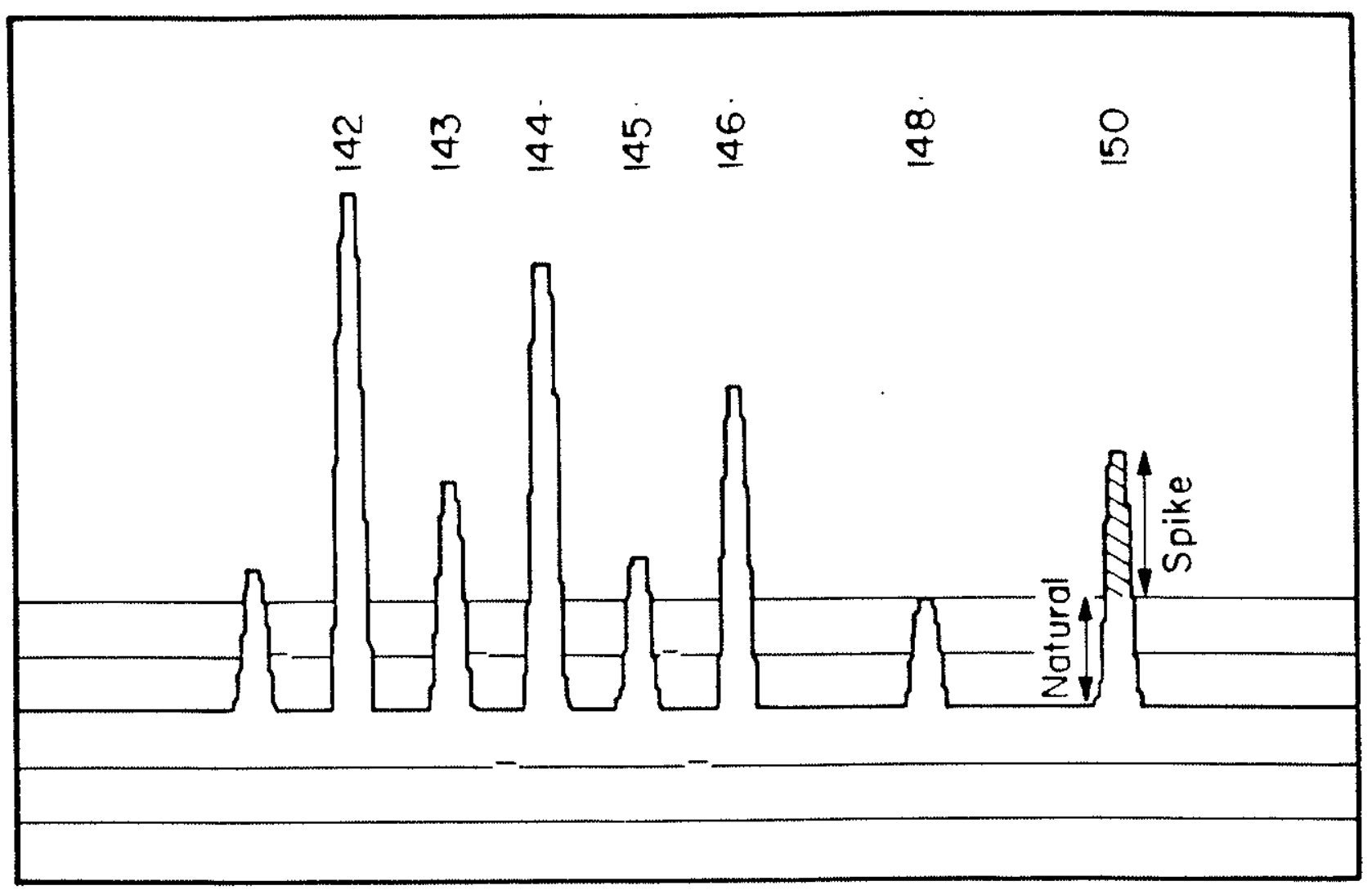

Figura 3.1 - Espectro de Neodímio
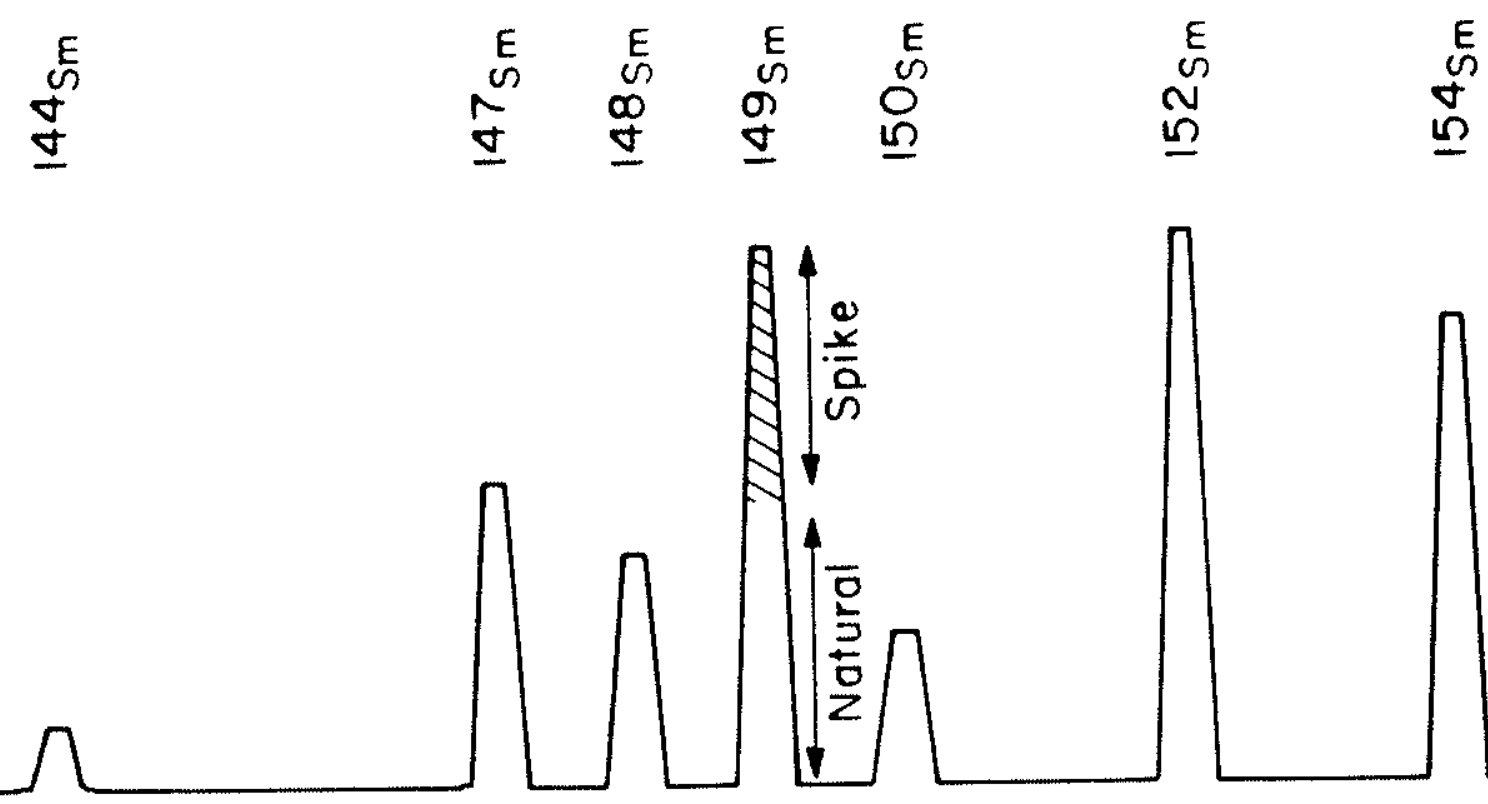

Figura 3.2 - Espectro de Samário 
A equação fundamental da geocronologia pode ser representada também pela seguinte expressão genérica:

$$
T=(1 / \lambda) \ln \left[1+\left(Y-Y_{0}\right) / X\right] \text { equação (3) }
$$

onde Yo é denominado razão inicial (RI) do elemento radiogênico, que no nosso caso é o neodímio $\left({ }^{143} \mathrm{Nd} /{ }^{144} \mathrm{Nd}\right)_{0}$. Esta forma da equação fundamental é interessante no caso da possibilidade de contar com várias amostras cogenéticas de uma mesma unidade rochosa, para as quais o valor de RI é idêntico. Neste caso as idades são calculadas através de diagramas isocrônicos, em que os resultados das medidas efetuadas em várias amostras são inseridos, e a equação isocrônica é expressa da seguinte forma:

$\left({ }^{143} \mathrm{Nd} /{ }^{144} \mathrm{Nd}\right)_{\mathrm{med}}=\left({ }^{143} \mathrm{Nd} /{ }^{144} \mathrm{Nd} /\right)_{\mathrm{O}}+\left({ }^{147} \mathrm{Sm} /{ }^{144} \mathrm{Nd}\right)_{\operatorname{med}}\left(\mathrm{e}^{\lambda \mathrm{T}_{-1}}\right)$

Sabendo-se que $\mathrm{e}^{\lambda \mathrm{T}}=1+\lambda \mathrm{T}+(\lambda \mathrm{T})^{2} / 2 !+(\lambda \mathrm{T})^{3} / 3 !+\ldots$ etc., mas que todos os termos deste desenvolvimento são muito pequenos a partir do terceiro, visto que $\lambda$ é da ordem de $10^{-11}$ e T é da ordem de $10^{9}$, pode-se aproximar a equação para a forma :

$$
\mathrm{Y} \cong(\lambda T) \mathrm{X}+\mathrm{Y}_{\mathrm{o}}
$$

que corresponde a uma equação linear do tipo $\mathrm{Y}=\mathrm{aX}+\mathrm{b}$, onde $\mathrm{a}=\lambda \mathrm{T}=\Delta \mathrm{Y} / \Delta \mathrm{X}$ (coeficiente angular) e $b=Y_{o}$ (razão inicial RI). A forma da equação isocrônica, no caso do método $\mathrm{Sm}-\mathrm{Nd}$, é a seguinte:

$$
\left(143 \mathrm{Nd} /{ }^{144} \mathrm{Nd}\right)_{\mathrm{p}} \cong\left({ }^{143} \mathrm{Nd} /{ }^{144} \mathrm{Nd} /\right)_{\mathrm{O}}+\left({ }^{147} \mathrm{Sm} /{ }^{144} \mathrm{Nd}\right) \lambda \mathrm{T}
$$

Para calcular idades através de diagrama isocrônico é necessário medir os valores de $\mathrm{X}$ e Y em várias amostras cogenéticas (idealmente em número de pelos menos sete). No caso específico do método $\mathrm{Sm}-\mathrm{Nd}$, isócronas podem ser obtidas em muitos tipos de rocha, inclusive rochas ultramáficas, ou em amostras isoladas, utilizando-se fases minerais apropriadas. 


\section{3 - Técnicas de análise}

A grande maioria das análises $\mathrm{Sm}-\mathrm{Nd}$ deste trabalho foi realizada pelo autor, no Centro de Pesquisas Geocronológicas da USP. Maiores pormenores a respeito das técnicas laboratoriais (digestão química, eluição, preparação e calibração das colunas de troca catiônica, deposição das amostras, análises espectrométricas e cálculos de diluição isotópica) pode ser encontrada em Sato et al. (1995). Os procedimentos analíticos podem ser resumidos como segue:

1 - As amostras após adicionados os "spikes" combinados ${ }^{149} \mathrm{Sm}$ e ${ }^{150} \mathrm{Nd}$ em dosagens adequadas, em cada caso, são atacadas em copo de savilex utilizando-se soluções ácidas (HF + $\mathrm{HNO}_{3}+\mathrm{HCl}$ ). No caso da presença de granada, zircão e de outros minerais refratários as amostras são atacadas dentro de uma bomba do tipo Par a $180^{\circ} \mathrm{C}$.

2 - Após a digestão química, a separação de Sm e de Nd é efetuada em duas etapas. Na primeira, as ETR são separadas mediante utilização de uma coluna de troca cationica, com resina $\mathrm{AG} 50 \mathrm{~W}-\mathrm{X} 8$; na segunda, a separação fina de $\mathrm{Sm}$ e $\mathrm{Nd}$ é efetuada em outra coluna, mediante utilização de pó de teflon revestido com ácido ortofosfórico.

3 - Após concentração, $\mathrm{Sm}$ e $\mathrm{Nd}$ são depositados sobre filamentos ultra-limpos. Normalmente, $\mathrm{Nd}$ é dissolvido com $\mathrm{HNO}_{3}$, e depositado sobre filamento simples de $\mathrm{Re}$, na forma de $(\mathrm{NdO})^{+}$. Para análises de $\mathrm{Nd}$ na forma metálica, amostra é dissolvida com $\mathrm{HCl}(0,1 \mathrm{~N})$ e depositado sobre um dos lados do filamento triplo (Ta-Re-Ta). Sm é dissolvido com $\mathrm{H}_{3} \mathrm{PO}_{4}$, e depositado sobre filamento simples de Ta, e analisado na forma metálica.

4 - Em alguns casos, a deposição da amostra de $\mathrm{Nd}$ é feita com $\mathrm{H}_{3} \mathrm{PO}_{4}$ e sílica gel em monofilamentos de $\mathrm{Re}$, quando as medidas isotópicas são efetuadas na forma de $(\mathrm{NdO})^{+} \mathrm{em}$ multicoletores.

5 - As razões isotópicas ${ }^{143} \mathrm{Nd} /{ }^{144} \mathrm{Nd}$, bem como as demais razões isotópicas de $\mathrm{Sm}$ e de Nd para os cálculos das concentrações de cada elemento, por diluição isotópica, são obtidas através de espectrômetro de massa multicoletor, tipo VG-354. As razões isotópicas de $\mathrm{Nd}$ foram normalizadas com ${ }^{146} \mathrm{Nd} /{ }^{144} \mathrm{Nd}=0.7219$

$\mathrm{Na}$ época em que foram realizadas as determinações $\mathrm{Sm}-\mathrm{Nd}$ deste trabalho, foram executadas também muitas medidas de controle em padrões internacionais inter-laboratórios (La Jolla e BCR-1). Os resultados, como pode ser verificado nas tabelas 3.1 e 3.2 , abaixo, 
foram plenamente satisfatórios. Para cada análise do CPGeo-USP foram medidas pelo menos uma centena de razões, e os erros nas razões isotópicas são dados com intervalo de confiança de $95 \%$ (critério $2 \sigma$ ).

Tab. 3.1: medidas das razões ${ }^{143} \mathrm{Nd} /{ }^{144} \mathrm{Nd}$ nos padrões de La-Jolla e BCR-1

\begin{tabular}{|c|c|c|c|c|c|}
\hline Padroes & $\begin{array}{l}\text { ra } \mathrm{Nd}^{4 A} \mathrm{Nd} \\
\text { valores de cosenso }\end{array}$ & $\begin{array}{l}113 \mathrm{Nd}^{44 \mathrm{~A}} \\
\text { valores }\end{array}$ & d. & $\begin{array}{l}\text { Nodde } \\
\text { andit. }\end{array}$ & Sistemas de medidas \\
\hline 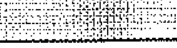 & 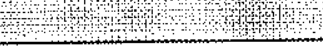 & CPGeo & $\sqrt{40}$ & & monocoletor (metal) \\
\hline La Jolla & & 0,511850 & $\pm(29)$ & 22 & monocoletor (metal) \\
\hline La Jolla & & 0,511853 & $\pm(15)$ & 15 & \\
\hline La Jolla & & 0.511857 & $\pm(23)$ & 4 & $\begin{array}{l}\text { multicoletor (óxido } \\
\text { din/est. }\end{array}$ \\
\hline La Jolla & & 0,511847 & $\pm(22)$ & 14 & $\begin{array}{l}\text { multicoletor (metal)- } \\
\text { estático }\end{array}$ \\
\hline La Jolla & $0,511848^{*} \pm(4)$ & & & & \\
\hline BCR-1 & & 0,512662 & $\pm(27)$ & 4 & monocoletor (óxido) \\
\hline BCR-1 & & 0.512650 & $\pm(20)$ & 4 & multicoletor (óxido - din/est \\
\hline BCR-1 & $0.512639^{* *} \pm(20)$ & & & & \\
\hline
\end{tabular}

Obs.: $\left({ }^{*}\right)$ valor de La Jolla; $\left({ }^{*}\right)$ Wasseburg et. al. (1981);

Tab. 3.2: Concentrações de Sm e Nd para o padrão BCR-1

\begin{tabular}{lll}
\hline & $\begin{array}{l}\text { valores de } \\
\text { consenso }^{\#}\end{array}$ & $\begin{array}{l}\text { valores de } \\
\text { CPGeo }\end{array}$ \\
\hline Sm(ppm) & 6,58 & $6,53 \pm 0.005$ \\
Nd (ppm) & 28,7 & $28,52 \pm 0.01$ \\
razão Sm/Nd & 0.229 & .228 \\
\hline
\end{tabular}

( (\#) Gladney (1982) apud Nakamura e Misawa (1989);.

Os erros nos dados Sm e Nd para o padrão BCR-1 são

relativo ao desvio padrão de 8 análises efetuadas em dias diferentes.

BRANCO - A contaminação total do laboratório durante obtenção dos dados Sm-Nd deste trabalho foi em torno de $30 \mathrm{pg}$ para Sm e em torno de 70pg para o Nd. Para análises de rochas máficas e ultramáficas com teores abaixo de $1 \mathrm{ppm}$ foram iniciadas com 150 a $200 \mathrm{mg}$ de material para minimizar o efeito de contaminção. As reprodutibilidades nas idades em duas análises químicas/isotópicas para tais rochas foram concordantes, com os valores situando-se dentro do erro experimental. 


\section{4 - Cronograma}

A metodologia empregada na elaboração do trabalho obedeceu aos seguintes critérios:

1 - Extensa compilação bibliográfica de trabalhos geocronológicos regionais, de toda a América do Sul, com a finalidade de selecionar amostras especiais para as análises $\mathrm{Sm}-\mathrm{Nd}$. Basicamente, foram escolhidas aquelas amostras consideradas adequadas e disponíveis no acervo do CPGeo-USP

2 - Desenvolvimento e operação das técnicas analíticas para as análises de Sm e de Nd no CPGeo-USP. Os procedimentos químicos foram implantados com a colaboração de vários pesquisadores, e encontram-se plenamente descritos em Sato et al. (1995).

3 - Interpretação geotectônica regional, efetuada com a colaboração de diversos pesquisadores do Instituto de Geociências da USP, e também de outras instituições congêneres.

4 - Elaboração de ilustrações, desenhos e gráficos interpretativos, inteiramente via computacional, utilizando programas (softwares) AUTOCAD, Corel, e Excel. 


\section{CAPÍTULO 4}

\section{SISTEMÁTICA INTERPRETATIVA $\mathrm{Sm}-\mathrm{Nd}$}




\section{4 - SISTEMÁTICA INTERPRETATIVA Sm-Nd}

\section{1 - Generalidades}

Ambos os elementos, Samário $(\mathrm{Sm})$ e Neodímio $(\mathrm{Nd})$, pertencem ao grupo das terras raras (ETR) ou lantanídios. Formam íons positivos de mesma valência (carga $3+$ ), e raios iônicos muito próximos $\left(0.96\right.$ e $\left.1.00 \mathrm{~A}^{0}\right)$, o que faz com que se tornem elementos praticamente isoquímicos. Consequentemente, nos minerais e nas rochas, as razões $\mathrm{Sm} / \mathrm{Nd}$ são pouco diferenciadas, variando, na prática, apenas entre 0.10 a 0.54 .

Como integrantes dos ETR, Samário e Neodimio são encontrados em quase todos os sistemas minerais, normalmente como substitutos de ions grandes. A Tabela 4.1, adaptada de Faure (1988), inclui valores médios de concentrações de $\mathrm{Sm}$ e $\mathrm{Nd}$ nos minerais e rochas mais comuns.

A tabela 4.1 indica que os ETR têm preferência pelos retículos cristalinos de micas, anfibólios, feldspatos potássicos, clinopiroxênios, e também de granadas, que são os sistemas minerais com razões $\mathrm{Sm} / \mathrm{Nd}$ mais elevadas. Estes são os principais minerais a serem analisados pelo método Sm-Nd. Em alguns casos, os ETR concentram-se como constituintes importantes de minerais acessórios de rochas granitóides, como é o caso de allanita, apatita, monazita, xenotima, fluorita, cassiterita, etc.

Como os ETR têm forte carga (3+) e número atômico elevado (57 a 71), eles não se difundem facilmente no estado sólido. Desta forma, durante um evento metamórfico, embora possa ocorrer uma redistribuição de ETR (e portanto de $\mathrm{Sm}$ e $\mathrm{Nd}$ ) entre as fases minerais neoformadas, normalmente os sistemas de rocha total permanecem fechados com relação a migrações de ETR.

Apesar de um comportamento aproximadamente isoquímico de $\mathrm{Sm}$ e $\mathrm{Nd}$, como o íon $\mathrm{Nd}^{3+1}$ possui volume e massa inferiores aos do íon $\mathrm{Sm}^{3+}$, durante certos processos geoquímicos pode ocorrer fracionamento entre estes dois elementos. Isto é observado, em especial, naqueles processos de fusão parcial de determinados protolitos mantélicos ou crustais, que levam à formação de magmas diferenciados. 
TAB. 4.1 : concentrações médias de Sm e Nd

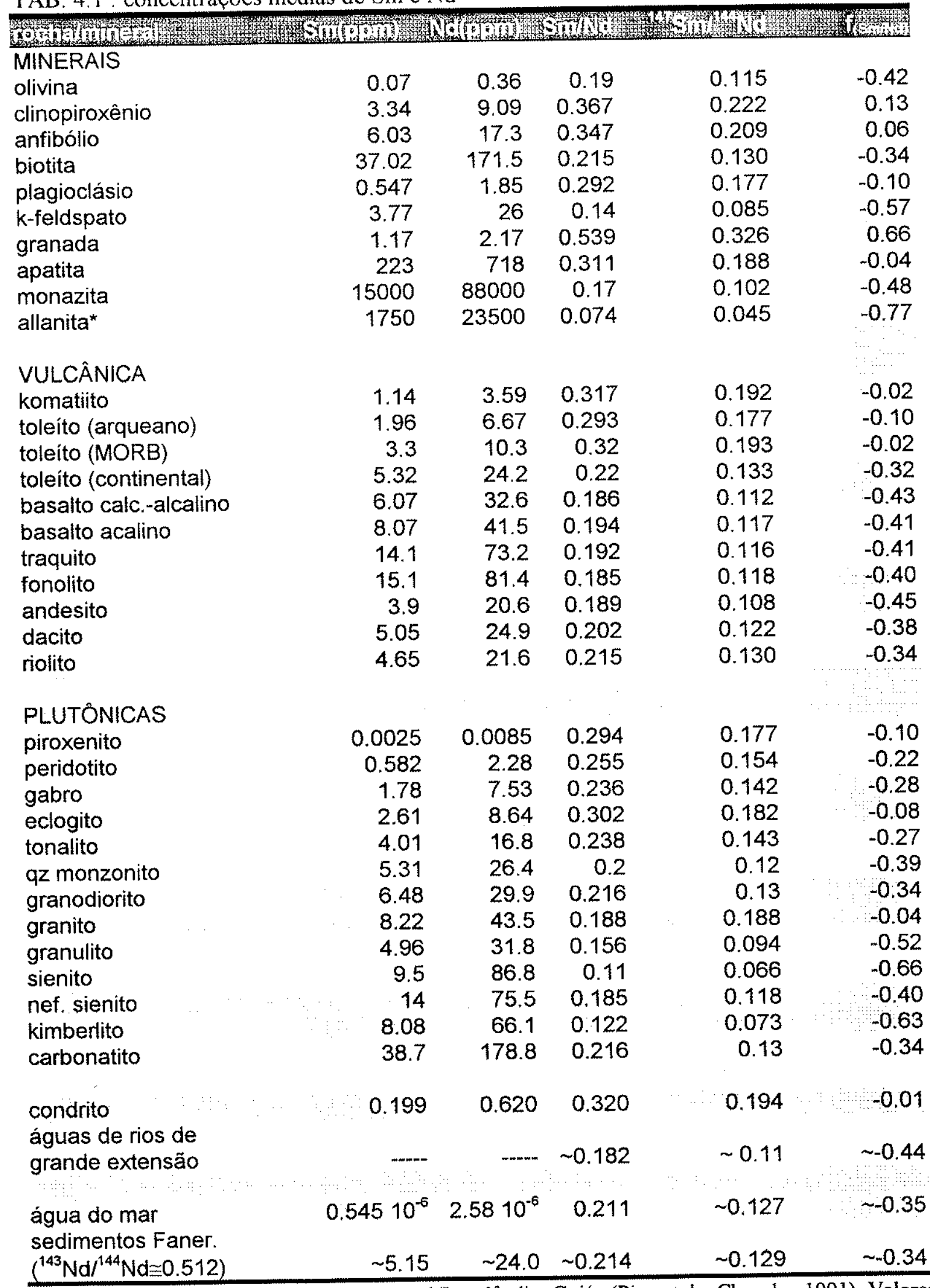

* valor médio das allanitas da região de Iporá/Israelândia, Goiás (Pimentel e Charnley 1991). Valores de CHUR (reservatório uniforme condrítico )e DM ("depleted mantle") utilizados nos cálculos de idades modelo - CHUR: ${ }^{147} \mathrm{Sm} /{ }^{144} \mathrm{Nd}=0.1967 \mathrm{e}^{143} \mathrm{Nd} /{ }^{144} \mathrm{Nd}=0.512638$ (se normalizado com ${ }^{146} \mathrm{Nd} /{ }^{144} \mathrm{Nd}=$ 0.7219 ); manto empobrecido "DM": ${ }^{147} \mathrm{Sm} /{ }^{144} \mathrm{Nd} \cong 0.222 \mathrm{e}{ }^{143} \mathrm{Nd} /{ }^{144} \mathrm{Nd} \cong 0.513114$. 
A modificação mais significativa da razão $\mathrm{Sm} / \mathrm{Nd}$, observada sistematicamente, é a que ocorre durante os eventos de diferenciação do manto superior, quando magmas toleiitotonalíticos primários são formados a partir de processos de fusão parcial do material peridotítico. Neste processo, modelado por De Paolo (1988), o valor de $\alpha_{S m i N d}$ é sempre menor do que l no magma basáltico resultante, e maior do que 1 no resíduo sólido ultramáfico. $O$ parâmetro $\alpha$ é definido como:

\begin{tabular}{ll}
$\alpha_{\mathrm{Sm} / \mathrm{Nd}}=$ & $\begin{array}{l}\text { Conc. Sm (liq., resíd.) / Conc. Sm (sólido.original) } \\
\text { Conc. Nd (liq., resíd.) / Conc. Nd (sólido original) }\end{array}$ \\
\hline
\end{tabular}

Analogamente, em quaisquer outros processos envolvendo fusão parcial de fontes mantélicas ou crustais, o líquido magmático se enriquece preferencialmente em $\mathrm{Nd}$, resultando portanto em rochas magmáticas com razões $\mathrm{Sm} / \mathrm{Nd}$ sempre mais baixas do que as do material original (fig.4.1). Mais ainda, a partir do momento em que magmas tonalíticos primários são incorporados à crosta, nos processos de diferenciação mantélica, modificações posteriores na sua razão $\mathrm{Sm} / \mathrm{Nd}$, com raras exceções, são pequenas, quando comparadas com o fracionamento inicial. Isto quer dizer que os sistemas $\mathrm{Sm} / \mathrm{Nd}$, normalmente, são pouco afetados por processos crustais tais como alteração intempérica ou hidrotermal, metamorfismo, e produção de magmas secundários. As considerações acima são as que habitualmente regem as interpretações geológicas de dados isotópicos Sm-Nd.

\section{2- Variações geoquímicas no manto superior}

Com a formação de crosta oceânica, por extração de material basáltico, e com a incorporação de boa parte desse material, que não retorna ao manto, este torna-se gradativamente empobrecido em elementos litófilos de íons grandes, tais como $\mathrm{Ba}, \mathrm{K}, \mathrm{Rb}, \mathrm{U}, \mathrm{Th}$, e também ETR. Neste contexto, também diminuem as concentrações de Sm e Nd no manto superior empobrecido $(\mathrm{DM}=$ "depleted mantle"), em relação à do manto primordial (considerado homogêneo e denominado CHUR : reservatório uniforme condrítico). Os valores médios aproximados desses reservatórios geoquímicos podem ser vistos na tabela 4.1. Além disso, desde que o $\mathrm{Nd}$ é um 


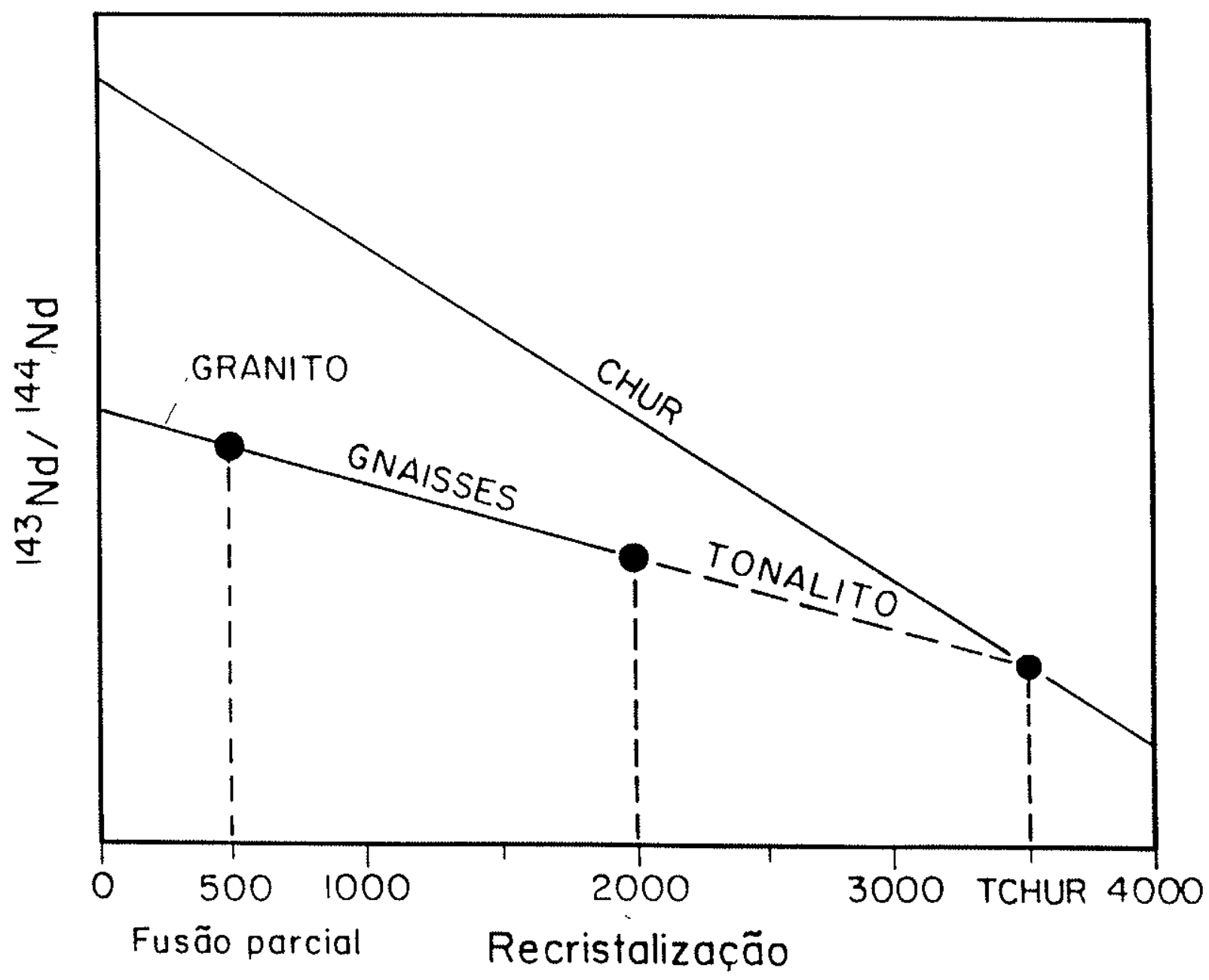

Fig. 4.1: Diagrama de evolução isotópica da razão ${ }^{143} \mathrm{Nd} /{ }^{144} . \mathrm{Vd}$ do manto condrítico (CHUTR) e da crosta continental no tempo geológico. No ponto de intersecção da linha de evolução do CHUR com rocha crustal é definido como idade modelo $\mathrm{T}_{\mathrm{CH}}$ ( $\left.3.5 \mathrm{Ga}\right)$, que corresponde à época de diferenciação do magma do manto para crosta. Este material diferenciado sofreu um processo de recristalização a $2.0 \mathrm{Ga}$ associado a um evento metamórfico de alto grau e que por sua vez sofreu uma fusão parcial a $0.5 \mathrm{Ga}$. 
pouco mais "incompatível" do que o $\mathrm{Sm}$, a razão $\mathrm{Sm} / \mathrm{Nd}$ diminui na crosta continental em formação, e aumenta, de modo complementar, a razão $\mathrm{Sm} / \mathrm{Nd}$ do manto superior empobrecido.

$\mathrm{O}$ fato da razão $\mathrm{Sm} / \mathrm{Nd}$ sofrer fracionamento significativo e relevante somente durante a diferenciação manto superior - crosta oceânica permite obter, para qualquer rocha da crosta continental, a época aproximada em que o seu magma parental diferenciou-se do manto, qualquer que tenha sido sua história geológica posterior (fig. 4.1). Este é o raciocínio utilizado para o cálculo das assim chamadas "idades modelo", que utilizam as medidas das relações atuais ${ }^{143} \mathrm{Nd} /{ }^{144} \mathrm{Nd}$ e ${ }^{147} \mathrm{Sm} /{ }^{144} \mathrm{Nd}$ das amostras em questão, inseridas num modelo de evolução isotópica de Nd no manto, como será descrito a seguir.

$\mathrm{O}$ paradigma das idades modelo $\mathrm{Sm}-\mathrm{Nd}$ serem consideradas como relativas a época de extração dos protolitos das rochas crustais analisadas, a partir do manto superior, foi largamente utilizado logo após o desenvolvimento do próprio método, seguindo as propostas de De Paolo (1981). Mais recentemente, com a consciência da heterogeneidade inicial do próprio manto, bem como da complexidade dos processos mantélicos e crustais, tal paradigma simplista inicial tem sido questionado (Arndt, 1987; Patchett, 1992), e as interpretações da evolução isotópica do Nd nas ròchas crustais têm sido mais elaboradas.

\section{3 - - Utilização dos isótopos de Nd em petrogênese}

As razões ${ }^{143} \mathrm{Nd} /{ }^{144} \mathrm{Nd}$ iniciais são largamente utilizadas como indicadores de processos formadores de rochas crustais, e especialmente na caracterização de seu material fonte.

Mediante o cálculo de um parâmetro, denominado $\varepsilon_{\mathrm{Nd}}$ (veja a equação 8), que corresponde à comparação entre o valor atual da razão ${ }^{143} \mathrm{Nd} /{ }^{144} \mathrm{Nd}$ da amostra em questão, ou do valor da mesma razão em qualquer época da história geológica dessa amostra, com o valor que teria o reservatório condrítico uniforme (CHUR) já definido, e representativo da "Terra Global", na mesma época, temos idéia da origem e do tempo de residência crustal do material analisado.

Por exemplo, se o valor de $\varepsilon_{\mathrm{Nd}}$ relativo à época de cristalização de uma rocha crustal $\varepsilon_{\mathrm{Nd}}$ resultar positivo, o material fonte apresenta razão $\mathrm{Sm} / \mathrm{Nd}$ mais elevada que o CHUR, sugerindo material fonte oriunda do manto superior empobrecido (DM - depleted mantle). Alternativamente, se o valor de $\varepsilon_{\mathrm{Nd}}$ resultar negativo, o material fonte, de razão $\mathrm{Sm} / \mathrm{Nd}$, neste caso, menor do que o CHUR, teria como origem provável, a crosta superior com tempo de residencia crustal, tanto maior quanto maior negativo for o valor de $\varepsilon_{\mathrm{Nd}}$. 
Evidentemente, as situações imaginadas no parágrafo anterior são simplistas, visto que na natureza os processos geoquímicos e tectônicos são freqüentemente complexos, envolvendo fontes anômalas, misturas de material, processos de assimilação e de diferenciação, etc., que ocasionam modificações e flutuações importantes dos valores de $\varepsilon_{\mathrm{Nd}}$. Os valores médios atuais de $\varepsilon_{\mathrm{Nd}}$, ou os intervalos de variação mais comuns, em vários sistemas e reservatórios geoquímicos maiores da Terra, segundo DePaolo (1988) estão relacionados na Tabela 4.2.

Tabela 4.2 : Valores de $\varepsilon_{\mathrm{Nd}}$ em diferentes ambientes geotectônicos . Feição geotectônica

$$
\varepsilon_{\mathrm{Nd}}
$$

CHUR (Manto inferior "primitivo" = Terra Global) zero

Manto superior empobrecido (DM) $+10$

Vulcanismo de dorsal médio-oceânica (MORB) $+10$

llhas oceânicas e montes submarinos (IOB) $+5 a+10$

Vulcanismo oceânico intraplaca ("Hot spots") zero $a+8$

Cratons continentais -30 a -5

Vulcanismo de "rifts" continentais $-5 a+8$

Arcos magmáticos em margens continentais $-20 a+8$

\section{4 - Datações geocronológicas pelo método $\mathrm{Sm}-\mathrm{Nd}$}

$\mathrm{O}$ comportamento geoquímico similar dos íons $\mathrm{Sm}$ e $\mathrm{Nd}$ faz com que modificações posteriores na razão $\mathrm{Sm} / \mathrm{Nd}$ sejam pequenas, quaisquer que sejam os processos sofridos pelos sistemas a que pertencem. Desta forma, não há fases minerais, na natureza, em que predomine grandemente o isótopo radioativo (o $\mathrm{Sm}$ ), para permitir datações geocronológicas precisas e diretas, tal como ocorre nos outros sistemas geocronológicos.

Datações Sm-Nd são efetuadas, normalmente, através de idades denominadas modelo, de acôrdo com determinadas premissas, como será verificado mais adiante, ou então através de diagramas isocrônicos, quando são disponiveis materiais cogenéticos das rochas a serem datadas. Neste último caso, o significado geológico das idades isocrônicas é similar ao de outros sistemas $(\mathrm{Rb}-\mathrm{Sr}, \mathrm{Pb}-\mathrm{Pb})$. A principal vantagem de se aplicar o método $\mathrm{Sm}-\mathrm{Nd}$ está no fato destes elementos serem pouco móveis no estado sólido, e portanto os sistemas que os possuem pouco 
sofrem por modificações geoquímicas posteriores aos eventos significativos datados pelas isócronas. Por outro lado, a sistemática isocrônica em rocha total é dificultada devida a pequena dispersão das razões $\mathrm{Sm} / \mathrm{Nd}$, não permitindo uma distribuição adequado dos pontos analíticos em diagrama isocrônico.

Isócronas $\mathrm{Sm}-\mathrm{Nd}$ em minerais são comumente utilizadas, visto que as razões $\mathrm{Sm}-\mathrm{Nd}$ podem ser bastante distintas (ver tab. 4.1). Geralmente utilizam-se concentrados de granada, anfibólio, clinopiroxênio, plagioclásio e biotita, além de ponto representativo do sistema rocha total. Como no caso de outros sistemas geocronológicos, as idades isocrônicas obtidas devem ser interpretadas como relativas às épocas de formação das paragêneses minerais analisadas.

\section{5 - Idades modelo Sm-Nd em estágio único}

Hoje em dia, em função de estudos geoquímicos, abrangendo principalmente geoquímica isotópica, o manto não é considerado como integralmente homogêneo. Os materiais provenientes do manto superior denotam muitas vezes características geoquímicas distintas. Dois modelos de evolução isotópica de $\mathrm{Nd}$ para o manto superior são utilizados (fig. 4.2): um baseado na evolução dos condritos (CHUR - "Chrondritic Uniform Reservoir"), e um outro baseado na evolução do manto superior, que admite uma modelagem em que o manto sofreria episódios de fracionamento envolvendo a extração de magmas basálticos, permanecendo um manto residual enriquecido na razão $\mathrm{Sm} / \mathrm{Nd}$ e empobrecido geoquimicamente em elementos litófilos de íons grandes (DM, "Depleted Mantle").

$\mathrm{O}$ cálculo de idades modelos $\mathrm{T}_{\mathrm{CHUR}}$ ou $\mathrm{T}_{\mathrm{DM}}$ é feito através da seguinte maneira:

Da equação 4 temos,

$$
\begin{aligned}
& \left({ }^{143} \mathrm{Nd} /{ }^{144} \mathrm{Nd}\right)_{\mathrm{X}}=\left({ }^{143} \mathrm{Nd} /{ }^{144} \mathrm{Nd} /\right)_{\mathrm{O}}+\left({ }^{147} \mathrm{Sm} /{ }^{144} \mathrm{Nd}\right)_{\mathrm{X}}\left(\mathrm{e}^{\lambda \mathrm{T}_{-1}}\right)-->\text { (manto) } \\
& \left({ }^{143} \mathrm{Nd} /{ }^{144} \mathrm{Nd}\right)_{\mathrm{am}}=\left({ }^{143} \mathrm{Nd} /{ }^{144} \mathrm{Nd} /\right)_{\mathrm{O}}+\left({ }^{147} \mathrm{Sm} /{ }^{144} \mathrm{Nd}\right)_{\mathrm{am}}\left(\mathrm{e}^{\left.\lambda \mathrm{T}_{-1}\right)}--->(\text { amostra })\right. \\
& \text { onde X pode ser CHUR ou DM e am }=\text { amostra (razão medida hoje) }
\end{aligned}
$$

No ponto de interseção das duas retas acima define-se a idade modelo $\mathrm{T}_{\mathrm{CHUR}}$ ou $\mathrm{T}_{\mathrm{DM}}$. Subtraindo-se a equação da reta do manto pela equação da amostra temos a seguinte fórmula:

$$
\mathrm{T}(\mathrm{x})=(1 / \lambda) \ln \left\{1+\left[\left({ }^{143} \mathrm{Nd} /{ }^{144} \mathrm{Nd}\right)_{\mathrm{X}}-\left({ }^{143} \mathrm{Nd} /{ }^{144} \mathrm{Nd}\right)_{\mathrm{am}}\right] /\left[\left({ }^{147} \mathrm{Sm} /{ }^{144} \mathrm{Nd}\right)_{\mathrm{X}}-\left({ }^{147} \mathrm{Sm} /{ }^{144} \mathrm{Nd}\right)_{a \mathrm{am}}\right]\right\} \quad \text { eq. } 5
$$



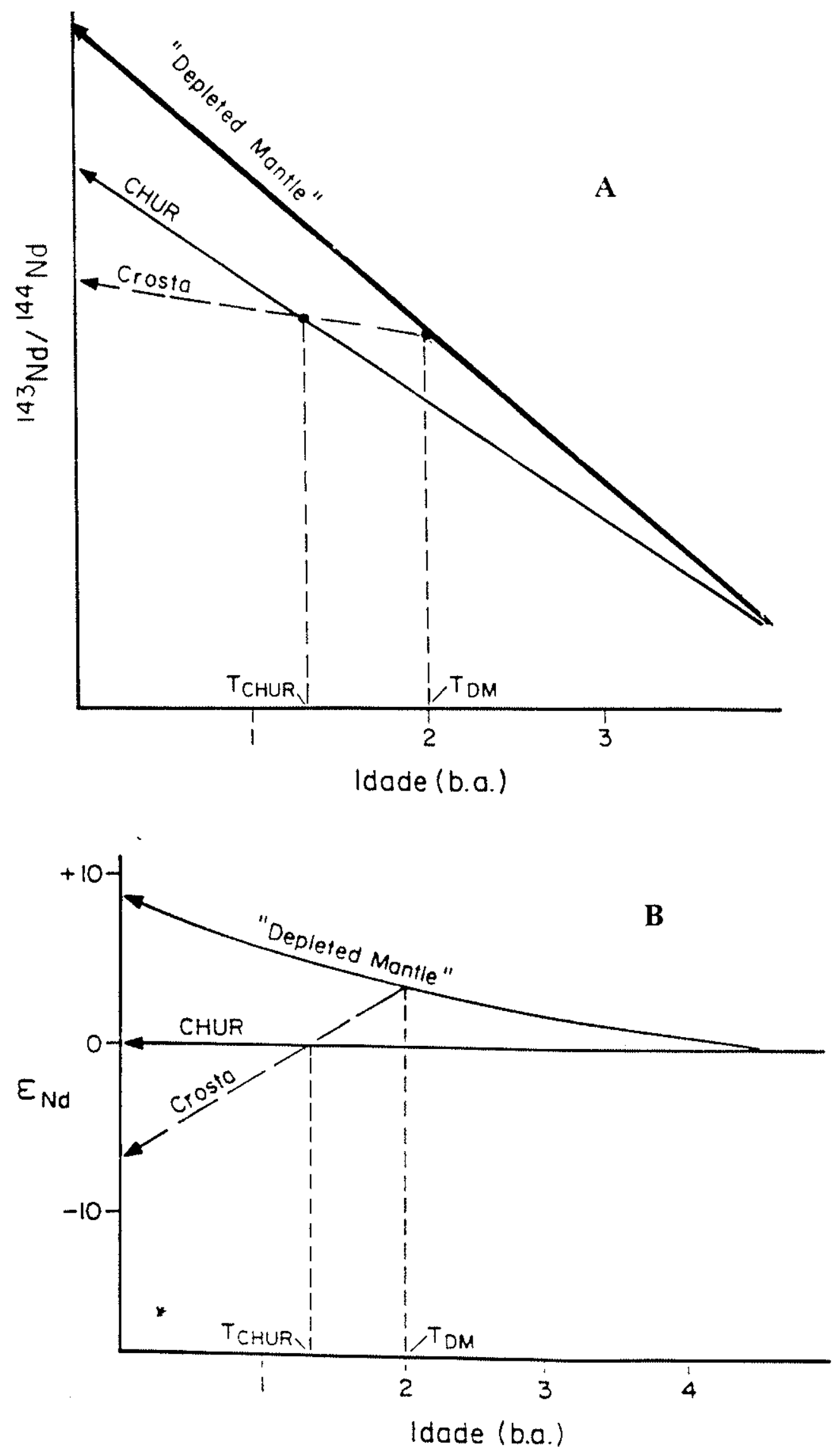

Fig. 4.2 - Dlagramas de evolucão isotópica de Nd no tempo geológico:

A - Inhas de evolucão isotópica de $\mathrm{Nd}$ no tempo geológico (modelo finear). As idades modelo $\mathrm{T}_{\mathrm{Crug}}$ e $\mathrm{T}_{\mathrm{DM}}$ são calculadas com base na equaçāo 5 . 6 e 7 . 
A equação acima caracteriza à uma evolução linear dos isótopos de $\mathrm{Nd}$ no manto superior. DePaolo (1981), modelou uma evolução isotópica de $\mathrm{Nd}$ não linear para o manto superior fracionado, mas uma evolução segundo uma equação do segundo grau em T (parábola), (fig. 4.2) e neste caso a idade modelo é obtida resolvendo-se a seguinte equação:

$$
\begin{aligned}
\varepsilon_{\mathrm{Nd}}(\mathrm{T})= & 0,25 \mathrm{~T}^{2}-3 \mathrm{~T}+8,5 \text { curva do manto empobrecido }(\mathrm{DM}) \\
\varepsilon_{\mathrm{Nd}}(\mathrm{T})= & \varepsilon_{\mathrm{Nd}}(0)-\mathrm{Qf} \mathrm{f}_{(\mathrm{Sm} / \mathrm{Nd})}\left\{0.512638 /\left({ }^{143} \mathrm{Nd} /{ }^{144} \mathrm{Nd}\right)_{\mathrm{CIUR}}(\mathrm{T})\right\}\left[\mathrm{e}^{\lambda \mathrm{T}}-1\right] \\
& \text { considerando } \mathrm{e}^{\lambda \mathrm{T}}-1 \cong \lambda \mathrm{T} \text { e } 0.512638 /\left({ }^{143} \mathrm{Nd} /{ }^{144} \mathrm{Nd}\right)_{\mathrm{Crur}}(\mathrm{T}) \cong 1 \\
\varepsilon_{\mathrm{Nd}}(\mathrm{T}) \cong & \varepsilon_{\mathrm{Nd}}(0)-\mathrm{Q} \mathrm{f}_{(\mathrm{Sm} / \mathrm{Nd})} \mathrm{T} \text { evolução da rocha crustal }
\end{aligned}
$$

onde o parâmetro $\mathrm{Q}_{\mathrm{Nd}}$ é uma constante que insere o valor da constante de desintegração $\lambda_{\mathrm{Sm}}$,

$$
\begin{aligned}
\mathrm{Q}_{\mathrm{Nd}} & =\left[10^{4} \lambda_{\mathrm{Nd}}\left({ }^{147} \mathrm{Sm} /{ }^{144} \mathrm{Nd}\right)_{\mathrm{CHUR}}(0)\right] /\left({ }^{143} \mathrm{Nd} /{ }^{144} \mathrm{Nd}\right)_{\text {CHUR }}(0) \\
& =\left[10^{4} \times 0.00654 \times 0.1967\right] / 0.512638=25.09 \text { b.a. }{ }^{-1}
\end{aligned}
$$

O parâmetro $\varepsilon_{\mathrm{Nd}}(0)$ é definido como a razão atual ${ }^{143} \mathrm{Nd} /{ }^{144} \mathrm{Nd}$ da amostra sobre a razão ${ }^{143} \mathrm{Nd} /{ }^{144} \mathrm{Nd}$ do manto CHUR, subtraido de 1 e multiplicado por um fator 10000 :

$$
\varepsilon_{\mathrm{Nd}}(0)=\left\{\frac{\left({ }^{143} \mathrm{Nd} /{ }^{144} \mathrm{Nd}\right)(0)_{\mathrm{am}}}{\left({ }^{143} \mathrm{Nd} /{ }^{144} \mathrm{Nd}\right)(0)_{\mathrm{CHUR}}}-1\right\} 10000 \quad \text { equação } 8
$$

O parâmetro $\mathrm{f}_{\mathrm{Sm} / \mathrm{Nd}}$ indica o grau de fracionamento da razão ${ }^{147} \mathrm{Sm} /{ }^{144} \mathrm{Nd}$ da amostra em relação ao manto CHUR:

$$
\mathrm{f}_{(\mathrm{Sm} / \mathrm{Nd})}=\frac{\left({ }^{147} \mathrm{Sm} /{ }^{144} \mathrm{Nd}\right)_{\mathrm{am}}-\left({ }^{147} \mathrm{Sm} /{ }^{144} \mathrm{Nd}\right)_{\mathrm{CHUR}}}{\left({ }^{147} \mathrm{Sm} /{ }^{\left.144_{\mathrm{Nd}}\right)_{\mathrm{CHUR}}}\right.}
$$

A razão ${ }^{147} \mathrm{Sm} /{ }^{144} \mathrm{Nd}$ é calculada a partir da concentração total (em ppm) de Sm e Nd da seguinte forma (DePaolo, 1988): 


$$
{ }^{147} \mathrm{Sm} /{ }^{144} \mathrm{Nd}=0,6049 \times[\mathrm{Sm}(\mathrm{ppm}) / \mathrm{Nd}(\mathrm{ppm})]
$$

O ponto de interseção relativas as curvas das equações (6) e (7b) é definido como idade modelo $\mathrm{T}_{\mathrm{DM}}$. Igualando-se as equações (6) e (7b) é obtida uma expressão matemática do segundo grau em T:

$$
\begin{aligned}
& \mathbf{a} \mathbf{T}^{2}+\mathbf{b} \mathbf{T}+\mathbf{c}=\mathbf{0} \quad \text { onde } \mathrm{a}=0.25 ; \mathrm{b}=-3+\mathrm{Qf} \mathrm{f}_{\mathrm{Su} / \mathrm{Nd}} ; \mathrm{c}=8.5-\varepsilon_{\mathrm{Nd}}(0) \\
& \mathbf{T}=\left\{\mathbf{- b}-\left[\mathbf{b}^{2}-\mathbf{4 a c}\right\rfloor^{1 / 2}\right\} / \mathbf{2 a} \quad \text { onde } \mathrm{T} \text { é dado em Ga }
\end{aligned}
$$

As diferenças entre as idades modelo obtidas através das equações $7 \mathrm{a}$ (sem aproximação) e $7 \mathrm{~b}$ (com aproximação) são relativamente pequenas: Neoproterozóico $<\sim 10 \mathrm{Ma}$; Paleoproterozóico $<\sim 15 \mathrm{Ma}$; Arqueano $<\sim 35 \mathrm{Ma}$. Os erros devido a inhomogeneidade do manto supera as aproximações acima referida.

As constantes utilizadas na equação 5 segundo Ben Othman et, al 1984, Michard et. al 1985 são: do presente até $2,8 \mathrm{Ga} . \rightarrow\left({ }^{143} \mathrm{Nd} /{ }^{144} \mathrm{Nd}\right)_{\mathrm{DM}}=0,513114$ e $\left({ }^{147} \mathrm{Sm} /{ }^{144} \mathrm{Nd}\right)_{\mathrm{DM}}=$ 0,222 . Para idades mais antigas que $2,8 \mathrm{Ga}$ a evolução isotópica de $\mathrm{Nd}$ no manto superior fracionado torna-se praticamente assintótica à do "bulk earth" (CHUR) ou seja, assume-se que a crosta continental produzida entre 4,55 a $2,8 \mathrm{Ga}$ tinha vida muita curta e a maior parte dela era reincorporada ao manto. Dessa forma, o processo de empobrecimento no manto superior tornouse significativo apenas após a $2,8 \mathrm{Ga}$., e o valor utilizado para as constantes acima são passa a ser para 0,512638 e 0,1967 respectivamente. Outros de pesquisadores adotam diferentes parâmetros de DM para o modelo de manto empobrecido, para toda a escala de tempo geológico (por exemplo ver Rollinson, 1993). A incerteza na curva de evolução do manto empobrecido poderá acarretar discrepâncias nos cálculos das idades modelos. As constantes relativas ao CHUR utilizadas nas equações 8 e 9 são as mesmas referidas acima.

\section{6 -Problemas na interpretação de idades modelo:}

\section{i) Variação química e isotópica do manto:}

As idades modelo não terão qualquer significado geológico, se o manto que produziu o magma parental da rocha estudada for diferente do reservatório DM (manto empobrecido "normal"). Por exemplo, através de estudos isotópicos dos basaltos de cadeias meso oceânica e ilhas oceânicas (OIB) foram revelados padrões distintos para o enriquecimento $\mathrm{e} / \mathrm{ou}$ empobrecimento dos elementos traços ( $\mathrm{He}, \mathrm{Ne}, \mathrm{Sr}, \mathrm{Nd}, \mathrm{Hf}, \mathrm{Os}$ e $\mathrm{Pb}$ ) em regiões do manto 
superior atual. Zindler e Hart (1986) observaram 4 componentes isotópicos mantélicos para os basaltos oceânicos, que podem ser caracterizadas resumidamente da seguinte forma:

DMM (“depleted Morb Mantle") - fonte empobrecida nos elementos incompatíveis (Rb, $\mathrm{Nd}$, Hf, etc), para a maioria dos basaltos das dorsais meso oceânicas (MORB). O DMM apresentam razões ${ }^{87} \mathrm{Sr} /{ }^{86} \mathrm{Sr}$ muito baixa (geralmente $<0,703$ ), altas razões ${ }^{143} \mathrm{Nd} /{ }^{144} \mathrm{Nd}$ $(\sim 0,51315), \mathrm{e}^{176} \mathrm{Hf} /{ }^{177} \mathrm{Hf}(>0,2381)$.

HIMU (manto com alta razão U/Pb). Enriquecimento pronunciado em ${ }^{206} \mathrm{~Pb}$ e ${ }^{208} \mathrm{~Pb}$, indicativo de fonte mantélica enriquecida em $\mathrm{U}$ e $\mathrm{Th}$ e altamente empobrecida em $\mathrm{Pb}$. Esta componente poderia ser gerada pela reciclagem de litosfera oceânica subductada, ou pela migração ascendente de fusões subsaturadas em sílica, a partir da astenosfera, gerando um reservatório enriquecido localizado no manto litosférico. A componente HIMU pode ser diferenciada de DMM através das seguintes composições isotópicas: $\mathrm{Pb}-->{ }^{206} \mathrm{~Pb} /{ }^{204} \mathrm{~Pb}>20 \mathrm{e}$ Os $-\rightarrow>{ }^{187} \mathrm{Os} /{ }^{188} \mathrm{Os}>0,134$. (bulk-earth $-->{ }^{187} \mathrm{Os} /{ }^{188} \mathrm{Os}=\sim 0,1275$ ).

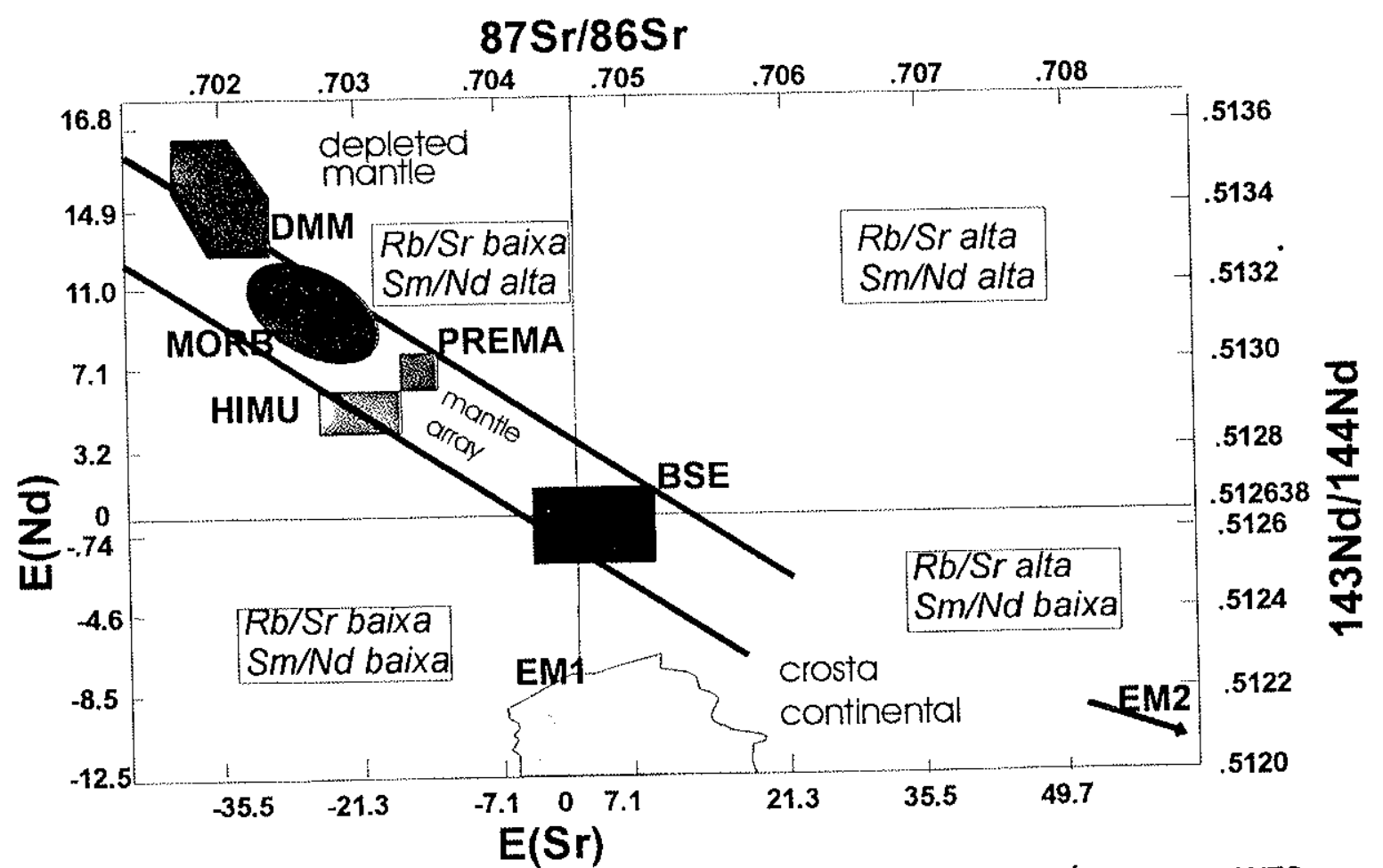

FIG. 4-3: DIAGRAMA E(Sr) X E(Nd) - VARIAÇĀO QUIMICA E ISOTÓPICA DO MANTO.

Ref. : Zindler e Hart, (1986), DePaolo e Wasserburg, (1979).

BSE = "bulk silicate earth"; DMM = "depleted MORB mantle"; HIMU = manto enriquecido em U e Th; EM1 e EM2 = manto enriquecido (enriched mantle); PREMA = "prevalent mantle" 
EM ( manto enriquecido). Corresponde a componentes mantélicas enriquecidas em $\mathrm{Rb}, \mathrm{Sm}$ e $\mathrm{U}$ (e $\mathrm{Th}$ ) relativamente a $\mathrm{Sr}, \mathrm{Nd}, \mathrm{Pb}$, quando comparadas com o manto primordial. A componente do manto enriquecido pode ser classificada em dois tipos: EM1 e EM2.

EM1 - Pode ser identificada através das seguintes razões isotópicas: ${ }^{143} \mathrm{Nd} /{ }^{144} \mathrm{Nd}<0,51264$ (bulk-earth); $\left.{ }^{87} \mathrm{Sr} /{ }^{86} \mathrm{Sr}<0,706 \mathrm{e}{ }^{206} \mathrm{~Pb} /{ }^{204} \mathrm{~Pb}<18\right)$. Frequentemente tem sido sugerido que EM1 seria derivado de manto litosférico continental delaminado, ou alternativamente de componente isolada do manto inferior não diferenciado.

EM2 - Pode ser distinguida de EM1 através das seguintes razões isotópicas: ${ }^{87} \mathrm{Sr} /{ }^{86} \mathrm{Sr}>$ $0,706 \mathrm{e}{ }^{206} \mathrm{~Pb} /{ }^{204} \mathrm{~Pb} \sim 18,8$. A razão isotópica em $\mathrm{Pb}$ de EM2 situa-se no intervalo característico dos sedimentos de origem continental e tem sido sugerido ultimamente que esta componente teria derivada da crosta continental, possivelmente através da reciclagem de sedimentos pelágicos.

$\mathrm{O}$ diagrama $\varepsilon_{\mathrm{Sr}} \times \varepsilon_{\mathrm{Nd}}$ da fig. 4.3 ilustra os padrões acima mencionados. De um modo geral, fontes do tipo manto empobrecido "depleted mantle" posicionam-se no segundo quadrante e fontes do tipo crustal situam-se no quarto quadrante. Dados relativos ao manto litosférico enriquecido, tipo EM1, posicionam-se entre o terceiro e o quarto quadrante, próximos a origem, enquanto os EM2, com características isotópicas em $\mathrm{Nd}$ e em $\mathrm{Sr}$ muito similares aos de crosta continental, posicionam-se no quarto quadrante.

ii) Alteração na razão ${ }^{147} \mathrm{Sm} /{ }^{144} \mathrm{Nd}$ em rochas crustais:

Outro fator importante que pode alterar os valores das idades modelo ocorre ao se datar rochas granitóides fortemente enriquecidas em certos minerais, que concentram seletivamente os elementos terras raras leves, por exemplo a allanita, conforme demonstrado por Pimentel e Charnley (1991). A formação de uma quantidade significativa desse mineral resulta no enriquecimento progressivo de $\mathrm{Nd}$ no magma, com a consequente diminuição da razão $\mathrm{Sm} / \mathrm{Nd}$. Por outro lado a razão $\mathrm{Sm} / \mathrm{Nd}$ aumenta significativamente na fração residual, mesmo que tenha pequena quantidade de allanita segregada da fusão. Do mesmo modo razão $\mathrm{Sm} / \mathrm{Nd}$ aumenta significativamente para as rochas portadoras de granada (ver tab. 4.1). Tais casos fornecem idades modelo que não correspondem a realidade. Por exemplo, no caso de rocha formada por fusão parcial de protolito crustal, o erro introduzido por meio de fracionamento $\mathrm{Sm} / \mathrm{Nd}$ é dado pela seguinte equação:

$$
\begin{aligned}
& \text { Erro }(\mathrm{T})=(\Delta \mathrm{f} \mathrm{Sm} / \mathrm{Nd}) \times\left(\mathrm{T}_{\mathrm{fc}}{ }^{-\mathrm{T}_{\mathrm{fp}}}\right)(\text { Nelson e DePaolo, 1985) equação (10) } \\
& \text { onde } \mathrm{f}_{\mathrm{Sm} / \mathrm{Nd}} \text { é a razão }\left\{\left[\left[^{147} \mathrm{Sm} /{ }^{144} \mathrm{Nd} \text { amostra } /{ }^{147} \mathrm{Sm} /{ }^{144} \mathrm{Nd}_{\mathrm{CHUR}}\right]-1\right\}\right. \text { e o }
\end{aligned}
$$




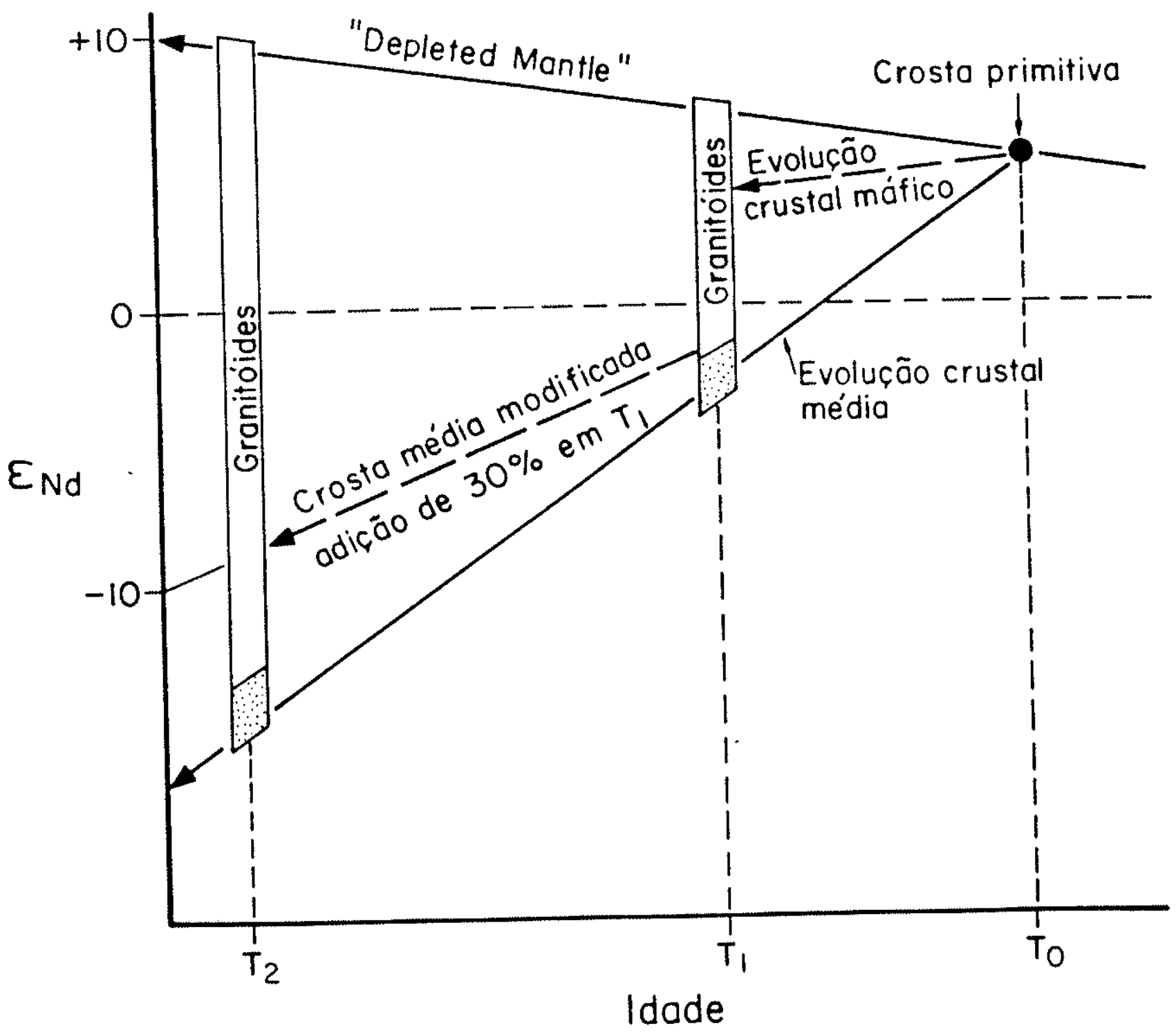

Fig. 4-4 - Diagrama de mistura caracterizando modificação da linha de evolução isotópica de $\varepsilon_{\mathrm{Nd}}$ da rocha crustal diferenciado do manto em $\mathrm{T}_{0}$. em função da adição de $30 \%$ de magma juvenil em $\mathrm{T}_{1}$. Em T2 ocorreu apenas o metamorfismo. 
$\Delta \mathrm{f}=\left[\mathrm{f}_{\mathrm{Stw} / \mathrm{Nd}} \mathrm{cm} \mathrm{T}(\mathrm{fc})-\mathrm{f}_{\mathrm{Sm} / \mathrm{Nd}} \mathrm{cm} \mathrm{T}(\mathrm{fp})\right]$ é relativo à mudança na razão $\mathrm{Sm} / \mathrm{Nd}$ ocorrida, $\mathrm{T}_{\mathrm{fp}}$ é a idade da cristalização da rocha, e $\mathrm{T}_{\mathrm{fc}}$ é a idade do protolito relativa à época da separação manto-crosta $\left(\mathrm{T}_{\mathrm{DM}}\right)$.

O erro devido ao fracionamento $\mathrm{Sm} / \mathrm{Nd}$ ocorrido durante processos de fusão parcial não excede mais que 100Ma quando $\left(\mathrm{T}_{\mathrm{fc}}-\mathrm{T}_{\mathrm{fp}}\right)$ é menor que 400 - $600 \mathrm{Ma}$., de acordo com o modelo de Hanson (1978), no qual $\Delta \mathrm{f}_{\mathrm{Sm} / \mathrm{Nd}}<|0,2|$. No entanto, quando ocorre cristalização, por exemplo, de allanita, o $\Delta$ f poderá ser muito maior que 0,2 e por conseguinte a idade modelo não será confiável (Pimentel e Charnley, 1991). Não é recomendad, portanto, a utilização de idades modelo em granitóides enriquecidos em allanitas e granadas.

iii) Misturas de duas ou mais fontes: Quando ocorre fusão com participação de fontes distintas (manto/crosta ou crosta $\mathrm{A} /$ crosta $\mathrm{B}$ ), a interpretação das idades modelo é bem complicada. De um modo geral a idade modelo representará uma época intermediária para as derivações últimas dos protolitos, a partir de materiais do manto. DePaolo (1988) mostra um exemplo onde a rocha crustal sofre assimilação de $30 \%$ de material juvenil (fig. 4.4).

iv) Sedimentos e metassedimentos, incluindo paragnaisses: Outro fator que pode produzir idades modelo $\mathrm{Sm-Nd}$ que não correspondem ao processo de diferenciação mantélica dos protólitos crustais das rochas estudadas, ocorre quando se trabalha com materiais derivados da fusão parcial de sedimentos heterogêneos, provenientes de diversas fontes. A idade obtida seria um valor intermediário entre os diversos episódios de diferenciação manto-crosta que geraram os protólitos das rochas fontes dos sedimentos. A idade obtida será em função do conteúdo em ETR proveniente de cada fonte, e o valor será mais próximo daquela, cuja participação na constituição dos sedimentos e/ou metassedimentos foi mais significativo. 


\section{7 - Cálculos de idades modelo em estágio duplo}

Para rochas que possuem grandes quantidades de minerais acessórios tais como a granadas ou allanitas, em que o $\mathrm{Sm}$ fraciona muito fortemente em relação ao $\mathrm{Nd}$ as idades modelo de um estágio único não teriam qualquer significado geológico. Isto ocorre também nos casos de rochas de natureza máfica e ultramáfica, quando devido aos baixos teores de $\mathrm{Sm}$ e de $\mathrm{Nd}$, pode ocorrer o fracionamento entre Sm e Nd durante evento metamórfico de médio a alto grau .

O grau de fracionamento pode-se ser medido através do valor $\mathrm{f}_{\mathrm{Sm} \mathrm{Nd}}$ da equação 9 . A tabela 4.1 fornece uma estimativa dos valores de $\mathrm{f}_{\mathrm{Sm} \mathrm{N}}$ para diferentes graus de fracionamento de minerais e das rochas crustais em relação ao CHUR.

Os problemas interpretativas que decorrem da heterogeneidade mantélica, ou da evolução complexa sofrida pelos sistemas rochosos crustais já foram indicados no item anterior (4.6). No caso de rochas granitóides, incorporadas à crosta continental por acreção, por magmatismo em arcos magmáticos, normalmente os valores ${ }^{147} \mathrm{Sm} /{ }^{144} \mathrm{Nd}$ são da ordem de $0.085 \mathrm{a}$ 0.125. Quando os valores escapam do intervalo referido, muito provavelmente o cálculo pelo modelo do estágio único estará desprovido de significação geológica.

Neste trabalho, para situações em que o valor de $\mathrm{f}_{\mathrm{Sm} N \mathrm{Nd}}$ mostrou-se incompativel com o modelo de estágio único, buscou-se um modelo alternativo (estágio duplo, a partir de um processo inicial gerador de protolito com $\mathrm{f}_{\mathrm{Sm} / \mathrm{Nd}} \cong 0.11$ ), na tentativa de obter valores compatíveis com a história geológica regional.

A equação matemática para o modelo em estágio duplo, conforme a figura 4.5 , pode ser deduzida de seguinte forma : 


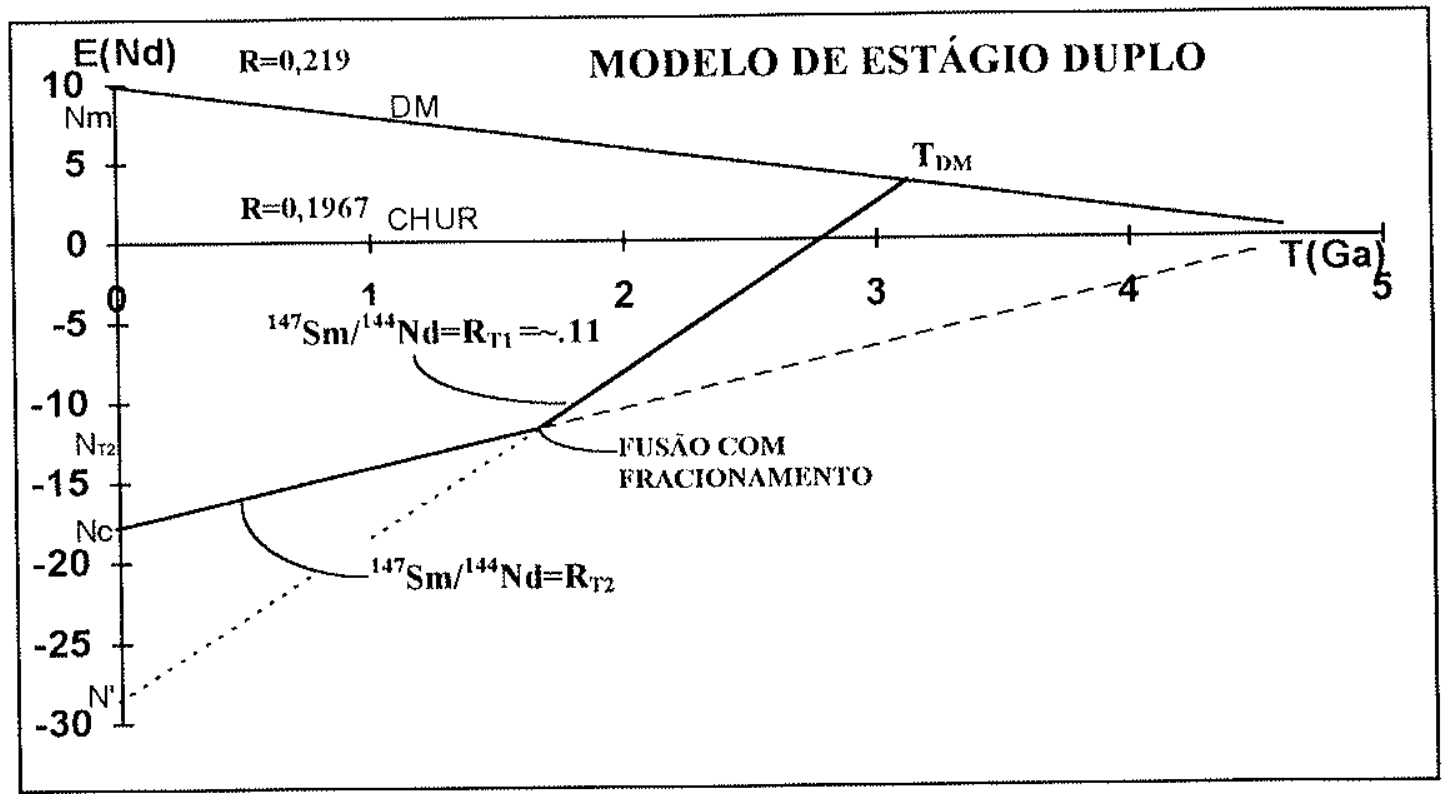

Fig. 4.5: EXEMPLO DE EVOLUÇÃO SEGUNDO MODELO em ESTÁGIO DUPLO - Diagrama de evolução isotópica de $\mathrm{Nd}$ em função do tempo geológico. Em $3.2 \mathrm{Ga}$ o magma separou-se do manto tendo ${ }^{147} \mathrm{Sm} /{ }^{144} \mathrm{Nd}=\mathrm{R}_{\mathrm{T} 1}=0,11$. A $1,7 \mathrm{Ga}$ ocorreu re-fusão deste material, com novo fracionamento entre Sm e $\mathrm{Nd} \mathrm{a}\left(\right.$ razão ${ }^{147} \mathrm{Sm} /{ }^{144} \mathrm{Nd}=\mathrm{R}_{\mathrm{T} 2}$ ). Em $\mathrm{T}=0$ (hoje) o valor de o $\varepsilon_{\mathrm{Nd}}$ é igual a Nc. A regressão direta de $\varepsilon_{\mathrm{Nd}}=\mathrm{Nc}$ com a inclinação de $\mathrm{R}_{\mathrm{T} 2}$ até a linha de manto empobrecido (DM) condicionaria um valor de $\mathrm{T}_{\mathrm{DM}}$ sem significado geológico.

Da eq. (1) $\rightarrow->N_{m}=N_{0}+R_{m}\left(e^{\lambda T d m}-1\right)$ para manto empobrecido.

$\mathrm{N}^{\prime}=\mathrm{N}_{0}+\mathrm{R}_{\mathrm{T} 1}\left(\mathrm{e}^{\lambda \mathrm{Tdm}}-1\right)$ rochas crustais formadas em eventos tectono-magmáticos primário.

$N_{m}-N^{\prime}=\left(R_{m}-R_{T 1}\right)\left(e^{\lambda T d m}-1\right)$.

$\left(\mathrm{e}^{\lambda \mathrm{Tdm}}-1\right)=\left(\mathrm{N}_{\mathrm{m}}-\mathrm{N}^{\prime}\right) /\left(\mathrm{R}_{\mathrm{m}}-\mathrm{R}_{\mathrm{T} 1}\right)$.

$\mathrm{T}_{\mathrm{dm}}=(1 / \lambda) \ln \left\{1+\left(\mathrm{N}_{\mathrm{m}}-\mathrm{N}^{\prime}\right) /\left(\mathrm{R}_{\mathrm{m}}-\mathrm{R}_{\mathrm{Tl}}\right)\right\}-->$ equação (11).

onde $\mathbf{N}={ }^{143} \mathrm{Nd} /{ }^{144} \mathrm{Nd}$ e $\mathbf{R}={ }^{147} \mathrm{Sm} /{ }^{144} \mathrm{Nd} ; \mathbf{T}_{1}=1^{\text {o. }}$ estágio e $\mathbf{T}_{2}=2^{\text {o. }}$ estágio (valor imposto correspondendo a idade do evento tectono magmático secundário).

$N_{c}=N_{T 2}+R_{T 2}\left(e^{\lambda \mathrm{r} 2}-1\right)$ rochas crustais com fracionamento em $T_{2}$.

$N^{\prime}=N_{T 2}+R_{T 1}\left(e^{\lambda T^{2}}-1\right)$ rochas crustais sem fracionamento em $T_{2}$.

$N^{\prime}-N_{c}=\left(R_{T 1}-R_{T 2}\right)\left(e^{\lambda T 2}-1\right)$.

$N^{\prime}=N_{c}+\left(R_{T 1}-R_{T 2}\right)\left(e^{\lambda T 2}-1\right)--->$ equação (12).

substituindo-se $N^{\prime}$ da eq. (12) em eq. (11) temos, 
$T_{\mathrm{dm}}=(1 / \lambda) \ln \left\{1+\left\{\mathrm{N}_{\mathrm{m} 1}-\left[\mathrm{N}_{\mathrm{c}}+\left(\mathbf{R}_{\mathrm{T} 1}-\mathbf{R}_{\mathrm{T} 2}\right)\left(\mathrm{e}^{\lambda \mathrm{T} 2}-1\right)\right]\right\} /\left(\mathbf{R}_{\mathrm{m}}-\mathbf{R}_{\mathrm{T} 1}\right)\right\}-->$ eq. $(13)$

onde $\mathrm{N}_{\mathrm{c}}=\left({ }^{143} \mathrm{Nd} /{ }^{144} \mathrm{Nd}\right) \rightarrow>$ medido hoje, na rocha crustal;

$\mathrm{N}_{\mathrm{m}}=\left({ }^{143} \mathrm{Nd} /{ }^{144} \mathrm{Nd}\right)=0,51315$ (manto empobrecido)

$\mathrm{R}_{\mathrm{T} 2}={ }^{147} \mathrm{Sm} /{ }^{144} \mathrm{Nd}-->$ medido hoje, na rocha crustal;

$\left.\mathrm{R}_{\mathrm{T} 1}={ }^{147} \mathrm{Sm} /{ }^{144} \mathrm{Nd}\right)=$ valor estimado.

$\mathrm{R}_{\mathrm{m}}=0,219$-..-> manto empobrecido.

Obs.: as constantes Nm e Rm foram baseadas em Millisenda et. al. (1994).

DePaolo e Schubert 1991 apresentam o cálculo de idades modelo $\mathrm{Sm-Nd}\left(\mathrm{T}_{\mathrm{DM}}\right)$ em estágio duplo através da seguinte expressão matemática:

$\varepsilon_{\mathrm{Nd}}-Q_{\mathrm{Nd}} \mathbf{f}_{\mathrm{Sm} / \mathrm{Nd}} \mathrm{T}_{2}=\left(8.6-1.91 \mathrm{~T}_{\mathrm{DM}}\right)+\mathbf{Q}_{\mathrm{Nd}}\left[-0.25-0.08 \mathrm{~T}_{\mathrm{DM}}\right]\left(\mathrm{T}_{\mathrm{DM}}-\mathrm{T}_{2}\right)$ onde $\mathrm{T} 2$ é o evento de cristalização secundário. Nesta equação é adotado uma evolução da razão ${ }^{143} \mathrm{Nd} /{ }^{144} \mathrm{Nd}$ do manto superior "DM" linear no tempo geológico $\left\{\varepsilon_{\mathrm{Nd}}(\mathrm{T})=8.6-1.91 \mathrm{~T}\right\}$. O termo $-0.25-$ $0.08 \mathrm{~T}_{D M}$ representa a razão $\mathrm{f}_{S \mathrm{Sm} N d}$ empírica da amostra, relativa a separação manto-crosta (evento primário). Resolvendo a equação em T temos a seguinte expressão:

$\mathrm{aT}^{2}+\mathrm{bT}+\mathrm{c}=0 \quad(\mathrm{~T}$ em Ga $)$

onde $\mathrm{a}=-2.0072 ; \quad \mathrm{b}=-8.1725+2.0072 \mathrm{~T}_{2} ; \quad \mathrm{c}=8.6+6.2725-\varepsilon_{\mathrm{Nd}}+25.09 \mathrm{f}_{\mathrm{Sm} / \mathrm{Nd}(\mathrm{hoje})} \mathrm{T}_{2}$

O autor preferiu não utilizar neste trabalho a equação de DePaolo e Schubert (1991) devido a considerável incerteza no fator $\mathrm{f}_{\mathrm{Sm} / \mathrm{Nd}}(\mathrm{T})=-0.25-0.08 \mathrm{~T}_{\mathrm{DM}}$.

O modelo de evolução em estágio duplo de ${ }^{143} \mathrm{Nd} /{ }^{144} \mathrm{Nd}$ em função do tempo geológico poderá minimizar os desvios ocasionados por problemas de fracionamento, se forem conhecidas a idade do evento $T_{2}$ e a razão $R_{T 1}\left({ }^{147} \mathrm{Sm} /{ }^{144} \mathrm{Nd}\right)$. A idade $\mathrm{T}_{2}$ pode ser estimada através de isócrona $\mathrm{Sm} / \mathrm{Nd}$ ou através de outras metodologias (U-Pb em zircões, isócronas $\mathrm{Rb}-\mathrm{Sr}$, etc). O valor do $\mathrm{R}_{\mathrm{T} 1}$ pode ser estimado com base no valor médio de várias determinações da região. Caso não hajam outras análises Sm-Nd, em terrenos similares, pode ser utilizado o valor $\mathrm{RT}_{1}$ médio relativo a crosta continental de $0,11 \pm 0,01$ (válido para granitóides). 


\section{CAPÍTULO 5}

\section{DISCUSSÃO DOS RESULTADOS}




\section{1 - Antecedentes a respeito da Evolução da Plataforma Sul}

\section{Americana}

Embora existam vários estudos parciais anteriores, a primeira síntese a respeito da evolução geotectônica, incluindo avaliação do crescimento da crosta continental da Plataforma Sul Américana no tempo geológico, é devida a Cordani et al. (1988). Esses autores basearam-se no acervo de cerca de dez mil datações individuais $\mathrm{Rb}-\mathrm{Sr}$ em rocha total, a maioria delas obtida no CPGeo-USP, e caracterizando cerca de 500 diagramas isocrônicos, bem como as relativamente poucas análises $\mathrm{U}-\mathrm{Pb}, \mathrm{Pb}-\mathrm{Pb}$ e $\mathrm{Sm}-\mathrm{Nd}$ disponíveis na época, e obtidas em diversos laboratórios estrangeiros, em projetos de colaboração científica com o CPGeo.

Segundo o citado trabalho, os principais períodos de acreção crustal, na Plataforma Brasileira foram:

- Arqueano ( 3.1 a $2.5 \mathrm{Ga}$ - vários episódios)- $45 \%$ da crosta continental

Eoproterozóico (2.1 a 1.9 Ga.- Ciclo Transamazônico) - 35\%

Droterozóico Médio (1.8 a 1.6 Ga. - Arco RioNegro-Juruena) - 15\%

(1,3 a 1,0 Ga. - Ciclos Rondoniano e Sunsás) - 5\%

- Neoproterozóico (0.8 a 0.6 Ga. - Ciclo Brasiliano) - mínima.

Os ciclos orogênicos Rondoniano e Sunsás, que contribuíram para a formação do Supercontinente de Rodínia, e o Ciclo Brasiliano, que resultou na consolidação da parte ocidental do Supercontinente Gondwana, foram caracterizados como sendo essencialmente de natureza ensiálica, contribuindo dessa forma muito pouco para o crescimento de crosta continental.

Pela quantificação acima resumida, a taxa de acreção foi de $45 \%$ durante o Arqueano, chegando a $80 \%$ no final da orogênese Transamazônica, e atingindo virtualmente $100 \%$ antes do Neoproterozóico. Portanto, em termos quantitativos, segundo Cordani et al.(1988), o Proterozóico foi mais importante em termos de acreção de crosta continental do que o Arqueano, no caso da Plataforma Sul Americana. A fig. 5.1 mostra a curva de crescimento da Plataforma Sul Americana mostrando o super evento de acreção durante o Paleoproterozóico (curva 1). Crescimento com padrão similar ocorre na porção SW do Est. Unidos (curva 2; DePaolo 1991).

$\mathrm{Na}$ concepção do presente trabalho, o ponto de partida foi justamente a sintese referida, de Cordani et al.(1988), aproveitando-se, para efeito comparativo, praticamente os mesmos domínios crustais estabelecidos por aqueles autores. Apenas alguns dos limites de domínios foram 


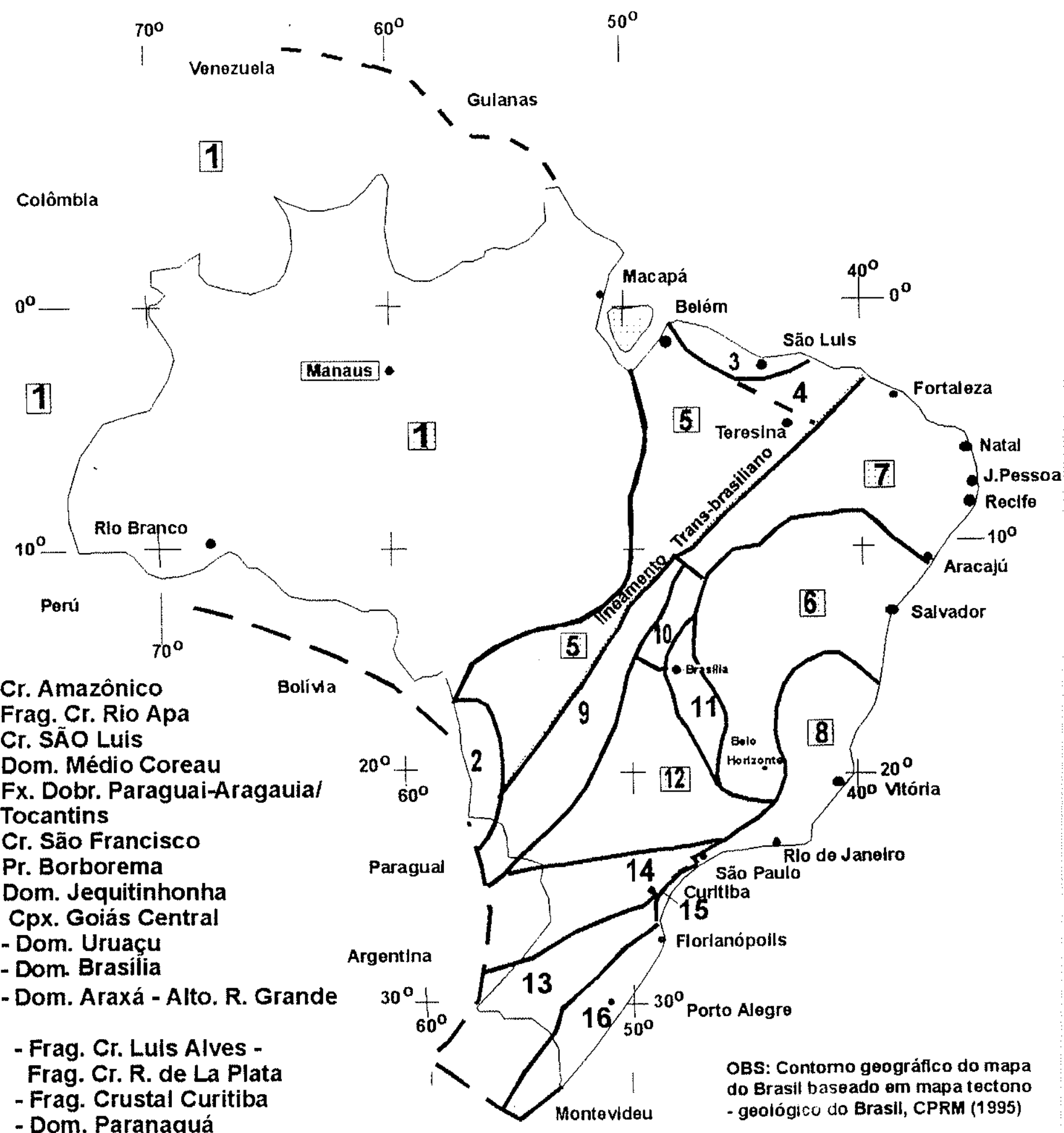

15 - Dom. Paranaguá

16 - Dom. D. Feliciano

FIG. 5.1-2 - COMPARTIMENTAÇÃO GEOCTECTÓNICA BASEADO EM CORDANI ET. AL. (1988, MODIFIC 


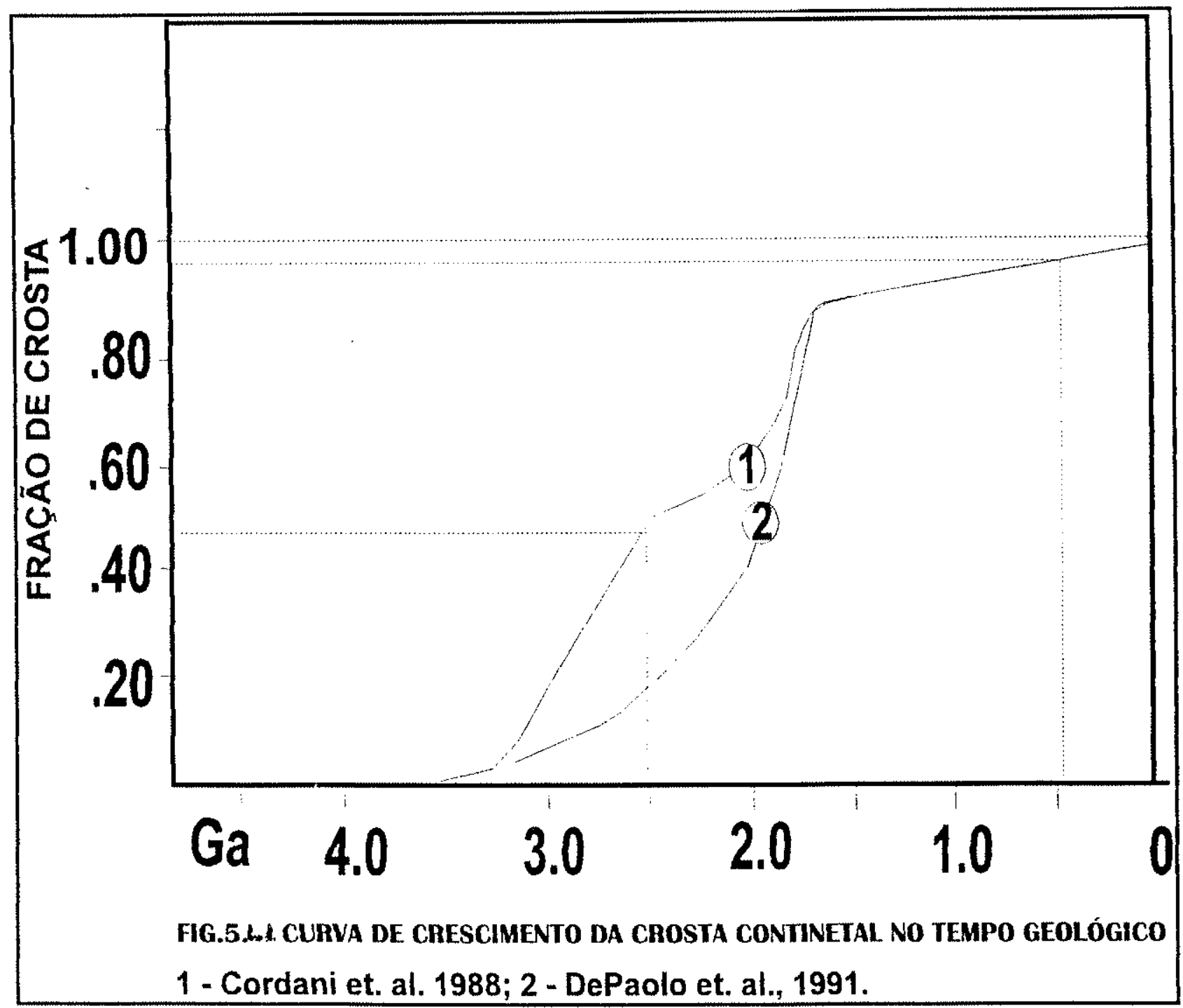


modificados, por causa de informações adicionais recentes, seja de geologia regional como de geocronologia.

Como no caso do trabalho de Cordani et al. (op cit.), foram utilizados os limites das unidades geotectônicas maiores, os cratons sin-brasilianos em relação às suas faixas móveis adjacentes. Desta forma, foram destacados para análises em separado os cratons Amazônico e do São Francisco, bem como os fragmentos cratônicos menores (São Luiz, Luiz Alves, Rio de La Plata, e Rio Apa). Além disso, em cada uma das faixas móveis brasilianas estudadas, foram separados para análises individuais determinados blocos tectônicos, separados quase sempre por descontinuidades tectônicas importantes, e sempre que possível caracterizados pela coerência de suas histórias geológicas.

A figura 5.2 exibe a compartimentação geotectônica escolhida para os estudos interpretativos deste trabalho. Cada uma das unidades maiores indicada foi objeto de análise interpretativa individualizada, num dos sub-itens deste capitulo 5 . Na figura, é muito nítida a importância do Lineamento Trans-brasiliano, que corta completamente a Plataforma Sul Americana de NE para SW, e representa quase seguramente a sutura principal que conectou as grandes massas continentais contendo os cratons Amazônico e do São Francisco/Congo, no Neoproterozóico, como etapa maior do processo de aglutinação do Gondwana (Brito Neves e Cordani, 1991). O craton Amazônico atuou de modo mais ou menos rígido, mantendo sua integridade tectônica, apesar da ativação tectônica em suas faixas marginais. Entretanto, a articulação das massas cratônicas menores do lado sudeste do lineamento Trans-brasiliano, São Francisco, Luiz Alves, Rio de La Plata e Paraná(?), produziu um complexo "collage" de faixas marginais, microcontinentes, blocos e fragmentos tectônicos, etc. completamente afetados pela tectônica Brasiliana.

Há duas diferenças importantes no conhecimento das duas grandes áreas a NW e a SE do Lineamento Trans-brasiliano. Primeiramente em termos de conhecimento geral da geologia e da geotectônica, visto que a região a SE inclui todas as regiões mais conhecidas do Brasil (Minas Gerais e Bahia, Nordeste, Sudeste, Sul e Centro-Oeste ). Em segundo lugar, em termos de geocronologia e geoquímica isotópica (e especialmente no tocante a datações $\mathrm{Sm}-\mathrm{Nd}$ ), visto que na região Amazônica os trabalhos atingem apenas o nivel de reconhecimento. Isto se reproduz neste trabalho, de modo que as interpretações a respeito da evolução crustal somente podem ser efetuadas de modo incipiente na região centro-norte da Plataforma Sul Americana (sub-capítulos 5.2 a 5.5 ) enquanto que podem elas serem mais elaboradas nas demais regiões. 
Nos sub-capítulos que se seguem, o autor procurou sempre apresentar um mapa de localização das amostras analisadas, em contexto geotectônico simplificado. Acompanham cada sub-capitulo tabelas contendo os dados analíticos completos das amostras analisadas, inclusive aqueles mais utilizados nas interpretações $\left(\mathrm{T}_{\mathrm{DM}}, \mathrm{f}, \varepsilon_{\mathrm{Nd}}\right)$ e que serviram para a elaboração dos diferentes diagramas interpretativos utilizados nas interpretações a respeito de evolução crustal

Para a caracterização litológica das amostras analisadas, nem todas tiveram análises petrográficas completas, e muitas foram indicadas pelos seus respectivos coletores com denominação aproximada, após exame macroscópico, de campo. Em vista disso, para maior clareza e simplificação, o autor resolveu utilizar apenas oito categorias litológicas em suas tabelas, como segue:

1 - granitóides (GTD) - referem-se a grande maioria das amostras analisadas para este trabalho, e incluem rochas tipicamente magmáticas (granitos, granodioritos, tonalitos, qzmonzonitos, trondhjemitos, etc.) ao lado de tipos deformados (gnaisses de composição variada) e de algumas rochas descritas como anatexitos, migmatitos diversos, augen-gnaisses, etc.

2 - granulitos e gnaisses de alto grau (GNL) - rochas supostamente indicadoras de origem da crosta inferior, incluindo charnoquitos e granulitos félsicos.

3 - rochas básicas (BAS) - prováveis representantes de litosfera oceânica (metabasaltos, metagabros, anfibolitos) ou de intrusões básicas e intermediárias diversas, como dioritos e diabásios.

4 - rochas ultrabásicas (UBA) - representam rochas metavulcânicas de natureza komatiitica, normalmente associadas com cinturões de rochas verdes ("greenstone belts").

5 - rochas vulcânicas ácidas (VAC) - aparecem em alguns casos, em sequências supracrustais em que aparecem termos vulcânicos e metavulcânicos, principalmente félsicos, tais como meta/riolitos, meta/dacitos, meta/riodacitos, meta/andesitos e meta/shoshonitos.

6 - metassedimentos (MSE) - trata-se de poucos casos, em que aparecem sequências supracrustais incluindo termos metasedimentares.

7 - metassedimentos químicos (MSQ) - tais como formação ferrífera bandada e chert.

8 - concentrados de minerais ( $\mathbf{M x x}$ ) - onde xx representa tipo de minerais tais como af = anfibólio, $\mathrm{bi}=$ biotita, $\mathrm{pl}=$ plagioclásio, $\mathrm{pi}=$ piroxênio, $\mathrm{gr}=$ granada e al = allanita .

Nota explicativa completa das tabelas $\mathrm{Sm}$ e Nd chamadas neste capítulo encontra-se no apêndice 1 . 


\section{2 - CRATON AMAZÔNICO}

\section{2-1 - GENERALIDADES}

Embora trate-se de um área enorme da Plataforma Sul-Americana, cobrindo pelo menos $4530 \times 10^{3} \mathrm{Km}^{2}$, visto que seus limites ocidentais perdem-se sob as coberturas mesocenozóicas das bacias marginais andinas, são disponíveis para a interpretação da sua evolução crustal apenas 70 idades modelo $\mathrm{Sm}-\mathrm{Nd}\left(\mathrm{T}_{\mathrm{DM}}\right)$, principalmente em granitóides de amostras isoladas provenientes de diversas regiões do Craton. As rochas analisadas foram coletadas principalmente pelo PROJETO RADAMBRASIL e se encontram disponíveis no acervo do CPEGeo-IG-USP.

\section{2-2 - CONTEXTO GEOLÓGICO-GEOTECTÔNICO DO CRÁTON AMAZÔNICO}

O Craton Amazônico estabilizou-se tectônicamente no final do Mesoproterozóico. Dados geocronológicos (U-Pb, $\mathrm{Rb}-\mathrm{Sr}, \mathrm{Pb}-\mathrm{Pb}$ e K-Ar) obtidos em amostras do embasamento e de granitóides pós-tectônicos, têm demonstrado que a sua evolução crustal pode ser descrita a partir de alguns núcleos arqueanos, que foram amalgamados através cinturões móveis do ciclo orogênico Transamazônico, e que, por sua vez, às grandes massas continentais assim formadas foram adicionados arcos magmáticos sucessivos, com idades variáveis desde $1.9 \mathrm{Ga}$. até $1.55 \mathrm{Ga}$. Finalmente a imensa área continental resultante aglutinou-se, em sua borda sudoeste, com outra massa continental menor, durante dois eventos orogênicos, de natureza predominantemente ensiálica, denominados de Rondoniano San Ignácio e Sunsás (Cordani et. al., 1979 ; Teixeira et. al. 1989, Tassinari 1996).

Neste sentido, o Cráton é dividido nas seguintes províncias tectônicas e geocronológicas: Província Amazônia Central (> 2,5 Ga), Provincia Maroni-Itacaiúnas (2,2 1,95 Ga), Província Ventuari - Tapajós (1,95 - 1,80 Ga), Província Rio Negro-Juruena (1,80 - 1,55 Ga) Provincia Rondoniana - San Ignácio (1,5 - 1,3 Ga) e Província Súnsás (1,25 - 1,0 Ga) (Fig. 5.2-1) 
A Província Amazônia Central (PAC) constitui uma importante entidade tectônica do Craton Amazònico, que inclui fragmentos continentais com idades radiométricas arqueanas. Esses fragmentos foram preservados pela orogenia transamazonica, mantendo-se tectônicamente estáveis desde o arqueano, servindo entretanto de palco para importantes atividades igneas cratogênicas durante todo o Proterozóico.

A Província Maroni - Itacaiúnas (PMI) teve sua evolução metamórfica entre aproximadamente 2.2 - $1.95 \mathrm{Ga}$. Este domínio possui uma grande extensão, ocorrendo no Suriname, Guiana Francesa e partes do Brasil (Pará e Amapá) e da Venezuela. Em grandes traços esta província geocronológica compreende uma parte formada por terrenos gnáissicogranuliticos com protólitos arqueanos, e outra parte com terrenos granito-greenstone, incluindo inúmeros granitóides do tipo TTG diferenciados do manto durante a orogênese Transamazônica

\section{A Província Ventuari - Tapajós (PVT) e a Província Rio Negro (PRNJ)} ocorrem na porção ocidental do Cráton Amazônico constituindo uma zona de intensa granitização e migmatização, desenvolvida através de uma sucessão de arcos magmáticos juvenis entre 1,95 e 1,55 Ga. A primeira teve a sua evolução crustal entre 1,95 e 1,8 Ga enquanto que a segunda que desenvolveumse entre 1,80 e 1,55 Ga (Tassinari et. al. 1996), O histograma da fig. 5.2-2 mostra claramente que a orogênese Ventuari - Tapajós é mais antiga que a Rio Negro-Juruena.

A Província Rondoniana - San Ignácio (PRSI) situa-se na parte sudoeste do Craton Amazônico, e inclui rochas polimetamórficas em grande parte granitóides, formadas principalmente dentro do intervalo de tempo 1, 5 a 1,30 Ga, mas também contem núcleos preservados de rochas mais antigas. A presença destes núcleos antigos, aliada a parâmetros de geoquímica isotópica de $\mathrm{Sr}$ e $\mathrm{Nd}$, confere ao domínio Rondoniano - San Ignácio um caráter ensiálico, com o evento datado em 1,50 - 1,30 Ga retrabalhando rochas mais antigas formadas principalmente no Paleoproterozóico.

A Província Sunsás (PS) ocorre no extremo sudoeste do Cráton Amazônico e inclui as rochas geradas durante a orogenia Sunsás, definida por Litherland e Bloomfield (1981). Atividade granitica relacionada à orogenia Sunsás compreende vários tipos de plútons, a grande maioria deles tipicamente cratogênicos, de natureza subvulcânica, e com idades entre 1100 e $990 \mathrm{Ma}$ 


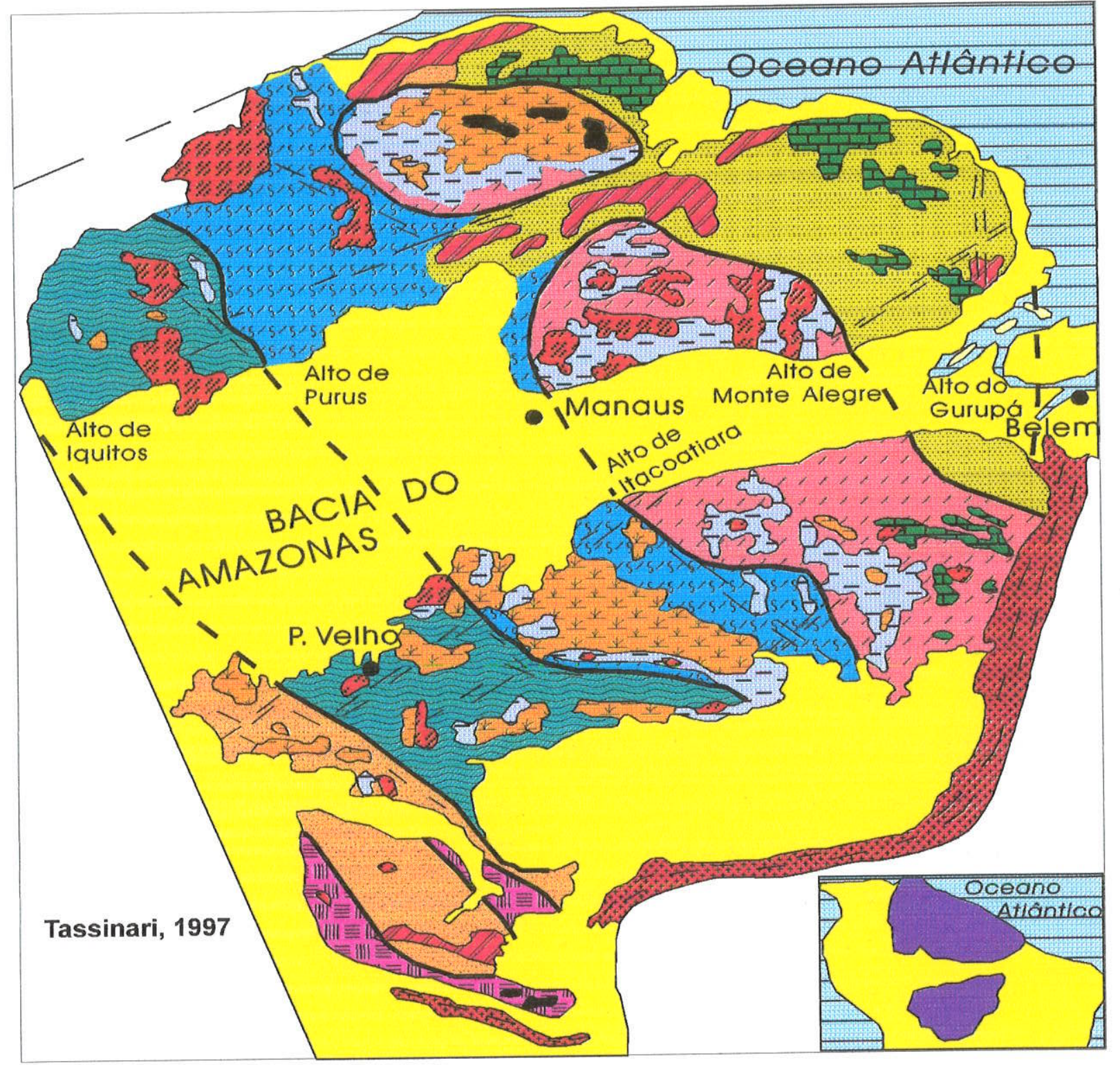

PROVÍNCIAS GEOCRONOLÓGICAS

1. Amazonia Central $>2.3 \mathrm{Ga}$

Maroni - Itacaiunas

$2.2-1.9 \mathrm{Ga}$

ए5:- Ventuari-Tapajós

$1,9-1,8 \mathrm{Ga}$

Rio Negro - Juruena $1.8-1.55 \mathrm{Ga}$

Rondoniana - San Ignácio $1.5-1.3 \mathrm{Ga}$

Sunsás

1.25-1.0 Ga
UNIDADES GEOLÓGICAS

Coberturas Fanerozóicas

\$\$2 Granitóides

Coberturas Sedimentares Pré-cambrianas

[-- Coberturas Vulcânicas

Vulcanismo básico

Greenstone Belts

1.1. Complexos Granulíticos

Faixa de Dobramentos Neoproterozóica

FIG. 5.2.1 - PROVÍNCIAS TECTÔNICAS DO CRATON AMAZÔNICO 


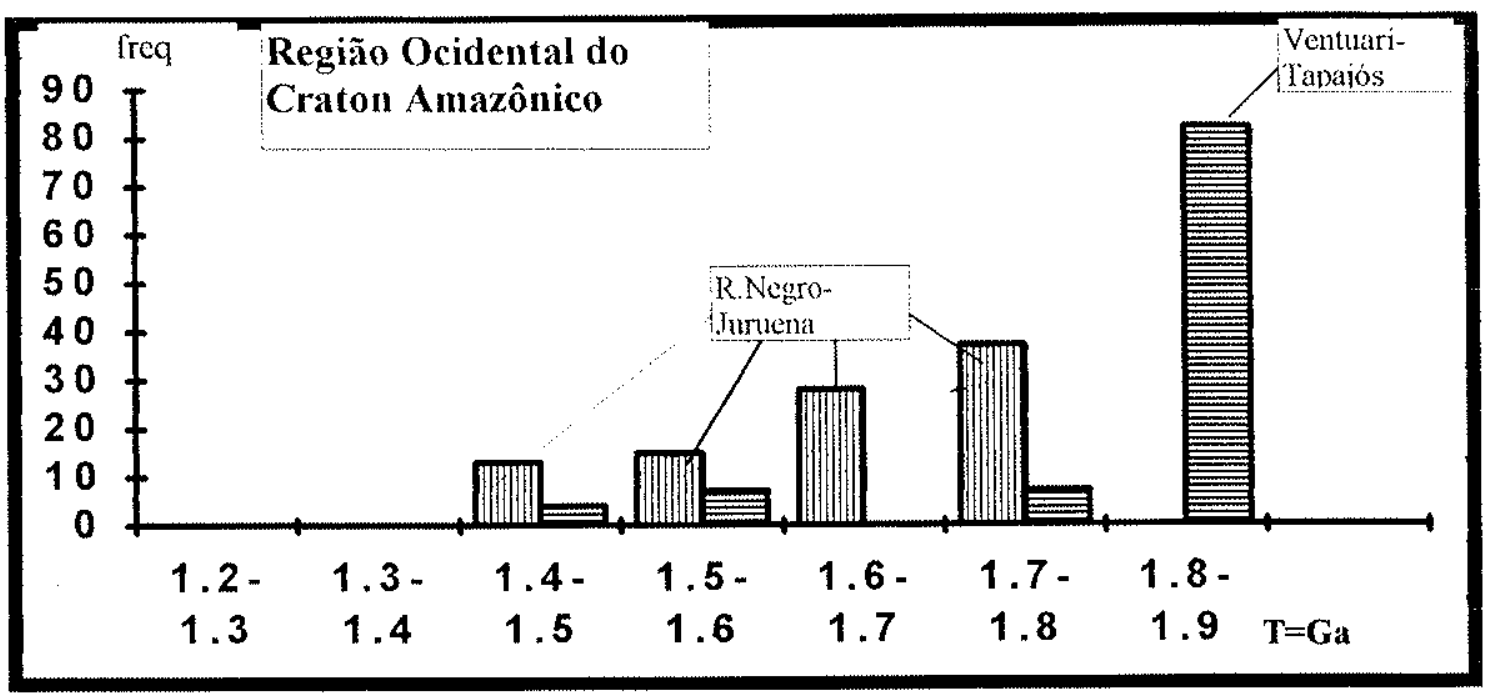

Fig. 5.2-2: Histograma mostrando a frequência nas idades $\mathrm{Rb}-\mathrm{Sr}$ de todos os tipos de litologias na região Ocidental do Craton Amazônico nas faixas Ventuari-Tapajós e Rio Negro - Negro Juruena. Na região da PVT ocorrem rochas granitóides sistematicamente mais velhas em relação à região PRNJ, com pico de idade entre $1,9 \mathrm{Ga}$ a $1.8 \mathrm{Ga}$ (retângulos com listras horizontais). Entre 1,6 a 1,4Ga. na PVT, ocorreram intrusões anorogênicas tais como granitos Rapakivi (Venezuela). Por outro lado as idades Rb-Sr da PRNJ variaram entre 1,8 a $1,4 \mathrm{Ga}$ (retângulos com listras verticais). Aqui também as idades mais novas correspondem intrusões anorogênicas. (Dados compilados a partir de Tassinari,1981) e Barrios, 1983).

A seguir serão discutidos os dados $\mathrm{Sm}-\mathrm{Nd}$ obtidos nestas provincias. $\mathrm{Na}$ fig. $5.2-3$ encontram-se representadas as localizações aproximadas das amostras datadas pelo método $\mathrm{Sm}-\mathrm{Nd}$.

\section{2-3 IDADES MODELO Sm-Nd}

\section{PROVÍNCIA AMAZÔNIA CENTRAL (PAC)}

Na região da Serra dos Carajás as idades $T_{D M}$ obtidas para os granitóides do embasamento, distribuem-se entre 3,04 a 2,8 Ga (amostras A,C,D, E e F da tab. 5.2 -1). Estes resultados confirmam as idades $\mathrm{Rb}-\mathrm{Sr}$ e U-Pb arqueanas $(3,1-2,7 \mathrm{Ga})$, já reportadas em trabalhos prévios.

As rochas vulcânicas ácidas (amostras L,M,N da tab. 5.2-1) da parte Sul da PAC e o granitóide anorogênico neste dominio (amostra G), situado a NW da Serra dos Carajás (fig. 5.2-3) foram formados no Paleoproterozóico, com idades $\mathrm{Rb}$-Sr variando entre 1,8 a $1,7 \mathrm{Ga}$ 
com RI entre 0,705 a 0,706 . Seus protólitos foram diferenciados do manto superior entre 2,6 a $2,5 \mathrm{Ga}$, conforme indicado pelo valores de $\mathrm{T}_{\mathrm{DN}}$.

A fig. 5.2-4 corresponde à integração dos dados isotópicos da PAC onde, entre as linhas contínuas contendo símbolos quadrados são representadas as rochas plutônicas da Serra de Carajás e suas vizinhanças e entre as linhas tracejadas (contendo circulos fechados) são representadas a rochas vulcânicas e metavulcânicas ácidas.

A correlação isotópica entre as assinaturas isotópicas iniciais $\varepsilon_{\mathrm{Sr}}(\mathrm{t})$ versus $\varepsilon_{\mathrm{Nd}}(t)$ para $t$ relativo à época da formação (idade $\mathrm{Rb}-\mathrm{Sr}$ ) dos granitóides de Carajás e das rochas vulcânicas ácidas, é apresentada na fig.5.2-5. Observa-se que os dados relativos aos granitóides de Carajás (pontos A a F) distribuem-se próximos da origem, e alguns dentro do campo relativo ao manto, sugerindo que o intervalo de tempo foi muito curto entre a época da diferenciação do material do manto superior (DM) e a formação dessas rochas. As vulcânicas ácidas, por sua vez, bem como os granitos (amostras $G, L, M$ e $N$ da tab. 5.2-1; fig.5.2-5) mostram comportamento distinto com $\varepsilon_{\mathrm{Nd}}(\mathrm{t})$ mais negativos e $\varepsilon_{\mathrm{Sr}-\mathrm{Rl}}(\mathrm{t})$ mais positivos, sugerindo um período maior de residência crustal dos protolitos dessas rochas.

As rochas metavulcânicas do Grupo Grão Pará (amostras $\mathrm{O}$ a $\mathrm{Z}$, tab. 5.2-1) foram datadas através de diagrama isocrônico $\mathrm{Sm}-\mathrm{Nd}$, obtendo-se uma idade aparente em torno de 2,8Ga (Gibbs 1983). As idades modelo, calculadas com base em estágio duplo, indicaram valores discordantes distribuidos entre 3,09 a $2,6 \mathrm{Ga}$, com uma maior concentração de resultados em torno de $2,8 \mathrm{Ga}$. Entre estas rochas metavulcânicas encontram-se duas amostras com características típicas de rocha máfica (amostras $R$ e $S$, tab. 5.2-1). Os cálculos de idades modelo $\mathrm{Sm-Nd}$ para tais rochas máficas não são apropriados, pois possuem razão ${ }^{147} \mathrm{Sm} /{ }^{144} \mathrm{Nd}$ muito próxima do manto CHUR ou DM.

\section{PROVÍNCIA MARONI-ITACAIÚNAS (PMI)}

No âmbito da PMI foram analisadas rochas diversas, incluindo granitóides, granulíticas, ultrabásicas e básicas que indicaram idades modelos $\mathrm{T}_{\mathrm{DM}}$ relativas ao Paleoproterozóico, com valores relativamente concordantes, distribuindo-se entre 2,3 a 2,06Ga, figs. 5.2-6 e 5.2-7 e tab. 5.2-2. Duas amostras de rochas tonalíticas (amostras G e $H$, tab. 5.2-2) proveniente da região de Cupixi - Sul do Amapá, evidenciaram idades $T_{D M} 3,1$ e 3,06Ga, confirmando a existência de um fragmento crustal arqueano, preservado como "inlier" dentro da PMI, em concordância com a idade arqueana de 2,9Ga previamente obtida por Montalvão e Tassinari (1983) e Siga Jr. (1986). Na mesma região do rio Cupixi 


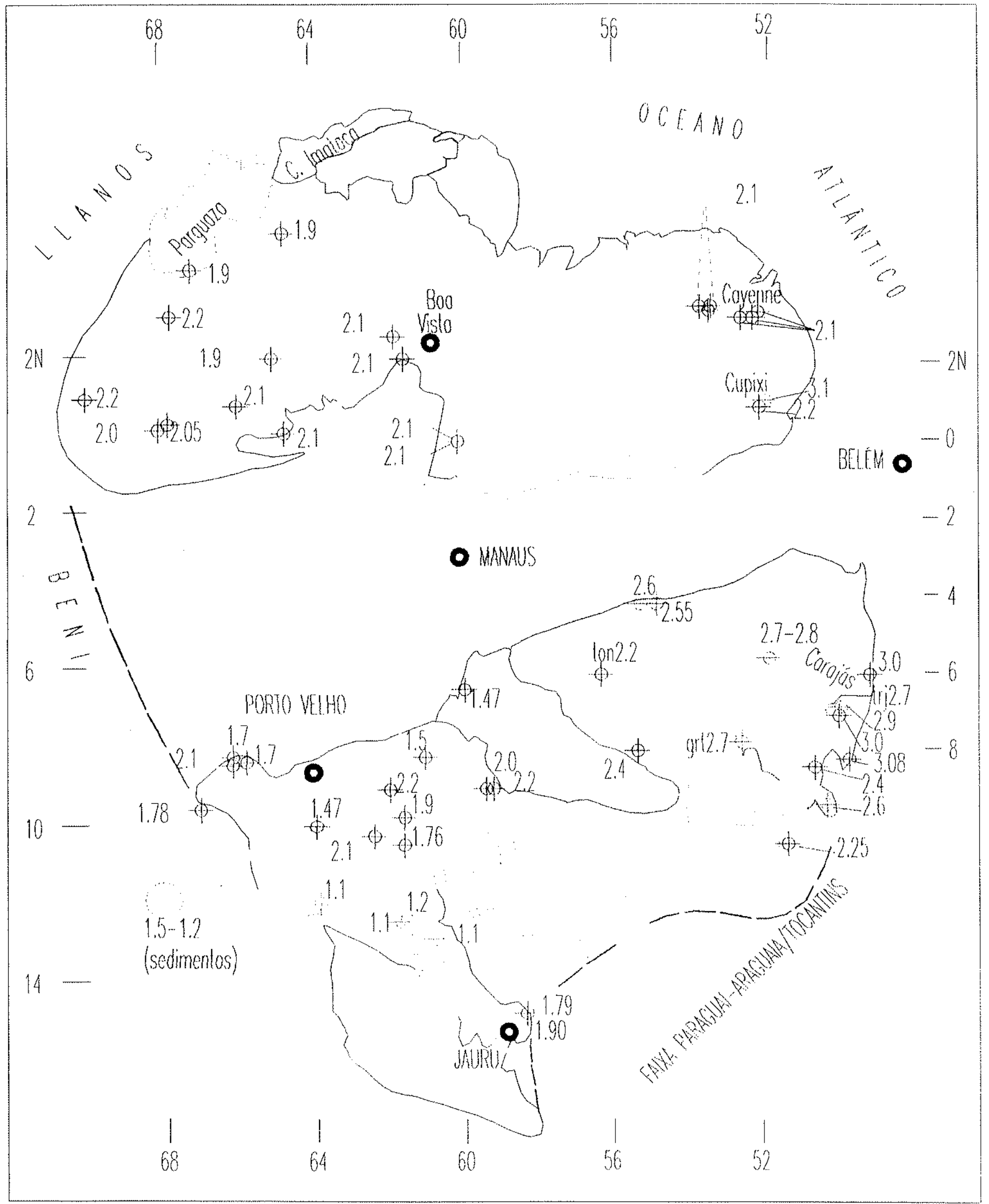

Fi6. 5.2-2. Locolizaçóo dos amosiros datodos peto método Sm-Nd. Os numeros representam idodes $\mathrm{Tdm}$ em ( 60 ). 


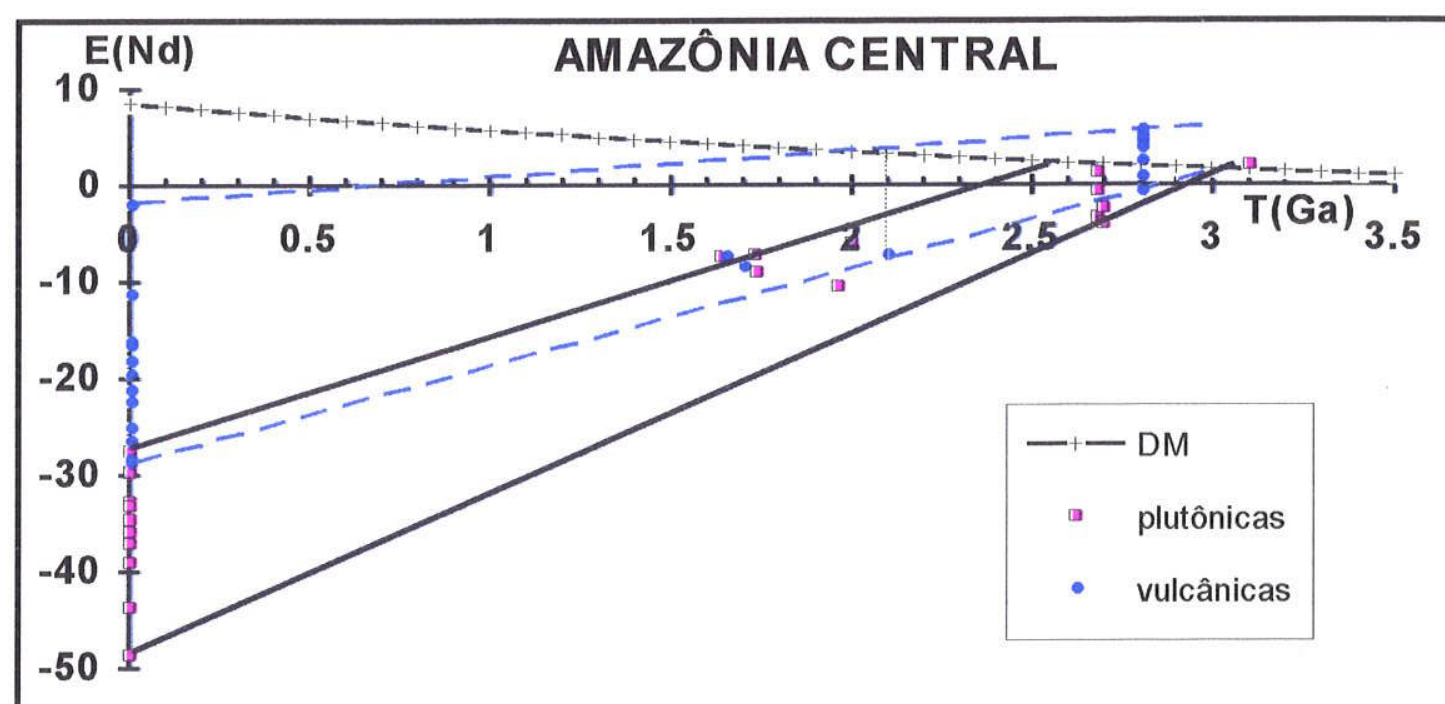

fig. 5.2-4: Diagrama de evolução isotópico $\varepsilon_{\mathrm{Nd}}$ em função do tempo geológico relativos às plutônicas (quadrado) e vulcânicas da Amazônia Central (tab. 5.2-1). Os pontos assinalados próximo ao eixo da abcissa representam os valores de $\varepsilon_{\mathrm{Nd}}$ calculados para a época do evento de fechamento do Sistema Rb-Sr.

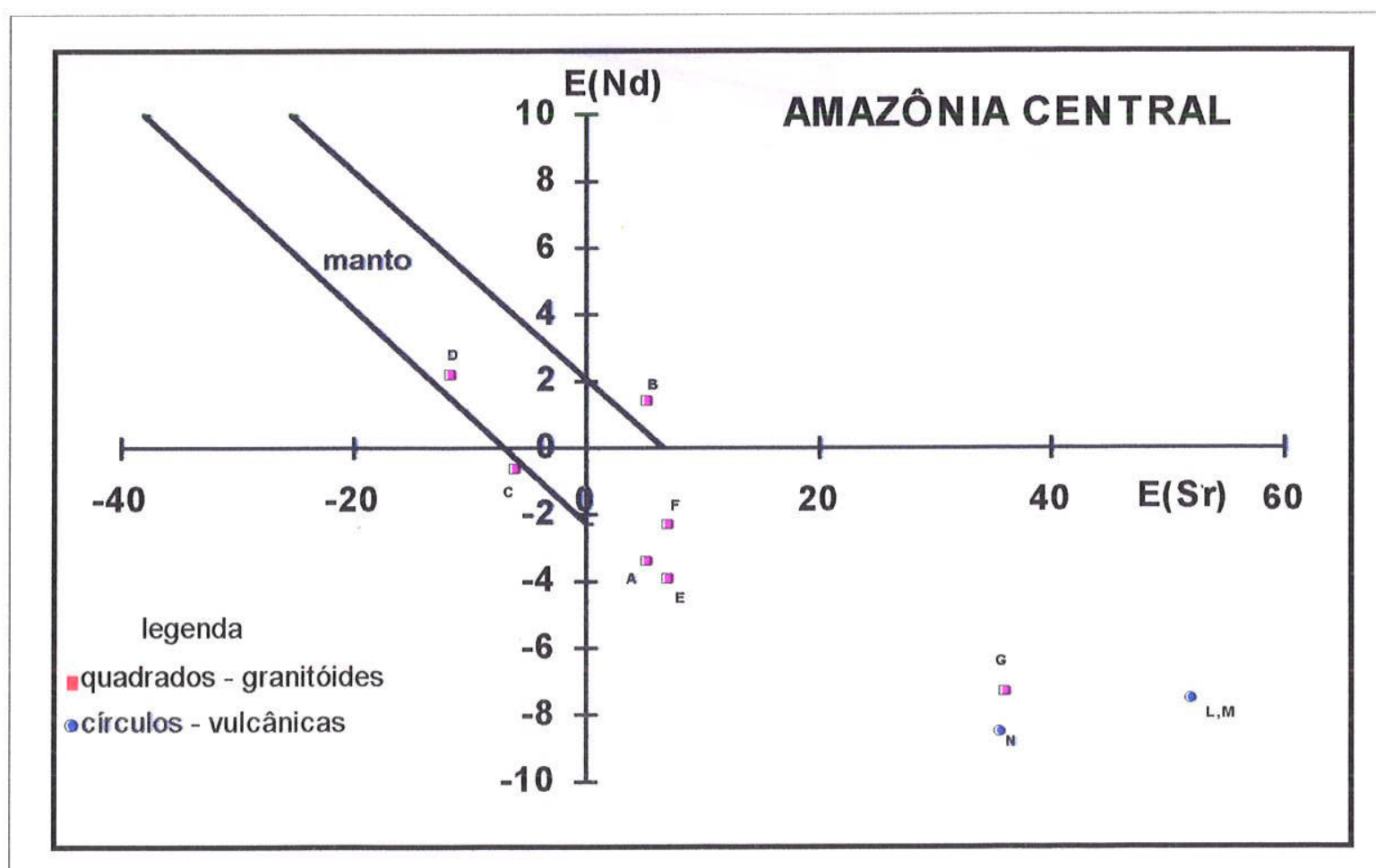

Fig. 5.2-5: Diagrama de $\varepsilon_{\mathrm{Sr}}(\mathrm{t})$ versus $\varepsilon_{\mathrm{Nd}}(\mathrm{t})$ - Amazônia Central. Os dados isotópicos encontram-se na tab. 5.2-1. 


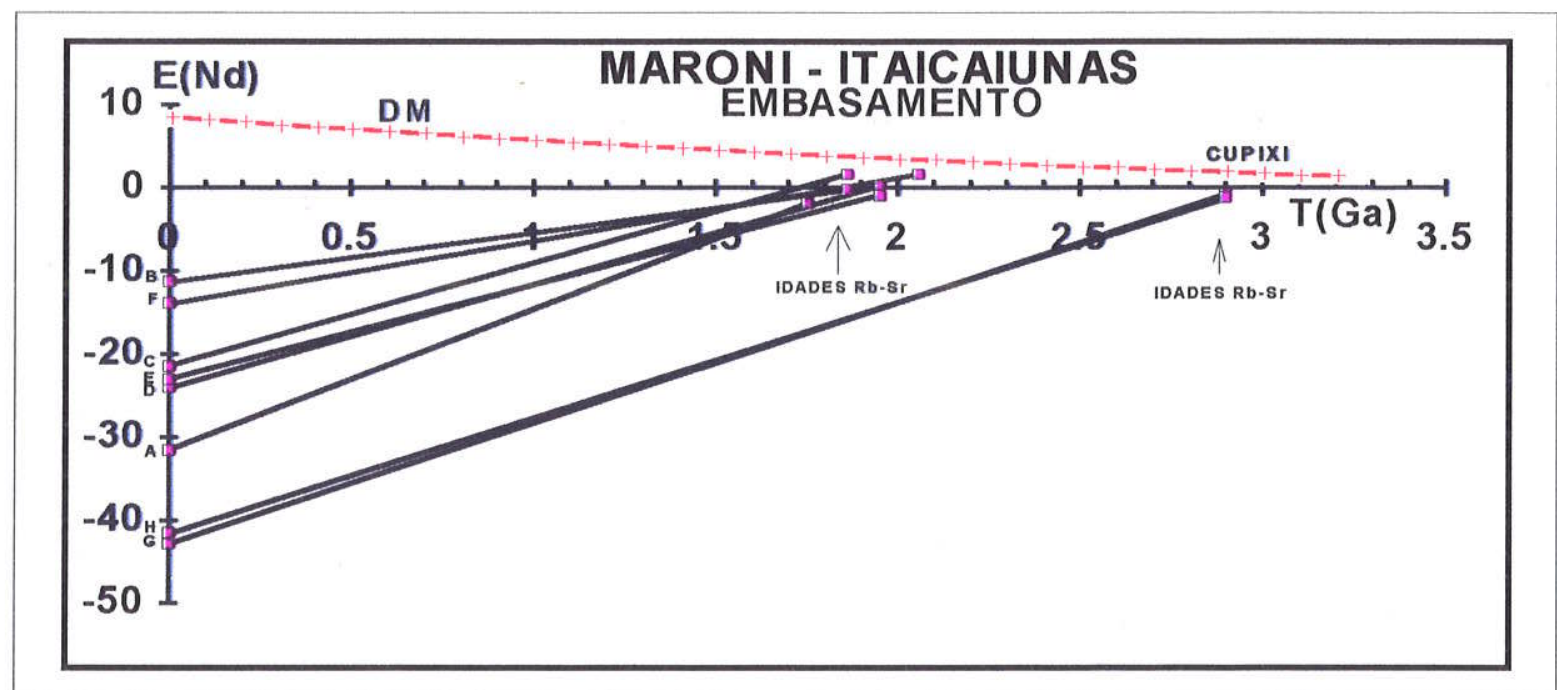

Fig. 5.2-6: Diagrama de evolução isotópica $\varepsilon_{\mathrm{Nd}}$ versus tempo geológico $\mathrm{T}(\mathrm{Ga})$ das rochas da Província Maroni-Itacaiúnas. Os dados isotópicos encontram-se na tab. 5.2-2

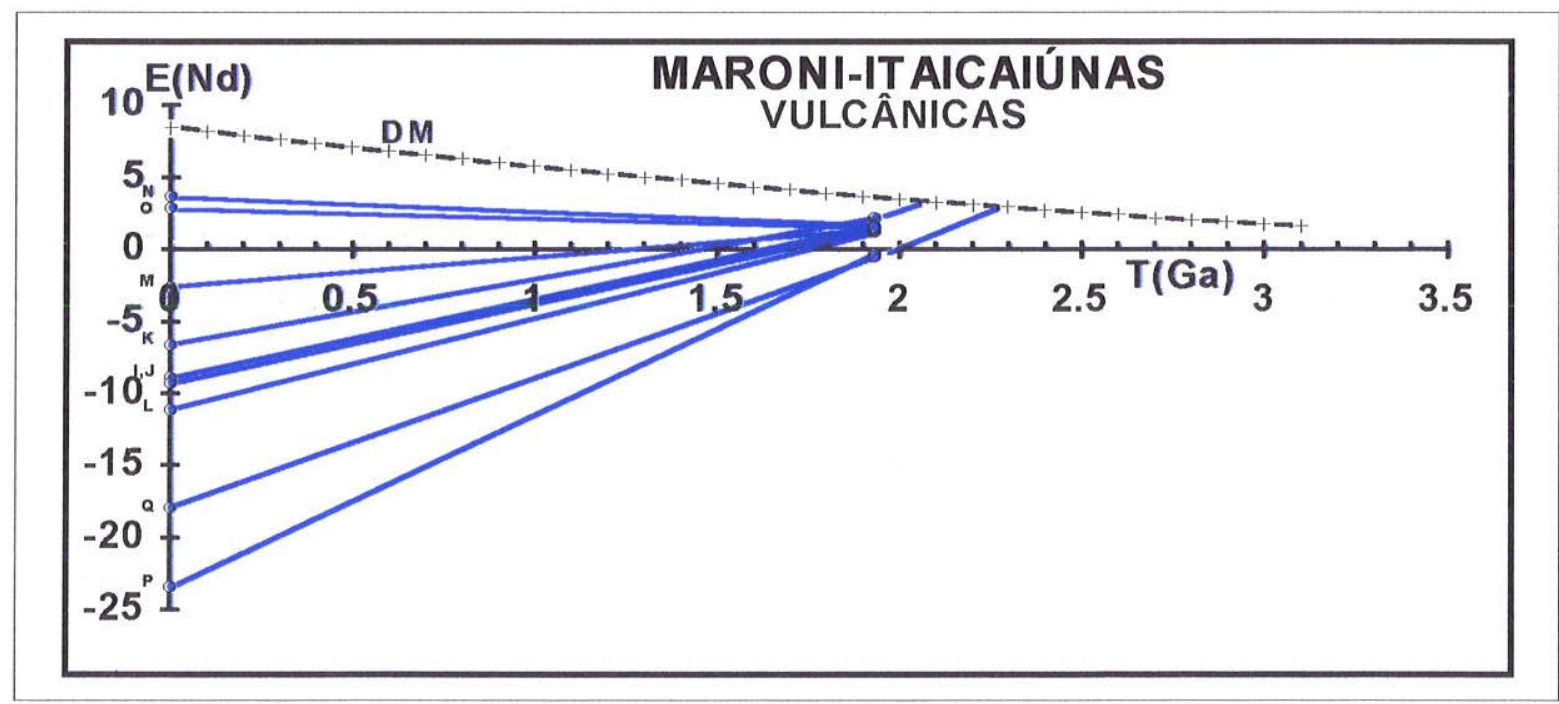

Fig. 5.2-7: diagrama de evolução isotópica $\varepsilon_{\mathrm{Nd}}$ versus tempo geológico $\mathrm{T}(\mathrm{Ga})$ das metavulcânicas da Província Maroni-Itacaiúnas. Os dados isotópicos encontram-se na tab. 5.2-2 
(Complexo Tumucumaque) ocorrem rochas granitóides com idades Rb-Sr de 2,06 Ga e com RI de 0,760, Siga Jr. (1986) interpretou essa idade como a época de formação de tais rochas por retrabalhamento de rochas preexistentes. A idade modelo Sm-Nd do granitoide $\mathrm{F}$ (tab. 5.2-2) sugere que o respectivo protólito crustal formou-se ainda no Paleoproterozóico $(2,2 \mathrm{Ga})$.

As rochas básicas e ultrabásicas das sequências do tipo granito-greenstone que ocorrem na Guiana Francesa, analisadas conjuntamente, mostraram uma idade isocrônica SmNd de 1,93Ga (Gruau et. al. 1988, fig. 5.2-8; tab. 5.2-2 - amostras I a Q), interpretada pelos referidos autores como a idade do vulcanismo. Observa-se que os valores do $\varepsilon_{\mathrm{Nd}}(t=1,93)$ são positivos $(\sim+2)$ e posicionaram-se entre as curvas de evolução isotópica de $\varepsilon_{\mathrm{Nd}}$ do manto DM e CHUR, fig. 5.2-7. O ponto de convergência das retas situa-se em torno de 2,1Ga, sugerindo que os protólitos destas rochas crustais poderiam ser constituidos por materiais do tipo manto litosférico enriquecido (EMI).

\section{PROVÍNCIAS VENTUARI-TAPAJÓS (PVT) e RIO NEGRO-JURUENA (PRNJ)}

Várias amostras de rochas granitóides e granulíticas que ocorrem no Domínio Ventuari-Tapajós ( tab. 5.2-3) indicaram valores de $\mathrm{T}_{\mathrm{DM}}$ vinculados ao Paleoproterozóico, distribuindo-se entre 2,2 a 1,9Ga, e muito similares às idades obtidas para as rochas da PMI. A fig. 5.2-9 mostra claramente que na PVT, pelo menos até o presente momento, não foram encontradas evidências de protólitos arqueanos.

Do mesmo modo foram analisadas pelo método Sm-Nd 12 amostras de rochas granitóides e granulíticas, tab. 5.2-4, pertencentes à PRNJ. As idades $\mathrm{T}_{\mathrm{DM}}$ indicaram que o principal evento de diferenciação manto-crosta para esta província também ocorreu durante o Paleoproterozóico $\left(\mathrm{T}_{\mathrm{DM}}=2,2\right.$ a $\left.1,7 \mathrm{Ga}\right)$.

Os dados $\varepsilon_{\mathrm{Nd}}$ das amostras das PVT e PRNJ, quando analisados conjuntamente, apresentam padrões isotópicos similares, fig. 5.2-9. O periodo principal de acreção de material juvenil para a PRNJ parece estender-se pouco mais além do que para a PVT. Os simbolos triangulares (PVT) e quadrados (PRNJ) assinalados na fig.5.2-9 correspondem aos valores de $\varepsilon_{\mathrm{Nd}}(\mathrm{t})$ calculados para $\mathrm{t}$ correspondente às idades de formação das rochas obtidas pelo método $\mathrm{Rb}-\mathrm{Sr}$.

Por outro lado, os valores de $\varepsilon_{\mathrm{Nd}}(\mathrm{t})$ e $\varepsilon_{\mathrm{sr}}(\mathrm{t})$ relativos à época da formação das rochas das PVT e PRNJ, quando analisados em diagramas $\varepsilon_{S \mathrm{r}}$ versus $\varepsilon_{\mathrm{Nd}}$, figs. $5.2-10$ e 11 , apresentam padrões isotópicos distintos. Os dados da PVT (triângulos), delimitados por uma 
elipse, posicionaram-se em torno do eixo $\mathrm{X}$ e próximos da origem, sugerindo protólitos com afinidades com o manto litosférico enriquecido ou crosta inferior. Os dados relativos às rochas da PRNJ (quadrados, fig. 5.2-11) mostraram em alguns casos comportamento semelhante aos de PVT, situando-se próximos da origem (campo delimitado por elipse), mas a maioria dos pontos posicionou-se distante da origem. Para os dados com $\varepsilon_{\mathrm{Nd}}(\mathrm{t})$ negativos $\mathrm{e}$ $\varepsilon_{S r-R I}(t)$ positivos sugere-se uma fonte (protólito) com participação expressiva de material proveniente de fusão parcial da crosta continental inferior, podendo envolver também uma parcela subordinada de material mantélico.

\section{PROVÍNCIAS RONDONIANA - SAN IGNÁCIO (PRSI) e SUNSÁS (PS)}

As amostras analisadas pelo método $\mathrm{Sm}-\mathrm{Nd}$ em rochas granulíticas e granitóides relativas à PRSI apresentaram idades $\mathrm{T}_{\mathrm{DM}}$ paleoproterozóicas, distribuindo-se entre $2,08 \mathrm{e}$ 1,67Ga, fig. 5.2-12 e tab. 5.2-5, com padrões isotópicos muito similares aos da PRNJ, sugerindo a participação de rochas da PRNJ como protólitos, em muitos casos.

Por outro lado, as rochas básicas relacionados à orogenia Sunsás, no diagrama de $\varepsilon_{\mathrm{Nd}}$ versus tempo geológico, (fig. 5.2-12 - circulos e na tab. 5.2-5, amostras I a M), indicaram a possibilidade de eventos de acreção juvenil claramente mais jovens (Meso a Neoproterozóicos). Observa-se na tab. 5.2-5 e na fig. 5.2-12 que algumas rochas (tais como I e K), apresentaram idades $\mathrm{T}_{\mathrm{DM}}$ concordantes com as suas próprias idades de formação, obtidas pelo método K-Ar.

Os valores de $\varepsilon_{\mathrm{Nd}}$ analisados para ambas as províncias, conjuntamente, na fig. 5.2-12 mostraram padrões isotópicos bem distintos onde os eventos relacionados à orogenia Sunsás aparecem claramente mais jovens do que aqueles observados para a PRSI.

Basu et, al. (1990) coletaram 26 amostras de sedimentos das areias fluviais provenientes de regiões da Bolívia e do Perú, e depositadas nas margens do rio Madre Dios (bacia Amazônica). Estes sedimentos apresentaram idades $\mathrm{T}_{\mathrm{DM}}$ variadas, indicando a participação de várias fontes. Os dados isotópicos encontram-se na tab. 5.2-6 e as idades $\mathrm{T}_{\mathrm{DM}}$ recalculadas foram incluidas na fig. 5.2-13 na forma de histograma. Observa-se na figura que as idades $T_{D M}$ situam-se entre 1,65 a 1,3Ga, com um valor médio em torno de 1,45Ga, coerente com o padrão geocronológico regional, que inclui as PRSI, PS e também as rochas vulcânicas dos Andes. 


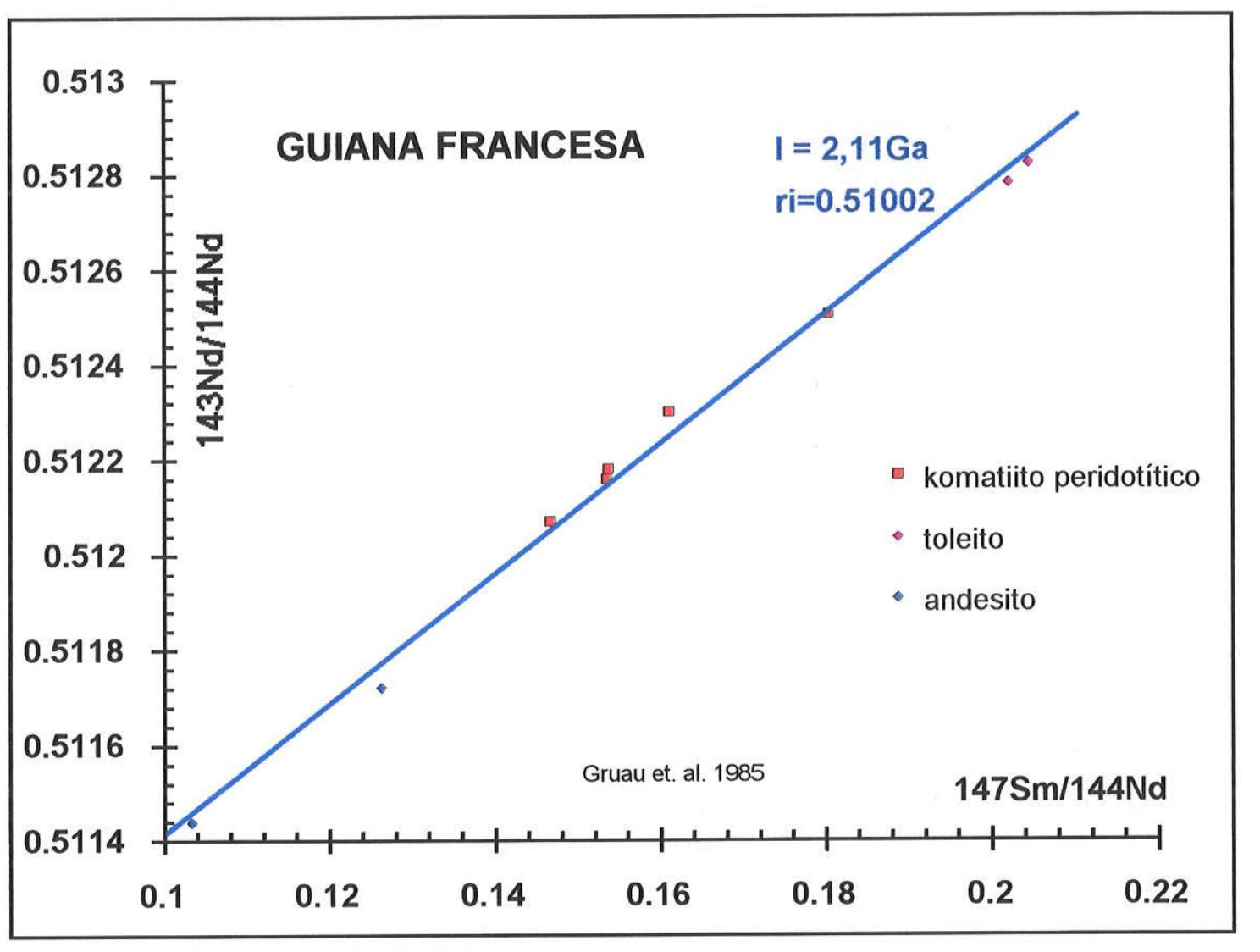

Fig. 5.2- 8: Diagrama isocrônico Sm-Nd das metavulcânicas da região da Guiana Francesa.

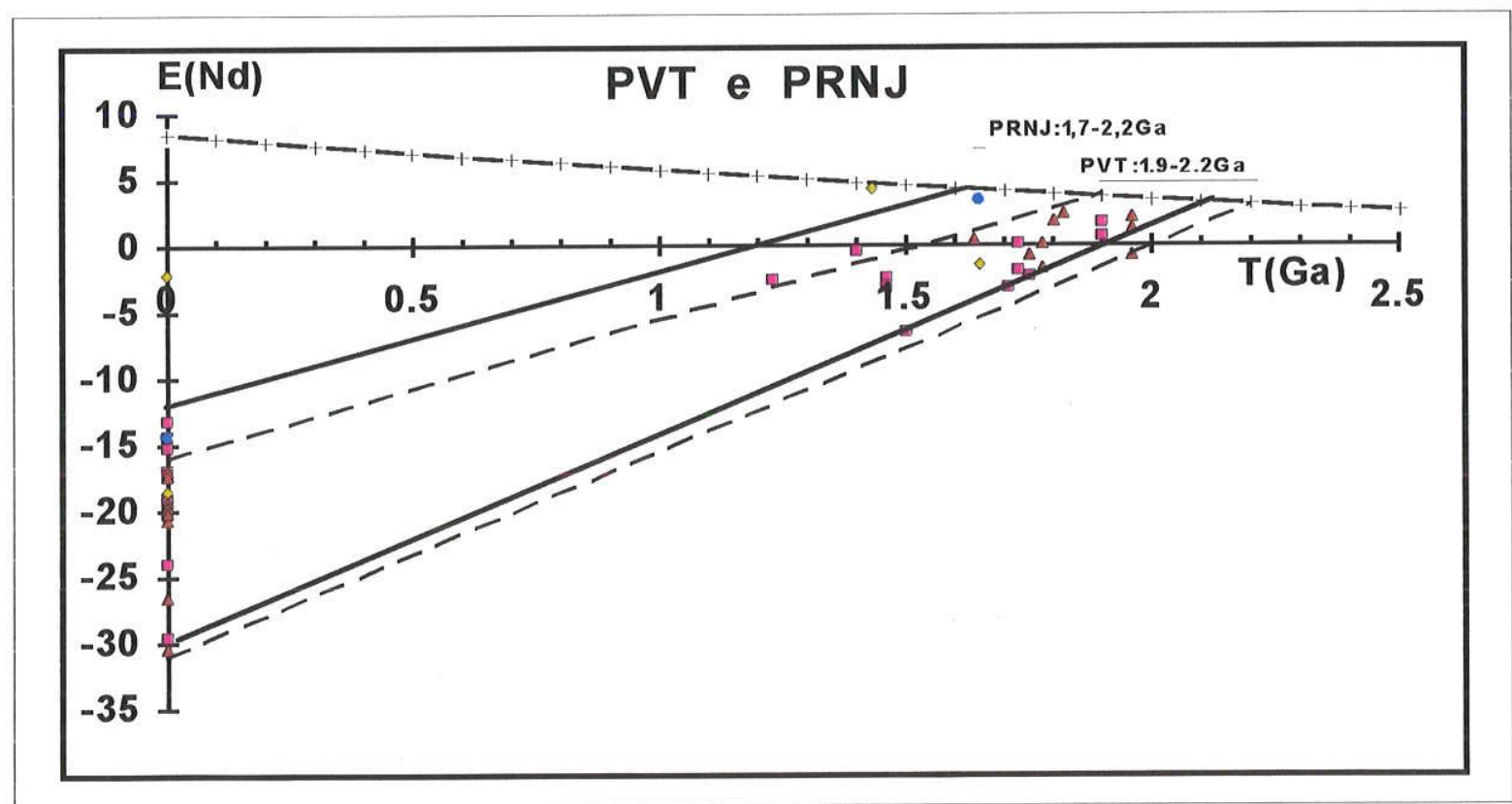

Fig. 5.2-9 : diagrama de evolução isotópica $\varepsilon_{\mathrm{Nd}}$ versus tempo geológico $\mathrm{T}(\mathrm{Ga})$. Os dados isotópicos Os dados isotópicos encontram-se na tab. 5.2-3 e 4.0 envelope entre as linhas tracejadas representa ao conjunto de linhas de evolução isotópica $\varepsilon_{\mathrm{Nd}}$ das amostras da PVT (triângulo - plutônicas, losangos - vulcânicas); e o envelope entre as linhas contínuas representa o conjunto PRNJ (quadrados - plutônicas, círculo - vulcânica). 


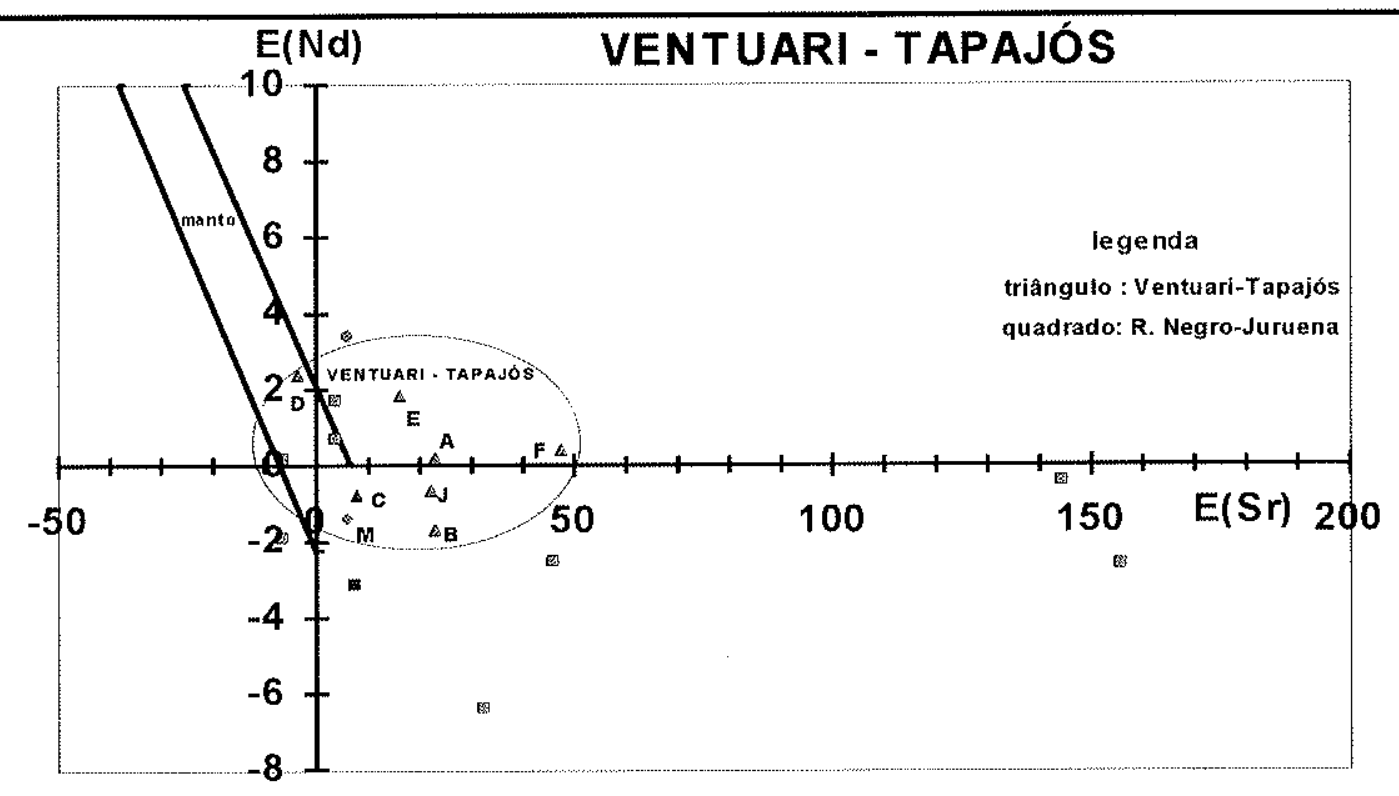

Fig. 5.2-10: diagrama de $\varepsilon_{\mathrm{Sr}-\mathrm{RI}}(\mathrm{t})$ versus $\varepsilon_{\mathrm{Nd}}(1)$-PVT (triângulos e losangos). Os dados isotópicos encontramse na tab. 5.2-3. Os quadrados são relativos à região da PRNJ.

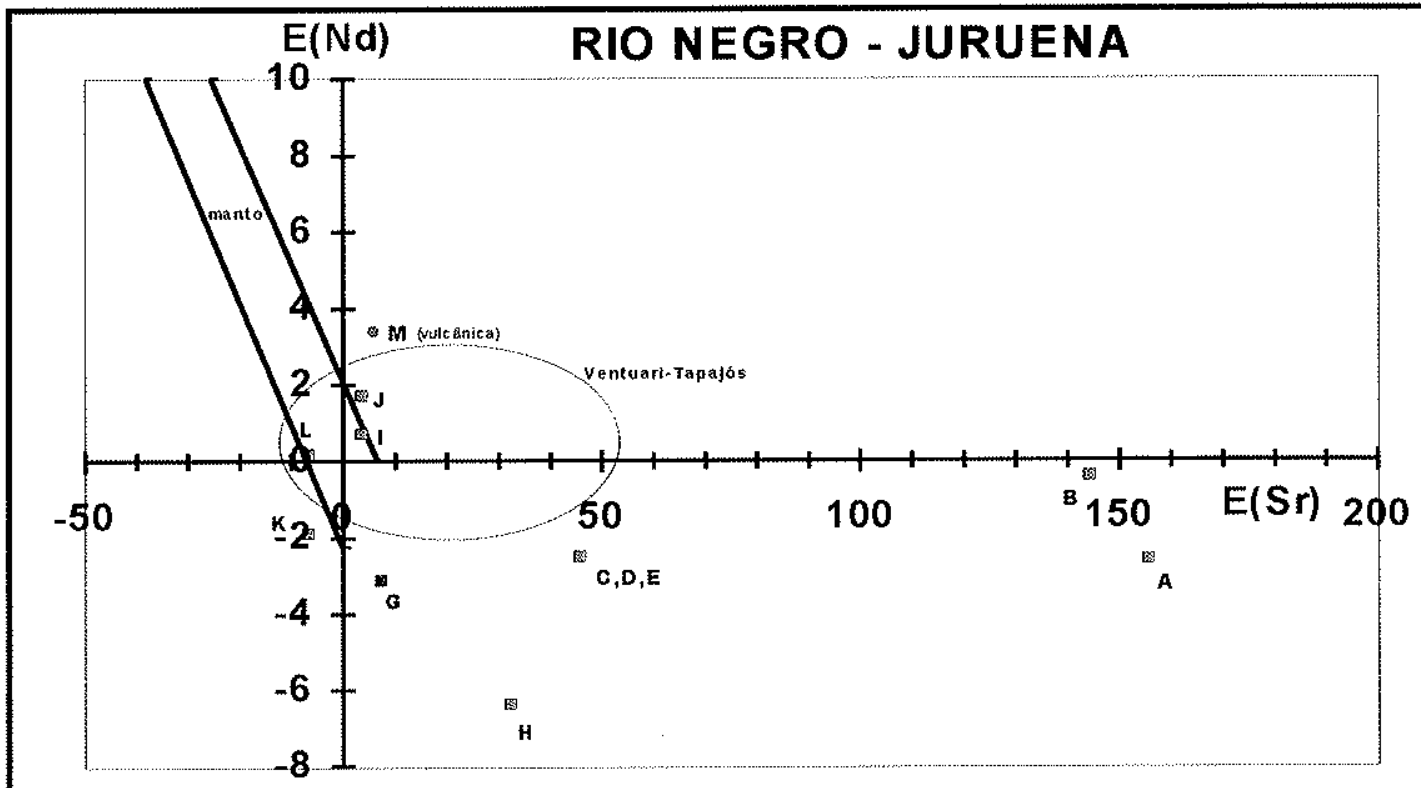

Fig. 5.2-11: diagrama de $\varepsilon_{\mathrm{Sr}}(\mathfrak{l})$ versus $\varepsilon_{\mathrm{Nd}}(\mathrm{t})-\mathrm{PRNJ}$ (quadrados e círculo). Os dados isotópicos encontram-se na tab. 5.2-4. A elipse representa o campo dos dados isotópicos $\varepsilon_{\mathrm{st}}$ e $\varepsilon_{\mathrm{Nd}}$ da região da PVT. 


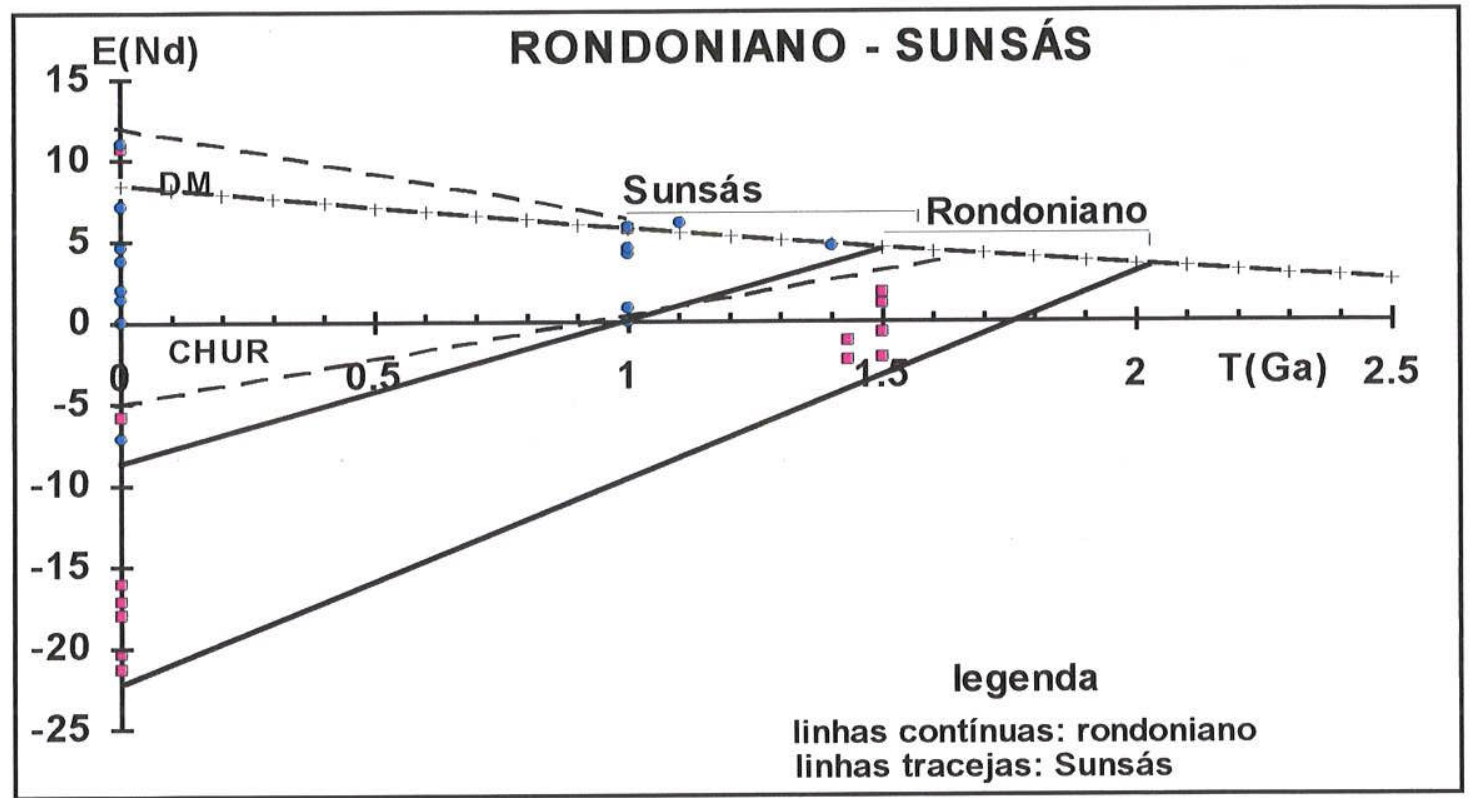

Fig. 5.2-12 : diagrama de evolução isotópica $\varepsilon_{\mathrm{Nd}}$ versus tempo geológico $\mathrm{T}(\mathrm{Ga})$. O envelope entre as linhas tracejadas representa ao conjunto de linhas de evolução isotópica $\varepsilon_{\mathrm{Nd}}$ das rochas básicas relacionadas à orogenia Sunsás (círculos ); e o envelope entre as linhas contínuas representa plutônicas da Província Rondoniana (quadrados ). Os dados isotópicos encontram-se na tab. 5.2-5

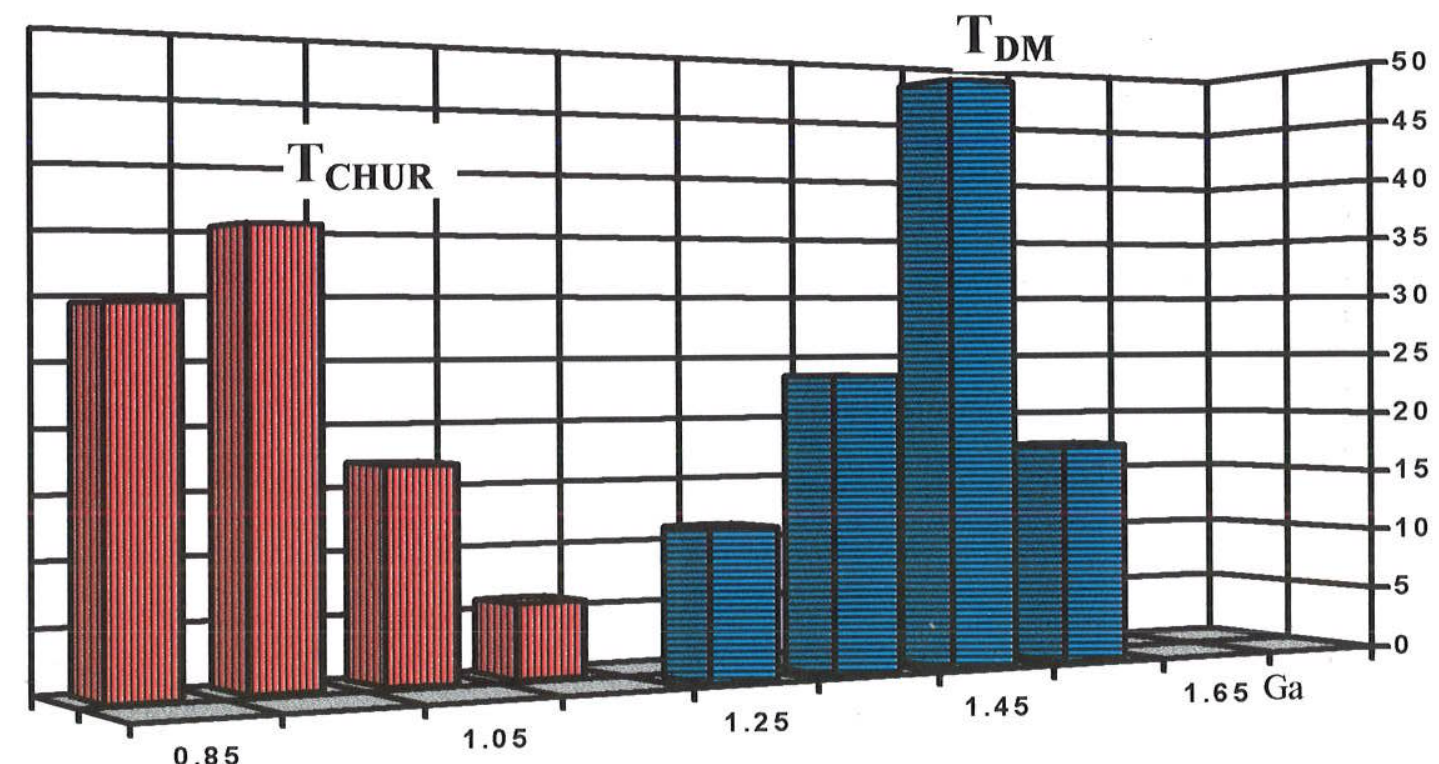

Fig. 5.2-13: histogramas de idades modelo dos sedimentos das areias fluviais das margens do Rio Madre Dios. Sedimentos provenientes da regiões da Bolívia e Peru. 


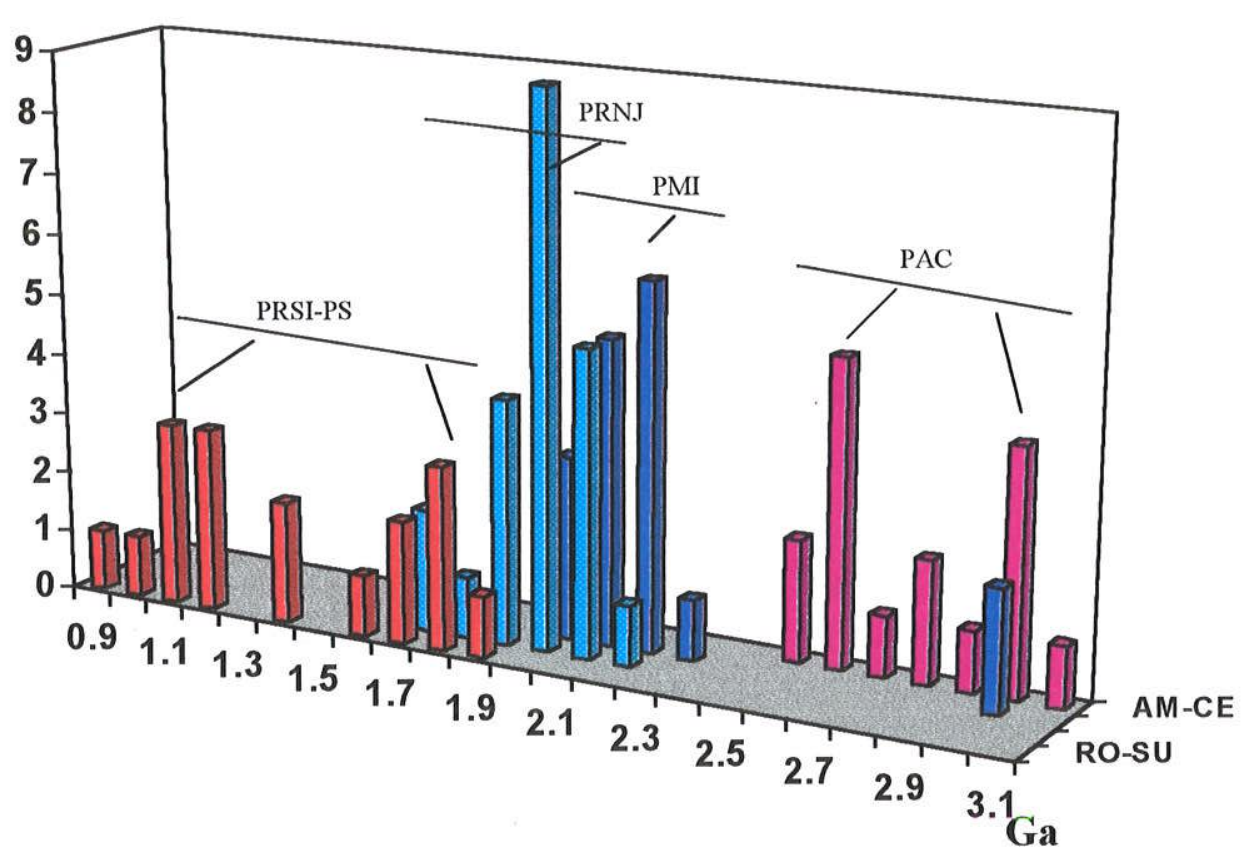

Fig. 5.2-14 Histograma dos principais eventos de acreção do Craton. Amazônico. Observam-se no diagrama períodos distintos de acreção na região de Amazônia Central (AM-CE) entre Arqueano e Paleoproterozóico. O período principal de acreção entre 2,25 a 1,8Ga, compreendendo as Províncias Maroni - Itacaiúnas (PMI), Ventuari-Tapajós (PVT) e Rio Negro - Juruena (PRNJ). As acreçoes juvenis Meso-Neoproterozoicas na nas Províncias Rondoniana-San Ignácia e Sunsás (PS), ocorreram com menor intensidade. 


\section{2-4 - RESUMO DO CRATON AMAZÔNICO}

As idades modelo Sm-Nd apresentaram valores variando desde 3,0 até 1,0 Ga, corroborando com os modelos de evolução tectònica do Craton Amazònico já previamente estabelecidos (Cordani et. al 1979, Teixeira et. al 1989 e Tassinari 1996) os quais preconizam uma evolução de cinturões móveis do Paleoproterozóico e Mesoproterozóico circundando núcleos arqueanos

Até o presente momento, idades $\mathrm{T}_{\mathrm{IM}}$ maiores do que $2,5 \mathrm{Ga}$ foram encontradas de modo sistemático apenas na porção oriental da Província Amazônia Central.

$\mathrm{Na}$ Província Maroni-Itacaiúnas as idades $\mathrm{T}_{\mathrm{DM}}$ variaram entre 2,25 a 2,0Ga, com exceção do fragmento arqueano da região do Rio Cupixi, que tem confirmada a sua idade $\mathrm{T}_{\mathrm{DM}}$ arqueana, já obtida por outros métodos.

Na Provincia Ventuari - Tapajós a grande maioria das idades $\mathrm{T}_{\mathrm{DM}}$ indicou acreção juvenil entre 2,1 a 1,9Ga, enquanto que na Provincia Rio Negro - Juruena os eventos ocorreram desde 2,2 até 1,7Ga. Nas províncias Rondoniana-San Ignacio e Sunsás as idades $\mathrm{T}_{\mathrm{DM}}$ variaram entre 2,2 a $1,0 \mathrm{Ga}$.

Com base nas idades modelo Sm-Nd e conforme o histograma da fig. 5.2-14, os principais periodos de acreção manto - crosta continental no Craton Amazônico podem ser resumidos da seguinte forma:

3,1 a 2,5Ga - PAC (região de Carajás);

2,2 a 2,0Ga - PMI (pico em 2,15Ga);

2,2 a 1,6Ga - PVT e PRNJ ( pico em 1,9Ga);

2,0 a 1,0Ga - PRSI e PS (picos em 1,8 e 1,15Ga) 
TAB. 5.2-1: AMAZÔNIA CENTRAL (obs. : nota explicativa dos dados Sm-Nd encontra-se no apêndice 1)

\begin{tabular}{|c|c|c|c|c|c|c|c|c|c|c|c|c|c|c|c|c|c|}
\hline $\begin{array}{l}\text { sps } \\
/ \text { lit. }\end{array}$ & $\begin{array}{l}\text { coord. } \\
\mathrm{g}^{\circ} \mathrm{m}^{\prime} / \mathrm{g}^{\circ} \mathrm{m}\end{array}$ & $\begin{array}{l}\text { n.campo/ } \\
\text { região }\end{array}$ & $\begin{array}{l}\text { lito- } \\
\text { logia }\end{array}$ & $\begin{array}{l}\text { iden } \\
\mathbf{t} \\
\text { diagra } \\
\text { ma }\end{array}$ & $\begin{array}{l}\mathbf{T}_{\text {chur }} \\
\text { GA }\end{array}$ & $\begin{array}{l}\mathbf{T}_{\mathrm{DM} 2} \\
\mathrm{GA}\end{array}$ & $\begin{array}{l}\mathbf{T}_{\mathrm{DM}} \\
\mathrm{GA}\end{array}$ & $\begin{array}{l}{ }^{1+7} \mathrm{Sm} / \\
{ }^{1+4} \mathrm{Nd}\end{array}$ & $\begin{array}{l}{ }^{1+3} \mathrm{Nd} / \\
{ }^{1+4} \mathrm{Nd}\end{array}$ & $\begin{array}{l}\mathrm{Sm} \\
\text { ppm }\end{array}$ & $\begin{array}{l}\mathrm{Nd} \\
\mathrm{pinm}\end{array}$ & f & $\begin{array}{l}\varepsilon_{\mathrm{Nd}} \\
(\mathrm{t}=0)\end{array}$ & $\begin{array}{l}\varepsilon_{\mathrm{Nd}} \\
(\mathrm{t})\end{array}$ & $\begin{array}{l}\mathbf{t}_{\text {mátodo }} \\
\mathbf{R I} \mathbf{I}_{\text {: fontus }}\end{array}$ & $\begin{array}{l}\varepsilon_{\mathrm{Sr}} \\
(1)\end{array}$ & ref. \\
\hline $\begin{array}{l}243 \\
\text { gnd }\end{array}$ & $7^{\circ} 2 / 50^{\circ} 15^{\prime}$ & $\begin{array}{l}\text { AS1683-6 } \\
\text { Carajás }\end{array}$ & GTD & $\mathrm{A}$ & $\begin{array}{l}2.87 \\
.03\end{array}$ & & $\begin{array}{r}3.03 \\
\pm .03\end{array}$ & $\begin{array}{l}.078375 \\
\pm .00004\end{array}$ & $\begin{array}{r}.510393 \\
\pm .00002\end{array}$ & $\begin{array}{l}3.086 \\
\pm .001\end{array}$ & $\begin{array}{l}23.81 \\
\pm .011\end{array}$ & -.60 & -43.8 & -3.3 & $\begin{array}{l}2.68_{\mathrm{Rb}-\mathrm{Sr}} \\
.70117_{(\mathrm{c})}\end{array}$ & 5.2 & $\mathrm{nt}$ \\
\hline $\begin{array}{l}2+6 \\
\mathrm{trj}\end{array}$ & $76 / 5029$ & $\begin{array}{l}\text { AH513-1/ } \\
\text { Carajás }\end{array}$ & GTD & $B$ & $\begin{array}{l}2.55 \\
.03\end{array}$ & & $\begin{array}{l}2.73 \\
0.02\end{array}$ & $\begin{array}{l}.0880 .38 \\
.000063\end{array}$ & $\begin{array}{l}.510810 \\
.000018\end{array}$ & $\begin{array}{l}1.994 \\
0.001\end{array}$ & $\begin{array}{l}13.696 \\
.007\end{array}$ & -.55 & -35.7 & +1.5 & $\begin{array}{l}2.68 \\
.7017_{101}\end{array}$ & 5.2 & $n t$ \\
\hline $\begin{array}{l}245 \\
\text { gnd }\end{array}$ & $715 / 5018$ & $\begin{array}{l}\text { AH796-4 } \\
\text { / Carajás }\end{array}$ & GTD & $\mathrm{C}$ & $\begin{array}{l}2.69 \\
.03\end{array}$ & & $\begin{array}{l}2.86 \\
0.03\end{array}$ & $\begin{array}{l}.096463 \\
.000066\end{array}$ & $\begin{array}{l}.510862 \\
.000022\end{array}$ & $\begin{array}{l}3.610 \\
0.002\end{array}$ & $\begin{array}{l}22.630 \\
.009\end{array}$ & -.51 & -34.6 & -0.4 & $\begin{array}{l}2.68 \mathrm{kBr}-\mathrm{Sr} \\
.70099_{\mathrm{CO}}\end{array}$ & -6.2 & $\mathrm{ni}$ \\
\hline $\begin{array}{l}24+4 \\
\text { gnd }\end{array}$ & $715 / 5018$ & $\begin{array}{l}\text { AH796-3 } \\
\text { / Carajás }\end{array}$ & GTD & $\mathrm{D}$ & $\begin{array}{l}2.86 \\
.06\end{array}$ & & $\begin{array}{l}3.04 \\
0.06\end{array}$ & $\begin{array}{l}.107626 \\
.000036\end{array}$ & $\begin{array}{l}.510956 \\
.000033\end{array}$ & $\begin{array}{l}3.177 \\
0.001\end{array}$ & $\begin{array}{l}17.850 \\
.002\end{array}$ & -.45 & -32.8 & +2.4 & $\begin{array}{l}3.100_{\mathrm{kg}-\mathrm{Si}} \\
.70000_{\mathrm{col}}\end{array}$ & -12 & $\mathrm{nt}$ \\
\hline $\begin{array}{l}160 \\
\text { gns }\end{array}$ & $-610 / 4930$ & $\begin{array}{l}\text { PP05A/ } \\
\text { Carajás }\end{array}$ & GTD & $E$ & $\begin{array}{l}2.90 \\
.04\end{array}$ & & $\begin{array}{l}3.03 \\
0.04\end{array}$ & $\begin{array}{l}.066835 \\
.000066\end{array}$ & $\begin{array}{l}.510149 \\
.000032\end{array}$ & $\begin{array}{l}5.553 \\
0.002\end{array}$ & $\begin{array}{l}50.242 \\
.046\end{array}$ & -.66 & -48.6 & -3.8 & $\begin{array}{l}2.70 \mathrm{R}(b-\mathrm{Sr} \\
.70188_{(d)}\end{array}$ & 7.0 & $\mathrm{nl}$ \\
\hline $\begin{array}{l}161 \\
10 n\end{array}$ & $-610 / 4930$ & $\begin{array}{l}\mathrm{PP}(05 \mathrm{H} / \\
\text { Carajás }\end{array}$ & GRT & $\mathrm{F}$ & $\begin{array}{l}2.83 \\
.04\end{array}$ & & $\begin{array}{l}2.98 \\
0.04\end{array}$ & $\begin{array}{l}.089724 \\
.000235\end{array}$ & $\begin{array}{l}.510641 \\
.000028\end{array}$ & $\begin{array}{l}1.175 \\
.0003\end{array}$ & $\begin{array}{l}7.919 \\
.004\end{array}$ & -.54 & -39.0 & -2.1 & $\begin{array}{l}2.70) \\
\left..70()_{3}\right)-S i\end{array}$ & 7.0 & $\mathrm{nt}$ \\
\hline $\begin{array}{l}388 \\
\text { git }\end{array}$ & $420 / 550$ & $\begin{array}{l}\text { AP 13C / } \\
\text { Tapajos }\end{array}$ & GTD & $G$ & $\begin{array}{l}2.32 \\
.05\end{array}$ & & $\begin{array}{l}2.55 \\
0.04\end{array}$ & $\begin{array}{l}.105098 \\
.000352\end{array}$ & $\begin{array}{l}.511236 \\
.000028\end{array}$ & $\begin{array}{l}19.670 \\
.065\end{array}$ & $\begin{array}{l}113.33 \\
.05\end{array}$ & -.47 & -27.4 & -7.1 & $\begin{array}{l}1.73_{\mathrm{Rb}-\mathrm{Sr}} \\
.705_{(t)}\end{array}$ & 36 & nt \\
\hline $\begin{array}{l}399 \\
\text { grt }\end{array}$ & $837 / 5059$ & $\begin{array}{l}\text { 470pbko2 } \\
\text { s Carajás }\end{array}$ & GTD & $\mathrm{H}$ & $\begin{array}{l}2.18 \\
.04\end{array}$ & & $\begin{array}{l}2.40 \\
0.03\end{array}$ & $\begin{array}{l}.09171 \\
.00009\end{array}$ & $\begin{array}{l}.511130 \\
.000026\end{array}$ & $\begin{array}{l}1.155 \\
.001\end{array}$ & $\begin{array}{l}7.616 \\
.003\end{array}$ & -.53 & -29.4 & -7.5 & $\begin{array}{l}1.64 \\
.704\end{array}$ & & $\mathrm{nt}$ \\
\hline $\begin{array}{l}400 \\
\text { grt }\end{array}$ & $803 / 5243$ & $\begin{array}{l}424 b c 151 \\
\text { S Carajás }\end{array}$ & GTD & 1 & $\begin{array}{l}2.48 \\
.02\end{array}$ & & $\begin{array}{l}2.69 \\
0.02\end{array}$ & $\begin{array}{l}.10361 \\
.00006\end{array}$ & $\begin{array}{l}.511118 \\
.000018\end{array}$ & $\begin{array}{l}5.834 \\
.002\end{array}$ & $\begin{array}{l}34.05 \\
0.015\end{array}$ & -.47 & -29.7 & -9.0 & $\begin{array}{l}1.74 \\
.719\end{array}$ & & $n t$ \\
\hline $\begin{array}{l}401 \\
g r t\end{array}$ & $947 / 5038$ & $\begin{array}{l}\text { ptogA } \\
\text { S Carajás }\end{array}$ & GTD & J & $\begin{array}{l}2.43 \\
.04\end{array}$ & & $\begin{array}{l}2.62 \\
0.03\end{array}$ & $\begin{array}{l}.09037 \\
.00005\end{array}$ & $\begin{array}{l}.510938 \\
.000025\end{array}$ & $\begin{array}{l}9.270 \\
0.002\end{array}$ & $\begin{array}{l}62.03 \\
.03\end{array}$ & -.54 & -33.2 & -6.0 & $\begin{array}{l}2.00 \\
.705\end{array}$ & & $n t$ \\
\hline $\begin{array}{l}234 \\
\text { rdc }\end{array}$ & $545 / 525$ & $\begin{array}{l}\text { XMV-78L/ } \\
\text { Xingu-Iriri }\end{array}$ & $\mathrm{VAC}$ & $\mathrm{L}$ & $\begin{array}{l}1.81 \\
.14\end{array}$ & & $\begin{array}{l}2.63 \\
0.03\end{array}$ & $\begin{array}{l}.101528 \\
.000085\end{array}$ & $\begin{array}{l}.511121 \\
.000027\end{array}$ & $\begin{array}{l}6.705 \\
0.003\end{array}$ & $\begin{array}{l}39.935 \\
.028\end{array}$ & -.48 & -29.6 & -7.5 & $\begin{array}{l}1.82 \mathrm{Rb}-\mathrm{Sr} \\
.706(\mathrm{~b})\end{array}$ & 52 & $\mathrm{nt}$ \\
\hline
\end{tabular}




\begin{tabular}{|c|c|c|c|c|c|c|c|c|c|c|c|c|c|c|c|c|c|}
\hline $\begin{array}{l}235 \\
\mathrm{rdc}\end{array}$ & $545 / 525$ & $\begin{array}{l}\text { XMV78M } \\
/ \\
\text { Xingu//riri }\end{array}$ & $\mathrm{VAC}$ & $\mathrm{M}$ & $\begin{array}{l}2.42 \\
.04\end{array}$ & & $\begin{array}{l}2.67 \\
0.03\end{array}$ & $\begin{array}{l}.102759 \\
.000100\end{array}$ & $\begin{array}{l}.511115 \\
.000021\end{array}$ & $\begin{array}{l}8.651 \\
0.006\end{array}$ & $\begin{array}{l}50.908 \\
.034\end{array}$ & -.48 & -29.7 & -7.9 & $\begin{array}{l}1.82 \mathrm{~kb}-\mathrm{s} \\
.706(\mathrm{~b})\end{array}$ & 52 & nt \\
\hline $\begin{array}{l}389 \\
\text { rdc }\end{array}$ & $420 / 5525$ & $\begin{array}{l}\text { AL } 90 / \\
\text { Tapajós }\end{array}$ & VAC & $\mathrm{N}$ & $\begin{array}{l}2.38 \\
.08\end{array}$ & & $\begin{array}{l}2.60 \\
0.03\end{array}$ & $\begin{array}{l}.102801 \\
.000059\end{array}$ & $\begin{array}{l}.511165 \\
.000051\end{array}$ & $\begin{array}{l}6.903 \\
0.002\end{array}$ & 40.605 & -.48 & -28.7 & -8.4 & $\begin{array}{l}1.70_{\mathrm{R}} \mathrm{k}-\mathrm{Si} \\
.705_{\mathrm{in}}\end{array}$ & 36 & $\mathrm{nt}$ \\
\hline moul & & $\begin{array}{l}23.1 \\
\mathrm{~N}-\text { Carajás }\end{array}$ & VAC & $\mathrm{O}$ & 23.1 & & 2.53 & .13766 & .511789 & 2.70 & 11.86 & -.30 & -16.6 & -.7 & 2. 1 sitis & & 4 \\
\hline mval & & $\begin{array}{l}24.1 \\
\mathrm{~N} \text { - Carajas }\end{array}$ & VAC & $P$ & 2.84 & & 3.07 & .13500 & .511483 & 2.90 & 12.99 & -.31 & -22.5 & -6.0 & 2.1 мะ:เін & & 4 \\
\hline$\ldots$ & & $\begin{array}{l}18.1 \\
\mathrm{~N} \text { - Carajás }\end{array}$ & VAC & $Q$ & 2.16 & & 2.51 & .13640 & .511781 & 2.70 & 11.97 & -.31 & -16.1 & -.6 & 2.1 : & & 4 \\
\hline mul & & $\begin{array}{l}19.1 \\
\mathrm{~N}-\text { - Carajás }\end{array}$ & VAC & $\mathrm{R}$ & 0.71 & & $2.00 ?$ & .17553 & .512540 & 3.55 & 12.23 & -.11 & -1.9 & 3.8 & 2.1 estun & & 4 \\
\hline mvul & & $\begin{array}{l}19.2 \\
\text { N - Carajás }\end{array}$ & VAC & $\mathrm{S}$ & $\begin{array}{l}5.75 \\
?\end{array}$ & $2.90^{* 4}$ & $5.62 ?$ & .18162 & .512060 & 3.55 & 11.82 & -.08 & -11.3 & -7.2 & 2.1 cstim & & 4 \\
\hline mval & & $\begin{array}{l}19.3 \\
\mathrm{~N} \text { - Carajas }\end{array}$ & VAC & $\mathrm{T}$ & 2.33 & & 2.57 & .10868 & .511286 & 13.61 & 75.73 & -.45 & -26.4 & -2.8 & 2.1 stam & & 4 \\
\hline$m-$ & & $\begin{array}{l}19.4 \\
\text { N-Carajás: }\end{array}$ & VAC & $\mathrm{U}$ & 2.29 & & 2.61 & .13525 & .511711 & 2.76 & 12.34 & -.31 & -18.1 & -1.6 & 2.1 simm & & 4 \\
\hline$m$ & & $\begin{array}{l}19.5 \\
\text { N - Caarajás }\end{array}$ & VAC & V & 2.85 & & 3.09 & .13846 & .511544 & 2.94 & 12.84 & -.30 & -21.3 & -5.7 & 2.1 & & 4 \\
\hline \multirow[t]{2}{*}{ mval } & & $\begin{array}{l}20.1 \\
N \text { - Carajás }\end{array}$ & VAC & $X$ & $2 .+6$ & & 2.76 & .13492 & .511634 & 3.03 & 13.58 & -.31 & -19.6 & -3.0 & 2.1 estirti & & 4 \\
\hline & & $\begin{array}{l}21.1 \\
\mathrm{~N} \text { - Carajás }\end{array}$ & VAC & Z & 2.69 & & 2.92 & .12423 & .511352 & 3.25 & 15.82 & -.37 & -25.1 & -5.7 & 2.1 estimt & & 4 \\
\hline
\end{tabular}


TAB: 5.2-2: MARONI-ITACAIUNAS

\begin{tabular}{|c|c|c|c|c|c|c|c|c|c|c|c|c|c|c|c|c|c|}
\hline $\begin{array}{l}\text { sps } \\
/ 11 \text { it. }\end{array}$ & $\begin{array}{l}\text { coord. } \\
\mathrm{g}^{\circ} \mathrm{m}^{1} / \mathrm{g}^{\circ} \mathrm{m}\end{array}$ & $\begin{array}{l}\text { n.campo/ } \\
\text { regiãos }\end{array}$ & $\begin{array}{l}\text { lito- } \\
\text { logia }\end{array}$ & $\begin{array}{l}\text { ident } \\
\text { diagta } \\
\text { naa }\end{array}$ & $\begin{array}{l}T_{\text {chur }} \\
\text { GA }\end{array}$ & $\underset{(\mathrm{i} \Lambda}{\mathbf{T}_{\mathrm{DM2}}}$ & $\begin{array}{l}\mathbf{T}_{\mathrm{DMM}} \\
\mathrm{GA}\end{array}$ & $\begin{array}{l}{ }^{147} \mathrm{Sm} / \\
{ }^{144} \mathrm{Nd}\end{array}$ & $\begin{array}{l}{ }^{1+3} \mathrm{Nd} / \\
{ }^{144} \mathrm{Nd}\end{array}$ & $\begin{array}{l}\text { Sn } \\
\text { ppm }\end{array}$ & $\begin{array}{l}\mathbf{N d} \\
p m ?\end{array}$ & f & $\begin{array}{l}\varepsilon \mathrm{Nd} \\
(\mathrm{t}=0)\end{array}$ & $\begin{array}{l}\varepsilon_{\mathrm{Ndd}} \\
(\mathrm{t})\end{array}$ & $\begin{array}{l}\mathbf{t}_{\text {métodos }} \\
\mathbf{R I}_{\text {timites }}\end{array}$ & $\begin{array}{l}\varepsilon_{\mathrm{Sr}} \\
\text { (1) }\end{array}$ & $\begin{array}{l}\text { re } \\
\text { f. }\end{array}$ \\
\hline kpe & $322 \mathrm{~N} / 538$ & $\begin{array}{l}\text { T100/ } \\
\text { G.Francesa }\end{array}$ & UBA & I & $\begin{array}{l}1.59 \\
.13\end{array}$ & & $\begin{array}{l}2.17 \\
0.09\end{array}$ & .1531 & $\begin{array}{l}.512182 \\
.000038\end{array}$ & 1.656 & 6.54 & -.22 & -8.9 & +1.8 & $1.93 \mathrm{Sm}-\mathrm{Nd}$ & & 2 \\
\hline $\mathrm{kpe}$ & $326 \mathrm{~N} / 537$ & $\begin{array}{l}\text { T]11/ } \\
\text { G.Francesa }\end{array}$ & UBA & $\mathrm{J}$ & $\begin{array}{l}1.64 \\
.07\end{array}$ & & $\begin{array}{l}2.20 \\
0.04\end{array}$ & .1524 & $\begin{array}{l}.512162 \\
.000019\end{array}$ & 1.878 & 7.45 & -.23 & -9.3 & +1.6 & $\begin{array}{l}1.93 \mathrm{sm}-\mathrm{Nd} \\
.5100(1 \mathrm{dn}\end{array}$ & & 2 \\
\hline kpe & $3 N 22 / 538$ & $\begin{array}{l}\text { T160 } \\
\text { G.Francesa }\end{array}$ & UBA & $\mathrm{K}$ & $\begin{array}{l}1.40 \\
.12\end{array}$ & & $\begin{array}{l}2.11 \\
0.08\end{array}$ & .1601 & $\begin{array}{l}.512302 \\
.000028\end{array}$ & 1.811 & 6.84 & -.19 & -6.6 & +2.5 & $\begin{array}{l}1.93 \mathrm{Sm}-\mathrm{id} \\
.510\left(02_{(\mathrm{n})}\right.\end{array}$ & & 2 \\
\hline kpe & $323 \mathrm{~N} / 539$ & $\begin{array}{l}\text { T188/ } \\
\text { G.Francesa }\end{array}$ & UBA & $\mathrm{L}$ & $\begin{array}{l}1.69 \\
.09\end{array}$ & & $\begin{array}{l}2.18 \\
0.06\end{array}$ & .1457 & $\begin{array}{l}.512070 \\
.000030\end{array}$ & 2.539 & 10.54 & -.26 & -11.1 & +1.5 & $\begin{array}{l}1.93_{\mathrm{Smn} \mathrm{Nd}} \\
.51002_{\{\mathrm{n}\}}\end{array}$ & & 2 \\
\hline kpe & $320 \mathrm{~N} / 5235$ & $\begin{array}{l}\text { L,303/ } \\
\text { G.Francesa }\end{array}$ & UBA & M & $\begin{array}{l}1.17 \\
.30\end{array}$ & $2.28^{\# 4}$ & $2.4 ?$ & .1794 & $\begin{array}{l}.512505 \\
.000034\end{array}$ & 0.831 & 2.801 & -.09 & -2.6 & +1.7 & $\begin{array}{l}1.93 \mathrm{sm-Nd} \\
.51002\end{array}$ & & 2 \\
\hline tol & $329 \mathrm{~N} / 5335$ & $\begin{array}{l}\text { I1919/ } \\
\text { G.Francesa }\end{array}$ & BAS & $\mathrm{N}$ & $\cdots$ & $2.25^{t+4}$ & $\cdots$ & .2033 & $\begin{array}{l}.512825 \\
.000038\end{array}$ & 2.189 & 6.512 & .03 & +3.6 & +2.0 & $\begin{array}{l}1.93 \mathrm{sin}-\mathrm{Nid} \\
.510\left(02_{\mathrm{m}}\right.\end{array}$ & & 2 \\
\hline and & $311 N / 5251$ & $\begin{array}{l}1,200 / \\
\text { G.Francesa }\end{array}$ & BAS & $\mathrm{P}$ & $\begin{array}{l}1.93 \\
.03\end{array}$ & & $\begin{array}{l}2.20 \\
0.02\end{array}$ & .1026 & $\begin{array}{l}.511440 \\
.000016\end{array}$ & 4.69 & 27.65 & -.48 & -23.4 & -0.2 & $\begin{array}{l}1.93 \mathrm{str- \cdots id} \\
.510\left(02_{(n)}\right.\end{array}$ & & 2 \\
\hline and & $311 \mathrm{~N} / 5230$ & $\begin{array}{l}\text { 1.365 } \\
\text { G.Francesa }\end{array}$ & BAS & $Q$ & $\begin{array}{l}1.96 \\
.12\end{array}$ & & $\begin{array}{l}2.29 \\
0.09\end{array}$ & .1255 & $\begin{array}{l}.511722 \\
.000055\end{array}$ & 4.16 & 20.04 & -.36 & -17.9 & -0.3 & $\begin{array}{l}1.93 \mathrm{Sm-Nd} \\
.510\left(02_{(n)}\right.\end{array}$ & & 2 \\
\hline $\begin{array}{l}152 \\
\text { gns }\end{array}$ & $05 \mathrm{~N} / 6440$ & $\begin{array}{l}\text { MR-RI-3I } \\
O-B . \text { Vista }\end{array}$ & GRT & A & $\begin{array}{l}1.85 \\
.03\end{array}$ & 2.08 & $\begin{array}{l}2.06 \\
0.02\end{array}$ & $\begin{array}{l}.064007 \\
.000043\end{array}$ & $\begin{array}{l}.511026 \\
.000022\end{array}$ & $\begin{array}{l}2.953 \\
0.001\end{array}$ & $\begin{array}{l}27.898 \\
.016\end{array}$ & -.67 & -31.5 & -1.8 & $1.75 \mathrm{~kb}-\mathrm{si}$ & & $\mathrm{nt}$ \\
\hline gnl & $-240 N / 6150$ & $\begin{array}{l}\text { PL-R5/ } \\
\text { Caracarai }\end{array}$ & GNL & B & $\begin{array}{l}1.90 \\
.05\end{array}$ & $2.2^{\sharp 2}$ & $\begin{array}{l}2.38 \\
0.03\end{array}$ & .15 & $\begin{array}{l}.512053 \\
.000016\end{array}$ & -...- & -...-.- & -.24 & -11.4 & -0.3 & 1.86 & 95 & 1 \\
\hline $\mathrm{gnl}$ & $-240 N / 6150$ & $\begin{array}{l}\text { PL-R18/ } \\
\text { Caracarai }\end{array}$ & GNL & $\mathrm{C}$ & $\begin{array}{l}1.72 \\
.02\end{array}$ & & $\begin{array}{l}2.02 \\
0.02\end{array}$ & .10 & $\begin{array}{l}.511541 \\
.000014\end{array}$ & -...-- & -.-.-. & -.49 & -21.4 & +1.5 & 1.86 & 95 & 1 \\
\hline
\end{tabular}




\begin{tabular}{|c|c|c|c|c|c|c|c|c|c|c|c|c|c|c|c|c|}
\hline gnl & -...... & $\begin{array}{l}8204 \\
\text { Guiana }\end{array}$ & GNL & $\mathrm{D}$ & $\begin{array}{l}1.93 \\
.03\end{array}$ & $\begin{array}{l}2.19 \\
0.03\end{array}$ & .0990 & $\begin{array}{l}.511400 \\
.000020\end{array}$ & 10.751 & 65.663 & -.50 & -24.1 & +0.1 & $1.95_{\text {esitm }}$ & & 3 \\
\hline gnl & ------ & $\begin{array}{l}8332 \\
\text { Suriname }\end{array}$ & GNL & $\mathrm{E}$ & $\begin{array}{l}1.81 \\
.14\end{array}$ & $\begin{array}{l}2.29 \\
0.03\end{array}$ & .1080 & $\begin{array}{l}.511460 \\
.000020\end{array}$ & -..-- & ---.-- & -.45 & -23.0 & -0.9 & 1.95 & & 3 \\
\hline $\begin{array}{l}231 \\
\text { grt }\end{array}$ & ON $50 / 5220$ & $\begin{array}{l}\text { EG83AP684 } \\
-2 / \text { Capixi }\end{array}$ & GRT & $F$ & $\begin{array}{l}2.02 \\
.03\end{array}$ & $\begin{array}{l}2.22 \\
0.11\end{array}$ & $\begin{array}{l}.136602 \\
.000447\end{array}$ & $\begin{array}{l}.511921 \\
.000054\end{array}$ & $\begin{array}{l}0.464 \\
0.005\end{array}$ & $\begin{array}{l}2.05 t \\
.001\end{array}$ & -.31 & -14.0 & +1.8 & $\begin{array}{l}2.06 \mathrm{Rb}-\mathrm{Sr} \\
.760(\mathrm{a})\end{array}$ & 825 & nt \\
\hline $\begin{array}{l}232 \\
\text { ton }\end{array}$ & $1 \mathrm{No} / 5210$ & $\begin{array}{l}\text { eg } 1 \text { 8am281 } \\
\text { 2/ Cupixi }\end{array}$ & GRT & $\mathrm{G}$ & $\begin{array}{l}2.92 \\
.02\end{array}$ & $\begin{array}{l}3.06 \\
0.02\end{array}$ & $\begin{array}{l}.082788 \\
.000081\end{array}$ & $\begin{array}{l}.510443 \\
.000018\end{array}$ & $\begin{array}{l}7.143 \\
0.006\end{array}$ & $\begin{array}{l}52.174 \\
.026\end{array}$ & -.58 & -42.8 & -0.7 & $\begin{array}{l}2.90()_{i k 1} . \mathrm{si} \\
.702(a)\end{array}$ & 13 & $\mathrm{nt}$ \\
\hline $\begin{array}{l}2.33 \\
\text { ton }\end{array}$ & $1 \mathrm{~N} 0 / 5210$ & $\begin{array}{l}\text { EG021.P62 } \\
\text { / Cupixi }\end{array}$ & GRT & $\mathrm{H}$ & $\begin{array}{l}2.95 \\
.04\end{array}$ & $\begin{array}{l}3.10 \\
0.05\end{array}$ & $\begin{array}{l}.087394 \\
.000085\end{array}$ & $\begin{array}{l}.510508 \\
.000032\end{array}$ & $\begin{array}{l}7.180 \\
0.003\end{array}$ & $\begin{array}{l}49.680 \\
.043\end{array}$ & -.56 & -41.6 & -1.1 & $\begin{array}{l}2.90 \mathrm{Rh}-\mathrm{Sr} \\
.702(\mathrm{a})\end{array}$ & 13 & $\mathrm{nt}$ \\
\hline
\end{tabular}

TAB. 5.2-3: VENTUARI - TAPAJÓS

\begin{tabular}{|c|c|c|c|c|c|c|c|c|c|c|c|c|c|c|c|c|c|}
\hline $\begin{array}{l}\text { sps } \\
\text { /lit. }\end{array}$ & $\begin{array}{l}\text { coord. } \\
\mathrm{g}^{\circ} \mathrm{m}^{\prime} / \mathrm{g}^{\circ} \mathrm{m}\end{array}$ & $\begin{array}{l}\text { n.campo/ } \\
\text { região }\end{array}$ & $\begin{array}{l}\text { lito- } \\
\text { logia }\end{array}$ & $\begin{array}{l}\text { ident } \\
\text { diagra } \\
\text { ma } \\
\end{array}$ & $\begin{array}{l}\mathbf{T}_{\text {chur }} \\
\text { GA }\end{array}$ & $\begin{array}{l}\mathbf{T}_{\mathrm{DB} / 2} \\
\mathrm{GA}\end{array}$ & $\begin{array}{l}\mathbf{T}_{\mathrm{DM}} \\
\mathrm{GA}\end{array}$ & $\begin{array}{l}{ }^{147} \mathrm{Sm} / \\
{ }^{1+4} \mathrm{Nd}\end{array}$ & $\begin{array}{l}{ }^{143} \mathrm{Nd} / \\
{ }^{144} \mathrm{Nd}\end{array}$ & $\begin{array}{l}\mathbf{S m} \\
\text { ppm }\end{array}$ & $\begin{array}{l}\mathbf{N d} \\
p p m\end{array}$ & $f$ & $\begin{array}{l}\varepsilon \times \mathrm{vd} \\
(t=0)\end{array}$ & $\begin{array}{l}\varepsilon_{\mathrm{Nd}} \\
(\mathrm{t})\end{array}$ & $\begin{array}{l}\mathbf{t}_{\text {metords }} \\
\mathbf{R} \mathbf{I}_{\text {ifontes }} \\
\end{array}$ & $\begin{array}{l}\varepsilon_{\mathrm{Sr}} \\
(\mathrm{t})\end{array}$ & $\begin{array}{l}\text { re } \\
\text { f. }\end{array}$ \\
\hline $\begin{array}{l}208 \\
g r t\end{array}$ & $005 / 6010$ & $\begin{array}{l}\text { PT-25/ } \\
\text { N.Manaus }\end{array}$ & GRT & A & $\begin{array}{l}1.73 \\
.05\end{array}$ & & $\begin{array}{l}2.08 \\
0.04\end{array}$ & $\begin{array}{l}.119316 \\
.000104\end{array}$ & $\begin{array}{l}.511758 \\
.000027\end{array}$ & $\begin{array}{l}6.289 \\
0.005\end{array}$ & $\begin{array}{l}31.873 \\
.011\end{array}$ & -.39 & -17.2 & +0.4 & $\begin{array}{l}1.78_{\mathrm{Rb}-\mathrm{Sr}} \\
.704_{\mathrm{Bg}}\end{array}$ & 23 & $n t$ \\
\hline $\begin{array}{l}209 \\
\text { gnd }\end{array}$ & $005 / 6010$ & $\begin{array}{l}\text { PT-26/ } \\
\text { N.Manaus }\end{array}$ & GRT & B & $\begin{array}{l}1.87 \\
.04\end{array}$ & & $\begin{array}{l}2.09 \\
0.03\end{array}$ & $\begin{array}{l}.070159 \\
.000072\end{array}$ & $\begin{array}{l}.511081 \\
.000033\end{array}$ & $\begin{array}{l}4.441 \\
0.003\end{array}$ & $\begin{array}{l}38.277 \\
.029\end{array}$ & -.64 & -30.4 & -1.6 & $\begin{array}{l}1.78_{\mathrm{R} t \mathrm{t}-\mathrm{Sr}} \\
.704_{(p)}\end{array}$ & 23 & $\mathrm{nt}$ \\
\hline $\begin{array}{l}163 \\
\text { gnl }\end{array}$ & $2 \mathrm{~N} 5 / 6135$ & $\begin{array}{l}\text { M68/ } \\
\text { N.Manaus }\end{array}$ & GNL & $\mathrm{C}$ & $\begin{array}{l}1.79 \\
.04\end{array}$ & & $\begin{array}{l}2.11 \\
0.03\end{array}$ & $\begin{array}{l}111662 \\
.000091\end{array}$ & $\begin{array}{l}.511636 \\
.000021\end{array}$ & $\begin{array}{l}6.954 \\
0.003\end{array}$ & $\begin{array}{l}37.569 \\
.026\end{array}$ & -.43 & -19.6 & -0.6 & $\begin{array}{l}1.75_{\mathrm{Rb}-\mathrm{Sr}} \\
.703_{(11 !}\end{array}$ & 7.9 & $\mathrm{nt}$ \\
\hline $\begin{array}{l}293 \\
\text { gns }\end{array}$ & $522 \mathrm{~N} 6444$ & $\begin{array}{l}\text { MT1036/ } \\
\text { Venezuela }\end{array}$ & GRT & $\mathrm{D}$ & $\begin{array}{l}1.61 \\
.03\end{array}$ & & $\begin{array}{l}1.91 \\
0.03\end{array}$ & $\begin{array}{l}.099+77 \\
.000068\end{array}$ & $\begin{array}{l}.511610 \\
.000022\end{array}$ & $\begin{array}{l}14.133 \\
00.003\end{array}$ & $\begin{array}{l}85.912 \\
.055\end{array}$ & -.49 & -20.1 & +2.5 & $\begin{array}{l}1.82_{\mathrm{Rb}-\mathrm{Sr}} \\
.702_{\mathrm{ib}}\end{array}$ & -3.8 & $\mathrm{nt}$ \\
\hline $\begin{array}{l}290 \\
\text { gns }\end{array}$ & $424 N / 678$ & $\begin{array}{l}\text { BA-28/ } \\
\text { Venezuela }\end{array}$ & GRT & $\mathrm{E}$ & $\begin{array}{l}1.64 \\
.03\end{array}$ & & $\begin{array}{l}1.94 \\
0.03\end{array}$ & $\begin{array}{l}.098240 \\
.000049\end{array}$ & $\begin{array}{l}.511575 \\
.000020\end{array}$ & $\begin{array}{l}3.850 \\
0.001\end{array}$ & $\begin{array}{l}23.698 \\
.010\end{array}$ & -.50 & -20.7 & +1.9 & $\begin{array}{l}1.80_{\mathrm{Rb}-\mathrm{Sr}} \\
.7035_{\{i\}}\end{array}$ & 16 & $\mathrm{nt}$ \\
\hline
\end{tabular}




\begin{tabular}{|c|c|c|c|c|c|c|c|c|c|c|c|c|c|c|c|c|c|}
\hline $\begin{array}{l}292 \\
\text { gns }\end{array}$ & $25 \mathrm{~N} / 650$ & $\begin{array}{l}\text { H508A/ } \\
\text { Venezuel } \\
\mathrm{a}\end{array}$ & GRT & $\mathrm{F}$ & $\begin{array}{l}1.59 \\
.04\end{array}$ & & $\begin{array}{l}1.90 \\
0.03\end{array}$ & $\begin{array}{l}.102601 \\
.000053\end{array}$ & $\begin{array}{l}511656 \\
.000026\end{array}$ & $\begin{array}{l}7.611 \\
0.002\end{array}$ & 44.857 & -.48 & -19.2 & +0.5 & $\begin{array}{l}1.64_{\mathrm{Rb}-\mathrm{Sr}} \\
.7059_{\mathrm{ij}}\end{array}$ & 47 & $\mathrm{nt}$ \\
\hline $\begin{array}{l}386 \\
\text { ton }\end{array}$ & $.610 / 4930$ & $\begin{array}{l}\text { MA5/ } \\
\text { Tapajós }\end{array}$ & GRT & $\mathrm{G}$ & $\begin{array}{l}1.73 \\
.07\end{array}$ & & $\begin{array}{l}2.09 \\
0.05\end{array}$ & $\begin{array}{l}.120884 \\
.000341\end{array}$ & $\begin{array}{l}.511773 \\
.000033\end{array}$ & $\begin{array}{l}9.020 \\
0.025\end{array}$ & $\begin{array}{l}45.121 \\
.019\end{array}$ & -.39 & -16.9 & +2.1 & $\begin{array}{l}1.96 \mathrm{Rt}-\mathrm{s} \\
\cdots\end{array}$ & & $\mathrm{nt}$ \\
\hline $\begin{array}{l}387 \\
\text { ton }\end{array}$ & & $\begin{array}{l}\text { MA 13/ } \\
\text { Tapajós }\end{array}$ & GRT & $\mathrm{H}$ & $\begin{array}{l}1.81 \\
.05\end{array}$ & & $\begin{array}{l}2.16 \\
0.04\end{array}$ & $\begin{array}{l}122166 \\
.000057\end{array}$ & $\begin{array}{l}.511749 \\
.000026\end{array}$ & $\begin{array}{l}9.365 \\
0.002\end{array}$ & $\begin{array}{l}46.355 \\
.019\end{array}$ & -.38 & -17.3 & +1.3 & $\begin{array}{l}1.96 \mathrm{Rb}-\mathrm{St} \\
-\mathrm{ct}\end{array}$ & & $\mathrm{nt}$ \\
\hline $\begin{array}{l}373 \\
\text { grt }\end{array}$ & & $\begin{array}{l}\text { CR16/ } \\
\text { Tapajós }\end{array}$ & GRT & 1 & $\begin{array}{l}2.68 \\
.03\end{array}$ & & $\begin{array}{l}2.85 \\
0.03\end{array}$ & $\begin{array}{l}.089559 \\
.000058\end{array}$ & $\begin{array}{l}.5107+1 \\
.000023\end{array}$ & $\begin{array}{l}8.366 \\
0.004\end{array}$ & $\begin{array}{l}56.487 \\
.024\end{array}$ & -.54 & -37.0 & -10.2 & $\begin{array}{l}1.96 \mathrm{Rb}-\mathrm{Sr} \\
.7037_{(\mathrm{e})}\end{array}$ & 22 & $\mathrm{nt}$ \\
\hline $\begin{array}{l}374 \\
\text { grt }\end{array}$ & & $\begin{array}{l}\text { CR 09/ } \\
\text { Tapajós }\end{array}$ & GRT & $\mathrm{J}$ & $\begin{array}{l}2.00 \\
.03\end{array}$ & & $\begin{array}{l}2.24 \\
0.03\end{array}$ & $\begin{array}{l}.093462 \\
.000064\end{array}$ & $\begin{array}{l}.511281 \\
.000018\end{array}$ & $\begin{array}{l}10.411 \\
0.006\end{array}$ & $\begin{array}{l}67.359 \\
.025\end{array}$ & -.52 & -26.5 & -0.7 & $\begin{array}{l}1.96 \mathrm{Rb}-\mathrm{Sr} \\
.7\left(037_{(\mathrm{c})}\right.\end{array}$ & 22 & $\mathrm{nt}$ \\
\hline $\begin{array}{l}155 \\
\text { ril }\end{array}$ & $1020 / 565$ & $\begin{array}{l}\text { PT } 13-2 / \\
\text { SE.Manaus }\end{array}$ & $\mathrm{VAC}$ & $\mathrm{K}$ & $\begin{array}{l}1.76 \\
.04\end{array}$ & & $\begin{array}{l}2.09 \\
0.03\end{array}$ & $\begin{array}{l}.11+770 \\
.000096\end{array}$ & $\begin{array}{l}511688 \\
.000021\end{array}$ & $\begin{array}{l}9.189 \\
0.003\end{array}$ & $\begin{array}{l}+8.415 \\
.037\end{array}$ & -.42 & -18.5 & -1.3 & $\begin{array}{l}1.65_{\mathrm{Rg}-\mathrm{Sr}} \\
.703_{\mathrm{fr}}\end{array}$ & 6.2 & $\mathrm{nt}$ \\
\hline $\begin{array}{l}210 \\
\text { mdia }\end{array}$ & $635 / 600$ & $\begin{array}{l}\text { PT } 36 / \\
\text { S.Manaus }\end{array}$ & BAS & $\mathrm{L}$ & --- & $1.53^{21}$ & $\begin{array}{l}1.47 \\
0.11\end{array}$ & .118 & $\begin{array}{l}.512527 \\
.000045\end{array}$ & $\begin{array}{l}2.837 \\
0.001\end{array}$ & $\begin{array}{l}14.454 \\
.010\end{array}$ & -.18 & -2.2 & +4.3 & $\begin{array}{l}1 .+3 \mathrm{k}-\mathrm{A} \\
\text { (h) }\end{array}$ & & $\mathrm{nt}$ \\
\hline $\begin{array}{l}376 \\
\text { ril } \\
\end{array}$ & $810 / 5530$ & $\begin{array}{l}\text { PT29-3/ } \\
\text { SEManaus }\end{array}$ & $\mathrm{VAC}$ & M & $\begin{array}{l}2.21 \\
.04 \\
\end{array}$ & & $\begin{array}{l}2.44 \\
0.03 \\
\end{array}$ & $\begin{array}{l}.097512 \\
.000058 \\
\end{array}$ & $\begin{array}{l}.511192 \\
.000023 \\
\end{array}$ & $\begin{array}{l}6.305 \\
0.003 \\
\end{array}$ & $\begin{array}{l}39.099 \\
014 \\
\end{array}$ & -.50 & -28.2 & -7.3 & $1.65 \mathrm{Rb}-\mathrm{si}_{\mathrm{i}}$ & & $\mathrm{nt}$ \\
\hline
\end{tabular}


TAB. 5.2-4: Rio Negro - Juruena

\begin{tabular}{|c|c|c|c|c|c|c|c|c|c|c|c|c|c|c|c|c|c|}
\hline $\begin{array}{l}\text { sps } \\
\text { / lit. }\end{array}$ & $\begin{array}{l}\text { coord. } \\
g^{\circ} 117^{\circ} / g^{\prime \prime} 113^{\prime}\end{array}$ & $\begin{array}{l}\text { n.campo/ } \\
\text { região }\end{array}$ & $\begin{array}{l}\text { lito- } \\
\text { logia }\end{array}$ & $\begin{array}{l}\text { ident } \\
\text { diagra } \\
\text { ma }\end{array}$ & $\begin{array}{l}\mathrm{T}_{\text {chur }} \\
\mathrm{GA}\end{array}$ & $\begin{array}{l}T_{\mathrm{DN} 2} \\
\mathrm{GA}\end{array}$ & $\begin{array}{c}T_{\mathrm{DMr}} \\
\mathrm{C} A\end{array}$ & $\begin{array}{l}{ }^{147} \mathrm{Sm} / \\
{ }^{1+4} \mathrm{Nd}\end{array}$ & $\begin{array}{l}{ }^{1+3} \mathrm{Nd} / \\
{ }^{1+4} \mathrm{Nd}\end{array}$ & $\begin{array}{l}\mathrm{Sm} \\
\mathrm{pl} \mathrm{m}\end{array}$ & $\begin{array}{l}\mathrm{Nd} \\
p p m\end{array}$ & $\bar{f}$ & $\begin{array}{l}\varepsilon \times \mathrm{Nd} \\
(\mathrm{t}=0)\end{array}$ & $\begin{array}{l}\varepsilon \mathrm{Nd} \\
(t)\end{array}$ & $\begin{array}{l}\mathbf{t}_{\text {mitodo }} \\
\mathbf{R I}_{\text {i torted }}\end{array}$ & $\begin{array}{l}\varepsilon_{S_{r}} \\
(1)\end{array}$ & $\begin{array}{l}\text { re } \\
\text { f. }\end{array}$ \\
\hline $\begin{array}{l}377 \\
\text { grt }\end{array}$ & $956 / 6133$ & $\begin{array}{l}\text { PT2/-1/ } \\
\text { RNI-Rond. }\end{array}$ & GRT & $\bar{A}$ & $\begin{array}{l}1.47 \\
.05\end{array}$ & & $\begin{array}{l}1.87 \\
0.04\end{array}$ & $\begin{array}{l}.120314 \\
.000075\end{array}$ & $\begin{array}{l}.511898 \\
.000025\end{array}$ & $\begin{array}{l}12.523 \\
0.006\end{array}$ & $\begin{array}{l}62.941 \\
025\end{array}$ & -.39 & -14.4 & -2.5 & $\begin{array}{l}1.23 \mathrm{RB}-\mathrm{Sr} \\
.71 \mathrm{f}_{\mathrm{in}}\end{array}$ & 156 & $n t$ \\
\hline $\begin{array}{l}378 \\
\text { grt }\end{array}$ & 10396133 & $\begin{array}{l}\text { PT39A } \\
\text { R.N.Jur. }\end{array}$ & GRT & $\mathrm{B}$ & $\begin{array}{l}1 .+2 \\
.04\end{array}$ & & $\begin{array}{l}1.76 \\
.03\end{array}$ & $\begin{array}{l}.103660 \\
.000050\end{array}$ & $\begin{array}{l}.511772 \\
.000023\end{array}$ & $\begin{array}{l}11.845 \\
0.003\end{array}$ & $\begin{array}{l}69.098 \\
.028\end{array}$ & -.47 & -16.9 & -0.3 & $\begin{array}{l}1.40)_{\mathrm{Rb}-\mathrm{Sr}} \\
.713_{\mathrm{tbr}}\end{array}$ & 144 & $\mathrm{nt}$ \\
\hline 364 & $012 \mathrm{~N} / 6757$ & $\begin{array}{l}\text { PT } 33 \text { ASU } \\
\text { /R.N.Jur. }\end{array}$ & GRT & $\mathrm{C}$ & $\begin{array}{l}1.67 \\
.04\end{array}$ & & $\begin{array}{l}1.98 \\
0.03\end{array}$ & $\begin{array}{l}.104547 \\
.000047\end{array}$ & $\begin{array}{l}.511624 \\
.000023\end{array}$ & $\begin{array}{l}1+.973 \\
0.003\end{array}$ & $\begin{array}{l}86.604 \\
.035\end{array}$ & -.47 & -19.8 & -2.6 & 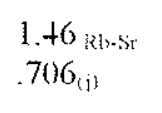 & 46 & $\mathrm{nt}$ \\
\hline 365 & $012 \mathrm{~N} / 6757$ & $\begin{array}{l}\text { PT 33ASW } \\
\text { /R.N.Jur. }\end{array}$ & GRT & $\mathrm{D}$ & $\begin{array}{l}1.73 \\
.06\end{array}$ & & $\begin{array}{l}2.05 \\
0.05\end{array}$ & $\begin{array}{l}.111550 \\
.000061\end{array}$ & $\begin{array}{l}.511671 \\
.000035\end{array}$ & $\begin{array}{l}17.167 \\
0.006\end{array}$ & $\begin{array}{l}93.060 \\
.039\end{array}$ & -.43 & -18.9 & -3.0 & $\begin{array}{l}1.46 \sigma_{0 b-s t} \\
.706_{(1)}\end{array}$ & 46 & $\mathrm{nt}$ \\
\hline 366 & $012 \mathrm{~N} / 6757$ & $\begin{array}{l}\text { UA-6w-6n/ } \\
\text { R.N.Jur. }\end{array}$ & GRT & $\mathrm{E}$ & $\begin{array}{l}1.70 \\
.05\end{array}$ & & $\begin{array}{l}2.02 \\
0.04\end{array}$ & $\begin{array}{l}.108585 \\
.000073\end{array}$ & $\begin{array}{l}.511651 \\
.000028\end{array}$ & $\begin{array}{l}14.688 \\
0.008\end{array}$ & $\begin{array}{l}81.796 \\
.031\end{array}$ &.-+5 & -19.3 & -2.8 & $\begin{array}{l}1 .+6 \\
.706_{(1)}\end{array}$ & 46 & $\mathrm{nt}$ \\
\hline $\begin{array}{l}156 \\
\text { ton }\end{array}$ & $310 \mathrm{~N} / 6740$ & $\begin{array}{l}5532 / \\
\text { R.N.Jur. }\end{array}$ & GRT & $\mathrm{F}$ & $\begin{array}{l}1.92 \\
.05\end{array}$ & & $\begin{array}{l}2.18 \\
0.04\end{array}$ & $\begin{array}{l}.099730 \\
.000119\end{array}$ & $\begin{array}{l}.511+15 \\
.000031\end{array}$ & $\begin{array}{l}11.397 \\
00.005\end{array}$ & $\begin{array}{l}69.104 \\
.076\end{array}$ & -.49 & -23.9 & -2.2 & 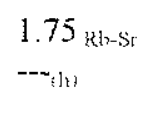 & & $\mathrm{nt}$ \\
\hline $\begin{array}{l}150 \\
\text { ton }\end{array}$ & $10 \mathrm{~N} 6950$ & $\begin{array}{l}\text { PA-SP-35/ } \\
\text { R.N.Jin. }\end{array}$ & GRT & $G$ & $\begin{array}{l}2.05 \\
.05\end{array}$ & & $\begin{array}{r}2.40 \\
0.04\end{array}$ & $\begin{array}{l}.132+80 \\
.000105\end{array}$ & $\begin{array}{l}.511771 \\
.000021\end{array}$ & $\begin{array}{l}2.087 \\
0.001\end{array}$ & $\begin{array}{l}9.526 \\
.006\end{array}$ & -.33 & -16.9 & -2.9 & $\begin{array}{l}1.71 \\
.703_{\mathrm{b} j}\end{array}$ & 7.2 & nt \\
\hline $\begin{array}{l}151 \\
\text { gnd }\end{array}$ & $050 \mathrm{~N} / 6555$ & $\begin{array}{l}\text { Mi-AB-16-1 } \\
\text { /R.N.Jur. }\end{array}$ & GRT & $\mathrm{H}$ & $\begin{array}{l}1.90 \\
.03\end{array}$ & & $\begin{array}{l}2.12 \\
0.03\end{array}$ & $\begin{array}{l}.075288 \\
.000080\end{array}$ & $\begin{array}{l}.511123 \\
.000024\end{array}$ & $\begin{array}{l}2.675 \\
0.002\end{array}$ & $\begin{array}{l}21.485 \\
.016\end{array}$ & -.62 & -29.6 & -6.3 & $\begin{array}{l}1.50)_{\mathrm{Rb}} \mathrm{st} \\
.705_{\{3\}}\end{array}$ & 32 & $n t$ \\
\hline $\begin{array}{l}154 \\
\text { gnl }\end{array}$ & 9126155 & $\begin{array}{l}\text { PT } 61 / \\
\text { R.N.Jur. }\end{array}$ & GNL & I & $\begin{array}{l}1.78 \\
.04\end{array}$ & & $\begin{array}{l}2.17 \\
0.03\end{array}$ & $\begin{array}{l}.130123 \\
.000091\end{array}$ & $\begin{array}{l}.511857 \\
.000018\end{array}$ & $\begin{array}{l}8.893 \\
0.003\end{array}$ & $\begin{array}{l}+1.327 \\
.025\end{array}$ & -.34 & -15.2 & +0.9 & $\begin{array}{l}1.90)_{\mathrm{Rb}-\mathrm{Sr}} \\
.703_{\mathrm{H}}\end{array}$ & 3.7 & $\mathrm{nt}$ \\
\hline $\begin{array}{l}164 \\
\text { gn1 }\end{array}$ & $1025 / 6220$ & $\begin{array}{l}\text { PT72El / } \\
\text { R.N.Jur. }\end{array}$ & GNL & $\mathrm{J}$ & $\begin{array}{l}1.65 \\
.10\end{array}$ & & $\begin{array}{l}2.08 \\
0.07\end{array}$ & $\begin{array}{l}.134611 \\
.000146\end{array}$ & $\begin{array}{l}.511964 \\
.000042\end{array}$ & $\begin{array}{l}7.243 \\
0.004\end{array}$ & $\begin{array}{l}32.537 \\
.030\end{array}$ & -.32 & -13.2 & +1.9 & $\begin{array}{l}1.90_{\mathrm{Rb}-\mathrm{Sr}} \\
.703_{\mathrm{hH}}\end{array}$ & 3.7 & $\mathrm{nt}$ \\
\hline
\end{tabular}




\begin{tabular}{|c|c|c|c|c|c|c|c|c|c|c|c|c|c|c|c|}
\hline $\begin{array}{l}149 \\
\text { gns }\end{array}$ & $910 / 5915$ & $\begin{array}{l}\text { PT 19/ } \\
\text { R.N.Jur. }\end{array}$ & GRT & $\mathrm{K}$ & $\begin{array}{l}1.88 \\
.04\end{array}$ & $\begin{array}{l}2.19 \\
0.03\end{array}$ & $\begin{array}{l}.113097 \\
.000060\end{array}$ & $\begin{array}{l}.511602 \\
.000023\end{array}$ & $\begin{array}{l}5.745 \\
0.003\end{array}$ & $\begin{array}{l}30.717 \\
.003\end{array}$ & -.43 & -20.2 & -1.8 & $\begin{array}{l}1.73_{\mathrm{kb}-\mathrm{Sr}} \\
.702_{\mathrm{h}}\end{array}$ & $-6.7 \mathrm{nt}$ \\
\hline $\begin{array}{l}162 \\
\text { gns }\end{array}$ & $1010 / 5915$ & $\begin{array}{l}\text { PT - 7/ } \\
\text { R.N.Jur. }\end{array}$ & GRT & $\mathrm{L}$ & $\begin{array}{l}1.69 \\
.04\end{array}$ & $\begin{array}{l}2.04 \\
0.03\end{array}$ & $\begin{array}{l}.117557 \\
.000148\end{array}$ & $\begin{array}{l}.511757 \\
.000022\end{array}$ & $\begin{array}{l}4.767 \\
0.002\end{array}$ & $\begin{array}{l}24.521 \\
.029\end{array}$ & -.40 & -17.2 & +0.3 & $\begin{array}{l}1.73_{\mathrm{Rb}-\mathrm{Sr}} \\
.7\left(02_{\mathrm{thr}}\right.\end{array}$ & -6.7 \\
\hline $\begin{array}{l}379 \\
\text { dac }\end{array}$ & $821 / 611$ & $\begin{array}{l}\text { PT5l } \\
\text { R.N.Jur. }\end{array}$ & $\mathrm{VAC}$ & $\mathrm{M}$ & $\begin{array}{l}1.31 \\
.04\end{array}$ & $\begin{array}{r}1.70 \\
0.03\end{array}$ & $\begin{array}{l}.111464 \\
.000091\end{array}$ & $\begin{array}{l}.511902 \\
.000024\end{array}$ & $\begin{array}{l}21.478 \\
0.015\end{array}$ & $\begin{array}{l}116.52 \\
.(148\end{array}$ & -.43 & -14.4 & +3.6 & $\begin{array}{l}1.65 \mathrm{Rb}-\mathrm{sr} \\
.703_{i \mathrm{f}_{3}}\end{array}$ & 6.2 \\
\hline
\end{tabular}

TAB. 5.2-5: RONDONIANO/SUNSÁS

\begin{tabular}{|c|c|c|c|c|c|c|c|c|c|c|c|c|c|c|c|c|c|}
\hline $\begin{array}{l}\text { sps } \\
\text { / lit. }\end{array}$ & $\begin{array}{l}\text { coord. } \\
\mathrm{g}^{\circ} \mathrm{m}^{\prime} / \mathrm{g}^{\circ} \mathrm{m}\end{array}$ & $\begin{array}{l}\text { n.campo/ } \\
\text { região }\end{array}$ & $\begin{array}{l}\text { lito- } \\
\text { logia }\end{array}$ & $\begin{array}{l}\text { iden } \\
\mathbf{t} \\
\text { diagra } \\
\text { ma }\end{array}$ & $\begin{array}{l}\mathbf{T}_{\text {chur }} \\
\mathrm{GA}\end{array}$ & $\begin{array}{l}T_{\text {DM2 }} \\
\text { GA }\end{array}$ & $\mathbf{T}_{\mathrm{INM}}$ & $\begin{array}{l}{ }^{147} \mathrm{Sm} / \\
{ }^{1+4} \mathrm{Nd}\end{array}$ & $\begin{array}{l}{ }^{143} \mathrm{Nd} / \\
{ }^{14} \mathrm{Nd}\end{array}$ & $\begin{array}{l}\mathrm{Sm} \\
p p m\end{array}$ & $\begin{array}{l}\mathbf{N d} \\
\text { plum }\end{array}$ & $\bar{f}$ & $\begin{array}{l}\varepsilon_{\mathrm{idd}} \\
(\mathrm{l}=0)\end{array}$ & $\begin{array}{l}\varepsilon_{\mathrm{Nd}} \\
(\mathrm{t})\end{array}$ & $\begin{array}{l}\mathbf{t}_{\text {método }} \\
\mathbf{R I} \mathbf{I}_{\text {bioner }}\end{array}$ & $\begin{array}{l}\varepsilon_{\mathrm{Sr}} \\
(1)\end{array}$ & ref. \\
\hline $\begin{array}{l}211 \\
\mathrm{gnl}\end{array}$ & $835 / 660$ & $\begin{array}{l}\text { PT 14F-2/ } \\
\text { R. Branco }\end{array}$ & GNL & $\bar{A}$ & $\begin{array}{l}1.35 \\
.05\end{array}$ & & $\begin{array}{l}1.67 \\
0.04\end{array}$ & $\begin{array}{l}.092614 \\
.000036\end{array}$ & $\begin{array}{l}.511715 \\
.000033\end{array}$ & $\begin{array}{l}28.377 \\
0.011\end{array}$ & $\begin{array}{l}185.28 \\
.008\end{array}$ & -.53 & -18.0 & +1.9 & $\begin{array}{l}1.50_{\mathrm{Rb}-\mathrm{Sr}} \\
.703_{\mathrm{hi}}\end{array}$ & 3.7 & $\mathrm{nt}$ \\
\hline $\begin{array}{l}2+2 \\
\operatorname{trj}\end{array}$ & $835 / 660$ & $\begin{array}{l}P\left[\mid 4 \mathrm{~F}^{-3} /\right. \\
\text { R.Branco }\end{array}$ & GRT & $\mathrm{B}$ & $\begin{array}{l}1.71 \\
.07\end{array}$ & 0 & $\begin{array}{l}2.118 \\
0.05\end{array}$ & $\begin{array}{l}.123635 \\
.000180\end{array}$ & $\begin{array}{r}.511815 \\
.000034\end{array}$ & $\begin{array}{l}27.665 \\
0.016\end{array}$ & $\begin{array}{l}135.31 \\
.18\end{array}$ & -.37 & -16.1 & -2.1 & $\begin{array}{l}1.500_{k+-\mathrm{sr}} \\
.706_{\mathrm{k}}\end{array}$ & 46 & $\mathrm{nt}$ \\
\hline gnl & $-822 / 660$ & $\begin{array}{l}\text { pt l } 5 \text { f Porto } \\
\text { Vello/Ron }\end{array}$ & GNL & $\mathrm{C}$ & 1.38 & & 1.72 & .10 & $\begin{array}{l}.511763 \\
.000011\end{array}$ & -.... & -....- & -.49 & -17.1 & +1.4 & $1.5_{\text {esturn }}$ & & 1 \\
\hline gnl & $945 / 6650$ & $\begin{array}{l}\text { pt143int/P. } \\
\text { Vetho/Ron }\end{array}$ & GNL & $\mathrm{D}$ & 1.69 & $1.92^{\# 1}$ & 2.47 & .17 & $\begin{array}{l}.512342 \\
.000009\end{array}$ & -...- & -...-. & -.14 & -5.8 & -0.7 & $1.5_{\text {estim }}$ & & 1 \\
\hline $\begin{array}{l}484 \\
\text { ton }\end{array}$ & - & $\begin{array}{l}\text { PO 05/ } \\
\text { Jaurú }\end{array}$ & GRT & $\mathrm{E}$ & $\begin{array}{l}1.57 \\
.06\end{array}$ & & $\begin{array}{l}1.95 \\
0.04\end{array}$ & $\begin{array}{l}.119499 \\
.000052\end{array}$ & $\begin{array}{l}511841 \\
.000028\end{array}$ & $\begin{array}{l}5.110 \\
0.001\end{array}$ & $\begin{array}{l}25.858 \\
.0010\end{array}$ & -.39 & -15.5 & -2.7 & $1.3_{\text {estim }}$ & & \\
\hline $\begin{array}{l}159 \\
\text { grt }\end{array}$ & $1527 / 585$ & $\begin{array}{l}\text { 537ammr7 } \\
\text { 9/Rond. } \mathrm{S}\end{array}$ & GRT & $\mathrm{F}$ & $\begin{array}{l}1.60 \\
.03\end{array}$ & & 1.90 & $\begin{array}{l}.097464 \\
.000022\end{array}$ & .511593 & 5.853 & 36.314 & -.50 & -20.4 & -2.3 & $\begin{array}{l}1.43_{\mathrm{Kb}-\mathrm{Sr}} \\
.70 \mathrm{I}_{\mathrm{b}}\end{array}$ & -26 & ni \\
\hline
\end{tabular}




\begin{tabular}{|c|c|c|c|c|c|c|c|c|c|c|c|c|c|c|c|c|c|}
\hline $\begin{array}{l}157 \\
\text { gnd }\end{array}$ & $\begin{array}{l}153 / 58 \\
24\end{array}$ & $\begin{array}{l}537 \text { amm } 10 \\
1.2 \text {-Rm.s }\end{array}$ & GRT & $\bar{G}$ & $\begin{array}{l}1.50 \\
.03\end{array}$ & & 1.79 & $\begin{array}{l}.086198 \\
.000026\end{array}$ & .511547 & 4.074 & 28.580 & -.56 & -21.3 & -1.1 & $\begin{array}{l}1.43 \mathrm{Ri}-\mathrm{Sr} \\
.7()]\end{array}$ & -26 & $\mathrm{nt}$ \\
\hline $\begin{array}{l}184 \\
\text { dio }\end{array}$ & $1240 / 6138$ & $\begin{array}{l}\text { P1 19/ } \\
\text { Guaporé }\end{array}$ & BAS & $\mathrm{H}$ & -.-- & $1.06^{-1}$ & $-7 ?$ & $\begin{array}{l}.2320 \\
.0024\end{array}$ & $\begin{array}{l}.513187 \\
.000033\end{array}$ & $\begin{array}{l}.498 \\
.005\end{array}$ & $\begin{array}{l}1.298 \\
.001\end{array}$ & .18 & +10.7 & +6.2 & 1.0 estinis & & $\mathrm{nt}$ \\
\hline $\begin{array}{l}213 \\
\text { anf }\end{array}$ & 12106344 & $\begin{array}{l}\mathrm{PT}-04-1 / \\
\text { Guaporé }\end{array}$ & BAS & I & --- & & $\begin{array}{l}0.93 \\
0.07\end{array}$ & $\begin{array}{l}.178596 \\
.000095\end{array}$ & $\begin{array}{l}.512832 \\
.000018\end{array}$ & $\begin{array}{l}6.295 \\
0.002\end{array}$ & $\begin{array}{l}21.314 \\
.009\end{array}$ & -.09 & +3.8 & +6.3 & $1.1 \mathrm{~K}+\mathrm{Hr}$ & & $\mathrm{nt}$ \\
\hline $\begin{array}{l}183 \\
\text { anf }\end{array}$ & $136 \% 6040$ & $\begin{array}{l}\mathrm{PT}-03 / \\
\text { Guaporé }\end{array}$ & BAS & J & -.-- & $1.48^{\wedge}$ & $-7 ?$ & $\begin{array}{l}.23226 \\
.00017\end{array}$ & $\begin{array}{l}.513209 \\
.000028\end{array}$ & $\begin{array}{l}1.786 \\
0.001\end{array}$ & $\begin{array}{l}4.650 \\
.002\end{array}$ & .18 & +11.1 & +4.8 & $1.4_{K \rightarrow \mathrm{r}}$ & & $\mathrm{n}$ \\
\hline $\begin{array}{l}212 \\
\text { anf }\end{array}$ & 1366040 & $\begin{array}{l}\mathrm{PT}+03 \mathrm{Al} / \\
\text { Guaporé }\end{array}$ & BAS & K & $-\ldots$ & & $\begin{array}{l}0.7 \\
0.19\end{array}$ & $\begin{array}{l}.202655 \\
.000089\end{array}$ & $\begin{array}{l}.513004 \\
.0000222\end{array}$ & $\begin{array}{l}3.847 \\
0.001\end{array}$ & $\begin{array}{l}11.479 \\
.004\end{array}$ & .03 & +7.1 & +6.3 & $1.1 \mathrm{~K}-\mathrm{Ar}$ & & $n t$ \\
\hline $\begin{array}{l}375 \\
\text { bas }\end{array}$ & $1010 / 6350$ & $\begin{array}{l}\text { pt74/ Porto } \\
\text { Velho/Ron }\end{array}$ & BAS & $\mathrm{L}$ & $\begin{array}{l}.89 \\
.07\end{array}$ & & $\begin{array}{l}1.47 \\
0.05\end{array}$ & $\begin{array}{l}.133994 \\
.000088\end{array}$ & $\begin{array}{l}.512274 \\
.000028\end{array}$ & $\begin{array}{l}7.530 \\
0.004\end{array}$ & $\begin{array}{l}33.982 \\
.013\end{array}$ & -.32 & -7.1 & +0.9 & $1.00 \mathrm{~K} \cdot \mathrm{Ar}$ & & $\mathrm{nt}$ \\
\hline $\begin{array}{l}380 \\
\text { bas }\end{array}$ & $1235 / 6130$ & $\begin{array}{l}\text { PTozA } \\
\text { Gluaporé }\end{array}$ & BAS & M & -- & $1.18^{-1}$ & $\begin{array}{l}1.20 \\
0.07\end{array}$ & $\begin{array}{l}.162298 \\
.000079\end{array}$ & $\begin{array}{l}.512639 \\
.000024\end{array}$ & $\begin{array}{l}3.936 \\
0.0(01\end{array}$ & $\begin{array}{l}1+.665 \\
.006\end{array}$ & -.17 & +0.02 & +4.4 & $1.0_{\mathrm{K}-\mathrm{Ar}}$ & & $\mathrm{nt}$ \\
\hline
\end{tabular}

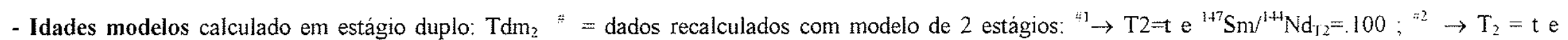
${ }^{147} \mathrm{Sm}^{144} \mathrm{Nd}_{\mathrm{T} 2}=0.11 ;{ }^{* 3} \rightarrow \mathrm{T}_{2}=2,1 \mathrm{e}^{147} \mathrm{Sm} /{ }^{144} \mathrm{Nd}_{\mathrm{T} 2}=0.11 ;{ }^{* 4} \rightarrow=\mathrm{T} 2=\mathrm{te} \mathrm{e}^{1+7} \mathrm{Sm} /{ }^{144} \mathrm{Nd}_{\mathrm{T} 2}=0.15$ (valor médio das amostras ident. I a Q)

- Referências: $n t=$ neste trabalho e idades modelos recalculados para este trabalho a partir de dados isotópicos de : $1=$ Vignol $1987,2=$ Gruau et. al. 1985 e $3=$ Ben Othman et. al 1984, Gibbs 1983.

- Fonte Bibliográfica para a coluna $t_{\text {métado }} \mathbf{a}=$ Siga júnior $1986, \mathrm{~b}=$ Santos et al $1988, \mathrm{c}=$ Montalvão et. al. $1988, \mathrm{~d}=\mathrm{Siga}$ Júnior 1988 , e=Tassinari dados inéditos, $\mathrm{f}=$ Basei 1975, $\mathrm{g}=$ Tassinari et. al. $1977, \mathrm{~h}=$ Tassinari $198 \mathrm{l}, \mathrm{i}=$ Barrios 1983, $\mathrm{j}=$ Dall'Agno et al $1992, \mathrm{k}=\mathrm{Tassinari}$ et al $1976, \mathrm{l}=$ Tassianri $1980, \mathrm{~m}=$ Vignol 1987, $\mathrm{n}=$ Gruau et al 1985, o = Ben Otman et. al 1984. 
Tabela 5.2-6: dados isotópicos de Nd nas areias fluviais da Bacia Amazônica nas margens do Rio Madre de Dios, provenientes das regiöes de Bolivia e Peru. Dados de Basu et. al 1990, recalculados para este trabalho. O erro nas razões ${ }^{143} \mathrm{Nd} /{ }^{144} \mathrm{Nd}$ tem um valor constante de 0.000015 . Aos demais erros não foram encontrados na bibliografia acima referida. Os $\varepsilon_{\text {nd }}$ (1.3) foram calculados com $t=1.3$ estimado. Tám1 são calculados usando seguintes constantes : $\left({ }^{143} \mathrm{Nd} /{ }^{144} \mathrm{Nd}\right) d m=513114 \mathrm{e}\left({ }^{147} \mathrm{Sm} /{ }^{144} \mathrm{Nd}\right) \mathrm{dm}=222$; Tdm2 é baseado na eq. de DePaolo $1981 \mathrm{com}{ }^{143} \mathrm{Nd} /{ }^{144} \mathrm{Nd}_{\text {chur }}=.512638 \mathrm{e}^{147} \mathrm{Sm} / 1^{44} \mathrm{Nd}_{\text {chur }}=.1967$.

\begin{tabular}{lllllllllll}
\hline $\begin{array}{l}\text { amos } \\
\text { tra }\end{array}$ & Tchur & $\begin{array}{l}\text { Tdm } \\
(1)^{\#}\end{array}$ & $\begin{array}{l}T d m \\
(2)^{\#}\end{array}$ & $\begin{array}{l}144 \mathrm{Sm} / \\
{ }^{144} \mathrm{Nd}\end{array}$ & $\begin{array}{l}{ }^{144} \mathrm{Nd} / \\
\mathrm{Nd}\end{array}$ & $\begin{array}{l}\mathrm{Sm} \\
\mathrm{ppm}\end{array}$ & $\mathrm{Nd} \mathrm{ppm}$ & $\varepsilon(0)$ & $\varepsilon(1.3)$ & $f$ \\
\hline & & & & & & & & & & \\
2 & 0.85 & 1.35 & 1.35 & .120875 & .512218 & 4.41 & 22.2 & -8.2 & +4.4 & -.39 \\
4 & 0.95 & 1.48 & 1.49 & .130598 & .512227 & 4.40 & 20.5 & -8.0 & +2.9 & -.34 \\
5 & 1.03 & 1.48 & 1.58 & .118644 & .512109 & 7.39 & 37.9 & -10.3 & +2.6 & -.40 \\
7 & 1.13 & 1.55 & 1.57 & .118234 & .512056 & 4.10 & 21.1 & -11.4 & +1.7 & -.40 \\
8 & 1.12 & 1.55 & 1.58 & .121217 & .512085 & 5.08 & 25.5 & -10.8 & +1.7 & -.38 \\
10 & 1.20 & 1.62 & 1.65 & .122065 & .512048 & 3.29 & 16.4 & -11.5 & +0.9 & -.38 \\
11 & 1.03 & 1.44 & 1.45 & .107902 & .512038 & 4.96 & 27.97 & -11.7 & +3.0 & -.45 \\
12 & 1.03 & 1.46 & 1.47 & .112732 & .512068 & 2.39 & 12.9 & -11.1 & +2.8 & -.43 \\
13 & 0.82 & 1.32 & 1.32 & .118705 & .512220 & 5.56 & 28.5 & -8.2 & +4.8 & -.40 \\
14 & 1.05 & 1.48 & 1.50 & .115712 & .512078 & 5.61 & 29.5 & -10.9 & +2.5 & -.41 \\
16 & 0.83 & 1.33 & 1.33 & .118797 & .512215 & 3.69 & 18.9 & -8.3 & +4.7 & -.40 \\
20 & 1.02 & 1.43 & 1.44 & .108916 & .512051 & 7.16 & 40.0 & -11.5 & +3.1 & -.45 \\
22 & 1.11 & 1.52 & 1.54 & .113888 & .512033 & 48.29 & 258.0 & -11.8 & +1.9 & -.42 \\
23 & 0.98 & 1.47 & 1.48 & .125034 & .512179 & 3.07 & 14.94 & -9.0 & +2.9 & -.36 \\
24 & 1.10 & 1.52 & 1.54 & .114959 & .512046 & 4.95 & 26.2 & -11.5 & +2.0 & -.42 \\
25 & 0.92 & 1.38 & 1.39 & .114959 & .512144 & 4.95 & 26.2 & -9.6 & +3.9 & -.42 \\
26 & 0.96 & 1.47 & 1.48 & .126478 & .512194 & 3.86 & 18.57 & -8.7 & +3.0 & -.36 \\
\hline
\end{tabular}




\section{3: FRAGMENTO CRATÔNICO RIO APA}

\section{3-1 - SÍNTESE GEOLÓGICA}

O termo fragmento cratônico Rio Apa foi utilizado por Cordani et. al., 1988, para os terrenos granito-gnáissicos que ocorrem na porção extremo oeste do Brasil, próximo à divisa com o Paraguai, fig. 5.3-1. A parte oriental desse fragmento encontra-se recoberta pelos sedimentos do Paleozóicos da Bacia do Paraná, de modo que as rochas pré-cambrianas ocorrem somente a norte do Rio Apa. As litologias predominantes são granito-gnáissicas, que mostram-se recobertas pelas lavas ácidas de Amoguijá (riolitos e riodacitos) e cortadas pelos granitos pós-tectònicos e rochas associadas da Suite Intrusiva do Lumiador (Correia et. al., 1979).

Os dados geocronológicos disponiveis para as rochas granito-gnáissicas, obtidos através do método isocrônico $\mathrm{Rb} / \mathrm{Sr}$, indicaram idades Paleoproterozóicas $(1,68 \pm 0.03 \mathrm{Ga}$; $\mathrm{RI}=0,706$; Tassinari 198 Ib). As idades $\mathrm{Rb}-\mathrm{Sr}$ obtidas para as rochas vulcânicas ácidas do Amoguijá foram de $1,65 \pm 0,06(\mathrm{RI}=0,702)$, interpretadas como relativas à sua formação, a partir da diferenciação direta de material mantélico. Por sua vez, as idades $\mathrm{Rb}-\mathrm{Sr}$ das rochas

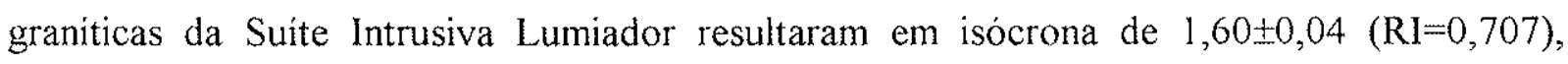
interpretada como referente à colocação destes corpos intrusivos, formados a partir de refusão de material crustal.

\section{3-2 - IDADES MODELO Sm-Nd, (T $\left.\mathrm{T}_{\mathrm{DM}}\right)$}

Os dados Sm-Nd obtidos tanto para as rochas gnáissicas como para as rochas graniticas e vulcânicas ácidas indicaram idades modelos $\left(\mathrm{T}_{\mathrm{DM}}\right)$ relativos ao Paleoproterozóico (2,3 a 1,9Ga, tab. 5.3). Tal intervalo de tempo representa o principal período de acreção de material juvenil, denotando ser contemporâneo ao super evento de acreção das província Ventuari-Tapajós e Maroni Itacaiúnas do Craton Amazônico. Do mesmo modo a fig. 5.3-2 mostra a evolução isotópica $\varepsilon_{\mathrm{N} d}$ no tempo geológico, em que as linhas de evolução apresentam padrão muito similar ao observado para as rochas da porção ocidental do Craton Amazônico.

Os valores de $\varepsilon_{\mathrm{Nd}}(\mathrm{t})$, quando calculados para idade de formação $(\mathrm{t} \mathrm{kb} / \mathrm{sr}=1,7 \mathrm{Ga})$, distribuiram-se entre $-4,1$ a $+0,8$, com um valor médio de $-0,16$, sugerindo tempo de residência crustal relativamente curto para os protólitos das rochas analisadas. 


\begin{tabular}{|c|c|c|c|c|c|c|c|c|c|c|c|c|c|c|c|c|c|}
\hline $\begin{array}{l}\text { SPS } \\
\text { /lit. }\end{array}$ & $\begin{array}{l}\text { coord./ } \\
\text { (p.local.) }\end{array}$ & $\begin{array}{l}\text { n.campo/ } \\
\text { região }\end{array}$ & $\begin{array}{l}\text { lito- } \\
\text { logia }\end{array}$ & ident. & \begin{tabular}{|l}
$T_{\text {chur }}$ \\
(GA) \\
Goldstein \\
et.al 1984 \\
\end{tabular} & ${ }_{(\mathrm{GA})} \mathbf{T}_{\mathrm{dm} 2}$ & \begin{tabular}{|l|}
$T_{\mathrm{dm}}$ \\
$(\mathrm{GA})$ \\
DePaole- \\
1981 \\
\end{tabular} & {$\left[\begin{array}{l}{ }^{143} \mathrm{Nd} / \\
{ }^{144} \mathrm{Nd}\end{array}\right.$} & \begin{tabular}{|l}
${ }^{147} \mathrm{Sm} /$ \\
${ }^{144} \mathrm{Nd}$
\end{tabular} & $\begin{array}{l}\text { Sm } \\
\text { ppm }\end{array}$ & $\begin{array}{l}\text { Nd } \\
\text { ppm }\end{array}$ & $f$ & $\begin{array}{l}\varepsilon_{N d} \\
(0)\end{array}$ & $\begin{array}{l}\varepsilon_{\mathrm{Nd}} \\
(t)\end{array}$ & $\begin{array}{l}\mathrm{t}(\mathrm{Ga})_{\text {mét }} \\
\mathbf{R i}_{\text {(fonte) }}\end{array}$ & $\begin{array}{l}\varepsilon_{\mathrm{Sr}} \\
(t)\end{array}$ & ref \\
\hline & & & & & & & & & & & & & & & & & \\
\hline \begin{tabular}{|l|}
$448 /$ \\
gns
\end{tabular} & $2045 / 5650$ & $4036 \mathrm{HA} 700$ & GTD & A & $\begin{array}{l}1.59 \\
0.05 \\
\end{array}$ & & $\begin{array}{l}1.95 \\
0.04 \\
\end{array}$ & $\begin{array}{l}.511817 \\
.000028 \\
\end{array}$ & $\begin{array}{l}.11802 \\
.00006 \\
\end{array}$ & $\begin{array}{l}11.45 \\
0.004 \\
\end{array}$ & $\begin{array}{l}58.706 \\
0.024 \\
\end{array}$ & -.40 & -16.0 & +.8 & $\begin{array}{c}1.68 \\
.706_{\mathrm{a}} \\
\end{array}$ & 49 & nt \\
\hline $\begin{array}{l}49 / \\
\text { gns }\end{array}$ & $2151 / 5650$ & $4007 \mathrm{HA} 5473$ & GTD & B & $\begin{array}{l}1.65 \\
0.04 \\
\end{array}$ & & $\begin{array}{l}1.93 \\
0.03 \\
\end{array}$ & $\begin{array}{l}.511528 \\
.000024 \\
\end{array}$ & $\begin{array}{l}.09425 \\
.00004 \\
\end{array}$ & $\begin{array}{l}8.696 \\
0.002 \\
\end{array}$ & $\begin{array}{l}55.893 \\
0.022 \\
\end{array}$ & -.52 & -21.7 & +.3 & $\begin{array}{l}1.68 \\
.706_{a} \\
\end{array}$ & & $\mathrm{nt}$ \\
\hline $\begin{array}{l}350 / \\
\text { rio } \\
\end{array}$ & $2135 / 5730$ & $4037 \mathrm{CH} 42$ & VAC & $\mathrm{C}$ & $\begin{array}{l}2.04 \\
0.04 \\
\end{array}$ & & \begin{tabular}{|l|}
2.34 \\
0.03 \\
\end{tabular} & $\begin{array}{l}.511576 \\
.000022 \\
\end{array}$ & $\begin{array}{l}.11778 \\
.00006 \\
\end{array}$ & $\begin{array}{l}8.207 \\
0.002 \\
\end{array}$ & $\begin{array}{l}42.135 \\
0.017 \\
\end{array}$ & -.40 & -20.7 & -4.1 & $\begin{array}{l}1.65 \\
.702_{\mathrm{a}} \\
\end{array}$ & -8 & $\mathrm{ni}$ \\
\hline $\begin{array}{l}351 / \\
\text { rdc }\end{array}$ & $2150 / 5735$ & 578HA458 & VAC & D & $\begin{array}{l}1.69 \\
0.03 \\
\end{array}$ & & $\begin{array}{l}1.96 \\
0.03 \\
\end{array}$ & $\begin{array}{l}.511442 \\
.000023\end{array}$ & $\begin{array}{l}.08905 \\
.00007\end{array}$ & $\begin{array}{l}1.803 \\
0.001\end{array}$ & $\begin{array}{l}12.243 \\
0.006\end{array}$ & -.55 & -23.3 & -0.7 & $\begin{array}{l}1.65 \\
.702_{a}\end{array}$ & & nt \\
\hline $\begin{array}{l}3521 \\
\text { grt }\end{array}$ & $2045 / 5655$ & $4036 \mathrm{HA} 702$ & GTD & $E$ & $\begin{array}{l}1.53 \\
0.04 \\
\end{array}$ & & $\begin{array}{l}1 . \overline{87} \\
0.03 \\
\end{array}$ & $\begin{array}{l}.511744 \\
.000025 \\
\end{array}$ & $\begin{array}{l}.10789 \\
.00006 \\
\end{array}$ & $\begin{array}{l}7.215 \\
0.002 \\
\end{array}$ & \begin{tabular}{|l|}
40.437 \\
0.017 \\
\end{tabular} & -.45 & -17.4 & +.7 & $\begin{array}{l}1.60 \\
.707 \\
\end{array}$ & 62 & $\mathrm{nt}$ \\
\hline & & & & & & & & & & & & & & & & & \\
\hline & & & & & & & & & & & & & & & & & \\
\hline
\end{tabular}

TAB. 5.3 - Dados Sm e Nd relativos ao Fragmento Cratônico Rio Apa. (Obs.: nota explicativa da tabela encontra-se no apêndice 1).

Ref: $:$ nt $=$ neste trabalho: $a=$ Tassinari $(1981 b)$ 


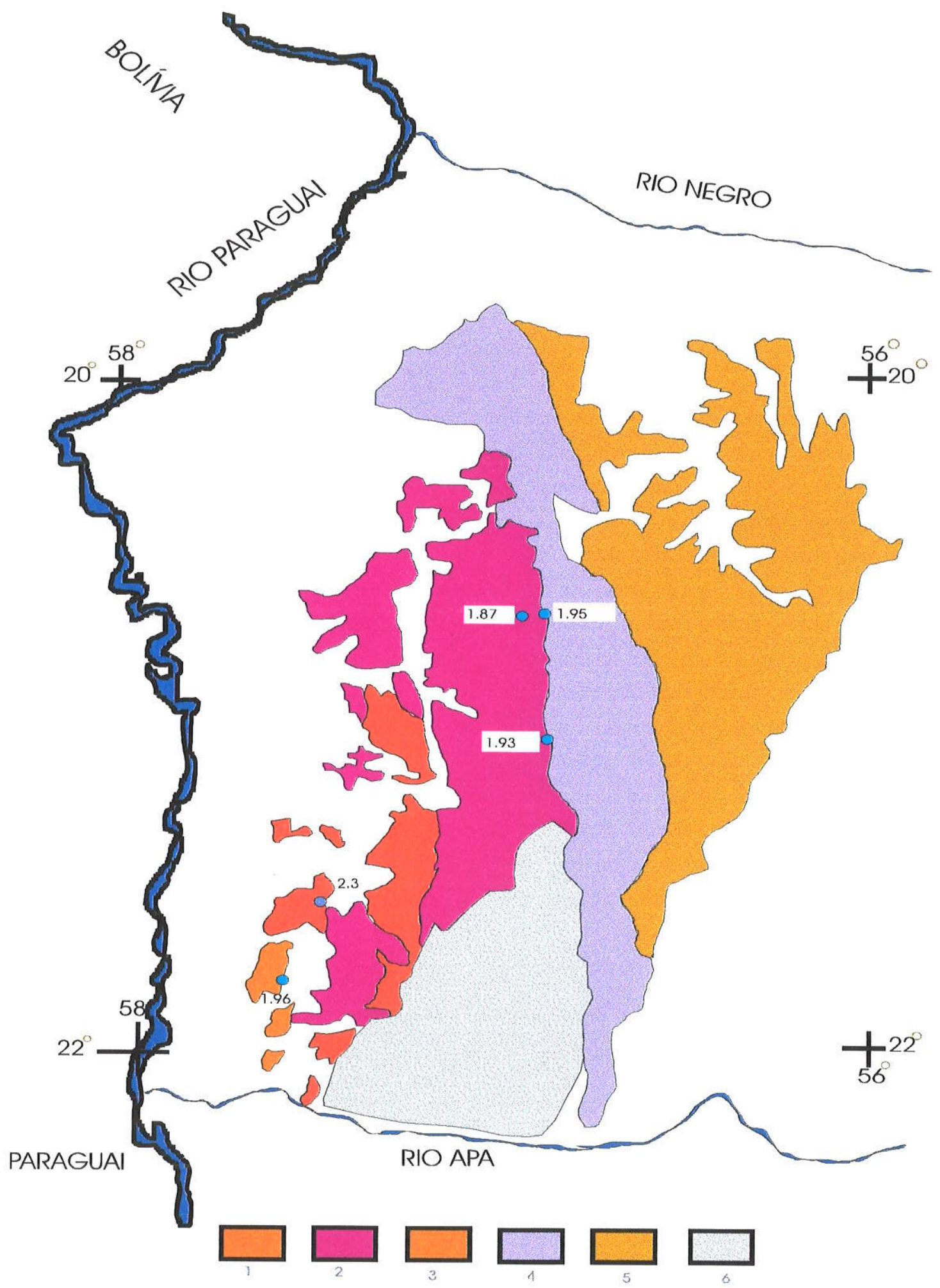

Fig.5.3-1: Mapa geológico simplificado do Fragmento Cratônico do Rio Apa (baseado em Schobbenhaus et. al. 1984). Localização das amostras com datação Sm-Nd (Tdm). Legenda: 1 - vucânica ácida; 2 - migmatito, gnaisse, granito, anfibolito, biotita-xisto; 3 granito; 4 - metassedimento (calcário, marga, dolomito, ...); 5 - metassemento (quartzito, filito, xisto...); 6 - migmatito, gnaisse, granitóide, anfibolito, granulito 


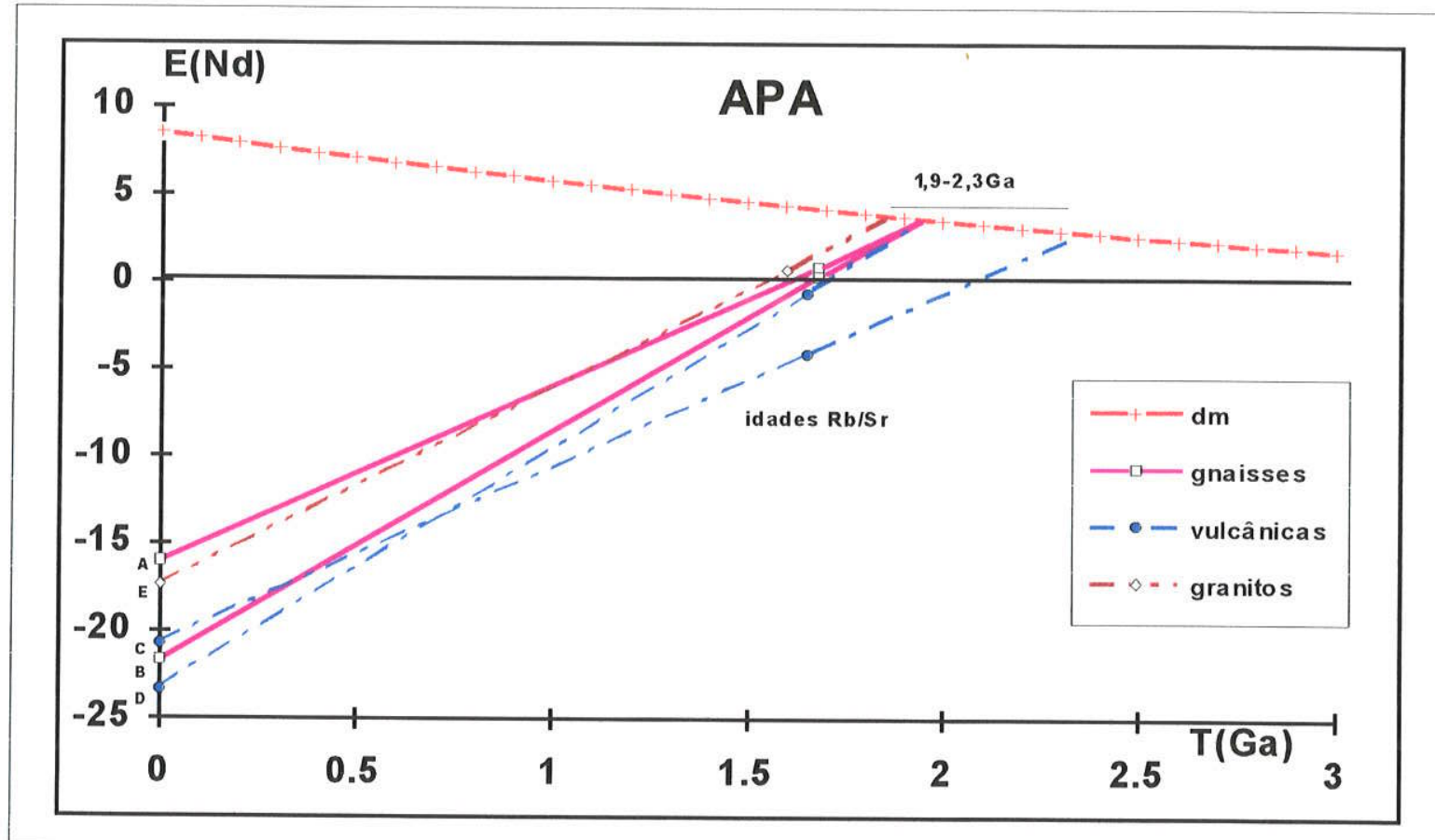

Fig.5.3-2: Diagrama $\varepsilon_{\mathrm{Nd}}$ versus tempo geológico - Fragmento Crustal Rio Apa. Os dados isotópicos das amostras encontram-se na tab. 5.3. 


\section{4: - CRATON DE SÃO LUIS}

\section{4-1 SÍNTESE GEOLÓGICA}

O Cráton de São Luís é considerado como uma pequena parte do Cráton Oeste Africano que sobrou no continente sulamericano após a fragmentação da Pangea. A denominação Craton de São Luís foi dada por Cordani (1968), através das evidências de uma área estável e antiga no litoral dos Estados de Maranhão e Pará.

O embasamento é constituído predominantemente de rochas gnáissico-migmtiticas, apresentando composição granitica a tonalítica.

As datações radiométricas $\mathrm{Rb}-\mathrm{Sr}$ e K-Ar de amostras do Craton de São Luis indicaram idades em torno de 2,0Ga (Hurley et. al., 1967). Estas idades Transamazônicas foram posteriormente confirmadas por Hama (apud Costa et. al., 1977). Do mesmo modo também encontram-se idades Paleoproterozóicas no embasamento a Oeste da Faixa móvel TransSahariana do cráton Oeste Africano, (Caby et. al. 1981).

\section{4-2 - IDADES MODELO Sm-Nd ( $\left.T_{D M}\right)$}

Apenas uma datação $\mathrm{Sm-Nd}\left(\mathrm{T}_{\mathrm{BM}}\right.$ ) foi efetuada neste trabalho em rocha granitóide pertencente ao Craton de São Luís. Esta rocha indicou idade $T_{D M}$ de 2,1Ga (tab. 5.4) sugerindo acreção de material juvenil durante Paleoproterozóico, contemporâneo aos eventos de acreção da região Setentrional do Cráton Amazônico (Província Maroni-Itacaiunas).

\section{TABELA:5.4 - Craton SÃO LUIS}

\begin{tabular}{|c|c|c|c|c|c|c|c|c|c|c|c|c|}
\hline $\begin{array}{l}\text { SPS } \\
\text { /lit. }\end{array}$ & $\begin{array}{l}\text { coord./ } \\
\text { (p.local.) }\end{array}$ & \begin{tabular}{|l|} 
n. campo \\
região
\end{tabular} & $\begin{array}{l}\text { lito- } \\
\text { logia }\end{array}$ & $\begin{array}{l}\mathbf{T}_{\text {chur }} \\
(\mathbf{G a}) \\
\text { Goldsteth } \\
\text { ctall1.1984 }\end{array}$ & $\begin{array}{l}T_{\text {dm2 }} \\
(\mathbf{G a}) \\
\text { estágio } \\
\text { duglo } \\
\end{array}$ & $\begin{array}{l}\mathbf{T}_{\mathrm{dm}} \\
(\mathbf{G a}) \\
\text { DePaslo } \\
\text { - } 1981\end{array}$ & $\begin{array}{l}{ }^{143} \mathrm{Nd}- \\
{ }^{144} \mathrm{Nd}\end{array}$ & $\begin{array}{l}{ }^{1+7} \mathrm{Sm}- \\
{ }^{144} \mathrm{Nd}\end{array}$ & $\begin{array}{l}\text { Sm } \\
\text { ppm }\end{array}$ & $\begin{array}{l}\text { Nd } \\
\text { ppm }\end{array}$ & $f$ & $\varepsilon_{\mathrm{Nd}}(0)$ \\
\hline $\begin{array}{l}301 \\
\text { ton }\end{array}$ & São Luis & $\begin{array}{l}\text { CSI. } \\
\text { SÃOLUIS }\end{array}$ & GTD & $\begin{array}{l}1.72 \\
0.05\end{array}$ & & $\begin{array}{l}2.10 \\
0.04\end{array}$ & $\begin{array}{l}.511844 \\
.000024\end{array}$ & $\begin{array}{l}.12671 \\
.00008\end{array}$ & $\begin{array}{l}2.596 \\
0.001\end{array}$ & 12.39 & -.36 & -15.5 \\
\hline
\end{tabular}

Obs.:dados obtidos neste trabalho. 


\section{CRATON DE SRO U'S}

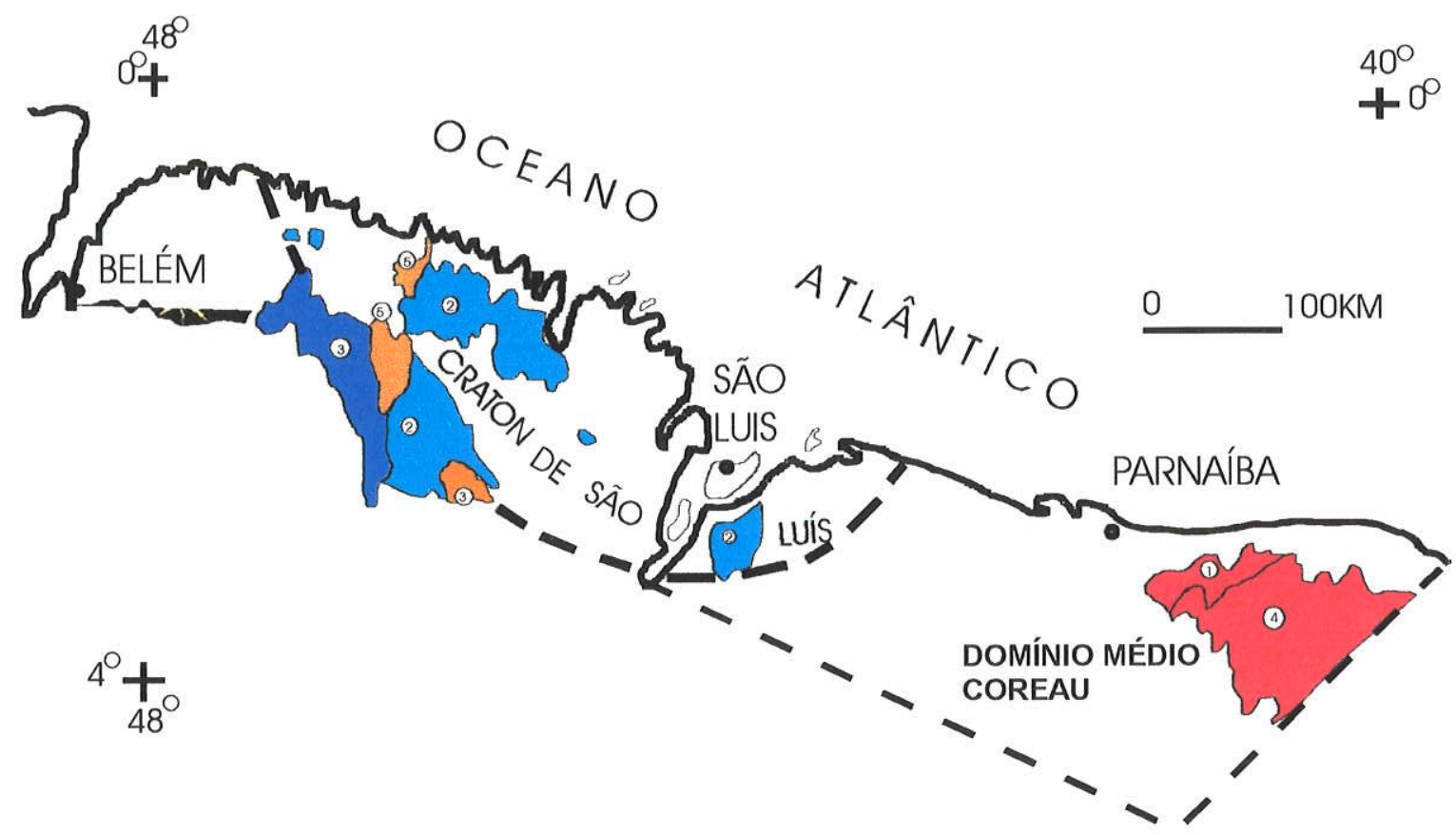

CRATON DE SÃO LUIS : 2 = MARACAÇUMÉ + TROMAí; - Tdm $=2.1 \mathrm{Ga}$

FAIXA DOBRADA 3 - SANTA LUZIA

DEPÓSITOS MOLÁSSICOS: PIRIÁ

DOMÍNIO MÉDIO COREAU - 1 = Granja; 4 = Medio Coreau $(\mathrm{Tdm}=\mathbf{2 . 4 - 2 . 7 G a )}$

FIG. 5-4.1: MAPA GEOLÓGICO DO CRÁTON S. LUIS 


\section{5-5: FAIXA DE DOBRAMENTOS PARAGUAI - ARAGUAIA / TOCANTINS E DOMÍNIO MÉDIO COREAU}

\section{5-1 SÍNTESE GEOLÓGICA}

FAIXA PARAguai-ARAguala/TOCANTINS - Esta faixa inclui um extenso conjunto de rochas metamórficas que ocorre desde a bacia do Rio Paraguai, nos Estados do Mato do Grosso do Sul e Mato Grosso até o baixo curso dos Rios Araguaia e Tocantins nos Estados de Goiás e Pará. Nos Estados de Mato Grosso e Mato Grosso do Sul, foi denominada de Faixa Paraguai - Araguaia (Almeida 1965), sendo representada pelos Grupos Cuiabá, Corumbá e Jacadigo. Na porção setentrional é representada pelo Supergrupo Baixo Araguaia, que inclui os Grupos Estrondo e Tocantins (Marini et. al. 1984). As exposições de rochas pertencentes ao embasamento cristalino ocorrem em pequena escala nas regiões de Colméia, Cantão e Porto Nacional (figs. 5.5-1 e 5.-9-2).

O Complexo Colméia inclui rochas gnáissicas e migmatíticas, interpretadas como possiveis núcleos de embasamento (Costa, 1980). Nas regiões de Cantão - Xambioá, a norte de Colméia, afloram núcleos com estruturas dômicas (Hasui et. al. 1984) de litologia ortognáissica. Os dados $\mathrm{Rb} / \mathrm{Sr}$ e K-Arobtidos por Hasui et. al. (1980) e idades $\mathrm{Pb}-\mathrm{Pb}$ em zircão (Moura e Gaudette, 1993) indicaram uma evolução policiclica para as rochas desse dominio. Foram obtidos valores próximos à $2,7 \mathrm{Ga}, 1,8 \mathrm{Ga}$, bem como entre 1,0 e $0,5 \mathrm{Ga}$, sugerindo tratar-se de terrenos arqueanos, retrabalhados no Paleoproterozóico e posteriormente durante Neoproterozóico.

Rochas gnáissico-migmatíticas, graníticas, tonalíticas, bem como rochas vulcânicas ácidas a intermediárias (riolitos, dacitos, riodacitos) que ocorrem a sudeste de Colméia, região de Brejinho de Nazaré, indicaram através do método isocrônico $\mathrm{Rb}-\mathrm{Sr}$ idades de $0,59 \mathrm{Ga}(\mathrm{RI}=0,712)$ e 1,86Ga ( $\mathrm{RI}=0,704$; Tassinari et. al. 1980). Rochas granulíticas incluídas assim no denominado Complexo Porto Nacional indicaram, através do método $\mathrm{Rb} / \mathrm{Sr}$, idades Paleoproterozóicas, entre 2.18 e $2.18 \mathrm{Ga}$ (Garayeb e Lafon, 1996), interpretadas pelos autores como relativas à época do metamorfismo de alto grau. 
No interior dos Grupos Estrondo, Tocantins, Cuiabá, Jacadigo e Coumbá foram obtidas datações pelo métodos $\mathrm{Rb}-\mathrm{Sr}$ e $\mathrm{K}$-Ar em rochas gnáissicas, filíticas, xistos e ardósias todas com idades Neproterozóicas variando desde 0,98 a 0,47Ga (Hasui, 1980, Marini et. al 1984; Cordani e Tassinari, 1979). Datação efetuada recentemente por Kawashita et. al. (1996), em rochas carbonáticas da Fm Araras (Gr. Corumbá) indicou idade de 0,595Ga (inferências com base em razões ${ }^{87} \mathrm{Sr}{ }^{86} \mathrm{Sr}$ ), sendo esta idade contemporânea à deposição do Super grupo São Francisco. Os registros fossiliferos do Gr. Corumbá, segundo Zaine e Fairchild (1987), sugerem seu posicionamento no Vendiano.

DOMíNIO MÉDIO COREAU - Os terrenos dobrados e retrabalhados no Ciclo Brasiliano, a NW de Lineamento Transbrasiliano tais como Granja e Médio Coreau serão denominados neste trabalho de Dominio Médio Coreau. Trata-se de regiões predominantemente gnáissicomigmatíticas consideradas como extensão da orogênese Transamazônica - Eburneana, retrabalhadas em parte no Ciclo Brasiliano (fig. 5.4-1 e 5.5-1), e considerados como borda tectonizada do Craton W. Africano.

\section{5-2 - IDADES MODELO Sm-Nd}

\section{FAIXA PARAGUAI-ARAGUAIA / TOCANTINS}

Quinze análises radiométricas Sm-Nd são disponiveis para os núcleos de embasamento neste setor (Colmeia e Porto Nacional), seis das quais obtidas neste trabalho (tab. 5.5A e figs 5.5-1 e 2).

Os terrenos gnáissico-migmatíticos pertencentes ao Complexo Colméia, apresentaram idades Sm-Nd ( $\left.\mathrm{T}_{\mathrm{DM}}\right)$ distribuidas entre 3,4 e 2,9Ga. (tab.5.5, amostras = D, E e J a O). Do mesmo modo as rochas ortognáissicas formadas durante o Ciclo Transamzônico, na região de Cantão, indicaram idades modelo $\mathrm{Sm}-\mathrm{Nd}\left(\mathrm{T}_{\mathrm{dm}}\right)$ arqueanas $(2,91$ a 2,82Ga; tab. 5.5, amostras $=\mathrm{G}, \mathrm{H}$ e I). Tais valores caracterizam o Arqueano como o principal período de diferenciação mantélica dos protólitos. Nota-se que diversas dessas rochas formadas no Arqueano $(2,8 \mathrm{Ga})$ apresentam idades de diferenciação manto - crosta bastante próximas às de cristalização magmática, caracterizando pequeno periodo de residência crustal. O mesmo não ocorre em relação aos gnaisses e migmatitos 
formados durante o Ciclo Transamazônico, cujos protólitos foram diferenciados do manto no Arqueano.

As rochas que ocorrem nos arredores de Porto Nacional, com datações Neoproterozóicas $(0,97-0,59 \mathrm{Ga})$ apresentam idades Sm-Nd $\left(\mathrm{T}_{\mathrm{DNM}}\right)$ de 2,93, 1,96 e 1,21 Ga (tab. 5.5, amostras $=\mathrm{A}, \mathrm{B}$ e C). Tal comportamento permite sugerir diferentes períodos de acreção juvenil ou, alternativamente, mistura de materiais diferentes em idade e conteúdo de ETR, para os protólitos dessas rochas.

$\mathrm{O}$ diagrama $\varepsilon_{\mathrm{Nd}} \times \mathrm{T}(\mathrm{Ga})$, figg. 5.5-3, mostra o padrão de evolução isotópica de Nd no tempo geológico para as rochas da porção setentrional (Cinturão Araguaia - Tocantins). Verifica-se que, de um modo geral, a acreção de material juvenil ocorreu predominantemente durante o Arqueano, sugerindo que a região constitui uma extensão da parte oriental da Província Amazônia Central do Craton Amazônico.

\section{DOMÍNIO MÉDIO COREAÚ}

As acreções de material juvenil nos terrenos do Domínio Médio Coreau ocorreram predominantemente a no final do Arqueano e inicio do Paleoproterozóico (2,7 a 2,4Ga), conforme as idades modelo $\mathrm{Sm}-\mathrm{Nd}$ indicadas na tab. 5.5B. 


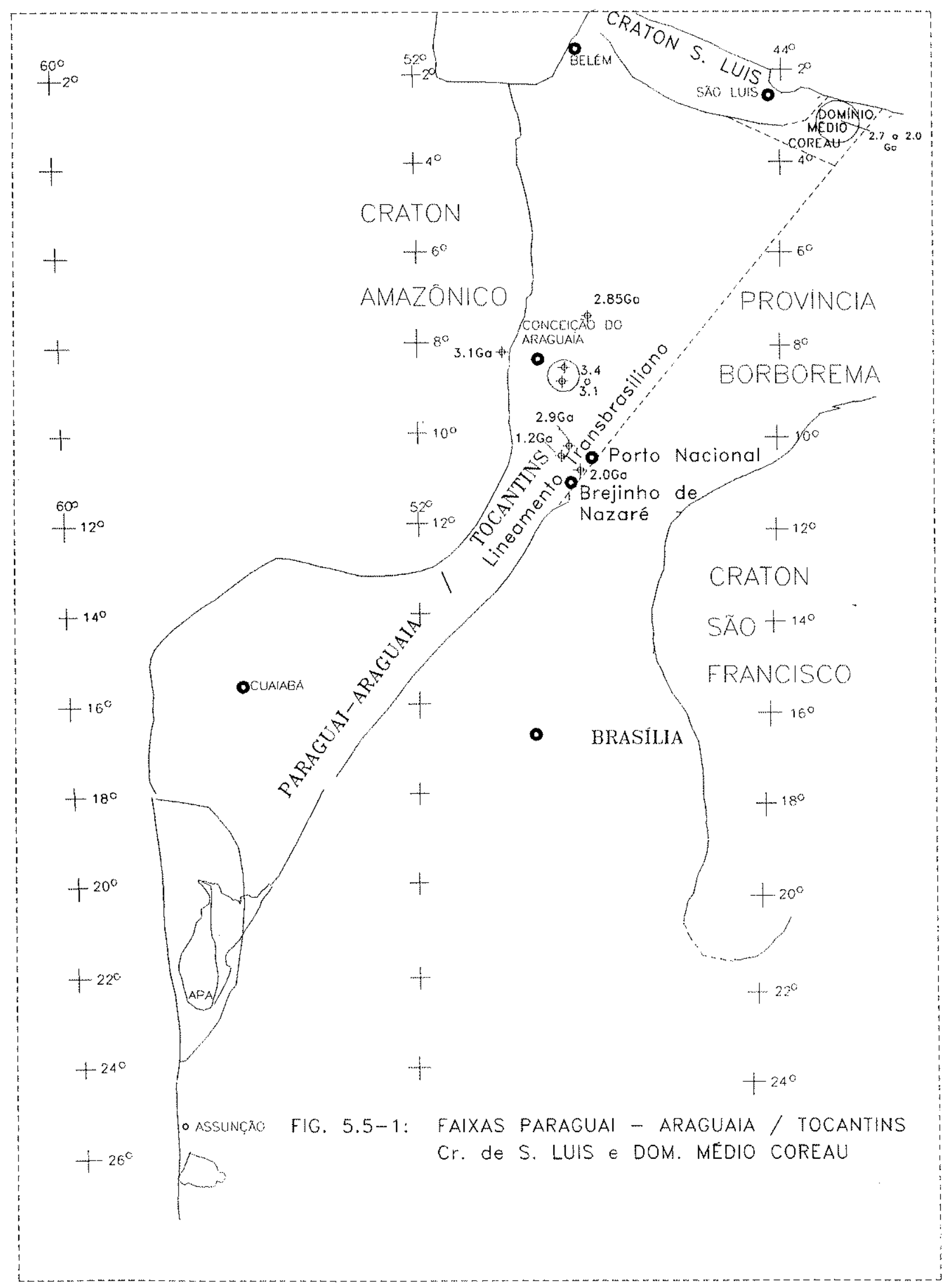




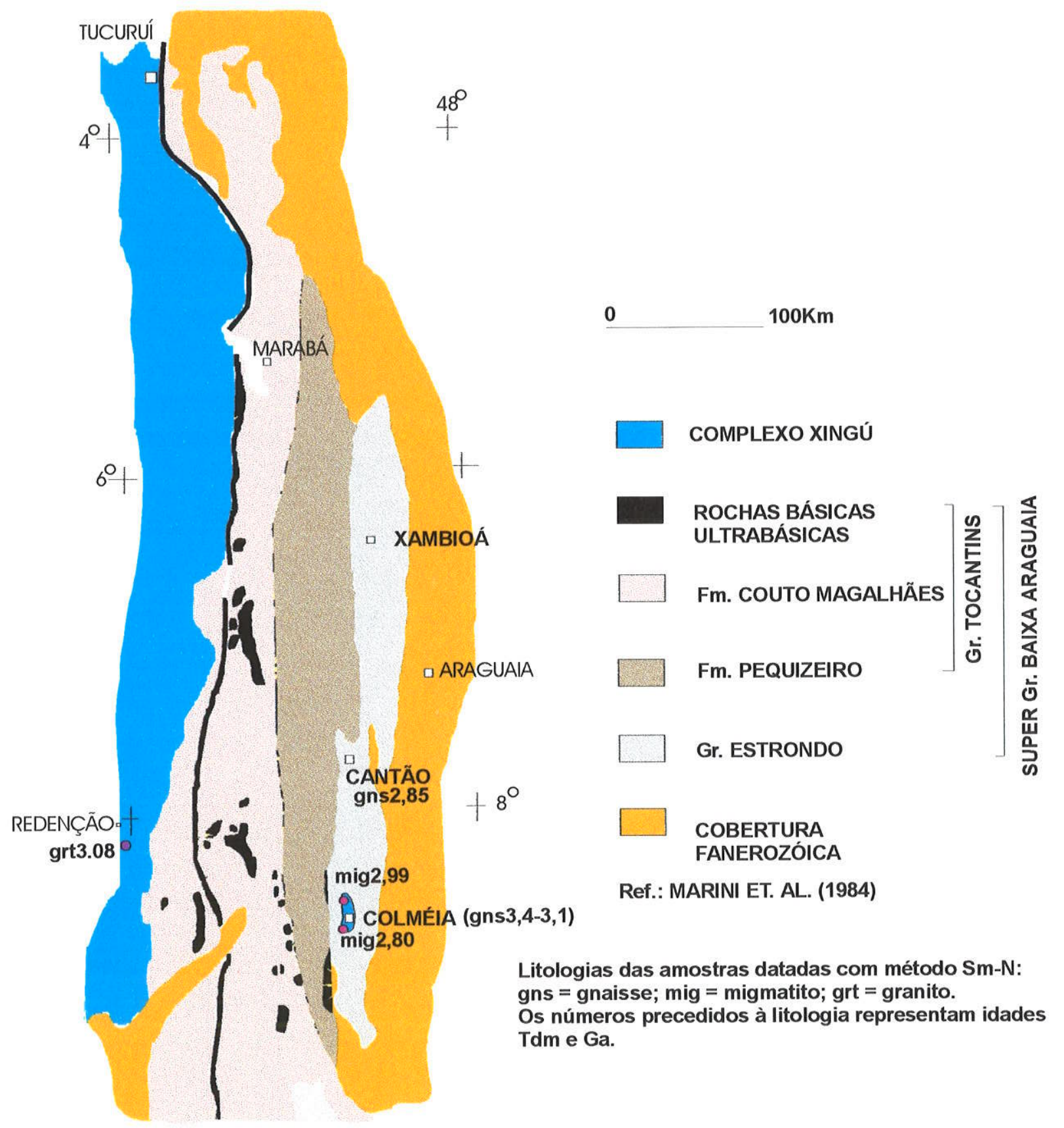

Fig. 5.5-2: Mapa geológico da porção setentrional da Faixa de dobramentos Paraguai-Araguaia / Tocantins. Localização aproximada das amostras datadas com método Sm-Nd. 


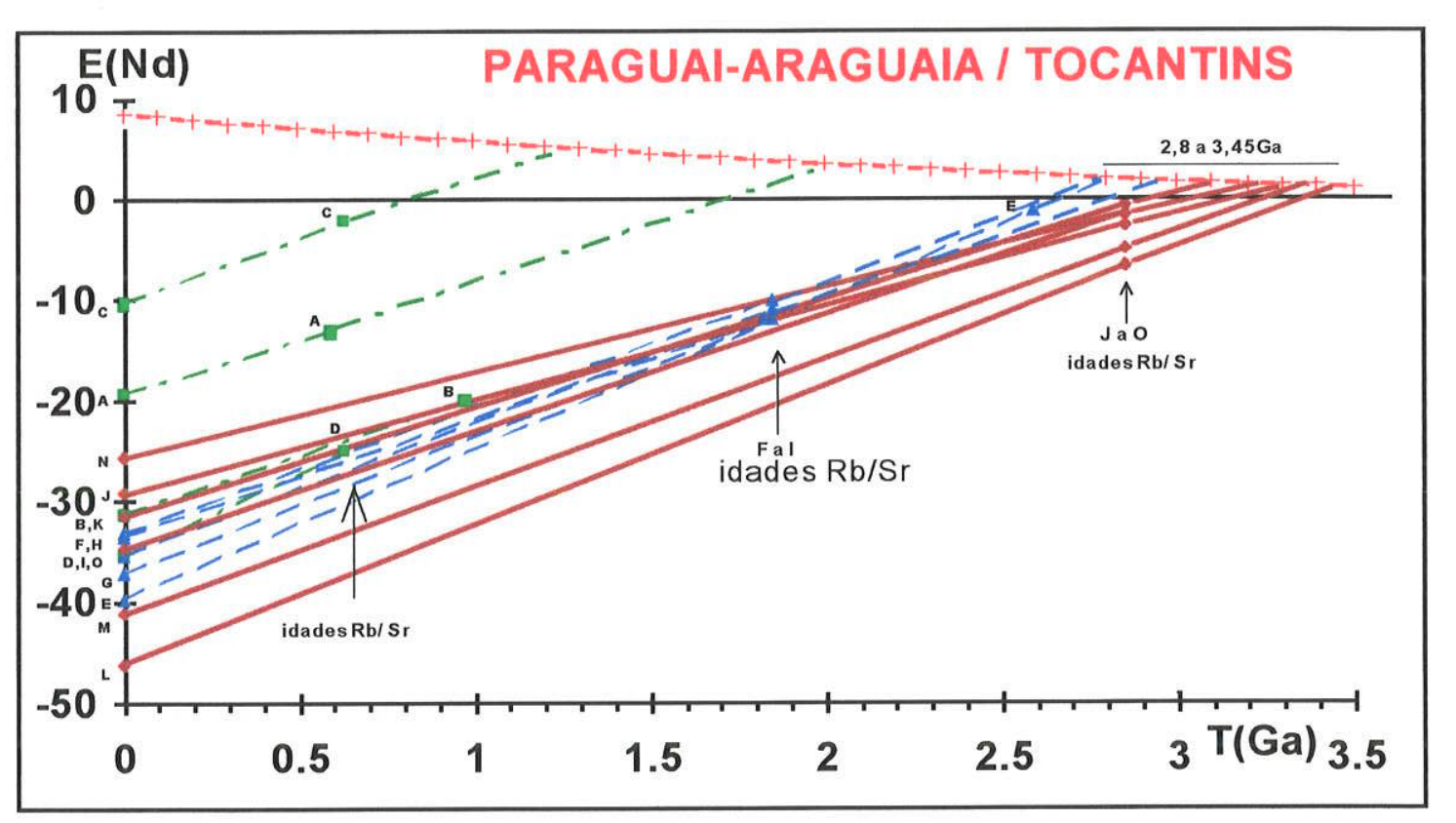

Fig. 5.5-3: Diagrama $\varepsilon_{\mathrm{Nd}}$ versus tempo geológico - Faixas Paraguai / Araguaia - Tocantins (porção Setentrional). Os dados isotópicos das amostras encontram-se na tab.5.6. 
TAB. 5.5 A- Idades modelo Sm-Nd $\left(\mathrm{T}_{\mathrm{dm}}\right)$, composições isotópicas e análises quantitativas Sm-Nd das amostras das Faixas PARAGUAl-ARAGUAIA /

TOCANTINS

\begin{tabular}{|c|c|c|c|c|c|c|c|c|c|c|c|c|c|c|c|c|c|}
\hline $\begin{array}{l}\text { SPS } \\
\text { /litol }\end{array}$ & $\begin{array}{l}\text { coord.I } \\
\text { (p.local.) }\end{array}$ & $\begin{array}{l}\text { n.campol } \\
\text { região }\end{array}$ & $\begin{array}{l}\text { lito- } \\
\text { logia }\end{array}$ & $\begin{array}{l}\text { ident. } \\
\text { (diagra } \\
\text { ma) }\end{array}$ & 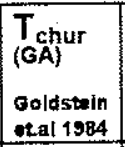 & $T_{(\mathrm{dm})}$ & \begin{tabular}{|l|}
$T_{d m}$ \\
$(G A)$ \\
DePaolo \\
-1981 \\
\end{tabular} & $\begin{array}{l}{ }^{143} \mathrm{Ndl} \\
{ }^{144} \mathrm{Nd}\end{array}$ & $\begin{array}{l}{ }^{144} \mathrm{Sm} / \\
{ }^{144} \mathrm{Nd}\end{array}$ & $\begin{array}{l}\mathrm{Sm} \\
\mathrm{ppm}\end{array}$ & $\begin{array}{l}\text { Nd } \\
\text { ppm }\end{array}$ & $f$ & $\begin{array}{l}\varepsilon_{\mathrm{Nd}} \\
(0)\end{array}$ & $\begin{array}{l}\varepsilon_{\mathrm{Nd}} \\
(t)\end{array}$ & $\begin{array}{l}t(G a)_{\text {mét }} \\
R^{(f \circ n t e)}\end{array}$ & $\begin{array}{l}\varepsilon_{\mathrm{sr}} \\
(\mathrm{t})\end{array}$ & ref \\
\hline $\begin{array}{l}396 / \\
\text { gns }\end{array}$ & $1057 / 4837$ & G0527 & GTD & $A$ & $\begin{array}{l}1.64 \\
0.06 \\
\end{array}$ & & $\begin{array}{l}1.96 \\
0.05 \\
\end{array}$ & $\begin{array}{l}.511641 \\
.000039 \\
\end{array}$ & $\begin{array}{l}.104421 \\
.000063 \\
\end{array}$ & $\begin{array}{l}8.048 \\
0.003 \\
\end{array}$ & $\begin{array}{l}46.606 \\
0.022 \\
\end{array}$ & -.47 & -19.4 & -13 & $\begin{array}{l}0.59_{\mathrm{Rb} / \mathrm{st}} \\
.712_{\mathrm{a}} \\
\end{array}$ & 116 & nt \\
\hline $\begin{array}{l}3971 \\
\text { gns }\end{array}$ & $1001 / 4855$ & GO-PN-422 & GTD & $B$ & \begin{tabular}{|l|}
2.74 \\
0.06 \\
\end{tabular} & & $\begin{array}{l}2.93 \\
0.04 \\
\end{array}$ & $\begin{array}{l}.511032 \\
.000033 \\
\end{array}$ & $\begin{array}{l}.107984 \\
.000051 \\
\end{array}$ & $\begin{array}{l}5.434 \\
0.001 \\
\end{array}$ & $\begin{array}{l}30.430 \\
0.013 \\
\end{array}$ & -.45 & -31.3 & -20 & $\begin{array}{l}0.97_{\mathrm{Rb} / \mathrm{Sr}} \\
.707_{\mathrm{a}} \\
\end{array}$ & 51 & nt \\
\hline $\begin{array}{l}398 / \\
\text { grt }\end{array}$ & $1018 / 4856$ & GO69 & GTD & C & $\begin{array}{l}0.80 \\
0.02\end{array}$ & & $\begin{array}{l}1.21 \\
0.01 \\
\end{array}$ & $\begin{array}{l}.512108 \\
.000010 \\
\end{array}$ & $\begin{array}{l}.095816 \\
.000042 \\
\end{array}$ & $\begin{array}{l}3.980 \\
0.001 \\
\end{array}$ & $\begin{array}{l}25.118 \\
0.009 \\
\end{array}$ & -.51 & -10.3 & -2.2 & $\begin{array}{l}0.63_{\mathrm{Rb} / \mathrm{sr}} \\
.709_{\mathrm{a}} \\
\end{array}$ & 74 & nt \\
\hline $\begin{array}{l}661 \\
\text { grt }\end{array}$ & $810 / 5003$ & $458 \mathrm{az}-\mathrm{rm}-201$ & GTD & $D$ & & $3.08^{\# 2}$ & $\begin{array}{l}2.66 \\
0.04 \\
\end{array}$ & $\begin{array}{l}.510844 \\
.000031 \\
\end{array}$ & $\begin{array}{l}.086795 \\
.000052\end{array}$ & $\begin{array}{l}8.407 \\
.003 \\
\end{array}$ & $\begin{array}{l}58.575 \\
.029 \\
\end{array}$ & & -35.0 & -26 & $\begin{array}{l}.63_{\mathrm{Rb} / \mathrm{sr}} \\
.709_{\mathrm{b}} \\
\end{array}$ & 74 & nt \\
\hline $\begin{array}{l}402 / \\
\mathrm{mig}\end{array}$ & $844 / 4844$ & CMO7 & GTD & $E$ & $\begin{array}{l}2.64 \\
0.05 \\
\end{array}$ & & $\begin{array}{l}2.80 \\
0.04\end{array}$ & $\begin{array}{l}.510604 \\
.000040 \\
\end{array}$ & $\begin{array}{l}.080034 \\
.000160 \\
\end{array}$ & $\begin{array}{l}0.521 \\
0.001 \\
\end{array}$ & $\begin{array}{l}3.944 \\
0.002 \\
\end{array}$ & -.59 & -39.7 & -1.1 & $\begin{array}{l}2.59_{\mathrm{Rb} / \mathrm{Sr}} \\
.705_{\mathrm{b}} \\
\end{array}$ & 50 & nt \\
\hline $\begin{array}{l}3951 \\
\mathrm{mig}\end{array}$ & $833 / 4850$ & $497 \mathrm{BC} 38-2$ & GTD & $F$ & $\begin{array}{l}2.81 \\
0.03 \\
\end{array}$ & & $\begin{array}{l}2.99 \\
0.03 \\
\end{array}$ & $\begin{array}{l}.510922 \\
.000018 \\
\end{array}$ & $\begin{array}{l}.104246 \\
.000056\end{array}$ & $\begin{array}{l}10.57 \\
0.04 \\
\end{array}$ & $\begin{array}{l}61.319 \\
0.023 \\
\end{array}$ & -.47 & -33.5 & -12 & $\begin{array}{l}1.83_{\mathrm{Rb} / \mathrm{Sr}} \\
.715_{\mathrm{b}} \\
\end{array}$ & 180 & $n t$ \\
\hline \begin{tabular}{l|}
-- \\
$o . g n s$ \\
\end{tabular} & $\sim 9--1 \sim 49--$ & $\begin{array}{l}\text { 88-19/ Cantảo } \\
\text { (C. Araguaia) }\end{array}$ & GTD & $G$ & 2.75 & & 2.91 & .510731 & .09144 & 9.148 & 60.5 & -.54 & -37.2 & -12 & $1.85_{\mathrm{Rb} / \mathrm{sr}}$ & & 1 \\
\hline o.gns & $-9-1 \sim 49-$ & $\begin{array}{l}\text { 88-22/ Cantão } \\
\text { (C. Araguaia) }\end{array}$ & GTD & $\mathrm{H}$ & 2.65 & & 2.83 & .510936 & .09917 & 14.694 & 89.6 & -.50 & -33.2 & -10 & $1.85_{\mathrm{Rb} / \mathrm{Sr}}$ & & 1 \\
\hline o.gns & $-9-1 \sim 49-$ & $\begin{array}{l}\text { fc127/ Cantão } \\
\text { (C. Araguaia) }\end{array}$ & GTD & 1 & 2.65 & & 2.82 & .510822 & .09266 & 15.66 & 102.2 & -.53 & -35.4 & -11 & $1.85_{\mathrm{Rb} / \mathrm{Sr}}$ & & 1 \\
\hline o.gns & $\sim 9--/ \sim 49--$ & $\begin{array}{l}\text { 88-08/Gr.Rica } \\
\text { (C. Araguaia) }\end{array}$ & GTD & $\mathrm{J}$ & 3.10 & & 3.28 & .511142 & .12377 & 3.234 & 15.80 &. .37 & -29.2 & -2.6 & $2.85_{\mathrm{Rb} / \mathrm{Sr}}$ & & 1 \\
\hline o.gns & $\sim 9-1 \sim 49-$ & $\begin{array}{l}\text { 88-11/Gr.Rica } \\
\text { (C. Araguaia) }\end{array}$ & GTD & $\mathrm{K}$ & 2.92 & & 3.10 & .511027 & .11322 & 3.651 & 19.5 & -.42 & \begin{tabular}{|l|}
-31.4 \\
\end{tabular} & -0.7 & $2.85_{\mathrm{R} D / S r}$ & & 1 \\
\hline o.gns & $\sim 9--1 \sim 49-$ & $\begin{array}{l}\begin{array}{l}88-13 / G r . ~ R i c a \\
\text { (C. Araguaia) }\end{array} \\
\end{array}$ & GTD & $L$ & 3.33 & & 3.45 & .510277 & .08959 & 3.363 & 22.7 & -.54 & -46.1 & -6.7 & $2.85_{\mathrm{Rb} / \mathrm{St}}$ & & 1 \\
\hline o.gns & $\sim 9-1 \sim 49-$ & $\begin{array}{l}90-37 / \text { Cacol. } \\
\text { (C. Araguàia) }\end{array}$ & GTD & $M$ & 3.23 & & 3.36 & .510531 & .09804 & 3.129 & 19.3 & -.50 & -41.1 & -4.9 & $2.85_{\mathrm{Rb} / \mathrm{Sr}}$ & & 1 \\
\hline o.gns & $-9-1-49-$ & $\begin{array}{l}90-39 / \text { Cacol. } \\
\text { (C. Araguaia) }\end{array}$ & GTD & $\mathrm{N}$ & 3.03 & & 3.23 & .511325 & .13115 & 2.299 & 10.6 & -.33 & -25.6 & -1.5 & $2.85_{\mathrm{Rb} / \mathrm{Sr}}$ & & 1 \\
\hline o.gns & $\sim 9-1 \sim 49-$ & $\begin{array}{l}90.40 / \text { Cacol. } \\
\text { (C. Araguaia) }\end{array}$ & GTD & 0 & 2.99 & & 3.15 & .510861 & .10671 & 1.447 & 8.2 & -.46 & -34.7 & -1.5 & $2.85_{\mathrm{Rb} / \mathrm{sr}}$ & & 1 \\
\hline
\end{tabular}

o.gns

nt = neste trabaiho; 1 = Moura e Gaudette, 1994

Ver nota explicativa da tabela no anexo 1 
TABELA:5.5B - DOMÍNIO MÉDIO COREAU

\begin{tabular}{|c|c|c|c|c|c|c|c|c|c|c|c|c|c|c|c|c|c|}
\hline $\begin{array}{l}\text { SPS } \\
\text { /lit. }\end{array}$ & $\begin{array}{l}\text { coord. } \\
\text { (p.local.) }\end{array}$ & $\begin{array}{l}\text { n. campo/ } \\
\text { região }\end{array}$ & $\begin{array}{l}\text { lito- } \\
\text { logia }\end{array}$ & $\begin{array}{l}\text { diag. } \\
\text { pontos }\end{array}$ & $\begin{array}{l}T_{\text {chur }} \\
(\mathrm{Ga}) \\
\text { Goldsteln } \\
\text { etal.1984 }\end{array}$ & $\begin{array}{l}\mathbf{T}_{\text {dm2 }} \\
(\mathbf{G a}) \\
\text { estáglo } \\
\text { dupio }\end{array}$ & $\begin{array}{l}\mathrm{T}_{\mathrm{dm}} \\
(\mathbf{G a}) \\
\text { DePaolo- } \\
\text { 198i }\end{array}$ & $\begin{array}{l}{ }^{143} \mathrm{Nd}- \\
{ }^{144} \mathrm{Nd}\end{array}$ & $\begin{array}{l}{ }^{147} \mathrm{Sm}- \\
{ }^{144} \mathrm{Nd}\end{array}$ & $\begin{array}{l}\mathrm{Sm} \\
\mathrm{ppm}\end{array}$ & $\begin{array}{l}\mathrm{Nd} \\
\mathrm{ppm}\end{array}$ & f & $\begin{array}{l}\varepsilon_{\mathrm{Nd}} \\
(0)\end{array}$ & $\begin{array}{l}\varepsilon_{\mathrm{Nd}} \\
(\mathrm{t})\end{array}$ & $\begin{array}{l}\mathbf{t}(\mathbf{G a})_{\text {mét }} \\
\mathbf{R i}_{\text {(fonte) }}\end{array}$ & $\begin{array}{l}\varepsilon_{\mathrm{Sr}} \\
(\mathrm{t})\end{array}$ & ref \\
\hline & & & & & & & & & & & & & & & & & \\
\hline $\begin{array}{l}302 \\
\text { gns }\end{array}$ & GRANJA & $\begin{array}{l}\text { MG I5 } \\
\text { GRANAA }\end{array}$ & GTD & & $\begin{array}{l}2.15 \\
0.08 \\
\end{array}$ & & $\begin{array}{l}2.40 \\
0.06 \\
\end{array}$ & $\begin{array}{l}.511365 \\
.000046 \\
\end{array}$ & $\begin{array}{l}.10669 \\
.00011 \\
\end{array}$ & $\begin{array}{l}6.716 \\
0.003 \\
\end{array}$ & $\begin{array}{l}38.066 \\
0.036\end{array}$ & -.46 & -24.8 & -4.2 & 1.8 & & $\mathrm{nt}$ \\
\hline $\begin{array}{l}+15 \\
\text { gns }\end{array}$ & $321 / 4030$ & $\begin{array}{l}\text { MCO B-1 } \\
\text { M.Coreaú }\end{array}$ & GTD & & $\begin{array}{l}2.35 \\
.03 \\
\end{array}$ & & $\begin{array}{l}2.56 \\
.02 \\
\end{array}$ & $\begin{array}{l}.511055 \\
.000019 \\
\end{array}$ & $\begin{array}{l}.094687 \\
.000055 \\
\end{array}$ & $\begin{array}{l}4.727 \\
002\end{array}$ & $\begin{array}{l}30.188 \\
.012 \\
\end{array}$ & -.52 & -30.9 & -20 & $\begin{array}{l}.86_{\mathrm{Rb} / \mathrm{Sr}} \\
.709_{(\mathrm{a})} \\
\end{array}$ & 78 & nt \\
\hline $\begin{array}{l}416 \\
\mathrm{gnl}\end{array}$ & $34 / 4050$ & $\begin{array}{l}\text { MG 5A } \\
\text { S.Luiz/Coreaú }\end{array}$ & GNL & & $\begin{array}{l}2.10 \\
.04 \\
\end{array}$ & & $\begin{array}{l}.39 \\
.03 \\
\end{array}$ & $\begin{array}{l}.511514 \\
.000022 \\
\end{array}$ & $\begin{array}{l}.115546 \\
.000056 \\
\end{array}$ & $\begin{array}{l}3.796 \\
.001 \\
\end{array}$ & $\begin{array}{l}19.866 \\
.008 \\
\end{array}$ & -.41 & -21.9 & -5.3 & $\begin{array}{l}1.6 l_{\mathrm{Kb} / \mathrm{Sr}} \\
\text { (b) }\end{array}$ & & nt \\
\hline grt & $314 / 4111$ & BRPI 94.1 & GTD & & 2.44 & & 2.69 & $\begin{array}{l}.511406 \\
.000009 \\
\end{array}$ & .12011 & 2.89 & 14.55 & -.39 & -24 & -2.5 & $2.20_{\text {est }}$ & & 3 \\
\hline gnl & & BRCE94.3 & $\mathrm{GNL}$ & & 2.30 & & 2.54 & $\begin{array}{l}.511334 \\
.000010 \\
\end{array}$ & .11058 & 4.93 & 26.96 & -.44 & -25.4 & -1.3 & 2.2 & & 3 \\
\hline grt & $347 / 4042$ & BRCE94.5 & GTD & & 1.62 & & 1.96 & $\begin{array}{l}.511727 \\
.000010 \\
\end{array}$ & .11140 & 19.92 & 108.13 &. .43 & -17.8 & 6.2 & $2.2_{\text {est }}$ & & 3 \\
\hline gtd & $333 / 4027$ & BRCE94.14 & GTD & & $0.25 ?$ & & $1.33 ?$ & $\begin{array}{l}.512578 \\
.000008 \\
\end{array}$ & .16072 & 2.82 & 10.61 & -.18 & -1.2 & 2.5 & $0.8_{\text {est }}$ & & 3 \\
\hline sie & $315 / 4021$ & BRCE94.18 & GTD & & 1.74 & & 2.01 & $\begin{array}{l}.511439 \\
.000009 \\
\end{array}$ & .09181 & 8.87 & 58.42 & -.53 & -23.4 & & & & 3 \\
\hline $\begin{array}{l}\cdots- \\
\text { gns }\end{array}$ & $314 / 4021$ & BRCE 94.19 & GTD & & $2.27 ?$ & $2.63^{\# 2}$ & $2.45 ?$ & $\begin{array}{l}.510717 \\
.000007 \\
\end{array}$ & .06835 & 3.60 & 31.85 & -.65 & -37.5 & -4.7 & $2.0_{\text {est }}$ & & 3 \\
\hline gns.m & $325 / 4041$ & BRCE94.29 & GTD & & 2.26 & & 2.49 & $\begin{array}{l}.511216 \\
.000008 \\
\end{array}$ & .10111 & 1.55 & 9.27 & -.49 & -27.7 & -.9 & $2.0_{\text {est }}$ & & 3 \\
\hline
\end{tabular}

REF: $n t=$ neste trabalho; 3 = Fetter et. al dados inéditos ( trabalho de doutorado em andamento - Kansas - USA).

Ver nota explicativa da tabela no anexol. 


\section{6: CRATON DE SÃO FRANCISCO}

\section{6-1 - SÍNTESE GEOLÓGICA}

O Craton de São Francisco é uma plataforma sin-Brasiliana que ocupa, além do Estado da Bahia, grande parte do Estado de Minas Gerais, e cujo embasamento consolidou-se em época préBrasiliana (Almeida 1977). Os seus limites tectônicos são representados pelas faixas móveis Neoproterozóicas denominadas de Sergipano (Nordeste), Riacho do Pontal - Rio Preto (Norte), Araçuai (Sudeste) e Brasilia (Oeste), fig. 5.6-0.

Da literatura especializada constam vários trabalhos especificos sobre a evolução geológica e a terminologia lito-estratigráfica dos elementos geotectônicos, permitindo ao autor concentrar-se na parte geocronológica. Os comentários seguintes serão efetuados com base em Sato (1986) e conforme as subdivisões sugeridas por Mascarenhas e Garcia (1989).

- Arqueano Inferior - Médio > 3,0Ga: Na porção setentrional do craton (região central da Bahia), encontram-se vários registros radiométricos com idades superiores a 3,0Ga $(\mathrm{U}-\mathrm{Pb}, \mathrm{Rb}-\mathrm{Sr}$ e $\mathrm{Pb}$ $\mathrm{Pb}$ ); na forma de núcleos isolados e preservados, a exemplo dos terrenos granodiorito / tonaliticos de Boa Vista, Sete Voltas, Rio Capim e dos granulitos de Mutuipe. Os dados geocronológicos disponiveis até 1986 apontavam a existência de terrenos antigos nesses setores, mas não caracterizavam um quadro geoctectônico definido. As novas determinações radiométricas com o método Sm-Nd efetuadas por Sato (1986), Wilson (1987), Barbosa (1990), Marinho (1991), Martin et. al. (1996), bem como as determinações U-Pb em zircão através técnica de SHRIMP (Nutman e Cordani, 1993), permitiram reconstituir os principais eventos de acreção manto crosta continental destes terrenos, e que serão discutidos adiante.

- Arqueano Superior (3,0 a 2,5Ga): o período mais expressivo em termos de formação de rochas, no Craton do São Francisco, distribui-se entre 2,9 a 2,65 Ga, a exemplo dos terrenos granulíticos de Jequié, e gnáissico-migmatíticos do Bloco de Gavião (BA), Bonfim, (MG) e Campo Belo (MG).

- Paleoproterozóico (2,5 a 1,6Ga): o Ciclo Transamazônico (2,15 a 1,75Ga) foi marcante como formador de rochas graníticas, gnáissicas e migmatíticas nas faixas móveis Salvador - Juazeiro e Correntina - Guanambi. Neste periodo, a porção oriental (Complexo Jequié e região de Itabuna Salvador - Juazeiro) sofreu importante soerguimento, promovendo resfriamento de terrenos que se encontravam a isotermas superiores a $500{ }^{\circ} \mathrm{C}$ conforme indicado pela maioria dos resultados $\mathrm{K}$ Ar. 
- Mesoproterozóico (1,6 a 1,0Ga): este periodo caracteriza-se pela dinâmica geológica ocorrida com o desenvolvimento do Ciclo Espinhaço $(1,75$ a $1,0 \mathrm{Ga})$ especialmente na região Central do Craton. As fases terminais do Ciclo Transamazônico (1,8 a 1,7Ga) desencadearam os processos tectono-magmáticos (metariolitos Rio dos Remédios e rochas graníticas de Lagoa Real). O clímax da evolução tectônica do Ciclo Espinhaço foi estimado em torno de 1,3 t-0,1Ga, pelo metamorfismo regional de fácies xisto-verde a anfibolito que afetou essas seqüencias, seladas por magmatismo de caráter anorogênico da ordem de 1,0Ga.

- Neoproterozóico $(1,0$ a $0,57 \mathrm{Ga})$ : o início deste período geológico foi marcado pela deposição dos sedimentos do Grupo Bambuí e de seus possíveis cronocorrelatos (Una, Rio Pardo, Miaba, etc.).

A maioria dos dados $\mathrm{Rb}-\mathrm{Sr}$ e $\mathrm{K}$-Ar indicaram resfriamento final entre 0,6 a $0,45 \mathrm{Ga}$, nos sistemas de dobramentos marginais e também na região do Espinhaço. As idades K-Ar Neoproterozóicas no Espinhaço são consideradas como reativações localizadas, reflexos dos sistemas marginais de dobramentos Brasilianos.

\section{6-2 - EVOLUÇÃO CRUSTAL DO CRATON DE SÃO FRANCISCO COM BASE NAS IDADES MODELO Sm-Nd, $\mathrm{T}_{\mathrm{DM}}$}

\section{GENERALIDADES:}

Segundo Sato (1986) os terrenos da porção setentrional do Craton do S. Francisco, com base em diagramas de evolução isotópica de $\mathrm{Sr}$, cerca de $70 \%$ de material crustal teria sido formado no Arqueano, e aproximadamente 30\% como material juvenil, no Paleoproterozóico. Dos terrenos formados no Arqueano, cerca $30 \%$ teriam permanecido como núcleos preservados, e cerca de $40 \%$ teriam sido inteiramente ou parcialmente retrabalhados no Paleo-Mesoproterozóico.

Os dados de $\mathrm{Sr}$ de $\mathrm{Pb}$, acoplados aos obtidos recentemente através do método $\mathrm{Sm}-\mathrm{Nd}$ $\left(\mathrm{T}_{\mathrm{DM}}\right)$ permitiram um importante refinamento em termos de evolução crustal. Para uma melhor visualização do quadro evolutivo, serão discutidos separadamente os padrões isotópicos relativos aos Complexos Contendas-Mirante, Jequié, Campo Belo-Bonfim-Belo Horizonte, Bloco do Gavião, Jacobina, Lagoa Real - Riacho de Santana, e Norte-Oriental do C. S. Francisco, e NorteOcidental (Correntina) (fig. 5.6.0). 


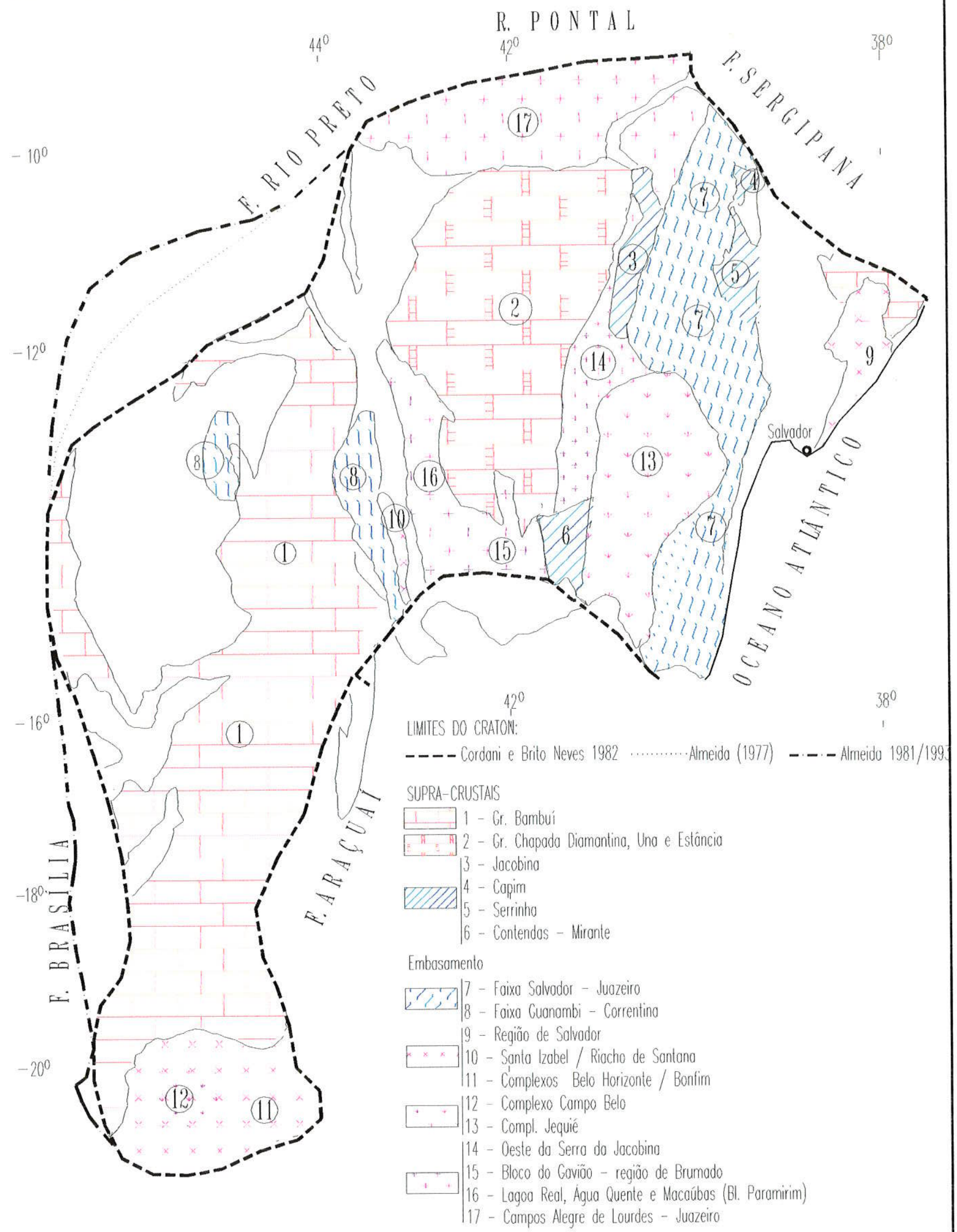

FIG. 5.6-0 MAPA GEOLÓGICO SIMPLFFICADO BASEADO EM CORDANI E BRTIO NEVES 1982: Coberturos do Proterozóico Superior e Médio (1 e 2); Proter. Inferior - sequências supra crustais $(3,4,5$ e 6), terrenos de allo grou $(7$ e 8), terrenos granítico -gnaíssico-migmattíicos $(9$ ); Arqueano - terrenos de alto grou (12 e 13), terrenos granito-gnoíssico-migmatíicos, em parte do Prot. inferior (10, 11, 14, 15, 16 e 17) 


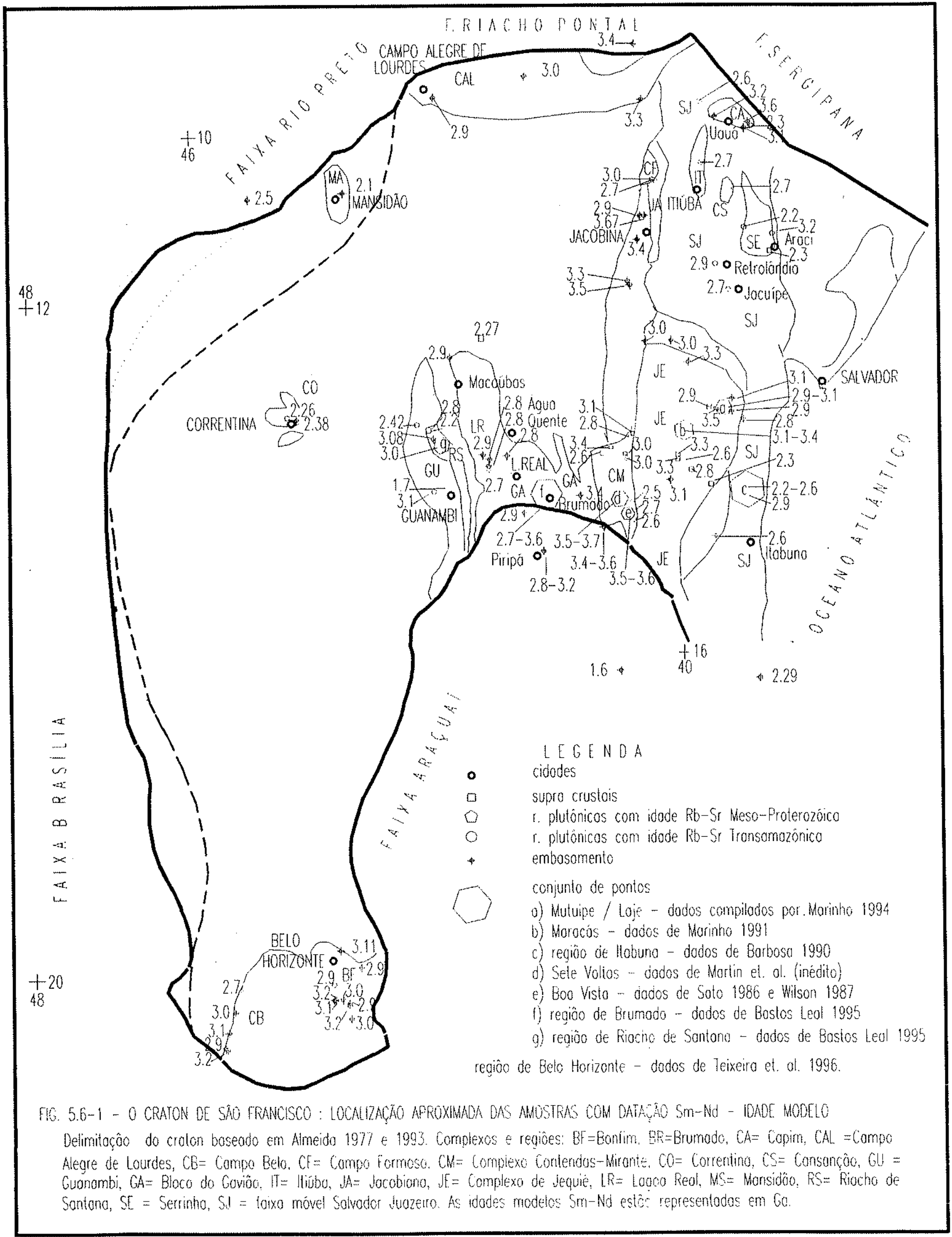




\section{COMPLEXO CONTENDAS - MIRANTE}

O Complexo Contendas - Mirante (fig. 5.6-0, dominio 6) é representado por um conjunto de rochas metavulcano-sedimentares que exibem núcleos graniticos, granodioriticos, tonalíticos, e gnáissico-migmatíticos, encaixados em meio a rochas metamórficas de médio a alto grau, distribuidos na porção central do Craton do S. Francisco. Estes maciços são interpretados como rochas do embasamento que foram reativados tectonicamente e colocados dentro das rochas supracrustais do Complexo Contendas-Mirante durante a orogênese Transamazônica (Marinho 1991).

As rochas granito-granodioritico-tonalíticas e gnáissicas associadas são as principais litologias expostas e estudadas.

As primeiras datações pelo método $\mathrm{Sm}-\mathrm{Nd}$ foram efetuadas nas rochas granitóides de Boa Vista (Sato 1986). As idades $\mathrm{T}_{\mathrm{DM}}$ obtidas nestas rochas distribuiram-se entre 3,7 a $3,4 \mathrm{Ga}$ caracterizando as épocas de diferenciação manto-crosta mais antigas da Plataforma Sul Americana. A evolução geocronológica dos granitóides de Boa Vista / Mata Verde pode ser descrita de seguinte modo, conforme Sato (1986): o evento de diferenciação química com extração de magma do manto superior para a crosta continental ocorreu entre 3,7 a 3,4Ga. Estes materiais crustais sofreram um processo de metamorfismo na crosta inferior, com rehomogeneização isotópica completa de $\mathrm{Sr}$ e de $\mathrm{Pb}$, onde as isócronas $\mathrm{Rb}-\mathrm{Sr}$ e $\mathrm{Pb}-\mathrm{Pb}$ indicaram idades entre 3,43 a 3,35Ga. Dados adicionais Sm-Nd obtidos por Wilson (1987) e Marinho (1991) e a idade U-Pb SHRIMP em zircão obtida por Nutman e Cordani, (1992), confirmaram os eventos de acreção manto-crosta, e as épocas de formação destas rochas crustais antigas (vide tab. 5.6.1.). As razões ${ }^{87} \mathrm{Sr} /{ }^{86} \mathrm{Sr}$ iniciais variaram de 0,7008 a 0,7017 , e quando expressas na forma de $\varepsilon_{\mathrm{Sr}}$ $t=3,4)$ apresentaram valores positivos de 6 e 17 respectivamente. Do mesmo modo, os valores de $\varepsilon_{\mathrm{Nd}(t=3,4)}$ mostraram-se ligeiramente negativos $(-1,5$ a $-0,1)$, a exceção de uma única rocha tonalítica indicando um valor positivo de 4 , (tab. 5.6-1). Os dados de $\varepsilon_{\mathrm{Sr}}$ positivos e $\varepsilon_{\mathrm{Nd}}$ negativos, associados ao valor de $\mu_{1}=8,67$ sugerem processos intracrustais.

No maciço de Sete Voltas, as rochas granitóides formadas no Arqueano, similarmente ao observado para as rochas de Boa Vista/Mata Verde, apresentaram idade Sm-Nd ( $\left.\mathrm{T}_{\mathrm{DM}}\right)$ distribuidas entre 3,72 e 3,51Ga, denotando acreções manto-crosta em épocas pouco anteriores à diferenciação / metamorfismo dessas rochas (Martin et. al., 1991).

Na porção Sul do Complexo Contendas-Mirante afloram os granitóides de Lagoa do Morro que apresentaram idades Rb-Sr de 2,8Ga com RI=0,704 (Marinho 1991). As idades $\mathrm{T}_{\mathrm{DM}}$ 
desses granitóides variaram entre 3,6 a $3,4 \mathrm{Ga}$, sugerindo que o periodo de diferenciação mantélica para seus protólitos crustais foi similar ao observado para as rochas granitóides de Sete Voltas e Boa Vista.

O diagrama da fig. 5.6-2 analisa conjuntamente a evolução isotópica $\varepsilon_{N d}$ no tempo geológico, onde os granitóides de Boa Vista / Mata Verde estão representados por linhas pontilhadas, Sete Voltas por linhas tracejadas e Logoa do Morro por linhas contínuas. Observa-se um padrão coerente na grande maioria das linhas de evolução isotópica, com a razão ${ }^{147} \mathrm{Sm} /{ }^{144} \mathrm{Nd}$ distribuindo-se entre 0,11 a 0,083 . Regressão até a curva do manto (DM) a intercepta entre 3,7 a $3,4 \mathrm{Ga}$.

Os valores de $\varepsilon_{\mathrm{Sr} R \mathrm{ru}}(\mathrm{t})$ e $\varepsilon_{\mathrm{Nd}}(\mathrm{t})$ relativo à época da formação (onde $\mathrm{t}=$ idade $\mathrm{Rb}-\mathrm{Sr}$ ) das rochas granitóides de Sete Voltas, Boa Vista e Lagoa do Morro, foram analisados conjuntamente no diagrama $\varepsilon_{\mathrm{sr}}$ versus $\varepsilon_{\mathrm{Nd}}$ da fig. 5.6-3, onde apresentaram padrões isotópicos distintos. Os pontos dos dados relativos aos granitóides Sete Voltas e Boa Vista posicionaram-se bem próximo e em torno da origem (asteriscos e losangos), sugerindo que o tempo de residência crustal para seus protólitos foi relativamente curto. Por outro lado, os pontos relativos aos granitóides de Lagoa do Morro (quadrados) posicionaram-se distantes da origem, sugerindo maior afinidade dos protolitos com rochas da crosta continental. Valores de $\varepsilon_{\mathrm{Sr}}$ e $\varepsilon_{\mathrm{Sr}}$ negativos foram obtidos para os granitóides (rochas gnáissicas) do maciço de Sete Voltas, posicionando-se os pontos no terceiro quadrante deste diagrama. Tal posicionamento é indicativo de que poderia ter ocorrido uma abertura no sistema $\mathrm{Rb}-\mathrm{Sr}$ após $3.4 \mathrm{Ga}$ ou, alternativamente, que estas rochas crustais foram derivadas a partir de um manto enriquecido.

A seqüência vulcano - sedimentar do Complexo Contendas-Mirante foi subdividida por Marinho (1991), em 3 unidades: inferior, média e superior.

$\mathrm{Na}$ unidade inferior predominam rochas vulcânicas básicas ácidas e metassedimentares (formações ferriferas bandadas). As idades modelo $\mathrm{Sm}-\mathrm{Nd}, \mathrm{T}_{\mathrm{DM}}$ e $\mathrm{T}_{\mathrm{CHUR}}$ encontram-se na tab. 5.62 e as linhas de evolução $\varepsilon_{\mathrm{Nd}}$ no tempo geológico na fig. 5.6-4. As idades modelo ( $\mathrm{T}_{\mathrm{DM}}$ ) observadas para as rochas básicas e metassedimentares distribuem-se de 3,5 a 2,8Ga, caracterizando épocas arqueanas para a diferenciação manto-crosta dos protólitos crustais dessas rochas. A grande maioria dos valores de $\varepsilon_{\mathrm{Nd}(\mathrm{t}=3,0(\mathrm{i}) \mathrm{a})}$ para as rochas básicas desta unidade inferior são positivos, sugerindo que o protólito dessas rochas teria afinidade com o manto. No entanto algumas rochas indicam valores de $\varepsilon_{\mathrm{Nd}}(\mathrm{t}=3.0 \mathrm{Ga})$ negativos $(-11)$ indicando que para a época 


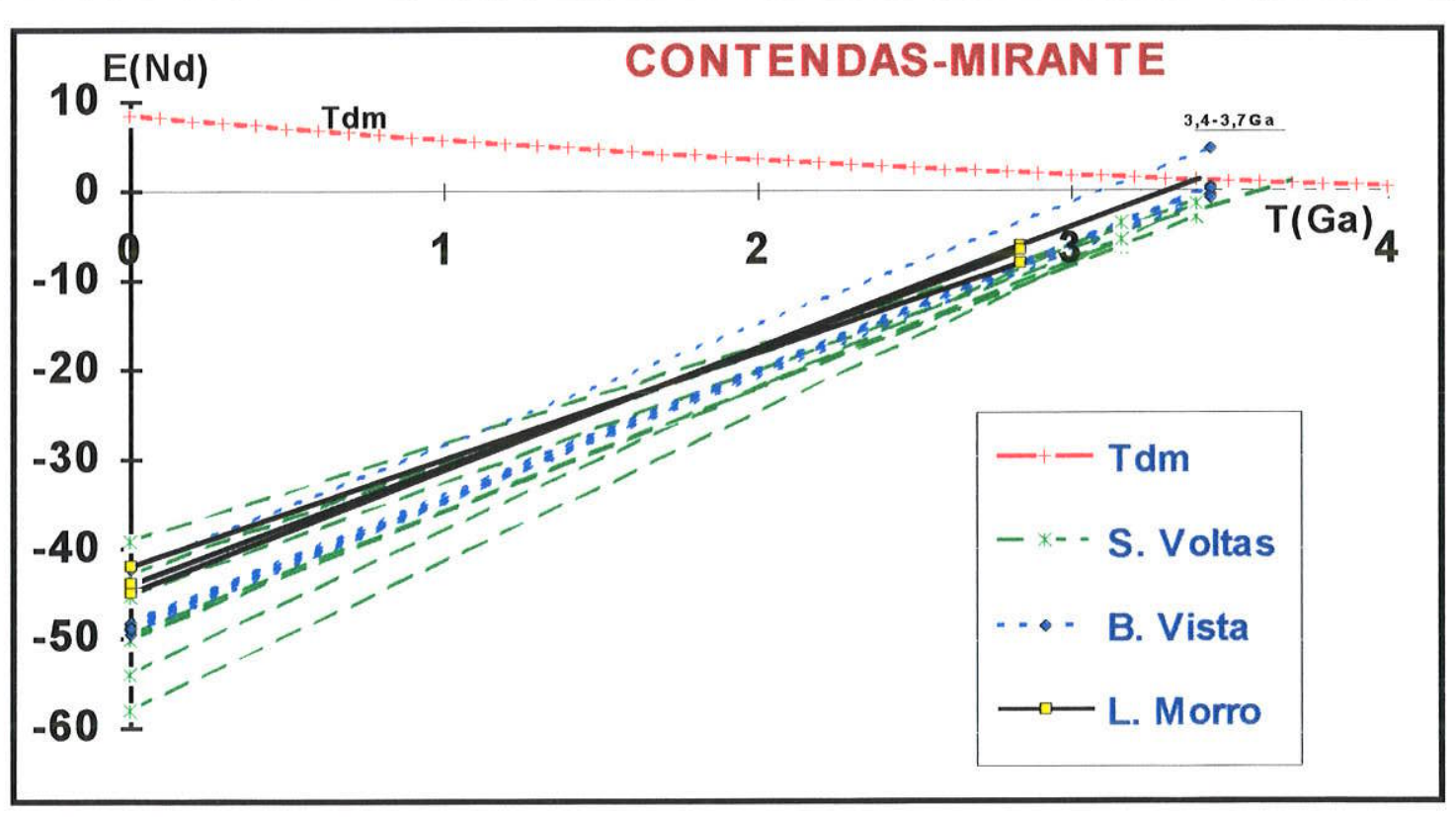

FIG. 5.6-2: diagrama $\varepsilon N d(t)$ versus tempo geológico $T(G a)$. Legenda: Rochas granitóides de Sete Vostas (linhas tracejadas); rochas granitóides de Boa Vista (linhas pontilhadas); granitóide intrusivo - Lagoa do Morro (linhas contínuas). Os dados isotópicos encontram-se na tab. 5.6-1

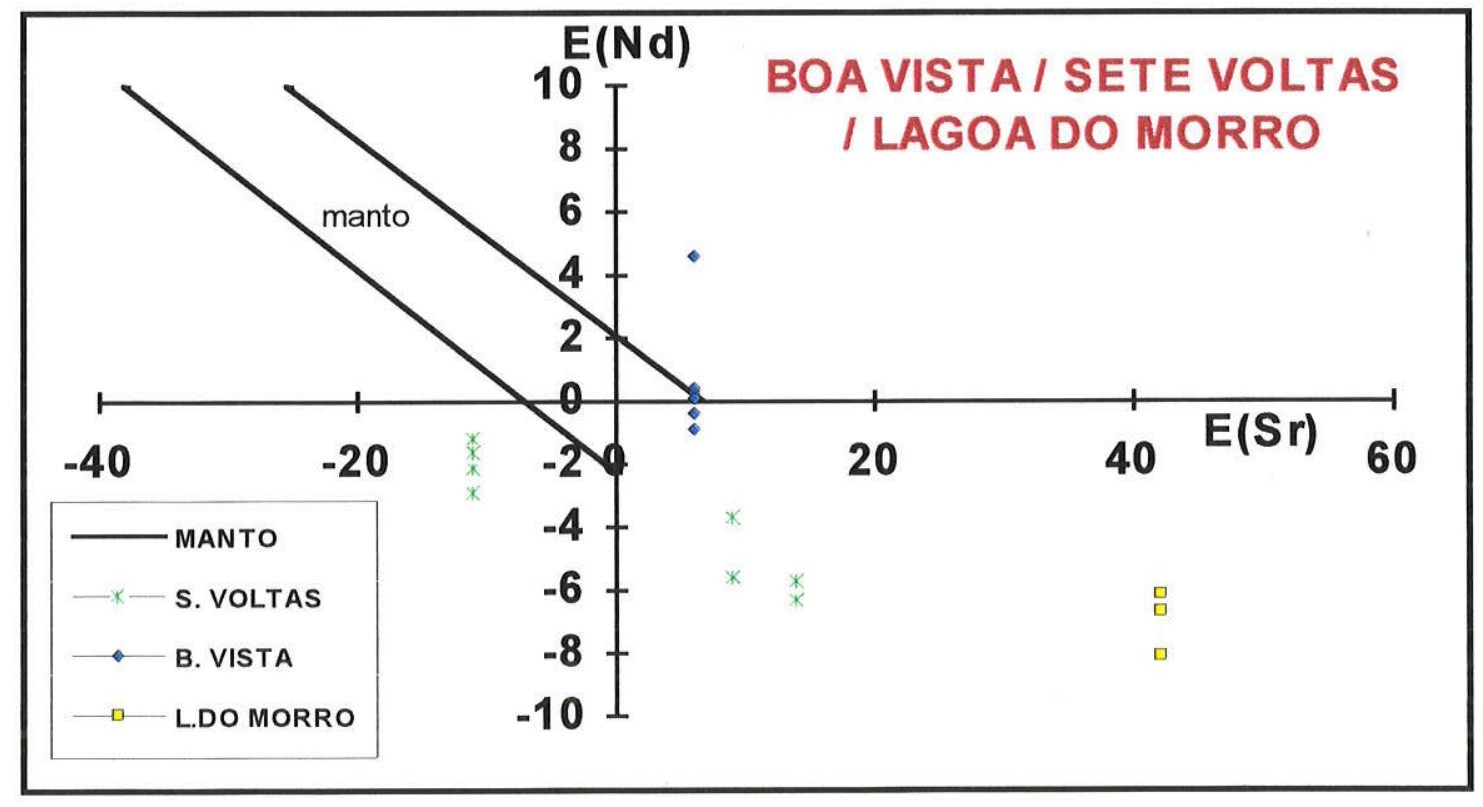

Fig.5.6-3: diagrama $\varepsilon_{S r-R I}(t)$ versus $\varepsilon_{N d}(t)$ das rochas do Compl. Contendas Mirante. Os valores de $\varepsilon$ foram calculados para $t=$ ao evento da formação da rocha com a idade baseada pelo método geocronológico $\mathrm{Rb}-\mathrm{Sr}$. Os dados isotópicos encontramse na tab.5.6-1. 


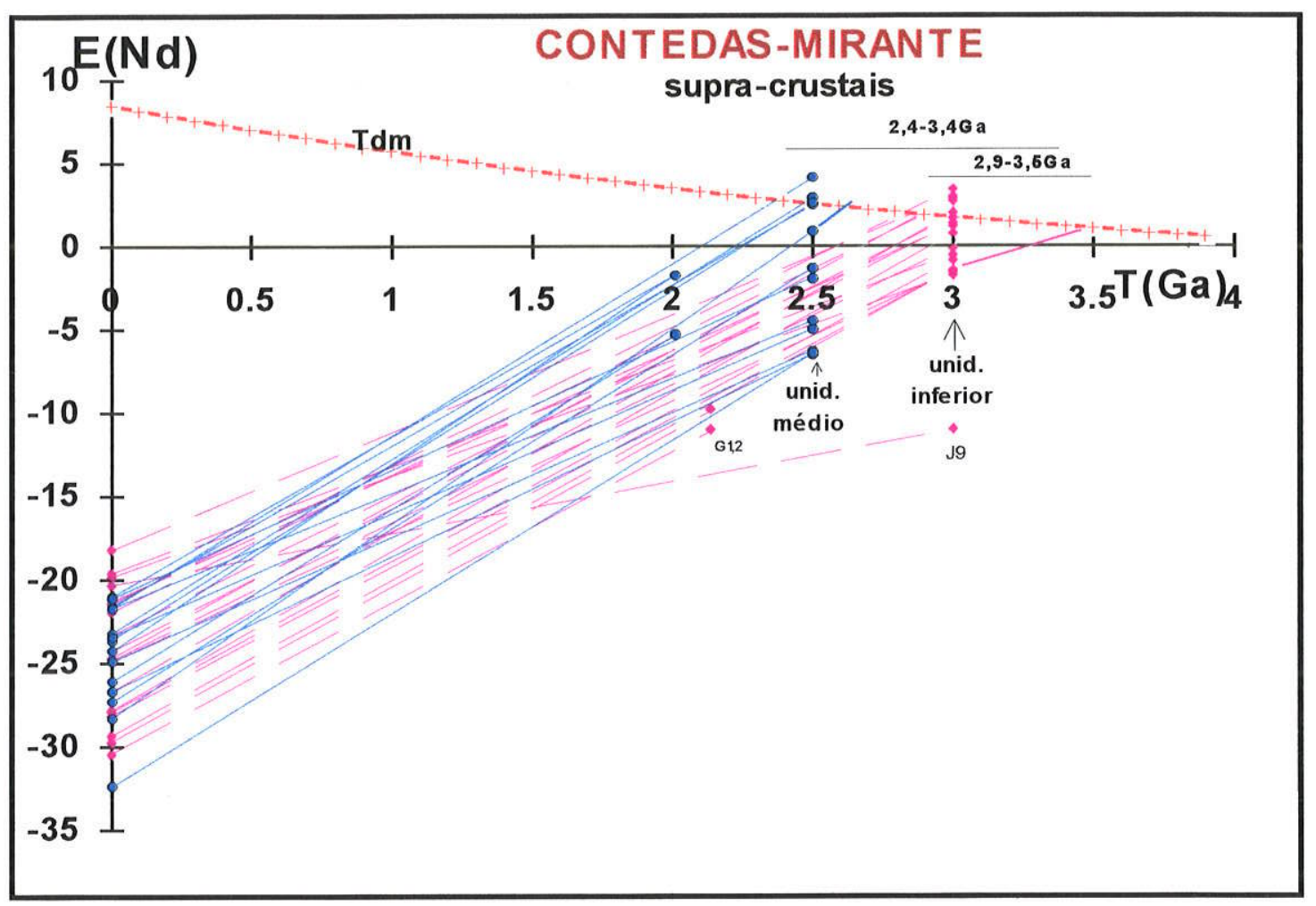

FIG. 5.6-4: diagrama $\varepsilon_{\mathrm{Nd}(\mathrm{t})}$ versus tempo geológico $\mathrm{T}(\mathrm{Ga})$ das rochas vulcanosedimentares do Complexo de Contendas mirantes. Legenda: rochas básicas e metassedimentares da unidade inferior (linhas tracejadas - pontos losangos); vulcânicas ácidas e metassedimentos - (linhas contínuas e círculos fechados). Os dados isotópicos encontram-se na tab. 5.6-2.

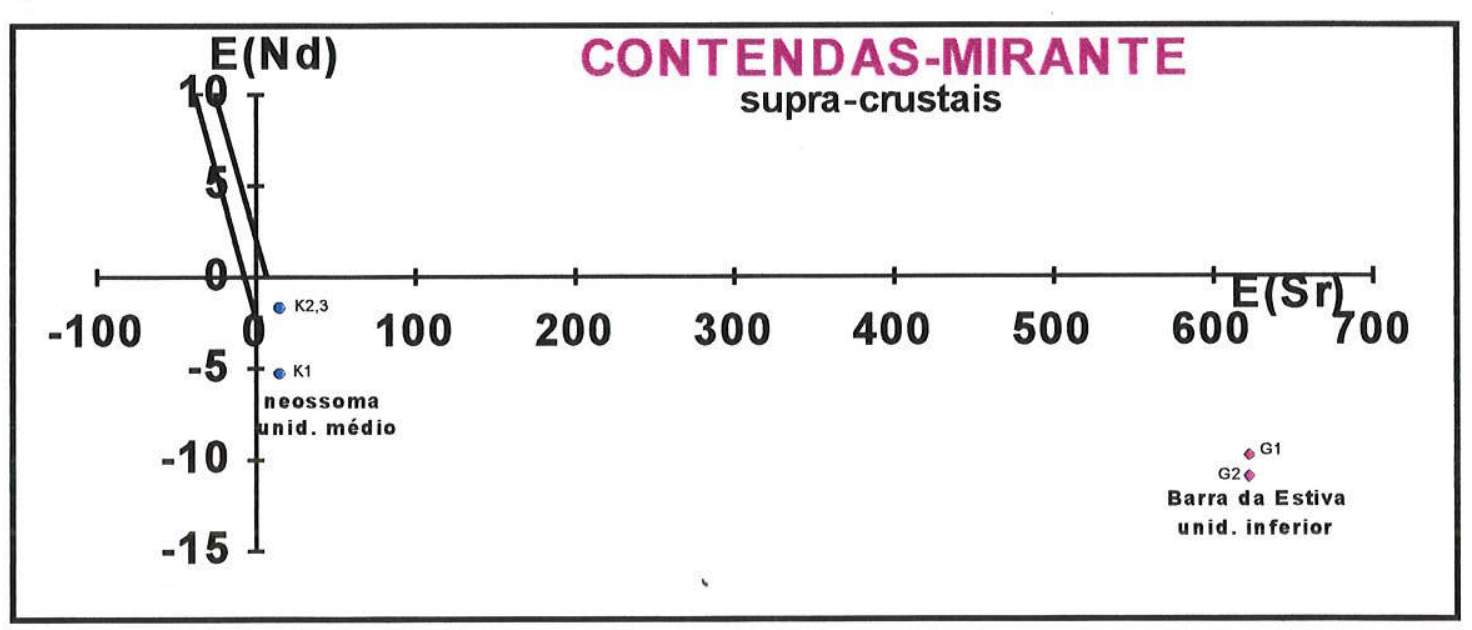

Fig.5.6-5: diagrama $\varepsilon_{\mathrm{Sr}-\mathrm{RI}}(\mathrm{t})$ versus $\varepsilon_{\mathrm{Nd}}(\mathrm{t})$ das rochas vulcânicas do Complexo Contendas-Mirante. Os valores de $\varepsilon$ foram calculados para $t=$ ao evento da formação da rocha com a idade baseada pelo método $\mathrm{Rb}-\mathrm{Sr}$. Os dados isotópicos encontram-se na tab.5.6-2. 
$t=3.0$ já se encontravam instaladas na crosta inferior. Os valores de $\varepsilon_{\mathrm{Nd}}(\mathrm{t})$ para as formações ferriferas bandadas também indicaram valores positivos, sugerindo fontes de tipo toleitico para tais sedimentos químicos. Distintamente, os valores de $\varepsilon_{\text {vif }}$ para as rochas dos corpos básicos quando calculados para a idade de formação $\left(\mathrm{t}_{\mathrm{Rb}-\mathrm{Sr}_{\mathrm{r}}}=2,1 \mathrm{Ga}\right)$ são todos negativos, sugerindo uma rehomogeneização isotópica de $\mathrm{Sr}$ ocorrida nesta época a partir de material crustal pré-existente, corroborando com os dados $\mathrm{Pb}-\mathrm{Pb}$

A unidade média é representada principalmente por rochas metapelíticas associadas a granitoides e rochas vulcânicas ácidas. As idades modelo $\mathrm{Sm}-\mathrm{Nd}\left(\mathrm{T}_{\mathrm{DM}}=3,5\right.$ a $\left.3,0 \mathrm{Ga}\right)$ das rochas vulcânicas ácidas formadas no Paleoproterozóico são similares às idades modelo da unidade inferior. Por sua vez, as idades Sm-Nd dos metapelitos ( $\mathrm{T}_{\mathrm{DM}}=2,9$ a 2,4Ga) são interpretadas como produzidas por mistura de diversas fontes. Diferentes proporções de fontes com 3,5 e 2,2Ga, existentes nesta unidade e em áreas vizinhas, podem resultar em idades variadas $\mathrm{T}_{\mathrm{DM}} \mathrm{Sm-Nd}$. Analisando os parâmetros petrogenéticos ( $\mathrm{ri}, \mu \mathrm{l}$ e $\varepsilon_{\mathrm{Nd}}(\mathrm{t})$ para $\mathrm{t}=2,5$ e 2,0Ga - épocas de formação) pode-se sugerir que os protólitos das rochas da unidade média mostram afinidade com crosta continental.

As linhas de evolução isotópica relativas às unidades inferior e média, quando analisadas conjuntamente em diagrama $\varepsilon_{\mathrm{Nd}}$ versus tempo geológico, fig. 5.6-4, mostram padrões de fracionamento "f" relativamente similares entre si, e distintos do padrão observado para as rochas metassedimentares da unidade média. Estas (linhas contínuas da figura) apresentaram maior grau de fracionamento ( $\cong-0,41)$, quando comparadas com as rochas vulcânicas ácidas desta unidade e as rochas básicas da unidade inferior ( $\mathrm{f} \cong-0,28$, linhas tracejadas). Estas linhas, quando regredidas à curva do manto (DM), interceptam-na entre 3,5 a 2,9Ga. Observa-se adicionalmente neste diagrama que algumas amostras pertinentes a rochas toleiticas (unidade inferior) apresentam padrão de fracionamento distinto das demais. Idades modelo calculadas segundo evolução isotópica em estágio único, para estas amostras, não teriam significado geológico. Observa-se, por exemplo, que a amostra referente ao ponto $\mathrm{J} 9$ mostrou padrão completamente diferente dos demais, na fig. 5.6-4, sugerindo um certo fracionamento químico entre $\mathrm{Sm}$ e $\mathrm{Nd}$ durante evento geológico posterior à separação do material do manto. A idade aparente $\mathrm{Sm}-\mathrm{Nd}\left(\mathrm{T}_{\mathrm{DM}}\right)$ de 3,2 $\mathrm{Ga}$ foi obtida admitindo-se modelo em estágio duplo, supondo-se que o fracionamento entre Sm e Nd tenha ocorrido em torno de 3,0Ga (evento de metamorfismo regional) e considerando no estágio primário uma relação ${ }^{147} \mathrm{Sm} /{ }^{144} \mathrm{Nd} \cong 0,11$.

Os valores de $\varepsilon_{\mathrm{Nd}}(\mathrm{t})$ e $\varepsilon_{\mathrm{Sr}}(\mathrm{t})$ iniciais (tab. 5.6-2), quando calculados para a época da formação das rochas, para as unidades inferior e média, e analisados no diagrama da fig. 5.6-5, 
revelaram que o protolito do corpo de rochas básicas ( $\mathrm{t}_{\mathrm{Rb} \mathrm{Sr}}=2,14 \mathrm{Ga}$, pontos $\mathrm{G} 1$ e $\mathrm{G} 2$ da figura) tem afinidade clara com a crosta inferior. Do mesmo modo, o protólito das rochas granitóides da unidade média $\left(\mathrm{t}_{\mathrm{Rb} / \mathrm{Sr}}=2,01 \mathrm{Ga}\right.$, pontos $\mathrm{K} 1$ e $\mathrm{K} 3$ ) revela material pouco reciclado, mas também sugere afinidade com a crosta inferior

Na unidade superior predominam seqüencias meta-ardosianas e camadas conglomeráticas. As idades U-Pb em zircões detríticos desta unidade, obtidas por Nutmam et. al. (1994) indicaram idades entre 2,7 a 2,15Ga. A fonte dos zircões detríticos mais jovens parece ter estar relacionada com os granitóides intrusivos Transamazônicos existente na área.

O complexo Contendas - Mirante inclui também rochas intrusivas Paleoproterozóicas, reconhecidas principalmente através de dados $\mathrm{Rb} / \mathrm{Sr}$ obtidos nas rochas granitóides que ocorrem na sua borda oriental. De um modo genérico, observa-se que os protólitos crustais das rochas de Pé de Serra, Rio Jacaré, Gameleira e Riacho das Pedras foram diferenciados do manto no Arqueano, entre 3,3 a 2,7Ga conforme as idades modelo $\mathrm{Sm}-\mathrm{Nd} \mathrm{T}_{\mathrm{DM}}$, fig. 5.6-6 e tab. 5.6-3. Por outro lado, os granitos de Lagoinha, Lagoa Grande e Caetano sugerem ter protólitos mais jovens, diferenciados do manto superior no final do Arqueano (2,7 a 2,5Ga - tab. 5.6-3). As idades modelo Sm-Nd para os granitóides de Riacho das Pedras e Rio Jacaré foram calculadas com modelo em dois estágios, uma vez que os valores de $\mathrm{f}_{\mathrm{Sm} / \mathrm{Nd}}$ são bem superiores a $-0,30$. Os valores de $\varepsilon_{\mathrm{Nu}}(\mathrm{t})$ e $\varepsilon_{\mathrm{Sr}}(\mathrm{t})$ relativos à época da formação $(\mathrm{t}=$ idade $\mathrm{Rb}-\mathrm{Sr}$ ) dessas rochas posicionaram-se no quarto quadrante e relativamente distante da origem (fig. 5.6-7), sugerindo para os seus protolitos um certo tempo de residência crustal, corroborando as idades modelo obtidas.

\section{BLOCO GAVIÃo E REGIÃO A OESTE DA SERRA DE JACOBINA}

O Bloco Gavião (GA) inclui terrenos gnáissico-migmatiticos, com granitos associados. (Fig. 5.6-0, dominio 15).

Os dados Rb-Sr pré-existentes indicam idades arqueanas entre 2,8 a 2,6 Ga nas imediações de Brumado, Aracatu e Anagé. Algumas determinações recentemente obtidas, tais como análises isotópicas por SHRIMP em zircões detríticos da Umburanas, apresentaram idades arqueanas ainda mais antigas $(3,34 \mathrm{Ga}$ a 3,16Ga). Do mesmo modo, nos terrenos granitóides do Bloco do Gavião, através de analises de $\mathrm{Pb}-\mathrm{Pb}$ por evaporação térmica em mono cristais de zircão também apareceram idades arqueanas variando de 3,3Ga a 3,13Ga (Bastos Leal et. al., 1996).

Os protólitos das rochas crustais formadas no Paleo e Mesoproterozóico foram todos diferenciados do manto no Arqueano (3,6 a 2,7Ga; tab. 5.6-4, amostras $\mathrm{G}$ a $\mathrm{Q}$ e fig. 5.6-8). 


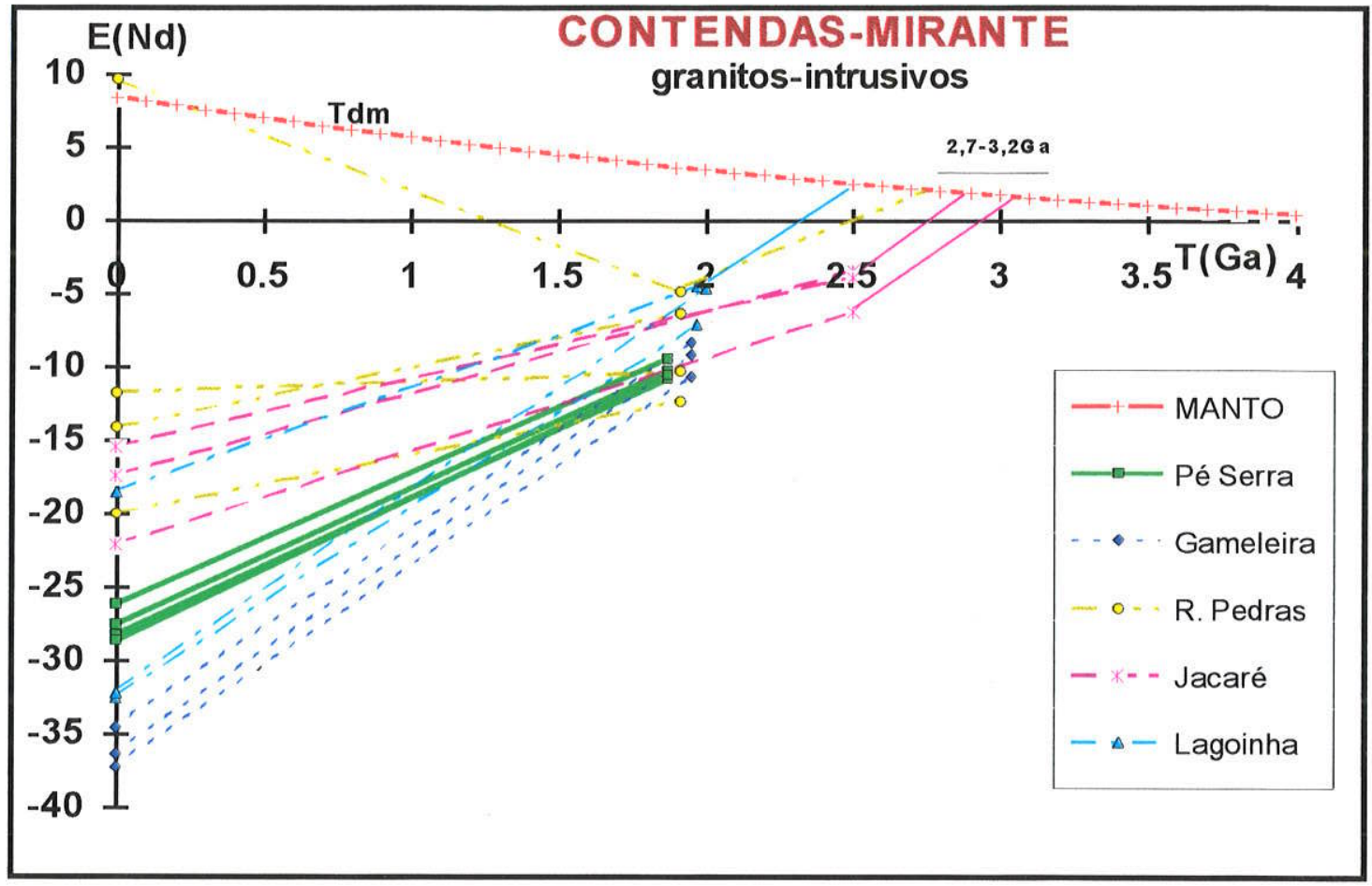

FIG. 5.6-6: diagrama $\varepsilon_{N d}(t)$ versus tempo geológico $T(G a)$ das rochas intrusivas do Complexo Contendas Mirante. Legenda: granitóide de Pé de Serra (quadrados); granitóide de Gameleira (losangos); granitóide de Riachos das Pedras (círculos); granitóide do Rio Jacaré (astericos) e granitóide de Lagoinha, Caetano e Lagoa Grande (triângulos). Os dados isotópicos encontram-se na tab.5.6-3

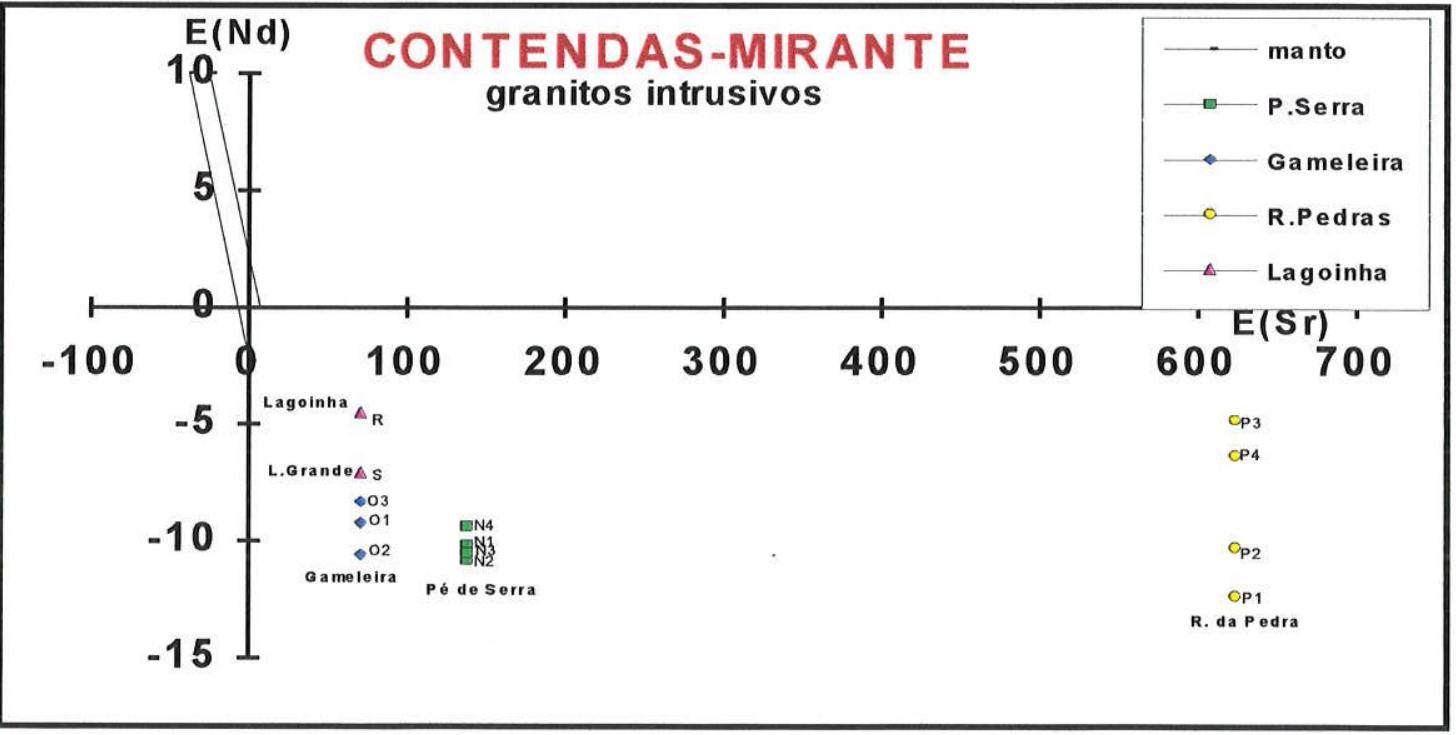

Fig.5.6-7: diagrama $\varepsilon_{\mathrm{Sr}-\mathrm{RI}}(\mathrm{t})$ versus $\varepsilon_{\mathrm{Nd}}(\mathrm{t})$ dos granitóides Transamazônicos intrusivos do Compl. Contendas Mirante. Os valores de $\varepsilon$ foram calculados para $t=$ ao evento da formação da rocha com a idade baseada pelo método $\mathrm{Rb}-\mathrm{Sr}$. Os dados isotópicos encontram-se na tab.5.6-3. 


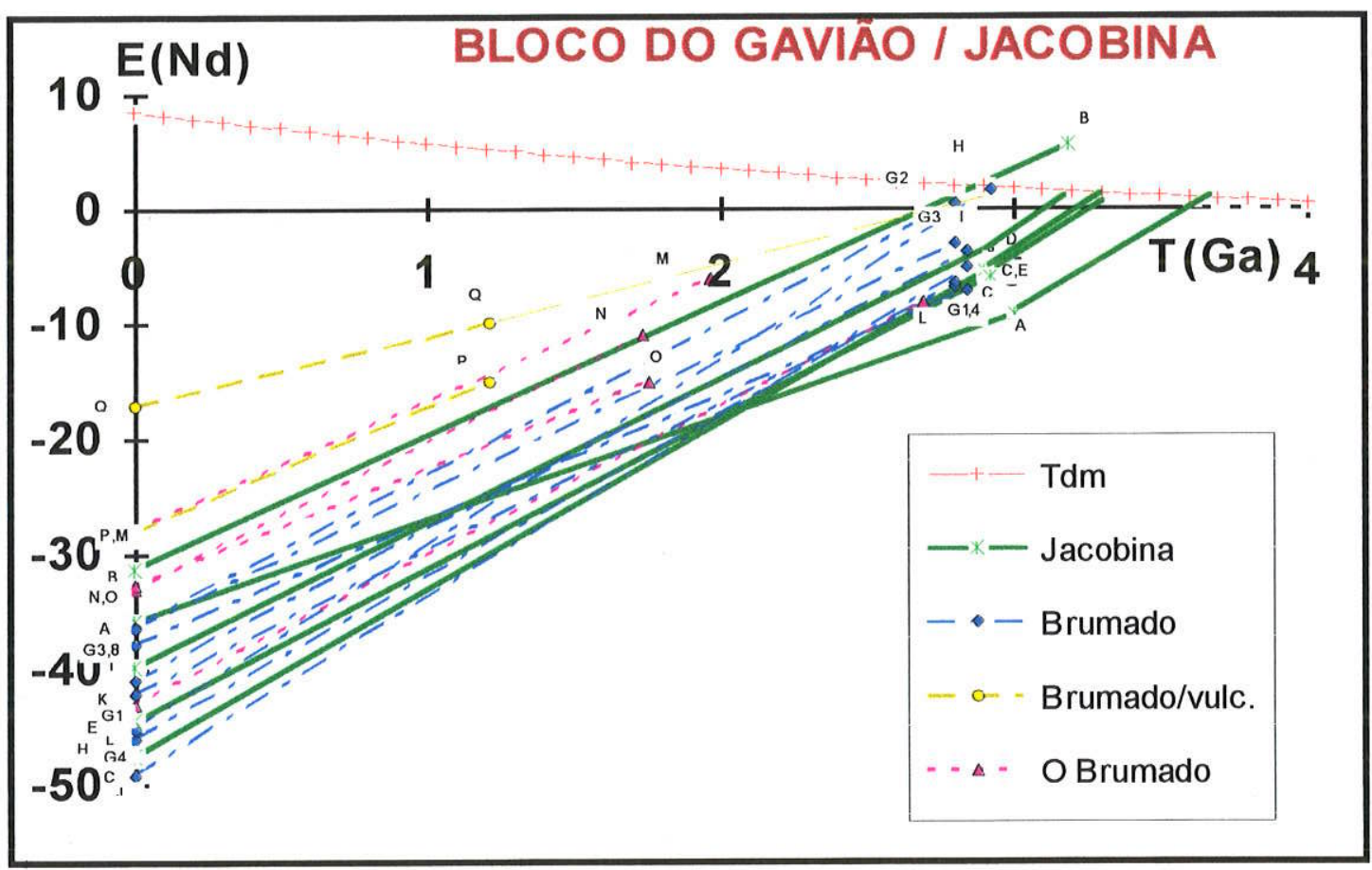

FIG. 5.6-8: diagrama $\varepsilon_{\mathrm{Nd}}(\mathrm{t})$ versus tempo geológico $\mathrm{T}(\mathrm{Ga})$ do Bloco Gavião e da região de Jacobina. As identificações das amostras e seus respectivos dados isotópicos encontram-se na tab. 5.4-4 Legenda: granitóides da região de Jacobina (linhas contínuas); granitóides da região de Brumado (linhas pontilhadas); vulcânicas da região de Brumado (linhas tracejadas).

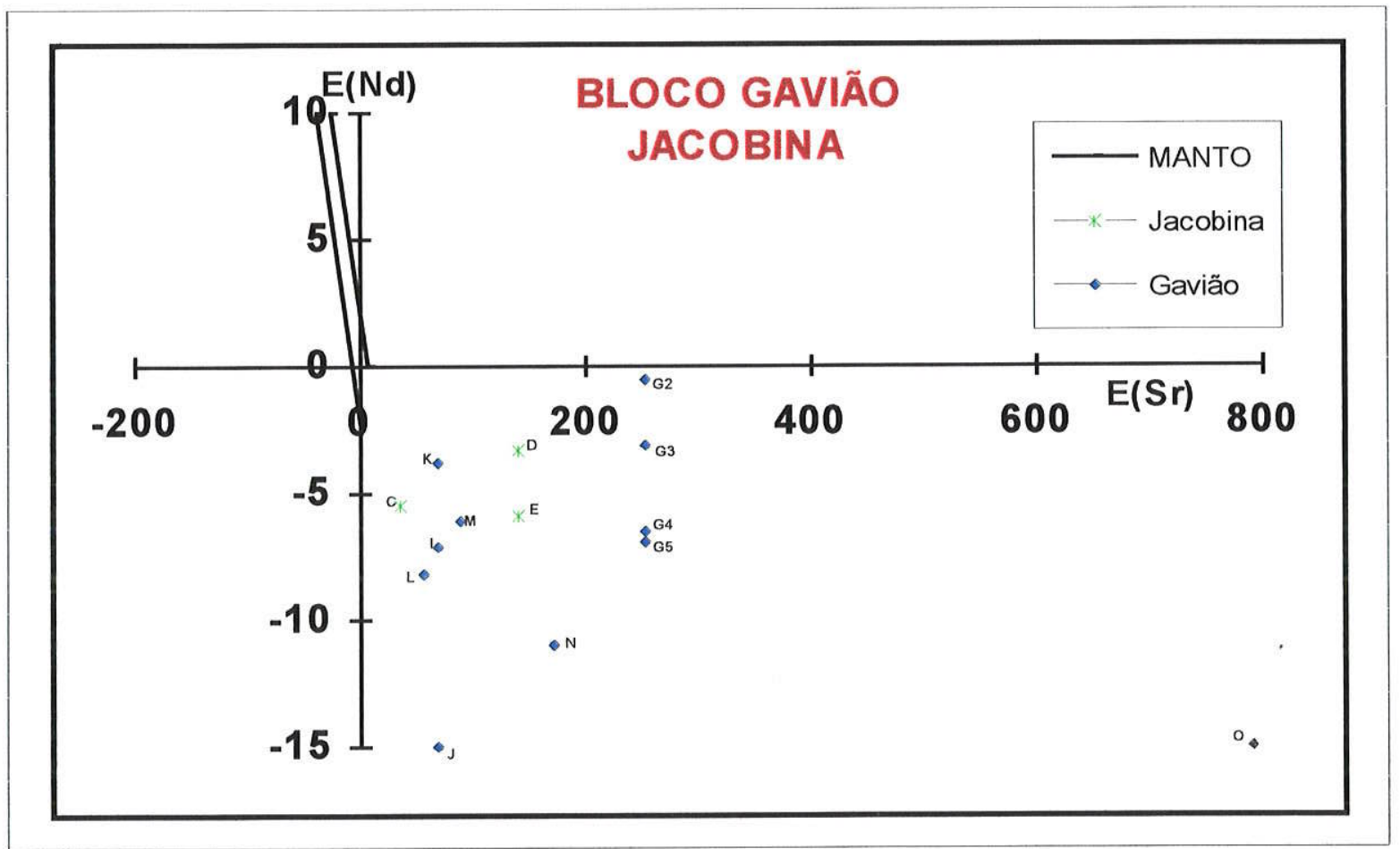

Fig.5.6-9: diagrama $\varepsilon_{\mathrm{Sr}-\mathrm{RI}}(\mathrm{t})$ versus $\varepsilon_{\mathrm{Nd}}(\mathrm{t})$ das amostras da região de Jacobina e do Bloco de Gavião. Os valores de $\varepsilon$ foram calculados para $t=$ ao evento da formação da rocha com a idade baseada pelo método $\mathrm{Rb}-\mathrm{Sr}$. Os dados isotópicos encontram-se na tab.5.6-4. 
As rochas granitóides que ocorrem a oeste da serra de Jacobina (SW da cidade de Jacobina, fig. 5.6-0, região 14), com idades $\mathrm{Rb}-\mathrm{Sr}$ próximas de 2,9Ga, (tab. 5.6-4, amostras C,D e E) apresentaram idades modelo $\mathrm{Sm}-\mathrm{Nd}$ de 3,46 a 3,29Ga. Por sua vez, as rochas granitóides que ocorrem a NW de Jacobina, com idades $\mathrm{Rb}-\mathrm{Sr}$ convencionais também arqueanas, apresentaram idades $T_{13 M}$ entre 3,67 e 2,87Ga (identificação na tab. 5.6-4 = A e B).

O embasamento arqueano parece estender-se sob a Bacia de Lençois indo até a região de Campo Alegre de Lourdes, (fig. 5.6-0, região 17), extremo norte do craton e próximo à Faixa de Dobramentos Riacho do Pontal, (Fig. 5.6-0, área 17) onde as rochas granitóides apresentaram idades modelo Sm-Nd ( $\mathrm{T}_{\mathrm{DM}}$ ) entre 3.2 e $2.9 \mathrm{Ga}$. Do mesmo modo, idade $\mathrm{T}_{\mathrm{DM}}$ arqueana (3.4Ga) foi obtida dentro da Faixa de dobramentos Riacho do Pontal.

No diagrama de evolução isotópica $\varepsilon_{\mathrm{Nd}}$ versus tempo geológico (fig. 5.6-8), os valores de $\varepsilon_{\mathrm{Nd}}$, quando calculados para o evento de formação das rochas (idade $\mathrm{Rb}-\mathrm{Sr}$ ), mostraram-se predominantemente negativos, com a maioria dos pontos analíticos posicionada abaixo do eixo da abscissa (pontos entre 1,1 a $3 \mathrm{Ga}$ ). Os valores $\varepsilon_{\mathrm{Sr}}(\mathrm{t})$ e $\varepsilon_{\mathrm{Nd}}(\mathrm{t})$ de rochas granitóides do Bloco Gavião, bem como da região oeste da Serra da Jacobina, quando calculados para o evento de formação das rochas $(\mathrm{t}=$ idade $\mathrm{Rb}-\mathrm{Sr})$, foram respectivamente positivos $\mathrm{e}$ negativos $\mathrm{e}$ distribuiram-se no quarto quadrante do diagrama fig. 5.6-9, sugerindo protólitos com afinidade crustal. Os dados de $\varepsilon_{\mathrm{Nd}_{\mathrm{d}}}$ e $\varepsilon_{\mathrm{Sr}}$ dos dois terrenos considerados nos diagramas das figuras 5.6-8 e 5.6-9 indicam padrões isotópicos semelhantes, sugerindo que o material acrescido em épocas distintas no Arqueano Inferior a Médio foi posteriormente retrabalhado e amalgamado, durante o final do Arqueano e no Proterozóico inferior.

\section{COMPLEXO GRANULÍTICO DE JEQUIÉ}

O Complexo de Jequié é representado por um conjunto de rochas orto e paraderivadas, metamorfisadas na fácies granulito (fig. 5.6-0, dominio 13). As principais referências bibliográficas contendo dados geocronológicos encontram-se em Cordani e Iyer (1978), Mascarenhas e Garcia (1989), Sato (1986), Marinho (1991), Wilson (1987) e Barbosa 1990.

Os dados $\mathrm{Rb}$-Sr dessas rochas granulíticas distribuem-se entre 3,0 a 2,65Ga com a maior concentração de idades no intervalo entre 2,8 a $2,7 \mathrm{Ga}$ e com as razões iniciais ${ }^{87} \mathrm{Sr} /{ }^{86} \mathrm{Sr}$ relativamente elevadas $(0,704$ a 0,712$)$. Sato (1986), com base nas linhas de evolução isotópica de estrôncio, e também em três determinações pelo método $\mathrm{Sm}-\mathrm{Nd}$, sugeriu origem por retrabalhamento crustal, com protólitos diferenciados do manto no período entre 3,2 e $2,8 \mathrm{Ga}$. 
Isócronas $\mathrm{Sm}-\mathrm{Nd}$ em rocha total e em rochas plutònicas ácidas, normalmente, são difíceis de ser elaboradas, devido à pouca dispersão na variável ${ }^{1+7} \mathrm{Sm} /{ }^{144} \mathrm{Nd}$. Apesar da pouca dispersão, os dados $\mathrm{Sm}-\mathrm{Nd}$ relativos às rochas do Complexo de Jequié, distribuidos regionalmente, foram tentativamente plotados em um único diagrama isocrônico (Fig. 5.6-10). Os pontos analíticos distribuiram-se em torno da reta de $2,7 \mathrm{Ga}$, valor coerente com as datações $\mathrm{Rb}-\mathrm{Sr}$ e U-Pb (em zircão) existentes.

O diagrama de evolução isotópica $\varepsilon_{\mathrm{X} \text { d }}$ versus tempo geológico (fig. 5.6-11) mostra padrões isotópicos similares, tanto para as rochas plutônicas como para as rochas vulcânicas do complexo. As linhas de regressão de $\varepsilon_{\mathrm{Nd}}$ (algumas em estágio duplo) interceptam a curva do manto (DM) entre 3,3 a $2,9 \mathrm{Ga}$, intervalo de tempo que representa provavelmente a época da separação do manto para os protólitos das rochas granuliticas.

Os valores de $\varepsilon_{\mathrm{Nd}}$ dos granulitos de Mutuipe / Laje, calculados para a época da formação destas rochas $(\mathrm{t}=2,9 \mathrm{Ga}$ - idade $\mathrm{Rb}-\mathrm{Sr})$, distribuiram-se bem próximos à curva do manto (DM). (fig. 5.6-11, tab. 5.6-6; pontos $\mathrm{Cl}$ a $\mathrm{C} 8$ ). As demais rochas do complexo apresentaram valores de $\varepsilon_{\mathbb{N d}}$ negativos, posicionando-se seus pontos abaixo da reta CHUR. Acrescente-se que os valores de $\varepsilon_{\mathrm{Sr}}$ relativos às rochas granuliticas de Mutuipe (amostras $\mathrm{Cl}$ a $\mathrm{C} 8$ ) e também às supra crustais (amostras H, I e J) mostraram-se muito positivos (13 a 394 ). Por outro lado, a correlação das razões iniciais $\varepsilon_{\mathrm{Sr}}$ versus $\varepsilon_{\mathrm{Nd}}$ dessas amostras (fig. 5.6-12) indica padrão isotópico bem distinto. As seqüências supra-crustais (rochas granulíticas de Jequié e Eng. França) distribuem-se no quarto quadrante, sugerindo derivação crustal, enquanto que os dados relativos às rochas granuliticas de Mutuipe mostram uma afinidade com protólitos mantélicos, ou da crosta inferior.

\section{REGIÕES DE LAGOA REAL, RIACHO DE SANTANA E GUANAMBI:}

$\mathrm{Na}$ região uranifera de Lagoa Real predominam rochas granitóides (Fig. 5.6-0, região 16). Os estudos geocronológicos realizados por Cordani et. al. (1992) e Pimentel et. al. (1994), empregando diversos métodos de datação radiométrica, tais como U-Pb, $\mathrm{Rb}-\mathrm{Sr}, \mathrm{Pb}-\mathrm{Pb}$ e K-Ar, sugerem uma história evolutiva complexa para a região, resumida aqui da seguinte forma: (a) formação dos gnaisses e migmatitos do embasamento em $2,7 \mathrm{Ga}$; (b) intrusão do granitóide de São Timóteo em 1,73Ga; (c) atividade hidrotermal - metassomática responsável pela mineralização de urânio entre 1,5 e 0,9 Ga; (d) rejuvenescimento isotópico associado ao Ciclo Brasiliano ocorrido entre 0,6 a $0,5 \mathrm{Ga}$. 


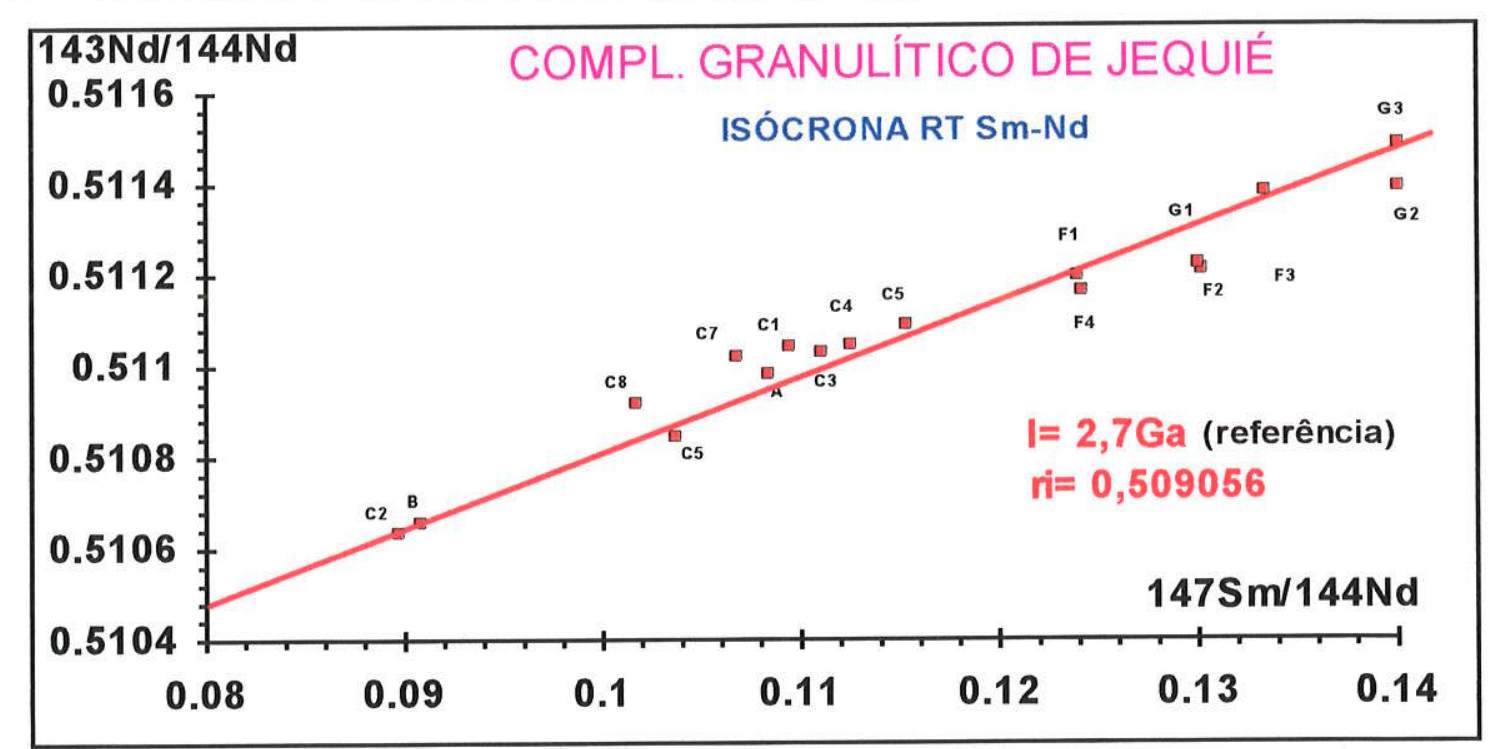

Fig. 5.6-10: isócrona de referência $\mathrm{Sm}-\mathrm{Nd}$ (rocha total) das rochas granulíticas do Complexo de Jequié. Os dados isotópicos encontram-se na tab. 5.6-6. A linha de 2,7 Ga foi colocada apenas para dar o referêncial da distribuição espacial dos pontos.

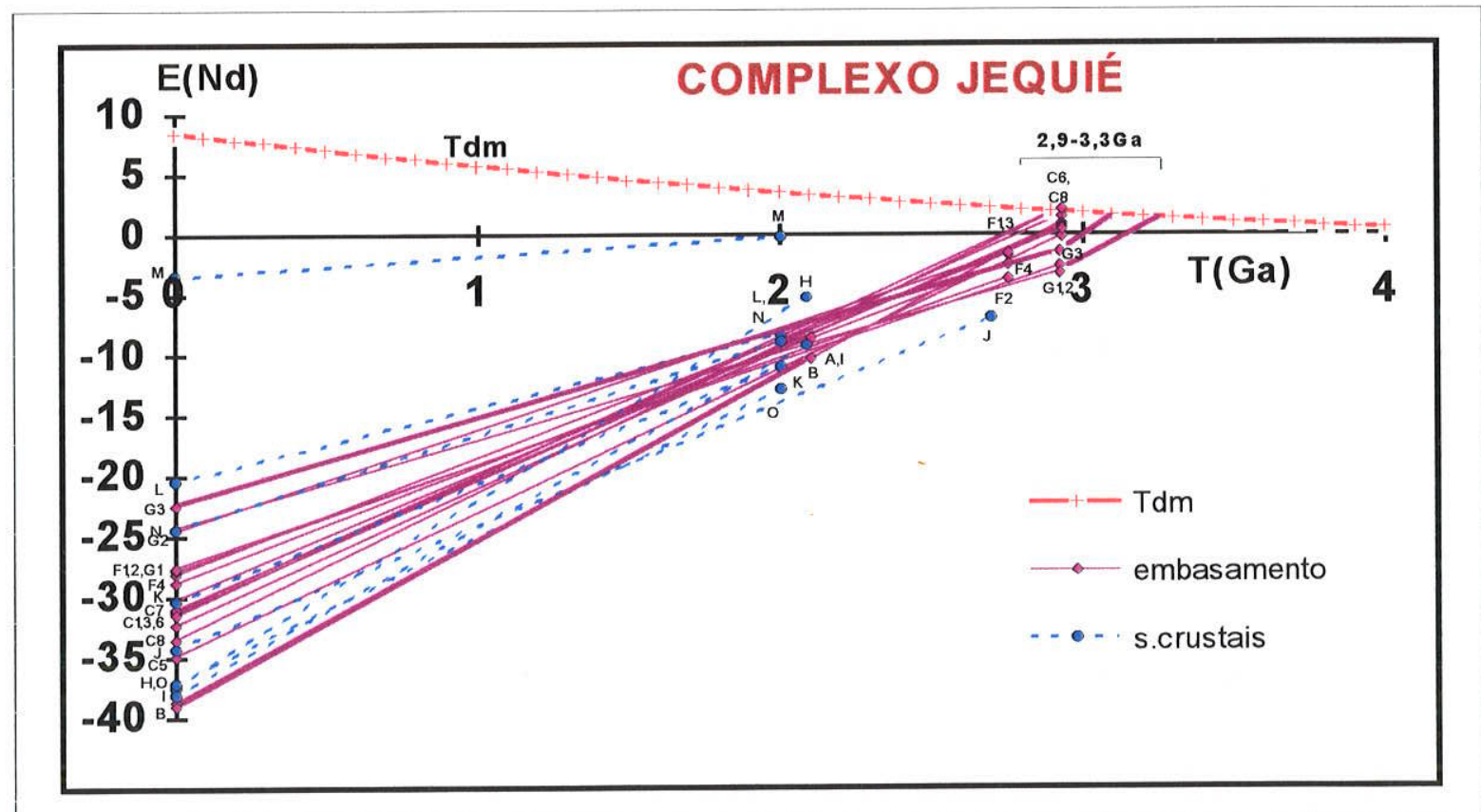

FIG. 5.6-11: diagrama $\varepsilon_{\mathrm{Nd}(\mathrm{t})}$ versus tempo geológico $\mathrm{T}(\mathrm{Ga})$ da rochas granulíticas do Complexo Jequié. As identificações das amostras e seus respectivos dados isotópicos encontram-se na tab. 5.6-6/7 Legenda: rochas granulíticas (linhas contínuas); supra-crustais metamorfoseado em fácies granulito (linhas pontilhadas). 


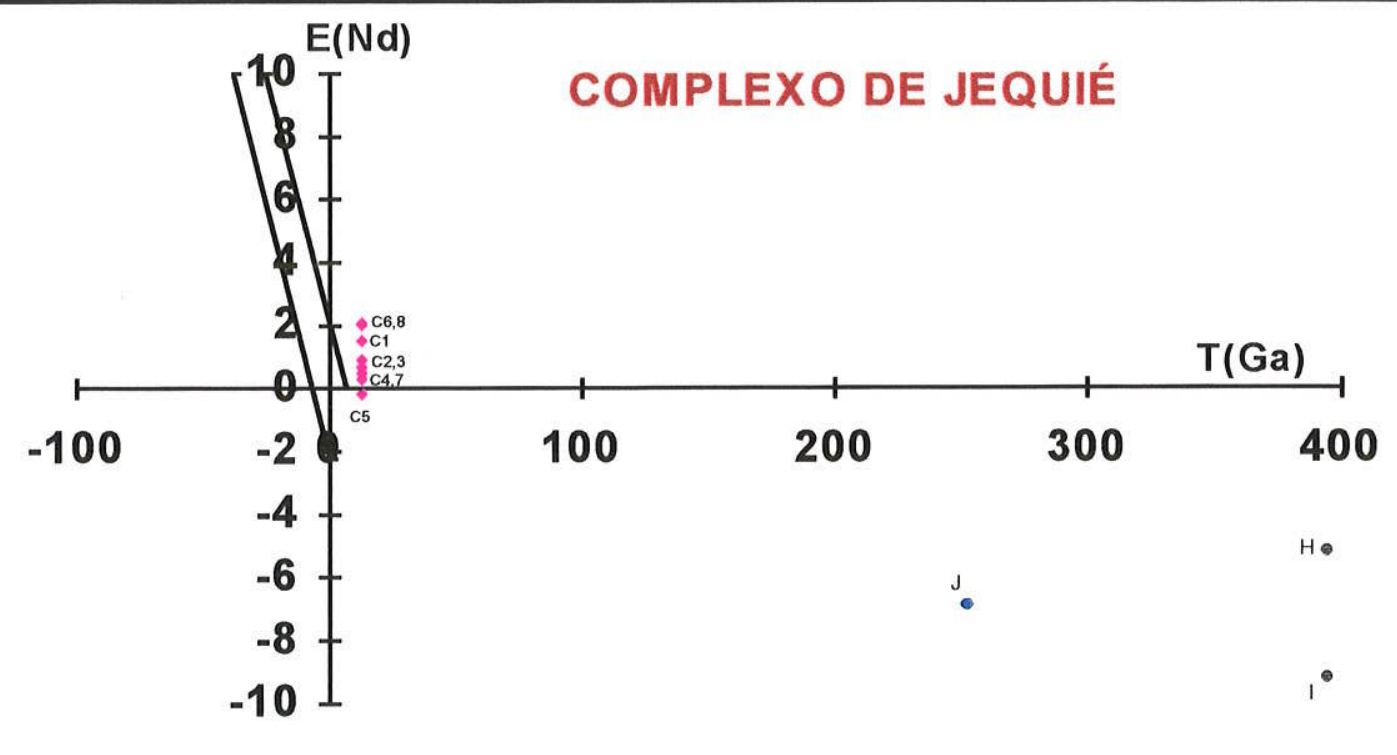

Fig.5.6-12: diagrama $\varepsilon_{\mathrm{Sr}-\mathrm{RI}}(\mathrm{t})$ versus $\varepsilon_{\mathrm{Nd}}(\mathrm{t})$ das rochas granulíticas do Compl. de Jequié. Os valores de $\varepsilon$ foram calculados para $t=$ ao evento da formação da rocha com a idade baseada pelo método $\mathrm{Rb}-\mathrm{Sr}$. Os dados isotópicos encontram-se na tab.5.6-6/7. Legenda: rochas granulíticas (losangos); supracrustais metamorfoseadas na fácies granulítica (círculos).

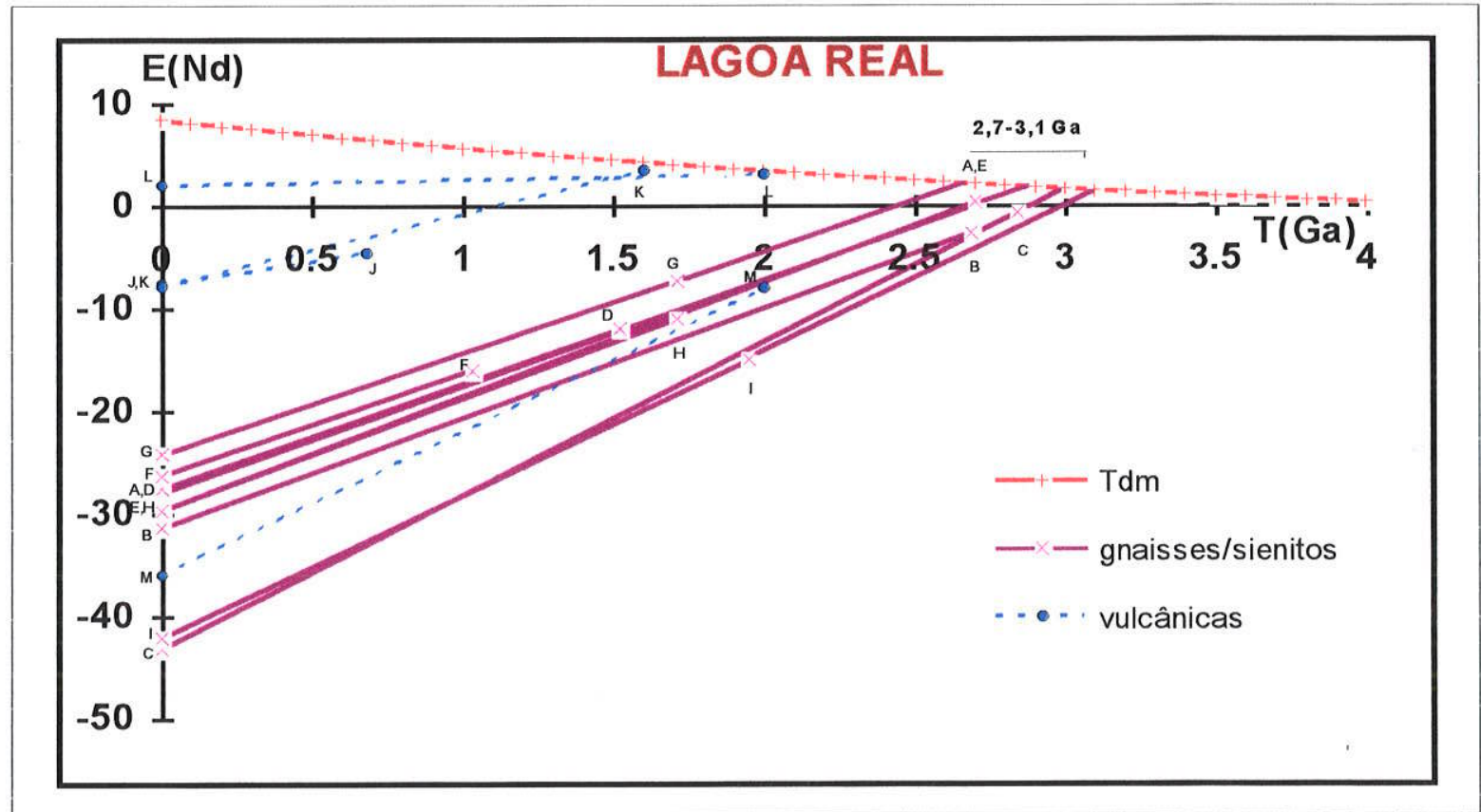

FIG. 5.6-13: diagrama $\varepsilon_{\mathrm{Nd}(\mathrm{t})}$ versus tempo geológico $\mathrm{T}(\mathrm{Ga})$ das amostras da região de Lagoa Real, Norte de Macaúbas, Guanambi e Riacho de Santana. As identificações das amostras e seus respectivos dados isotópicos encontram-se na tab. 5.6-8 Legenda: rochas granitóides (linhas contínuas); rochas vulcânicas (linhas pontilhadas). 
Todas as idades modelo $\mathrm{Sm-Nd}\left(\mathrm{T}_{13 \times 1}\right)$, tanto as obtidas para as rochas do embasamento. como as das rochas ggranitóides intrusivas e rochas associadas à mineralização de urânio. distribuiram-se entre 2,9 a $2,8 \mathrm{Ga}$, sugerindo que seus protólitos diferenciaram-se do manto superior (DM) no mesmo intervalo tempo (veja fig. 5.6-13 e tab 5.6-8, amostras D a H).

As razões iniciais ${ }^{87} \mathrm{Sr} /{ }^{86} \mathrm{Sr}$ relativamente elevadas, os valores de $\varepsilon_{\mathrm{Sr}}\left(\mathrm{t}_{\mathrm{Rr}-\mathrm{Sr}}\right)$ extremamente positivos $(67$ a 285$)$ e os valores de $\varepsilon_{\mathrm{Nd}}\left(\mathrm{t}_{\mathrm{Rb}-\mathrm{Sr}}\right)$ relativamente negativos $(-12 \mathrm{a}-7$ ), (tab. 5.6-8, amostras $\mathrm{D}$ a $\mathrm{H}$ ), denotam tratar-se de rochas com vida crustal anterior e tempo de residencia crustal relativamente longo (a única exceção encontrada foi a da amostra $E$, que teve valor positivo de $\varepsilon_{\mathrm{Nd}}=0,4$ ). No diagrama $\varepsilon_{\mathrm{Sr} \times} \varepsilon_{\mathrm{Nd}}$ (fig. 5.6-14), os pontos distribuem-se no quarto quadrante, sugerindo que as rochas, formadas no Proterozóico, seriam produtos de retrabalhamento de material crustal pré-existente, diferenciado do manto no Arqueano.

A Norte de Lagoa Real e próximo às cidades de Paramirim - Água Quente ocorrem rochas vulcânicas ácidas (Formação Rio dos Remédios), posicionadas na base do Supergrupo Espinhaço (Inda e Barbosa 1978). Essas rochas, datadas pelo método U-Pb em zircão (Schobbenhaus et. al. - 1994 e Babinski et. al. - 1994) apresentaram idades próximas de 1.75Ga. Tais valores mostram-se similares aos observados para os granitóides intrusivos de São Timóteo (Lagoa Real) e rochas básicas da região Guanambi $\left(\mathrm{T}_{\mathrm{DM}}=1,72 \mathrm{Ga}\right.$; tab. 5.6-8 - amostra $\mathrm{K}$ ) e permitem correlação com os riolitos do Supergrupo Espinhaço, em Minas Gerais (Brito Neves et. al 1979) e também com os riolitos da base do Grupo Arai em Goiás (Pimentel et. al., 1991).

Para Oeste, nas regiões de Guanambi e Riacho de Santana, aparecem rochas gnáissicomigamtíticas formadas no Arqueano ( $\mathrm{T}_{\mathrm{Rb}-\mathrm{Sr}}: 2,7$ a $2,6 \mathrm{Ga}$ ) pertencentes aos Complexos Santa Izabel e Riacho de Santana bem como rochas granito-gnáissicas formadas no Paleoproterozóico ( $\mathrm{T}_{\mathrm{Rb}-\mathrm{Sr}}$ : 2,0 a $\left.1,9 \mathrm{Ga}\right)$, e pertencentes ao Complexo Guanambi.

As idades modelo Sm-Nd indicaram, para todas essas rochas, protólitos do Arqueano, variando entre 3,08 a 2,88Ga (tab. 5.6-8; amostras A, B, C e 1). O padrão de evolução isotópica $\varepsilon_{\mathrm{Nd}}$ no tempo geológico (fig. 5.6-13) mostra-se similar ao observado para rochas do Complexo de Lagoa Real. Escapam deste padrão as rochas vulcânicas de natureza básica(Tab. 5.6-8, amostras $\mathrm{J}, \mathrm{K}$ e L), que apresentaram idades modelo entre $2,3-2,1 \mathrm{Ga}$, sugerindo protolitos diferenciados do manto no Paleoproterozóico. Por outro lado, a vulcânica básica de Riacho de Santana apresentou idade $\mathrm{T}_{\mathrm{DM}}$ de $2.74 \mathrm{Ga}$, indicando evento de acreção juvenil no Arqueano (amostra $\mathrm{M}$ da tab. 5,6-8). 


\section{EXTREMIDDE SUL - REGIÃO DO QUADRILÁTERO FERRIFERO E}

ADJACÊNCIAS

A região meridional do Craton São Francisco está coberta pela sedimentação NeoProterozóica do Grupo Bambui. No extremo Sul afloram terrenos granítico-gnaíssicomigmatíticos (fig. 5.6-0, dominios 11 e 12), que incluem os Complexos Bonfim, Belo Horizonte, Campo Belo e o Cinturão Mineiro, (fig. 5.6-15).

Trabalho de sintese geocronológica, empregando os métodos $\mathrm{Sm}-\mathrm{Nd}, \mathrm{U}-\mathrm{Pb}, \mathrm{Pb}-\mathrm{Pb}, \mathrm{Rb}-$ Sr e K-Ar, recentemente publicado por Teixeira et. al (1996), sugere uma complexa história de evolução crustal, que pode ser resumida da seguinte forma:

- eventos de acreção de material juvenil, entre 3,2 a 2,8Ga;

- metamorfismo regional com plutonismo associado e com o retrabalhamento crustal, entre 2,8 a $2,75 \mathrm{Ga}$;

- estabilização final da crosta arqueana a 2,6Ga;

- acreção de material juvenil e retrabalhamento de material anterior, principalmente no Cinturão Mineiro, entre 2,3 a 2,0Ga;

- estabilização e resfriamento regional do Cinturão Mineiro entre 2,0 a 1,8Ga;

- eventos isolados de reativação durante Meso-Neoproterozóico entre1,3 a 0,98Ga.

A localização das amostras com datação pelo método Sm-Nd encontra-se na fig. 5.6-15. Os dados isotópicos ${ }^{143} \mathrm{Nd} /{ }^{144} \mathrm{Nd}$, as concentrações $\mathrm{Sm}$ e $\mathrm{Nd}$ e as respectivas idades modelo encontram-se na tab. 5.6-9A. 


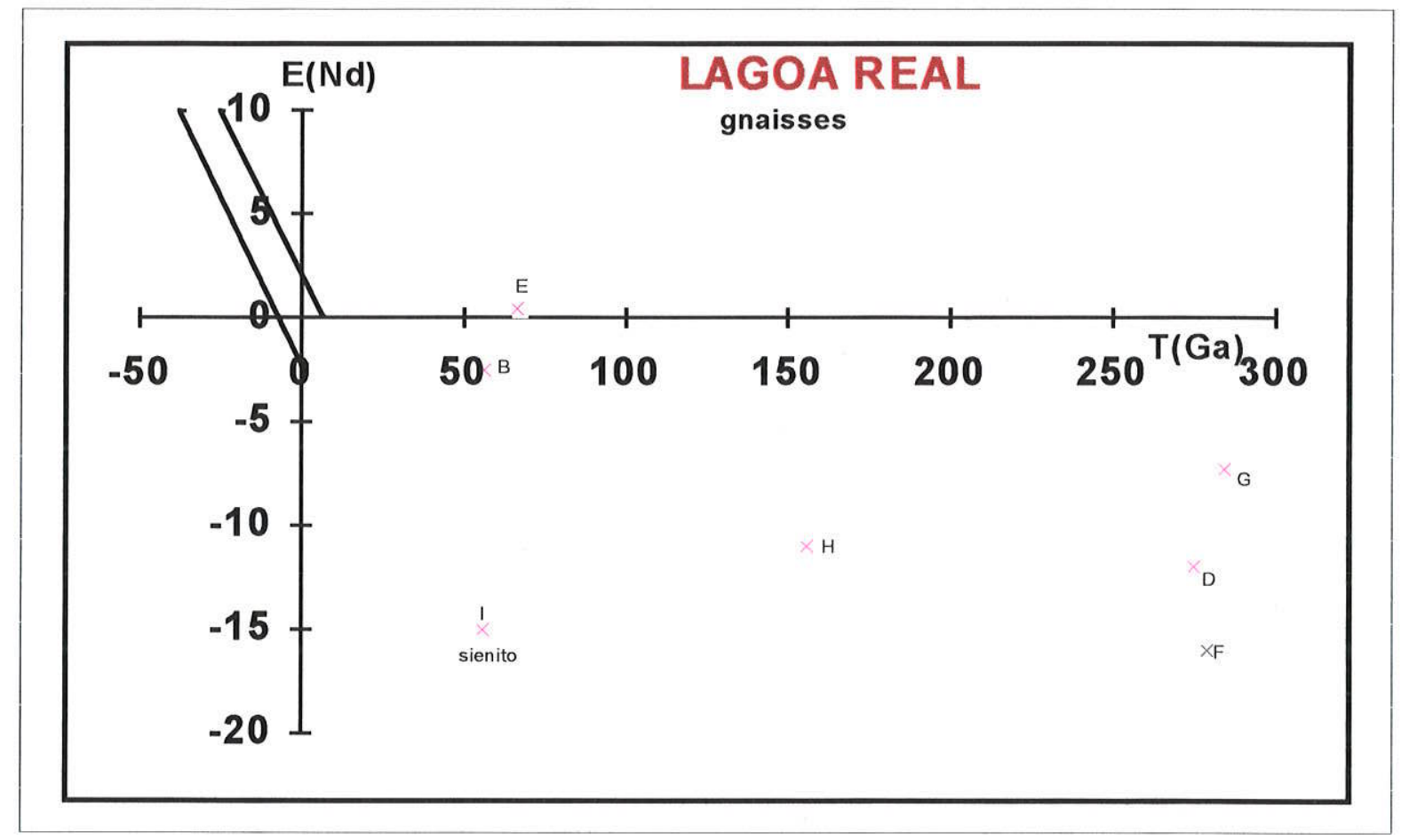

Fig.5.6-14: diagrama $\varepsilon_{\mathrm{Sr}-\mathrm{RI}}(\mathrm{t})$ versus $\varepsilon_{\mathrm{Nd}}(\mathrm{t})$ das rochas granitóides da região de Lagoa Real. Os dados isotópicos encontram-se na tab.5.6-8. 


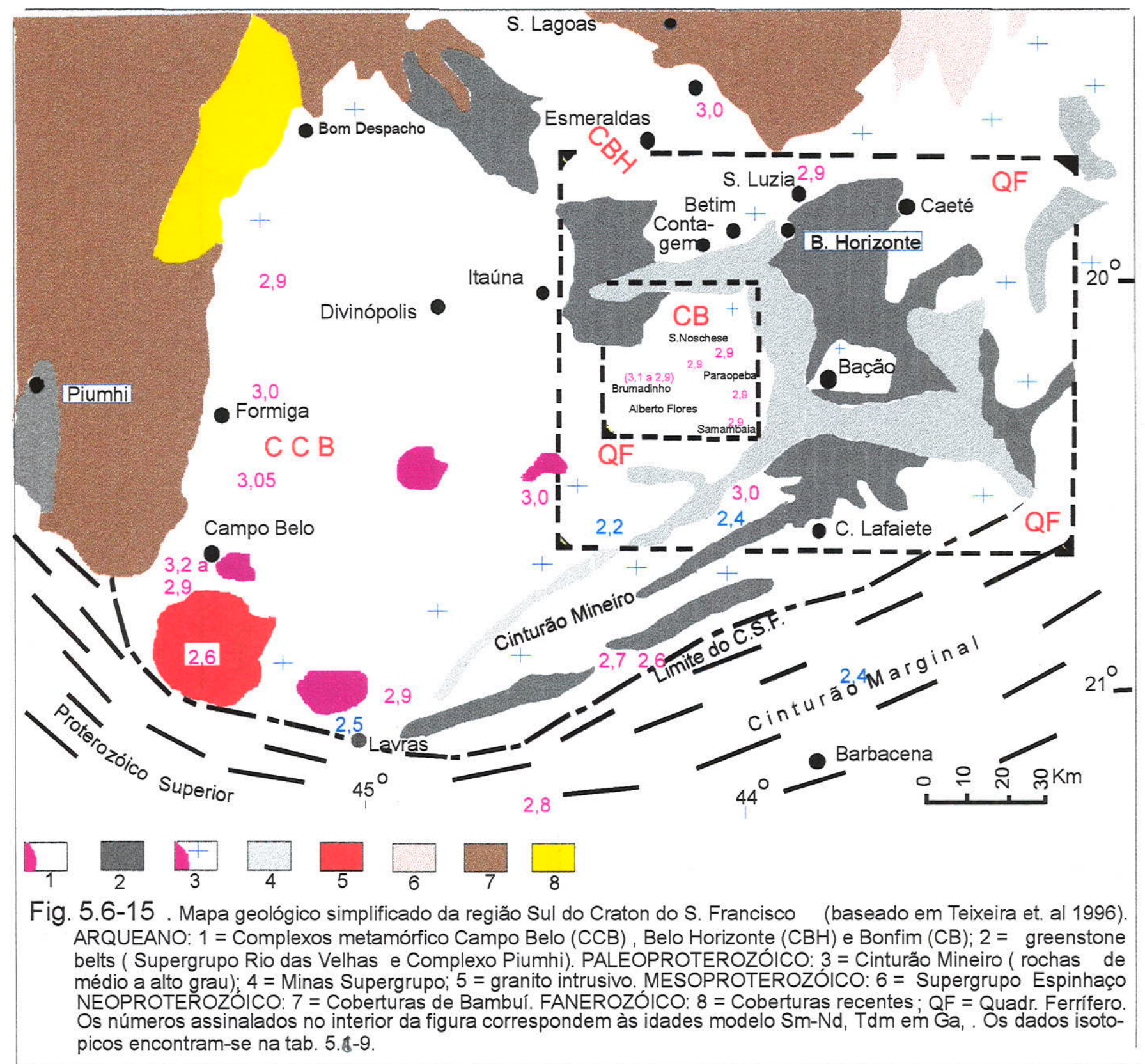




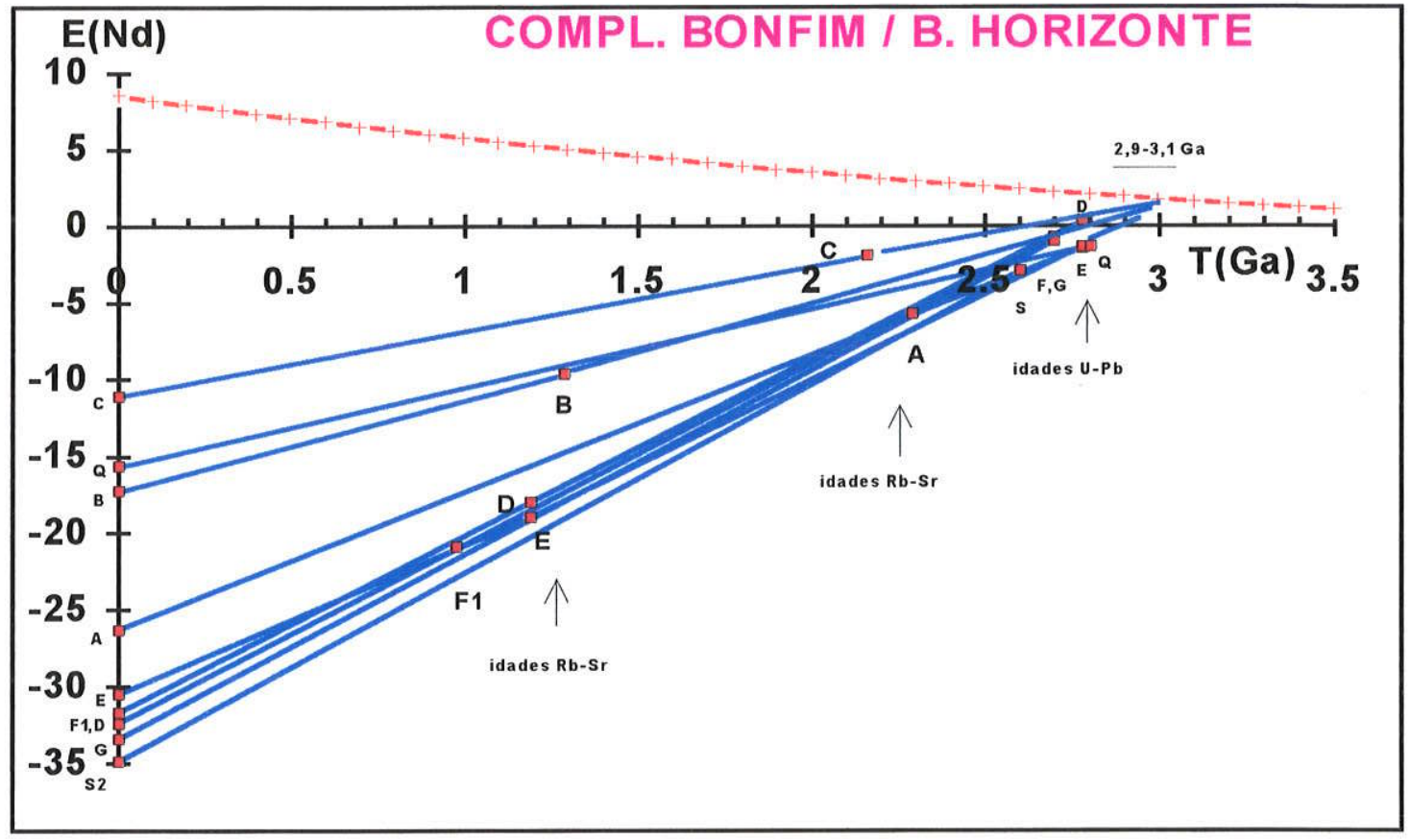

FIG. 5.6-16A: diagrama $\varepsilon_{\mathrm{Nd}(\mathrm{t})}$ versus tempo geológico $\mathrm{T}(\mathrm{Ga})$ das rochas granitóides e básicas do Complexo Bonfim (Belo Horizonte $-M G$ ). As identificações das amostras e seus respectivos dados isotópicos encontram-se na tab. 5.6-9A.

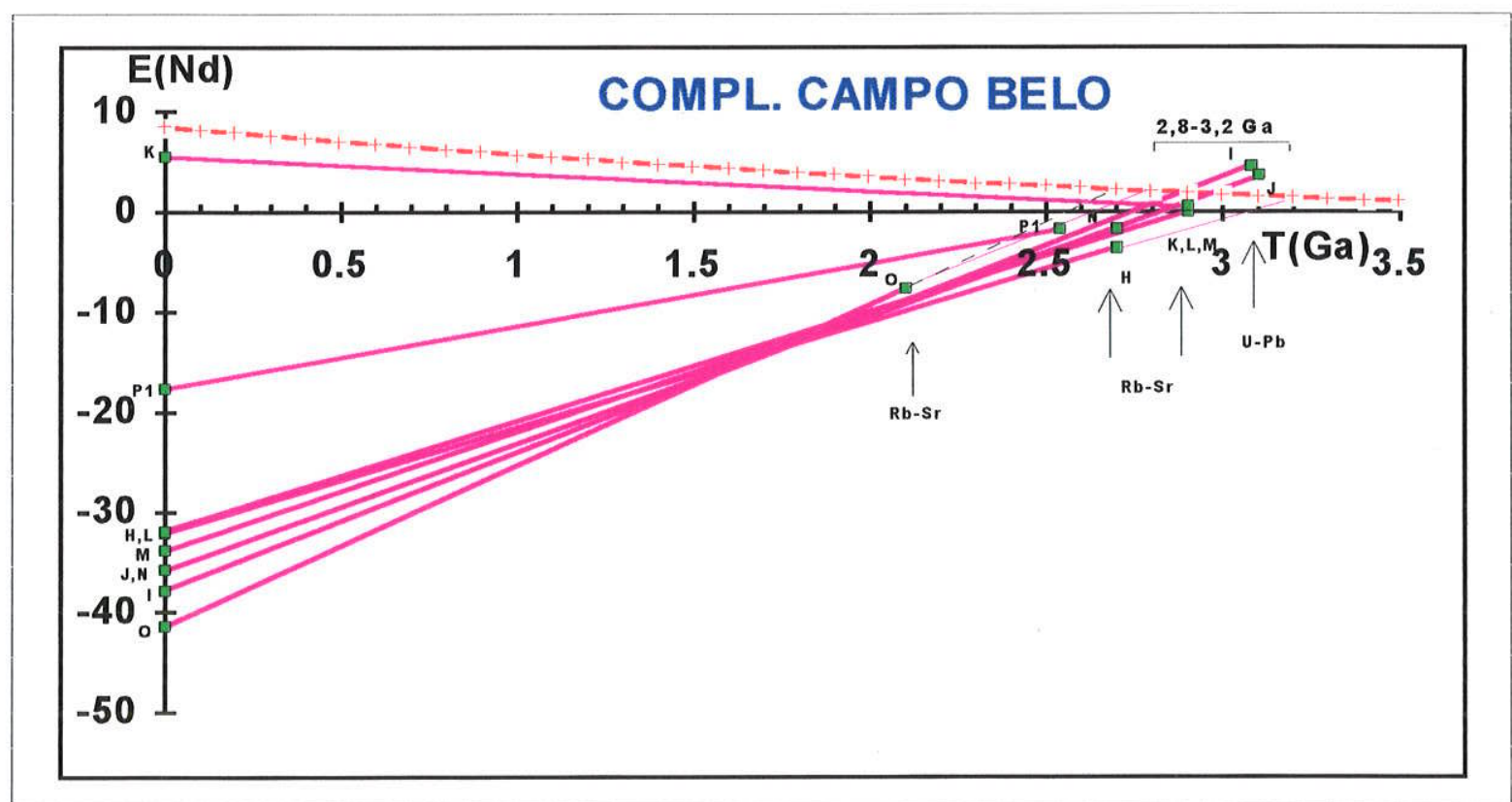

FIG. 5.6-16B: diagrama $\varepsilon_{\mathrm{Nd}(\mathrm{t})}$ versus tempo geológico $\mathrm{T}(\mathrm{Ga})$ das rochas granitóides e básicas do Compl. Campo Belo (Belo Horizonte - MG). As identificações das amostras e seus respectivos dados isotópicos encontram-se na tab. 5.6-9A. 


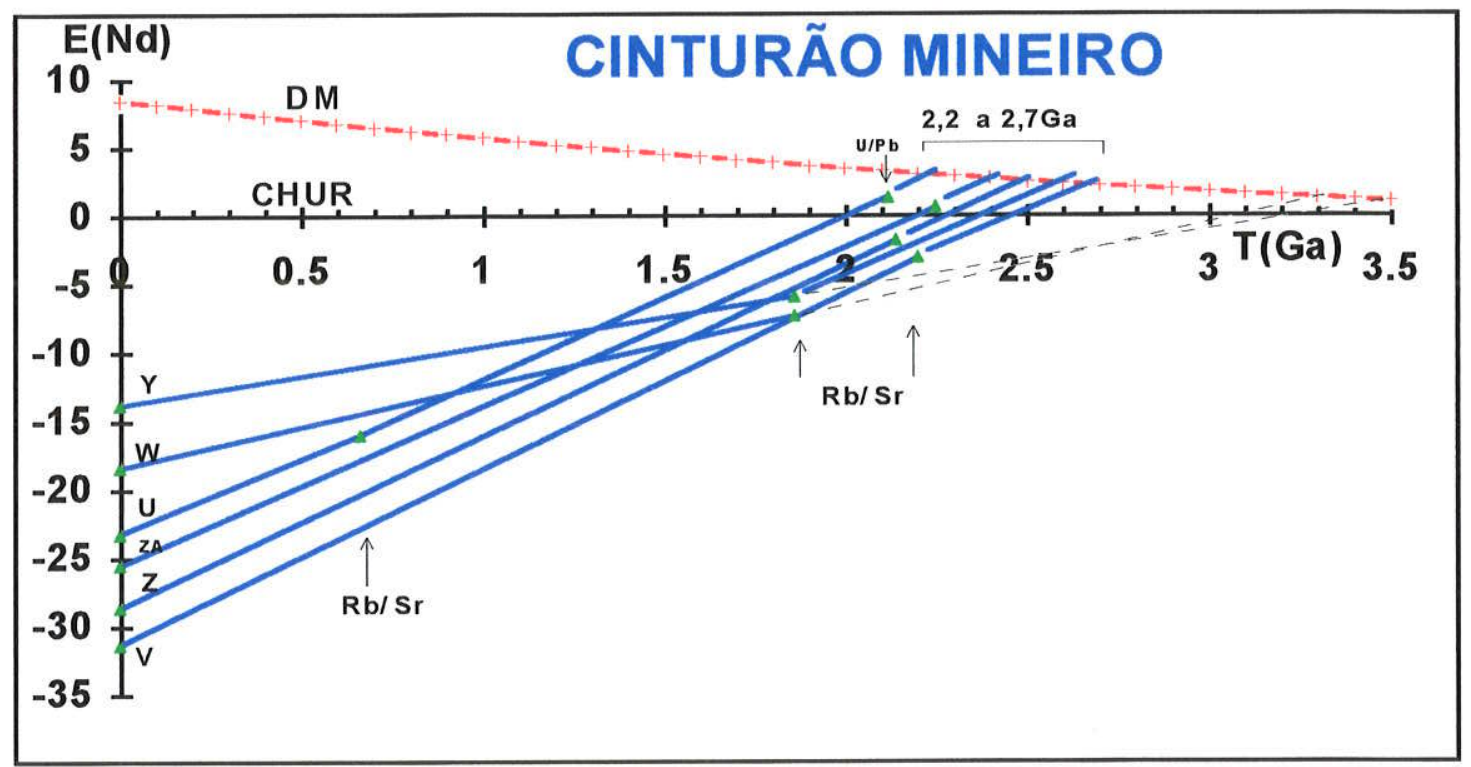

Fig. 5.6-16C: diagrama $\varepsilon_{\mathrm{Nd}(\mathrm{t})}$ versus tempo geológico $\mathrm{T}(\mathrm{Ga})$ das rochas granitóides do Cinturão Mineiro. As identificações das amostras e seus respectivos dados isotópicos encontram-se na tab. 5.6-9A.

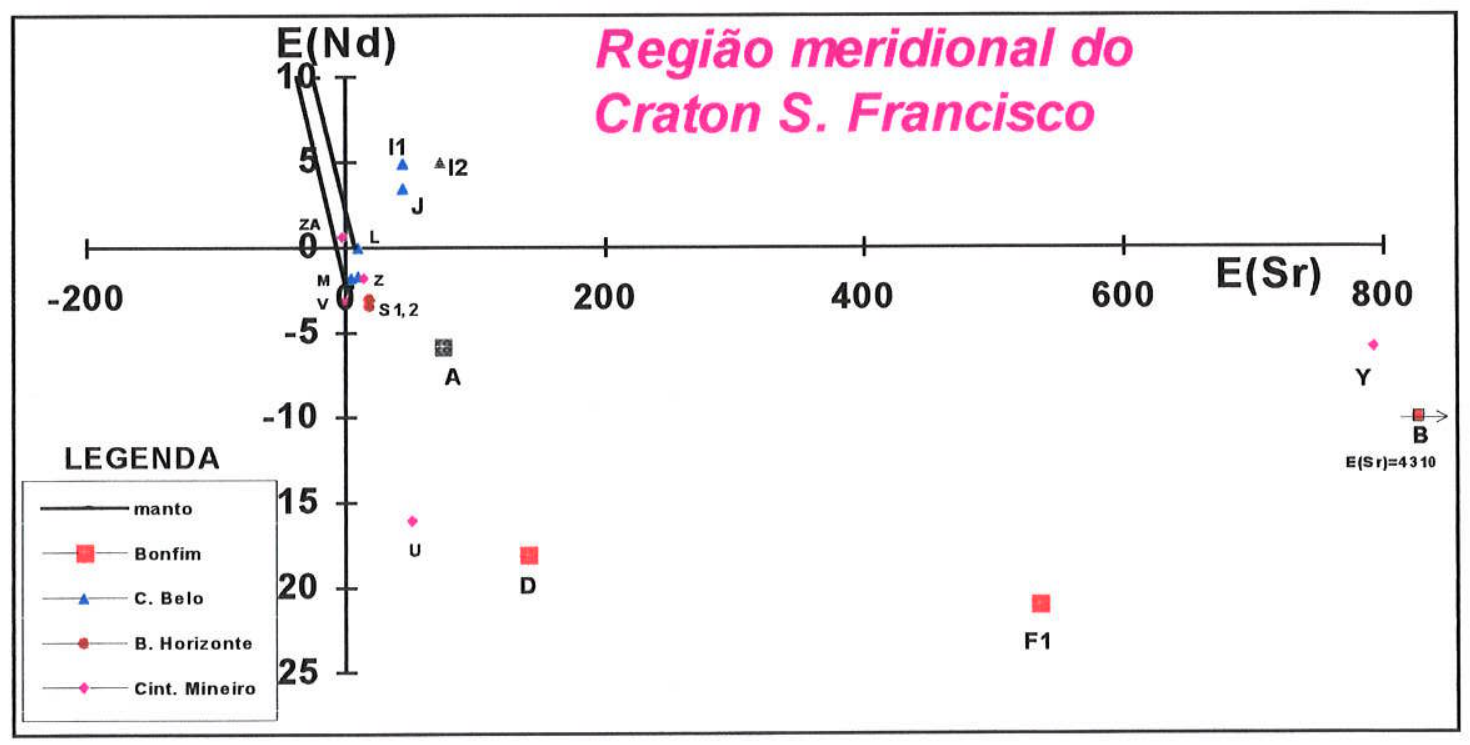

FIG. 5.6-17: diagrama $\varepsilon_{\mathrm{Sr}-\mathrm{RI}}(\mathrm{t})$ versus $\varepsilon_{\mathrm{Nd}}(\mathrm{t})$ das rochas granitóides da região meridional do Craton do São Francisco. Os dados isotópicos encontram-se na tab.5.6-9A. 
As rochas granitóides dos Complexos Bonfim, Belo Horizonte e Campo Belo apresentam linhas de evolução isotópica $\varepsilon_{\mathrm{Nd}}$ no tempo geológico que, quando regredidas até à curva do manto empobrecido, a interceptam entre 3,2 a 2,9Ga (figuras 5.6-16a e b). A rocha granitóide de Souza Noschese e a rocha básica de Paraopeba (Compl. Bonfim) apresentam fator de fracionamento relativamente baixo. ( $\mathrm{f}=-.24$ e -.17 ; tab. 5.6-9, amostras $\mathrm{B}$ e $\mathrm{C}$ ) quando comparado com o das rochas graníticas, da ordem de -0.45 . Suas idades $T_{D M}$ discordantes tornar-se-ão concordantes ao utilizarmos modelo de estágio duplo. No caso do granitóide WT2, que apresenta valor positivo de f (tab. 5.6-9, amostra $\mathrm{K}$; fig. 5.6-16B), sua idade $\mathrm{T}_{\mathrm{DM}}$ não pode ser calculada utilizando-se o modelo de DePaolo (1981), no entanto, com o modelo de estágio duplo a idade aparente obtida $\left(\mathrm{T}_{\mathrm{dm} 2}=2,98 \mathrm{Ga}\right)$ torna-se concordante com as demais observadas para este complexo.

O Cinturão Mineiro definido por Teixeira et. al. (1987) representa um conjunto de rochas granitóides que bordeja os terrenos arqueanos do embasamento meridional do Craton do São Francisco, (fig. 5.6-15) e que inclui granitos Transamazônicos, formados num ambiente tectônico colisional, segundo Pires e Barbosa (1993). As idades modelo Sm-Nd ( $\left.\mathrm{T}_{\mathrm{DM}}\right)$ relativas às rochas granitóides indicaram diferentes épocas de diferenciação manto - crosta continental, durante o Arqueano e o Paleoproterozóico, (tab. 5.6-9A e fig. 5.6-16C). Os valores de $\varepsilon_{\mathrm{sr}}$ positivos e $\varepsilon_{\mathrm{Nd}}$ negativos sugerem protólitos crustais para estas rochas distinguindo-se desse padrão o granito situado a NE de Lavras (amostra ZA da tab. 5.6-9A) e o batólito de Alto do Maranhão (amostra $U$, tab. 5.6-9A,), que apresentam $\varepsilon_{\mathrm{Sr}}$ negativo e $\varepsilon_{\mathrm{Nd}}$ positivo sugerindo fonte mantélica, ou periodo relativamente curto de residência crustal.

No diagrama $\varepsilon_{\mathrm{St}}$ versus $\varepsilon_{\mathbb{N d}}$ (fig. 5.6.17), observam-se padrões isotópicos distintos para as amostras dos diferentes complexos. A maioria das rochas granitóides dos Complexos Campo Belo e Belo Horizonte posicionaram-se próximo da origem, sugerindo protólitos mantélicos, ou período curto de residência crustal, enquanto que os valores de $\varepsilon_{\mathrm{Sr}}$ e $\varepsilon_{\mathrm{Nd}}$ das rochas do Complexo Bonfim posicionaram relativamente distantes da origem, sugerindo neste caso retrabalhamento e mobilização isotópica de $\mathrm{Sr}$ durante o Proterozóico. 


\section{PORÇ̃̃O NORTE-ORIENTAL DO CRATON DO SÃO FRANCISCO}

Na região nordeste do Craton do S. Francisco, ao norte de Salvador, aparecem rochas gnáissico-migmatíticas de médio e alto grau associadas a rochas intrusivas graníticas, alcalinas e básicas. Ao sul de Salvador (região de Itabuna), aparecem granulitos derivados de rochas vulcânicas e plutônicas diversas (Barbosa 1986). Estes domínios estão representados na fíg. 5.60 nos subdominios $3,4,5,7$, e 9 .

As idades radiométricas $\mathrm{Rb}-\mathrm{Sr}$ referem-se predominantemente ao Ciclo Transamazônico (Paleoproterozóico), associadas à evolução da Faixa móvel Salvador-Juazeiro (Cordani e Brito Neves, 1982). No interior deste cinturão foram registrados núcleos arqueanos preservados, a exemplo das regiões de Serrinha e Rio Capim (Mascarenhas e Garcia 1989).

As tabelas 5.6-10 A e B resumem os dados isotópicos Sm- $\mathrm{Nd}$ disponiveis para o Cinturão Salvador - Juazeiro. As localizações das amostras datadas encontram-se na fig. 5.6-1.

Na fig. 5.6-18, as linhas de regressão de $\varepsilon_{\mathrm{Nd}}$ em função do tempo geológico interceptam a curva "DM" entre 3,6 a 3,1Ga para rochas granitóides tipo TTGs (tab. 5.6-10A, amostras B a $\mathrm{F}$, linhas contínuas da figura) e entre 3.0 a $2.2 \mathrm{Ga}$ para os granitóides Transamazônicos (linhas ponto-tracejadas e tab. 5.6-10A, amostras $\mathrm{G}$ a L). Tais dados indicam que a maioria das rochas granitóides formadas no Transamazônico apresenta idades modelo $\mathrm{Sm}-\mathrm{Nd}\left(\mathrm{T}_{\mathrm{DM}}\right)$ mais jovens em relação às rochas granitóides tipo TTGs, sugerindo provir de protólitos distintos, ou então de fontes mistas (Arqueano e Paleoproterozóico) para os granitóides Transamazônicos. As metavulcânicas do Rio Capim e de Araci (amostras M e N, linhas pontilhadas) apresentaram idades $\mathrm{T}_{\mathrm{DM}}$ de $2,3 \mathrm{Ga}$ praticamente concordantes com as idades $\mathrm{Rb}-\mathrm{Sr}$ sugerindo derivação juvenil.

As linhas de evolução isotópica $\varepsilon_{\mathrm{Nd}}$ da fig. 5.6-19 interceptam a curva do manto (DM) entre 2,6 a 2,2Ga, a exceção de duas amostras com idades $\mathrm{T}_{\mathrm{DM}}$ de 2,9 e 2,8Ga (tab. 5.6-10B). Os valores acima indicados podem ser interpretados como mistura de fontes crustais e mantélicas, não podendo ser excluida a hipótese de manto anômalo (ver capítulo 4.6).

No diagrama $\varepsilon_{\mathrm{Sr}}$ versus $\varepsilon_{\mathrm{Nd}}($ fig. 5.6-20), os valores de $\varepsilon(\mathrm{t})$ distribuiram-se no quarto quadrante, sugerindo que os protólitos destas rochas tiveram certo tempo de residência crustal, com exceção da rocha vulcânica BA-3 (amostra N) que parece ter sido derivada diretamente do manto.

A evolução crustal da região em questão pode ser resumida da seguinte forma:

- Acreção de material juvenil no Arqueano precoce (>3,0Ga): Granitóides de Uauá, Rio Capim e Araci (Serrinha). 


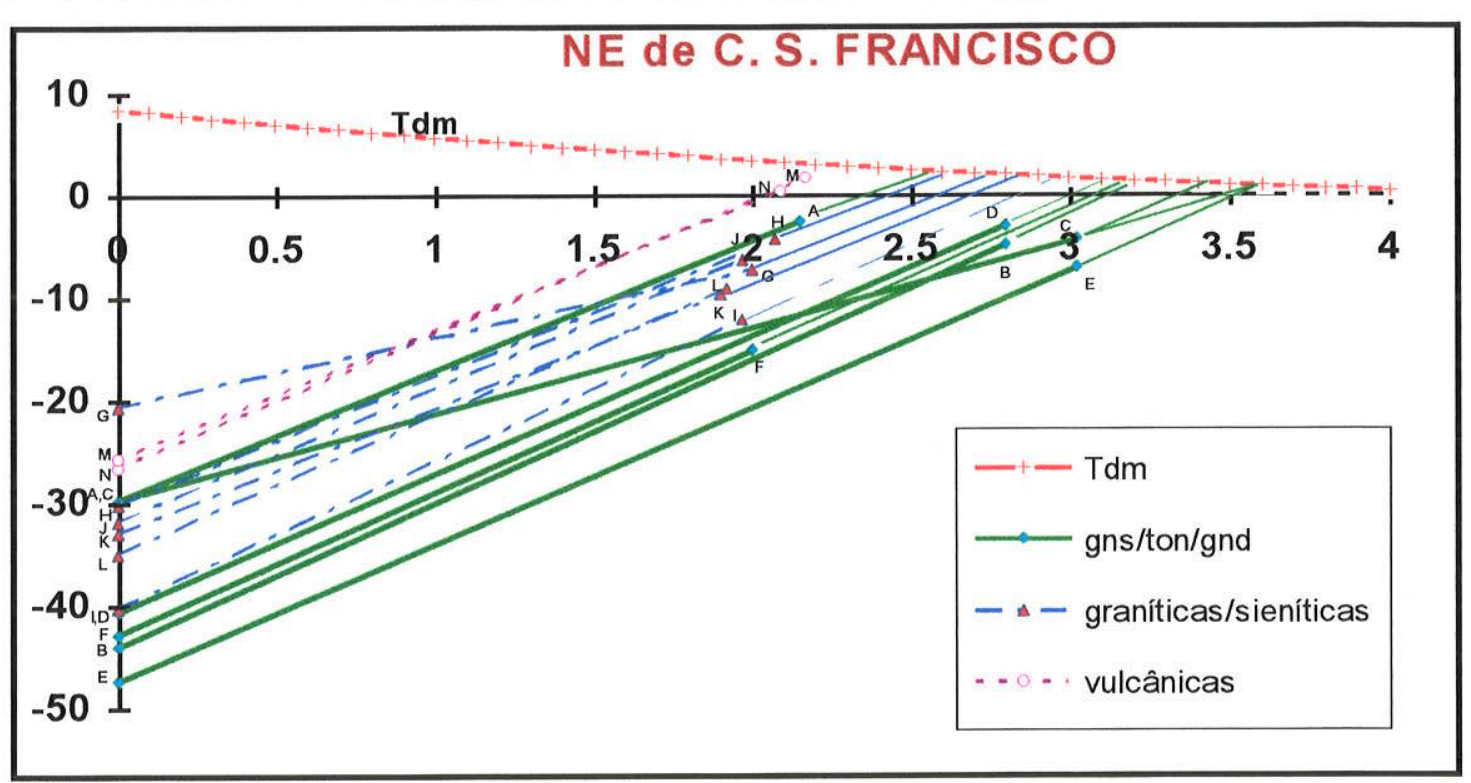

FIG. 5.6-18: diagrama $\varepsilon \mathrm{Nd}(\mathrm{t})$ versus tempo geológico $\mathrm{T}(\mathrm{Ga})$ a Nordeste do C. S. Francisco (faixa Salvador - Juazeiro, regiões de Serrinha e Capim). Os dados isotópicos encontram-se na tab. 5.6-10 Legenda: granitóides de Serrinha e Capim (rochas tipo TTGs - linhas contínuas), granitóides (rochas graníticas/ sieníticas - linhas tracejadas); vulcânicas (linhas pontilhadas).

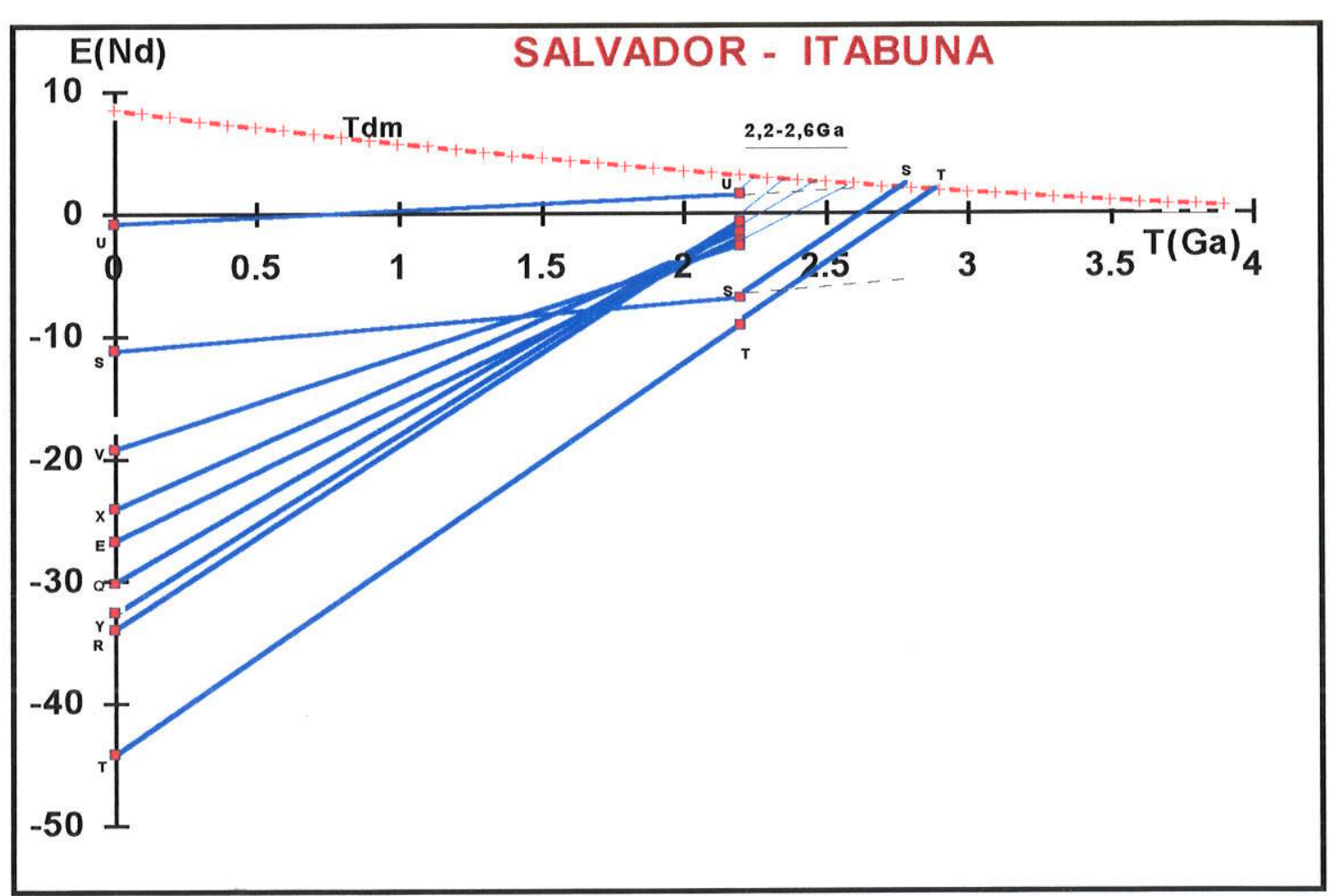

FIG. 5.6-19: diagrama $\varepsilon_{N d}(\mathrm{t})$ versus tempo geológico $T(\mathrm{Ga})$ das rochas granulíticas da região de Salvador-Itabuna. Os dados isotópicos encontram-se na tab. 5.6-10. 


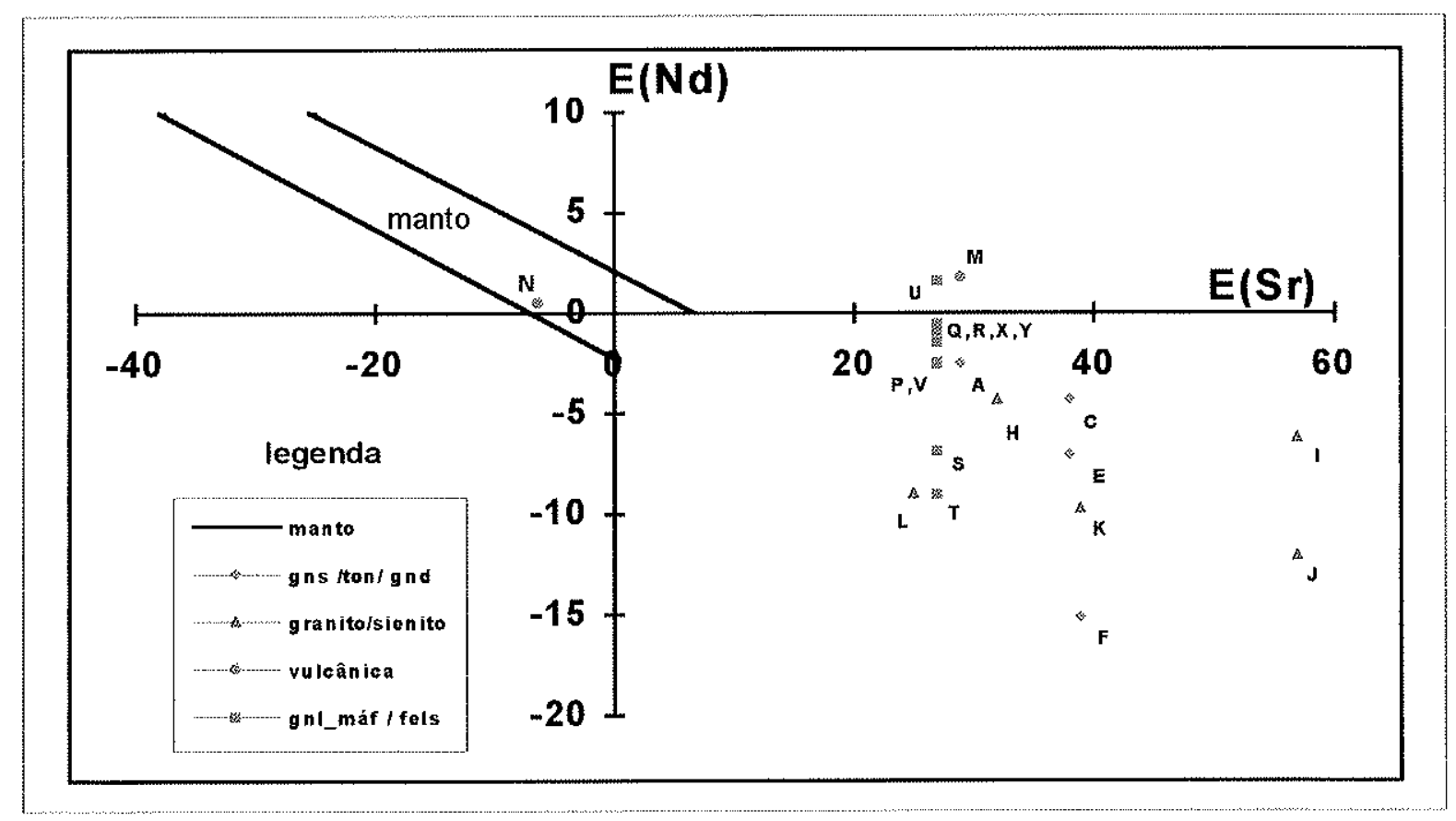

Fig.5.6-20: diagrama $\varepsilon_{S r-R I}(t)$ versus $\varepsilon_{\text {Nd }}(t)$ das rochas da região Nordeste do $C$. $S$. Francisco. Os valores de $\varepsilon$ foram calculados para $t=$ ao evento da formação da rocha com a idade baseada pelo método $\mathrm{Rb}-\mathrm{Sr}$. Os dados isotópicos encontram-se na tab.5.6-10. Símbolos quadrados referem-se às amostras localizadas entre Salvador e ltabuna e aos demais ao norte de Salvador. 
- Acreção de material juvenil no Arqueano Superior (3,0 a 2,5Ga): Granulitos de Poço de Fora e granitóides de Itiúba, Retrolândia, Campo Formoso e Jacuípe.

- Acreção de material juvenil durante o Paleoproterozóico (2,5 a 1,6Ga): Granitóide de Santa Luz, vulcânicas ácidas do Rio Capim e Araci e rochas granulitico-básicas da região Salvador-Itabuna

\section{PORÇÃO NORTE-OCIDENTAL DO CRATON SÃO FRANCISCO}

O domínio localizado a Oeste do Espinhaço Setentrional está coberto por sedimentos do Grupo Bambuí com exceção de uma janela de embasamento próximo da cidade de Correntina, onde afloram rochas de natureza granitica/monzonitica e migmatítica (fig. 5.6-1) formadas no Ciclo Transamazônico (isócrona $\mathrm{Rb}-\mathrm{Sr}$ com 2,0Ga com $\mathrm{RI}=0,7043$; Mascarenhas e Garcia 1989). A norte da cidade de Guanambi ocorrem rochas sieníticas, cujas idades Rb-Sr também são relativas ao Ciclo Transamazônico $(I=1,94 \mathrm{Ga}$ com $\mathrm{RI}=0,7076)$. As idades modelo Sm-Nd $\left(\mathrm{T}_{\mathrm{DM}}\right.$ ) resultaram pouco mais antigas, entre 2,4 e 2,1Ga, (tab. 5.6-11, amostras A,B,C,D) podendo caracterizar material juvenil, com pequena (ou nenhuma) proporção de assimilação crustal

\section{COBERTURAS DO GRUPO BAMBUI:}

De acordo com o Kawashita (1996), os dados radiométricos $\mathrm{Rb} / \mathrm{Sr}, \mathrm{K} / \mathrm{Ar} /, \mathrm{Pb} / \mathrm{Pb}$ e $\mathrm{Sm} / \mathrm{Nd}$ sugerem para a sedimentação do Grupo Bambuí, em especial na porção Sul do Craton do $\mathrm{S}$. Francisco, o intervalo 0,64 a $0,54 \mathrm{Ga}$ (fig. 5.6-0, região 1). Idades modelo $\mathrm{Sm} / \mathrm{Nd}$ em rochas sedimentares representam valores médios retratando a geoquímica de ETR de suas áreas fontes.

As idades $\mathrm{T}_{\mathrm{DM}}$ obtidas em sedimentos e metassedimentos do Gr. Bambuí, quando calculadas segundo equação de estágio único, distribuiram-se entre 2,84Ga e zero, (Kawashita 1996). Em função da evidência de fracionamento quimico entre $\mathrm{Sm}$ e $\mathrm{Nd}$ ocorrido a $0,57 \mathrm{Ga}$ (isócrona Sm-Nd, Kawashita 1996) nas rochas carbonáticas, as idades foram recalculadas utilizando-se a premissa de estágio duplo. Dessa forma, as idades $\mathrm{T}_{\mathrm{DM}}$ convergiram para um intervalo entre 1,74 a 1,73 Ga para amostras das formações Sete Lagoas e Lagoa do Jacaré, (tab. 5.6-9B) e entre 1,61 a 1,5Ga. para as demais formações. 
Considerando-se que as rochas do embasamento do Craton do $\mathrm{S}$. Francisco possuem idades $\mathrm{T}_{\mathrm{DM}}$ normalmente superiores a $1,8 \mathrm{Ga}$ e freqüentemente superiores a $2.5 \mathrm{Ga}$, as fontes dos sedimentos do Grupo Bambuí da região meridional do Craton devem representar misturas com componentes mais jovens, até do Neoproterzóico.

O quadro abaixo mostra algumas das combinações da mistura obtidas utilizando um modelo simplista envolvendo 4 fontes distintas no tempo geológico.

\begin{tabular}{l|l|l|l|l|l}
\hline & $\begin{array}{l}\mathrm{A}=3,1 \mathrm{Ga} \\
\% \text { em vol }\end{array}$ & $\begin{array}{l}\mathrm{B}=2,0 \mathrm{Ga} \\
\% \text { em vol }\end{array}$ & $\begin{array}{l}\mathrm{C}=1,5 \mathrm{Ga} \\
\% \text { em vol }\end{array}$ & $\begin{array}{l}\mathrm{D}=1,0 \mathrm{Ga} \\
\% \text { em vol }\end{array}$ & $\begin{array}{l}\mathrm{T}_{\mathrm{DM}}(\mathrm{Ga}) \\
\text { (mistura) }\end{array}$ \\
\hline 1 & 10 & & 90 & & 1,66 \\
\hline 2 & 30 & & & 70 & 1,63 \\
\hline 3 & 10 & 45 & & 45 & 1,66 \\
\hline 4 & 10 & 30 & 30 & 30 & 1,66 \\
\hline 5 & & 30 & 70 & & 1,65 \\
\hline 6 & & 65 & & 35 & 1,65 \\
\hline 7 & & 27 & 55 & 28 & 1,65 \\
\hline
\end{tabular}

Considerandomse que os teores de ETR em rochas continentais não mudaram significativamente ao longo do tempo geológico, verifica-se que qualquer que sejam as combinações da mistura é necessária uma maior participação de material fonte do Proterozóico e uma menor contribuição de material fonte do Arqueano. Tal fato sugere que a maioria das fontes dos sedimentos do Grupo Bambui parece tenha vindo dos cinturões marginais, (Faixa Sergipana, Brasília, Araçuaí), com menor participação de materias do próprio craton. 


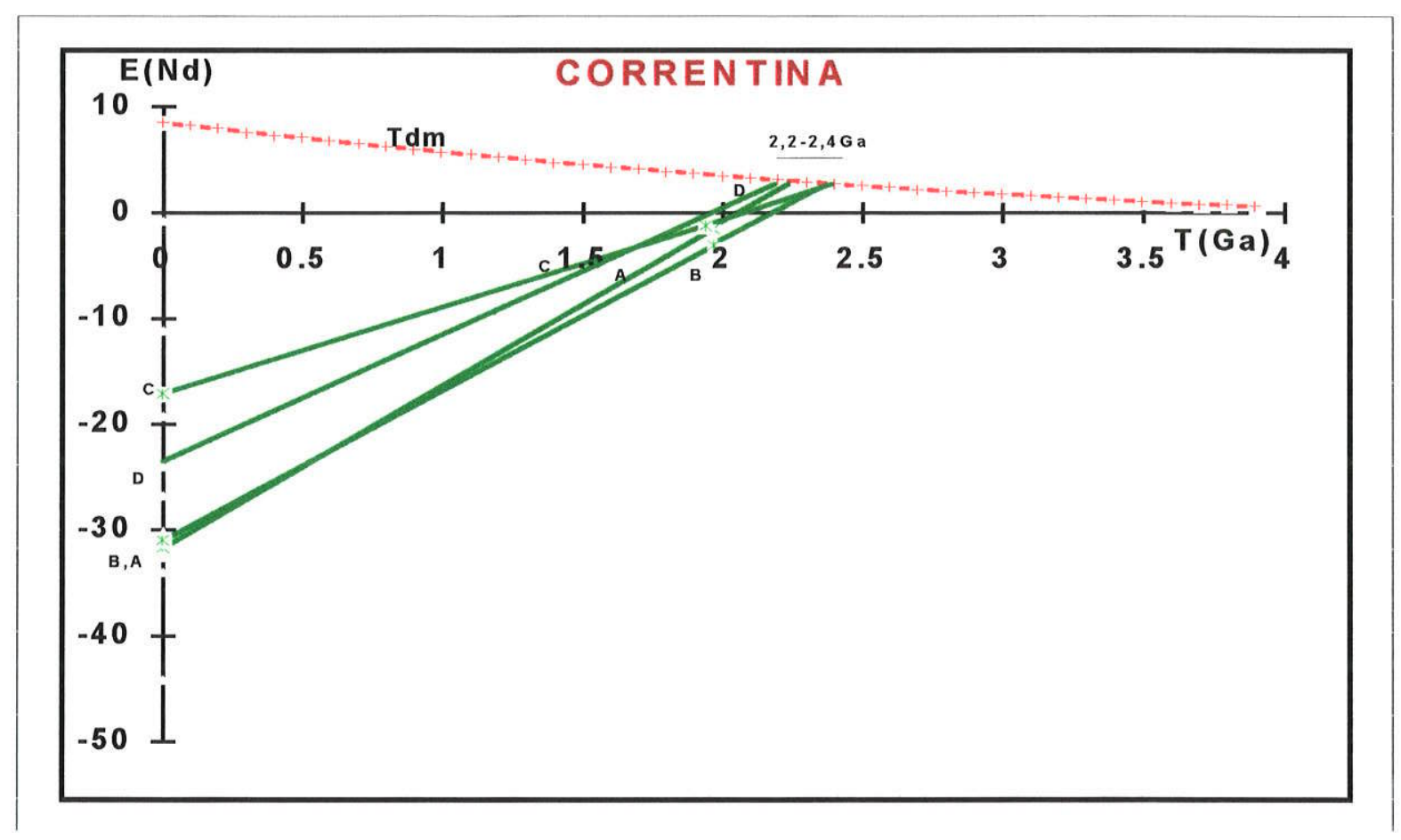

Fig.5.6-21: Diagrama $\varepsilon_{\mathrm{Nd}}(\mathrm{t})$ versus Tempo geológico relativo às rochas da região de Correntina - Mansidão (porção norte-ocidental do Craton). Os dados isotópicos encontram-se na tab.5.6-11. 


\section{6-3: RESUMO PARCIAL DO CRATON DO SÃO FRANCISCO}

Os principais periodos de acreção juvenil, com base nas idades modelo $\mathrm{Sm}-\mathrm{Nd}\left(\mathrm{T}_{\mathrm{DM}}\right)$ no Craton do São Francisco são:

\begin{tabular}{l|l|l}
\hline periodo & $\begin{array}{l}\text { volume } \\
\text { acrescido }\end{array}$ & observação \\
\hline$>2,8 \mathrm{Ga}$ & $82 \%$ & $\begin{array}{l}\text { vários eventos magmáticos juvenis com formação de } \\
\text { TrGs - pico de acreção em 3,1Ga. }\end{array}$ \\
\hline 2,8 a $2,5 \mathrm{Ga}$ & $10 \%$ & $\begin{array}{l}\text { intenso retrabalhamento de material crustal nos terrenos } \\
\text { do Complexo Jequié, Bloco Gavião e região do } \\
\text { Quadrilátero Ferrifero. }\end{array}$ \\
\hline 2,5 a $1,8 \mathrm{Ga}$ & $\sim 6 \%$ & $\begin{array}{l}\text { generalizado retrabalhamento de material crustal no } \\
\text { Ciclo Transamazônico, principalmente na faixa Salvador- } \\
\text { Juazeiro e no Cinturão Mineiro. }\end{array}$ \\
\hline 1,8 a 1,0 & $\sim 2 \%$ & $\begin{array}{l}\text { magmatismo associado a processo extensional em } \\
\text { ambiente intracontinental - região de Espinhaço. }\end{array}$ \\
\hline$<1,0$ & $\sim$ zero & $\begin{array}{l}\text { reativações plataformais; evolução tectono-magmática } \\
\text { associada às de faixas móveis brasilianas nas bordas do } \\
\text { Craton e Espinhaço. }\end{array}$ \\
\hline
\end{tabular}


TAB. 5.6-1: Granitóides de Sete Voltas, Boa Vista e L. do Morro / Complexo Contendas - Mirante

\begin{tabular}{|c|c|c|c|c|c|c|c|c|c|c|c|c|c|c|c|c|c|}
\hline $\begin{array}{l}\text { SPS } \\
\text { / lit. }\end{array}$ & coord. & \begin{tabular}{|l|}
$\begin{array}{l}\text { n. campol } \\
\text { regiāo }\end{array}$ \\
\end{tabular} & \begin{tabular}{|l|} 
litolo \\
gia
\end{tabular} & \begin{tabular}{|l|} 
ident. \\
(diagr.)
\end{tabular} & $T_{\text {chur }}$ & $T_{d m 2}$ & $\begin{array}{l}T_{\mathrm{dm}} \\
\text { DePaolo }\end{array}$ & $\begin{array}{l}{ }^{143} \mathrm{Nd}- \\
{ }^{144} \mathrm{Nd}\end{array}$ & $\begin{array}{l}{ }^{147} \mathrm{Sm}- \\
{ }^{144} \mathrm{Nd} \\
\end{array}$ & $\begin{array}{l}\mathrm{Sm} \\
\mathrm{ppm}\end{array}$ & $\begin{array}{l}\text { Nd } \\
\text { ppm }\end{array}$ & $f$ & $\begin{array}{l}\varepsilon_{\mathrm{Nd}} \\
(0)\end{array}$ & $\begin{array}{l}\varepsilon_{\mathrm{Nd}} \\
(\mathrm{t})\end{array}$ & $\begin{array}{l}t_{\mathrm{Rb} / \mathrm{Sr}} \\
\mathrm{Ri}_{\text {(fonte) }} \\
\end{array}$ & $\begin{array}{l}\varepsilon_{\mathrm{Sr}} \\
(\mathrm{t})\end{array}$ & ref \\
\hline \begin{tabular}{|l}
--- \\
gns \\
\end{tabular} & $1419 / 4053$ & $\begin{array}{l}\text { SVO } 4 \text { I } \\
\text { Sete Voltas }\end{array}$ & GTD & A1 & 3.55 & & 3.67 & 0.510627 & 0.1111 & 4.063 & 22.108 & -.44 & -39.2 & -2.1 & \begin{tabular}{|l|}
3.40 \\
$6997(a)$ \\
\end{tabular} & -11 & 1 \\
\hline gns & $1419 / 4052$ & $\begin{array}{l}\text { SV } 071 \\
\text { Sete Voltas }\end{array}$ & GTD & A2 & 3.46 & & 3.58 & .510441 & .10075 & 4.830 & 28.990 & -.49 & -42.9 & -1.2 & \begin{tabular}{|l|}
3.40 \\
$.6997(\mathrm{a})$ \\
\end{tabular} & -11 & 1 \\
\hline gns & & $\begin{array}{l}\text { SV } 111 \\
\text { Sete Voltas } \\
\end{array}$ & GTD & $A 3$ & 3.57 & & 3.67 & .510078 & .08832 & 6.498 & 44.488 & -.55 & -49.9 & $\mid-2.9$ & \begin{tabular}{|l|}
3.40 \\
$.6997(a)$ \\
\end{tabular} & -11 & 1 \\
\hline gns & & \begin{tabular}{|l|} 
SV 281 \\
Sete Voltas \\
\end{tabular} & GTD & A4 & 3.46 & & 3.56 & .509660 & .06653 & 3.370 & 30.630 & -.66 & \begin{tabular}{|l|}
-58.1 \\
\end{tabular} & -1.6 & \begin{tabular}{|l|}
3.40 \\
$.6997(\mathrm{a})$ \\
\end{tabular} & -11 & 1 \\
\hline gns & $1419 / 4053$ & \begin{tabular}{|l|} 
SV 021 \\
Sete Voltas \\
\end{tabular} & GTD & B1 & 3.58 & & 3.68 & .510102 & .08953 & 4.760 & 32.150 & -.54 & -49.5 & $\mid-6.3$ & \begin{tabular}{|l|}
3.16 \\
$.7017(\mathrm{a})$ \\
\end{tabular} & 14 & 1 \\
\hline gns & & 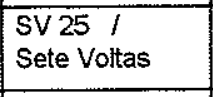 & GTD & B2 & 3.52 & & 3.63 & .510071 & .08661 & 5.588 & 39.015 & -.56 & -50.1 & -5.7 & \begin{tabular}{|l|}
3.16 \\
$.7017(a)$ \\
\end{tabular} & 14 & 1 \\
\hline gnd & $1418 / 4051$ & \begin{tabular}{|l|} 
SV 141 \\
Sete Voltas \\
\end{tabular} & GTD & C1 & 3.40 & & 3.51 & .509875 & .07380 & 3.043 & 24.935 & -.62 & $\mid-53.9$ & -3.7 & \begin{tabular}{|l|}
3.16 \\
$.7014(\mathrm{a})$ \\
\end{tabular} & 9 & 1 \\
\hline gnd & $1419 / 4052$ & 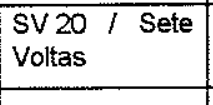 & GTD & $\mathrm{C2}$ & 3.61 & & 3.72 & .510318 & .09950 & 5.680 & 34.520 & -.49 & -45.3 & \begin{tabular}{|l|}
-5.6 \\
\end{tabular} & \begin{tabular}{|l|}
3.16 \\
$.7014(a)$ \\
\end{tabular} & 9 & 1 \\
\hline gtd & $1429 / 4043$ & $\begin{array}{l}\text { AC 1B I I } \\
\text { Boa Vista }\end{array}$ & GTD & & 3.58 & & 3.65 & & & & & & & & $\begin{array}{l}3.38 \\
.7017_{\{\mathrm{b}\}}\end{array}$ & 17 & 2 \\
\hline gtd & $1429 / 4043$ & $\begin{array}{l}31 \\
\text { B.Vista_M.V. }\end{array}$ & GTD & E1 & 3.38 & & 3.49 & .510098 & .08315 & 4.4 & 32.0 & -.58 & -49.5 & -.3 & $\begin{array}{l}3.4^{*} \\
.7008_{(c)}\end{array}$ & 6 & 3 \\
\hline gtd & $1429 / 4043$ & $\begin{array}{l}32 \\
\text { B.Vista_M.V. }\end{array}$ & GTD & E2 & 3.43 & & 3.54 & .510155 & .08720 & 4.6 & 31.9 & -.56 & -48.4 & -.95 & $\begin{array}{l}3.40^{\star} \\
.7008_{(\mathrm{c})} \\
\end{array}$ & 6 & 3 \\
\hline gtd & $1429 / 4043$ & $\begin{array}{l}33 \\
\text { B.Vista_M.V. }\end{array}$ & GTD & E3 & 3.37 & & 3.49 & .510168 & .08593 & 5.4 & 38.0 & -.56 & -48.2 & -.14 & \begin{tabular}{|l|}
$3.4^{*}$ \\
$.7008_{(c)}$ \\
\end{tabular} & 6 & 3 \\
\hline gtd & $1429 / 4043$ & $\begin{array}{l}35 \\
\text { B.Vista_M.V. } \\
\end{array}$ & GTD & E4 & 3.37 & & 3.48 & .510124 & .08393 & 3.9 & 28.1 & -.57 & $\mid-49.0$ & -.13 & $\begin{array}{l}.4^{*} \\
.7008_{(0)} \\
\end{array}$ & 6 & 3 \\
\hline gtd & $1429 / 4043$ & $36, \ldots$. Bista_M.V. & GTD & E5 & 3.40 & & 3.51 & .510141 & .08550 & 5.5 & 38.9 & -.57 & -48.7 & -.48 & $\begin{array}{l}3.4^{*} \\
.7008_{(c)}\end{array}$ & 6 & 3 \\
\hline gid & $1429 / 4043$ & $\begin{array}{l}37 \\
\text { B.Vista_M.V }\end{array}$ & GTD & E6 & 3.47 & & 3.58 & .510135 & .08753 & 10.9 & 75.3 & -.55 & -48.8 & -1.5 & \begin{tabular}{|l}
$3.4^{*}$ \\
$.7008_{(\mathrm{C})}$
\end{tabular} & 6 & 3 \\
\hline
\end{tabular}




\begin{tabular}{|c|c|c|c|c|c|c|c|c|c|c|c|c|c|c|c|c|}
\hline gtd & $1429 / 4043$ & $\begin{array}{l}38 \\
\text { B.Vista_M.V }\end{array}$ & GTD & $E 7$ & 3.07 & 3.21 & .510475 & .09016 & 7.5 & 50.3 & -.54 & -42.2 & 4.0 & $\begin{array}{l}3.4^{\star} \\
.7008_{(c)}\end{array}$ & 6 & 3 \\
\hline & & & & & & & & ¿ & & & & & & & & \\
\hline gtd & $1437 / 4100$ & $\begin{array}{l}\text { MM200 (intr.) } \\
\text { L. do Morro }\end{array}$ & GTD & $F 1$ & 3.48 & 3.60 & .510489 & .10342 & 9.76 & 57.07 & -.47 & -41.9 & -8.1 & \begin{tabular}{|l|}
2.84 \\
$.7041(c)$ \\
\end{tabular} & 42 & 4 \\
\hline gtd & $1437 / 4100$ & $\begin{array}{l}\text { MM210 (intr.) } \\
\text { L. do Morro } \\
\end{array}$ & GTD & $\mathrm{F} 2$ & 3.26 & 3.38 & .510342 & .09001 & 10.94 & 73.5 & -.54 & -44.8 & -6.1 & $\begin{array}{l}2.84 \\
.7041_{(c)}\end{array}$ & 42 & 4 \\
\hline gtd & $1437 / 4100$ & $\begin{array}{l}\text { MM211 (intr.) } \\
\text { L. do Morro }\end{array}$ & GTD & $F 3$ & 3.31 & 3.43 & .510385 & .09377 & 10.49 & 67.65 & -.52 & -43.9 & -6.7 & $\begin{array}{l}2.84 \\
.7041_{(0)} \\
\end{array}$ & 42 & 4 \\
\hline & & & & & & & & & & & & & & & & \\
\hline
\end{tabular}

TAB. 5.6-2: Sequência Vulcano Sedimentar do Complexo Contendas Mirantes

\begin{tabular}{|c|c|c|c|c|c|c|c|c|c|c|c|c|c|c|c|c|c|}
\hline $\begin{array}{l}\text { SPS } \\
/ \text { lit. }\end{array}$ & coord. & $\begin{array}{l}\text { n. campol } \\
\text { região }\end{array}$ & $\begin{array}{l}\text { litolo } \\
\text { gia }\end{array}$ & $\begin{array}{l}\text { ident. } \\
\text { (diagr.) }\end{array}$ & $T_{\text {chur }}$ & $T_{\mathrm{dm} 2}$ & $\mathrm{~T}_{\mathrm{dm}}$ & ${ }^{144} \mathrm{Nd}-$ & \begin{tabular}{|l}
${ }^{147} \mathrm{Sm}-$ \\
${ }^{144} \mathrm{Nd}$
\end{tabular} & $\begin{array}{l}\mathrm{Sm} \\
\mathrm{ppm}\end{array}$ & $\begin{array}{l}\text { Nd } \\
\text { ppm }\end{array}$ & $f$ & $\begin{array}{l}\varepsilon_{\mathrm{Nd}} \\
(0)\end{array}$ & $\begin{array}{l}\varepsilon_{\text {Nd }} \\
(t)\end{array}$ & $\begin{array}{l}t_{\mathrm{Rb} / \mathrm{Sr}} \\
\mathrm{Ri}_{\text {(fonte) }}\end{array}$ & $\begin{array}{l}\varepsilon_{S r} \\
(t)\end{array}$ & ref \\
\hline svulc & $1339 / 4053$ & $\begin{array}{l}42 \mathrm{E} / \mathrm{Barra} \\
\text { Estiva (u.inf.) }\end{array}$ & BAS & G1 & 3.17 & & 3.34 & .511118 & .12416 & 10.8 & 52.6 & -.37 & -29.7 & -9.8 & $\begin{array}{l}2.14 \\
.7457_{(d)} \\
\end{array}$ & 622 & 5 \\
\hline svulc & $1339 / 4053$ & $\begin{array}{l}42 \mathrm{G} / \text { Barra } \\
\text { Estiva (u. inf.) }\end{array}$ & BAS & G2 & 3.31 & & 3.47 & .511079 & .12546 & 11.1 & 53.5 & -.36 & -30.4 & -11 & $\begin{array}{l}2.14 \\
.7457 \text { (d) }\end{array}$ & 622 & 5 \\
\hline & & & & & & & & & & & & & & & & & \\
\hline bif & $1347 / 4044$ & $\begin{array}{l}\text { MM 213C } \\
\text { (unid. inferior) }\end{array}$ & MSE & $\mathrm{H1}$ & 2.81 & & 3.06 & .511546 & .13788 & 1.40 & 6.14 & -.30 & -21.3 & 1.2 & $(3.0)$ & & 4 \\
\hline bif & $1347 / 4044$ & $\begin{array}{l}\text { MM213B (unid. } \\
\text { inferior) }\end{array}$ & MSE & $\mathrm{H} 2$ & 2.77 & & 3.00 & .511442 & .13121 & 1.15 & 5.30 & -.33 & -23.3 & 1.7 & $(3.0)$ & & 4 \\
\hline bif & $1347 / 4044$ & $\begin{array}{l}\text { MM2003E (unid. } \\
\text { inferior) }\end{array}$ & MSE & 11 & 2.65 & & 2.88 & .511372 & .12431 & 1.33 & 6.47 & -.37 & -24.7 & 3.0 & $(3.0)$ & & 4 \\
\hline bif & $1347 / 4044$ & $\begin{array}{l}\mathrm{MM} 230 \mathrm{~B} \\
\text { (unid. inferior) }\end{array}$ & MSE & 12 & 2.81 & & 3.04 & .511391 & .12951 & 1.330 & 6.210 & -.34 & -24.3 & 1.4 & $(3.0)$ & & 4 \\
\hline bif & $1347 / 4044$ & $\begin{array}{l}\text { MM2300 } \\
\text { (unid. inferior) }\end{array}$ & MSE & 13 & 2.89 & & 3.09 & .511213 & .12196 & 2.40 & 11.9 & -.38 & -27.8 & +.8 & $(3.0)$ & & 4 \\
\hline tol & & $\begin{array}{l}\text { MM } 40 \\
\text { (unidade infer.) }\end{array}$ & BAS & J1 & 2.56 & & 2.86 & .511703 & .14134 & 3.45 & 14.76 & -.28 & -18.2 & 2.9 & $(3.0)$ & & 4 \\
\hline$\cdots$ & & MM 6B & BAS & 32 & 2.57 & & 2.84 & .511540 & .13197 & 3.59 & 16.45 & -.33 & -21.4 & 3.4 & $(3.0)$ & & 4 \\
\hline
\end{tabular}




\begin{tabular}{|c|c|c|c|c|c|c|c|c|c|c|c|c|c|c|c|c|c|}
\hline tol & & (unidade infer.) & & & & & & & & & & & & & & & \\
\hline tol & & $\begin{array}{l}\text { MM 6Bbs } \\
\text { (unidade infer.) }\end{array}$ & BAS & J3 & 2.64 & & 2.90 & .511517 & .13241 & 3.81 & 17.4 & -.33 & -21.9 & 2.7 & $(3.0)$ & & 4 \\
\hline tol & & $\begin{array}{l}\text { MM } 8 \\
\text { (unidade infer.) }\end{array}$ & BAS & $J 4$ & 3.12 & & 3.30 & .511197 & .12678 & 5.95 & 28.38 & -.36 & -28.1 & -1.4 & $(3.0)$ & & 4 \\
\hline tol & & $\begin{array}{l}\text { MM 9 } \\
\text { (unidade infer.) }\end{array}$ & BAS & $\sqrt{5}$ & 3.06 & & 3.25 & .511207 & .12592 & 5.82 & 27.95 & -.36 & -27.9 & -.8 & $(3.0)$ & & 4 \\
\hline tol & & $\begin{array}{l}\text { MM 15 } \\
\text { (unidade infer.) }\end{array}$ & BAS & 16 & 2.98 & & 3.19 & .511367 & .13210 & 5.23 & 23.94 & -.33 & -24.8 & -.1 & $(3.0)$ & & 4 \\
\hline--- & & \begin{tabular}{|l|} 
MM 17 \\
(unidade infer.) \\
\end{tabular} & BAS & 37 & 2.76 & & 2.98 & .511269 & .12165 & 5.86 & 29.13 & -.38 & -26.7 & 2.0 & $(3.0)$ & & 4 \\
\hline tol & & $\begin{array}{l}\text { MM } 20 \\
\text { (unidade infer.) }\end{array}$ & BAS & 58 & 3.11 & & 3.29 & .511136 & .12368 & 6.60 & 32.27 & -.37 & -29.3 & -1.4 & $(3.0)$ & & 4 \\
\hline tol & & $\begin{array}{l}\text { MM 21 } \\
\text { (unidade infer.) }\end{array}$ & BAS & J9 & $\ldots$ & $3.8^{\# 2}$ & $-\cdots$ & .511599 & .17339 & 4.41 & 15.38 & -.12 & -20.3 & -11 & $(3.0)$ & & 4 \\
\hline tol & & $\begin{array}{l}\text { MM 22C } \\
\text { (unidade infer.) }\end{array}$ & BAS & 110 & 3.16 & & 3.36 & .511363 & .13573 & 4.68 & 20.85 & -.31 & -24.9 & -1.5 & $(3.0)$ & & 4 \\
\hline tol & & $\begin{array}{l}\text { MM } 23 \\
\text { (unidade infer.) }\end{array}$ & BAS & J11 & 3.25 & & 3.47 & .511622 & .14936 & 7.01 & 28.38 & -.24 & -19.8 & -1.7 & $(3.0)$ & & 4 \\
\hline tol & & $\begin{array}{l}\text { MM 100B } \\
\text { (unidade infer.) }\end{array}$ & BAS & $\mathrm{J} 12$ & 3.05 & & 3.29 & .511632 & .14676 & 8.47 & 34.9 & -.25 & -19.6 & -.5 & $(3.0)$ & & 4 \\
\hline & & & & & & & & & & & & & & & & & \\
\hline mig.m & & $\begin{array}{l}\text { MM } 200 \mathrm{~B} \\
\text { (unid. média) }\end{array}$ & GTD & $\mathrm{K} 1$ & 2.48 & & 2.72 & .511301 & .11507 & 3.92 & 20.6 & -.42 & -26.1 & -5.3 & $\begin{array}{l}2.01 \\
.7032_{(c)} \\
\end{array}$ & 15 & 4 \\
\hline mig.m & & $\begin{array}{l}\text { MM 205A } \\
\text { (unid. média) }\end{array}$ & GTD & $\mathrm{K} 2$ & 2.14 & & 2.39 & .511390 & .10796 & 4.26 & 23.86 & -.45 & -24.3 & -1.7 & \begin{tabular}{|l}
2.01 \\
$.7032(c)$ \\
\end{tabular} & 15 & 4 \\
\hline mig.m & & $\begin{array}{l}\begin{array}{l}\text { MM 2068 } \\
\text { (unid. média) }\end{array} \\
\end{array}$ & GTD & K3 & 2.16 & & 2.45 & .511562 & .12094 & 0.59 & 2.95 & -.39 & -21.0 & -1.7 & \begin{tabular}{|l|}
2.01 \\
$.7032(c)$ \\
\end{tabular} & 15 & 4 \\
\hline mse & $1344 / 4101$ & $\begin{array}{l}\text { MM 1A } \\
\text { (unid.média) }\end{array}$ & MSE & L1 & 2.09 & & 2.37 & .511526 & .11577 & 3.85 & 20.11 & -.41 & -21.7 & 4.1 & $(2.5)$ & & 4 \\
\hline mse & $1344 / 4101$ & $\begin{array}{l}\text { MM } 67 \\
\text { (unid.média) }\end{array}$ & MSE & $L 2$ & 2.40 & & 2.62 & .511189 & .10521 & 4.08 & 23.45 & -.47 & -28.3 & +.9 & $(2.5)$ & & 4 \\
\hline mse & $1344 / 4101$ & $\begin{array}{l}\text { MM } 72 \\
\text { (unid.média) }\end{array}$ & MSE & L.3 & 2.23 & & 2.51 & .511529 & .12104 & 4.70 & 23.48 & -.38 & -21.6 & 2.5 & $(2.5)$ & & 4 \\
\hline mse & $1344 / 4101$ & $\begin{array}{l}\text { MM } 79 \\
\text { (unid.média) }\end{array}$ & MSE & L4 & 2.60 & & 2.82 & .511239 & .11510 & 4.53 & 23.8 & -.41 & -27.3 & -1.3 & $(2.5)$ & & 4 \\
\hline $\begin{array}{l}m \\
\text { mse }\end{array}$ & $1344 / 4101$ & $\begin{array}{l}\text { MM 145 } \\
\text { (unid.média) }\end{array}$ & MSE & L5 & 2.21 & & 2.48 & .511451 & .11510 & 6.23 & 32.73 & -.41 & -23.2 & 2.9 & $(2.5)$ & & 4 \\
\hline
\end{tabular}




\begin{tabular}{|c|c|c|c|c|c|c|c|c|c|c|c|c|c|c|c|}
\hline $\begin{array}{l}-- \\
\text { mse } \\
\end{array}$ & $1344 / 4101$ & $\begin{array}{l}\text { MM 157A } \\
\text { (unid.média) }\end{array}$ & MSE & 16 & 2.23 & 2.49 & .511427 & .11436 & 4.00 & 21.15 & -.42 & -23.6 & 2.6 & $(2.5)$ & 4 \\
\hline & & & & & & & &. & & & & & & & \\
\hline vca & & \begin{tabular}{|l} 
MM 25A \\
(unid.média)
\end{tabular} & VAC & $\overline{\mathrm{M} 1}$ & 3.32 & 3.50 & .511363 & .13860 & 6.31 & 27.53 & -.30 & -24.9 & -6.3 & $(2.5)$ & 4 \\
\hline vca & & $\begin{array}{l}\text { MM } 39 \\
\text { (unid.média) }\end{array}$ & VAC & M2 & 3.15 & 3.36 & .511440 & .13920 & 3.40 & 14.77 & \begin{tabular}{|l|}
-.29 \\
\end{tabular} & -23.4 & -5.0 & $(2.5)$ & 4 \\
\hline vca & & $\begin{array}{l}\text { MM151C } \\
\text { (unid.média) }\end{array}$ & VAC & $\overline{\mathrm{M} 3}$ & 3.12 & 3.34 & .511526 & .14277 & 2.76 & 11.69 & -.27 & -21.7 & -4.5 & $(2.5)$ & 4 \\
\hline vca & & \begin{tabular}{|l} 
MM152C \\
(unid.média) \\
\end{tabular} & VAC & $\overline{M 4}$ & 2.72 & 2.97 & .511556 & .13636 & 4.58 & 20.31 & -.31 & -21.1 & -1.9 & $(2.5)$ & 4 \\
\hline vca & & $\begin{array}{l}\text { MM1588 } \\
\text { (unid.média) } \\
\end{array}$ & VAC & M5 & 3.27 & 3.44 & .511267 & .13322 & 5.62 & 25.51 & -.32 & -26.7 & -6.5 & $(2.5)$ & 4 \\
\hline vca & & \begin{tabular}{|l|l} 
MM 98 \\
(unid.média)
\end{tabular} & VAC & M6 & 3.08 & 3.25 & .510975 & .11503 & 8.45 & 44.42 & \begin{tabular}{|l|}
-.42 \\
\end{tabular} & -32.4 & -6.4 & (25) & 4 \\
\hline & & & & & & & & & & & & & & & \\
\hline
\end{tabular}

TAB. 5.6-3: Granitos intrusivos no Paleo-Proterozóico (Proterozóico Inferior) - Compl. Contendas-Mirante

\begin{tabular}{|c|c|c|c|c|c|c|c|c|c|c|c|c|c|c|c|c|c|}
\hline $\begin{array}{l}\text { SPS } \\
\text { / lit. }\end{array}$ & coord. & $\begin{array}{l}\text { n. campol } \\
\text { região }\end{array}$ & \begin{tabular}{|l|} 
litolo \\
gia
\end{tabular} & $\begin{array}{l}\text { ident. } \\
\text { (diagr.) }\end{array}$ & $T_{\text {chur }}$ & $T_{\mathrm{dm} 2}$ & $T_{\mathrm{dm}}$ & $\begin{array}{l}{ }^{143} \mathrm{Nd}- \\
{ }^{144} \mathrm{Nd}\end{array}$ & $\begin{array}{l}{ }^{147} \mathrm{Sm-} \\
{ }^{144} \mathrm{Nd}\end{array}$ & $\begin{array}{l}\mathrm{Sm} \\
\mathrm{ppm}\end{array}$ & $\begin{array}{l}\mathrm{Nd} \\
\mathrm{ppm}\end{array}$ & $f$ & $\begin{array}{l}\varepsilon_{\mathrm{Nd}} \\
(0)\end{array}$ & $\varepsilon_{\mathrm{Nd}}(\mathrm{t})$ & $\begin{array}{l}t_{R b / S r} \\
R i_{\text {(fonte) }}\end{array}$ & $\begin{array}{l}\varepsilon_{\mathrm{Sr}} \\
(\mathrm{t})\end{array}$ & ref \\
\hline & & & & & & & & & & & & & & & & & \\
\hline grt & & $\begin{array}{l}\text { MM } 30 \text { A / Pé } \\
\text { de Serra }\end{array}$ & GTD & $\mathrm{N} 1$ & 2.94 & & 3.13 & .511226 & .12388 & 9.70 & 47.35 & -.37 & -27.5 & -10.2 & $\begin{array}{l}1.87 \\
.712(c) \\
\end{array}$ & 138 & 4 \\
\hline git & & $\begin{array}{l}\text { MM } 160 / \mathrm{Pe} \\
\text { de Serra }\end{array}$ & GTD & N2 & 2.99 & & 3.18 & .511192 & .12352 & 11.89 & 58.21 & -.37 & -28.2 & -10.8 & $\begin{array}{l}1.87 \\
.712_{(\mathrm{c})} \\
\end{array}$ & 138 & 4 \\
\hline git & & $\begin{array}{l}\text { MM } 11219 / P e ́ \\
\text { de Serra }\end{array}$ & GTD & N3 & 2.93 & & 3.12 & .511170 & .12075 & 12.80 & 64.10 & -.39 & -28.6 & -10.5 & \begin{tabular}{|l|}
1.87 \\
$.712_{(c)}$ \\
\end{tabular} & 138 & 4 \\
\hline grt & & $\begin{array}{l}\text { MM 132/Pé } \\
\text { de Serra }\end{array}$ & GTD & N4 & 2.90 & & 3.11 & .511300 & .12680 & 23.24 & 110.83 & -.36 & -26.1 & -9.4 & $\begin{array}{l}.87 \\
.712_{(G)} \\
\end{array}$ & 138 & 4 \\
\hline & & & & & & & & & & & 2812 & .55 & -36.3 & -9.2 & \begin{tabular}{|l|l}
1.95 & \\
\end{tabular} & 71 & 4 \\
\hline git & & $\begin{array}{l}\text { MM 921 } \\
\text { Gameleira }\end{array}$ & GTD & 01 & 2.59 & & 2.76 & .510779 & .08774 & 4.08 & 28.12 & & & & $.7072_{(c)}$ & & \\
\hline grt & & $\begin{array}{l}\text { MM 95/ } \\
\text { Gameleira }\end{array}$ & GTD & 02 & 2.70 & & 2.87 & .510730 & .08975 & 4.80 & 32.34 & -.54 & -37.2 & -10.6 & $\begin{array}{l}1.95 \\
.707_{(\mathrm{C})}\end{array}$ & 71 & 4 \\
\hline$-\cdots$ & & 112181 & GTD & 03 & 2.54 & & 2.73 & .510869 & .09115 & 4.10 & 27.2 & -.54 & -34.5 & -8.3 & $1.95_{(\mathrm{c})}$ & 71 & 5 \\
\hline
\end{tabular}




\begin{tabular}{|c|c|c|c|c|c|c|c|c|c|c|c|c|c|c|c|c|c|}
\hline grt & & Gameleira & & & & & & & & & & & & & & & \\
\hline & & & & & & & & & & & & & & & & & \\
\hline grt & & $\begin{array}{l}\text { MM } 99 \text { D I } \\
\text { Riacho Pedras }\end{array}$ & GTD & P1 & $-\cdots$ & $3.28^{\# 3}$ & -- & .511612 & .16509 & .86 & 3.15 & -.16 & -20.0 & -12.3 & \begin{tabular}{|l|}
1.91 \\
$.746_{(c)}$
\end{tabular} & 623 & 4 \\
\hline grt & & $\begin{array}{l}\text { MM } 99 \mathrm{HI} \\
\text { Riacho Pedras }\end{array}$ & GTD & P2 & --- & $3.16^{\# 3}$ & -- & .512039 & .19096 & .48 & 1.52 & -.03 & -11.7 & -10.3 & $\begin{array}{l}1.91 \\
.746_{(c)} \\
\end{array}$ & 623 & 4 \\
\hline grt & & $\begin{array}{l}\text { MM } 99 \text { I/ } \\
\text { Riacho Pedras }\end{array}$ & GTD & $\mathrm{P3}$ & $\cdots$ & $2.68^{\# 3}$ & $\cdots$ & .513135 & .25618 & 1.72 & 4.06 & +.3 & +9.7 & -4.8 & $\begin{array}{l}1.91 \\
.746_{(\mathrm{c})}\end{array}$ & 623 & 4 \\
\hline grt & & $\begin{array}{l}11217 / \text { Ricaho } \\
\text { Pedras }\end{array}$ & GTD & P4 & $-\cdots$ & $2.80^{\# 33}$ & $\ldots$ & .511914 & .16465 & .55 & 2.02 & -.16 & -14.1 & -6.3 & $\begin{array}{l}1.91 \\
.746_{(\mathrm{c})}\end{array}$ & 623 & 5 \\
\hline grt & $1349 / 4044$ & $\begin{array}{l}\text { MM 35/Rio } \\
\text { Jacaré }\end{array}$ & GTD & Q1 & 3.07 & $2.90^{\# 1}$ & $3.33 ?$ & .511746 & .15277 & 2.87 & 11.36 & -.22 & -17.4 & -3.4 & $(2.5)$ & & 4 \\
\hline grt & $1349 / 4044$ & $\begin{array}{l}\text { MM 224C' } \\
\text { Rio Jacaré }\end{array}$ & GTD & Q2 & 3.28 & $2.93^{\# 1}$ & $3.53 ?$ & .511848 & .16026 & 1.50 & 5.66 & -.19 & -15.4 & -3.8 & (2.5) & & 4 \\
\hline git & $1349 / 4044$ & $\begin{array}{l}\text { MM } 228 / \text { Rio } \\
\text { Jacaré }\end{array}$ & GTD & Q3 & 3.43 & $3.08^{* 11}$ & $3.61 ?$ & .511504 & .14664 & 2.83 & 11.67 & -.25 & -22.1 & -6.2 & $(2.5)$ & & 4 \\
\hline gtd & $\sim 1435 / 4037$ & $\begin{array}{l}\text { GO9HC-BC I } \\
\text { Lagoinha }\end{array}$ & GTD & $R$ & 2.61 & $2.55^{\# 1}$ & $2.90 ?$ & .51169 & .14167 & 4.1 & 17.5 & -.28 & -18.5 & -4.5 & $\begin{array}{l}1.97 \\
.7072_{(d)} \\
\end{array}$ & 71 & 6 \\
\hline gtd & $\sim 1430 / 4040$ & $\begin{array}{l}\mathrm{G} 58 \mathrm{HC} / \\
\text { Lagoa Grande }\end{array}$ & GTD & $S$ & 2.53 & & 2.73 & .510970 & .09691 & 2.5 & 15.6 & -.51 & -32.5 & -7.1 & \begin{tabular}{|l|}
1.97 \\
$.7072_{(\mathrm{d})}$ \\
\end{tabular} & 71 & 6 \\
\hline gtd & $\sim 1421 / 4043$ & $\begin{array}{l}\text { CAE 2I } \\
\text { Caetano }\end{array}$ & GTD & $T$ & 2.31 & & 2.52 & .510990 & .08863 & 1.47 & 10.03 & -.55 & -32.1 & -4.6 & $\begin{array}{l}(2.0) \\
\end{array}$ & & 6 \\
\hline & & & & & & & & & & & & & & & & & \\
\hline
\end{tabular}

Ver nota explicativa da tabela no apêndice 1.

Ref. : Idades modelos recalculados para este trabalho a partir dos dados istópicos de $1=$ Martin et al 1996; Sato 1986; $3=$ Wilson $1987 ; 4=$ Marinto 1991; $5=$ dados compilados pelo Marinho et. al 1994 (b); $6=$ Sabaté et. al - 1990. Fonte de referência para coluna t: $a=$ Martin et al 1996; $b=S a t o$ 1986; $c=$ Wilson $1987 ; d=S a b a t e ́$ et al $1990 ;$ idade em entre parêntese $=$ época de cristalização estimada. ${ }^{*}=$ valor médio de $\mathrm{Rb}-\mathrm{Sr}, \mathrm{U}-\mathrm{Pb}$ e $\mathrm{Pb}-\mathrm{Pb}$

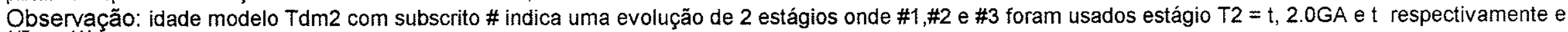
${ }^{147} \mathrm{Sm} /{ }^{144} \mathrm{Nd}_{\mathrm{T} 2}=.100, .100$ e .125 respectivamente.

TAB. 5.6-4: Bloco do Gavião e região de Jacobina

\begin{tabular}{|c|c|c|c|c|c|c|c|c|c|c|c|c|c|c|c|c|c|}
\hline $\begin{array}{l}\text { SPS } \\
\text { / lit. }\end{array}$ & coord. & $\begin{array}{l}\text { n. campol } \\
\text { regiäo }\end{array}$ & \begin{tabular}{|l|} 
litolo- \\
gia
\end{tabular} & \begin{tabular}{|l|} 
ident. \\
(diagr.)
\end{tabular} & $T_{\text {chur }}$ & $T_{d m 2}$ & $T_{d m}$ & $\begin{array}{l}{ }^{143} \mathrm{Nd}- \\
{ }^{144} \mathrm{Nd}\end{array}$ & $\begin{array}{l}{ }^{147} \mathrm{Sm}- \\
{ }^{144} \mathrm{Nd}\end{array}$ & $\begin{array}{l}\text { Sm } \\
\mathrm{ppm}\end{array}$ & $\begin{array}{l}\text { Nd } \\
\text { ppm }\end{array}$ & f & $\begin{array}{l}\varepsilon_{\mathrm{Nd}} \\
(0)\end{array}$ & $\begin{array}{l}\varepsilon_{\mathrm{Nd}} \\
(\mathrm{t})\end{array}$ & \begin{tabular}{|l}
$\mathrm{t}_{\mathrm{Rb} / \mathrm{Sr}}$ \\
$\mathrm{Ri}_{\text {(fonte) }}$ \\
\end{tabular} & $\begin{array}{l}\varepsilon_{\mathrm{Sr}} \\
(\mathrm{t})\end{array}$ & ref \\
\hline $291 /$ & $1057 / 4030$ & $\begin{array}{l}\mathrm{JB} 378 \mathrm{C} / 1 \\
\text { Jacobina }\end{array}$ & GTD & $A$ & $3.99 ?$ & & $4.09 ?$ & .510805 & .12742 & 1.774 & 8.419 & -.35 & -35.8 & $\mid-9.2$ & $3.0 \mathrm{conv}$ & & nt \\
\hline
\end{tabular}




\begin{tabular}{|c|c|c|c|c|c|c|c|c|c|c|c|c|c|c|c|c|c|}
\hline gns & & & & & .04 & & .05 & .000024 & .00010 & .001 & .004 & & & & & & \\
\hline $\begin{array}{l}\text { 291a } \\
\text { gns }\end{array}$ & idem & $\begin{array}{l}\mathrm{JB378C} / \\
\text { repet. química }\end{array}$ & GTD & A1 & $\begin{array}{l}3.99 ? \\
.07\end{array}$ & $3.67^{\# 1}$ & $\begin{array}{l}4.09 ? \\
.07 \\
\end{array}$ & $\begin{array}{l}.510810 \\
.000030\end{array}$ & $\begin{array}{l}.12749 \\
.00009 \\
\end{array}$ & $\begin{array}{l}1.728 \\
.001 \\
\end{array}$ & $\begin{array}{l}8.196 \\
.003 \\
\end{array}$ & -.35 & -35.7 & -9.2 & $3.0_{\text {conv }}$ & & $\mathrm{nt}$ \\
\hline $\begin{array}{l}330 / \\
\text { gns }\end{array}$ & $1057 / 4030$ & $\begin{array}{l}\text { JB 378 E / } \\
\text { Jacobina }\end{array}$ & GTD & $B$ & $\begin{array}{l}2.68 \\
.03 \\
\end{array}$ & & \begin{tabular}{|l|}
2.87 \\
.03 \\
\end{tabular} & $\begin{array}{l}.511038 \\
.000020 \\
\end{array}$ & $\begin{array}{l}.10616 \\
.00005 \\
\end{array}$ & $\begin{array}{l}4.385 \\
.001 \\
\end{array}$ & $\begin{array}{l}24.978 \\
.010 \\
\end{array}$ & -.46 & -31.2 & +5.6 & $3.19_{\mathrm{conv}}$ & & nt \\
\hline $\begin{array}{l}327 / \\
\mathrm{mig}\end{array}$ & $1114 / 4035$ & $\begin{array}{l}\text { BA-82-38-1/ } \\
\text { Jacobina }\end{array}$ & GTD & $C$ & $\begin{array}{l}3.25 \\
.04 \\
\end{array}$ & & $\begin{array}{l}3.37 \\
.04 \\
\end{array}$ & $\begin{array}{l}.510209 \\
.000028 \\
\end{array}$ & $\begin{array}{l}.08359 \\
.00004 \\
\end{array}$ & $\begin{array}{l}.773 \\
.001 \\
\end{array}$ & \begin{tabular}{|l|}
5.592 \\
.002 \\
\end{tabular} & -.58 & -47.4 & -5.5 & $\begin{array}{l}2.90 \\
.7036_{(\mathrm{a})} \\
\end{array}$ & 36 & nt \\
\hline $\begin{array}{l}328 / \\
\mathrm{mig}\end{array}$ & $1143 / 4042$ & $\begin{array}{l}\text { G-6I } \\
\text { Jacobina }\end{array}$ & GTD & $D$ & $\begin{array}{l}3.15 \\
.05 \\
\end{array}$ & & $\begin{array}{l}3.29 \\
.05 \\
\end{array}$ & $\begin{array}{l}.510601 \\
.000031 \\
\end{array}$ & $\begin{array}{l}.09891 \\
.00005 \\
\end{array}$ & $\begin{array}{l}11.92 \\
.003\end{array}$ & $\begin{array}{l}72.888 \\
.028 \\
\end{array}$ & -.50 & -39.7 & -3.3 & $\begin{array}{l}2.92 \\
.7109_{(\mathrm{a})} \\
\end{array}$ & 141 & nt \\
\hline $\begin{array}{l}329 / \\
\mathrm{mig}\end{array}$ & $1146 / 4040$ & $\begin{array}{l}G-9 / \\
\text { Jacobina }\end{array}$ & GTD & $E$ & 3.33 & & 3.46 & $\begin{array}{l}.510363 \\
.000027 \\
\end{array}$ & $\begin{array}{l}.09351 \\
.00005 \\
\end{array}$ & $\begin{array}{l}2.756 \\
.001 \\
\end{array}$ & $\begin{array}{l}17.823 \\
.007 \\
\end{array}$ & -.52 & -44.4 & -5.9 & \begin{tabular}{|l|}
2.92 \\
$.7109_{(\mathrm{a})}$ \\
\end{tabular} & 141 & nt \\
\hline $\begin{array}{l}275 \\
\text { gns }\end{array}$ & - & $\begin{array}{l}\text { BRJC178B I } \\
\text { Brumado } \\
\end{array}$ & GTD & 1 & $\begin{array}{l}3.46 \\
.05 \\
\end{array}$ & & $\begin{array}{l}3.59 \\
.05 \\
\end{array}$ & $\begin{array}{l}.510702 \\
.000030\end{array}$ & $\begin{array}{l}.11215 \\
.00008 \\
\end{array}$ & $\begin{array}{l}3.698 \\
.001 \\
\end{array}$ & $\begin{array}{l}19.939 \\
.013\end{array}$ & -.43 & -37.8 & -7.1 & $\begin{array}{l}2.84 \\
.706_{(\mathrm{b})}\end{array}$ & 69 & 1 \\
\hline $\begin{array}{l}\text { gns } \\
274 \\
\end{array}$ & - & $\begin{array}{l}\text { BRJC } 11 \mathrm{HI} \\
\text { sul-Brumado }\end{array}$ & GTD & $J$ & $\begin{array}{l}3.14 \\
.03 \\
\end{array}$ & & $\begin{array}{l}3.26 \\
.03 \\
\end{array}$ & $\begin{array}{l}.510115 \\
.000024 \\
\end{array}$ & $\begin{array}{l}.07496 \\
.00006 \\
\end{array}$ & $\begin{array}{l}4.802 \\
.002 \\
\end{array}$ & $\begin{array}{l}38.737 \\
.026 \\
\end{array}$ & -.62 & -49.2 & -5.1 & $\begin{array}{l}2.84 \\
.706_{(\mathrm{b})} \\
\end{array}$ & 69 & 1 \\
\hline $\begin{array}{c}\text { gns } \\
276 \\
\end{array}$ & - & \begin{tabular}{|l|} 
BRJC $300 /$ \\
Brumado
\end{tabular} & GTD & $\mathrm{K}$ & $\begin{array}{l}3.10 \\
.04 \\
\end{array}$ & & $\begin{array}{l}3.24 \\
.04 \\
\end{array}$ & $\begin{array}{l}.510540 \\
.000030 \\
\end{array}$ & $\begin{array}{l}.09428 \\
.00006 \\
\end{array}$ & $\begin{array}{l}2.851 \\
.001 \\
\end{array}$ & \begin{tabular}{|l|}
18.287 \\
.010 \\
\end{tabular} & -.52 & -40.9 & -3.8 & $\begin{array}{l}2.84 \\
.706_{(\mathrm{b})} \\
\end{array}$ & 69 & 1 \\
\hline $\begin{array}{l}169 / \\
\mathrm{grt}\end{array}$ & $1415 / 41\} 6$ & $\begin{array}{l}\mathrm{AC}-3 \mathrm{EI} \\
\text { este-Brumado }\end{array}$ & GTD & $L$ & $\begin{array}{l}3.29 \\
.05 \\
\end{array}$ & & $\begin{array}{l}3.42 \\
.05\end{array}$ & $\begin{array}{l}.510432 \\
.000030 \\
\end{array}$ & $\begin{array}{l}.09528 \\
.00008 \\
\end{array}$ & $\begin{array}{l}4.390 \\
.002 \\
\end{array}$ & \begin{tabular}{|l|}
27.862 \\
.019 \\
\end{tabular} & -.52 & -43.0 & -8.2 & $\begin{array}{l}2.69 \\
.7053_{(a)} \\
\end{array}$ & 57 & nt \\
\hline $\begin{array}{r}\text { grt } \\
418 \\
\end{array}$ & - & $\begin{array}{l}\text { BRJC } 300 / \\
\text { Brumado }\end{array}$ & GTD & $M$ & $\begin{array}{l}2.49 \\
.05 \\
\end{array}$ & & $\begin{array}{l}2.71 \\
.04 \\
\end{array}$ & $\begin{array}{l}.511214 \\
.000028 \\
\end{array}$ & $\begin{array}{l}.11005 \\
.00007 \\
\end{array}$ & $\begin{array}{l}14.73 \\
.007 \\
\end{array}$ & \begin{tabular}{|l|}
80.945 \\
.033 \\
\end{tabular} & -.44 & -27.8 & -6.1 & $\begin{array}{l}1.96 \\
.7084_{(b)} \\
\end{array}$ & 88 & 1 \\
\hline $\begin{array}{l}423 \\
\text { grt }\end{array}$ & - & $\begin{array}{l}\text { BRJC } 234 / \\
\text { oeste.Brumad }\end{array}$ & GTD & $N$ & $\begin{array}{l}2.57 \\
.06 \\
\end{array}$ & & $\begin{array}{l}2.76 \\
.05 \\
\end{array}$ & $\begin{array}{l}.510944 \\
.000037 \\
\end{array}$ & $\begin{array}{l}.09679 \\
.00007 \\
\end{array}$ & $\begin{array}{l}30.05 \\
.02 \\
\end{array}$ & $\begin{array}{l}187.73 . \\
103 \\
\end{array}$ & -.51 & -33.0 & -11 & $\begin{array}{l}1.73 \\
.7145_{(b)} \\
\end{array}$ & 171 & 1 \\
\hline $\begin{array}{l}\text { grt } \\
424\end{array}$ & - & \begin{tabular}{|l|} 
BRJC 304 I \\
norte. Brumado
\end{tabular} & GTD & 0 & $\begin{array}{l}3.28 \\
.05 \\
\end{array}$ & & $\begin{array}{l}3.43 \\
.05 \\
\end{array}$ & $\begin{array}{l}.510963 \\
.000025 \\
\end{array}$ & $\begin{array}{l}.11947 \\
.00006 \\
\end{array}$ & \begin{tabular}{|l|}
10.97 \\
.003 \\
\end{tabular} & $\begin{array}{l}55.506 \\
.022 \\
\end{array}$ & -.39 & -32.7 & -15 & $\begin{array}{l}1.75 \\
.758_{(\mathrm{b})} \\
\end{array}$ & 790 & 1 \\
\hline $\begin{array}{l}420 \\
\mathrm{mba}\end{array}$ & - & $\begin{array}{l}\text { BRJC 479J } \\
\text { Brumado }\end{array}$ & BAS & $Q$ & $\begin{array}{l}2.82 \\
.08\end{array}$ & & $\begin{array}{l}3.10 \\
.08 \\
\end{array}$ & $\begin{array}{l}.511754 \\
.000026 \\
\end{array}$ & $\begin{array}{l}.14913 \\
.00009 \\
\end{array}$ & $\begin{array}{l}2.932 \\
.001 \\
\end{array}$ & $\begin{array}{l}11.889 \\
.006 \\
\end{array}$ & -.24 & $\mid-17.2$ & -9.9 & $(1.21)$ & & 1 \\
\hline
\end{tabular}

Ref : nt = neste trabalho. Idades modelos recalculados para este trabalho a partir dos dados istópicos de $1=$ Bastos Leal 1995.

Ronte

Fonte bibliográfica para coluna t: a 


\begin{tabular}{|c|c|c|c|c|c|c|c|c|c|c|c|c|c|c|c|c|}
\hline char & \begin{tabular}{|l|} 
MM $138 /$ \\
Maracás
\end{tabular} & GNL & F2 & 3.24 & & 3.42 & .511211 & .13016 & 29.69 & 137.93 & -.34 & -27.8 & -3.7 & \begin{tabular}{|l|}
$(2.84)$ \\
$(.7066)_{\mathrm{m}}$
\end{tabular} & $(77)$ & 2 \\
\hline char & $\begin{array}{l}\text { MM 140A } \\
\text { Maracás }\end{array}$ & GNL & F3 & 3.00 & & 3.21 & .511382 & .13335 & 15.43 & 69.97 & -.32 & -24.5 & -1.6 & $\begin{array}{l}(2.84) \\
(.7066)_{\mathrm{m}}\end{array}$ & (77) & 2 \\
\hline char & $\begin{array}{l}\text { MM 170/ } \\
\text { Maracás }\end{array}$ & GNL & F4 & 3.08 & & 3.26 & .511163 & .12410 & 19.06 & 92.87 & -.37 & -28.8 & -2.5 & $\begin{array}{l}(2.84) \\
(.7066)_{m}\end{array}$ & (77) & 2 \\
\hline gn! & $\begin{array}{l}\text { RP O21 } \\
\text { Rio_Piau }\end{array}$ & GNL & G1 & 3.21 & & 3.38 & .511224 & .13000 & 4.07 & 25.5 & -.34 & -27.6 & -2.7 & $\begin{array}{l}2.92_{\text {(c) }} \\
\text { isócrsmind }\end{array}$ & & 3 \\
\hline gn! & $\begin{array}{l}\text { RP 15I } \\
\text { Rio_Piau }\end{array}$ & GNL & G2 & $3.33 ?$ & $3.28^{\# 1}$ & $3.51 ?$ & .511391 & .14000 & 4.07 & 25.5 & -.29 & -24.3 & -3.2 & \begin{tabular}{|l|l|}
$2.92_{\text {(c) }}$ \\
isócrsmNd
\end{tabular} & & 3 \\
\hline gni & $\begin{array}{l}\text { RP 181 } \\
\text { Rio_Piau }\end{array}$ & GNL & G3 & 3.08 & $3.10^{\#-1}$ & $3.30 ?$ & .511484 & .14000 & 4.07 & 25.5 & -.29 & -22.5 & -1.4 & $\begin{array}{l}2.92_{\text {(c) }} \\
\text { isócrsmid }\end{array}$ & & 3 \\
\hline
\end{tabular}

TAB. 5.6-7: Rochas supra-crutais metamorfoseado no fácie granulito - Complexo Jequié

\begin{tabular}{|c|c|c|c|c|c|c|c|c|c|c|c|c|c|c|c|c|c|}
\hline $\begin{array}{l}\text { SPS } \\
\text { /lit. }\end{array}$ & coord.I & $\begin{array}{l}\text { n. campol } \\
\text { região }\end{array}$ & $\begin{array}{l}\text { litolo } \\
\text { gia }\end{array}$ & \begin{tabular}{|l|} 
ident. \\
(diagr.)
\end{tabular} & $T_{\text {chur }}$ & $T_{\mathrm{dm} 2}$ & $T_{d m}$ & $\begin{array}{l}{ }^{143} \mathrm{Nd}- \\
{ }^{144} \mathrm{Nd}\end{array}$ & $\begin{array}{l}{ }^{147} \mathrm{Sm}- \\
{ }^{144} \mathrm{Nd}\end{array}$ & $\begin{array}{l}\mathrm{Sm} \\
\mathrm{ppm}\end{array}$ & $\begin{array}{l}\text { Nd } \\
\mathrm{ppm}\end{array}$ & $f$ & $\begin{array}{l}\varepsilon_{\mathrm{Nd}} \\
(0)\end{array}$ & $\begin{array}{l}\varepsilon_{\mathrm{Nd}} \\
(\mathrm{t})\end{array}$ & \begin{tabular}{|l|}
$t_{\mathrm{Rb} / \mathrm{Sr}}$ \\
$\mathrm{Ri}_{\text {(fonte) }}$
\end{tabular} & $\begin{array}{l}\varepsilon_{\mathrm{Sr}} \\
(\mathrm{t})\end{array}$ & ref \\
\hline$\overline{g n l}$ & & 17A / Jequié & GNL & $\mathrm{H}$ & 2.41 & $2.73^{\# 2}$ & 2.59 & .510714 & .07559 & 7.0 & 56.0 & -.62 & -37.5 & $\frac{119}{-5.2}$ & $\begin{array}{l}2.09 \\
.7297_{(b)}\end{array}$ & 394 & 1 \\
\hline$\overline{a n}$ & & $17 \mathrm{D} /$ Jequié & GNL. & $\pi$ & 2.73 & $3.01^{\# 2}$ & 2.89 & .510680 & .08788 & 4.2 & 28.9 & -.55 & -38.2 & -9.2 & \begin{tabular}{|l|}
2.09 \\
$.7297_{(b)}$
\end{tabular} & 394 & 1 \\
\hline gn! & & \begin{tabular}{|l}
$16 \mathrm{~B} /$ \\
Eng.França
\end{tabular} & GNL & $J$ & 3.34 & & 3.48 & .510878 & .11695 & 12.3 & 63.6 & -.41 & -34.3 & -6.9 & $\begin{array}{l}2.70 \\
.7194_{(b)} \\
\end{array}$ & 252 & 1 \\
\hline gnim & & $\begin{array}{l}\text { 12E3PJRO9/ } \\
\text { Jequié }\end{array}$ & GNL & $\mathrm{K}$ & 3.15 & & 3.32 & .511082 & .12189 & 9.53 & 47.28 & -.38 & \begin{tabular}{|l|}
-30.4 \\
\end{tabular} & -11 & $(2.0)$ & & $2^{*}$ \\
\hline gnim & & $\begin{array}{l}\text { 12ळ3PJR10 I } \\
\text { Jitaúna }\end{array}$ & GNL & L & 3.32 & $2.81^{\text {m1 }}$ & $3.53 ?$ & .511586 & .14877 & 4.33 & 17.6 & -.24 & -20.5 & -8.3 & (2.0) & & $2^{*}$ \\
\hline \begin{tabular}{|l|} 
gnlm \\
gnlm \\
\end{tabular} & & $\begin{array}{l}\text { 12জ3 PJR11/ } \\
\text { Ipiaú }\end{array}$ & GNL & $M$ & 2.08 & $2.29^{\# 1-1}$ & $3.08 ?$ & .512461 & .18378 & 3.72 & 12.24 & -.07 & -3.5 & -.2 & $(2.0)$ & & $2^{\star}$ \\
\hline gnim & & $\begin{array}{l}1263 \text { PJRO4/ } \\
\text { Eng. França }\end{array}$ & GNL & $N$ & 3.11 & $2.85^{\# 1}$ & $3.31 ?$ & .511386 & \begin{tabular}{|l}
.13579 \\
\end{tabular} & 5.03 & 22.4 & -.31 & \begin{tabular}{|l|}
-24.4 \\
\end{tabular} & -8.9 & $(2.0)$ & & $2^{\star}$ \\
\hline grt & & $\begin{array}{l}\text { 1263 PJROS/ } \\
\text { Santa Inês }\end{array}$ & GTD & 0 & 3.03 & & 3.19 & .510733 & .10160 & 4.8 & 28.57 & -.48 & -37.2 & 12.9 & $(2.0)$ & & $2^{\star}$ \\
\hline
\end{tabular}

Ref.: $\mathrm{nt}=$ neste trabalho. Idades modelos recalculados para este trabalho a partir dos dados istópicos de $: 1=$ Wilson $1987 ; 2=$ Marinho $1991 ; 2^{*}=$ dados compilados pelo Marinho 1994(a); $3=$ Vignol 1987.

Fonte bibliográfica para coluna $t: b=$ Wilson $1987 ; c=$ Vignol 1987; m=média de 9 isócronas compilado no trabalho de Mascarenhas et. al 1989; idade em entre parêntese = época de cristalização

estimada.
Observação : Tdm2 com sobrescrito \#1 indicam um modelo de 2 estágios com $T 2=t \mathrm{e}^{147} \mathrm{Sm} /{ }^{144} \mathrm{Nd}_{\mathrm{T} 2}=.100$ 
TAB. 5.6-5: Complexo granulítico de Jequié

\begin{tabular}{|l|l|l|l|l|l|l|l|l|l|}
\hline no campo & coordenadas & & litologia & $\begin{array}{l}T_{\text {chur }} \\
(\mathrm{GA})\end{array}$ & $\begin{array}{l}T_{\text {DM-Sm/Nd }} \\
(\mathrm{GA})\end{array}$ & $\begin{array}{l}T_{\text {DM-Rb/Sr }} \\
(\mathrm{GA})\end{array}$ & $\begin{array}{l}\text { isócrona } \\
\text { Rb-Sr }\end{array}$ & $\begin{array}{l}\text { Razão } \\
\text { inicial }\end{array}$ & Referência \\
\hline JM/BA 3C & $13^{\circ} 11^{\prime} / 39^{\circ} 30^{\prime}$ & & granulito & 2.97 & 3.09 & 3.20 & $2.78_{(a)}$ & .7045 & Sato 1986 \\
\hline JM/BA 244C & $14^{\circ} 04^{\prime} / 40^{\circ} 13^{\prime}$ & & granulito & 2.93 & 3.11 & 3.12 & $2.71_{(\text {a) }}$ & .712 & Sato 1986 \\
\hline JM/BA 206 & $13^{\circ} 15^{\prime} / 39^{\circ} 30^{\prime}$ & & granulito & 2.72 & 2.86 & 2.95 & $2.79_{(a)}$ & .7035 & Sato 1986 \\
\hline JM/BA 214C & $13^{\circ} 21^{\prime} / 39^{\circ} 22^{\prime}$ & & granulito & 2.68 & 2.81 & 2.88 & $2.044_{(a)}$ & .7093 & Sato 1986 \\
\hline
\end{tabular}

Observações: amostras de Sm e Nd analisadas em Oxford / Inglaterra; subscrito (a) = dados de Mascarenhas et. al \{989; os dados isotópicos de Nde de $\mathrm{Sm}$ não sāo disponiveis.

\section{TAB. 5.6-6: - Complexo granulítico de Jequié}

\begin{tabular}{|c|c|c|c|c|c|c|c|c|c|c|c|c|c|c|c|c|c|}
\hline $\begin{array}{l}\text { SPS } \\
\text { /lit. }\end{array}$ & coord. & $\begin{array}{l}\text { n. campo/ } \\
\text { regiäo }\end{array}$ & $\begin{array}{l}\text { litolo } \\
\text { gia }\end{array}$ & $\begin{array}{l}\text { ident. } \\
\text { (diagr.) }\end{array}$ & $T_{\text {chur }}$ & $T_{\mathrm{dm} 2}$ & $T_{d m 4}$ & ${ }^{144} \mathrm{Nd}-$ & ${ }^{144} \mathrm{Sm}-$ & $\begin{array}{l}\text { Sm } \\
\text { ppm }\end{array}$ & $\begin{array}{l}\text { Nd } \\
\text { ppm }\end{array}$ & $f$ & $\begin{array}{l}\varepsilon_{\mathrm{Nd}} \\
(0)\end{array}$ & $\begin{array}{l}\varepsilon_{\text {Nd }} \\
(t)\end{array}$ & $\begin{array}{l}t_{\text {Rb/Sr }} \\
R i_{\text {fonte) }}\end{array}$ & $\begin{array}{l}\varepsilon_{\text {sr }} \\
(t)\end{array}$ & ref \\
\hline $\begin{array}{l}116 \\
\text { char }\end{array}$ & $12^{\circ} 25^{\prime} / 40^{\circ} 12^{\prime}$ & $\begin{array}{l}\mathrm{MJ} 303 \mathrm{~A} / \\
\text { Itaberaba }\end{array}$ & GNL & A & $\begin{array}{r}2.84 \\
\pm .06 \\
\end{array}$ & & $\begin{array}{r}3.02 \\
\pm .06 \\
\end{array}$ & $\begin{array}{l}0.510982 \\
\pm .000033 \\
\end{array}$ & $\begin{array}{l}0.10831 \\
\pm .00013 \\
\end{array}$ & $\begin{array}{r}1.639 \\
\pm .001 \\
\end{array}$ & $\begin{array}{r}9.151 \\
\pm .009 \\
\end{array}$ & -.45 & -32.3 & -8.6 & $(2.1)$ & & nt \\
\hline $\begin{array}{l}497 \\
a t x\end{array}$ & $12^{\circ} 26^{\prime} / 40^{\circ} 30^{\prime}$ & $\begin{array}{l}2-101-4 \text { I } \\
\text { Itaberaba }\end{array}$ & GTD & $\mathrm{B}$ & $\begin{array}{l}2.84 \\
.03 \\
\end{array}$ & & $\begin{array}{l}2.99 \\
.03 \\
\end{array}$ & $\begin{array}{l}.510655 \\
.000024 \\
\end{array}$ & $\begin{array}{l}.09078 \\
.00009 \\
\end{array}$ & \begin{tabular}{|l|}
1.161 \\
.001 \\
\end{tabular} & $\begin{array}{l}7.734 \\
.003 \\
\end{array}$ & -.54 & -38.7 & 10.3 & $(2.1)$ & & nt \\
\hline char & & $\begin{array}{l}\text { 1/Mutuípe- } \\
\text { Laje }\end{array}$ & GNL & C1 & 2.77 & & 2.96 & .511042 & .10942 & 1.9 & 10.5 & -.44 & -31.1 & +1.5 & $\begin{array}{l}2.93 \\
.702(b) \\
\end{array}$ & 13 & 1 \\
\hline char & & $\begin{array}{l}/ \text { Mutuípe - } \\
\text { Laje }\end{array}$ & GNL & $\mathrm{C2}$ & 2.83 & & 2.99 & .510635 & .08966 & 9.0 & 60.7 & -.54 & -39.1 & +.9 & $\begin{array}{l}2.93 \\
.702_{(b)}\end{array}$ & 13 & 1 \\
\hline char & & \begin{tabular}{|l}
$6 /$ Mutuipe - \\
Laje \\
\end{tabular} & GNL & C3 & 2.84 & & 3.02 & .511032 & .11103 & 12.1 & 65.9 & -.44 & -31.3 & +.7 & $\begin{array}{l}2.93 \\
.702_{(\mathrm{b})}\end{array}$ & 13 & 1 \\
\hline char & & $\begin{array}{l}10 / \text { Mutuípe - } \\
\text { Laje }\end{array}$ & GNL & $\mathrm{C4}$ & 2.86 & & 3.04 & .511049 & .11254 & 6.7 & 36.0 & -.43 & -31.0 & +.5 & $\begin{array}{l}2.93 \\
.702_{(b)} \\
\end{array}$ & 13 & 1 \\
\hline $\begin{array}{l}-- \\
\text { char }\end{array}$ & & $\begin{array}{l}13 / \text { Mutuípe - } \\
\text { Laje }\end{array}$ & GNL & C5 & 2.92 & & 3.08 & .510847 & .10366 & 1.8 & 10.5 & -.47 & -34.9 & -.2 & $\begin{array}{l}2.93 \\
.702_{(b)} \\
\end{array}$ & 13 & 1 \\
\hline char & & $\begin{array}{l}21 / \text { Mutípe - } \\
\text { Laje }\end{array}$ & GNL & C6 & 2.73 & & 2.91 & .511021 & .10679 & 15.7 & 88.9 & -.46 & -31.5 & 2.1 & $\begin{array}{l}2.93 \\
.702_{(b)} \\
\end{array}$ & 13 & 1 \\
\hline char & & $\begin{array}{l}14 / \text { Mutuípe - } \\
\text { Laje }\end{array}$ & GNL & C7 & 2.88 & & 3.06 & .511091 & .11527 & 11.8 & 61.9 & -.41 & -30.2 & .3 & $\begin{array}{l}2.93 \\
.702_{(\mathrm{b})} \\
\end{array}$ & 13 & 1 \\
\hline char & & $\begin{array}{l}23 \mathrm{~A} / \text { Mutuípe } \\
\text { - Laje }\end{array}$ & GNL & $\mathrm{CB}$ & 2.74 & & 2.92 & .510920 & .10173 & 10.7 & 63.6 & -.48 & -33.5 & 2.0 & $\begin{array}{l}2.93 \\
.702_{(b)} \\
\end{array}$ & 13 & 1 \\
\hline char & & $\begin{array}{l}\text { MM 137/ } \\
\text { Maracás }\end{array}$ & GNL & F1 & 3.00 & & 3.18 & .511198 & .12390 & 21.76 & 106.2 & -.37 & -28.1 & -1.7 & $\begin{array}{l}(2.84) \\
(.7066)_{\mathrm{m}}\end{array}$ & $(77)$ & 2 \\
\hline
\end{tabular}


TAB. 5.6-8: Regiōes de Lagoa Real, Riacho de Santana, norte de Macaúbas e Guanambi

\begin{tabular}{|c|c|c|c|c|c|c|c|c|c|c|c|c|c|c|c|c|c|}
\hline $\begin{array}{l}\text { SPS } \\
\text { /lit }\end{array}$ & coord. & $\begin{array}{l}\text { n. campol } \\
\text { região }\end{array}$ & $\begin{array}{l}\text { litolo } \\
\text { gia }\end{array}$ & $\begin{array}{l}\text { ident. } \\
\text { (diagr.) }\end{array}$ & $\mathrm{T}_{\text {chur }}$ & $T_{\mathrm{dm} 2}$ & $T_{d m}$ & $\begin{array}{l}{ }^{143} \mathrm{Nd}- \\
{ }^{144} \mathrm{Nd}\end{array}$ & ${ }^{144} \mathrm{Sm}-$ & $\begin{array}{l}\text { Sm } \\
\text { ppm }\end{array}$ & $\begin{array}{l}\text { Nd } \\
\text { ppm }\end{array}$ & $f$ & $\begin{array}{l}\varepsilon_{\mathrm{Nd}} \\
(0)\end{array}$ & $\begin{array}{l}\varepsilon_{N d} \\
(t)\end{array}$ & $\begin{array}{l}t_{\mathrm{Rb} / \mathrm{Sr}} \\
\mathrm{Ri} \mathrm{i}_{\text {(fonte) }}\end{array}$ & $\begin{array}{l}\varepsilon_{\mathrm{Sr}_{\mathrm{r}}} \\
(\mathrm{t})\end{array}$ & ref \\
\hline $\begin{array}{l}371 \\
\text { gnl }\end{array}$ & $1237 / 4247$ & $\begin{array}{l}\text { PEW59/ norte } \\
\text { Macaúbas }\end{array}$ & GTD & $A$ & $\begin{array}{l}2.67 \\
.05 \\
\end{array}$ & & $\begin{array}{l}2.88 \\
.03 \\
\end{array}$ & $\begin{array}{l}.511208 \\
.000024 \\
\end{array}$ & $\begin{array}{l}.11540 \\
.00007 \\
\end{array}$ & $\begin{array}{l}13.47 \\
.005 \\
\end{array}$ & $\begin{array}{l}70.579 \\
.032 \\
\end{array}$ & -.41 & -27.9 & .1 & $2.70_{(\mathrm{conv})}$ & & nt \\
\hline $\begin{array}{l}69 \\
\text { gns }\end{array}$ & $1335 / 4259$ & $\begin{array}{l}\mathrm{BA}-46 / \text { Ria- } \\
\text { de Santana }\end{array}$ & GTD & $B$ & $\begin{array}{l}2.89 \\
.05 \\
\end{array}$ & & $\begin{array}{l}3.08 \\
.05 \\
\end{array}$ & $\begin{array}{l}.511035 \\
.000027 \\
\end{array}$ & $\begin{array}{l}.11283 \\
.00006 \\
\end{array}$ & \begin{tabular}{|l|}
7.989 \\
.003 \\
\end{tabular} & $\begin{array}{l}42.817 \\
.016 \\
\end{array}$ & -.43 & -31.3 & -2.5 & $\begin{array}{l}2.69 \\
.7053_{(a)} \\
\end{array}$ & 57 & nt \\
\hline $\begin{array}{l}417 \\
\text { gns }\end{array}$ & -... & $\begin{array}{l}\text { BR WP } 12 \mathrm{~A} / \\
\text { R.Santana }\end{array}$ & GTD & C & $\begin{array}{l}2.85 \\
.03\end{array}$ & & $\begin{array}{l}3.00 \\
.03 \\
\end{array}$ & $\begin{array}{l}.510430 \\
.000021 \\
\end{array}$ & $\begin{array}{l}.07938 \\
.00004 \\
\end{array}$ & $\begin{array}{l}5.387 \\
.002 \\
\end{array}$ & \begin{tabular}{|l|}
41.035 \\
.017 \\
\end{tabular} & -.60 & -43.1 & -.6 & $(2.84)$ & & 1 \\
\hline $\begin{array}{l}\text { gns } \\
324 \\
\end{array}$ & $1349 / 4219$ & $\begin{array}{l}\text { FEN-83.50-84. } \\
\text { Lagoa Real }\end{array}$ & GTD & $D$ & $\begin{array}{l}2.59 \\
.07 \\
\end{array}$ & & $\begin{array}{l}2.80 \\
.05 \\
\end{array}$ & $\begin{array}{l}.511226 \\
.000037 \\
\end{array}$ & $\begin{array}{l}.11397 \\
.00006 \\
\end{array}$ & $\begin{array}{l}26.38 \\
.006 \\
\end{array}$ & \begin{tabular}{|l|}
139.98 \\
.06 \\
\end{tabular} & -.42 & -27.5 & -12 & $\begin{array}{l}1.52 \\
.722_{(\mathrm{b})} \\
\end{array}$ & 275 & nt \\
\hline $\begin{array}{l}\text { gns } \\
326\end{array}$ & $1347 / 4242$ & $\begin{array}{l}\text { LR-2OD / } \\
\text { Lagoa Real }\end{array}$ & GTD & $E$ & $\begin{array}{l}2.64 \\
.09 \\
\end{array}$ & & $\begin{array}{l}2.84 \\
.07 \\
\end{array}$ & $\begin{array}{l}.511119 \\
.000049 \\
\end{array}$ & $\begin{array}{l}.10956 \\
.00006 \\
\end{array}$ & \begin{tabular}{|l|}
4.800 \\
.001 \\
\end{tabular} & $\begin{array}{l}26.492 \\
.012 \\
\end{array}$ & -.44 & -29.6 & .4 & $\begin{array}{l}2.70 \\
.706_{(b)}\end{array}$ & 67 & $n t$ \\
\hline $\begin{array}{l}\text { gns } \\
325 \\
\end{array}$ & $1354 / 4220$ & $\begin{array}{l}\text { LRA66.-66.50/ } \\
\text { Lagoa Real }\end{array}$ & GTD & $F$ & $\begin{array}{l}2.54 \\
.05 \\
\end{array}$ & & $\begin{array}{l}2.76 \\
.04 \\
\end{array}$ & $\begin{array}{l}.511295 \\
.000024 \\
\end{array}$ & $\begin{array}{l}.11639 \\
.00021 \\
\end{array}$ & \begin{tabular}{|l|}
15.83 \\
.028 \\
\end{tabular} & \begin{tabular}{|l|}
82.218 \\
.033 \\
\end{tabular} & -.41 & -26.2 & -16 & $\begin{array}{l}1.03 \\
.7229_{(b)} \\
\end{array}$ & 279 & nt \\
\hline $\begin{array}{l}323 \\
\text { gns }\end{array}$ & $1357 / 4220$ & $\begin{array}{l}\text { GSWB28-1/ } \\
\text { Lagoa Real }\end{array}$ & GTD & $G$ & $\begin{array}{l}2.42 \\
.05 \\
\end{array}$ & & $\begin{array}{l}2.67 \\
.04 \\
\end{array}$ & \begin{tabular}{|l|}
.511398 \\
.000025 \\
\end{tabular} & \begin{tabular}{|l|}
.11903 \\
.00187 \\
\end{tabular} & $\begin{array}{l}55.11 \\
.09 \\
\end{array}$ & \begin{tabular}{|l|}
279.98 \\
.011 \\
\end{tabular} & -.39 & -24.2 & -7.3 & \begin{tabular}{|l|}
1.71 \\
$.7225_{(b)}$ \\
\end{tabular} & 285 & nt \\
\hline $\begin{array}{l}492 \\
\text { gns }\end{array}$ & $1346 / 4224$ & $\begin{array}{l}\text { PEMLWB22/ } \\
\text { Lagoa Real }\end{array}$ & GTD & $\mathrm{H}$ & \begin{tabular}{|l|}
2.71 \\
.04 \\
\end{tabular} & & $\begin{array}{l}2.91 \\
.03 \\
\end{array}$ & $\begin{array}{l}.511119 \\
.000022 \\
\end{array}$ & $\begin{array}{l}.11166 \\
.00005 \\
\end{array}$ & 13.11 & \begin{tabular}{|l|}
70.983 \\
.028 \\
\end{tabular} & -.43 & -29.6 & -11 & $\begin{array}{l}1.71 \\
.7135_{(\mathrm{b})} \\
\end{array}$ & 156 & nt \\
\hline \multirow[t]{2}{*}{$\begin{array}{l}182 \\
\text { sie }\end{array}$} & $1412 / 4258$ & $\begin{array}{l}\text { JM BA 611/ } \\
\text { Guanambi }\end{array}$ & GTD & 1 & $\begin{array}{l}2.96 \\
.06 \\
\end{array}$ & & $\begin{array}{l}3.10 \\
.06 \\
\end{array}$ & $\begin{array}{l}.510483 \\
.000036 \\
\end{array}$ & \begin{tabular}{|l|}
.08645 \\
.00129 \\
\end{tabular} & \begin{tabular}{|l|}
56.09 \\
.18 \\
\end{tabular} & $\begin{array}{l}392.36 \\
5.7 \\
\end{array}$ & -.56 & -42 & -15 & $\begin{array}{l}1.95 \\
.7062_{(a)} \\
\end{array}$ & 56 & $n t$ \\
\hline & supra - & crustais & & & & & & & & & & & & & & & \\
\hline $\begin{array}{l}123 \\
\text { bas }\end{array}$ & $1224 / 4224$ & $\begin{array}{l}\mathrm{JM} B A 43 \mathrm{C} / \\
\text { nort Mabaúbas }\end{array}$ & BAS & $J$ & $\begin{array}{l}1.63 \\
.13 \\
\end{array}$ & & $\begin{array}{l}2.27 \\
.08 \\
\end{array}$ & $\begin{array}{l}.512245 \\
.000032 \\
\end{array}$ & \begin{tabular}{|l}
.15993 \\
.00010 \\
\end{tabular} & $\begin{array}{l}2.600 \\
.001 \\
\end{array}$ & \begin{tabular}{|l|}
9.831 \\
.005 \\
\end{tabular} & -.19 & -7.7 & -4.5 & $0.68_{\text {KIAr }}$ & & $\mathrm{nt}$ \\
\hline $\begin{array}{l}168 \\
\text { dia }\end{array}$ & $1407 / 4247$ & $\begin{array}{l}\text { GSWB61.21 } \\
\text { Guanambi }\end{array}$ & BAS & $\mathrm{K}$ & $\begin{array}{l}1.10 \\
.08 \\
\end{array}$ & & $\begin{array}{l}1.69 \\
.05 \\
\end{array}$ & $\begin{array}{l}.512238 \\
.000028 \\
\end{array}$ & $\begin{array}{l}.14119 \\
.00012 \\
\end{array}$ & $\begin{array}{l}4.468 \\
.002 \\
\end{array}$ & $\begin{array}{l}19.136 \\
.013 \\
\end{array}$ & -.28 & -7.8 & +3.5 & $1.60_{\text {KAA }}$ & & nt \\
\hline \begin{tabular}{|l|}
277 \\
bas \\
\end{tabular} & .......... & $\begin{array}{l}\text { WPR116/ } \\
\text { Riach.Santana }\end{array}$ & BAS & $L$ & $-\cdots$ & & \begin{tabular}{|l|}
2.18 \\
.18 \\
\end{tabular} & $\begin{array}{l}.512746 \\
.000035 \\
\end{array}$ & $\begin{array}{l}.19296 \\
.00014 \\
\end{array}$ & $\begin{array}{l}2.587 \\
.001 \\
\end{array}$ & $\begin{array}{l}8.107 \\
.005 \\
\end{array}$ & -.02 & 2.1 & 3.1 & $(2.0)$ & & nt \\
\hline $\begin{array}{l}500 \\
\text { vulfe }\end{array}$ & - & $\begin{array}{l}\text { WPR } 208 \\
\text { Riach.Santana }\end{array}$ & VAC & $M$ & $\begin{array}{l}2.56 \\
.05\end{array}$ & & $\begin{array}{l}2.74 \\
.04 \\
\end{array}$ & $\begin{array}{l}.510805 \\
.000039 \\
\end{array}$ & $\begin{array}{l}.08809 \\
.00009 \\
\end{array}$ & \begin{tabular}{|l}
16.35 \\
.011 \\
\end{tabular} & $\begin{array}{l}112.27 \\
.081 \\
\end{array}$ & -.55 & -36 & -8.0 & $(2.0)$ & & $n t$ \\
\hline
\end{tabular}

Ver nota explicativa da tabela no apêndice 1 .

Ref.: $\mathrm{nt}=$ neste trabalho; 1 = idades modelos recalculados para este trabalho a partir dos dados isotópicos $1=$ Bastos Leal 1995.

Fonte bibliográfica para coluna t: a = Mascarenhas e Garcia 1989; $b=$ Cordani et. al 1992; idade em entre parêntese = época de cristalização estimada; conv $=$ idade convencional com ri $=.705$.

Observação: Idade Modelo Tdm2 com sobrescrito $\# 1$ indica uma evolução de 2 estágios com $T 2=\mathrm{t} e{ }^{147} \mathrm{Sm}^{144} \mathrm{Nd}_{\mathrm{T} 2}=.100$. 
TAB. 5.6-9A: Sul do C.S.F - Complexo Bonfim (CB), Complexo Campo Belo (CCB), Complexo B. Horizonte (CBH) e CINTURÃO MINEIRO (CM)

\begin{tabular}{|c|c|c|c|c|c|c|c|c|c|c|c|c|c|c|c|c|c|}
\hline $\begin{array}{l}\text { SPS } \\
/ \text { lit. }\end{array}$ & $\begin{array}{l}\text { coord.l } \\
\text { (p.local.) }\end{array}$ & $\begin{array}{l}\text { n. campo/ } \\
\text { regiāo }\end{array}$ & $\begin{array}{l}\text { litolo } \\
\text { gia }\end{array}$ & $\begin{array}{l}\text { ident. } \\
\text { (diagr.) }\end{array}$ & $T_{\text {chur }}$ & $T_{\mathrm{dm} 2}$ & $T_{d m}$ & ${ }^{144} \mathrm{Nd}-$ & $\begin{array}{l}{ }^{147} \mathrm{Sm}- \\
{ }^{144} \mathrm{Nd}\end{array}$ & $\begin{array}{l}\text { Sm } \\
\text { ppm }\end{array}$ & $\begin{array}{l}\text { Nd } \\
\text { ppm }\end{array}$ & $f$ & $\begin{array}{l}\varepsilon_{\mathrm{Nd}} \\
(0)\end{array}$ & $\begin{array}{l}\varepsilon_{\mathrm{Nd}} \\
(\mathrm{t})\end{array}$ & $\begin{array}{l}t_{\text {método }} \\
\mathbf{R i}_{(\text {)=fonte }} \\
\text { bibl. }\end{array}$ & $\begin{array}{l}\varepsilon_{s r} \\
(t)\end{array}$ & r \\
\hline & & & & & & & & & & & & & & & & & \\
\hline & Complexo & Bonfim & & & & & & & & & & & & & & & \\
\hline $\begin{array}{l}82 / \\
\text { gns }\end{array}$ & $2011 / 4411$ & $\begin{array}{l}\text { 11.1/Aiberto } \\
\text { Flores }\end{array}$ & GTD & $A$ & $\begin{array}{l}2.91 \\
0.05\end{array}$ & & $\begin{array}{l}3.12 \\
.05\end{array}$ & $\begin{array}{l}.511291 \\
.000025\end{array}$ & $\begin{array}{l}.12667 \\
.00012\end{array}$ & $\begin{array}{l}1.888 \\
.001\end{array}$ & $\begin{array}{l}9.013 \\
.007\end{array}$ & -.36 & -26.3 & $\begin{array}{l}-5.8 \\
-1.5 \\
-1.5 \\
\end{array}$ & $\begin{array}{l}2.29_{\mathrm{Rb} / \mathrm{Sr}} \\
\mathrm{ri}=.707_{(a)} \\
2.78_{\mathrm{U} / \mathrm{Pb}(\mathrm{i})}\end{array}$ & 74 & 1 \\
\hline $\begin{array}{l}83 / \\
\text { gns }\end{array}$ & $2010 / 4406$ & \begin{tabular}{|l}
$243-6 /$ Souza \\
Noschece
\end{tabular} & GTD & $\mathrm{B}$ & $\begin{array}{l}2.91 \\
0.10 \\
\end{array}$ & & $\begin{array}{l}3.19 ? \\
0.10\end{array}$ & $\begin{array}{l}.511749 \\
.000030 \\
\end{array}$ & $\begin{array}{l}.15047 \\
.00014 \\
\end{array}$ & $\begin{array}{l}7.066 \\
.003 \\
\end{array}$ & $\begin{array}{l}28.397 \\
.024 \\
\end{array}$ & -.24 & -17.3 & -9.7 & $\begin{array}{l}1.29_{\mathrm{Rb} / \mathrm{St}} \\
\mathrm{ri}=1.006_{(\mathrm{a})}\end{array}$ & \begin{tabular}{|l|}
4310 \\
\end{tabular} & 1 \\
\hline $\begin{array}{l}142 / \\
\text { anf }\end{array}$ & $?$ & $\begin{array}{l}1201 \\
\text { Paraopeba }\end{array}$ & BAS & C & $\begin{array}{l}2.63 \\
0.18 \\
\end{array}$ & & $\begin{array}{l}3.05 ? \\
.10 \\
\end{array}$ & $\begin{array}{l}.512071 \\
.000038 \\
\end{array}$ & $\begin{array}{l}.16399 \\
.00018 \\
\end{array}$ & $\begin{array}{l}4.269 \\
.001 \\
\end{array}$ & $\begin{array}{l}15.742 \\
.017 \\
\end{array}$ & -.17 & -11.1 & -2.0 & $2.16_{\text {K/Ar(a) }}$ & & 1 \\
\hline $\begin{array}{l}721 \\
\text { ton }\end{array}$ & $2013 / 4401$ & $\begin{array}{l}\text { 625F I } \\
\text { Samambaia }\end{array}$ & GTD & $D$ & $\begin{array}{l}2.73 \\
0.05\end{array}$ & & $\begin{array}{l}2.92 \\
.04\end{array}$ & $\begin{array}{l}.511014 \\
.000031\end{array}$ & $\begin{array}{l}.10660 \\
.00019\end{array}$ & $\begin{array}{l}11.83 \\
.006\end{array}$ & $\begin{array}{l}67.123 \\
.113\end{array}$ & -.46 & -31.7 & $\begin{array}{l}-18 \\
-.3 \\
\end{array}$ & $\begin{array}{l}1.19_{\mathrm{Rb} / \mathrm{Sr}} \\
\mathrm{ri}=.7130_{(a)} \\
2.78_{\mathrm{U} / \mathrm{Pb}(\mathrm{i})}\end{array}$ & 140 & 1 \\
\hline $\begin{array}{l}731 \\
\text { ton }\end{array}$ & $2014 / 441$ & $\begin{array}{l}656 \mathrm{C} / \\
\text { Samambaia }\end{array}$ & GTD & $E$ & $\begin{array}{l}2.88 \\
0.08\end{array}$ & & $\begin{array}{l}3.07 \\
0.08\end{array}$ & $\begin{array}{l}.511073 \\
.000043\end{array}$ & $\begin{array}{l}.11451 \\
.00017\end{array}$ & $\begin{array}{l}10.38 \\
.006\end{array}$ & $\begin{array}{l}54.799 \\
.075\end{array}$ & -.42 & -30.5 & $\begin{array}{l}-21 \\
-1.4 \\
\end{array}$ & $\begin{array}{l}1.19_{\mathrm{Rb} / \mathrm{St}} \\
\mathrm{ri}=.7130_{\{\mathrm{a}\}} \\
2.78_{\mathrm{U} / \mathrm{Pb}(\mathrm{i})}\end{array}$ & 140 & 1 \\
\hline $\begin{array}{l}70 / \\
\text { grt }\end{array}$ & $2000 / 4412$ & $\begin{array}{l}11.15 / \\
\text { Brumadinho }\end{array}$ & GTD & $\overline{F 1}$ & $\begin{array}{l}2.74 \\
0.07\end{array}$ & & $\begin{array}{l}2.92 \\
0.06\end{array}$ & $\begin{array}{l}.510976 \\
.000041\end{array}$ & $\begin{array}{l}.10469 \\
.00008\end{array}$ & $\begin{array}{l}2.489 \\
.002\end{array}$ & $\begin{array}{l}14.377 \\
.105\end{array}$ & -.47 & -32.4 & \begin{tabular}{|l|}
-21 \\
-0.7 \\
\end{tabular} & $\begin{array}{l}.98_{\mathrm{Rb} / \mathrm{St}} \\
\mathrm{ri}=.741_{(\mathrm{a})} \\
2.70_{\mathrm{U} / \mathrm{Pb}(\mathrm{i})}\end{array}$ & 535 & 1 \\
\hline $\begin{array}{l}71 / \\
\text { grt } \\
\end{array}$ & $2011 / 4412$ & $\begin{array}{l}1.18 / \\
\text { Brumadinho } \\
\end{array}$ & GTD & $F 2$ & $\begin{array}{l}.90 \\
0.05 \\
\end{array}$ & & $\begin{array}{l}3.08 \\
0.05 \\
\end{array}$ & $\begin{array}{l}.510991 \\
.000028 \\
\end{array}$ & $\begin{array}{l}.11071 \\
.00007 \\
\end{array}$ & $\begin{array}{l}2.802 \\
.001 \\
\end{array}$ & $\begin{array}{l}15.305 \\
.007 \\
\end{array}$ & -.44 & -32.1 & $\begin{array}{l}-2.5 \\
-8.4 \\
\end{array}$ & $\begin{array}{l}2.7_{\text {estimado }} \\
2.16 \\
\end{array}$ & $71_{\text {est }}$ & 1 \\
\hline $\begin{array}{l}346 / \\
\text { grt }\end{array}$ & $2009 / 4405$ & APWT 15G & GTD & $G$ & $\begin{array}{l}2.76 \\
0.04 \\
\end{array}$ & & $\begin{array}{l}2.94 \\
0.03 \\
\end{array}$ & $\begin{array}{l}.510925 \\
.000024 \\
\end{array}$ & $\begin{array}{l}.10263 \\
.00006 \\
\end{array}$ & $\begin{array}{l}2.274 \\
0.001 \\
\end{array}$ & $\begin{array}{l}13.399 \\
0.005 \\
\end{array}$ & -.48 & -33.4 & 1.02 & 2.7 estimado & & 4 \\
\hline & Complexo & Campo & & & Belo & & & & & & & & & & & & \\
\hline & & & & & & & & & & & & & & & & & \\
\hline $\begin{array}{l}105 / \\
\text { gns }\end{array}$ & $2046 / 4527$ & \begin{tabular}{|l|} 
WT $3 /$ Campo \\
Belo
\end{tabular} & GTD & $H$ & $\begin{array}{l}3.01 \\
0.04 \\
\end{array}$ & & $\begin{array}{l}3.18 \\
0.04 \\
\end{array}$ & $\begin{array}{l}.510991 \\
.000023 \\
\end{array}$ & $\begin{array}{l}.11396 \\
.00012 \\
\end{array}$ & $\begin{array}{l}.574 \\
.003 \\
\end{array}$ & $\begin{array}{l}18.964 \\
.011 \\
\end{array}$ & -.42 & -32.1 & -3.6 & $2.7_{\text {estimado }}$ & & 1 \\
\hline $\begin{array}{l}100 / \\
\text { gns }\end{array}$ & $2045 / 4528$ & $\begin{array}{l}\text { WT-4I } \\
\text { Campo Belo }\end{array}$ & GTD & 11 & $\begin{array}{l}2.72 \\
.05\end{array}$ & & $\begin{array}{l}2.89 \\
.04\end{array}$ & $\begin{array}{l}.510700 \\
.000036\end{array}$ & $\begin{array}{l}.08881 \\
.00012\end{array}$ & $\begin{array}{l}4.959 \\
.004\end{array}$ & $\begin{array}{l}33.765 \\
.038\end{array}$ & -.55 & -37.8 & \begin{tabular}{|l|}
+4.9 \\
4.6 \\
\end{tabular} & $\begin{array}{l}3.1_{\mathrm{Rb} / \mathrm{Sr}(\mathrm{a})}{ }^{*} \\
\mathrm{ri}=0.702 \\
3.08_{\mathrm{U} / \mathrm{Pb}(\mathrm{c})}\end{array}$ & 45 & 1 \\
\hline 268 & $2045 / 4528$ & WT-4I & GTD & 12 & 2.71 & & 2.88 & .510714 & .08924 & 3.456 & 23.418 & -.55 & -37.5 & 5.0 & 3. $1_{\mathrm{Rb} / \mathrm{Sr}(a)}{ }^{*}$ & 73 & 4 \\
\hline
\end{tabular}




\begin{tabular}{|c|c|c|c|c|c|c|c|c|c|c|c|c|c|c|c|c|c|}
\hline gns & & Campo Belo & & & .05 & & .04 & .000038 & .00003 & .001 & .005 & & & & $\begin{array}{l}r i=0.706 \\
3.08_{U / P b(c)}\end{array}$ & & \\
\hline $\begin{array}{l}141 / \\
\text { gns }\end{array}$ & $2020 / 4521$ & $\begin{array}{l}\text { SFWT12-1B / } \\
\text { Formiga }\end{array}$ & GTD & $\mathrm{J}$ & $\begin{array}{l}2.83 \\
.06\end{array}$ & & $\begin{array}{l}3.00 \\
.06\end{array}$ & $\begin{array}{l}.510801 \\
.000038\end{array}$ & $\begin{array}{l}.09713 \\
.00014\end{array}$ & $\begin{array}{l}4.134 \\
.001\end{array}$ & $\begin{array}{l}25.375 \\
.036\end{array}$ & -.51 & -35.8 & $\begin{array}{l}3.5 \\
-- \\
3.5 \\
\end{array}$ & $\begin{array}{l}3.1_{\mathrm{Rb} / \mathrm{Sr}(\mathrm{a})}{ }^{*} \\
\mathrm{ri}=0.702 \\
3.10_{\text {U/Pbic) }}\end{array}$ & 45 & 1 \\
\hline $\begin{array}{l}99 / \\
\text { gtd }\end{array}$ & $2047 / 4526$ & $\begin{array}{l}\text { WT 2/ Campo } \\
\text { Belo }\end{array}$ & GTD & $K$ & $\begin{array}{l}.19 \\
.38 \\
\end{array}$ & $2.98^{\# 2}$ & -- & $\begin{array}{l}.512919 \\
.000033 \\
\end{array}$ & $\begin{array}{l}.21004 \\
.00024 \\
\end{array}$ & $\begin{array}{l}2.513 \\
.002 \\
\end{array}$ & $\begin{array}{l}7.235 \\
.006 \\
\end{array}$ & .07 & 5.5 & .5 & $2.9_{\text {est }}$ & & 1 \\
\hline $106 /$ & $2034 / 4526$ & $\begin{array}{l}\text { WTGA I } \\
\text { Formiga }\end{array}$ & GTD & $\mathrm{L}$ & $\begin{array}{l}2.87 \\
.04 \\
\end{array}$ & & \begin{tabular}{|l|}
3.05 \\
.04 \\
\end{tabular} & $\begin{array}{l}.511001 \\
.000024 \\
\end{array}$ & \begin{tabular}{|l|}
.11043 \\
.00010 \\
\end{tabular} & \begin{tabular}{|l|}
1.444 \\
.001 \\
\end{tabular} & $\begin{array}{l}7.907 \\
.005 \\
\end{array}$ & -.44 & -31.9 & 0 & $\begin{array}{l}2.90_{\mathrm{Rb} / \mathrm{Sr}} \\
\mathrm{ri}=.7018_{(\mathrm{a})}\end{array}$ & 10 & 1 \\
\hline $\begin{array}{l}143 / \\
\text { ton }\end{array}$ & $\sim 2026 / 4526$ & \begin{tabular}{|l|} 
WT-8 I \\
Formiga
\end{tabular} & GTD & $M$ & $\begin{array}{l}3.02 \\
.05 \\
\end{array}$ & & $\begin{array}{l}3.19 \\
.05\end{array}$ & $\begin{array}{l}.510902 \\
.000030 \\
\end{array}$ & $\begin{array}{l}.10972 \\
.00003 \\
\end{array}$ & $\begin{array}{l}8.909 \\
.002 \\
\end{array}$ & $\begin{array}{l}49.100 \\
.074 \\
\end{array}$ & -.44 & -33.9 & -1.7 & $\begin{array}{l}2.90_{\mathrm{Rb} / \mathrm{Sr}} \\
\mathrm{ri}=.7018_{(\mathrm{a})}\end{array}$ & 10 & 1 \\
\hline $\begin{array}{l}335 / \\
\text { lep }\end{array}$ & $2032 / 4429$ & $\begin{array}{l}\text { APWT21 DI } \\
\text { "E" C. Belo } \\
\end{array}$ & GTD & $\mathrm{N}$ & $\begin{array}{l}2.86 \\
.04 \\
\end{array}$ & & $\begin{array}{l}3.02 \\
.04\end{array}$ & $\begin{array}{l}.510765 \\
.000025 \\
\end{array}$ & $\begin{array}{l}.09735 \\
.00002 \\
\end{array}$ & $\begin{array}{l}6.263 \\
.001 \\
\end{array}$ & $\begin{array}{l}38.902 \\
.005 \\
\end{array}$ & -.51 & -36.5 & -2.3 & $2.7_{\text {est }}$ & & 4 \\
\hline $\begin{array}{l}489 / \\
\text { gns }\end{array}$ & $2004 / 4516$ & $\begin{array}{l}\text { WT 15021 } \\
\text { Divinópolils }\end{array}$ & GTD & 0 & $\begin{array}{l}2.55 \\
0.03 \\
\end{array}$ & $2.91^{\# 2}$ & $\begin{array}{l}2.71 \\
0.02 \\
\end{array}$ & $\begin{array}{l}.510517 \\
.000021 \\
\end{array}$ & $\begin{array}{l}.07061 \\
.00004 \\
\end{array}$ & $\begin{array}{l}.7021 \\
.002 \\
\end{array}$ & $\begin{array}{l}60.131 \\
.025 \\
\end{array}$ & -.64 & 41.4 & -7.6 & $\begin{array}{l}2.10_{\mathrm{Rb} / \mathrm{sr}} \\
.705_{\mathrm{d}}\end{array}$ & & 2 \\
\hline & & & & & & & & & & & & & & & & & \\
\hline $\begin{array}{l}179 / \\
\text { bas.n }\end{array}$ & $\sim 214 / \sim 4453$ & $\begin{array}{l}55 \text { (dique) } \\
\text { "N" Lavras }\end{array}$ & BAS & P2 & 2.82 & $2.97^{34}$ & 3.12 & $\begin{array}{l}.511789 \\
.000042 \\
\end{array}$ & .15118 & 1.9 & 7.6 & -.23 & -16.6 & -1.8 & $\begin{array}{l}2.54 \mathrm{Rb} / \mathrm{Sr} \\
.70183_{\mathrm{b}}\end{array}$ & 4.7 & 3 \\
\hline $\begin{array}{l}180 / \\
\text { bas.n }\end{array}$ & $\sim 214 / \sim 4453$ & \begin{tabular}{|l|}
64 (dique) \\
"N" Lavras \\
\end{tabular} & BAS & P3 & 2.58 & $2.82^{14}$ & 2.84 & $\begin{array}{l}.511527 \\
.000023 \\
\end{array}$ & .13146 & 2.0 & 9.2 & -.33 & -21.7 & -.5 & $\begin{array}{l}2.54 \mathrm{Rb} / \mathrm{Sr} \\
.70183_{\mathrm{b}}\end{array}$ & 4.7 & 3 \\
\hline $\begin{array}{l}284 / \\
\text { bas.n }\end{array}$ & $-21 / 4 / 4453$ & $\begin{array}{l}54 \text { (dique - } \\
\text { plagioclásio) }\end{array}$ & BAS & P4 & $-\cdots$ & $2.93^{74}$ & -.-- & $\begin{array}{l}.513081 \\
.000028 \\
\end{array}$ & .2188 & $.5 ?$ & 1.5 & .02 & 8.6 & 7.1 & $\begin{array}{l}2.54 \mathrm{Rb} / \mathrm{Sr} \\
.70183_{\mathrm{b}}\end{array}$ & 4.7 & 3 \\
\hline & & & & & & & & & & & & & & & & & \\
\hline \multicolumn{18}{|c|}{ Complexo Belo Horizonte } \\
\hline $\begin{array}{l}197 / \\
\text { gns }\end{array}$ & $\sim 1935 / 4407$ & $\begin{array}{l}\text { MP O8-1E I } \\
\text { S Sete Lagoas }\end{array}$ & GTD & $Q$ & $\begin{array}{l}3.03 \\
.11 \\
\end{array}$ & $3.03^{\# 2}$ & \begin{tabular}{|l|}
$3.31 ?$ \\
.11 \\
\end{tabular} & $\begin{array}{l}.511832 \\
.000029 \\
\end{array}$ & $\begin{array}{l}.15643 \\
.00011 \\
\end{array}$ & $\begin{array}{l}2.354 \\
.001 \\
\end{array}$ & $\begin{array}{l}9.100 \\
.005\end{array}$ & -.20 & -15.7 & -1.3 & $2.8_{\text {est }}$ & & 5 \\
\hline $\begin{array}{l}198 / \\
\text { anf }\end{array}$ & $?$ & M301 & BAS & $\mathrm{R}$ & $\begin{array}{l}2.48 \\
.09 \\
\end{array}$ & & $\begin{array}{l}2.90 \\
.06 \\
\end{array}$ & $\begin{array}{l}.512027 \\
.000023 \\
\end{array}$ & $\begin{array}{l}.15939 \\
.00005 \\
\end{array}$ & $\begin{array}{l}5.108 \\
.001 \\
\end{array}$ & $\begin{array}{l}19.379 \\
.005 \\
\end{array}$ & -.19 & -11.9 & +1.4 & $2.8_{\text {est }}$ & & \\
\hline $\begin{array}{l}256 / \\
\text { gitd }\end{array}$ & $\sim 1948 / 4353$ & \begin{tabular}{|l|} 
N 33-1/ \\
N B. Horizonte
\end{tabular} & GTD & S1 & $\begin{array}{l}2.92 \\
.07\end{array}$ & & $\begin{array}{l}3.10 \\
.07\end{array}$ & $\begin{array}{l}.511028 \\
.000038 \\
\end{array}$ & $\begin{array}{l}.11313 \\
.00001\end{array}$ & $\begin{array}{l}15.00 \\
.001\end{array}$ & $\begin{array}{l}80.191 \\
.005\end{array}$ & -.42 & -31.4 & $\begin{array}{l}-3.5 \\
-0.9 \\
\end{array}$ & $\begin{array}{l}2.62_{\mathrm{Rb} / \mathrm{Sr}} \\
\mathrm{ri}=.7027_{(\mathrm{e})} \\
2.86_{\mathrm{U} / \mathrm{Pb}}(\mathrm{e})\end{array}$ & 18 & 6 \\
\hline $\begin{array}{l}452 / \\
\text { gtd }\end{array}$ & $-1948 / 4353$ & $\begin{array}{l}\text { N 338-R } \\
\text { N B. Horizonte }\end{array}$ & GTD & $\$ 2$ & $\begin{array}{l}2.84 \\
.06\end{array}$ & & 3.01 & $\begin{array}{l}.510849 \\
.000036\end{array}$ & $\begin{array}{l}.10137 \\
.00003\end{array}$ & $\begin{array}{l}3.886 \\
.001\end{array}$ & $\begin{array}{l}23.181 \\
.005\end{array}$ & -.48 & -34.9 & -3.0 & $\begin{array}{l}2.62_{\mathrm{Rb} / \mathrm{Sr}} \\
\mathrm{ri}=.7027_{(\mathrm{e})} \\
2.86_{\mathrm{U} / \mathrm{Pb}(\mathrm{e})}\end{array}$ & 18 & 6 \\
\hline
\end{tabular}




\begin{tabular}{|c|c|c|c|c|c|c|c|c|c|c|c|c|c|c|c|c|c|}
\hline $\begin{array}{l}488 / \\
\text { gns }\end{array}$ & $2024 / 4400$ & $\begin{array}{l}\text { JD 123B } \\
\text { "S" Q.Ferrifero }\end{array}$ & GTD & $\bar{T}$ & $\begin{array}{l}2.81 \\
0.03 \\
\end{array}$ & & $\begin{array}{l}2.99 \\
0.03 \\
\end{array}$ & $\begin{array}{l}.510890 \\
.000017 \\
\end{array}$ & $\begin{array}{l}.10258 \\
.00007 \\
\end{array}$ & $\begin{array}{l}1.984 \\
.001 \\
\end{array}$ & $\begin{array}{l}11.696 \\
.005 \\
\end{array}$ & -.48 & -34.1 & -1.7 & $\begin{array}{l}2.70_{\mathrm{Rb} / \mathrm{Sr}} \\
.704_{\mathrm{C}} \\
\end{array}$ & & 2 \\
\hline & & & & & & & & & 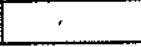 & & & & & & & & \\
\hline \multicolumn{18}{|c|}{\begin{tabular}{|c|c|c|c|c|c|c|}
070 &
\end{tabular}} \\
\hline $\begin{array}{l}255 / \\
\text { gtd }\end{array}$ & $2037 / 4420$ & \begin{tabular}{|l|}
$\mathrm{N}-18 /$ \\
Sul Q.Ferrifero
\end{tabular} & GTD & $U$ & $\begin{array}{l}1.99 \\
.07\end{array}$ & & $\begin{array}{l}2.26 \\
.06\end{array}$ & $\begin{array}{l}.511449 \\
.000043\end{array}$ & $\begin{array}{l}.10573 \\
.00005\end{array}$ & $\begin{array}{l}3.078 \\
.001\end{array}$ & $\begin{array}{l}17.604 \\
.005\end{array}$ & -.46 & -23.2 & $\begin{array}{l}-16 \\
+1,4 \\
\end{array}$ & $\begin{array}{l}0.66_{\mathrm{Rb} / \mathrm{sr}} \\
\mathrm{ri}=.7074 \text { (e) } \\
2.12 \mathrm{U} / \mathrm{Pb}(\mathrm{e})\end{array}$ & 52 & 7 \\
\hline $\begin{array}{l}499 \\
\text { grt }\end{array}$ & $2057 / 4523$ & \begin{tabular}{|l|} 
SFWTO7F I \\
Porto Mendes
\end{tabular} & GTD & $\mathrm{V}$ & $\begin{array}{l}2.42 \\
.06 \\
\end{array}$ & & $\begin{array}{l}2.62 \\
.04 \\
\end{array}$ & $\begin{array}{l}.511031 \\
.000037 \\
\end{array}$ & $\begin{array}{l}.09604 \\
.00003 \\
\end{array}$ & $\begin{array}{l}4.274 \\
.001 \\
\end{array}$ & $\begin{array}{l}26.911 \\
.005 \\
\end{array}$ & -.51 & -31.3 & -3.1 & $\begin{array}{l}2.2 \mathrm{Rb} / \mathrm{Sr} \\
\mathrm{ri}=.702_{(\mathrm{f})}\end{array}$ & 1.3 & 6 \\
\hline $\begin{array}{l}347 \\
\text { ton }\end{array}$ & $2037 / 4401$ & $\begin{array}{l}\text { APWT27FI } \\
\text { C. Lafaiete }\end{array}$ & GTD & $x$ & $\begin{array}{l}2.11 \\
.06 \\
\end{array}$ & & $\begin{array}{l}2.42 \\
.04 \\
\end{array}$ & $\begin{array}{l}.511608 \\
.000029 \\
\end{array}$ & $\begin{array}{l}.12275 \\
.00012 \\
\end{array}$ & $\begin{array}{l}1.223 \\
.001 \\
\end{array}$ & $\begin{array}{l}6.025 \\
.003 \\
\end{array}$ & -.38 & -20.1 & -1.2 & $2.0_{\text {est }}$ & & 4 \\
\hline $\begin{array}{l}582 \\
\text { grt }\end{array}$ & $2057 / 4421$ & $\begin{array}{l}95-01 / \\
\text { "So" C.Lafaiete }\end{array}$ & GTD & $\bar{Y}$ & $\begin{array}{l}3.24 ? \\
.15 \\
\end{array}$ & $2.62^{\# 2}$ & $\begin{array}{l}3.52 ? \\
.15 \\
\end{array}$ & $\begin{array}{l}.511933 \\
.000033 \\
\end{array}$ & $\begin{array}{l}.16381 \\
.00009 \\
\end{array}$ & $\begin{array}{l}.822 \\
.003 \\
\end{array}$ & $\begin{array}{l}28.875 \\
.012 \\
\end{array}$ & -.17 & -13.8 & -5.9 & $\begin{array}{l}1.86 \mathrm{Rb} / \mathrm{Sr} \\
\mathrm{ri}=.7584(\mathrm{~g})\end{array}$ & 793 & 8 \\
\hline $\begin{array}{l}583 \\
\text { grt }\end{array}$ & $2059 / 4419$ & $\begin{array}{l}95-021 \\
\text { "SO" C.Lafaiete }\end{array}$ & GTD & $W$ & $\begin{array}{l}3.04 \\
.08 \\
\end{array}$ & $2.70^{72}$ & \begin{tabular}{|l|}
$3.30 ?$ \\
.08 \\
\end{tabular} & $\begin{array}{l}.511693 \\
.000026 \\
\end{array}$ & $\begin{array}{l}.14972 \\
.00010 \\
\end{array}$ & $\begin{array}{l}11.537 \\
.006 \\
\end{array}$ & $\begin{array}{l}46.598 \\
.023 \\
\end{array}$ & -.24 & -18.4 & -7.3 & $\begin{array}{l}1.86 \\
\mathrm{ri}=.7584(\mathrm{~g})\end{array}$ & 793 & 8 \\
\hline $\begin{array}{l}451 \\
\text { gns }\end{array}$ & $2120 / 4504$ & \begin{tabular}{|l|} 
LAV-1B-R I \\
Lavras \\
\end{tabular} & GTD & $\mathbf{Z}$ & $\begin{array}{l}2.26 \\
.06 \\
\end{array}$ & & $\begin{array}{l}2.49 \\
.04 \\
\end{array}$ & $\begin{array}{l}.511172 \\
.000036 \\
\end{array}$ & $\begin{array}{l}.09837 \\
.00004 \\
\end{array}$ & $\begin{array}{l}3.489 \\
.001 \\
\end{array}$ & $\begin{array}{l}21.448 \\
.005 \\
\end{array}$ & -.50 & -28.6 & -1.8 & $\begin{array}{l}2.14 \mathrm{Rb} / \mathrm{sr} \\
\mathrm{ri}=.703_{(\mathrm{f})}\end{array}$ & 14 & 6 \\
\hline $\begin{array}{l}584 \\
\text { git }\end{array}$ & $2100 / 4438$ & $\begin{array}{l}95-03 / \\
\text { "NE" Lavras }\end{array}$ & GTD & $Z A$ & $\begin{array}{l}2.19 \\
.04 \\
\end{array}$ & & $\begin{array}{l}2.43 \\
.03 \\
\end{array}$ & $\begin{array}{l}.511329 \\
.000023 \\
\end{array}$ & $\begin{array}{l}.10580 \\
.00007 \\
\end{array}$ & \begin{tabular}{|l|}
6.303 \\
.003 \\
\end{tabular} & $\begin{array}{l}36.025 \\
.016 \\
\end{array}$ & -.46 & -25.5 & +6 & $\begin{array}{l}2.25 \mathrm{Rb} / \mathrm{Sr} \\
\mathrm{ri}=.7017_{(\mathrm{q})}\end{array}$ & -1.7 & 8 \\
\hline \multicolumn{18}{|c|}{$\frac{\text { gnt }}{\text { Cinturão Marginal }}$} \\
\hline $\begin{array}{l}585 \\
\text { grt }\end{array}$ & $2119 / 4438$ & $\begin{array}{l}95-04 / \\
\text { "SE" Lavras }\end{array}$ & GTD & $\alpha$ & $\begin{array}{l}3.36 \\
.09 \\
\end{array}$ & $2.85^{\# 2}$ & $\begin{array}{l}3.58 ? \\
.09 \\
\end{array}$ & $\begin{array}{l}.511740 \\
.000024 \\
\end{array}$ & $\begin{array}{l}.15623 \\
.00008 \\
\end{array}$ & $\begin{array}{l}3.085 \\
.001 \\
\end{array}$ & \begin{tabular}{|l|}
11.941 \\
.005 \\
\end{tabular} & -.21 & -17.5 & -6.8 & $\begin{array}{l}2.08 \mathrm{Rb} / \mathrm{Sr} \\
\mathrm{ri}=.7033_{(\mathrm{g})} \\
\end{array}$ & \begin{tabular}{|l|}
17.8 \\
\end{tabular} & 8 \\
\hline $\begin{array}{l}586 \\
g r t\end{array}$ & $2106 / 4343$ & $\begin{array}{l}95-05 / \\
\text { "N" Barbacena }\end{array}$ & GTD & $\beta$ & $\begin{array}{l}2.09 \\
.08 \\
\end{array}$ & & $\begin{array}{l}2.30 \\
.06 \\
\end{array}$ & $\begin{array}{l}.511043 \\
.000060 \\
\end{array}$ & \begin{tabular}{|l|}
.08054 \\
.00006 \\
\end{tabular} & $\begin{array}{l}1.954 \\
.001 \\
\end{array}$ & $\begin{array}{l}14.671 \\
.007 \\
\end{array}$ & -.59 & -31.1 & -1.3 & $\begin{array}{l}2.01 \mathrm{Rb} / \mathrm{Sr} \\
\mathrm{ri}=.7086_{(\mathrm{g})}\end{array}$ & 92 & 8 \\
\hline & & & & & & & & & & & & & & & & & \\
\hline
\end{tabular}


TAB. 5.6-9B : COBERTURAS DE BAMBUÍ

\begin{tabular}{|c|c|c|c|c|c|c|c|c|c|c|c|c|c|c|c|c|c|}
\hline $\begin{array}{l}\text { SPS } \\
/ \text { lit. }\end{array}$ & coord. & $\begin{array}{l}\text { n. campol } \\
\text { região }\end{array}$ & litolo & $\begin{array}{l}\text { ident. } \\
\text { (diagr.) }\end{array}$ & $\mathrm{T}_{\text {chur }}$ & $T_{\mathrm{dm} 2}$ & $\mathrm{~T}_{\mathrm{dm}}$ & $\begin{array}{l}{ }^{143} \mathrm{Nd}- \\
{ }^{144} \mathrm{Nd}\end{array}$ & $\begin{array}{l}{ }^{147} \mathrm{Sm}- \\
{ }^{144} \mathrm{Nd}\end{array}$ & $\begin{array}{l}\text { Sm } \\
\text { ppm }\end{array}$ & $\begin{array}{l}\text { Nd } \\
\mathrm{ppm}\end{array}$ & $f$ & $\begin{array}{l}\varepsilon_{\mathrm{Nd}} \\
(0)\end{array}$ & $\begin{array}{l}\varepsilon_{N d} \\
(t)\end{array}$ & $\begin{array}{l}\mathbf{t}_{\text {método }} \\
\mathrm{Ri}_{\text {refer. bibl. }}\end{array}$ & $\begin{array}{l}\varepsilon_{s r} \\
(t)\end{array}$ & $\begin{array}{l}r \\
e \\
f\end{array}$ \\
\hline $\begin{array}{l}478 \\
\text { re_ca }\end{array}$ & 20714538 & $\begin{array}{l}\text { MF10B } \\
\text { Fm. S. Lagoas }\end{array}$ & MSE & $A$ & $\begin{array}{l}1.67 \\
.06 \\
\end{array}$ & $1.73^{\# 2}$ & $\begin{array}{l}2.14 \\
.04 \\
\end{array}$ & $\begin{array}{l}.512037 \\
.000022 \\
\end{array}$ & $\begin{array}{l}.14194 \\
.00031\end{array}$ & $\begin{array}{l}.469 \\
.001 \\
\end{array}$ & $\begin{array}{l}1.998 \\
.001\end{array}$ & -.28 & -11.7 & -7.7 & $\begin{array}{l}.57 \mathrm{Sm} / \mathrm{Nd} \\
\mathrm{ri}=.51150_{(\mathrm{n})}\end{array}$ & & 9 \\
\hline $\begin{array}{l}483 \\
\text { re_ca }\end{array}$ & $1502 / 4400$ & $\begin{array}{l}\text { MF19A } \\
\text { Fm S. Lagoas }\end{array}$ & MSE & $B$ & $\begin{array}{l}2.28 \\
.50 \\
\end{array}$ & $1.72^{\# 2}$ & $\begin{array}{l}2.77 \\
.29 \\
\end{array}$ & $\begin{array}{l}.512110 \\
.000110 \\
\end{array}$ & $\begin{array}{l}.1615 \\
.0022\end{array}$ & $\begin{array}{l}.222 \\
.003 \\
\end{array}$ & $\begin{array}{l}.831 \\
.001\end{array}$ & -.18 & -10.3 & -7.7 & $\begin{array}{l}.57 \mathrm{Sm} / \mathrm{Nd} \\
\mathrm{ri}=.51150_{(\mathrm{m})}\end{array}$ & & 9 \\
\hline $\begin{array}{l}480 \\
\text { re_ca }\end{array}$ & $1904 / 4419$ & $\begin{array}{l}\text { MF5E8 } \\
\text { Fm. L. Jacaré }\end{array}$ & MSE & $C$ & $\cdots$ & $1.74^{\text {\#2 }}$ & -- & $\begin{array}{l}.512260 \\
.000030 \\
\end{array}$ & $\begin{array}{l}.20360 \\
.00018 \\
\end{array}$ & $\begin{array}{l}1.238 \\
.001 \\
\end{array}$ & $\begin{array}{l}3.677 \\
.001 \\
\end{array}$ & .04 & -7.4 & -7.9 & $\begin{array}{l}.57 \mathrm{Sm}_{\mathrm{No}} \\
\mathrm{rj}=.51150_{\mathrm{fn} 2}\end{array}$ & & 9 \\
\hline $\begin{array}{l}479 \\
\text { re_ma }\end{array}$ & $1916 / 4344$ & $\begin{array}{l}\text { MF12 } \\
\text { Fm. L. Jacaré }\end{array}$ & MSE & D & $\begin{array}{l}1.10 \\
.04\end{array}$ & $1.74^{\# 2}$ & $\begin{array}{l}1.42 \\
.03\end{array}$ & $\begin{array}{l}.511792 \\
.000027 \\
\end{array}$ & $\begin{array}{l}.0796 \\
.0017\end{array}$ & $\begin{array}{l}.139 \\
.003 \\
\end{array}$ & $\begin{array}{l}1.506 \\
.001\end{array}$ & -.60 & -16.5 & -8.0 & $\begin{array}{l}.57 \mathrm{Sm} / \mathrm{Nol} \\
\mathrm{rj}=.51150_{\mathrm{fm}}\end{array}$ & & 9 \\
\hline $\begin{array}{l}476 \\
\text { sil }\end{array}$ & $1730 / 4444$ & $\begin{array}{l}\text { AY3 } \\
\text { Fm. Pirapora }\end{array}$ & MSE & $E$ & $\begin{array}{l}1.12 \\
.06\end{array}$ & & $\begin{array}{l}1.55 \\
.04 \\
\end{array}$ & $\begin{array}{l}.512028 \\
.000030 \\
\end{array}$ & $\begin{array}{l}.13393 \\
.00011\end{array}$ & $\begin{array}{l}9.042 \\
.007\end{array}$ & $\begin{array}{l}47.991 \\
.024 \\
\end{array}$ & -.42 & -11.9 & -5.9 & $\begin{array}{l}.57 \mathrm{sm} / \mathrm{Nd} \\
\mathrm{ri}=.51150_{(\mathrm{m})}\end{array}$ & & 9 \\
\hline $\begin{array}{l}477 \\
\text { sil } \\
\end{array}$ & $1500 / 4352$ & $\begin{array}{l}\text { CYG } \\
\text { Fm. Pirapora }\end{array}$ & MSE & $F$ & $\begin{array}{l}1.81 \\
.12 \\
\end{array}$ & $1.61^{\# 2}$ & $\begin{array}{l}2.39 \\
.07 \\
\end{array}$ & $\begin{array}{l}.512179 \\
.000029 \\
\end{array}$ & $\begin{array}{l}.15822 \\
.00017 \\
\end{array}$ & $\begin{array}{l}8.849 \\
.008 \\
\end{array}$ & $\begin{array}{l}33.82 \\
.02 \\
\end{array}$ & -.20 & -9.0 & -6.2 & $.506_{\mathrm{Sm} / \mathrm{Nd}}$ & & 9 \\
\hline $\begin{array}{l}475 \\
\text { sil }\end{array}$ & $1842 / 4445$ & $\begin{array}{l}\text { BX10 } \\
\text { Fm. Três Maria }\end{array}$ & MSE & $G$ & $\begin{array}{l}1.11 \\
.05\end{array}$ & & $\begin{array}{l}1.53 \\
.04 \\
\end{array}$ & $\begin{array}{l}.512028 \\
.000025\end{array}$ & $\begin{array}{l}.11263 \\
.00021\end{array}$ & $\begin{array}{l}7.498 \\
.013\end{array}$ & $\begin{array}{l}40.256 \\
.021\end{array}$ & -.43 & -11.9 & -5.8 & $.506_{\mathrm{Sm} / \mathrm{Nd}}$ & & 9 \\
\hline
\end{tabular}

ver nota explicativa da tabela no apêndice 1.

Ref : Idades modelos recalculados para este trabalho a partir dos dados istópicos de: $1=$ Teixeira et al $1996,2=n e s t e$ trabalho $3=$ Pinese et. al $1995 ; 4=$

Teixeira, dados inéditos; $5=$ Carneiro, dados inéditos; $6=$ Noce e Teixeira, dados inéditos; $7=$ Noce $1995 ; 8=$ Souza Martins $1997 ; 9=$ Kawashita 1996 .

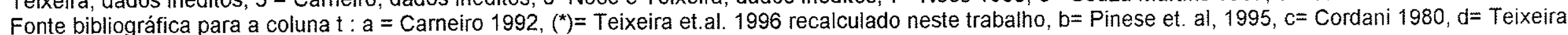
1982 $\mathrm{e}=$ Noce 1995, $\mathrm{f}=$ Teixeira 1985, $\mathrm{g}=$ Souza Martins 1997, $\mathrm{h}=$ Kawashita 1996, (i)= Machado e Carneiro 1992.

$\# 1->\mathrm{T} 2=\mathrm{t}, \# 3=\mathrm{T} 2=2.8^{147} \mathrm{Sm} /{ }^{144} \mathrm{Nd}=.1 ; \# 2->\mathrm{T} 2=\mathrm{t}, \# 4-->\mathrm{T} 2=2.83 \mathrm{com}{ }^{147} \mathrm{Sm} /{ }^{144} \mathrm{Nd}=.11$

TAB. 5.6-10A: Região norte-oriental do CSF (Serrinha, Rio Capim e faixa móvel Salvador-Juazeiro)

\begin{tabular}{|c|c|c|c|c|c|c|c|c|c|c|c|c|c|c|c|c|c|}
\hline $\begin{array}{l}\text { SPS } \\
\text { I lit. }\end{array}$ & $\begin{array}{l}\text { coord. } \\
\text { (p.local.) }\end{array}$ & $\begin{array}{l}\text { n. campol } \\
\text { região }\end{array}$ & $\begin{array}{l}\text { litolo } \\
\text { gia }\end{array}$ & \begin{tabular}{|l|} 
ident. \\
(diagr.)
\end{tabular} & $T_{\text {chur }}$ & $T_{\mathrm{dm} 2}$ & $T_{\mathrm{dm}}$ & $\begin{array}{l}{ }^{143} \mathrm{Nd}- \\
\mathrm{Nd}\end{array}$ & $\begin{array}{l}{ }^{147} \mathrm{Sm}- \\
\mathrm{Nd}\end{array}$ & $\begin{array}{l}\text { Sm } \\
\text { ppm }\end{array}$ & $\begin{array}{l}\text { Nd } \\
\text { ppm }\end{array}$ & $f$ & $\begin{array}{l}\varepsilon_{\mathrm{Nd}} \\
(0)\end{array}$ & $\varepsilon_{\mathrm{Nd}}(t)$ & $\begin{array}{l}t_{\text {Rb/sr }} \\
\mathrm{Ri}_{\text {(fonte) }}\end{array}$ & $\begin{array}{l}\varepsilon_{\mathrm{sr}} \\
(\mathrm{t})\end{array}$ & ref \\
\hline $\begin{array}{l}170 / \\
\text { chgn }\end{array}$ & $936 / 3950$ & $\begin{array}{l}\text { EG 81/Poço } \\
\text { de Fora }\end{array}$ & GNL & A & $\begin{array}{l}2.33 \\
.04 \\
\end{array}$ & & .03 & & $\begin{array}{l}.09773 \\
.00010 \\
\end{array}$ & \begin{tabular}{|l|}
3.806 \\
.001 \\
\end{tabular} & $\begin{array}{l}23.550 \\
.024 \\
\end{array}$ & -.50 & -29.7 & -2.5 & $\begin{array}{l}2.15 \\
.704(a) \\
\end{array}$ & 29 & nt \\
\hline \begin{tabular}{|l|}
1221 \\
gns
\end{tabular} & $40^{\prime}$ & $\begin{array}{l}\text { JM/BA 345 I } \\
\text { Uauá }\end{array}$ & GTD & B & $\begin{array}{l}3.11 \\
.03 \\
\end{array}$ & & \begin{tabular}{|l|}
3.24 \\
.03 \\
\end{tabular} & \begin{tabular}{|l|}
.510382 \\
.000020 \\
\end{tabular} & $\begin{array}{l}.08691 \\
.00008 \\
\end{array}$ & $\begin{array}{l}1.644 \\
.001 \\
\end{array}$ & $\begin{array}{l}11.439 \\
.008 \\
\end{array}$ & -.56 & -44.0 & -4.8 & $(2.8)$ & & nt \\
\hline $\begin{array}{l}113 / \\
\text { ton }\end{array}$ & $951^{1 / 3917}$ & $\begin{array}{l}\text { JM/BA 180A / } \\
\text { CAPIM }\end{array}$ & GTD & C & \begin{tabular}{|l|}
3.47 \\
.06 \\
\end{tabular} & & \begin{tabular}{|l|}
3.62 \\
.06 \\
\end{tabular} & \begin{tabular}{|l|}
.511114 \\
.000028 \\
\end{tabular} & $\begin{array}{l}.13037 \\
.00011 \\
\end{array}$ & \begin{tabular}{|l|}
8.355 \\
.002 \\
\end{tabular} & \begin{tabular}{|l|}
38.754 \\
.030 \\
\end{tabular} & -.34 & -29.7 & -4.3 & $\begin{array}{l}.02 \\
.7036_{(a)} \\
\end{array}$ & 38 & $n t$ \\
\hline \begin{tabular}{|l|}
$121 /$ \\
gns
\end{tabular} & $955 / 3920$ & $\begin{array}{l}\text { JM/BA 377A / } \\
\text { Uauá }\end{array}$ & GTD & $D$ & $\begin{array}{l}2.98 \\
.04 \\
\end{array}$ & & \begin{tabular}{|l|}
3.13 \\
.04 \\
\end{tabular} & $\begin{array}{l}.510559 \\
.000028 \\
\end{array}$ & $\begin{array}{l}.09121 \\
.00033 \\
\end{array}$ & $\begin{array}{l}17.41 \\
.008 \\
\end{array}$ & $\begin{array}{l}115.42 \\
0.41 \\
\end{array}$ & -.54 & -40.6 & -2.9 & $(2.8)$ & & nt \\
\hline
\end{tabular}




\begin{tabular}{|c|c|c|c|c|c|c|c|c|c|c|c|c|c|c|c|c|c|}
\hline $\begin{array}{l}181 / \\
\text { ton }\end{array}$ & $951 / 3917$ & $\begin{array}{l}\text { JM/BA 1808/ } \\
\text { CAPIM }\end{array}$ & GTD & $E$ & $\begin{array}{l}3.50 \\
.02 \\
\end{array}$ & & $\begin{array}{l}3.61 \\
.02 \\
\end{array}$ & $\begin{array}{l}.510214 \\
.000015\end{array}$ & $\begin{array}{l}.09212 \\
.00009\end{array}$ & $\begin{array}{l}1.674 \\
.001 \\
\end{array}$ & $\begin{array}{l}10.989 \\
.008\end{array}$ & -.53 & -47.3 & -7.1 & $\begin{array}{l}.02 \\
.7036_{(a)} \\
\end{array}$ & 38 & $\mathrm{nt}$ \\
\hline $\begin{array}{l}119 / \\
\text { gtd }\end{array}$ & $1110 / 3858$ & $\begin{array}{l}\text { JM/BA 405A/ } \\
\text { Araci }\end{array}$ & GTD & $F$ & $\begin{array}{l}3.06 \\
.03\end{array}$ & & $\begin{array}{l}3.19 \\
.03 \\
\end{array}$ & $\begin{array}{l}.510442 \\
.000020\end{array}$ & $\begin{array}{l}.08789 \\
.00005\end{array}$ & $\begin{array}{l}2.783 \\
.001\end{array}$ & $\begin{array}{l}19.147 \\
.009\end{array}$ & -.55 & -42.8 & -15.1 & $\begin{array}{l}2.00 \\
.7049_{(a)}\end{array}$ & 39 & nt \\
\hline $\begin{array}{l}496 / \\
\text { grt }\end{array}$ & $1037 / 3927$ & $\begin{array}{l}\text { BA 15 A I } \\
\text { Cansançăoo }\end{array}$ & GTD & $G$ & $\begin{array}{l}3.04 ? \\
.12\end{array}$ & $2.74^{\# 1}$ & $\begin{array}{l}3.27 ? \\
.12 \\
\end{array}$ & $\begin{array}{l}.511580 \\
.000036 \\
\end{array}$ & $\begin{array}{l}.14404 \\
.00088 \\
\end{array}$ & $\begin{array}{l}1.161 \\
.007 \\
\end{array}$ & $\begin{array}{l}4.874 \\
.003 \\
\end{array}$ & -.27 & -20.6 & -7.2 & $(2.0)$ & & nt \\
\hline $\begin{array}{l}294 / \\
\text { sie } \\
\end{array}$ & $1020 / 3950$ & $\begin{array}{l}\text { JM/BA 442 I } \\
\text { Itiúba }\end{array}$ & GTD & $\mathrm{H}$ & $\begin{array}{l}2.39 \\
.04 \\
\end{array}$ & & $\begin{array}{l}2.60 \\
.03 \\
\end{array}$ & $\begin{array}{l}.511088 \\
.000023 \\
\end{array}$ & $\begin{array}{l}.09848 \\
.00007 \\
\end{array}$ & $\begin{array}{l}18.83 \\
.008 \\
\end{array}$ & 115.62 & -.50 & -30.2 & -4.3 & $\begin{array}{l}2.07 \\
.7043_{(a)} \\
\end{array}$ & 32 & $\mathrm{nt}$ \\
\hline $\mathrm{gtd} / \mathrm{p}$ & $1023 / 4023$ & $\begin{array}{l}\text { 6/ Campo } \\
\text { Formoso }\end{array}$ & GTD & 1 & 2.82 & & 2.97 & .51057 & .08548 & 5.81 & 41.1 & -.57 & -40.3 & -12.0 & $\begin{array}{l}1.97 \\
.7062_{\text {(b) }} \\
\end{array}$ & 57 & 1 \\
\hline $\mathrm{gtd} / \mathrm{p}$ & $1023 / 4023$ & $\begin{array}{l}\text { 13/Campo } \\
\text { Formoso }\end{array}$ & GTD & $\mathrm{J}$ & 2.46 & & 2.66 & .511010 & .09652 & 4.07 & 25.5 & -.51 & -31.8 & -6.2 & $\begin{array}{l}1.97 \\
.7062_{(b)}\end{array}$ & 57 & 1 \\
\hline $\begin{array}{l}118 / \\
\text { dio }\end{array}$ & $1105 / 3920$ & $\begin{array}{l}\text { JM BA 411/ } \\
\text { Santa Luz }\end{array}$ & GTD & & $\cdots$ & & $\begin{array}{l}2.31 \\
0.06 \\
\end{array}$ & $\begin{array}{l}.512224 \\
.000023\end{array}$ & $\begin{array}{l}.15938 \\
.00012 \\
\end{array}$ & $\begin{array}{l}2.136 \\
.001 \\
\end{array}$ & $\begin{array}{l}8.104 \\
.001\end{array}$ & -.19 & -8.1 & 1.4 & $(2.0)$ & & nt \\
\hline $\begin{array}{l}167 \\
\text { gtd }\end{array}$ & $1132 / 3940$ & $\begin{array}{l}\text { BA 23 D/ } \\
\text { Retrolandia }\end{array}$ & GTD & $\mathrm{K}$ & $\begin{array}{l}2.67 \\
.05 \\
\end{array}$ & & $\begin{array}{l}2.85 \\
.04 \\
\end{array}$ & $\begin{array}{l}.510944 \\
.000032 \\
\end{array}$ & $\begin{array}{l}.10046 \\
.00029 \\
\end{array}$ & $\begin{array}{l}31.07 \\
.024 \\
\end{array}$ & $\begin{array}{l}187.03 \\
.51\end{array}$ & -.49 & -33.0 & -9.7 & $\begin{array}{l}1.90 \\
.705_{(a)}\end{array}$ & 39 & nt \\
\hline $\begin{array}{l}493 \\
\text { grt }\end{array}$ & $1149 / 3932$ & $\begin{array}{l}1163 \text { EO29/ } \\
\text { R. do Jacuipe }\end{array}$ & GTD & $L$ & $\begin{array}{l}2.56 \\
.05 \\
\end{array}$ & & $\begin{array}{l}2.74 \\
.04 \\
\end{array}$ & $\begin{array}{l}.510833 \\
.000036 \\
\end{array}$ & $\begin{array}{l}.08986 \\
.00006 \\
\end{array}$ & $\begin{array}{l}25.43 \\
.011 \\
\end{array}$ & $\begin{array}{l}171.10 \\
.089 \\
\end{array}$ & -.54 & -35.2 & -9.0 & $\begin{array}{l}1.92 \\
.704_{(\mathrm{a})} \\
\end{array}$ & 25 & $\mathrm{nt}$ \\
\hline \multicolumn{18}{|c|}{ supra-crustais } \\
\hline $\begin{array}{l}114 / \\
\text { mvul }\end{array}$ & 9523915 & $\begin{array}{l}\text { JM/BA 184 A I } \\
\text { Capim }\end{array}$ & VAC & $\mathrm{M}$ & $\begin{array}{l}2.05 \\
.03 \\
\end{array}$ & & $\begin{array}{l}.2 .29 \\
.02 \\
\end{array}$ & $\begin{array}{l}.511275 \\
.000020\end{array}$ & $\begin{array}{l}.09561 \\
.00008 \\
\end{array}$ & $\begin{array}{l}2.011 \\
.001 \\
\end{array}$ & $\begin{array}{l}12.719 \\
.008\end{array}$ & -.51 & -26.6 & +1.8 & $\begin{array}{l}2.17 \\
.704_{(a)} \\
\end{array}$ & 29 & nt \\
\hline $\begin{array}{l}495 / \\
\text { mvul }\end{array}$ & 112233002 & $\begin{array}{l}\text { BA - 3BI } \\
\text { Araci }\end{array}$ & VAC & $N$ & $\begin{array}{l}2.04 \\
.05 \\
\end{array}$ & & $\begin{array}{l}2.29 \\
.04 \\
\end{array}$ & $\begin{array}{l}.511322 \\
.000034\end{array}$ & $\begin{array}{l}.09868 \\
.00006 \\
\end{array}$ & $\begin{array}{l}2.569 \\
.001 \\
\end{array}$ & $\begin{array}{l}15.742 \\
.007\end{array}$ & -.50 & -25.7 & +.5 & $\begin{array}{l}2.09 \\
.7016_{(a)}\end{array}$ & -6.3 & nt \\
\hline
\end{tabular}

TAB. 5.6-10B: SALVADOR - ITABUNA

\begin{tabular}{|c|c|c|c|c|c|c|c|c|c|c|c|c|c|c|c|c|c|}
\hline $\begin{array}{l}\text { SPS } \\
/ \text { lit. }\end{array}$ & coord. & $\begin{array}{l}\text { n. campol } \\
\text { região }\end{array}$ & $\begin{array}{l}\text { litolo } \\
\text { gia }\end{array}$ & $\begin{array}{l}\text { ident. } \\
\text { (diagr.) }\end{array}$ & $\mathrm{T}_{\text {chur }}$ & $\mathrm{T}_{\mathrm{dm} 2}$ & $T_{d m}$ & $\begin{array}{l}{ }^{143} \mathrm{Nd}- \\
{ }^{144} \mathrm{Nd}\end{array}$ & $\begin{array}{l}{ }^{147} \mathrm{Sm}- \\
{ }^{144} \mathrm{Nd}\end{array}$ & $\begin{array}{l}\text { Sm } \\
\text { ppm }\end{array}$ & $\begin{array}{l}\text { Nd } \\
\text { ppm }\end{array}$ & $f$ & $\begin{array}{l}\varepsilon_{\mathrm{Nd}} \\
(0)\end{array}$ & $\varepsilon_{\mathrm{Nd}}(\mathrm{t})$ & $\begin{array}{l}t_{\mathrm{Rb} / \mathrm{sr}} \\
\mathrm{Ri} \\
\text { (fonte) }\end{array}$ & $\begin{array}{l}\varepsilon_{\mathrm{sr}} \\
(\mathrm{t})\end{array}$ & ref \\
\hline gnl & $1321 / 3922$ & $\begin{array}{l}\mathrm{JMBA} 214 \mathrm{Cl} \\
\text { Moenda }\end{array}$ & GNL & 0 & $2.68-$ & & 2.81 & --- & --- & $-\cdots$ & $\ldots$ & $\cdots$ & $\cdots$ & $-\cdots$ & $\begin{array}{l}2.04 \\
.7093_{(\mathrm{c})}\end{array}$ & 103 & 3 \\
\hline gni & $1444 / 3942$ & $\begin{array}{l}\text { JM BA 279/ } \\
\text { Almandina }\end{array}$ & GNL & $P$ & $\begin{array}{l}2.36 \\
.05\end{array}$ & & $\begin{array}{l}2.60 \\
.04\end{array}$ & $\begin{array}{l}.511271 \\
.000026\end{array}$ & $\begin{array}{l}.10896 \\
.00009 \\
\end{array}$ & $\begin{array}{l}4.283 \\
.001 \\
\end{array}$ & $\begin{array}{l}23.769 \\
.019 \\
\end{array}$ & -.45 & -26.7 & -2.5 & $\begin{array}{l}(2.2)_{\text {estim }} \\
.7038_{\text {(d) }}\end{array}$ & 27 & $n t$ \\
\hline sho & & $\begin{array}{l}\text { PJRO12(2)! } \\
\text { Rod. BR101 }\end{array}$ & GTD & $Q$ & 2.24 & & 2.46 & .511094 & .09231 & 13.87 & 90.86 & -.53 & -30.1 & -.82 & $\begin{array}{l}(2.2)_{\text {estim }} \\
.7038\end{array}$ & 27 & 2 \\
\hline gnlf & & $\begin{array}{l}\text { CJ } 21 \text { / ituberá } \\
\text { - Gandu }\end{array}$ & GNL & $R$ & 2.24 & & 2.44 & .510900 & .07909 & 4.12 & 31.5 & -.60 & -33.9 & -.9 & $\begin{array}{l}\text { (2.2)estim } \\
.7038\end{array}$ & & 2 \\
\hline gnim & & $\begin{array}{l}\text { C」 } 33 / \\
\text { Ubaitaba-Marú }\end{array}$ & GNL & $S$ & -- & $2.78^{72}$ & $\cdots$ & .512066 & .17863 & 1.480 & 5.010 & -.09 & -11.2 & -6.9 & $\begin{array}{l}(2.2)_{\text {estim }} \\
.7038\end{array}$ & & 2 \\
\hline
\end{tabular}




\begin{tabular}{|c|c|c|c|c|c|c|c|c|c|c|c|c|c|c|c|c|c|}
\hline gnlf & & $\begin{array}{l}\text { CJ 34A I } \\
\text { Ubaitaba-Marú }\end{array}$ & GNL & $T$ & 2.74 & & 2.89 & .510370 & .07144 & .56 & 4.74 & -.64 & -44.2 & -9.1 & \begin{tabular}{|l|}
$(2.2)_{\text {estim }}$ \\
.7038 \\
\end{tabular} & & 2 \\
\hline gnlm & & $\begin{array}{l}\text { CJ } 348 / \\
\text { Ubaitaba-Marú }\end{array}$ & GNL & $\mathrm{U}$ & $\cdots$ & $2.21^{\# 2}$ & $2.75 ?$ & .512599 & .18840 & 2.29 & 7.35 & -.04 & -.8 & 1.57 & $\begin{array}{l}(2.2)_{\text {estim }} \\
7038\end{array}$ & & 2 \\
\hline gnlm & & $\begin{array}{l}\text { CJ19/ltuberá } \\
\text { - Gandú }\end{array}$ & GNL & $\mathrm{V}$ & 2.59 & $2.59^{72}$ & $2.82 ?$ & .511653 & .13756 & 3.31 & 14.55 & -.30 & -19.2 & -2.6 & $\begin{array}{l}(2.2)_{\text {estin }} \\
.7038 \\
\end{array}$ & & 2 \\
\hline gnlf & & $\begin{array}{l}\text { CJ 11/ } \\
\text { Maricoabo }\end{array}$ & GNL & $x$ & 2.33 & & 2.58 & .511403 & .11611 & 4.57 & 23.8 & -.41 & -24.1 & -1.5 & $\begin{array}{l}(2.2)_{\text {estim }} \\
.7038_{\text {(d) }}\end{array}$ & & 2 \\
\hline sho & & $\begin{array}{l}\text { CJ13/ } \\
\text { Cajaíba }\end{array}$ & GTD & $\bar{Y}$ & 2.19 & & 2.39 & .510965 & .08063 & 20.0 & 150.0 & -.59 & -32.6 & -0.6 & $\begin{array}{l}(2.2)_{\text {estum }} \\
.7038\end{array}$ & & 2 \\
\hline $\begin{array}{l}394 \\
\text { gns }\end{array}$ & $1624 / 3912$ & $\begin{array}{l}\text { JD } 233 \text { / Porto } \\
\text { Seguro - Faixa } \\
\text { Araçuai }\end{array}$ & GTD & $Z$ & $\begin{array}{l}2.01 \\
.05\end{array}$ & & $\begin{array}{l}2.28 \\
.04\end{array}$ & $\begin{array}{l}.511446 \\
.000028\end{array}$ & $\begin{array}{l}.10649 \\
.00006\end{array}$ & 12.72 & $\begin{array}{l}72.221 \\
.027\end{array}$ & -.46 & -23.3 & -12 & $.96_{\mathrm{K} / \mathrm{Ar}}$ & -- & nt \\
\hline
\end{tabular}

Ver nota explicativa da tabela no apêndice 1.

Ref. : nt $=$ neste trabalho; idades modelos recalculados para este trabalho a partir dos dados istópicos de $1=$ Sabaté et. al. $1990 ; 2=$ Barbosa $1987 ; 3=$ Sato 1986.

Observação: Idade modelo Tdm2 com sobrescrito \#2 indica uma evolução de 2 estágios com T2=2Ga e ${ }^{147} \mathrm{Sm}^{144} \mathrm{Nd} \mathrm{T}_{\mathrm{T}}=.110$

Fonte bibliográfica p/ coluna t: $a=$ Mascarenhas e Garcia $1989 ; b=$ Sabaté et al 1990; $c \approx$ Mascarenhas e Garcia 1989; $d=$ Mascrenhas dados inéditos, Sato 1986; est. = idades estimadas.

TAB. 5.6-11: Região Norte-Ocidental (Correntina, Mansidão e "NO" de Guanambi)

\begin{tabular}{|c|c|c|c|c|c|c|c|c|c|c|c|c|c|c|c|c|c|}
\hline $\begin{array}{l}\text { SPS } \\
\text { / lit. }\end{array}$ & $\begin{array}{l}\text { coord.I } \\
\text { (p.local.) }\end{array}$ & $\begin{array}{l}\text { n. campol } \\
\text { região }\end{array}$ & \begin{tabular}{|l|} 
litolo \\
gia
\end{tabular} & $\begin{array}{l}\text { ident. } \\
\text { (diagr.) }\end{array}$ & $T_{\text {chur }}$ & $T_{d m 2}$ & $T_{d m}$ & $\begin{array}{l}{ }^{143} \mathrm{Nd}- \\
{ }^{144} \mathrm{Nd}\end{array}$ & $\begin{array}{l}{ }^{147} \mathrm{Sm}- \\
{ }^{144} \mathrm{Nd}\end{array}$ & $\begin{array}{l}\text { Sm } \\
\text { ppm }\end{array}$ & $\begin{array}{l}\text { Nd } \\
\text { ppm }\end{array}$ & $f$ & $\begin{array}{l}\varepsilon_{\mathrm{Nd}} \\
(0)\end{array}$ & $\begin{array}{l}\varepsilon_{\mathrm{Nd}} \\
(\mathrm{t})\end{array}$ & $\begin{array}{l}t_{\mathrm{Rb} / \mathrm{Sr}} \\
\mathrm{Ri}_{\text {(fonte) }} \\
\end{array}$ & $\begin{array}{l}\varepsilon_{\mathrm{Sr}} \\
(\mathrm{t})\end{array}$ & ref \\
\hline $\begin{array}{l}165 \\
q m z\end{array}$ & $1320 / 4441$ & $\begin{array}{l}\text { JM BA191 B/ } \\
\text { Correntina }\end{array}$ & GTD & A & $\begin{array}{l}2.05 \\
.05 \\
\end{array}$ & & $\begin{array}{l}2.26 \\
.04 \\
\end{array}$ & $\begin{array}{l}.511011 \\
.000040 \\
\end{array}$ & $\begin{array}{l}.07640 \\
.00020\end{array}$ & $\begin{array}{l}8.809 \\
.004 \\
\end{array}$ & $\begin{array}{l}69.721 \\
.182 \\
\end{array}$ & -.61 & -31.7 & -1.5 & $\begin{array}{l}1.97 \\
.7092_{(a)} \\
\end{array}$ & 100 & nt \\
\hline $\begin{array}{l}166 \\
\text { gns }\end{array}$ & $1321 / 4435$ & $\begin{array}{l}\text { JM BA } 193 \mathrm{G} / \\
\text { Correntina }\end{array}$ & GTD & B & $\begin{array}{l}2.17 \\
.06\end{array}$ & & $\begin{array}{l}2.38 \\
.05\end{array}$ & $\begin{array}{l}.511051 \\
.000040 \\
\end{array}$ & $\begin{array}{l}.08578 \\
.00041 \\
\end{array}$ & $\begin{array}{l}9.011 \\
.004 \\
\end{array}$ & $\begin{array}{l}63.524 \\
.302 \\
\end{array}$ & -.56 & -31.0 & -3.1 & $\begin{array}{l}1.97 \\
.7092_{(a)} \\
\end{array}$ & 100 & $n t$ \\
\hline $\begin{array}{l}370 \\
\text { sie }\end{array}$ & $1326 / 4310$ & $\begin{array}{l}\text { BA } 37 / \text { Norte } \\
\text { de Guanambi }\end{array}$ & GTD & C & $\begin{array}{l}2.07 \\
.06\end{array}$ & & $\begin{array}{l}2.42 \\
.04 \\
\end{array}$ & \begin{tabular}{|l|}
.511759 \\
.000026 \\
\end{tabular} & $\begin{array}{l}.13232 \\
.00008 \\
\end{array}$ & $\begin{array}{l}8.648 \\
.003 \\
\end{array}$ & $\begin{array}{l}39.522 \\
.018 \\
\end{array}$ & \begin{tabular}{|l|}
-.33 \\
\end{tabular} & -17.1 & -1.2 & $\begin{array}{l}1.94 \\
.7076_{\text {(a) }} \\
\end{array}$ & 77 & nt \\
\hline 296 & $0933 / 4257$ & $\begin{array}{l}\text { JM/BA-608H } \\
\text { Mansidão }\end{array}$ & GTD & D & & & 2.14 & $\begin{array}{l}.511477 \\
.000029 \\
\end{array}$ & $\begin{array}{l}.10181 \\
.00007 \\
\end{array}$ & $\begin{array}{l}5.312 \\
.002 \\
\end{array}$ & $\begin{array}{l}31.551 \\
018 \\
\end{array}$ & -.48 & $\mid-22.6$ & +2.2 & $\begin{array}{l}2.05 \\
.7016_{(a)}\end{array}$ & $\mid-7$ & nt \\
\hline
\end{tabular}

Ref. : nt = neste trabalho. Fonte bibliográfica p/ coluna t: a = Mascarenhas e Garcia 1989; 


\section{7: PROVÍNCIA BORBOREMA}

\section{7-1 - GENERALIDADES:}

A Província Borborema ocupa a porção nordeste do Brasil e tem sua estruturação final relacionada ao ciclo orogênico Brasiliano. Nessa província destacam-se, de maneira simplista, os maciços gnáissico-migmatitico-graniticos e as faixas de dobramento, representadas por rochas meta-vulcano-sedimentares (Brito Neves 1983). Para efeito deste trabalho, a Província Borborema foi subdivida em cinco subdomínios tectônicos denominados informalmente de: Nordeste, Central, Sul, Norte e Oeste (fig. 5.7-1). O Sub-Dominio Sul é representado pelos Sistemas de Dobramentos Sergipano, Riacho do Pontal e Rio Preto. O Sub- Dominio Central engloba as faixas dobradas Pajeú - Paraiba, Piancó - Alto Brígida e Maciço Pernambuco Alagoas. O Sub-Dominio Nordeste é representado pelos Maciços Rio Piranhas e Caldas Brandão e a Faixa Dobrada Seridó. O Sub-Dominio Norte corresponde às Faixas Jaguaribeana e Rio Curu e Maciços de Tróia e Santa Quitéria. Finalmente, o Sub-Domínio Oeste é representado pelo embasamento dos sedimentos da Bacia do Parnaíba. As denominações aqui utilizadas (faixas e maciços) seguiram as proposições de Almeida et. al. (1976) e Brito Neves (1975).

Os dados geocronológicos pré-existentes na província neste domínio caracterizam a presença de fragmentos crustais de idade Arqueana bem como de porções formadas no Paleoproterozóico. O Neoproterozóico (Ciclo Brasiliano), atuou de maneira intensa, na aglutinação dos fragmentos crustais mencionados, e dando a origem aos principais eventos tectono-magmáticos da provincia. As idades $\mathrm{K}$-Ar obtidas em minerais separadas indicam o resfriamento regional, sempre por volta de 0.5-0.6Ga, no Ciclo Brasiliano.

Determinações Sm-Nd e U-Pb obtidas por Van Schmus et. al. (1995), e acopladas às realizadas neste trabalho, permitiram uma melhor definição quanto às épocas de acreção mantocrosta continental, e serão discutidos a seguir. A figura 5.7-2 reune as localizações aproximadas das amostras datadas através do método $\mathrm{Sm}-\mathrm{Nd}$. 


\section{7-2: SUB DOMINIO NORDESTE:}

MACIÇO RIO PIRANHAS (MRP) - As idades modelo $\mathrm{Sm}-\mathrm{Nd}, \mathrm{T}_{\mathrm{D} M \mathrm{M}}$, relativas às rochas pertencentes ao embasamento do MRP (ver tabela 5.7-1) distribuiram-se entre 3,2 a 2,6Ga. Os valores do parâmetro $\varepsilon_{\mathrm{Nd}}$ (calculados para idade $\mathrm{U}-\mathrm{Pb}$ em zircão, $\mathrm{t}=2,15 \mathrm{Ga}$ ) mostram-se desde pouco negativos $(-2,9)$ a significativamente negativos $(-13)$, sugerindo tratar-se de rochas formadas no Paleoproterozóico, (Ciclo Transamazônico) a partir de protolitos derivados do manto durante o Arqueano.

Neste sub-domínio ocorrem adicionalmente corpos graníticos cujas idades de formação referem-se ao Neoproterozóico (Ciclo Brasiliano). As idades modelo Sm-Nd indicam para esses corpos valores relativos ao Paleoproterozóico, tratando-se portanto de corpos graníticos formados no Neoproterozóico, a partir de protólitos derivados do manto no Paleoproterozóico. Os valores de $\varepsilon_{\mathrm{Nd}}(\mathrm{t}=0,60)$ calculados para estes plutons variaram-se entre -20 a -18 , refletindo tempo de residência crustal longo (>1,5Ga) para seus protólitos (tabela 5.7-1).

$\mathrm{Na}$ fig. 5.7-3 (diagrama de evolução isotópica de $\mathrm{Nd}$ ), observam-se os valores de $\varepsilon_{\mathrm{Nd}}(0.6)$ abaixo da reta CHUR, confirmando certa vivência crustal para os protólitos de tais rochas graniticas. Adicionalmente a amostra $\mathrm{H}$ sugere, em função do enriquecimento em Sm relativo ao $\mathrm{Nd}$, ter sofrido processos de fracionamento possivelmente ocorridos há $2,0 \mathrm{Ga}$, quando da sua formação. De um modo geral, observa-se que a média das razões ${ }^{147} \mathrm{Sm} /{ }^{144} \mathrm{Nd}$ relativas às amostras do embasamento do MRP encontram-se em torno de 0,11 . Por outro lado, os plutons brasilianos apresentaram razões ${ }^{147} \mathrm{Sm} /{ }^{144} \mathrm{Nd}$ de 0,084 (valor médio) relativamente menores do que as observadas para as rochas do embasamento. As idades modelo $\mathrm{Sm}-\mathrm{Nd}$, utilizando-se o modelo em estágio duplo e atribuindo-se razão ${ }^{147} \mathrm{Sm} /{ }^{144} \mathrm{Nd}=0.11$ para o estágio primário, apresentam-se distribuidas entre 2,6 e 2,5Ga, valores esses muito próximos dos observados para as amostras do embasamento, tab. 5.7-1 e fig. 5.7-4. Entretanto, não se pode ser descartada aqui a possibilidade desses granitóides terem se formado a partir de misturas de materiais oriundos de fontes distintas (p. ex: embasamento arqueano $(2,7 \mathrm{Ga})$ e fonte juvenil Paleoproterozóica $(2,0 \mathrm{Ga})$ resultando idades $\mathrm{T}_{\mathrm{DM}}$ aparentes variando entre tais limites.

MACIÇO CALdAS BRANDÃo (MCB) O MCB constitui um núcleo Arqueano circundado por terrenos Paleoproterozóicos. As idades modelo $\mathrm{Sm}-\mathrm{Nd}, \mathrm{T}_{\mathrm{DM}}$, relativas aos granitóides que ocorrem no seu embasamento distribuem-se entre $3,8 \mathrm{Ga}$ a $1,8 \mathrm{Ga}$. Os dados 


\section{PROVINCIA DE BORBOREMA}

TOCANTINS

C. $\mathrm{SAO}_{\mathrm{O}}{ }^{2}$
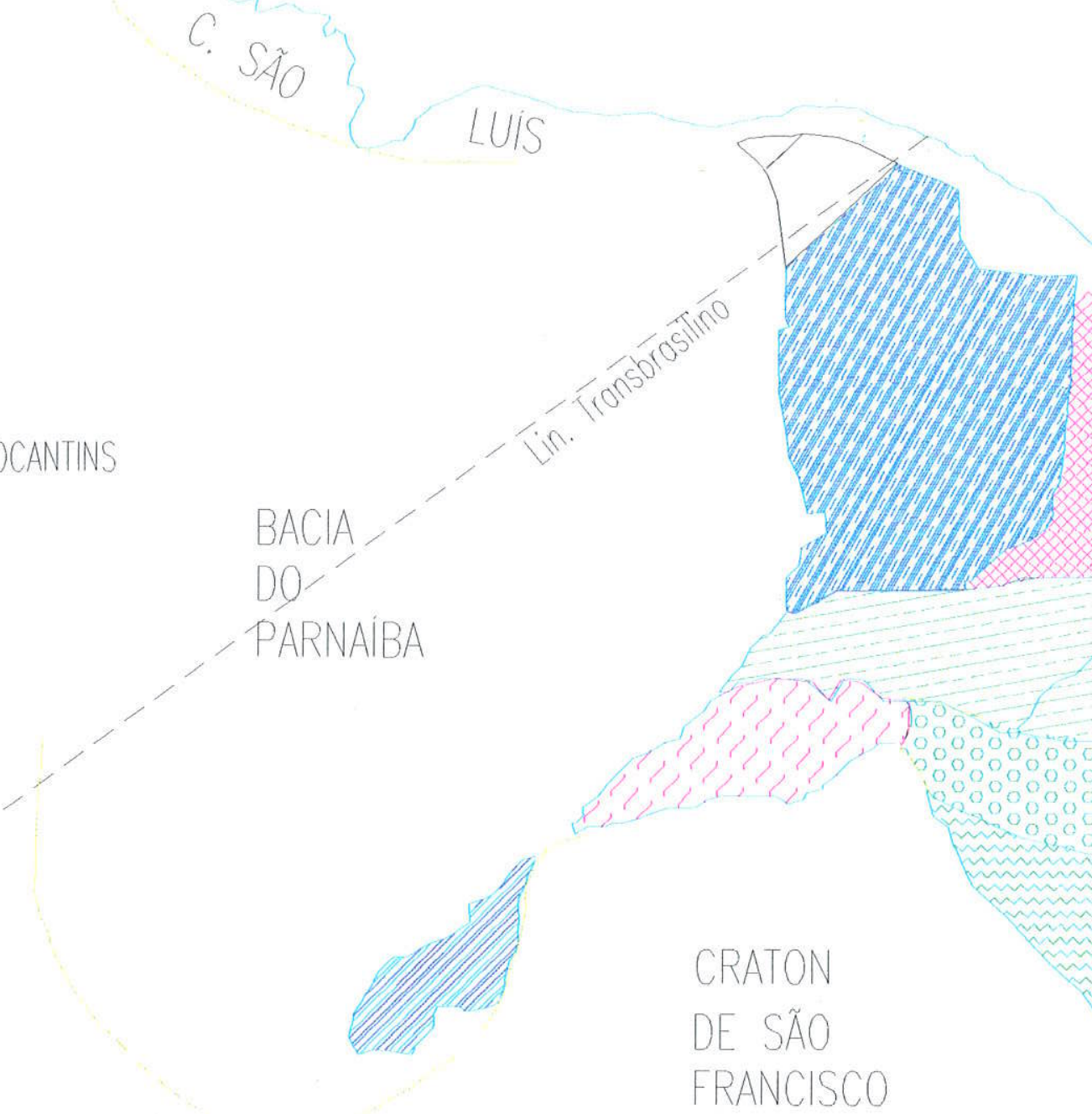

FIG. 5.7-1: mapa geológico simplificado (Schobbenhaus et. al. 1984 - modificado)

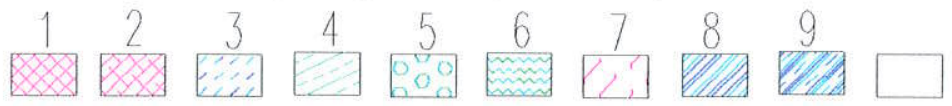

$1=$ RIO PIRANHAS; 2 = CALDAS BRANDÃO; 3 = SERIDó;

$4=$ PAJEÚ-PARAibA $/$ PIANCÓ-ALTO BRIGIDA, $5=$ PERNAMBUCO - ALAGOAS

$6=$ FAIXA SERGIPANA; 7 = SIST. DOBR. R. DO PONTAL, $8=$ S.D. RIO PRETO

9 = DOMINIO CEARENSE (JAGUARIBEANA, TRÓIA, SANTA QUITÉRIA) 


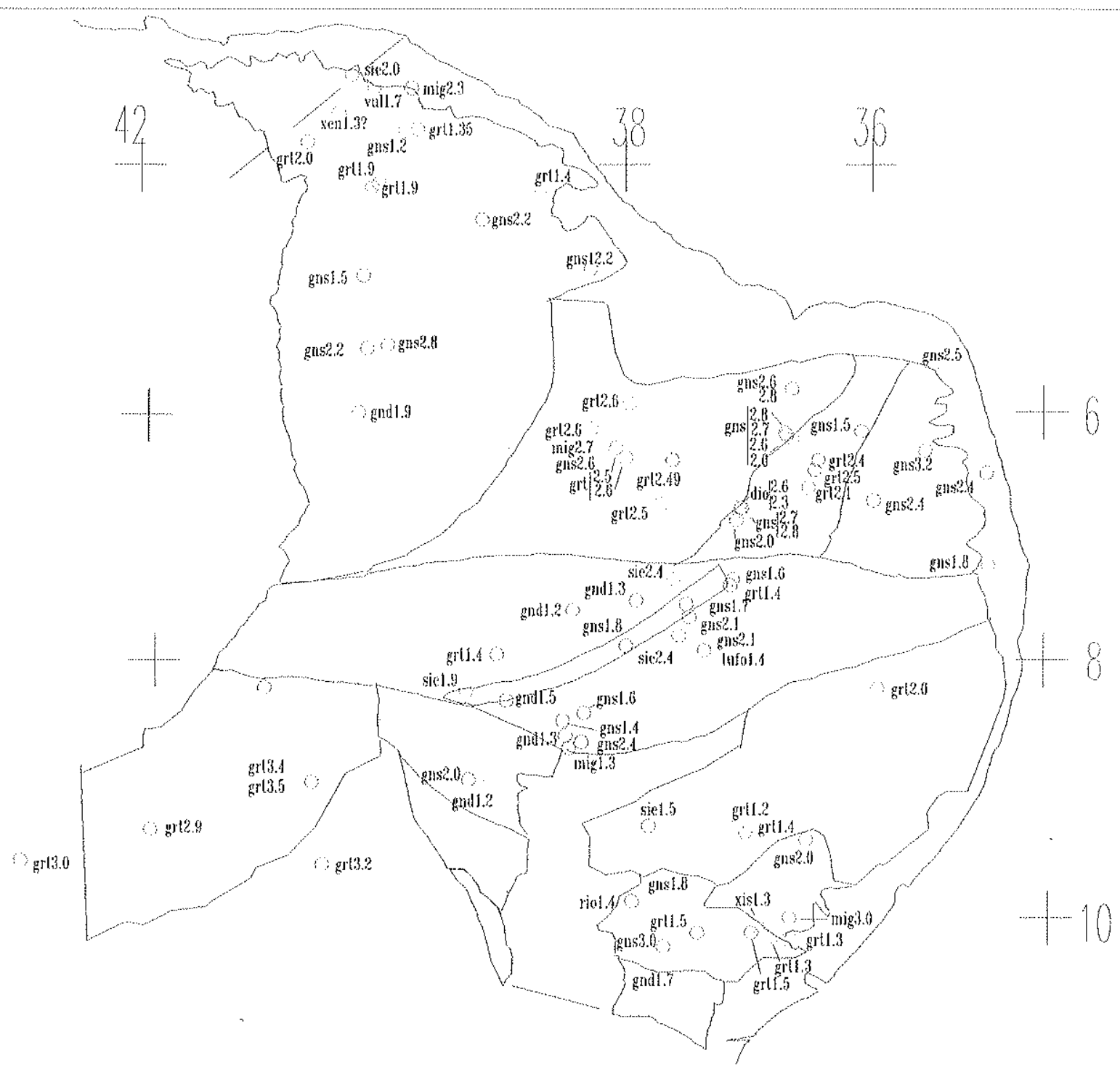

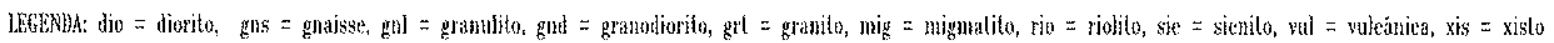

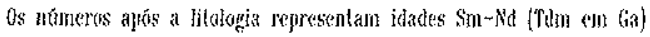

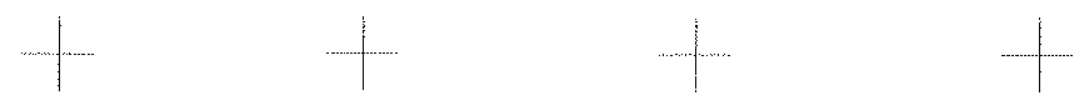

FI6.5.2-2: PROVINCIA DE BORBOREMA - círulos abertos representam pontos datados pelo méldo Sm-Nd, idades modelo - Tdm. 


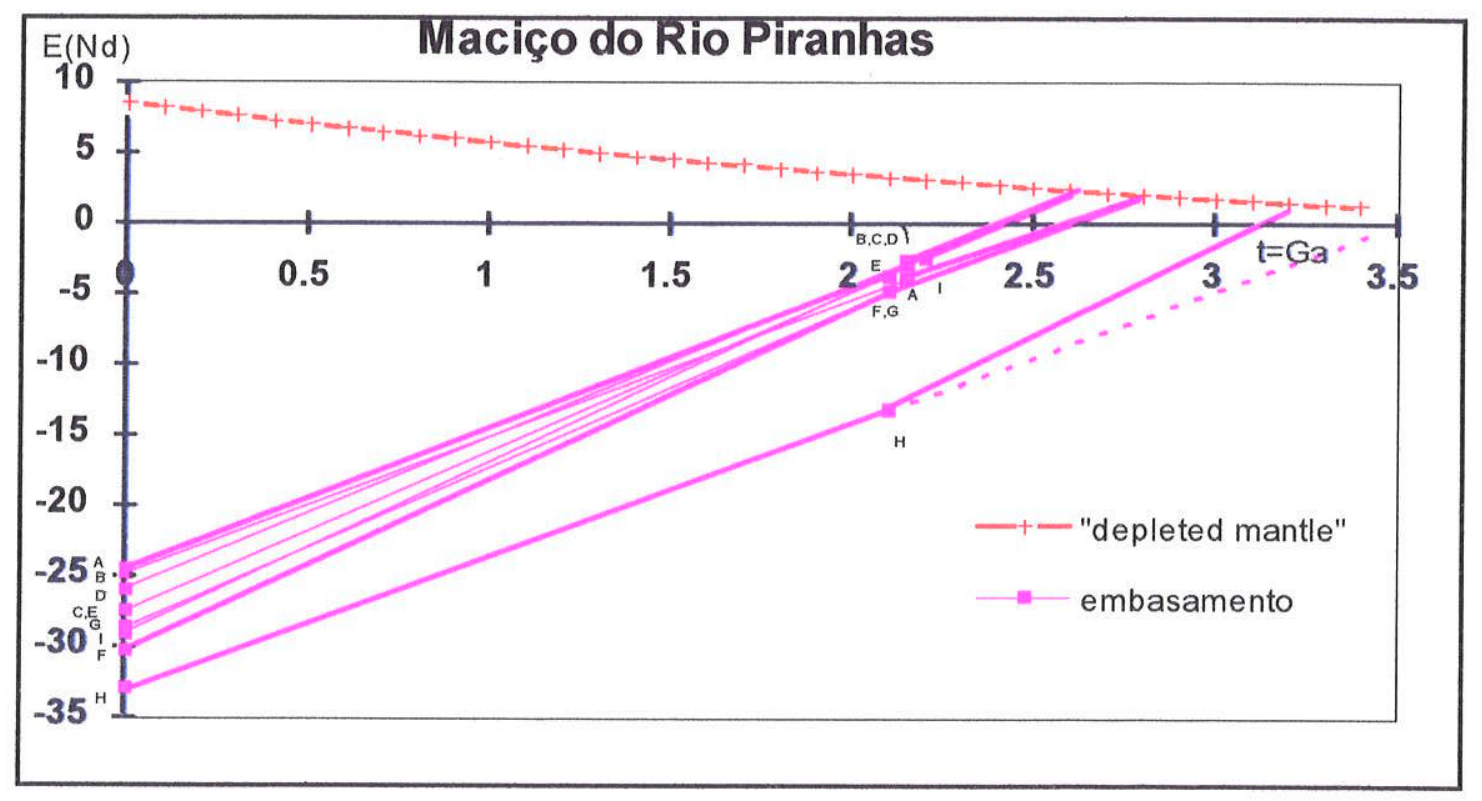

Fig. 5.7-3: diagrama de evolução isotópica $\varepsilon_{N d}$ versus tempo geológico $T(G a)$ das rochas granitóides e básicas do embasamento Maciço Rio Piranhas.

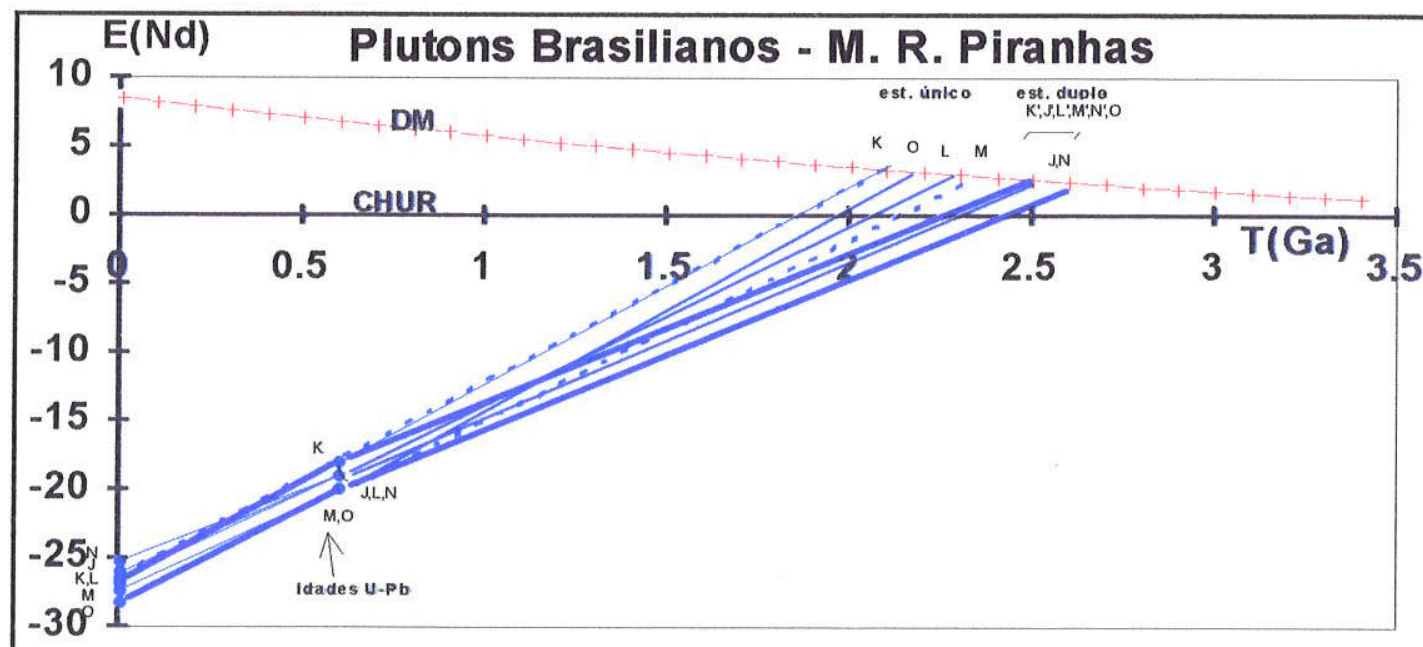

Fig. 5.7-4: diagrama de evolução isotópica $\varepsilon_{N d}$ versus tempo geológico $T(G a)$ das rochas plutônicas brasilianas Maciço Rio Piranhas. 


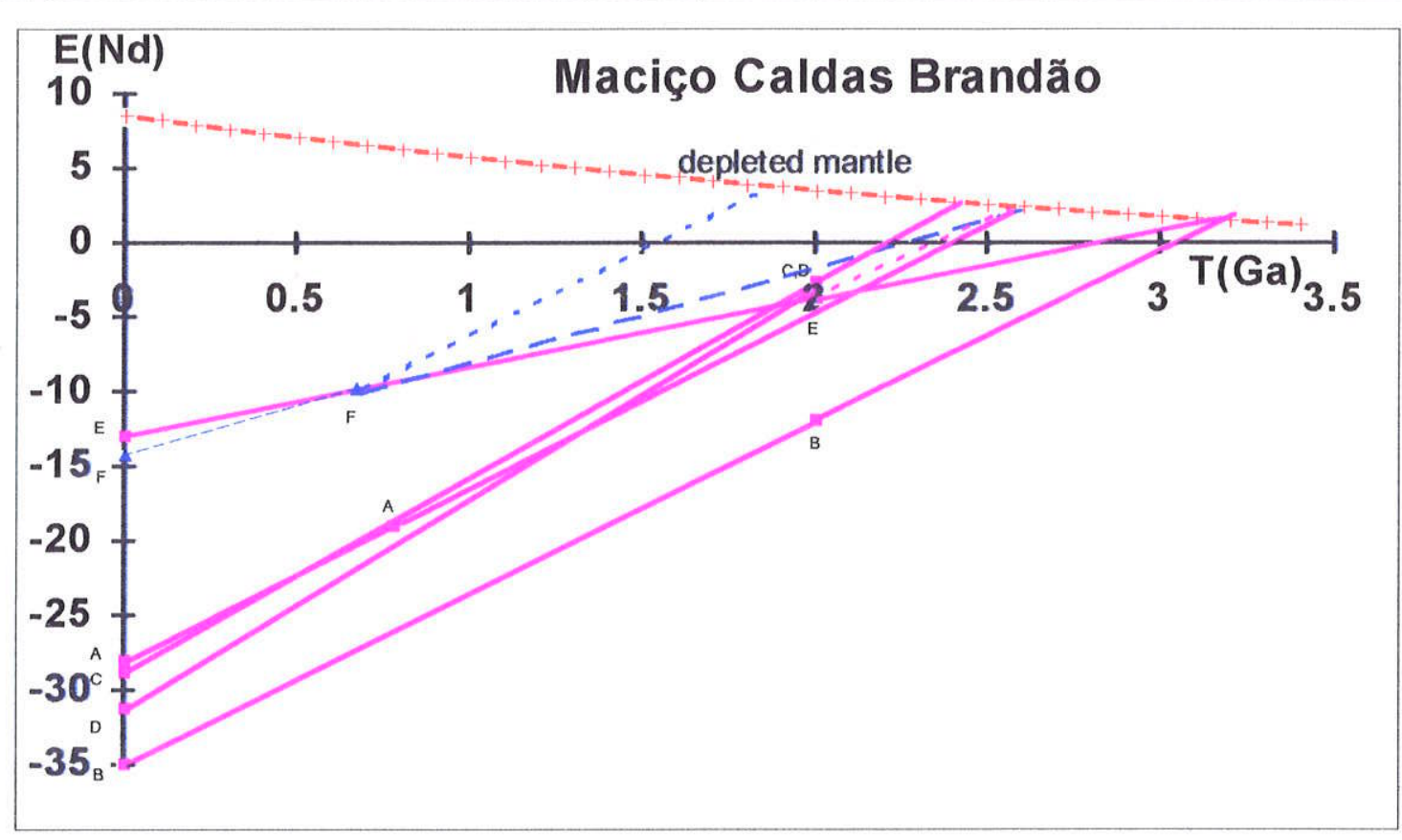

Fig. 5.7-5: diagrama de evolução isotópica $\varepsilon_{\mathrm{Nd}}$ versus tempo geológico $T(\mathrm{Ga})$ das rochas granitóides e granulíticas do embasamento do Maciço Caldas Brandão.

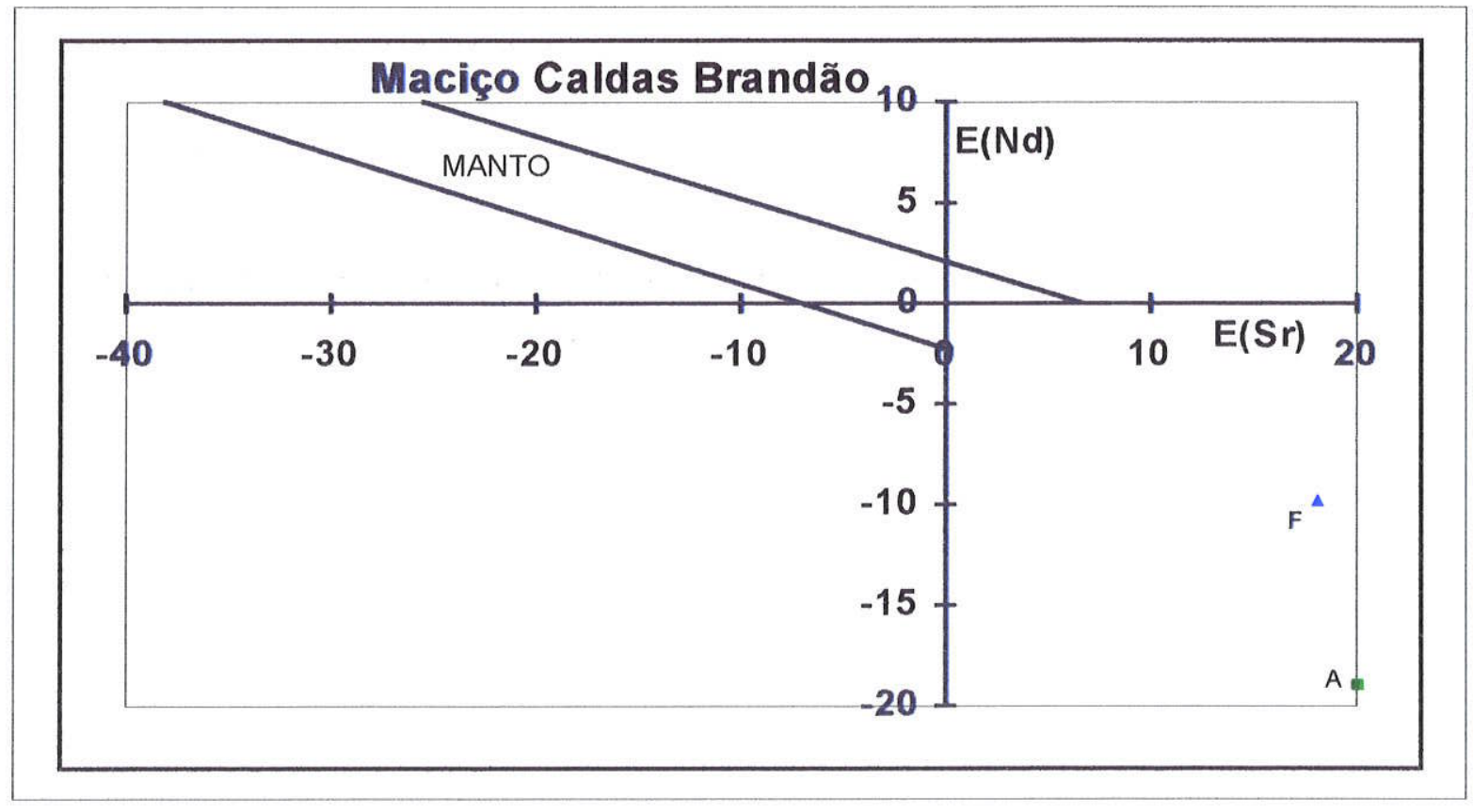

Fig. 5.7-6: diagrama $\varepsilon_{S r}(t)$ versus $\varepsilon_{N d}(t)$ das rochas granitóides do MCB 
isotópicos $\mathrm{Sm}-\mathrm{Nd}$, as idades $\mathrm{T}_{\mathrm{DN}}$ e os valores de $\varepsilon_{\mathrm{d} d}$ encontram-se relacionados na tabela 5.7-2, conjuntamente com algumas idades $\mathrm{Rb}-\mathrm{Sr}$.

As idades modelo Sm-Nd obtidas neste trabalho, bem como por Dantas et. al. (1996), caracterizam o Paleoproterozóico como o principal periodo de acreção/diferenciação de materiais do manto. Subordinadamente, entre Presidente Juscelino e Senador Eloi de Souza, ocorrem rochas tonaliticas cujos protólitos crustais são do Arqueano precoce (Dantas (1997), com idades comparáveis às rochas granitóides de Sete Voltas do Craton São Francisco. As idades U-Pb (zircões) dessa região, obtidas por método convencional e por SHRIMP, resultaram entre 3.45 e 2.0Ga. Por outro lado as idades isocrônicas $\mathrm{Rb}-\mathrm{Sr}$ disponiveis, bem como em algumas idades $\mathrm{U}_{-}$ $\mathrm{Pb}$ (intercepto inferior), distribuem-se no Neoporterozóico caracterizando a formação dessas rochas.

Os valores de $\varepsilon_{\mathrm{Nd}}(t=0.7)$ em duas rochas granitóides mostraram-se negativos, de $-19 \mathrm{e}$ 9,8 (amostras A e F, tab. 5.7-2). Em diagrama $\varepsilon_{\mathrm{Nd}}$ versus $\varepsilon_{\mathrm{Sr}}$ ( fig. 5.7-6), observa-se posicionamento dessas amostras no quarto quadrante, distantes da origem, sugerindo o retrabalhamento de materiais crustais pré-existentes, corroborando com as idades modelo acima citadas. Para as demais rochas granitóides do Maciço Caldas Brandão formadas no Paleoproterozóico, os valores de $\varepsilon_{\mathrm{Nd}}(\mathrm{t}=2,0)$, também se mostraram negativos, $(-12$ a $-3,1$; tabela 5.7-2 e fig. 5.7-5) sugerindo certa vivência crustal dos protólitos dessas rochas.

FAIXA SERIDÓ (SED): Os dados isotópicos pré-existentes nesta porção da Província Borborema indicam a presença de terrenos granitóides formados no Paleoproterozóico (Ciclo Transamazônico), bem como de granitóides do Neoproterozóico (Ciclo Brasiliano).

$\mathrm{O}$ estudo $\mathrm{Sm-Nd}$ revela a presença de rochas granito-gnáissicas, no embasamento, formadas a partir de protólitos diferenciados do manto tanto no Arqueano como no Paleoproterozóico (tabela 5.7-3 e fig. 5.7-7). As idades modelo Sm-Nd ( $\mathrm{T}_{\mathrm{DM}}$ ) concentram-se predominantemente no Paleo e Mesoproterozóico, os principais períodos de acreção juvenil, na região. Os valores de $\varepsilon_{\mathrm{Nd}}(t)$ para $t_{\mathrm{Rb}}$, Sr, quando plotados em diagrama $\varepsilon_{\mathrm{Sr}}$ versus $\varepsilon_{\mathrm{Nd}}$, fig.5.7-9, posicionam-se todos no terceiro quadrante, sugerindo que as rochas se formaram por processos de retrabalhamento crustal, com rehomogeneização isotópica de $\mathrm{Sr}$ (coluna $\mathrm{t}$ da tabela 5.7-7).

As idades modelo $\mathrm{T}_{\mathrm{DM}}$ das rochas supracrustais (xistos do Grupo Seridó) variaram de 1,6 a 1,2Ga ( Van Schmus et. al 1996) e as idades $T_{D M}$ relativas às metavulcânicas da Formação Jucurutu distribuiram-se entre 2,6 a 2,3Ga (Jardim de Sá, 1994; pontos J a P da fig. 5.7-8 e tab. 5.7-3). Os valores de $\varepsilon_{\mathrm{Nd}}\left(\mathrm{t}_{\mathfrak{V}: \mathrm{Pb}}=2.0\right)$ obtidos para tais metavulcânicas mostraram-se relativamente negativos, distribuindo-se entre $-8,1$ e 0,2 sugerindo derivação de protólitos pouco mais antigos. 
As metavulcânicas localizadas a SW de Florândia, por outro lado, parecem representar acreções juvenís ocorridas no Paleoproterozóico com idades $\mathrm{T}_{\mathrm{DM}}$ (estágio duplo) distribuidas entre 2,0 a $1,8 \mathrm{Ga}$ (pontos $\mathrm{S}, \mathrm{T}, \mathrm{U}$ e $\mathrm{V}$ da fig. 5.7-8). Os valores $\varepsilon_{\mathrm{Nd}}(1,8)$ mostraram-se positivos, variando de $+1,8$ a $+5,05$ sugerindo derivação direta do manto, no Paleoproterozóico.

Os metassedimentos (xistos do Grupo Seridó ) apresentaram valores $\varepsilon_{\mathrm{N} d(t=1.2)}$ próximos de zero, sugerindo tratar-se de materiais oriundos de fontes externas mais jovens e diferentes de seu próprio embasamento. (Van Schmus et. al 1996).

\section{7-3: SUB DOMÍNIO CENTRAL}

\section{Sistemas de dobramento PAJEÚ-PARAíba (SPP) e PIANÇó - Alto}

BRÍGIDA (SPAB): As Faixas Dobradas SPP e SPAB são caracterizadas por seqüências de rochas vulcano-sedimentares de natureza predominantemente psamítico-pelítica. As tabelas 5.74, 5.7-5A e 5.7-5B reunem os dados isotópicos $\mathrm{Sm}-\mathrm{Nd}$ e idades U-Pb em zircões disponiveis deste setor.

As idades modelo $\mathrm{Sm}-\mathrm{Nd}\left(\mathrm{T}_{\mathrm{DM}}\right.$ ), apresentaram padrão significativamente mais jovem do que o observado para o sub-domínio Nordeste (MRP e MCB). Os granitóides pertencentes ao embasamento do SPP apresentaram valores $\mathrm{T}_{\mathrm{DM}}$ predominantemente Paleoproterozóicos, variando de 2,4 al,6 Ga, (amostras A, B e C da fig. 5.7-10 e tab. 5.7-5A). Os valores de $\varepsilon_{\mathrm{Nd}}\left(\mathrm{t}_{\mathrm{t} \text {.m }}\right.$ $\left.p_{b}=1.0\right)$ para estas rochas, resultaram valores negativos $(-17 \mathrm{a}-1,4)$ sugerindo tratar-se de rochas formadas através de retrabalhamento de materiais crustais.

As rochas granitóides e vulcânicas com idades de formação (Rb-Sr e U-Pb) relativas ao Neoproterozóico, sugerem para seus protolitos, eventos de diferenciação predominantemente do Mesoproterozóico (figs. 5.7-10 e 5.7-11). Distingue-se desse padrão os sienitos (Alto Teixeira), que apresentaram idades $\mathrm{T}_{\mathrm{DM}}$ Paleoproterozóicas, distribuidas entre 2,4 e 1,7Ga, (fig. 5.7-12). Os valores de $\varepsilon_{\mathrm{Nd}}(\mathrm{t})$, calculados para $\mathrm{t}=0,6$ e 1,0 Ga $(\mathrm{U}-\mathrm{Pb})$, mostraram-se negativos, variando de 10 a -1 , sugerindo fontes crustais para a formação dessas rochas. 


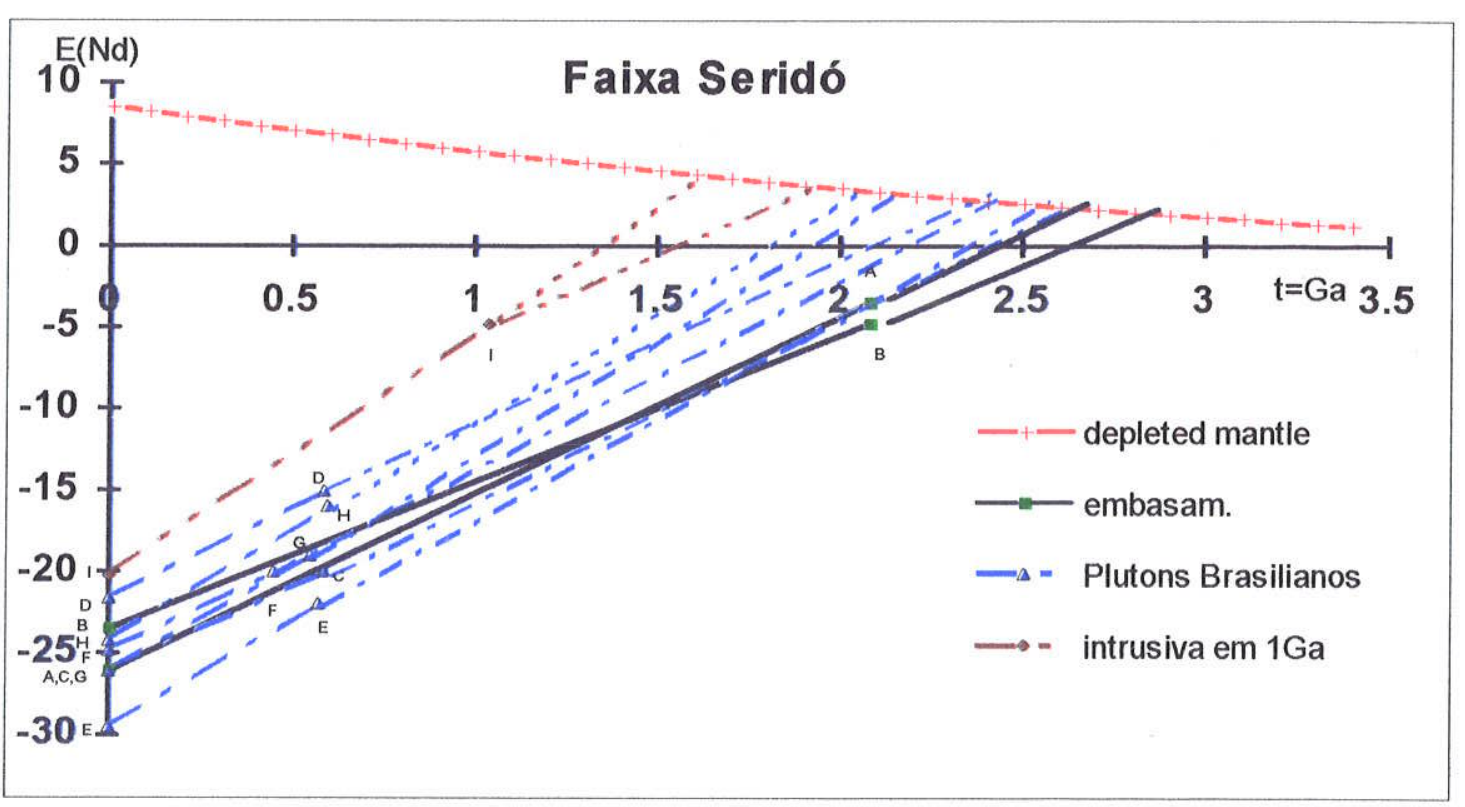

Fig. 5.7-7: diagrama de evolução isotópica $\varepsilon_{N d}$ versus tempo geológico T(Ga) das rochas granitóides (quadrados), granitóides e básicas- plutons brasilianos (triângulos) e granitóide intrusivo em $1 \mathrm{Ga}$ (losango) da Faixa Seridó.

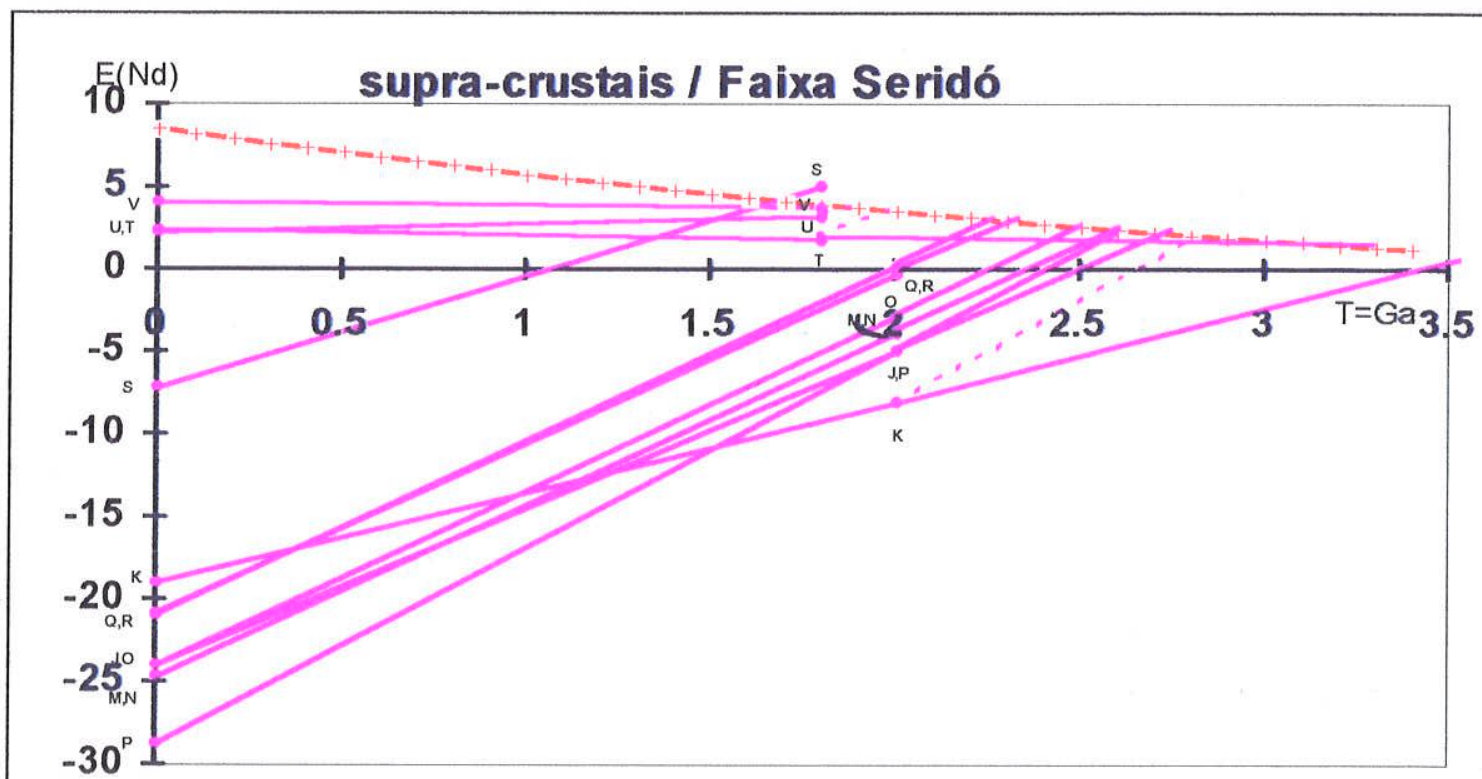

Fig. 5.7-8: diagrama de evolução isotópica $\varepsilon_{\mathrm{Nd}}$ versus tempo geológico $\mathrm{T}(\mathrm{Ga})$ das rochas granitóides e vulcânicas ácidas da Faixa Seridó. 


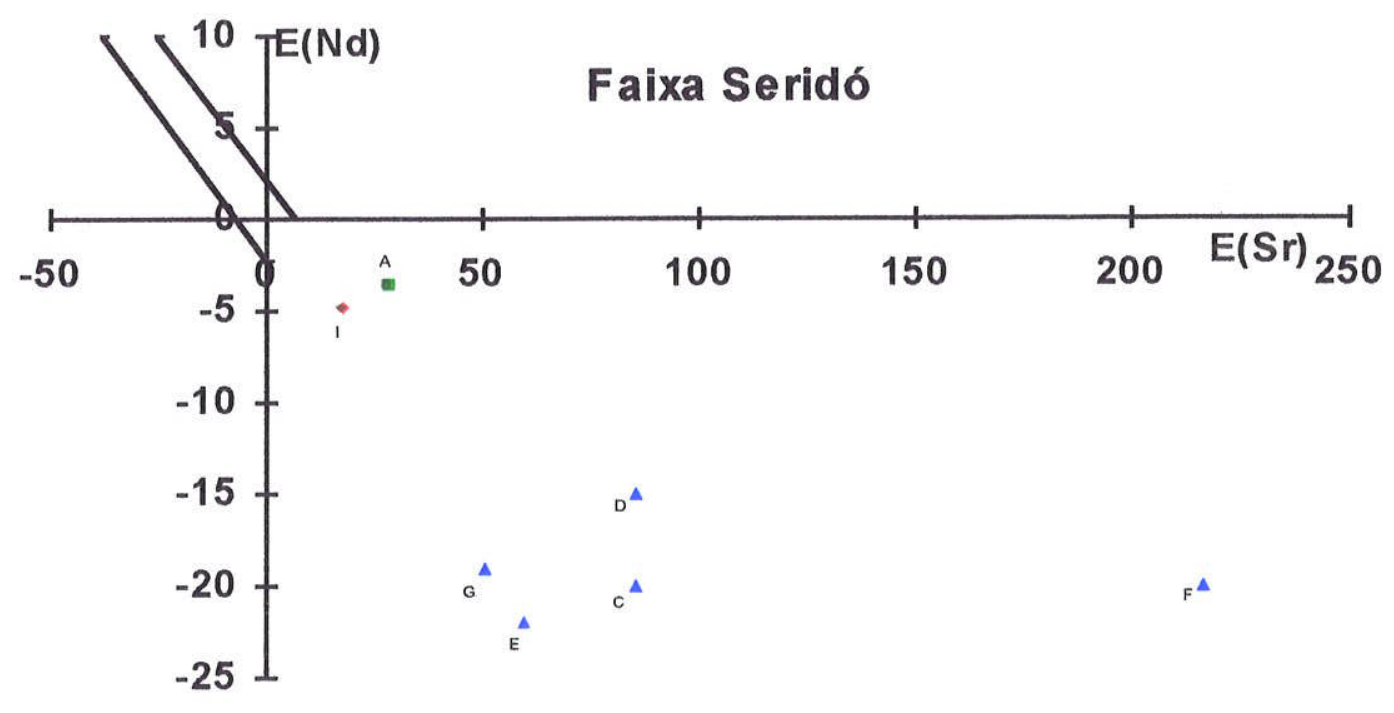

Fig. 5.7-9: diagrama $\varepsilon_{S r}(t)$ versus $\varepsilon_{N d}(t)$. As legendas são as mesmas da fig. 5.2-7

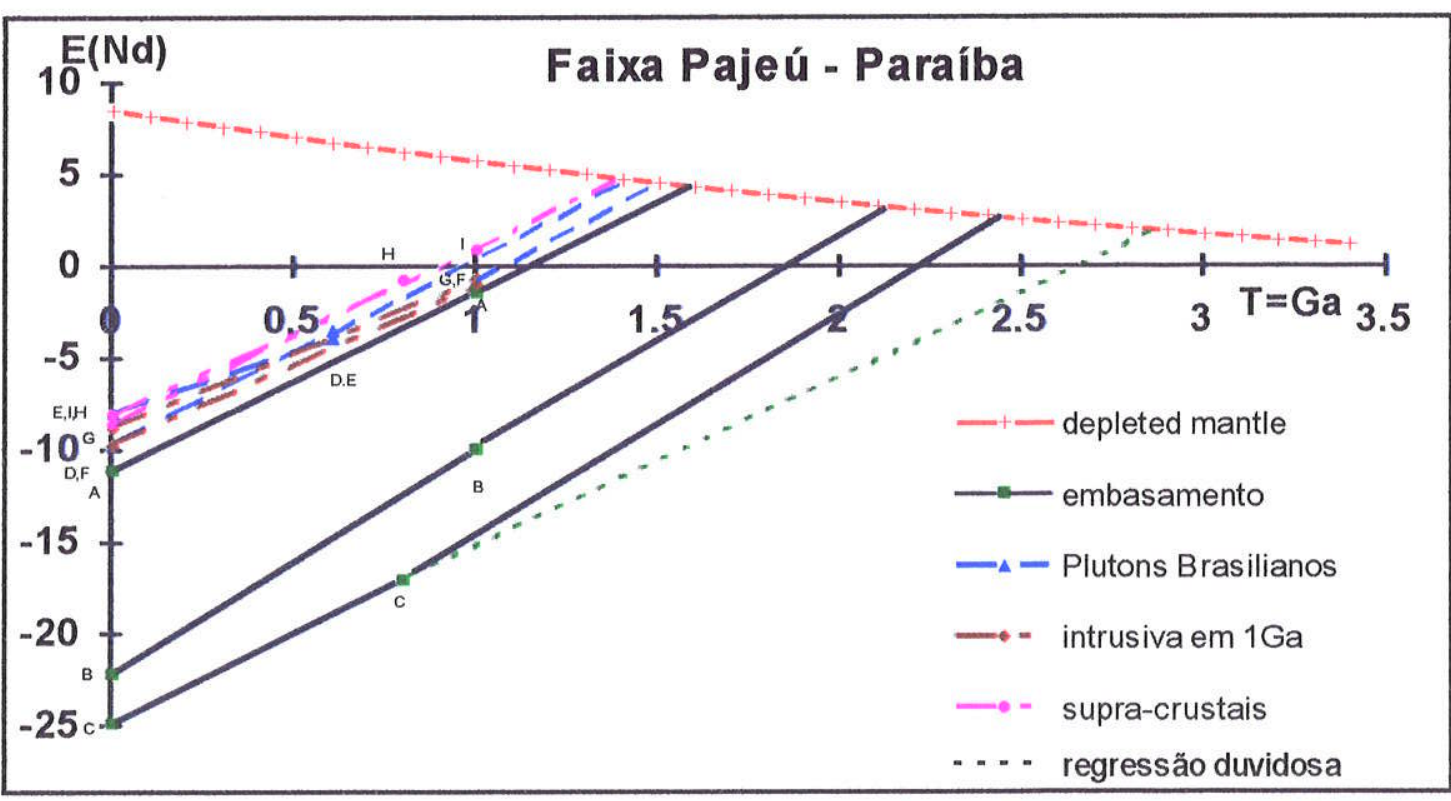

Fig. 5.7-10: diagrama de evolução isotópica $\varepsilon_{\mathrm{Nd}}$ versus tempo geológico $\mathrm{T}(\mathrm{Ga})$ das rochas granitóides do embasamento da Faixa Dobradas Pajeú-Paraíba (quadrados); rochas granitóides brasilianas (triângulos); rochas granitóides formadas em $1 \mathrm{Ga}$ (losangos); supra-crustal - tufo (círculos). A linha pontilhada - evolução isotópica de $\varepsilon_{\mathrm{Nd}}$ de estágio único. 


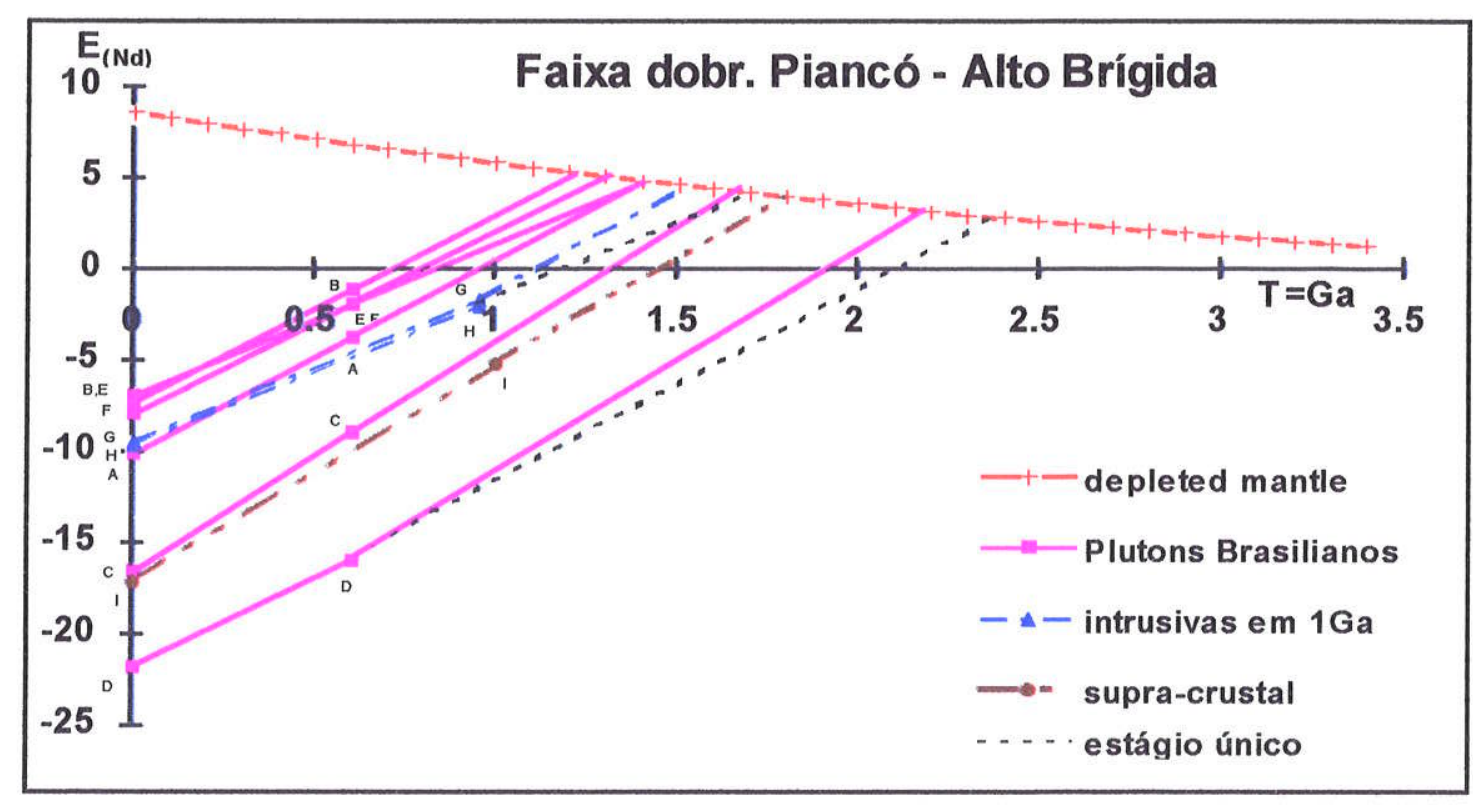

Fig. 5.7-11: diagrama de evolução isotópica $\varepsilon_{\text {Nd }}$ versus tempo geológico $T(G a)$ das rochas plutônicas brasilianas da faixa dobrada Piancó A. Brígida ( quadrados); rochas granitóides formadas em $1 \mathrm{Ga}$ (triângulos); rochas vulcânicas ácidas formadas em $1 \mathrm{Ga}$ (círculo).

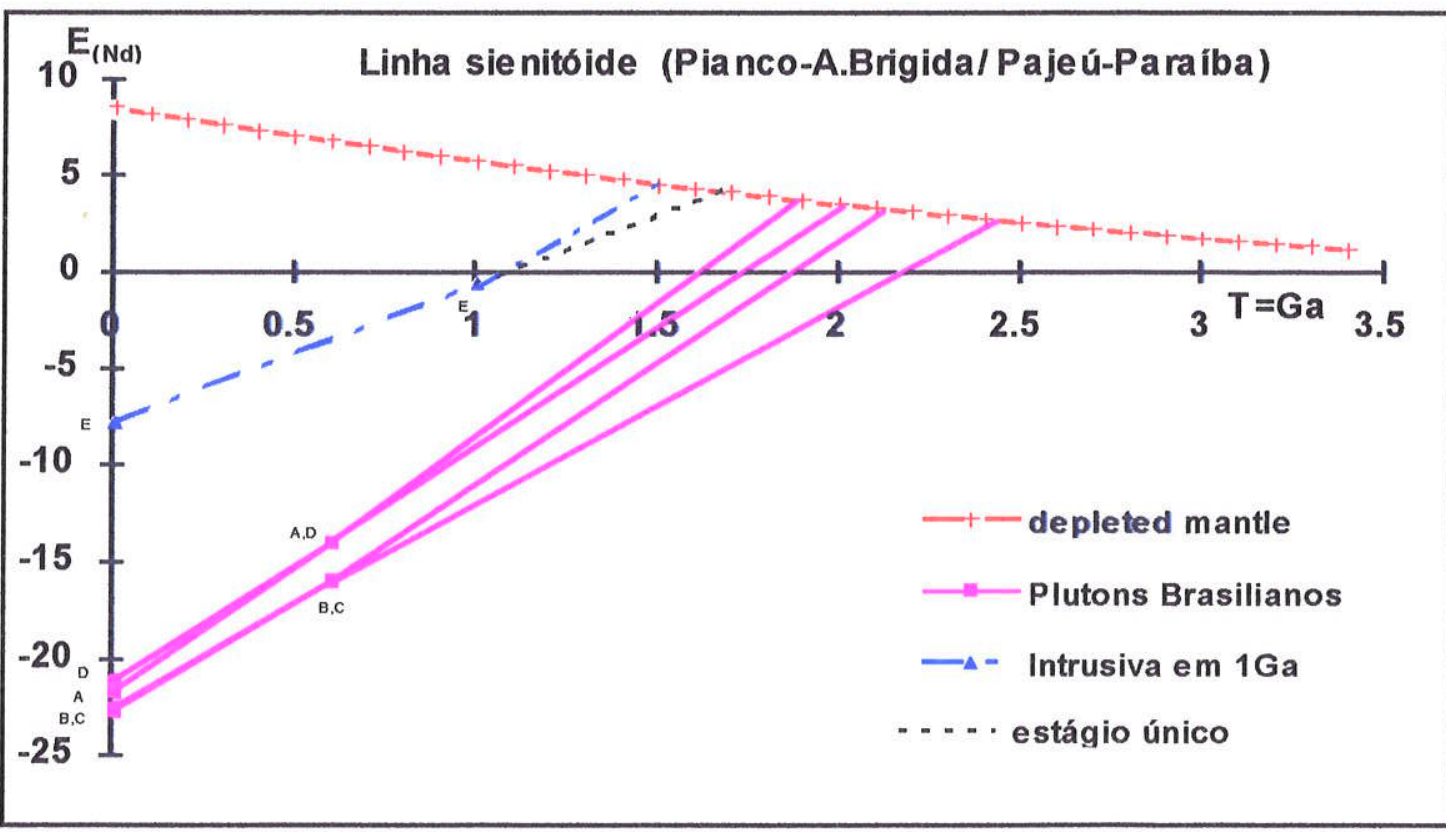

Fig. 5.7-12: diagrama de evolução isotópica $\varepsilon_{\mathrm{Nd}}$ versus tempo geológico $\mathrm{T}(\mathrm{Ga})$ das rochas granitóides - Linha Sienitóide (Alto Teixeira). 


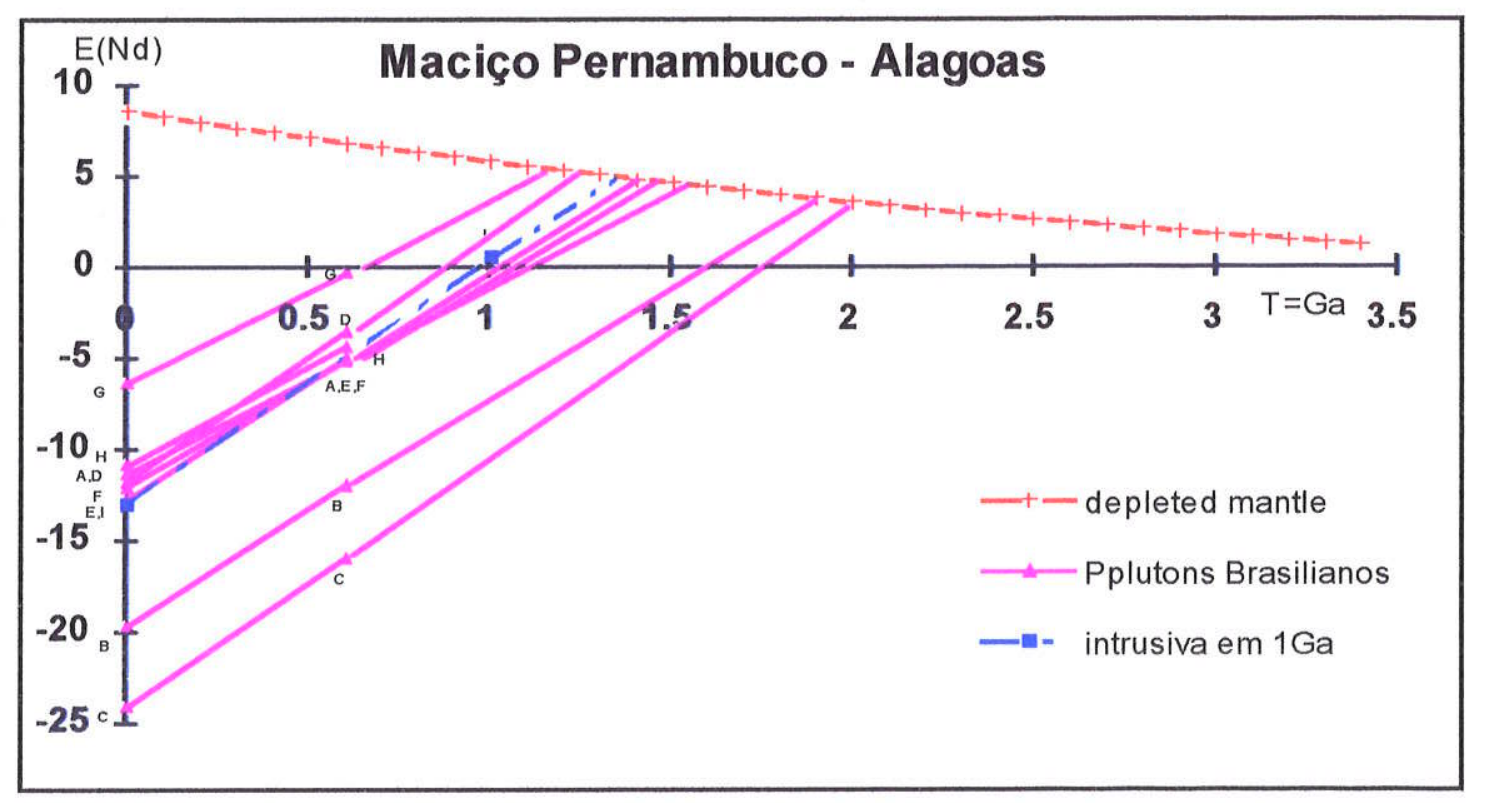

Fig. 5.7-13: diagrama de evolução isotópica $\varepsilon_{\mathrm{Nd}}$ versus tempo geológico $T(\mathrm{Ga})$ das rochas granitóides - rochas plutônicas brasilianas (triângulos) e rochas granitóides formado em $1 \mathrm{Ga}$ (quadrados) relativos ao M. PEAL.

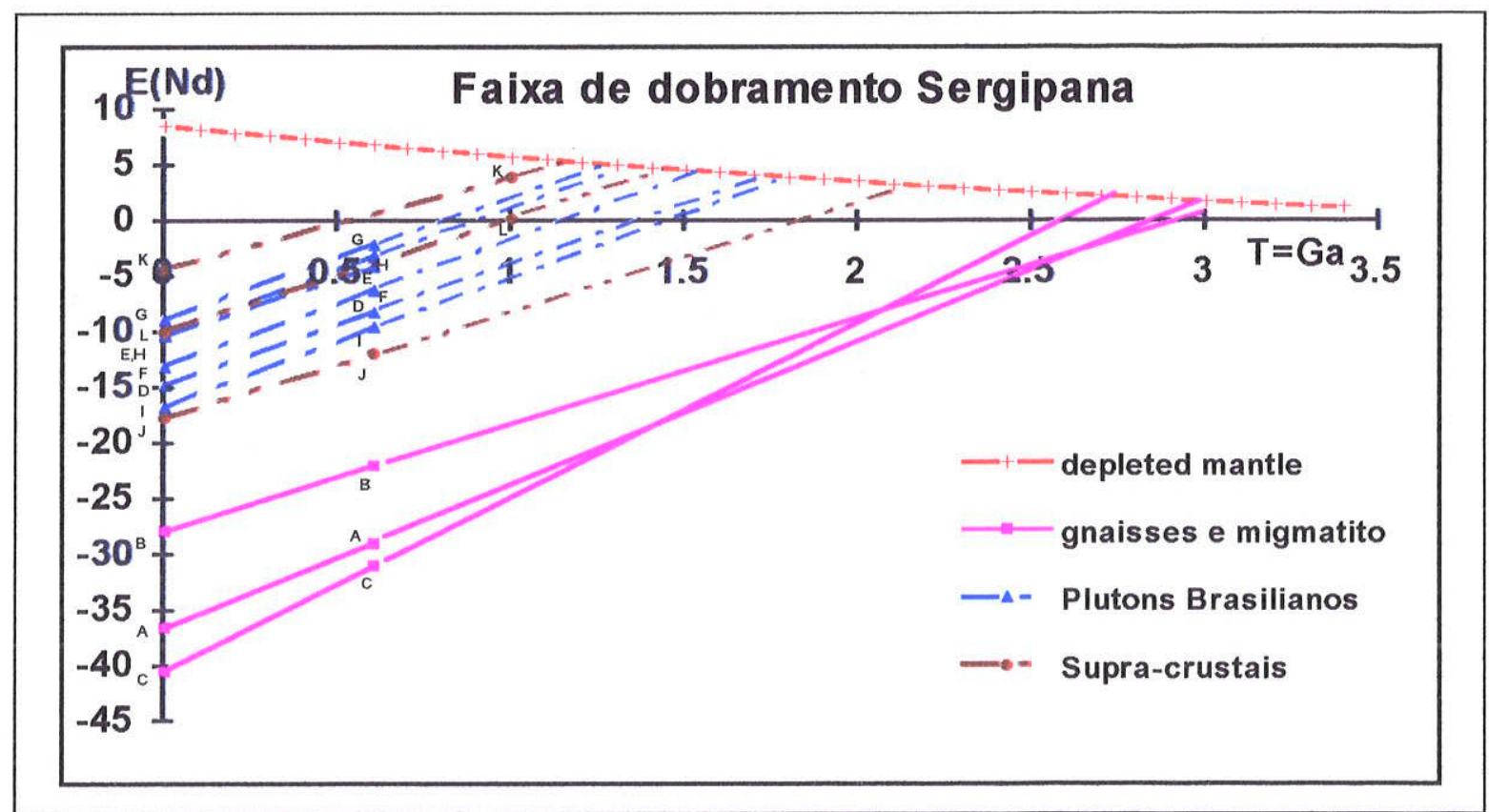

Fig. 5.7-14: diagrama de evolução isotópica $\varepsilon_{\mathrm{Nd}}$ versus tempo geológico $\mathrm{T}(\mathrm{Ga})$ das rochas granitóides (quadrados); rochas granitóides brasilianas (triângulos); metasedimento e vulcânicas ácidas (losangos). 
- MACiÇO PERnAmbuCo - AlagoAS (MPEAL): O MPEAL situa-se a sul do Lineamento de Pernambuco (Brito Neves 1975) e as idades U-Pb em zircões dos plutons graniticos que ocorrem neste maciço caracterizam épocas de formação relacionadas ao Neoproterozóico, (Van Schmus, 1995).

As assinaturas isotópicas de Nd do MPEAL mostram-se bastante similares às observadas no SPP e SPAB. As idades Sm-Nd ( $\left.\mathrm{T}_{D M}\right)$ indicam épocas Paleo e Mesoproterozóicas (1,9 a 1,17Ga) para a diferenciação dos protólitos dessas rochas, mas o principal período de acreção manto-crosta continental ocorreu durante o Mesoproterozóico (fig. 5.7-13 e tab. 5.7-6). Os parâmetros de $\varepsilon_{\mathbb{N} d}(t=0.6)$ mostram-se negativos variando de -16 a $-0,4$, com concentração de valores em -5 .

\section{7-4: SUB-DOMÍNIO SUL}

SISTEMA DE DOBRAMENTOS SERGIPANO (SDS) - O SDS ocorre como uma faixa marginal, ao Craton de S. Francisco, sendo representado por metassedimentos com embasamento formado por rochas gnáissico-migmatíticas e com muitos granitóides associados. As idades Rb$\mathrm{Sr}$, bem como K-Ar, caracterizam a formação dessas rochas durante o Neoproterozóico (Ciclo Brasiliano).

As análises isotópicas de $\mathrm{Nd}$ das rochas granitóides resultaram em idades modelo $\mathrm{Sm}-\mathrm{Nd}$ ( $\left.\mathrm{T}_{\mathrm{DM}}\right)$ predominantemente Mesoproterozóicas, e os $\varepsilon_{\mathrm{Nd}}\left(\mathrm{t}_{\ell-\mathrm{P}_{\mathrm{b}}}=0,6\right)$ desses plutons são negativos, variando entre $-8,2$ a $-2,1$. Observa-se no diagrama $\varepsilon_{\mathrm{Nd}}$ versus $\mathrm{T}(\mathrm{Ga})$ (fig. 5.7-14) que a grande maioria dos pontos assinalados (valores de $\varepsilon_{\mathrm{Nd}}\left(\mathrm{t}_{\mathrm{r}-\mathrm{pl}}\right)$ ) posicionaram-se abaixo da reta CHUR (eixo das abcissas), sugerindo tratar-se de rochas formadas através de retrabalhamento de material crustal pré-existente.

Adicionalmente ocorrem neste setor rochas gnáissicas e migmatíticas referidas como representantes de uma janela de embasamento do Craton do $\mathrm{S}$. Francisco. As idades $\mathrm{T}_{\mathrm{DM}}$ distribuem-se entre 3,02 e $2,74 \mathrm{Ga}$, com valores de $\varepsilon_{\mathrm{Nd}}\left(\mathrm{t}_{\mathrm{u}-\mathrm{ph}}=0.6\right)$ negativos distribuidos entre -31 e -29 (tabela 5.2-7), sugerindo longo tempo de residência crustal ( $>2 \mathrm{Ga}$ ) para os seus protólitos.

No caso dos valores $T_{D M}$ mais jóvens $(1.5-1.2 \mathrm{Ga})$ em rochas dos SDS, como também é o caso do MPEAL e SPP/SPAB, não se pode descartar a possibilidade de misturas de fontes tais 
como material juvenil Neoproterozóico, e material retrabalhado Paleoproterozóico ou Arqueano. Por outro lado, pesquisas futuras se fazem necessárias se quizer caracterizar, inequivocamente, a presença de material juvenil de idade Brasiliana.

SISTEMA DE DOBRAMENTOS RICHO DO PONTAL (SRP) - O SRP é representado predominantemente por rochas graniticas, gnáissicas e migamatíticas bem como por sequências vulcanossedimentares que balizam a porção Norte do Craton do S. Francisco.

As análises isotópicas Sm-Nd dessas rochas indicam o Arqueano como o principal período de acreção de material do manto, com idades modelo $T_{D M}$ variando entre 3,4 a 3,0Ga), similares às observadas para os dominios correspondentes do Craton São Francisco. Os dados isocrônicos $\mathrm{Rb}-\mathrm{Sr}$ caracterizam épocas de formação relativas ao Arqueano e ao Paleoproterozóico. Os valores de $\varepsilon_{\mathrm{Nd}}\left(\mathrm{t}_{\mathrm{Rb}-\mathrm{Sr}}\right)$ posicionam-se próximo à curva da evolução do manto $(+3,6 \mathrm{a}-0,9)$.

Distingue-se desse padrão amostra $\mathrm{D}$ (tabela $5.7-8$ e fig. 5.7-15), que apresenta valor de $\varepsilon_{\mathrm{Nd}}\left(\mathrm{t}_{\mathrm{R} b-\mathrm{Sr}}=2,06\right)$ de -14 e $\mathrm{f}_{\mathrm{Sm} \mathrm{Nd}}=+1.02$, sugerindo fracionamento químico do sistema $\mathrm{Sm}-\mathrm{Nd}$ ocorrido possivelmente durante o metamorfismo Paleoproterozóico. Considerando-se modelo de evolução de $\mathrm{Nd}$ em estágio duplo, resulta uma idade aparente Arqueana para o protólito crustal dessa rocha, concordante com os demais dados observados para essa região.

Adicionalmente ocorrem rochas graníticas intrusivas nas sequências gnáissicomigmatíticas. Os dados U-Pb em zircões indicam para a formação desses granitóides idades de 0,97Ga, e para os seus protólitos época de derivação do manto relacionada ao Mesoproterozóico $\left(\mathrm{Sm}-\mathrm{Nd}, \mathrm{T}_{\mathrm{DM}}\right.$ de $1,44 \mathrm{Ga}$ ), similar às observadas em áreas vizinhas tais como MPEAL e SDS. No diagrama $\varepsilon_{\mathrm{Nd}}$ versus $\varepsilon_{\mathrm{Sr}}$ ( fig.5.7-16) observa-se as amostras A e B próximas da origem, sugerindo periodo relativamente curto de residência crustal para os seus protolitos.

FAIXA RIO PRETO - Esta faixa é constituída por um embasamento granito-gnáissico e por coberturas supracrustais (Inda e Barbosa, 1978). As idades Sm-Nd, $\mathrm{T}_{\mathrm{DM}}$, obtidas refletem acreções de material juvenil tanto no Arqueano quanto no Paleoproterozóico. Algumas rochas indicam idades Paleoproterozóicas tanto no método $\mathrm{Rb}-\mathrm{Sr}$ ( isócrona) bem como no $\mathrm{Sm}-\mathrm{Nd}$ ( $\mathrm{T}_{\mathrm{DM}}$ ) sugerindo tempo curto entre diferenciação mantélica e formação, como é o caso da rocha gnáissica $G$ (figs. 5.7-15, 5.7-16 e tab.5.7-9). Por outro lado, os valores de $\varepsilon_{\mathbb{N d}}$ e $\varepsilon_{\mathrm{Sr}}\left(\mathrm{t}_{\mathrm{Rb}-\mathrm{Sr}=1,88 \mathrm{Ga}}\right)$ para a rocha granitóide $F$, são respectivamente negativo e positivo, posicionando-se no quarto quadrante e distante da origem, sugerindo intervalo da residência crustal relativamente longo para o protólito dessa rocha (maior que $1 \mathrm{Ga}$ ). Note-se que acreções Paleoproterozóicas com 


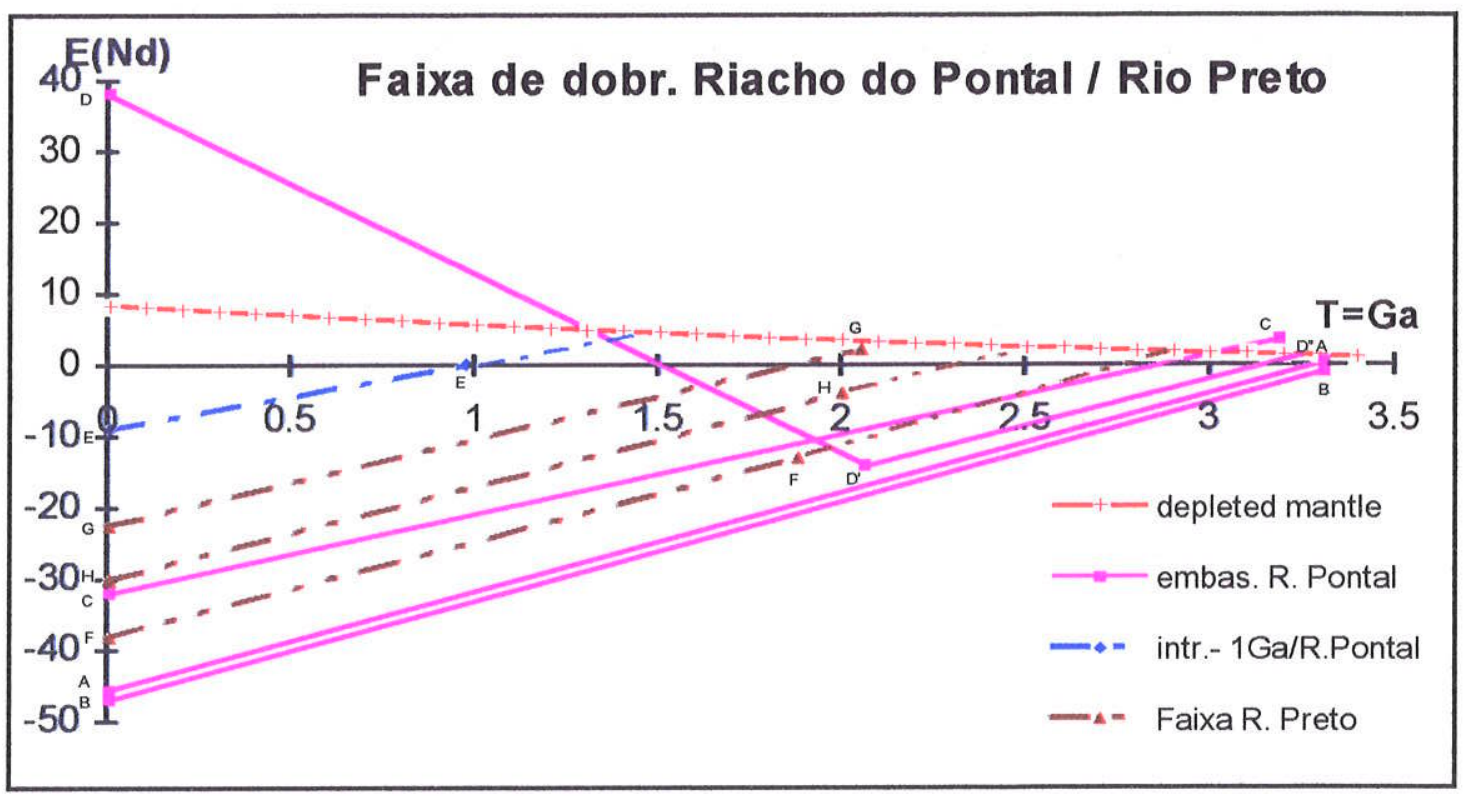

Fig. 5.7-15: diagrama de evolução isotópica $\varepsilon_{\mathrm{Nd}}$ versus tempo geológico $\mathrm{T}(\mathrm{Ga})$ das rochas granitóides (quadrados) do embas. Riacho do Pontal; rochas granitóides intrusivas no embas. R. do Pontal (losangos); rochas granitóides da Faixa de dobramento do R. Preto (triângulos).

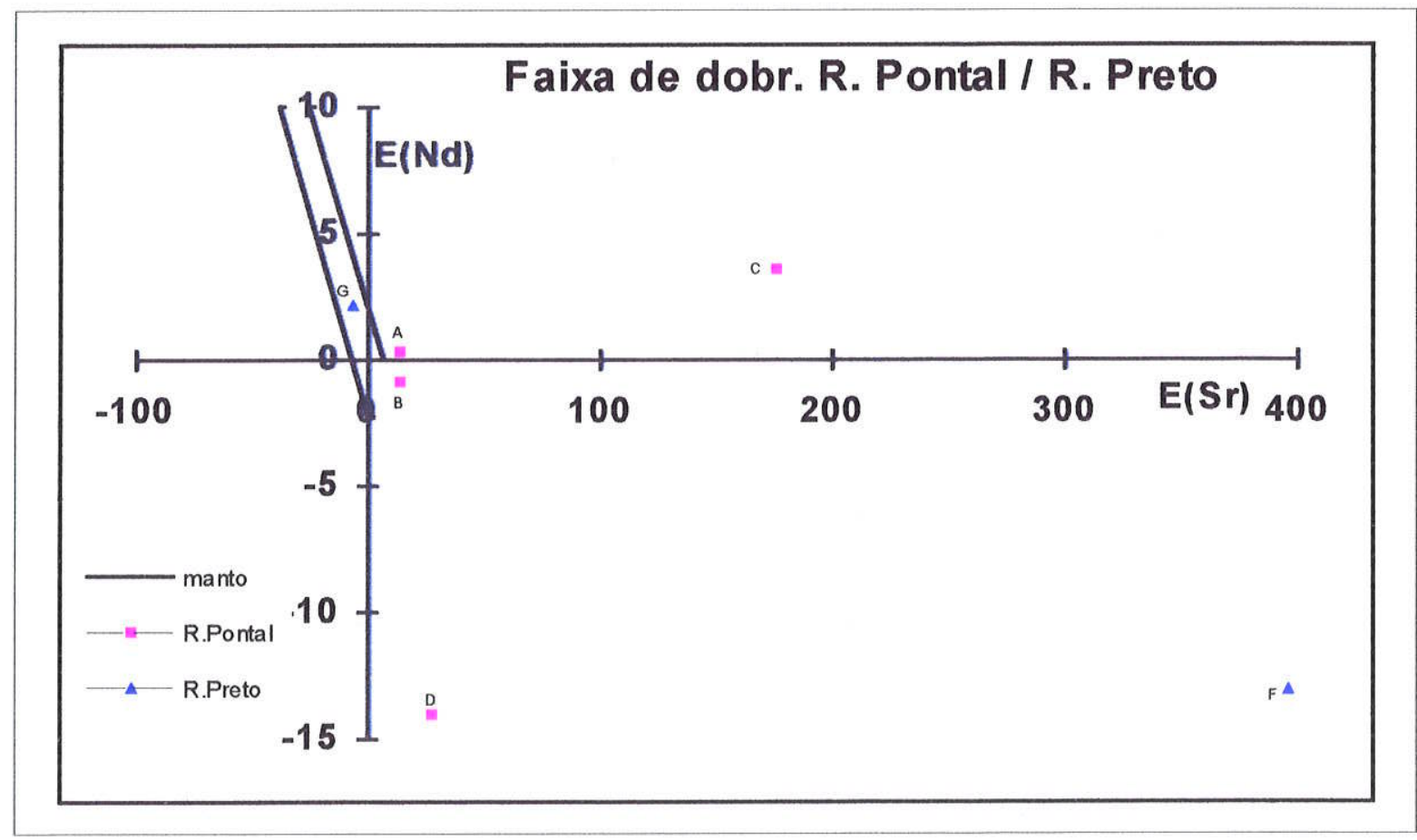

Fig. 5.7-16: diagrama $\varepsilon_{S r}(t)$ versus $\varepsilon_{N d}(t)$. As legendas são as mesmas da fig. 5.7-15 


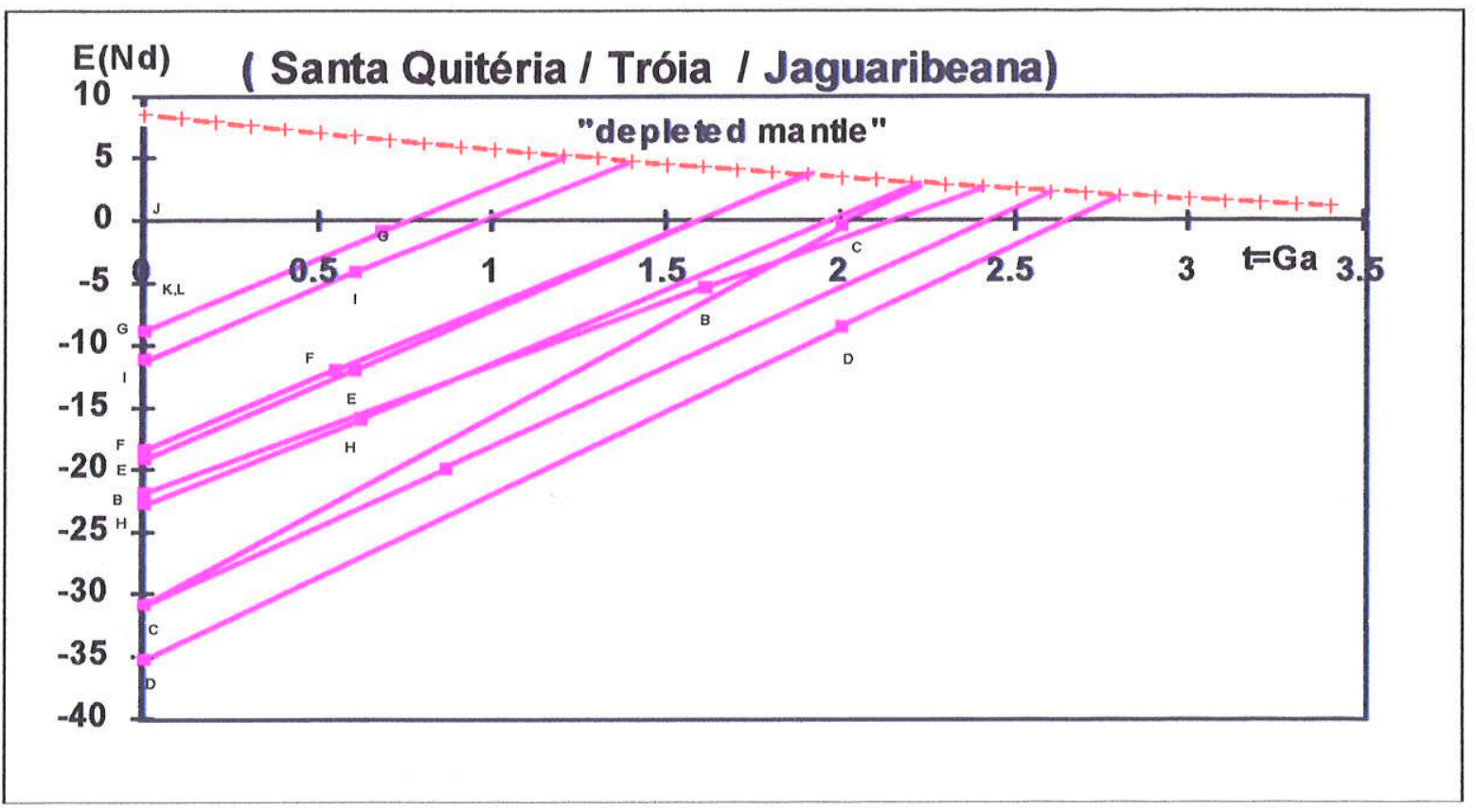

Fig. 5.7-17: diagrama de evolução isotópica $\varepsilon_{\mathbb{N d}}$ versus tempo geológico $T(\mathrm{Ga})$ das rochas granulíticas e granitóides da região Norte da Prov. Borborema ( Sta. Quitéria, Tróia, e Jaguaribeana).

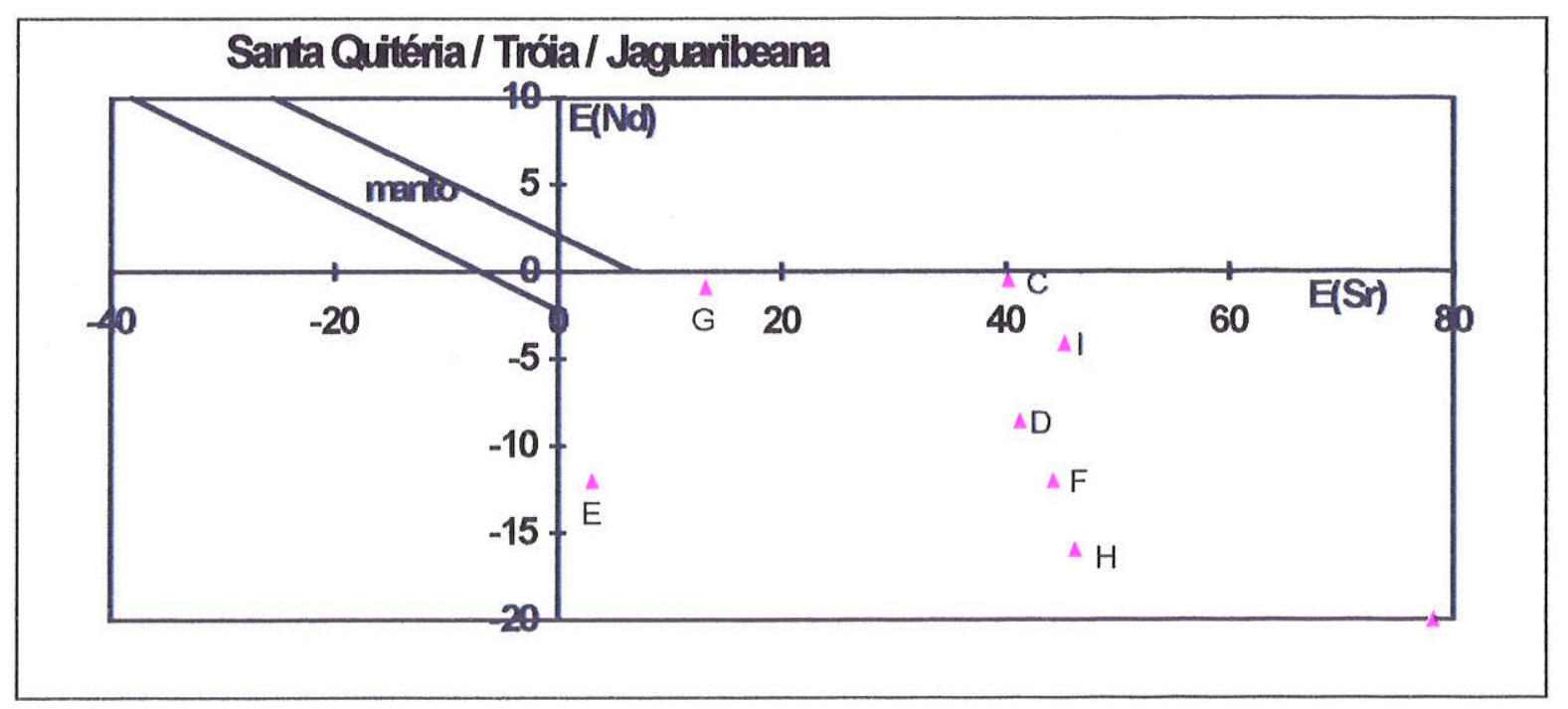

Fig. 5.7-18: diagrama $\varepsilon_{\mathrm{Sr}}(\mathrm{t})$ versus $\varepsilon_{\mathrm{Nd}}(\mathrm{t})$ das rochas granitóides - porção Norte da Província Borborema. 
padrões similares às observadas nesta faixa foram descritas para a região vizinha de Correntina, parte noroeste do Craton do S. Francisco.

\section{7-5: SUB DOMÍNIO NORTE}

A porção Norte e Noroeste da Provincia Borborema é representada pelas Faixas de Dobramento Rio Curu (RC) e Jaguaribeana (JG) e Maciços Medianos de Tróia e Santa Quitéria (Domínio Cearense). Na literatura especializada encontram-se descrições geológicas destas faixas e maciços de forma detalhada, por exemplo em Brito Neves (1975). De um modo geral predominam neste setor rochas de médio a alto grau metamórfico, formadas no Paleoproterozóico (Ciclo Transamazônico) ou no Neoproterozóico (Ciclo Brasiliano). A tabela 5.7-10 resume os principais dados geocronológicos deste sub-dominio.

As análises Sm-Nd existentes, em rochas granitóides, indicam o Paleoproterozóico como o principal período de diferenciação de material do manto, notadamente no setor centro - sul do Ceará. Idade modelo $\mathrm{Sm}-\mathrm{Nd}\left(\mathrm{T}_{\mathrm{DM}}\right)$ relativa ao Arqueano foi obtida em granitóide pertencente ao Maciço de Tróia $(2,8 \mathrm{Ga})$, enquanto que valores relativos ao Mesoproterozóico ocorrem na porção norte, principalmente em sequências supracrustais (figs. 5.7-2 e 5.7-17 e tab. 5.7-10).

Os valores de $\varepsilon_{\mathrm{Nd}}\left(\mathrm{t}_{\text {idades } \mathrm{Rb}-\mathrm{S}_{\mathrm{r}}}\right)$, mostram-se negativos, distribuindo-se entre -20 e $-0,5$ (tabela 5.7-10), sugerindo origem a partir de fusão parcial de material crustal pre-existente.

Os dados relativos às rochas desse sub-domínio, quando analisados em diagrama $\varepsilon_{\mathbb{N d}} \times \varepsilon_{\mathrm{Nd}}$ (fig. 5.7-18), concentram-se no quarto quadrante, sugerindo intervalo de tempo relativamente longo entre acreção de material do manto e os episódios formadores de rochas.

\section{7-6: SUB - DOMÍNIO OESTE}

O sub Domínio Oeste da Província Borborema encontra-se recoberto pelos sedimentos Fanerozóicos da Bacia do Parnaíba. Embora não existam dados isotópicos relativos ao seu embasamento neste setor, observamos que idades $\mathrm{Sm}-\mathrm{Nd}\left(\mathrm{T}_{\mathrm{DM}}\right)$ Paleo-Mesoproterozóicas ocorrem ao longo do lineamento Transbrasiliano, retratando possivelmente a maior parte do substrato da Bacia do Parnaiba. Dados isotópicos a serem obtidos em amostras de sondagens, poderão ser de grande valia para o conhecimento geotectônico da porção oeste da Província Borborema. 


\section{7-7 - RESUMO DA PROVÍNCIA BORBOREMA:}

Os principais eventos de acreção manto-crosta continental em terrenos da Província Borborema, tendo por base idades modelos $\mathrm{Sm}-\mathrm{Nd}, \mathrm{T}_{\mathrm{DM}}$, são:

\section{1 - NORDESTE}

1- Maciço de Rio Piranhas: embasamento - 3,2 a 2,6Ga; plutons intrusivos - 2,6 a $2,5 \mathrm{Ga}$.

2 - Maciço Caldas Brandão: embasamento - 3,7 a $1,8 \mathrm{Ga}$ (concentração no Paleoproteroz.).

3 - Faixa Seridó: embasamento - 2,8 a 2,6Ga

plutons intrusivos - 2,56 a $2,3 \mathrm{Ga}$; supracrustais - 2,8 a $1,49 \mathrm{Ga}$.

II - CENTRAL

4 - Faixa de Dobramentos Pajeú Paraíba: embasamento - 2,4 a 1,6Ga; plutons intrusivos - 1,8 a 1,3Ga; supracrustal - 1,4Ga.

Faixa de Dobramentos Pincó-Alto Brigida - plutons brasilianos - 2,4 a 1,2Ga; supracrustal - $1,8 \mathrm{Ga}$; linha sienitóide (Alto Teixeira ) - 2,4 a 1,7Ga.

5 - Maciço Pernambuco - Alagoas: plutons brasilianos - 1,98 a 1,17Ga.

III - SUL

6 - Sistema de Dobramentos Sergipano: fragmento arqueano - 3,02 a 2,7Ga;

$$
\begin{aligned}
& \text { plutons intrusivos - 1,75 a } 1,25 \mathrm{Ga} \text {; } \\
& \text { supracrustais - 2,1 a 1,1 Ga. }
\end{aligned}
$$

7 - Sistema de Dobramentos Rio Preto: granitóides 2,9Ga e / 2,5 a 2,1Ga.

8 - Sistema de Dobramentos Riacho do Pontal : embasamento - 3,45 a 3,02Ga; plutons intrusivos $-1,46 \mathrm{Ga}$

IV - NORTE

9 -Faixas dobrada Jaguaribeana - granitóides - 2,2 a 1,2 Ga;

10- Maciços: Tróia - granitóides 2,8 (fragmento Arqueano) e 1,9Ga; Santa Quitéria - granitóides= 1,9 a 1,2Ga.

Os principais domínios de acreção da crosta juvenil podem ser vista na fig. 5.7-19. 
TAB. 5.7: Província Borborema

TAB. 5.7-1: Embasamento do Rio Piranhas

\begin{tabular}{|c|c|c|c|c|c|c|c|c|c|c|c|c|c|c|c|c|c|}
\hline $\begin{array}{l}\text { SPS } \\
\text { /litol }\end{array}$ & $\begin{array}{l}\text { coord.l } \\
\text { (p.local.) }\end{array}$ & $\begin{array}{l}\text { n. campo/ } \\
\text { região }\end{array}$ & $\begin{array}{l}\text { lito- } \\
\text { logia }\end{array}$ & $\begin{array}{l}\text { diag. } \\
\text { pontos }\end{array}$ & \begin{tabular}{|l|}
$T_{\text {chur }}$ \\
(Ga) \\
Goldstein \\
et.al 19844
\end{tabular} & $\begin{array}{l}T_{\text {dm2 }} \\
\text { (Ga) } \\
\text { estagio } \\
\text { duplo }\end{array}$ & $\begin{array}{l}T_{d m} \\
\text { (Ga) } \\
\text { Depaolo- } \\
1981\end{array}$ & $\begin{array}{l}{ }^{743} \mathrm{Nd}- \\
{ }^{144} \mathrm{Nd}\end{array}$ & $\begin{array}{l}{ }^{447} \mathrm{Sm}- \\
{ }^{144} \mathrm{Nd}\end{array}$ & $\begin{array}{l}\mathrm{Sm} \\
\mathrm{ppm}\end{array}$ & $\begin{array}{l}\mathrm{Nd} \\
\mathrm{ppm}\end{array}$ & $f$ & $\begin{array}{l}E_{\text {ivd }} \\
(0)\end{array}$ & $\begin{array}{l}\varepsilon_{\text {Nd }} \\
(t)\end{array}$ & $\begin{array}{l}\mathbf{t}(\mathrm{Ga})_{\text {mét. }} \\
\mathrm{Ri}_{\text {(fonte) }}\end{array}$ & $\begin{array}{l}\mathcal{E}_{\mathrm{Sr}} \\
(t)\end{array}$ & ref \\
\hline m_gab & $608 / 3650$ & $\mathrm{BR}-\mathrm{PH}-\mathrm{E} 17 \mathrm{I}$ & BAS & A & 2.53 & & 2.77 & $\begin{array}{l}.511366 \\
.000010\end{array}$ & .120365 & 5.44 & 27.33 & -.39 & -24.8 & -3.9 & $2.15_{\mathrm{U} / \mathrm{Pb}}$ & & 1 \\
\hline$m$ & $609 / 3649$ & BR-PH-E19 & BAS & B & 2.41 & & 2.65 & $\begin{array}{l}.511336 \\
.000009\end{array}$ & .114743 & 4.74 & 24.98 & -.42 & -25.4 & -2.9 & $2.15 \mathrm{U} / \mathrm{PD}$ & & 1 \\
\hline gns $t$ & $609 / 3649$ & BR-PH-E2O & GTD & C & 2.39 & & 2.62 & $\begin{array}{l}.511255 \\
.000007\end{array}$ & .108985 & 3.30 & 18.31 & -.45 & -27.0 & -2.9 & 2.15 U/Pb & & 1 \\
\hline m_gab & $611 / 3647$ & BR-PH-E24 & BAS & $D$ & 2.38 & & 2.62 & $\begin{array}{l}.511308 \\
.000038\end{array}$ & .112001 & 4.36 & 23.54 & -.43 & -25.9 & -2.7 & $\begin{array}{l}2.15 \mathrm{U} / \mathrm{Pb} \\
\text { (a) }\end{array}$ & & 1 \\
\hline a_gns & $616 / 3811$ & BR 92.431 & GTD & $E$ & 2.41 & & 2.64 & $\begin{array}{l}.511233 \\
.000011\end{array}$ & .108307 & 21.76 & 121.49 & -.45 & -27.4 & -3.7 & $(2.1)_{\text {est }}$ & & 1 \\
\hline $\mathrm{mig}$ & $614 / 38 \quad 14$ & BR $92-441$ & GTD & $F$ & 2.47 & & 2.68 & $\begin{array}{l}.511091 \\
.000011 \\
\end{array}$ & .101857 & 4.27 & 25.35 & -.48 & -30.2 & -4.8 & $(2.1) \mathrm{est}$ & & 1 \\
\hline a_gns & $601 / 3811$ & BR $92.47 /$ & GTD & $G$ & $2.50 ?$ & & $2.71 ?$ & $\begin{array}{l}.511172 \\
.000011\end{array}$ & $\begin{array}{l}.107664 \\
.000013 \\
\end{array}$ & 11.50 & 64.59 & -.45 & -28.6 & -4.8 & $(2.1)_{\text {est }}$ & & $1^{*}$ \\
\hline a_gns & $?$ & BR-92-70 & GTD & $\bar{H}$ & $3.44 ?$ & $3.20^{\# 1}$ & $3.58 ?$ & $\begin{array}{l}.510944 \\
.000010\end{array}$ & $\begin{array}{l}.122150 \\
.000013 \\
\end{array}$ & 13.33 & 65.99 & -.38 & -33 & -13 & $(2.1) \mathrm{est}$ & & $1^{\star}$ \\
\hline gns_f & $?$ & $S W P-V 1 a$ & GTD & 1 & 2.38 & & 2.60 & $\begin{array}{l}.511150 \\
.000011 \\
\end{array}$ & .101906 & 3.63 & 21.54 & -.48 & -29 & -2.4 & $2.2 \mathrm{UPPB}$ & & $1^{*}$ \\
\hline \multicolumn{18}{|c|}{ plutons Brasilianos } \\
\hline git & $642 / 3749$ & BR-92-38/ & GTD & $J$ & 2.27 & & 2.51 & $\begin{array}{l}.511301 \\
.000012 \\
\end{array}$ & .107176 & 8.55 & 48.24 & -.46 & -26.1 & -19 & $6_{\mathrm{U} / \mathrm{Po}(\mathrm{g})}$ & & 1 \\
\hline git & $621 / 3744$ & $B R 92-391$ & GTD & $\mathrm{K}$ & 1.84 & $2.49^{\# 2}$ & 2.08 & $\begin{array}{l}.511257 \\
.000013\end{array}$ & $\begin{array}{l}.082659 \\
.000007\end{array}$ & 13.53 & 98.98 & -.58 & -26.9 & -18 & $.6 \mathrm{U} / \mathrm{PD}(g)$ & & 1 \\
\hline grt & $620 / 3806$ & $\overline{B R} 92-41$ & GTD & $L$ & 2.01 & $2.53^{* 2}$ & 2.25 & $\begin{array}{l}.511273 \\
.000012 \\
\end{array}$ & $\begin{array}{l}.093321 \\
.000014 \\
\end{array}$ & 8.67 & 56.18 & -.53 & -26.6 & -19 & $.6 \mathrm{U} / \mathrm{Pb}(\mathrm{g})$ & & 1 \\
\hline grt & $615 / 3811$ & $\mathrm{BR} 92.421$ & GTD & $\bar{M}$ & 2.09 & $2.59^{\# 2}$ & 2.33 & $\begin{array}{l}.511232 \\
.000014 \\
\end{array}$ & .094690 & 10.49 & 66.99 & -.52 & -27.4 & -20 & $.6 \mathrm{UPP}(\mathrm{g})$ & & 1 \\
\hline grt & $606 / 3822$ & BR 92-46I & GTD & $\mathrm{N}$ & 2.31 & & 2.55 & $\begin{array}{l}.511339 \\
.000012 \\
\end{array}$ & $\begin{array}{l}.111361 \\
.000032 \\
\end{array}$ & 4.72 & 25.63 & -.43 & -25.3 & -19 & $.6 \mathrm{vPb}(\mathrm{g})$ & & 1 \\
\hline grt & $554 / 3804$ & BR $92-48$ & GTD & 0 & 1.88 & $2.60^{\# 2}$ & 2.11 & $\begin{array}{l}.511156 \\
.000018 \\
\end{array}$ & $\begin{array}{l}.076793 \\
.000007\end{array}$ & 14.01 & 110.32 & -.61 & -28.9 & -20 & $.6 \mathrm{U} / \mathrm{Pb}(\mathrm{g})$ & & 1 \\
\hline
\end{tabular}




\begin{tabular}{|c|c|c|c|c|c|c|c|c|c|c|c|c|c|c|c|c|c|}
\hline $\begin{array}{l}\text { SPS } \\
\text { /litol }\end{array}$ & $\begin{array}{l}\text { coord./ } \\
\text { (p.local.) }\end{array}$ & $\begin{array}{l}\text { n. campol } \\
\text { região }\end{array}$ & $\begin{array}{l}\text { lito- } \\
\text { logia }\end{array}$ & $\begin{array}{l}\text { diag. } \\
\text { pontos }\end{array}$ & \begin{tabular}{l|}
$T_{\text {chur }}$ \\
$(\mathrm{Ga})$ \\
Goldstein \\
et.al.1984 \\
\end{tabular} & $\begin{array}{l}T_{\text {dm2 }} \\
\text { (Ga) } \\
\text { estaglio } \\
\text { duplo }\end{array}$ & $\begin{array}{l}T_{d m} \\
(\mathrm{Ga}) \\
\text { DePaolo- } \\
1981\end{array}$ & $\begin{array}{l}{ }^{144} \mathrm{Nd}- \\
{ }^{144} \mathrm{Nd}\end{array}$ & $\begin{array}{l}{ }_{144}^{14} \mathrm{Sm}- \\
{ }^{\mathrm{Nd}}\end{array}$ & $\begin{array}{l}\mathrm{Sm} \\
\mathrm{ppm}\end{array}$ & $\begin{array}{l}\mathrm{Nd} \\
\mathrm{ppm}\end{array}$ & $f$ & $\begin{array}{l}\varepsilon_{\text {Nd }} \\
(0)\end{array}$ & $\begin{array}{l}\varepsilon_{\text {Nd }} \\
(t)\end{array}$ & $\begin{array}{l}\mathrm{t}(\mathrm{Ga})_{\text {met. }} \\
\mathrm{Ri} \mathrm{i}_{\text {(fonte) }}\end{array}$ & $\begin{array}{l}\varepsilon_{\mathrm{Sr}} \\
(t)\end{array}$ & ref \\
\hline & & & & & & & & & & & & & & & & & \\
\hline $\begin{array}{l}406 / \\
\text { gns }\end{array}$ & $537 / 3540$ & $S C-B-4$ & GTD & $A$ & $\begin{array}{l}2.25 \\
.03\end{array}$ & & $\begin{array}{l}2.47 \\
.02\end{array}$ & $\begin{array}{l}.511196 \\
.000019\end{array}$ & $\begin{array}{l}.099279 \\
.000048\end{array}$ & $\begin{array}{l}12.82 \\
.004\end{array}$ & $\begin{array}{l}78.104 \\
.029\end{array}$ & -.50 & -28.1 & -19 & $\begin{array}{l}0.78 \\
\text { Rors } \\
.705_{(d)}\end{array}$ & 20 & nt \\
\hline gns & $616 / 3543$ & SCB CE $116 /$ & GTD & $B$ & 3.05 & & 3.21 & $\begin{array}{l}.510842 \\
.000013\end{array}$ & $\begin{array}{l}.107679 \\
.000007\end{array}$ & 21.16 & 118.83 & -.45 & -35.0 & -12 & $(2.0)_{e s t}$ & & 1 \\
\hline \begin{tabular}{l|}
$\cdots+-$ \\
gns.gl
\end{tabular} & $627 / 3514$ & BR-93-18G & GTD & C & 2.20 & & 2.42 & $\begin{array}{l}.511161 \\
.000015 \\
\end{array}$ & .094607 & 2.17 & 13.87 & -.52 & -28.8 & -2.7 & $(2.0)_{\mathrm{est}}$ & & 1 \\
\hline gns_m & $640 / 368$ & $\mathrm{BR}-93-471$ & GTD & $D$ & 2.21 & & 2.42 & $\begin{array}{l}.511036 \\
.000015 \\
\end{array}$ & .086488 & 4.83 & 33.77 & -.56 & -31.3 & -3.1 & $(2.0)_{\text {est }}$ & & 1 \\
\hline git & $?$ & $\overrightarrow{S C B}-G-2$ & GTD & $E$ & 2.78 & $1.95^{\# 2}$ & $3.14 ?$ & $\begin{array}{l}.511974 \\
.000009 \\
\end{array}$ & .160500 & 4.69 & 17.67 & -.18 & -13.0 & & $(0.67)_{\text {est }}$ & & 1 \\
\hline $\begin{array}{l}403 / \mathrm{g} \\
\mathrm{ns}\end{array}$ & $711 / 3513$ & $\begin{array}{l}\text { B11 - 3B } \\
\text { Teixeira }\end{array}$ & GTD & $F$ & $\begin{array}{l}2.15 \\
.02\end{array}$ & $1.84^{\# 1}$ & $\begin{array}{l}2.55 ? \\
.01\end{array}$ & $\begin{array}{l}.511908 \\
.000005\end{array}$ & $\begin{array}{l}.145197 \\
.000067\end{array}$ & $\begin{array}{l}4.742 \\
.001\end{array}$ & $\begin{array}{l}19.749 \\
.008\end{array}$ & -.26 & -14.2 & -9.8 & $\begin{array}{l}0.67 \\
\mathrm{Rb} / \mathrm{Sr} \\
.705_{(b)} \\
\end{array}$ & 18 & nt \\
\hline & & & & & & & & & & & & & & & & & \\
\hline \multicolumn{18}{|c|}{ TAB. 5.7-3: Embasamento da Faixa Seridó } \\
\hline gns & $547 / 3646$ & $\begin{array}{l}\text { Gs - } 43 / f \text {.Se- } \\
\text { ridó / Piranhas }\end{array}$ & GTD & A & 2.38 & & 2.61 & .512299 & .111270 & 6.26 & 34.02 & -.43 & -26.1 & -3.5 & $\begin{array}{l}2.08 \\
R 0 / S r \\
.7040_{(\mathrm{h})}\end{array}$ & 28 & 2 \\
\hline gns & $547 / 3647$ & GS. 511 & GTD & $B$ & 2.59 & $2.50^{72}$ & 2.84 & .511433 & .126220 & 2.319 & 11.11 & -.36 & -23.5 & & $(0.67)_{\text {est }}$ & & 2 \\
\hline \multicolumn{18}{|c|}{ Plutons Brasilianos } \\
\hline dio & $643 / 3712$ & $\mathrm{ED}-59 /$ & BAS & $\mathrm{C}$ & 2.32 & & 2.56 & $\begin{array}{l}.511300 \\
.000015 \\
\end{array}$ & .109044 & 3.3 & 18.3 & -.45 & -26.1 & -20 & $\begin{array}{l}.59 \mathrm{Rb} / \mathrm{Sr} \\
.7098_{(\mathrm{h})} \\
\end{array}$ & 85 & 2 \\
\hline dio & $644 / 3711$ & $E D-62$ & BAS & $D$ & 2.02 & & 2.31 & $\begin{array}{l}.511530 \\
.000015 \\
\end{array}$ & $\begin{array}{l}.113381 \\
.000021 \\
\end{array}$ & 7.5 & 40.0 & -.42 & -21.6 & -15 & $\begin{array}{l}.59 \mathrm{Rb} / \mathrm{Sr} \\
.7098_{\mathrm{hb}}\end{array}$ & 85 & 2 \\
\hline grt & $626 / 3636$ & $\mathrm{MS}-122 \mathrm{Al}$ & GTD & $E$ & 2.27 & & 2.49 & .511124 & .095479 & 4.8 & 30.4 & -.51 & -29.5 & -22 & $\begin{array}{l}.57 \mathrm{Rb} / \mathrm{Sr} \\
.7080_{(\mathrm{h})}\end{array}$ & 59 & 2 \\
\hline grt & $621 / 3634$ & $A C-1 A l$ & GTD & $F$ & 2.18 & & 2.43 & .511365 & .108064 & 4.7 & 26.3 & -.45 & -24.8 & -20 & $\begin{array}{l}.45 \mathrm{Rb} / \mathrm{sr} \\
.7192 \text { (h) } \\
\end{array}$ & 216 & 2 \\
\hline
\end{tabular}




\begin{tabular}{|c|c|c|c|c|c|c|c|c|c|c|c|c|c|c|c|c|c|}
\hline grt & $625 / 3639$ & $A C-7 B$ & GTD & $G$ & 1.88 & $2.47^{32}$ & 2.12 & .511298 & .088134 & 3.6 & 24.7 & -.55 & -26.1 & -19 & $\begin{array}{l}.55 \mathrm{Ro} / \mathrm{Sr} \\
.7074_{(\mathrm{n})}\end{array}$ & 50 & 2 \\
\hline gns & $650 / 3713$ & SED GN36/ & GTD & $H$ & 1.77 & $2.34^{172}$ & 2.03 & $\begin{array}{l}.511395 \\
.000010\end{array}$ & .089741 & 2.56 & 17.25 & -.54 & -24.2 & -16 & $.6 \cup / \mathrm{Pb}(g)$ & & 1 \\
\hline \multicolumn{18}{|c|}{ intrusiva em $1 \mathrm{Ga}$} \\
\hline grt & $624 / 3638$ & $A C-4 B /$ & GTD & 1 & 1.36 & & 1.65 & .511602 & .080744 & 9.2 & 68.9 & -.59 & -20.2 & -4.8 & $\begin{array}{l}1.04 \\
\mathrm{Rb} / \mathrm{s} \\
.7045 \text { (n) }\end{array}$ & 17 & 2 \\
\hline \multicolumn{18}{|c|}{ supra - crustais } \\
\hline gns $f$ & $647 / 3709$ & SED - J-4I & GTD & $J$ & 2.50 & & 2.75 & $\begin{array}{l}.511410 \\
.000009 \\
\end{array}$ & .122337 & 5.43 & 26.84 & -.38 & -24 & -5.0 & $(2.0)_{\text {est }}$ & & 1 \\
\hline gns $f$ & $647 / 3709$ & SED-J-11 & GTD & $\mathrm{K}$ & $\ldots$ & $2.80^{71}$ & $3.66 ?$ & $\begin{array}{l}.511666 \\
.000051\end{array}$ & .154235 & .63 & 2.47 & -.22 & -19 & -8.1 & $(2.0)_{\mathrm{est}}$ & & 1 \\
\hline gns & $607 / 3614$ & SED-Gf - 55 & GTD & $L$ & 1.04 & & 1.49 & $\begin{array}{l}.512098 \\
.000010\end{array}$ & .117333 & 5.14 & 26.49 & -.40 & -10.5 & +7.7 & $1.8_{\mathrm{U} / \mathrm{Pb}(\mathrm{g})}$ & & 1 \\
\hline m_vul & Jucurutu & 65401 & VAC & $M$ & 2.35 & & 2.60 & $\begin{array}{l}.511370 \\
.000027\end{array}$ & .114973 & 9.75 & 51.28 & -.42 & -24.7 & -3.9 & $\begin{array}{l}2.0 \\
\mathrm{UPb}(\mathrm{h})\end{array}$ & & 2 \\
\hline m_vul & Jucurutu & 65421 & VAC & $\mathrm{N}$ & 2.35 & & 2.60 & $\begin{array}{l}.511372 \\
.000028\end{array}$ & .115109 & 9.87 & 51.85 & -.41 & -24.7 & -3.9 & $\begin{array}{l}2.0 \\
\text { U/Pb(h) }\end{array}$ & & 2 \\
\hline m_vul & Jucurutu & 65431 & VAC & 0 & 2.26 & & 2.52 & $\begin{array}{l}.511410 \\
.000027\end{array}$ & .114188 & 9.64 & 51.05 & -.42 & -24.0 & -2.9 & $\begin{array}{l}2.0 \\
\mathrm{U} / \mathrm{PE}(\mathrm{A})\end{array}$ & & 2 \\
\hline m_vul & Jucurutu & 6548 & VAC & $\bar{P}$ & 2.41 & & 2.62 & $\begin{array}{l}.511168 \\
.000024\end{array}$ & .103979 & 6.29 & 36.58 & -.47 & -28.7 & -5.0 & $\begin{array}{l}2.0 \\
\mathrm{U} / \mathrm{PU}(\mathrm{n})\end{array}$ & & 2 \\
\hline m_vul & Jucurutu & 65491 & VAC & $Q$ & 1.96 & & 2.26 & $\begin{array}{l}.511566 \\
.000215\end{array}$ & .113801 & -.31 & 49.47 & -.42 & -20.9 & .2 & $\begin{array}{l}2.0 \\
\text { U/Pbin }) \\
\end{array}$ & & 2 \\
\hline$m_{m}$ vul & Jucurutu & 65541 & VAC & $\mathrm{R}$ & 2.02 & & 2.31 & $\begin{array}{l}.511574 \\
.000040\end{array}$ & .116556 & 7.55 & 39.17 & -.41 & -20.8 & -.3 & $\begin{array}{l}2.0 \\
\text { UPSE(h) }\end{array}$ & & 2 \\
\hline m_vul & $\begin{array}{l}\text { SW de } \\
\text { Florândia }\end{array}$ & ED 44I & VAC & $S$ & 1.05 & & 1.67 & $\begin{array}{l}.512270 \\
.000030 \\
\end{array}$ & $\begin{array}{l}.143438 \\
.000038 \\
\end{array}$ & 5.84 & 24.62 & -.27 & -7.2 & 5.05 & $(1.8)_{\text {est }}$ & & 2 \\
\hline m_vul & $\begin{array}{l}\text { SW de } \\
\text { Florândia }\end{array}$ & ED 46! & VAC & $T$ & -- & $2.00^{\#+}$ & $3.33 ?$ & $\begin{array}{l}.512760 \\
.000030 \\
\end{array}$ & .199294 & 3.80 & 11.53 & .01 & 2.4 & 1.8 & $\overline{(1.8)_{\text {est }}}$ & & 2 \\
\hline m_vul & $\begin{array}{l}\text { SW de } \\
\text { Florândia }\end{array}$ & ED 48/ & VAC & $\mathrm{U}$ & $\cdots$ & & 2.07 & $\begin{array}{l}.512750 \\
.000030 \\
\end{array}$ & .192220 & 4.25 & 13.37 & -.02 & 2.2 & 3.2 & $(1.8)_{\text {est }}$ & & 2 \\
\hline m_vul & $\begin{array}{l}\text { SW de } \\
\text { Florândia }\end{array}$ & ED $50 /$ & VAC & $\bar{V}$ & --- & & 1.83 & $\begin{array}{l}.512670 \\
.000030 \\
\end{array}$ & .182919 & 5.82 & 19.24 & -.07 & 4.1 & 3.8 & $(1.8)_{\text {est }}$ & & 2 \\
\hline
\end{tabular}




\begin{tabular}{|c|c|c|c|c|c|c|c|c|c|c|c|c|c|c|c|c|c|}
\hline $\begin{array}{l}\text { SPS } \\
\text { flitol }\end{array}$ & $\begin{array}{l}\text { coord. } \\
\text { (p.local.) }\end{array}$ & $\begin{array}{l}\text { n. campol } \\
\text { região }\end{array}$ & $\begin{array}{l}\text { lito- } \\
\text { logia }\end{array}$ & $\begin{array}{l}\text { diag. } \\
\text { pontos }\end{array}$ & $\begin{array}{l}T_{\text {chur }} \\
\text { (Ga) } \\
\text { Goldstern } \\
\text { et.al.1984 }\end{array}$ & $\begin{array}{l}T_{d m 2} \\
\text { (Ga) } \\
\text { estágio } \\
\text { duple }\end{array}$ & $\begin{array}{l}T_{\mathrm{dm}} \\
(\mathrm{Ga}) \\
\text { Depaclo- } \\
1981\end{array}$ & $\begin{array}{l}{ }^{143} \mathrm{Nd}- \\
{ }^{144} \mathrm{~d}\end{array}$ & $\begin{array}{l}{ }^{147} \mathrm{Sm}- \\
{ }^{144} \mathrm{Nd}\end{array}$ & $\begin{array}{l}\mathrm{Sm} \\
\mathrm{ppm}\end{array}$ & $\begin{array}{l}\mathrm{Nd} \\
\mathrm{ppm}\end{array}$ & $f$ & $\begin{array}{l}\varepsilon_{\text {No }} \\
(0)\end{array}$ & $\begin{array}{l}\varepsilon_{\mathrm{NC}} \\
(\mathrm{t})\end{array}$ & $\begin{array}{l}\mathrm{t} \text { (Ga)mét. } \\
\mathrm{Ri} \mathrm{i}_{\text {(fonte) }}\end{array}$ & $\begin{array}{l}\varepsilon_{\mathrm{St}} \\
(\mathrm{t})\end{array}$ & ref \\
\hline \multicolumn{18}{|c|}{ TAB. 5.7-4: Plutons Brasilianos da faixa dobrada Pianco-A.Brigida } \\
\hline grt & $754 / 398 ?$ & SPAB - G Sal & GTD & $A$ & .95 & & 1.40 & $\begin{array}{l}.512113 \\
.000009\end{array}$ & .112413 & 11.39 & 61.27 & -.43 & -10.2 & -3.8 & $(.6)_{\text {est }}$ & & 1 \\
\hline gnd & $733 / 3831$ & -Gd-Conc2. & GTD & $B$ & .72 & & 1.22 & $\begin{array}{l}.512257 \\
.000009 \\
\end{array}$ & $\begin{array}{l}.115844 \\
.000026\end{array}$ & 6.32 & 32.99 & -.41 & -7.4 & -1.2 & $(.6)_{\text {est }}$ & & 1 \\
\hline $\begin{array}{l}z-1 \\
\text { grt }\end{array}$ & $718 / 3840$ & GA- Itab. & GTD & C & 1.31 & & 1.65 & $\begin{array}{l}.511787 \\
.000010 \\
\end{array}$ & .097471 & 8.68 & 53.85 & -.50 & -16.6 & -9 & $(.6)_{\text {est }}$ & & 1 \\
\hline sie & $706 / 3734$ & SPAB-Sy-Cat. & GTD & D & 2.11 & & 2.39 & $\begin{array}{l}.511522 \\
.000015\end{array}$ & .116234 & 2.47 & 12.85 & -.41 & -21.8 & -16 & $(6)_{\text {est }}$ & & 1 \\
\hline $\begin{array}{l}-- \\
\text { gnd }\end{array}$ & $728 / 3801$ & SPAB-Gd-Nol. & GTD & $E$ & .84 & $1.30^{\text {F2 }}$ & 1.41 & .512277 & .131245 & 7.82 & 36.03 & -.33 & -7.0 & -2.0 & $(.6)_{\text {est }}$ & & 1 \\
\hline gnd & $718 / 3743$ & Gd-Emas 1. & GTD & $F$ & .80 & & 1.30 & .512228 & .118307 & 6.65 & 33.99 & -.40 & -8.0 & -2.0 & $(.6)_{\text {est }}$ & & 1 \\
\hline \multicolumn{18}{|c|}{ intrusivas em $1 \mathrm{Ga}$} \\
\hline gnd & $816 / 393$ & SPAB - G1/ & GTD & G & 1.16 & $1.54^{\# 1}$ & 1.68 & $\begin{array}{l}.512152 \\
.000023 \\
\end{array}$ & .133056 & 8.50 & 38.63 & -.32 & -9.5 & -1.8 & $.95 \mathrm{U} / \mathrm{Pb}$ & & 1 \\
\hline gnd & $816 / 3903$ & SPAB-G-1a. & GTD & $H$ & 1.20 & $1.56^{\# 1}$ & 1.71 & $\begin{array}{l}.512140 \\
.000009 \\
\end{array}$ & .133529 & 5.07 & 22.96 & -.32 & -9.7 & -2.1 & $\begin{array}{l}.95 \mathrm{U} / \mathrm{PD} \\
\mathrm{a}\end{array}$ & & 1 \\
\hline \multicolumn{18}{|c|}{ supra-crustal } \\
\hline m_rio & $736 / 382$ & SPAB V-6Ob. & VAC & 1 & 1.44 & & 1.77 & $\begin{array}{l}.511755 \\
.000010\end{array}$ & .103102 & 11.19 & 65.63 & -.48 & -17.2 & -5.3 & $\begin{array}{l}1.0_{\text {UIPB }} \\
\text { (g) }\end{array}$ & & 1 \\
\hline \multicolumn{18}{|c|}{ Plutons Brasilianos - Linha Sienitóide (Pianco-A. Brigida / Pajeú-Paraíba) } \\
\hline sie & $812 / 3922$ & SL-SY-TN & GTD & A & 1.58 & & 1.86 & $\begin{array}{l}.511526 \\
.000008\end{array}$ & .089587 & 18.19 & 122.78 & -.54 & -21.7 & -14 & $.6 \cup / P b(g)$ & & 1 \\
\hline sie & $750 / 3806$ & $\begin{array}{l}\text { SL-SY-Tr I } \\
\text { BR92-31 }\end{array}$ & GTD & B & 2.17 & & 2.44 & $\begin{array}{l}.511483 \\
.000012 \\
\end{array}$ & .115816 & 5.56 & 29.03 & -.41 & -22.5 & -16 & $.6 \mathrm{LipD}(\mathrm{g})$ & & 1 \\
\hline gns.g & $736 / 3736$ & SL-G-Sol & GTD & C & 1.87 & & 2.14 & $\begin{array}{l}.511474 \\
.000009 \\
\end{array}$ & .101949 & 4.52 & 26.81 & -.48 & -22.7 & -16 & $.6 \mathrm{U} / \mathrm{Pb}(\mathrm{g})$ & & 1 \\
\hline sie & $714 / 3715$ & $\begin{array}{l}\text { SL-SG-TX } \\
\text { BR92-35 }\end{array}$ & GTD & $\mathrm{D}$ & 1.74 & & 2.04 & $\begin{array}{l}.511555 \\
.000018 \\
\end{array}$ & .102307 & 4.70 & 27.78 & -.48 & -21.1 & -14 & $6 \mathrm{U} / \mathrm{Pb}(\mathrm{g})$ & & 1 \\
\hline o.gns & $730 / 3737$ & SL-Gd-ABr & GTD & $E$ & 1.10 & $1.51^{\# 1}$ & 1.69 & $\begin{array}{l}.512236 \\
.000015 \\
\end{array}$ & .141267 & 8.84 & 37.84 & -.28 & -7.8 & +6 & $\begin{array}{l}1.0_{\mathrm{U} / \mathrm{Pb}} \\
\text { (a) }\end{array}$ & & 1 \\
\hline
\end{tabular}




\section{TAB. 5.7-5A: Embasamento da Faixa dobrada Pajeú - Paraiba}

\begin{tabular}{|c|c|c|c|c|c|c|c|c|c|c|c|c|c|c|c|c|c|}
\hline $\begin{array}{l}\text { SPS } \\
\text { /litol }\end{array}$ & $\begin{array}{l}\text { coord. } \\
\text { (p.local.) }\end{array}$ & $\begin{array}{l}\text { n. campo/ } \\
\text { região }\end{array}$ & $\begin{array}{l}\text { lito- } \\
\text { logia }\end{array}$ & $\begin{array}{l}\text { diag. } \\
\text { pontos }\end{array}$ & 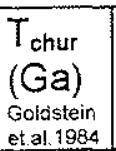 & $\begin{array}{l}T_{\text {dm2 }} \\
\text { (Ga) } \\
\text { estagio } \\
\text { duplo }\end{array}$ & $\begin{array}{l}T_{\mathrm{dm}} \\
(\mathrm{Ga}) \\
\text { DePaolo- } \\
1981\end{array}$ & $\begin{array}{l}{ }^{143} \mathrm{Nd}- \\
{ }^{144} \mathrm{Nd}\end{array}$ & $\begin{array}{l}{ }^{147} \mathrm{Sm}- \\
{ }^{144} \mathrm{Nd}\end{array}$ & $\begin{array}{l}\text { Sm } \\
\text { ppm }\end{array}$ & $\begin{array}{l}\mathrm{Nd} \\
\mathrm{ppm}\end{array}$ & $f$ & $\begin{array}{l}\varepsilon_{N d} \\
(0)\end{array}$ & $\begin{array}{l}\varepsilon_{\mathrm{Nd}} \\
(t)\end{array}$ & $\begin{array}{l}\mathrm{t}_{(\mathrm{G} a)_{\text {mét. }}} \\
\mathrm{Ri}_{\text {(fonte) }}\end{array}$ & $\begin{array}{l}\varepsilon_{S r} \\
(t)\end{array}$ & ref \\
\hline gns & $718 / 3715$ & BR 92341 & GTD & $\bar{A}$ & 1.14 & & 1.60 & $\begin{array}{l}.512068 \\
.000009 \\
\end{array}$ & $\begin{array}{l}.120729 \\
.000019 \\
\end{array}$ & 9.14 & 45.78 & -.39 & -11.1 & -1.4 & $(1.0)_{\text {est }}$ & & 1 \\
\hline gns & $745 / 3741$ & $\begin{array}{l}\text { SPP-GN-SA } \\
\text { BR92-32 }\end{array}$ & GTD & B & 1.86 & & 2.14 & $\begin{array}{l}.511502 \\
.000016\end{array}$ & .103740 & 4.97 & 28.97 & -.47 & -22.2 & -10 & $1.0 \mathrm{U} / \mathrm{Pb}$ & & 1 \\
\hline gns & $836 / 3827$ & SPP-Am-35 & GTD & C & 2.62 & $2.44^{\# 7}$ & 2.86 & $\begin{array}{r}.511364 \\
.000016 \\
\end{array}$ & .123096 & 3.54 & 17.39 & -.37 & -24.9 & -17 & $8 \mathrm{upb}(\mathrm{g})$ & & 1 \\
\hline \multicolumn{18}{|c|}{ gns 1} \\
\hline grt & $721 / 3716$ & BR $92-33$ & GTD & D & 1.39 & & 1.40 & $\begin{array}{l}.512139 \\
.000009 \\
\end{array}$ & .115539 & 5.22 & 27.32 & -.41 & -9.7 & -3.5 & 6 upp (g) & & 1 \\
\hline grt & $822 / 3826$ & $\mid \overrightarrow{B R} 92-281$ & GTD & $E$ & $\cdots$ & $1.40^{\# T}$ & 1.76 & $\begin{array}{l}.512226 \\
.000013 \\
\end{array}$ & .143231 & 2.93 & 12.37 & -.27 & -8.0 & -3.9 & $.6 \mathrm{upb}(\mathrm{g})$ & & 1 \\
\hline \multicolumn{18}{|c|}{ int } \\
\hline gnd & $833 / 3835$ & SPP-G-10 & GTD & $F$ & 0.84 & & 1.28 & $\begin{array}{l}.512140 \\
.000013\end{array}$ & .105803 & 9.59 & 54.81 & -.46 & -9.7 & -1.0 & $1.0 \mathrm{UPb}$ & & 1 \\
\hline $\begin{array}{l}- \\
\text { a.gns }\end{array}$ & $822 / 3826$ & BR $92-29$ & GTD & G & 1.08 & $1.51^{\# 1}$ & 1.61 & $\begin{array}{r}.512185 \\
.000022 \\
\end{array}$ & .132732 & 8.87 & 40.41 & -.33 & -8.8 & -.7 & $1.0 \mathrm{U} / \mathrm{PD}$ & & 1 \\
\hline \multicolumn{18}{|c|}{$\begin{array}{l}\text { a.gns } 1 \\
\text { supra - crustais }\end{array}$} \\
\hline gns.gd & $826 / 3836$ & BR 92261 & GTD & $\vec{H}$ & 0.91 & & 1.42 & $\begin{array}{l}.512199 \\
.000010\end{array}$ & .123464 & 10.76 & 52.70 & -37 & -8.6 & +.8 & $8 \mathrm{UIPb}(g)$ & & 1 \\
\hline tufo & $752 / 3729$ & $B R-93-64 A$ & VAC & I & 0.90 & & 1.42 & .512224 & .126208 & 2.30 & 11.02 & -.36 & -8.1 & +9 & $1.0 \mathrm{U} / \mathrm{Pb}$ & & 1 \\
\hline
\end{tabular}




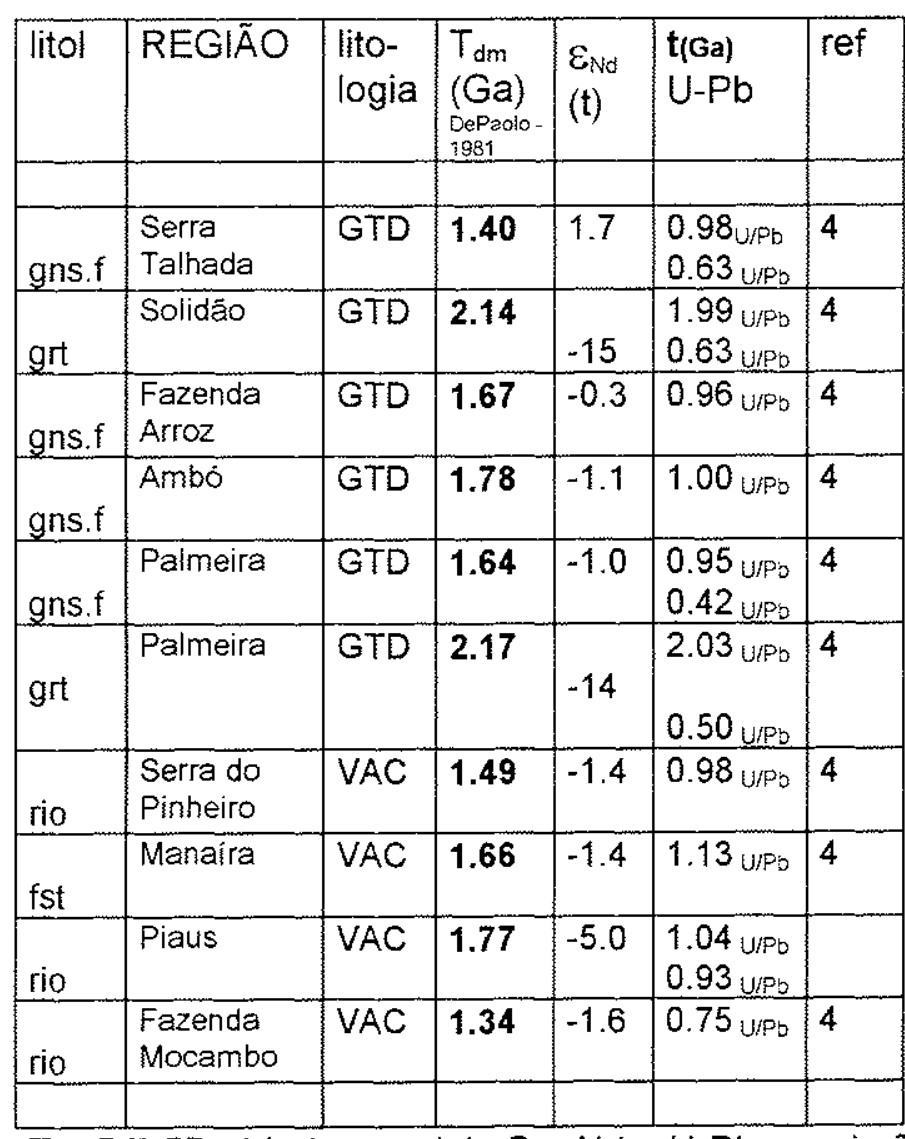

Tab5.7-5B.: Idades modelo Sm-Nd e U-Pb em zircão ref. : POSTER apresentado por Kozuch et. al. (1997)

Regiões de Pajeú-Paraíba / Piancó-A. Brígida. 


\section{TAB. 5.7-6: Plutons Brasilianos do Maciço Pernambuco - Alagoas}

\begin{tabular}{|c|c|c|c|c|c|c|c|c|c|c|c|c|c|c|c|c|c|}
\hline $\begin{array}{l}\text { SPS } \\
\text { /litol }\end{array}$ & $\begin{array}{l}\text { coord./ } \\
\text { (p.local.) }\end{array}$ & $\begin{array}{l}\text { n. campo/ } \\
\text { região }\end{array}$ & $\begin{array}{l}\text { lito- } \\
\text { logia }\end{array}$ & $\begin{array}{l}\text { diag. } \\
\text { pontos }\end{array}$ & $\begin{array}{l}T_{\text {chur }} \\
\text { (Ga) } \\
\text { Goldstein } \\
\text { et.al.1984 }\end{array}$ & $\begin{array}{l}\mathrm{T}_{\mathrm{dm} 2} \\
\text { (Ga) } \\
\text { estagio } \\
\text { duplo }\end{array}$ & $\begin{array}{l}T_{\mathrm{dm}} \\
(\mathrm{Ga}) \\
\text { DePaolo- } \\
1981\end{array}$ & $\begin{array}{l}{ }_{143}^{143} \mathrm{Nd}- \\
{ }^{144} \mathrm{Nd}\end{array}$ & $\begin{array}{l}{ }^{147} \mathrm{Sm}- \\
{ }^{144} \mathrm{Nd}\end{array}$ & $\begin{array}{l}\text { Sm } \\
\text { ppm }\end{array}$ & $\begin{array}{l}\text { Nd } \\
\text { ppm }\end{array}$ & $f$ & $\begin{array}{l}\varepsilon_{\mathrm{Nd}} \\
(0)\end{array}$ & $\begin{array}{l}\varepsilon_{\text {Nd }} \\
(t)\end{array}$ & $\begin{array}{l}\left.\mathrm{t}_{(\mathrm{Ga}}\right)_{\text {mét. }} \\
\mathrm{Ri}_{\text {(fonte) }}\end{array}$ & $\begin{array}{l}\varepsilon_{S r} \\
(t)\end{array}$ & ref \\
\hline grt & $839 / 3833$ & BR - 92231 & GTD & A & 1.11 & & 1.55 & $\begin{array}{l}.512055 \\
.000009 \\
\end{array}$ & .116491 & 15.03 & 78.02 & -.41 & -11.4 & -5.2 & $.6 \mathrm{U} / \mathrm{Pb}(\mathrm{g})$ & & 1 \\
\hline git & $810 / 3606$ & PEAL-GP-FN & GTD & $B$ & 1.61 & & 1.92 & $\begin{array}{l}.511628 \\
.000009 \\
\end{array}$ & .101229 & 11.36 & 67.86 & -.49 & -19.7 & -12 & $.6 \mathrm{U} / \mathrm{Pb}(\mathrm{g})$ & & 1 \\
\hline gns & $923 / 3640$ & PEAL-Mi-15 & GTD & c & 1.71 & & 1.98 & $\begin{array}{l}.511402 \\
.000010 \\
\end{array}$ & .087059 & 9.42 & 65.43 & -.56 & -24.1 & -16 & .6 UPD $(g)$ & & 1 \\
\hline grt & $917 / 3713$ & BR92 18 & GTD & $D$ & .86 & & 1.24 & $\begin{array}{l}.512031 \\
.000015 \\
\end{array}$ & .089475 & 1.20 & 8.11 & -.55 & -11.8 & -3.6 & $6 \mathrm{uPb}(\mathrm{g})$ & & 1 \\
\hline grt g & $919 / 3709$ & BR92-19 & GTD & $E$ & .99 & & 1.37 & $\begin{array}{l}.511981 \\
.000008 \\
\end{array}$ & $\begin{array}{l}.095167 \\
.000011 \\
\end{array}$ & 10.93 & 69.45 & -.52 & -12.8 & -5.0 & $6 \cup / \mathrm{Pb}(g)$ & & 1 \\
\hline sie & $916 / 3757$ & BR $92-20$ & GTD & $F$ & 1.05 & & 1.46 & $\begin{array}{l}.512016 \\
.000013 \\
\end{array}$ & .106634 & 17.80 & 100.94 &.$- \overline{46}$ & -12.1 & -5.2 & $6_{\mathrm{U} / \mathrm{Pb}\{\mathrm{g}\}}$ & & 1 \\
\hline $\begin{array}{l}150 \\
\text { gnd }\end{array}$ & $857 / 3912$ & $J M-B A / 480$ & GTD & $G$ & $\begin{array}{l}.64 \\
.05 \\
\end{array}$ & & $\begin{array}{l}1.17 \\
.04 \\
\end{array}$ & $\begin{array}{l}.512308 \\
.000028 \\
\end{array}$ & $\begin{array}{l}.117662 \\
.000069 \\
\end{array}$ & $\begin{array}{l}5.247 \\
.002 \\
\end{array}$ & $\begin{array}{l}26.966 \\
.012 \\
\end{array}$ & -.40 & -6.4 & -.4 & $(.6)_{\text {est }}$ & & nt \\
\hline $\begin{array}{l}494 \\
\text { gns.g }\end{array}$ & $854 / 3921$ & $J M-B A-475$ & GTD & $\mathrm{H}$ & $\begin{array}{l}1.00 \\
.07 \\
\end{array}$ & & $\begin{array}{l}1.44 \\
.06 \\
\end{array}$ & $\begin{array}{l}.512081 \\
.000040 \\
\end{array}$ & $\begin{array}{l}.112175 \\
.000084 \\
\end{array}$ & $\begin{array}{l}1.674 \\
.001 \\
\end{array}$ & $\begin{array}{l}9.024 \\
.004\end{array}$ & -.43 & -10.9 & -4.4 & $(.6)_{\text {est }}$ & & nt \\
\hline \multicolumn{18}{|c|}{ intrusiva em $1 \mathrm{Ga}$} \\
\hline mig & $839 / 3833$ & $B R 92-221$ & GTD & 1 & 0.96 & & 1.33 & $\begin{array}{l}.511969 \\
.000011 \\
\end{array}$ & .090523 & 3.97 & 26.52 & -.54 & -13.1 & +.5 & $1.0 \mathrm{upb}$ & & 1 \\
\hline
\end{tabular}




\section{TAB. 5.7-7: Faixa de Dobramento Sergipano}

\begin{tabular}{|c|c|c|c|c|c|c|c|c|c|c|c|c|c|c|c|c|c|}
\hline $\begin{array}{l}\text { SPS } \\
\text { /litol }\end{array}$ & $\begin{array}{l}\text { coord./ } \\
\text { (p.local.) }\end{array}$ & $\begin{array}{l}\text { n. campo/ } \\
\text { região }\end{array}$ & $\begin{array}{l}\text { litolo } \\
\text { gia }\end{array}$ & $\begin{array}{l}\text { diag. } \\
\text { pontos }\end{array}$ & $\begin{array}{l}T_{\text {chur }} \\
\text { (Ga) } \\
\text { Goldstein } \\
\text { et.al.1984 }\end{array}$ & $\begin{array}{l}T_{\mathrm{dm} 2} \\
(\mathrm{Ga}) \\
\text { estagio } \\
\text { duplo }\end{array}$ & $\begin{array}{l}T_{\text {dm }} \\
(\mathrm{Ga}) \\
\text { DePaolo. } \\
1981\end{array}$ & $\begin{array}{l}143 \mathrm{Nd}- \\
{ }^{144} \mathrm{Nd}\end{array}$ & $\begin{array}{l}{ }^{147} \mathrm{Sm}- \\
{ }^{144} \mathrm{Nd}\end{array}$ & $\begin{array}{l}\mathrm{Sm} \\
\mathrm{ppm}\end{array}$ & $\begin{array}{l}\text { Nd } \\
\text { ppm }\end{array}$ & $f$ & $\begin{array}{l}\varepsilon_{N d} \\
(0)\end{array}$ & $\begin{array}{l}\varepsilon_{\mathrm{Nd}} \\
(\mathrm{t})\end{array}$ & $\begin{array}{l}\mathrm{t}(\mathrm{Ga})_{\text {mét. }} \\
\mathrm{R} \mathrm{i}_{\text {(fonte) }}\end{array}$ & $\begin{array}{l}\varepsilon_{S t} \\
(t)\end{array}$ & ref \\
\hline gns & $1014 / 3748$ & BR $92-03$ & GTD & A & 2.82 & & 2.98 & $\begin{array}{l}.510763 \\
.000012\end{array}$ & $\begin{array}{l}.095867 \\
.000086\end{array}$ & 1.43 & 9.02 & -.51 & -36.6 & -29 & $(6)_{\text {est }}$ & & 1 \\
\hline mig & $1000 / 3648$ & BR92-13 & GTD & $B$ & 2.82 & & 3.02 & $\begin{array}{l}.511209 \\
.000012 \\
\end{array}$ & .119828 & 3.88 & 19.58 & -.39 & -27.9 & -22 & $(.6)_{\text {est }}$ & & 1 \\
\hline $\begin{array}{l}300 \\
\text { gns }\end{array}$ & & SDS-Gn-A & GTD & $\mathrm{C}$ & 2.58 & & $\begin{array}{l}2.74 \\
.03 \\
\end{array}$ & $\begin{array}{l}.510561 \\
.000029 \\
\end{array}$ & $\begin{array}{l}.074626 \\
.000214\end{array}$ & $\begin{array}{l}1.067 \\
.003 \\
\end{array}$ & $\begin{array}{l}8.646 \\
.004 \\
\end{array}$ & -.62 & -40.5 & -31 & $(.6)_{\mathrm{est}}$ & & nt \\
\hline \multicolumn{18}{|c|}{ plutons Brasilianos } \\
\hline gnd & $1024 / 3737$ & BR92-04 & GTD & $\mathrm{D}$ & 1.33 & & 1.71 & $\begin{array}{l}.511878 \\
.000010\end{array}$ & .109945 & 7.12 & 39.16 & -.44 & -14.8 & -8.2 & $.6 \mathrm{UPb}(\mathrm{g})$ & & 1 \\
\hline grt & $1007 / 3732$ & BR $92-061$ & GTD & $E$ & 1.01 & & 1.46 & $\begin{array}{l}.512107 \\
.000013\end{array}$ & $\begin{array}{l}.116389 \\
.000021 \\
\end{array}$ & 7.57 & 39.33 & -.41 & -10.4 & -4.2 & $.6 \cup P \mathrm{~Pb}(9)$ & & 1 \\
\hline gnd & $1007 / 3706$ & $B R 92-081$ & GTD & $F$ & 1.14 & & 1.53 & $\begin{array}{l}.511966 \\
.000013 \\
\end{array}$ & .106529 & 4.45 & 25.26 & -.46 & -13.1 & -6.2 & $6_{\mathrm{UPb}(g)}$ & & 1 \\
\hline grt & $1009 / 3656$ & BR $92-111$ & GTD & $G$ & 0.79 & & 1.25 & $\begin{array}{l}.512181 \\
.000021\end{array}$ & .108177 & 5.56 & 31.08 & -.45 & -8.9 & -2.1 & $.6 \mathrm{uPb}(\mathrm{g})$ & & 1 \\
\hline grt & $1010 / 3648$ & BR $92-121$ & GTD & $\mathrm{H}$ & 0.87 & & 1.30 & $\begin{array}{l}.512116 \\
.000021 \\
\end{array}$ & .105130 & 6.45 & 6.45 & -.47 & 10.2 & -3.2 & $.6 \mathrm{UPb}(\mathrm{g})$ & & 1 \\
\hline $\operatorname{mix}$ & $951 / 3740$ & $B R 93-867$ & GTD & 1 & 1.40 & & 1.75 & $\begin{array}{l}.511779 \\
.000015 \\
\end{array}$ & .103447 & 4.79 & 28.00 & -.47 & -16.8 & -9.6 & $(.6)_{\text {est }}$ & & 1 \\
\hline \multicolumn{18}{|c|}{ supra-crustais } \\
\hline 367 & & SDS-V-PFI & & $\mathrm{J}$ & $\begin{array}{l}1.79 \\
0.04 \\
\end{array}$ & & $\begin{array}{l}2.13 \\
.03 \\
\end{array}$ & $\begin{array}{l}.511728 \\
.000022 \\
\end{array}$ & .119437 & $\begin{array}{l}7.758 \\
.002 \\
\end{array}$ & $\begin{array}{l}39.278 \\
.015 \\
\end{array}$ & -.39 & -17.8 & -12 & $(.6)_{\mathrm{est}}$ & & $n t$ \\
\hline xis & $1004 / 3703$ & SDS-BS-GA & MSE & $\mathrm{K}$ & 0.53 & & 1.17 & $\begin{array}{l}.512413 \\
.000011\end{array}$ & .131763 & 6.55 & 30.06 & -.33 & -4.4 & 3.9 & $\begin{array}{l}1.0_{\mathrm{U} / \mathrm{Pb}} \\
\text { (g) }\end{array}$ & & 1 \\
\hline m_rio & $952 / 3803$ & SDS-V-Min / & VAC & $L$ & 0.98 & & 1.44 & $\begin{array}{l}.512123 \\
.000017\end{array}$ & .116625 & 5.46 & 28.31 & -.41 & -10.0 & +2 & $\begin{array}{l}1.0 \mathrm{UPb} \\
\text { (g) }\end{array}$ & & 1 \\
\hline
\end{tabular}




\begin{tabular}{|c|c|c|c|c|c|c|c|c|c|c|c|c|c|c|c|c|c|}
\hline $\begin{array}{l}\text { SPS } \\
\text { litol }\end{array}$ & $\begin{array}{l}\text { coord. } t \\
\text { (p.local.) }\end{array}$ & $\begin{array}{l}\text { n. campo/ } \\
\text { região }\end{array}$ & $\begin{array}{l}\text { lito- } \\
\text { logia }\end{array}$ & $\begin{array}{l}\text { diag. } \\
\text { pontos }\end{array}$ & \begin{tabular}{|l|}
$T_{\text {chur }}$ \\
(Ga) \\
Goldstein \\
et.al.1984 \\
\end{tabular} & $\begin{array}{l}T_{\mathrm{dm} 2} \\
\text { (Ga) } \\
\text { estagio } \\
\text { duplo }\end{array}$ & \begin{tabular}{|l|}
$T_{\mathrm{dm}}$ \\
(Ga) \\
DePaolo- \\
1981
\end{tabular} & ${ }^{144} \mathrm{Nd}$ & $\begin{array}{l}{ }^{147} \mathrm{Sm}- \\
{ }^{144} \mathrm{Nd}\end{array}$ & $\begin{array}{l}\mathrm{Sm} \\
\mathrm{ppm}\end{array}$ & $\begin{array}{l}\mathrm{Nd} \\
\mathrm{ppm}\end{array}$ & $f$ & $\begin{array}{l}\varepsilon_{\mathrm{Nd}} \\
(0)\end{array}$ & $\begin{array}{l}\varepsilon_{\mathrm{Nd}} \\
(\mathrm{t})\end{array}$ & $\mathrm{t}_{\text {(Ga) mét. }}$ & $\begin{array}{l}\varepsilon_{\mathrm{Sr}} \\
(\mathrm{t})\end{array}$ & ref \\
\hline $\begin{array}{l}503 \\
\text { git }\end{array}$ & $855 / 4036$ & $\begin{array}{l}1592 \mathrm{CA} 199-5 \\
\text { R.Pontal/SFC }\end{array}$ & GTD & A & \begin{tabular}{|l|}
3.26 \\
0.04
\end{tabular} & & $\begin{array}{l}3.38 \\
.04\end{array}$ & $\begin{array}{l}.510299 \\
.000025\end{array}$ & $\begin{array}{l}.088002 \\
.000053\end{array}$ & $\begin{array}{l}2.201 \\
.001\end{array}$ & $\begin{array}{l}15.124 \\
.006\end{array}$ & -.55 & -45.6 & +.3 & $\begin{array}{l}3.31 \\
\text { Rorsr } \\
.7015\end{array}$ & 13 & nt \\
\hline $\begin{array}{l}504 \\
\mathrm{git}\end{array}$ & $855 / 4036$ & $\begin{array}{l}1592 \mathrm{CA} 199-9 \\
\text { R.Pontal/SFC }\end{array}$ & GTD & $B$ & $\begin{array}{l}3.34 \\
0.08\end{array}$ & & $\begin{array}{l}3.45 \\
.08\end{array}$ & $\begin{array}{l}.510228 \\
.000055\end{array}$ & $\begin{array}{l}.087468 \\
.000116\end{array}$ & $\begin{array}{l}2.020 \\
.001\end{array}$ & $\begin{array}{l}13.965 \\
.017\end{array}$ & -.56 & -47.0 & -.9 & $\begin{array}{l}3.31 \\
\mathrm{Rb} / \mathrm{si} \\
.7015 \\
\end{array}$ & 13 & $n t$ \\
\hline $\begin{array}{l}297 \\
\text { gns }\end{array}$ & $918 / 4153$ & $\begin{array}{l}\text { JM-BA } 604 \mathrm{~J} \\
\text { R.Pontal/SFC }\end{array}$ & GTD & C & $\begin{array}{l}2.84 \\
0.06\end{array}$ & & $\begin{array}{l}3.02 \\
.06\end{array}$ & $\begin{array}{l}.510994 \\
.000035\end{array}$ & $\begin{array}{l}.109089 \\
.000043\end{array}$ & $\begin{array}{l}10.64 \\
.002\end{array}$ & $\begin{array}{l}58.996 \\
.020\end{array}$ & -.45 & -32.1 & 3.6 & $\begin{array}{l}3.19 \\
\mathrm{RD} / \mathrm{Sr} \\
.713 \\
\end{array}$ & 175 & nt \\
\hline $\begin{array}{l}298 \\
\text { grt }\end{array}$ & $935 / 4031$ & $\begin{array}{l}\text { JM-BA } 600 \mathrm{C} \\
\text { R.Pontal/CSF }\end{array}$ & GTD & D & 1.51 & $3.25^{\# T}$ & -- & $\begin{array}{l}.514622 \\
.000034\end{array}$ & .39707 & .371 & .565 & 1.02 & +38 & -14 & $\begin{array}{l}2.06 \\
\mathrm{Rb} / \mathrm{Sr} \\
.704 \\
\end{array}$ & 27 & nt \\
\hline \multicolumn{18}{|c|}{ intrusiva em $1 \mathrm{Ga}$} \\
\hline gnt & $810 / 4059$ & $\begin{array}{l}\text { SRP-G - } 10 \\
\text { R.Pontal } \\
\end{array}$ & GTD & $E$ & 0.96 & & 1.46 & $\begin{array}{l}.512174 \\
.000015 \\
\end{array}$ & .123198 & 8.73 & 42.85 & -.37 & -9.1 & +0.0 & $\begin{array}{l}.97 \text { upb } \\
\text { (q) }\end{array}$ & & 1 \\
\hline & & & & & & & & & & & & & & & & & \\
\hline \multicolumn{18}{|c|}{ TAB. 5.7-9: Gnaisses e granito da faixa de dobramento Rio Preto } \\
\hline $\begin{array}{l}299 \\
\text { grt }\end{array}$ & $933 / 4257$ & JM-BA $608 \mathrm{H}$ & GTD & $\bar{F}$ & $\begin{array}{l}2.77 \\
0.04\end{array}$ & & $\begin{array}{l}2.93 \\
.03\end{array}$ & $\begin{array}{l}.510680 \\
.000025\end{array}$ & $\begin{array}{l}.089530 \\
.000074\end{array}$ & $\begin{array}{l}3.047 \\
.002\end{array}$ & $\begin{array}{l}20.580 \\
.010\end{array}$ & -.54 & -38.2 & -13 & $\begin{array}{l}1.88 \\
\mathrm{Rb} / \mathrm{sr} \\
.730 \\
\end{array}$ & 395 & nt \\
\hline $\begin{array}{l}296 \\
\text { gns }\end{array}$ & $1041 / 4401$ & JM-BA $195 \mathrm{~B}$ & GTD & G & $\begin{array}{l}1.86 \\
0.05\end{array}$ & & $\begin{array}{l}2.14 \\
.04\end{array}$ & $\begin{array}{l}.511477 \\
.000029\end{array}$ & $\begin{array}{l}.101809 \\
.000070\end{array}$ & $\begin{array}{l}5.312 \\
.002\end{array}$ & $\begin{array}{l}31.551 \\
.018\end{array}$ & -.48 & -22.6 & +2.2 & $\begin{array}{l}2.05_{\mathrm{R}} \\
\mathrm{b} / \mathrm{sr} \\
.7016_{(1)}\end{array}$ & -7 & nt \\
\hline $\begin{array}{l}295 \\
\text { gns }\end{array}$ & $1045 / 4508$ & $J M-21-18$ & GTD & $\bar{H}$ & \begin{tabular}{|l|}
2.29 \\
0.11 \\
\end{tabular} & & $\begin{array}{l}2.50 \\
.09 \\
\end{array}$ & $\begin{array}{l}.511089 \\
.000075 \\
\end{array}$ & $\begin{array}{l}.093961 \\
.000079 \\
\end{array}$ & \begin{tabular}{|l|}
.779 \\
.001 \\
\end{tabular} & $\begin{array}{l}11.449 \\
.007 \\
\end{array}$ & -.52 & -30.2 & -4.0 & $(2.0)_{\text {est }}$ & & nt \\
\hline & & & & & & & & & & & & & & & & & \\
\hline
\end{tabular}




\begin{tabular}{|c|c|c|c|c|c|c|c|c|c|c|c|c|c|c|c|c|c|}
\hline $\begin{array}{l}\text { SPS } \\
\text { /litol }\end{array}$ & $\begin{array}{l}\text { coord./ } \\
\text { (p.local.) }\end{array}$ & $\begin{array}{l}\text { n. campo/ } \\
\text { região }\end{array}$ & $\begin{array}{l}\text { lito- } \\
\text { logia }\end{array}$ & $\begin{array}{l}\text { diag. } \\
\text { pontos }\end{array}$ & $\begin{array}{l}T_{\text {chur }} \\
(\mathrm{Ga}) \\
\text { Goldstein } \\
\text { et.ai.1984 }\end{array}$ & $\begin{array}{l}\mathrm{T}_{\mathrm{dm} 2} \\
\text { (Ga) } \\
\text { estagio } \\
\text { duplo }\end{array}$ & $\begin{array}{l}T_{\mathrm{dm}} \\
(\mathrm{Ga}) \\
\text { DePaolo- } \\
1981 \\
\end{array}$ & \begin{tabular}{|l}
${ }^{143} \mathrm{Nd}-$ \\
${ }^{144} \mathrm{Nd}$
\end{tabular} & $\begin{array}{l}{ }^{147} \mathrm{Sm}- \\
{ }^{144} \mathrm{Nd}\end{array}$ & $\begin{array}{l}\mathrm{Sm} \\
\mathrm{ppm}\end{array}$ & $\begin{array}{l}\mathrm{Nd} \\
\mathrm{ppm}\end{array}$ & $f$ & $\begin{array}{l}\varepsilon_{\mathrm{Nd}} \\
(0)\end{array}$ & $\begin{array}{l}\varepsilon_{\text {Nd }} \\
(t)\end{array}$ & $\begin{array}{l}t_{(G a)_{\text {mét. }}} \\
R i_{\text {(fonte) }}\end{array}$ & $\begin{array}{l}\varepsilon_{\mathrm{Sr}} \\
(\mathrm{t})\end{array}$ & ref \\
\hline & & & & & & & & & & & & & & & & & \\
\hline $\begin{array}{l}410 / \\
\text { gns }\end{array}$ & $426 / 3915$ & $\begin{array}{l}214 \text { JR } 5 a \\
\text { P.Jaguaribe }\end{array}$ & GTD & C & $\begin{array}{l}2.02 \\
.03 \\
\end{array}$ & & $\begin{array}{l}2.23 \\
.03 \\
\end{array}$ & $\begin{array}{l}.511058 \\
.000027 \\
\end{array}$ & $\begin{array}{l}.077839 \\
.000039\end{array}$ & $\begin{array}{l}3.898 \\
.001\end{array}$ & $\begin{array}{l}30.282 \\
.013 \\
\end{array}$ & -.60 & -30.8 & -0.5 & $\begin{array}{l}2.0_{\mathrm{Rb} / \mathrm{Sr}} \\
.705_{(\mathrm{c})}\end{array}$ & 40 & nt \\
\hline $\begin{array}{l}407 / \\
\text { gns }\end{array}$ & $526 / 400$ & B 6-14/Tróia & GTD & $D$ & $\begin{array}{l}2.62 \\
.02 \\
\end{array}$ & & $\begin{array}{l}2.80 \\
.02 \\
\end{array}$ & $\begin{array}{l}.510834 \\
.000017 \\
\end{array}$ & $\begin{array}{l}.092425 \\
.000073\end{array}$ & $\begin{array}{l}1.408 \\
.001 \\
\end{array}$ & $\begin{array}{l}9.212 \\
.003 \\
\end{array}$ & -.53 & -35.2 & -8.6 & $\begin{array}{l}2.0 \mathrm{Rb} / \mathrm{Sr} \\
.705_{(\mathrm{d})}\end{array}$ & 41 & $\mathrm{nt}$ \\
\hline $\begin{array}{l}408 / \\
\text { gnd }\end{array}$ & $558 / 4014$ & $\begin{array}{l}36-10 \mathrm{~b} / \\
\text { Tróia }\end{array}$ & GTD & $E$ & $\begin{array}{l}1.57 \\
.05 \\
\end{array}$ & & $\begin{array}{l}1.89 \\
.04 \\
\end{array}$ & $\begin{array}{l}.511658 \\
.000028 \\
\end{array}$ & $\begin{array}{l}.101739 \\
.000058\end{array}$ & $\begin{array}{l}8.603 \\
.003 \\
\end{array}$ & $\begin{array}{l}51.163 \\
.023 \\
\end{array}$ & -.48 & -19.1 & -12 & $\begin{array}{l}0.66_{\mathrm{Rb} / \mathrm{Sr}} \\
.704_{(\mathrm{d})}\end{array}$ & 2.8 & nt \\
\hline $\begin{array}{l}411 \\
\text { grt }\end{array}$ & $410 / 408$ & $\begin{array}{l}\text { B-7-8I } \\
\text { Santa Quitéria }\end{array}$ & GTD & $F$ & $\begin{array}{l}1.60 \\
.04 \\
\end{array}$ & & $\begin{array}{l}1.93 \\
.03 \\
\end{array}$ & $\begin{array}{l}.511696 \\
.000026 \\
\end{array}$ & $\begin{array}{l}.107006 \\
.000019\end{array}$ & $\begin{array}{l}5.663 \\
.001 \\
\end{array}$ & $\begin{array}{l}32.002 \\
.001 \\
\end{array}$ & -.46 & -18.4 & -12 & $\begin{array}{l}.54 \mathrm{Ro} / \mathrm{Sr} \\
.707_{(\mathrm{d})}\end{array}$ & 44 & nt \\
\hline $\begin{array}{l}414 \\
\text { gns }\end{array}$ & $343 / 3952$ & $\begin{array}{l}\text { B 7-2dS } \\
\text { Santa Quitéria }\end{array}$ & GTD & $G$ & $\begin{array}{l}.75 \\
.04 \\
\end{array}$ & & $\begin{array}{l}1.21 \\
.03 \\
\end{array}$ & $\begin{array}{l}.512186 \\
.000023 \\
\end{array}$ & $\begin{array}{l}.105203 \\
.000059\end{array}$ & $\begin{array}{l}5.919 \\
.002 \\
\end{array}$ & $\begin{array}{l}34.022 \\
.015 \\
\end{array}$ & -.47 & -8.8 & -.9 & $\begin{array}{l}.68 \mathrm{Rb} / \mathrm{Sr} \\
.7046_{(\mathrm{d})}\end{array}$ & 13 & $n t$ \\
\hline $\begin{array}{l}412 \\
\text { gns }\end{array}$ & $449 / 3823$ & $\begin{array}{l}214 \text { JR - } 14 \\
\text { P.JJaguribe }\end{array}$ & GTD & $H$ & $\begin{array}{l}1.96 \\
.04 \\
\end{array}$ & & $\begin{array}{l}2.23 \\
.03 \\
\end{array}$ & $\begin{array}{l}.511469 \\
.000026 \\
\end{array}$ & \begin{tabular}{|l|}
.105966 \\
.000048 \\
\end{tabular} & \begin{tabular}{|l|}
6.294 \\
.001 \\
\end{tabular} & $\begin{array}{l}35.917 \\
.015 \\
\end{array}$ & -.46 & -22.8 & -16 & $\begin{array}{l}.62 \mathrm{Rb} / \mathrm{Si} \\
.707_{(\mathrm{c})}\end{array}$ & 46 & $n t$ \\
\hline $\begin{array}{l}413 \\
\text { git }\end{array}$ & $411 / 3847$ & $\begin{array}{l}214 \text { JR - } 30 \\
\text { P./Jaguaribe }\end{array}$ & GTD & 1 & $\begin{array}{l}.95 \\
.04 \\
\end{array}$ & & $\begin{array}{l}1.37 \\
.03 \\
\end{array}$ & $\begin{array}{l}.512064 \\
.000022 \\
\end{array}$ & $\begin{array}{l}.104418 \\
.000061 \\
\end{array}$ & \begin{tabular}{|l|}
2.485 \\
.001 \\
\end{tabular} & $\begin{array}{l}14.391 \\
.006 \\
\end{array}$ & -.47 & -11.2 & -4.1 & $\begin{array}{l}(.600) \text { est } \\
.707 ?(\mathrm{c})\end{array}$ & $45 ?$ & $\mathrm{nt}$ \\
\hline & & & & & & & & & & & & & & & & & \\
\hline
\end{tabular}

CEARÁ- CENTRAL (este da Falha de Sobral, Fetter et. al., 1997, dados inéditos)

\begin{tabular}{|c|c|c|c|c|c|c|c|c|c|c|c|c|c|}
\hline $\begin{array}{l}-- \\
\text { vul }\end{array}$ & $321 / 4010$ & BRCE94.20 & VAC & 1.30 & 1.72 & $\begin{array}{l}.511983 \\
.000006 \\
\end{array}$ & .12009 & 10.69 & 53.83 & -.39 & -12.8 & & 3 \\
\hline$\overline{\mathrm{mig}}$ & $321 / 3952$ & BRCE94.21 & GTD & 2.05 & 2.30 & $\begin{array}{l}.511305 \\
.000011 \\
\end{array}$ & .09801 & 17.25 & 106.43 & -.50 & -26.0 & 2.10 & 3 \\
\hline grt & $341 / 3949$ & BRCE94.23 & GTD & 0.95 & 1.35 & $\begin{array}{l}.512032 \\
.000010 \\
\end{array}$ & .09937 & 6.69 & 40.71 & -.49 & -11.8 & & 3 \\
\hline$\ldots$ & & \begin{tabular}{|l|} 
BRCE94.25 \\
\end{tabular} & & 0.59 & 1.15 & $\begin{array}{r}512349 \\
.000007 \\
\end{array}$ & .12151 & 10.70 & 53.25 & -.38 & -5.6 & 0.62 & 3 \\
\hline & & BRCE94.37 & & 1.93 & 2.24 & $\begin{array}{l}.511634 \\
.000009 \\
\end{array}$ & .11772 & 3.22 & 16.54 & -.40 & -19.6 & & 3 \\
\hline & & BRCE 94.38 & & 1.32 & 1.63 & $\begin{array}{l}.511700 \\
.000008 \\
\end{array}$ & .08818 & 5.19 & 35.59 & -.55 & -18.3 & & 3 \\
\hline & & \begin{tabular}{|l|} 
BRCE 94.39 \\
\end{tabular} & & 2.39 & 2.43 & .511318 & .10502 & 10.66 & 61.38 & -.47 & -25.7 & & 3 \\
\hline
\end{tabular}




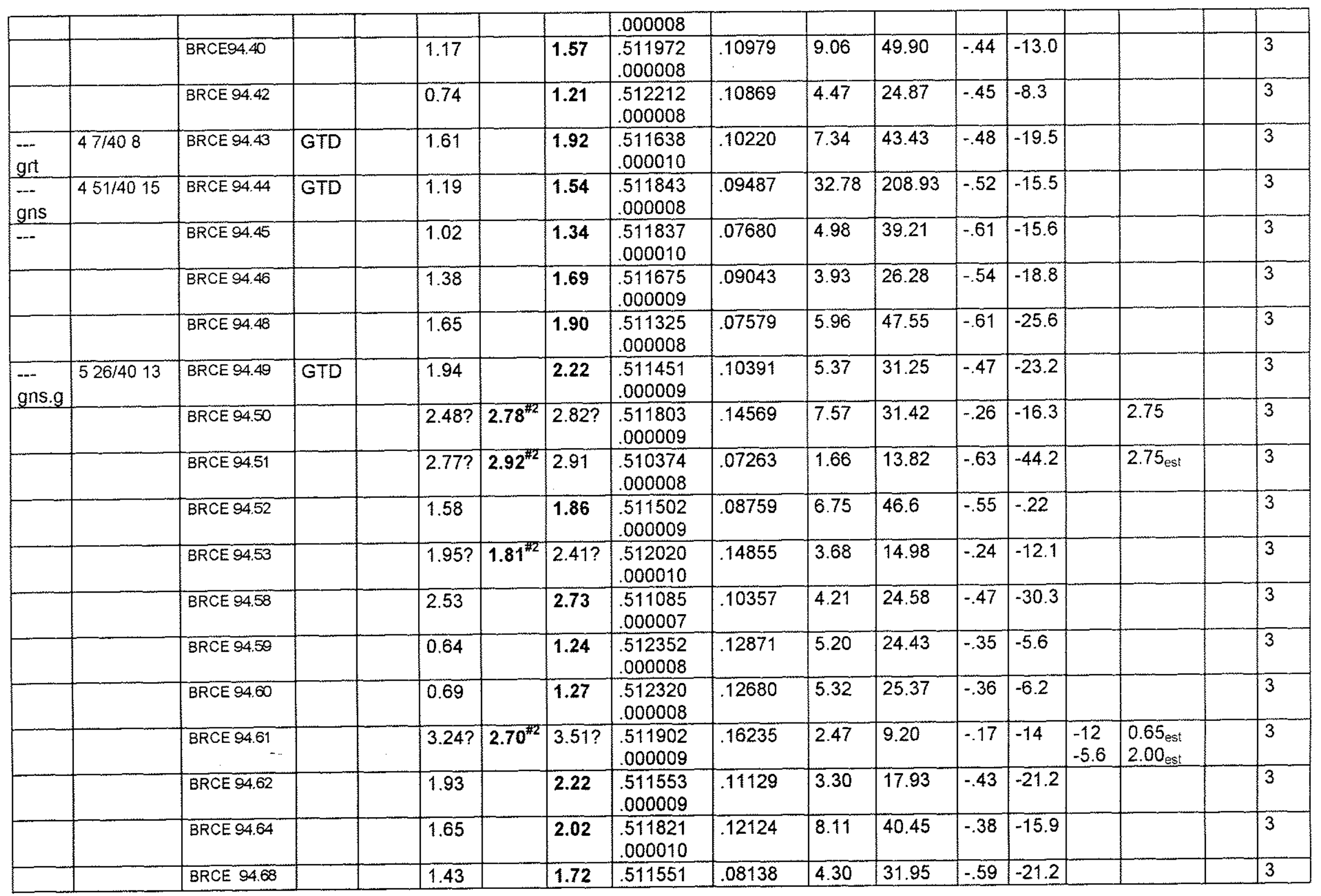




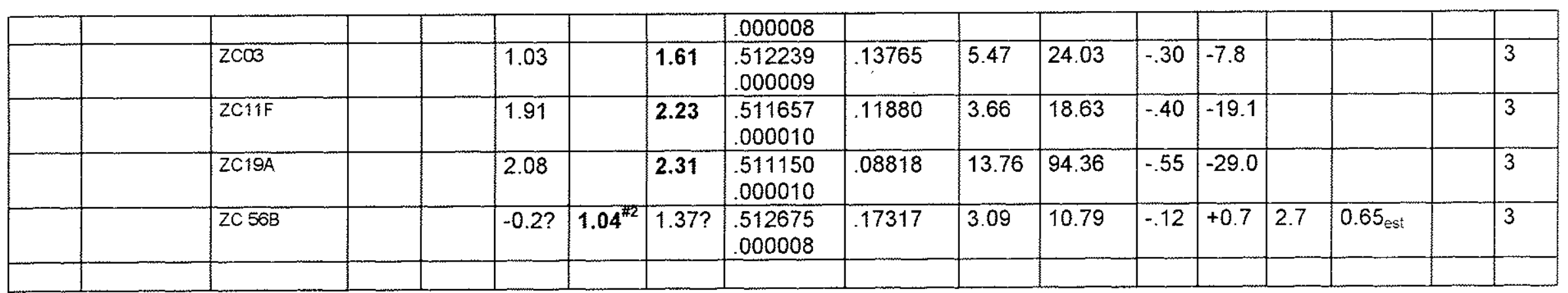

\section{Ver notas explicativas no capítulo 5.1 (pg 31).}

\# = Tdm calculado com modelo de 2 estágios: \#1 --> T2=t e $147 \mathrm{Sm} / 144 \mathrm{Nd}=1$; \#2 -.-> T2=t e $147 \mathrm{Sm} / \mathrm{Nd} 144=0.110$

ref.: $\mathrm{nt}=$ neste trabalho, idades modelos recalculados para este trabalho a partir dos dados isotópicos de: $1=$ Van Schmuss et al 1995 (1* $\ldots$ excluído), 2 = Jardim de Sá 1994, 3 = Fetter, A. et. al. (1997, dados inéditos); Van Schmus et. al., 1997 (dados inéditos, U. of Kansas,

Lawrence), $4=$ Kozuch et. al. ,(1997, dados inéditos).

Ref. para a coluna t : $a=$ Teixeira et.al. $1978, b=$ Brito Neves 1978, $c=$ Teixeira 1981, $d=$ Brito Neves 1975, e Rodrigues 1976, $f=$ Nunes 1973, g = Van Schmuss et. al. 1995, h = Jardim de Sá 1994, $\mathrm{l}=$ Santos et. al 1990, $\mathrm{j}=$ Mascarenhas et. al 1989, est = idade estimada. Observação: Tdm do Maciço R. Piranhas : embasamento $\rightarrow>\mathrm{Sm}$ (média de 6, sem augen gnaisses) $=4.29 \mathrm{ppm} ; \mathrm{Nd}(\mathrm{Média}-\mathrm{idem})=23.5 \mathrm{ppm}$; razão $147 \mathrm{Sm} / 144 \mathrm{Nd}=.110 ; \mathrm{Tdm} 2$ (médio) $=2.65 \mathrm{Ga}$. Plutons Brasilianos -..> só para os granitos fracionados $\cdots>\mathrm{Sm}(\mathrm{média} \mathrm{de} \mathrm{4)}=11,68 \mathrm{ppm}$; $\mathrm{Nd}$ (média de 4 ) $=83.12 \mathrm{ppm} ;$ razão $147 \mathrm{Sm} / 144 \mathrm{Nd}=0.084 ; \mathrm{Tdm} 2$ (médio) $=2.55 \mathrm{Ga}$ 


\section{8 - DOMÍNIO JEQUITINHONHA}

\section{8-1: SÍNTESE GEOCRONOLÓGICA}

O Dominio Jequitinhonha (fig. 5.8-1), que reconstitui aproximadamente o que foi definido por Cordani et. al. (1988) como Faixa Jequitinhonha, situa-se nas porções e Sudeste do Brasil, e inclui as Faixas de dobramentos Araçuai / Rio Pardo e os Grupos ou Complexos Embu, Mantiqueira, Juiz de Fora, Paraiba do Sul e Costeiro.

Como base cartográfica, para a localização das amostras datadas, será utilizado o mapa de Campos Neto e Figueiredo (1995), fig. 5.8-2. A compartimentação geotectônica aqui adotada, informalmente, devido à heterogeneidade da unidade, incluirá vários sub-domínios denominados Costeiro (Micro placa Serra do Mar/Faixa Costeira), Juiz de Fora, Mantiqueira, Guanhães, Embu, Paraiba do Sul, Cabo Frio e Araçuai / Rio Pardo.

Uma síntese da complexa história geológica deste domínio será apresentada a seguir:

- ARQUEANO: A ocorrência de terrenos arqueanos preservados é muito pequena, tendo sido caracterizados somente no âmbito dos sub-domínios Mantiqueira e Juiz de Fora. Acredita-se, em função dos dados isotópicos, que os eventos orogênicos subseqüentes (Transamazônico e Brasiliano) afetaram e transformaram grande parte dos terrenos preexistentes de seu embasamento

- PAleoproterozóico: Durante o Paleoproterozóico o principal evento orogênico formador de rochas é o Ciclo Transamazônico (2,2 a 1,8Ga), presente de modo relevante nos sub-dominios Mantiqueira, Guanhães e Juiz de Fora. Adicionalmente, idades Paleoproterozóicas foram também assinaladas nos sub-domínios Embu e Cabo Frio.

Análises $\mathrm{Pb}-\mathrm{Pb}$ obtidas por ICP-MS em zircões detríticos dos metassedimentos dos subdomínios Juiz de Fora (RJ) e Costeiro (RJ) forneceram idades aparentes com a maior população $(\sim 80 \%)$ nos intervalos entre 2,2 a $2,0 \mathrm{Ga}$, e com uma população bem menor nos intervalos entre 
$2,9-2,2$ e 2,0 - 1,5Ga. Tais valores indicam que os sedimentos originais foram derivados predominantemente da erosão de materiais Transamazônicos (Valadares et. al. 1997).

- MESO-NEOPROTEROZÓICO: Poucos registros $\mathrm{Rb}-\mathrm{Sr}$, U-Pb e $\mathrm{Pb}-\mathrm{Pb}$ relativos ao Mesoproterozóico foram observados nesse domínio. Por outro lado, o Ciclo orogênico Brasiliano foi marcante, principalmente nos sub-domínios Costeiro e Araçuai/Rio Pardo, e Paraiba do Sul. A orogênese Brasiliana é caracterizada como intenso retrabalhamento de materiais crustais preexistentes. Os reflexos da tectônica brasiliana encontram-se amplamente distribuido em todo o domínio Jequitinhonha.

A seguir serão discutidos os dados $\mathrm{Sm}-\mathrm{Nd}$ nos diversos sub-domínios tectônicos. Os dados Sm-Nd encontram-se nas tabelas 5.8-1 a 5.8-8. Os diagramas de evolução isotópica $\varepsilon_{\mathrm{Nd}}$ no tempo geológico, bem como as correlações isotópicas $\varepsilon_{\mathrm{Sr}} \times \varepsilon_{\mathrm{Nd}}$, podem ser observadas nas figuras $5.8-3$ a $5.8-10$.

\section{8-2) - IDADES MODELO Sm - Nd}

SUB-DOMíNIO GUANHÃES: As rochas granitóides e vulcânicas ácidas que ocorrem na região de Borrachudos (Guanhães), a NE de Belo Horizonte, apresentaram idades Rb-Sr em rocha total de $1,72 \mathrm{Ga}$ (razão inicial $=0,7057$ ) e U-Pb em zircão de $1,73 \mathrm{Ga}$, interpretados por Dussim (1994) como relativas à época de colocação das intrusivas. As idades modelo Sm-Nd ( $\mathrm{T}_{\mathrm{DM}}$ ) para as rochas granitóides distribuiram entre 3,02 a 2.97Ga (amostras $\mathrm{C} 1$ a C3, da tab. 5.81), e para as rochas vulcânicas ácidas entre 2,86 a 2,57Ga (amostras B1 a B3; tab. 5.8-1), sugerindo que os protólitos destes corpos crustais foram derivados do manto no Arqueano. A fig. 5.8-3 ilustra a evolução isotópica de $\varepsilon_{\mathrm{Nd}}$ para estes corpos, observando-se os valores de $\varepsilon_{\mathrm{Nd}}$ negativos relativos à época de colocação desta suite a $1,72 \mathrm{Ga}$. As correlações isotópicas $\varepsilon_{\mathrm{Sr}}$ versus $\varepsilon_{\mathrm{Nd}}$ (pontos $\mathrm{C}$ e B da fig. 5.8-9), mostram claramente a origem crustal destas rochas. 


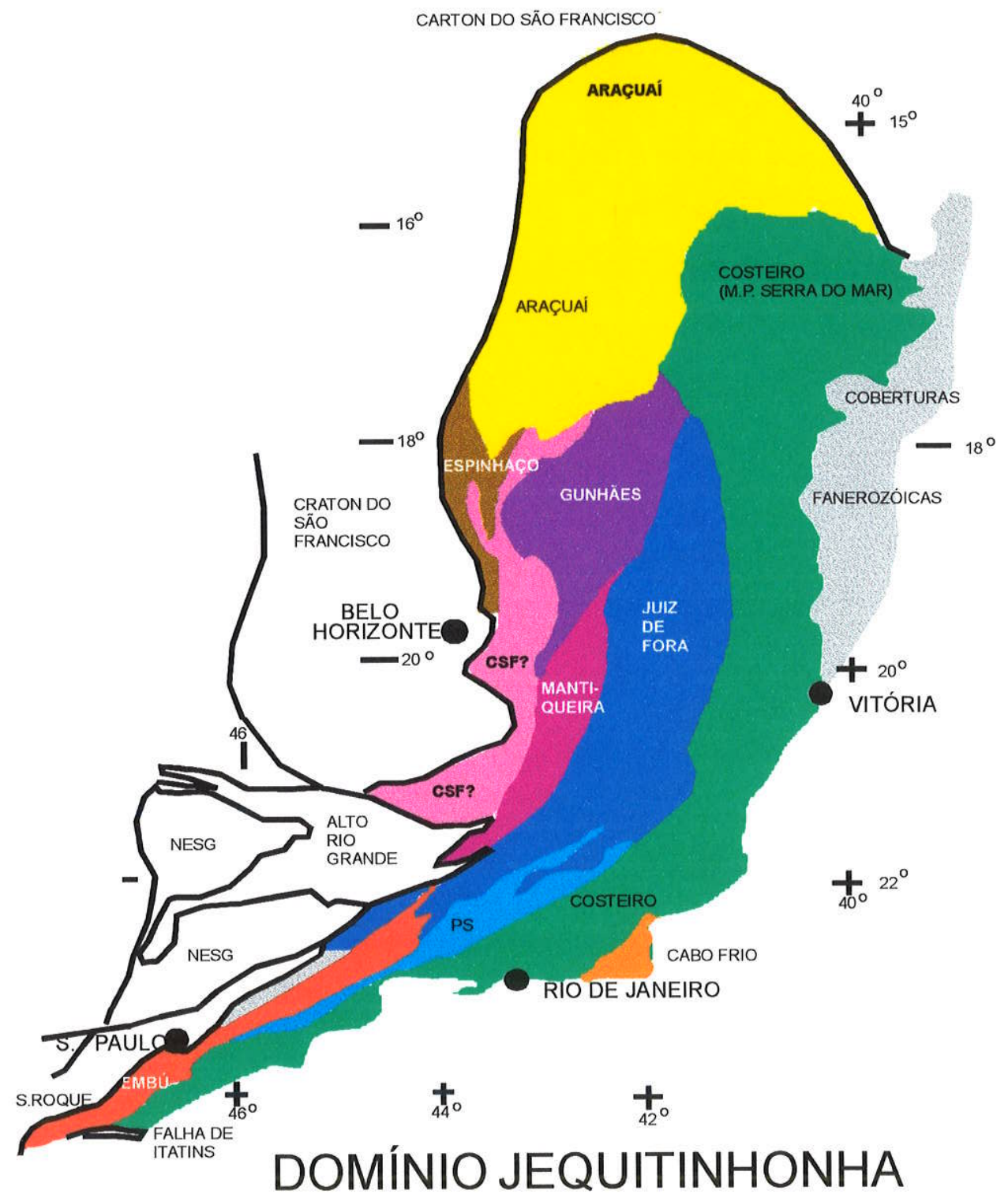

FIG. 5.8-1 UNIDADES TECTÔNICAS BASEADAS EM CAMPOS NETO e FIGUEIREDO (1995)

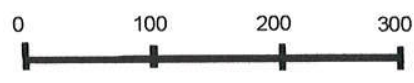




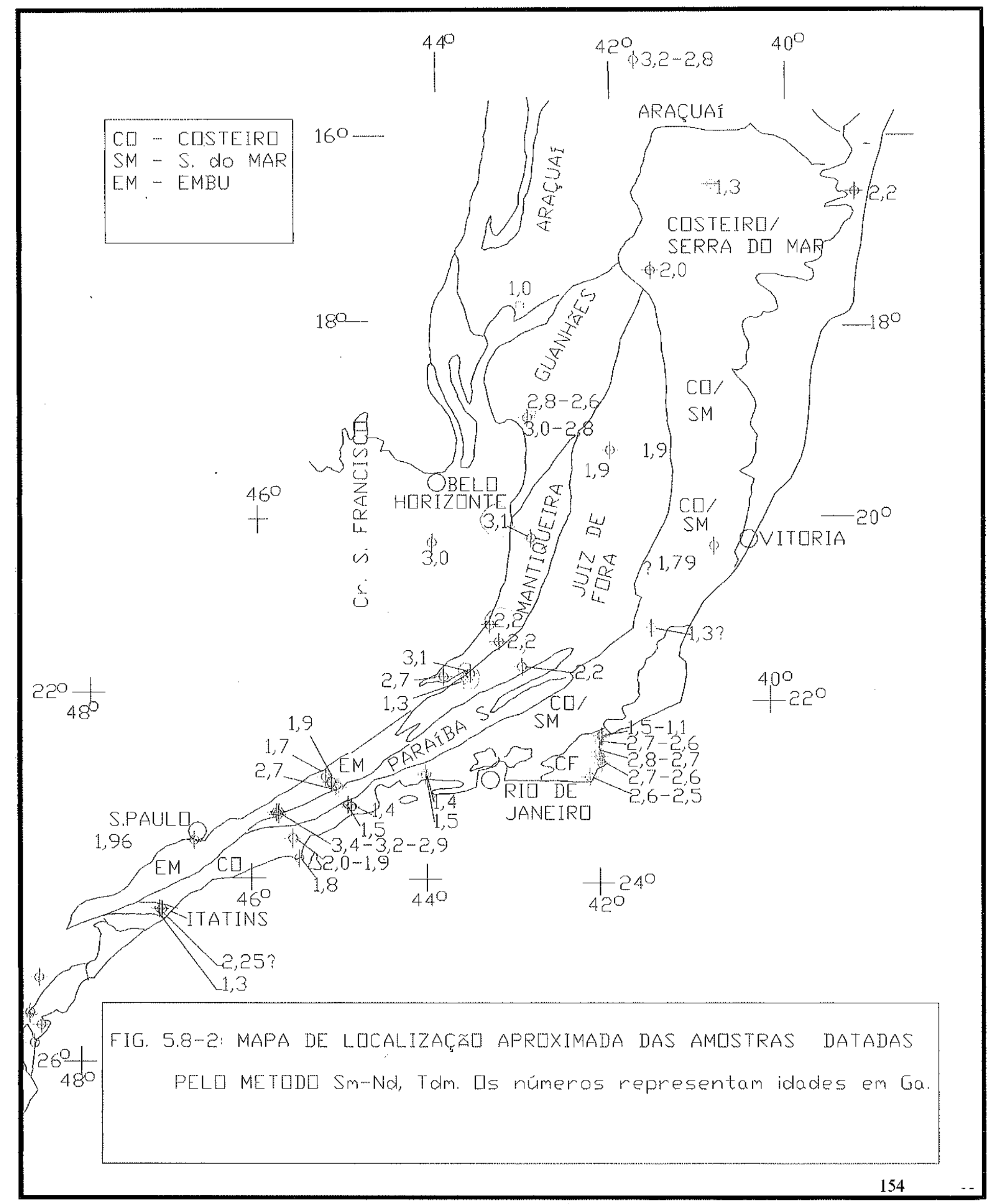




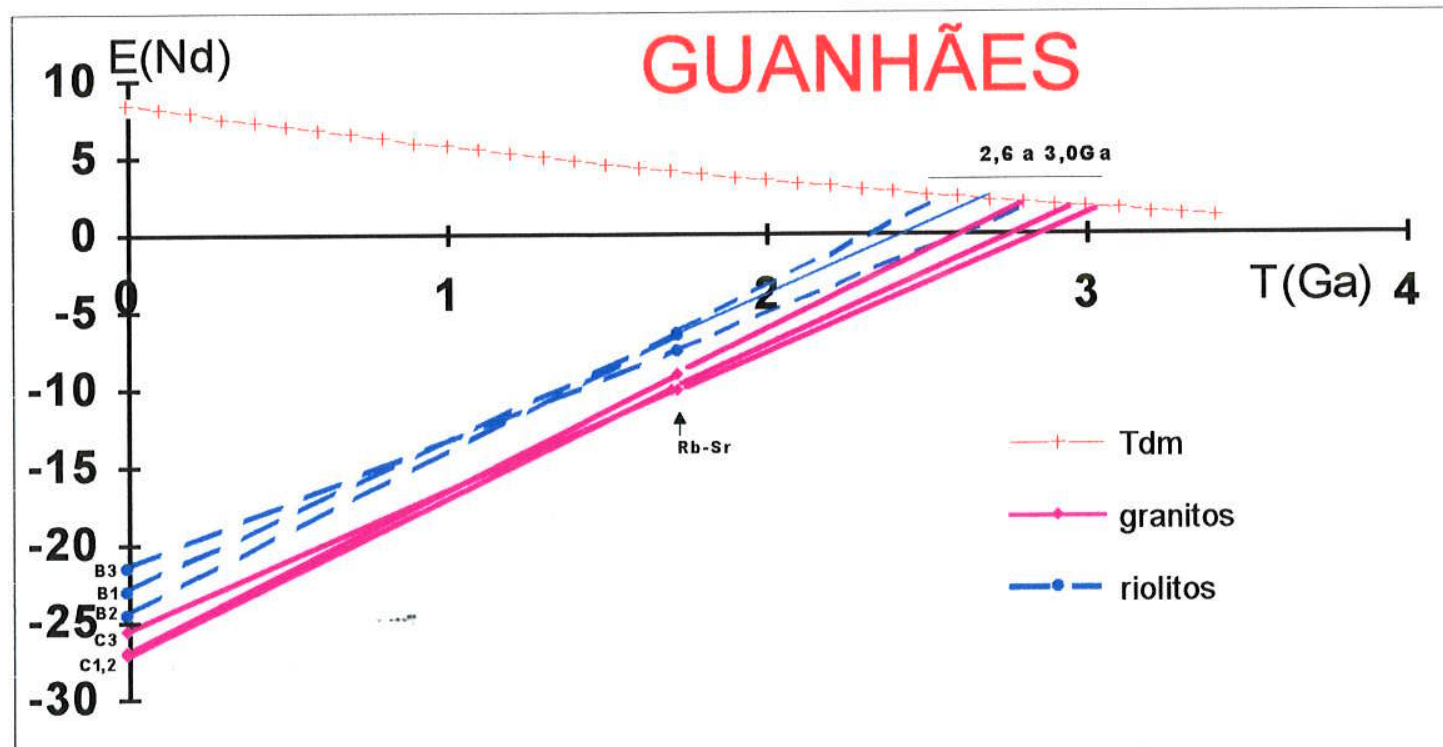

Fig. 5.8-3 : Diagrama $\varepsilon_{\mathrm{Nd}}$ versus tempo geológico. Os dados isotópicos encontram-se na tab 5.8-1

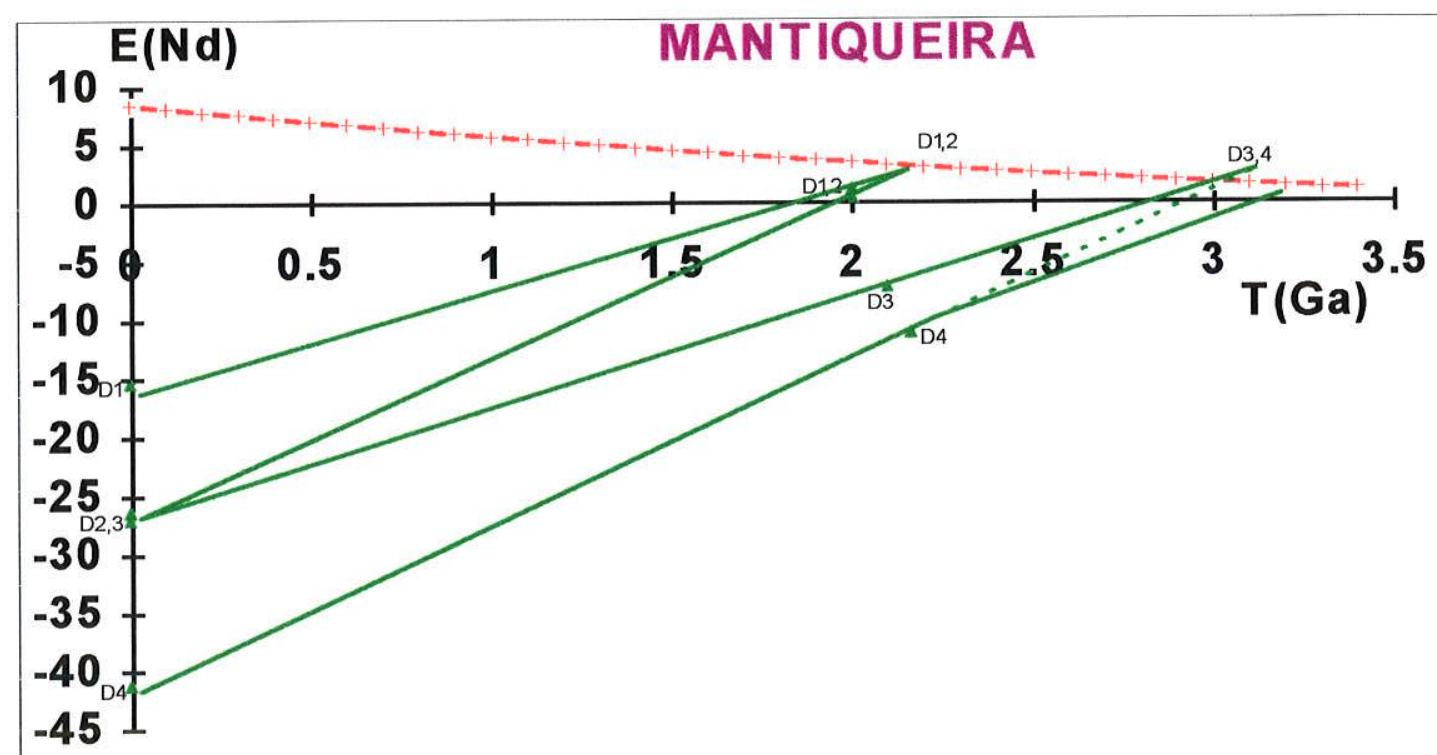

FIG. 5.8-4: Diagrama $\varepsilon_{\text {Nd }}$ versus tempo geológico. Os dados isotópicos encontram-se na tab 5.8-2. 
SUB-DOMíNIOS MANTIQUEIRA E BARBACENA - O sub-dominio Mantiqueira situase a SE de Belo Horizonte. Compõe-se essencialmente de biotita -hornblenda gnaisses de composição tonalítico-granodiorítica e rochas migmatíticas, com rochas máficas e metassedimentos subordinados, bem como granitóides intrusivos (Figueiredo e Teixeira, 1996). Estudos geocronológicos $\mathrm{Rb}-\mathrm{Sr}$ indicam que o principal evento de metamorfismo e deformação ocorreu entre 2,3 a 2,1 Ga. As idades modelo $\mathrm{Sm}-\mathrm{Nd}\left(\mathrm{T}_{\mathfrak{M}}\right.$; tabela 5.8-2 e fig. 5.8-4) indicam protólitos derivados do manto durante o Arqueano, bem como durante o Paleoproterozóico.

O sub-domínio Barbacena corresponde a parte do Complexo Barbacena, assinalada como CSF na fig. 5.8-1. Na interface entre o sub-dominio Mantiqueira e o Craton do S. Francisco ocorrem as rochas gnáissico-migmatíticas do cinturão Mineiro, formado durante o Ciclo Transamazônico (Teixeira 1985). Nesses terrenos encontram-se disponiveis apenas duas análises $\mathrm{Sm}-\mathrm{Nd}$, uma relativa ao granitóide de Itutinga, que acusou idade Arqueana $(2,85 \mathrm{Ga})$ e outra relativa ao corpo granitóide localizado nas vizinhanças de Ressaquinha, que apresentou idade modelo $\mathrm{T}_{\mathrm{DM}}$ Paleoproterozóica $(2,4 \mathrm{Ga})$.

SUB-DOMíNIO JUIZ DE FORA: No sub-domínio Juiz Fora predominam seqüências de alto grau, derivadas de rochas plutônicas cálcio-alcalinas, charnockitizadas e com lentes de ortognaisses preservadas (Campos Neto e Figueiredo 1995). As idades $\mathrm{Pb}-\mathrm{Pb}$ relativas a 75 zircões detríticos dos metassedimentos deste sub-domínio, (Valladares et. al. 1997) distribuiramse em sua maioria ( $80 \%$ da população) no Paleoproterozóico, e o restante no Arqueano.

As idades modelo $\left(\mathrm{T}_{\mathrm{DM}}\right.$ ) relacionadas na tabela 5.8-3 e fig. 5.8-5 aliadas com as idades $\mathrm{Pb}-\mathrm{Pb}$, sugerem protólitos acrescidos à crosta continental durante o Arqueano e o Paleoproterozóico.

SUB-DOMínio EMBU - No sub-domínio Embu predominam rochas gnáissicomigmatíticas. Segundo Tassinari (1988) as principais épocas de formação dessas rochas foram 2,5, 1,5 e 0,75Ga (idades Rb-Sr). As idades modelo $\mathrm{Sm}-\mathrm{Nd}$ ( $\mathrm{T}_{\mathrm{DN}}$ ) (tab. 5.8-4) sugerem protólitos do Arqueano para as rochas granitóides dos arredores de S. José dos Campos, onde as idades $\mathrm{T}_{\mathrm{DM}}$ distribuem-se entre 3,4 a 2,8Ga (amostras Q1, Q2, Q3 e P3 da fig: 5.8-6). Outro evento marcante de acreção neste sub-domínio refere-se ao Paleoproterozóico (Jaguaré , Quebra Cangalha e Cunha), onde as idades $\mathrm{T}_{\mathrm{DM}}$ distribuíram-se entre 2,2 a 1,9Ga (Ciclo Transamazonico / amostras O1, O2, P1 e P4 da fig. 5.8-6). 
SUb-domínio PARAíba do SUL - O sub-dominio Paraíba do Sul é composto predominantemente por ortognaisses e por rochas metassedimentares, ambos em fácies anfibolito. Neste sub-dominio, as datações U-Pb em zircões de rochas gnáissicas apresentaram idades Transamazònicas (intercepto superior no diagrama de concórdia; Machado et. al, 1996).

Não se dispõe, até presente momento, de qualquer datação Sm-Nd deste sub-domínio.

SUB-Domínio COSTEIRO - O sub-dominio Costeiro, definido por Campos Neto e Figueiredo (1995) como Microplaca Serra do Mar (fig. 5.8-1), é constituído predominantemente por rochas magmáticas cálcio-alcalinas, granitos peraluminosos, incluindo também bolsões de rochas granulíticas e gnaíssico-migmatíticas. Cerca de $90 \%$ das idades isocrônicas $\mathrm{Rb}-\mathrm{Sr}$ disponiveis situam-se entre 0,70 a $0,50 \mathrm{Ga}$, com razões iniciais ${ }^{87} \mathrm{Sr}{ }^{86} \mathrm{Sr}$ sempre acima de 0,705 .

As idades modelo, relacionadas na tabela 5.8-6, sugerem protólitos crustais Paleo a Mesoproterozóicos. Algumas idades modelo foram recalculadas admitindo-se modelo em estágio duplo (amostras R3, U3, V4 e V5, tab. 5.8-6), por apresentarem razões ${ }^{147} \mathrm{Sm} /{ }^{144} \mathrm{Nd}$ muito distintas do padrão normal de granitóides. As idades modelo em minerais (amostras V1 a V3 e V6 a V8) também foram calculadas de acordo com o modelo em estágio duplo, e mostraram certa consistência nos valores obtidos, o que não ocorre normalmente quando calculadas em estágio único

Os metassedimentos (paragnaisses - amostras S1 e S2, tab. 5.8-6) cuja idade de metamorfismo é próxima a $0,6 \mathrm{Ga}$, indicaram idades modelo $\mathrm{T}_{\mathrm{DM}}$ em torno de $1,4 \mathrm{Ga}$. Pela própria gênese destas rochas, que podem incluir materiais de diferentes procedências, tais valores estão sendo interpretados como idades de mistura. Os valores de $\varepsilon_{\mathrm{Nd}}$ negativos $(\sim-4)$, para $t=0,6$, sugerem fontes dos sedimentos não mais antigas que o Paleoproterozóico.

As idades $\mathrm{Pb}-\mathrm{Pb}$ relativas a 21 zircões detriticos dos metassedimentos do Sub-Dominio Costeiro, no Estado de Rio de Janeiro, (Valladares et. al 1997), distribuiram-se predominantemente no Paleoproterozóico. Do mesmo modo, os dados $\mathrm{U}-\mathrm{Pb}$ em zircões das rochas gnáissicas e granitóides que ocorrem nas vizinhanças de Vitória (ES) mostraram valores relativos ao Paleoproterozóico, com idades aparentes variando entre 2,1 a $1,8 \mathrm{Ga}$.

Os dados referidos sugerem que, neste sub-domínio, o Paleoproterozóico foi o principal periodo de acreção juvenil. 


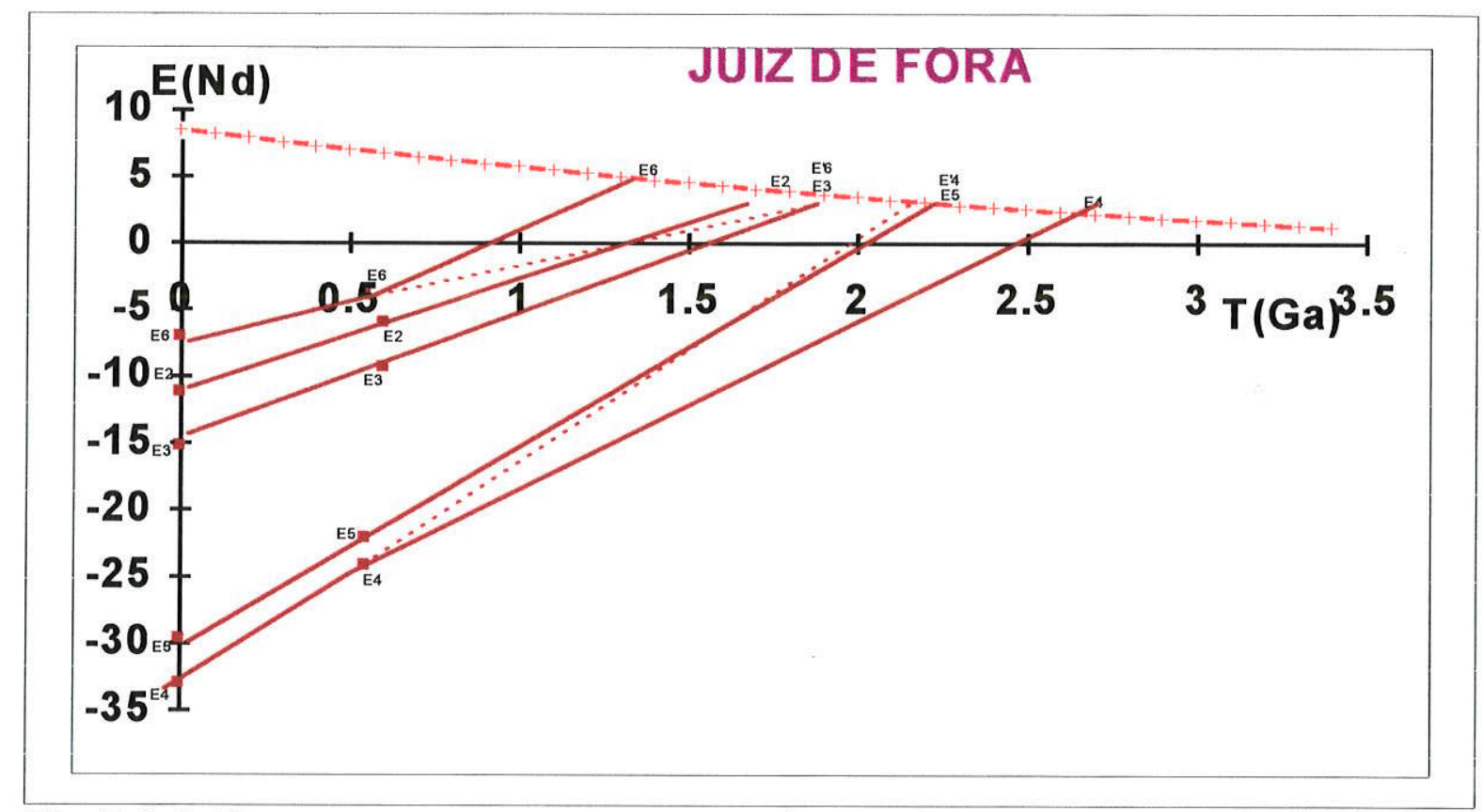

Fig. 5.8-5: Diagrama $\varepsilon_{\mathrm{Nd}}$ versus tempo geológico. Os dados isotópicos encontram-se na tab 5.8-3

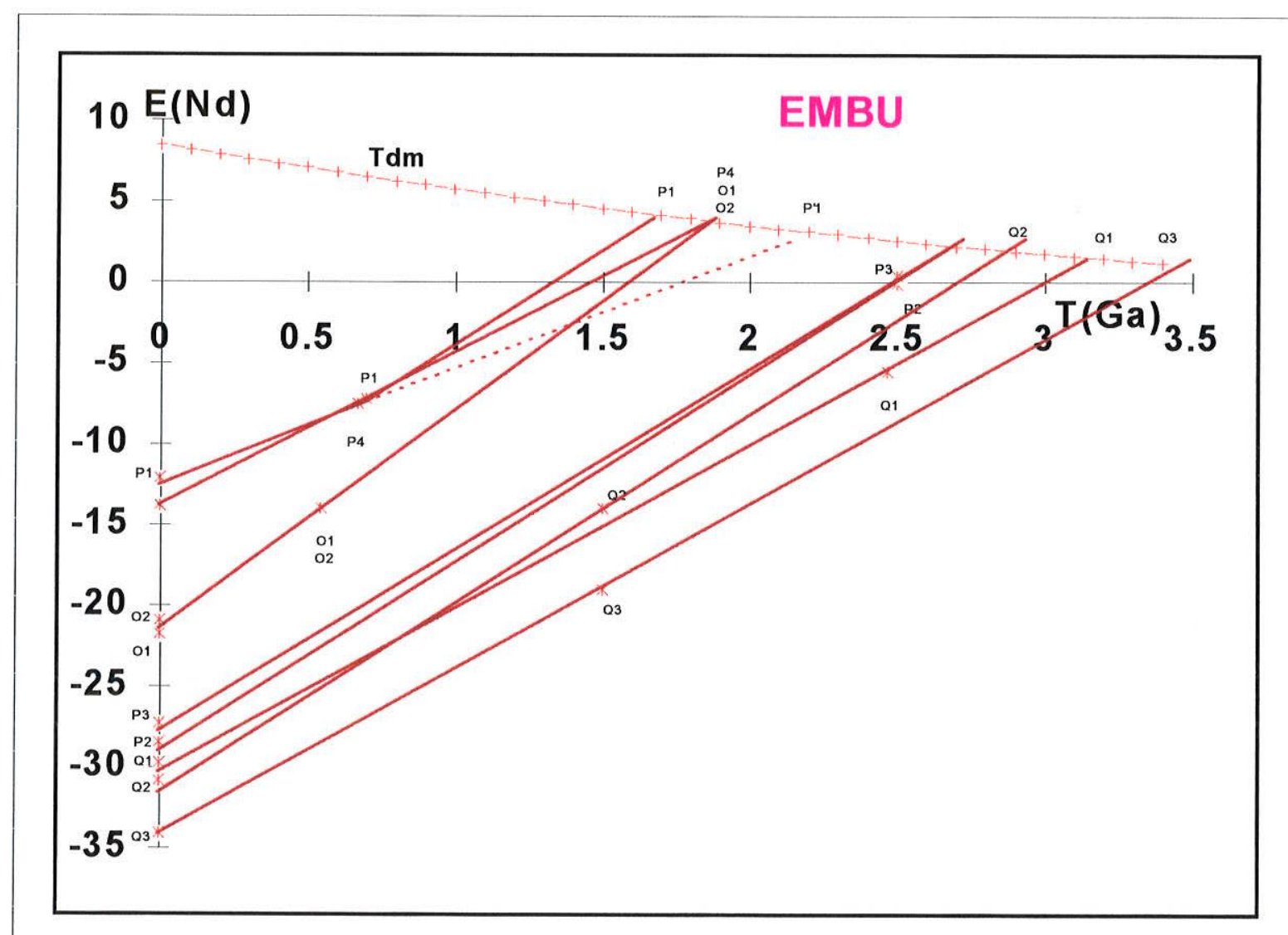

FIG. 5.8-6: Diagrama $\varepsilon_{N d}$ versus tempo geológico. Os dados isotópicos encontram-se na tab 5.8-4. 


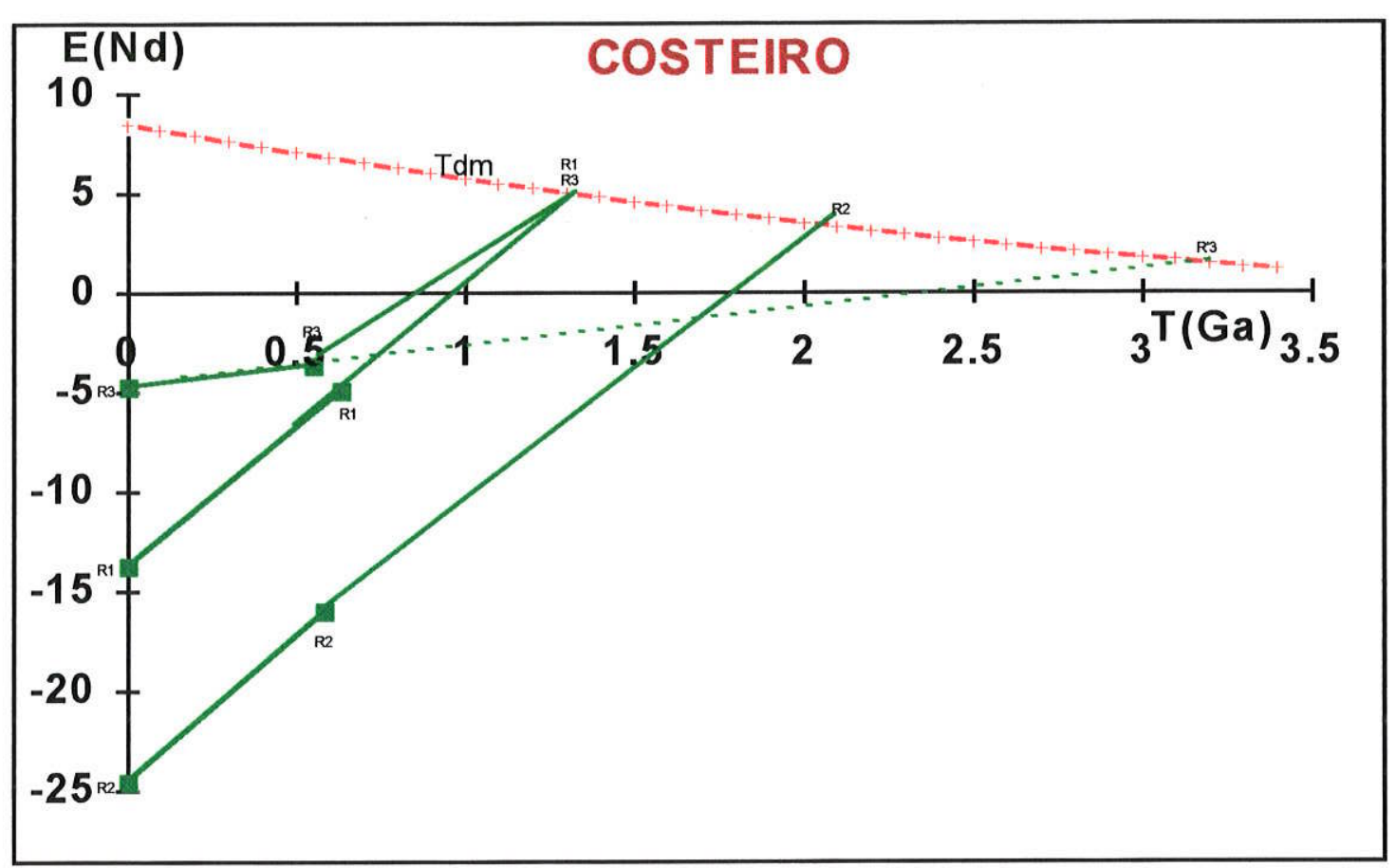

FIG. 5.8-7a: Diagrama $\varepsilon_{\text {Nd }}$ versus tempo geológico - COSTEIRO (porção NE DE S. PAULO). Os dados isotópicos encontram-se na tab 5.8-6

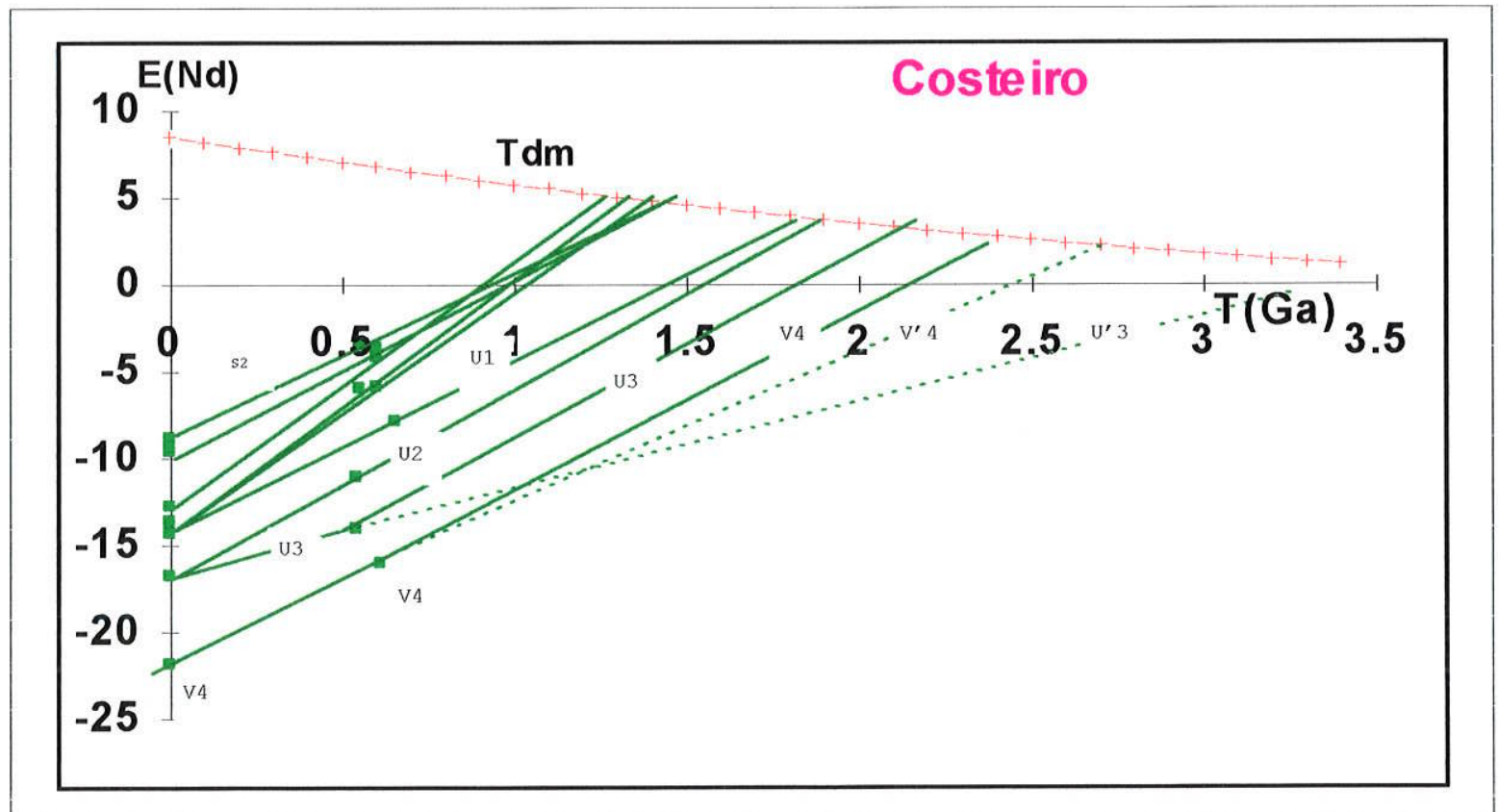

FIG. 5.8-7b: Diagrama $\varepsilon_{\text {Nd }}$ versus tempo geológico - COSTEIRO (região de SP) 
SUB-DOMínio ARAÇAí - As rochas que ocorrem na Faixa Araçuaí são predominantemente metassedimentos e intrusivas associadas pertencentes ao Ciclo Brasiliano. Neste sub-dominio encontram-se rochas meta-ultramáficas e orto-anfiboliticas com idade isocrônica $\mathrm{Sm}-\mathrm{Nd}$ de $0.79 \pm .09$ e com valor inicial $\varepsilon_{\mathrm{Nd}(\mathrm{t} .79)}$ de +4.1 (Soares et. al.,1992). A fig. 5.8-8 (pontos de amostras Al a A8) mostra a evolução isotópica $\varepsilon_{\mathrm{Nd}}$ no tempo geológico para estas rochas máficas, cujas linhas convergem para $0,79 \mathrm{Ga}$. Este ponto de convergência, ilustrado na figura, representa o valor da razão inicial ${ }^{143} \mathrm{Nd} /{ }^{344} \mathrm{Nd}$ encontrada na isócrona Sm-Nd. Quando expressa na forma de $\varepsilon_{\mathrm{Nd}(1=0.79)}$, ela apresenta um valor de $+\sim 4$, que situa-se entre as curvas do manto empobrecido (DM) e do manto condrítico (CHUR), (ver a fig. 5.8-8) sugerindo tratar-se de acreção juvenil a partir de um manto enriquecido. As idades modelos, $\mathrm{T}_{\mathrm{DM}}$, quando calculadas segundo o modelo de manto DM modelado por DePaolo (1981) mostram-se muito dispersas $(1,85$ a $0,97 \mathrm{Ga})$ e sem significação geológica.

No extremo Norte da Faixa Araçuai, próximo ao limite com o Craton do S. Francisco, afloram as rochas granitóides de Piripá, uma extensão do embasamento Arqueano relativo ao Bloco Gavião (CSF). Trata-se de uma área geologicamente complexa onde se encontram disponiveis análises $\mathrm{Sm}-\mathrm{Nd}, \mathrm{U}-\mathrm{Pb}, \mathrm{Rb}-\mathrm{Sr}$ e K-Ar. Cordani et. al. (1997), elaboraram o seguinte modelo evolutivo: 1) em torno de 3,2Ga ocorreu a formação dos protólitos ígneos (idades Sm$\mathrm{Nd}, \mathrm{T}_{\mathrm{DM}} ; 2$ ) durante a orogênese Transamazônica, em torno de $2,0 \mathrm{Ga}$, ocorreu metamorfismo de alto grau; 3) em torno de $0,6 \mathrm{Ga}$ ocorreu então metamorfismo de médio grau, associado à faixa móvel Araçuai (isócrona mineral $\mathrm{Rb}-\mathrm{Sr}$ e K-Ar em anfibólio).

SUB-DOMínio CABO FRIO - O sub-domínio Cabo Frio é constituído de uma seqüência de paragnaisses e quartzitos associados a ortognaisses cuja idade de formação refere-se ao Paleoproterozóico (Heibron et. al., 1982; Campos Neto e Figueiredo, 1995). Este sub-domínio tem sido descrito como um possivel fragmento da porção ocidental do Craton do Congo.

Os dados isotópicos $\mathrm{Sm}-\mathrm{Nd}$, relacionados na tabela 5.8-7, referem-se aos estudos geocronológicos realizados por Fonseca (1994). As razões ${ }^{147} \mathrm{Sm} /{ }^{144} \mathrm{Nd}$ variaram em torno de $0,086 \pm 0,024$ (amostras G5 a G22, tab. 5.8-7), anormalmente baixos considerando-se o padrão normal das rochas granitóides $(\sim 0,11 \pm 0.02)$. As idades modelo $\mathrm{Sm}-\mathrm{Nd}, \mathrm{T}_{\mathrm{DM}_{2}}$ variaram entre 2,7 a 2,3Ga, quando calculadas através do modelo em estágio único (Fonseca 1994; vide tab. 5.8-7).

Considerando-se a possibilidade de fracionamento entre Sm e Nd ocorrido durante a formação das rochas granitoides, as idades $\mathrm{T}_{\mathrm{DM}}$ foram recalculadas utilizando-se o modelo em estágio duplo, resultando valores pouco mais antigos, entre 2,8 a $2,53 \mathrm{Ga}$. 
Adicionalmente. Fonseca 1994, obteve também as idades modelo $\mathrm{T}_{\mathrm{DM}}$ para os paragnaisses, com resultados entre 1,6 a 1,45Ga, interpretadas como mistura de diferentes fontes, incluindo material do Neoproterozóico como no caso dos metassedimentos já comentados do sub-dominio Costeiro.

\section{5-8-3: DIAGRAMA $\varepsilon_{\mathrm{Sr}}$ versus $\varepsilon_{\mathrm{Nd}}$}

$\mathrm{O}$ diagrama $\varepsilon_{\mathrm{Sr}}$ versus $\varepsilon_{\mathrm{Nd}}$ (fig. 5.8-9) sugere que as rochas granitóides (amostras P1 e P4) do sub-dominio Embu, formadas no Ciclo Brasiliano, e a rocha granitóide (amostra Q2), formada no Ciclo Espinhaço, têm uma contribuição significativa de material crustal com alta razão $\mathrm{Rb} / \mathrm{Sr}$. Por sua vez, os migmatitos (amostras P2 e P3) formados já no final do Arqueano $(\sim 2,5 \mathrm{Ga})$, apresentam os valores de $\varepsilon_{\mathrm{sr}}$ e $\varepsilon_{\mathrm{Nd}}$ relativamente próximos da origem, significando que seu tempo de residência crustal foi curto, da ordem de $0.2 \mathrm{Ga}$.

As rochas granitóides do sub-domínio Costeiro (amostras T1, T2 e T3), formadas no Ciclo Brasiliano $(t=0,6 \mathrm{Ga})$ possuem valores de $\varepsilon_{\mathrm{Sr}}(t)$ em torno de +100 e $\varepsilon_{\mathrm{Nd}}(t)$ próximo de -5 , sugerindo tempo de residência crustal relativamente longo para os seus protólitos.

As rochas granitóides (monzoníticas) do maciço de Morungaba, formadas no Ciclo Brasiliano (elipse na fig. 5.8-9), mostram comportamento geoquímico enriquecido em terras raras, quando comparado aos demais conjuntos e o tempo de residência crustal de seus protolitos, relativamente longo.

Do mesmo modo, as rochas dos sub-domínios Mantiqueira, Juiz de Fora, Guanhães e Costeiro (porção norte de Rio de Janeiro) apresentaram valores de $\varepsilon_{\mathrm{Nd}}$ negativos e $\varepsilon_{\mathrm{Sr}}$ positivos quando calculados para evento de formação dessas rochas (Fig. 5.8-10). No diagrama, os pontos mais afastados da origem e para o a direita indicam tempos de residência relativamente longos para os protólitos crustais. 


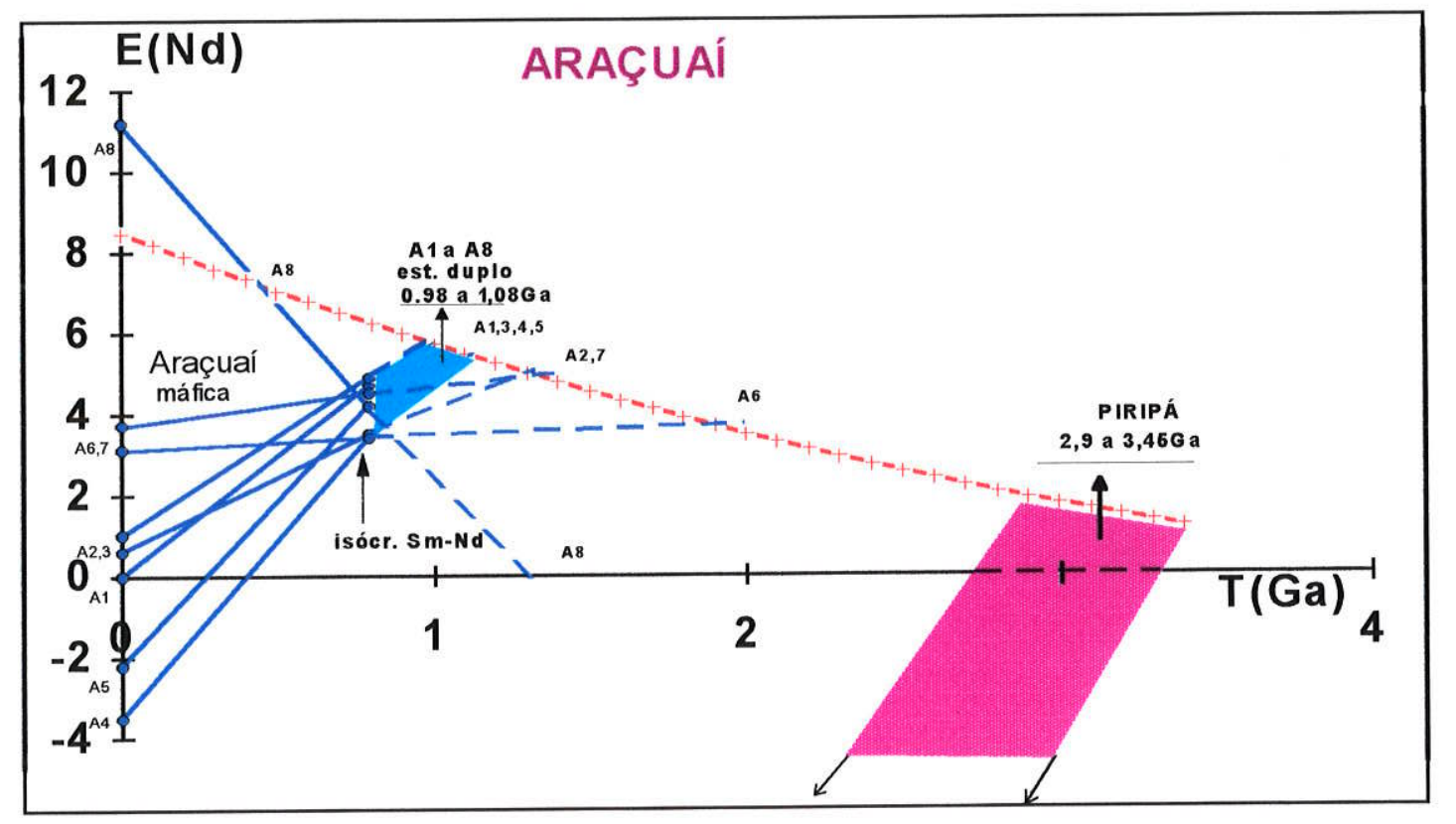

Fig. 5.8-8 : Diagrama $\varepsilon_{\mathrm{Nd}}$ versus tempo geológico. Os dados isotópicos encontram-se na tab 5.8-5

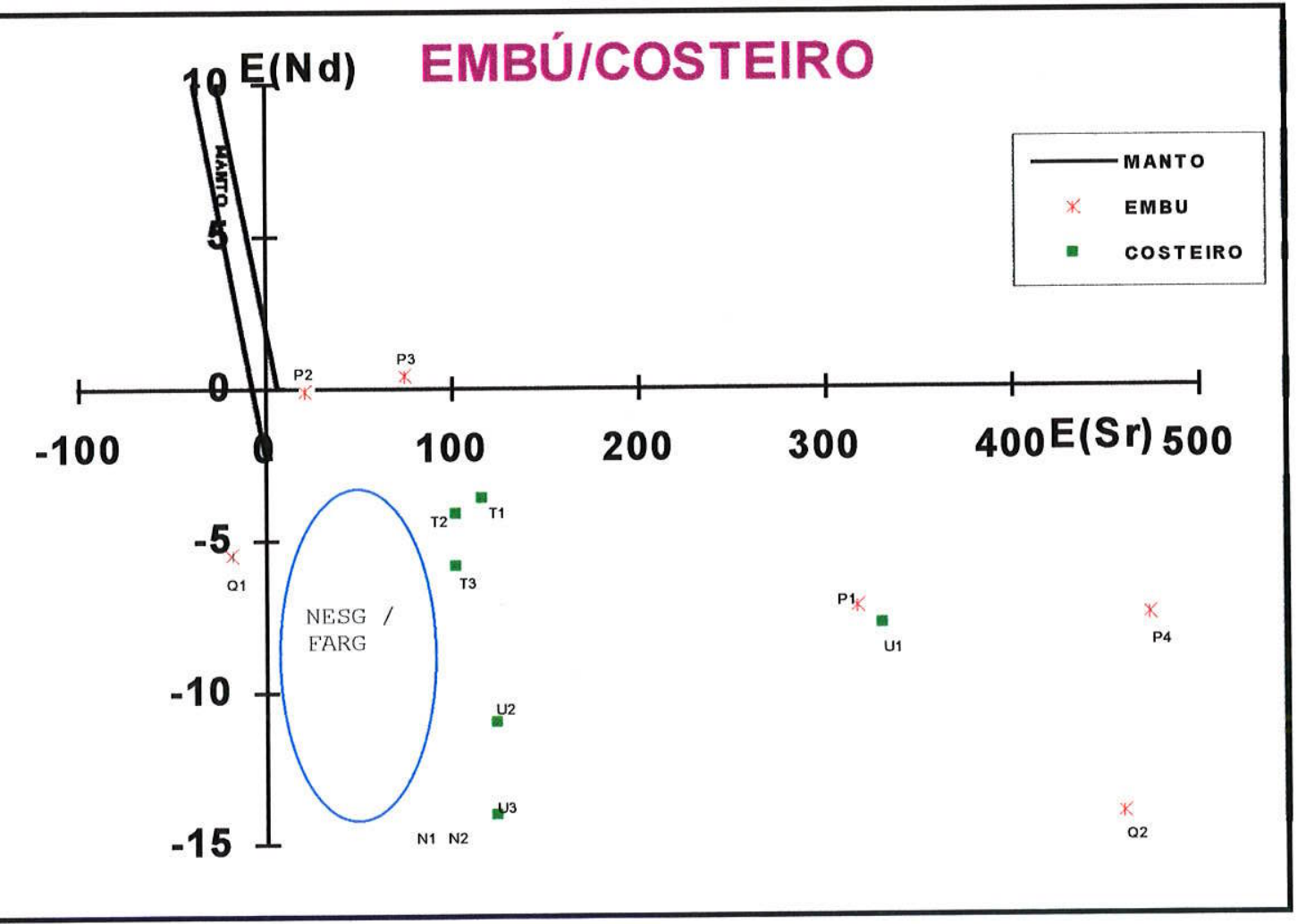

Fig. 5.8-9: Diagrama $\varepsilon_{\mathrm{Sr}}$ versus $\varepsilon_{\mathrm{Nd}}$ 


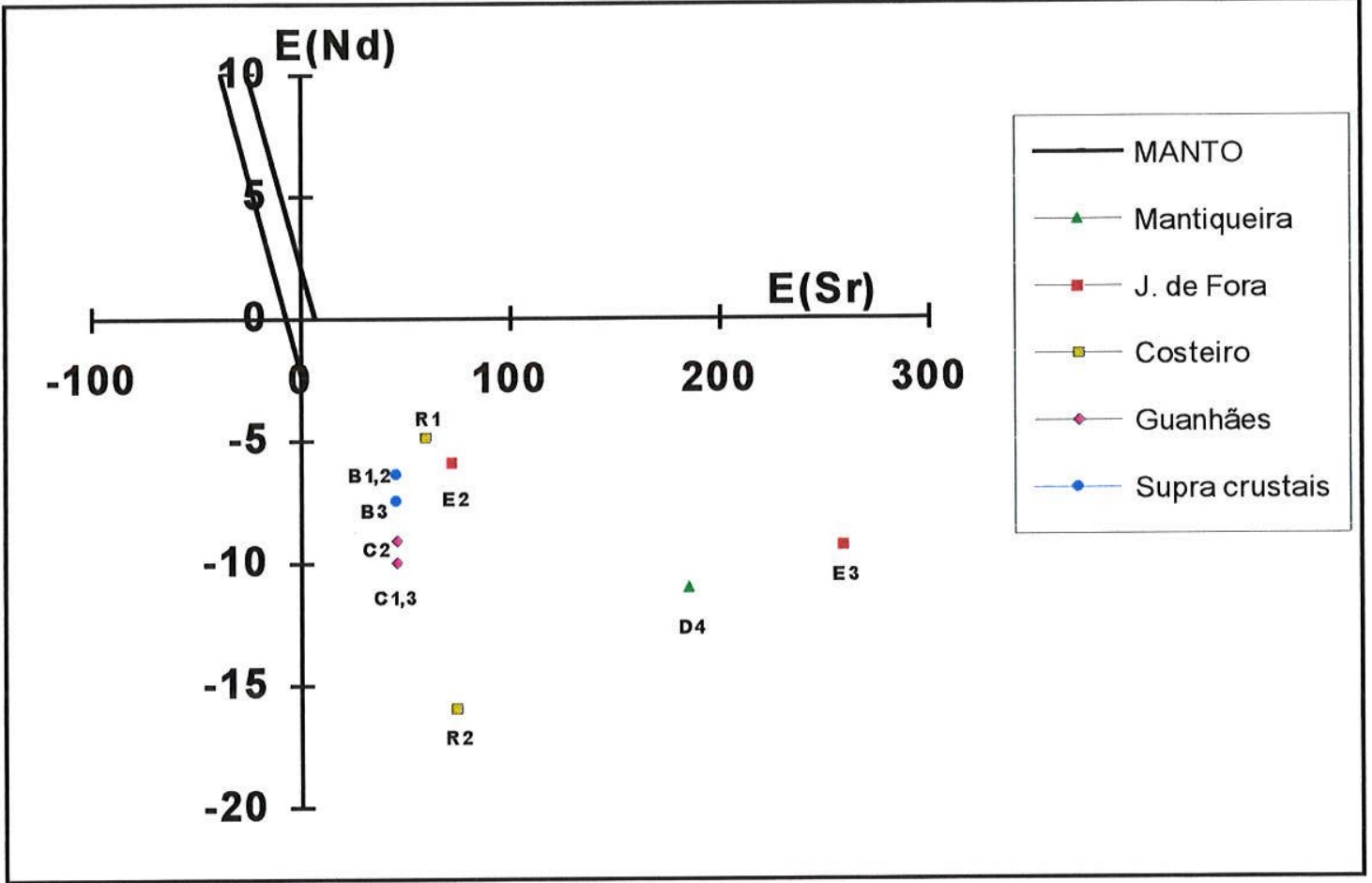

Fig. 5.8-10: Diagrama $\varepsilon_{S_{r}}$ versus $\varepsilon_{N d}$. GUANHÃES, MANTIQUEIRA, JUIZ de FORA e COSTEIRO (PORÇÃO NE de S. PAULO)

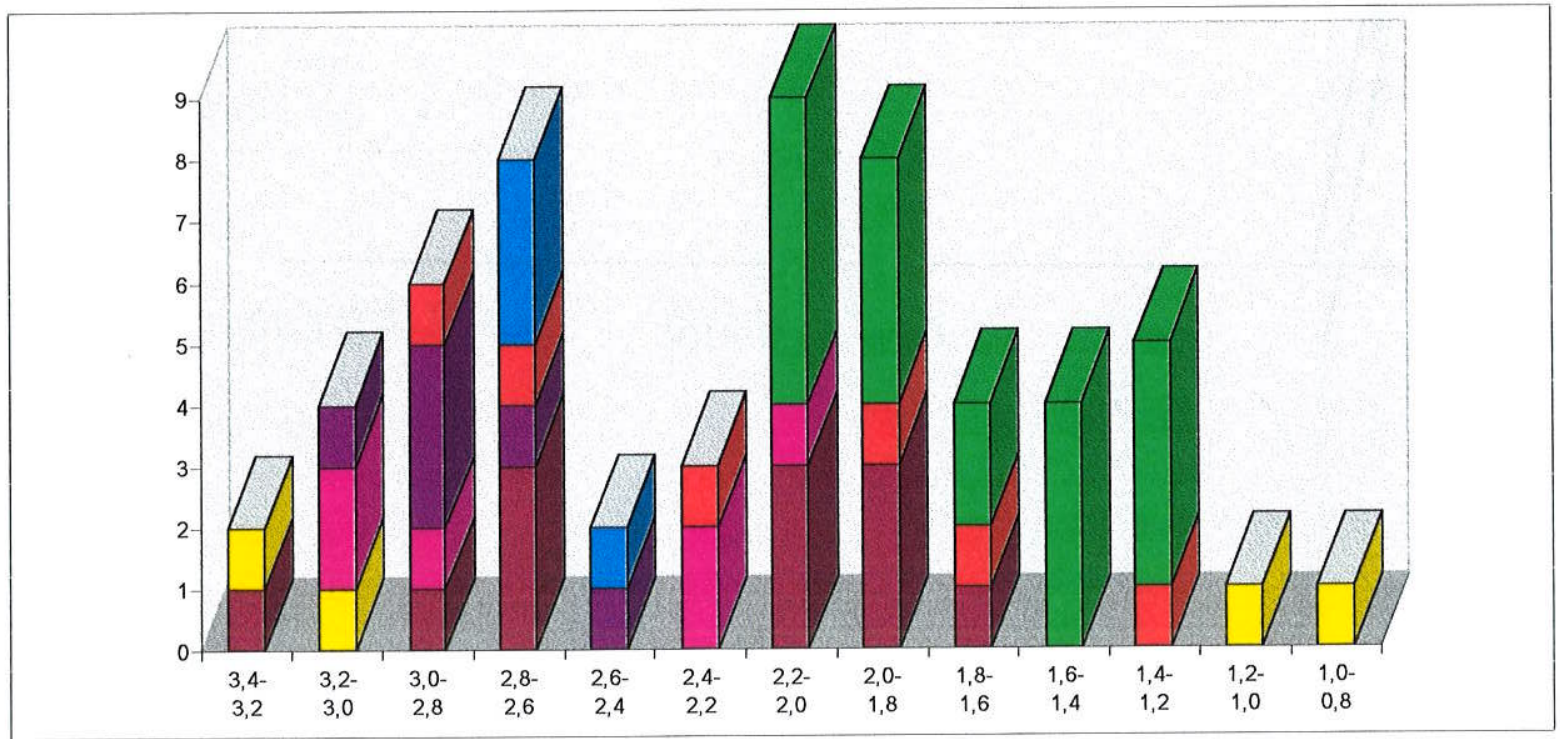

FIG. 5.8-11: Histograma das idades modelo Sm-Nd (Tdm) - Domínio Jequitinhonha. Um valor médio foi tomado em caso da existência de varias idades Tdm em um único afloramento. Legenda: Amarelo Araçuaí; Verde - Costeiro; Vermelho - Juiz de Fora; Marrom - Embú; Rosa - Mantiqueira; Roxo Guanhães; Azul - Cabo Frio. 


\section{8-4: RESUMO PARCIAL DO DOMÍNIO JEQUITINHONHA}

As idades modelo $\mathrm{Sm}-\mathrm{Nd}\left(\mathrm{T}_{\mathrm{DNM}}\right)$ apresentaram valores variáveis desde 3,4 a $1,0 \mathrm{Ga}$, confirmando a complexidade da evolução tectônica da porção Sudeste do Brasil, descrita por dezenas de pesquisadores. Os principais periodos de acreção manto-crosta continental no Dominio Jequitinhonha podem ser verificadas no histograma da fig. 5.8-11, e resumidos da seguinte forma:

i) Acreção de material juvenil arqueano ocorreu nos sub-domínios Mantiqueira, Guanhães e Cabo Frio. Fragmentos de material arqueano foram registrados também ao norte do sub-dominio Araçuaí, no interior dos sub-domínios Embu e Juiz de Fora.

ii) No Paleoproterozóico, a acreção manto - crosta continental ocorreu principalmente nos sub-domínios Costeiro, Paraíba do Sul e Juiz de Fora, sendo o período entre 2,2 a 1,8 Ga o que gerou a maior quantidade de crosta continental juvenil.

iii) Durante o Meso e Neoproterozóico predominaram os processos de retrabalhamento, a partir de materiais previamente estabelecidos na crosta continental. Material juvenil parece ter sido adicionado, nestas épocas, em quantidades menores. 
TAB. 5.8-1: DADOS ISOTÓPICOS Sm - Nd: JEQUITINHONHA

\begin{tabular}{|c|c|c|c|c|c|c|c|c|c|c|c|c|c|c|c|c|c|}
\hline $\begin{array}{l}\text { SPS } \\
/ \text { lit. }\end{array}$ & coord. & $\begin{array}{l}\text { n.campo / } \\
\text { região }\end{array}$ & $\begin{array}{l}\text { litolo } \\
\text { gia }\end{array}$ & ident. & $\begin{array}{l}\mathrm{T}_{\text {chur }} \\
\text { (GA) } \\
\text { Goldstein } \\
\text { etal 1984 }\end{array}$ & $\mathrm{T}_{(\mathrm{GA})}$ & $\begin{array}{l}T_{d m} \\
(G A) \\
\text { DePaoto } \\
\text { - 1989 }\end{array}$ & $\begin{array}{l}{ }^{143} \mathrm{Nd} l \\
{ }^{14 d} \mathrm{Nd}\end{array}$ & ${ }_{{ }^{144} \mathrm{Nd}}^{147} /$ & $\begin{array}{l}\mathrm{Sm} \\
\mathrm{ppm}\end{array}$ & $\begin{array}{l}\text { Nd } \\
\text { ppm }\end{array}$ & $f$ & $\begin{array}{l}\varepsilon_{\mathrm{Nd}} \\
(0)\end{array}$ & $\begin{array}{l}\varepsilon_{N d} \\
(t)\end{array}$ & $\begin{array}{l}t(G a)_{\text {mét }} \\
R i_{\text {(fonte) }}\end{array}$ & $\begin{array}{l}\varepsilon_{\mathrm{Sr}} \\
(\mathrm{t})\end{array}$ & ref \\
\hline \multicolumn{18}{|c|}{ TAB. 5.8-1: GUANHÃES } \\
\hline rio & $1856 / 4328$ & $\begin{array}{l}\text { ER 14C / MG } \\
\text { Guanhães }\end{array}$ & VAC & $\mathrm{B1}$ & $\begin{array}{l}2.37 \\
0.03 \\
\end{array}$ & & $\begin{array}{l}2.63 \\
0.02 \\
\end{array}$ & $\begin{array}{l}.511459 \\
.000015 \\
\end{array}$ & .12124 & 36.56 & 182.35 & -.38 & -23.0 & -6.4 & $\begin{array}{l}1.72_{\mathrm{Rb} / \mathrm{St}} \\
.7057_{\mathrm{I}} \\
\end{array}$ & 46 & 6 \\
\hline rio & $1856 / 4328$ & $\begin{array}{l}\text { ER 16/MG } \\
\text { Guanhães }\end{array}$ & VAC & B2 & $\begin{array}{l}2.32 \\
0.03 \\
\end{array}$ & & $\begin{array}{l}2.57 \\
0.02 \\
\end{array}$ & $\begin{array}{l}.511381 \\
.000015 \\
\end{array}$ & .1146304 & 23.18 & 122.28 & -.42 & -24.5 & -6.5 & $\begin{array}{l}1.72_{\mathrm{Ro} / \mathrm{Sr}} \\
.7057_{\mathrm{i}} \\
\end{array}$ & 46 & 6 \\
\hline rio & $1856 / 4328$ & $\begin{array}{l}\text { ER 16F / MG } \\
\text { Guanhães }\end{array}$ & VAC & B3 & $\begin{array}{l}2.60 \\
0.04\end{array}$ & & $\begin{array}{l}2.86 \\
0.03\end{array}$ & $\begin{array}{l}.511528 \\
.000015\end{array}$ & .1320934 & 29.42 & 134.68 & -.33 & -21.7 & -7.5 & $\begin{array}{l}1.72_{\mathrm{Rb} / \mathrm{Sr}} \\
.7057_{\mathrm{i}} \\
\end{array}$ & 46 & 6 \\
\hline grt & $1859 / 4255$ & $\begin{array}{l}\text { UR 87/MG } \\
\text { Guanhāes }\end{array}$ & GTD & $\mathrm{C1}$ & $\begin{array}{l}2.76 \\
0.03\end{array}$ & & $\begin{array}{l}2.97 \\
0.02\end{array}$ & $\begin{array}{l}.511248 \\
.000015\end{array}$ & .12038 & 8.14 & 40.89 & -.39 & -27.1 & -10 & $\begin{array}{l}1.72_{\mathrm{Rb} / \mathrm{Sr}} \\
.7057\end{array}$ & 46 & 6 \\
\hline grt & $1841 / 4309$ & $\begin{array}{l}\text { SF } 90 / \mathrm{MG} \\
\text { Guanhāes }\end{array}$ & GTD & $\mathrm{C} 2$ & $\begin{array}{l}2.57 \\
0.03 \\
\end{array}$ & & $\begin{array}{l}2.80 \\
0.02 \\
\end{array}$ & $\begin{array}{l}.511261 \\
.000015 \\
\end{array}$ & .11560 & 22.74 & 118.95 & -.41 & -26.9 & -9.1 & $\begin{array}{l}1.72_{\mathrm{Rb} / \mathrm{Sr}} \\
.7057\end{array}$ & 46 & 6 \\
\hline grt & $1841 / 4309$ & $\begin{array}{l}\text { SF } 52 / M G \\
\text { Guanhāes }\end{array}$ & GTD & C3 & $\begin{array}{l}2.80 \\
0.03 \\
\end{array}$ & & $\begin{array}{l}3.02 \\
0.03\end{array}$ & $\begin{array}{l}.511331 \\
.000015\end{array}$ & .12608 & 14.21 & 68.15 & -.36 & -25.5 & -10 & $\begin{array}{l}1.72_{\mathrm{Rb} / \mathrm{Sr}} \\
.7057_{\mathrm{I}}\end{array}$ & 46 & 6 \\
\hline
\end{tabular}

TAB. 5.8-2: MANTIQUEIRA

\begin{tabular}{|c|c|c|c|c|c|c|c|c|c|c|c|c|c|c|c|c|c|}
\hline $\begin{array}{l}262 \\
\text { trj }\end{array}$ & $2133 / 4626$ & $\begin{array}{l}\text { JF-27C/MG } \\
\text { Mantiqueira }\end{array}$ & GTD & D1 & $\begin{array}{l}1.84 \\
0.06\end{array}$ & & $\begin{array}{l}2.22 \\
0.04 \\
\end{array}$ & $\begin{array}{l}.511855 \\
.000024 \\
\end{array}$ & $\begin{array}{l}.13198 \\
.00006\end{array}$ & $\begin{array}{l}5.403 \\
.001 \\
\end{array}$ & $\begin{array}{l}24.756 \\
.011 \\
\end{array}$ & -.33 & -15.3 & 1.2 & $2.0_{\text {est }}$ & & nt: \\
\hline $\begin{array}{l}261 \\
\text { trj.gn }\end{array}$ & $2147 / 4334$ & $\begin{array}{l}\text { LD7 44A / MG } \\
\text { Mantiqueira }\end{array}$ & GTD & D2 & $\begin{array}{l}1.95 \\
0.03 \\
\end{array}$ & & $\begin{array}{l}2.19 \\
0.02 \\
\end{array}$ & $\begin{array}{l}.511252 \\
.000020 \\
\end{array}$ & $\begin{array}{l}.08867 \\
.00006 \\
\end{array}$ & $\begin{array}{l}1.788 \\
.001 \\
\end{array}$ & $\begin{array}{l}12.194 \\
.005 \\
\end{array}$ & -.55 & -27.0 & .52 & $2.0_{\text {est }}$ & & $\mathrm{nt}$ \\
\hline $\begin{array}{l}250 \\
\text { ton.gn }\end{array}$ & $2151 / 4.59$ & $\begin{array}{l}\text { BJ 1C/MG } \\
\text { Mantiqueira }\end{array}$ & GTD & D3 & $\begin{array}{l}2.86 \\
0.06\end{array}$ & & $\begin{array}{l}3.06 \\
0.06\end{array}$ & $\begin{array}{l}.511291 \\
.000026 \\
\end{array}$ & $\begin{array}{l}.12524 \\
.00010\end{array}$ & $\begin{array}{l}7.294 \\
.002 \\
\end{array}$ & $\begin{array}{l}35.217 \\
.027 \\
\end{array}$ & -.36 & -26.3 & -7.1 & 2.1 est & & $\mathrm{nt}$ \\
\hline $\begin{array}{l}490 \\
\text { gns }\end{array}$ & $2021 / 4253$ & $\begin{array}{l}2833 \mathrm{~B} \\
\text { Mantiqueira }\end{array}$ & GTD & D4 & $\begin{array}{l}2.91 \\
0.03 \\
\end{array}$ & & $\begin{array}{l}3.06 \\
0.03 \\
\end{array}$ & $\begin{array}{l}.510527 \\
.000019 \\
\end{array}$ & $\begin{array}{l}.08677 \\
.00008 \\
\end{array}$ & $\begin{array}{l}1.287 \\
.001 \\
\end{array}$ & $\begin{array}{l}8.969 \\
.004 \\
\end{array}$ & -.56 & -41.2 & -11 & $\begin{array}{l}2.16_{\mathrm{Rb} / \mathrm{sr}} \\
.715_{\mathrm{h}} \\
\end{array}$ & & nt \\
\hline \multicolumn{18}{|c|}{ BARBACENA } \\
\hline $\begin{array}{l}585 \\
\mathrm{grt}\end{array}$ & $2119 / 4438$ & $\begin{array}{l}95-04 / \text { tutinga } \\
\text { SE de Lavras }\end{array}$ & GTD & & $3.36 ?$ & $2.85^{\# 2}$ & $\begin{array}{l}3.58 ? \\
.09 \\
\end{array}$ & $\begin{array}{l}.511740 \\
.000024 \\
\end{array}$ & $\begin{array}{l}.15623 \\
.00008 \\
\end{array}$ & $\begin{array}{l}3.085 \\
.001 \\
\end{array}$ & $\begin{array}{l}11.941 \\
.005 \\
\end{array}$ & -.21 & -17.5 & -6.8 & $\begin{array}{l}2.08_{\mathrm{Rb} / \mathrm{St}} \\
.7035_{\mathrm{I}}\end{array}$ & 17.8 & 8 \\
\hline $\begin{array}{l}586 \\
\text { grt }\end{array}$ & $21.06 / 4343$ & $\begin{array}{l}95-05 / R e s s a q . \\
\text { "N" Barbacena }\end{array}$ & GTD & & $\begin{array}{l}2.09 \\
0.08\end{array}$ & $2.40^{72}$ & $\begin{array}{l}2.30 \\
.06 \\
\end{array}$ & $\begin{array}{l}.511043 \\
.000060 \\
\end{array}$ & $\begin{array}{r}.08054 \\
.00006 \\
\end{array}$ & $\begin{array}{l}1.954 \\
.001 \\
\end{array}$ & $\begin{array}{l}14.671 \\
.007 \\
\end{array}$ & -.59 & -31.1 & -1.3 & $\begin{array}{l}2.01 \\
.7086\end{array}$ & 92 & 8 \\
\hline
\end{tabular}


TAB. 5.8-3: JUIZ DE FORA

\begin{tabular}{|c|c|c|c|c|c|c|c|c|c|c|c|c|c|c|c|c|}
\hline 153 & & $\begin{array}{l}\text { IT - 4A /MG } \\
\text { Itatiaia }\end{array}$ & GTD & E1 & $\begin{array}{l}2.14 ? \\
0.04\end{array}$ & $2.85^{\# 1}$ & $\begin{array}{l}2.33 ? \\
0.04\end{array}$ & $\begin{array}{l}.510793 \\
.000036\end{array}$ & $\begin{array}{l}.06597 \\
.00006\end{array}$ & $\begin{array}{l}4.475 \\
.002\end{array}$ & $\begin{array}{l}41.022 \\
.031\end{array}$ & -.66 & -36.0 & -27 & $\begin{array}{l}.55 \\
\mathrm{C}\end{array}$ & $\mathrm{nt}$ \\
\hline $\begin{array}{l}506 \\
\text { gns }\end{array}$ & $1923 / 4141$ & $w-05-1.1185$ & GTD & E2 & $\begin{array}{l}1.29 \\
0.05\end{array}$ & & $\begin{array}{l}1.76 \\
0.04\end{array}$ & $\begin{array}{l}.512071 \\
.000022\end{array}$ & $\begin{array}{l}.12966 \\
.00006\end{array}$ & $\begin{array}{l}4.733 \\
.001\end{array}$ & $\begin{array}{l}22.073 \\
.009\end{array}$ & -.34 & -11.1 & -5.9 & $\begin{array}{l}.60_{\mathrm{Rb} / \mathrm{Sr}} \\
.709\end{array}$ & nt \\
\hline $\begin{array}{l}507 \\
\text { gns }\end{array}$ & $1921 / 4159$ & W.m1.05.67.1b & GTD & E3 & $\begin{array}{l}1.54 \\
0.04\end{array}$ & & $\begin{array}{l}1.92 \\
0.03\end{array}$ & $\begin{array}{l}.511861 \\
.000020\end{array}$ & $\begin{array}{l}.11975 \\
.00007\end{array}$ & $\begin{array}{l}11.353 \\
.004\end{array}$ & $\begin{array}{l}57.331 \\
.024\end{array}$ & -.39 & -15.2 & -9.3 & $\begin{array}{l}.60 \mathrm{Ru} / \mathrm{Sr} \\
.722_{1}\end{array}$ & nt \\
\hline $\begin{array}{l}263 \\
\text { m.to } \\
n\end{array}$ & $2155 / 4348$ & $\begin{array}{l}\text { LD1-7C/MG } \\
\text { Andrelândia }\end{array}$ & GTD & E4 & $\begin{array}{l}2.03 \\
0.03\end{array}$ & $2.70^{\# 1-1}$ & $\begin{array}{l}2.23 ? \\
0.02\end{array}$ & $\begin{array}{l}.510925 \\
.000024\end{array}$ & $\begin{array}{l}.06875 \\
.00020\end{array}$ & $\begin{array}{l}1.074 \\
.003\end{array}$ & $\begin{array}{l}9.447 \\
.004\end{array}$ & -.65 & -.33 & -24 & .55 est & $n t$ \\
\hline $\begin{array}{l}249 \\
\text { gnl }\end{array}$ & $2147 / 4318$ & $\begin{array}{l}\text { JF } 198 / M G \\
\text { Juiz de Fora }\end{array}$ & GNL & E5 & $\begin{array}{l}2.02 \\
0.04\end{array}$ & & $\begin{array}{l}2.25 \\
0.03\end{array}$ & $\begin{array}{l}.511121 \\
.000027\end{array}$ & $\begin{array}{l}.08281 \\
.00008\end{array}$ & $\begin{array}{l}6.555 \\
.003\end{array}$ & $\begin{array}{l}47.866 \\
.038\end{array}$ & -.58 & -29.6 & -22 & $.55 \mathrm{est}$ & $n t$ \\
\hline $\begin{array}{l}258 \\
\text { end }\end{array}$ & $2157 / 4342$ & $\begin{array}{l}\mathrm{LDX}-51 / \mathrm{MG} \\
\text { Juiz de Fora }\end{array}$ & GNL & E6 & $\begin{array}{l}1.24 \\
0.08\end{array}$ & $1.36^{\# T}$ & $\begin{array}{l}1.90 ? \\
0.05\end{array}$ & $\begin{array}{l}.512278 \\
.000024\end{array}$ & $\begin{array}{l}.15259 \\
.00008\end{array}$ & $\begin{array}{l}7.440 \\
.001\end{array}$ & $\begin{array}{l}29.485 \\
.015\end{array}$ & -.22 & -7.0 & -3.9 & .55 est & $n t$ \\
\hline
\end{tabular}

\section{TAB. 5.8-4: EMBU}

\begin{tabular}{|c|c|c|c|c|c|c|c|c|c|c|c|c|c|c|c|c|c|}
\hline $\begin{array}{l}381 \\
\text { mig.p }\end{array}$ & $\begin{array}{l}1 \mathrm{Km} \text { de } \\
\text { USP }\end{array}$ & $\begin{array}{l}\text { Jaguaré 5/ SP } \\
\text { próximo a USP }\end{array}$ & GTD & 01 & $\begin{array}{l}1.63 \\
0.04\end{array}$ & & $\begin{array}{l}1.91 \\
0.03\end{array}$ & $\begin{array}{l}.511526 \\
.000027\end{array}$ & $\begin{array}{l}.09269 \\
.00004\end{array}$ & $\begin{array}{l}8.908 \\
.001\end{array}$ & $\begin{array}{l}58.154 \\
.021\end{array}$ & -.53 & -21.7 & -14 & .55 est & & nt \\
\hline $\begin{array}{l}382 \\
\text { mig.p }\end{array}$ & $\begin{array}{l}1 \mathrm{Km} \text { de } \\
\text { USP }\end{array}$ & $\begin{array}{l}\text { Jaguaré } 7 \text { / SP } \\
\text { próximo a USP }\end{array}$ & GTD & 02 & $\begin{array}{l}1.60 \\
0.04\end{array}$ & & $\begin{array}{l}1.89 \\
0.03\end{array}$ & $\begin{array}{l}.511567 \\
.000027\end{array}$ & $\begin{array}{l}.09482 \\
.00004\end{array}$ & $\begin{array}{l}9.544 \\
.002\end{array}$ & $\begin{array}{l}60.863 \\
.022\end{array}$ & -.52 & -20.9 & -14 & .55 est & & $\mathrm{nt}$ \\
\hline $\begin{array}{l}306 \\
\text { grt }\end{array}$ & & $\begin{array}{l}\text { KK-81-36B/SP } \\
\text { Q.Cangalha }\end{array}$ & GTD & P1 & $\begin{array}{l}1.73 \\
0.06 \\
\end{array}$ & $1.70^{\#+}$ & $\begin{array}{l}2.19 \\
0.04 \\
\end{array}$ & $\begin{array}{l}.512018 \\
.000020\end{array}$ & $\begin{array}{l}.14212 \\
.00007 \\
\end{array}$ & $\begin{array}{l}9.099 \\
.002\end{array}$ & $\begin{array}{l}38.716 \\
.017 \\
\end{array}$ & -.28 & -12.1 & -7.2 & $\begin{array}{l}.70 \\
.726 n \\
\end{array}$ & 317 & $\mathrm{nt}$ \\
\hline $\begin{array}{l}312 \\
\mathrm{mig}\end{array}$ & $2303 / 4503$ & $\begin{array}{l}\mathrm{OR}-4 \mathrm{~N} / \mathrm{SP} \\
\text { Embu }\end{array}$ & GTD & P2 & $\begin{array}{l}2.49 \\
0.04 \\
\end{array}$ & & $\begin{array}{l}.70 \\
0.03 \\
\end{array}$ & $\begin{array}{l}.511183 \\
.000024\end{array}$ & $\begin{array}{l}.10794 \\
.00005\end{array}$ & $\begin{array}{l}9.988 \\
.002\end{array}$ & $\begin{array}{l}55.954 \\
.022 \\
\end{array}$ & -.45 & -28.4 & -.08 & $\begin{array}{l}2.50 \\
.703_{n}\end{array}$ & 21 & $n t$ \\
\hline $\begin{array}{l}313 \\
\mathrm{mig}\end{array}$ & $2303 / 4503$ & $\begin{array}{l}\mathrm{OR}-4 \mathrm{G} / \mathrm{SP} \\
\text { Embu }\end{array}$ & GTD & P3 & $\begin{array}{l}2.44 \\
0.06 \\
\end{array}$ & & $\begin{array}{l}2.67 \\
0.05 \\
\end{array}$ & $\begin{array}{l}.511238 \\
.000034\end{array}$ & $\begin{array}{l}.10979 \\
.00008\end{array}$ & $\begin{array}{l}6.436 \\
.004 \\
\end{array}$ & $\begin{array}{l}35.447 \\
.015 \\
\end{array}$ & -.44 & -27.3 & +4 & $\begin{array}{l}2.50 \\
.703 n \\
\end{array}$ & $\overline{75}$ & $n t$ \\
\hline $\begin{array}{l}314 \\
\text { gns }\end{array}$ & $2249 / 4511$ & $\begin{array}{l}\overline{O R-1 \mathrm{C} / \mathrm{SP}} \\
\text { Embu }\end{array}$ & GTD & $\overrightarrow{P 4}$ & $\begin{array}{l}1.47 \\
0.05\end{array}$ & & $\begin{array}{l}1.88 \\
0.04 \\
\end{array}$ & $\begin{array}{l}.511933 \\
.000024\end{array}$ & $\begin{array}{l}.12359 \\
.00006\end{array}$ & $\begin{array}{l}3.970 \\
.001 \\
\end{array}$ & $\begin{array}{l}19.424 \\
.008 \\
\end{array}$ & -.37 & -13.8 & -7.5 & $\begin{array}{l}.67 \\
.737 n\end{array}$ & 473 & nt \\
\hline mig & $2320 / 4543$ & $\begin{array}{l}\text { J-I-C/SP } \\
\text { S.J.Campos }\end{array}$ & GTD & Q1 & 3.00 & & 3.18 & .511115 & .11983 & $\ldots$ & -- & -.39 & -29.7 & -5.5 & $\begin{array}{l}2.47 \\
.7003 p \\
\end{array}$ & -18 & 7 \\
\hline $\mathrm{mig}$ & $2320 / 4543$ & $\begin{array}{l}\text { J-l-R / SP } \\
\text { S.J.Campos }\end{array}$ & GTD & Q2 & 2.71 & & 2.91 & .511058 & .10848 & $\ldots$ & $\ldots$ & -.45 & -30.8 & -14 & $\begin{array}{l}1.50 \\
.735 p \\
\end{array}$ & 459 & 7 \\
\hline mig & $2320 / 4543$ & $\begin{array}{l}\mathrm{J}-\mathrm{H}-\mathrm{Gr} / \mathrm{SP} \\
\text { S.J.Campos }\end{array}$ & GTD & Q3 & 3.24 & & 3.39 & .510889 & .11492 & $\cdots$ & -- & -.42 & -34.1 & -19 & $1.50_{\text {est }}$ & $-\cdots$ & 7 \\
\hline & & & & & & & & & & & & & & & & & \\
\hline
\end{tabular}




\begin{tabular}{|c|c|c|c|c|c|c|c|c|c|c|c|c|c|c|}
\hline $\begin{array}{l}737 \\
\text { o.gns }\end{array}$ & $\begin{array}{l}\text { Ragatky,D. } \\
\text { dados inéd. }\end{array}$ & $\begin{array}{l}\text { Di6-6/ } \\
\text { Sta. Izabel }\end{array}$ & GTD & $\begin{array}{l}1.75 \\
0.04\end{array}$ & $\begin{array}{l}2.04 \\
0.04\end{array}$ & $\begin{array}{l}.511525 \\
.000028\end{array}$ & $\begin{array}{l}.09998 \\
.00007\end{array}$ & $\begin{array}{l}9.765 \\
0.004\end{array}$ & $\begin{array}{l}59.063 \\
0.030\end{array}$ & -.49 & -21.7 & -14 & .6 est & $\begin{array}{l}\text { Rag } \\
\text { atky }\end{array}$ \\
\hline $\begin{array}{l}751 \\
\text { p.gns }\end{array}$ & " & $\begin{array}{l}\text { Di6-5-g } \\
\text { Sta Izabel }\end{array}$ & MSE & $\begin{array}{l}1.82 \\
0.05 \\
\end{array}$ & $\begin{array}{l}2.09 \\
0.04\end{array}$ & $\begin{array}{l}.511458 \\
.000030 \\
\end{array}$ & $\begin{array}{l}.09813 \\
.00007 \\
\end{array}$ & $\begin{array}{l}4.482 \\
0.003 \\
\end{array}$ & $\begin{array}{l}27.612 \\
0.011 \\
\end{array}$ & -.50 & -23.0 & -16 & .6 est & " \\
\hline $\begin{array}{l}752 \\
\text { p.gns }\end{array}$ & " & $\begin{array}{l}\text { DI6-5-9 } \\
\text { Sta lazabel }\end{array}$ & MSE & $\begin{array}{l}2.25 \\
0.04 \\
\end{array}$ & $\begin{array}{l}2.48 \\
0.03 \\
\end{array}$ & $\begin{array}{l}.511275 \\
.000023 \\
\end{array}$ & $\begin{array}{l}.10460 \\
.00005 \\
\end{array}$ & $\begin{array}{l}7.948 \\
0.003\end{array}$ & $\begin{array}{l}45.948 \\
0.019 \\
\end{array}$ & -.47 & -26.6 & -20 & .6 est & |“ \\
\hline $\begin{array}{l}753 \\
\text { p.gns }\end{array}$ & 3 & $\begin{array}{l}\text { D16-5-g } \\
\text { Sta. izabel }\end{array}$ & MSE & $\begin{array}{l}2.02 \\
0.03 \\
\end{array}$ & $\begin{array}{l}2.29 \\
0.03 \\
\end{array}$ & $\begin{array}{l}.511412 \\
.000021 \\
\end{array}$ & $\begin{array}{l}.10464 \\
.00005 \\
\end{array}$ & $\begin{array}{l}8.153 \\
0.002\end{array}$ & $\begin{array}{l}47.118 \\
0.019 \\
\end{array}$ & -.47 & -23.9 & -17 & $.6 \mathrm{est}$ & " \\
\hline
\end{tabular}

\section{TAB. 5.8-5: ARAÇÚAÍ}

\begin{tabular}{|c|c|c|c|c|c|c|c|c|c|c|c|c|c|c|c|c|c|}
\hline mu.maf & $\sim 17,7 / \sim 43,0$ & \begin{tabular}{|}
$T-138 /$ Faixa \\
Araçuaí
\end{tabular} & UBA & A1 & $\begin{array}{l}0.01 ? \\
0.04\end{array}$ & & $\begin{array}{l}0.98 \\
0.03\end{array}$ & $\begin{array}{l}.512636 \\
.000013\end{array}$ & .15011 & 1.06 & 4.27 & -.24 & 0.0 & 4.7 & $\begin{array}{l}79 \mathrm{Sm} / \mathrm{Nd} \\
\mathrm{k}\end{array}$ & & 5 \\
\hline mu.maf & $\sim 17,7 / \sim 43,0$ & $\begin{array}{l}T-141 / \text { Faixa } \\
\text { Araçuai }\end{array}$ & UBA & A2 & $\begin{array}{l}-.17 ? \\
.08\end{array}$ & & $\begin{array}{l}1.23 \\
0.04\end{array}$ & $\begin{array}{l}.512670 \\
.000015\end{array}$ & .16779 & 1.01 & 3.64 & -.15 & 0.6 & 3.5 & $79 \mathrm{sm} / \mathrm{Nd}$ & & 5 \\
\hline ma.maf & $\sim 17,7 / \sim 43,0$ & $\begin{array}{l}T-152 / \text { Faixa } \\
\text { Araçuai }\end{array}$ & UBA & A3 & $\begin{array}{l}-.20 ? \\
.04\end{array}$ & & $\begin{array}{l}0.97 \\
0.03\end{array}$ & $\begin{array}{l}.512689 \\
.000011 \\
\end{array}$ & .15760 & 3.19 & 12.24 & -.20 & 1.0 & 4.9 & $.79 \mathrm{Sm} / \mathrm{Nd}$ & & 5 \\
\hline 0. anf & $-17,7 / \sim 43,0$ & $\begin{array}{l}T-114 \mathrm{C} / \\
\text { Faixa Araçuaí }\end{array}$ & BAS & A4 & $\begin{array}{l}0.40 ? \\
0.02\end{array}$ & $1.08^{\#+1}$ & $\begin{array}{l}1.05 \\
0.02 \\
\end{array}$ & $\begin{array}{l}.512461 \\
.000011 \\
\end{array}$ & .12916 & 3.77 & 17.65 & -.34 & -3.5 & 3.4 & $\begin{array}{l}79 \mathrm{Sm} / \mathrm{Nd} \\
\mathrm{k}\end{array}$ & & 5 \\
\hline o.anf & $\sim 17,7 / \sim 43,0$ & $\begin{array}{l}T-119 / \text { Faixa } \\
\text { Araçuai }\end{array}$ & BAS & A5 & $\begin{array}{l}0.27 ? \\
0.03\end{array}$ & $1.02^{\# 1}$ & $\begin{array}{l}0.99 \\
0.02 \\
\end{array}$ & $\begin{array}{l}.512525 \\
.000011 \\
\end{array}$ & .13314 & 7.290 & 33.11 & -.32 & -2.2 & 4.2 & $.79 \mathrm{Sm} / \mathrm{Nd}$ & & 5 \\
\hline o.anf & $\sim 17,7 / \sim 43,0$ & $\begin{array}{l}T-120 / \text { Faixa } \\
\text { Araçuai }\end{array}$ & $\overrightarrow{B A S}$ & $\overline{A 6}$ & $\begin{array}{l}-8.4 ? \\
0.7 \\
\end{array}$ & $1.08^{\#+7}$ & $\begin{array}{l}1.85 ? \\
0.06 \\
\end{array}$ & $\begin{array}{l}.512797 \\
.000011 \\
\end{array}$ & .19371 & 3.04 & 9.49 & -.02 & 3.1 & 3.4 & $.79 \mathrm{Sm} / \mathrm{Nd}$ & & 5 \\
\hline 0. anf & $\sim 17,7 / \sim 43,0$ & $\begin{array}{l}T-123 / \text { Faixa } \\
\text { Araçuaí }\end{array}$ & BAS & A7 & $\begin{array}{l}-3.7 ? \\
0.3\end{array}$ & $1.00^{* 1-1}$ & $\begin{array}{l}1.30 ? \\
0.07 \\
\end{array}$ & $\begin{array}{l}.512828 \\
.000015 \\
\end{array}$ & .18875 & 1.08 & 3.46 & -.04 & 3.7 & 4.5 & $\begin{array}{l}.79 \mathrm{sm} / \mathrm{Nd} \\
\mathrm{k}\end{array}$ & & 5 \\
\hline o.anf & $\sim 17,7 / \sim 43,0$ & $\begin{array}{l}T-121 \text { / Faixa } \\
\text { Araçuaí }\end{array}$ & $\overline{B A S}$ & A8 & $\begin{array}{l}1.3 ? \\
0.2\end{array}$ & $1.03^{\# 1}$ & --- & $\begin{array}{l}.513213 \\
.000013 \\
\end{array}$ & .26667 & 0.71 & 1.61 & .36 & 11.2 & 4.2 & $\begin{array}{l}79 \mathrm{Sm} / \mathrm{Nd} \\
\mathrm{k}\end{array}$ & & 5 \\
\hline $\begin{array}{l}394 \\
\text { gns }\end{array}$ & $1624 / 3912$ & \begin{tabular}{|l|}
$\mathrm{JD} 233 / \mathrm{BA}$ \\
Porto Seguro
\end{tabular} & GTD & & $\begin{array}{l}2.01 \\
0.05 \\
\end{array}$ & & $\begin{array}{l}2.28 \\
0.04 \\
\end{array}$ & $\begin{array}{l}.511446 \\
.000028 \\
\end{array}$ & $\begin{array}{l}.10649 \\
.00006\end{array}$ & 12.72 & $\begin{array}{l}72.22 \\
.03\end{array}$ & -.46 & -23.3 & -12 & $.96_{\mathrm{K} / \mathrm{Ar}}$ & & nt \\
\hline $\begin{array}{l}111 / \\
\text { gns }\end{array}$ & $1454 / 4142$ & $\begin{array}{l}\text { JM/BA } 329 \mathrm{HI} / \\
\text { Sul-Brumado }\end{array}$ & GTD & & $\begin{array}{l}3.31 \\
.04 \\
\end{array}$ & & $\begin{array}{l}3.44 \\
.04 \\
\end{array}$ & $\begin{array}{l}.510477 \\
.000029 \\
\end{array}$ & $\begin{array}{l}.09805 \\
.00004 \\
\end{array}$ & $\begin{array}{l}2.520 \\
.001 \\
\end{array}$ & $\begin{array}{l}15.542 \\
.001\end{array}$ & -.50 & -42.2 & -6.9 & $\begin{array}{l}2.8 \\
719_{(s)}\end{array}$ & 253 & nt \\
\hline $\begin{array}{l}\text { gns/ } \\
112\end{array}$ & $1454 / 4142$ & $\begin{array}{l}\text { JM/BA } 3291 / \\
\text { Piripá }\end{array}$ & GTD & & $\begin{array}{l}2.74 \\
.06 \\
\end{array}$ & & $\begin{array}{l}2.91 \\
.04\end{array}$ & $\begin{array}{l}.510782 \\
.000037 \\
\end{array}$ & $\begin{array}{l}.09399 \\
.00009 \\
\end{array}$ & $\begin{array}{l}1.081 \\
.001 \\
\end{array}$ & $\begin{array}{l}6.955 \\
.003 \\
\end{array}$ & -.52 & -36.2 & +.5 & $\begin{array}{l}2.8 \\
.719_{(\mathrm{s})} \\
\end{array}$ & 253 & $n t$ \\
\hline $\begin{array}{l}\text { gns / } \\
115 \\
\end{array}$ & $1454 / 4142$ & $\begin{array}{l}\text { JM/BA } 329 \mathrm{~F} / \\
\text { Piripá }\end{array}$ & GTD & & $\begin{array}{l}3.03 \\
.06 \\
\end{array}$ & & $\begin{array}{l}3.18 \\
.06 \\
\end{array}$ & $\begin{array}{l}.510774 \\
.000037 \\
\end{array}$ & $\begin{array}{l}.10355 \\
.00011 \\
\end{array}$ & $\begin{array}{l}1.097 \\
.001\end{array}$ & $\begin{array}{l}6.406 \\
.003 \\
\end{array}$ & -.47 & -36.4 & -3.1 & $\begin{array}{l}2.8 \\
.719_{(\mathrm{s})} \\
\end{array}$ & 253 & $\mathrm{nt}$ \\
\hline $\begin{array}{l}\text { 158/ } \\
\text { gns }\end{array}$ & $1454 / 4142$ & $\begin{array}{l}\text { JM BA } 329 \text { E / } \\
\text { Sul-Brumado }\end{array}$ & GTD & & $\begin{array}{l}3.33 \\
.05\end{array}$ & & $\begin{array}{l}3.46 \\
.05\end{array}$ & $\begin{array}{l}.510665 \\
.000025\end{array}$ & $\begin{array}{l}.10709 \\
.00070 \\
\end{array}$ & $\begin{array}{l}.082 \\
.001\end{array}$ & $\begin{array}{l}.463 \\
.001 \\
\end{array}$ & -.46 & -38.5 & -6.5 & $\begin{array}{l}2.8 \\
.719_{(\mathrm{s})}\end{array}$ & 253 & nt \\
\hline
\end{tabular}




\begin{tabular}{|c|c|c|c|c|c|c|c|c|c|c|c|c|c|c|c|}
\hline $\begin{array}{l}511 / \\
\text { gns }\end{array}$ & $1454 / 4142$ & $\begin{array}{l}\text { JM BA 329H / } \\
\text { (biotita)-Piripá }\end{array}$ & GTD & $\begin{array}{l}3.21 \\
.03\end{array}$ & $\begin{array}{l}3.34 \\
.03 \\
\end{array}$ & $\begin{array}{l}.510559 \\
.000022 \\
\end{array}$ & $\begin{array}{l}.09869 \\
.00006\end{array}$ & $\begin{array}{l}2.454 \\
.001\end{array}$ & $\begin{array}{l}15.037 \\
.006\end{array}$ & -.50 & -40.6 & -5.5 & $\begin{array}{l}2.8 \\
.719 \text { (s) } \\
\end{array}$ & 253 & $\mathrm{nt}$ \\
\hline $\begin{array}{l}512 / \\
\text { gns }\end{array}$ & $1454 / 4142$ & $\begin{array}{l}\text { JM BA 3294 / } \\
\text { (felds) - Piripá }\end{array}$ & GTD & $\begin{array}{l}3.14 \\
.03\end{array}$ & $\begin{array}{l}3.28 \\
.03\end{array}$ & $\begin{array}{l}.510490 \\
.000019\end{array}$ & $\begin{array}{l}.09327 \\
.00012\end{array}$ & $\begin{array}{l}.809 \\
.001\end{array}$ & $\begin{array}{l}5.245 \\
.002 \\
\end{array}$ & -.53 & -41.9 & -5.0 & $\begin{array}{l}2.8 \\
.719(\mathrm{~s}) \\
\end{array}$ & 253 & $n t$ \\
\hline $\begin{array}{l}513 / \\
\text { gns }\end{array}$ & $1454 / 4142$ & $\begin{array}{l}\text { JM BA } 329 \mathrm{HI} \\
\text { (r.total)-Piripá }\end{array}$ & GTD & $\begin{array}{l}3.23 \\
.03 \\
\end{array}$ & $\begin{array}{l}3.36 \\
.03 \\
\end{array}$ & $\begin{array}{l}.510546 \\
.000021 \\
\end{array}$ & $\begin{array}{l}.09869 \\
.00023\end{array}$ & $\begin{array}{l}4.034 \\
.009 \\
\end{array}$ & $\begin{array}{l}24.718 \\
.010 \\
\end{array}$ & -.50 & -40.8 & -5.8 & $\begin{array}{l}2.8 \\
.719_{(\mathrm{s})} \\
\end{array}$ & 253 & $\mathrm{nt}$ \\
\hline
\end{tabular}

\section{TAB. 5.8-6: COSTEIRO}

\begin{tabular}{|c|c|c|c|c|c|c|c|c|c|c|c|c|c|c|c|c|c|}
\hline $\begin{array}{l}505 \\
\text { gns }\end{array}$ & $1619 / 4049$ & m1-jgm-w1132 & GTD & R1 & $\begin{array}{l}0.98 \\
0.02\end{array}$ & & $\begin{array}{l}1.34 \\
0.02 \\
\end{array}$ & $\begin{array}{l}.511935 \\
.000017 \\
\end{array}$ & $\begin{array}{l}.08727 \\
.00005\end{array}$ & $\begin{array}{l}5.191 \\
.001 \\
\end{array}$ & $\begin{array}{l}35.970 \\
.017 \\
\end{array}$ & -.56 & -13.7 & -4.9 & $\begin{array}{l}.63 \mathrm{Rb} / \mathrm{Sr} \\
.708 \\
\end{array}$ & & $\mathrm{nt}$ \\
\hline $\begin{array}{l}508 \\
\text { grt }\end{array}$ & $1718 / 4131$ & $\mathrm{jm} . \mathrm{w} .167 .2$ & GTD & R2 & $\begin{array}{l}1.75 \\
0.05\end{array}$ & & $\begin{array}{l}2.01 \\
0.04\end{array}$ & $\begin{array}{l}.511384 \\
.000037\end{array}$ & $\begin{array}{l}.08793 \\
.00005 \\
\end{array}$ & $\begin{array}{l}12.943 \\
.004 \\
\end{array}$ & $\begin{array}{l}89.006 \\
.040\end{array}$ & -.55 & -24.5 & -16 & $\begin{array}{l}.58 \mathrm{Rb} / \mathrm{Sr} \\
.709\end{array}$ & & nt \\
\hline 639 & & $\begin{array}{l}\text { ES73B / ES } \\
\text { Vitória }\end{array}$ & GTD & & & & $\begin{array}{l}1.79 \\
0.14 \\
\end{array}$ & $\begin{array}{l}.511980 \\
.000090 \\
\end{array}$ & $\begin{array}{l}.12337 \\
.00008 \\
\end{array}$ & $\begin{array}{l}8.345 \\
.002\end{array}$ & $\begin{array}{l}40.906 \\
.02\end{array}$ & & -12.8 & & & & \\
\hline $\begin{array}{l}260 \\
\text { ton }\end{array}$ & $2124 / 4132$ & $\begin{array}{l}\text { NRJ } 130 / \text { RJ } \\
\text { Rio de Janeiro }\end{array}$ & GTD & R3 & $\begin{array}{l}2.42 ? \\
.20 \\
\end{array}$ & $1.34^{\# 1}$ & $\begin{array}{l}3.20 ? \\
.08 \\
\end{array}$ & $\begin{array}{l}.512398 \\
.000020\end{array}$ & $\begin{array}{l}.18165 \\
.00011 \\
\end{array}$ & $\begin{array}{l}9.739 \\
.003\end{array}$ & $\begin{array}{l}32.421 \\
.017 \\
\end{array}$ & -.08 & -4.7 & -3.6 & $.55_{\mathrm{est}}$ & & nt \\
\hline $\begin{array}{l}307 \\
\text { gns }\end{array}$ & & QB-47D/SP & GTD & S1 & $\begin{array}{l}0.96 \\
0.03 \\
\end{array}$ & & $\begin{array}{l}1.31 \\
0.03\end{array}$ & $\begin{array}{l}.511926 \\
.000025\end{array}$ & $\begin{array}{l}.08336 \\
.00004 \\
\end{array}$ & $\begin{array}{l}13.932 \\
.003 \\
\end{array}$ & $\begin{array}{l}101.07 \\
.04\end{array}$ & -.58 & -13.9 & -5.9 & .55 & & nt \\
\hline $\begin{array}{l}308 \\
\text { gns }\end{array}$ & & $\mathrm{QB}-46 \mathrm{H} / \mathrm{SP}$ & GTD & S2 & $\begin{array}{l}0.92 \\
0.05 \\
\end{array}$ & & $\begin{array}{l}1.42 \\
0.04 \\
\end{array}$ & $\begin{array}{l}.512188 \\
.000023 \\
\end{array}$ & $\begin{array}{l}.12189 \\
.00007 \\
\end{array}$ & $\begin{array}{l}7.688 \\
.003 \\
\end{array}$ & $\begin{array}{l}38.141 \\
.016 \\
\end{array}$ & -.38 & -8.8 & -3.5 & .55 & & $n t$ \\
\hline $\begin{array}{l}309 \\
\text { grt }\end{array}$ & $2308 / 4456$ & $\begin{array}{l}\mathrm{OR}-5 \mathrm{H} / \mathrm{SP} \\
\text { Natividade }\end{array}$ & GTD & T1 & $\begin{array}{l}0.96 \\
0.05\end{array}$ & & $\begin{array}{l}1.44 \\
0.04 \\
\end{array}$ & $\begin{array}{l}.512152 \\
.000024 \\
\end{array}$ & $\begin{array}{l}.11942 \\
.00006\end{array}$ & $\begin{array}{l}3.674 \\
.001\end{array}$ & $\begin{array}{l}18.604 \\
.007 \\
\end{array}$ & -.39 & -9.5 & -3.6 & $\begin{array}{l}0.60 \\
.712 \mathrm{n}\end{array}$ & 116 & nt \\
\hline $\begin{array}{l}310 \\
\mathrm{mig}\end{array}$ & $2309 / 4453$ & $\begin{array}{l}O R-6 A / S P \\
\text { Costeiro }\end{array}$ & GTD & T2 & $\begin{array}{l}0.91 \\
0.04\end{array}$ & & $\begin{array}{l}1.27 \\
0.03 \\
\end{array}$ & $\begin{array}{l}.511989 \\
.000028\end{array}$ & $\begin{array}{l}.08757 \\
.00004\end{array}$ & $\begin{array}{l}10.21 \\
.002 \\
\end{array}$ & $\begin{array}{l}70.500 \\
.026 \\
\end{array}$ & -.55 & -12.7 & -4.1 & $\begin{array}{l}.60 \\
.711_{n}\end{array}$ & 102 & nt \\
\hline $\begin{array}{l}311 \\
\mathrm{mig}\end{array}$ & $2309 / 4453$ & $\begin{array}{l}\mathrm{OR}-6 \mathrm{D} / \mathrm{SP} \\
\text { Costeiro }\end{array}$ & GTD & T3 & $\begin{array}{l}1.01 \\
0.04 \\
\end{array}$ & & $\begin{array}{l}1.36 \\
0.03 \\
\end{array}$ & $\begin{array}{l}.511910 \\
.000026\end{array}$ & $\begin{array}{l}.08676 \\
.00004\end{array}$ & $\begin{array}{l}11.282 \\
.002 \\
\end{array}$ & $\begin{array}{l}78.636 \\
.029 \\
\end{array}$ & -.56 & -14.2 & -5.8 & $\begin{array}{l}.60 \\
.711_{n} \\
\end{array}$ & 102 & $n t$ \\
\hline gn.mig & $2352 / 4530$ & $\begin{array}{l}\text { S1D/SP } \\
\text { S.Sebastiāo }\end{array}$ & GTD & U1 & $1 . \overline{42}$ & & 1.82 & .511904 & .11815 & $\ldots$ & $\cdots$ & -.40 & -14.3 & -7.8 & $\begin{array}{l}0.65 \\
.727 \mathrm{p} \\
\end{array}$ & 330 & 7 \\
\hline gtd & $2333 / 4531$ & $\begin{array}{l}\mathrm{C3} \mathrm{K} / \mathrm{SP} \\
\text { Caraguatatuba }\end{array}$ & GTD & U2 & 1.54 & & 1.90 & .511780 & .11218 & $\cdots$ & $\cdots$ & -.43 & -16.7 & -11 & $\begin{array}{l}0.54 \\
.7126 \mathrm{p} \\
\end{array}$ & 124 & 7 \\
\hline gtd & $2333 / 4531$ & $\begin{array}{l}\text { C3 B / SP } \\
\text { Caraguatatuba }\end{array}$ & GTD & U3 & $3.14 ?$ & $2.00^{31}$ & $3.40 ?$ & .511781 & .15535 & -- & -- & -.21 & -16.7 & -14 & $\begin{array}{l}0.54 \\
.7126 p \\
\end{array}$ & 124 & 7 \\
\hline $\mathrm{pi}^{*^{4}}$ & $2418 / 4710$ & $\begin{array}{l}3 \mathrm{~B} 7 \mathrm{~B} / \mathrm{SP} \\
\text { itatins }\end{array}$ & Mpi & V1 & - & $2.21^{\# 1}$ & $\cdots$ & $\begin{array}{l}.511578 \\
.000038 \\
\end{array}$ & .1386 & 22.4 & 97.7 & -.30 & -20.7 & -16 & $\begin{array}{l}.61 \mathrm{Sm} / \mathrm{Nd} \\
.51102_{\mathrm{a}}\end{array}$ & & 1 \\
\hline $\begin{array}{l}75 \\
p^{*^{1}}\end{array}$ & $2418 / 4710$ & $\begin{array}{l}\mathrm{JB} 7 \mathrm{~B} / \mathrm{SP} \\
\text { Itatins }\end{array}$ & $\mathrm{Mpl}$ & $\mathrm{V} 2$ & $-\cdots$ & $2.21^{\# 1}$ & -- & $\begin{array}{l}.511409 \\
.000022 \\
\end{array}$ & .0976 & 4.6 & 28.5 & -.50 & -24.0 & -16 & $\begin{array}{l}.61_{\mathrm{Sm} / \mathrm{Na}} \\
.51102_{\mathrm{a}}\end{array}$ & & 1 \\
\hline
\end{tabular}




\begin{tabular}{|c|c|c|c|c|c|c|c|c|c|c|c|c|c|c|c|c|}
\hline $\begin{array}{l}76 \\
\mathrm{bi}^{*^{1}}\end{array}$ & $2418 / 4710$ & $\begin{array}{l}\text { JB 7B / SP } \\
\text { Itatins }\end{array}$ & $\mathrm{Mbi}$ & V3 & --- & $2.23^{\# 7}$ & --- & $\begin{array}{l}.511540 \\
.000046 \\
\end{array}$ & .1341 & 4.9 & 22.1 & -.32 & -21.4 & -17 & $\begin{array}{l}.61_{\mathrm{Sm} / \mathrm{Nd}} \\
.51102_{\mathrm{a}}\end{array}$ & 1 \\
\hline $\begin{array}{l}77 \\
\text { gni }\end{array}$ & $2418 / 4710$ & $\begin{array}{l}\mathrm{JB} 7 \mathrm{~B} / \mathrm{SP} \\
\text { Itatins }\end{array}$ & GTD & V4 & $\begin{array}{l}.46 ? \\
0.08 \\
\end{array}$ & $2.22^{\# 1}$ & $\begin{array}{l}2.73 \\
0.06 \\
\end{array}$ & $\begin{array}{l}.511523 \\
.000036 \\
\end{array}$ & 1279 & 1.1 & 5.2 & -.35 & -21.8 & -16 & & 1 \\
\hline $\begin{array}{l}8 \\
\text { p.gns } \\
\end{array}$ & $2418 / 4711$ & $\begin{array}{l}J P 48 \mathrm{~A} / \mathrm{SP} \\
\text { Itatins }\end{array}$ & $\overline{M S E}$ & V5 & $\begin{array}{l}0.98 \\
0.05 \\
\end{array}$ & $1.38^{\# 1}$ & $\begin{array}{l}1.47 \\
0.03 \\
\end{array}$ & $\begin{array}{l}.512162 \\
.000022 \\
\end{array}$ & .1223 & 5.4 & 26.7 & -.38 & -9.3 & -3.8 & & 1 \\
\hline $\begin{array}{l}79 \\
p^{\star^{2}}\end{array}$ & $2418 / 4711$ & $\begin{array}{l}\mathrm{JP} 48 \mathrm{~A} / \mathrm{SP} \\
\text { itatins }\end{array}$ & $\mathrm{Mpl}$ & V6 & $\cdots$ & $1.36^{\# 1}$ & -- & $\begin{array}{l}.512350 \\
.000018\end{array}$ & .1693 & 2.1 & 7.5 & -.14 & -5.6 & -3.6 & $\begin{array}{l}.58 \mathrm{Sm} / \mathrm{Nd} \\
.51170_{\mathrm{a}}\end{array}$ & 1 \\
\hline 80 & $2418 / 4711$ & $\begin{array}{l}\mathrm{JP} 48 \mathrm{~A} / \mathrm{SP} \\
\text { Itatins }\end{array}$ & $\mathrm{Mbi}$ & $\mathrm{V} 7$ & $\cdots$ & $1.35^{\#-1}$ & --- & $\begin{array}{l}.512248 \\
.000029\end{array}$ & .1396 & .6 & 2.6 & -.29 & -7.6 & -3.4 & $\begin{array}{l}.58 \mathrm{Sm} / \mathrm{Nd} \\
.51170_{\mathrm{a}} \\
\end{array}$ & 1 \\
\hline $\begin{array}{l}81 \\
g^{\star^{2}}\end{array}$ & $2418 / 4711$ & $\begin{array}{l}\mathrm{JP} 48 \mathrm{~A} / \mathrm{SP} \\
\text { ltatins }\end{array}$ & $\mathrm{Mgd}$ & V8 & $\cdots$ & $1.36^{41}$ & --- & $\begin{array}{l}.513124 \\
.000032 \\
\end{array}$ & .3721 & 2.4 & 3.9 & .89 & 9.5 & -3.5 & $\begin{array}{l}.58 \mathrm{Sm} / \mathrm{Nd} \\
.51170_{\mathrm{a}}\end{array}$ & 1 \\
\hline
\end{tabular}

\section{TAB. 5.8-7: CABO FRIO}

\begin{tabular}{|c|c|c|c|c|c|c|c|c|c|c|c|c|c|c|c|c|c|}
\hline p.gns & $2245 / 4155$ & $\begin{array}{l}\text { RJ }-8 / \text { RJ } \\
\text { Cabo Frio }\end{array}$ & MSE & G1 & $\begin{array}{l}0.92 \\
0.05 \\
\end{array}$ & & $\begin{array}{l}1.45 \\
0.03 \\
\end{array}$ & $\begin{array}{l}.512217 \\
.000021 \\
\end{array}$ & .12731 & 8.0 & 38.0 & -.35 & -8.2 & -3.4 & $\begin{array}{l}.54 \mathrm{Rb} / \mathrm{St} \\
.7133_{\mathrm{b}} \\
\end{array}$ & 134 & 2 \\
\hline p.gns & $2245 / 4155$ & $\begin{array}{l}\text { RJ - 8d / RJ } \\
\text { Cabo Frio }\end{array}$ & MSE & $\mathrm{G} 2$ & $\begin{array}{l}1.21 \\
0.04 \\
\end{array}$ & & $\begin{array}{l}1.65 \\
0.03 \\
\end{array}$ & $\begin{array}{l}.512037 \\
.000021\end{array}$ & .12094 & 7.1 & 35.5 & -.39 & -11.7 & -6.5 & $\begin{array}{l}.54 \mathrm{Rb} / \mathrm{Sr} \\
.7133_{\mathrm{b}}\end{array}$ & 134 & 2 \\
\hline p.gns & $2245 / 4155$ & $\begin{array}{l}\mathrm{RJ}-11 \mathrm{i} / \mathrm{RJ} \\
\text { Cabo Frio }\end{array}$ & MSE & G3 & $\begin{array}{l}1.05 \\
0.04 \\
\end{array}$ & & $\begin{array}{l}1.45 \\
0.03 \\
\end{array}$ & $\begin{array}{l}.512015 \\
.000024 \\
\end{array}$ & .10591 & 6.2 & 35.4 & -.46 & -12.2 & -5.9 & $\begin{array}{l}.54 \mathrm{Rb} / \mathrm{Sr} \\
.7133 \\
\end{array}$ & 134 & 2 \\
\hline o.gns & $2 2 \longdiv { 4 8 / 4 1 5 7 }$ & $\begin{array}{l}\text { RJ - 5b/RJ } \\
\text { Cabo Frio }\end{array}$ & GTD & G4 & $\begin{array}{l}2.55 \\
0.05 \\
\end{array}$ & & $\begin{array}{l}2.76 \\
0.04 \\
\end{array}$ & $\begin{array}{l}.511181 \\
.000028 \\
\end{array}$ & .11010 & 6.3 & 34.6 & -.44 & -28.4 & -5.6 & $\begin{array}{l}2.07_{\mathrm{Rb} / \mathrm{Sr}} \\
.7033_{\mathrm{b}} \\
\end{array}$ & 18 & 2 \\
\hline o.gns & $2248 / 4157$ & $\begin{array}{l}\text { RJ-5d/RJ } \\
\text { Cabo Frio }\end{array}$ & GTD & G5 & $\begin{array}{l}2.40 \\
0.06 \\
\end{array}$ & & $\begin{array}{l}2.60 \\
0.04 \\
\end{array}$ & $\begin{array}{r}.510980 \\
.000038 \\
\end{array}$ & .09209 & 9.0 & 59.1 & -.53 & -32.3 & -4.7 & $\begin{array}{l}2.07_{\mathrm{Rb} / \mathrm{Sr}} \\
.7033_{\mathrm{b}}\end{array}$ & 18 & 2 \\
\hline o.gns & $2248 / 4157$ & $\begin{array}{l}\mathrm{RJ}-5 \mathrm{e} / \mathrm{RJ} \\
\text { Cabo Frio }\end{array}$ & GTD & G6 & $\begin{array}{l}2.33 \\
0.04 \\
\end{array}$ & $2.62^{2+1}$ & $\begin{array}{l}2.50 \\
0.03 \\
\end{array}$ & $\begin{array}{r}.510644 \\
.000031 \\
\end{array}$ & .06680 & 5.7 & 51.6 & -.66 & -38.9 & -4.6 & $\begin{array}{l}2.07_{\mathrm{Rb} / \mathrm{Sr}} \\
.7033_{\mathrm{b}}\end{array}$ & 18 & 2 \\
\hline o.gns & $2248 / 4157$ & $\begin{array}{l}\mathrm{RJ}-5 \mathrm{j} / \mathrm{RJ} \\
\text { Cabo Frio }\end{array}$ & GTD & G7 & $\begin{array}{l}2.31 \\
0.04 \\
\end{array}$ & $2.56^{41}$ & $\begin{array}{l}2.51 \\
0.03 \\
\end{array}$ & $\begin{array}{l}.510982 \\
.000030 \\
\end{array}$ & .08787 & 7.6 & 52.3 & -.55 & -32.3 & -3.6 & $\begin{array}{l}2.07_{\mathrm{Rb} / \mathrm{Sr}} \\
.7033_{\mathrm{b}}\end{array}$ & 18 & 2 \\
\hline o.gns & $2248 / 4157$ & $\begin{array}{l}\mathrm{RJ}-5 \mathrm{q} / \mathrm{RJ} \\
\text { Cabo Frio }\end{array}$ & GTD & G8 & $\begin{array}{l}2.38 \\
0.04 \\
\end{array}$ & $2.64^{* 1}$ & $\begin{array}{l}2.57 \\
0.03 \\
\end{array}$ & $\begin{array}{l}.510819 \\
.000030 \\
\end{array}$ & .08093 & 3.6 & 26.9 & -.59 & -35.5 & -4.9 & $\begin{array}{l}2.07 \mathrm{Rb} / \mathrm{sr} \\
.7033_{\mathrm{b}}\end{array}$ & 18 & 2 \\
\hline o.gns & $2250 / 4200$ & $\begin{array}{l}\text { RJ-14n/RJ } \\
\text { Cabo Frio }\end{array}$ & GTD & 69 & $\begin{array}{l}2.35 \\
0.05 \\
\end{array}$ & $2.65^{\# 1}$ & $\begin{array}{l}2.55 \\
0.04 \\
\end{array}$ & $\begin{array}{r}.510915 \\
.000038 \\
\end{array}$ & .08556 & 7.4 & 52.3 & -.57 & -33.6 & -10 & $\begin{array}{l}1.66_{\mathrm{Rb} / \mathrm{sr}} \\
.7084 \\
\end{array}$ & 83 & 2 \\
\hline o.gns & $2250 / 4200$ & $\begin{array}{l}R J-\{40 / R J \\
\text { Cabo Frio }\end{array}$ & GTD & G10 & $\begin{array}{l}2.52 \\
0.04 \\
\end{array}$ & & $\begin{array}{l}2.73 \\
0.03 \\
\end{array}$ & $\begin{array}{l}.511123 \\
.000024 \\
\end{array}$ & .10570 & 10.4 & 59.5 & -.46 & -29.6 & -10 & $\begin{array}{l}1.66_{\mathrm{Rb} / \mathrm{Sr}} \\
.7084_{\mathrm{b}} \\
\end{array}$ & 83 & 2 \\
\hline
\end{tabular}




\begin{tabular}{|c|c|c|c|c|c|c|c|c|c|c|c|c|c|c|c|c|c|}
\hline o.gns & $2250 / 4200$ & $\begin{array}{l}\mathrm{RJ}-14 \mathrm{q} / \mathrm{RJ} \\
\text { Cabo Frio }\end{array}$ & GTD & G11 & $\begin{array}{l}2.31 \\
0.04\end{array}$ & & $\begin{array}{l}2.52 \\
0.03\end{array}$ & $\begin{array}{l}.511095 \\
.000027 \\
\end{array}$ & .09518 & 11.9 & 75.6 & -.52 & -30.1 & -8.6 & $\begin{array}{l}1.66_{\mathrm{Rb} / \mathrm{Sr}} \\
7084_{\mathrm{b}}\end{array}$ & 83 & 2 \\
\hline $0 . \mathrm{gns}$ & $2250 / 4200$ & $\begin{array}{l}\text { RJ - } 14 r / \text { RJ } \\
\text { Cabo Frio }\end{array}$ & GTD & G12 & $\begin{array}{l}2.34 \\
0.05\end{array}$ & & $\begin{array}{l}2.54 \\
0.04 \\
\end{array}$ & $\begin{array}{l}.510993 \\
.000032\end{array}$ & .09003 & 10.6 & 71.2 & -.54 & -32.1 & -9.5 & $\begin{array}{l}1.66_{\mathrm{Rb} / \mathrm{Sr}} \\
.7084_{\mathrm{b}}\end{array}$ & 83 & 2 \\
\hline o.gns & $2250 / 4200$ & $\begin{array}{l}\text { RJ - 14s/RJ } \\
\text { Cabo Frio }\end{array}$ & GTD & G13 & $\begin{array}{l}2.45 \\
0.03\end{array}$ & & $\begin{array}{l}2.65 \\
0.03 \\
\end{array}$ & $\begin{array}{l}.511032 \\
.000021\end{array}$ & .09731 & 8.4 & 52.2 & -.51 & -31.3 & -10 & $\begin{array}{l}1.66_{\mathrm{Rb} / \mathrm{St}} \\
.7084_{\mathrm{b}}\end{array}$ & 83 & 2 \\
\hline o.gns & $2249 / 4158$ & $\begin{array}{l}\text { RJ - }\{5 a / R J \\
\text { Cabo Frio }\end{array}$ & GTD & G14 & $\begin{array}{l}2.37 \\
0.03\end{array}$ & $2.76^{\# 7}$ & $\begin{array}{l}2.56 \\
0.02\end{array}$ & $\begin{array}{l}.510870 \\
.000021\end{array}$ & .08331 & 3.1 & 22.5 & -.58 & -34.5 & -29 & $\begin{array}{l}0.37_{\mathrm{Rb} / \mathrm{Sr}} \\
.7121_{\mathrm{b}}\end{array}$ & 114 & 2 \\
\hline o.gns & $2249 / 4158$ & $\begin{array}{l}\text { RJ - } 15 \mathrm{j} / \overline{\mathrm{RJ}} \\
\text { Cabo Frio }\end{array}$ & GTD & G15 & $\begin{array}{l}2.27 \\
0.03\end{array}$ & $2.70^{\# 1}$ & $\begin{array}{l}2.46 \\
0.03\end{array}$ & $\begin{array}{l}.510888 \\
.000025\end{array}$ & $\begin{array}{l}.07963 \\
.00003\end{array}$ & 3.2 & 24.3 & -.60 & -34.1 & -29 & $\begin{array}{l}0.37_{\mathrm{Rb} / \mathrm{Sr}} \\
.7121_{\mathrm{b}}\end{array}$ & 114 & 2 \\
\hline $0 . g n s$ & $2249 / 4158$ & $\begin{array}{l}\text { RJ - } 15 i / R J \\
\text { Cabo Frio }\end{array}$ & GTD & G16 & $\begin{array}{l}2.27 \\
0.03\end{array}$ & $2.73^{\text {\#1 }}$ & $\begin{array}{l}2.46 \\
0.03\end{array}$ & $\begin{array}{l}.510834 \\
.000025 \\
\end{array}$ & $\begin{array}{l}.07590 \\
.00003\end{array}$ & 3.0 & 23.9 & -.61 & -35.2 & -30 & $\begin{array}{l}0.37 \mathrm{Rb} / \mathrm{sr} \\
.7121_{\mathrm{b}}\end{array}$ & 114 & 2 \\
\hline o.gns & $2249 / 4158$ & $\begin{array}{l}\text { RJ - } 150 / R J \\
\text { Cabo Frio }\end{array}$ & GTD & G17 & $\begin{array}{l}2.27 \\
0.04\end{array}$ & $2.82^{\text {\#1 }}$ & $\begin{array}{l}2.45 \\
0.03\end{array}$ & $\begin{array}{l}.510701 \\
.000035\end{array}$ & .06719 & 3.2 & 28.8 & -.66 & -37.8 & -32 & $\begin{array}{l}037_{\mathrm{Rb} / \mathrm{Sr}} \\
.7121\end{array}$ & 114 & 2 \\
\hline o.gns & $2249 / 4158$ & $\begin{array}{l}\text { RJ } \cdot 15 r / R J \\
\text { Cabo Frio }\end{array}$ & GTD & G18 & $\begin{array}{l}2.49 \\
0.04\end{array}$ & $2.75^{\#+1}$ & $\begin{array}{l}2.68 \\
0.04 \\
\end{array}$ & $\begin{array}{l}.510943 \\
.000030 \\
\end{array}$ & $\begin{array}{l}.09328 \\
.00004\end{array}$ & 2.9 & 18.8 & -.53 & -33.1 & -28 & $\begin{array}{l}0.37_{\mathrm{kb} / \mathrm{sr}} \\
.7121_{\mathrm{b}}\end{array}$ & 114 & 12 \\
\hline o.gns & $2300 / 4205$ & $\begin{array}{l}\text { RJ - } 19 b / R J \\
\text { Cabo Frio }\end{array}$ & GTD & G19 & $\begin{array}{l}2.27 \\
0.03\end{array}$ & $2.56^{\# 7}$ & $\begin{array}{l}2.45 \\
0.03 \\
\end{array}$ & $\begin{array}{l}.510737 \\
.000026\end{array}$ & .06982 & 6.2 & 53.7 & -.65 & -37.1 & -3.6 & $\begin{array}{l}2.07_{\mathrm{Rb} / \mathrm{Sr}} \\
.7037\end{array}$ & 23 & 2 \\
\hline o.gns & $2300 / 4202$ & $\begin{array}{l}\text { RJ }-19 \mathrm{j} / \mathrm{RJ} \\
\text { Cabo Frio }\end{array}$ & GTD & G20 & $\begin{array}{l}2.30 \\
0.03\end{array}$ & $2.58^{\# 1}$ & $\begin{array}{l}2.48 \\
0.03\end{array}$ & $\begin{array}{l}.510729 \\
.000025\end{array}$ & .07059 & 3.0 & 25.7 & -.64 & -37.2 & -3.9 & $\begin{array}{l}2.07 \mathrm{~kb} / \mathrm{Sr} \\
.7037_{\mathrm{b}}\end{array}$ & 23 & 2 \\
\hline o.gns & $2300 / 4202$ & $\begin{array}{l}\text { RJ - 19n/RJ } \\
\text { Cabo Frio }\end{array}$ & GTD & G21 & $\begin{array}{l}2.22 \\
0.03\end{array}$ & $2.51^{\# 1}$ & $\begin{array}{l}2.40 \\
0.02\end{array}$ & $\begin{array}{l}.510668 \\
.000026\end{array}$ & .06202 & 9.6 & 93.6 & -.68 & -38.4 & -2.9 & $\begin{array}{l}2.07_{\mathrm{Rb} / \mathrm{Sr}} \\
.7037_{\mathrm{b}}\end{array}$ & 23 & 2 \\
\hline o.gns & $2300 / 4202$ & $\begin{array}{l}\text { RJ } 190 / \mathrm{RJ} \\
\text { Cabo Frio }\end{array}$ & GTD & G22 & $\begin{array}{l}2.25 \\
0.04\end{array}$ & $2.53^{\# 3}$ & $\begin{array}{l}2.43 \\
0.03\end{array}$ & $\begin{array}{l}.510735 \\
.000033\end{array}$ & .06806 & 6.1 & 54.2 & -.65 & -37.1 & -3.2 & $\begin{array}{l}2.07 \\
\mathrm{Ro} / \mathrm{Sr}_{\mathrm{r}} \\
.7037_{\mathrm{b}}\end{array}$ & 23 & 2 \\
\hline $0 . \mathrm{gns}$ & $2300 / 4202$ & $\begin{array}{l}\text { RJ }-19 u / R J \\
\text { Cabo Frio }\end{array}$ & GTD & G23 & $\begin{array}{l}2.41 \\
0.04 \\
\end{array}$ & & $\begin{array}{l}2.63 \\
0.03 \\
\end{array}$ & $\begin{array}{l}.511184 \\
.000024\end{array}$ & .10503 & 13.2 & 76.0 & -.47 & -28.4 & -4.2 & $\begin{array}{l}2.07 \mathrm{Rb} / \mathrm{sr} \\
.7037_{\mathrm{b}}\end{array}$ & 23 & 2 \\
\hline
\end{tabular}

Ver nota explicativa no apêndice 1.

ref. : $n t=$ neste trabalho, $1=$ Picanço 1995, 2 = Fonseca 1994, 5 = Soares $1992,6=$ Dussin $1994 ; 7=$ Tassinari e Sato 1996; $8=$ Souza Martins 1997.

ref. citadas na coluna $t(G A)_{\text {met: }} a=$ Picanço $1995, b=$ Fonseca $1994, c=$ Kinoshita e Cordani $e=$ Tassinari 199?, $f=$ Cordani 1980, $\mathrm{g}=$ Teixeira 1982, $\mathrm{h}=$ Teixeira 1983, $\mathrm{i}=$ Siga Jr. 1982, $\mathrm{j}=$ Cordani 1970, $\mathrm{k}=$ Soares $1992, \mathrm{l}=$ Dussin $1994, \mathrm{~m}=$ Carvalho et. al 1992, $n=$ Tassinari e Silva 1990 $\mathrm{p}=$ Tassinari 1988; $r=$ Souza Martins, 1997; $\mathrm{s}=$ Mascarenhas e Garcia 1989.

$\#-.->1=\mathrm{T} 2=\mathrm{te} \mathrm{e}^{147} \mathrm{Sm} /{ }^{144} \mathrm{Nd}=.1 ; 2=\mathrm{T} 2=\mathrm{te} \mathrm{e}^{147} \mathrm{Sm} /{ }^{144} \mathrm{Nd}=.11 ; 3=\mathrm{T} 2=\mathrm{t} \mathrm{e}^{147} \mathrm{Sm} / /^{144} \mathrm{Nd}=.122 ; 4=\mathrm{T} 2=\mathrm{t} \mathrm{e}^{147} \mathrm{Sm} /{ }^{144} \mathrm{Nd}=.128$ 


\section{9 - COMPLEXO GOIÁS - CENTRAL}

\section{9-1 SÍNTESE GEOLÓGICA:}

o Complexo Goiás Central apresenta forma alongada, sendo balizado a oeste pela Faixa Paraguai-Araguaia e a leste pelos domínios Uruaçu-Brasilia / Araxá, conforme ilustrado nas figuras. 5.9-1 e 5.9-2. Nele predominam rochas graniticas, gnáissicas, e migmatiticas, estas últimas normalmente na fácies anfibolito alto. Esses terrenos foram denominados sucessivamente de Complexo Basal Goiano (Almeida, 1967), Maciço Mediano de Goiás (Almeida et. al., 1976) e Complexo Goiano (Tassinari et. al., 1981).

O complexo é afetado por importantes lineamentos tectonicos, tais como o Transbrasiliano, de Pirenópolis e Araguaia-Tocantins, referidos como falhamentos profundos e sugestivos de importantes translações de massas continentais (Cordani e Brito Neves, 1982). Neste sentido, tais terrenos constituem representar ser um mosáico de fragmentos cratônicos de diferentes origens, justapostos e amalgamados durante o Meso-Neoproterozóico.

Os dados geocronológicos principais, pré-existentes podem ser resumidos da seguinte forma:

Arqueano - Terrenos do tipo granito-greenstone da região de Crixás: isócrona $\mathrm{Rb}-\mathrm{Sr}$ de 2,9Ga $(\mathrm{RI}=0,7001)$; rochas granito-gnáissicas de Rubiataba - Itapirapuã (sul de Crixás): isócronas $\mathrm{Rb}-\mathrm{Sr}$ de $2.85 \mathrm{Ga}(\mathrm{RI}=705)$ e $2,65 \mathrm{Ga}(\mathrm{RI}=0,700)$

Paleoproterozóico - Rochas granito-gnássicas da região de Crixás: isócronas $\mathrm{Rb} / \mathrm{Sr}$ e $\mathrm{Pb}$ $\mathrm{Pb}$ de $2,47 \mathrm{Ga}(\mathrm{RI}=.701 ; \mu 1=7,699)$; terrenos granito-gnáissicos de Hidrolina: isócrona $\mathrm{Rb}-\mathrm{Sr}$ de $2,12 \mathrm{Ga}(\mathrm{ri}=0.702)$.

Neoproterozóico - Rochas granodiorítico-granítica-migmatíticas da região entre Crixás e Rubiataba: isócrona de referência $\mathrm{Rb} / \mathrm{Sr}, \mathrm{I}=1,0 \mathrm{Ga}$; $\mathrm{RI}=0,708$; rochas granítico-gnáissicas das regiões de Porangatu $(I=0,59 \mathrm{Ga}-\mathrm{RI}=.705)$ e Santa Fé (norte de Iporá, $\mathrm{I}=0,47 \mathrm{Ga}-\mathrm{RI}=0,705)$. Adicionalmente têm sido identificados no complexo, maciços de composição tonalitogranodiorítica, cálcio alcalina, interpretados como possiveis representantes de arcos magmáticos. 
Tais rochas ocorrem nas proximidades de Arenópolis, Matrinxã, Sancrerlândia e Mara Rosa, apresentando idades de formação relativas ao Neoproterozóico $(0,94-0,86 \mathrm{Ga}, \mathrm{U} / \mathrm{Pb}$ - zircões e Rb/Sr-isócronas; Pimentel et. al., 1997)

\section{9-2 IDADES MODELO Sm-Nd ( $\left.\mathrm{T}_{\mathrm{DM}}\right)$}

GENERALIDADES: Os dados Rb-Sr e U-Pb, ora apresentados de modo bastante sucinto, acoplados às recentes análises realizadas através do método Sm-Nd permitiram um importante refinamento em termos de evolução crustal dos terrenos que compõem o Complexo Goiás Central. Para uma melhor visualização deste quadro evolutivo, serão discutidos a seguir os padrões $\mathrm{Sm-Nd}$ (idades modelo $\mathrm{T}_{\mathrm{DN}}$ ) relativos às regiões de Crixás-Hidrolina, Arenópolis-Iporá, Mara Rosa-Porangatu e Jussara - Goiás. Os dados analiticos e a localização das amostras datadas através do método Sm-Nd encontram-se na tab. 5.9-2 e fig.5.9-3.

REGIÃO DE CRIXÁS - HIDROLINA / JUSSARA - GOIÁS - Os dados isotópicos Rb-Sr e U-Pb caracterizam neste setor terrenos granito-greenstone Arqueanos (Crixás), rochas granitóides Paleoproterozóicas (Hidrolina), e rochas granitóides Meso/Neoproterozóicas (CrixásRubiataba e Jussara - Goiás).

$\mathrm{Na}$ região ocorrem também rochas metassedimentares, bem como corpos ultrabásicos que foram analisados através do método isocrônico $\mathrm{Sm-Nd}$ em rocha total (fig.5.9 -4). Os pontos relativos às rochas ultramáficas mostraram-se relativamente dispersos no diagrama, com certo alinhamento em torno da reta de $0,80 \pm 0,20 \mathrm{Ga}\left(\mathrm{RI}=0,5115 ; \varepsilon_{\mathrm{Nd}}=-1,8\right)$. Por outro lado, os dados $\mathrm{Sm}-\mathrm{Nd}$ relativos às rochas metassedimentares definiram uma isócrona com $\mathrm{T}=$ $2,14 \pm 0,05 \mathrm{Ga}\left(\mathrm{RI}=0,5096, \varepsilon_{\mathrm{Nd}}=-5.2\right)$. Tais valores podem ser interpretados como relativos às épocas de formação de ambos os conjuntos, relacionando-os portanto às orogêneses Transamazônica e Brasiliana. No diagrama $\varepsilon_{\mathrm{Nd}}$ versus tempo geológico (fig. 5.9-5), devido aos valores de $\varepsilon_{\mathrm{Nd}}$ negativos na razão ${ }^{143} \mathrm{Nd} /{ }^{144} \mathrm{Nd}$ inicial, acredita-se ter ocorrido fracionamento químico entre $\mathrm{Sm}$ e Nd durante o metamorfismo dessas rochas metassedimentares e ultramáficas. Deste modo, as idades modelo $\mathrm{Sm}-\mathrm{Nd}$ foram calculadas em estágio duplo, resultando idades Arqueanas $(2,95$ a $2,82 \mathrm{Ga}$; tab. 5:9-2, amostra $=$ B8-B10) para as rochas metassedimentares e 


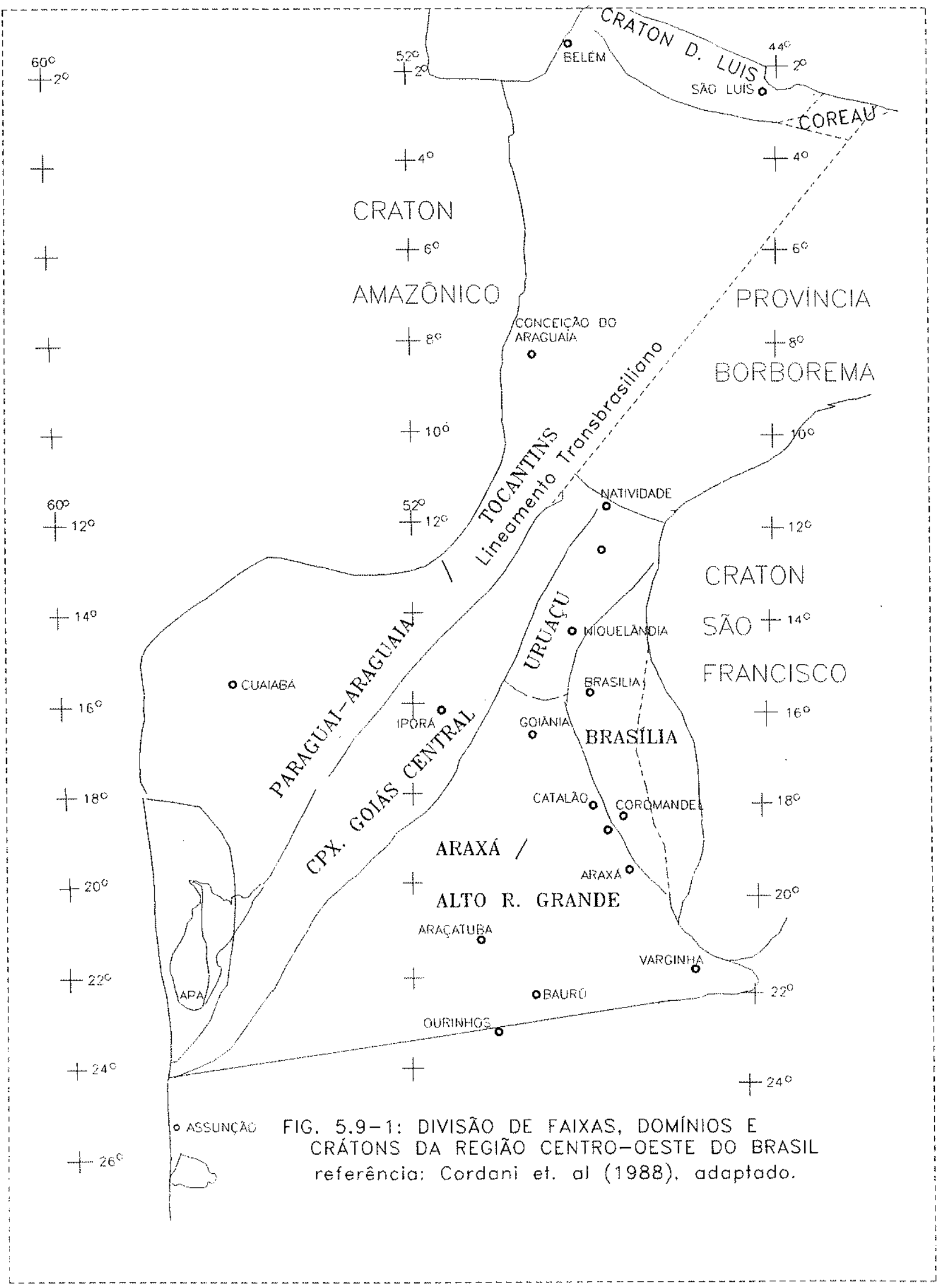




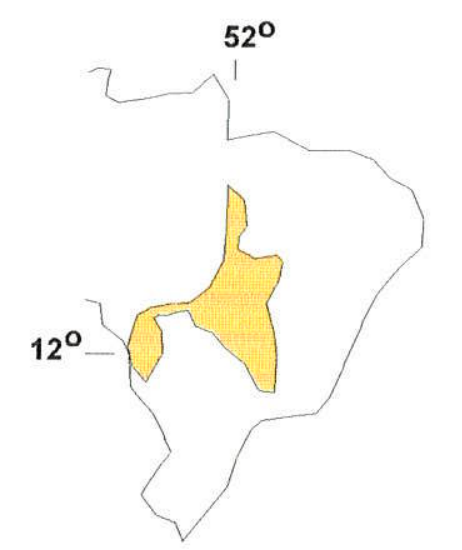

$50^{\circ}$ $48^{\circ}$
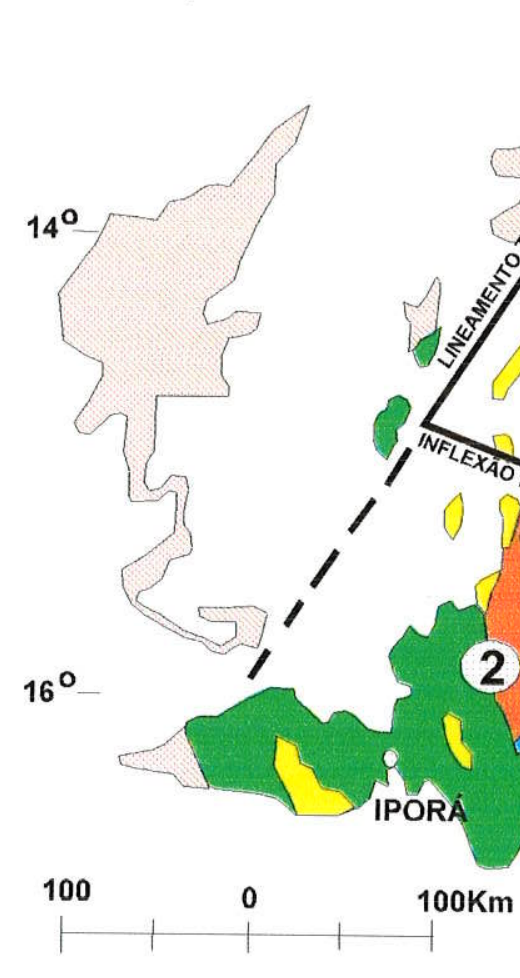

Baseado em Pimentel et. al, 1997 Fuck et. al. 1994 - (adaptado) $18^{\circ}$ LEGENDA

FAIXA PARAGUAI - ARAGUIA 1

Faixa dobrada supracrustal

Embasamento siálico

\section{CPX. GOIÁS CENTRAL 2}

Sequências vulcano-sedimentares

Ortognaisses

Greestone belts ortognaisses

\section{DOMINIO BRASILIA 5}

Sequências de margem passiva (Grupos Paranoá e Canastra, Formações Ibiá, Vazante e Minaçu)

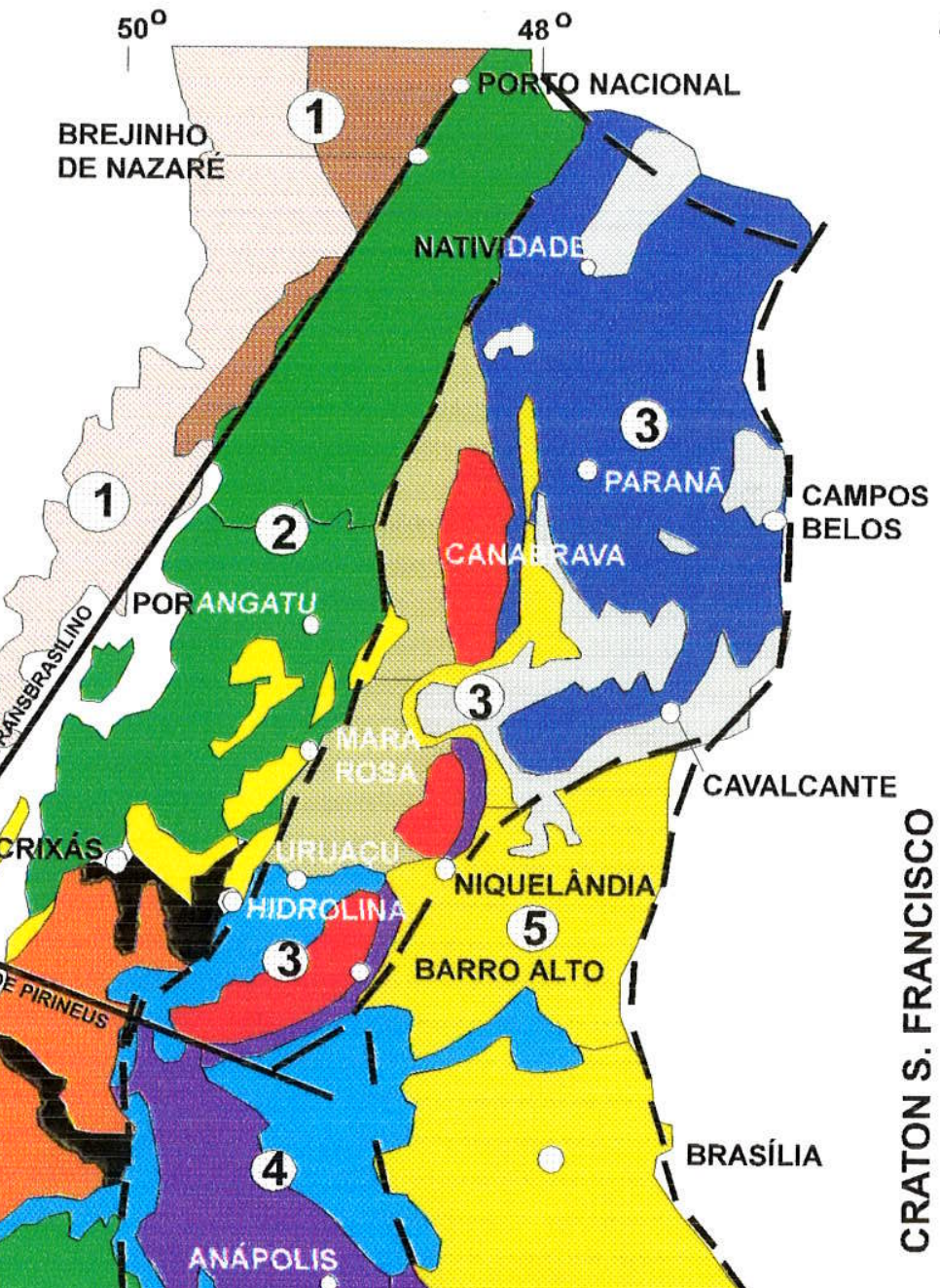

\section{DOMÍNIO ARAXÁ 4}

Ortognaisses e granulitos

Faixa dobrada (Grupo Araxá)
Cobertura metassedimentar grupo Serra da Mesa

Complexos máfico-ultramáfico sequências vulcano-sedimentares

Sequência de rift (Gr. Araí)

Greesntone belts / ortognaisses
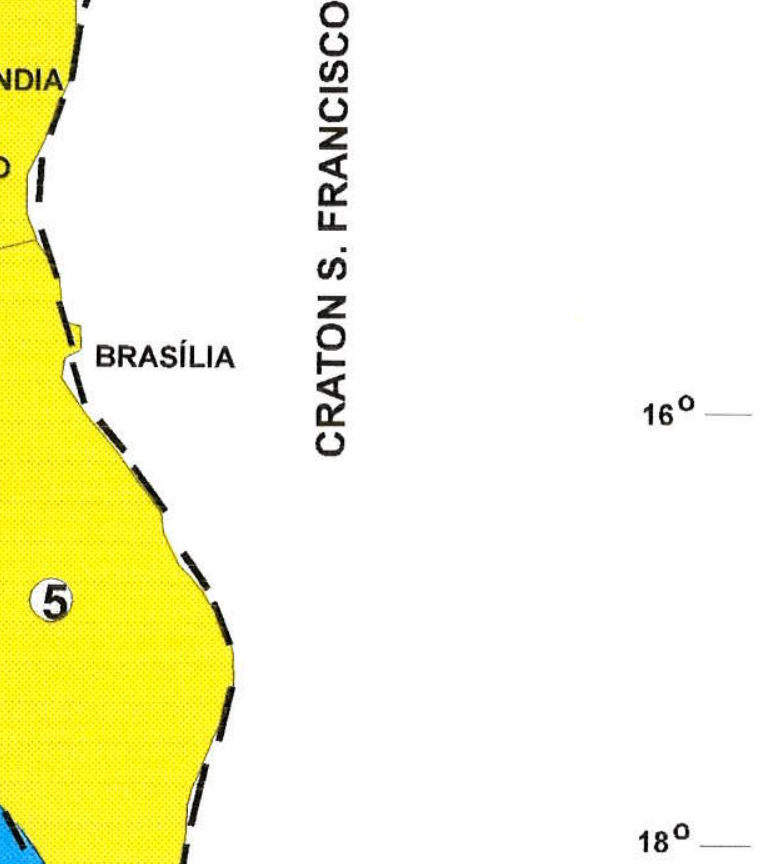

Fig. 5.9-2 Mapa geológico simplificado da parção centro-oeste do Brasil 


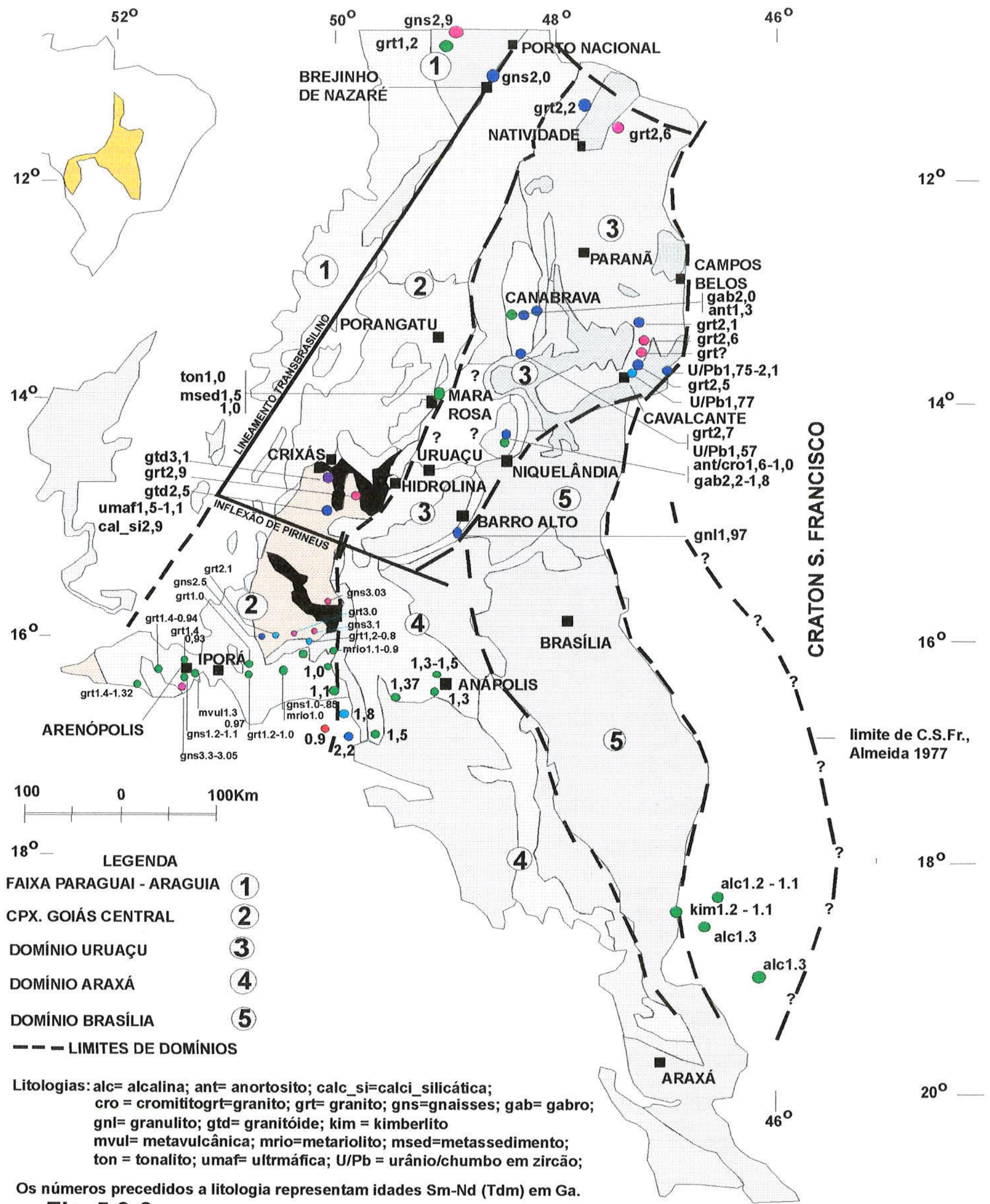

Fig. 5.9-3: Localização aproximada das amostras datadas por método Sm-Nd. Porção Centro-Oeste 


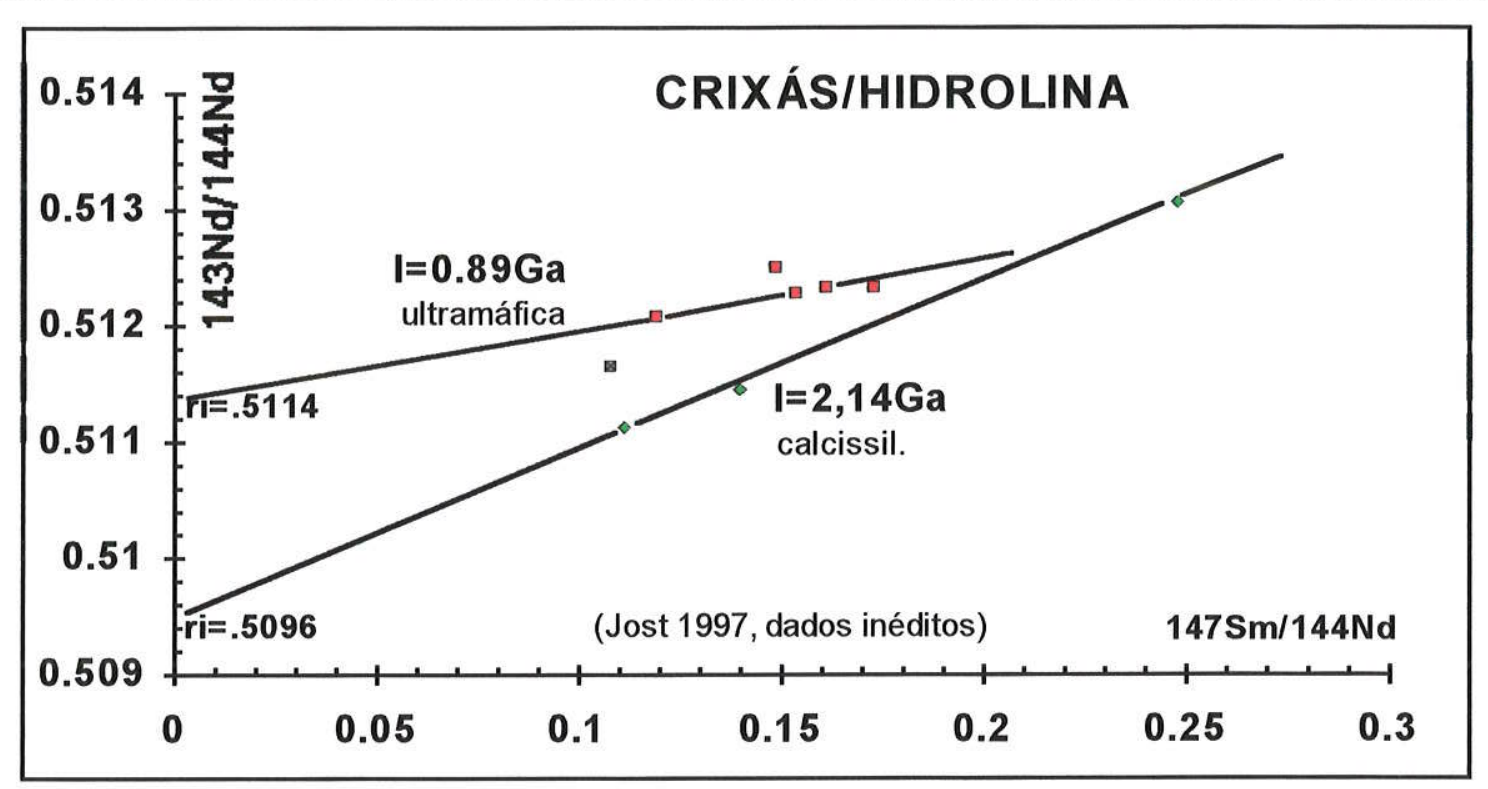

Fig. 5.9-4: Diagrama isocrônico Sm-Nd da região de Crixás.

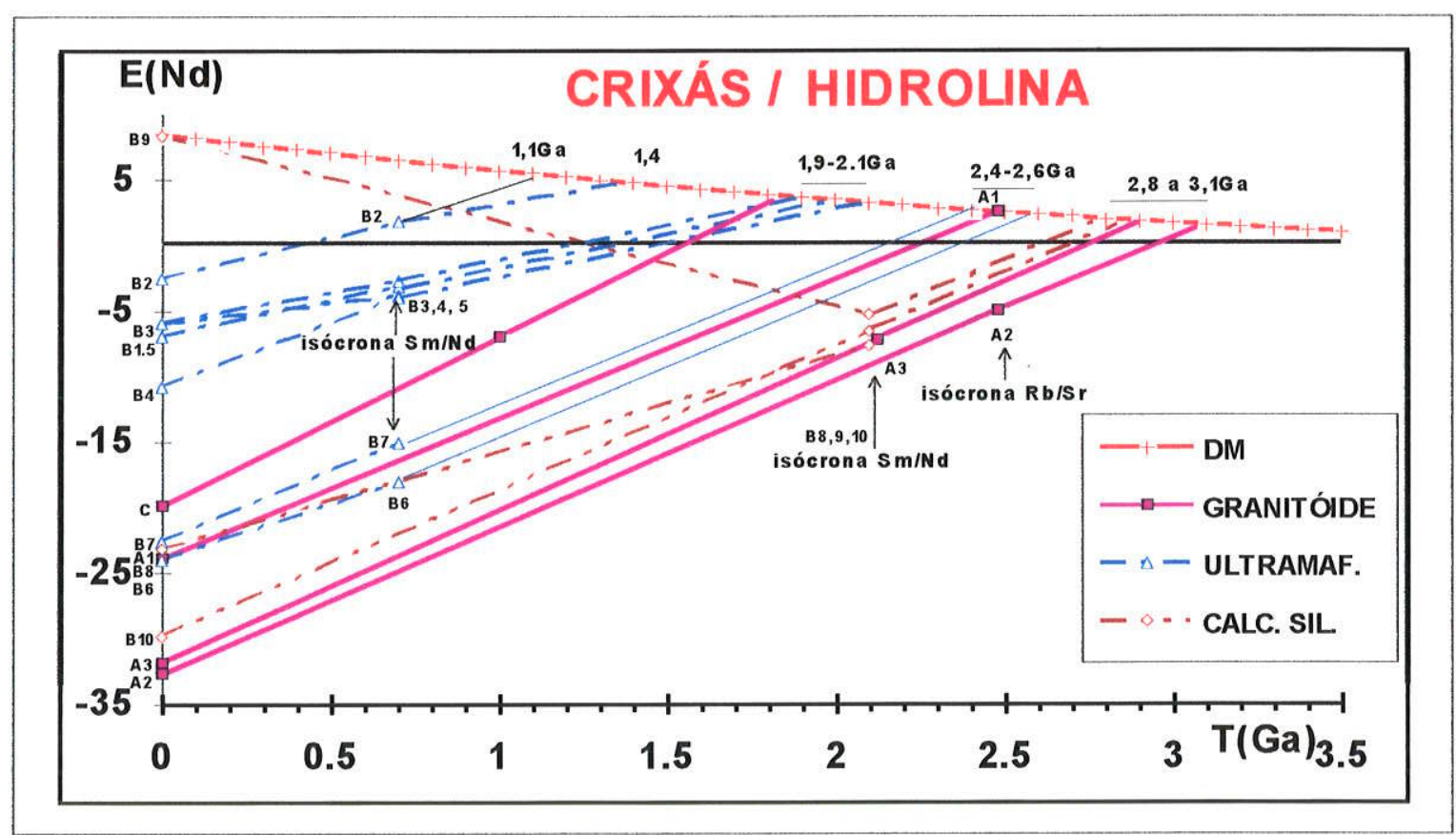

Fig. 5.9-5: Diagrama $\varepsilon_{\mathrm{Nd}}$ versus tempo geológico - regiões de Crixás - Hidrolina. Os dados isotópicos das amostras encontram-se na tab.5.9-2 


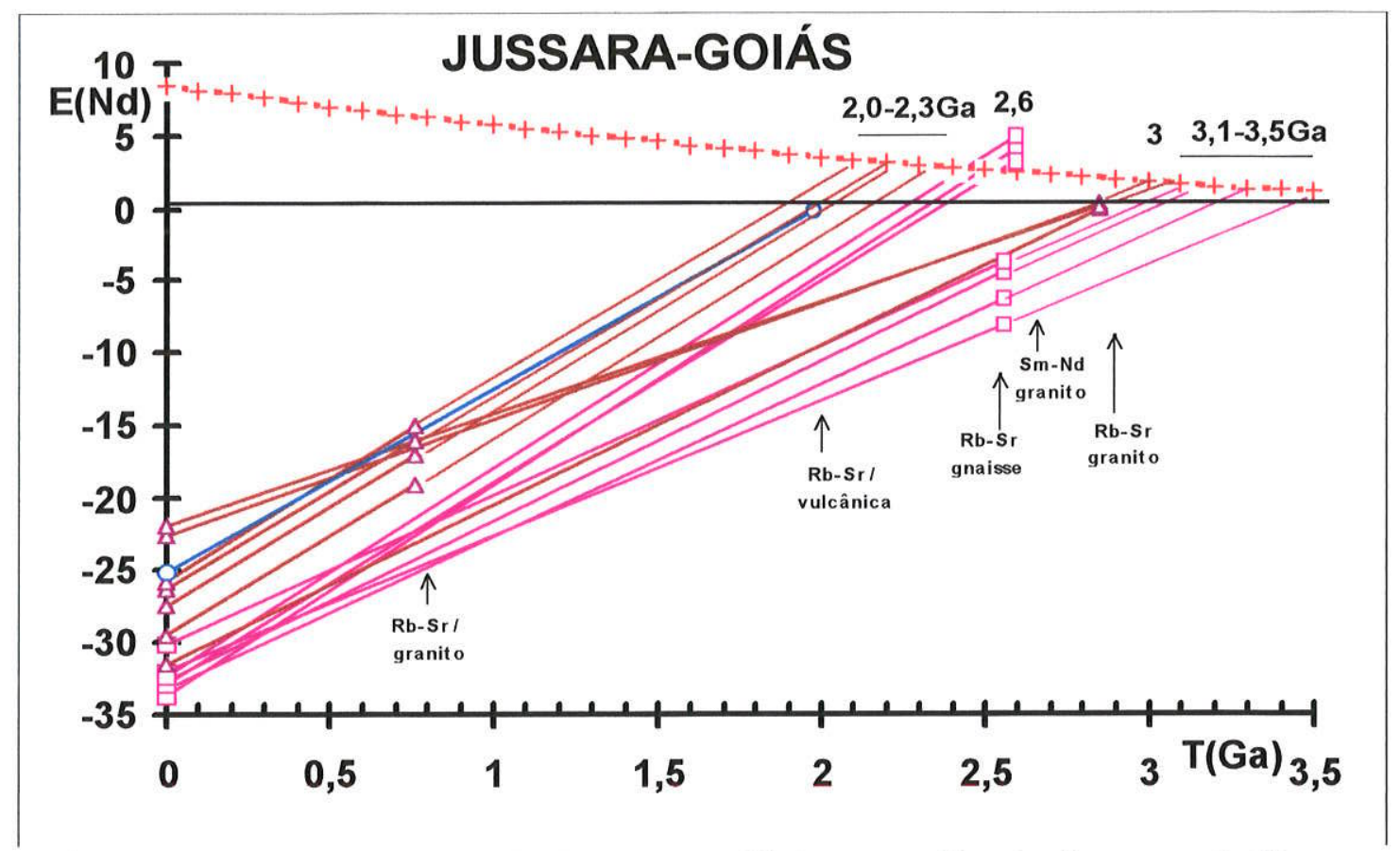

Fig. 5.9-6: Diagrama $\varepsilon_{N d}$ versus tempo geológico - região de Jussara-GoiásMossâmedes. Os dados isotópicos encontram-se na tab.5.9-2 (amostras X a Z). As setas assinladas no gráfico indicam idades isocrônicas $\mathrm{Rb}-\mathrm{Sr}$ e $\mathrm{Sm}-\mathrm{Nd}$

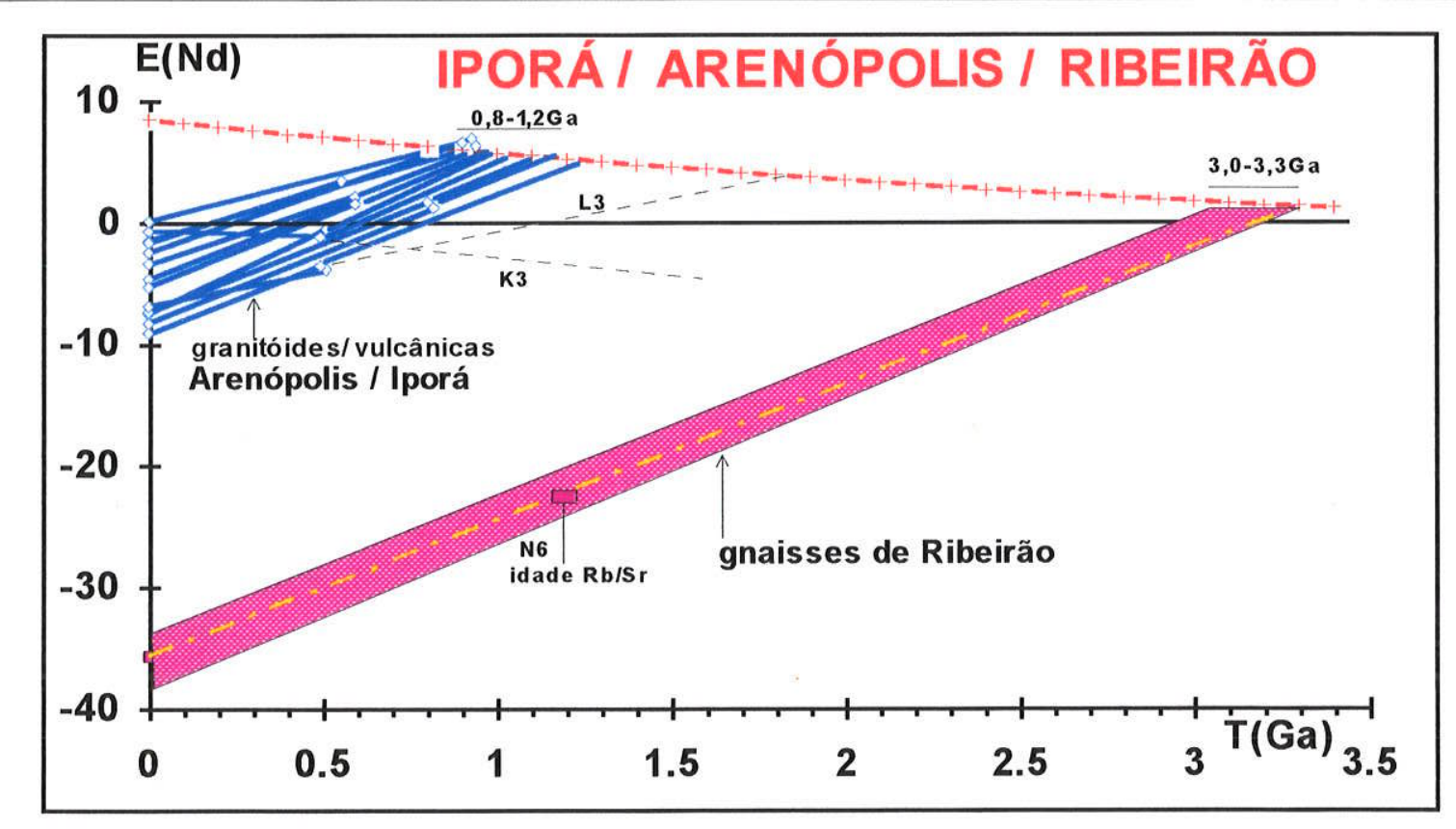

Fig. 5.9-7: Diagrama $\varepsilon_{N d}$ versus tempo geológico - região de Iporá e áreas vizinhas (Riberão, Arenópolis, Matrinxã, Sancrelândia, Fazenda Nova, Japuci, Caiapó, Serra do Irã, Serra Negra e Israelândia). Para cada afloramento está representada apenas uma única linha de evolução isotópica (dados isotópicos baseado em Pimentel et. al., 1992, ver tab. 5.92). 
Paleo a Mesoproterozóicas (2.0 a 1,1Ga; tab. 5.9 -2, amostras $=$ B1-B5) para as rochas ultramáficas.

Para os granitóides formados no Paleoproterozóico duas idades modelo Sm-Nd são disponiveis: uma de 2,48Ga (concordante com a idade $\mathrm{Rb}-\mathrm{Sr}$ ) e outra de 3,06Ga (tab. 5.9-2, amostras A1 e A2 respectivamente). Os valores obtidos sugerem a existência de fontes distintas na geração dos granitóides. Acrescente-se que existem dados $\mathrm{Rb} / \mathrm{Sr}$ com idades próximas de 2,98Ga (RI=0,700; Montalvão, 1985) em corpos graniticos do mesmo setor.

Datações Sm-Nd ( $\mathrm{T}_{1 \mathrm{M}}$ ) efetuadas por Pimentel et. al. (1996) em rochas granitóides e vulcânicas ácidas da região de Jussara-Goiás-Mossâmedes, apresentaram um grupo de rochas granitóides com idades Arqueanas (3,5 a 3,0Ga) e outro conjunto de rochas granitóides, bem como vulcânicas ácidas, com idades Paleoproterozóicas (2.5 a 2,2Ga), sugerindo eventos de acreção em épocas distintas.

No diagrama $\varepsilon_{\mathbb{N d}}$ versus tempo geológico (fig. 5.9-6) observa-se um conjunto de retas sub paralelas que interceptam à curva de evolução do manto (DM) entre 3,5 a 2,0Ga, sugerindo épocas distintas de acreção de material juvenil (Arqueano e Paleoproterozóico). A figura mostra

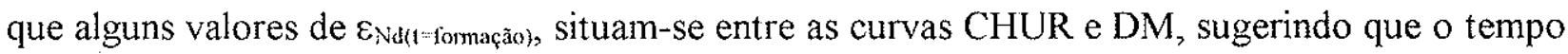
de residência crustal foi relativamente curto para os protólitos dessas rochas. Por outro lado outro tipo de rochas granitóides apresentou valores $\varepsilon_{\mathfrak{N} \mathrm{d}(t=\text { formação) }}$ muito negativos, bem abaixo do campo relativo ao manto, indicando tempo de residência crustal relativamente longo para seus protolitos.

REGIÃO DE MARA ROSA - Nesta região ocorrem rochas metatonalíticas e metavulcânicas félsicas com idades U-Pb em zircões próximas de $0.86 \mathrm{Ga}$, interpretadas como relativas à sua época de formação. Dados $\mathrm{U}-\mathrm{Pb}$ em esfeno indicam valores próximos à $0,63 \mathrm{Ga}$, retratando provavelmente ao episódio de metamorfismo regional dessas rochas.

Os dados Sm-Nd relativos às rochas granitóides indicaram idades $\mathrm{T}_{\mathrm{DM}}$ do início do Neoproterozóico (1,0Ga). Isto, acoplado aos valores obtidos para os traçadores petrogenéticos de $\mathrm{Sr}$ e de $\mathrm{Nd}\left(\mathrm{RI}_{87 \mathrm{Sr} / 86 \mathrm{Sr}}=0,703\right.$ e $\left.\varepsilon_{\mathrm{Nd}(\mathrm{t}=0,86 \mathrm{Ga})}>3,7\right)$, bem como ao comportamento dos elementos traço, sugere padrão similar ao de rochas formadas em ambiente de arcos de ilha (Pimentel et. al., 1997; e Pimentel, comunicação escrita).

Adicionalmente, foram analisadas através do método $\mathrm{Sm}-\mathrm{Nd}$ rochas metassedimentares da mesma região, que forneceram idades modelo entre 1,46 a 1,01Ga (tab. 5.9-2, amostras 12 I6; Pimentel e Junges, 1997). Os autores sugerem, para tais sedimentos, fontes de idade similar às 
dos granitóides e das vulcânicas ácidas, estas interpretadas como integrantes de possivel arco magmático Neoproterozóico.

REGIÃO DE IPORÁ/ARENÓPOLIS - Os estudos isotópicos e geoquímicos realizados por Pimentel e Fuck, (1991) e Pimentel e Charnley, (1992) em rochas ortognáissicas e metavulcânicas da região de Iporá/Arenópolis indicaram idades relativas ao Neoproterozoico. Os autores sugeriram a possibilidade dessas rochas fazerem parte de um arco de ilhas dessa época.

O diagrama $\varepsilon_{\mathrm{Nd}} \times \mathrm{T}(\mathrm{Ga})$ (fig. 5.9-7) indica a existência de dois padrões evolutivos bem distintos:

- O primeiro relativo às rochas granitóides cujos dados $\mathrm{Sm}-\mathrm{Nd}$ indicaram idades modelo ( $\left.\mathrm{T}_{\mathrm{DM}}\right)$ Meso-Neoproterozóicas;

- O segundo relativo às rochas granitóides de Ribeirão, cujos dados $\mathrm{Sm}-\mathrm{Nd}$ indicaram acreção de material juvenil durante o Arqueano.

Devido ao grande número de dados Sm-Nd existentes na região, apresenta-se na fig. 5.9-8 um histograma das idades modelo Sm-Nd, $\mathrm{T}_{\mathrm{DM}}$. Observa-se, nesta figura, uma distribuição de idades com pico entre 1,2 a 1,0Ga, sugerindo este intervalo como sendo o principal evento de acreção ocorrido no final do Mesoproterozóico.

Datações U-Pb em zircão realizadas em rochas granitóides e vulcânicas ácidas da região de Arenópolis, bem como nas rochas vulcânicas ácidas de Jaupaci, apresentaram valores entre 0.93 e $0.76 \mathrm{Ga}$, próximos às idades $\mathrm{T}_{\mathrm{DM}}$. Tal padrão indica período relativamente curto entre a diferenciação mantélica e os processos posteriores de diferenciação magmática e consequente formação das rochas.

Na figura 5.9-9, os dados relativos às rochas granitóides e vulcânicas ácidas de Iporá/Arenópolis distribuem-se predominantemente no segundo quadrante, campo este característico das rochas oriundas do manto ("mantle array"), e confirmando tempo reduzido de residência crustal, e em alguns casos processos de derivação direta do manto empobrecido (DM). Distintamente, as rochas granitóides de Ribeirão (ponto $\mathrm{N}=$ valor médio de $\mathrm{N} 2$ a $\mathrm{N} 9 ; \mathrm{t}_{\mathrm{Rb} / \mathrm{sr}} \cong$ $1,2 \mathrm{Ga}$ ) e a rocha granitóide de Crixás (ponto $\mathrm{C} ; \mathrm{t}_{\mathrm{Rb} / \mathrm{sr}}=1,0 \mathrm{Ga}$ ) possuem seus pontos no quadrante, sugerindo derivação a partir de fontes com afinidade crustal. 


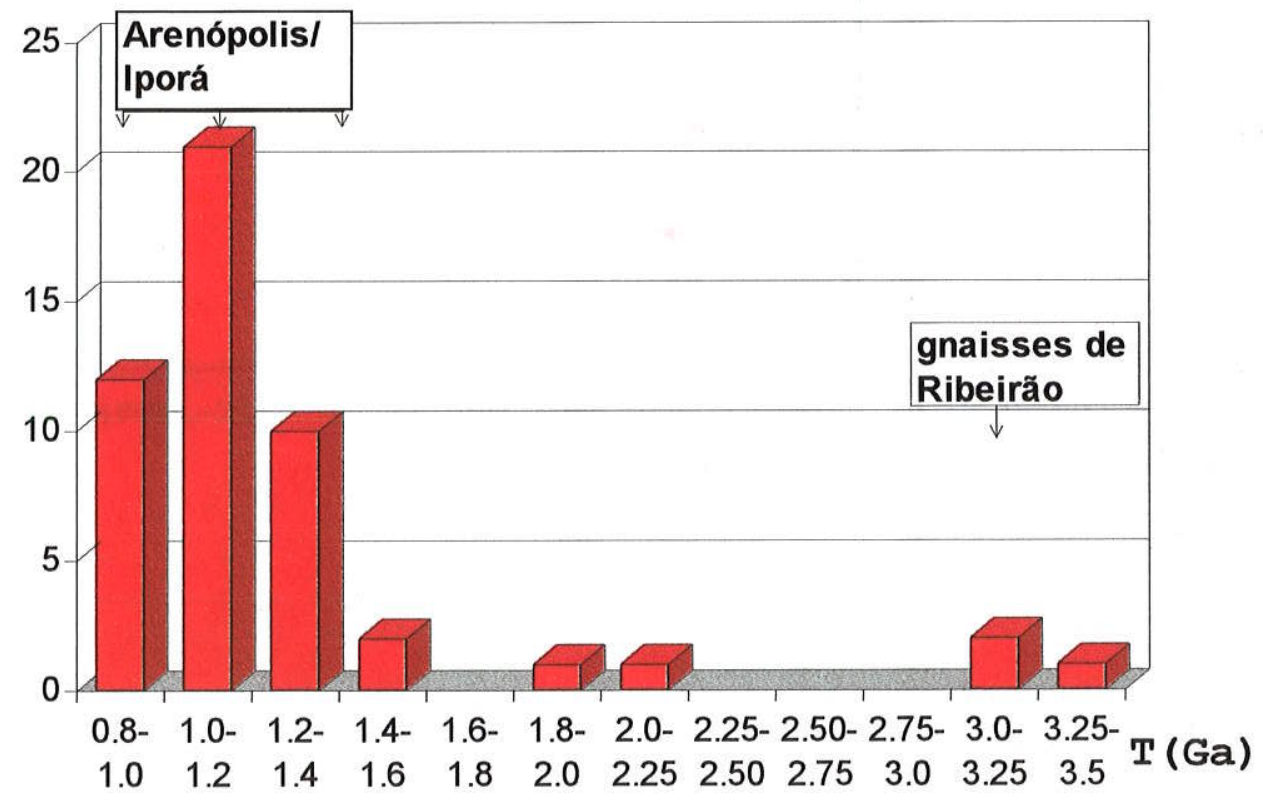

Fig. 5.9-8: Histograma das idades modelo $\left(T_{d m}\right)$ na região de Iporá com base nos dados da tab. 5.9-2. Obs. - computado apenas um $\mathrm{T}_{\mathrm{DM}}$ médio por afloramento. 


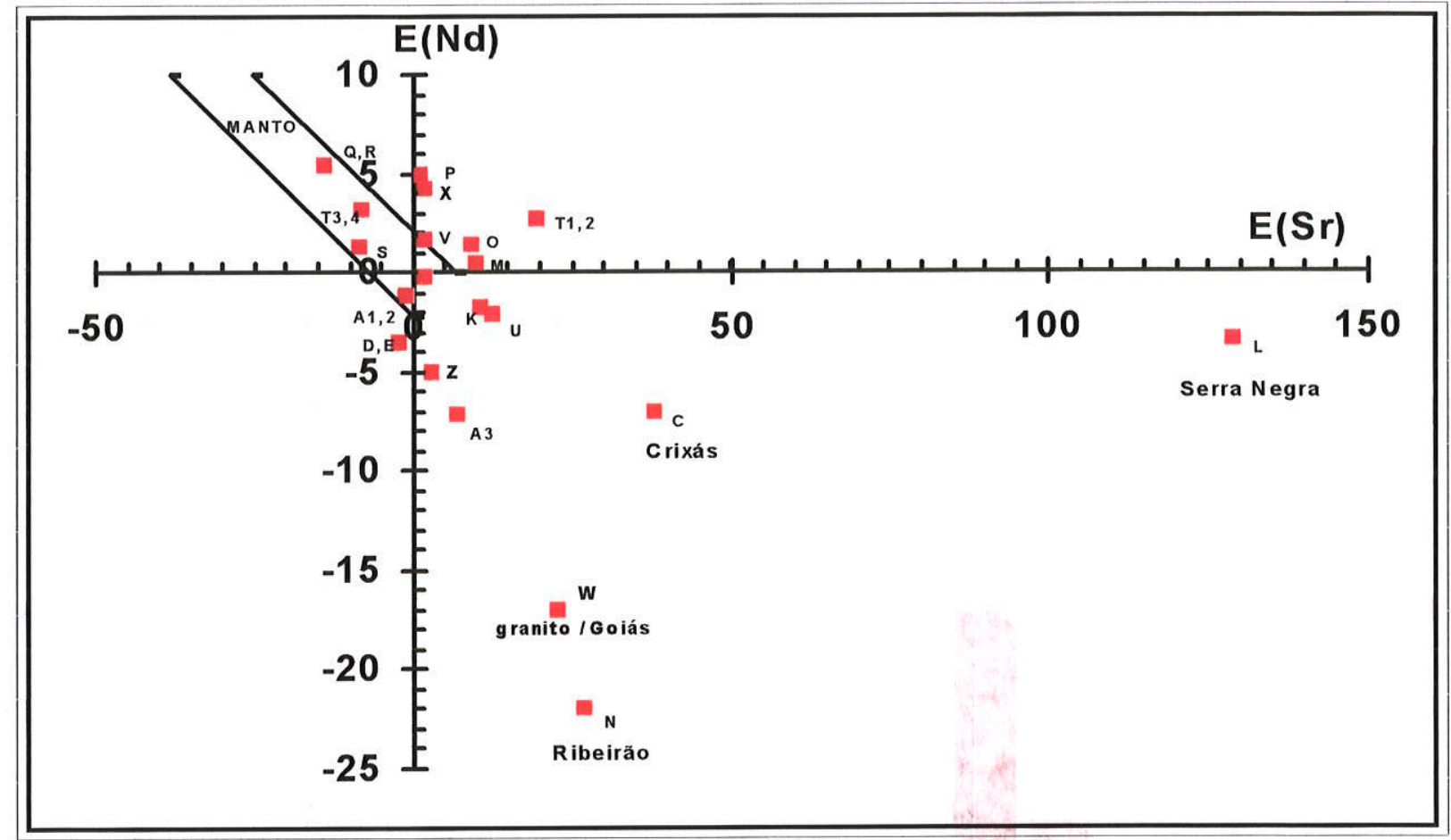

Fig. 5.9-9: Diagrama $\varepsilon_{\mathrm{Sr}}$ versus $\varepsilon_{\mathrm{Nd}}$ : Iporá-Arenópolis/ Crixás-Jussara (dados isotópicos encontram-se na tab.5.9-2). 


\section{9-3 RESUMO PARCIAL DO COMPLEXO GOIÁS CENTRAL:}

Os principais periodos de acreção de material do manto que contribuiram na formação da crosta continental no Complexo Goiás Central, tendo por base idades modelo $\mathrm{Sm}-\mathrm{Nd}$, $\left(\mathrm{T}_{\mathrm{DM}}\right)$ podem ser resumidos da seguinte forma:

- Arqueano (3,31 - 3,05Ga): rochas granitóides do fragmento crustal de Ribeirão; $(3,06-2,80 \mathrm{Ga})$ : das rochas granitóides e metassedimentares das regiões de Crixás - Hidrolina e Jussara - Goiás;

- Paleoproterozóico : $(2,5$ - 1,84): rochas granitóides, vulcânicas ácidas, básicas e ultrabásicas das regiões de Crixás - Hidrolina e Jussara-Mossâmides;

- Mesoproterozóico (1,45 - 1,0Ga): rochas granitóides e vulcânicas ácidas das regiões de Mara Rosa e Arenópolis-Iporá. O principal período de acreção ocorreu entre 1,2 a $1,0 \mathrm{Ga}$, conforme ilustrado no histograma da fig. 5.9-8;

- Neoproterozóico (1,0 - 0,8Ga): região de Arenópolis - Iporá. 
TAB. 5.9-2: - DADOS Sm-Nd DAS AMOSTRAS DO COMPLEXO GOIÁS CENTRAL

\begin{tabular}{|c|c|c|c|c|c|c|c|c|c|c|c|c|c|c|c|c|c|}
\hline $\begin{array}{l}\text { SPS } \\
\text { /litol }\end{array}$ & $\begin{array}{l}\text { coord./ } \\
\text { (p.local.) }\end{array}$ & $\begin{array}{l}\text { n.campol } \\
\text { região }\end{array}$ & $\begin{array}{l}\text { litolo } \\
\text { gia }\end{array}$ & \begin{tabular}{|l|} 
ident \\
(diagra \\
ma)
\end{tabular} & $\begin{array}{l}T_{\text {chur }} \\
\text { (GA) } \\
\text { Goldstein } \\
\text { otal 1984 }\end{array}$ & $\mathrm{T}_{\mathrm{dmA} 2}$ & $\begin{array}{l}T_{\text {dm }} \\
\text { (GA) } \\
\text { DePaolo } \\
-1981 \\
\end{array}$ & ${ }^{144} \mathrm{Nd} /$ & $\mid{ }^{144} \mathrm{Sm} /$ & $\begin{array}{l}\mathrm{Sm} \\
\mathrm{ppm}\end{array}$ & $\begin{array}{l}\text { Nd } \\
\text { ppm }\end{array}$ & $f$ & $\begin{array}{l}\varepsilon_{\mathrm{Nd}} \\
(0)\end{array}$ & $\begin{array}{l}\varepsilon_{\mathrm{Nd}} \\
(\mathrm{t})\end{array}$ & $\begin{array}{l}\mathbf{t}(\mathrm{Ga})_{\text {mét }} \\
R \mathrm{i}_{\text {(fonte) }}\end{array}$ & $\begin{array}{l}\varepsilon_{s r} \\
(t)\end{array}$ & ref \\
\hline $\begin{array}{l}655 \\
\text { gtd }\end{array}$ & $1459 / 5006$ & $510 / \mathrm{HA} / 233$ & GTD & A1 & $\begin{array}{l}2.22 \\
0.07 \\
\end{array}$ & & $\begin{array}{l}2.48 \\
0.06 \\
\end{array}$ & $\begin{array}{l}.511411 \\
.000040\end{array}$ & $\begin{array}{l}.11278 \\
.00005 \\
\end{array}$ & $\begin{array}{l}1.574 \\
.001 \\
\end{array}$ & \begin{tabular}{|l|}
8.442 \\
.003 \\
\end{tabular} & -.43 & -23.9 & 2.61 & $\begin{array}{l}2.48_{\mathrm{Rb}-\mathrm{Sr}} \\
.7015_{\mathrm{g}} \\
\end{array}$ & -1.1 & nt \\
\hline $\begin{array}{l}654 \\
\text { gtd }\end{array}$ & $1434 / 5002$ & $544 / \mathrm{HA} 310.1$ & GTD & A2 & $\begin{array}{l}2.89 \\
0.06 \\
\end{array}$ & & $\begin{array}{l}3.06 \\
0.06 \\
\end{array}$ & $\begin{array}{l}.510963 \\
.000036 \\
\end{array}$ & $\begin{array}{l}.10889 \\
.00016 \\
\end{array}$ & $\begin{array}{l}1.861 \\
.003 \\
\end{array}$ & $\begin{array}{l}10.334 \\
.004 \\
\end{array}$ & -.45 & -32.7 & -4.9 & $\begin{array}{l}2.48_{\mathrm{Rb}-\mathrm{Sr}} \\
.7015_{\mathrm{g}}\end{array}$ & -1.1 & $n t$ \\
\hline $\begin{array}{l}656 \\
\text { grt }\end{array}$ & $1441 / 4928$ & eg16/rmpp113 & GTD & $A 3$ & $\begin{array}{l}2.71 \\
0.07 \\
\end{array}$ & & $\begin{array}{l}2.90 \\
0.05 \\
\end{array}$ & $\begin{array}{l}.511007 \\
.000040 \\
\end{array}$ & $\begin{array}{l}.10155 \\
.00004 \\
\end{array}$ & $\begin{array}{l}1.338 \\
.001 \\
\end{array}$ & $\begin{array}{l}7.966 \\
.003 \\
\end{array}$ & -.46 & -31.8 & -7.2 & $\begin{array}{l}2.12_{\mathrm{Rb} / \mathrm{Sr}} \\
7025_{\mathrm{g}}\end{array}$ & 7.0 & nt \\
\hline $\begin{array}{l}522 \\
\text { u.maf } \\
\end{array}$ & $\begin{array}{l}\text { Crixás } / \\
\text { Hidrolina }\end{array}$ & $\begin{array}{l}\text { Hardi (dados } \\
\text { inéditos) }\end{array}$ & UBA & $B 1$ & $\begin{array}{l}1.26 \\
0.08 \\
\end{array}$ & $2.02^{12 h}$ & $\begin{array}{l}1.93 \\
0.05\end{array}$ & $\begin{array}{l}.512284 \\
.000022 \\
\end{array}$ & $\begin{array}{l}.15378 \\
.00052 \\
\end{array}$ & $\begin{array}{l}0.310 \\
0.001 \\
\end{array}$ & $\begin{array}{l}1.219 \\
0.001 \\
\end{array}$ & -.22 & -6.9 & -3.1 & $0.7_{\mathrm{Sm}-\mathrm{Nd}}$ & - & 4 \\
\hline $\begin{array}{l}523 \\
\text { u.maf }\end{array}$ & $\begin{array}{l}\text { Crixás / } \\
\text { Hidrolina }\end{array}$ & $\begin{array}{l}\text { Hardi (dados } \\
\text { inéditos) }\end{array}$ & UBA & B2 & $\begin{array}{l}0.40 \\
0.06 \\
\end{array}$ & $1.40^{\# 4}$ & $\begin{array}{l}1.24 \\
0.04 \\
\end{array}$ & $\begin{array}{l}.512512 \\
.000020 \\
\end{array}$ & $\begin{array}{l}.14855 \\
.00034 \\
\end{array}$ & $\begin{array}{l}0.453 \\
0.001 \\
\end{array}$ & $\begin{array}{l}1.844 \\
0.001 \\
\end{array}$ & -.24 & -2.5 & +1.8 & $0.7_{\mathrm{Sm}-\mathrm{Nd}}$ & - & 4 \\
\hline $\begin{array}{l}615 \\
\text { u. maf }\end{array}$ & $\begin{array}{l}\text { Crixás / } \\
\text { Hidrolina }\end{array}$ & $\begin{array}{l}\text { Hardi J.(dados } \\
\text { inéditos) }\end{array}$ & UBA & B3 & $\begin{array}{l}1.95 \\
0.13 \\
\end{array}$ & $2.04^{44}$ & $\begin{array}{l}2.70 \\
0.06\end{array}$ & $\begin{array}{l}.512332 \\
.000020 \\
\end{array}$ & $\begin{array}{l}.17286 \\
.00033 \\
\end{array}$ & $\begin{array}{l}0.546 \\
0.001 \\
\end{array}$ & \begin{tabular}{|l|}
1.910 \\
0.001 \\
\end{tabular} & -.12 & -6.0 & -3.8 & $0.7_{\mathrm{SM}-\mathrm{NC}}$ & -- & 4 \\
\hline $\begin{array}{l}616 \\
\text { u.maf }\end{array}$ & $\begin{array}{l}\text { Crixás / } \\
\text { Hidrolina }\end{array}$ & \begin{tabular}{|l}
$\begin{array}{l}\text { Hardi (dados } \\
\text { inéditos) }\end{array}$ \\
\end{tabular} & UBA & B4 & $\begin{array}{l}1.09 \\
0.04\end{array}$ & $2.04^{74}$ & $\begin{array}{l}1.54 \\
0.03 \\
\end{array}$ & $\begin{array}{l}.512085 \\
.000020\end{array}$ & $\begin{array}{l}.11917 \\
.00007\end{array}$ & $\begin{array}{l}2.273 \\
0.001 \\
\end{array}$ & $\begin{array}{l}11.534 \\
0.004\end{array}$ & -.39 & -10.8 & -3.9 & $0.7_{\text {Sm-Nd }}$ & - & 4 \\
\hline $\begin{array}{l}685 \\
\text { u.maf }\end{array}$ & $\begin{array}{l}\text { Crixás / } \\
\text { Hidrolina }\end{array}$ & $\begin{array}{l}\text { Hardi (dados } \\
\text { inéditos) }\end{array}$ & UBA & $B 5$ & $\begin{array}{l}1.28 \\
0.09 \\
\end{array}$ & $1.91^{\text {\#4 }}$ & $\begin{array}{l}2.03 \\
0.05 \\
\end{array}$ & $\begin{array}{l}.512337 \\
.000021\end{array}$ & $\begin{array}{l}.16079 \\
.00024 \\
\end{array}$ & $\begin{array}{l}.711 \\
.001 \\
\end{array}$ & $\begin{array}{l}2.674 \\
.001 \\
\end{array}$ & -.18 & -5.9 & -2.7 & $0.7_{\mathrm{Sm}-\mathrm{Nd}}$ & - & 4 \\
\hline $\begin{array}{l}617 \\
\text { chert }\end{array}$ & $\begin{array}{l}\text { Crixás / } \\
\text { Hidrolina }\end{array}$ & \begin{tabular}{|l}
$\begin{array}{l}\text { Hardi (dados } \\
\text { inéditos) }\end{array}$ \\
\end{tabular} & MSE & $B 6$ & $\begin{array}{l}2.75 ? \\
0.19\end{array}$ & \#\# & $\begin{array}{l}2.98 ? \\
0.14\end{array}$ & $\begin{array}{l}.511409 ? \\
.000032 \\
\end{array}$ & $\begin{array}{l}.12905 \\
.00440 \\
\end{array}$ & $\begin{array}{l}0.035 \\
0.001\end{array}$ & $\begin{array}{l}0.164 \\
.003\end{array}$ & -.34 & -24.0 & -18 & $0.7_{\mathrm{Sm}-\mathrm{N} d}$ & - & 4 \\
\hline $\begin{array}{l}735 \\
\text { chert }\end{array}$ & $\begin{array}{l}\text { Crixás / } \\
\text { Hidrolina }\end{array}$ & $\begin{array}{l}\text { Hardi (dados } \\
\text { inéditos) }\end{array}$ & MSE & 87 & & \#\# & $\begin{array}{l}2.27 \\
0.03 \\
\end{array}$ & $\begin{array}{l}.511480 \\
.000024\end{array}$ & $\begin{array}{l}.10834 \\
.00009\end{array}$ & $\begin{array}{l}0.064 \\
0.001\end{array}$ & $\begin{array}{l}0.360 \\
0.001\end{array}$ & & -22.6 & -15 & $0.7_{\mathrm{Sm}-\mathrm{Nd}}$ & - & 4 \\
\hline $\begin{array}{l}674 \\
\text { cal.si }\end{array}$ & $\begin{array}{l}\text { Crixás / } \\
\text { Hidrolina }\end{array}$ & $\begin{array}{l}\text { Hardi (dados } \\
\text { inéditos) }\end{array}$ & MSE & 88 & $\begin{array}{l}3.15 \\
0.07 \\
\end{array}$ & $2.95^{\$ 2}$ & $\begin{array}{l}3.36 \\
0.07 \\
\end{array}$ & $\begin{array}{l}.511450 \\
.000022\end{array}$ & $\begin{array}{l}.13971 \\
.00077 \\
\end{array}$ & \begin{tabular}{|l|}
.201 \\
.001 \\
\end{tabular} & $\begin{array}{l}.870 \\
.002 \\
\end{array}$ & -.29 & -23.2 & -7.6 & $2.1_{\mathrm{Sm} \cdot \mathrm{Nd}}$ & - & 4 \\
\hline $\begin{array}{l}675 \\
\text { cal.si }\end{array}$ & $\begin{array}{l}\text { Crixás / } \\
\text { Hidrolina }\end{array}$ & $\begin{array}{l}\begin{array}{l}\text { Hardi (dados } \\
\text { inéditos) }\end{array} \\
\end{array}$ & MSE & B9 & $\ldots$ & $2.82^{* 2}$ & $\cdots$ & $\begin{array}{l}.513071 \\
.000020 \\
\end{array}$ & $\begin{array}{l}.24812 \\
.00012 \\
\end{array}$ & $\begin{array}{l}8.548 \\
.003 \\
\end{array}$ & $\begin{array}{l}20.833 \\
.008\end{array}$ & & 8.45 & -5.3 & $2.1_{\mathrm{Sm} \cdot \mathrm{Nd}}$ & - & 4 \\
\hline $\begin{array}{l}676 \\
\text { cal.si } \\
\end{array}$ & $\begin{array}{l}\text { Crixás / } \\
\text { Hidrolina }\end{array}$ & $\begin{array}{l}\text { Hardi (dados } \\
\text { inéditos) }\end{array}$ & MSE & 810 & $\begin{array}{l}2.71 \\
0.22 \\
\end{array}$ & $2.86^{\# 2}$ & $\begin{array}{l}2.91 \\
0.17 \\
\end{array}$ & $\begin{array}{l}.511112 \\
.000120 \\
\end{array}$ & $\begin{array}{l}.11138 \\
.00040 \\
\end{array}$ & $\begin{array}{l}.282 \\
.001 \\
\end{array}$ & $\begin{array}{l}1.531 \\
.001 \\
\end{array}$ & -.43 & -29.8 & -6.5 & $2.1_{\mathrm{Sm} \cdot \mathrm{Nd}}$ & -- & 4 \\
\hline $\begin{array}{l}658 \\
\text { gnd }\end{array}$ & $1416 / 4953$ & 51OHA/RMES & GTD & C & $\begin{array}{l}1.54 \\
0.06\end{array}$ & & $\begin{array}{l}1.84 \\
0.05 \\
\end{array}$ & $\begin{array}{l}.511620 \\
.000041 \\
\end{array}$ & $\begin{array}{l}.09600 \\
.00006\end{array}$ & \begin{tabular}{|l|}
3.372 \\
.001 \\
\end{tabular} & $\begin{array}{l}21.242 \\
.010 \\
\end{array}$ & & -19.9 & -7.0 & $\begin{array}{l}1.00_{\mathrm{Rb}-\mathrm{St}} \\
.706_{\mathrm{f}} \\
\end{array}$ & 38 & nt \\
\hline
\end{tabular}




\begin{tabular}{|c|c|c|c|c|c|c|c|c|c|c|c|c|c|c|c|c|c|}
\hline mton & $\sim 1405 / 4902$ & $\begin{array}{l}\text { Mara Rosa I } \\
\text { (O) Niquel. }\end{array}$ & GTD & 11 & & & 1.0 & Pimentel & dados & inédi- & tos & & & & & & 5 \\
\hline msed & $-1405 / 4902$ & $\begin{array}{l}\text { MR111C/ } \\
\text { Mara Rosa }\end{array}$ & MSE & 12 & $\begin{array}{l}0.34 \\
0.02 \\
\end{array}$ & & $\begin{array}{l}1.01 \\
0.01\end{array}$ & $\begin{array}{l}.512487 \\
.000008 \\
\end{array}$ & 129 & 2.18 & 10.22 & -.34 & -2.9 & 2.5 & $\begin{array}{l}0.63_{\mathrm{U}} \mathrm{Pb} \\
\text { esf.(h) }\end{array}$ & & 6 \\
\hline msed & $\sim 1405 / 4902$ & $\begin{array}{l}\text { MR1101A I } \\
\text { Mara Rosa }\end{array}$ & MSE & 13 & 0.44 & & 1.11 & $\begin{array}{l}.512449 \\
.000009\end{array}$ & .1318 & 3.41 & 15.65 & -.33 & -3.7 & 1.5 & $\begin{array}{l}0.63_{\mathrm{u} p \mathrm{p}} \\
\text { esf. (m) }\end{array}$ & & 6 \\
\hline msed & $-1405 / 4902$ & $\begin{array}{l}\text { MR137A' } \\
\text { Mara Rosa }\end{array}$ & MSE & 14 & 1.05 & & 1.60 & $\begin{array}{l}.512209 \\
.000012\end{array}$ & .1345 & 4.77 & 21.45 & -.32 & -8.4 & -3.4 & $\begin{array}{l}0.63_{u . P b} \\
\text { esf.(h) }\end{array}$ & & 6 \\
\hline msed & $-1405 / 4902$ & $\begin{array}{l}\text { MR152A I } \\
\text { Mara Rosa }\end{array}$ & MSE & 15 & 0.56 & & 1.20 & $\begin{array}{l}.512400 \\
.000006\end{array}$ & .1319 & 5.53 & 25.35 & -.33 & -4.6 & 0.5 & $\begin{array}{l}0.63_{\text {ups }} \\
\text { esf. (hi }\end{array}$ & & 6 \\
\hline msed & $\sim 1405 / 4902$ & $\begin{array}{l}\text { MR18/ } \\
\text { Mara Rosa }\end{array}$ & MSE & 16 & 0.61 & & 1.22 & $\begin{array}{l}.512374 \\
.000010\end{array}$ & .1302 & 3.56 & 16.53 & -.34 & -5.1 & 0.2 & $\begin{array}{l}0.63 \mathrm{upo} \\
\text { esf. (m) }\end{array}$ & & 6 \\
\hline $\begin{array}{l}353 / \\
\text { grt }\end{array}$ & $16 \quad 17 / 5042$ & 4058 AZ $69-3$ & GTD & $J 1$ & $\begin{array}{l}0.55 \\
0.04\end{array}$ & & $\begin{array}{l}0.98 \\
0.04\end{array}$ & $\begin{array}{l}.512260 \\
.000030 \\
\end{array}$ & $\begin{array}{l}.090993 \\
.000044\end{array}$ & $\begin{array}{l}2.999 \\
.001\end{array}$ & $\begin{array}{l}19.930 \\
.007\end{array}$ & -.54 & -7.4 & -.5 & $\begin{array}{l}.51_{\mathrm{Rb}-\mathrm{Sr}} \\
.705_{\mathrm{z}}\end{array}$ & 15 & $\mathrm{nt}$ \\
\hline $\begin{array}{l}429 \\
\text { vul }\end{array}$ & $\begin{array}{l}\text { Pimentel } \\
\text { (dados inéd.) }\end{array}$ & $1 P 7 C$ & VAC & $\sqrt{2}$ & $\begin{array}{l}0.04 \\
0.06\end{array}$ & & $\begin{array}{l}0.76 \\
0.04\end{array}$ & $\begin{array}{l}.512622 \\
.000027\end{array}$ & $\begin{array}{l}.12838 \\
.00006\end{array}$ & $\begin{array}{l}4.713 \\
0.001\end{array}$ & $\begin{array}{l}22.337 \\
0.008\end{array}$ & -.35 & -0.31 & 6.7 & $0.8_{\text {est }}$ & & 5 \\
\hline $\begin{array}{l}430 \\
\text { vul }\end{array}$ & $\begin{array}{l}\text { Pimentel } \\
\text { (dados inéd.) }\end{array}$ & IP $33 \mathrm{~F}$ & VAC & J3 & $\begin{array}{l}0.54 \\
0.06\end{array}$ & & $\begin{array}{l}1.01 \\
0.05\end{array}$ & $\begin{array}{l}.512307 \\
.000039\end{array}$ & .10258 & $\begin{array}{l}8.083 \\
0.004\end{array}$ & $\begin{array}{l}47.947 \\
0.021 \\
\end{array}$ & -.48 & -6.46 & 3.1 & $0.8_{\text {est }}$ & & 5 \\
\hline $\begin{array}{l}431 \\
\text { vul }\end{array}$ & $\begin{array}{l}\text { Pimentel } \\
\text { (dados inéd.) }\end{array}$ & IP 196 & VAC & J4 & $\begin{array}{l}0.66 \\
0.04\end{array}$ & & $\begin{array}{l}1.07 \\
0.03\end{array}$ & $\begin{array}{l}.512183 \\
.000026 \\
\end{array}$ & $\begin{array}{l}.09179 \\
.00004\end{array}$ & $\begin{array}{l}2.520 \\
0.001\end{array}$ & $\begin{array}{l}16.707 \\
0.007\end{array}$ & -.54 & -8.88 & 1.9 & $0.8_{\text {es: }}$ & & 5 \\
\hline $\begin{array}{l}432 \\
\text { vul }\end{array}$ & $\begin{array}{l}\text { Pimentel } \\
\text { (dados inéd.) }\end{array}$ & $1 \mathrm{P} 136$ & VAC & $\sqrt{5}$ & $\begin{array}{l}0.65 \\
0.04 \\
\end{array}$ & & $\begin{array}{l}1.13 \\
0.03\end{array}$ & $\begin{array}{l}.512265 \\
.000024 \\
\end{array}$ & $\begin{array}{l}.10847 \\
.00007\end{array}$ & $\begin{array}{l}4.058 \\
0.002\end{array}$ & $\begin{array}{l}22.762 \\
0.010\end{array}$ & -.45 & -7.28 & 1.7 & $0.8_{\text {est }}$ & & 5 \\
\hline $\begin{array}{l}472 \\
\text { m.gab }\end{array}$ & $\begin{array}{l}\text { Pimentel } \\
\text { (dados inéd.) }\end{array}$ & SBO3 & BAS & 56 & 1.85 & & $2.59 ?$ & .512321 & .17072 & & & -.13 & -6.2 & -1.9 & $1.3_{\text {est }}$ & & 5 \\
\hline $\begin{array}{l}473 \\
\text { dia }\end{array}$ & $\begin{array}{l}\text { Pimentel } \\
\text { (dados inéd.) }\end{array}$ & $\mid \overline{B 101}$ & BAS & $\sqrt{7}$ & 1.90 & & 2.25 & .511764 & .12678 & & & -.36 & -17.0 & -5.5 & $1.3_{\text {est }}$ & & 5 \\
\hline $\begin{array}{l}474 \\
\mathrm{~m} \cdot \mathrm{gab}\end{array}$ & $\begin{array}{l}\text { Pimentel } \\
\text { (dados inéd.) }\end{array}$ & DATO1 & BAS & 18 & 0.74 & & 1.35 & .512335 & .13382 & & & -.32 & -5.9 & 4.5 & 1.3 est & & 5 \\
\hline $\begin{array}{l}-a-1 \\
\text { grt }\end{array}$ & $1622 / 5102$ & $\begin{array}{l}\text { MP 487D I } \\
\text { lporá }\end{array}$ & GTD & K1 & 0.95 & $1.22^{\# 2}$ & 2.01 & $\begin{array}{l}.512478 \\
.000022\end{array}$ & .17094 & 8.0 & 28.3 & -.13 & -3.1 & -1.5 & $\begin{array}{l}.49 \mathrm{R} b / \mathrm{sr} \\
.7047_{\mathrm{d}}\end{array}$ & 10.9 & 3 \\
\hline grt & $1615 / 5101$ & $\begin{array}{l}\text { MP481 A / } \\
\text { Iporá }\end{array}$ & GTD & $\mathrm{K} 2$ & 0.52 & & 1.01 & $\begin{array}{l}.512329 \\
.000019\end{array}$ & .10590 & 10.0 & 57.1 & -.46 & -6.0 & -.35 & $\begin{array}{l}.49_{\mathrm{R} b / \mathrm{Sr}} \\
.7047_{\mathrm{d}}\end{array}$ & & 3 \\
\hline grt & $1622 / 5102$ & $\begin{array}{l}\text { MP 487B / } \\
\text { lporá }\end{array}$ & GTD & K3 & -0.55 & $1.19^{\# 2}$ & --- & $\begin{array}{l}.512608 \\
.000020\end{array}$ & .20498 & 8.0 & 23.6 & -.04 & -0.6 & -1.1 & $\begin{array}{l}.49_{\mathrm{R} b / \mathrm{Sr}} \\
.7047_{\mathrm{d}}\end{array}$ & & 3 \\
\hline grt & $1620 / 5104$ & $\begin{array}{l}\text { MP541/ } \\
\text { pporá }\end{array}$ & GTD & $\mathrm{K} 4$ & 0.79 & & 1.24 & $\begin{array}{l}.512172 \\
.000020 \\
\end{array}$ & .10638 & 17.1 & 97.2 & -.46 & -9.1 & -3.5 & $\begin{array}{l}.49_{\mathrm{R} \mathrm{b} / \mathrm{Sr}} \\
.7047_{\mathrm{d}}\end{array}$ & & 3 \\
\hline
\end{tabular}




\begin{tabular}{|c|c|c|c|c|c|c|c|c|c|c|c|c|c|c|c|c|c|}
\hline $\begin{array}{l}--1 \\
\text { grt }\end{array}$ & $1620 / 5106$ & $\begin{array}{l}\text { MP544| } \\
\text { Iporáa }\end{array}$ & GTD & $\mathrm{K} 5$ & 0.43 & & 1.03 & $\begin{array}{l}.512431 \\
.000020\end{array}$ & .12263 & 11.6 & 57.2 & -.38 & -4.0 & +0.6 & $\begin{array}{l}.49_{\mathrm{R} \mathrm{b} / \mathrm{Sr}} \\
.7047_{\mathrm{d}}\end{array}$ & & 3 \\
\hline $\begin{array}{l}--1 \\
\text { grt }\end{array}$ & $1625 / 5148$ & $\begin{array}{l}\text { MP437A / } \\
\text { Serra Negra }\end{array}$ & GTD & L1 & 0.80 & & 1.32 & $\begin{array}{l}.512235 \\
.000018\end{array}$ & $: 12019$ & 9.6 & 48.3 & -.39 & -7.9 & -2.9 & $\begin{array}{l}.51_{\mathrm{Rb} / \mathrm{Sr}} \\
.7130_{\mathrm{d}}\end{array}$ & 129 & 3 \\
\hline grt & $1626 / 5148$ & $\begin{array}{l}\text { MP448B / } \\
\text { Serra Negra }\end{array}$ & GTD & L2 & 0.99 & $1.37^{* 2}$ & 1.61 & $\begin{array}{l}.512282 \\
.000020\end{array}$ & .14192 & 6.9 & 29.4 & -.28 & -6.9 & -3.4 & $\begin{array}{l}.51 \mathrm{Rb} / \mathrm{Sr} \\
.7130_{\sigma}\end{array}$ & & 3 \\
\hline grt & $1625 / 5148$ & $\begin{array}{l}\text { MP437E / } \\
\text { Serra Negra }\end{array}$ & GTD & L3 & 1.19 & $1.40^{42}$ & 1.85 & $\begin{array}{l}.512288 \\
.000020\end{array}$ & .15172 & 7.0 & 27.9 & -.23 & -6.8 & -3.9 & $\begin{array}{l}.51 \mathrm{R} \mathrm{b} / \mathrm{Sr} \\
7130_{\mathrm{d}}\end{array}$ & & 3 \\
\hline grt & $1623 / 5140$ & $\begin{array}{l}\text { MP } 433 \mathrm{C} / \\
\text { Serra do Iran }\end{array}$ & GTD & M1 & 0.41 & & 0.94 & $\begin{array}{l}.512400 \\
.000021\end{array}$ & .10854 & 7.0 & 39.0 & -.45 & -4.6 & +2.0 & $\begin{array}{l}.59 \mathrm{R} \mathrm{b} / \mathrm{Sr} \\
.7044_{\mathrm{d}}\end{array}$ & & 3 \\
\hline grt & $1620 / 5139$ & $\begin{array}{l}\text { MP 440A / } \\
\text { Serra do Iran }\end{array}$ & GTD & M2 & 0.85 & & 1.37 & $\begin{array}{l}.512228 \\
.000021\end{array}$ & .12291 & 2.5 & 12.3 & -.38 & -8.0 & -2.4 & $\begin{array}{l}.59 \mathrm{R} \mathrm{d} / \mathrm{sr} \\
.7044\end{array}$ & & 3 \\
\hline $\begin{array}{l}-1 \\
\text { grt }\end{array}$ & $1622 / 5142$ & $\begin{array}{l}\text { MP } 430 / \\
\text { Serra do Iran }\end{array}$ & GTD & M3 & 0.49 & & 0.98 & .512340 & .10356 & 11.2 & 65.4 & -.47 & -5.8 & +1.2 & $\begin{array}{l}.59_{\mathrm{R} \mathrm{b} / \mathrm{Sr}} \\
.7044_{\mathrm{d}} \\
\end{array}$ & & 3 \\
\hline grt & $1623 / 5140$ & $\begin{array}{l}\text { MP434/ } \\
\text { Serra do Iran }\end{array}$ & GTD & M4 & 0.50 & & 1.01 & $\begin{array}{l}.512352 \\
.000019\end{array}$ & .10850 & 8.2 & 45.7 & -.45 & -5.6 & +1.1 & $\begin{array}{l}.59 \mathrm{R} \mathrm{b} / \mathrm{Sr} \\
.7044_{\mathrm{d}}\end{array}$ & & 3 \\
\hline $\begin{array}{l}\text { gns } \\
\text { gns }\end{array}$ & $1630 / 5138$ & $\begin{array}{l}\text { MP 343A / } \\
\text { Ribeirão }\end{array}$ & GTD & N1 & 0.77 & $1.46^{\# 2}$ & 1.60 & $\begin{array}{l}.512429 \\
.000018\end{array}$ & .15539 & 6.938 & 27.00 & -.21 & -4.1 & +2.2 & 1.2 & & 2 \\
\hline $\begin{array}{l}-1 \\
\text { gns }\end{array}$ & $1630 / 5138$ & $\begin{array}{l}\text { MP3431/ } \\
\text { Ribeirão }\end{array}$ & GTD & N2 & 2.95 & & 3.11 & $\begin{array}{l}.510735 \\
.000020\end{array}$ & .09913 & 4.713 & 28.75 & -.50 & -37.1 & -22 & $\begin{array}{l}1.2 \mathrm{Rb} / \mathrm{Sr} \\
.705 \\
\end{array}$ & 27 & 2 \\
\hline gns & $1630 / 5138$ & $\begin{array}{l}\text { MP343D I } \\
\text { Ribeirão }\end{array}$ & GTD & N3 & 2.71 & & 2.88 & $\begin{array}{l}.510724 \\
.000020\end{array}$ & .08985 & 10.3 & 69.32 & -.54 & -37.3 & -21 & $\begin{array}{l}1.2 \mathrm{Rb} / \mathrm{si} \\
.705_{\mathrm{c}}\end{array}$ & & 2 \\
\hline $\begin{array}{l}\text { gns } \\
-1\end{array}$ & $1630 / 5138$ & $\begin{array}{l}\text { MP343E / } \\
\text { Ribeirão }\end{array}$ & GTD & N4 & 2.68 & & 2.84 & $\begin{array}{l}.510672 \\
.000020 \\
\end{array}$ & .08536 & 16.29 & 115.4 & -.57 & -38.4 & -21 & $\begin{array}{l}1.2_{\mathrm{Ro} / \mathrm{s}} \\
.705_{\mathrm{c}}\end{array}$ & & 2 \\
\hline $\begin{array}{l}-1 \\
\text { gns }\end{array}$ & $1630 / 5138$ & $\begin{array}{l}\text { MP343B / } \\
\text { Ribeirão }\end{array}$ & GTD & N5 & 3.34 & & 3.48 & $\begin{array}{l}.510862 \\
.000020\end{array}$ & .11629 & 12.04 & 62.61 & -.41 & -34.6 & -22 & $\begin{array}{l}1.2 \mathrm{Rb} / \mathrm{Sr} \\
.705_{\mathrm{C}}\end{array}$ & & 2 \\
\hline gns & $1630 / 5138$ & $\begin{array}{l}\text { MP343C / } \\
\text { Ribeirão }\end{array}$ & GTD & N6 & 3.21 & & 3.36 & $\begin{array}{l}.510815 \\
.000021\end{array}$ & .11089 & 10.77 & 58.73 & -.44 & -35.6 & -22 & $\begin{array}{l}1.2 \mathrm{Rb} / \mathrm{Sr} \\
.705\end{array}$ & & 2 \\
\hline gns & $1630 / 5138$ & $\begin{array}{l}\text { MP343G / } \\
\text { Ribeirão }\end{array}$ & $\overline{\text { GTD }}$ & N7 & 3.71 & $3.31^{\# 2}$ & $3.83 ?$ & $\begin{array}{l}.510880 \\
.000017 \\
\end{array}$ & .12506 & 11.61 & 56.14 & -.36 & -34.3 & -23 & $\begin{array}{l}1.2 \mathrm{Rb} / \mathrm{Sr} \\
.705_{\mathrm{C}}\end{array}$ & & 2 \\
\hline $\begin{array}{l}\text {-- } \\
\text { gns }\end{array}$ & $1630 / 5138$ & $\begin{array}{l}\text { MP343/1 } \\
\text { Ribeirão }\end{array}$ & GTD & N8 & 3.02 & & 3.17 & .510719 & .10042 & 13.37 & 80.51 & -.49 & -37.3 & -23 & $\begin{array}{l}1.2 \mathrm{Rb} / \mathrm{st} \\
.705_{\mathrm{C}}\end{array}$ & & 2 \\
\hline $\begin{array}{l}\text { gns } \\
\text { gns }\end{array}$ & $1630 / 5138$ & $\begin{array}{l}\text { MP343L / } \\
\text { Ribeiräo }\end{array}$ & GTD & N9 & 2.68 & & 2.86 & $\begin{array}{l}.510857 \\
.000020\end{array}$ & .09595 & 3.808 & 24.00 & -.51 & -34.7 & -19 & $\begin{array}{l}1.2_{\mathrm{R} b / \mathrm{s}} \\
705_{\mathrm{C}}\end{array}$ & & 2 \\
\hline gns & $1625 / 5136$ & $\begin{array}{l}\text { MP557C / } \\
\text { Arenópolis }\end{array}$ & GTD & 01 & 0.75 & & 1.17 & $\begin{array}{l}.512146 \\
.000021\end{array}$ & .09635 & .427 & 2.68 & -.51 & -9.6 & +.9 & $\begin{array}{l}.82 \mathrm{Rb} / \mathrm{sr} \\
.7042_{\mathrm{b}} \\
\end{array}$ & 9.3 & 1 \\
\hline
\end{tabular}




\begin{tabular}{|c|c|c|c|c|c|c|c|c|c|c|c|c|c|c|c|c|c|}
\hline $\begin{array}{l}\text { gns } \\
\text { gns }\end{array}$ & $1625 / 5136$ & $\begin{array}{l}\text { MP557M I } \\
\text { Arenópolis }\end{array}$ & GTD & $\mathrm{O} 2$ & 0.71 & & 1.18 & $\begin{array}{l}.512219 \\
.000020\end{array}$ & .10721 & 2.865 & 16.16 & -.45 & -8.2 & +1.2 & $\begin{array}{l}0.82_{\mathrm{Rb} / \mathrm{Sr}} \\
.7042_{\mathrm{b}}\end{array}$ & & 1 \\
\hline gns & $1626 / 5136$ & $\begin{array}{l}\text { MP154M/ } \\
\text { Arenópolis }\end{array}$ & GTD & 03 & 0.67 & & 1.07 & $\begin{array}{l}.512164 \\
.000020\end{array}$ & 08847 & 2.935 & 20.06 & -.55 & -9.2 & +2.1 & $\begin{array}{l}.82 \mathrm{Ri} / \mathrm{Sr} \\
.7042_{\mathrm{b}}\end{array}$ & & 1 \\
\hline $\begin{array}{l}--1 \\
\text { m.vul }\end{array}$ & $1628 / 5137$ & $\begin{array}{l}\text { MP 64/ } \\
\text { Arenópolis }\end{array}$ & BAS & P1 & 2.43 & $1.0^{74}$ & $-7 ?$ & $\begin{array}{l}.513204 \\
.000025\end{array}$ & .23197 & 1.371 & 3.574 & .18 & 11.0 & +6.9 & $\begin{array}{l}.93 \mathrm{RD} / \mathrm{sr} \\
.7035_{\mathrm{b}}\end{array}$ & 1.2 & 1 \\
\hline $\begin{array}{l}--1 \\
\text { m.vul }\end{array}$ & $1630 / 5135$ & $\begin{array}{l}\text { MP 235A / } \\
\text { Arenópolis }\end{array}$ & $\overline{B A S}$ & P2 & 0.42 & & 1.41 & $\begin{array}{l}.512536 \\
.000020\end{array}$ & .15928 & 2.50 & 9.491 & -.19 & -2.0 & +2.4 & $\begin{array}{l}.93 \text { Ro/sr } \\
.7035_{\mathrm{b}}\end{array}$ & & 1 \\
\hline $\begin{array}{l}--1 \\
m . v u l\end{array}$ & $1630 / 5136$ & $\begin{array}{l}\text { MP } 3361 \\
\text { Arenöpolis }\end{array}$ & BAS & $\mathrm{P3}$ & -1.0 & & 1.15 & $\begin{array}{l}.512770 \\
.000024\end{array}$ & .17771 & 1.564 & 5.322 & -.10 & +2.6 & +4.8 & $\begin{array}{l}.93 \mathrm{Rb} / \mathrm{s} \\
.7035_{\mathrm{b}}\end{array}$ & & 1 \\
\hline $\begin{array}{l}--1 \\
\text { m.vul }\end{array}$ & $(+)$ & $\begin{array}{l}\text { MP334A I } \\
\text { Arenópolis }\end{array}$ & BAS & P4 & -0.89 & & 0.95 & $\begin{array}{l}.512784 \\
.000019\end{array}$ & .17160 & 1.924 & 6.78 & -.13 & 2.8 & +5.8 & $\begin{array}{l}.93 \mathrm{Ro} / \mathrm{Sr} \\
.7035 \mathrm{~b}\end{array}$ & & 1 \\
\hline gns & $1630 / 5055$ & \begin{tabular}{|l|} 
VIS572B / \\
Matrin:xã
\end{tabular} & GTD & Q1 & 0.24 & & 0.85 & $\begin{array}{l}.512514 \\
.000021\end{array}$ & .11795 & 5.319 & 27.27 & -.40 & -2.4 & +6.6 & $\begin{array}{l}.90 \mathrm{Rb} / \mathrm{Sr} \\
.7025 \\
\end{array}$ & -14 & 1 \\
\hline gns & $1630 / 5055$ & \begin{tabular}{|l|} 
VIS $572 \mathrm{FI}$ \\
Matrinxã
\end{tabular} & GTD & Q2 & 0.26 & & 0.89 & $\begin{array}{l}.512513 \\
.000020\end{array}$ & .12188 & 5.458 & 27.08 & -.38 & -2.4 & +6.2 & $\begin{array}{l}.90_{\text {Rers }} \\
.7025_{\mathrm{b}} \\
\end{array}$ & & 1 \\
\hline gns & $1630 / 5055$ & \begin{tabular}{|l|} 
VIS567P I \\
Matrinxã
\end{tabular} & GTD & Q3 & 0.48 & & 1.04 & $\begin{array}{l}.512385 \\
.000022\end{array}$ & .11699 & 3.165 & 16.36 & -.41 & -4.9 & +4.2 & $\begin{array}{l}0.9_{\mathrm{Rb} / \mathrm{Sr}} \\
.7025_{\mathrm{b}}\end{array}$ & & 1 \\
\hline gns & $(\div)$ & $\begin{array}{l}\text { MP 590D / } \\
\text { Sancleriândia }\end{array}$ & GTD & R1 & 0.18 & & 0.91 & $\begin{array}{l}.512564 \\
.000030 \\
\end{array}$ & .13252 & 3.068 & 14.0 & -.33 & -1.4 & +6.3 & $\begin{array}{l}.94 \mathrm{Rb} / \mathrm{Sr} \\
.7024_{\mathrm{b}}\end{array}$ & -14 & 1 \\
\hline $\begin{array}{l}--1 \\
\text { gns }\end{array}$ & $(+)$ & $\begin{array}{l}\text { MP590F I } \\
\text { Sancleriândia }\end{array}$ & GTD & $R 2$ & 0.39 & & 1.09 & $\begin{array}{l}.512480 \\
.000019\end{array}$ & .13458 & 3.316 & 14.9 & -.32 & -3.1 & +4.4 & $\begin{array}{l}.94 \mathrm{Rb} / \mathrm{Sr} \\
.7024 \mathrm{~b}\end{array}$ & & 1 \\
\hline gns & $(+)$ & $\begin{array}{l}\text { MP590C / } \\
\text { Sanclerlândia }\end{array}$ & GTD & R3 & 0.30 & & 1.02 & .512519 & .13532 & 3.144 & 14.050 & -.31 & 2.3 & +5.0 & $\begin{array}{l}.94 \mathrm{Rb} / \mathrm{s} \\
.7024\end{array}$ & & 1 \\
\hline m.rio & $16 \quad 12 / 5047$ & $\begin{array}{l}\text { MP489C / } \\
\text { Fazenda Nova }\end{array}$ & VAC & S1 & 0.58 & & 1.14 & $\begin{array}{l}.512354 \\
.000018 \\
\end{array}$ & .12137 & 9.919 & 49.42 & -.38 & -5.5 & +0.3 & $\begin{array}{l}.61 \mathrm{Rb} / \mathrm{St} \\
.7032 \mathrm{~b}\end{array}$ & -8.4 & 1 \\
\hline $\begin{array}{l}m-1 \\
m . r i o\end{array}$ & $1612 / 5047$ & $\begin{array}{l}\text { MP489F I } \\
\text { Fazenda Nova }\end{array}$ & $\overline{V A C}$ & S2 & 0.38 & & 0.93 & $\begin{array}{l}.512427 \\
.000023\end{array}$ & .11247 & 16.06 & 86.35 & -.43 & -4.1 & +2.4 & $\begin{array}{l}.61 \mathrm{Rb} / \mathrm{Sr} \\
.7032 \mathrm{~g}\end{array}$ & & 1 \\
\hline $\begin{array}{l}m-1 \\
m . r i o\end{array}$ & $1620 / 5056$ & $\begin{array}{l}\text { VIS556l / } \\
\text { Jaupaci }\end{array}$ & $\overline{V A C}$ & $\mathrm{T1}$ & 0.17 & & 0.93 & $\begin{array}{l}.512568 \\
.000022 \\
\end{array}$ & .13504 & 7.271 & 32.56 & -.31 & -1.4 & +3.3 & $\begin{array}{l}.59_{\mathrm{Ro} / \mathrm{s}} \\
.7052_{\mathrm{b}} \\
\end{array}$ & 19.7 & 1 \\
\hline $\begin{array}{l}m-1 \\
\text { m.rio }\end{array}$ & $1620 / 5056$ & $\begin{array}{l}\text { VIS556/ / } \\
\text { Jaupaci }\end{array}$ & VAC & T2 & 0.36 & & 0.98 & $\begin{array}{l}.512465 \\
.000022\end{array}$ & .12295 & 3.80 & 18.69 & -.37 & -3.4 & +2.2 & $\begin{array}{l}.59 \mathrm{Rb} / \mathrm{sr}_{\mathrm{r}} \\
.7052_{\mathrm{b}}\end{array}$ & & 1 \\
\hline $\begin{array}{l}--1 \\
\text { grt.sv }\end{array}$ & $1620 / 5056$ & $\begin{array}{l}\text { VIS267F I } \\
\text { Jaupaci }\end{array}$ & GTD & T3 & 0.27 & & 0.96 & $\begin{array}{l}.512521 \\
.000020\end{array}$ & .13027 & 10.78 & 50.04 & -.34 & -2.3 & +3.1 & $\begin{array}{l}.64 \mathrm{Rb} / \mathrm{sr} \\
.7032_{\mathrm{b}}\end{array}$ & -7.9 & 1 \\
\hline $\begin{array}{l}\text { grt.sv } \\
\text { grt }\end{array}$ & $1620 / 5056$ & $\begin{array}{l}\text { VIS267C/ } \\
\text { Jaupaci }\end{array}$ & GTD & T4 & 0.24 & & 0.95 & $\begin{array}{l}.512536 \\
.000019 \\
\end{array}$ & .13141 & 10.97 & 50.48 & -.33 & -2.0 & +3.3 & $\begin{array}{l}.64 \mathrm{Rb} / \mathrm{Sr} \\
.7032_{\mathrm{b}}\end{array}$ & & 1 \\
\hline & & & & & & & & & & & & & & & & & \\
\hline
\end{tabular}




\begin{tabular}{|c|c|c|c|c|c|c|c|c|c|c|c|c|c|c|c|c|c|}
\hline $\begin{array}{l}--1 \\
\text { grt }\end{array}$ & $1622 / 5135$ & $\begin{array}{l}\text { MP 446/ } \\
\text { Caiapó }\end{array}$ & GTD & U1 & 0.83 & & 1.23 & $\begin{array}{l}.512078 \\
.000020\end{array}$ & .09438 & 2.7 & 17.3 & -.52 & -10.9 & -3.2 & $\begin{array}{l}.59 \mathrm{R} \mathrm{b} / \mathrm{St} \\
.7047_{\mathrm{d}}\end{array}$ & 12.6 & 3 \\
\hline $\begin{array}{l}\text { grt } \\
\text { grt }\end{array}$ & $(+)$ & $\begin{array}{l}\text { MP 495A I } \\
\text { Caiapó }\end{array}$ & GTD & U2 & 0.46 & & 0.93 & $\begin{array}{l}.512344 \\
.000016\end{array}$ & .09876 & 6.5 & 39.8 & -.50 & -5.7 & +1.6 & $\begin{array}{l}.59_{\mathrm{R} b / \mathrm{sr}} \\
.7047_{\mathrm{d}}\end{array}$ & & 3 \\
\hline grt & $1622 / 5135$ & $\begin{array}{l}\text { MP 461A / } \\
\text { Caiapó }\end{array}$ & GTD & U3 & 0.81 & & 1.18 & $\begin{array}{l}.512040 \\
.000020 \\
\end{array}$ & .08385 & 5.2 & 37.5 & -.57 & -11.7 & -3.2 & $\begin{array}{l}.59_{\mathrm{R} b / \mathrm{s}} \\
.7047_{\mathrm{d}}\end{array}$ & & 3 \\
\hline grt & $1622 / 5135$ & $\begin{array}{l}\text { MP 461C / } \\
\text { Caiapó }\end{array}$ & GTD & U4 & 0.97 & & 1.32 & $\begin{array}{l}.511922 \\
.000019\end{array}$ & .08425 & 4.5 & 32.3 & -.57 & -14.0 & -5.5 & $\begin{array}{l}.59_{\mathrm{R}} \mathrm{d} / \mathrm{Si} \\
.7047_{\mathrm{d}}\end{array}$ & & 3 \\
\hline $\begin{array}{l}--1 \\
\text { grt }\end{array}$ & $1623 / 5137$ & $\begin{array}{l}\text { MP 444| / } \\
\text { Caiapó }\end{array}$ & GTD & U5 & 0.61 & & 1.02 & $\begin{array}{l}.512197 \\
.000020 \\
\end{array}$ & .08677 & 3.2 & 22.3 & -.56 & -8.6 & -0.3 & $\begin{array}{l}.59_{\mathrm{R}} \mathrm{b} / \mathrm{st} \\
.7047_{\mathrm{d}}\end{array}$ & & 3 \\
\hline grt & $1618 / 5053$ & $\begin{array}{l}\text { MP 488C I } \\
\text { Israelândia }\end{array}$ & GTD & V1 & 0.23 & & 0.93 & $\begin{array}{l}.512537 \\
.000022\end{array}$ & .13010 & 12.5 & 58.1 & -.34 & -2.0 & +2.7 & $\begin{array}{l}.55_{\mathrm{R} \mathrm{b} / \mathrm{sr}} \\
.7047_{\mathrm{d}}\end{array}$ & 1.9 & 3 \\
\hline $\begin{array}{l}--1 \\
\text { grt }\end{array}$ & $1618 / 5053$ & $\begin{array}{l}\text { MP 478A / } \\
\text { Israelândia }\end{array}$ & GTD & V2 & 0.17 & & 0.84 & $\begin{array}{l}.512556 \\
.000019\end{array}$ & .12485 & 11.5 & 55.7 & -.37 & -1.6 & +3.4 & $\begin{array}{l}.55 \mathrm{R} \mathrm{b} / \mathrm{sr} \\
.7047_{\mathrm{d}}\end{array}$ & & 3 \\
\hline $\begin{array}{l}--1 \\
\text { grt }\end{array}$ & $1618 / 5053$ & $\begin{array}{l}\text { MP 478D / } \\
\text { Israelândia }\end{array}$ & GTD & V3 & 1.86 & $1.23^{\# 2}$ & $3.38 ?$ & $\begin{array}{l}.512561 \\
.000019\end{array}$ & .19042 & 7.4 & 23.5 & -.03 & -1.5 & -1.1 & $\begin{array}{l}.55_{\mathrm{R} b / \mathrm{St}} \\
.7047_{\mathrm{d}}\end{array}$ & & 3 \\
\hline gns & $1553 / 5021$ & $\begin{array}{l}\text { MP 581LI } \\
\text { Uvá }\end{array}$ & GTD & $\mathrm{X} 1$ & 3.14 & & 3.30 & $\begin{array}{l}.510942 \\
.000019 \\
\end{array}$ & .1148 & 2.63 & 13.85 & -.42 & -33.1 & -6.3 & $\begin{array}{l}2.56_{\mathrm{Rb} / \mathrm{Se}} \\
.7017_{\mathrm{j}}\end{array}$ & 3.2 & 7 \\
\hline gns & $1553 / 5021$ & $\begin{array}{l}\text { MP581F / } \\
\text { Uvá }\end{array}$ & GTD & $\mathrm{X} 2$ & 2.93 & & 3.10 & $\begin{array}{l}.510963 \\
.000016\end{array}$ & .1101 & 2.65 & 14.55 & -.44 & -32.7 & -4.4 & 3 & $"$ & 7 \\
\hline gns & $1553 / 5021$ & $\begin{array}{l}\text { MP 581G I } \\
\text { Uvá }\end{array}$ & GTD & $\times 3$ & 2.90 & & 3.09 & $\begin{array}{l}.511095 \\
.000016\end{array}$ & .1161 & 2.61 & 13.59 & -.41 & -30.1 & -3.8 & 3 & $"$ & 7 \\
\hline gns & $15.53 / 5021$ & $\begin{array}{l}\text { MP581B I I } \\
\text { Uvá }\end{array}$ & GTD & $\times 4$ & 3.40 & & 3.55 & $\begin{array}{l}.510995 \\
.000023\end{array}$ & .1237 & 2.87 & 14.03 & -.37 & -32.0 & -8.2 & 4 & " & 7 \\
\hline grt & $1555 / 5530$ & MP 578A I & GTD & $Y 1$ & 2.79 & & 3.03 & $\begin{array}{l}.511486 \\
.000020\end{array}$ & .1342 & .438 & 1.974 & -.32 & -22.5 & 0.3 & $\begin{array}{l}2.85_{\mathrm{Sm} / \mathrm{Nd}} \\
\varepsilon_{\mathrm{Nd}}=0.3\end{array}$ & & 7 \\
\hline grt & $1555 / 5530$ & MP 579A I & GTD & $Y 2$ & 2.83 & & 3.01 & $\begin{array}{l}.511030 \\
.000024\end{array}$ & .1105 & .237 & 1.297 & -.44 & -31.4 & 0 & 4 & & 7 \\
\hline grt & $1555 / 5530$ & MP 5780 I & GTD & Y3 & 2.81 & & 3.05 & $\begin{array}{l}.511513 \\
.000020\end{array}$ & .1360 & .655 & 2.912 & -.31 & -21.9 & 0.1 & $"$ & & 7 \\
\hline grt & $1550 / 5044$ & MP 57 $\overline{4 A}$ & GTD & W1 & 1.92 & & 2.16 & $\begin{array}{l}.511289 \\
.000020\end{array}$ & .0897 & 4.45 & 30.01 & -.54 & -26.3 & -16 & $\begin{array}{l}0.76 \mathrm{Rb} / \mathrm{sr} \\
.70525\end{array}$ & 23 & 7 \\
\hline grt & $1550 / 5044$ & MP 574C / & GTD & W2 & 1.99 & & 2.23 & $\begin{array}{l}.511235 \\
.000019\end{array}$ & .0896 & 4.16 & 28.06 & -.54 & -27.4 & -17 & $"$ & $"$ & 7 \\
\hline grt & $1550 / 5044$ & MP 575A / & GTD & W3 & 2.09 & & 2.31 & $\begin{array}{l}.511130 \\
.000017\end{array}$ & .0869 & 3.00 & 20.88 & -.56 & -29.4 & -19 & 4 & " & 7 \\
\hline & & & & & & & & & & & & & & & & & \\
\hline
\end{tabular}




\begin{tabular}{|c|c|c|c|c|c|c|c|c|c|c|c|c|c|c|c|c|}
\hline grt & $1550 / 5044$ & MP 575B / & GTD & W4 & 1.75 & 2.00 & $\begin{array}{l}.511313 \\
.000019\end{array}$ & .0815 & 3.73 & 27.68 & -.59 & -25.8 & -15 & " & " & 7 \\
\hline gns & $1552 / 5047$ & MP 573A / & GTD & 21 & 2.29 & 2.49 & $\begin{array}{r}.510908 \\
.000021 \\
\end{array}$ & .0822 & 5.17 & 38.04 & -.58 & -33.7 & 4.2 & $\begin{array}{l}2.60_{\mathrm{Rb} / \mathrm{Sr}} \\
.70156_{\mathrm{i}}\end{array}$ & 1.8 & 7 \\
\hline gns & $1552 / 5047$ & MP 5738I & GTD & 22 & 2.35 & 2.55 & $\begin{array}{l}.510958 \\
.000019\end{array}$ & .0883 & 4.43 & 30.33 & -.55 & -32.8 & 3.2 & $"$ & $"$ & 7 \\
\hline gns & $1552 / 5047$ & MP $576 /$ & GTD & $\mathrm{Z2}$ & 2.23 & 2.44 & $\begin{array}{r}.510980 \\
.000021 \\
\end{array}$ & .0840 & 3.29 & 23.69 & -.57 & -32.3 & 5.0 & " & " & 7 \\
\hline muvil & $-169 / 5010$ & $\begin{array}{l}\text { MP 593E } / \\
\text { Mossâmedes }\end{array}$ & VAC & $2 A$ & 1.97 & 2.22 & $\begin{array}{l}.511353 \\
.000024\end{array}$ & .0975 & 11.72 & 72.70 & -.50 & -25.1 & 0.0 & $\begin{array}{l}1.98 \mathrm{Rb} / \mathrm{s} \\
.70232_{\mathrm{i}}\end{array}$ & 2.1 & 7 \\
\hline muvi & $\sim 169 / 5010$ & $\begin{array}{l}\text { MP } 5931 / \\
\text { Mossâmedes }\end{array}$ & VAC & $\mathrm{ZB}$ & 1.99 & 2.24 & $\begin{array}{l}.511350 \\
.000020\end{array}$ & .0983 & 10.78 & 66.30 & -.50 & -25.1 & -0.3 & $"$ & $"$ & 7 \\
\hline gns & $\sim 1550 / 502$ & $\begin{array}{l}\text { MP 583F/ } \\
\text { Goiás }\end{array}$ & GTD & $\mathrm{ZC}$ & 2.91 & 3.06 & $\begin{array}{l}.510580 \\
.000019\end{array}$ & .0894 & 2.73 & 18.46 & -.55 & -40.1 & -13 & $(2,0)_{\text {est }}$ & -- & 7 \\
\hline
\end{tabular}

ver nota explicativa da tabela no apêndice 1 .

coordenadas $(+) \rightarrow->$ amostras situadas entre $15^{\circ} 40^{\prime}$ a $16^{\circ} 40^{\prime} / 50^{\circ} 30^{\prime}$ a $52^{\circ} 00^{\prime}$.litol. $\rightarrow>$ dia=diabásio, grt= granito,

referências para idades $\mathrm{Rb} / \mathrm{Sr}$ : $a=$ Tassinari $1983, b=$ Pimentel et. al 1992, $c=$ Pimentel 1992 (recalculado para este trabalho), $d=$ Pimentel e Charnley 1991, e = Tassinari 1982, $\mathrm{f}=$ Tassinari e Montalvão 1980, $\mathrm{g}=$ Montalvão $1985, \mathrm{~h}=$ Pimentel e Junges $-1997, \mathrm{i}$ $=$ Pimentel et. al 1996, est $=$ idadede formação estimada.

referências para dados isotópicos Sm-Nd: $n t=$ neste trabalho, $1=$ Pimentel et. al 1992, $2=$ Pimentel $1992,3=$ Pimentel e Charnley 1991, 4 = Hardi dados inéditos, $5=$ Pimente dados inéditos, $6=$ Pimentel e Junges $-1997,7=$ Pimentel et. al. 1996. (As idades modelos foram todos recalculados para este trabalho).

Obs. \#2 = estágio duplo com ${ }^{147} \mathrm{Sm} /{ }^{144} \mathrm{Nd}(\mathrm{t})=0,11 ; \# 4=0.15$ (média das amostras $\mathrm{B} 1$ a $\mathrm{B} 5$ ); \# = não determinados devido teores de Sm e Nd muito baixo 


\subsection{0: - DOMÍNIO URUAÇU}

\subsection{0 - 1 SINTÉSE GEOLÓGICA}

O termo Dominio Uruaçu aqui empregado, compreende os Complexos de Barro Alto, Canabrava e Niquelândia e os Grupos Serra da Mesa e Arai (Fig.5.9-2). Este domínio é balizado por terrenos que integram a sul a inflexão de Pirineus, a oeste o Complexo Goiás Central, a leste o Dominio Brasilia e a norte a Província Borborema.

Os dados geocronológicos pré-existentes deste dominio podem ser resumidos da seguinte forma :

COMPlEXo bARRO Alto - Os dados disponiveis, obtidos em rochas granulíticas de natureza máfica, bem como em rochas gnáissicas, totalizam 5 isócronas com idades de formação relativas ao Mesoproterozóico, entre 1,33Ga e $1.2 \mathrm{Ga}$, com razões iniciais (RI) entre 0,708 a 0,733 (Fuck et. al. 1989);

GRUPOS SERRA DA MESA E ARAí - Nas vizinhanças de Nova Roma, as rochas metavulcânicas pertencente ao Grupo Araí apresentaram idades $\mathrm{Rb}-\mathrm{Sr}$ de 1,17 Ga (RI=0,710; Hasui et. al. 1980), e as rochas graniticas idades isocrônicas $\mathrm{Rb}-\mathrm{Sr}$ de 1,23 $\mathrm{Ga}(\mathrm{RI}=0,705$; Reis Neto, 1980). Análises Rb-Sr adicionais, quando plotadas em conjunto com os dados obtidos por Reis Neto (op. cit.), indicaram duas tendências de alinhamento: uma de idade Paleoproterozóica (2,0Ga; RI=0,704) e outra Mesoproterozóica (1,20Ga, RI=0,278; Tassinari et. al., 1981).

REGIÃO DE NATIVIDADE: Os dados disponiveis $\mathrm{Rb}$-Sr para a região referem-se a rochas graniticas com idades de formação relativas ao Paleoproterozóico (Ciclo Transamazônico, Tassinari et. al., 1981).

COMPLEXO NIQUELÂNDIA - As primeiras datações $\mathrm{Rb}-\mathrm{Sr}$ obtidas em rochas gnáissicas desta região indicaram idades relativas ao Neoproterozóico (Ciclo Brasiliano) com valores próximos a $0,76 \mathrm{Ga}(\mathrm{RI}=0,706$; Tassinari, et. $\mathrm{al}, 1981)$ interpretados como relativos à época do metamorfismo regional. Rochas granodioriticas deste setor indicaram idades isocrônicas $\mathrm{Rb}-\mathrm{Sr}$ de 1,3Ga (RI=0,713; Bizzi, 1993), sugerindo terem se formado durante o Mesoproterozóico. Datações U-Pb obtidas em zircões de rochas granodioríticas acusaram idades entre 1,56 e 1,60Ga (Ferreira Filho et. al, 1996), caracterizando um evento magmático do no Mesoproterozóico. Adicionalmente foram analisados zircões provenientes de rochas básicas do Maciço de Niquelândia utilizando-se técnica do SHRIMP. Os dados obtidos distribuiram-se entre 2,0Ga (intercepto superior) e 0,78Ga (intercepto inferior), com populações intermediárias, 
sugerindo idades proximas de $0,85 \mathrm{Ga}, 1,2 \mathrm{Ga}$ e 1,7Ga (Correia et. al, 1996). Tais valores foram interpretados pelos autores da seguinte forma: - Aqueles próximos à 2,0Ga como relativos à época de colocação das rochas máficas, e os demais interpretados como relativos a perdas episódicas de $\mathrm{Pb}$, resultantes de múltiplos eventos metamórficos (Uruaçuano e Brasiliano).

COMPLEXO CANABRAVA - As rochas gabro-anfiboliticas e gabronoriticas que compõem o Complexo Canabrava indicaram, através do método isocrônico $\mathrm{Sm}-\mathrm{Nd}$ em rocha total, idades de $1,97 \mathrm{Ga}\left(\mathrm{ri}=0,510015 ; \varepsilon_{\mathrm{Nd}}=-1,4\right)$ e $1,09 \mathrm{Ga}\left(\mathrm{ri}=0.510986 ; \varepsilon_{\mathrm{Nd}}=-4,8\right)$, (Fugi, 1989).). Tais valores foram interpretados como relativos a épocas distintas de formação destes corpos máfico-ultramáficos, o primeiro relacionado à orogênese Transamazônica e o segundo a orogênese Uruaçuana. Os valores iniciais de $\varepsilon_{\mathrm{Nd}}$ negativos foram interpretados por aquele autor como resultados de contaminação crustal.

\subsection{0-2 - IDADES MODELO Sm-Nd ( $\left.\mathrm{T}_{\mathrm{DM}}\right)$}

COMPleXo BARRo AlTo - Apenas uma datação Sm-Nd foi efetuda em rocha granulitica deste complexo, com idade $\mathrm{T}_{\mathrm{DM}}$ próxima de 1,97Ga (amostra $=\mathrm{D} 1$, tab 5.10 calculada em estágio duplo), sugerindo um evento de acreção de material juvenil neste setor durante o Paleoproterozóico (Ciclo Transamazônico).

COMPLEXo CANABRAVA - As rochas básicas e ultrabásicas pertencentes ao Complexo Canabrava mostram intenso fracionamento isotópico entre $\mathrm{Sm}$ e $\mathrm{Nd}$, com $\mathrm{f}_{\mathrm{Sm} / \mathrm{Nd}}$ variando entre $-0,37$ a $+0,03$, permitindo a construção de duas isócronas $\mathrm{Sm-Nd}$, uma onde os pontos se alinham em torno de uma reta com idade próxima de 1,97Ga, e outra com 1,09Ga .

No diagrama $\varepsilon_{\mathrm{Nd}}$ versus tempo geológico (fig. 5.10-1) os dados indicam uma convergência das linhas de evolução isotópica em torno da idade de $1,09 \mathrm{Ga}$, sugerindo ter ocorrido uma rehomogeneização isotópica de $\mathrm{Nd}$. Os valores de $\varepsilon_{\mathrm{Nd}}(\mathrm{t})$ para $\mathrm{t}=1,09$ variaram, nestas rochas básicas / ultrabásicas, desde -8.0 a $-3,9$, à exceção de uma amostra que apresentou um valor positivo de 3,5 (amostras $\mathrm{Cl}$ a $\mathrm{C} 9$; tabela 5.10 ). Os valores de $\varepsilon_{\mathrm{Nd}}$ negativos, bem como os variados valores de $\mathrm{f}_{\mathrm{Sm} / \mathrm{Nd}}$, são indicativos de uma rehomogeneização isotópica de 


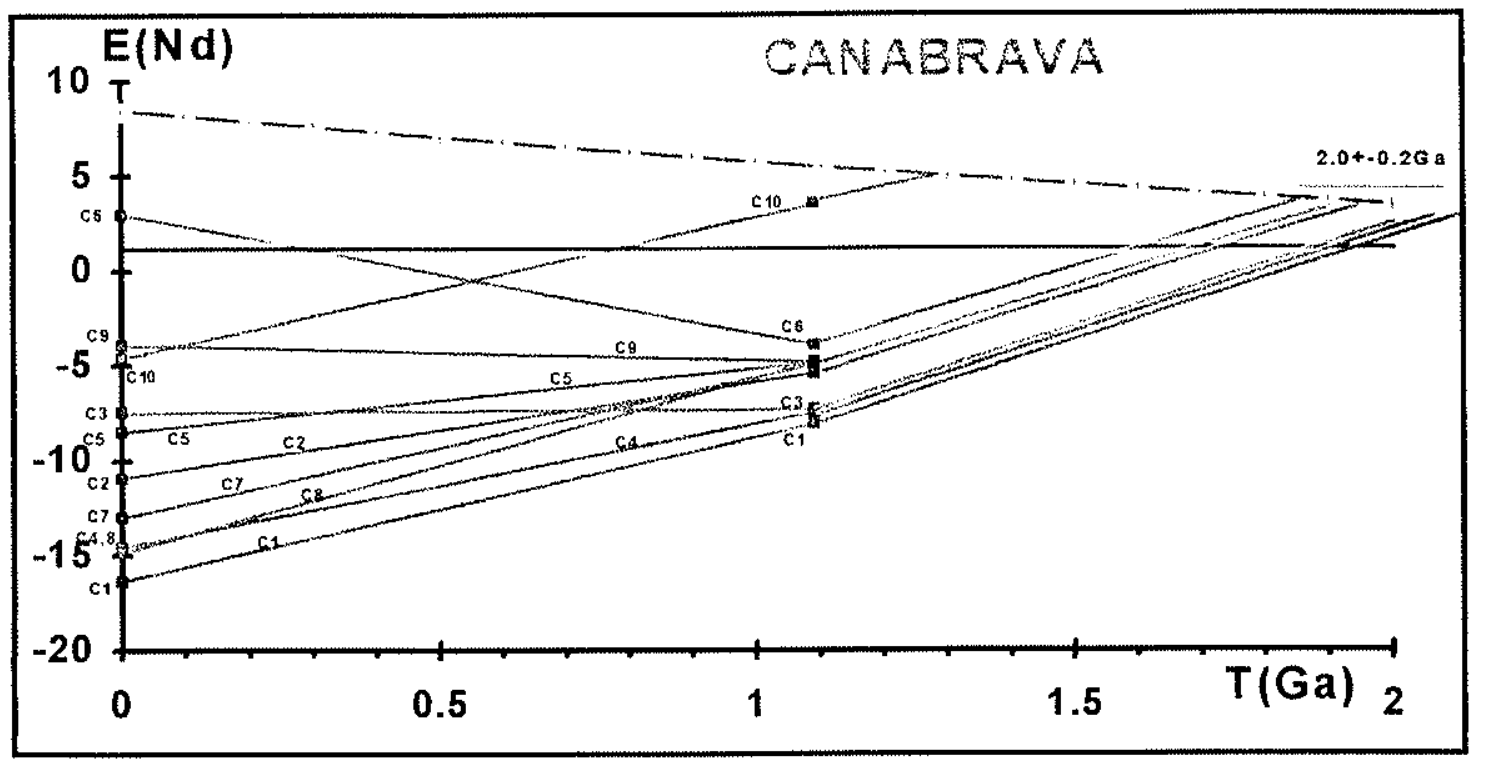

Fig. 5.10-1: Diagrama $\varepsilon_{\mathrm{Nd}}$ versus tempo geológico - região de Canabrava. Os dados isotópicos das amostras encontram-se na tab. 5.10

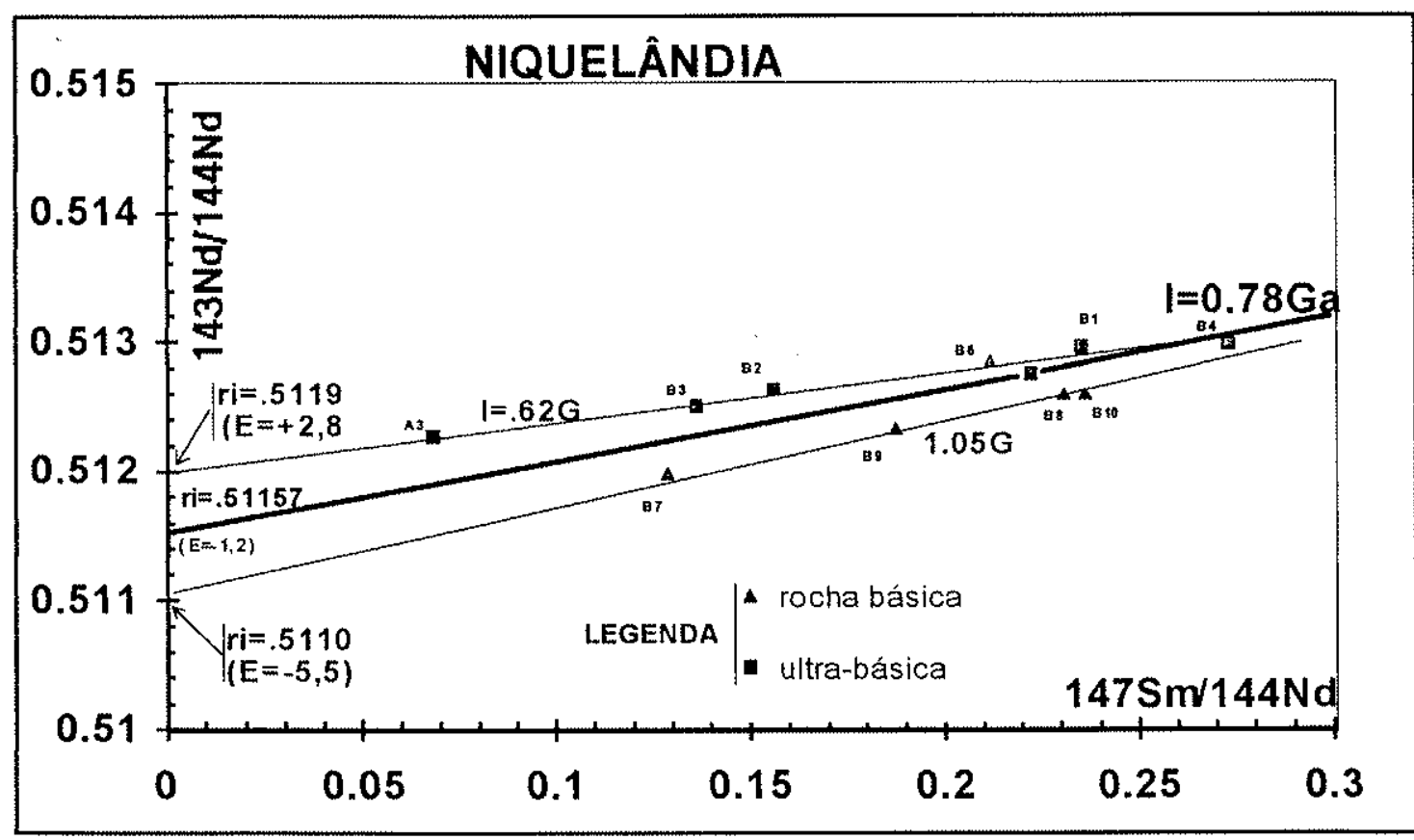

Fig. 5.10-2:Diagrama isocrônico Sm-Nd das rochas ultrabásicas e básicas de Niquelândia. 
$\mathrm{Nd}$ acompanhada de fracionamento químico entre $\mathrm{Sm}$ e $\mathrm{Nd}$, ocorrido provavelmente durante o metamorfismo do Neoproterozóico. O comportamento observado sugere que as idades modelo $\mathrm{Sm-Nd}$, quando calculadas segundo modelo de estágio único, são desprovidas de significado geológico. Por outro lado, considerando-se a evolução de $\mathrm{Nd}$ em estágio duplo, as idades $\mathrm{T}_{\mathrm{DM}}$ distribuem-se entre 2,1 e 1,8Ga (tab. 5.10), caracterizando o Paleoproterozoico como o principal periodo de acreção manto-crosta continental neste setor. A única exceção refere-se à rocha básica C10 (tab. 5.10) que indicou uma idade $T_{D M}$ Mesoproterozóica (1,3Ga.). Dados adicionais são necessários para uma melhor caracterização de materiais juvenis durante o Mesoproterozóico. Embora as idades modelo obtidas, quando calculadas segundo modelo de estágio duplo, se mostrem bastante concordantes, não podemos descartar a possibilidade dessas rochas serem oriundas de um manto litosférico extremamente enriquecido ou então de fontes mistas.

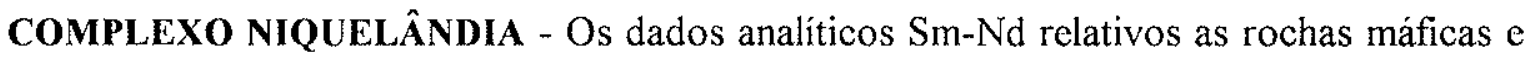
ultramáficas pertencentes ao Complexo Niquelândia são indicativos de intensa remobilização isotópica de Nd ocorrida provavelmente o durante metamorfismo de idade Neoproterozóica. Em diagrama isocrônico Sm-Nd (fig, 5.10-2) os dados analíticos sugerem três tendências de alinhamento:

i) as rochas básicas tendem a se alinhar em torno da reta com $\mathrm{T}=1,05 \pm 0,10 \mathrm{Ga}$ $\left(\mathrm{ri}=5110 ; \varepsilon_{\mathrm{Nd}}=-5,5\right)$;

ii) as rochas ultrabásicas tendem a se alinhar em torno da reta com $\mathrm{T}=0,62 \pm 0,10 \mathrm{Ga}$ $\left(\mathrm{ri}=51198 ; \varepsilon_{\mathrm{Nd}}=+2,8\right)$

iii) uma reta intermediária envolvendo todos os pontos analíticos pode ser tentativamente construida, indicando neste caso, uma idade de $0,78 \mathrm{Ga}\left(\mathrm{ri}=51157 ; \varepsilon_{\mathrm{Nd}}=-1,2\right)$.

A opção iii foi sugerida por Correia et. al., (1997), sendo que tal idade é suportada por isócrona $\mathrm{Re} / \mathrm{Os}$, que acusou idade de 0,80Ga (rocha total) e de análises U-Pb em zircões, que apresentaram idade de 0,78Ga (intercepto inferior; Correia et. al., 1996). Tais valores foram interpretados pelos autores como indicativos do metamorfismo Neoproterozóico que afetou as rochas regionais.

Os valores de $\left.\varepsilon_{\mathrm{Nd}(\mathrm{t}: 0,78 \mathrm{Ga}}\right)$ obtidos para as rochas ultrabásicas do Complexo Niquelândia distribuiram-se entre $+5,8$ e 1,1, com valor médio positivo de $+2,8$ (tab. 5.10, amostras, A3 e B1 a B4). As rochas básicas, distintamente, apresentaram valores de $\varepsilon_{\mathrm{Nd}}$ distribuídos entre $\quad-6,0$ a 2,43 com valor médio de $-4,1$ (tab 5.10, amostras B6 a B10). 
As idades modelo $\mathrm{Sm}-\mathrm{Nd}\left(\mathrm{T}_{\mathrm{MM}}\right)$ relativas às rochas básicas, calculadas em estágio único, são desprovidas de significado geológico (fig. 5.10-3). Quando calculadas em estágio duplo indicaram o Paleoproterozóico como principal evento de acreção manto - crosta continental, ( $\mathrm{T}_{\mathrm{DM}}$ $=2,18$ a 1,80Ga para as rochas $\mathrm{B} 5$ e $\mathrm{B} 7$ a $\mathrm{B} 10$ ). Exceção é feita para a rocha básica $\mathrm{B} 6$, que indicou idade Mesoproterozóica $\left(\mathrm{T}_{\mathrm{DM}}=1,56 \mathrm{Ga}\right.$; tab. 5.10). Tais valores se aproximam daqueles determinados através dos métodos U-Pb (2,0Ga, intercepto superior, SHRIMP) e Re/Os (isócrona de 2,07Ga; Correia et. al, 1996). Por outro lado, as rochas ultrabásicas indicaram para seus protólitos idades modelo Sm-Nd Mesoproterozóicas $\left(\mathrm{T}_{\mathrm{DM}}=1,4\right.$ a $0,9 \mathrm{Ga}$, amostras A3 e B1 a B4, tab. 5.10).

A dispersão obtida nas idades modelo das rochas máficas poderia indicar mistura de materiais oriundos pelo menos de duas fontes distintas (entre 2,0 e $0,9 \mathrm{Ga}$ ) produzindo valores intermediários. Entretanto tal hipótese não encontra suporte geoquímico, uma vez que essas rochas foram formadas a partir de uma única fonte (Correia informação escrita). Outra opção envolveria uma pequena contaminação crustal, que poderia ocasionar dispersão dos pontos da isócrona e variações nas idades modelo, pois os teores de Sm são muito baixos, da ordem de 100 ppb (tab. 5.10). Por último a fonte destas rochas máficas poderia ser de um manto anômalo tipo EM1.

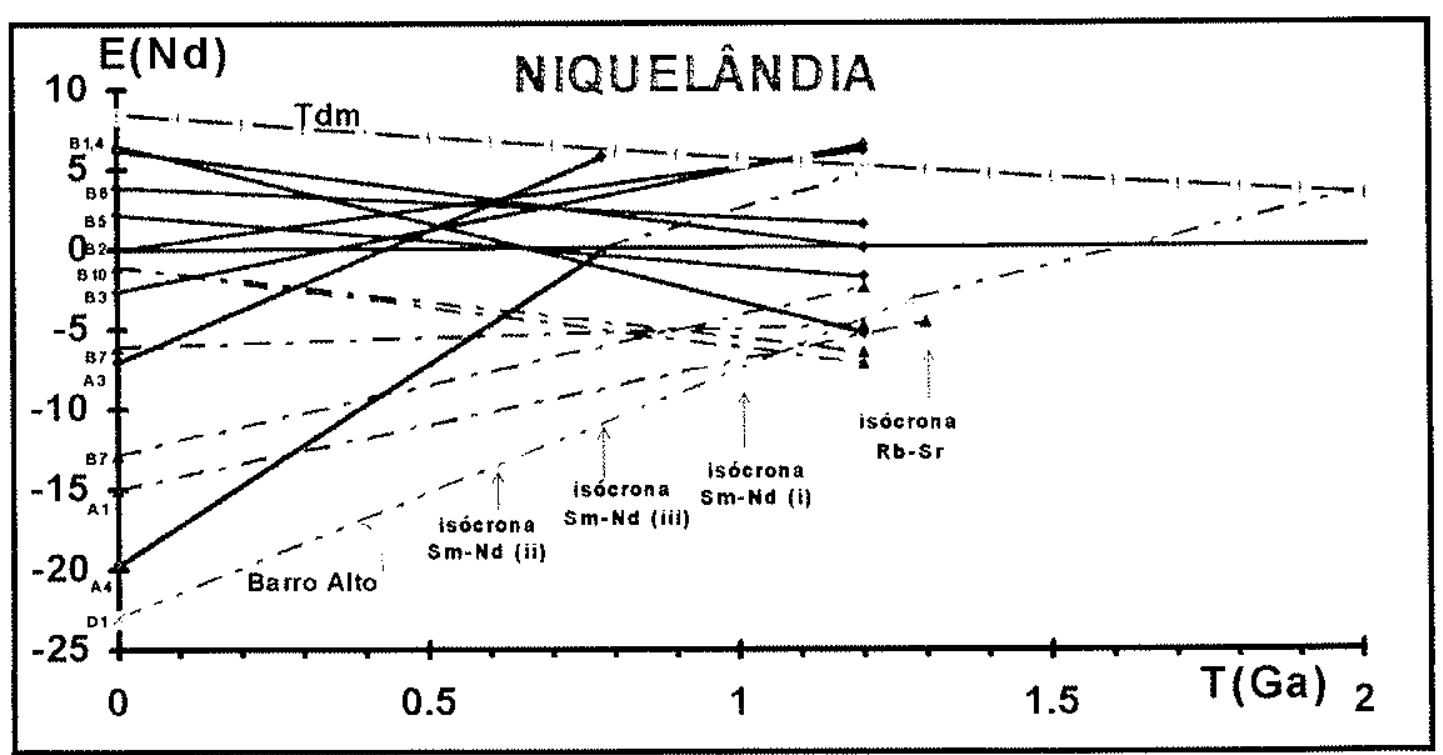

Fig. 5.10-3: Diagrama $\varepsilon_{\mathrm{Nd}}$ versus tempo geológico - região de Niquelândia e Barro Alto. Os dados isotópicos das amostras encontram-se na tab.5.10. Observa-se no diagrama duas tendências de convergências das linhas de evolução isotópica: uma em torno de $0,6 \mathrm{Ga}$ para rochas básicas e outra em entre 0,9 a $1,1 \mathrm{Ga}$ para rochas ultrabásicas a básicas. A idade modelo em estágio único não tem significado geológico. A linha D1 representa a região de $B$. Alto. 
REgióes de CAVAlCANTE - CAMpo Belo - NATIVIdAde - Entre as cidades de Cavalcante e Campo Belo ocorrem rochas graniticas intrusivas no embasamento gnáissico da região. Os dados U-Pb obtidos em zircões destas rochas indicaram idades entre 1,77 e 1,58Ga e os dados Sm-Nd acusaram idades modelo do Arqueano $(2,7$ a 2,5Ga) e do Paleoproterozóico $(2,1 \mathrm{Ga})$, sugerindo dois períodos principais de acreção manto - crosta continental (Pimentel informação escrita).

Na região de Natividade ocorrem corpos graníticos com épocas de formação relativas ao Ciclo Transamazônico. Os dados $\mathrm{Sm}-\mathrm{Nd}\left(\mathrm{T}_{\mathrm{DM}}\right)$ dessas rochas indicam dois valores distintos: um de idade Paleoproterozóica $(2,22 \mathrm{Ga}$, Tab. 5.10, amostra E ) para o corpo granitóide situado a noroeste de Natividade e outro relativo ao final do Arqueano $(2,61 \mathrm{Ga}$, amostras $=\mathrm{F})$ para corpo granitico situado a leste de Natividade. Tais idades indicam a presença de granitóides formados no Paleoproterozóico, a partir de processos de acreção - diferenciação (granitóides a NW de Natividade) e também de retrabalhamento crustal de rochas mais antigas (granitóides à E de Natividade). Tais valores de $\mathrm{T}_{\mathrm{DM}}(2,2$ e $2,6 \mathrm{Ga})$ encontrados nesta região são similares aos observados em rochas granitóides da região de Cavalcante-Campo Belo.

\subsection{0-3 - RESUMO PARCIAL DO DOMÍNIO URUAÇU}

Os principais períodos de acreção manto-crosta continental no domínio Uruaçu podem ser resumidos da seguinte forma:

$\begin{array}{lcc}\text { Arqueano } & 2,7 \text { a } 2,5 \mathrm{Ga} & \begin{array}{c}\text { Cavalcante - Campo Belo } \\ \text { Natividade }\end{array} \\ \text { Paleoproterozóico } & 2,2 \text { a } 1,6 \mathrm{Ga} & \begin{array}{c}\text { Complexos Canabrava, Niquelândia, } \\ \text { Barro Alto e região de } \\ \text { Natividade }\end{array}\end{array}$

Meso-Neoproterozóico $\quad 1,3$ a $0,9 \mathrm{Ga}$ Complexo Niquelândia 


\subsection{1: - DOMÍNIO BRASÍLIA}

\subsection{1-1 SÍNTESE GEOLÓGICA}

O Sistema de Dobramentos Brasilia é representado por uma extensa faixa de rochas metassedimentares (grau incipiente a xisto-verde) que se extende ao longo da margem oeste do Cráton do S. Francisco, e cuja evolução relaciona-se ao Ciclo Brasiliano (Almeida, 1968). Inclui os terrenos pertencentes às Formações Canastra, Ibiá e Vazante, Grupo Paranoá e a parte do Super Grupo Paraopeba (fig. 5.9-2).

Com base em determinação de estromatólitos colunares bem preservados, a deposição desta seqüência sedimentária parece ter ocorrido entre 1,6 a 0,6Ga (Dardenne et. al., 1973).

Dados geocronológicos recentes, acoplados a estudos geológico-estruturais, (Pimentel et. al., 1997) sugerem que a evolução geotectônica da faixa Brasília apresenta similaridades com a de margens continentais modernas: i) seqüência sedimentar de margem passiva invertida (Grupo Paranoá); ii) melange ofiolitica associada com os metassedimentos do Grupo Araxá; iii) terrenos de arco magmático (Arenópolis/Iporá e Mara Rosa); iv) magmatismo granítico relacionado à colisão e v) nappes e "thrust sheets" indicando transporte tectônico francamente em direção ao Cráton S. Francisco.

Os principais estágios de evolução tectônica da Faixa Brasilia podem, segundo Pimentel et. al. (op.cit.), ser resumidos da seguinte forma: i) - estágio de abertura entre 1,77-1,60 (dados $\mathrm{U}-\mathrm{Pb}$ em zircões nos granitos intrusivos no embasamento gnáissico antigo (Arqueano / Paleoproterozóico); ii) - magmatismo sin colisional entre 0,9 e 0,63 (rochas tipo arcos de ilha intraoceânica da região de Iporá - Arenópolis e Mara Rosa - fig. 5.9-2); iii) - fechamento final entre os Cratons Amazônico e S. Francisco em torno de 0,6Ga, acompanhado de magmatismo bimodal impresso em toda extensão da Faixa Brasilia.

\subsection{1-2 - IDADES MODELO Sm-Nd}

Análises isotópicas $\mathrm{Sm}-\mathrm{Nd}$ relativas aos terrenos do Domínio Brasilia resumem-se às rochas kimberliticas e alcalinas do Cretáceo que ali ocorrem, cujos teores de Sm e Nd mostramse extremamente enriquecidos ( $\mathrm{Sm}=\sim 25 \mathrm{ppm}$ e $\mathrm{Nd}=\sim 180 \mathrm{ppm}$; tab.5.11; dados de Bizzi, 1993). $\mathrm{O}$ grau de fracionamento $\mathrm{f}_{\mathrm{SnwNd}} \cong-0,55$ sugere enriquecimento preferencial de $\mathrm{Nd}$ em relação ao 
$\mathrm{Sm}$. De um modo geral, teores elevados em $\mathrm{Sm}$ e Nd bem como valores de $\mathrm{f}_{\mathrm{Sm} \times \mathrm{Nd}}$ bem negativos são padrões que se observam de forma frequente (ver tabela 4.- capitulo 4).

As idades modelo $\mathrm{Sm}-\mathrm{Nd}$ obtidas para essas rochas ultrabásicas, quando calculadas em estágio único, distribuiram-se entre 1,1 a $0,8 \mathrm{Ga}$ (tab.5.11 e fig. 5.11). A fonte dessas rochas poderia estar relacionada a um manto litosférico enriquecido, e que por sua vez separou-se do manto normal (tipo DM) em torno de $1,1 \mathrm{Ga}$.

Embora não se disponha de dados $\mathrm{Sm}-\mathrm{Nd}$ em rochas do embasamento do Domínio Brasília, pode-se, através de correlação com os domínios adjacentes, sugerir eventos de acreção de material juvenil durante o Proterozóico inteiro, com predominio no Mesoproterozóico. Acrescente-se que é possivel a existência de fragmentos Arqueanos no interior deste domínio, representando uma extensão dos terrenos do Craton do S. Francisco.

Estudos isotópicos adicionais se fazem necessários para um melhor entedimento de sua evolução geotectônica.

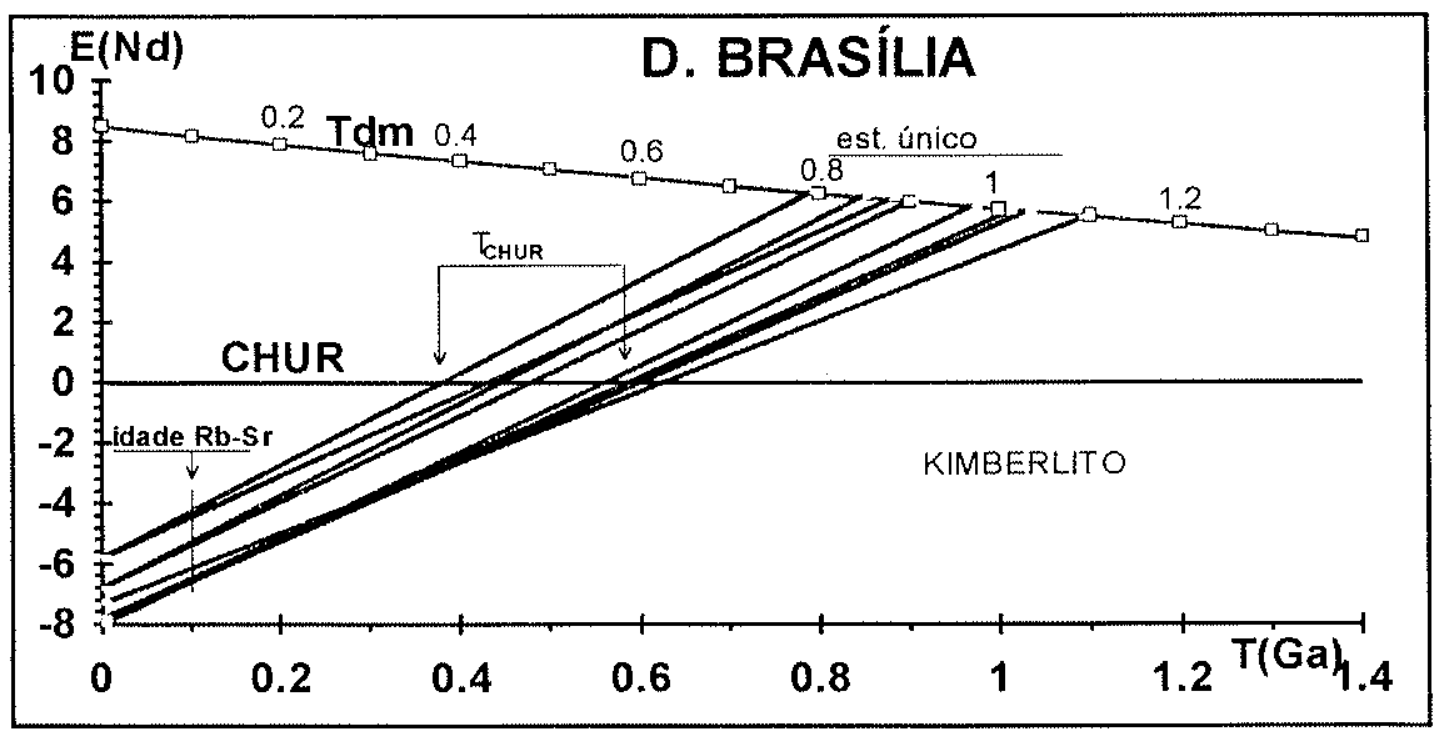

Fig. 5.11: Diagrama $\varepsilon_{\mathrm{Nd}}$ versus tempo geológico -Domínio Brasília. Os dados isotópicos das amostras encontram-se na tab.5.11 
TAB. 5.10 - DADOS Sm-Nd - DOMÍNIO URUAÇU

\begin{tabular}{|c|c|c|c|c|c|c|c|c|c|c|c|c|c|c|c|c|c|}
\hline $\begin{array}{l}\text { SPS } \\
\text { /litol }\end{array}$ & $\begin{array}{l}\text { coord./ } \\
\text { (p.local.) }\end{array}$ & $\begin{array}{l}\text { n.campo/ } \\
\text { região }\end{array}$ & $\begin{array}{l}\text { litolo } \\
\text { gia }\end{array}$ & $\begin{array}{l}\text { ident } \\
\text { (diagra } \\
\text { ma) }\end{array}$ & \begin{tabular}{|l|}
$T_{\text {chur }}$ \\
$(\mathrm{GA})$ \\
Ooldstein \\
otal 1984 \\
\end{tabular} & $T_{(\mathrm{gAm} 2}$ & \begin{tabular}{|l|}
$T_{\mathrm{dm}}$ \\
$(\mathrm{GA})$ \\
DePaolo \\
-1989 \\
\end{tabular} & ${ }^{144} \mathrm{Nd} /$ & $\begin{array}{l}{ }^{147} \mathrm{Sm} / \\
{ }^{144} \mathrm{Nd}\end{array}$ & $\begin{array}{l}\text { Sm } \\
\text { ppm }\end{array}$ & $\begin{array}{l}\text { Nd } \\
\text { ppm }\end{array}$ & $f$ & $\begin{array}{l}\varepsilon_{\mathrm{Nd}} \\
(0)\end{array}$ & $\begin{array}{l}\varepsilon_{\mathrm{Nd}} \\
(\mathrm{t})\end{array}$ & \begin{tabular}{l|}
$t(G a)_{\text {mét }}$ \\
$R i_{\text {(fonte) }}$
\end{tabular} & $\begin{array}{l}\varepsilon_{S r} \\
(t)\end{array}$ & ref \\
\hline gnd & $\sim 1425 / 4825$ & $\begin{array}{l}\text { NIQ13/ } \\
\text { Niquelândia }\end{array}$ & GTD & A1 & 1.84 & $2.07^{32}$ & 2.23 & .511870 & .133344 & 4.30 & 19.5 & -.32 & -15.0 & -4.5 & $\begin{array}{l}1.3_{\mathrm{Rb} / \mathrm{Sr}} \\
.7113_{\mathrm{b}} \\
\end{array}$ & 118 & 1 \\
\hline $\begin{array}{l}--1 \\
\text { gnd }\end{array}$ & $\sim 1425 / 4825$ & \begin{tabular}{|l|} 
NIQ13/ \\
Niquelândia
\end{tabular} & GTD & A2 & 1.96 & $2.11^{\# 2}$ & 2.35 & .511870 & .137148 & 4.40 & 19.4 & -.30 & -15.0 & -5.1 & $\begin{array}{l}1.3 \mathrm{Rb} \text { st } \\
.7113_{\mathrm{b}} \\
\end{array}$ & & 1 \\
\hline ant & $\sim 1425 / 4825$ & $\begin{array}{l}\text { NIQ15/ } \\
\text { Niquelândia }\end{array}$ & BAS & A3 & 0.43 & & 0.81 & .512280 & .068223 & .44 & 3.90 & -.65 & -7.0 & +5.8 & $.78_{\text {est }}$ & & 1 \\
\hline $\begin{array}{l}-1 \\
\text { gns.g }\end{array}$ & $\sim 1425 / 4825$ & $\begin{array}{l}\text { NiQ2/ } \\
\text { Niquelândia }\end{array}$ & GTD & A4 & 0.78 & $1.34^{42}$ & 1.01 & .511630 & $.000573 ?$ & $.017 ?$ & 17.933 & -1.0 & -19.7 & -.15 & $.78_{\text {est }}$ & & 1 \\
\hline $\begin{array}{l}610 \\
\text { cro } \\
\end{array}$ & Niquelândia & $\begin{array}{l}\text { Correia (dados } \\
\text { inéditos) }\end{array}$ & UBA & $B 1$ & $\begin{array}{l}1.22 \\
0.15 \\
\end{array}$ & & - & $\begin{array}{l}.512957 \\
.000026 \\
\end{array}$ & $\begin{array}{l}.2365 \\
.0037 \\
\end{array}$ & $\begin{array}{l}.070 \\
.001 \\
\end{array}$ & $\begin{array}{l}.179 \\
.001 \\
\end{array}$ & .20 & 6.2 & 2.3 & $\begin{array}{l}.78_{\mathrm{Sm} / \mathrm{Nd}} \\
.51157_{\mathrm{e}}\end{array}$ & & 4 \\
\hline $\begin{array}{l}611 \\
\text { cro }\end{array}$ & Niquelândia & $\begin{array}{l}\text { Correia (dados } \\
\text { inéditos) }\end{array}$ & UBA & B2 & $\overline{--}$ & & $\begin{array}{l}1.08 \\
0.05 \\
\end{array}$ & \begin{tabular}{|l}
.512637 \\
.000021 \\
\end{tabular} & $\begin{array}{l}.1561 \\
.0014 \\
\end{array}$ & $\begin{array}{l}.118 \\
.001 \\
\end{array}$ & $\begin{array}{l}.457 \\
.001 \\
\end{array}$ & -.21 & 0.0 & 4.0 & $\begin{array}{l}.78_{\mathrm{Sm} / \mathrm{Nd}} \\
.51157_{\mathrm{e}} \\
\end{array}$ & & 4 \\
\hline $\begin{array}{l}613 \\
\text { ant }\end{array}$ & Niquelândia & $\begin{array}{l}\begin{array}{l}\text { Correia (dados } \\
\text { inéditos) }\end{array} \\
\end{array}$ & UBA & B3 & $\begin{array}{l}0.34 \\
0.07 \\
\end{array}$ & & $\begin{array}{l}1.07 \\
0.06 \\
\end{array}$ & $\begin{array}{l}.512506 \\
.000029 \\
\end{array}$ & $\begin{array}{l}.1370 \\
.0011 \\
\end{array}$ & $\begin{array}{l}.118 \\
.001 \\
\end{array}$ & $\begin{array}{l}.521 \\
.001 \\
\end{array}$ & -.30 & -2.6 & 3.4 & $\begin{array}{l}.78_{\mathrm{Sn} / \mathrm{No}} \\
.51157_{\ell} \\
\end{array}$ & & 4 \\
\hline $\begin{array}{l}614 \\
\text { pir } \\
\end{array}$ & Niquelândia & \begin{tabular}{|l|} 
Correia (dados \\
inéditos)
\end{tabular} & UBA & $B 4$ & & & & $\begin{array}{l}.512971 \\
.000022 \\
\end{array}$ & $\begin{array}{l}.2731 \\
.0002 \\
\end{array}$ & $\begin{array}{l}.266 \\
.001 \\
\end{array}$ & $\begin{array}{l}.589 \\
.001 \\
\end{array}$ & & 6.50 & 1.1 & $\begin{array}{l}.78_{\mathrm{Sm} / \mathrm{Na}} \\
.51157_{\mathrm{e}}\end{array}$ & & 4 \\
\hline $\begin{array}{l}677 \\
\text { gab }\end{array}$ & Niquelândia & $\begin{array}{l}\text { Correia (dados } \\
\text { inéditos) }\end{array}$ & BAS & B5 & & & & \begin{tabular}{|l|}
.512752 \\
.000026 \\
\end{tabular} & \begin{tabular}{|l|}
.2224 \\
.0001 \\
\end{tabular} & $\begin{array}{l}.521 \\
.001 \\
\end{array}$ & $\begin{array}{l}1.417 \\
0.001 \\
\end{array}$ & & 2.22 & -.34 & $\begin{array}{l}.78_{\mathrm{Sm} / \mathrm{Nd}} \\
.51157_{\mathrm{e}} \\
\end{array}$ & & 4 \\
\hline $\begin{array}{l}681 \\
\text { gab }\end{array}$ & Niquelândia & $\begin{array}{l}\begin{array}{l}\text { Correia (dados } \\
\text { inéditos) }\end{array} \\
\end{array}$ & BAS & B6 & & & & $\begin{array}{l}.512840 \\
.000420 \\
\end{array}$ & $\begin{array}{l}.2119 \\
.0007 \\
\end{array}$ & $\begin{array}{l}.302 \\
.001 \\
\end{array}$ & $\begin{array}{l}.862 \\
.001 \\
\end{array}$ & .08 & 3.9 & 2.43 & $\begin{array}{l}.78_{\mathrm{Sm} N \mathrm{Nd}} \\
.51157_{\mathrm{e}}\end{array}$ & & 4 \\
\hline $\begin{array}{l}612 \\
\mathrm{gab}\end{array}$ & Niquelândia & $\begin{array}{l}\begin{array}{l}\text { Correia (dados } \\
\text { inéditos) }\end{array} \\
\end{array}$ & BAS & B7 & $\begin{array}{l}1.47 \\
0.05 \\
\end{array}$ & & $\begin{array}{l}1.90 \\
0.04 \\
\end{array}$ & $\begin{array}{l}.511982 \\
.000023 \\
\end{array}$ & \begin{tabular}{|l|}
.12882 \\
.00011 \\
\end{tabular} & $\begin{array}{l}3.255 \\
0.002 \\
\end{array}$ & $\begin{array}{l}15.279 \\
0.008 \\
\end{array}$ & -.35 & -12.8 & -6.0 & \begin{tabular}{|l|}
$.78_{\text {Sm/No }}$ \\
$.51157_{e}$ \\
\end{tabular} & & 4 \\
\hline $\begin{array}{l}678 \\
\text { gab }\end{array}$ & Niquelândia & $\begin{array}{l}\text { Correia (dados } \\
\text { inéditos) }\end{array}$ & BAS & B8 & & & & $\begin{array}{l}.512585 \\
.000028 \\
\end{array}$ & \begin{tabular}{|l|}
.2316 \\
.0016 \\
\end{tabular} & $\begin{array}{l}.149 \\
.001 \\
\end{array}$ & $\begin{array}{l}.389 \\
.001 \\
\end{array}$ & .18 & -1.0 & -4.5 & $\begin{array}{l}.78_{\mathrm{Sm} / \mathrm{Nd}} \\
.51157_{\mathrm{e}} \\
\end{array}$ & & 4 \\
\hline $\begin{array}{l}679 \\
\text { gab }\end{array}$ & Niquelândia & \begin{tabular}{|l|} 
Correia (dados \\
inéditos)
\end{tabular} & BAS & 89 & & & & $\begin{array}{l}.512324 \\
.000021 \\
\end{array}$ & $\begin{array}{l}.1874 \\
.0020 \\
\end{array}$ & $\begin{array}{l}.097 \\
.001 \\
\end{array}$ & $\begin{array}{l}.313 \\
.001 \\
\end{array}$ & -.05 & -6.1 & -5.2 & $\begin{array}{l}.78_{\mathrm{Sm} / \mathrm{Nd}} \\
.51157_{\mathrm{e}} \\
\end{array}$ & & 4 \\
\hline $\begin{array}{l}680 \\
\text { per }\end{array}$ & Niquelândia & $\begin{array}{l}\text { Correia (dados } \\
\text { inéditos) }\end{array}$ & UBA & B10 & & & & $\begin{array}{l}.512583 \\
.000039 \\
\end{array}$ & $\begin{array}{l}.2362 \\
.0016 \\
\end{array}$ & $\begin{array}{l}.157 \\
.001 \\
\end{array}$ & $\begin{array}{l}.402 \\
.001 \\
\end{array}$ & .20 & -1.1 & -5.0 & $\begin{array}{l}.78_{\mathrm{Sm} / \mathrm{Nd}} \\
.51157_{\mathrm{e}}\end{array}$ & & 4 \\
\hline gab & $1319 / 4816$ & $\begin{array}{l}\mathrm{CB} 41 \\
\text { Cana Brava } \\
\end{array}$ & BAS & $\mathrm{C1}$ & 2.13 & & 2.48 & $\begin{array}{l}.511800 \\
.000056 \\
\end{array}$ & .136866 & 3.747 & 16.555 & -.30 & -16.3 & & $1.09_{\mathrm{Sm} / \mathrm{Nd}}$ & & 2 \\
\hline $\begin{array}{l}--1 \\
\text { gb.no }\end{array}$ & $1316 / 4812$ & $\begin{array}{l}\mathrm{CB} 15 / \\
\text { Cana Brava }\end{array}$ & BAS & $\mathrm{C} 2$ & 2.24 & & 2.71 & $\begin{array}{l}.512078 \\
.000028 \\
\end{array}$ & .158677 & 0.973 & 3.708 & -.19 & -10.9 & & $1.09_{\mathrm{Sm} / \mathrm{N}}$ & & 2 \\
\hline $\begin{array}{l}-1 \\
\text { gbono }\end{array}$ & $1326 / 4814$ & $\begin{array}{l}\text { CB 32B I } \\
\text { Cana Brava } \\
\end{array}$ & BAS & C3 & -- & & $\ldots$ & $\begin{array}{l}.512256 \\
.000024 \\
\end{array}$ & .195161 & 1.178 & 3.650 & -.01 & -7.5 & & $1.09_{\mathrm{Sm} / \mathrm{Nd}}$ & & 2 \\
\hline anf & $1323 / 4810$ & $\begin{array}{l}\text { CB 33/ } \\
\text { Cana Brava }\end{array}$ & BAS & $\mathrm{C4}$ & 2.22 & 3.36 & 2.61 & $\begin{array}{l}.511896 \\
.000040 \\
\end{array}$ & .146019 & 8.135 & 33.689 & -.26 & -14.5 & & $1.09_{\mathrm{Sm} / \mathrm{Nd}}$ & & 2 \\
\hline pir & $1321 / 4815$ & $\begin{array}{l}\text { CB 37/ } \\
\text { Cana Brava }\end{array}$ & UBA & C5 & 2.49 & 2.95 & 3.02 & $\begin{array}{l}.512203 \\
.000022 \\
\end{array}$ & .170194 & 1.962 & 6.971 & -.13 & -8.5 & & $1.09_{\mathrm{Sm} / \mathrm{Nd}}$ & & 2 \\
\hline
\end{tabular}




\begin{tabular}{|c|c|c|c|c|c|c|c|c|c|c|c|c|c|c|c|c|c|}
\hline $\begin{array}{l}--1 \\
\text { o.pir }\end{array}$ & $1328 / 4813$ & $\begin{array}{l}\mathrm{CB} 39 / \\
\text { Cana Brava }\end{array}$ & UBA & C6 & $\ldots$ & 2.80 & $-\cdots$ & .512791 & .24606 & .153 & .376 & -.25 & +3.0 & & $1.09_{\mathrm{Sm} / \mathrm{Nd}}$ & & 2 \\
\hline $\begin{array}{l}--1 \\
\text { gb.no }\end{array}$ & $1318 / 4804$ & $\begin{array}{l}\text { CB 10I } \\
\text { Cana Brava }\end{array}$ & BAS & C7 & 1.73 & 2.96 & 2.17 & $\begin{array}{l}.511970 \\
.000026\end{array}$ & .138069 & 2.44 & 10.704 & -.30 & -13.0 & & $1.09_{\text {Smind }}$ & & 2 \\
\hline gb no & $1319 / 4804$ & $\begin{array}{l}\text { CB 11a I } \\
\text { Cana Brava }\end{array}$ & BAS & $\mathrm{C8}$ & 1.60 & 2.94 & 1.99 & .511879 & 124588 & 4.310 & 20.919 & -.37 & -14.8 & & $1.09_{\text {Smind }}$ & & 2 \\
\hline gbno & $1319 / 4804$ & $\begin{array}{l}\text { CB 11b/ } \\
\text { Cana Brava }\end{array}$ & BAS & $C 9$ & 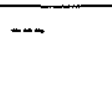 & 2.94 & $\ldots$ & $\begin{array}{l}.512436 \\
.000066\end{array}$ & .202662 & 1.912 & 5.705 & .03 & -3.9 & & $1.09_{\mathrm{sm} / \mathrm{kd}}$ & & 2 \\
\hline anf & $1323 / 4818$ & $\begin{array}{l}\text { CB 47/ } \\
\text { Cana Brava }\end{array}$ & BAS & C10 & 0.61 & 1.62 & 1.29 & $\begin{array}{l}.512402 \\
.000024\end{array}$ & .138130 & 2.589 & 11.334 & -.30 & -4.6 & & $1.09_{\text {est }}$ & & 2 \\
\hline $\begin{array}{l}643 \\
\text { gni.b }\end{array}$ & $\sim 1515 / 4915$ & $\begin{array}{l}\text { GAM-7D } \\
\text { Barro Alto }\end{array}$ & GNL & D1 & $\begin{array}{l}\sim 1.49 \\
0.11\end{array}$ & $1.97^{\# 2}$ & $\begin{array}{l}1.77 \\
0.10\end{array}$ & $\begin{array}{l}\sim .511460 \\
0.000090\end{array}$ & $\begin{array}{l}\sim 0.0776 \\
0.0002\end{array}$ & \begin{tabular}{|l|}
1.55 \\
0.01
\end{tabular} & $\begin{array}{l}12.06 \\
0.01\end{array}$ & & -23.0 & & $\begin{array}{l}1.27_{\mathrm{Rb}-\mathrm{St}} \\
.73473\end{array}$ & 451 & nt \\
\hline $\begin{array}{l}361 / \\
\text { grt }\end{array}$ & $1117 / 4737$ & $\begin{array}{l}379-1 \mathrm{~A} / \\
\text { Natividade }\end{array}$ & GTD & $E$ & $\begin{array}{l}1.87 \\
0.06\end{array}$ & & $\begin{array}{l}2.22 \\
0.04\end{array}$ & $\begin{array}{l}.511763 \\
.000026\end{array}$ & $\begin{array}{l}.125730 \\
.000081\end{array}$ & $\begin{array}{l}8.347 \\
0.004\end{array}$ & $\begin{array}{l}40.145 \\
0.017\end{array}$ & -.36 & -17.1 & 1.0 & $\begin{array}{l}2.00_{\mathrm{Rb} / \mathrm{s}} \\
.7021_{e}\end{array}$ & -2.1 & nt \\
\hline $\begin{array}{l}360 / \\
\text { grt }\end{array}$ & $1135 / 4715$ & $\begin{array}{l}381 / \\
\text { Natividade }\end{array}$ & GTD & $\mathrm{F}$ & $\begin{array}{l}2.42 \\
0.04\end{array}$ & & $\begin{array}{l}2.61 \\
0.04\end{array}$ & $\begin{array}{l}.510949 \\
.000031\end{array}$ & $\begin{array}{l}.090764 \\
.000064\end{array}$ & $\begin{array}{l}3.702 \\
0.002\end{array}$ & $\begin{array}{l}24.664 \\
0.011\end{array}$ & -.54 & -32.9 & -5.9 & $\begin{array}{l}2.00_{\mathrm{Rb} / \mathrm{Sr}} \\
.7021_{\mathrm{e}}\end{array}$ & -2.1 & nt \\
\hline grt & $-1343 / 4820$ & $\begin{array}{l}\text { Cavalcante / } \\
\text { Campos Belos }\end{array}$ & GTD & & & & 2.7 & Pimentel & dados & inédi- & tos & & & & 1.6 U.Po & & 3 \\
\hline grt & $\sim 1320 / 4714$ & $\begin{array}{l}\text { Cavalcante I } \\
\text { Campos Belos }\end{array}$ & GTD & & & & 2.6 & Pimentel & dados & inédi- & tos & & & & & & \\
\hline grt & $\sim 1309 / 4714$ & $\begin{array}{l}\text { Cavalcante / } \\
\text { Campos Belos }\end{array}$ & GTD & & & & 2.1 & Pimentel & dados & inédi- & tos & & & & $\ldots$ & & 3 \\
\hline grt & $\sim 1336 / 4715$ & $\begin{array}{l}\text { Cavalcante / } \\
\text { Campos Belos }\end{array}$ & GTD & & & & 2.5 & Pimentel & dados & inédi- & tos & & & & $1.78 \mathrm{u}-\mathrm{pb}_{\mathrm{b}}$ & & 3 \\
\hline
\end{tabular}

TAB. 5.11 - DADOS Sm-Nd - Domínio Brasilia

\begin{tabular}{|c|c|c|c|c|c|c|c|c|c|c|c|c|c|c|c|c|c|}
\hline $\begin{array}{l}\text { SPS } \\
\text { /litol }\end{array}$ & $\begin{array}{l}\text { coord. } \\
\text { (p.local.) }\end{array}$ & $\begin{array}{l}\text { n.campol } \\
\text { região }\end{array}$ & $\begin{array}{l}\text { litolo } \\
\text { gia }\end{array}$ & $\begin{array}{l}\text { ident } \\
\text { (diagra } \\
\text { ma) }\end{array}$ & \begin{tabular}{|l|}
$T_{\text {chur }}$ \\
$(G A)$ \\
Goldstein \\
etal 1984
\end{tabular} & $T_{(\mathrm{GA})} \mathrm{T}_{\mathrm{dm} 2}$ & \begin{tabular}{|l}
$T_{\text {dm }}$ \\
$(\mathrm{GA})$ \\
DePaolo \\
-1981 \\
\end{tabular} & {$\left[\begin{array}{l}{ }^{143} \mathrm{Nd} / \\
{ }^{144} \mathrm{Nd}\end{array}\right.$} & $\mid \begin{array}{l}{ }^{147} \mathrm{Sm} / \\
{ }^{144} \mathrm{Nd}\end{array}$ & $\begin{array}{l}\mathrm{Sm} \\
\mathrm{ppm}\end{array}$ & $\begin{array}{l}\text { Nd } \\
\text { ppm }\end{array}$ & $f$ & $\begin{array}{l}\varepsilon_{\mathrm{Nd}} \\
(0)\end{array}$ & $\begin{array}{l}\varepsilon_{\mathrm{Nd}} \\
(\mathrm{t})\end{array}$ & $\begin{array}{l}\mathbf{t}(\mathrm{Ga})_{\text {mét }} \\
\mathrm{Ri} \mathrm{i}_{(\text {fonte })}\end{array}$ & $\begin{array}{l}\varepsilon_{S r} \\
(t)\end{array}$ & ref \\
\hline $\begin{array}{l}-\cdots 1 \\
\text { kim.p }\end{array}$ & $1829 / 4648$ & $\begin{array}{l}\text { PAN / } \\
\text { Pantano }\end{array}$ & UBA & A1 & 0.45 & & 0.85 & .512290 & .077477 & 24.6 & 192.0 & -.61 & -6.8 & -5.3 & $.1_{\text {est }}$ & & 1 \\
\hline kim.p & $1829 / 4648$ & $\begin{array}{l}\text { PAN/ } \\
\text { Pantano }\end{array}$ & UBA & A2 & 0.38 & & 0.79 & .512340 & .075833 & 23.2 & 185.0 & -.61 & -5.8 & -4.3 & $.1_{\mathrm{est}}$ & & 1 \\
\hline $\begin{array}{l}-1 \\
\text { kim.p }\end{array}$ & $1829 / 4648$ & $\begin{array}{l}\text { PAN } 1 \\
\text { Pantano }\end{array}$ & UBA & A3 & 0.43 & & 0.88 & .512340 & .090350 & 26.7 & 178.7 & -.54 & -5.8 & -4.5 & $.1_{\text {est }}$ & & 1 \\
\hline
\end{tabular}

Ver nota explicativa da tabela no capítulo 5.1

$\# 2 \rightarrow\left(\mathrm{T} 2=\mathrm{t} ;{ }^{147} \mathrm{Sm} /{ }^{144} \mathrm{Nd}=0.11\right) ;{ }^{\# 3} \rightarrow\left(\mathrm{T} 2=\mathrm{t} ;{ }^{147} \mathrm{Sm} /{ }^{144} \mathrm{Nd}=0.17\right) ;{ }^{\# 4} \rightarrow\left(\mathrm{T} 2=\mathrm{t} ;{ }^{147} \mathrm{Sm} /{ }^{144} \mathrm{Nd}=0.15\right)$

Referências: $b=$ idades $\mathrm{Rb}-\mathrm{Sr}$, Bizzi $-1993 ; \mathrm{c}=$ isócrona $\mathrm{Sm}-\mathrm{Nd}$ recalculado neste trabalho, $\mathrm{d}=$ isócrona $\mathrm{Sm}-\mathrm{Nd}, \mathrm{Fugi}-1989, \mathrm{e}=\mathrm{Correia}$ et. al. -1997 , est= idades estimadas. Referências para dados Sm/Nd: $n t=$ neste trabalho, $1=$ dados isotópicos de Bizzi $-1993,2=$ dados isotópico de Fugi $-1989,3=$ Pimentel informação verbal, $4=$ Correia et. al. (dados inéditos). . As idades modelos foram todos calculado e/ ou recalculados neste trabalho. 


\subsection{DOMÍNIO ARAXÁ - ALTO RIO GRANDE}

\subsection{2-1: SÍNTESE GEOLÓGICA}

GENERALIDADES : O dominio Araxá-Alto Rio Grande inclui as Faixas de Dobramentos Araxá, Alto Rio Grande (incluindo o Complexo Amaparo) e a Nappe de Empurrão Socorro Guaxupé, além embasamento da porção norte da Bacia do Paraná (Figs. 5.9-1, 5.12-1 e 5.12-4).

FAIXA DE DOBRAMENTOS ARAXÁ: O Grupo Araxá faz parte da denominada Faixa Uruaçú, originalmente definida por Almeida (1968), que atribui para o seu metamorfismo idades entre 1,0 a 1,2Ga (Ciclo Uruaçuano). Schobbenhaus Filho et. al (1975) incluiram o Grupo Araxá, a Formação Canastra e o Grupo Araí no denominado Sistema de Dobramentos Araxá. Neste trabalho, a Faixa de dobramentos Araxá (FDA) corresponde apenas aos terrenos envolvendo o Grupo Araxá ao sul da inflexão de Pirineus (Fig.5.12-1).

Rochas granulíticas da região de Anápolis forneceram idades $\mathrm{Rb}-\mathrm{Sr}$ do final do Mesoproterozóico e início do Neoproterozóico (1,1 e 0,95 Ga; Tassinari, 1983). Estudos geocronológicos Rb-Sr e U-Pb adicionais (Pimentel et. al., 1992), realizadas em rochas metariolíticas da seqüência Maratá (Grupo Araxá, $\sim 100 \mathrm{Km}$ a SE de Goiânia), forneceram idades aparentes por volta de $0,8 \mathrm{Ga}$. tanto por isócrona $\mathrm{Rb}-\mathrm{Sr}$ como por datações $\mathrm{U}-\mathrm{Pb}$ em zircões. Os dados geocronológicos $\mathrm{Rb}-\mathrm{Sr}$ e U-Pb indicam que pelo menos parte do Grupo Araxá foi depositado no Neoproterozóico, contemporâneo à evolução dos grupos Paranoá e Bambuí (Faixa Brasilia). Idades Neoproterozóicas também foram obtidas por Bizzi (1993) nos granodioritos e dioritos situados entre Catalão e Monte Carmelo (isócrona $\mathrm{Rb}-\mathrm{Sr}$ de $0.71 \mathrm{Ga} / \mathrm{ri}=0.711$; isócrona $\mathrm{Sm}-\mathrm{Nd}$ em rocha total de $0.82 \mathrm{Ga} / \mathrm{ri}=0.51136$ ). 
FAIXA DE DOBRAMENTOS ALTO RIO GRANDE (FARG): Esta faixa corresponde a uma parte do setor central da Provincia Mantiqueira, incluindo rochas pertencentes aos Grupos São Del Rey, Andrelândia e parte do Maciço de Guaxupé (Hasui e Oliveira, 1984). Ela estendese como uma estreita faixa até a região de Amparo / Serra Negra, como se vê na fig. 5.12-4A.

A FARG representa, sob ponto de vista geotectônico, uma margem continental passiva, acrescida à borda meridional do Craton do São Francisco (Campos Neto, 1991). Trata-se de terrenos alóctones, formados no Ciclo Uruaçuano, e interpretados como bacia marginal de retroarco.

As idades radiométricas pre-existentes nesta faixa podem ser resumidas da seguinte forma:

ARQUEANO e PALEOPROTEROZÓICO - Rochas migmatiticas da região de Amparo e de Fortaleza de Minas apresentaram idades isocrônicas $\mathrm{Rb}-\mathrm{Sr}$ arqueanas, representanto fragmentos antigos, preservados dos eventos tectônicos subsequentes.

Rochas gnáissico-migmatíticas com idades Paleoproterozóicas (do Ciclo Transamazônico) ocorrem adcionalmente neste domínio, sugerindo tratar-se de terrenos formados tanto a partir de retrabalhamento crustal como por derivação direta do manto nesta época.

MESOPROTEROZÓICO - A fragmentação dos microcontinentes formados no Paleoproterozóico parece ter condicionado a formação das bacias de deposição do Ciclo Uruaçuano (1,75 -1,2Ga; Campos Neto, 1991). Dados isotópicos que indicam a formação de rochas nesse periodo referem-se principalmente aos Grupos Carrancas, Andrelândia e Itapira.

NEOPROTEROZÓICO - O Ciclo orogênico Brasiliano, interpretado na região como uma série de fases compressivas, foi marcado por intenso retrabalhamento de materiais crustais préexistentes, como sugerem as razões isotópicas ${ }^{87} \mathrm{Sr}^{86} \mathrm{Sr}_{0}$ iniciais das rochas granitóides, com valores normalmente superiores a 0,709 . 


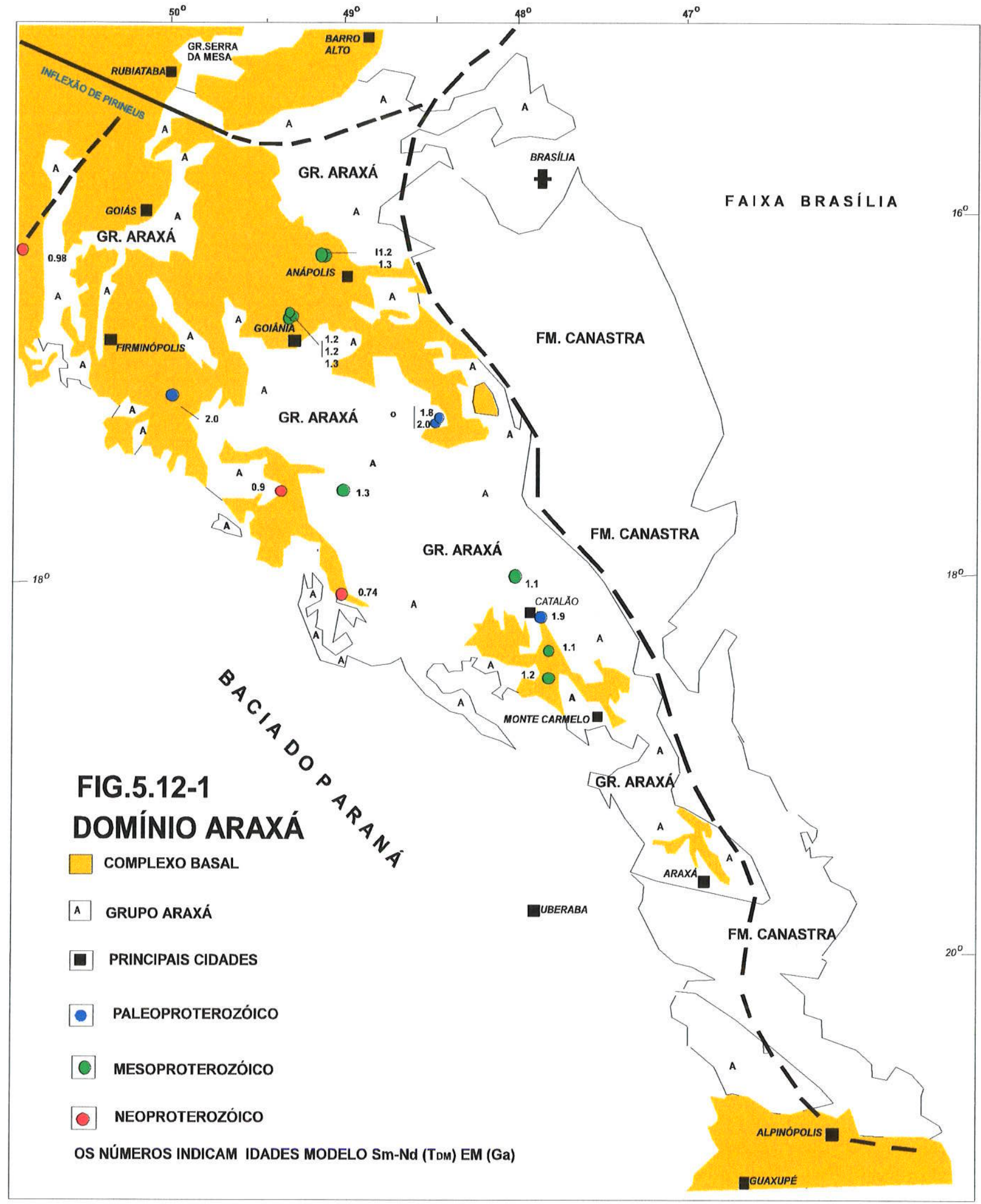




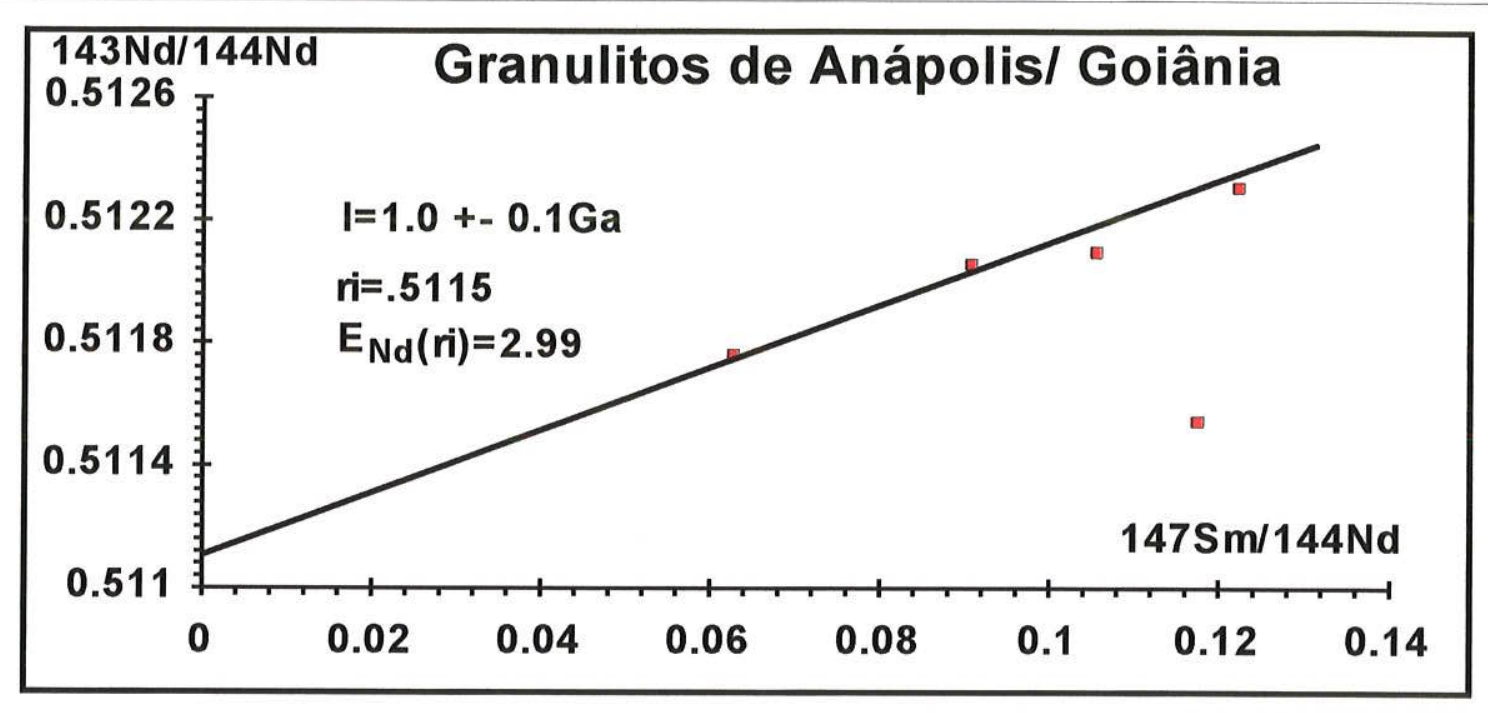

Fig. 5.12-2: Diagrama isocrônico $\mathrm{Sm}-\mathrm{Nd}$ das rochas granulíticas da região de Anápolis/Goiânia.

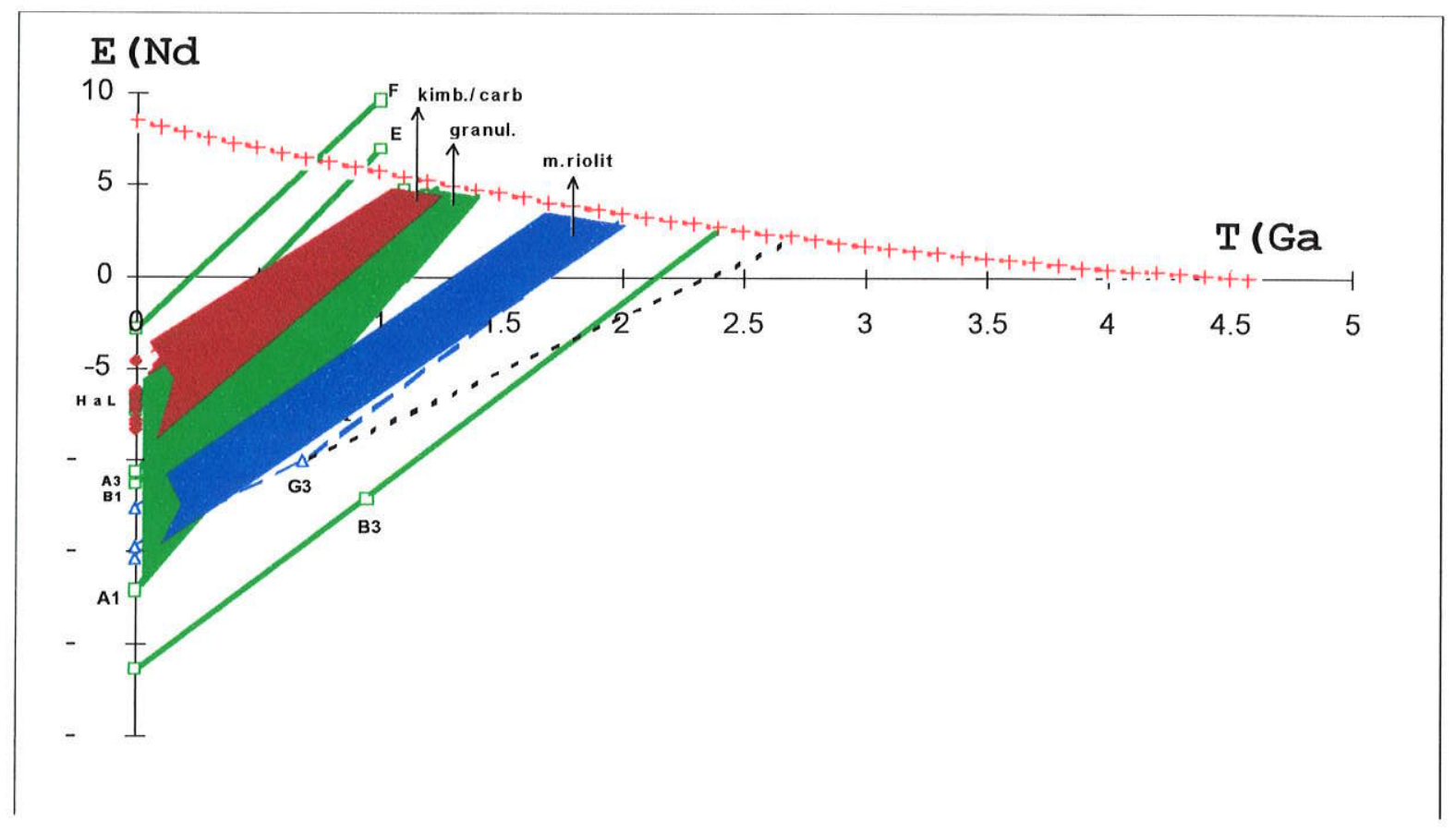

FIG.5.12-3: Diagrama de evolução isototópica $\varepsilon_{N d} \times$ tempo geológico - Domínio Araxá. Os dados isotópicos encontram-se na tab. 5.12-1 


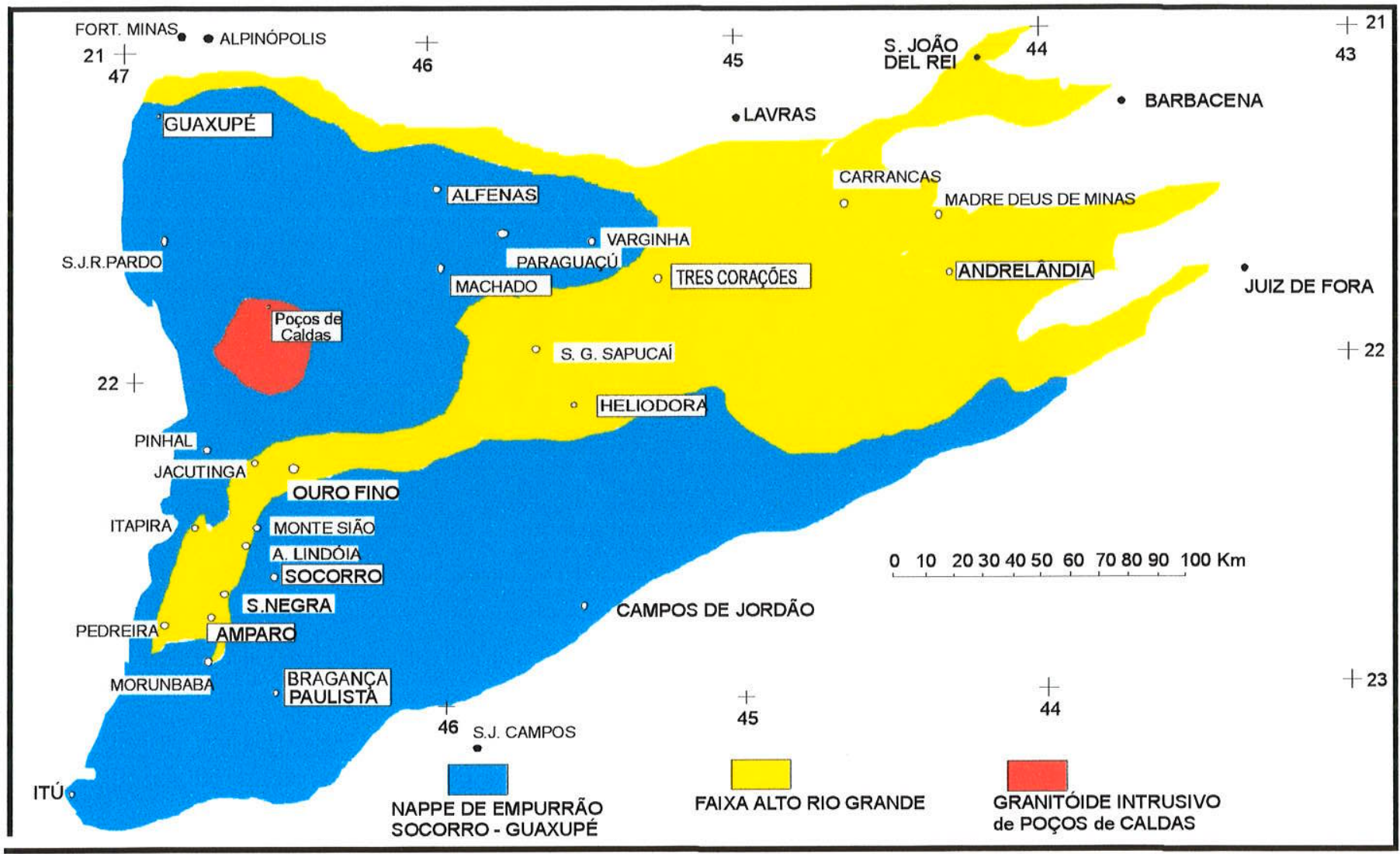

FIG. 5.12-4A : MAPA GEOLÓGICO SIMPLIFICADO COM PRINCIPAIS CIDADES (BASEADO EM CAMPOS NETO 1991) CITADAS NO TEXTO.

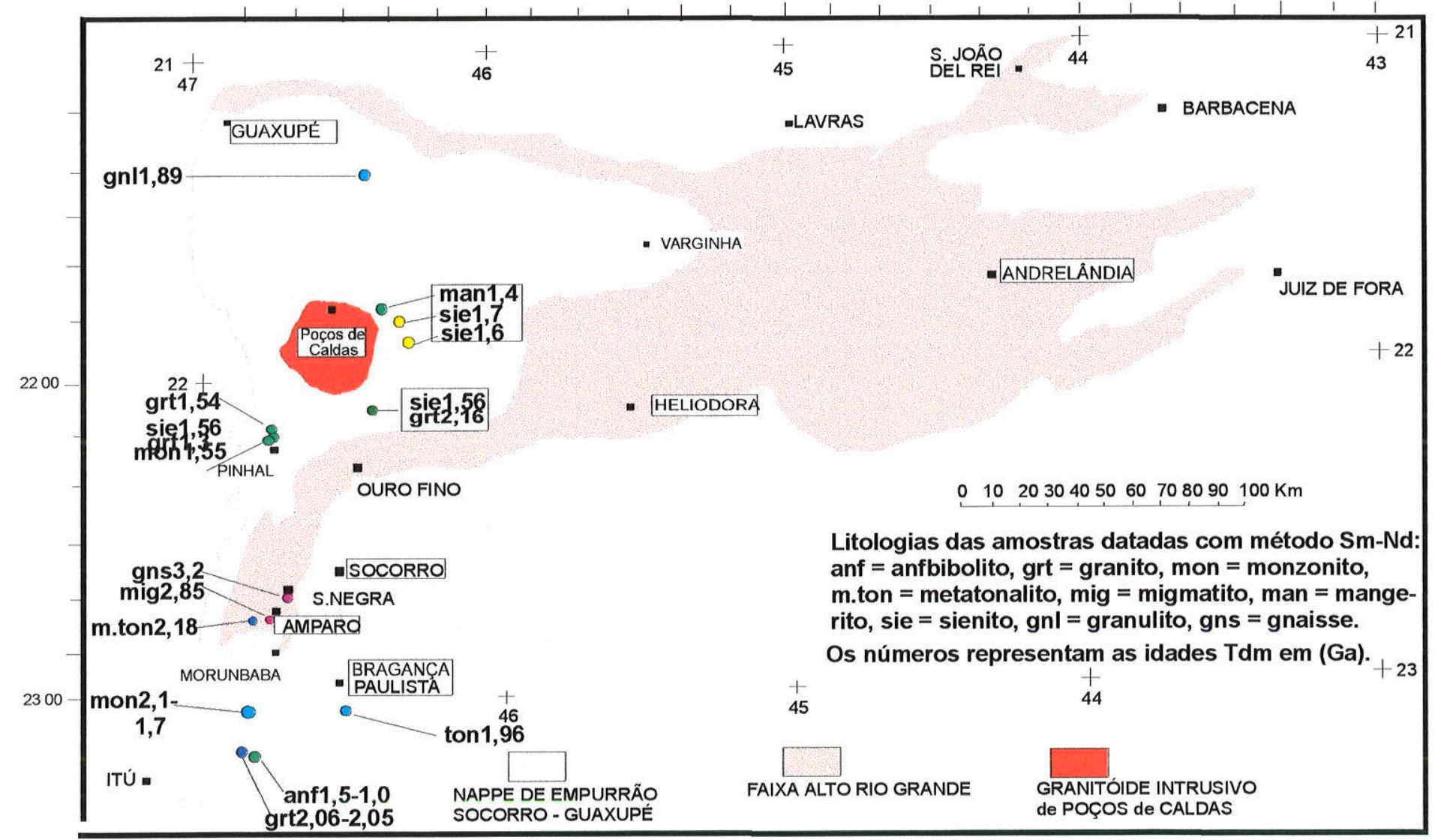

FIG. 5.12-4B: LOCALIZAÇÃO APROXIMADA DAS AMOSTRAS DATADAS COM MÉTODO Sm-Nd. 
NAPPE DE EMPURRÃo SOCORRO-GUAXUPÉ (NESG) - A Nappe de Empurrão Socorro Guaxupé (figura 5.12-4A), compreende terrenos orto e paraderivados de alto grau metamórfico (Campos Neto, 1991). Predominam rochas de infraestrutura, comumente representadas por granitos, migmatitos e granulitos. Os dados geocronológicos $\mathrm{Rb}-\mathrm{Sr}, \mathrm{U}-\mathrm{Pb}$ e $\mathrm{Pb}-\mathrm{Pb}$ pré-existente podem ser resumidos da seguinte forma:

PALEOPROTEROZÓICO - Até o presente não há registro de Arqueano no âmbito da NESG e um único dado indica a formação de rochas no Paleoproterozóico $\left(\mathrm{I}_{\mathrm{Rb}-\mathrm{Sr}}=2,25 \mathrm{Ga} / \mathrm{RI}=\right.$ 0,7001 ; Pedreira Cantière).

MESOPROTEROZÓICO - Dados radiométricos relativos à formação de rochas no Mesoproterozóico foram obtidos principalmente através do método $\mathrm{Pb}-\mathrm{Pb}$, em migmatitos das regiões de S. José dos Campos, Pinhalzinho e Delfim Moreira, com idades distribuidas entre 1,58 a $1,37 \mathrm{Ga}$ e com valores de $\mu 1$ entre 8,01 a 8,11 .

NEOPROTEROZÓICO - Os terrenos da NESG se formaram predominantemente durante o Ciclo Orogênico Brasiliano ( 1,0 a 0,5 Ga), estendendo-se até o início do Fanerozóico. A orogênese Brasiliana provocou intenso retrabalhamento na região, com rehomogeneizações isotópicas de $\mathrm{Sr}, \mathrm{Pb}$ e perdas completas de Ar. As razões ${ }^{87} \mathrm{Sr} /{ }^{86} \mathrm{Sr}$ iniciais, sempre maiores que 0,706, corroboram a interpretação acima mencionada.

BACiA do PARANá: A Faixa de Dobramentos Araxá é recoberta em sua porção ocidental pelos sedimentos Fanerozóicos da Bacia do Paraná.

\subsection{2-2 - IDADES MODELO Sm-Nd, $\mathrm{T}_{\mathrm{DM}}$}


DOMínIO ARAXÁ - As idades modelo e as razões isotópicas Sm-Nd obtidas em rochas granuliticas, vulcânicas ácidas, ultrabásicas e em granitóides pertencentes à FDA encontram-se na tab. 5.12-1. Até o presente momento não há registros isotópicos de idades Arqueanas no ambiento do Dominio Araxá. De um modo geral, observa-se que as idades modelo Sm-Nd, ( $\left.\mathrm{T}_{\mathrm{DM}}\right)$ distribuem-se entre 2,0 a $0,9 \mathrm{Ga}$.

Dados isotópicos $\mathrm{Sm}-\mathrm{Nd}$ em rocha total, relativos às rochas granulíticas do Complexo Anápolis-Itauçu, alinharam-se em diagrama isocrônico (fig. 5.12-2) indicando a idade de formação no limite entre o Mesoproterozóico e o Neoproterozóico $\left(1,0 \pm 0,1 \mathrm{Ga}\right.$; $\left.\varepsilon_{\mathrm{Nd} \text { (inicial) }}=2,9\right)$. Tal idade concorda, dentro dos erros experimentais, com a idade isocrônica $\mathrm{Rb}-\mathrm{Sr}$ de 1,1Ga, referida anteriormente. As idades modelo $\mathrm{Sm}-\mathrm{Nd}\left(\mathrm{T}_{\mathrm{DM}}\right)$ apresentaram valores em torno de $1,2 \mathrm{Ga}$ (tab. 5,12-1A, amostras $\mathrm{Bl}, 2$ e C), sendo que apenas uma amostra acusou idade $\mathrm{T}_{\mathrm{DM}}$ de $2,3 \mathrm{Ga}$ (amostra B3). Do mesmo modo, rochas granulíticas de natureza básica, localizadas próximas à Goiânia, formadas no final do Mesoproterozóico, apresentaram idades $\mathrm{T}_{\mathrm{DM}}$ de 1,3Ga, (amostras A1 e A3, tab. 5.12-1A).

Por outro lado, as rochas granitóides localizadas entre as cidades de Goiânia e Araxá, (com idades de formação próximas de 1,0Ga) apresentaram idades modelo Sm-Nd $\left(\mathrm{T}_{\mathrm{DM}}\right.$ ) distribuidas entre 0,9 a $0,74 \mathrm{Ga}$ (amostras E e F), sugerindo eventos de acreção durante o Neoproterozóico. No diagrama de evolução isotópica de $\varepsilon_{\mathrm{Nd}}$ no tempo geológico (fig. 5.12-3) verifica-se que estas duas rochas (E e F) têm pontos analíticos situados bem acima da curva do manto empobrecido (DM) quando regredidas até $1,1 \mathrm{Ga}$. Também verifica-se no diagrama $\varepsilon_{\mathrm{Sr}} \mathrm{x}$ $\varepsilon_{\mathrm{Nd}}$ (fig. 5.12-6), posicionamento anômalo do ponto $\mathrm{E}$ (primeiro quadrante). Novas análises precisam ser realizadas nestas rochas granuliticas, para caracterizar se houve problemas com a mobilidade química de $\mathrm{Rb}$ ou $\mathrm{Sr}$ durante o evento de alto grau, ou então para verificar-se se trata de fonte mantélica anômala ( $\mathrm{T}_{\mathrm{DM}}$ mais jovens do que as idades aparentes $\mathrm{Rb}-\mathrm{Sr}$ ). 
Idades modelo Sm-Nd obtidas por Pimentel (comunicação escrita) em rochas granitóides localizadas entre as cidades de Goiânia e Catalão (fig. 5.12-1) distribuiram-se entre 2,0 a 1,1Ga, predominando valores relativos ao Mesoproterozóico.

As rochas kimberlíticas e carbonatiticas que ocorrem entre as cidades de Catalão e Araxá apresentaram idades isocrônicas $\mathrm{Rb}-\mathrm{Sr}$ de $0,1 \mathrm{Ga}$, indicando a formação dessas rochas no Cretáceo (Bizzi 1993). As análises geoquimicas nestas rochas indicam forte enriquecimento em ETR, não caracterizando derivação direta de um manto normal empobrecido (DM). Tais rochas (amostras J1 a J13, tabela 5.12-1A), além de terem concentrações elevadas em terras raras mostram também enriquecimento preferencial no elemento $\mathrm{Nd}$ em relação ao $\mathrm{Sm}$, (as razões ${ }^{147} \mathrm{Sm} /{ }^{144} \mathrm{Nd}$ são na maioria menores que 0,085 ), padrão similar ao observado nas rochas kimberliticas da porção oeste da Austrália (McCulloch et. al, 1983), e interpretado como decorrente de manto enriquecido tipo EMII. Quando datadas pelo método Sm-Nd, forneceram idades modelo entre 1,28 a 0,8Ga, coerente com o superevento de acreção do início do Neoproterozóico para a FDA. O parâmetro $\varepsilon_{\mathrm{Nd}}$ quando calculado para a idade de formação $(0,1 \mathrm{Ga})$, forneceu valores negativos, distribuidos entre $-3,8$ a $-6,2$ ( tab. 5.12-1, amostras = J1 a $\mathrm{J} 13$ e fig. 5.12-3), sugestivo de materiais fontes com afinidade com manto litosférico enriquecido.

FAIXA DE DOBRAMENTOS ALTO RIO GRANDE (FARG) - Com a relação às idades modelo $\mathrm{Sm}-\mathrm{Nd}\left(\mathrm{T}_{\mathrm{DM}}\right)$, os granitóides que ocorrem no âmbito da FARG apresentaram dois padrões distintos: um mais antigo, com valores entre 3,2 e $2,9 \mathrm{Ga}$, e outro mais jovem, com valores próximos a 2,2Ga (Tassinari e Sato 1996; Sato e Campos Neto, 1996). Confirmam-se o Arqueano e o Paleoproterozóico como os principais periodos de acreção de material à crosta continental, responsáveis pela formação dos protolitos crustais da grande maioria das rochas da FARG.

NAPPE DE EMPURRÃo SOCORRO GUAXUPÉ - Da figura 5.12-4 e da tabela 5.12-2 constam as localizações das amostras, os dados isotópicos $\mathrm{Sm}-\mathrm{Nd}$ e as respectivas idades modelo, bem como dados anteriores obtidos por Vlach (1993), Vlach (comunicação escrita), Ragatky (1997), Ragatky (comunicação escrita) e Janasi (1997) para os terrenos pertencente a NESG. De um modo geral, as idades modelo $\mathrm{Sm}-\mathrm{Nd}, \mathrm{T}_{\mathrm{DM}}$, calculadas em estágio único, e em alguns casos em estágio duplo, distribuiram-se entre 2,14 a 1,26 Ga.

As rochas monzoníticas e dioríticas que ocorrem da região de Morungaba (formadas durante o Ciclo Brasiliano $-0,6 \mathrm{Ga}$ ) apresentam idades modelo $\mathrm{Sm}-\mathrm{Nd}, \mathrm{T}_{\mathrm{DM}}$, entre 2,2 a 1,75Ga 
(Vlach 1993). Idades $\mathrm{T}_{\mathrm{IM}}$ similares foram observadas ao longo de toda extensão da NESG, como nas rochas granitóides que ocorrem nos arredores de Bragança Paulista, Guaxupé, Pedra Branca, Capituva e Nazaré Paulista. Idades $T_{D M}$ relativas ao Mesoproterozóico, entre 1.6 e 1,4Ga, foram obtidas nas rochas sieniticas de Pinhal e Santa Rita de Caldas (Janasi, 1997), bem como nas rochas mangeríticas situadas a leste de Poços de Caldas (Sato e Campos Neto 1996).

Adicionalmente, idades modelo $\mathrm{Sm}-\mathrm{Nd}, \mathrm{T}_{\mathrm{IDM}}$. Neoproterozóicas $(\sim 0,6 \mathrm{Ga})$ foram obtidas em rochas vulcânicas que ocorrem nas proximidades de Poços de Caldas (Vlach, comunicação verbal).

Verifica-se portanto, que grande parte dos terrenos de médio a alto grau da NESG se formaram no Ciclo Brasiliano, a partir de protólitos derivados do manto, principalmente durante o Paleo e o Mesoproterozóico. Até o presente, não á qualquer dado registrado de material Arqueano.

BACIA DO PARANÁ: As idades modelo $\left(\mathrm{T}_{\mathrm{DM}}\right)$ relativas às rochas vulcânicas do Cretáceo da Bacia do Paraná variam entre 2,1 a $0,9 \mathrm{Ga}$, com maior concentração em torno de $1.3 \mathrm{Ga}$ (Mantovani, 1985 e Chiaramonti, et. al. - comunicação escrita). Tais estudos isotópicos, acoplados a estudos geoquímicos, sugerem que tais rochas vulcânicas tiveram origem a partir de manto litosférico enriquecido. Embora não existam dados isotópicos relativos ao seu embasamento, é possivel inferir que o substrato da Bacia do Paraná apresente continuidade com as províncias crustais do Paleo e Mesoproterozóico encontradas na FDA e NESG. 


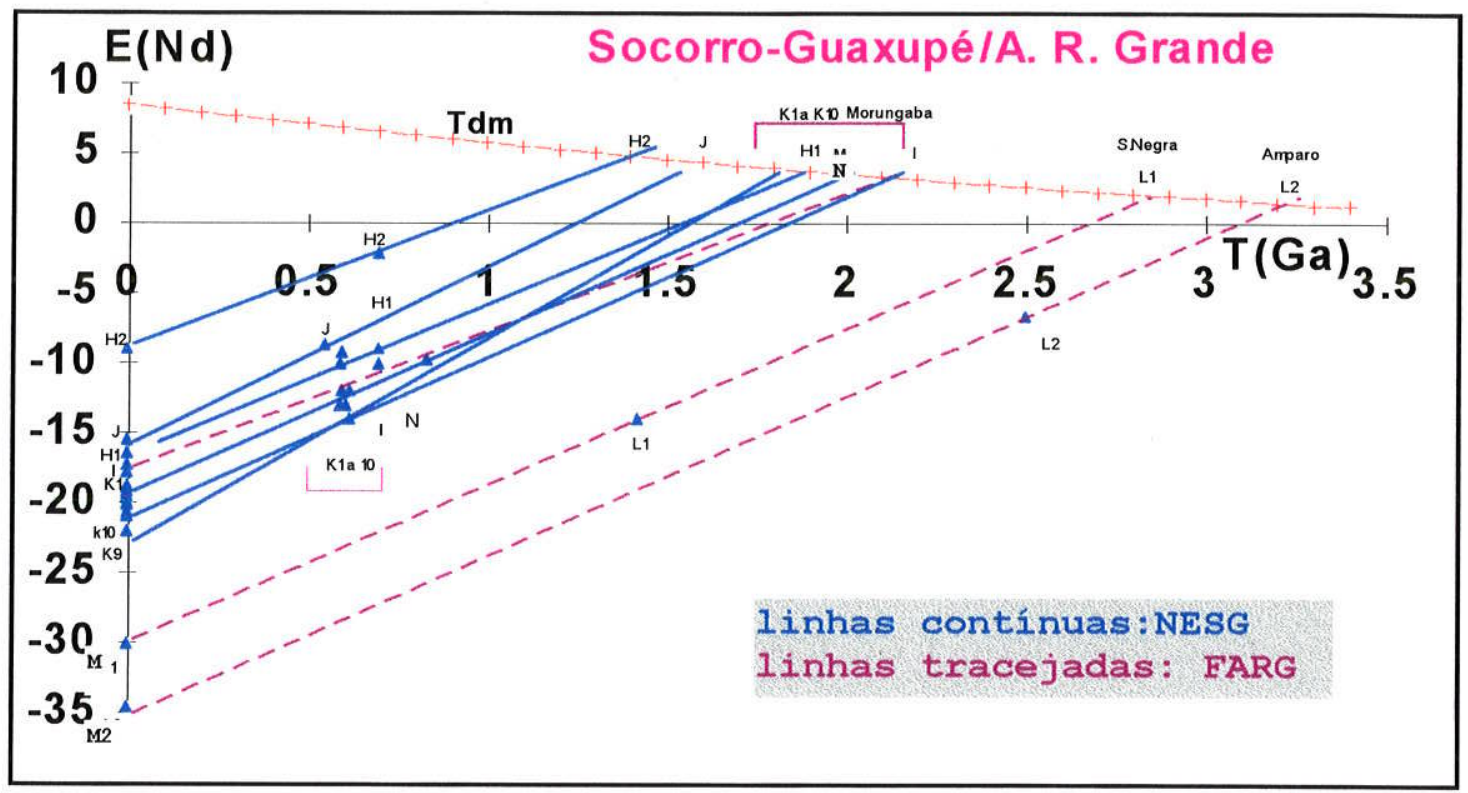

FIG.5.12-5: Diagrama de evolução isototópica $\varepsilon_{\mathrm{Nd}} \times$ tempo geológico - FARG e NESG. Os dados isotópicos encontram-se nas tabelas 5.12-4A e 5.12.12-4B.

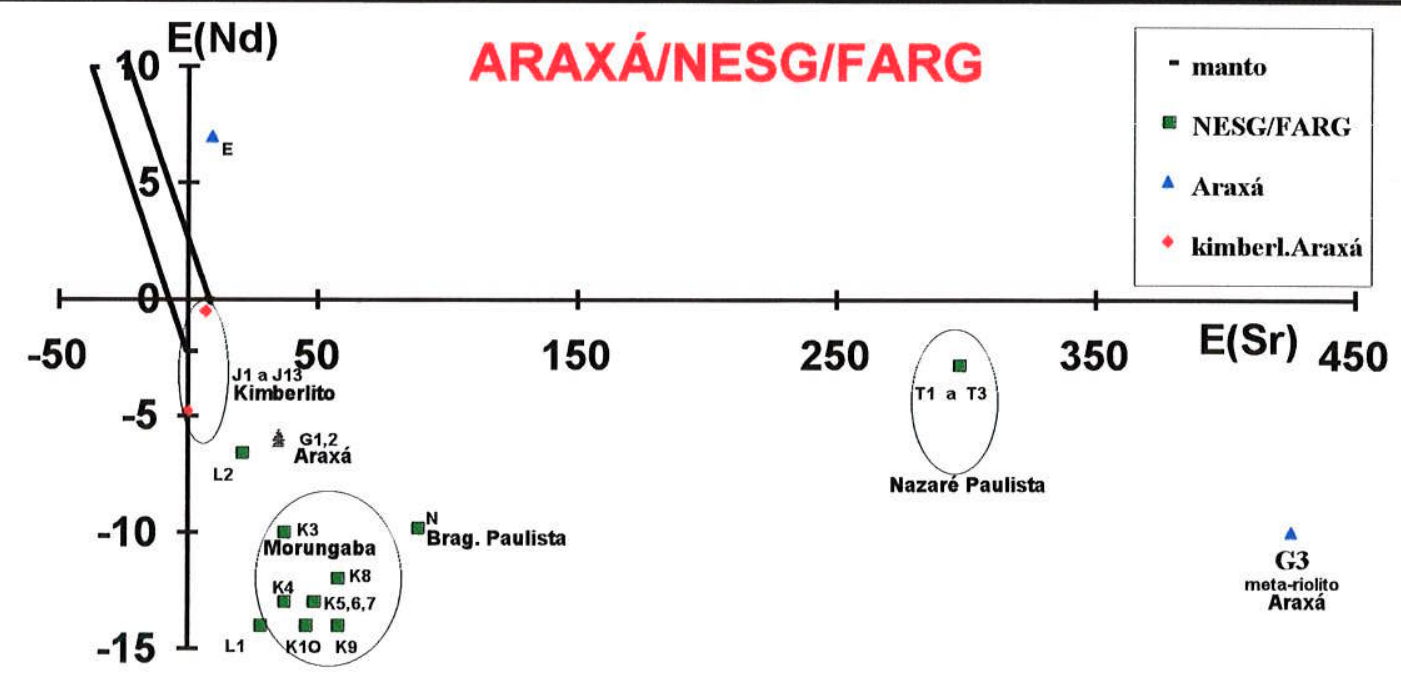

FIG.5.12-6: Diagrama $\varepsilon_{S r} \times \varepsilon_{N d}-A R A X A ́, F A R G$ e NESG 


\section{DIAGRAMA $\varepsilon_{\Upsilon_{\mathrm{d}}} \times$ TEMPO GEOLÓGICO E DIAGRAMA $\varepsilon_{\mathrm{Sr}_{\mathrm{r}}} \mathrm{x} \varepsilon_{\mathrm{Nd}}$ :}

A fig. 5.12-5 os mostra dados relativos à evolução isotópica de $\mathrm{Nd}$ no tempo geológico de rochas pertencentes à FARG e à NESG. Neste diagrama observam-se claramente dois padrões evolutivos distintos: um relativo às rochas gnáissico-migmatiticas de Amparo e Serra Negra (linhas tracejadas $\mathrm{L} 1$ e L2), com idades $\mathrm{T}_{\mathrm{DM}}$ Arqueanas, e outro relativo às demais rochas, cujas linhas evolutivas, quando regredidas no tempo geológico, interceptam a curva do manto empobrecido (DM) no intervalo entre Paleo e Mesoproterozóico.

$\mathrm{O}$ diagrama $\varepsilon_{\mathrm{Sr}} \times \varepsilon_{\mathrm{Nd}}$ (fig. 5.12-6) mostra o padrão de valores $\varepsilon_{\mathrm{Sr}}$ e $\varepsilon_{\mathrm{Nd}}$ iniciais, observado para os terrenos pertencente à FDA, NESG e FARG. Os valores de $\varepsilon_{\mathrm{Nd}}$ negativos, quando calculados para a época da formação dessas rochas, com base nas idades $\mathrm{Rb}$ - $\mathrm{Sr}$, sugerem fontes com afinidade crustal. Quanto mais afastados da origem os pontos analíticos, maiores são os tempos de residência crustal, como é o caso das rochas granitóides de Nazaré Paulista (amostras Tl a T3) e das vulcânicas ácidas de Araxá (amostra G3).

\subsection{2-3: RESUMO PARCIAL:}

FAIXA DE DOBRAMENTOS ARAXÁ (FDA)- Os principais períodos de acreção crustal foram o Paleoproterozóico (Ciclo Transamazônico - 2,2-1,8Ga), e Mesoproterozóico (Ciclo Uruaçu - 1,3 a 1,1Ga). Há registros em menor escala de acreções no início do Neoproterozóico $(1,0-0,8 \mathrm{Ga})$.

FAIXA ALTO RIO GRANDE (FARG): devido às poucas determinações Sm-Nd disponíveis serão levadas em conta os dados de $\mathrm{Sr}$ (idades $\mathrm{Rb}-\mathrm{Sr}$ e razões ${ }^{87} \mathrm{Sr} /{ }^{86} \mathrm{Sr}$ iniciais; tab. 5.12-2). De um modo geral estima-se acreções juvenis em torno de 40 a $50 \%$ durante o Arqueano, cerca de 30 a $40 \%$ durante o Paleoproterozóico e restante durante Meso/Neoproterozóico.

NAPPE DE EMPURRÃO SOCORRO - GUAXUPÉ (NESG): Nestes terrenos destacam-se eventos acrecionários de materiais juvenís durante o Paleoproterozóico (Ciclo Transamazônico entre 2,1 e 1,80Ga) e Mesoproterozóico (entre 1,55 a 1,3Ga) tal como ocorre para a FDA, anteriormente descrita. 
TAB. 5.12-1: IDADES MODELO Sm-Nd, COMPOSIÇÕES ISOTÓPICAS e CONCENTRAÇÕES de Nd e Sm

TAB. 5.12-1A: DOMINIO ARAXÁ

\begin{tabular}{|c|c|c|c|c|c|c|c|c|c|c|c|c|c|c|c|c|c|}
\hline $\begin{array}{l}\text { SPS } \\
\text { /litol }\end{array}$ & $\begin{array}{l}\text { coord.I } \\
\text { (p.local.) }\end{array}$ & $\begin{array}{l}\text { n.campol } \\
\text { região }\end{array}$ & $\begin{array}{l}\text { litolo } \\
\text { gia }\end{array}$ & ident. & $\begin{array}{l}T_{\text {chur }} \\
\text { (GA) } \\
\text { Goldstein } \\
\text { otal 1984 }\end{array}$ & $T_{(\mathrm{GA})} \mathrm{T}_{\mathrm{dm} 2}$ & $\begin{array}{l}T_{\mathrm{dm}} \\
(\mathrm{GA}) \\
\\
\text { DePaolo } \\
-1981 \\
\end{array}$ & $\begin{array}{l}{ }^{144} \mathrm{Nd} / \\
{ }^{14 d} \mathrm{Nd}\end{array}$ & $\begin{array}{l}{ }^{147} \mathrm{Sml} \\
{ }^{144} \mathrm{Nd}\end{array}$ & $\begin{array}{l}\mathrm{Sm} \\
\mathrm{ppm}\end{array}$ & $\begin{array}{l}\text { Nd } \\
\text { ppm }\end{array}$ & $f$ & $\begin{array}{l}\varepsilon_{\mathrm{Nd}} \\
(0)\end{array}$ & $\begin{array}{l}\varepsilon_{N d} \\
(t)\end{array}$ & $\begin{array}{l}\mathrm{t}(\mathrm{Ga})_{\text {mét }} \\
\mathrm{Ri} \mathrm{i}_{\text {(fonte) }}\end{array}$ & $\begin{array}{l}\varepsilon_{\mathrm{sr}} \\
(\mathrm{t})\end{array}$ & ref \\
\hline $\begin{array}{l}354 / \\
\text { gnl.b }\end{array}$ & $1634 / 4908$ & $\begin{array}{l}\text { CO 23D } \\
\text { Anápolis }\end{array}$ & BAS & A1 & $\begin{array}{l}1.00 \\
0.04\end{array}$ & $1.43^{\text {t2 }}$ & $\begin{array}{l}1.30 \\
0.09\end{array}$ & $\begin{array}{l}.511759 \\
.000087\end{array}$ & 0.0627 & $\begin{array}{l}0.128 \\
0.004\end{array}$ & $\begin{array}{l}1.235 \\
0.001\end{array}$ & -.68 & -17.1 & 1.66 & $\begin{array}{l}1.1 \mathrm{Rb} / \mathrm{Sr} \\
\mathrm{b}^{*}\end{array}$ & & nt \\
\hline $\begin{array}{l}355 / \\
\text { gnl.b }\end{array}$ & $1634 / 4908$ & $\begin{array}{l}\mathrm{CO} 23 \mathrm{~F} \\
\text { Anápolis }\end{array}$ & BAS & A3 & $\begin{array}{l}0.91 \\
0.39\end{array}$ & & $\begin{array}{l}1.34 \\
0.30\end{array}$ & $\begin{array}{l}.512096 \\
.000230 \\
\end{array}$ & $\begin{array}{l}.10572 \\
.00014\end{array}$ & $\begin{array}{l}0.814 \\
0.001 \\
\end{array}$ & $\begin{array}{l}4.656 \\
0.002\end{array}$ & -.46 & -10.6 & 4.8 & $\begin{array}{l}1.1_{\mathrm{Rb} / \mathrm{Sr}} \\
\mathrm{b}^{*}\end{array}$ & & nt \\
\hline $\begin{array}{l}356 / \\
\text { gnl }\end{array}$ & $1613 / 4859$ & $\begin{array}{l}\text { CO } 639 \mathrm{C} \\
\text { Goiânia }\end{array}$ & GNL & B1 & $\begin{array}{l}0.83 \\
0.04\end{array}$ & & $\begin{array}{l}1.22 \\
0.03\end{array}$ & $\begin{array}{l}.512059 \\
.000025\end{array}$ & $\begin{array}{l}.09087 \\
.00005\end{array}$ & $\begin{array}{l}2.619 \\
0.001\end{array}$ & $\begin{array}{l}17.429 \\
0.007 \\
\end{array}$ & -.54 & -11.3 & 3.6 & $\begin{array}{l}1.1 \mathrm{Rb} / \mathrm{Sr} \\
\mathrm{D}^{*}\end{array}$ & & nt \\
\hline $\begin{array}{l}357 / \\
\mathrm{gnI}\end{array}$ & $1613 / 4859$ & $\begin{array}{l}\text { CO } 649 \mathrm{~A} \\
\text { Goiânia }\end{array}$ & GNL & B2 & $\begin{array}{l}0.68 \\
0.06\end{array}$ & & $\begin{array}{l}1.23 \\
0.04\end{array}$ & $\begin{array}{l}.512307 \\
.000027\end{array}$ & $\begin{array}{l}.12233 \\
.00005 \\
\end{array}$ & $\begin{array}{l}6.076 \\
0.001\end{array}$ & $\begin{array}{l}30.035 \\
0.012 \\
\end{array}$ & -.38 & -6.5 & 4.0 & $\begin{array}{l}1.1 \mathrm{Rb} / \mathrm{Sr} \\
\mathrm{b}^{*}\end{array}$ & & nt \\
\hline $\begin{array}{l}358 / \\
\mathrm{gnl}\end{array}$ & 16134559 & $\begin{array}{l}\text { CO } 649 \text { B } \\
\text { Goiânia }\end{array}$ & $\overline{G N L}$ & B3 & $\begin{array}{l}2.10 \\
0.50\end{array}$ & & $\begin{array}{l}2.39 \\
0.38 \\
\end{array}$ & $\begin{array}{l}.511541 \\
.000260 \\
\end{array}$ & $\begin{array}{l}.11746 \\
.00007\end{array}$ & $\begin{array}{l}7.932 \\
0.003\end{array}$ & $\begin{array}{l}40.834 \\
0.020 \\
\end{array}$ & -.40 & -21.4 & -12 & $\begin{array}{l}.95 \mathrm{Rb} / \mathrm{Sr} \\
\mathrm{b}^{+}\end{array}$ & & nt \\
\hline $\begin{array}{l}359 / \\
\text { gnl }\end{array}$ & $1613 / 4559$ & $\begin{array}{l}\text { CO ๔38C } \\
\text { Goiânia }\end{array}$ & GNL & C & $\begin{array}{l}0.75 \\
0.07\end{array}$ & & $\begin{array}{l}1.28 \\
0.05\end{array}$ & $\begin{array}{l}.512269 \\
.000034 \\
\end{array}$ & $\begin{array}{l}.12175 \\
.00090 \\
\end{array}$ & $\begin{array}{l}8.168 \\
0.060 \\
\end{array}$ & $\begin{array}{l}40.570 \\
0.017 \\
\end{array}$ & -.38 & -7.2 & +1.9 & $\begin{array}{l}.95 \mathrm{Rb} / \mathrm{Sr} \\
\mathrm{b}^{*}\end{array}$ & & nt \\
\hline $\begin{array}{l}362 / \\
\text { gtd }\end{array}$ & $1727 / 4928$ & $4126 / A Z 98$ & GTD & $E$ & $\begin{array}{l}0.49 \\
0.04\end{array}$ & & $\begin{array}{l}0.92 \\
0.04 \\
\end{array}$ & $\begin{array}{l}.512289 \\
.000031 \\
\end{array}$ & $\begin{array}{l}.08880 \\
.00006 \\
\end{array}$ & $\begin{array}{l}10.801 \\
0.007\end{array}$ & 73.801 & -.55 & -6.8 & 7.0 & $\begin{array}{l}1.00_{\mathrm{Rb} / \mathrm{Sr}} \\
.704_{b}\end{array}$ & 9.5 & nt \\
\hline $\begin{array}{l}363 / \\
\text { gtd }\end{array}$ & $1801 / 4902$ & $4077 / \mathrm{JH}-\mathrm{MS} 94$ & GTD & $F$ & $\begin{array}{l}0.23 \\
0.04\end{array}$ & & $\begin{array}{l}0.74 \\
0.03 \\
\end{array}$ & $\begin{array}{l}.512493 \\
.000027\end{array}$ & $\begin{array}{l}.09875 \\
.00007 \\
\end{array}$ & $\begin{array}{l}9.621 \\
.005 \\
\end{array}$ & $\begin{array}{l}58.912 \\
.025 \\
\end{array}$ & -.50 & -2.8 & 9.7 & $\begin{array}{l}<1 \mathrm{RO} / \mathrm{Sr} \\
\mathrm{ri}=.704_{\mathrm{b}}\end{array}$ & & nt \\
\hline m.rio & $\sim 1705 / 4825$ & $\begin{array}{l}\text { MP549N } \\
\text { Seq. Maratá }\end{array}$ & VAC & G1 & 1.37 & & 1.74 & $\begin{array}{l}.511853 \\
.000019\end{array}$ & .1093 & 7.3 & 40.6 & -.44 & -15.3 & -6.1 & $\begin{array}{l}.83 \mathrm{Rb} / \mathrm{sr} \\
.706_{\mathrm{d}}\end{array}$ & 35 & 2 \\
\hline m.rio & $-1705 / 4825$ & $\begin{array}{l}\text { MP5490 } \\
\text { Seq. Maratá }\end{array}$ & VAC & G2 & 1.54 & $1.79^{\$ 2}$ & 1.98 & $\begin{array}{l}.511990 \\
.000020\end{array}$ & .1325 & 7.6 & 34.7 &.-33 & -12.6 & -5.8 & $\begin{array}{l}.83_{\mathrm{Rb} / \mathrm{Sr}} \\
.706_{\mathrm{d}} \\
\end{array}$ & 35 & 2 \\
\hline m.rio & $-1705 / 4825$ & $\begin{array}{l}\text { MP596C } \\
\text { Seq. Maratá }\end{array}$ & VAC & G3 & 2.20 & $1.99^{\# 2}$ & 2.58 & $\begin{array}{l}.511882 \\
.000020 \\
\end{array}$ & .1445 & 9.2 & 38.3 & -.27 & -14.7 & -10 & $\begin{array}{l}.69_{\mathrm{Rb} / \mathrm{Sr}} \\
.733_{\mathrm{d}}\end{array}$ & 426 & 2 \\
\hline$\overline{\text { dio }}$ & $\begin{array}{l}\sim 1830 / 4755 \\
\text { sul de Cataläo }\end{array}$ & $\begin{array}{l}\text { PDD } \\
\text { (Perdizes) }\end{array}$ & BAS & $\mathrm{Ha}$ & $\begin{array}{l}1.08 \\
0.03 \\
\end{array}$ & $\begin{array}{l}1.64^{52} \\
0.02\end{array}$ & $\begin{array}{l}1.43 \\
0.02 \\
\end{array}$ & $\begin{array}{l}.511870 \\
.000020 \\
\end{array}$ & .08839 & 12.60 & 86.20 & -.55 & -15.0 & -4.6 & $\begin{array}{l}.71 \mathrm{Rb} / \mathrm{Sr} \\
.71188_{\mathrm{c}} \\
\end{array}$ & 117 & 1 \\
\hline gnd & $\begin{array}{l}\sim 1830 / 4755 \\
\text { sul de Catalào }\end{array}$ & $\begin{array}{l}\text { RAG (Ribeirão } \\
\text { Areado) }\end{array}$ & GTD & $\mathrm{Hb}$ & $\begin{array}{l}1.44 \\
0.03\end{array}$ & & $\begin{array}{l}1.79 \\
0.02\end{array}$ & $\begin{array}{l}.511810 \\
.000015\end{array}$ & .10903 & 12.8 & 59.9 & -.45 & -16.2 & -7.8 & $\begin{array}{l}.71 \mathrm{Rb} / \mathrm{Sr} \\
.71188_{\mathrm{c}}\end{array}$ & & 1 \\
\hline m.bas & $\begin{array}{l}\sim 1830 / 4755 \\
\text { sul de Catalão }\end{array}$ & AMB (Abadia) & BAS & $\mathrm{HC}$ & 1.96 & $1.91^{* 2}$ & 2.37 & .511940 & .1425 & 4.10 & 17.4 & -.28 & -13.6 & -8.4 & $\begin{array}{l}.71 \mathrm{Rb} / \mathrm{sr} \\
.71188_{\mathrm{C}}\end{array}$ & & 1 \\
\hline
\end{tabular}




\begin{tabular}{|c|c|c|c|c|c|c|c|c|c|c|c|c|c|c|c|c|c|}
\hline anf & $\begin{array}{l}-1830 / 4755 \\
\text { sul de Cataläo }\end{array}$ & $\begin{array}{l}\text { RAX (Ribeirăo } \\
\text { Areado) }\end{array}$ & BAS & $\mathrm{Hd}$ & 1.25 & $1.66^{\# 2}$ & 1.88 & .512250 & .1495 & 4.50 & 18.2 & -.24 & -7.6 & -.95 & $\begin{array}{l}1.1 \mathrm{Rb} / \mathrm{st} \\
.7035_{\mathrm{c}} \\
\end{array}$ & 4.1 & 1 \\
\hline kim & $1818 / 4749$ & TRX & UBA & $\sqrt{ } 1$ & 0.40 & & 0.79 & .512310 & .07105 & 46.0 & 391.0 & -.64 & -6.4 & -4.8 & $\begin{array}{l}.1 \mathrm{Rb} / \mathrm{Sr} \\
.7044_{\mathrm{C}}\end{array}$ & 0.2 & 1 \\
\hline kim & $1818 / 4749$ & TRX & UBA & $\sqrt{2}$ & 0.40 & & 0.78 & .512300 & .06701 & 25.4 & 229.2 & -.66 & -6.6 & -4.9 & $\begin{array}{l}.1 \mathrm{Rb} / \mathrm{Sr} \\
.7044_{\mathrm{C}} \\
\end{array}$ & & 1 \\
\hline kim & $1818 / 4749$ & TRX & UBA & $\sqrt{3}$ & 0.57 & & 1.22 & .512400 & .13309 & 9.64 & 43.8 & -.32 & -4.6 & -3.8 & $\begin{array}{l}.1 \mathrm{Rb} / \mathrm{Sr} \\
.7044_{\mathrm{C}} \\
\end{array}$ & & 1 \\
\hline kim & $1832 / 4748$ & LIM & UBA & $\sqrt{4}$ & 0.49 & & 0.88 & .512240 & .07342 & 27.9 & 229.8 & -.63 & -7.8 & -6.2 & $\begin{array}{l}.1 \mathrm{Ro} / \mathrm{St} \\
.7049_{\mathrm{C}} \\
\end{array}$ & & 1 \\
\hline kim & $1832 / 4748$ & LIM & UBA & 55 & 0.44 & & 0.87 & .512310 & .08391 & 29.5 & 212.6 & -.57 & -6.4 & -5.0 & $\begin{array}{l}.1 \mathrm{Rb} / \mathrm{Sr} \\
.7049_{\mathrm{C}}\end{array}$ & 7.3 & 1 \\
\hline kim & \begin{tabular}{|l|}
$1832 / 4748$ \\
\end{tabular} & LIM & UBA & $\mathrm{J} 6$ & 0.48 & & 0.89 & .512280 & .08277 & 32.4 & 236.7 & -.58 & -7.0 & -5.5 & $\begin{array}{l}.1 \mathrm{Rorsr} \\
.7049_{\mathrm{C}} \\
\end{array}$ & & 1 \\
\hline kim.p & $1832 / 4748$ & JAP 60 & $\overline{U B A}$ & 57 & 0.45 & & 0.87 & .512300 & .08310 & 6.50 & 47.3 & -.58 & -6.6 & -5.1 & $\begin{array}{l}.1 \mathrm{Rb} / \mathrm{Sr} \\
\mathrm{C} \\
\end{array}$ & & 1 \\
\hline kim.p & $1832 / 4748$ & JAP $D$ & UBA & 58 & 0.43 & & 0.83 & .512300 & .07682 & 7.00 & 55.1 & -.61 & -6.6 & -5.1 & $\begin{array}{l}1 \mathrm{Rb} / \mathrm{St} \\
\mathrm{c} \\
\end{array}$ & & 1 \\
\hline kim.p & $1832 / 4748$ & JAP 60 & $\overline{U B A}$ & 19 & 0.50 & & 0.88 & .512230 & .07190 & 6.10 & 51.3 & -.63 & -8.0 & -6.4 & $\begin{array}{l}1 \mathrm{Rb} / \mathrm{Sr} \\
\mathrm{c}\end{array}$ & & 1 \\
\hline kim.p & $1832 / 4748$ & JAP $\subseteq 0$ & UBA & 510 & 0.53 & & 0.92 & .512230 & .07845 & 6.50 & 50.1 & -.60 & -8.0 & -6.5 & $\begin{array}{l}1 \mathrm{Rb} / \mathrm{Sr} \\
\mathrm{C} \\
\end{array}$ & & 1 \\
\hline car & $1801 / 4751$ & CATF & UBA & $\mathrm{J} 11$ & 0.44 & & 0.88 & .512320 & .08738 & 46.7 & 323.2 & -.56 & -6.2 & -4.8 & $\begin{array}{l}.1 \mathrm{Rb} / \mathrm{Sr} \\
\mathrm{c} \\
\end{array}$ & & 1 \\
\hline car & $180\} / 4751$ & CAT.S & UBA & $\sqrt{12}$ & 0.53 & & 1.02 & .512210 & .07306 & 53.1 & 439.5 & -.63 & -8.3 & -6.8 & $\begin{array}{l}.1 \mathrm{Rb} / \mathrm{Sr} \\
\mathrm{C} \\
\end{array}$ & & 1 \\
\hline car & $1801 / 4751$ & CATIL & UBA & $J 13$ & 0.47 & & 0.88 & .512270 & .07826 & 28.2 & 217.9 & -.60 & -7.2 & -5.7 & $\begin{array}{l}1 \mathrm{Rb} / \mathrm{Sr} \\
\mathrm{c} \\
\end{array}$ & & 1 \\
\hline
\end{tabular}

Obs.: a nota explicativa desta tabela encontram-se no anexo1.

\section{TAB. 5.12-2A: ALTO RIO GRANDE}

\begin{tabular}{|c|c|c|c|c|c|c|c|c|c|c|c|c|c|c|c|c|c|}
\hline $\begin{array}{l}\text { SPS } \\
\text { /litol }\end{array}$ & $\begin{array}{l}\text { coord./ } \\
\text { (p.local.) }\end{array}$ & $\begin{array}{l}\text { n.campol } \\
\text { região }\end{array}$ & $\begin{array}{l}\text { litolo } \\
\text { gia }\end{array}$ & ident. & $\begin{array}{l}T_{\text {chur }} \\
\text { (GA) } \\
\text { Ooldstein } \\
\text { otal } 1984\end{array}$ & $\begin{array}{l}T_{\mathrm{dm} 2} \\
(\mathrm{GA})\end{array}$ & $\begin{array}{l}T_{\mathrm{dm}} \\
\text { (GA) } \\
\text { DePaolo } \\
\text {-1981 } \\
\end{array}$ & $\begin{array}{l}{ }^{143} \mathrm{Nd} l \\
{ }^{144} \mathrm{Nd}\end{array}$ & $\begin{array}{l}{ }^{147} \mathrm{Sml} \\
{ }^{144} \mathrm{Nd}\end{array}$ & $\begin{array}{l}\mathrm{Sm} \\
\mathrm{ppm}\end{array}$ & $\begin{array}{l}\mathrm{Nd} \\
\mathrm{ppm}\end{array}$ & $f$ & $\begin{array}{l}\varepsilon_{\mathrm{Nd}} \\
(0)\end{array}$ & $\begin{array}{l}\varepsilon_{\mathrm{Nd}} \\
(\mathrm{t})\end{array}$ & $\begin{array}{l}t(\mathrm{Ga})_{\text {mét }} \\
\mathrm{Ri}_{\text {(fonte) }}\end{array}$ & $\begin{array}{l}\varepsilon_{s r_{r}} \\
(t)\end{array}$ & ref \\
\hline $\begin{array}{l}259 \\
\text { m.ton }\end{array}$ & $2240 / 4647$ & $\begin{array}{l}\text { Alll-69/SP } \\
\text { Andrelândia }\end{array}$ & GTD & 1 & $\begin{array}{l}1.83 \\
0.05\end{array}$ & & $\begin{array}{l}2.18 \\
0.04\end{array}$ & $\begin{array}{l}.511749 \\
.000024\end{array}$ & $\begin{array}{l}.12299 \\
.00007\end{array}$ & $\begin{array}{l}5.064 \\
.001\end{array}$ & $\begin{array}{l}24.898 \\
.013 \\
\end{array}$ &. .37 & -17.3 & .10 & .7 est & & $\mathrm{nt}$ \\
\hline
\end{tabular}




\begin{tabular}{|c|c|c|c|c|c|c|c|c|c|c|c|c|c|c|c|c|}
\hline gns? & $2242 / 4645$ & $\begin{array}{l}\text { AMP / - SP } \\
\text { Amparo }\end{array}$ & GTD & L1 & 2.65 & 2.85 & .511102 & .1090 & -- & $+\cdots$ & -.45 & -30.0 & -14 & $\begin{array}{l}1.42 \mathrm{est} \\
.7048 \mathrm{es}\end{array}$ & 28 & 7 \\
\hline o.gns & $2237 / 4641$ & $\begin{array}{l}\text { A171A / SP } \\
\text { S. Negra }\end{array}$ & GTD & 12 & 3.06 & 3.22 & .510867 & .1091 & --- & $-\infty$ & -.45 & -34.5 & -6.6 & $\begin{array}{l}2.50 \\
.703_{p} \\
\end{array}$ & 21 & 7 \\
\hline
\end{tabular}

\begin{tabular}{|c|c|c|c|c|c|c|c|c|c|c|c|c|c|c|c|c|c|}
\hline $\begin{array}{l}247 \\
\text { gnl }\end{array}$ & $2122 / 4624$ & $\begin{array}{l}\text { GX-1OA/MG } \\
\text { Soc/Guaxupé }\end{array}$ & GNL & $\mathrm{H1}$ & $\begin{array}{l}1.53 \\
0.06\end{array}$ & & $\begin{array}{l}1.89 \\
0.04 \\
\end{array}$ & $\begin{array}{l}.511795 \\
.000031\end{array}$ & $\begin{array}{l}.11283 \\
.00020 \\
\end{array}$ & $\begin{array}{l}24.54 \\
.007 \\
\end{array}$ & $\begin{array}{l}131.53 \\
0.23 \\
\end{array}$ & -.43 & $\mid-16.4$ & -9.0 & $.77_{\text {est }}$ & & nt \\
\hline $\begin{array}{l}257 \\
\text { man }\end{array}$ & $2146 / 4621$ & $\begin{array}{l}\text { CA 110B / MG } \\
\text { Soc./Guaxupé }\end{array}$ & GTD & $\mathrm{H} 2$ & $\begin{array}{l}0.92 \\
0.05\end{array}$ & & $\begin{array}{l}1.41 \\
0.04 \\
\end{array}$ & $\begin{array}{l}.512175 \\
.000026 \\
\end{array}$ & $\begin{array}{l}.12008 \\
.00064 \\
\end{array}$ & $\begin{array}{l}12.89 \\
.07 \\
\end{array}$ & $\begin{array}{l}64.198 \\
.07\end{array}$ & -39 & -9.0 & -2.2 & .7 est & & $\mathrm{nt}$ \\
\hline $\begin{array}{l}214 \\
\mathrm{mz} . \mathrm{grt}\end{array}$ & & $\begin{array}{l}\text { A } 1208 / \mathrm{SP} \\
\text { Morungaba }\end{array}$ & GTD & $\mathrm{K} 1$ & $\begin{array}{l}1.23 ? \\
0.03 \\
\end{array}$ & $1.75^{\text {ath }}$ & $\begin{array}{l}1.55 ? \\
0.03 \\
\end{array}$ & $\begin{array}{l}.511726 \\
.000025 \\
\end{array}$ & $\begin{array}{l}.08403 \\
.00007 \\
\end{array}$ & $\begin{array}{l}7.495 \\
.003\end{array}$ & $\begin{array}{l}53.933 \\
.038 \\
\end{array}$ & -.57 & -17.8 & -9.2 & $60_{\text {est }}$ & & 5 \\
\hline $\begin{array}{l}215 \\
\text { dio }\end{array}$ & & $\begin{array}{l}\text { A 515/SP } \\
\text { Morungaba }\end{array}$ & GTD & $\mathrm{K} 2$ & $\begin{array}{l}1.60 \\
0.04 \\
\end{array}$ & & $\begin{array}{l}1.92 \\
0.03 \\
\end{array}$ & $\begin{array}{l}.511674 \\
.000023 \\
\end{array}$ & $\begin{array}{l}.10511 \\
.00007\end{array}$ & $\begin{array}{l}11.794 \\
.005 \\
\end{array}$ & $\begin{array}{l}67.849 \\
034\end{array}$ & -.47 & -18.8 & -12 & $60_{\text {est }}$ & & 5 \\
\hline mon & $2300 / 4655$ & $\begin{array}{l}\text { A-239 / SP } \\
\text { Morungaba }\end{array}$ & GTD & K3 & $\begin{array}{l}1.27 ? \\
.07 \\
\end{array}$ & $1.80^{\#+1}$ & $\begin{array}{l}1.57 ? \\
.05 \\
\end{array}$ & $\begin{array}{l}.511660 \\
.000050 \\
\end{array}$ & .07931 & 6.4 & 48.8 & -.60 & -19.1 & -10 & $\begin{array}{l}.59_{\mathrm{Rb} / \mathrm{Sr}} \\
.7065_{\mathrm{e}}\end{array}$ & 37 & 4 \\
\hline mon & $2257 / 4656$ & $\begin{array}{l}\text { A - } 79 / \mathrm{SP} \\
\text { Morungaba }\end{array}$ & GTD & $\mathrm{K} 4$ & $\begin{array}{l}1.91 \\
.10 \\
\end{array}$ & & $\begin{array}{l}2.23 \\
.07 \\
\end{array}$ & $\begin{array}{l}.511670 \\
.000050 \\
\end{array}$ & .11979 & 8.3 & 41.9 & -39 & -18.9 & -13 & $\begin{array}{l}.59_{\mathrm{Rb} / \mathrm{Sr}} \\
.7065_{\mathrm{e}}\end{array}$ & 37 & 4 \\
\hline mon & $2250 / 4650$ & $\begin{array}{l}\text { A-18/SP } \\
\text { Morungaba }\end{array}$ & GTD & K5 & $\begin{array}{l}1.73 \\
.07 \\
\end{array}$ & & $\begin{array}{l}2.04 \\
.05 \\
\end{array}$ & $\begin{array}{l}.511610 \\
.000040 \\
\end{array}$ & .10660 & 11.0 & 62.4 & -.46 & -20.1 & -13 & $\begin{array}{l}.61 \mathrm{Ro} / \mathrm{sr} \\
.7072 \mathrm{e}\end{array}$ & 49 & 4 \\
\hline mon & $2249 / 4650$ & $\begin{array}{l}\text { A 202/SP } \\
\text { Morungaba }\end{array}$ & GTD & $\mathrm{K} 6$ & $\begin{array}{l}1.65 \\
.02 \\
\end{array}$ & & $\begin{array}{l}1.95 \\
.01 \\
\end{array}$ & $\begin{array}{l}.511850 \\
.000010 \\
\end{array}$ & .09937 & 12.9 & 78.5 & -.49 & -20.6 & -13 & $\begin{array}{l}.61 \mathrm{Rb} / \mathrm{Sr} \\
.7072 \mathrm{e} \\
\end{array}$ & 49 & 7 \\
\hline dio & $2252 / 4656$ & $\begin{array}{l}\text { A } 696 / \mathrm{SP} \\
\text { Morungaba }\end{array}$ & GTD & $\mathrm{K} 7$ & $\begin{array}{l}1.66 \\
.12 \\
\end{array}$ & & $\begin{array}{l}1.97 \\
.09 \\
\end{array}$ & $\begin{array}{l}.511640 \\
.000070\end{array}$ & .10502 & 9.1 & 52.4 & -.47 & -19.5 & -13 & $\begin{array}{l}.61 \mathrm{Rb} / \mathrm{Sr} \\
.7072 \mathrm{e}\end{array}$ & 49 & 4 \\
\hline mon & $2247 / 4646$ & $\begin{array}{l}\text { A- } 962 / \mathrm{SP} \\
\text { Morungaba }\end{array}$ & GTD & $\mathrm{K} 8$ & $\begin{array}{l}1.56 \\
.05 \\
\end{array}$ & & $\begin{array}{l}1.86 \\
.04 \\
\end{array}$ & $\begin{array}{l}.511610 \\
.000030 \\
\end{array}$ & .09623 & 16.9 & 106.2 & -.51 & -20.1 & -12 & $\begin{array}{l}.62 \mathrm{Rb} / \mathrm{sr} \\
.7078_{\mathrm{e}} \\
\end{array}$ & 58 & 4 \\
\hline grt & $2248 / 4647$ & $\begin{array}{l}\text { A - 1181/SP } \\
\text { Morungaba }\end{array}$ & GTD & $\mathrm{K} 9$ & $\begin{array}{l}1.64 \\
.04 \\
\end{array}$ & & $\begin{array}{l}1.93 \\
.04\end{array}$ & $\begin{array}{l}.511510 \\
.000030\end{array}$ & .09231 & 17.6 & 115.3 & -.53 & -22.0 & -14 & $\begin{array}{l}.62 \mathrm{Ro} / \mathrm{sr} \\
7078_{\mathrm{e}}\end{array}$ & 58 & 4 \\
\hline grt & $2247 / 4647$ & $\begin{array}{l}\text { A-973/SP } \\
\text { Morungaba }\end{array}$ & GTD & $\mathrm{K} 10$ & $\begin{array}{l}1.85 \\
.09 \\
\end{array}$ & & $\begin{array}{l}2.14 \\
.07\end{array}$ & $\begin{array}{l}.511560 \\
.000050\end{array}$ & .10793 & 7.8 & 43.7 & -.45 & -21.0 & -14 & $\begin{array}{l}.62 \mathrm{Rb} / \mathrm{sr} \\
.707_{e}\end{array}$ & 46 & 4 \\
\hline ton & $2301 / 4629$ & $\begin{array}{l}\mathrm{CT} 17 / \mathrm{SP} \\
\text { Brag. Paulista }\end{array}$ & GTD & $N$ & 1.65 & & 1.96 & .511635 & .1043 & $-\cdots$ & -- & -.47 & -19.6 & -9.8 & $\begin{array}{l}0.83 \\
.7098_{f}\end{array}$ & 89 & 7 \\
\hline $\begin{array}{l}533 \\
\text { grt }\end{array}$ & $2208 / 4644$ & $\begin{array}{l}\mathrm{PH}-143 / \mathrm{SP}) \\
\text { Pinhal }\end{array}$ & GTD & 0 & $\begin{array}{l}1.17 \\
0.04 \\
\end{array}$ & & $\begin{array}{l}1.54 \\
.03 \\
\end{array}$ & $\begin{array}{l}.511889 \\
.000028 \\
\end{array}$ & $\begin{array}{l}.09934 \\
.00008\end{array}$ & $\begin{array}{l}7.989 \\
0.003 \\
\end{array}$ & $\begin{array}{l}48.631 \\
0.021\end{array}$ & -.49 & -14.6 & -6.5 & $0.65_{\text {est }}$ & & 9 \\
\hline $\begin{array}{l}534 \\
\text { mon }\end{array}$ & $2209 / 4624$ & $\begin{array}{l}\text { SC } 337 \text { (SP) } \\
\text { Sta R. Caldas }\end{array}$ & GTD & $\mathrm{P1}$ & $\begin{array}{l}1.16 \\
0.04 \\
\end{array}$ & & $\begin{array}{l}1.55 \\
0.03\end{array}$ & $\begin{array}{l}.511936 \\
.000025 \\
\end{array}$ & $\begin{array}{l}.10462 \\
.00010\end{array}$ & $\begin{array}{l}10.287 \\
.006 \\
\end{array}$ & $\begin{array}{l}59.462 \\
.028\end{array}$ & -.47 & -13.7 & -6.1 & 0.65 est & & 9 \\
\hline
\end{tabular}




\begin{tabular}{|c|c|c|c|c|c|c|c|c|c|c|c|c|c|c|c|c|c|}
\hline $\begin{array}{l}535 \\
\text { grt }\end{array}$ & $2210 / 4627$ & $\begin{array}{l}\text { SC } 347 \text { (SP) } \\
\text { Sta R. Caldas }\end{array}$ & GTD & P2 & $\begin{array}{l}1.00 \\
0.03 \\
\end{array}$ & & $\begin{array}{l}1.32 \\
0.03\end{array}$ & $\begin{array}{l}.511841 \\
.000026\end{array}$ & $\begin{array}{l}.07493 \\
.00010\end{array}$ & $\begin{array}{l}3.157 \\
0.004\end{array}$ & \begin{tabular}{|l|}
25.478 \\
0.013
\end{tabular} & -.62 & -15.5 & -5.5 & $0.65_{\text {est }}$ & & 9 \\
\hline $\begin{array}{l}462 \\
\text { sie }\end{array}$ & $2200 / 4624$ & $\begin{array}{l}\text { PB8A } \\
\text { Pedra Branca }\end{array}$ & GTD & $Q$ & $\begin{array}{l}1.20 \\
0.05 \\
\end{array}$ & & $\begin{array}{l}1.56 \\
0.04\end{array}$ & $\begin{array}{l}.511854 \\
.000031 \\
\end{array}$ & $\begin{array}{l}.09735 \\
.00008 \\
\end{array}$ & $\begin{array}{l}33.356 \\
0.019 \\
\end{array}$ & \begin{tabular}{|l|}
207.19 \\
0.13 \\
\end{tabular} & -.51 & -15.3 & -7.1 & 0.65 est & & 9 \\
\hline $\begin{array}{l}461 \\
\text { sie }\end{array}$ & $2151 / 4618$ & $\begin{array}{l}\text { CA } 3698 \\
\text { Capituba }\end{array}$ & GTD & $\mathrm{R} 1$ & $\begin{array}{l}1.29 \\
0.05\end{array}$ & & $\begin{array}{l}1.62 \\
0.04\end{array}$ & $\begin{array}{l}.511786 \\
.000030\end{array}$ & $\begin{array}{l}.09583 \\
.00009\end{array}$ & $\begin{array}{l}18.320 \\
.012\end{array}$ & \begin{tabular}{|l|}
115.61 \\
.08
\end{tabular} & -.51 & -16.6 & -8.3 & 0.65 est & & 9 \\
\hline $\begin{array}{l}460 \\
\text { sie }\end{array}$ & $2149 / 4619$ & $\begin{array}{l}\text { CA957 } \\
\text { Capituba }\end{array}$ & GTD & $\mathrm{R} 2$ & $\begin{array}{l}1.39 \\
.04 \\
\end{array}$ & & $\begin{array}{l}1.72 \\
0.03 \\
\end{array}$ & $\begin{array}{l}.511754 \\
.000025\end{array}$ & $\begin{array}{l}.09975 \\
.00008\end{array}$ & \begin{tabular}{|l|}
13.699 \\
.008 \\
\end{tabular} & $\begin{array}{l}83.044 \\
.044 \\
\end{array}$ & -.49 & -17.2 & -9.2 & $0.65_{\text {est }}$ & & 9 \\
\hline 715 & $\begin{array}{l}\text { Diana } \\
\text { dados inéd. }\end{array}$ & $\begin{array}{l}\text { P1-41-c } \\
\text { Piracaia }\end{array}$ & GTD & $S$ & \begin{tabular}{|l|}
1.23 \\
0.04 \\
\end{tabular} & & $\begin{array}{l}1.57 \\
0.03 \\
\end{array}$ & $\begin{array}{l}.511817 \\
.000027 \\
\end{array}$ & $\begin{array}{l}.09482 \\
.00005 \\
\end{array}$ & $\begin{array}{l}10.583 \\
0.003 \\
\end{array}$ & \begin{tabular}{|l|}
67.490 \\
0.026 \\
\end{tabular} & -.52 & 16.0 & -8.2 & $0.6_{\text {est }}$ & & 8 \\
\hline $\begin{array}{l}555 \\
\text { anf }\end{array}$ & " & $\begin{array}{l}\text { Dpi230a I } \\
\text { Nazaré Paul. }\end{array}$ & BAS & $\mathrm{T} 1$ & $\begin{array}{l}1.10 \\
0.0\end{array}$ & $1.45^{\# 2}$ & $\begin{array}{l}1.70 \\
0.04\end{array}$ & $\begin{array}{l}.512250 \\
.000019\end{array}$ & $\begin{array}{l}.14289 \\
.00007\end{array}$ & $\begin{array}{l}7.933 \\
.002\end{array}$ & $\begin{array}{l}33.573 \\
0.015\end{array}$ & -.27 & -7.6 & -2.8 & $\begin{array}{l}0.6_{\mathrm{Rb} / \mathrm{Sr}} \\
.724 \\
.69 \mathrm{Sm} / \mathrm{Nd} \\
\end{array}$ & 297 & 8 \\
\hline $\begin{array}{l}551 \\
\text { grt }\end{array}$ & 4 & $\begin{array}{l}\text { Dpi230b-2l } \\
\text { Nazaré Paul. }\end{array}$ & GTD & T2 & $\begin{array}{l}2.26 \\
0.07\end{array}$ & $2.05^{22}$ & $\begin{array}{l}2.61 \\
0.05\end{array}$ & $\begin{array}{l}.511802 \\
.000026\end{array}$ & $\begin{array}{l}.14057 \\
.00010\end{array}$ & $\begin{array}{l}5.093 \\
.002\end{array}$ & $\begin{array}{l}21.909 \\
.012\end{array}$ & -.29 & -16.3 & -12 & $\begin{array}{l}0.6_{\mathrm{Rb} / \mathrm{Sr}} \\
.724 \\
69_{\mathrm{Sm} / \mathrm{Nd}}\end{array}$ & 297 & 8 \\
\hline $\begin{array}{l}548 \\
\text { grt }\end{array}$ & $"$ & $\begin{array}{l}\text { Dpi 230b-1/ } \\
\text { Nazaré Paul. }\end{array}$ & GTD & T3 & & $2.16^{\# 2}$ & $\begin{array}{l}2.68 \\
0.04\end{array}$ & $\begin{array}{l}.511711 \\
.000023\end{array}$ & $\begin{array}{l}.13731 \\
.00010\end{array}$ & & & & -18.1 & & $\begin{array}{l}0.6_{\mathrm{Rb} / \mathrm{Sr}} \\
.724 \\
.69 \mathrm{Sm} / \mathrm{Nd} \\
\end{array}$ & 297 & 8 \\
\hline $\begin{array}{l}559 \\
\text { anf }\end{array}$ & " & DPi212-br & BAS & T4 & \begin{tabular}{|l|}
0.13 \\
0.13 \\
\end{tabular} & $1.03^{\# 2}$ & $\begin{array}{l}1.16 \\
0.08\end{array}$ & $\begin{array}{l}.512602 \\
.000035\end{array}$ & $\begin{array}{l}.15574 \\
.00016\end{array}$ & \begin{tabular}{|l|}
4.286 \\
.003 \\
\end{tabular} & \begin{tabular}{|l|}
16.641 \\
0.013 \\
\end{tabular} & -.21 & -.7 & 2.6 & $.63 \mathrm{sm} / \mathrm{Na}$ & & 8 \\
\hline vul. & Silvio & Guaxupé & UBA & $\mathrm{U}$ & & & $\sim .57$ & $\begin{array}{l}.512607 \\
.000061\end{array}$ & $\begin{array}{l}.09467 \\
.00005\end{array}$ & & & & & & & & 4 \\
\hline
\end{tabular}

Ver nota explicativa da tabela no anexo1

ref. para as idades $\mathrm{Rb} / \mathrm{Sr}: \mathrm{b}=$ Tassinari $1983, b^{\star}=$ Tassinari 1983 recalculado para este trabalho, $c=$ Bizzi 1993, $d=$ Pimentel et. al. 1992 , e = Vlach 1993, $\mathrm{f}=$ Tassinari $1988, \mathrm{~g}=$ Pimentel dados inéditos.

ref. para dados isotópicos Sm/Nd: nt = neste trabalho, $1=$ Bizzi 1993, $2=$ Pimentel et. al, 1992, 3= Pimentel dados inéditos, $4=$ Vlach $19935=$

Vlach (inédito), $7=$ Tassinari e Sato 1996, $8=$ Ragatky (dados inéditos), $9=$ Janasi 1997. Obs : idades modelos recalculados para este trabalho.

\# idades modelo em estágio duplo onde \# 1 --> T2 = $\mathrm{te}{ }^{147} \mathrm{Sm} /{ }^{144} \mathrm{Nd}=.1 ; \# 2-->\mathrm{T} 2=\mathrm{te}{ }^{147} \mathrm{Sm} /{ }^{144} \mathrm{Nd}=.11$ 


\subsection{3 - FRAGMENTOS CRATÔNICOS LUIS ALVES \\ E RIO DE LA PLATA \\ E BLOCOS TAQUAREMBO E SÃO GABRIEL}

\subsection{3-1 -SÍNTESE GEOLÓGICA:}

FRAGMENTO CRATÔNICO LUIS ALVES: A fig. 5.13-1, base deste trabalho, mostra a compartimentação tectônica dos Fragmentos Cratônicos Luis Alves e Rio de La Plata e suas regiões marginais

O Dominio Luis Alves (fig.5.13-2) é representado, em parte, por rochas de alto grau metamórfico, tendo como litotipo principal gnaisses-granuliticos, de composição tonalitogranodioriítica, com frequentes variações a granulitos básicos. Inclui seqüências de natureza básica e ultrabásica, que em alguns locais, a exemplo de Barra Velha, Piên e Tijucas do Sul constituem a litologia predominante. A maior expressão, em área, desse domínio, ocorre na porção meridional ( Luis Alves, Blumenau, Barra Velha, Joinville, Jaraguá do Sul e São Bento do Sul), onde também se concentram a grande maioria dos trabalhos publicados. Esses terrenos parecem se estender para nordeste (Siga Jr., 1995) rumo a Morretes e Serra Negra, atingindo o Maciço de Itatins, onde ocorrem como uma estreita faixa afilada, entre os Domínios Curitiba e Paranaguá

A extensão desse segmento para SW, envolvendo os Blocos São Gabriel e Taquarembó (no Rio Grande do Sul) e o Bloco Flórida ( no Uruguai), integrando o Cráton Rio de La Plata, foi proposta por Fragoso César ( 1991). Os dados gravimétricos, no entanto, (Hallinan et. al, 1993) indicam a continuidade do Domínio Luis Alves para SW, apenas até a latitude aproximadamente $29^{\circ}$, onde a continuidade seria interrompida por anomalia negativa E-W, não caracterizando sua ligação com os demais terrenos a sul.

Os dados $\mathrm{Rb}-\mathrm{Sr}, \mathrm{U}-\mathrm{Pb}$ (zircões e monazitas analisados no método convencional e em SHRIMP), e $\mathrm{Pb}-\mathrm{Pb}$ indicam terrenos formados no Arqueano $(2,8$ - 2,5Ga) e no Paleoproterozóico $(2,2-1,9 \mathrm{Ga})$. Os dados $\mathrm{K}-\operatorname{Ar}(2,0$ a 1,7Ga) sugerem que grande parte desses 
terrenos encontravam-se relativamente frios, abaixo de $200^{\circ} \mathrm{C}$ no Neoproterozóico, representando possivelmente, nessa época, uma série de fragmentos continentais (microcontinentes).

FRAgMENTO CRATônico Rio De la PlATA: Não há dados Sm-Nd nesta região, mas os dados $\mathrm{Rb}-\mathrm{Sr}$ em rochas do complexo granito-gnáissico da região ocidental do Uruguai, obtidos recententemente por Cingolani et. al (1997), indicaram idades relativas ao Ciclo Transamazônico em seis isócronas, entre 2.15 e $1.90 \mathrm{Ga}$, com razões iniciais todas inferiores a 0.702. Devido a baixa razão inicial registrada nestas rochas sugere-se para a crosta continental deste setor uma derivação direta do manto superior, durante o Paleoproterozóico.

BLOCOS TAQUAREMBÓ e SÃO GRABIEL : Entre os fragmentos cratônicos Luis Alves (SC) e Rio de La Plata (Uruguai) ocorrem terrenos gnássicos-migmatíticos, de médio a alto grau, denominados informalmente de Blocos Taquarembó e São Gabriel (fig. 5.13-3). Esses blocos foram considerados, em diversos trabalhos, parte integrante do Craton Rio de La Plata, por se tratarem de rochas formadas em épocas pré-brasilianas. Outras denominações de cunho geotectônico foram sugeridas, tais como embasamento de faixa móvel e borda cratônica reativada (Fragoso Cesar, 1991), função do maior ou menor envolvimento frente a Orogênese Brasiliana.

O Bloco São Gabriel (fig. 5,13-3A), foi definido originalmente por Jost e Hartmann (1984) e redefinido por Naumann et. al. (1984) para reunir os corpos rochosos aflorantes na porção NW do Escudo Sul Rio-Grandense. O seu contato oriental, com o Cinturão Dom Feliciano, se faz através de uma zona de cisalhamento parcialmente coberta pelas molassas da Bacia de Camaquã, e, o contato S-SW, com os terrenos do Bloco Taquarembó, através de outra zona de cisalhamento de Ibaré. Possui internamente exposições de rochas do embasamento antigo e compõe-se de corpos básicos-ultrabásicos (interpretados como possíveis ofiolitos), ortognaisses cálcio-alcalinos e metavulcano-sedimentares (representantes de um suposto arco de ilhas intraoceânico obductado sobre uma margem continental oriental). Em adição, os granitos de cálcioalcalinos a shoshoníticos (São Sepé, Caçapava, Lavras, etc.) associados, são admitidos como representantes de um complexo orogênico cordilherano autóctone, não metamórfico e pouco deformado, típicos de raiz de arco magmático com polaridade dirigida para a leste, aos quais associam-se, ainda, sedimentos e vulcânicas desenvolvidas em uma bacia de retro-arco (Fragoso César, 1991). 


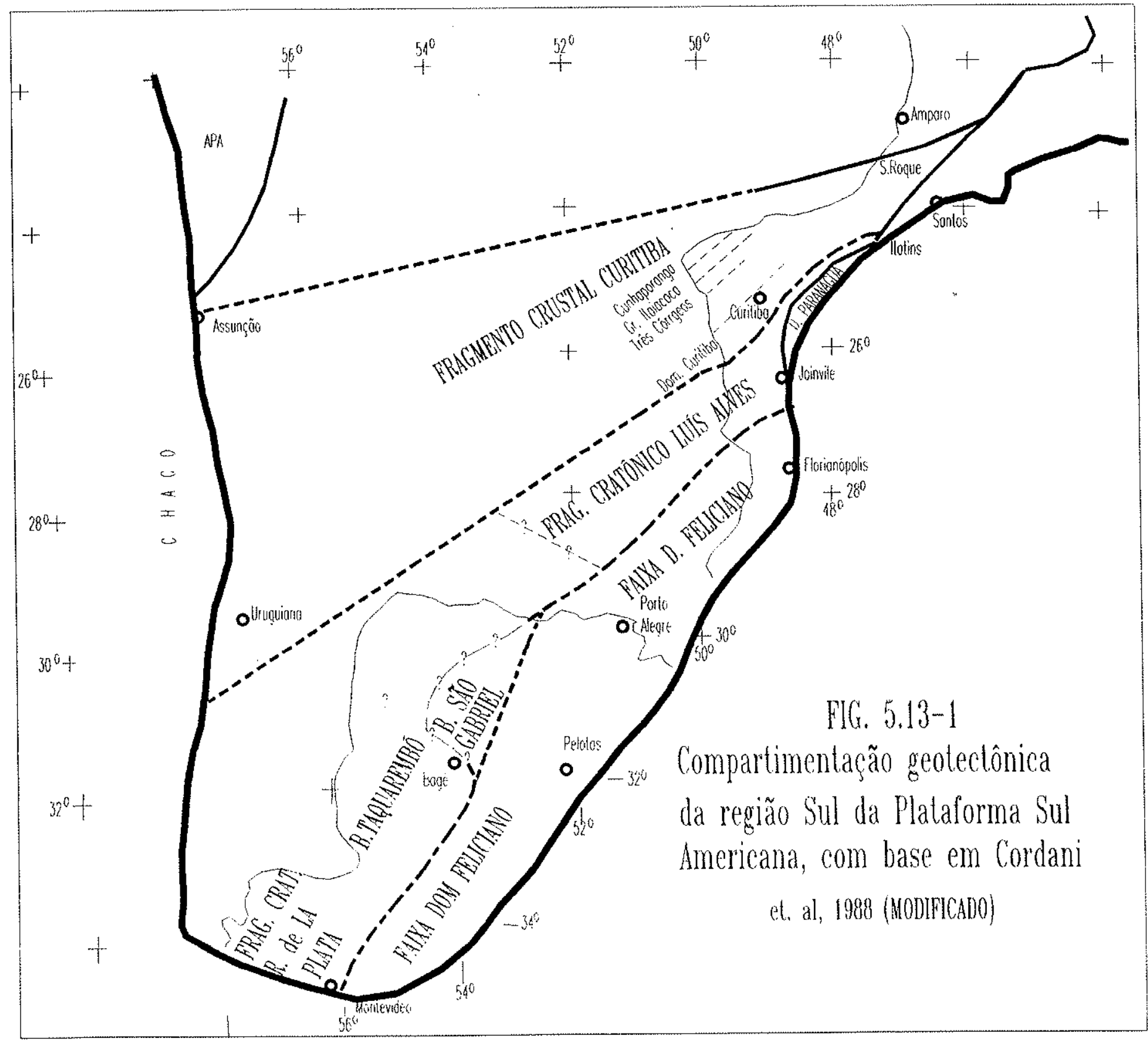




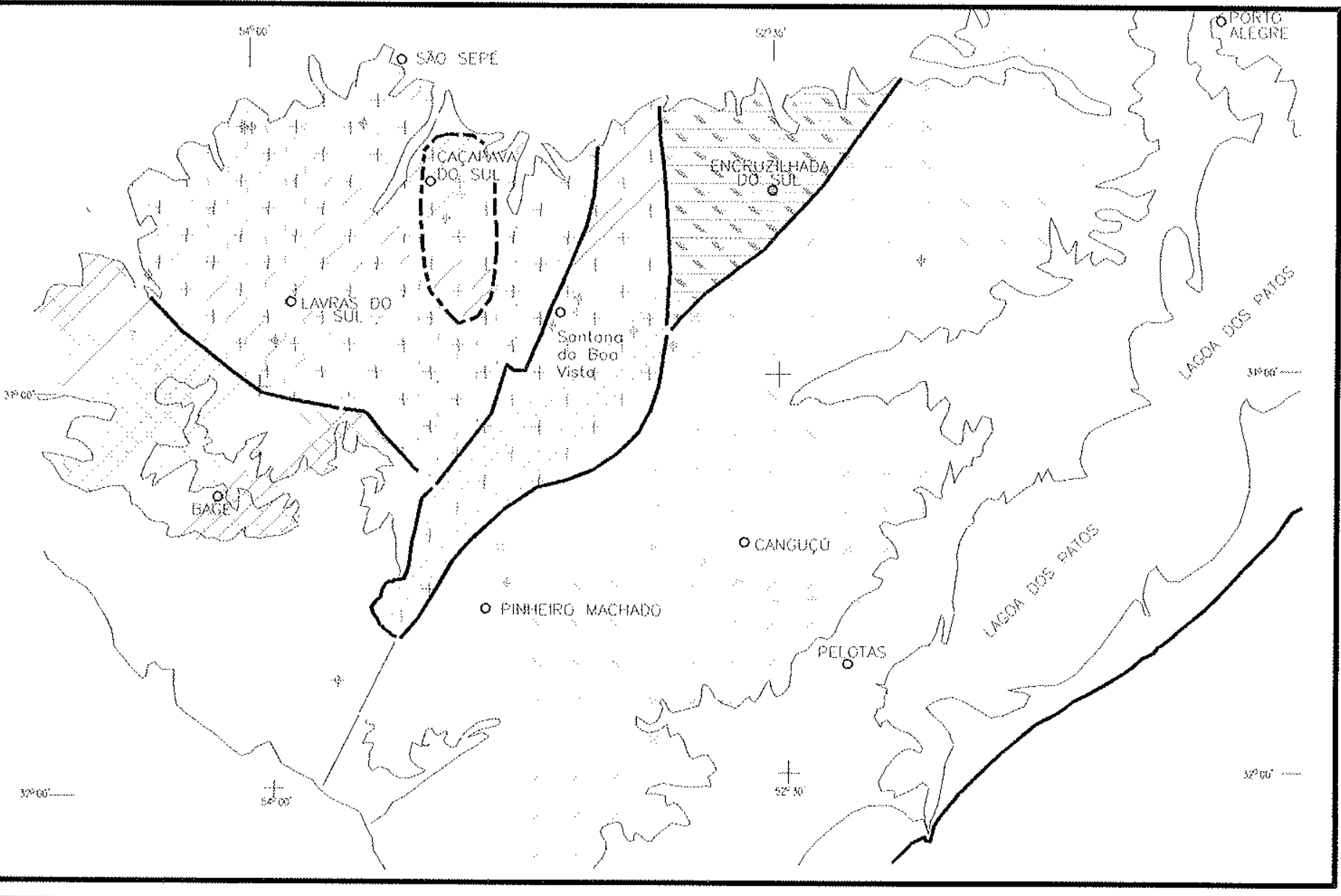

HCONDA
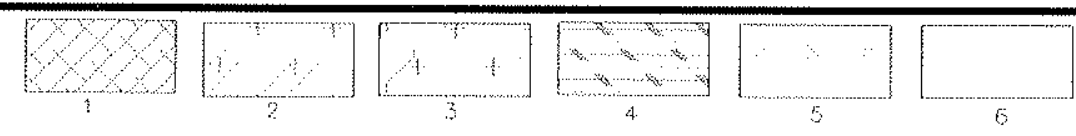

$\circ$

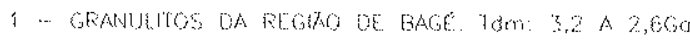
FRA CH BO DE LA PLATA? BLECO TAOUAREMBC CINTURAO D. FEIBIANO BATHOLITO UE CACAPAVA 00 SUl. Tom: 2,5 A 2200 (gronodionito e monzogronito)

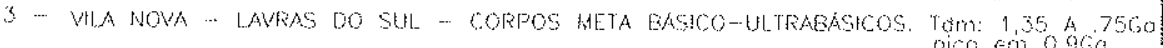

A -- BATOUTO ENGUZZLHATA DO SUL.

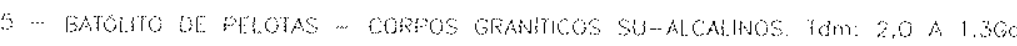
BLOC SAO OAOEL

6 - COBERTURAS

7 -- PRNCWAS COANS 


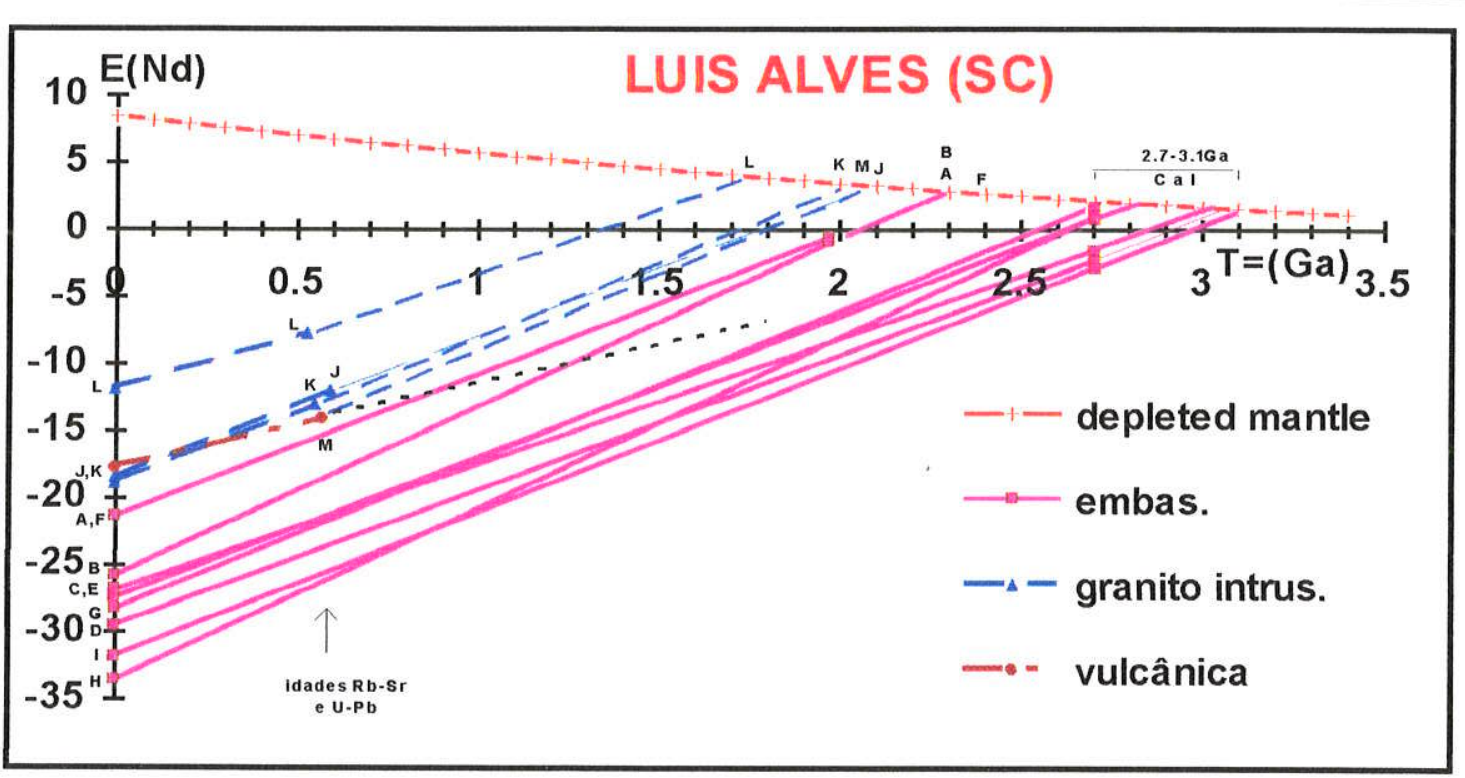

Fig. 5.13-4: Diagrama de evolução isotópico $\varepsilon_{N d}$ versus tempo geológico $T(G a)$ do fragmento cratônico Luis Alves. Os dados isotópicos encontram-se na tabela (5.131).

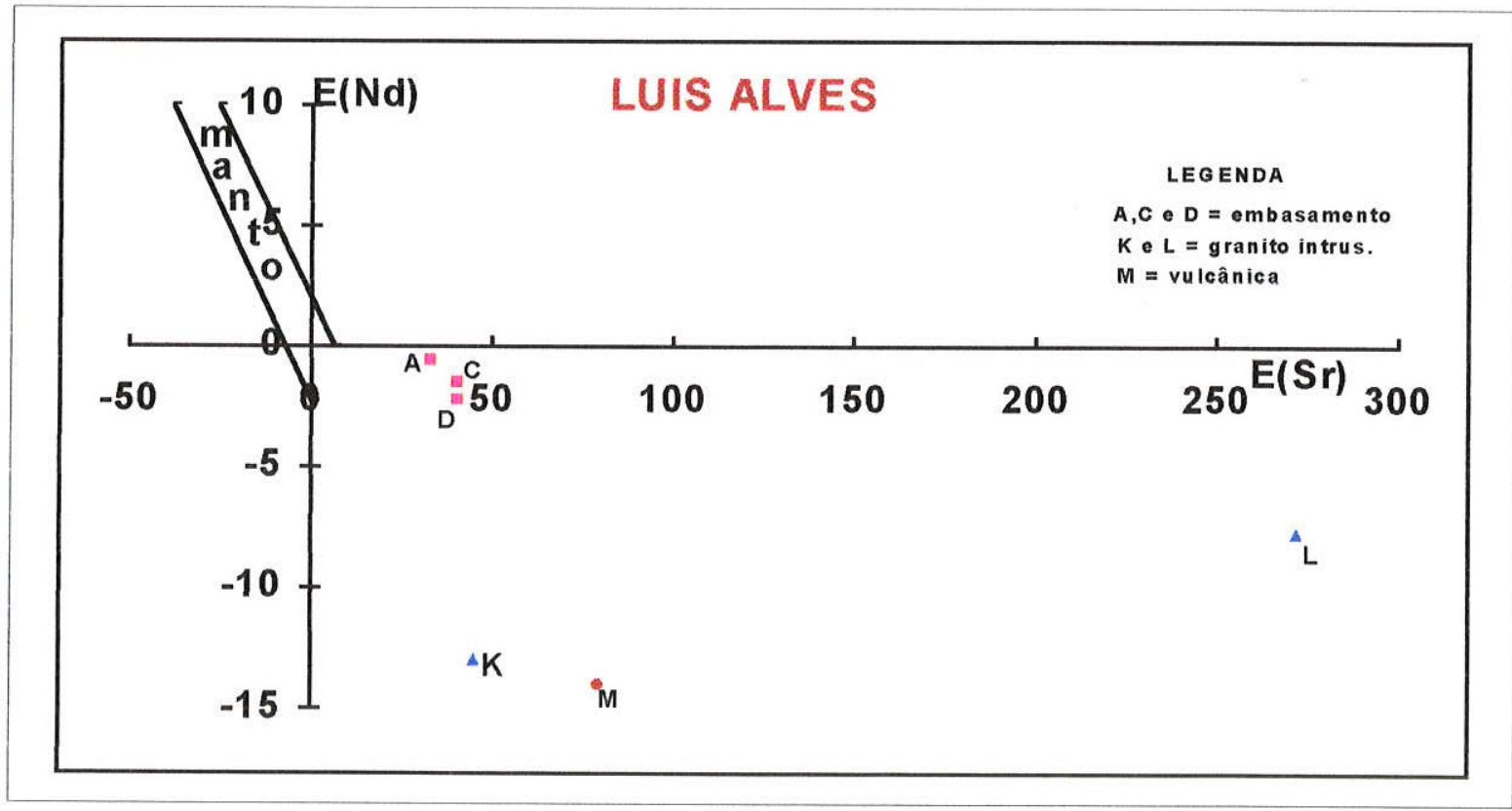

Fig. 5.13-5: Diagrama $\varepsilon_{S r-R I}(t)$ versus $\varepsilon_{N d}(t)$ com dados baseados na tab. 5.13-1. 


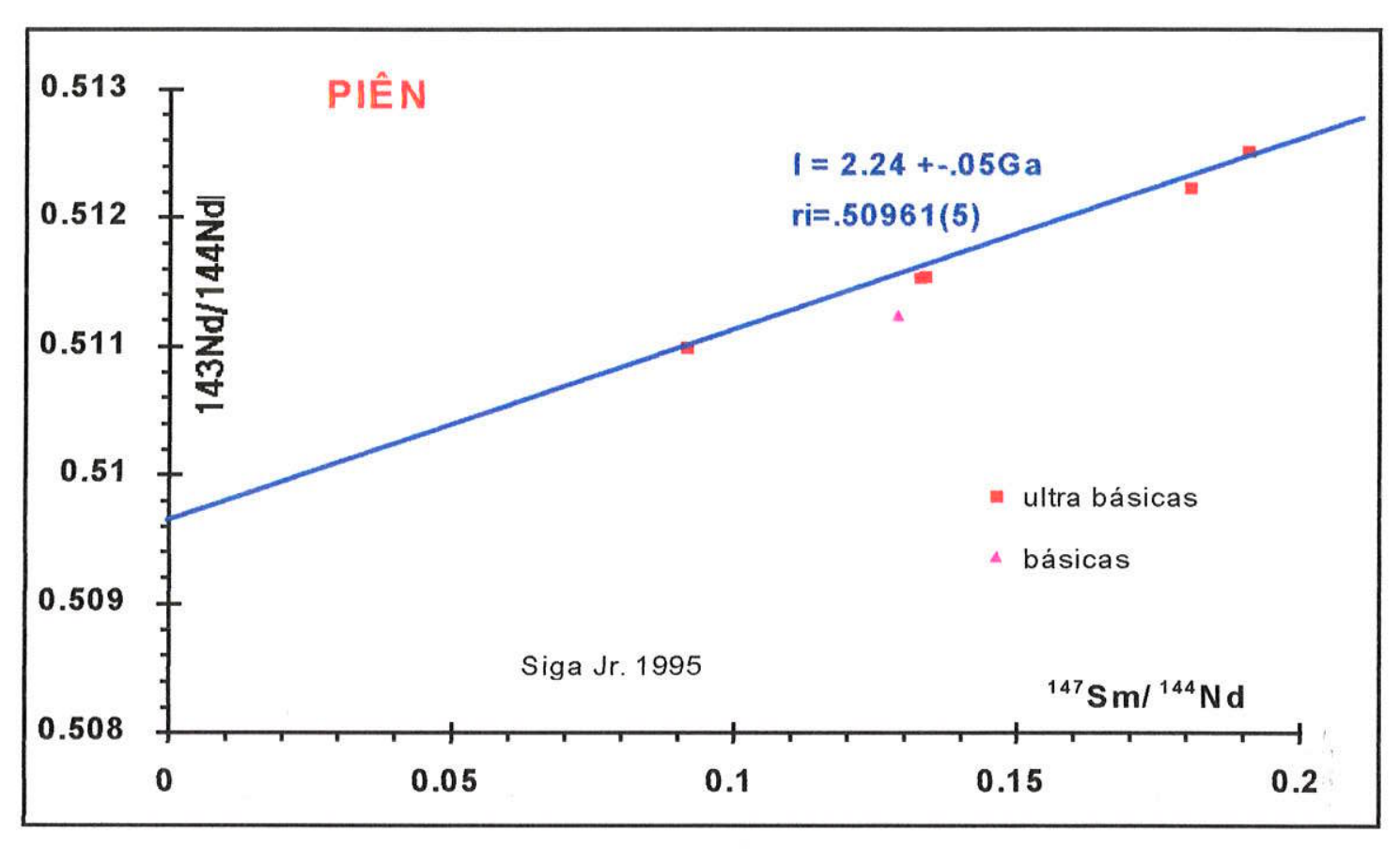

Fig. 5.13-6: Diagrama isocrônico Sm-Nd (RT) das amostras ultrabásicas localizadas próxima à cidade de Piên.

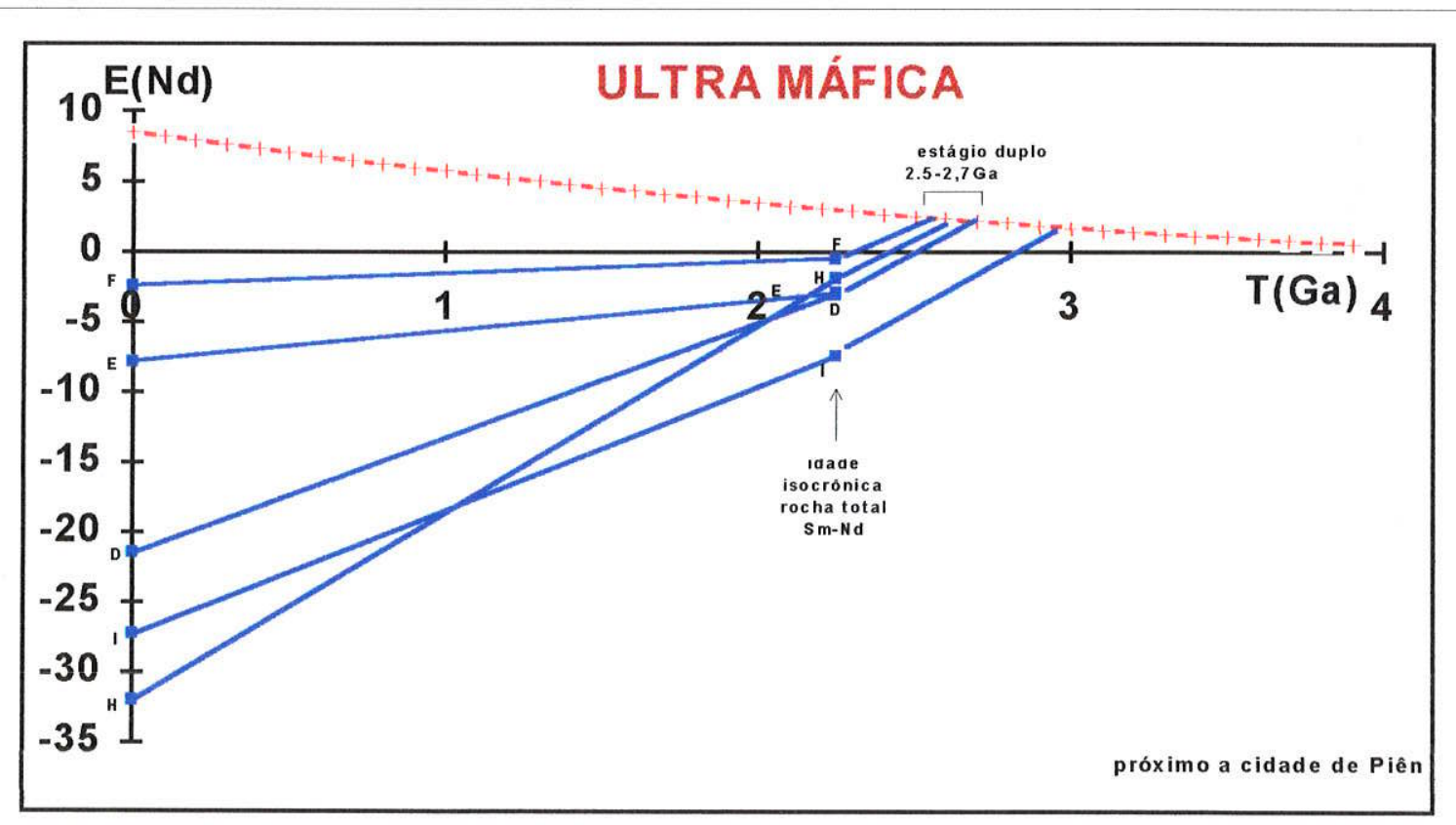

Fig. 5.13-7: Diagrama de evolução isotópico $\varepsilon_{N d}$ versus tempo geológico $T(\mathrm{Ga})$ das rochas ultrabásicas do Piên - Domínio Luis Alves. Os dados isotópicos amostras encontram-se na tabela (5.13-1). Linhas de evolução isotópica de $\mathrm{Nd}$ convergem em 2.2Ga e a regressão em estágio duplo interceptam a curva do manto DM entre 2.5 e $2.7 \mathrm{Ga}$. A linha I (rocha básica) indica uma evolução diferente em relação ao demais podendo ser fontes distintas. 


\subsection{3-2 - IDADES MODELO Sm-Nd, $T_{D M}$}

GENERALIDADES - As tabelas 5.13-1 e 5.13-2 reúnem os dados Sm-Nd e as coordernadas geográficas das amostras datadas do fragmento cratônico Luis Alves e dos Blocos Taquarembó e São Gabriel. Nas figs. 5.13-2 e 5.13-3B encontram-se representadas as localizações aproximadas dessas amostras.

FRAGMENTO CRATÔNICO LUIS ALVES - As idades modelo Sm-Nd relativas aos terrenos gnássicos-granuliticos deste setor distribuem-se em dois intervalos principais, entre $3.1 \mathrm{e}$ 2.7Ga e entre 2.3 e $1.7 \mathrm{Ga}$, caracterizando para os protólitos dessas rochas acreções do manto durante o Arqueano e o Paleoproterozóico (tab. 5.13-1). Os maciços graníticos de natureza alcalina e peralcalina, intrusivos nesses terrenos no Neoproterozóico (Ciclo Brasiliano), indicam para os materiais fontes derivação direta do manto durante o Paleoproterozóico. A figura 5.13-4 ilustra os principais épocas de acreção de material do manto e de formação desses terrenos.

No diagrama $\varepsilon_{\mathrm{Sr}}(\mathrm{t})$ e $\varepsilon_{\mathrm{Nd}}(\mathrm{t})$, fig. 5.13-5, observam-se os protólitos das amostras A, C e D, cujo tempo de residência crustal foi relativamente curto $(<0,5 \mathrm{Ga})$. Por outro lado os granitos intrusivos ( $\mathrm{K}$ e L) bem como a vulcânica (M), situam-se distantes da origem, sugerindo vida crustal relativamente longa para os seus protólitos.

Próximo aos limites dos Domínios Curitiba e Luis Alves (região de Piên-Tijucas do Sul), ocorrem rochas básicas e ultrabásicas, interpretadas por Basei et. al., (1992) e Machiavelli (1992) como prováveis ofiolitos, relacionados à evolução e consequente colisão desses dois blocos no no Neoproterozóico. Os dados Sm-Nd em rocha total forneceram idade isocrônica de 2,24Ga $\left(\mathrm{RI}=0,5091 ; \varepsilon_{\mathrm{Nd}}=-2,46 ;\right.$ fig.5.13-6), interpretada por Siga $\mathrm{Jr}$ (1995), representando o metamorfismo de alto grau impresso nessas rochas. Os dados geoquímicos relativos a essas rochas básicas e ultrabásicas indicaram que pode ter ocorrido durante o metamorfismo um certo grau de fracionamento entre Sm-Nd. A idade modelo com evolução isotópica de Nd em estágio único, regredindo até a curva do manto tipo DM, não teria significado geológico, pois resultaria numa enorme discordância entre os valores das idades $\mathrm{T}_{\mathrm{DM}}$. Por outro lado, se calcularmos as idades $\mathrm{T}_{\mathrm{DM}}$ com o modelo de evolução isotópica de $\mathrm{Nd}$ em estágio duplo, admitindo-se a razão ${ }^{147} \mathrm{Sm} /{ }^{144} \mathrm{Nd}=0,11$ para o estágio primário e $\mathrm{T}_{2}=2,24 \mathrm{Ga}$, as idades $\mathrm{T}_{\mathrm{BM}}$ (aparentes) distribuiramse em torno de 2,63 $\pm 0,07 \mathrm{Ga}$ com razoável concordância (tabela 5.13-1 e fig.5.13-7). A única exceção foi a rocha básica, que parece ser mais antiga que $2.9 \mathrm{Ga}$, e cuja fonte parece ser distinta 
das demais rochas de natureza ultrabásica, provavelmente mais antiga que $2,9 \mathrm{Ga}$. Uma interpretação alternativa quanto á origem das rochas ultrabásicas seria considerar a derivação das mesmas diretamente de um manto litosférico enriquecido (EM), durante o Paloeproterozóico $(2,24 \mathrm{Ga})$.

A figura 5.13-8 apresenta o diagrama isocrônico $\mathrm{Sm}-\mathrm{Nd}$ em minerais (clinopiroxênio, anfibólio, esfeno, microclínio e allanita) concentrados de rocha gnássico-granulítica, localizada nas proximidades de Barra Velha. A isócrona resultante marca, para a formação dessa paragênese a idade de 2,26+-0,67Ga (Hartman et. al., 1995, in: Siga Jr. 1995). O valor de $\varepsilon_{\mathbb{N}}$ da razão inicial mostra-se positivo $(+0,29)$, sugerindo derivação direta de um manto litosférico enriquecido (EM). Se considerarmos o material como diferenciado de um manto tipo DM, o intervalo de tempo entre acreção e formação da rocha teria sido relativamente curto. Isto pode ser visualizado através das linhas de evolução isotópica do $\varepsilon_{\mathrm{Nd}}$ no tempo geológico $\mathrm{T}(\mathrm{Ga})$ que convergem muito próximo da curva do manto (fig. 5.13-9). As idades modelo $\mathrm{T}_{\mathrm{DM}}$ dos minerais apresentam boa concordância, demonstrando significado geológico, mesmo que tenham sofrido variado graus de fracionamento na razão $\mathrm{Sm}-\mathrm{Nd}$ ( tab 5.13-1).

CRATON RIO DE LA PLATA - Até o presente, não há dados Sm-Nd disponiveis para o Craton Rio de La Plata.

BLOCO TAQUAREMBó - As idades modelo $\mathrm{Sm-Nd}$ relativas às rochas gnássicomigmatíticas e granitóides pertencentes ao Bloco Taquarembó indicam para os protolitos dessas rochas épocas de derivação do manto no Arqueano (2.9 a 2.6Ga) e no Paleoproterozóico (2.3 a $1.9 \mathrm{Ga}$ ), (fig. 5.13-10).

BLOCO SÃO GABRIEL - Os dados Sm e Nd relativos às rochas granodioríticotonalíticas e aos corpos básicos, localizados entre São Sepé, Vila Nova e Lavras do Sul, quando incluidos em diagrama de evolução isotópica $\varepsilon_{\mathbb{N} d}$ versus tempo geológico (fig. 5.13-11), indicam um super-evento de acreção de materiais juvenís entre o final do Mesoproterozóico e o início do Neoproterozóico (1,35 a 0,85Ga; tab. 5.13-2). Trata-se de rochas cujas idades $\mathrm{Rb}-\mathrm{Sr}$ (RT) e U$\mathrm{Pb}$ (zircões) distribuem-se entre 0,7 e $0,5 \mathrm{Ga}$, formadas, portanto, no Neoproterozóico (Ciclo Orogênico Brasiliano). Os valores de $\varepsilon_{\mathbb{N d}}(t)$, quando calculados para a idade de cristalização, posicionaram-se entre as curvas CHUR e DM, indicando para o protólitos dessas rochas 


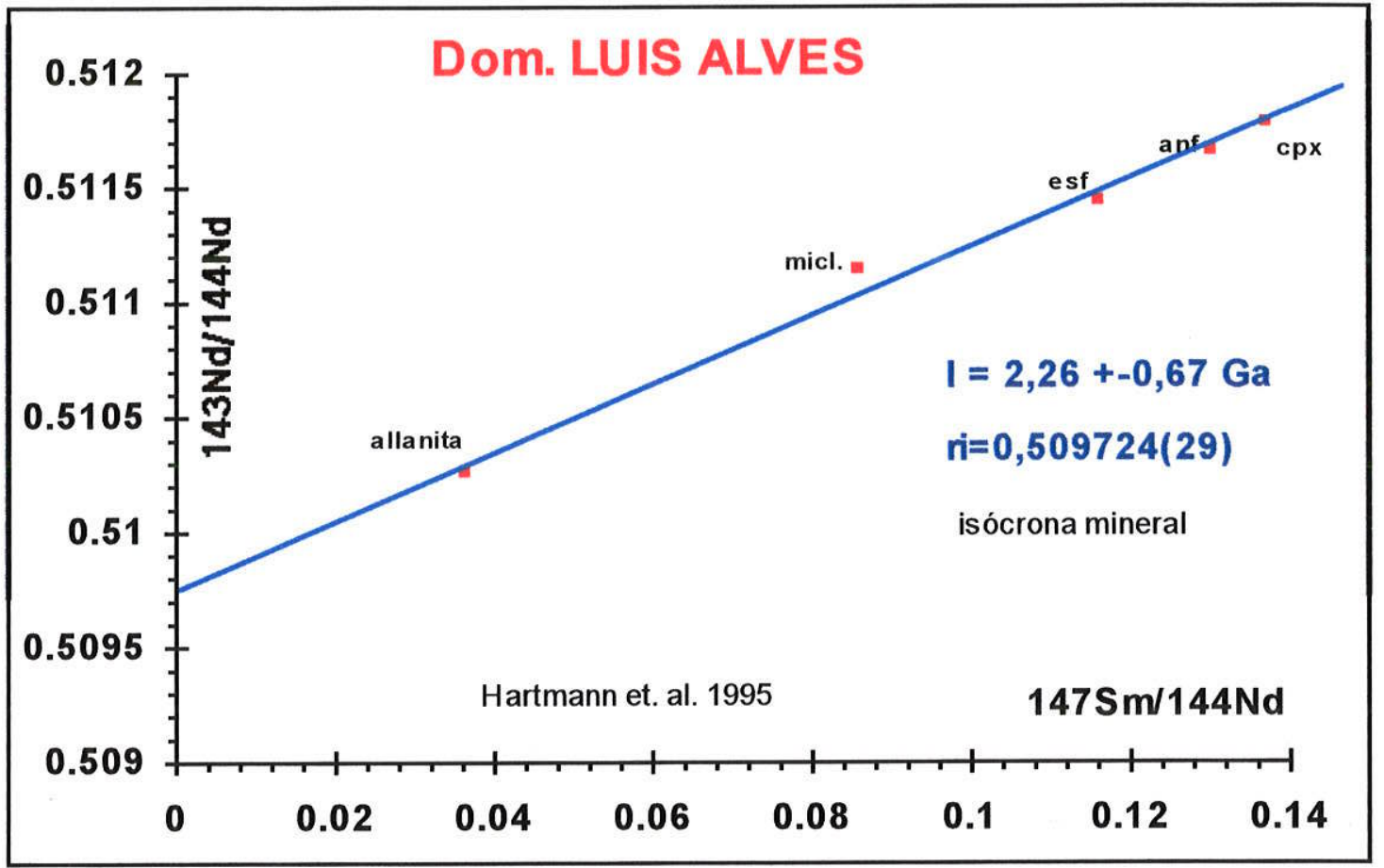

Fig. 5.13-8: Isócrona mineral Sm-Nd (concentrados em allanita, micloclíneo, esfeno, anfibólio e clinoprioxênio).

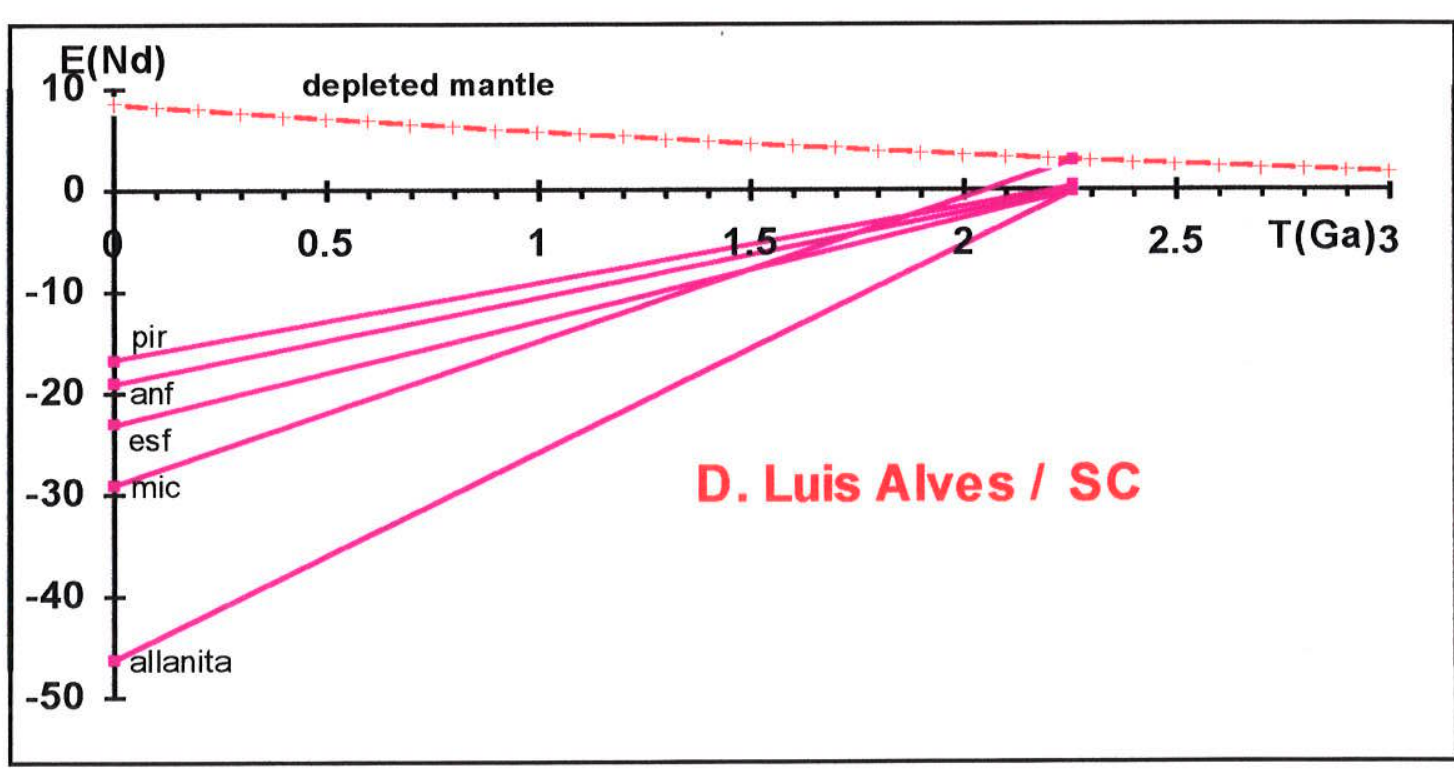

Fig. 5.13-9: Diagrama de evolução isotópico $\varepsilon_{N d}$ versus tempo geológico $T(G a)$ dos minerais separados da rocha granulítica . Os dados isotópicos encontram-se na tabela (5.131). As linhas de evolução isotópica regredindo (em estágio único de $\mathrm{Nd}$ ) convergem muito próximos às curvas do mantos CHUR e DM, tendo assim idades Tdm dos minerais relativamente concordante $(2,5$ a $2,3 \mathrm{Ga})$ sugerindo que o evento de diferenciação mantélica não estaria muito longe deste intervalo. 


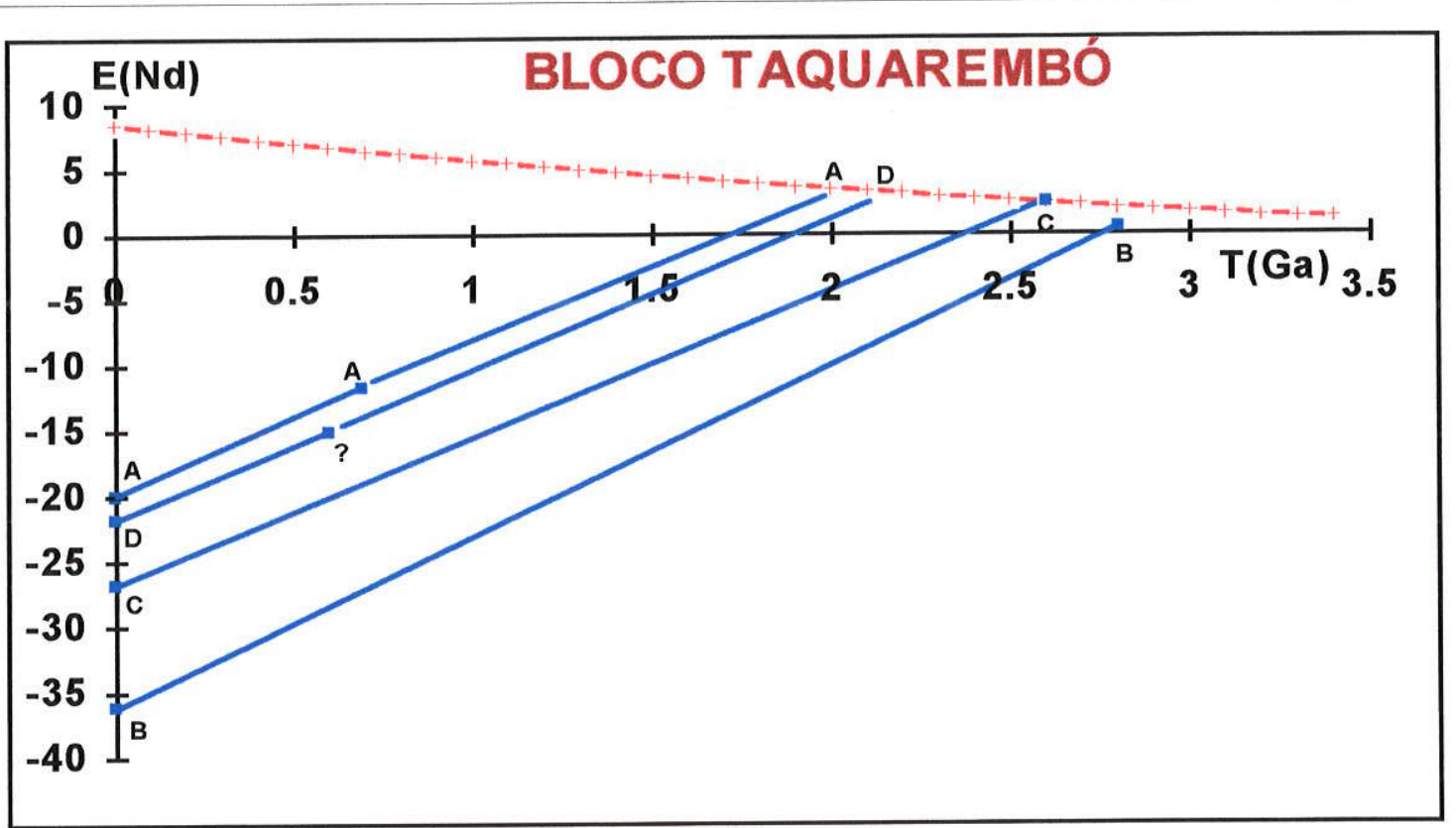

Fig. 5.13-10: Diagrama de evolução isotópico $\varepsilon_{N d}$ versus tempo geológico $T(G a)$. Os dados isotóicos das amostras encontram-se na tabela 5.13-2. Linhas de evolução isotópica de Nd regredindo até a curva do manto superior (DM) indicam idades Tdm arqueanas e paleoproterozóicas (linha de evolução $A=$ região de Uruguai; $B, C$ e $D=$ região de Bagé (RS).

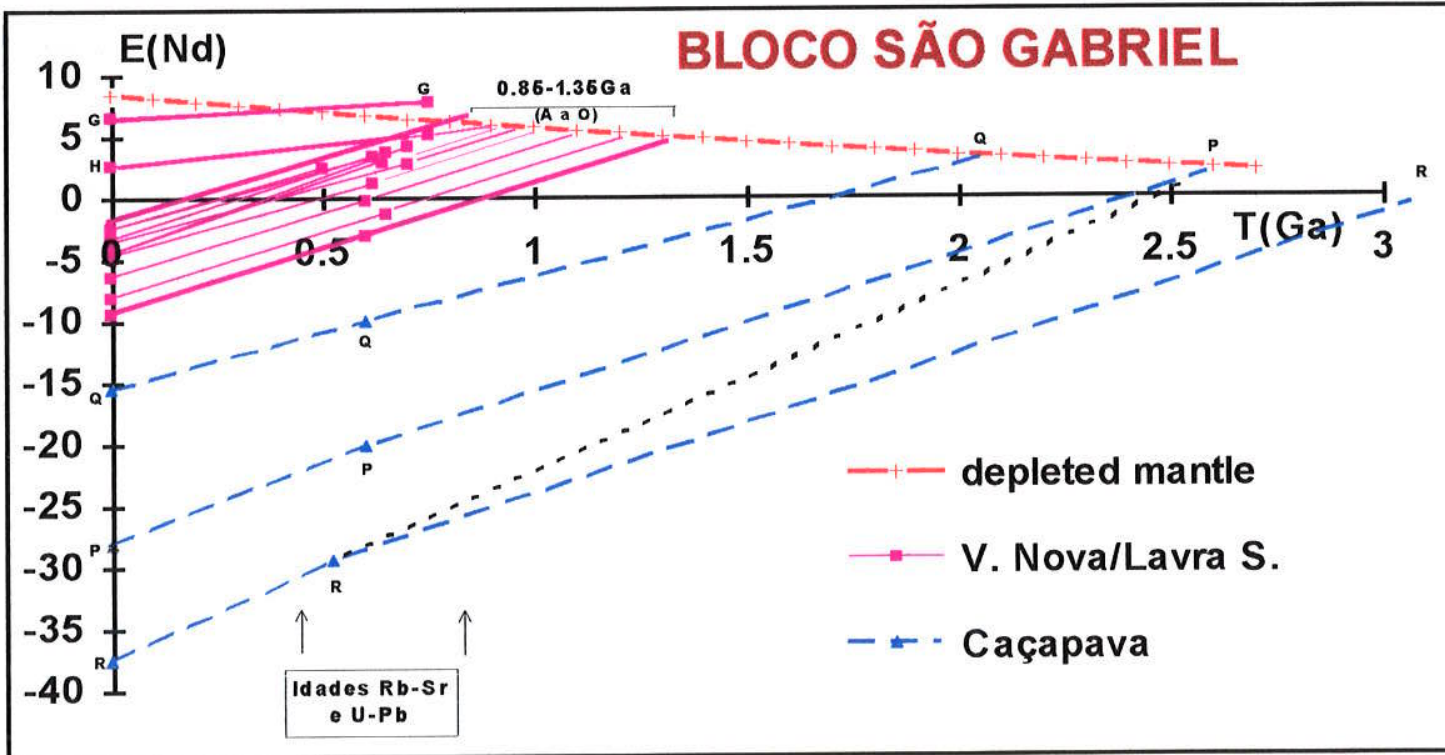

Fig. 5.13-11: Diagrama de evolução isotópico $\varepsilon_{\mathrm{Nd}}$ versus tempo geológico $\mathrm{T}(\mathrm{Ga})$ dos granitoides formados no Ciclo Orogênico Brasilianos onde as idades $\mathrm{Rb}-\mathrm{Sr}$ e U-Pb assinaladas com a seta variaram entre 0,75 a $0,5 \mathrm{Ga}$. Os dados isotópicos das amostras encontram-se na tabela 5.13-2. Linhas de evolução isotópica de $\varepsilon_{N d}$ (linhas tracejadas $P, Q$ e R - granitóides de Caçapava do Sul) regredindo até a curva do manto superior (DM) indicaram idades $T_{D M}$ Arqueanas a Paleoproterozóicas. A linha pontilhada $\mathrm{R}$ representa a evolução em estágio único. As linhas de evolução isotópica $\varepsilon_{N d}$ da região Vila Nova - São Sepé (linhas contínuas), regredindo em estágio único até a curva DM, indicaram eventos de acreção juvenil entre Meso-Neoproterozóica. 
intervalo de tempo relativamente curto de residência crustal (fig. 5.13-11), ou então derivação direta de manto listosférico enriquecido. No diagrama $\varepsilon_{\mathrm{N} d}(\mathrm{t})$ versus $\varepsilon_{\mathrm{sr}}(\mathrm{t})$ observa-se que as rochas de número de campo ESJ-05, RG273B e ESJ - Gl (amostras A, B e C, fig. 5.13-12), tem seus pontos posicionados próximos à origem, sugerindo fontes tipo crustal, ou manto litosférico enriquecido, corroborando com a interpretação acima proposta.

Os terrenos pertencentes ao Bloco São Gabriel mostram para os seus protólitos idades Meso-Neoproterozóicas, distintas das observadas para o fragmentos cratônicos Luis Alves (SC) e Rio de La Plata (Bloco Florida - Uruguai) cujos valores referem-se ao Arqueano e Paleoproterozóico, descaracterizando portanto, uma continuidade física entre tais segmentos.

Os granitóides da região de Caçapava do Sul apresentam padrão de evolução isotópica $\varepsilon_{\mathrm{Nd}}$ (t) distinto dos terrenos localizados entre Vila Nova e São Sepé (fig. 5.13-11, linhas tracejadas com triângulos, pontos $\mathrm{P}, \mathrm{Q}$ e R). Trata-se de granitóides formados no Neoproterozóico (Ciclo Brasiliano ) cujos protólitos diferenciaram-se do manto empobrecido (DM) entre o Arqueano e o Paleoproterozóico ( 3 a 2Ga). Tais dados mostram-se similares aos observados para os granitóides da região de Santana de Boa Vista na Faixa Tijucas (RS).

A amostra $R$ poscionou-se no terceiro quadrante (fig. 5.13-12), e parece ter sofrido processo de fracionamento químico anormal entre $\mathrm{Sm}$ e $\mathrm{Nd}$ onde " $\mathrm{f}=-0,65$ " (o normal estaria em torno de -0,4). A linha pontilhada da fig. 5.13-11 representa a evolução isotópica de $\varepsilon_{\mathrm{Nd}}(\mathrm{t})$ de estágio único, obtendo-se idade $\mathrm{T}_{\mathrm{DM}}$ de $2,56 \mathrm{Ga}$ (provável idade mínima) enquanto que para estágio duplo a idade aparente $\mathrm{T}_{\mathrm{DM}}$ seria de $3,2 \mathrm{Ga}$ (provável idade máxima). 


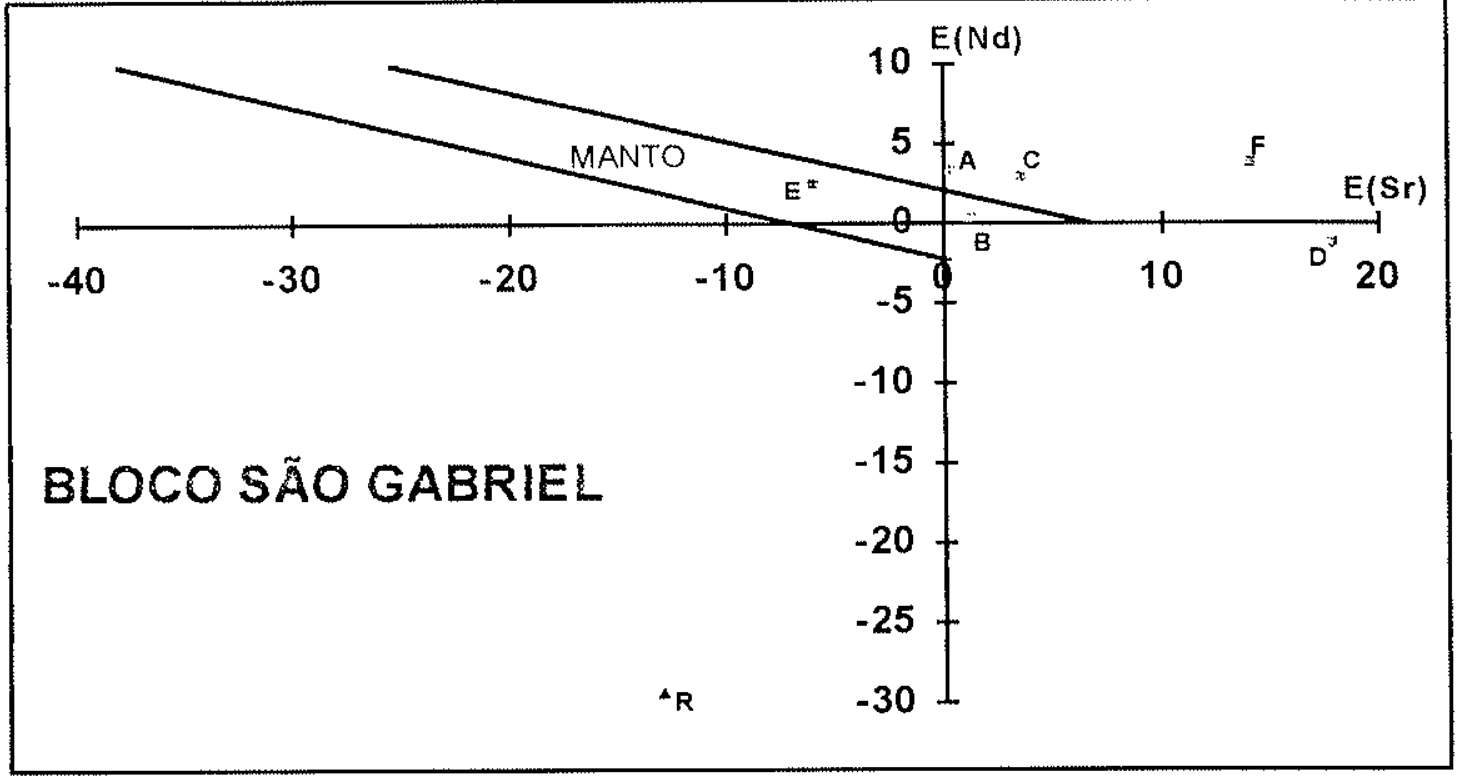

Fig. 5.13-12: Diagrama $\varepsilon_{S r-R I}(t)$ versus $\varepsilon_{N d}(t)$ com dados baseados na tab. 5.13-2. Os pontos assinalados estão próximos da origem com valores de $\varepsilon_{N d}(t)$ ligeiramente positivos (exceto 0 ponto $R$, granito da Caçapava do Sul) e $\varepsilon_{S r}(t)$ também ligeiramente positivos para $\cong 0,6 \mathrm{Ga}$, espalhados ao longo do eixo $\varepsilon_{S_{r}}$ sugerindo que a fonte (protólito) poderia ser do manto tipo litosférico enriquecido ou então de origem crustal mas com tempo residência relativamente curto.

\subsection{3 - 3 - RESUMO PARCIAL - FRAGMENTO CRATÔNICO LUIS ALVES:}

-Fragmento cratônico Luis Alves - terrenos gnáissico-granulítico formados predominantemente no Arqueano com porções Paleoproterozóicas: TDM entre 3,1 e 2,3Ga; Granitóides formados no Ciclo Brasiliano: $\mathrm{T}_{\mathrm{DM}}$ Paleoproterozóicas $(2,1$ a 1,6Ga); Vulcânica formada no Ciclo Brasiliano: $\mathrm{T}_{\mathrm{DM}}$ Paleoproterozóica $(2,06 \mathrm{Ga})$.

-Bloco Taquarembó - rochas gnássico-granulíticas da região de Bagé (RS):

$\mathrm{T}_{\mathrm{DM}}$ Arqueanas $(3,2$ a $2,6 \mathrm{Ga})$.

-Bloco S. Grabriel - rochas básicas e granitóides de V. Nova - Lavras do Sul formadas no Ciclo Brasiliano - $\mathrm{T}_{\mathrm{DM}}$ (Meso - Neoproterozóicas): 1,35 a 0,75Ga; Granitóides de Caçapava do Sul formado no Neoproterozóico - $\mathrm{T}_{\mathrm{DM}}$ Paleoproterocas : $(2,5$ a $2,2 \mathrm{Ga})$. 


\subsection{4 - FRAGMENTO CRUSTAL CURITIBA}

\subsection{4-1 - SÍNTESE GEOLÓGICA:}

O fragmento Crustal Curitiba (Cordani et. al 1988) engloba a Faixa Apiai, o Grupo São Roque, o Dominio Curitiba, bem como parte do embasamento da Bacia do Paraná (fig 5.13-1).

A Faixa Apiaí (Fragoso César 1991) ocupa a porção centro-oeste do assim chamado Escudo Paranaense, prolongando-se para nordeste e atingindo a porção meridional do Estado de São Paulo. É representada por uma complexa associação de rochas metassedimentares e metavulcânicas, estruturadas como nappes vergindo para SE e contendo intrusões batolíticas e stocks de granitóides diversos. Todo o conjunto se deixa seccionar por grandes falhamentos transcorrentes de direção predominantemente NE-SW.

Os terrenos pertencentes ao Grupo São Roque (Hasui et. al 1984) ocupam a porção SE do Estado de São Paulo e constituem um pacote metapelítico, metamorfizado na fácies xistoverde (localmente anfibolito), e afetado por inúmero corpos graníticos intrusivos.

O Domínio Curitiba, fig. 5.13-1 e 5.13-2, (Siga Jr. 1995) ocupa a porção SE paranaense sendo limitado a noroeste, através de zonas de cisalhamento, pelas sequências metassedimentares da Faixa Apiai. Predominam nele rochas gnáissico-migmatíticas do fácies anfibolito, ocorrendo em sua borda meridional rochas granitóides de composição cálcio alcalina (Suíte de R. Piên, Machiavelli, 1992), de idade brasiliana bem como rochas básicas-ultrabásicas.

\subsection{4-2 - DADOS ISOTÓPICOS RELATIVOS AOS DOMÍNIOS DAS FAIXAS APIAÍ (PR) E SÃO ROQUE (SP)}

No âmbito da faixa Apiai, os dados Sm-Nd concentram-se nos Complexos Três Corregos e Cunhaporanga, cujas idades Rb-Sr indicam valores relativos ao Ciclo Brasiliano (figs. 5.14-1). As idades modelo $\mathrm{Sm}-\mathrm{Nd}\left(\mathrm{T}_{\mathrm{DM}}\right)$ caracterizam o Paleoproterozóico como o principal período de acreção do manto, dos protólitos dessas rochas graníticas. As idades $T_{1 \mathrm{M}}$ relativas aos granitóides do Complexo Três Córregos distribuiram-se entre 2,27 a $2,21 \mathrm{Ga}$ e as do Complexo Cunhaporanga entre 2,25 a 2,21 Ga. (fig. 5.14-2; dados isotópicos de Reis Neto, 1994; tab. 5.141). 
A fig. 5.14-3 mostra a correlação geoquímica envolvendo as razões isotópicas iniciais de $\mathrm{Sr}$ versus $\mathrm{Nd}$ dessas rochas. Na figura observam-se os valores de $\varepsilon_{\mathrm{Nd}}(\mathrm{t})$ negativos e os de $\varepsilon_{\mathrm{sr}}(\mathrm{t})$ positivos, quando reduzidos para o evento de cristalização ( $t_{\mathrm{Rl}-S \mathrm{~s}}$, tabela 5.14-1), o que é típico de material originário de ambiente crustal.

Propositadamente foram plotados no diagrama 5.14-3, os dados de $\mathrm{Sm}$ e $\mathrm{Nd}$ relativos às rochas graníticas e granodioriticas pertencentes ao Domínio São Roque (SP). Tratamse de rochas que apresentam idades modelo predominantemente Paleoproterozóicas, muito similares às observadas para os Complexos Cunhaporanga e Três Córregos, fig. 5.14-2. Dados recentes SmNd obtidos por Ragatky (1997) em rochas graníticas desta região também indicam o Paleoproterozóico como o principal evento formador de crosta continental juvenil do setor e pequena parcela da crosta adicionada durante o Mesoproterozóico (tab. 5. 14-1).

Os traçadores petrogenéticos $\varepsilon_{\mathrm{Nd}}(\mathrm{t})$ e $\varepsilon_{\mathrm{Sr}}(\mathrm{t})$ indicam processos de re-equilibrio isotópico em ambiente crustal no Ciclo Orogênico Brasiliano (fig. 5.14-3), similares aos anterioremente observados.

Entre os Complexos Cunhaporanga e Três Córregos ocorre uma faixa de rochas metassedimentares e metavulcânicas, denominadas de Grupo Itaiacoca. Este grupo é constituido por quatro formações: Abapã, Serra dos Macacos, Bairro dos Campos e Água Clara, interpretadas como integrantes de uma margem continental do tipo passiva (fig. 5.14-1, Reis Neto 1994). Os dados isocrônicos Rb-Sr obtidos para rochas vulcânicas ácidas da Fm. Abapã são do Mesoproterozóico, com valores torno de 1,25+-0,13Ga. As idades modelo $\mathrm{Sm}-\mathrm{Nd}\left(\mathrm{T}_{\mathrm{DM}}\right)$ indicam valores do final do Arqueano e início do Paleoproterozóico $(2,65+-0,15 \mathrm{Ga})$ como relativos a eventos de acreção (manto-crosta continental) dos seus protólitos (fig.5.14-4e tabela 5.14-1). As rochas básicas (de natureza toleitica), pertencentes a Fm. Bairro dos Campos, bem como as rochas básicas da Fm. Água Clara apresentaram idades distribuidas entre 1,08 a 1,03Ga (idades $\mathrm{Rb}-\mathrm{Sr}, \mathrm{Pb}-\mathrm{Pb}$ e U-Pb), indicando novamente o Mesoproterozóico para a formação dessas sequências. Os dados $\mathrm{Sm}-\mathrm{Nd}, \mathrm{T}_{\mathrm{DM}}$, obtidos para as rochas básicas pertencentes à Formação Bairro dos Campos, quando interpretados através de modelo de evolução em estágio único, indicam para o seu evento de acreção valores entre 2,19 a 2,14Ga. Embora os valores de "f" encontrem-se próximos de CHUR (-0,19 a -0,16, tabela 5.14-1), as idades $\mathrm{T}_{\mathrm{DM}}$ mostram-se razoavelmente concordantes entre si. O mesmo não ocorre com as rochas básicas da Fm. Água Clara, onde as idades $\mathrm{T}_{\mathrm{DM}}$ mostram-se discordantes (amostra $\mathrm{O}=3,8 \mathrm{Ga}$ e amostra $\mathrm{N}=1,96 \mathrm{Ga} ; \mathrm{tab}$. 5.14-1 e fig. 5.14-4). Utilizando-se a o modelo de estágio duplo para a amostra $O$, considerandose a idade $\mathrm{t}=1,08 \mathrm{Ga}$ para o evento que ocasionou o fracionamento e a razão ${ }^{147} \mathrm{Sm} /{ }^{144} \mathrm{Nd}=0,134$ 


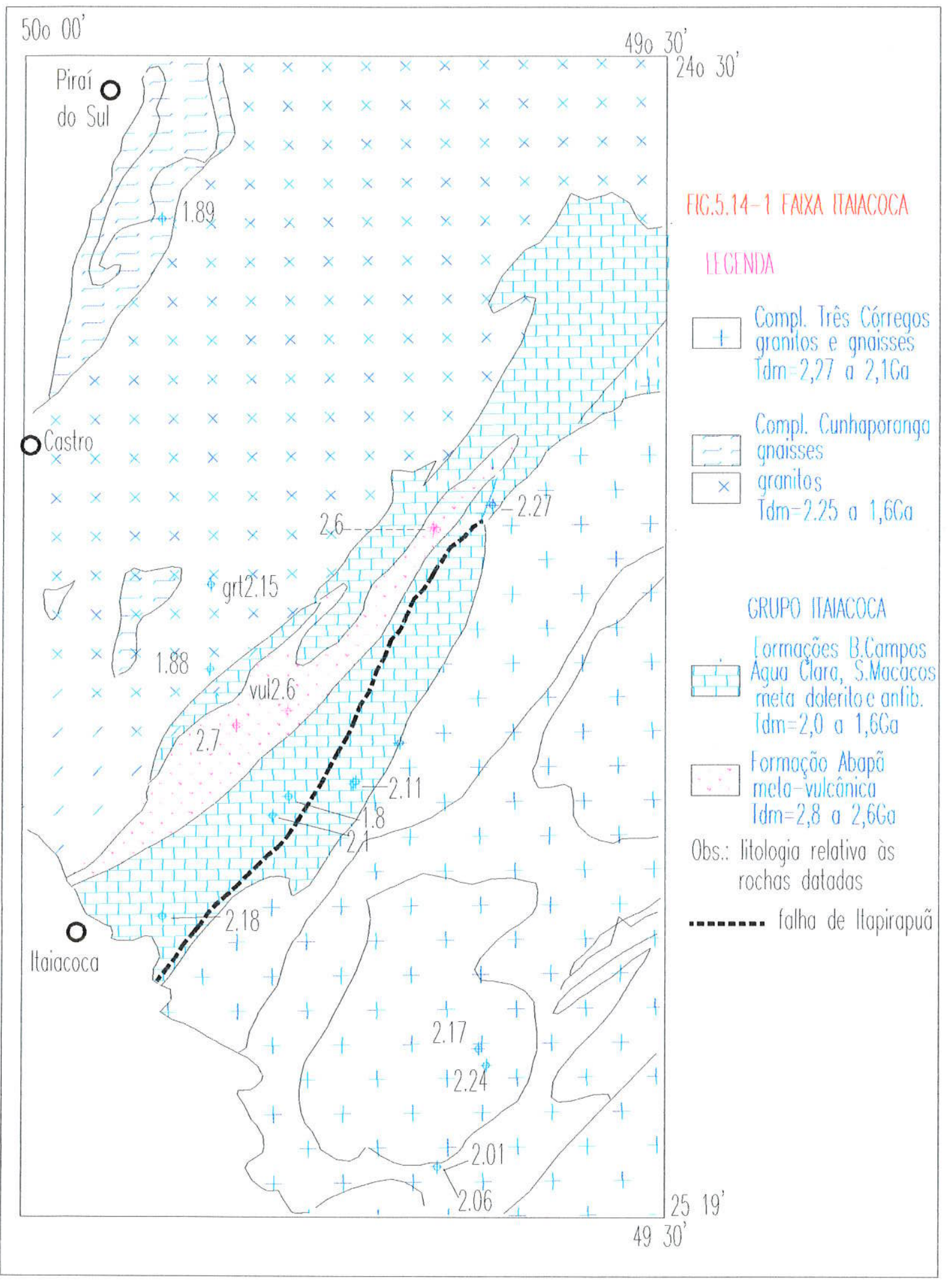




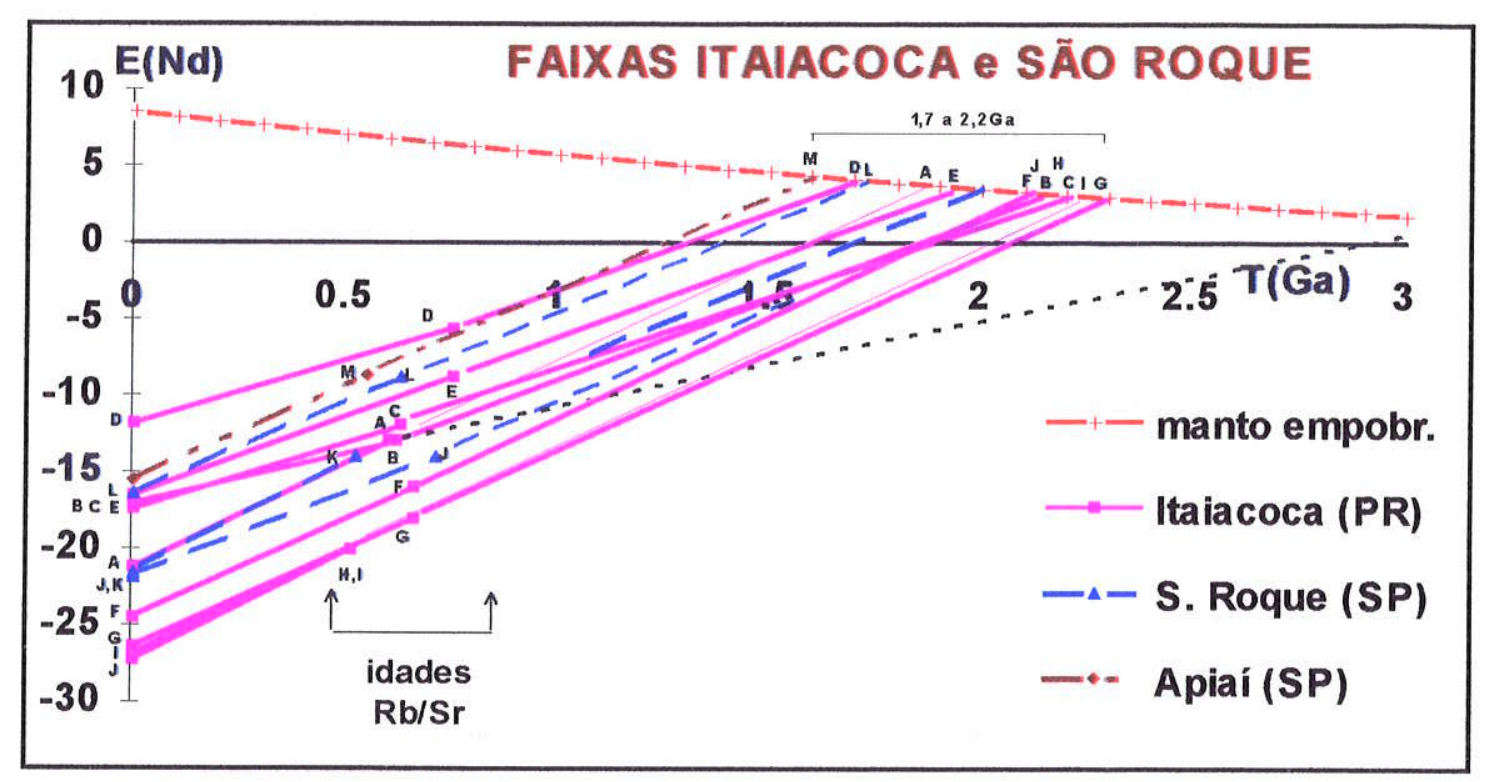

Fig. 5.14-2: Diagrama de evolução isotópico $\varepsilon_{N d}$ versus tempo geológico $T(G a)$ das Faixas Itaiacoca (Complexos Cunhaporanga e Três Córregos) e São Roque. Os dados isotópicos encontram-se na tabela 5.14-1.

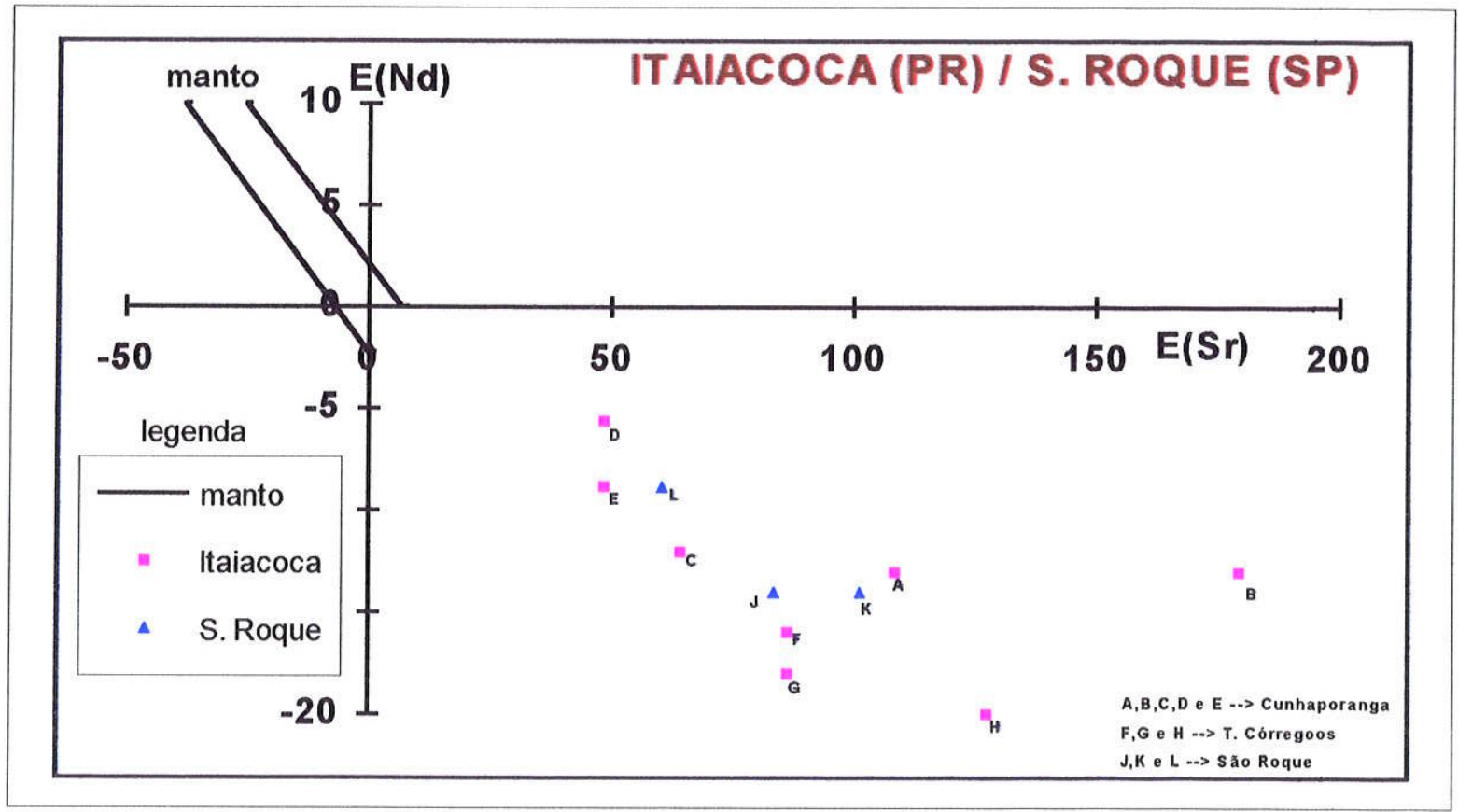

Fig. 5.14-3: Diagrama $\varepsilon_{S r-R I}(t)$ versus $\varepsilon_{N d}(t)$ das Faixas Itaiacoca (Complexos Cunhaporanga e Três Córregos) e São Roque. 


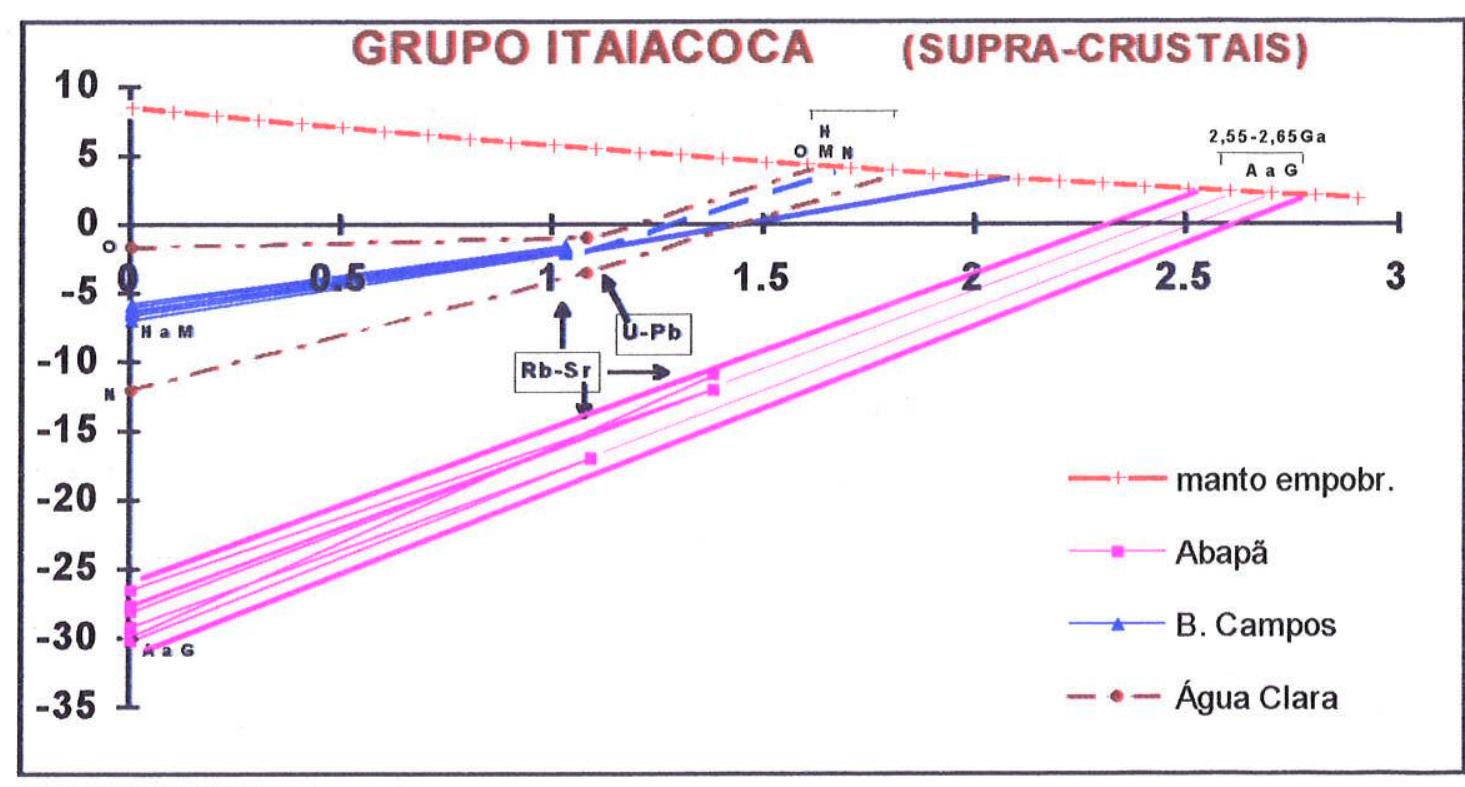

Fig. 5.14-4: Diagrama de evolução isotópico $\varepsilon_{N d}$ versus tempo geológico $T(G a)$ do Grupo Itaiacoca (formações Abapã, Bairro dos Campos, Água Clara e S. Macacos. Não possui análise Sm-Nd na formação Serra dos Macacos. Os dados isotópicos encontram-se na tabela (5.14-1).

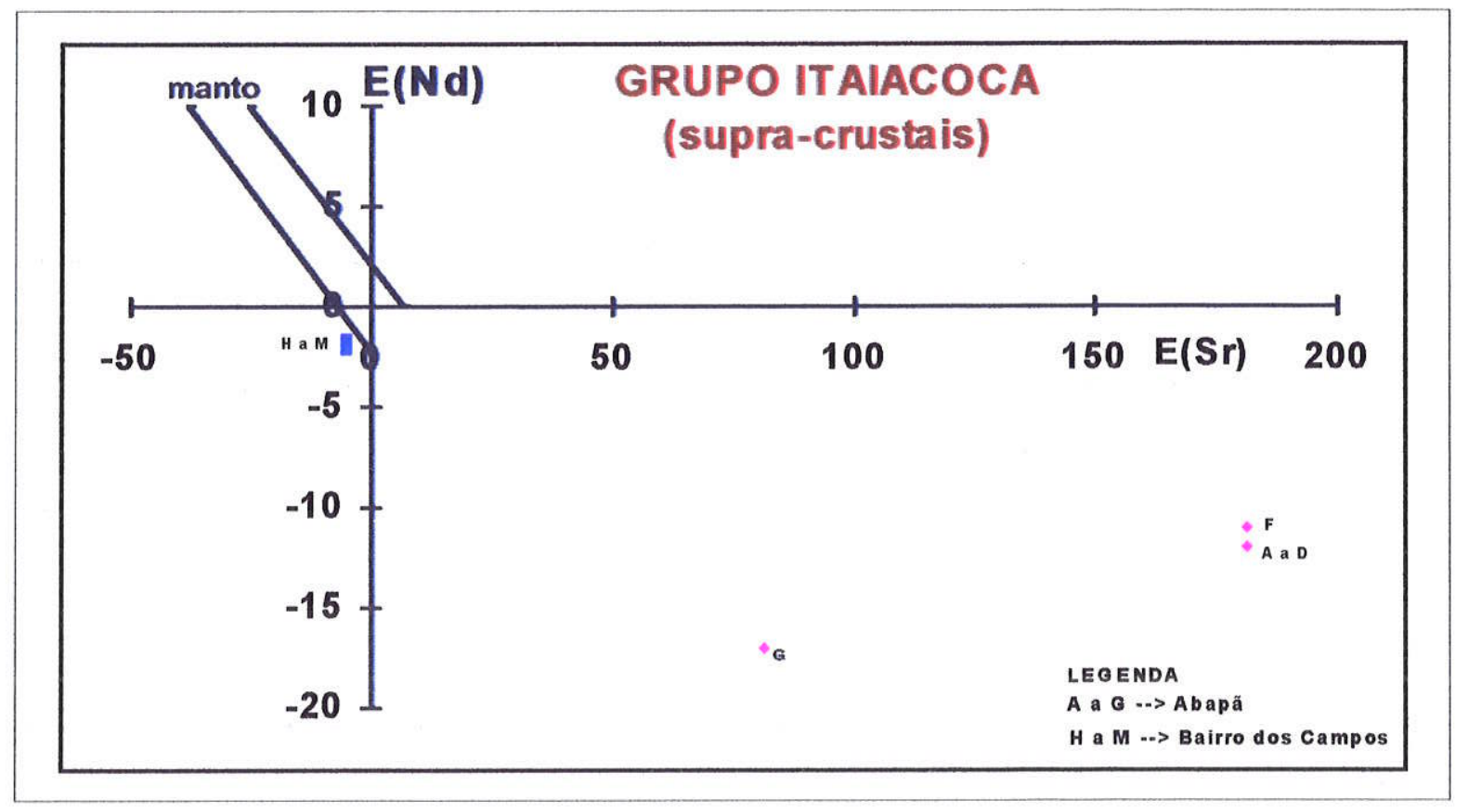

Fig. 5.14-5: Diagrama $\varepsilon_{S-R I}(t)$ versus $\varepsilon_{N d}(t)$ do Grupo Itaiacoca 
da amostra $\mathrm{N}$ para o estágio primário, então a idade modelo $\mathrm{T}_{D_{\mathrm{M}}}$ (aparente) obtida torna-se praticamente concordante $(1,81 \mathrm{Ga})$. O diagrama de evolução isotópica $\varepsilon_{\mathrm{Nd}}(\mathrm{t})$ versus tempo geológico $\mathrm{T}(\mathrm{Ga})$, fig. $5.14-4$ permite verificar que as fontes (protólitos) dessas rochas básicas apresentam valores $\varepsilon_{\mathrm{Nd}}(\mathrm{t})$ negativos, caracterizando a formação dessas rochas a partir de material reciclado no Mesoproterozóico.

A correlação das razões isotópicas iniciais $\varepsilon_{\mathrm{ST}}(\mathrm{t})$ e $\varepsilon_{\mathrm{Vd}}(\mathrm{t})$ relativas à época de formação das rochas básicas (Fm. Bairro dos Campos) e das vulcânicas ácidas (Fm Abapã), é apresentada na fig. 5.14-5. Observa-se que os dados relativos às rochas básicas da Fm. Bairro dos Campos posicionam-se no terceiro quadrante, próximos à origem (pontos $\mathrm{H}$ a $\mathrm{M}$ ), caracterizando razões isotópicas de $\mathrm{Sr}$ e de $\mathrm{Nd}$ (iniciais) baixas $\left({ }^{87} \mathrm{Sr} /{ }^{86} \mathrm{Sr}-->0.7045\right.$ a 0,699 e ${ }^{14.3} \mathrm{Nd} /{ }^{144} \mathrm{Nd}-->0.51264$ a 0,5067 ), e sugerindo tratar-se de material pouco reciclado (crosta inferior ou manto listosférico tipo EM1). As rochas metavulcânicas de Abapã, por outro lado, apresentam comportamento distinto, com os valores de $\varepsilon(t)$ situados no quarto quadrante e distantes da origem, sugerindo para os seus protólitos tempo da residência crustal relativamente grande. Não podemos aqui descartar a possibilidade de fontes relacionadas com manto litosférico sub continental enriquecido, tipo EMII.

\subsection{4-3 - DADOS ISOTÓPICOS RELATIVOS AO DOMÍNIO CURITIBA}

As idades $\mathrm{Rb}-\mathrm{Sr}$ ( $\mathrm{RT}$ ) e U-Pb (zircões) relativas às rochas gnáissico-migmatíticas que ocorrem a sul da Faixa Apiai, preservam registros evolutivos do Paleoproterozóico (2,2 a 1,8Ga; Siga Jr., 1995). Análises de zircões por SHRIMP efetuadas recentemente (Ohyama,T., informação escrita) indicam a presença de material do Arqueano e confirmam as idades Paleoproterozóicas deste domínio. Alguns dados Rb-Sr, bem como os dados $\mathrm{K}-\mathrm{Ar}$, caracterizam leucossomas e porções graniticas formadas no Neoproterozóico $(0.62-0.56 \mathrm{Ga})$, período em que as isotermas atingiram temperaturas superiores à $500{ }^{\circ} \mathrm{C}$. A figura 5.14-10 e tab. 5.14-2 reunem as localizações aproximadas e os dados Sm-Nd das amostras datadas pelo método Sm-Nd.

As idades modelo $\mathrm{Sm}-\mathrm{Nd}$ indicam para os precursores crustais dos anfibólio-gnaisses migmatíticos desse domínio derivação do manto superior no final do Arqueano $(2.6 \pm 0.2 \mathrm{Ga}) \mathrm{e}$ para os mobilizados migmatíticos de segunda geração, valores do Paleoproterozóico $(2.1 \pm 0.2 \mathrm{Ga})$. Distinguem-se desse padrão a rocha diorítica da região da Graciosa e o anfibólio-gnaisse da 
região de Mandirituba (amostras $\mathrm{E}$ e H, fig. 5.14-6; tab. 5.14-2) que apresentaram idades $\mathrm{T}_{\mathrm{DM}}$ relativas ao Mesoproterozóico (1,36-1,46Ga). Os dados isotópicos relativos a essas amostras apresentam um comportamento atipico. Observa-se que suas linhas de regressão de $\varepsilon_{\mathrm{Nd}}$ (em estágio único) na fig. 5.14-6, interceptam a curva do manto empobrecido (DM) em 1,14 e $1.36 \mathrm{Ga}$. Se estendermos estas linhas até o evento de cristalização para $\mathrm{t}=2,0 \mathrm{Ga}$ (idade $\mathrm{Rb}-\mathrm{Sr}$ ), os valores $\varepsilon_{\mathrm{Nd}}(\mathrm{t})$ situar-se-iam bem acima da curva do manto DM. Estudos complementares são necessários para um melhor entendimento de tais dados. Adicionalmente para a amostra $\mathrm{H}$ (obtido no mesmo afloramento que a amostra $\mathrm{M}$ ) foi analisada através do método isocrônico $\mathrm{Sm}-\mathrm{Nd}$ em minerais, (concentrados de granada, anfibólio, piroxênio e rocha total, fig. 5.14-7; Siga Jr 1995), e a idade obtida $(0,585 \mathrm{Ga})$ foi interpretada como relativa a época de formação dessa paragênese mineral. A razão inicial, expressa na forma de parâmetro $\varepsilon_{\mathrm{Nd}}$, indica valor positivo de $+0,35$ sugerindo que foi relativamente pequeno o intervalo entre evento de recristalização metamórfica e a idade original dos protólitos.

Cabe aqui uma pergunta: teria sentido calcular idades modelo $\mathrm{Sm}-\mathrm{Nd}$ para concentrados de minerais?. Observa-se que, num processo de cristalização-recristalização metamórfica, pode ocorrer um grau de fracionamento entre $\mathrm{Sm}$ e $\mathrm{Nd}$ muito variado, ao nível das fases minerais. Portanto, as idades modelo $\mathrm{T}_{\mathrm{DM}}$ (estágio único) poderiam ser muito discordantes, e não teriam qualquer significado geológico. Por outro lado, no caso em pauta, se calcularmos as idades $\mathrm{T}_{\mathrm{DM}}$ utilizando-se de modelo de evolução isotópica de $\mathrm{Nd}$ em estágio duplo (razão ${ }^{147} \mathrm{Sm} /{ }^{144} \mathrm{Nd}=0,1$ para o estágio primário e $T_{2}=0,585 \mathrm{Ga}$ ), observa-se uma grande concordância entre as idades $T_{D M}$ estimadas em minerais e em rocha total (1,12 a 1,03 Ga, fig.5.14-8 e tabela 5.14-2).

Os maciços graniticos de natureza alcalina-peralcalina, intrusivos nas rochas gnássicomigmatíticas desse domínio, apresentaram idades próximas de $0.6 \mathrm{Ga}(\mathrm{Rb}-\mathrm{Sr}$ e U-Pb), caracterizando o Neoproterozóico (Ciclo Brasiliano) na formação desses corpos. As idades SmNd ( $\mathrm{T}_{\mathrm{DM}}$ ) distribuiram-se entre 2,1 a 1,8Ga (fig. 5.14-6), o que indica a importância do Paleoproterozóico na formação dos protólitos crustais dessas rochas granitóides.

$\mathrm{Na}$ fig. 5.14-9 as razões isotópicas iniciais de $\mathrm{Sr}$ e $\mathrm{Nd}$ mostram valores de $\varepsilon_{\mathrm{Nd}}(\mathrm{t})$ negativos e de $\varepsilon_{\mathrm{Sr}}(\mathrm{t})$ positivos para $\mathrm{t}_{\mathrm{Rb}-\mathrm{Sr}}$ relacionado ao evento de cristalização das rochas, fig. 5.14-9. Tal padrão isotópico é indicativo de rochas formadas a partir de retrabalhamento de material crustal, ou então de manto litosférico sub continental enriquecido tipo EMII. Os números entre parênteses da fig. 5.14-9 indicam idades isocrônicas $\mathrm{Rb}$-Sr e aqueles sem parênteses idades 


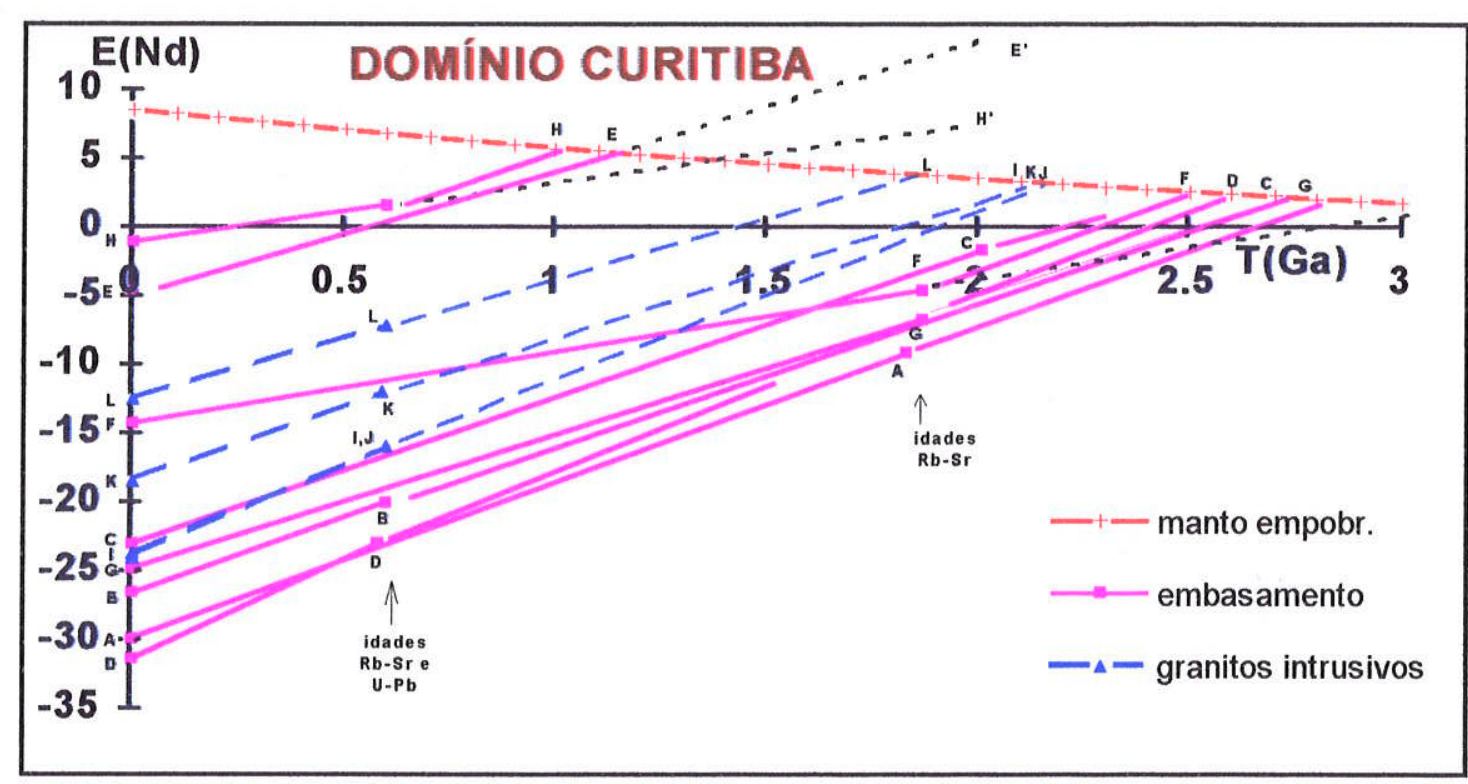

Fig. 5.14-6: Diagrama de evolução isotópico $\varepsilon_{N d}$ versus tempo geológico $T(G a)$ das amostras do Domínio Curitiba. Os dados isotópicos das amostras encontram-se na tabela 5.14-2.

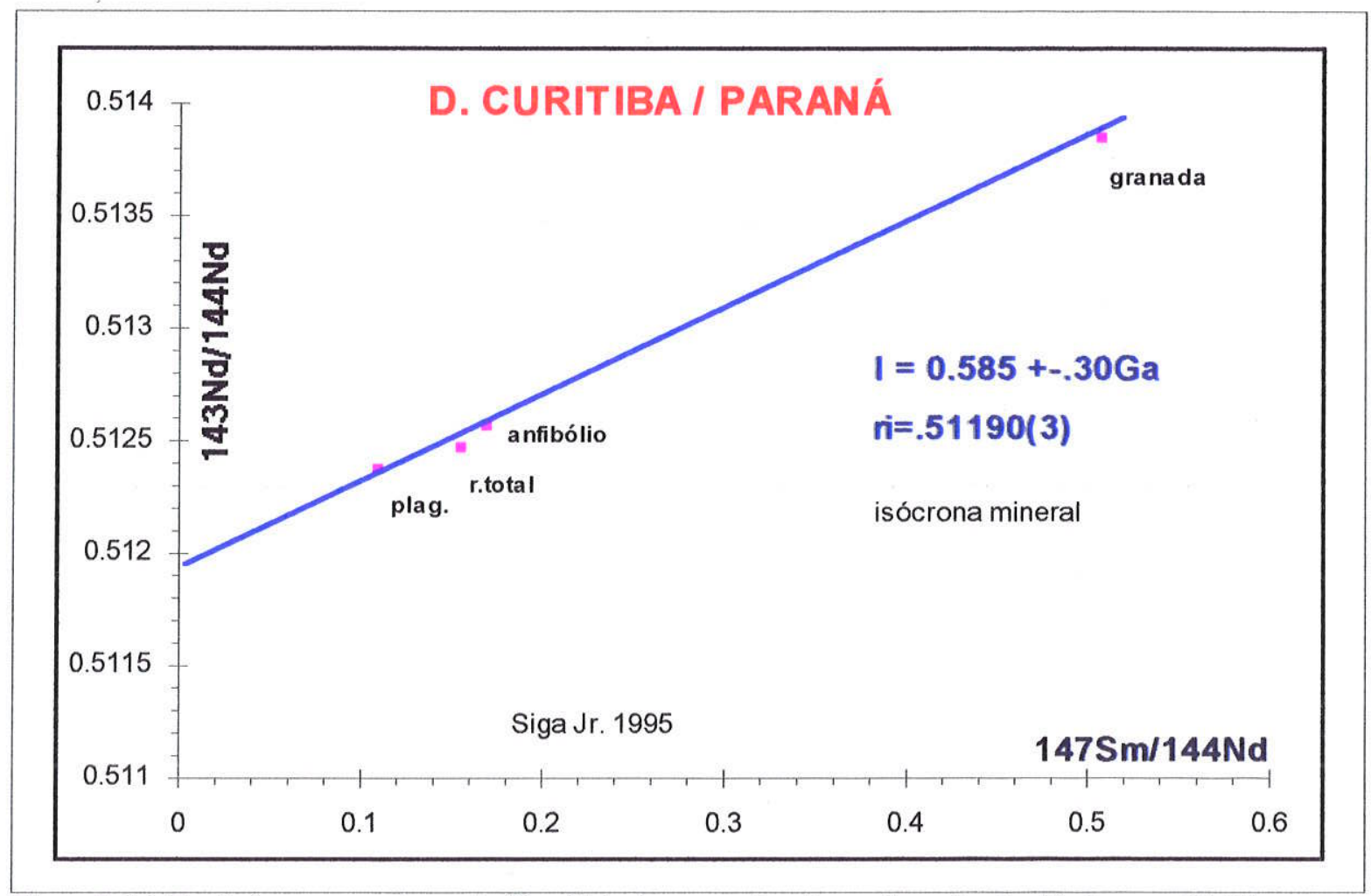

Fig. 5.14-7: Isócrona mineral Sm-Nd (concentrados de plagioclásio, anfibólio, granada e rocha total (gnaisse). As razões ${ }^{143} \mathrm{Nd} /{ }^{144} \mathrm{Nd}$ e ${ }^{147} \mathrm{Sm} /{ }^{144} \mathrm{Nd}$ encontram-se na tabela 5.14-2. 


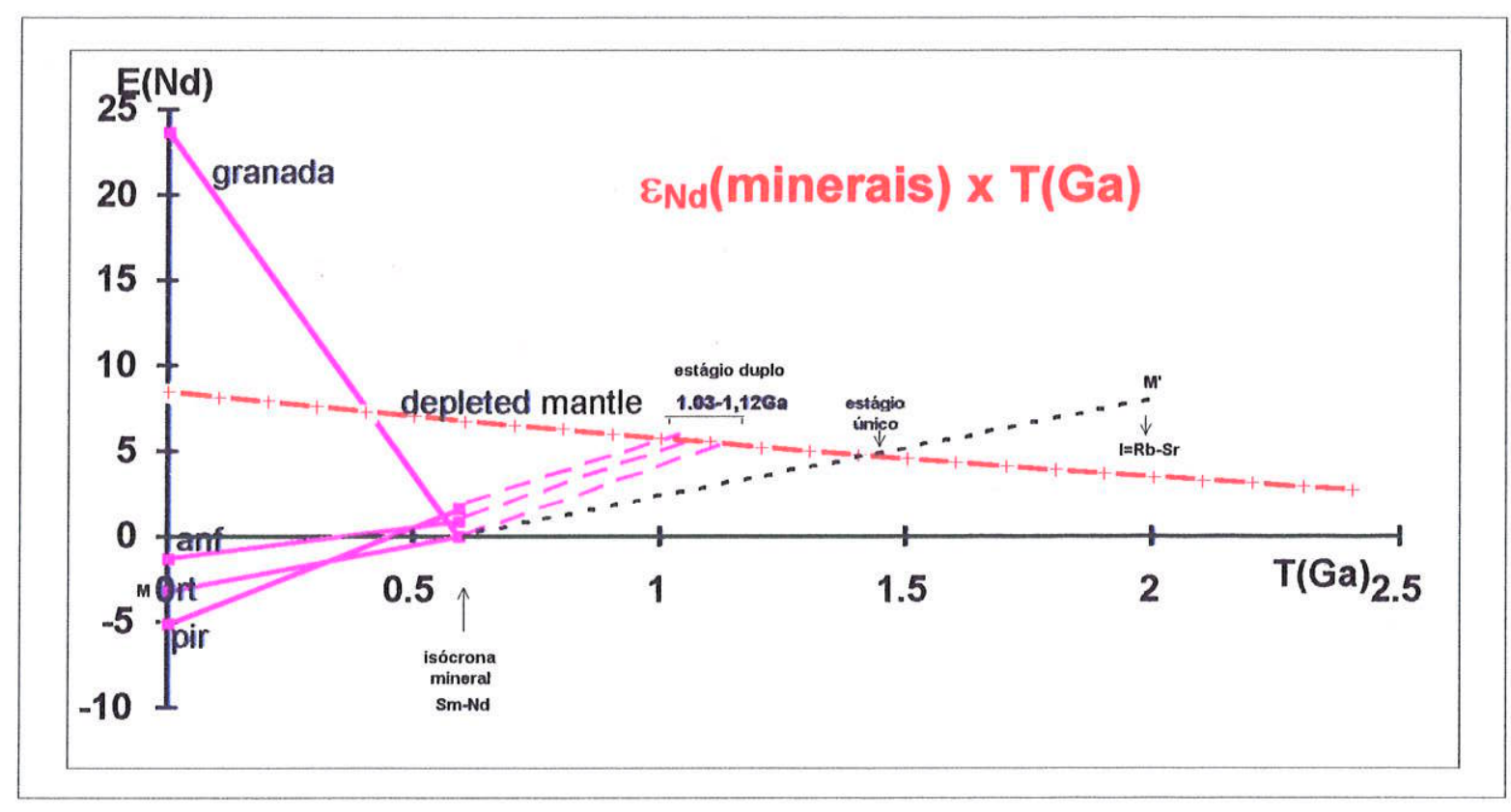

Fig. 5.14-8: Diagrama de evolução isotópico $\varepsilon_{\text {Nd }}$ versus tempo geológico $T(\mathrm{Ga})$ dos minerais concentrados da rocha gnaíssica. Os dados isotópicos das amostras encontram-se na tabela (5.14-2). A linha pontilhada refere-se à uma evolução isotópica de $\mathrm{Nd}$ (RT) em estágio único (sem significado geológico). A linha de evolução (estágio único) da granada regredindo até as curvas dos mantos intercepta primeiro a curva DM em 0,4Ga e em seguida a linha do CHUR em torno de 0,58Ga (também sem significado geológico). As linhas tracejadas referem-se evoluções de $\mathrm{Nd}$ em estágio duplo ( $\mathrm{Tdm}$ estimados dos minerais e da rocha total todos concordantes em torno de $1,07+-0,05 \mathrm{Ga}$ ).

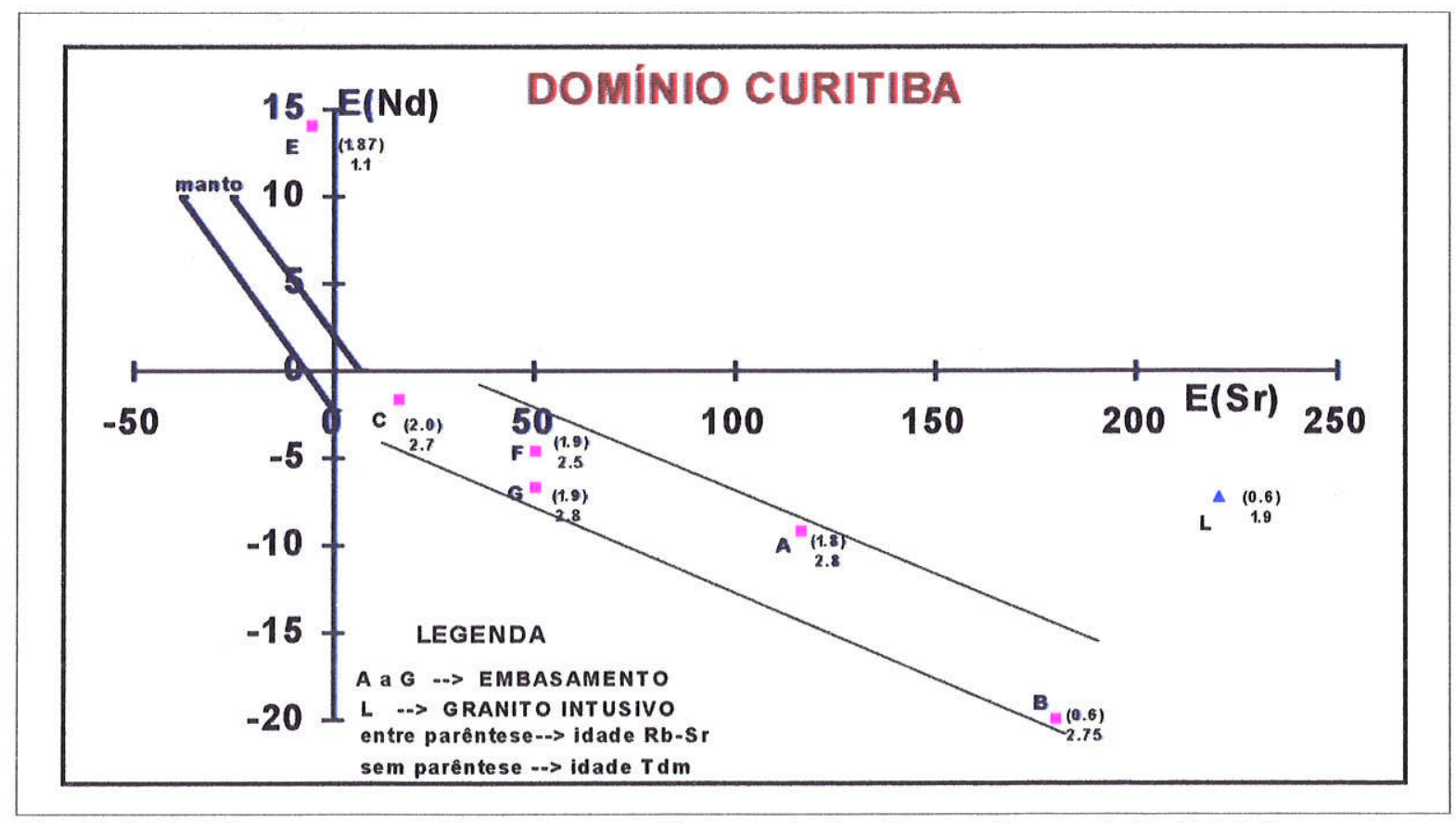

Fig. 5.14-9: Diagrama $\varepsilon_{S \mathrm{Sr} R \mathrm{II}}(\mathrm{t})$ versus $\varepsilon_{\mathrm{Nd}}(\mathrm{t})$ com dados baseados na tab. 5,14-2. 
modelo $\mathrm{Sm}-\mathrm{Nd}\left(\mathrm{T}_{\mathrm{DM}}\right)$. Observa-se que quanto maior a diferença entre as idades $\mathrm{Rb}-\mathrm{Sr}$ e $\mathrm{T}_{\mathrm{DN}}$ maior será o deslocamento em relação à origem, ou seja, quanto mais afastado da origem o ponto, maior será o tempo de residência crustal dos precursores crustais dessas rochas. Adicionalmente, os dados relativos ao embasamento gnáissico-migmatítico apresentam uma tendência clara, sugerindo tratar-se de rochas geradas a partir de uma mesma fonte primordial.

\subsection{4-4 - RESUMO PARCIAL:}

Os principais eventos de acreção manto-crosta continental com base em idades modelo $\mathrm{Sm}-\mathrm{Nd}$, $\mathrm{T}_{\mathrm{DM}}$, no fragmento crustal Curitiba são:

\section{Faixa Itaiacoca:}

- Complexo Cunhaporanga: Paleoproterozóico (2,15 - 1,7Ga).

- Complexo Três Córregos: Paleoproterozóico $(2,27$ - 2,11Ga).

- Grupo Itaiacoca :

Fm. Abapã (vulcânicas ácidas) :Arqueano (2,8 a 2.6Ga).

Fm Bairro dos Campos (rochas básicas): Paleoproterozóico $(<2.15 \mathrm{Ga})$.

Fm. Água Clara (rochas básicas): Paleoproterozóico $(<2.0 \mathrm{Ga})$

São Roque/Apiaí, próximo a São Paulo (granitóides): Paleo-Mesoproterozóico (2,14 -1,4Ga).

\section{Domínio Curitiba:}

- Embasamento gnáissico-migmatítico (granitóides): Arqueano (2,8a 2,5Ga) .

- Granitóides intrusivos: Paleoproterozóico (2,1 a 1,8Ga).

- Granitóides deformados da Suite Rio Piên: Paleoproterozóico (2,2 a 2,0Ga).

- Dados isolados (básicas e granitóides): final do Mesoproterozóico 1,03Ga. 


\subsection{5 - DOMÍNIOS PARANAGUÁ E DOM FELICIANO}

\subsection{5-1 - SÍNTESE GEOLÓGICA:}

Domínio paranaguá - Este domínio ocupa a porção oriental de partes dos Estados de Santa Catarina e do Paraná (Figs. 5.13-2 e 5.14-12), sendo representado por uma grande variedade de granitóides deformados e subordinadamente por rochas migmatíticas, gnáissicas e xistosas (Siga Jr., 1995). Sua característica litológica marcante é a presença de rochas graníticas, incipiente a intensamente foliadas, contendo megacristais de feldspatos potássicos brancos. Esses granitóides se estendem desde a ilha de São Francisco do Sul em Santa Catarina até a borda meridional do Maciço de Itatins (SP).

Os dados geocronológicos (U-Pb e Rb-Sr) sugerem a formação desses granitóides principalmente no intervalo $0,67-0,57 \mathrm{Ga}$. O padrão $\mathrm{K}-\operatorname{Ar}(0,56-0,48)$ indica que o resfriamento desse segmento ou parte dele, atingiu o Cambro-Ordoviciano.

DOMínio DOM FELICIANO - O Cinturão Dom Feliciano, segundo Fragoso César (1991), ocupa a porção sul oriental do Escudo Riograndense, em contato com os fragmentos cratônicos Rio de La Plata e Luís Alves através de zonas de cisalhamento. Este cinturão inclui a Faixa Tijucas (SC e RS), e os batólitos de Encruzilhada do Sul e de Pelotas (RS e SC).

A Faixa Tijucas (Fragoso Cesar 1991), compreende essencialmente quartzo-mica xistos vergindo para NW. Associa-se a esta faixa expressivo plutonismo que inclui intrusões graníticas de caráter sin, tardi e pós tectônico.

As idades $\mathrm{Rb}-\mathrm{Sr}(\mathrm{RT})$ e U-Pb (zircões) relativas as rochas graniticas, metassedimenatares e metavulcânicas que ocorrem na Faixa Tijucas indicam épocas de formação relacionadas ao Ciclo Orogênico Brasiliano (em torno de 0,6Ga). Distinguem-se desse padrão os terrenos gnáissicomigmatíticos que ocorrem na região de Camboriu, cujos dados isotópicos sugerem épocas de formação relativas ao Arqueano (Basei, 1985). 
O Batólito de Pelotas (Fragoso Cesar et. al 1986), (figs. 5.15-3 e 5.15-4) é representado por uma multiplicidade de corpos graniticos sub-alcalinos (monzogranitos, granodioritos, quartzo-monzonitos, tonalitos, etc.) associados a enxames de diques básicos, platôs riolíticos, tufos e ignimbritos, e contendo roof-pendents de granitóides cálcio-alcalinos interpretados como possível raiz de arco magmático. Esses terrenos parecem corresponder em Santa Catarina aos que Basei (1985) caracterizou como Domínio Interno do Cinturão Dom Feliciano, fig. 5.15-4 que incluem predominantemente rochas granitico-migmatiticas.

O Batólito Encruzilhada do Sul, inicialmente incorporado ao Sistema de Dobramentos Tijucas (Hasui et. al., 1975) e posteriormente considerado como integrante do Batólito de Pelotas (Fragoso Cesar et. al. 1986), inclui uma grande variedade de granitóides de natureza sin, tardi e pós-tectônica, e suas rochas encaixantes constituem-se predominantemente de terrenos gnáissicos, que compreendem litologias cálcio-alcalinas, consideradas raiz de arco magmático.

\subsection{5-2 IDADES MODELO Sm-Nd, $\left(\mathrm{T}_{\mathrm{DM}}\right)$ :}

DOMínio PARANAGuÁ: Análises Sm-Nd (tab 5.15-1), obtidas em granitóides que ocorrem no setor oriental do Domínio Paranaguá, denominados de tipo Morro Inglês (Siga Jr., 1995) e coletados em afloramentos localizados a oeste de Paranaguá (amostra A), próximo a Guaratuba (amostra C) e arredores de Matinhos (amosta B), apresentaram idades modelo $\mathrm{T}_{\mathrm{DM}}$ entre 2,22 e 1,19 Ga. Tais valores caracterizam o Paleoproterozóico como o periodo principal em que os precursores desses granitóides foram diferenciados do manto. Diferem desse padrão os dados relativos aos granitóides do setor ocidental, tipo Rio Canavieiras (amostras D e E) localizados próximos ao limite com o Domínio Luis Alves, cujas idades foram respectivamente de 2,57 e 2,71Ga (fig. 5.15-1 e tabela 5.15-1).

As razões isotópicas iniciais $\varepsilon_{\mathrm{Sr}}(\mathbf{t}) \times \varepsilon_{\mathrm{Nd}}(\mathbf{t})$ para $\mathrm{t}=\sim 0,6 \mathrm{Ga}$ (fig. 5.15-2), caracterizam pontos analíticos distribuídos no quarto quadrante com valores de $\varepsilon_{\mathrm{Nd}}(\mathbf{t})$ bastante negativos e de $\varepsilon_{\mathrm{Sr}}(\mathrm{t})$ positivos, sugerindo período de residência crustal relativamente longos.

DOM FEliciano - FAIXA TIJUCAS - Nas figs. 5.15-3 e 5.15-4 encontram-se representadas as localizações aproximadas das amostras datadas pelo método $\mathrm{Sm}-\mathrm{Nd}$, e a tabela 


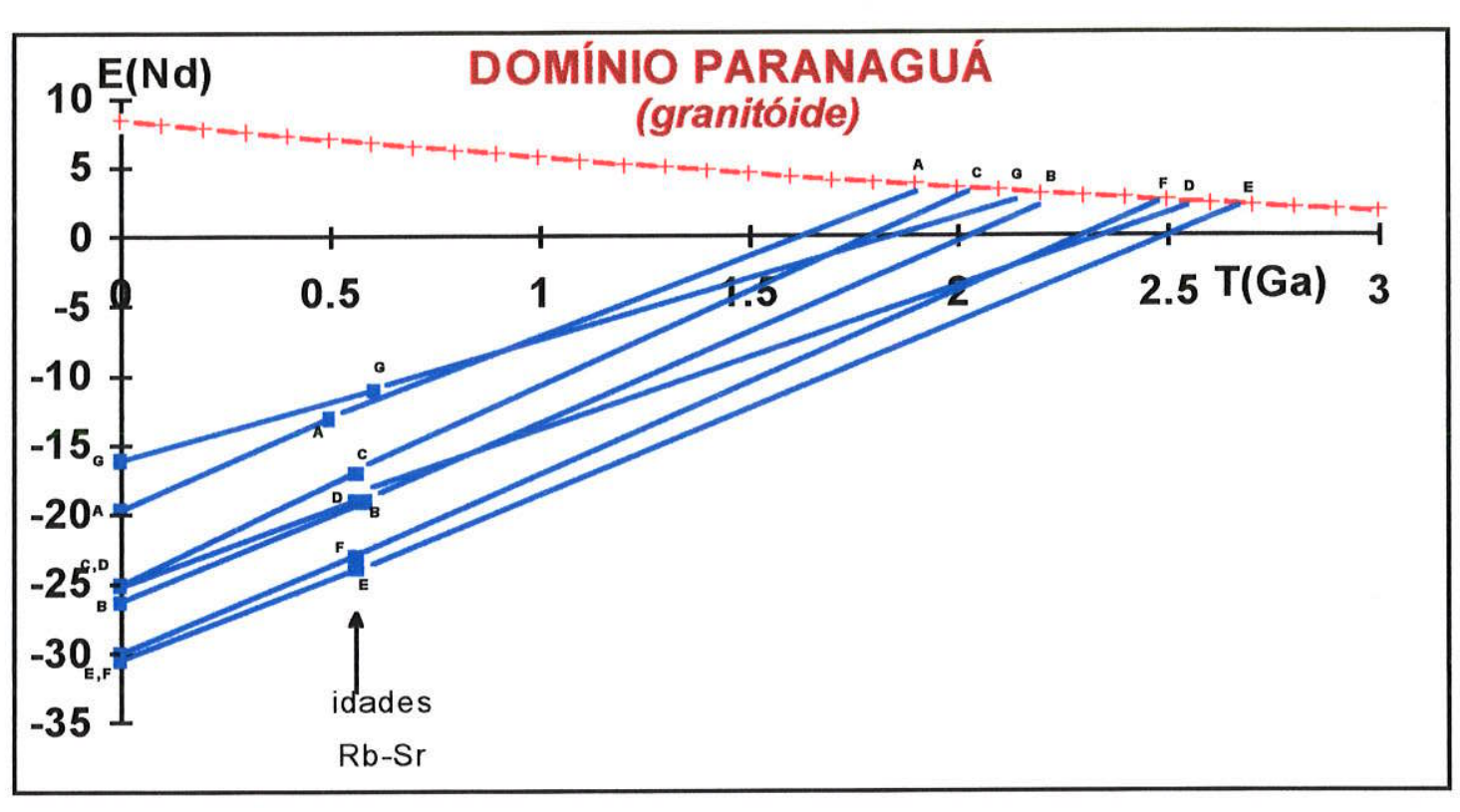

Fig. 5.15-1: Diagrama de evolução isotópico $\varepsilon_{N d}$ versus tempo geológico $T(G a)$ dos granitóides formados no Ciclo Orogênico Brasilianos onde as idades $\mathrm{Rb}-\mathrm{Sr}$ assinaladas com a seta variaram em torno de $0,6 \mathrm{Ga}$. Os dados isotópicos das amostras encontram-se na tabela (5.15-1). Linhas de evolução isotópica de $\varepsilon_{N d}$ regredindo até a curva do manto superior (DM) indicaram idades $\mathrm{T}_{\mathrm{DM}}$ Paleoproterozóicas (exceto $\mathrm{D}$ e $\mathrm{E}$ ).

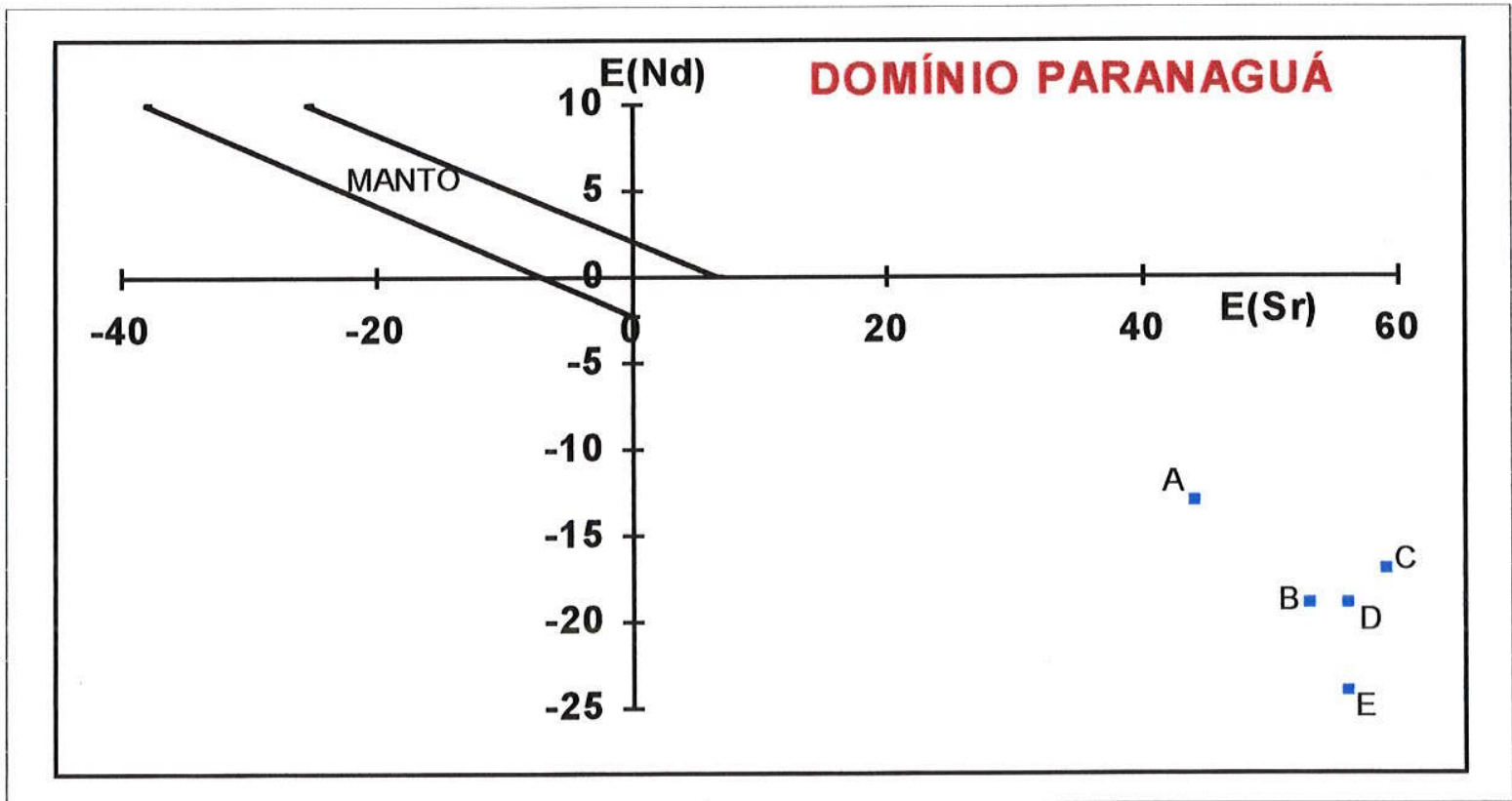

Fig. 5.15-2: Diagrama $\varepsilon_{S I-R I}(t)$ versus $\varepsilon_{N d}(t)$ com dados baseados na tab. 5.15-1. Os pontos assinalados estão bem distantes da origem com valores de $\varepsilon_{N d}(t)$ bem negativos e $\varepsilon_{\mathrm{Sr}-\mathrm{RI}}(\mathrm{t})$ positivos para $\mathrm{t} \sim 0,6 \mathrm{Ga}$ sugerindo que os granitos tiveram fonte de origem crustal. 


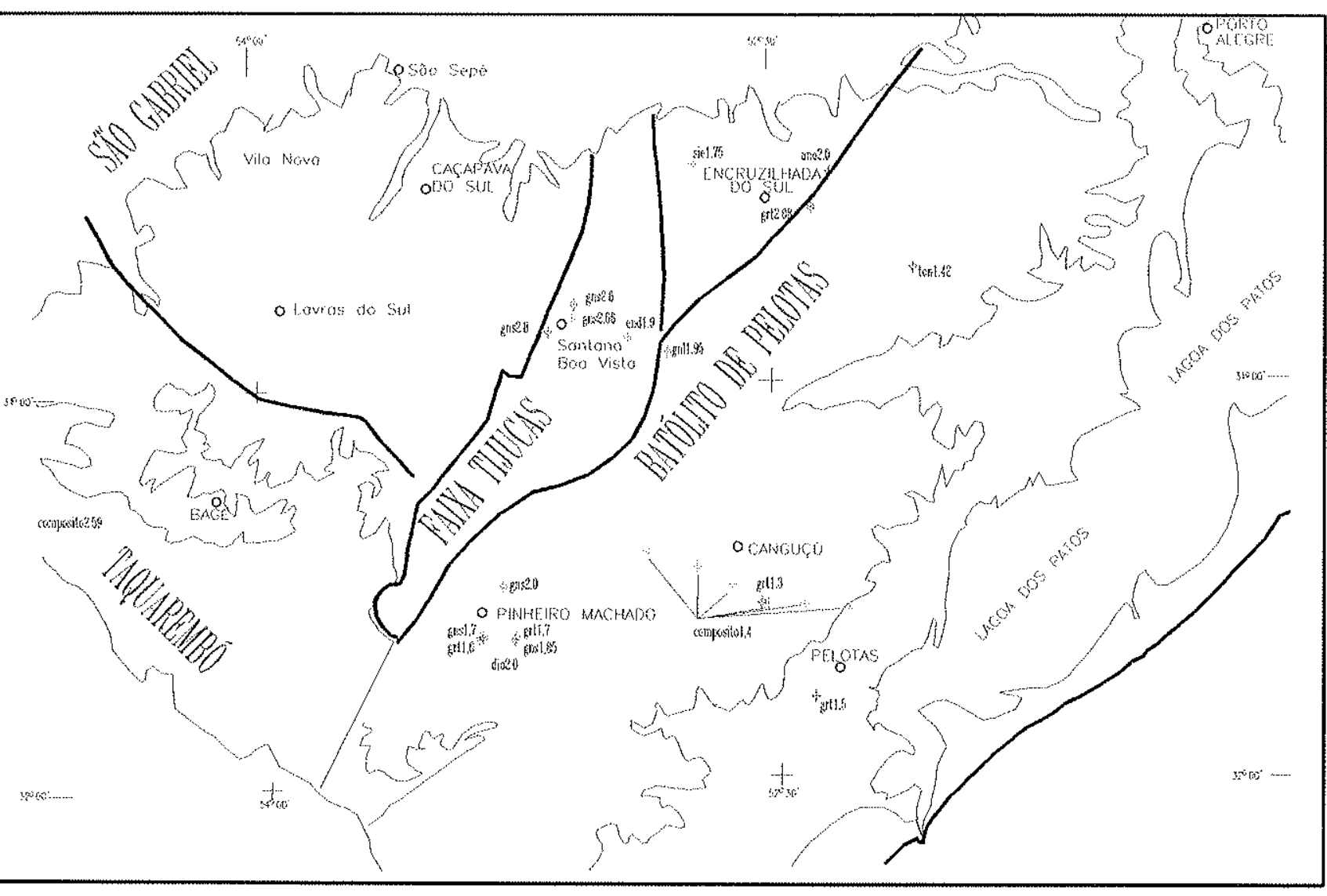

principas cidades ciladas e localizacano aproximada das amostras

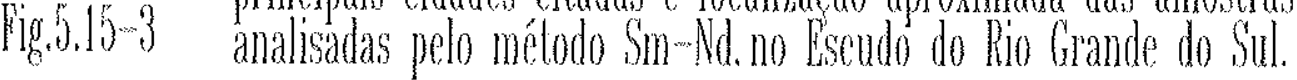




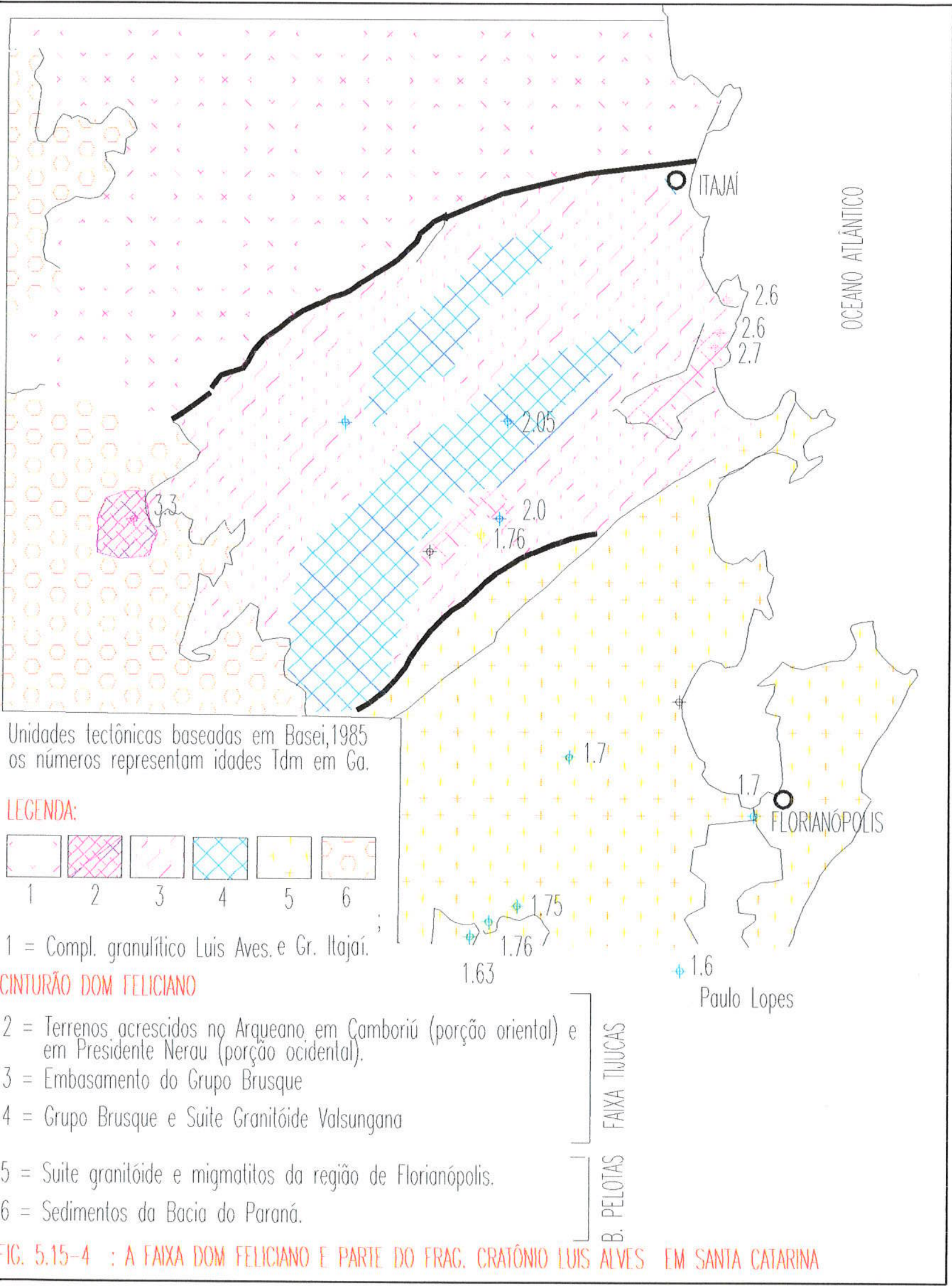




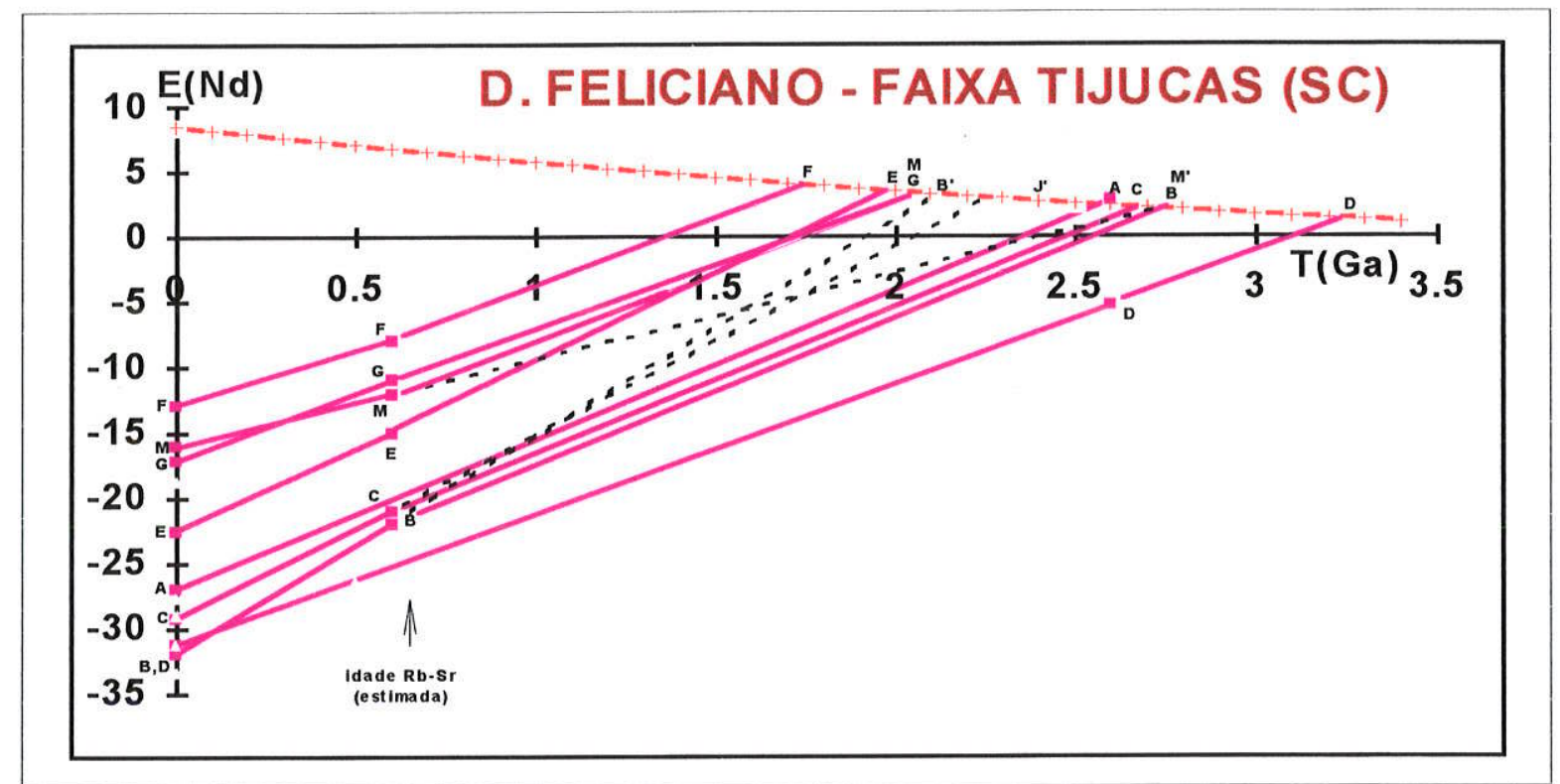

Fig. 5.15-5: Diagrama de evolução isotópico $\varepsilon_{N d}$ versus tempo geológico $T(G a)$ dos granitoides formados no Ciclo Orogênico Brasilianos com as idades $\mathrm{Rb}-\mathrm{Sr}$ estimadas em 0,6Ga (assinaladas com a seta). Os dados isotópicos das amostras encontram-se na tabela (5.15-2). Linhas de evolução isotópica (A e B - granitóides de Camboriú; C - granitóide de Guabiruba; D - granitóide de P. Nerau,), regredindo até a curva do manto superior (DM) indicaram idades Tdm Arqueanas. $F$ e $G$ metassedimentos do Grupo Brusque (idades Tdm de mistura). E - granitóide de Valsungana e M gnaisse de Itapema indicando acreções juvenis Paleoproterozóica. As linhas pontilhadas representam as evoluções de $\varepsilon_{\mathrm{Nd}}$ em estágio único, do presente até o evento da saída do magma do manto DM.

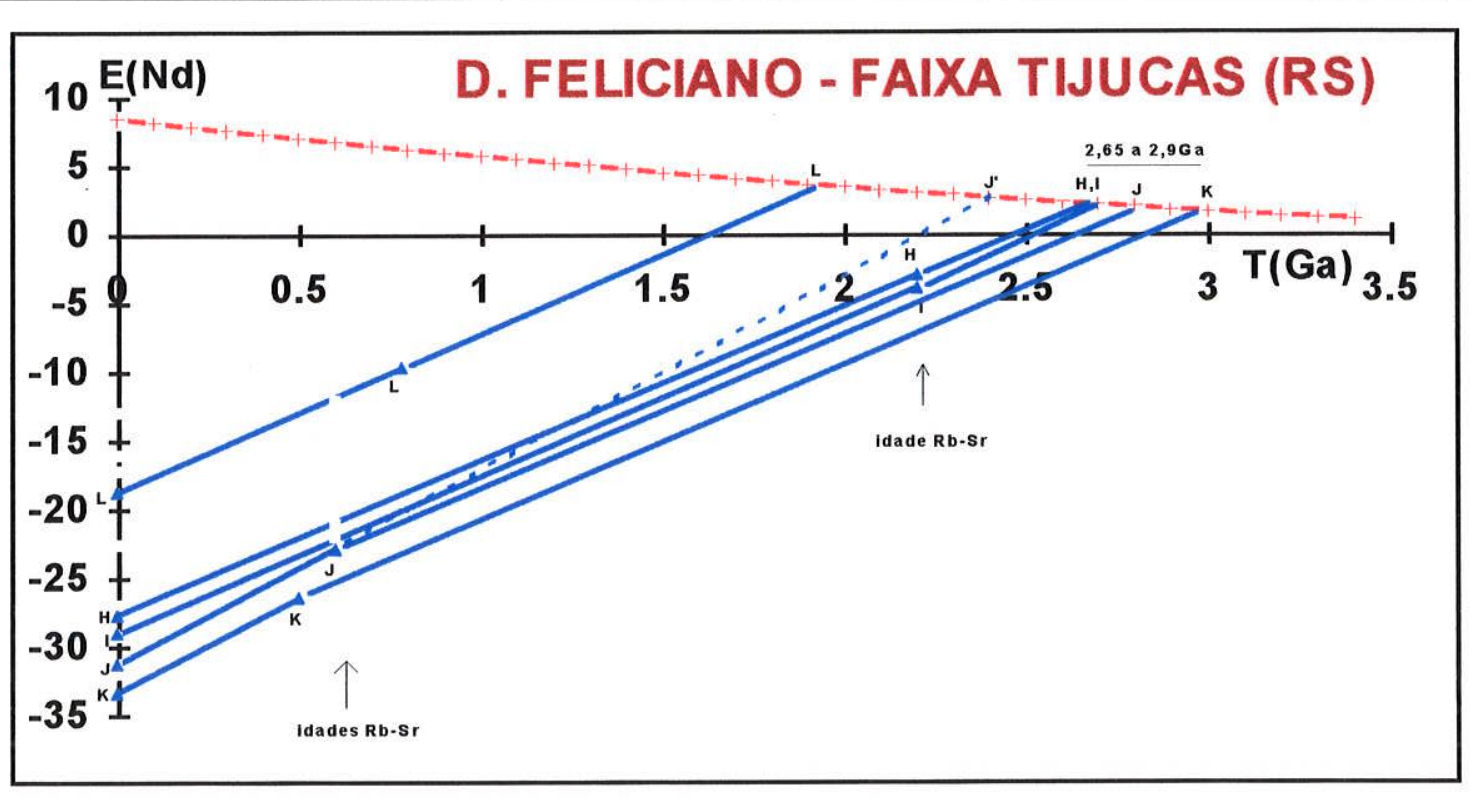

Fig. 5.15-6: Diagrama de evolução isotópico $\varepsilon_{N d}$ versus tempo geológico $T(G a)$ dos gnaisses da Santana de Boa Vista. Os dados isotópicos das amostras encontram-se na tabela (5.15-2). Idades Tdm arqueanas exceto amostra charno-enderbito "linha - L" paleoproterozóica. 


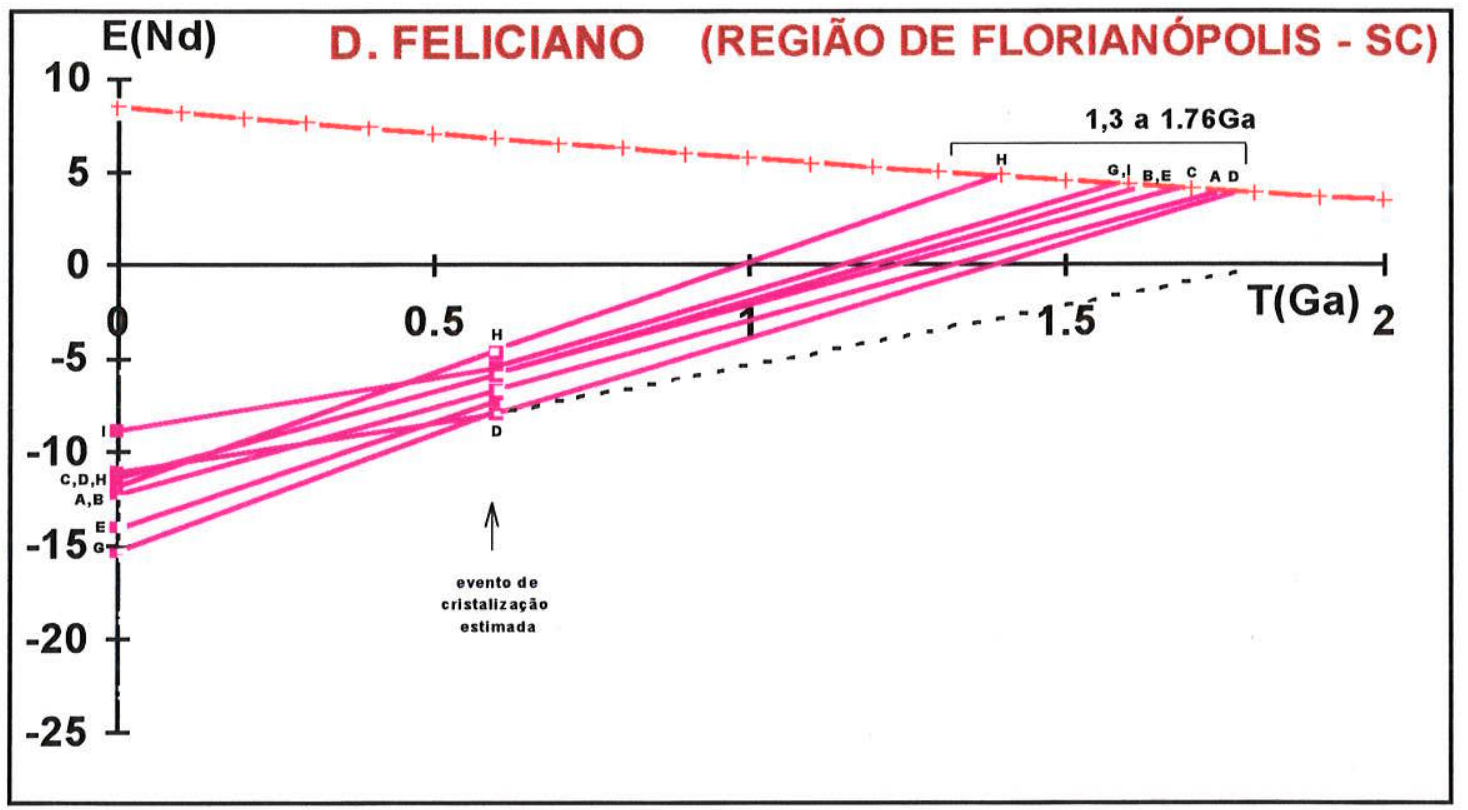

Fig. 5.15-7: Diagrama de evolução isotópico $\varepsilon_{N d}$ versus tempo geológico $T(G a)$ dos granitóides da região de Florianópolis. Os dados isotópicos das amostras encontram-se na tabela (5.15-3). Idades Tdm paleoproterozóicas a mesoproterozóicas.

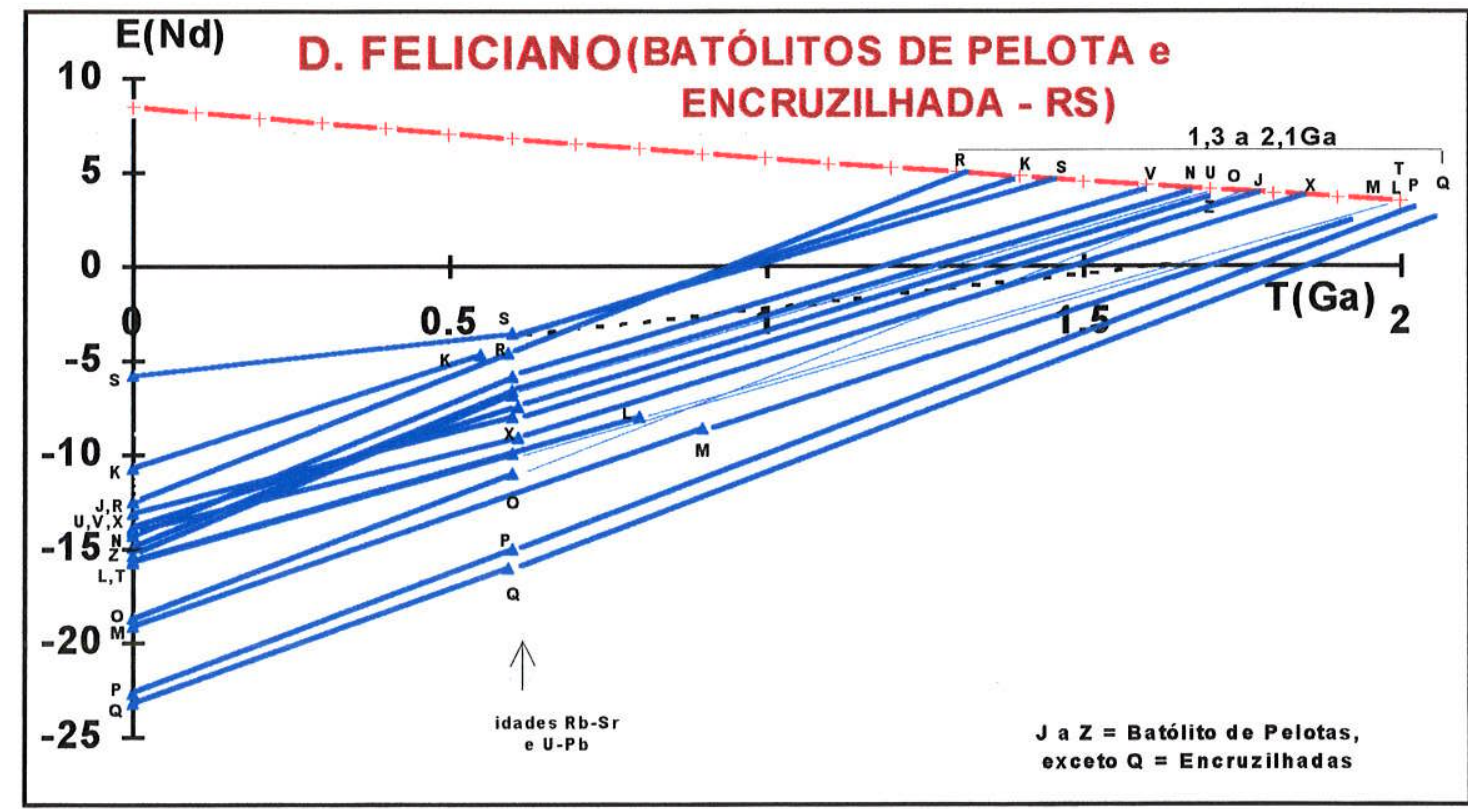

Fig. 5.15-8: Diagrama de evolução isotópico $\varepsilon_{\mathrm{Nd}}$ versus tempo geológico $\mathrm{T}(\mathrm{Ga})$. Os dados isotópicos das amostras encontram-se na tabela 5.15-3. As idades modelo Sm-Nd indicaram $\mathrm{T}_{\mathrm{DM}}$ paleoproterozóicas a mesoproterozóicas, de forma muito semelhante ao Batólito de Pelotas na região de Santa Catarina. Os valores de $\varepsilon_{\mathrm{Nd}}(\mathrm{t})$ para $\mathrm{t}$ igual idade $\mathrm{Rb}-\mathrm{Sr}$ ou U-Pb assinalada com a seta na fig. são relativamente negativos. 
Fig. 5.15-9: Diagrama de evolução isotópico $\varepsilon_{\mathrm{Nd}}$ versus tempo geológico $\mathrm{T}(\mathrm{Ga})$. Integração de duas figs, 5.15-7 e 5.15-8. O campo entre duas linhas contínuas corresponde ao Batólito de Pelotas - RS, e entre duas linhas tracejadas ao Batólito de Pelotas na região de Florianópolis - SC. Os símbolos triângulos e quadrados plotados no meio do diagrama correspondem aos valores de $\varepsilon_{\mathrm{Nd}}$ ( $\mathrm{t}$ ) calculados para $\mathrm{t}=$ idade de $\mathrm{Rb}-\mathrm{Sr}$ ou U-Pb. Nota-se que o valores $\varepsilon_{\mathbb{N d}}$ são todos negativos. Os intervalos nas idades Tdm apresentam padrões similares entre as duas regiões $(2,1$ a $1,3 \mathrm{Ga})$. 
5.15-2 reune os dados isotópicos ${ }^{14.3} \mathrm{Nd} /{ }^{14+} \mathrm{Nd}$ e razões ${ }^{147} \mathrm{Sm} /{ }^{1+4} \mathrm{Nd}$ (Mantovani et. al, 1987 e Babinski et. al., 1995).

Os dados relativos à Faixa Tijucas (SC, fig.5.15-5), quando plotados em diagrama de evolução isotópica $\varepsilon_{\mathrm{Nd}}(\mathrm{t})$ versus tempo geológico $\mathrm{T}(\mathrm{Ga})$, caracterizam acreções de materiais juvenis durante o Arqueano para os protolitos gnáissicos da região de Camboriú $(2,8$ a 2,6Ga), Guabiruba $(2,7 \mathrm{Ga})$ e Presidente Nereu $(3,2 \mathrm{Ga})$. Idades $\mathrm{T}_{\mathrm{DM}}$ Paleoproterozóicas foram registradas nos filitos pertencente ao Grupo Brusque $(2,05$ a $1,76 \mathrm{Ga})$, e na suíte granitica de Valsungana $(2,0 \mathrm{Ga})$. Trata-se de materiais diferenciados do manto durante $o$ Arqueano $e$ o Paleoproterozóico, que serviram de fonte para as rochas formadas no Ciclo Orogênico Brasiliano.

Os dados Sm-Nd relativos a rochas que ocorrem no Rio Grande do Sul, nas vizinhanças da Santana de Boa Vista (fig. 5.15-3), indicam para os seus precursores crustais relacionados ao Arqueano $(2,8$ a $2,6 \mathrm{Ga}$; fig. 5.15-6).

DOM FEliciano - batólitos de PElotas E ENCRUZlhada do SUL - Os dados isotópicos disponiveis para os batólitos de Pelotas e Encruzilhada do Sul (Mantovani et. al., 1987) integrados às novas determinações radiométricas (Babinski, 1995), em muito contribuíram para reconstituir os seus principais eventos acrecionários. De um modo geral, os diagramas de evolução isotópica $\varepsilon_{\mathbb{N}}(t)$ versus tempo geológico (figs. 5.15-7 e 5,15-8) indicaram acreções juvenis predominantemente durante o Paleoproterozóico, estendendo-se até o Mesoproterozóico (2,1 a 1,3Ga; tab. 5.15-3).

No caso dos valores mais jóvens $(1,5-1,3 \mathrm{Ga})$, não se pode descartar a possibilidade de mistura de fontes ( por exemplo: material juvenil Neoproterozóico, e material retrabalhado Paleoproterozóico ou Arqueano). Para caracterizar esta hipótese será necessário encontrar registros de idades $\mathrm{T}_{\mathrm{DM}}$ Neoproterozóicas, caracterizando a presença inequívoca de material juvenil desta idade. Até presente momento, todas as idades $\mathrm{T}_{\mathrm{DM}}$ obtidas são mais antigas do que $1,3 \mathrm{Ga}$.

A figura 5.15-9 mostra padrões similares de evolução isotópica de $\mathrm{Nd}$ para os batólitos de Pelotas (SC e RS) e Encruzilhada do Sul (RS). 


\subsection{5-3 - RESUMO PARCIAL - DOMÍNIOS PARANAGUÁ E DOM FELICIANO:}

Os principais eventos de acreção manto crosta continental com base em idades modelo $\mathrm{Sm}-\mathrm{Nd}$, $T_{D M M}$ foram:

Domínio Paranaguá (PR) - granitóides:

acreçoes juvenís predominantemente Paleoproterozóicas (pico em 2, $1 \mathrm{Ga}$ ), com ocorrências menores no Arqueano $(2,7$ a $2.5 \mathrm{Ga})$.

\section{Domínio Dom Feliciano:}

- Faixa Tijucas (SC) - granitóides: Arqueano (3,2-2.6Ga); granitóides intrusivos e metassedimentos Paleoproterozóicos: 2,05 - 1,76Ga.

- Faixa Tijucas (RS) - granitóides: Arqueano ( 3,0 - 2,6Ga); granulitos: Paleoproterozóicos (1,9Ga).

- Batólito Pelotas (SC) - granitóides: Paleoproterozóicos (2,06-1,7Ga); granitóides e metassedimento: Paleo-Mesoproterozóicos - (1,7- 1,4Ga).

- Batólito Pelotas (RS) - granulitos e rochas básicas:Paleoproterozóicos (2.0-1,7Ga); granitóides : Paleo-Mesoproterozóicos (1,8-1,3Ga).

- Batólito Encruzilhada do Sul - granitóides: Paleoproterozóicos (2,08Ga).

A figura 5.15-10 mostra de forma resumida os principais dominios de acreção com base nas idades podelo. 


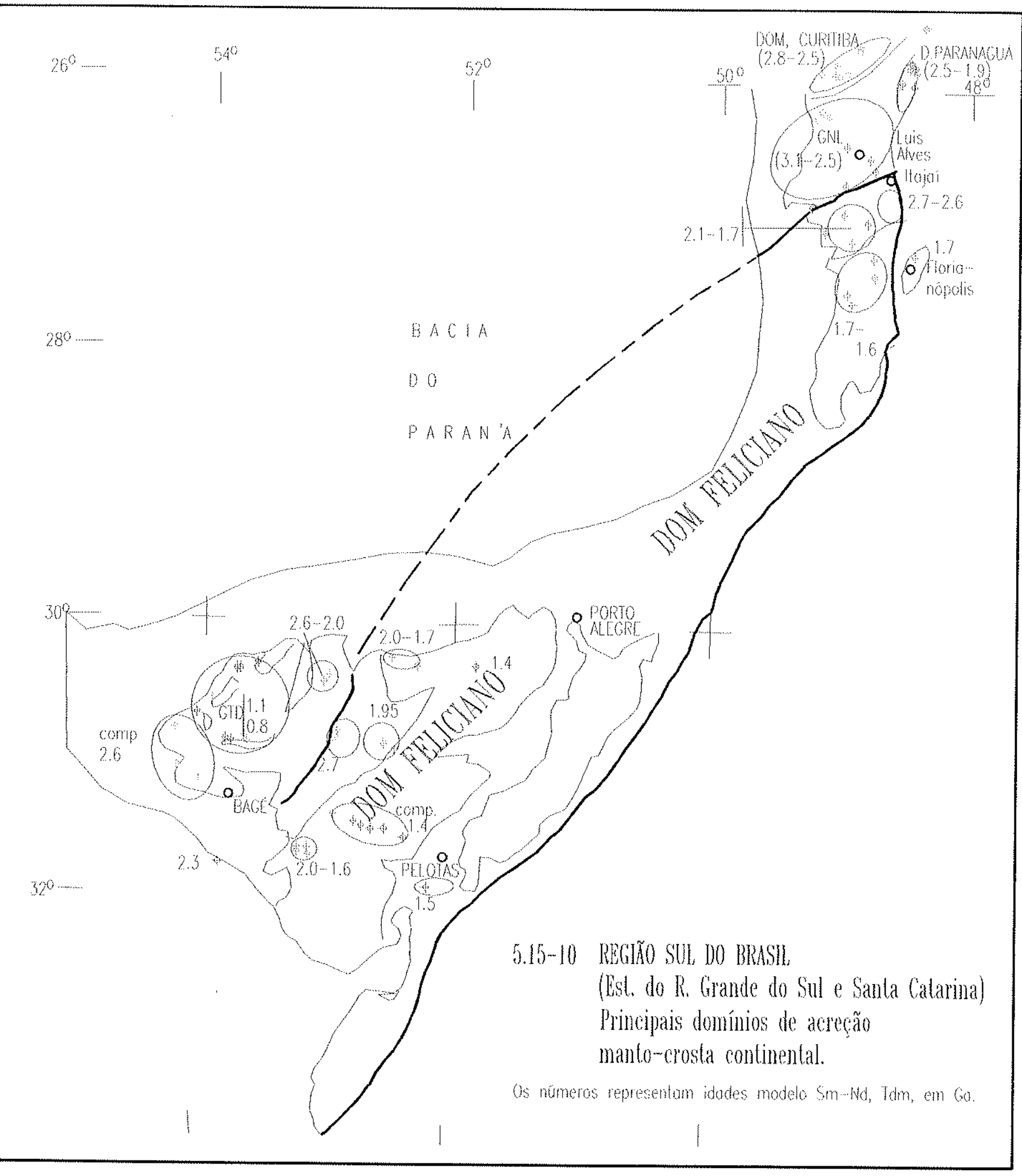


TAB. 5.13-1: FRAGMENTO CRATÔNICO LUIS ALVES

\begin{tabular}{|c|c|c|c|c|c|c|c|c|c|c|c|c|c|c|c|c|c|}
\hline $\begin{array}{l}\text { SPS } \\
/ \text { lit. }\end{array}$ & coord. & $\begin{array}{l}\text { n.campol } \\
\text { região }\end{array}$ & $\begin{array}{l}\text { litolo } \\
\text { gia }\end{array}$ & $\begin{array}{l}\text { ident } \\
\text { (diagra- } \\
\text { ma) }\end{array}$ & \begin{tabular}{|l|}
$T_{\text {chur }}$ \\
(GA) \\
Goldstein \\
etal 1984 \\
\end{tabular} & $\mathrm{T}_{(\mathrm{GA})}$ & $\begin{array}{l}T_{\mathrm{dm}} \\
(\mathrm{GA}) \\
\text { Depaolo } \\
\text { - } 1981 \\
\end{array}$ & ${ }^{144} \mathrm{Nd} /$ & ${ }^{144} \mathrm{Sm} /$ & $\begin{array}{l}\mathrm{Sm} \\
\mathrm{ppm}\end{array}$ & $\begin{array}{l}\text { Nd } \\
\text { ppm }\end{array}$ & $f$ & $\begin{array}{l}\varepsilon_{\text {Nd }} \\
(0)\end{array}$ & $\begin{array}{l}\varepsilon_{N d} \\
(t)\end{array}$ & $\begin{array}{l}\mathbf{t}(\mathrm{Ga})_{\text {mét }} \\
\mathrm{Ri}_{\text {(fonte) }}\end{array}$ & $\begin{array}{l}\varepsilon_{\mathrm{Sr}} \\
(\mathrm{t})\end{array}$ & ref \\
\hline & & & & & & & & & & & & & & & & & \\
\hline gn! & $2650 / 4907$ & $\begin{array}{l}\text { MJ27.14/SC } \\
\text { dom.Luis Alves }\end{array}$ & GNL & A & 2.01 & & 2.30 & $\begin{array}{r}0.511545 \\
\pm .000014 \\
\end{array}$ & $\begin{array}{l}0.113929 \\
\pm .00003 \\
\end{array}$ & 5.20 & 27.6 & -.42 & -21.3 & -.5 & $\begin{array}{l}1.97_{\mathrm{Rb} / \mathrm{Sr}} \\
.7045_{\mathrm{a}} \\
\end{array}$ & 33 & 1 \\
\hline gnl & $2639 / 4903$ & $\begin{array}{l}\text { MJ41.3/ SC } \\
\text { dom.Lus Alves }\end{array}$ & GNL & $B$ & 2.02 & & 2.27 & .511323 & .098040 & 2.74 & 16.90 & -.50 & -25.7 & -0.9 & 1.97 est & & $\overline{1}$ \\
\hline $\begin{array}{l}252 \\
\text { gnl }\end{array}$ & $2613 / 4903$ & $\begin{array}{l}\text { MJ195/SC } \\
\text { dom.Luis Alves }\end{array}$ & GNL & C & $\begin{array}{l}2.85 \\
\pm .06 \\
\end{array}$ & & $\begin{array}{r}3.06 \\
\pm .06 \\
\end{array}$ & \begin{tabular}{|l|}
.511253 \\
.000026 \\
\end{tabular} & $\begin{array}{l}.123169 \\
.000281 \\
\end{array}$ & \begin{tabular}{|l|}
4.244 \\
0.001 \\
\end{tabular} & $\begin{array}{l}20.836 \\
0.047 \\
\end{array}$ & -.37 & -26.8 & -1.5 & $\begin{array}{l}2.7 \mathrm{Rb} / \mathrm{Sr} \\
.70409_{\mathrm{a}} \\
\end{array}$ & 40 & 1 \\
\hline gni & $2613 / 4903$ & $\begin{array}{l}\text { MJ195/SC } \\
\text { dom.Luis Alves }\end{array}$ & GNL & $D$ & 2.89 & & 3.08 & $\begin{array}{l}.511133 \\
.000020 \\
\end{array}$ & $\begin{array}{l}.117743 \\
.000037 \\
\end{array}$ & 4.42 & 22.70 & -.40 & -29.4 & -2.2 & $\begin{array}{l}2.7 \mathrm{Rb} / \mathrm{Sr} \\
.7040 \mathrm{a}_{\mathrm{a}} \\
\end{array}$ & 40 & 1 \\
\hline gnl & $2908 / 4921$ & $\begin{array}{l}\text { MJ15a/PR } \\
\text { dom. Luis Alves }\end{array}$ & GNL & $E$ & 2.59 & & 2.81 & $\begin{array}{l}.511233 \\
.000016 \\
\end{array}$ & $\begin{array}{l}.114539 \\
.000233 \\
\end{array}$ & 0.68 & 3.59 & -.42 & -27.4 & 0.9 & $2.7 \mathrm{est}$ & & 1 \\
\hline $\mathrm{gnl}$ & $\begin{array}{l}\text { SERRA } \\
\text { NEGRA }\end{array}$ & $\begin{array}{l}\text { JR06 / PR } \\
\text { dom.Luis Alves }\end{array}$ & GNL & $F$ & 2.08 & & 2.37 & $\begin{array}{l}.511571 \\
.000020\end{array}$ & .118614 & 8.16 & 41.6 & -.40 & -20.8 & 6.1 & $2.7 \mathrm{est}$ & & 1 \\
\hline gnl & Composito $^{+}$ & $\begin{array}{l}\text { C11/ SC } \\
\text { dom. Luis Aives }\end{array}$ & GNL & $G$ & 2.51 & & 2.73 & \begin{tabular}{|l|}
.511193 \\
.000010 \\
\end{tabular} & .1095 & $\ldots$ & -m- & -.44 & -28.2 & 1.8 & $2.7 e s t$ & & 2 \\
\hline $\begin{array}{l}253 \\
\text { gnl }\end{array}$ & $2513 / 4834$ & $\begin{array}{l}\text { MJ367 / PR } \\
\text { dom. Luis Alves }\end{array}$ & GNL & $\mathrm{H}$ & $\begin{array}{l}2.66 \\
0.05\end{array}$ & & $\begin{array}{l}.84 \\
0.04\end{array}$ & $\begin{array}{l}.510920 \\
.000035\end{array}$ & $\begin{array}{l}0.098625 \\
0.000066\end{array}$ & $\begin{array}{l}2.864 \\
.001\end{array}$ & $\begin{array}{l}17.560 \\
.010\end{array}$ & -.51 & -33.5 & 1.0 & $2.7 e s t$ & & 1 \\
\hline $\begin{array}{l}89 \\
\text { m.nor }\end{array}$ & $2544 / 4907$ & $\begin{array}{l}\text { MJ461b/PR } \\
\text { dom.Luis Alves }\end{array}$ & BAS & 1 & 2.93 & & 3.11 & .511014 & .112709 & 6.60 & 35.410 & -.43 & -31.7 & -2.8 & 2.7 est & & 1 \\
\hline \multicolumn{18}{|c|}{ GRANITOS INTRUSIVOS } \\
\hline $\begin{array}{l}238 \\
\text { grt }\end{array}$ & $2555 / 4915$ & $\begin{array}{l}\mathrm{MJ132/PR-SC} \\
\text { D.Cur./L.Alves }\end{array}$ & GTD & $\mathrm{J}$ & $\begin{array}{l}1.81 \\
.06\end{array}$ & & \begin{tabular}{|l|}
2.13 \\
.05 \\
\end{tabular} & $\begin{array}{l}.511689 \\
.000031\end{array}$ & $\begin{array}{l}.116790 \\
.000094\end{array}$ & $\begin{array}{l}5.91 \\
.003\end{array}$ & \begin{tabular}{|l|}
30.599 \\
.019
\end{tabular} & -.41 & -18.5 & -12 & $.59 \mathrm{U}-\mathrm{Pb}$ & & 1 \\
\hline grt & $2621 / 4910$ & $\begin{array}{l}\text { MJízal SC } \\
\text { Dom. L. Alves }\end{array}$ & GTD & $\mathrm{K}$ & 1.62 & & 1.94 & $\begin{array}{l}.511672 \\
.000024 \\
\end{array}$ & $\begin{array}{l}.105823 \\
.000022 \\
\end{array}$ & 6.30 & 36.0 & -.46 & -18.8 & -13 & \begin{tabular}{|l|}
$.55_{\mathrm{Rb}-\mathrm{Sr}}$ \\
$.70703_{\mathrm{a}}$ \\
\end{tabular} & 45 & 1 \\
\hline grt & $2552 / 4859$ & $\begin{array}{l}\text { MJ275b/PR-SC } \\
\text { Dom. L. Alves }\end{array}$ & GTD & $\mathrm{L}$ & $1.51 ?$ & $\begin{array}{l}1.61^{\# 1} \\
1.74^{\# 2}\end{array}$ & $1.97 ?$ & $\begin{array}{l}.512033 \\
.000025 \\
\end{array}$ & .135649 & 3.32 & 14.80 & -.31 & -11.8 & -7.7 & $\begin{array}{l}0.53_{\mathrm{Rb} / \mathrm{sr}} \\
.723_{\mathrm{a}} \\
\end{array}$ & 272 & 1 \\
\hline \multicolumn{18}{|c|}{ VULCÂNICA } \\
\hline $\begin{array}{l}372 \\
\text { vul }\end{array}$ & $2546 / 4906$ & $\begin{array}{l}\mathrm{MJ} 376 / \mathrm{PR} \\
\text { f.Guaratubinha }\end{array}$ & VAC & $M$ & $\begin{array}{l}3.00 ? \\
0.12\end{array}$ & $2.06^{* 1}$ & $\begin{array}{l}3.26 ? \\
0.12\end{array}$ & $\begin{array}{l}.511731 \\
.000035\end{array}$ & $\begin{array}{l}.150910 \\
.000068\end{array}$ & $\begin{array}{l}20.19 \\
0.005\end{array}$ & \begin{tabular}{|l|}
80.890 \\
.030
\end{tabular} & -.23 & -17.7 & -14 & $\begin{array}{l}0.57_{\mathrm{Rb} / \mathrm{Sr}} \\
.709 \mathrm{a}_{\mathrm{a}}\end{array}$ & 79 & nt \\
\hline
\end{tabular}


ANÁLISE EM MINERAIS

\begin{tabular}{|c|c|c|c|c|c|c|c|c|c|c|c|c|c|c|c|c|}
\hline$\cdots$ & $2645 / 4844$ & $\begin{array}{l}\text { anfibólio* / SC } \\
\text { dom.Luis Alves }\end{array}$ & Maf & $\mathrm{N}$ & $\begin{array}{l}2.24 \\
0.15 \\
\end{array}$ & $2.50^{\# 2}$ & $\begin{array}{l}2.55 \\
0.11 \\
\end{array}$ & $\begin{array}{l}.511658 \\
.000006 \\
\end{array}$ & $\begin{array}{l}.130315 \\
.004300 \\
\end{array}$ & $m$ & -- & -.34 & -19.1 & 0.0 & $\begin{array}{l}2.26_{\mathrm{Sm}-\mathrm{Nd}} \\
.500724_{\mathrm{a}}\end{array}$ & 3 \\
\hline$\cdots$ & $2645 / 4844$ & $\begin{array}{l}\text { microclineo* SC } \\
\text { dom. Luis Alves }\end{array}$ & Mmi & 0 & $\begin{array}{l}2.04 \\
0.08\end{array}$ & $2.29^{\# 2}$ & $\begin{array}{l}2.27 \\
0.06 \\
\end{array}$ & $\begin{array}{l}.511146 \\
.000041\end{array}$ & $\begin{array}{l}.085819 \\
.002800 \\
\end{array}$ & $\cdots$ & $-\cdots$ & -.56 & -29.1 & 2.9 & $\begin{array}{l}2.26_{\mathrm{Sm}-\mathrm{Nd}} \\
.509724_{\mathrm{a}}\end{array}$ & 3 \\
\hline$\cdots$ & $2645 / 4844$ & $\begin{array}{l}\text { esfeno*/SC } \\
\text { dom. Luis Alves }\end{array}$ & Mes & $P$ & $\begin{array}{l}2.26 \\
0.11 \\
\end{array}$ & $2.51^{32}$ & $\begin{array}{l}2.52 \\
0.09 \\
\end{array}$ & $\begin{array}{l}.511442 \\
.000002 \\
\end{array}$ & $\begin{array}{l}.116226 \\
.003800 \\
\end{array}$ & $\because-$ & -- & -.41 & -23.3 & -.1 & $\begin{array}{l}2.266_{\mathrm{Sm}-\mathrm{Nd}} \\
509724_{\mathrm{a}}\end{array}$ & 3 \\
\hline$\cdots$ & $2645 / 4844$ & $\begin{array}{l}\text { piroxênio* / SC } \\
\text { dom. Luis Alves }\end{array}$ & Mpi & $Q$ & $\begin{array}{l}2.19 \\
0.17 \\
\end{array}$ & $2.48^{12}$ & $\begin{array}{l}2.53 \\
0.13 \\
\end{array}$ & $\begin{array}{l}.511781 \\
.000005 \\
\end{array}$ & $\begin{array}{l}.137209 \\
.004500 \\
\end{array}$ & -- & -- & -.30 & -16.7 & 0.4 & $\begin{array}{l}2.26 \mathrm{Sm}_{\mathrm{Sd}} \\
.509724 \mathrm{a} \\
\end{array}$ & 3 \\
\hline -- & $2645 / 4844$ & $\begin{array}{l}\text { a!lanita* / SC } \\
\text { dom.Luis Alves }\end{array}$ & Mal & $R$ & $\begin{array}{l}2.25 \\
0.07\end{array}$ & $2.50^{72}$ & $\begin{array}{l}2.40 \\
0.06 \\
\end{array}$ & $\begin{array}{l}.510265 \\
.000004\end{array}$ & $\begin{array}{l}.036375 \\
.004800 \\
\end{array}$ & -- & -- & -.82 & -46.3 & -.1 & $\begin{array}{l}2.26_{\mathrm{Sm}-\mathrm{No}} \\
.509724 \mathrm{a}\end{array}$ & 3 \\
\hline
\end{tabular}

\begin{tabular}{|c|c|c|c|c|c|c|c|c|c|c|c|c|c|c|c|c|}
\hline \multicolumn{17}{|c|}{ ROCHAS BÁSICAS - ULTRABÁSICAS - PIÊN / DOM. LUIS ALVES? (ROCHA TOTAL) } \\
\hline $\begin{array}{l}84 \\
\text { U.maf }\end{array}$ & $2606 / 4916$ & $M J 518 \mathrm{c} / \mathrm{PR}$ & $\overline{U B A}$ & $\mathrm{D}$ & 2.59 & $\begin{array}{l}2.67^{\# 1} \\
2.71^{\# 2}\end{array}$ & 2.85 & $\begin{array}{l}.511536 \\
.000032 \\
\end{array}$ & .132204 & 223 & 1.020 & -.33 & -21.5 & -3.0 & $2.25_{\mathrm{Sm}-\mathrm{Nd}}$ & 1 \\
\hline $\begin{array}{l}85 \\
\text { u.maf }\end{array}$ & $2 6 \longdiv { 0 6 / 4 9 1 6 }$ & M $3523 a / P R$ & $\overline{U B A}$ & $\bar{E}$ & $3.50 ?$ & $\begin{array}{l}2.66^{\# 1} \\
2.70^{\# 2}\end{array}$ & $3.84 ?$ & .512237 & .179394 & 0.089 & .300 & -.09 & -7.8 & -2.9 & $2.25_{\mathrm{Sm} \cdot \mathrm{Nd}}$ & 1 \\
\hline $\begin{array}{l}86 \\
\text { u.maf }\end{array}$ & $2606 / 4916$ & $M 3523 c / P R$ & $\overrightarrow{U B A}$ & $\bar{F}$ & 2.70 & $\begin{array}{l}2.51^{\# 1} \\
2.54^{* 2}\end{array}$ & $3.67 ?$ & .512513 & .189676 & .436 & 1.39 & -.04 & -2.4 & -0.4 & $2.25_{\mathrm{sm}-\mathrm{Nd}}$ & 1 \\
\hline $\begin{array}{l}125 \\
\text { u.maf }\end{array}$ & $2606 / 4916$ & $M 3523 c / P R$ & UBA & $G$ & 2.66 & $\begin{array}{l}2.49^{\# 1} \\
2.52^{\# 2}\end{array}$ & $3.66 ?$ & $\begin{array}{l}.512514 \\
.000039 \\
\end{array}$ & $\begin{array}{l}.189637 \\
.000770 \\
\end{array}$ & .461 & 1.47 & -.04 & -2.4 & -0.4 & $2.25_{\mathrm{Sm}-\mathrm{Nd}}$ & 1 \\
\hline $\begin{array}{l}131 \\
\text { u.maf }\end{array}$ & $2606 / 4916$ & MJ527a/PR & UBA & $\mathrm{H}$ & 2.37 & $\begin{array}{l}2.61^{\# 1} \\
2.64^{\# 2}\end{array}$ & 2.57 & $\begin{array}{l}.510988 \\
.000021 \\
\end{array}$ & .091103 & .229 & 1.52 & -.54 & -32 & -1.9 & $2.25_{\mathrm{Sm}-\mathrm{Nd}}$ & 1 \\
\hline $\begin{array}{l}88 \\
\text { gb.nor }\end{array}$ & $2609 / 4923$ & MJ534/PR & $\overrightarrow{\mathrm{BAS}}$ & 1 & 3.06 & $\begin{array}{l}3.02^{\# 1} \\
2.95^{\# 2} \\
\end{array}$ & $3.24 ?$ & $\begin{array}{l}.511240 \\
.000030 \\
\end{array}$ & .127428 & 2.082 & 9.88 & -.35 & -27.3 & -7.4 & $2.25_{\mathrm{Sm}-\mathrm{Nd}}$ & 1 \\
\hline & & & & & & & & & & & & & & & & \\
\hline
\end{tabular}


TAB. 5.13-2: Blocos Taquarembó e São Gabriel (RS)

\begin{tabular}{|c|c|c|c|c|c|c|c|c|c|c|c|c|c|c|c|c|c|}
\hline $\begin{array}{l}\text { SPS } \\
\text { /lit. }\end{array}$ & coord.I & $\begin{array}{l}\text { n.campo/ } \\
\text { região }\end{array}$ & $\begin{array}{l}\text { litolo } \\
\text { gia }\end{array}$ & $\begin{array}{l}\text { ident } \\
\text { (diagra- } \\
\text { ma) }\end{array}$ & \begin{tabular}{|l|}
$T_{\text {chur }}$ \\
(GA) \\
Goldstein \\
etal 1984 \\
\end{tabular} & $\mathrm{T}_{(\mathrm{dm})}$ & $\begin{array}{l}T_{\mathrm{dm}} \\
(\mathrm{GA}) \\
\text { DePaolo } \\
-1981 \\
\end{array}$ & $\begin{array}{l}{ }_{144}^{143} \mathrm{Nd} / \\
{ }^{144}\end{array}$ & $\begin{array}{l}{ }^{147} \mathrm{Sm} / \\
{ }^{144} \mathrm{Nd}\end{array}$ & $\begin{array}{l}\mathrm{Sm} \\
\mathrm{ppm}\end{array}$ & $\begin{array}{l}\text { Nd } \\
\text { ppm }\end{array}$ & $f$ & $\begin{array}{l}\varepsilon_{\mathrm{Nd}} \\
(0)\end{array}$ & $\varepsilon_{\mathrm{Nd}}$ & $\begin{array}{l}\mathrm{t}(\mathbf{G a})_{\text {mét }} \\
R \mathrm{i}_{\text {(fonte) }}\end{array}$ & $\begin{array}{l}\varepsilon_{\mathrm{Sr}} \\
(t)\end{array}$ & ref \\
\hline \multicolumn{18}{|c|}{ Bloco São Gabriel } \\
\hline $\begin{array}{l}191 / \\
\text { gns }\end{array}$ & $3021 / 5401$ & ESJ-05 & GTD & $A$ & $\begin{array}{l}0.26 \\
\pm .08\end{array}$ & & $\begin{array}{r}0.90 \\
\pm .06\end{array}$ & $\begin{array}{l}.512513 \\
\pm .000037 \\
\end{array}$ & $\begin{array}{r}0.12266 \\
\pm .00025\end{array}$ & $\begin{array}{r}0.542 \\
\pm .001 \\
\end{array}$ & $\begin{array}{r}2.672 \\
\pm .002 \\
\end{array}$ & -.38 & -2.4 & 3.4 & $\begin{array}{l}.62 \mathrm{Rp} / \mathrm{Sr} \\
.7038_{\mathrm{b}}\end{array}$ & 0.31 & nt \\
\hline $\begin{array}{l}192 / \\
\text { gns }\end{array}$ & $3022 / 5358$ & RG 273B & GTD & $B$ & $\begin{array}{l}0.49 \\
0.07\end{array}$ & & $\begin{array}{l}1.08 \\
0.05\end{array}$ & $\begin{array}{l}.512404 \\
.000035 \\
\end{array}$ & $\begin{array}{l}.123507 \\
.000099 \\
\end{array}$ & $\begin{array}{l}4.157 \\
0.002 \\
\end{array}$ & $\begin{array}{l}20.353 \\
0.013 \\
\end{array}$ & -.37 & -4.6 & 1.2 & $\begin{array}{l}.62_{\mathrm{Rb} / \mathrm{Sr}} \\
.7038_{\mathrm{b}} \\
\end{array}$ & 0.31 & $\mathrm{nt}$ \\
\hline $\begin{array}{l}193 / \\
\text { gnd }\end{array}$ & $3021 / 5400$ & $E S J-G 1$ & GTD & C & $\begin{array}{l}0.38 \\
0.05\end{array}$ & & $\begin{array}{l}0.90 \\
0.04\end{array}$ & $\begin{array}{l}.512414 \\
.000031 \\
\end{array}$ & $\begin{array}{l}.105909 \\
.000090 \\
\end{array}$ & $\begin{array}{l}1.443 \\
0.001 \\
\end{array}$ & $\begin{array}{l}8.239 \\
0.004 \\
\end{array}$ & -.46 & $-4 . \overline{4}$ & 3.0 & $\begin{array}{l}.64 \mathrm{Rb} / \mathrm{Sr} \\
.704_{\mathrm{b}}\end{array}$ & 3.5 & $\mathrm{nt}$ \\
\hline $\begin{array}{l}194 / \\
\text { dio }\end{array}$ & $3033 / 5408$ & $E S J-L 5$ & BAS & $D$ & $\begin{array}{l}0.76 \\
.06 \\
\end{array}$ & & $\begin{array}{l}1.25 \\
0.05 \\
\end{array}$ & $\begin{array}{l}.512227 \\
.000037 \\
\end{array}$ & $\begin{array}{l}.113916 \\
.000081 \\
\end{array}$ & $\begin{array}{l}5.650 \\
0.003 \\
\end{array}$ & $\begin{array}{l}29.922 \\
0.014 \\
\end{array}$ & -.42 & -8.0 & -1.2 & $\begin{array}{l}.65_{\mathrm{Rb} / \mathrm{Sr}} \\
.705_{\mathrm{b}} \\
\end{array}$ & 17.9 & $\mathrm{nt}$ \\
\hline $\begin{array}{l}195 / \\
\text { gns }\end{array}$ & $3053 / 5357$ & PM - 95 B & GTD & $E$ & $\begin{array}{l}0.25 \\
0.06 \\
\end{array}$ & & $\begin{array}{l}0.86 \\
0.04\end{array}$ & $\begin{array}{l}.512513 \\
.000028\end{array}$ & $\begin{array}{l}.119360 \\
.000105\end{array}$ & $\begin{array}{l}1.330 \\
0.001 \\
\end{array}$ & $\begin{array}{l}6.738 \\
0.003\end{array}$ & -.39 & -2.4 & 2.5 & $\begin{array}{l}.50 \mathrm{Rb} / \mathrm{sr} \\
.7035_{\mathrm{b}} \\
\end{array}$ & -6.0 & nt \\
\hline $\begin{array}{l}271 \\
\text { gnd }\end{array}$ & $3043 / 5418$ & $M N-199 A$ & GTD & $F$ & $\begin{array}{l}0.30 \\
0.05\end{array}$ & & $\begin{array}{l}0.87 \\
0.04 \\
\end{array}$ & $\begin{array}{l}.512476 \\
.000025 \\
\end{array}$ & $\begin{array}{l}.113281 \\
.000058\end{array}$ & $\begin{array}{l}3.254 \\
0.001\end{array}$ & \begin{tabular}{|l|}
17.370 \\
0.007 \\
\end{tabular} & -.42 & -3.2 & 3.8 & $\begin{array}{l}.65 \mathrm{Rb} / \mathrm{Sr} \\
.7047_{\mathrm{b}} \\
\end{array}$ & +14 & nt \\
\hline m.rd & $3021 / 5343$ & $\begin{array}{l}\text { RS-19/RS } \\
\text { Vacacai }\end{array}$ & VAC & $G$ & $\ldots$ & $.75^{\# 2}$ & .41 & $\begin{array}{l}.512978 \\
.000008\end{array}$ & .1841 & 3.94 & 12.94 & -.06 & 6.6 & 7.8 & $.75 \mathrm{U}-\mathrm{Pb}$ & & 5 \\
\hline mgab & $3011 / 5346$ & $\begin{array}{l}\text { RS-19-11/RS } \\
\text { Vacacai }\end{array}$ & BAS & $\mathrm{H}$ & -- & & .97 & $\begin{array}{l}.512777 \\
.000025 \\
\end{array}$ & .1714 & 0.53 & 1.87 & -.13 & 2.7 & 5.1 & .75 est & & 5 \\
\hline gns.d & $3014 / 5358$ & $\begin{array}{l}\text { RS-20E /RS } \\
\text { Cambaí }\end{array}$ & GTD & 1 & .39 & & 1.03 & $\begin{array}{l}.512460 \\
.000009 \\
\end{array}$ & .1268 & 4.03 & 19.23 & -.36 & -3.5 & 2.8 & $\begin{array}{l}.70_{\mathrm{U}-\mathrm{Pb}} \\
\mathrm{c}\end{array}$ & & 5 \\
\hline $\begin{array}{l}\text { m.to } \\
\mathrm{n}\end{array}$ & $3014 / 5358$ & $\begin{array}{l}\text { RS-20F / RS } \\
\text { Cambal }\end{array}$ & GTD & $\mathrm{J}$ & .36 & & .86 & $\begin{array}{l}.512415 \\
.000007\end{array}$ & .1009 & 5.90 & 35.36 & -.49 & -4.4 & 4.2 & $.70_{\text {est }}$ & & 5 \\
\hline peg & $3014 / 5358$ & $\begin{array}{l}\text { RS-20G / RS } \\
\text { Cambal }\end{array}$ & GTD & $\mathrm{K}$ & .10 & & .92 & $\begin{array}{l}.512603 \\
.000008\end{array}$ & .1405 & 1.28 & 5.51 & -.29 & -.7 & 4.3 & $.70_{\text {est }}$ & & 5 \\
\hline m.dio & $3014 / 5358$ & $\begin{array}{l}\mathrm{RS}-2 \mathrm{OH} / \mathrm{RS} \\
\text { Cambal }\end{array}$ & BAS & L & .27 & & .86 & $\begin{array}{l}.512498 \\
.000008 \\
\end{array}$ & .1161 & 6.39 & 33.27 & -.41 & -2.7 & 4.5 & $.70_{\text {est }}$ & & 5 \\
\hline m.grt & $3013 / 5402$ & $\begin{array}{l}\text { RS-24/RS } \\
\text { Sanga Jobim }\end{array}$ & GTD & $\mathrm{M}$ & .09 & & .82 & $\begin{array}{l}.512600 \\
.000009 \\
\end{array}$ & .1303 & 4.16 & 19.31 & -.34 & -0.7 & 5.2 & $.70_{\text {est }}$ & & 5 \\
\hline
\end{tabular}




\begin{tabular}{|c|c|c|c|c|c|c|c|c|c|c|c|c|c|c|c|c|c|}
\hline --- & $3045 / 5353$ & $\begin{array}{l}\text { RS 321/RS } \\
\text { Lavras }\end{array}$ & GTD & $N$ & 0.88 & & 1.35 & $\begin{array}{l}.512160 \\
.000010\end{array}$ & .11429 & 6.63 & 35.08 & -.42 & -9.3 & -3.0 & $.60_{\text {est }}$ & & 5 \\
\hline gnd & $3049 / 5353$ & $\begin{array}{l}\text { RS 32/RS } \\
\text { Lavras }\end{array}$ & GTD & 0 & 0.62 & & 1.15 & .512313 & .11685 & 13.44 & 69.55 & -.41 & -6.3 & -.2 & $.60_{\text {est }}$ & & 5 \\
\hline $\mathrm{mz} . \mathrm{gt}$ & $3024 / 5327$ & $\begin{array}{l}\text { CAC2 /RS } \\
\text { Caçapava }\end{array}$ & GTD & $\mathrm{P}$ & 1.97 & $2.58^{\text {\#2 }}$ & 2.20 & .511205 & .08624 & 7.36 & 51.61 & -.56 & -28.0 & -20 & $.60_{\text {est }}$ & & 5 \\
\hline gnd & $3029 / 5329$ & $\begin{array}{l}\text { CAC3/RS } \\
\text { Caçapava }\end{array}$ & GTD & $Q$ & 1.67 & & 2.05 & $\begin{array}{l}.511844 \\
.000009\end{array}$ & .12425 & 6.90 & 33.58 & -.37 & -15.5 & -9.9 & $.60_{\text {est }}$ & & 5 \\
\hline $\begin{array}{l}270 \\
\text { grt }\end{array}$ & & $\begin{array}{l}\text { ESJ - EP -55L } \\
\text { Caçapava }\end{array}$ & GTD & $\mathrm{R}$ & $\begin{array}{l}2.38 \\
0.04\end{array}$ & $3.2^{\text {*22 }}$ & $\begin{array}{l}2.56 ? \\
0.03\end{array}$ & $\begin{array}{l}.510715 \\
.000031 \\
\end{array}$ & $\begin{array}{l}.074043 \\
.000064 \\
\end{array}$ & $\begin{array}{l}1.360 \\
0.001\end{array}$ & $\begin{array}{l}11.107 \\
0.005 \\
\end{array}$ & -.62 & -37.5 & -29.4 & $\begin{array}{l}.52_{\mathrm{Rb} / \mathrm{Sr}} \\
.703_{\mathrm{b}} \\
\end{array}$ & -13 & $\mathrm{nt}$ \\
\hline & & & & & & & & & & & & & & & & & \\
\hline \multicolumn{18}{|c|}{ Bloco Taquarembo } \\
\hline & & & & & & & & & & & & & & & & & \\
\hline $\begin{array}{l}196 / \\
\text { grt }\end{array}$ & & $\begin{array}{l}\text { ESJ }-72 \mathrm{E} \\
\text { Uruguai }\end{array}$ & GTD & $A$ & $\begin{array}{l}1.65 \\
0.07\end{array}$ & & $\begin{array}{l}1.96 \\
0.05\end{array}$ & $\begin{array}{l}.511620 \\
0.00041\end{array}$ & $\begin{array}{l}.103121 \\
.000092 \\
\end{array}$ & $\begin{array}{l}7.270 \\
0.002 \\
\end{array}$ & $\begin{array}{l}42.631 \\
.036 \\
\end{array}$ & -.48 & -19.9 & -11.6 & $\begin{array}{l}.69_{\mathrm{Rb} / \mathrm{Sr}} \\
.701_{\mathrm{b}}\end{array}$ & -38 & nt \\
\hline $\begin{array}{l}269 \\
\text { m.grt }\end{array}$ & ??? & ESJ-100B & GTD & $B$ & $\begin{array}{l}2.73 \\
0.03\end{array}$ & & $\begin{array}{l}2.90 \\
0.03 \\
\end{array}$ & $\begin{array}{l}.510782 \\
.000022 \\
\end{array}$ & $\begin{array}{l}.093799 \\
.000050 \\
\end{array}$ & $\begin{array}{l}2.565 \\
0.001 \\
\end{array}$ & $\begin{array}{l}16.536 \\
0.006\end{array}$ & -.52 & -36.2 & 0.5 & $2.80_{\mathrm{Rb} / \mathrm{Sr}}$ & & nt \\
\hline gns.gl & composito $^{7+}$ & $\begin{array}{l}\text { Ci / RS } \\
\text { S.M. do Chico }\end{array}$ & GTD & C & 2.36 & & 2.59 & $\begin{array}{l}.511262 \\
.000026\end{array}$ & .1082 & $-\cdots$ & -+ & -.45 & -26.8 & 2.5 & $2.6_{\text {est }}$ & & 4 \\
\hline gtd & $3145 / 5347$ & $\begin{array}{l}\text { C3/RS } \\
\text { Aceguá }\end{array}$ & GTD & $\bar{D}$ & 2.04 & & 2.33 & $\begin{array}{l}.511523 \\
.000018 \\
\end{array}$ & .1137 & $-\cdots$ & -- & -.42 & -21.8 & -15 & $0.6_{\text {est }}$ & & 4 \\
\hline
\end{tabular}

ver nota explicativa da tabela no anexo 1

* concentrado de mineral (rocha granulitica); ${ }^{+}=$composito $\left(26^{\circ} 25^{\prime} / 49^{\circ} 01^{\prime}, 26^{\circ} 30^{\prime} / 48^{\circ} 48^{\prime}, 26^{\circ} 35^{\prime} / 48^{\circ} 47^{\prime}, 26^{\circ} 40^{\prime} / 49^{\circ} 02^{\prime}, 26^{\circ} 52^{\prime} /\right.$ $\left.49^{\circ} 18^{\prime}\right)$.

${ }^{\# 1}->\mathrm{T} 2=\mathrm{T}_{\text {mét. }}$ e $\left({ }^{147} \mathrm{Sm} /{ }^{144} \mathrm{Nd}\right)_{T_{2}}=0.1 ;{ }^{\# 2}=\mathrm{T} 2=\mathrm{T}_{\text {mét. }}$ e $\left({ }^{147} \mathrm{Sm} /{ }^{144} \mathrm{Nd}\right)_{\mathrm{T} 2}=0.11$

observ.: idades modelos dos minerais do domínio Luis Alves ---> quando o fracionamento ocorre logo após a separação manto-crosta (intervalo de tempo muito curto) então o modelo de 2 estágio praticamente não altera quando comparado com o de estágio simples.

ref. $a=1$ = Siga Jr. (1995), 2 = Mantovani et. al (1987), $3=$ Hartmann et. al (1995). 
TAB. 5.14-1: FAIXA ITAIACOCA + S. ROQUE

\begin{tabular}{|c|c|c|c|c|c|c|c|c|c|c|c|c|c|c|c|c|c|}
\hline $\begin{array}{l}\text { SPS } \\
\text { /lit. }\end{array}$ & coord. & $\begin{array}{l}\text { n.campol } \\
\text { região }\end{array}$ & $\begin{array}{l}\text { litolo } \\
\text { gia }\end{array}$ & $\begin{array}{l}\text { ident } \\
\text { (diagra- } \\
\text { ma) }\end{array}$ & $\begin{array}{l}T_{\text {chur }} \\
(G A) \\
\text { Goldstein } \\
\text { otal 1984 }\end{array}$ & $\mathrm{T}_{(\mathrm{GA})}{ }^{2}$ & \begin{tabular}{|l|}
$T_{\text {dm }}$ \\
$(G A)$ \\
DePaolo \\
-1981 \\
\end{tabular} & $\begin{array}{l}{ }^{143} \mathrm{Nd} / \\
{ }^{144} \mathrm{Nd}\end{array}$ & $\begin{array}{l}{ }^{144} \mathrm{Sm} / \\
{ }^{14 d}\end{array}$ & $\begin{array}{l}\mathrm{Sm} \\
\mathrm{ppm}\end{array}$ & $\begin{array}{l}\text { Nd } \\
\text { ppm }\end{array}$ & $f$ & $\begin{array}{l}\varepsilon_{\mathrm{Nd}} \\
(0)\end{array}$ & $\begin{array}{l}\varepsilon_{\text {Nd }} \\
(t)\end{array}$ & $\begin{array}{l}\mathbf{t}(\mathrm{Ga})_{\text {mèt }} \\
\mathrm{Ri}_{\text {(fonte) }}\end{array}$ & $\begin{array}{l}\varepsilon_{\mathrm{Sr}} \\
(\mathrm{t})\end{array}$ & ref \\
\hline & & & & & & & & & & & & & & & & & \\
\hline \multicolumn{18}{|c|}{ GRUPO ITAIACOCA ( Fm. Abapã, Bairro dos Campos, Água Clara e S. dos Macacos) } \\
\hline \multicolumn{18}{|c|}{ Formação Abapã } \\
\hline & & & & & & & & & & & & & & & & & \\
\hline m.vul & $2458 / 4950$ & $\begin{array}{l}\text { ABP 67B / PR } \\
\text { Abapa }\end{array}$ & VAC & $A$ & 2.58 & & 2.80 & .511279 & .116787 & 11.36 & 58.82 & -.41 & -26.5 & -12 & \begin{tabular}{l|}
$1.38_{\mathrm{Rb} / \mathrm{Sr}}$ \\
$.7156_{\mathrm{a}}$ \\
\end{tabular} & 181 & 1 \\
\hline m.vul & $2458 / 4950$ & $\begin{array}{l}\text { ABP 67D / PR } \\
\text { Abapa }\end{array}$ & VAC & $\mathrm{B}$ & 2.45 & & 2.67 & .511225 & .109074 & 17.87 & 99.07 & -.45 & -27.6 & -12 & $\begin{array}{l}1.38_{\mathrm{Rb} / \mathrm{Sr}} \\
.7156_{\mathrm{a}} \\
\end{array}$ & 181 & 1 \\
\hline \begin{tabular}{l|}
-- \\
m.vul
\end{tabular} & $2450 / 4941$ & $\begin{array}{l}\text { ABP } 70 C / P R \\
\text { Abapă }\end{array}$ & VAC & C & 2.43 & & 2.65 & .511216 & .107984 & 17.07 & 95.59 & -.45 & -27.7 & -12 & $\begin{array}{l}1.38_{\mathrm{Rb} / \mathrm{Sr}} \\
.7156 \\
\end{array}$ & 181 & 1 \\
\hline m.vul & $2450 / 4941$ & $\begin{array}{l}\text { ABP 7OE / PR } \\
\text { Abapa }\end{array}$ & VAC & D & 2.40 & & 2.63 & .511199 & .105914 & 15.93 & 90.95 & -.46 & -28.1 & -12 & $\begin{array}{l}1.38_{\mathrm{Rb} / \mathrm{Sr}} \\
.7156_{\mathrm{a}} \\
\end{array}$ & 181 & 1 \\
\hline m.vul & $2450 / 4941$ & $\begin{array}{l}\text { ABP 71B / PR } \\
\text { Abapa }\end{array}$ & VAC & $E$ & 2.45 & & 2.66 & .511088 & .100859 & 17.83 & 106.90 & -.49 & -30.2 & -17 & $\begin{array}{l}1.09 \\
.7089_{\mathrm{a}} \\
\end{array}$ & 81 & 1 \\
\hline \begin{tabular}{l|}
-- \\
$m . v u l$
\end{tabular} & $2457 / 4947$ & $\begin{array}{l}\text { ABP 13A / PR } \\
\text { Abapa }\end{array}$ & VAC & $\mathrm{F}$ & $2.14 ?$ & $2.57^{\mathrm{F2}}$ & $2.36 ?$ & .511106 & .088149 & 15.85 & 108.73 & -.55 & -29.9 & -11 & $\begin{array}{l}1.38 ? \\
.7156 \mathrm{a}\end{array}$ & 181 & 1 \\
\hline \begin{tabular}{l|l} 
m.vul \\
\end{tabular} & & $\begin{array}{l}78 \text { II / PR } \\
\text { Abapã }\end{array}$ & VAC & $G$ & 2.62 & & 2.83 & .511140 & .110100 & 17.45 & 95.84 & -.44 & -29.2 & -17 & $\begin{array}{l}1.09_{\mathrm{Rb} / \mathrm{Sr}} \\
.7089_{\mathrm{a}}\end{array}$ & 81 & 1 \\
\hline \multicolumn{18}{|c|}{ Formações Bairro dos Campos e Água Clara } \\
\hline & & & & & & & & & & & & & & & & & \\
\hline m.dlr & $2501 / 4947$ & $\begin{array}{l}\text { ELA 2C/PR } \\
\text { B. Campos }\end{array}$ & BAS & $\mathrm{H}$ & $1.40 ?$ & & 2.15 & .512328 & .163032 & 2.75 & 10.20 & -.17 & -6.0 & -1.6 & $\begin{array}{l}1.03 \mathrm{Rb} / \mathrm{sr} \\
.7029_{\mathrm{a}}\end{array}$ & -6 & 1 \\
\hline m.dir & $2502 / 4948$ & $\begin{array}{l}\text { ELA 7/PR } \\
\text { B. Campos }\end{array}$ & BAS & $T$ & 1.41 & & 2.19 & .512343 & .164918 & 2.82 & 10.34 & -.16 & -5.8 & -1.6 & $\begin{array}{l}1.03 \mathrm{Rb} / \mathrm{st} \\
.7029_{\mathrm{a}} \\
\end{array}$ & -5.7 & 1 \\
\hline m.dlr & & $\begin{array}{l}\text { ELA 10/PR } \\
\text { B. Campos }\end{array}$ & BAS & $\mathrm{J}$ & 1.40 & & 2.14 & .512316 & .161789 & 2.82 & 10.54 & -.18 & -6.3 & -1.7 & $\begin{array}{l}1.03_{\mathrm{Rb} / \mathrm{Sr}} \\
.7029_{\mathrm{a}} \\
\end{array}$ & -5.7 & 1 \\
\hline m.dlr & & $\begin{array}{l}\text { ELA 12A / PR } \\
\text { B. Campos }\end{array}$ & BAS & $\mathrm{K}$ & 1.41 & & 2.16 & .512279 & .159706 & 2.34 & 8.86 & -.19 & -7.0 & -2.1 & $\begin{array}{l}1.03_{\mathrm{Rb} / \mathrm{Sr}} \\
.7029_{\mathrm{a}} \\
\end{array}$ & -5.7 & 1 \\
\hline m.dir & & $\begin{array}{l}\text { ELA 20B / PR } \\
\text { B. Campos }\end{array}$ & BAS & $L$ & 1.48 & & 2.19 & .512299 & .161922 & 2.26 & 8.44 & -.18 & -6.6 & -2.0 & $\begin{array}{l}1.03_{\mathrm{Rb} / \mathrm{Sr}} \\
.7029_{\mathrm{a}}\end{array}$ & -5.7 & 1 \\
\hline
\end{tabular}




\begin{tabular}{|c|c|c|c|c|c|c|c|c|c|c|c|c|c|c|c|c|c|}
\hline m.dir & $2506 / 4953$ & $\begin{array}{l}\text { ELA 23/PR } \\
\text { B. Campos }\end{array}$ & BAS & $M$ & 1.46 & & 2.18 & .512310 & .162428 & 2.49 & 9.27 & -.17 & -6.4 & -1.9 & $\begin{array}{l}1.03_{\mathrm{Rb} / \mathrm{sr}} \\
.7029_{\mathrm{a}} \\
\end{array}$ & -5.7 & 1 \\
\hline$\overline{\text { anf }}$ & $2459 / 4942$ & $\begin{array}{l}\text { ABP 52A/PR } \\
\text { Água Clara }\end{array}$ & BAS & $N$ & 1.51 & & 1.96 & .512017 & .134007 & 67.83 & 306.08 & -.32 & -12.1 & -3.5 & \begin{tabular}{l|l}
$1.08_{\mathrm{PbPb}}$ \\
$\mu=8.07_{\mathrm{a}}$
\end{tabular} & & 1 \\
\hline anf & $2459 / 4942$ & $\begin{array}{l}\text { ABP 52E/PR } \\
\text { Água Clara } \\
\end{array}$ & BAS & 0 & $2.70 ?$ & $1.81^{\# 3}$ & $3.83 ?$ & .512553 & .191930 & 2.39 & 7.53 & -.02 & $\mid-1.7$ & -1.0 & $\begin{array}{l}1.08_{\mathrm{PbPb}} \\
\mu=8.07_{\mathrm{a}}\end{array}$ & & 1 \\
\hline \multicolumn{18}{|c|}{ COMPLEXOS CUNHAPORANGA E TRÊS CÓRREGOS } \\
\hline grt & $2456 / 4951$ & $\begin{array}{l}\mathrm{ABP} 45 \mathrm{D} / \mathrm{PR} \\
\text { Cunhaporanga }\end{array}$ & GTD & $A$ & 1.59 & 1.93 & 1.88 & .511552 & .093050 & 7.32 & 47.57 & -.53 & -21.2 & -13 & \begin{tabular}{|l|}
$60 ? \mathrm{RbST}$ \\
$.7114 ?_{\mathrm{a}}$
\end{tabular} & $\begin{array}{l}108 \\
?\end{array}$ & 1 \\
\hline grt & $2452 / 4951$ & $\begin{array}{l}\text { ABP } 68 D / P R \\
\text { Cunhaporanga }\end{array}$ & GTD & $B$ & $2.68 ?$ & $2.15^{\# 1}$ & $2.99 ?$ & .511765 & .147379 & 5.92 & 24.29 & -.25 & -27.0 & $\mid-13$ & \begin{tabular}{|l|}
$62 \mathrm{Rb} / \mathrm{Sr}$ \\
$.7164_{\mathrm{a}}$ \\
\end{tabular} & 179 & 1 \\
\hline rio & & \begin{tabular}{|l|} 
87V/PR \\
Cunhaporanga
\end{tabular} & VAC & $\mathrm{C}$ & 1.87 & & 2.21 & .511746 & .124137 & 2.33 & 11.35 & -.37 & -17.4 & -17 & $\begin{array}{l}.63 \mathrm{Rb} / \mathrm{Sr} \\
.7083_{\mathrm{a}}\end{array}$ & 64 & 1 \\
\hline gns & $2437 / 4957$ & $\begin{array}{l}\mathrm{ABP} \text { GA /PR } \\
\text { Cunhaporanga } \\
\end{array}$ & GTD & D & $1.43 ?$ & $1.71^{\# 2}$ & $1.89 ?$ & .512033 & .132191 & 11.89 & 54.39 & -.33 & -11.8 & -5.6 & $\begin{array}{l}75 \mathrm{Rb} / \mathrm{Sr} \\
.70698_{\mathrm{a}} \\
\end{array}$ & 48 & 1 \\
\hline$\overline{\text { gns }}$ & $2437 / 4957$ & $\begin{array}{l}\mathrm{ABP} \text { G3D/PR } \\
\text { Cunhaporanga }\end{array}$ & GTD & $E$ & 1.58 & & 1.93 & .511779 & .113945 & 8.47 & 44.95 & -42 & -16.5 & -8.8 & $\begin{array}{l}.75 \mathrm{Rb} / \mathrm{St} \\
.70698 \mathrm{a} \\
\end{array}$ & 48 & 1 \\
\hline gns & $2459 / 4942$ & \begin{tabular}{|l} 
ELA 25A /PR \\
Trếs Córregos
\end{tabular} & GTD & $F$ & 1.86 & & 2.11 & .511337 & .090493 & 6.83 & 45.64 & -.54 & -25.4 & -16 & $\begin{array}{l}.66_{\mathrm{Rb} / \mathrm{Sr}} \\
.7098_{\mathrm{a}} \\
\end{array}$ & 86 & 1 \\
\hline gns & $2449 / 4938$ & $\begin{array}{l}\text { ABP 58B/PR } \\
\text { Trés Corregos } \\
\end{array}$ & GTD & $G$ & 2.03 & & 2.27 & .511291 & .095748 & 13.50 & 85.26 & -.51 & -26.3 & -18 & $\begin{array}{l}.66_{\mathrm{Rb} / \mathrm{Sr}} \\
.7098_{\mathrm{a}} \\
\end{array}$ & 86 & 1 \\
\hline grt & $2512 / 4938$ & $\begin{array}{l}\text { ABP 42A / PR } \\
\text { Trés Córegos }\end{array}$ & GTD & $\mathrm{H}$ & 1.94 & & 2.17 & .511246 & .087398 & 5.92 & 40.96 & -.56 & -27.2 & -20 & $\begin{array}{ll}.51 \mathrm{Rb} / \mathrm{Sr} \\
.71285_{\mathrm{a}}\end{array}$ & 127 & 1 \\
\hline grt & $2513 / 4937$ & $\begin{array}{l}\mathrm{ABP} 43 \mathrm{~B} / \mathrm{PR} \\
\text { Trés Córregos }\end{array}$ & GTD & 1 & 2.00 & & 2.24 & .511265 & .092469 & 4.56 & 29.82 & -.53 & -26.8 & -20 & $\begin{array}{l}.51 \mathrm{Rb} / \mathrm{Sr} \\
.71285_{\mathrm{a}} \\
\end{array}$ & 127 & 1 \\
\hline \multicolumn{18}{|c|}{ FAIXA SÃO ROQUE / APIAÍ (próximo a o capital de S. Paulo) } \\
\hline & & & & & & & & & & & & & & & & & \\
\hline & $2 3 \longdiv { 1 4 / 4 6 1 9 }$ & & GTD & $J$ & 185 & & 214 & 511523 & 10524 & $\ldots$ & |--- & -46 & -21.8 & -14 & $|0.71 \mathrm{Rb} / \mathrm{Sr}|$ & 83 & 3 \\
\hline grt & & Moinho & & J & & & & & & & & & & & $.7074_{c}$ & & \\
\hline$\overline{\text { gnd }}$ & $2315 / 4610$ & $\begin{array}{l}\text { CT 11J/SP } \\
\text { Morro Azul }\end{array}$ & GTD & $\mathrm{K}$ & 1.55 & $2.00^{\# 1}$ & 1.84 & .511534 & .08861 & - & $-\cdots$ & -.55 & -21.5 & -14 & $\begin{array}{l}0.52 \mathrm{Rb} / \mathrm{Sr} \\
.711_{\mathrm{c}}\end{array}$ & 101 & 3 \\
\hline gnd & $2320 / 4632$ & $\begin{array}{l}\text { GAA/SP } \\
\text { Mairiporă }\end{array}$ & GTD & $\mathrm{L}$ & 1.36 & & 1.71 & .511798 & .10252 & $\cdots$ & --- & -.48 & -16.4 & -8.8 & $\begin{array}{l}0.63_{\mathrm{Rb} / \mathrm{s}} \\
.708_{\mathrm{c}}\end{array}$ & 60 & 3 \\
\hline
\end{tabular}




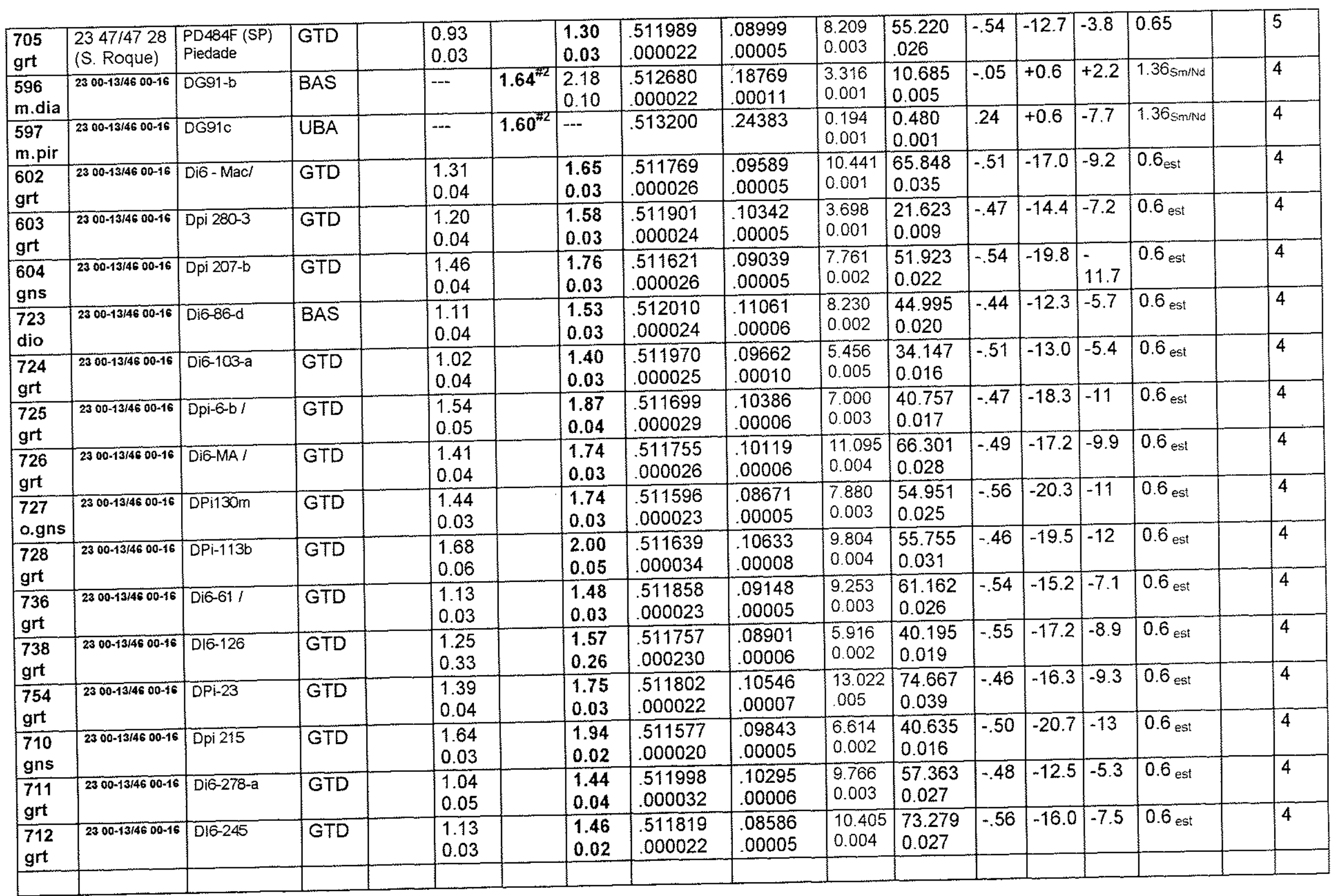




\begin{tabular}{|c|c|c|c|c|c|c|c|c|c|c|c|c|c|c|}
\hline 713 & $2300-13 / 4600-16$ & Di6-98c & GTD & $\begin{array}{l}1.22 \\
0.04\end{array}$ & $\begin{array}{l}1.57 \\
0.03\end{array}$ & $\begin{array}{l}.511826 \\
.000026\end{array}$ & $\begin{array}{l}.09536 \\
.00005\end{array}$ & $\begin{array}{l}11.429 \\
0.003\end{array}$ & $\begin{array}{l}72.471 \\
0.028\end{array}$ & -.52 & -15.8 & -8.1 & $0.6_{\text {est }}$ & 4 \\
\hline $\begin{array}{l}714 \\
\text { grt }\end{array}$ & $2300-13 / 4600-16$ & $\overline{D i 6-121-a}$ & GTD & $\begin{array}{l}1.45 \\
0.04 \\
\end{array}$ & $\begin{array}{l}1.72 \\
0.04 \\
\end{array}$ & $\begin{array}{l}.511482 \\
.000035 \\
\end{array}$ & $\begin{array}{l}.07539 \\
.00004\end{array}$ & $\begin{array}{l}13.923 \\
0.005\end{array}$ & $\begin{array}{l}111.68 \\
0.05\end{array}$ & -.62 & -22.6 & -14 & $0.6_{\text {est }}$ & 4 \\
\hline $\begin{array}{l}248 \\
\text { gnd }\end{array}$ & $2347 / 4735$ & PS 61/SP & GTD & $\begin{array}{l}1.57 \\
0.03\end{array}$ & $\begin{array}{l}1.59 \\
0.03\end{array}$ & $\begin{array}{l}.511842 \\
.000024\end{array}$ & $\begin{array}{l}.09894 \\
.00006\end{array}$ & $\begin{array}{l}2.499 \\
.001\end{array}$ & $\begin{array}{l}15.274 \\
.007\end{array}$ & -.50 & -15.5 & -8.7 & $.55_{\mathrm{est}}$ & $\mathrm{nt}$ \\
\hline
\end{tabular}

ver nota explicativa da tabela no anexo 1

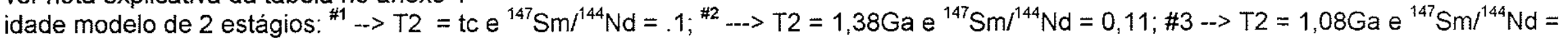
0,134 (= ao valor da amostra ABP52A)

Ref, bibliográficas: - -> Idades Rb-Sr e Pb-Pb foram compilados a partir de: a = Reis Neto (1994), c= Tassinari (1988);

os dados isotópicos de Sm-Nd a partir de : $1=$ Reis Neto (1994), $3=$ Tassinari e Sato (1996). $4=$ Ragatky (comunicação escrita), $5=$ Renato (comunicação escrita).

\section{TAB. 5.14-2: DOMÍNIO CURITIBA}

\begin{tabular}{|c|c|c|c|c|c|c|c|c|c|c|c|c|c|c|c|c|c|}
\hline SPS & coord.I & $\begin{array}{l}\text { n.campol } \\
\text { região }\end{array}$ & $\begin{array}{l}\text { litolo } \\
\text { gia }\end{array}$ & $\begin{array}{l}\text { ident } \\
\text { (diagra } \\
\text { ma) }\end{array}$ & $\begin{array}{l}T_{\text {chur }} \\
\text { (GA) } \\
\text { Goldstoin } \\
\text { etal 4984 }\end{array}$ & $\begin{array}{l}T_{\text {dm12 }} \\
\text { (GA) } \\
\text { Milisisenda } \\
\text { et.al } \\
\text { 1994 }\end{array}$ & $\begin{array}{l}T_{\mathrm{dm} 4} \\
(\mathrm{GA}) \\
\text { DePaolo } \\
\text { - } 9981\end{array}$ & $\begin{array}{l}{ }^{743} \mathrm{Nd} / \\
{ }^{144} \mathrm{Nd}\end{array}$ & $\begin{array}{l}{ }^{347} \mathrm{Sm} / \\
{ }^{144} \mathrm{Nd}\end{array}$ & $\begin{array}{l}\mathrm{Sm} \\
\mathrm{ppm}\end{array}$ & $\begin{array}{l}\text { Nd } \\
\text { ppm }\end{array}$ & $f$ & $\begin{array}{l}\varepsilon_{\mathrm{Nd}} \\
(0)\end{array}$ & $\begin{array}{l}\varepsilon_{\mathrm{Nd}} \\
(t)\end{array}$ & $\begin{array}{l}\mathbf{t}(\mathbf{G a})_{\text {mét }} \\
R \mathbf{i}_{\text {(fonte) }}\end{array}$ & $\begin{array}{l}\varepsilon_{\mathrm{sr}} \\
(\mathrm{t})\end{array}$ & ref \\
\hline & & & & & & & & & & & & & & & & & \\
\hline \multicolumn{18}{|c|}{ EMBASAMENTO } \\
\hline gnl & $2520 / 2913$ & $\mathrm{MJ} 25.3 / \mathrm{PR}$ & GNL & $A$ & 2.62 & & 2.82 & $\begin{array}{l}.511107 \\
.000020\end{array}$ & .108027 & 6.86 & 38.40 & -.45 & -29.9 & -9.2 & $\begin{array}{l}1.83_{\mathrm{Rb} / \mathrm{Sr}} \\
.7105_{\mathrm{b}}\end{array}$ & 116 & 2 \\
\hline $\mathrm{mig}$ & $2523 / 4912$ & MJ96.3/PR & GTD & B & 2.53 & & 2.75 & $\begin{array}{l}.511276 \\
.000018\end{array}$ & .114911 & 6.29 & 33.1 & -.42 & -26.6 & -20 & $\begin{array}{l}0.60_{\mathrm{Rb} / \mathrm{Sr}} \\
.7165_{\mathrm{b}}\end{array}$ & 180 & 2 \\
\hline $\begin{array}{l}288 \\
\text { gns }\end{array}$ & $2537 / 4918$ & $\mathrm{MJ138} / \mathrm{PR}$ & GTD & $\mathrm{C}$ & $\begin{array}{l}2.42 \\
.04\end{array}$ & & $\begin{array}{l}2.67 \\
.03\end{array}$ & $\begin{array}{l}.511392 \\
.000018\end{array}$ & $\begin{array}{l}.113664 \\
.000058\end{array}$ & $\begin{array}{l}4.162 \\
.001\end{array}$ & $\begin{array}{l}21.229 \\
.009 \\
\end{array}$ & -.42 & -23.0 & -1.7 & $\begin{array}{l}2.01_{\mathrm{Rb} / \mathrm{Sr}} \\
.70327_{\mathrm{b}}\end{array}$ & 16 & 2 \\
\hline $\mathrm{mig}$ & $2550 / 4919$ & $M J 123 a / P R$ & BAS & $\mathrm{D}$ & $2.06 ?$ & $2.61^{\# 1}$ & $2.27 ?$ & $\begin{array}{l}.511027 \\
.000020 \\
\end{array}$ & .078141 & 7.65 & 59.20 & -.60 & -31.4 & -23 & $.58_{\mathrm{K} \cdot \mathrm{Ar}}$ & & 2 \\
\hline dio & $2519 / 4854$ & MJ $296 / P R$ & GTD & $E$ & .53 & & 1.14 & $\begin{array}{l}.512398 \\
.000024\end{array}$ & .127265 & 8.25 & 39.2 & -.35 & -4.7 & 14.0 & $\begin{array}{l}2.11_{\mathrm{Rb} / \mathrm{Sr}} \\
.7016_{\mathrm{o}}\end{array}$ & -6.0 & 2 \\
\hline $\begin{array}{l}289 \\
\text { mig.m }\end{array}$ & $2552 / 4926$ & $\mathrm{MJ} 316 t / \mathrm{PR}$ & GTD & $F$ & $\begin{array}{l}2.74 \\
0.11\end{array}$ & $2.53^{72}$ & $\begin{array}{l}3.08 ? \\
0.06\end{array}$ & $\begin{array}{l}.511905 \\
.000028 \\
\end{array}$ & $\begin{array}{l}.156163 \\
.000086 \\
\end{array}$ & $\begin{array}{l}6.340 \\
.002 \\
\end{array}$ & $\begin{array}{l}24.550 \\
.011 \\
\end{array}$ & -.21 & -14.3 & -4.6 & $\begin{array}{l}1.87_{\mathrm{Rb} / \mathrm{Sr}} \\
.70584_{\mathrm{o}}\end{array}$ & 50 & 2 \\
\hline
\end{tabular}




\begin{tabular}{|c|c|c|c|c|c|c|c|c|c|c|c|c|c|c|c|c|c|}
\hline $\begin{array}{l}305 \\
\text { mig.m }\end{array}$ & $2552 / 4924$ & MU315a/PR & GTD & $G$ & $\begin{array}{l}2.53 \\
0.06\end{array}$ & & $\begin{array}{l}2.77 \\
0.04\end{array}$ & $\begin{array}{l}.511368 \\
.000028\end{array}$ & $\begin{array}{l}.120718 \\
.000060\end{array}$ & \begin{tabular}{|l|}
6.640 \\
.002 \\
\end{tabular} & $\begin{array}{l}33.261 \\
.013 \\
\end{array}$ & -.39 & -24.8 & -6.7 & \begin{tabular}{l|}
$1.87_{\mathrm{Rb} / \mathrm{sr}}$ \\
$.70584_{\mathrm{b}}$ \\
\end{tabular} & 50 & $n t$ \\
\hline $\begin{array}{l}254 \\
\text { anf }\end{array}$ & $2540 / 4917$ & $M J 23(137) P R$ & BAS & $\mathrm{H}$ & $\begin{array}{l}0.24 \\
0.12 \\
\end{array}$ & $1.04^{\# 1}$ & $\begin{array}{l}1.36 \\
0.07 \\
\end{array}$ & $\begin{array}{l}.512583 \\
.000028 \\
\end{array}$ & $\begin{array}{l}.162346 \\
.000125 \\
\end{array}$ & $\begin{array}{l}8.055 \\
0.003 \\
\end{array}$ & $\begin{array}{l}30.003 \\
0.020\end{array}$ & -.17 & $\mid-1.1$ & 1.6 & $0.6_{\mathrm{est}}$ & & nt \\
\hline \multicolumn{18}{|c|}{ GRANITOS INTRUSIVOS } \\
\hline grt & $\sim 2518 / 4940$ & MJ-271A / PR & GTD & 1 & 1.74 & & 2.01 & $\begin{array}{l}.511417 \\
.000012 \\
\end{array}$ & $\begin{array}{l}.089985 \\
.000011 \\
\end{array}$ & 10.00 & 67.20 & -.54 & -23.8 & -16 & $0.6_{\text {est }}$ & & 2 \\
\hline grt & $2518 / 4940$ & $M J 274 A / P R$ & GTD & $\mathrm{J}$ & 1.80 & & 2.06 & $\begin{array}{l}.511407 \\
.000020 \\
\end{array}$ & $\begin{array}{l}.092573 \\
.000013 \\
\end{array}$ & 9.17 & 59.90 & -.53 & -24.0 & -16 & $0.6_{\text {est }}$ & & 2 \\
\hline $\begin{array}{l}238 \\
\text { grt }\end{array}$ & $2555 / 4915$ & $\begin{array}{l}\text { MJ132/PR-SC } \\
\text { D.Cur./L.Alves }\end{array}$ & GTD & $K$ & $\begin{array}{l}1.81 \\
.06 \\
\end{array}$ & & $\begin{array}{l}2.13 \\
.05 \\
\end{array}$ & $\begin{array}{l}.511689 \\
.000031 \\
\end{array}$ & $\begin{array}{l}.116790 \\
.000094 \\
\end{array}$ & $\begin{array}{l}5.91 \\
.003 \\
\end{array}$ & $\begin{array}{l}30.599 \\
.019 \\
\end{array}$ & -.41 & -18.5 & -12 & $\begin{array}{l}.59_{\mathrm{U}-\mathrm{Pb}} \\
\mathrm{b}\end{array}$ & & 2 \\
\hline grt & $2521 / 4901$ & $\mathrm{M} / 291 \mathrm{c} / \mathrm{PR}$ & GTD & $L$ & 1.42 & & 1.86 & .511997 & .127882 & 14.0 & 66.2 & -.35 & -12.5 & -7.2 & $\begin{array}{l}.60 \mathrm{Rb} / \mathrm{Sr} \\
.7193_{\mathrm{b}}\end{array}$ & 220 & 2 \\
\hline \multicolumn{18}{|c|}{ ANÁLISE EM MINERAIS } \\
\hline gns & $2540 / 4917$ & MJ137(r. tot.*) & GTD & $\mathrm{M}$ & \begin{tabular}{|l|}
$0.59 ?$ \\
0.10 \\
\end{tabular} & $1.13^{\# 1}$ & \begin{tabular}{l|}
$1.45 ?$ \\
0.13 \\
\end{tabular} & $\begin{array}{l}.512474 \\
.000016 \\
\end{array}$ & $\begin{array}{l}.154158 \\
.005700 \\
\end{array}$ & $\ldots$ & -- & -.22 & -3.2 & 0.0 & $\begin{array}{l}.59 \mathrm{Sm} \cdot \mathrm{Nd} \\
.51190_{\mathrm{b}} \\
\end{array}$ & & 2 \\
\hline gns & $2540 / 4917$ & MJ137(anf. $\left.{ }^{*}\right)$ & Maf & $N$ & $\begin{array}{l}0.35 ? \\
0.08 \\
\end{array}$ & $1.08^{\# 1}$ & $\begin{array}{l}1.57 ? \\
0.16 \\
\end{array}$ & $\begin{array}{l}.512573 \\
.000006 \\
\end{array}$ & $\begin{array}{l}.168309 \\
.0056 \\
\end{array}$ & -- & $\cdots$ & -.14 & -1.3 & 0.9 & $\begin{array}{l}.59 \mathrm{Sm}-\mathrm{Nd} \\
.51190 \mathrm{~b}\end{array}$ & & 2 \\
\hline gns & $2540 / 4917$ & M3137granada" & $\mathrm{Mgd}$ & 0 & $\ldots$ & $1.12^{\#+1}$ & $-\infty$ & $\begin{array}{l}.513846 \\
.000010 \\
\end{array}$ & $\begin{array}{l}.506108 \\
.001670 \\
\end{array}$ & $\cdots$ & - & & & & $\begin{array}{l}.59 \mathrm{Sm} \cdot \mathrm{Nd} \\
.51190_{\mathrm{b}} \\
\end{array}$ & & 2 \\
\hline gns & $2540 / 4917$ & MJ137 (plag. ${ }^{*}$ ) & $\mathrm{Mpl}$ & $P$ & $\begin{array}{l}0.45 ? \\
0.02 \\
\end{array}$ & $1.03^{\# 1}$ & $\begin{array}{l}0.97 \\
0.03 \\
\end{array}$ & $\begin{array}{l}.512377 \\
.000008 \\
\end{array}$ & $\begin{array}{l}.107969 \\
.003600 \\
\end{array}$ & -- & -- & -.45 & -5.1 & 1.6 & $\begin{array}{l}.59 \mathrm{Sm-Nd} \\
.51190_{\mathrm{b}} \\
\end{array}$ & & 2 \\
\hline \multicolumn{18}{|c|}{ GRANITÓIDES DEFORMADOS - SUITE DO RIO PIÉN } \\
\hline $54 \mathrm{grt}$ & $2605 / 4925$ & MJ AM16/PR & GTD & $A$ & 1.85 & & 2.10 & $\begin{array}{l}.511318 \\
.000028 \\
\end{array}$ & .088033 & 6.03 & 41.42 & -.55 & \begin{tabular}{|l|}
-25.7 \\
\end{tabular} & -17. & \begin{tabular}{|l|}
$0.60_{\mathrm{Rb} / \mathrm{St}}$ \\
.706 \\
\end{tabular} & 31 & 2 \\
\hline $56 \mathrm{grt}$ & $2602 / 4919$ & MJ-AM95/PR & GTD & $B$ & 1.75 & & 2.03 & $\begin{array}{l}.511488 \\
.000032 \\
\end{array}$ & .096575 & 2.134 & 13.362 & -.51 & -22.4 & -15 & $\begin{array}{l}0.60_{\mathrm{Rb} / \mathrm{ST}} \\
.7045_{\mathrm{b}}\end{array}$ & 9.9 & 2 \\
\hline $55 \mathrm{grt}$ & $2605 / 4924$ & MJ-AM $20 / P R$ & GTD & C & 1.90 & & 2.15 & $\begin{array}{l}.511263 \\
.000030 \\
\end{array}$ & .086934 & 4.122 & 28.672 & -.56 & -26.8 & -18 & $\begin{array}{l}0.60_{\mathrm{Rb} / \mathrm{Sr}} \\
.706_{\mathrm{b}} \\
\end{array}$ & 31 & 2 \\
\hline & & & & & & & & & & & & & & & & & \\
\hline
\end{tabular}

Ver nota explicativa da tabela no anexo 1

* Concentrado de mineral (rocha fonte - granitóide).

${ }_{\# 1} \rightarrow \mathrm{T} 2=\mathrm{T}_{\text {met. }}$ e $\left({ }^{147} \mathrm{Sm} /{ }^{144} \mathrm{Nd}\right)_{\mathrm{T} 2}=0.1 ;{ }^{* 2}=\mathrm{T} 2=\mathrm{T}_{\text {mét. }}$ e $\left({ }^{147} \mathrm{Sm} /{ }^{144} \mathrm{Nd}\right)_{\mathrm{T} 2}=0.11$

Observ.: ${ }^{\prime \prime} \ldots$ met. quando o fracionamento ocorre logo após a separação manto-crosta (intervalo de tempo muito curto) então o modelo de 2 estágio praticamente não altera quando comparado com o de estágio simples.

ref.--> 2 = Siga Jr. (1995); coluna $T_{\text {mét }} b=$ Siga Jr. (1995). 


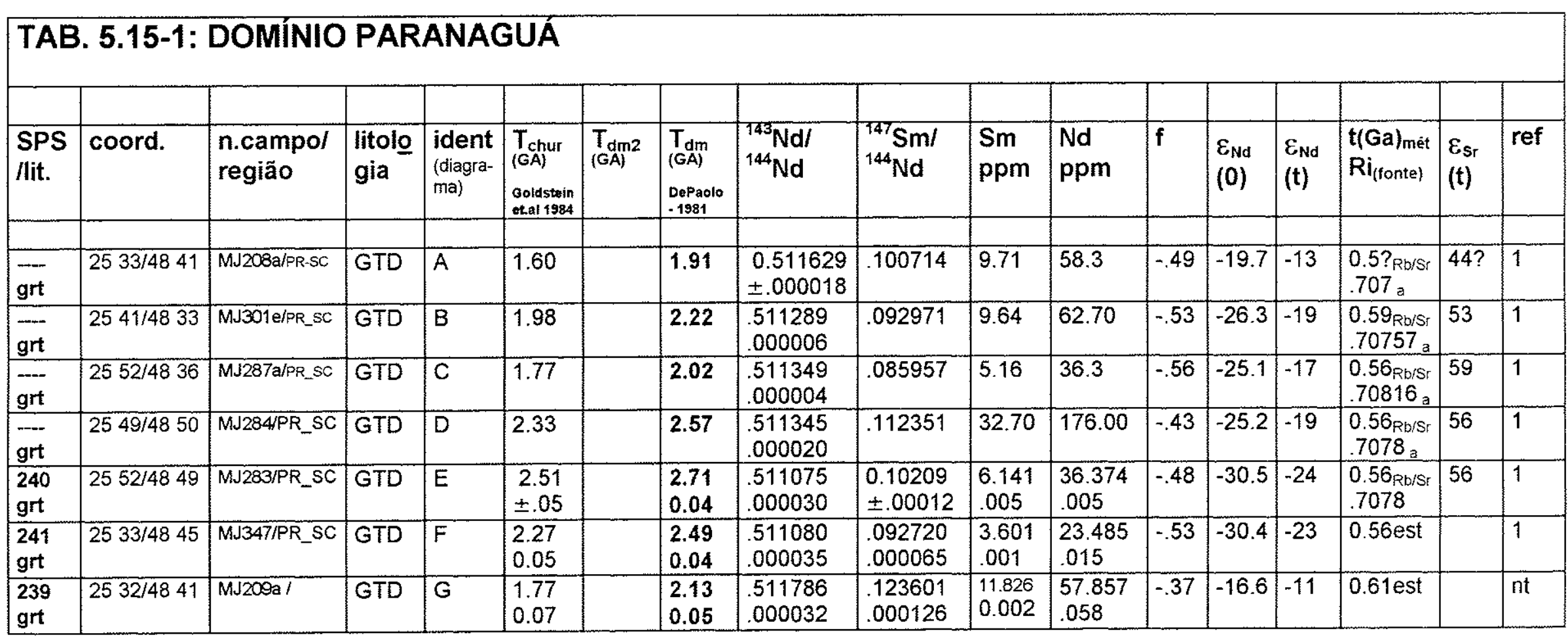

ref. : $1=$ Siga Jr, 1995, nt $=$ neste trabalho. 


\begin{tabular}{|c|c|c|c|c|c|c|c|c|c|c|c|c|c|c|c|c|c|}
\hline $\begin{array}{l}\text { SPS } \\
\text { /lit. }\end{array}$ & coord. & $\begin{array}{l}\text { n.campol } \\
\text { região }\end{array}$ & $\begin{array}{l}\text { litolo } \\
\text { gia }\end{array}$ & $\begin{array}{l}\text { ident } \\
\text { (diagra- } \\
\text { ma) }\end{array}$ & \begin{tabular}{|l|}
$T_{\text {chur }}$ \\
(GA) \\
Goldstein \\
etal 1984 \\
\end{tabular} & $\begin{array}{l}T_{d m 2} \\
(G A)\end{array}$ & $\begin{array}{l}T_{\text {dim }} \\
(\mathrm{GA}) \\
\text { Depaolo } \\
-1981 \\
\end{array}$ & $\begin{array}{l}{ }^{143} \mathrm{Nd} l \\
{ }^{144} \mathrm{Nd}\end{array}$ & ${ }^{144} \mathrm{Sm} /$ & $\begin{array}{l}\mathrm{Sm} \\
\mathrm{ppm}\end{array}$ & $\begin{array}{l}\text { Nd } \\
\text { ppm }\end{array}$ & $f$ & $\begin{array}{l}\varepsilon_{\mathrm{Nd}} \\
(0)\end{array}$ & $\begin{array}{l}\varepsilon_{\text {Nd }} \\
(t)\end{array}$ & $\begin{array}{l}t(G a)_{\text {mét }} \\
R i_{\text {(fonte) }}\end{array}$ & $\begin{array}{l}\varepsilon_{\mathrm{sr}} \\
(t)\end{array}$ & ref \\
\hline \multicolumn{18}{|c|}{ DOM FELICIANO } \\
\hline \multicolumn{18}{|c|}{ 5.15-2 - Faixa Tijucas (SC) } \\
\hline & & & & & & & & & & & & & & & & & \\
\hline $\mathrm{mig}$ & $2649 / 4834$ & $\begin{array}{l}\mathrm{C} 2 / \mathrm{SC} \\
\text { Camborius }\end{array}$ & GTD & A & 2.34 & & 2.57 & $\begin{array}{l}.511256 \\
.000010 \\
\end{array}$ & .1070 & $\ldots$ & -- & -.46 & -27.0 & 2.8 & $2.6_{\text {est }}$ & & 4 \\
\hline$\cdots$ & $27 \quad 10 / 4838$ & $\begin{array}{l}\text { SC 54// SC } \\
\text { Camboriú }\end{array}$ & GTD & $B$ & 1.95 & $2.77^{* 2}$ & 2.16 & .511001 & .06926 & 6.54 & 57.10 & -.65 & -31.9 & \begin{tabular}{|l|}
-22 \\
\end{tabular} & $0.6_{\text {est }}$ & & 6 \\
\hline grt & $2707 / 4836$ & $\begin{array}{l}\text { SC } 52 / S C \\
\text { Guabiruba }\end{array}$ & GTD & C & 2.02 & $2.66^{\text {fZ }}$ & 2.25 & $\begin{array}{l}.511142 \\
.000009\end{array}$ & .08436 & 6.38 & 45.73 & -.57 & -29.2 & -21 & .6 est & & 6 \\
\hline o.gns & $2704 / 4911$ & $\begin{array}{l}\text { C4/ SC } \\
\text { Presid. Nereu }\end{array}$ & GTD & D & 3.10 & & 3.27 & $\begin{array}{l}.511037 \\
.000012 \\
\end{array}$ & .1185 & $\ldots$ & $\cdots$ & -.40 & -31.2 & -5.3 & $2.6_{\mathrm{es} t}$ & & 4 \\
\hline gtd & $2658 / 4853$ & $\begin{array}{l}\mathrm{C} 5 / \mathrm{SC} \\
\text { Valsungana }\end{array}$ & GTD & $E$ & 1.73 & & 2.01 & $\begin{array}{l}.511487 \\
.000014 \\
\end{array}$ & .0955 & -- & $-\cdots$ & -.51 & -22.5 & -15 & $0.6_{\text {est }}$ & & 4 \\
\hline xis & $2707 / 4855$ & $\begin{array}{l}\text { C12/ SC } \\
\text { Brusque }\end{array}$ & MSE & $F$ & 1.54 & $1.76^{* 2}$ & $1.97 ?$ & $\begin{array}{l}.511975 \\
.000010 \\
\end{array}$ & .1312 & $-\cdots$ & $-\cdots$ & -.33 & -12.9 & -7.9 & $0.6_{\text {est }}$ & & 4 \\
\hline fil & $2657 / 4902$ & $\begin{array}{l}\text { C13/ SC } \\
\text { Brusque }\end{array}$ & MSE & $G$ & 1.70 & & 2.05 & $\begin{array}{l}.511758 \\
.000014 \\
\end{array}$ & .1179 & -- & $-\ldots$ & -.40 & -17.2 & -11 & $0.6_{\text {est }}$ & & 4 \\
\hline gns & & $\begin{array}{l}\text { SC } 49-1 \mid / S C \\
\text { Itapema }\end{array}$ & GTD & $M$ & 2.44 & $2.06^{\$ 2}$ & 2.78 & $\begin{array}{l}.511814 \\
.000009\end{array}$ & .14543 & 2.28 & 9.48 & -.26 & -16.1 & -12 & $0.6_{\text {est }}$ & & 6 \\
\hline \multicolumn{18}{|c|}{ 5.15-2 - Faixa Tijucas (RS) } \\
\hline $\begin{array}{l}185- \\
\text { gns }\end{array}$ & $3050 / 5306$ & $\begin{array}{l}\text { LK289C-1/RS } \\
\text { Sant. B. Vista }\end{array}$ & GTD & $\mathrm{H}$ & $\begin{array}{l}2.43 \\
.05\end{array}$ & & $\begin{array}{l}2.66 \\
.04 \\
\end{array}$ & $\begin{array}{l}.511221 \\
.000029\end{array}$ & $\begin{array}{l}.108384 \\
.000086 \\
\end{array}$ & $\begin{array}{l}3.905 \\
.002 \\
\end{array}$ & $\begin{array}{l}21.787 \\
.013\end{array}$ & -.45 & -27.6 & -2.9 & 2.2 & \begin{tabular}{|l|}
1.27 \\
\end{tabular} & nt \\
\hline $\begin{array}{l}186 / \\
\text { gns }\end{array}$ & $3050 / 5306$ & $\begin{array}{l}\text { LK } 289 \text { C-2/RS } \\
\text { Sant. B. Vista }\end{array}$ & GTD & 1 & $\begin{array}{l}2.43 \\
.05 \\
\end{array}$ & & $\begin{array}{l}2.66 \\
.04 \\
\end{array}$ & $\begin{array}{l}.511152 \\
.000043 \\
\end{array}$ & $\begin{array}{l}.107120 \\
.000124 \\
\end{array}$ & $\begin{array}{l}5.979 \\
.002 \\
\end{array}$ & $\begin{array}{l}33.752 \\
.037 \\
\end{array}$ & -.46 & -29.0 & -3.8 & $\begin{array}{l}2.2 \mathrm{Rb} / \mathrm{Sr} \\
.702_{\mathrm{b}}\end{array}$ & 1.27 & nt \\
\hline $\begin{array}{l}187 / \\
\text { gns }\end{array}$ & $3052 / 5310$ & $\begin{array}{l}\text { ES } 1115 / R S \\
\text { Sant. B. Vista } \\
\end{array}$ & GTD & $J$ & $\begin{array}{l}2.20 \\
.03\end{array}$ & & $\begin{array}{l}2.40 \\
.03 \\
\end{array}$ & $\begin{array}{l}.511037 \\
.000025 \\
\end{array}$ & $\begin{array}{l}.085992 \\
.000072 \\
\end{array}$ & $\begin{array}{l}2.371 \\
.001 \\
\end{array}$ & $\begin{array}{l}16.673 \\
.012 \\
\end{array}$ & -.56 & -31.2 & -23 & $0.6 ?$ & & nt \\
\hline $\begin{array}{l}188 / \\
\text { gns }\end{array}$ & $3048 / 5305$ & $\begin{array}{l}\text { ESJ } 116 \text { E/RS } \\
\text { Sant. B. Vista }\end{array}$ & GTD & $\mathrm{K}$ & $\begin{array}{l}2.38 \\
.04 \\
\end{array}$ & & $\begin{array}{l}2.58 \\
.04 \\
\end{array}$ & $\begin{array}{l}.510930 \\
.000029\end{array}$ & $\begin{array}{l}.088019 \\
.000056\end{array}$ & $\begin{array}{l}2.779 \\
.001 \\
\end{array}$ & $\begin{array}{l}19.092 \\
.010 \\
\end{array}$ & -.55 & -33.3 & -26 & $\begin{array}{l}0.5_{\mathrm{Rb} / \mathrm{Sr}} \\
7035_{\mathrm{b}}\end{array}$ & -6.0 & nt \\
\hline $\begin{array}{l}1901 \\
\text { c.end }\end{array}$ & $3053 / 5255$ & $\begin{array}{l}\text { LK 258B/RS } \\
\text { Sant. B. Vista }\end{array}$ & GNL & $L$ & $\begin{array}{l}1.60 \\
.07\end{array}$ & & $\begin{array}{l}1.93 \\
.05 \\
\end{array}$ & $\begin{array}{l}.511679 \\
.000040\end{array}$ & $\begin{array}{l}.105779 \\
.000219\end{array}$ & $\begin{array}{l}11.385 \\
.005\end{array}$ & $\begin{array}{l}65.084 \\
.131 \\
\end{array}$ & -.46 & -18.7 & -9.7 & $\begin{array}{l}.78_{\mathrm{Rb} / \mathrm{St}} \\
.706_{\mathrm{b}}\end{array}$ & $\overline{34}$ & nt \\
\hline
\end{tabular}




\begin{tabular}{|c|c|c|c|c|c|c|c|c|c|c|c|c|c|c|c|c|c|}
\hline \multicolumn{18}{|c|}{ 5.15-3 - Batólito de Pelotas - Região de Florianópolis (SC) } \\
\hline grt.mi & $2726 / 4847$ & C7/SC & GTD & A & 1.31 & & 1.75 & $\begin{array}{l}.512008 \\
.000026\end{array}$ & .1234 & $\ldots$ & $-\cdots$ & -.37 & -12.3 & -6.7 & $0.6_{\text {est }}$ & & 4 \\
\hline gtd & $2712 / 4827$ & $\begin{array}{l}\text { C8 / SC } \\
\text { Armaçăoo }\end{array}$ & GTD & $B$ & 1.20 & & 1.62 & $\begin{array}{l}.512009 \\
.000028\end{array}$ & .1167 & --- & --- & -.41 & -12.3 & -6.1 & $0.6_{\text {est }}$ & & 4 \\
\hline gtd & $2716 / 4847$ & $\begin{array}{l}\text { C9/ SC } \\
\text { Santa Luzia }\end{array}$ & GTD & $\mathrm{C}$ & 1.24 & & 1.69 & \begin{tabular}{|l|}
.512052 \\
.000014 \\
\end{tabular} & .1246 & -- & $\cdots$ & -.37 & -11.4 & -5.9 & $0.6_{\text {est }}$ & & 4 \\
\hline gtd & $2731 / 4901$ & $\begin{array}{l}\text { C10/SC } \\
\text { B. R. Bugres }\end{array}$ & GTD & $D$ & 2.10 & $1.76^{\pi 2}$ & $2.58 ?$ & $\begin{array}{l}.512067 \\
.000010\end{array}$ & .1554 & $=$ & -- & -.21 & -11.1 & -8.0 & $0.6_{\text {est }}$ & & 4 \\
\hline fil & $2737 / 4855$ & $\begin{array}{l}\text { C15/SC } \\
\text { Quebaça }\end{array}$ & MSE & $E$ & 1.24 & & 1.63 & $\begin{array}{l}.511915 \\
.000006\end{array}$ & .1082 & -- & 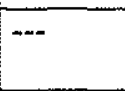 & -.45 & -14.1 & -7.3 & $0.6_{\text {est }}$ & & 4 \\
\hline grt & $2753 / 4842$ & $\begin{array}{l}\text { SC43/SC } \\
\text { Paulo Lopes }\end{array}$ & GTD & $G$ & 1.22 & & 1.58 & $\begin{array}{l}.511853 \\
.000009\end{array}$ & .09891 & 9.60 & 58.69 & -.50 & -15.3 & -7.8 & $.6_{\text {est }}$ & & 6 \\
\hline- & $2828 / 4859$ & $\begin{array}{l}\text { SC } 42 \text { / SC } \\
\text { Pedra Grande }\end{array}$ & GTD & $G$ & 0.98 & & 1.39 & $\begin{array}{l}.512032 \\
.000008\end{array}$ & .10269 & 9.98 & 58.77 & -.48 & -11.8 & -4.6 & 6 est & & 6 \\
\hline-- & $2828 / 4859$ & $\begin{array}{l}\text { SC } 42-11 \text { / SC } \\
\text { Pedra Grande }\end{array}$ & GTD & 1 & 1.60 & $1.59^{22}$ & 2.18 & $\begin{array}{l}.512184 \\
.000008 \\
\end{array}$ & .15350 & 4.79 & 18.87 & -.22 & -8.9 & -5.5 & .6 est & & 6 \\
\hline & & & & & & & & & & & & & & & & & \\
\hline \multicolumn{18}{|c|}{ 5.15-3 - Batólito de Pelotas e Encruzilhada do Sul (RS) } \\
\hline gtd & $3020 / 5149$ & $\begin{array}{l}\text { C14/RS } \\
\text { D.Feliciano }\end{array}$ & GTD & $\mathrm{J}$ & 1.52 & $1.77^{72}$ & $1.95 ?$ & $\begin{array}{l}.511964 \\
.000010\end{array}$ & .1294 & $-\cdots$ & 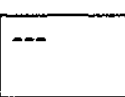 & -.34 & -13.1 & -8.0 & $0.6_{\text {est }}$ & & 4 \\
\hline $\begin{array}{l}303 \\
\text { ton }\end{array}$ & $3043 / 5205$ & LK135/RS & GTD & $\mathrm{K}$ & $\begin{array}{l}0.98 \\
0.07\end{array}$ & & $\begin{array}{l}1.42 \\
0.05\end{array}$ & $\begin{array}{l}.512090 \\
.000038\end{array}$ & $\begin{array}{l}.111745 \\
.000091\end{array}$ & $\begin{array}{l}9.934 \\
0.002\end{array}$ & $\begin{array}{l}53.757 \\
.042 \\
\end{array}$ & -.43 & -10.7 & -4.7 & $\begin{array}{l}.55_{\mathrm{Rb} / \mathrm{Sr}} \\
.709_{\mathrm{b}}\end{array}$ & 73 & $n t$ \\
\hline $\begin{array}{l}304 \\
\text { gns }\end{array}$ & $3130 / 5318$ & GF $331 / R S$ & GTD & $L$ & $\begin{array}{l}1.62 \\
0.07\end{array}$ & & $\begin{array}{l}2.00 \\
0.05\end{array}$ & $\begin{array}{l}.511839 \\
.000035\end{array}$ & $\begin{array}{l}.121887 \\
.000089\end{array}$ & $\begin{array}{l}4.995 \\
.002\end{array}$ & $\begin{array}{l}24.781 \\
.015\end{array}$ & -.38 & -15.6 & -8.0 & $\begin{array}{l}.80_{\mathrm{Rb} / \mathrm{Sr}} \\
.704_{\mathrm{b}}\end{array}$ & 6.1 & nt \\
\hline $\begin{array}{l}189 / \\
\text { gnl }\end{array}$ & $3055 / 5250$ & LK169/RS & GNL & $M$ & $\begin{array}{l}1.63 \\
.04\end{array}$ & & $\begin{array}{l}1.95 \\
.03\end{array}$ & $\begin{array}{l}.511660 \\
.000023\end{array}$ & $\begin{array}{l}.105678 \\
.000160\end{array}$ & $\begin{array}{l}10.515 \\
.007\end{array}$ & $\begin{array}{l}60.168 \\
.081 \\
\end{array}$ & -.46 & -19.1 & -8.6 & $\begin{array}{l}0.9_{\mathrm{Rb} / \mathrm{St}} \\
0.707 \mathrm{~b}\end{array}$ & 51 & nt \\
\hline gtd & composito ${ }^{7 \neq+}$ & $\begin{array}{l}\text { C6/RS } \\
\text { D.Feliciano }\end{array}$ & GTD & $N$ & 1.07 & & $1.42 ?$ & $\begin{array}{l}.511874 \\
.000012\end{array}$ & .0883 & $\cdots$ & $\cdots$ & -.55 & -14.9 & -6.6 & $0.6_{\text {est }}$ & & 4 \\
\hline sie & $3018 / 5248$ & \begin{tabular}{|l|} 
RS2 \\
Piquiri RS
\end{tabular} & GTD & 0 & 1.43 & & 1.75 & .511678 & .09487 & 14.32 & 91.28 & -.52 & -18.7 & -11 & 0.6 est & & 6 \\
\hline ano & $3019 / 5225$ & $\begin{array}{l}\text { RS5 } \\
\text { Capivarita/RS }\end{array}$ & BAS & $P$ & 1.74 & & 2.02 & $\begin{array}{l}.511480 \\
.000011 \\
\end{array}$ & .09579 & .32 & 2.02 & -.51 & -.226 & -15 & .6 est est & & 6 \\
\hline grt & $3025 / 5228$ & $\begin{array}{l}\text { RS4 } \\
\text { Encruzilhada }\end{array}$ & GTD & $Q$ & 1.80 & & 2.08 & $\begin{array}{l}.511449 \\
.000008\end{array}$ & .09655 & 29.26 & 183.26 & -.51 & -23.2 & -16 & $.595 \mathrm{U} \cdot \mathrm{Pb}$ & & 6 \\
\hline & & & & & & & & & & & & & & & & & \\
\hline
\end{tabular}




\begin{tabular}{|c|c|c|c|c|c|c|c|c|c|c|c|c|c|c|c|c|}
\hline$\overline{\text { grt }}$ & $3131 / 5236$ & $\begin{array}{l}\text { RS13l| } \\
\text { Moinho / RS }\end{array}$ & GTD & $R$ & 0.94 & & 1.32 & .511995 & .09220 & 6.87 & 45.06 & -.53 & -12.5 & -4.6 & $.595 \mathrm{U} \cdot \mathrm{Pb}$ & 6 \\
\hline grt & $3147 / 5227$ & $\begin{array}{l}\text { RS12 } \\
\text { Capåo Leão }\end{array}$ & GTD & $\mathrm{S}$ & 1.59 & $1.46^{\# 2}$ & 2.37 & $\begin{array}{l}.512340 \\
.000009\end{array}$ & .16826 & 12.53 & 45.03 & -.14 & -5.8 & -3.6 & 6 est & 6 \\
\hline m.dio & $3137 / 5323$ & $\begin{array}{l}\text { RS7A / RS } \\
\text { Pintheiro Mach. }\end{array}$ & BAS & $T$ & 1.64 & & 2.01 & $\begin{array}{l}.511831 \\
.000009 \\
\end{array}$ & .12164 & 6.65 & 33.06 & -.38 & -15.7 & -10 & .6 est & 6 \\
\hline gns & 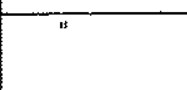 & $\begin{array}{l}\text { RS7B / RS } \\
\text { Pinh. Machado }\end{array}$ & GTD & $U$ & 1.29 & & 1.69 & .511928 & .11318 & 5.54 & 29.6 & -.42 & -13.8 & -7.4 & .61 U.Pb & 6 \\
\hline m.grt & $"$ & $\begin{array}{l}\text { RS7C / RS } \\
\text { Pinh. Machado }\end{array}$ & GTD & V & 1.02 & $1.62^{\# 2}$ & 1.37 & $\begin{array}{l}.511906 \\
.000008\end{array}$ & .08760 & 4.76 & 32.86 & -.55 & -14.3 & -5.9 & 6 est & 6 \\
\hline gns & $3137 / 5317$ & $\begin{array}{l}\text { RS9A / RS } \\
\text { Pinh. Machado }\end{array}$ & GTD & $x$ & 1.69 & $1.85^{72}$ & 2.10 & $\begin{array}{l}.511914 \\
.000012 \\
\end{array}$ & .13167 & 1.62 & 7.44 & -.33 & -14.1 & -9.1 & $.61 \mathrm{U}-\mathrm{Pb}_{\mathrm{b}}$ & 6 \\
\hline m.grt & $"$ & $\begin{array}{l}\text { RS9B / RS } \\
\text { Pinh. Machado }\end{array}$ & GTD & $Z$ & 1.07 & $1.68^{\# 2}$ & 1.41 & .511853. & .08492 & 3.39 & 24.14 & -.57 & -15.3 & -6.8 & $6_{\text {est }}$ & 6 \\
\hline & & & & & & & & & & & & & & & & \\
\hline
\end{tabular}

Ver nota explicativa da tabela no anexo 1

composito ${ }^{++} \ldots$ coordenadas : $\left(30^{\circ} 48^{\prime} / 54^{\circ} 15^{\prime} ; 31^{\circ} 05^{\prime} / 54^{\circ} 11^{\prime} ; 31^{\circ} 08^{\prime} / 54^{\circ} 00^{\prime}\right)$; composito ${ }^{t++} \ldots$... coordenadas $=\left(31^{\circ} 23^{\prime} / 52^{\circ} 55^{\prime} ; 31^{\circ} 25^{\prime} / 52^{\circ}\right.$ $\left.47^{\prime} ; 31^{\circ} 28^{\prime} / 52^{\circ} 41^{\prime} ; 31^{\circ} 31^{\prime} / 52^{\circ} 35^{\prime} ; 31^{\circ} 31^{\prime} / 52^{\circ} 29^{\prime} ; 31^{\circ} 32^{\prime} / 52^{\circ} 20^{\prime}\right)$.

ref. - 4 = dados isotópicos de Mantovani et. al (1987); $5=$ Babinski et. al. (1996) ;6= Babinski et. al 1995 --> idades modelos recalculados neste trabalho.

referências para coluna $t_{\text {metodo }}-a=$ Siga $J r, 1995$; $c=$ Babinski et. al. (1996); $b=$ Soliani $J r(1986)$--> idades Rb/Sr e razões iniciais; $n t=n e s t e$ trabalho. 


\section{CAPÍTULO 6}

\section{CONSIDERAÇÕES FINAIS}




\section{6 - CONSIDERAÇÕES FINAIS}

\section{1 - EVOLUÇ̃̃O CRUSTAL GLOBAL DA PLATAFORMA SUL AMERICANA}

Com base nos dados isotópicos de Nd obtidos nos domínios crustais da Plataforma Sul Americana, conforme exposto nos capitulos anteriores, foi construido o histograma da fig. 6.1. A figura mostra a proporção de acreção de material crustal juvenil, no tempo geológico, e foi construida levando em conta as idades modelo Sm-Nd ( TDM - Ver resumo na Tabela 6.1), bem como as áreas correspondentes a cada um dos dominios crustais considerados (tabela 6.2). A região considerada inclui, além do território brasileiro, porções de Venezuela, Uruguai e Guianas.

A figura indica pequena proporção de crosta continental remanescente anterior a 3.3 Ga., como ocorre em qualquer das áreas continentais do mundo. Possivelmente, isto seria devido à reciclagem intensa da crosta continental, de volta para o manto superior, como característica fundamental do regime tectônico permóvel, no início da evolução do planeta. Em seguida, o Arqueano aparece como um período importante no crescimento da crosta continental da América do Sul, com dois picos (3,1 e 2.7 Ga.), os quais correspondem aproximadamente aos valores mais freqüentes observados em escala mundial. $O$ Paleoproterozóico mostra-se claramente como a principal época de formação de crosta continental juvenil, com os valores principais entre 2.2 e $2.0 \mathrm{Ga}$. Acreção de material juvenil parece continuar durante o Meso e o Neoproterozóico, mas em taxas inferiores às dos periodos de tempo anteriores, e com um pico de razoável intensidade por volta de $1.3-1.2$ Ga., correspondendo ao Ciclo Grenville (Espinhaço/Rondoniano/Sunsás). É também evidente a pequena taxa de acreção que corresponde ao Ciclo Brasiliano.

A partir dos valores da figura 6.1 e tabela 6.2 , foi construída a curva acumulativa da figura 6.2, representando o crescimento da crosta continental na Plataforma Sul Americana. Cabe enfatizar que, em verdade, trata-se do crescimento "visivel", residual, visto que não há como conhecer aquela quantidade de material que pode ter sido reciclada de volta para o manto (subducção do tipo A), em qualquer época do tempo geológico. Na mesma figura foram incluidas, para comparação, a curva teórica global para o planeta (Reimer e Schubert, 1984) e 
a curva obtida por Cordani et al. (1988) com base essencialmente em dados Rb-Sr. Observa-se que a curva resultante do trabalho presente, com base em dados $\mathrm{Sm}-\mathrm{Nd}$, pouco difere daquela inferida por Cordani et al.(1988), baseada em dados Rb-Sr. As diferenças principais são aquelas relativas ao Arqueano, onde os dados de $\mathrm{Nd}$ indicam proporção maior de crosta mais antiga, mas em compensação o gradiente de crescimento no fim do Arqueano é menos acentuado. Padrão similar de evolução crustal é observado na porção SW dos U.S.A., entretanto o período rápido de crescimento de crosta continental ocorreu em época mais recente ( 1.9 a $1.7 \mathrm{Ga}$.) em relação ao da Plataforma Sul Americana.

Em resumo, a curva de crescimento da figura 6.2 indica que cerca de $34 \%$ da crosta continental já existia no fím do Arqueano, mas a maior taxa de acreção ocorreu no Paleoproterozóico, no final do qual já estava formada cerca de $80 \%$ da Plataforma Sul Americana. No início do Neoproterozóico (cerca de 1.0Ga.), cerca de $99 \%$ da crosta continental já estava formada, sobrando muito pouco para épocas posteriores.

Os principais domínios de acreção manto-crosta continental com base nas idades modelo Sm-Nd podem ser vistos na fig. 6.3. Observa-se nesta figura o predomínio de áreas juvenis durante o Paleoproterozóico (padrão de cores azul escuro e claro) correspondendo cerca de $55 \%$ da área total.

Comparando-se os valores das idades modelo $\mathrm{T}_{\mathrm{DM}}$ com as idades de cristalização das rochas envolvidas, obtidas por outros meios (isócronas $\mathrm{Rb}-\mathrm{Sr}$ e datações $\mathrm{U}-\mathrm{Pb}$ em zircão), pode ser estimada a razão entre os processos de acreção juvenil vs, retrabalhamento crustal. Neste trabalho, a partir dos dados tabela 6.3 , considerou-se como compatíveis com processos de derivação mantélica aquelas amostras para as quais a diferença entre as idades modelo Sm$\mathrm{Nd}$ e as idades de cristalização magmática era, no máximo, da ordem de 200 milhões de anos. Valores de $\varepsilon_{\mathrm{Nd}}$ menores do que (-2), e valores de ${ }^{87} \mathrm{Sr} /{ }^{86} \mathrm{Sr}$ menores do que 0.705 reforçaram a identificação de rochas de caráter juvenil.

Utilizando os critérios enunciados acima, para a Plataforma Sul Americana, o volume de crosta continental juvenil preservada resultou em torno de $45 \%$ sendo que o restante foi retrabalhado em épocas subsequentes. $\mathrm{O}$ acervo geocronológico indica o Ciclo orogênico Brasiliano como o principal responsável dos processos de retrabalhamento, em várias das províncias tectônicas cuja evolução tectônica foi discutida no capítulo 5. 


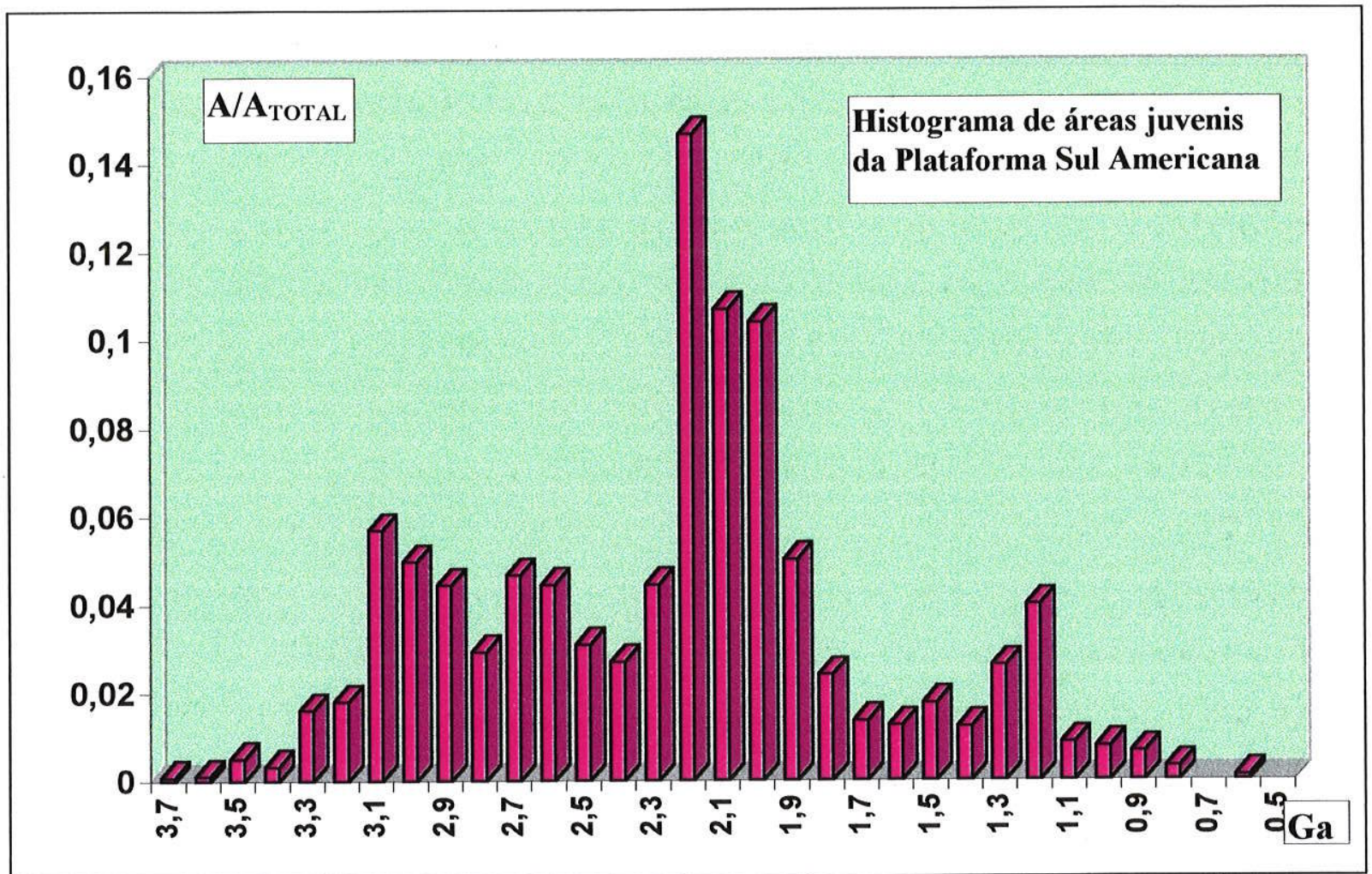

Fig. 6.1: Histograma de acreção manto-crosta continental, $(\mathrm{A}) /\left(\mathrm{A}_{\text {total }}\right)$, em função do tempo geológico, onde as áreas juvenis no tempo $\mathrm{T}(\mathrm{Ga})$ são representados por $(\mathrm{A})$ e a área total da Plataforma Sul Americana por $\left(\mathrm{A}_{\text {total }}\right)$. Os dados relativas às áreas encontram-se na tabela 6.2.

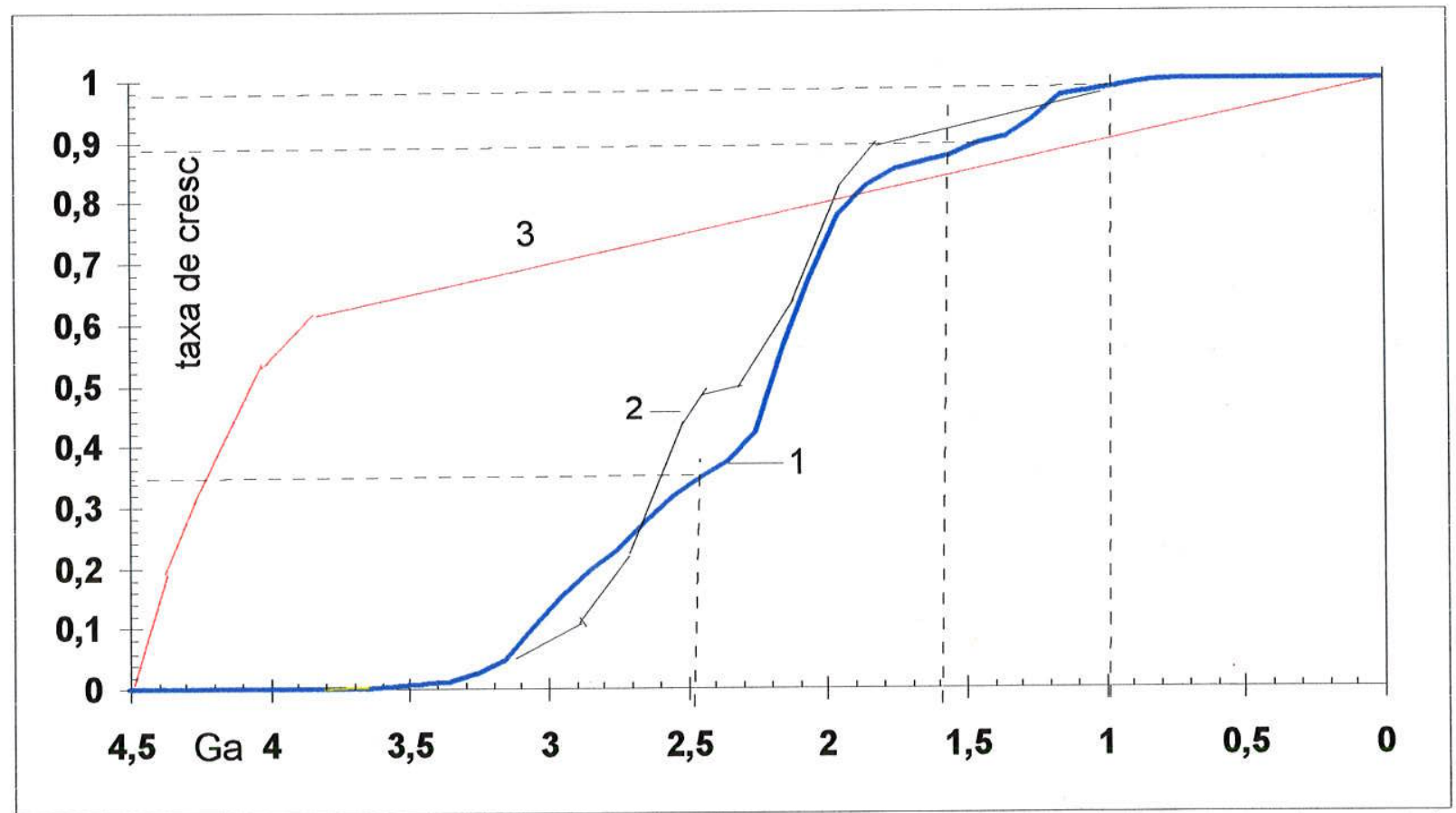

Fig. 6.2 - Curvas de crescimento da crosta continental no tempo geológico: 1 - Plataforma Sul Americana; 2 - Cordani et. al. (1988); 3 - Reymer e Schubert (1984). 


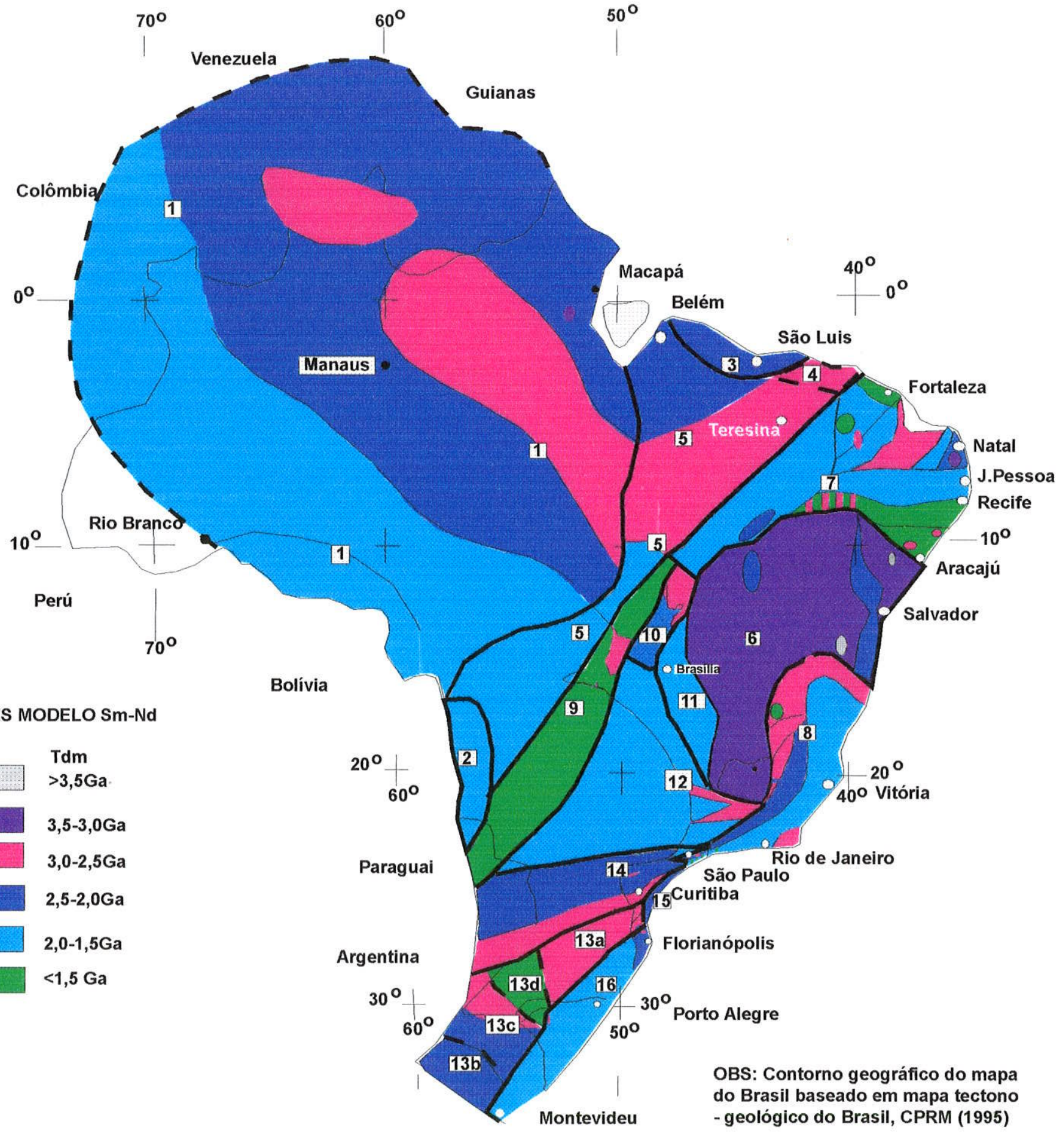

FIG.6.3: PRINCIPAIS DOMÍNIOS DE ACREÇÃO MANTO-CROSTA CONTINENTAL, COM BASE EM IDADES MODELO Sm-Nd, (Tom)

Compartimentação geotectônica:1-Craton Amazônico; 2- Fragmento Cratônico Rio Apa; 3 - Craton SãoLuis; 4 Domínio Médio Coreau; 5 - Faixa Paraguai-Araguaia/ Tocantins; 6 - Craton do São Francisco; 7 - Domínio Borborema; 8 - Domínio Jequitinhonha; 9 - Complexo Goiás Central; 10 - Domínio Uruaçu; 11 - Domínio Brasília; 13a - Fragmento Cratônico Luis Alves; 13b- Fragmento Cratônico R. de La Plata; 13c - Domínio Taquarembó; 13d - Domínio São Gabriel; 14 -Fragmento crustal Curitiba 15 - Domínio Paranaguá e 16- Domínio Dom Feliciano (adaptada de Cordani et. al. 1988, com modificações). 


\section{2 - EVOLUÇ̃̃ CRUSTAL SETORIAL PARA AS MASSAS CONTINENTAIS SEPARADAS PELO LINEAMENTO TRANSBRASILIANO}

As figuras $6.4,6.5$ e 6.6 foram traçadas com os mesmos critérios da figura anterior (6.1), mas inerentes às massas continentais separadas pelo Lineamento Transbrasiliano, considerado neste trabalho como uma das principais suturas que se articularam, no Neoproterozóico, para dar origem ao Supercontinente de Gondwana. Na parte Noroeste, foram incluidos o Craton Amazônico e o de São Luiz, este representando a porção meridional do Craton do Oeste Africano, bem como as suas respectivas regiões marginais, afetadas pelo tectonismo do Neoproterozóico. Por sua vez, na parte sudeste, foram incluidos os Cratons do São Francisco, do Rio de La Plata, e de Luiz Alves, bem como suas respectivas regiões marginais, e outros blocos tectônicos que participaram do processo de aglutinação do Gondwana.

Para efeito de comparação de suas características de evolução crustal, foi levado em conta o tamanho relativo das áreas envolvidas, de modo que na figura 6.4 os picos do histograma aparecem com mais saliência do que os da figura 6.5, embora o número de determinações $\mathrm{Sm}-\mathrm{Nd}$ tenha sido muito maior na região de Sudeste. A figura 6.6 mostra a taxa de crescimento da crosta continetal de cada um destes setores. A comparação entre as duas figuras dá ensejo aos comentários seguintes:

1 - Na massa continental de noroeste a grande maioria das determinações isotópicas $\mathrm{Sm}-\mathrm{Nd}$ disponiveis até o presente concentram-se no intervalo de idade entre 3.1 e $1.8 \mathrm{Ga}$. Por sua vez, do lado sudeste os valores de $\mathrm{T}_{\mathrm{DM}}$ aparecem muito mais espalhados, cobrindo o Precambriano inteiro.

2 - É marcante a semelhança na evolução crustal das duas grandes regiões durante o período acima indicado, entre 3.1 e $1.8 \mathrm{Ga}$. Em ambos os histogramas aparecem concentrações (picos) similares, no final do Arqueano (2.6Ga) e no inicio do Paleoproterozóico (2.2Ga). Tal semelhança na evolução crustal permite sugerir que, em épocas anteriores à formação do Supercontinente de Rodínia, as massas continentais hoje representadas pelos Cratons 
Amazônico-Oeste Africano, e pelos Cratons São Francisco-Congo teriam participado dos mesmos eventos maiores de geração de crosta, em posição possivelmente contígua.

3 - Os histogramas 6.3 e 6.4 diferem bastante em relação ao Arqueano precoce, visto que ainda não há dados, nas regiões do Craton Amazônico, indicando valores tão antigos como os do Bloco Gavião, na Bahia Central. Por outro lado, o grande desconhecimento que ainda persiste a respeito da região Amazônica não aconselha interpretações e conclusões muito categóricas a respeito das possiveis diferenças dos histogramas atuais.

4 - Por outro lado, a grande diferença que aparece nos histogramas em relação ao Meso e Neoproterozóico parece tectonicamente significativa para o presente autor. A região a sudeste do Lineamento Transamazônico inclui um intervalo importante em seu histograma entre 1.7 e 1.4, e um pico saliente por volta de $1.2 \mathrm{Ga}$. (Ciclo Espinhaço/Rondoniano) com continuidade até de $0.8 \mathrm{Ga}$ (Ciclo Brasiliano). Embora não possam ser descartadas outras alternativas para a interpretação de tais idades $\mathrm{T}_{\mathrm{DM}}$, conforme discutido no capítulo 4.6 , a recorrência dos valores sugere tratar-se de eventos reais de formação de crosta continental juvenil, a partir da reciclagem de litosfera oceânica Meso e Neoproterozóica. Parece claro que o resultado de tais subducções antigas apresentou-se como terrenos acrescidos essencialmente na região a sudeste do Lineamento Transbrasiliano, tendo os Cratons Amazônico-São Luiz permanecido como massas de crosta continental rigida e compacta, praticamente livre de eventos tecto-orogênicos a partir do Paleoproterozóico, a não ser em suas regiões marginais e parte na Província Rondoniana-Sunsás. Por outro lado, a região a sudeste do Lineamento Transbrasiliano teve uma evolução muito mais complexa, tendo participado da formação de pelo menos dois supercontinentes (Rodínia no Mesoproterozóico e Gondwana no Neoproterozóico). Dessa forma, os fragmentos cratônicos que se articularam são menores (São Francisco, Rio de La Plata, Luiz Alves, e possivelmente dois outros, no embasamento das sinéclises do Parnaíba e do Paraná) e os blocos tectônicos resultantes aparecem retrabalhados em pelo menos dois grandes ciclos orogênicos (Espinhaço e Brasiliano). Na região, o material acrescido no Meso e Neoproterozóico deve-se à atuação de arcos magmáticos relacionados com o desaparecimento de importantes regiões oceânicas, em várias de suas províncias tectônicas, como foi descrito nos capitulos anteriores. 


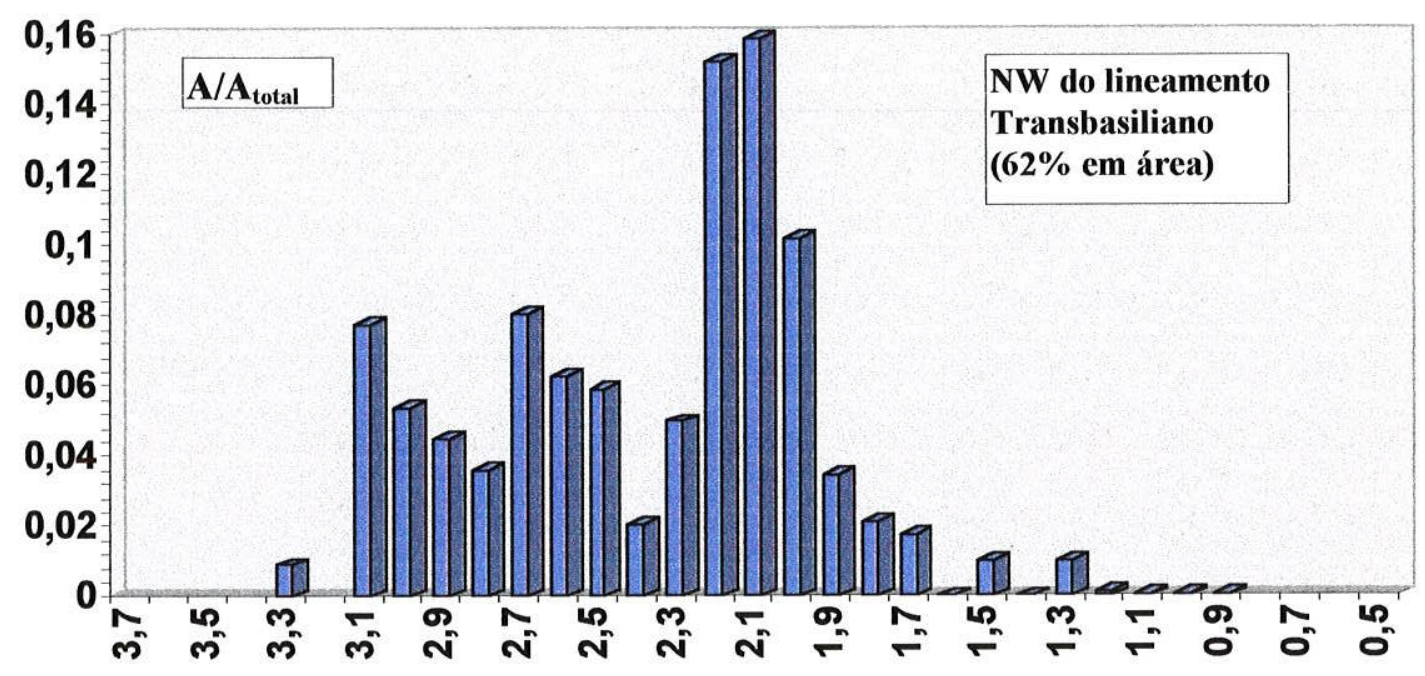

Fig. 6.4 - Histograma de áreas juvenis $(\mathrm{A}) /\left(\mathrm{A}_{\text {total }}\right)$ em função do tempo geológico da porção NW do lineamento Trasnsbrasiliano. $\mathrm{A}_{\text {total }}$ corresponde a $62 \%$ da área da Plataforma Sul Americana. Os dados das áreas encontram-se na tabela 6.2 .

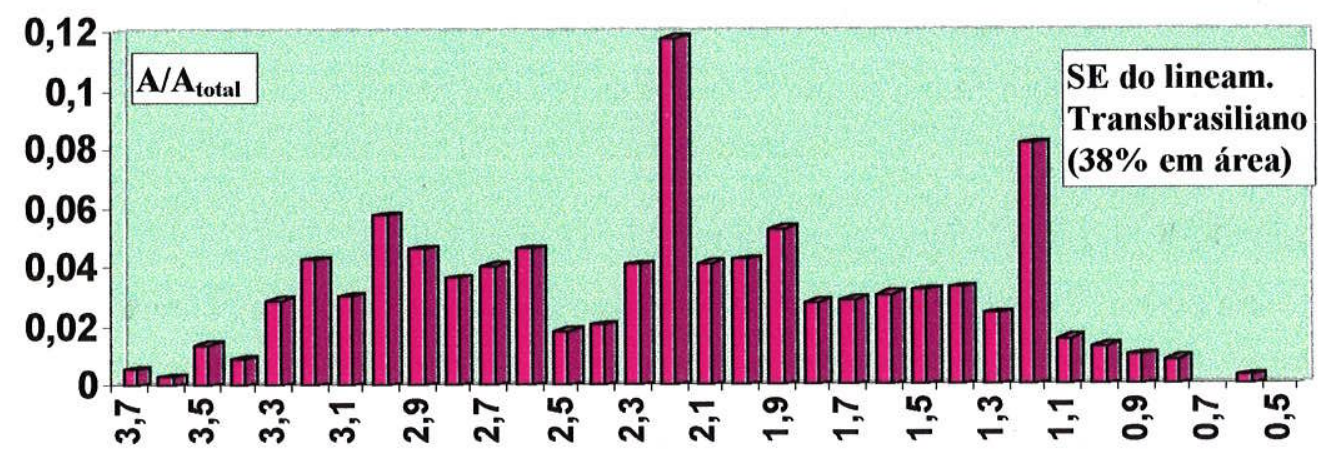

Fig. 6.5: Histograma (A) /( $\left.\mathrm{A}_{\text {total }}\right)$ em função do tempo geológico da porção $\mathrm{SE}$ do lineamento Transbrasiliano, onde (A) representam as áreas juvenis no tempo geológico e $\left(\mathrm{A}_{\text {total }}\right)$ corresponde a $38 \%$ da área da Plataforma Sul Americana. Os dados das áreas encontram-se na tab. 6.2.

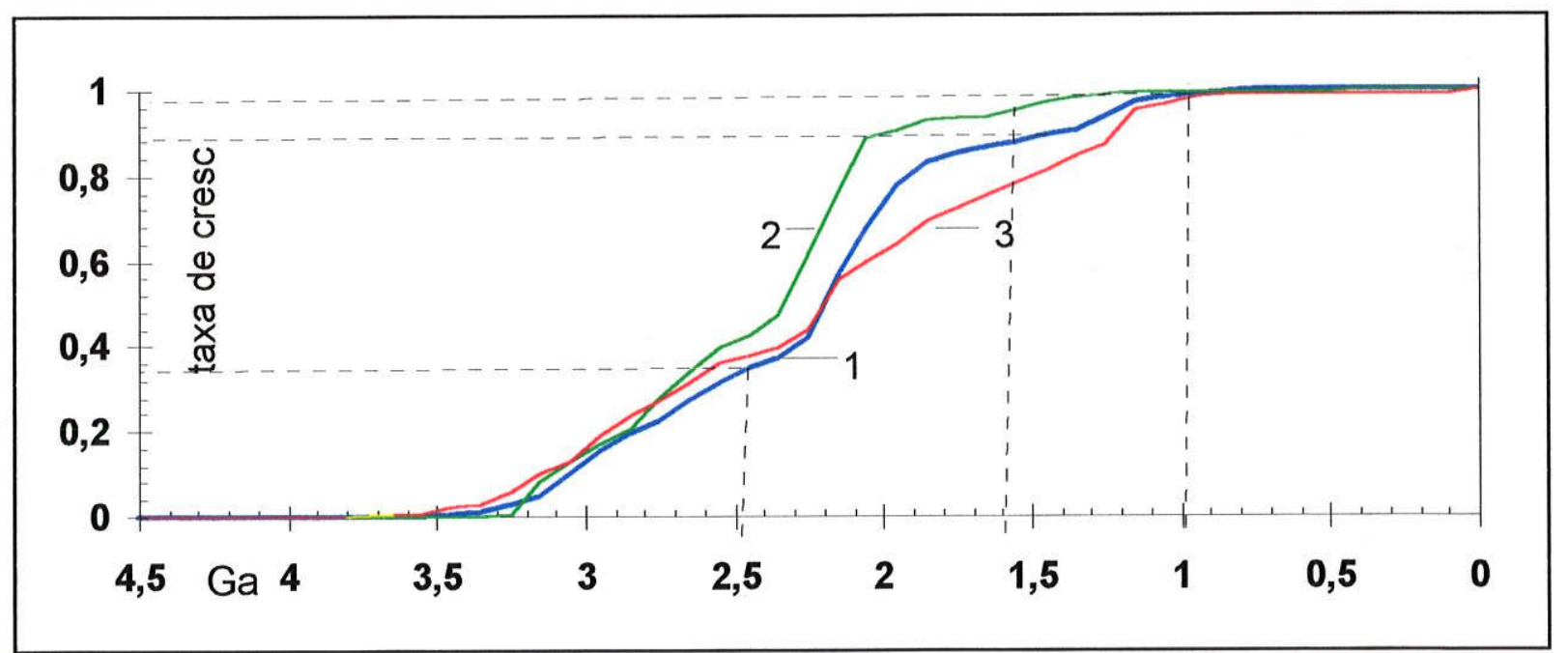

Fig. 6.6-Taxa de crescimento setorial para as crostas continentais separadas pelo Lineam. Transbasiliano. 1 - Plataforma Sul Americana; 2 - NW do Lineamento Transbasiliano; 3 - SE do Lineanmento Transbasiliano. Entre 2.2 e 1.9Ga ocorreu-se rápido crescimento na parção NW do lineamento, enquanto que na porção SE ocorreu de forma mais suave em toda a escala de tempo geológico. 


\section{3- IMPLICAÇÕES A RESPEITO DO VALOR INTERPRETATIVO DAS IDADES MODELO Sm-Nd}

Com base nos dados Sm-Nd apresentados no capítulo anterior podemos destacar os seguintes tópicos:

i) - A razão ${ }^{147} \mathrm{Sm} /{ }^{144} \mathrm{Nd}$ para a grande maioria (cerca de $80 \%$ ) das rochas granitóides da Plataforma Sul Americana variou entre 0,09 a 0,12 , correspondendo ao fator de

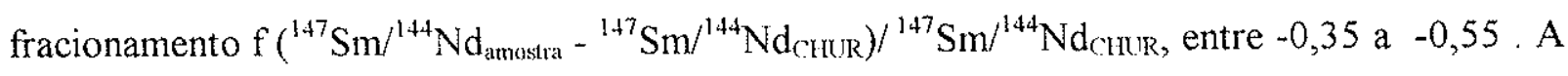
fig. 6.7 mostra a razão "f" das rochas granitóides (tipo TTGs) em função do tempo geológico. A relativa semelhança na razão $\mathrm{Sm} / \mathrm{Nd}$ nas rochas granitóides sugere que o processo relativo ao fracionamento geoquimico entre $\mathrm{Sm}$ e $\mathrm{Nd}$ parece não ter mudado significativamente ao longo do tempo geológico. Tal fato reflete diretamente a tendência para paralelismo nas linhas de evolução isotópica de Nd mostrada na fig. 6.8. Quando o fator "f" foge do valor $-0.45 \pm$ 0.10 , o presente autor sugere que teria ocorrido outro evento de fracionamento químico entre $\mathrm{Sm}-\mathrm{Nd}$, possivelmente durante fusão parcial de um protolito crustal já previamente reciclado e enriquecido. Neste caso será necessário usar o modelo de evolução isotópica de Nd em estágio duplo para o cálculo da idade $\mathrm{T}_{\mathrm{DM}}$.

ii) - Por causa da certa constância nas razões $\mathrm{Sm} / \mathrm{Nd}$ para as rochas granitóides, para a obtenção, a grosso modo, de sua idade modelo $\mathrm{Sm-Nd}$, basta saber apenas a razão ${ }^{143} \mathrm{Nd} /{ }^{144} \mathrm{Nd}$, por exemplo:

\begin{tabular}{ll|l}
\hline $\mathbf{1 4 3} \mathbf{N d} / \mathbf{1 4 4} \mathbf{N d}$ & \multicolumn{1}{c|}{$\varepsilon_{\mathbf{N d}}(\mathbf{t}=\mathbf{0})$} & \multicolumn{1}{|c}{ idade } \\
\hline$<\sim 0,5113$ & $<\sim-24$ & Arqueana \\
$\sim 0,511 \mathrm{a} \sim 0,5125$ & $\sim-24 \mathrm{a} \sim-13$ & Paleoproterozóica \\
$>\sim 0,5124$ & $\sim-13 \mathrm{a} \sim 0$ & Meso/Neoproterozóica \\
\hline
\end{tabular}

iii) - Rochas máficas-ultramáficas não são favoráveis para cálculos de idades modelo por possuirem razão ${ }^{147} \mathrm{Sm} /{ }^{344} \mathrm{Nd}$ muito próxima daquela do manto, ou seja os valores de $\mathrm{f}_{\mathrm{Sm} / \mathrm{Nd}}$ 
oscilam entre 0.35 a -0.35 (obs.: $\mathrm{f}=0$ significa que a amostra tem a mesma razão $\mathrm{Sm} / \mathrm{Nd}$ do manto CHUR, portanto a linha de evolução isotópica de $\mathrm{Nd}$ de tal amostra será paralela a do manto). Por outro lado as rochas meta-ultra-máficas são em geral, favoráveis para datação pelo método isocrônico devida à variação importante na razão ${ }^{147} \mathrm{Sm} /{ }^{144} \mathrm{Nd}$.

iv) - O diagrama $T_{R b-S r} \times T_{D M}$ ou $T_{C H U R}$ (fig. 6.9) para as rochas granitóides da tabela 6.3 mostra o seguinte comportamento:

$\begin{array}{lll}\mathrm{T}(\mathrm{Ga}) & \Delta \mathrm{T}=\mathrm{T}_{\mathrm{DM}}-\mathrm{T}_{\mathrm{Rb}-\mathrm{Sr}} & \Delta \mathrm{T}=\mathrm{T}_{\mathrm{CHUR}}-\mathrm{T}_{\mathrm{Rb}-\mathrm{Sr}} \\ & (\mathrm{Ga}) & (\mathrm{Ga}) \\ 3.5 & 0.15 & 0.08 \\ 2.5 & 0.20 & 0.05 \\ 1.6 & 0.25 & -0.07 \\ 1.0 & 0.28 & -0.12 \\ 0.0 & 0.35 & -0.25\end{array}$

v) Com relação à figura 6.9 , e à tabela 6.3 , é possivel verificar que diferença entre evento de acreção $\left(\mathrm{T}_{\mathrm{DM}}\right)$ e a idade de formação $\left(\mathrm{T}_{\mathrm{Rb}-\mathrm{Sr}}\right)$ da rocha. cresce com o tempo geológico. Durante o Arqueano a $3,5 \mathrm{Ga}$ o $\Delta \mathrm{T}$ está em torno de $0.10 \mathrm{Ga}$ enquanto que o presente dia o $\Delta \mathrm{T}$ está em torno de $0.30 \mathrm{Ga}$. Tais diferenças, entre o presente e o passado, podem estar relacionadas à velocidade das placas, muito mais rápidas durante o regime tectônico permóvel.

vi) A diferença entre idade modelo $T_{\text {CHUR }}$ (baseado em manto condrítico) e a idade de formação $\left(\mathrm{T}_{\mathrm{Rb}-\mathrm{Sr}}\right)$ diminui drasticamente com o tempo geológico. A rápida inflexão após $2,0 \mathrm{Ga}$ mostrada na fig. 6.9 pode estar relacionada a uma intensa retirada de material do manto superior para a crosta continental (ver fig. 6.1). 


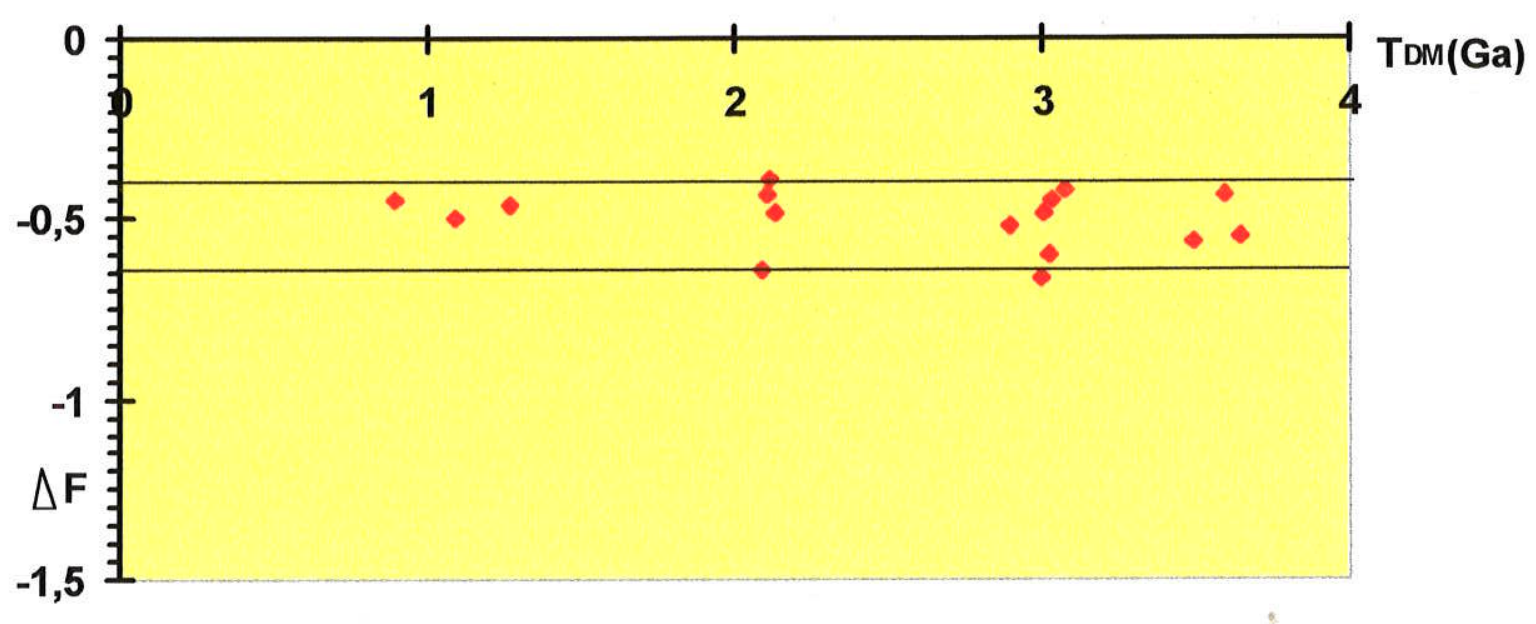

Fig. 6.7: DIAGRAMA $\mathrm{T}_{\mathrm{DM}} \mathrm{X} \mathrm{f}_{\mathrm{Sm} \text { INd. }}$ Rochas granitóides selecionadas (ver tabela 6.3).

Para as rochas granitóides os valores de $\mathbf{f}_{\mathrm{Sm} / \mathrm{Nd}}$, em geral variam entre $-0,50$ a $-0,40$.

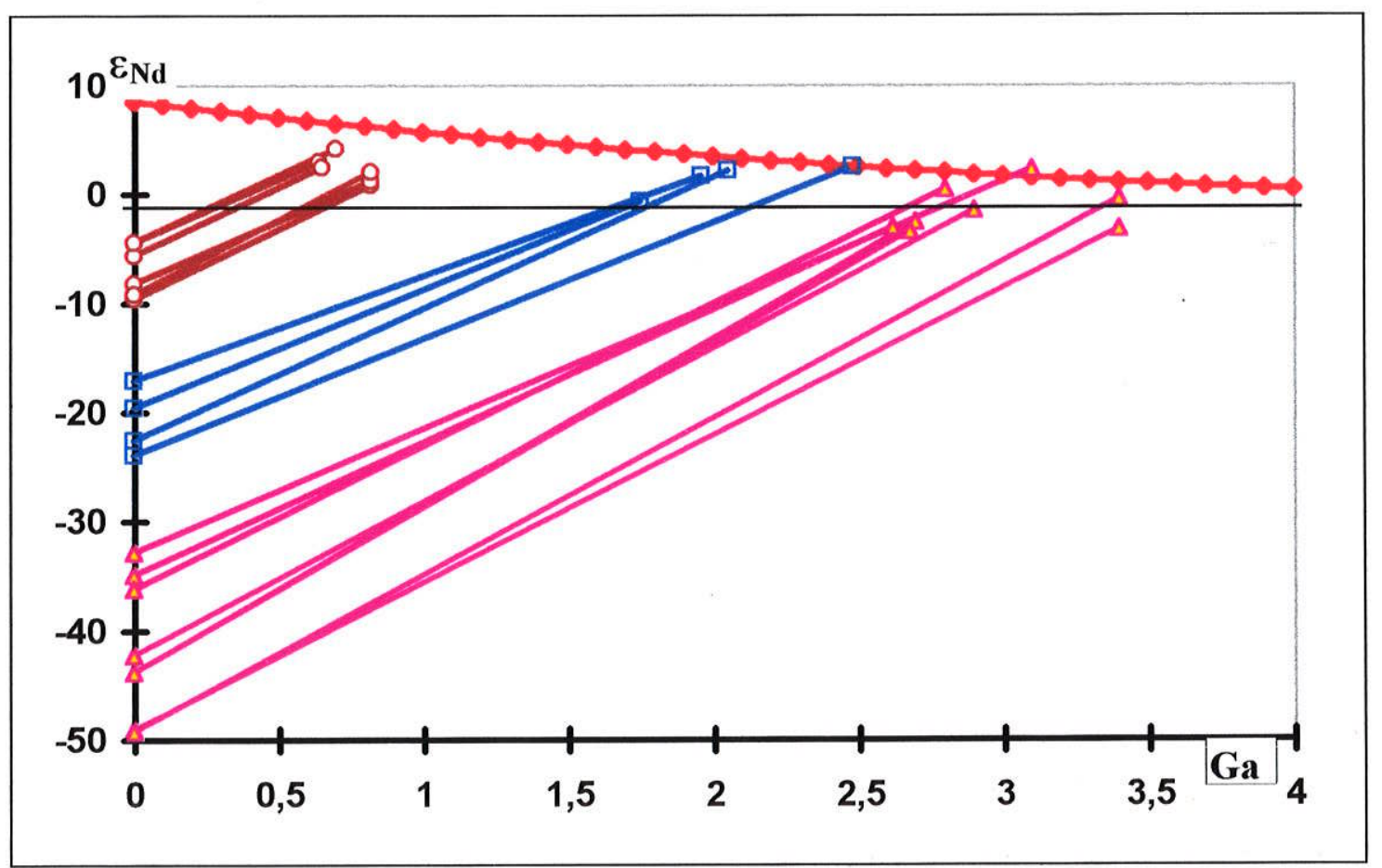

Fig. 6.8: DIGRAMA $\varepsilon_{\mathrm{Nd}} \times \mathrm{T}(\mathrm{Ga})$. Padrão de evolução isotópica de $\mathrm{Nd}$ para rochas granitóides selecionadas da Plataforma Sul Americana. As rochas foram escolhidas de tal forma que os valores de $\Delta\left(\mathrm{T}_{\mathrm{DM}}-\mathrm{T}_{\text {formąão }}\right)$ menores do que $0,30 \mathrm{Ga}$. Os dados isotópicos encontram-se na tab. 6.3 . 
TABELA 6.1: Números de datação pelo método Sm-Nd, idades modelo $\left(\mathrm{T}_{\mathrm{DN}}\right)$, por intervalo de tempo geológico e por : domínios geológicos.

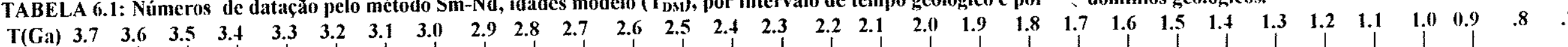

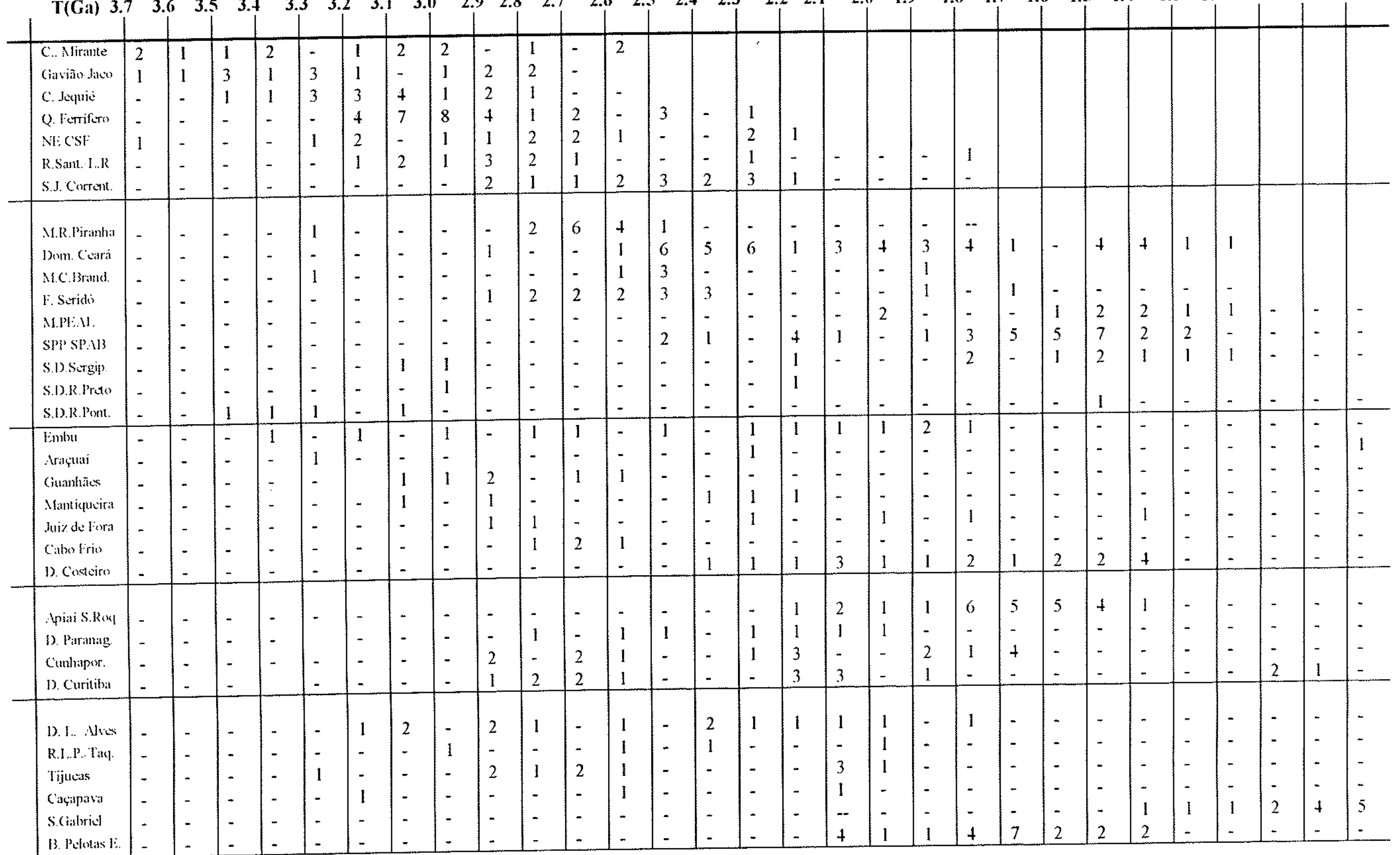


(continução da tab. 6.1)

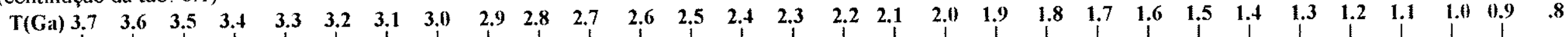

\begin{tabular}{|c|c|c|c|c|c|c|c|c|c|c|c|c|c|c|c|c|c|c|c|c|c|c|c|c|c|c|c|c|c|}
\hline $\begin{array}{l}\text { Amaz Cant. } \\
\text { Maroni - It. } \\
\text { Vutuari-I. } \\
\text { RN-Junuana } \\
\text { RO-Sunsás }\end{array}$ & $\begin{array}{l}- \\
- \\
- \\
-\end{array}$ & $\begin{array}{l}- \\
- \\
- \\
-\end{array}$ & $\begin{array}{l}- \\
- \\
- \\
-\end{array}$ & $\begin{array}{l}- \\
- \\
- \\
-\end{array}$ & $\begin{array}{l}- \\
- \\
- \\
- \\
\end{array}$ & $\begin{array}{l}- \\
- \\
- \\
- \\
-\end{array}$ & $\begin{array}{l}4 \\
2 \\
- \\
- \\
-\end{array}$ & $\begin{array}{l}2 \\
- \\
- \\
- \\
-\end{array}$ & $\begin{array}{l}2 \\
- \\
- \\
- \\
-\end{array}$ & $\begin{array}{l}2 \\
- \\
- \\
- \\
- \\
\end{array}$ & $\begin{array}{l}4 \\
- \\
- \\
- \\
-\end{array}$ & $\begin{array}{l}4 \\
- \\
- \\
-\end{array}$ & $\begin{array}{l}1 \\
- \\
1 \\
1 \\
- \\
\end{array}$ & $\begin{array}{l}- \\
1 \\
- \\
+ \\
-\end{array}$ & $\begin{array}{l}- \\
3 \\
1 \\
- \\
- \\
\end{array}$ & $\begin{array}{l}- \\
6 \\
2 \\
4 \\
- \\
\end{array}$ & $\begin{array}{l}- \\
3 \\
4 \\
4 \\
1\end{array}$ & $\begin{array}{l}- \\
- \\
3 \\
1 \\
3 \\
\end{array}$ & $\begin{array}{l}- \\
- \\
- \\
1 \\
-\end{array}$ & $\begin{array}{l}- \\
- \\
- \\
1 \\
2 \\
\end{array}$ & $\begin{array}{l}- \\
- \\
- \\
- \\
\end{array}$ & $\begin{array}{l}- \\
- \\
- \\
-\end{array}$ & $\begin{array}{l}- \\
- \\
- \\
- \\
\end{array}$ & $\begin{array}{l}- \\
- \\
- \\
- \\
-\end{array}$ & $\begin{array}{l}- \\
- \\
- \\
- \\
2\end{array}$ & $\begin{array}{l}- \\
- \\
- \\
- \\
\end{array}$ & $\begin{array}{l}- \\
- \\
- \\
- \\
1\end{array}$ & $\begin{array}{l}- \\
- \\
- \\
- \\
1\end{array}$ & $\begin{array}{l}- \\
- \\
- \\
- \\
1\end{array}$ \\
\hline $\begin{array}{l}\text { Cr. R.spa } \\
\text { Cr. S. I uis }\end{array}$ & - & - & - & - & - & - & - & - & - & - & - & - & - & $\begin{array}{l}1 \\
1\end{array}$ & - & - & - & $\begin{array}{l}3 \\
- \\
\end{array}$ & $\begin{array}{r}1 \\
- \\
\end{array}$ & -- & - & - & - & - & - & - & - & - & - \\
\hline $\begin{array}{l}\text { P. Araguaia } \\
\text { T(k:-Corcau }\end{array}$ & - & - & - & - & 1 & - & - & 3 & 2 & l & 3 & 1 & $2-$ & - & - & - & - & 1 & - & - & - & - & - & - & 1 & - & - & - & - \\
\hline $\begin{array}{l}\text { Crixás Rib. } \\
\text { fporáA } \mathrm{NIR}\end{array}$ & - & . & - & - & $\begin{array}{l}1 \\
-\end{array}$ & - & $\begin{array}{l}1 \\
-\end{array}$ & $\begin{array}{l}2 \\
-\end{array}$ & $\begin{array}{l}2 \\
- \\
\end{array}$ & - & - & - & - & $\begin{array}{r}1 \\
- \\
\end{array}$ & - & - & - & - & $\begin{array}{l}- \\
1\end{array}$ & - & - & - & $\begin{array}{l}1 \\
2 \\
\end{array}$ & - & 3 & + & $\begin{array}{l}- \\
5\end{array}$ & - & - \\
\hline $\begin{array}{l}\text { 3.A Ni Cann. } \\
\text { Natividacke } \\
\text { Paranã }\end{array}$ & - & - & $\begin{array}{l}- \\
- \\
-\end{array}$ & $\begin{array}{l}- \\
- \\
-\end{array}$ & $\begin{array}{l}- \\
- \\
-\end{array}$ & - & $\begin{array}{l}- \\
- \\
-\end{array}$ & $\begin{array}{l}- \\
- \\
-\end{array}$ & $\begin{array}{l}- \\
- \\
-\end{array}$ & $\begin{array}{l}- \\
- \\
1\end{array}$ & $\begin{array}{l}- \\
1 \\
1\end{array}$ & $\begin{array}{l}- \\
- \\
1 \\
\end{array}$ & $\begin{array}{l}- \\
- \\
-\end{array}$ & $\begin{array}{l}- \\
- \\
-\end{array}$ & $\begin{array}{l}- \\
1 \\
-\end{array}$ & $\begin{array}{r}2 \\
- \\
1\end{array}$ & $\begin{array}{l}3 \\
- \\
- \\
\end{array}$ & $\begin{array}{l}- \\
- \\
-\end{array}$ & $\begin{array}{r}- \\
1 \\
-\end{array}$ & $\begin{array}{l}- \\
- \\
-\end{array}$ & $\begin{array}{l}- \\
- \\
-\end{array}$ & $\begin{array}{l}- \\
- \\
-\end{array}$ & $\begin{array}{l}1 \\
- \\
-\end{array}$ & $\begin{array}{l}- \\
- \\
-\end{array}$ & $\begin{array}{l}- \\
- \\
-\end{array}$ & $\begin{array}{l}1 \\
- \\
-\end{array}$ & $\begin{array}{l}- \\
- \\
-\end{array}$ & $\begin{array}{l}- \\
- \\
-\end{array}$ & $\begin{array}{l}- \\
- \\
\end{array}$ \\
\hline 1). Brasilia & - & - & - & - & - & - & - & - & - & - & - & - & - & $=$ & - & - & - & - & - & - & - & - & - & 1 & 1 & 2 & - & 1 & - \\
\hline $\begin{array}{l}\text { 1). Araxi } \\
\text { NESC } \\
\text { FARcirande }\end{array}$ & - & - & - & $\begin{array}{l}- \\
-\end{array}$ & $\begin{array}{l}- \\
- \\
-\end{array}$ & $\begin{array}{l}- \\
- \\
1\end{array}$ & $\begin{array}{l}- \\
-\end{array}$ & $\begin{array}{l}- \\
-\end{array}$ & - & $\begin{array}{l}- \\
- \\
-\end{array}$ & - & $\begin{array}{l}- \\
- \\
-\end{array}$ & $\begin{array}{l}- \\
- \\
-\end{array}$ & $\begin{array}{l}- \\
-\end{array}$ & $\begin{array}{l}- \\
-\end{array}$ & $\begin{array}{l}- \\
1 \\
1\end{array}$ & $\begin{array}{l}2 \\
1 \\
-\end{array}$ & $\begin{array}{l}- \\
5 \\
-\end{array}$ & $\begin{array}{l}2 \\
2 \\
-\end{array}$ & $\begin{array}{l}- \\
2 \\
-\end{array}$ & $\dot{1}$ & $\begin{array}{l}- \\
4 \\
-\end{array}$ & $\begin{array}{l}- \\
2 \\
-\end{array}$ & $\begin{array}{l}1 \\
1 \\
-\end{array}$ & $\begin{array}{l}3 \\
- \\
-\end{array}$ & - & $\begin{array}{l}- \\
1 \\
-\end{array}$ & - & $\begin{array}{l}- \\
-\end{array}$ \\
\hline TOTiL & 4 & 2 & 6 & 6 & 14 & 16 & 28 & 26 & 34 & 28 & 33 & 28 & 28 & 19 & 28 & 39 & 43 & 31 & 22 & 30 & 29 & 21 & 28 & 22 & 18 & 14 & 12 & 10 & 7 \\
\hline
\end{tabular}

Obs.: Considerado apenas uma idade por afloramento. 


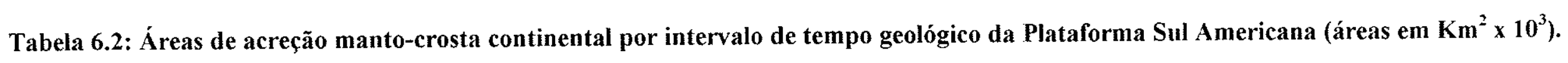

\begin{tabular}{|c|c|c|c|c|c|c|c|c|c|c|c|c|c|c|c|c|c|c|c|c|c|c|c|c|c|c|c|c|c|c|}
\hline$T(G a)$ & 3.7 & & 5 & .4 & 3.33 . & & & 0 & .9 & .8 & .7 & 6 & & & .3 & 2 & 2.1 & 2.0 & 1.9 & .8 & .7 & .6 & 1.5 & 1.4 & 1.3 & 1.2 & 1.1 & .0 & 0.90 .8 & |área \\
\hline C.. Mirante & 2.8 & 1.4 & 1.4 & 2.9 & -- & 1.4 & 2.9 & 2.9 & - & 1.4 & -- & 2.9 & - & - & - & -- & -- & - & - & - & - & - & $m$ & -- & - & - & - & - & -- & 20 \\
\hline GaviãolJac. & 9.3 & 9.3 & 28 & 9.3 & 28 & 9.3 & -- & 9.3 & 18.6 & 18.6 & -. & -- & -- & -- & -- & -- & -- & -- & - & - & -- & -- & - & -- & -- & -- & -- & -- & -- & 140 \\
\hline C. Jequié & -- & -- & 8 & 8 & 16 & 24 & 32 & 8 & 16 & 8 & -- & -- & $\ldots$ & -- & - & -- & -- & - & -- & - & - & -- & -- & - & -- & -- & -- & -- & - & 120 \\
\hline Q. Ferrifero & -- & $\ldots$ & -- & -- & -- & 8 & 14 & 16 & 8 & 2 & 4 & -- & 6 & -- & 2 & - &.- & -- & -- & -- & - & -- & -- & - & -- &.- & -- & -- & -- & 60 \\
\hline $\mathrm{NECSF}$ & 6.4 & - & -- & -- & 6.4 & 12.9 & -- & 6.4 & 6.4 & 12.9 & 12.9 & 6.4 & - & -- & 12.9 & 6.4 & -- & -- & - & -- & - & - & -- & - & -- & - & -- & -- & - & 90 \\
\hline R.Sant.LR & -- & -- & -- & -- & -- & 6.2 & 12.3 & 3.2 & 18.5 & 12.3 & 6.2 & -- & -- & -- & 6.2 & -- & 6.2 & -. & - & 6.2 & -- & -- & - & -- & -- & -. & $\cdots$ & -- & -- & 80 \\
\hline S.J./Corrent & - & - & -- & -- & -- & -- & -- & - & 6.7 & 3.3 & 3.3 & 6.7 & 10 & 6.7 & 10 & 3.3 & -- & - & -- & - & - & -- & - & - & -- & -- & - & - & $=$ & 50 \\
\hline MR.Pir. & - & - & - & - & 5 & $\ldots$ & - & - & - & 10 & 30 & 20 & 5 & - & - & -- & -- & - & - & - & - & - & - & $\ldots$ & - & - & -- & - & - & 70 \\
\hline Dom. Ceará & -- & - & -- & -- & -- & - & -- & 2 & 2 & 6 & 6 & 4 & 10 & 10 & 12 & 2 & 6 & 8 & 6 & 6 & 8 & 2 & -- & 8 & 8 & 2 & 2 & -- & -- & 110 \\
\hline M.C.Brand. & -- & -- & -- & -- & 2.5 & -- & - & - & -- & -- & - & 2.5 & 7.5 & -- & -- & -- & -- & - & 2.52 & -- & - & -- & -- & -- & -- & - & -- & -- & -- & 15 \\
\hline F. Seridó & -- & -- & - & -- & -- & $\cdots$ & -- & - & 1 & 2 & 2 & 2 & 3 & - & - & -- & $\ldots$ & - & 1 & -- & 1 & -- & -- & -- & - & - & -- & -- & -- & 15 \\
\hline MPEAL. & - & -- & -- & -- & -- & -- & -- & - & - & -- & $\ldots$ & -- & -- & -- & -- & - & - & 15.6 & - & - & -- & 7.8 & 15.6 & 15.6 & 7.8 & 7.8 & -- & -. & -- & 70 \\
\hline SPP/SPAB & - & -. & -- & -- & -- & -- & -- & - & -- & -. & -- & -- & 4.8 & 2.4 & -. & 9.7 & 2.4 & -- & 2.4 & 7.3 & 12.1 & 17 & 17 & 4.9 & 4.9 & -. & -- & -- & -- & 80 \\
\hline S.D.Sergip. & -. & -- & -- & -. & -- & -- & 5 & 5 & -- & -- & -- & -- & -- & -- & -- & 5 & - & - & -- & 10 & - & 5 & 10 & 5 & 5 & 5 & -- & -- & -- & 55 \\
\hline S.D.R.Preto & -- & -. & -- & -- & -- & -- & -. & 25 & -- & -- & - & -- & -- & -- & -- & 25 & - & -- & - & - & -- & -. & -- & -- & - & -- & -- & -- & -- & 50 \\
\hline S.D.R.Pont. & $\ldots$ & -- & 10 & 10 & 10 & -- & 10 & -- & -- & -- & - & -- & -- & -- &.- & -- & - & -- & - & - & - & - & 10 & -- & - & -- & -- & $\ldots$ & -- & 50 \\
\hline Fambu & - & - & -- & 1 & $\cdots$ & 1 & -- & 1.2 & $\ldots$ & 1.2 & 1.2 & -- & 1.2 &.- & 1.2 & 1.2 & 1.2 & 1.2 & 2.3 & 1.2 & - & - & -- & - & - & - & -- & -. & - & 15 \\
\hline Araçııali & -- & -- & -. & - & 17.5 & - & -- & - & -- & -- & -- & -- & -- & -- & 17.5 & -- & -- & -- & -- & - & - & - & - & - & -- & - & -- & -- & 17.5 & 70 \\
\hline Guanhães & -- & -- & -- & - & -- & -- & 5 & 5 & 10 & $\ldots$ & 5 & 5 & - & -- & -- & - & -- & $-\cdots$ & - & - & -- & -- & -- & - & -- & -- & -- & -- & $m$ & 30 \\
\hline Manticueira & -. & -- & -- & -. & -. & -- & 4 & 0 & 4 & -- & -- & -. & - & 4 & 4 & 4 & -- & - & -- & -- & $\ldots$ & -- & -- & - & -- & -- & -- & - & -- & 20 \\
\hline Juiz de Fora &.- & -- & -- & -- & -- & $\ldots$ & -. & -- & 6.7 & 6.7 & -- & -- & -- & -- & 6.7 & $\ldots$ & -- & 6.7 & -- & 6.7 & -- & -. & - & 6.7 & -- & -- & -- & - & - & 40 \\
\hline Cabo Frio & -- & - & .- & -- & -- & -- & -- & $\ldots$ & - & 1.3 & 2.5 & 1.3 & -- & -- &.- & -- & -- & -- & -- & -- & -- & -- & - & - & -- & -- & - & -- & $\rightarrow$ & 5 \\
\hline D. Costeiro & -- & -- & - & -- & -- & -. & - & - & -- & & - & - & - & 9.2 & 9.2 & 9.2 & 27.6 & 9.2 & 9.2 & 18.4 & 9.2 & 18.4 & 18.4 & 36.4 & -- & - & -- & - & -- & 174 \\
\hline S.Roque & - & - & -- & -- & -- & -- & - & - & - & - & $\ldots$ & $\ldots$ & - & -- & - & 2.1 & 4.2 & 2.1 & 2.1 & 12.5 & 10.4 & 6.2 & 8.3 & 2.1 & $\cdots$ & $\ldots$ & - & - & -- & 50 \\
\hline D. Paranag. & - & -- & -- & -- & - & -- & - & -- & -- & $\ldots$ & - & 7.1 & 7.1 & -- & 7.1 & 7.1 & 7.1 & 7.1 & - & -- & -- & -- & -- & -- & -- & -- & -- & -- & -- & 50 \\
\hline Cunh Curit & -. & - & -- & $\ldots$ & - & - & - & - & 26.5 & 17.6 & 35.3 & 17.6 & - & - & 26.5 & 26.5 & 26.5 & -- & 26.5 & 8.8 & 35.3 & - & - & - & -- & - & 17.6 & 8.82 & -- & 274 \\
\hline D. L. Alves & -- & -- & $\ldots$ & -- & -- & 3.5 & 7 & - & 7 & 3.5 & $\ldots$ & 3.5 & - & 7 & 3.5 & 3.5 & 3.5 & 3.5 & - & 3.5 & - & $\cdots$ & -- & - & -- & - & -- & -. & -- & 49 \\
\hline R.LP.Taq & -- & -- & -- & -- & - &.- & - & 27.5 & -- & - & -- & 27.5 & - & 27.5 & -- & -- & -. & 27.5 & -. & -. & -- & $\ldots$ & -- & -- & -- & -- & - & -- & - & 110 \\
\hline S.Gabriel & - & -. & -- & - & -- & -- & -- & - & - & -- & -- & -- & $\ldots$ & -- & - & - & -- & -- & - & - & -- & $\ldots$ & - & - & -- & - & -- & -. & -- & 49 \\
\hline Caçapava & - & - & - & $-m$ & -- & 1.7 & - & $\ldots$ & -. & -- & $\overline{--}$ & 1.7 & - & -- & - & -- & 1.7 & - & - & -- & - & - & -- & 3.3 & 3.3 & 3.3 & 6.5 & 13.1 & 16.3 & 5 \\
\hline Tijucas & $\ldots$ & - & -- & -- & 2.7 & -- & -- & - & 5.5 & 2.7 & 5.5 & 2.7 & - & -- & -- & -- & 8.2 & 2.7 & -- & -- & - & - & -- & -- & -- & -- & -- & -- & -- & 30 \\
\hline B. Pelotas & -. & - & -- & -- & -- & -- & ... & -- & -- & -- & - & - & - & -- & -- & -- & 12.2 & 3 & 3 & 12 & 21 & 6 & 6 & 6 & + & - & -- & -- & -. & 69 \\
\hline
\end{tabular}

ver nota explicativa na página seguinte. 
Continuação da tab. 6.2

\begin{tabular}{|c|c|c|c|c|c|c|c|c|c|c|c|c|c|c|c|c|c|c|c|c|c|c|c|c|c|c|c|c|c|c|}
\hline $\mathrm{T}(\mathrm{G} a)$ & 7 & & & .4 & .3 & 3. & 1 & 0 & .9 & 2.8 & 7 & .6 & .5 & 4 & .3 & .2 & .1 & 2.0 & .9 & & .7 & .6 & .5 & 1.4 & 1.3 & 1.2 & 1 & 0 & 0.9 & $\begin{array}{l}0.8 \\
\text { área } \\
\end{array}$ \\
\hline Crix./Rib/G & - & -- & - & - & 7.7 & - & 11.5 & 7.7 & 7.7 & -- & - & -- & 7.7 & - & 3.9 & - & - & -- & -- & - & - & - & 6.3 & -- & - & - & - & -- & - & 52 \\
\hline Iporá/A/MR & - & -- & - & -- & - & -- & -- & - & - & -- & - & $\cdots$ & - & -- & -- & 5 & - & -- & 5 & - & -- & $m$ & 10 & 5 & 15 & 20 & 25 & 15 & - & 100 \\
\hline $\mathrm{B} . \mathrm{A} / \mathrm{N} / \mathrm{Can}$ & -. & - & -- & $\cdots$ & -- & $\cdots$ & -- & $\cdots$ & - & -- & $\ldots$ & - & $\ldots$ & - & $-m$ & 8.6 & 13 & $\ldots$ & - & -- & - & -- & 4.3 & - & -- & 4.3 & - & - & -- & 30 \\
\hline Natividade & - & -- & - & -- & -- & -- & -- & -- & - & -- & 16.7 & - & -- & -- & 16.7 & -- & -- & -- & 16.7 & - & -- & -- & -- & -- & -- & - & - & - & -- & 50 \\
\hline Paranãt & -. & - & -- & -- & -- & -. & -- & - & -- & 7.5 & 7.5 & 7.5 & -. & -- & $-\cdots$ & 7.5 & -- & - & -- & -- & -- & -- & -- & -- & - & -- & -- & -- & -- & 30 \\
\hline D. Brasilia & -. & -- & -- & - & -- & - & -- & - & -- & -- & - & -- & - & -- & - & -- & -- & 50 & - & -- & -- & - & -- & 8.3 & 8.3 & 16.7 & - & 8.3 & -- & 100 \\
\hline D. Araxá & - & - & - & -- & -. & -- &.- & $\ldots$ & -- & - & -- & - & -- & -- & - & -- & 20 & -- & 20 & - & - & -- & - & 10 & 30 & $\cdots$ & - & -- & - & 80 \\
\hline $\mathrm{NESG}$ & - & - & - & - & -- & $-\cdots$ & -- & - & $\cdots$ & - & - & -- & $\cdots$ & -- & $-\cdots$ & 2 & 2 & 10 & 4 & 4 & 2 & 8 & 4 & 2 & -- & - & 2 & -- & - & 40 \\
\hline F.ARGrande & - & - & -- & - & - & 13.3 & - & - & 13.3 & - & -- & - & -- & - & -- & 13 & - & - & - & $\cdots$ & - & - & - & - & - & -- & -- & - & $\ldots$ & 40 \\
\hline Sul Iporá & - & $\ldots$ & - & -- & - & 15 & -- & 15 & $\cdots$ & - & $\ldots$ & -- & -- & - & - & 80 & - & -- & - & - & - & - & -- & - & -- & 80 & - & -- & - & 190 \\
\hline Oeste Araxá & - & - & -- & -- & - & 20 & - & 20 & - & -. & -- & -- & -- & -- & -- & 100 & .. & -- & -- & - & -- & - & -- & -- & -- & 100 & -- & - & -- & 240 \\
\hline B. Pamaiba & - & - & -- & - & -- & 50 & - & 50 & -- & - & -- & - & -- & - & - & 20 & -- & -- & 200 & - & - & - & 50 & -- & -- & 50 & - & -- & - & 600 \\
\hline Am. Central & - & -. & - & -- & - & - & 293 & 146 & 146 & 146 & 292 & 293 & 73 & -- & - & -- & -- & - & - & $\cdots$ & - & - & $\overline{--}$ & - & -- & - & -- & - & -- & 1389 \\
\hline MA-IT & - & -- & -- & -- & -- & -. & 129 & - & -- & - & -- & -- & -- & 65 & 194 & 388 & 194 & - & $\cdots$ & -- & -- & -- & - & -- & -- & -- & -- & - & -- & 970 \\
\hline VE-TA & -- & -- & -- & -- & -- & - & -- & - & -- & -- & -- & - & 77 & - & 77 & 155 & 309 & 232 & $\ldots$ & -. & -- & - & -- & -- & -- & -- & -- & -- & -- & 850 \\
\hline $\mathrm{RNI}$ & -- & - & -- & -- & - & -- & -- & -- & - & -- & - & -- & 73 & -- & - & 290 & 290 & 73 & 73 & 73 & -- & - & -- & -- & -- & -- & - & -- & -- & 870 \\
\hline RO-SU & -- & -- & -. & - & -- & -. & -- & - & -- & - & -- & $\ldots$ & -- & - & -- & - & 48 & 143 & - & 96 & 48 & -- & 96 & - & 5.3 & 7.9 & 2.7 & 2.7 & 2.7 & 452 \\
\hline Cr. R.Apa & -- & - & -- & - & -- & -- & - & - & $\cdots$ & - & - & -.- & - & 20 & $\rightarrow$ & -- & - & 60 & 20 & $-m$ & -- & -- & - & - & - & -- & -- & -- & -- & 100 \\
\hline Cr. S. Luis & -- & - & -- & -- & - & -- & -- & -- & - & -- & - & -- & -. & 25 & -- & -- & 25 & -- & -- & - & -- & -- & -- & -- & -- & -- & + & -- & -- & 50 \\
\hline P. $/ \mathrm{Arag} / \mathrm{Cor}$ & -- & - & -- & - & 53 & - & - & 106 & 106 & - & -- & -. & - & -- & -- & - & -- & 159 & - & -- & - & -- & - & - & 106 & -- & -- & - & - & 530 \\
\hline $\begin{array}{l}\text { área } x \\
10^{3} \mathrm{Km}^{2}\end{array}$ & 18 & 11 & 47 & 31 & 149 & 166 & 526 & 459 & 410 & 270 & 431 & 411 & 285 & 249 & 411 & 1354 & 1008 & 813 & 393 & 265 & $1+7$ & 116 & 206 & 113 & 194 & 297 & 56 & 48 & 37 & 8879 \\
\hline $\begin{array}{l}\text { área total } \\
\text { em }(\%)\end{array}$ & 0.2 & 0.1 & 0.6 & 0.3 & 1.7 & 1.9 & 5.9 & 5.2 & 4.6 & 3.0 & 4.8 & 4.6 & 3.2 & 2.0 & 4.6 & 15.2 & 11.4 & 9.1 & 4.4 & 3.0 & 1.7 & 1.3 & 2.3 & 1.3 & 2.2 & 3.3 & 0.6 & 0.5 & 1.4 & 99 \\
\hline $\begin{array}{l}\text { SE linean- } \\
\text { Transb- }(\%)\end{array}$ & 0.5 & 0.3 & 1.4 & 0.9 & 2.9 & 4.3 & 3.0 & 8.8 & 4.6 & 3.6 & 4.0 & 4.6 & 1.8 & 2.0 & 4.1 & 11.7 & 4.1 & 4.3 & 5.3 & 2.8 & 2.9 & 3.1 & 3.2 & 3.3 & 2.4 & 8.2 & 1.6 & 1.3 & 1.0 & 98 \\
\hline $\begin{array}{l}\text { NW Lineam. } \\
\text { Transb-(\%) }\end{array}$ & $\cdots$ & - & -- & -- & 0.9 & $\cdots$ & 7.7 & 5.4 & 4.5 & 3.6 & 8.0 & 6.3 & 5.9 & 2.0 & 5.0 & 15.2 & 15.9 & 10.2 & 3.5 & 2.1 & 1.8 & -- & 1.0 & - & 1.0 & 0.1 & 0.05 & $\begin{array}{l}0.0 \\
5 \\
\end{array}$ & \begin{tabular}{l|}
0.0 \\
5
\end{tabular} & 100 \\
\hline
\end{tabular}

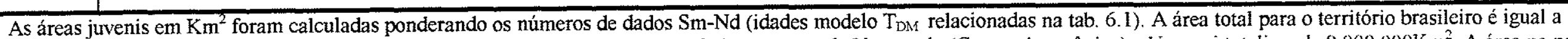

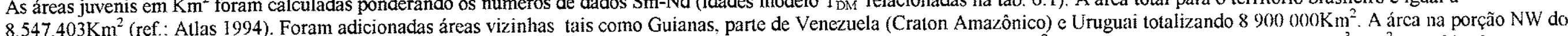

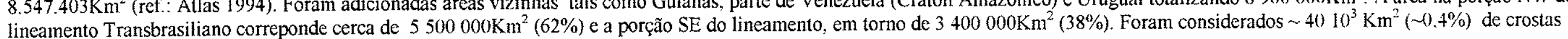
juvenis com idades menores que $0,8 \mathrm{Ga}$ (não relacionadas na tabela). 


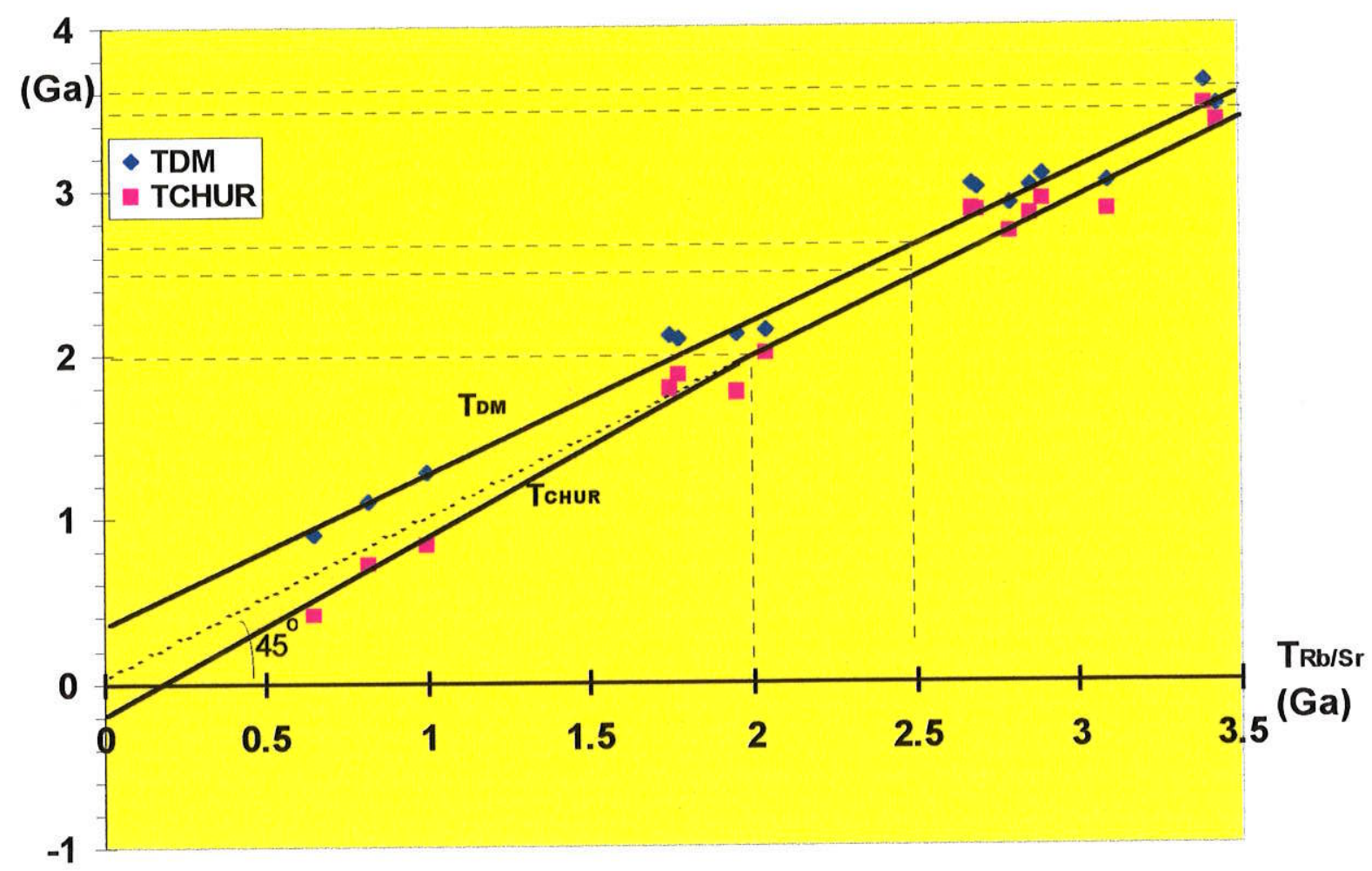

Fig. 6.9 : DIAGRAMA $\mathrm{T}_{\mathrm{Rb}-\mathrm{Sr}} \mathrm{X} \mathrm{T}_{\mathrm{DM}}$ e $\mathrm{T}_{\mathrm{Rb}-\mathrm{Sr}} \mathrm{X} \mathrm{T}_{\mathrm{CHUR}}$. Rochas granitóides selecionadas da Plataforma Sul Americana(ver tabela 6.3 abaixo).

\begin{tabular}{|c|c|c|c|c|c|c|c|c|}
\hline REGIÃO & Ident. & Tab. & $T_{\text {(Formação) }}$ & TDM & CHUR $f$ & $S \mathrm{~m} / \mathrm{Nd}$ & $\varepsilon_{N d}(0) \varepsilon$ & $d\left(T_{F}\right)$ \\
\hline S.Voltas - Craton S. Francisco & $\mathrm{A} 1, \mathrm{~A} 3, \mathrm{~A} 4$ & $5.6-1$ & $3,4^{*}$ & 3,65 & 3,5 & $-0,55$ & -49.1 & -2.2 \\
\hline B.Vista - Craton S. Francisco & E1 e E6 & $5.6-1$ & $3,44^{*}$ & 3,5 & 3,4 & $-0,56$ & -49.2 & -0.3 \\
\hline Cupixi - PMI -Craton Amazônico & $\mathrm{GeH}$ & $5.2-2$ & $2,9^{*}$ & 3,08 & 2,93 & $-0,42$ & -42.2 & -0.9 \\
\hline N. Eldorado- PAC -Craton Amazônico & $E$ e $F$ & $5.2-1$ & $2,7^{*}$ & 3,0 & 2,86 & $-0,66$ & -43.8 & 2.95 \\
\hline R. Maria- PAC -Craton Amazônico & D & $5.2-1$ & $3,1^{*}$ & 3,04 & 2,86 & $-0,45$ & -32.8 & 2.4 \\
\hline R. Maria- PAC -Craton Amazônico & A & $5.2-1$ & $2,68^{*}$ & 3,03 & 2,87 & $-0,60$ & -43.8 & -3.3 \\
\hline B. Horizonte - Craton S. Francisco & S2 & $5.6-9$ & $2,86^{* *}$ & 3,01 & 2,84 & $-0,48$ & -34.9 & -3.0 \\
\hline Taquarembo - Sul do Brasil & B & $5.13-2$ & $2,8^{*}$ & 2,9 & 2,73 & $-0,52$ & -36.2 & 0.5 \\
\hline Tapajós- PVT - Craton Amazônico & $\mathrm{GeH}$ & $5.2-3$ & $1,96^{*}$ & 2,12 & 1,77 & $-0,39$ & -17.1 & 1.7 \\
\hline N Manaus -PVT- Craton Amazônico & $B$ & $5.2-3$ & $1,78^{*}$ & 2,09 & 1,87 & $-0,64$ & -30.4 & -1.6 \\
\hline N Manaus -PVT- Craton Amazônico & C & $5.2-3$ & $1,75^{*}$ & 2,11 & 1,79 & $-0,43$ & -19.6 & -0.6 \\
\hline Mansidão - Craton S. Francisco & $\mathrm{D}$ & $5.6-11$ & $2,05^{*}$ & 2,14 & 2,0 & $-0,48$ & -22.6 & 2.2 \\
\hline S.Gabriel - Sul do Brasil & $C, D, F$ e J & $5.13-2$ & $0,65^{*}$ & 0,9 & 0,4 & $-0,45$ & -5.6 & 2.5 \\
\hline Arenópolis - Compl. Goiás Central & $01,02,03$ & $5.9-2$ & $0,82^{*}$ & 1,1 & 0,71 & $-0,5$ & -9.0 & 1.4 \\
\hline$S$ de L.Sienitóide-SPP-P. Borborema & $\mathrm{F}$ & $5.7-5 \mathrm{~A}$ & $1,0^{* *}$ & 1,28 & 0,84 & $-0,46$ & -9.7 & -1.0 \\
\hline
\end{tabular}

Tab. 6.3: Idades modelo $\mathrm{Sm}-\mathrm{Nd}\left(\mathrm{T}_{\mathrm{DM}}\right.$ e $\left.\mathrm{T}_{\mathrm{CHUR}}\right)$, idades $\mathrm{Rb}-\mathrm{Sr}$ e $\mathrm{f}_{\mathrm{Sm}-\mathrm{Nd}}$ das rochas granitóides (tipo TTGs) da Plataforma Sul Americana. Selecionadas apenas rochas granitóides com $\Delta \mathrm{T}\left(\mathrm{T}_{\mathrm{DM}}-\mathrm{T}_{\text {formação }}\right)$ $<0.3 \mathrm{Ga}$ e $\varepsilon_{\mathrm{Nd}}\left(\mathrm{T}_{\mathrm{F}}\right)>-3.0$ onde $\mathrm{T}_{\mathrm{F}}$ é. a idade de formação. Os dados das colunas $\mathrm{T}_{\mathrm{DM}}, \mathrm{T}_{\mathrm{CHUR}}, \varepsilon_{\mathrm{Nd}}\left(\mathrm{T}_{\mathrm{F}}\right)$ e $\varepsilon_{\mathrm{Nd}}(0)$ são valores médios das amostras relacionadas na coluna "ident.". A coluna "Tab." indica onde econtrar os dados Sm-Nd completos destas amostras no capítulo 5 .

Observação: * = Idade Rb-Sr; ** = Idade U-Pb (zircão). 


\section{REFERÊNCIAS BIBLIOGRÁFICAS}




\section{BIBLIOGRAFIAS}

Alibert, C. e Barbosa, J.S.F. - 1992 Ages U-Pb determiné a la SHRIMP des zircons du complexe de Jequié, Craton du S. Francisco, Bahia, Brésil, 14 reunion de Sciences de la Terre (RST). Toulouse * France, $\mathrm{p} 4$.

Alibert, C.; Barbosa, J.S.F.; Marinho, M.M. e Vidal, Ph. (in preparation). Le zonation des ages modeles $T_{D M}$ Nd dans le craton du S. Francisco, entre la Catê Atlantique e la Cinture Volcano-Sedimentaire de Contendas-Mirante.

Almeida, F.F.M. - 1965 - Geologia da Serra da Bodoquena. Bol. 219, Div. Geol. Min., DNPM, Rio de Janeiro.

Almeida, F.F.M. - 1967 - Nota sobre o Précambriano na região central de Goiás. Bol. Paran. De Geoc. (26): 19-22. Curitiba.

Almeida, F.F.M. - 1968 - Evolução tectônica do centro-oeste brasileiro no Proterozóico Superior. Am. Acad. Bras. Ciên., 40: 285-295

Almeida, F.F.; Amaral, G.; Cordani, U.G. e Kawshita, K. - 1973 - The Precambriam evolution of the South American Cratonic Margin South the Amazon River. In: Nair e Stehlz eds. The Ocean Basin and Margins, Plenum, p 141-1446, New York.

Almeida, F.F.M; Hasui, Y. e Neves, B.B. - 1976 - The upper Precambrian of South America. B. Inst. Geoc. USP, 7. 75-117.

Almeida, F.F.M de e Litiwinski, N. - 1984 - Província Mantiqueira. In: O Pré-Cambriano do Brasil. Coordernadores Fernando F.M. de Almeida e Yociteru Hasui. Editora Edgard Blücher Ltda. .282306

Almeida, F.F.M - 1993- Limites do Craton do S.Francisco em M. Gerais. Síntese de Conhecimentos.Anais do II Simp. do CSF, Salvador,p256-259.

Anderson. D. L. - 1989 - Theory of the Earth. Blackwell Scientific Publications, 366p.

Armstrong, R.L. - 1981 - Radiogenic isotopes: the case for crustal recycling on a near-steady-state nocontinental-growth Earth. Philosophical Transactions of the Royal Societh of London. Series A.V. $301, N^{0} \cdot 1461, \mathrm{p}-443-472$.

Artur, A.C. - 1980 - Rochas metamórficas dos arredores de Itapira, SP. Dissertação de Mestrado, IG-USP, $193 p$

Artur, A. C. - 1988 - Evolução policíclica da infra-estrutura da porção sul do Estado de Minas Gerais e regiões adjacentes do Estado de São Paulo. Tese de doutoramento. IG-USP, 231p.

Artur, A.C.; Wernick, E.; Kawashita, K - 1988 - Geocronologia de unidades litoestratrigráficas do embasamento cristalino da região sul de Minas Gerais e áreas adjacentes do Estado de São Paulo. Congr. Bras. de Geol., 35, Belém, SBG, v6, p2854-2869.

Babinski, M.; Chemale Jr. F.; Hartmann, L. A ; Van Schmus, W.R. e Silva, L.C. - 1996 - Juvenile accretion at 750-700Ma in Southern Brazil. Geology, V.24. No.5; p439-442.

Babinski, M.; Brito Neves, B.B.; Machado, N.; Noce, M.C.; Uhlein, A ;) Van Schmus, W.R. - 1994 Problemas da metodologia $\mathrm{U} / \mathrm{Pb}$ em zircões de vulcânicas continentais: caso do grupo Rio dos Remédios, Súper Grupo Espinhaço, no Estado da Bahia. $38^{\circ}$. Congr. Bras. Geol. Balneário de Camboriú. SC. P409,410

Babinski, M.; Chemale Jr. F.; Hartmann, L. A .; Van Schmus, W.R.; Silva, L.C. - 1995 - Acreção juvenil nos Blocos S. Gabriel e retrabalhamento crustal no Cinturão D. Feliciano durante o Ciclo Brasiliano: evidências isotópicas. $6^{\circ}$. Simp. S. Bras. de Geol. do Cone Sul. SBG pg. 105-107.

Barbosa, J.S.F. - 1990- The granulites of the Jequie Complex and Atlantic mobile belt, Southern Bahia, Brazil- An expression of Archaean Proterozoic Plate convergence. Granulites and Crustal Evolution. Clermont Ferrand (France), 1988-1990, 585 p. Springer - Verlarg.

Barrios, F.J. - 1983 - Caracterização geocronológica da região Amazônica da Venezuela. Dissertação de Mestrado. Inst. de Geociências - USP, p123.

Basei, M.A .S. - 1985 - O cinturão Dom Feliciano em Santa Catarina. Tese de Doutroado, IG-USP, 190pg.

Basei M. A . S. e Campos Neto, M. C. - 1992 - Late Proterozoic to Cambrian tectonic history of Eastern and Southern Brazil. In: 24th Congr. "Geology on the way to 2000". Abstracts, Bloemfontein, África do Sul, p.33-34.

Basei, M. A . S. - 1975 - Relatório interno - CPGeo IG. USP. Projeto RADAMBRASIL, folha SC/SB21 Tapajós 
Basei, M.A,S; Siga Júnior,O; Sato,K: Sproesser, W.M - (1995). A instalação da metodologia Urânio Chumbo na Univerisade de S. Paulo. Academia Brasileira de Ciências v67 (2), p221-237

Bastos Leal, L.R.; Teixeira, W.; Petrini, R.; Piccirillo, E.M. - 1994 - Geocronologia e inferencias isotópicas Sr e Nd nos diques máficos do Curaçá , Cr. do S. Francisco (Brasil): registro de um evento distensivo Neoproterozóico associado à evolução de Faixa Colisional Sergipana. Submetido em Geoch. Brasiliense (inédito)

Bastos Leal, L.R.; Teixeira, W. - 1994 - Investigação geocronlógica dos terrenos granitos gnaisses do Bloco do Gavião, C. S. Francisco - resultados parciais. 38". Congr. Bras. Geol. - Balneário de Camboriú, v1, p 74-75

Bastos Leal, L. R. - 1995 - Relatório para FAPESP. Dados inéditos.

Bastos Leal, L.R.; Teixeira, W.; Macambira, M.; Cordani, U.G.; Cunha, J.C. - 1996 - Evolução crustal dos terrenos TTGs arqueanos do Bloco do Gavião, C. S. Francisco. Geocronologia U-Pb (SHRIMP) e Pb-Pb em zircões: XXXIXCongr. Bras. Geol. SBG. Salvador - BA. V6, p539-54l.

Bastos Leal, L.R. - 1998 - Dados inéditos - Tese de doutoramento.

Basu, A.R.; Sharma, M. and DeCelles, P.G. - 1990 - Nd, Sr isotopic provenance and trace element geochemistry of Amazonian foreland basin fluvial sands, Bolivia and Peru: implications for ensialic Andean Orogeny. Earth and Planet. Sci. Lett., 100 p 1-17.

Batista, J.J., 1984 - Caracterização dos processos geológico-evolutivos precambrianos na região de São Fidélis, norte do Estado do rio de Janeiro, Tese. IG/USP, 123pg.

Bellieni G.; Petrini, R.; Piccirillo, E.M.; Brito, C.M.; Teixeira, W.; Chlarmont P.C.; Melfi, A J.; Min, A . De; Proterozoic dyke Swarms from S. Francisco craton (Brazil): Petrology, geochemistry and SrIsotopes. $3^{\circ}$. Congr. Bras. De Geoq. International Symposium on mafic dyques. P60-65.

Bellieni G; Piccirillo, E.M.; Petrini, R.; Girardi, V. A .; Menezes Leal, A . B.; Teixeira, W.; Bastos Leal, L.R.; De Min, A . - 1995 - Petrological and Sr-Nd evidence bearing on Early Proterozoic magmatic events of the sub continental mantle: S. Francisco craton (Uauá, NE - Brazil). Contr. Mineral. Petrol. $122: 252-261$.

Ben Othman, D.; Fourcade, S.e Allègre, C.J, 1984a - Recycling processes in granite-granodiorite complex genesis: the Querigut case studied by Nd-Sr isotope systematics. Earth and Planetary Science Letters, 69: $290-300$

Ben Othman, D.; Polvé, M. and Allègre, C.J.; 1984b - Nd-Sr isotopic composition of granulites and constraints on the evolution of the lower continental crust. Nature. v307, p510-515.

Besang, C. Eberle, W.G.; Lahner, L.; Lens, H.; Mollat, H.; Müller, P e Paulsen, S. - 1977 Radiometrische altersbestimmungen an gesteinem aus Minas Gerais und Espírito Santo / Brasilien. Geologisches Jahrbuch 24, 149-179.

Bizzi, L.A - 1993 - Mesozoic alkaline vulcanism and mantle evolution of the soutwestern. S.Francisco craton, Brazil, Tese de doutorado, Univ. de Cape Town, South Africa, 240p.

Brito Neva, B.B de - 1975 - Regionalização geotectônica do pré-cambriano nordestino. Tese de doutorado, IG-USP (SP), 198p.

Brito Neves, B.B. - 1978 - Estudo geocronógico da Faixa Costeira pré Cambriana do Nordeste. Relatório referente ao termo de concessão $22220884 / 75$. CNPq.

Brito Neves, B.B. et. al. - 1979 -Revista Bras. Geoc. 9(1): 71-85,

Brito Neves, B.B.; Cordani, U.G.; Torquato, J.R.F. - 1980 - Evolução geocronológica do pré-cambriano do Est. Da Bahia. Geol. e Recursos Minerais do Est. Da Bahia, Textos Básicos, SME / CPM, v3, $101 \mathrm{p}$.

Brito Neves, B.B.. - 1983 - O mapa geológico nordeste oriental do Brasil. Escala 1/1000.000. Tese de livre docência. IG-USP, SP, $177 \mathrm{pg}$

Brito Neves, B.B. e Cordani, U.G. - 1991 - Tectonic evolution of South America during the Late Proterozoic. Precambrian Research. 53 p23-40

Caby, R.; Bertrand, J.M.L. and Black, R. - 1981 - Pan-African clousure and continental collision in Hoggar-Iforas segment, central Sahara. In: Kröner (Edittor), Precambrian Plate Tectonics. Elsevier, Amsterdam, p407-434.

Campos Neto, M. - 1984 - Observações estruturais e estratigráficas no Cinturão D. Feliciano em Sta. Catarina. Relatório FAPESP, S. Paulo.

Campos Neto, M.C.; Figueiredo, M.C.H.; Janasi, V.A.; Basei, M.A.S.; Fryer, B.J. - 1988 - The São José do Rio Pardo Mangeritic-granitic suite, southeastern Brazil. Geochimica Brasiliensis, 2(2): 185-189. 
Campos Neto, M.C - 1991 - A porção ocidental da Faixa Alto Rio Grande - Ensaio de evolução tectônica. Tese de Doutorado. IG-USP, 210p.

Campos Neto, M.C e Figueiredo, M.C.H. - 1995 - The Rio Doce Orogeny, Southeastern Brazil. J. of South American Earth Sciences, vol 8, No.2, p. 143-162.

Carlson, R.W and Lugmair, G.W, (1981), Time and duration of lunar highlands crust formation. Earth Planetary Science Letters, 52: 227-238

Cameiro, M. A - - 1992 - O complexo metamórfico Bonfim Setentrional, (Quadril. Ferrifero, Minas Gerais): Litosestratigrafia e evolução geológica de um segmento de crosta continental do arqueano. Tese de doutoramento. IG-USP, SP. 234pg.

Carvalho, Heitor de; Tassinari, C.C.G - 1992 - Idades do magmatismo granítico da região de CaraculoBibala (SW de Angola) e suas aplicações na correlação geológica com o Cinturão Ribeira no Sudeste do Brasil. Rev. Bras. de Geoc., 22(1). 73-81.

Cavalcante, J.C.; Cunha, H.C.S; Chieregati, L.A.; Kaefer, L.Q.; Rocha,J.M.; Daitx, E.C.; Ramalho, R. 1979 - Projeto Sapucaí. Relatório final, MME/DNPM, Série Geologgia 4, Seç̧ão Geológica Básica 2, 299 p.

Cingolani, C.; Varela, R.; Dalla Salda, L.; Bossi, J.; Campal, N.; Ferrando, L.; Pineyro, D. e Schipilov, A. - 1997 - Rb-Sr geochronology from the Rio de La Plata craton of Uruguay. South American Symposium on Isotope Geology. Extended Abstracts. Campos de Jordão. São Paulo.

Comin-Chiaramonti, P.; Cundari, A.; Piccirillo, E.M.; Gomes, C.B; Castorina, F.; Censi,P.; Min, A. de; Marzoli, A.; Speziale, S.; Velasques, V.F. - 1997 - Potassic and sodic igneous rocks from eastern Paraguay: Their origin from lithospheric mantle and genetic relationships with the associted Parana flood tholeiites. Journal of Petrology (in press).

Condie, K. C. - 1990. Growth and accretion of continental crust: inferences based on Laurentia. Chem. Geol., 83: 183-194.

Condie, K. C. - 1997 - Episodic age distribuitions in the crust: Significance for earth history. South American Symposium on Isotope Geology, June 15-18, Campos de Jordão, SP. p. 1-2

Cordani, U.G. - 1968 - Esboço da geocronologia pré-cambriana da América do Sul. An. Acad. Bras. Ci., (RJ), 40(supl.): 47-51.

Cordani, U. G.,; Delhal, J.; Ledent, D. - 1973 - Orogêenese superposées dans le Pré-Cambrian du Brésil, sud oriental, Estats de Rio de Janeiro et de Minas Gerais. R. Bras. de Geociências. São Paulo, 3 (1):122.

Cordani, U.G. and Iyer, S.S., - 1978 - Geochronological investigation on the Precambrian Granulitic Terrain of Bahia - Brazil. Precambrian Res., 9: 255-274.

Cordani, U.G; Tassinari, C.C.G; Teixeira, W; Basei, M.A.S. and Kawashita K. - 1979 - Evolução tectônica de Amazônia com base nos dados geocronológicos. Actas do 2 congr. Geol. Chileno, Arica, Chile, 4: $137-148$.

Cordani, U.G.; Teixeira, W.; Siga Jr.; - 1980 - Geocronologia do Quadr. Ferrifero. SP.IG-USP. Projeto RADAMBRASIL. Trabalho apresentado na semana da geologia / SICEG, Ouro Preto.

Cordani, U.G. e Brito Neves, B.B de - 1982 - The geologic evolution of South America during the Archaean and Early Proterozoic. Rev. Bras. de Geoc., S. Paulo, V12 (1-3): 78-88.

Cordani, U. G.; Marinho, M.M.; Sato. K. ( 1884) - The geolog. evol. of anciente greesnt. terrane of Central - S. Bahia- Brazil. Proceeding of International Sy. on Precambriam Cr. Evol. - Geol. Socl. China, vol3.p213

Cordani, U.G.; Sato,K; Marinho, M.M. ( 1985) - The geologic evolution of ancient granite greenstone terrane of Central-Southern BA. Precambriam Research. V.27, p187-213.

Cordani, U.G.; Teixeira, W.; Tassinari, C.C.G.; Sato, K. (1988). The Grouth of the Brazilian shield. Epsodes - vol. 11 no.3, pl63-167.

Cordani, U.G.; Kawashita, K.; Teixeira, W.; Tassinari, C.C.G e Sato, K. - ( 1990) - Archean terranes in South America. Third International Archean Sy., Terth/ Austria. Extend abstract, p25.

Cordani, G.U; Iyer, S.S.; Taylor P.N; Kawashita K; Sato K; and McReath,I. (1992). Pb-Pb, Rb-Sr and KAr systematics of the Lagoa Real Uranium province (South-Central Bahia, Brazil) and The Espinhaço Cycle (Ca 1.5 - 1.0 Ga.). Joumal of South American Earth Sciences, Vol. $5 \mathrm{~N}^{\circ}$ 1, pp 3346.

Cordani, U.G.; Sato, K. e Nutman Allen (1995 ). Single zircon SHRIMP determinations from Archean tonalitic rocks near Uauá, Bahia, Brazil. Sessão Regular da Academia Brasileira de Ciências. Inst. Astronômico Geofísico da USP. Junho de 1995. 
Cordani, U. G; SATO, K. e Teixeira, W. - 1996 - The Early Geologic History of the South America Continent. Simpósio do Arqueano. Brasília.

Cordani, U.G.; Sato, K.; Coutinho, J.M.U.; Nutman, A . - 1997 - Geocronological interpretation in areas with complex geological evolution. The case of Piripá, Central-Southern Bahia, Brazil - Simpósio Sul Americano de Geologia Isotópica (SSAGI), Junho de 1997, Campos de Jordão, SP.

Cordani, U.G. e Sigolo, J.B. - 1997 - Composição e Estrutura Interna de Marte. In: Marte - Novas Descobertas. Organizadores - Oswaldo Massambani e Marta S. M. Mantovani. Inst. Astronômico e Geofísico - USP. Diagrama Texto. p121 - 138.

Corey, M.C e Chatterjee, A.K., (1990), Characteristics of REEs and other trace elements in response to sucessive and superimposed metassomatism within a portion of the south Mountain Batholith, Nova Scotia, Canada. Chem. Geol: 85: 265-285.

Correia, C. T.; Tassinari, C.C.G.; Lambert, D.D.; Kinny, P. e Girard. V.A.V. - 1997 - U-Pb (SHRIMP), $\mathrm{Sm}-\mathrm{Nd}$ and Re-Os systematics of the Cana Brava, Niquelândia and Barro alto layered intrusions in central Brazil, and constrains on the tectonic evolution. South - American Syposium on Isotope Geology. Extend abstracs, June 15-18, p88-90

Correia, C.T.; Girard, V.A.V.; Lambert, D.D.; Kinny, P.D. e Reeves S.J. - 1996 - 2Ga U-Pb (SHRIMP) and Re-Os ages for the Niquelândia basic-ultrabasic layered intrusion, Central Goiás, Brazil. XXXIX Congr. Bras. Geol., Salvador-Bahia, V-6, p187-189

Correia, J.A.; Correia Filho; Sicelwski, G.; Neto, C.; Cavallon, L.A.; Cerqueira, N.L.S.; Nogueira, V.L. 1979 - Geologia das regiões centro-oeste e oeste de Mato Grosso do Sul. Projeto Bodoquena, Série Geologia n. 6 - DNPM - Brasília.

Costa, J.L - 1977 - Projeto Gurupi. Relatório final de etapa Belém, DNPM-CPRM, V8.

Dall'Agnol, R; Bettencourt J.S.; Jorge João X.S.; Medeiros,H.; Costi,H.T.; Macambira, M.J.B - 1987 Granitogenesis in the Northern Brazilian Region, a review. Rev. Bras. de Geoc. 17 (4); 382-404.

Dall'Agnol, P. e Macambira, M.J.B - 1992 - Titanita, biot. granitos do baixo Rio Uapês, Província Rio Negro, Amazonas. Parte I: geologia, petrografia e geocronologia. Rev. Bras. Geoc. V.22, Nol, p3-14.

Dantas, E.L.; Van Schmus, W.R.; Hackcspacher, P.C.; Brito Neves, B.B. - 1996 - Crustal Nd isotopic evolution na differentiation during Archean na Paleoproterozoic of the Caldas Brandão Massif, Northeast Brazil. XXXIX Congr. Bras. Geol., V6, p.495-498

Dantas, E.L. - 1997 - Geocronologia U-Pb e Sm-Nd de terrenos arqueanos e paleoproterozóicos do maciço Caldas Brandão, NE do Brasil. Tese de doutoramento. Rio Claro - UNESP. 228pg.

Delhal, J.; Ledent, D. and Cordani, U.G. - 1969 - Ages U/Pb, Rb/Sr et K/Ar de formations métamorphiques et granitiques duSud-Est du Brésil (etats de Rio de Janeiro et de Minas Gerais). Ann. Géol. Belg., 92, p. $271-283$.

DePaolo, D.J - 1981 - A neodymium and strontium isotopic study of the Mesozoic calc-alkaline granitic batholiths of the Sierra Nevada and Peninsular Ranges, California. J. of Geoph. Res., v86, noB11, p 10470-10488.

DePaolo D.J. - 1988 - Neodymium isotope geochemistry. An introduction. Springer - Verlag.

DePaolo, D.J.; Linn, A.M. and Schubert, G., 1991 - The continental age distribution: methods of determing mantle separtation ages from Sm-Nd isotopic data and application to the southwestern United States. J. Geophys. Res., 96: 2071-2088.

Drago, V.A .; Pinto, A . C; Pinto, A . C.; Montalvão, R.M.G.; Santos, E.B.; Simões, M.A .; Oliveira, F.C.; Bezerra, P.E.L.; Prado, P.; Fernandes, C. ${ }^{a}$ C.; Tassinari, C.C.G. - 1981 - Geologia - In: Projeto RADAMBRASIL - Folha SD 22 Goiás.

Dias Neto, C.M.; Tassinari, C.C.G. e Egydio Silva, M. - 1995 - Idades Rb-Sr das rochas da região de Bananal- SP. Boletim do IG-USP, Série Cient.,26, p.59-68

Dussin, T.M. - 1994 - Associations volcano-plutoniques de L'Espinhaço meridional (SE - Brasil). Tese de doutaramento. Université d'Orleans, França. pg177.

Fairchild, T.R. et. al. - 1978 - Microfossil in the eopaleozoic Jacadigo group at Urucum, M. Grosso, Southern Brazil. Bol. Inst. de Geoc., S. Paulo, 9:74-79,

Faure, G, (1988) - Principles of Isotope Geology. (2 ${ }^{\text {nd }}$ ed.) New York, John Wiley \& Sons. 589.

Ferreira Filho, C. - 1996 - Fracionamento magmático do complexo máfico-ultramáfico de Niquelândia, GO. Implicações para a prosppecção de platinóides. XXXIX Congr. Bras. de Geol. - SBG - Salvador, BA, V6, p183-185.

Fetter, A . H.; Santos, T.J.S.; Nogueira Neto, J.A . e Van Schmus, R.W. - 1995 - Geocronologia U/Pb em zircão e $\mathrm{Sm} / \mathrm{Nd}$ em rocha total do Estado do Ceará.. Resultados iniciais . XVI Simp. Geol. do nordeste Recife. p418-421. 
Fetter, A.; Van Schmus, W.R.; Santos, T.S. dos; Arthaud, M. e Nogueira Neto, J. - 1997 - Geologic history and framework of Ceará State: NW Borborema Province, NE Brazil. South - American Symposium on Isotope Geology. Extend Abstracts, Campos do Jordão - p 112-114

Figueiredo, M.C.H. e Teixeira, W. - 1996 - The Mantiqueira Metamorphic Complex, Eastern Minas Gerais State: Preliminary geochronological and Geochemical Results. An. Acad. Bras. Ci. 68 (2), p. $223-246$

Fonseca, A.C. - 1986 - Geocronologia das rochas graníticas e suas encaixantes na cidade de Rio de Janeiro. Tese de mestrado. IG/USP, $28 \mathrm{lpg}$.

Fragoso César, A R.S. - 1991 - Tectônica de placa no Ciclo Brasiliano: As orogenias dos Cinturões D. Feliciano e Ribeira no R.G. Sul. Tese de doutoramento. IG-USP, SP. 367pg.

Fonseca, A. C. - 1994 - Esboço geocronológico da reigão do Cabo Frio, Estado de Rio de Janeiro. Tese de doutoramento, IG / USP: 186pg.

Fuck, R.A.; Brito Neves, B.B.; Cordani, U,G. e Kawashita, K. - 1989 - Geocronologia Rb-Sr no Complexo Barro Alto, Goiás: evidência de metamorfismo de alto grau e colisão continental há $1300 \mathrm{Ma}$ no Brasil Central. Geochim. Brasil., 3(2): 125-140

Fuck, R.A - 1993 - Resumo expand., 4". Congr. Bras. Geoq. P.246-249, Brasilia.

Fuck, R.A; Pimentel, M.M; Silva.L.J.H.D. - 1994 - Compartimentação tectônica da porção oriental da Provincia Tocantins. In: Congr. Bras. Geol., 38. Boletim de resumos expand. Balneário de Camboriú, SBG1:215-216.

Fugi, M.Y - 1989 - REE Geochemistry and Sm/Nd geocronology of the Cana Brava Complex. Brazil. Master Thesis. Kobe University. Department of Earth Science.

Fyfe, W.S., 1978. The evolution of earth's crust: modern plate tectonics to ancient hot spot tectonics? Chemical Geology, v. 23, No.2, p89-114.

Gasparini, P. e Mantovani, M.S.M. - 1979 - Geochemistry of charnockites from São Paulo Sate, Brazil. Earth and Planetary Science Letters, 42. 311-320.

Gibs, A.K. and Olsewski, W.J.Jr - 1982 - Zircon U-Pb ages of Guyana greenstone - gneiss terrane. Precambriam Res., 17:199-214

Gibbs, A.K. e Barron C.K. - 1983 - The Guyana Shield reviewed. Episodes, (2); 7-14.

Goldstein, S.L.; O'Nions, R.K.; Hamilton, P.J. - 1984 - A Sm - Nd study of atmosphera dusts and particulates from major river systems. Earth Planet. Sci. Lett. 70, 221 - 236.

Goldstein, S.L. and Arndt, N.T. - 1989 - The age components of a sediment. EOS - Transaction, American Geoph Union.V22A-11 1550H.

Gorayeb, P.S. S. e Lafon, J.M. - 1996 - Resultados geocronológicos Rb-Sr como indicadores do metamorfismo granulitico de Porto Nacional. XXXIX Congr. Bras. Geol., Salvador (BA), V6, p300302.

Gruau, G.; Martin, H.; Leueque, B and Capdevila, R. - 1985 Rb-Sr and Sm-Nd geochronology of Lower Proterozoic granite greenstone terrains in French Guiana. South America. Precambrian Res. V30 p6381.

Hallinan, S. E.; Mantovani, M.S.M; Shukowsky, W.; Braggion, Jr., I. - 1993 - Estrutura do Escudo SulBrasileiro: Uma revisão atravérs de dados gravimétricos e magnetométricos. Rev. Bras. Geosc.. 23 (2).

Hanson, G.N., (1978), The aplication of trace elements to the petrogenesis rocks granitic composition Earth Planetary Sciences Letters, 38: 26-43.

Hartmann, L.A ., Basei, M.A .S.; Sommer, M.W - 1995 - Geochemstry of the lower Proterozoic granulite facies grant potassic syenite, southern Brazil.

Hasui, Y.; Carneiro, C.D.R. e Coimbra, A . M. - 1975 - The Ribeira Folded Belt. Ver. Bras. Geoc.; 5 (4): p257-266

Hasui, Y.; Costa, J.B.S.; Abreu, F.A.M. - 1980 - Evolução crustal da região de Colméia, GO. - XXXI Congr. Bras. de Geol. Camboriú, SC.5: 2648-2658.

Hasui, Y. - 1980 - Datações Rb-Sr e K-Ar do centro-norte do Brasil e seu signifícado geológico. An. XXXI congr. Bras. de Geol., Camboriú, SC. 5:2659-2676.

Hasui, Y.; Tassinari, C.C.G.; Siga Jr, O . Teixeira, W.; Almeida, F.F. e Kawshita, K. - 1980 - Datações Rb-Sr e K-Ar do Centro Norte do Brasil e seu significado geológico-geoctectônico. XXXI. Congr. Bras. Geol. - Camboriú, SC. V5, p2659-76.

Hasui, Y.; Fonseca, M.J.G; Ramalho, R - 1984 - A parte central da região de dobramentos sudeste e o maciço mediano de Guaxupé. In: Geologia do Brasil - DNPM - Texto explicativo do mapa geologico do Brasil - DNPM . 
Hawkesworth, (1984), Radiogenic Isotopes - Some Geological Applications. Rare Earth Element Geochemistry.-Amsterdan - Elsevier .

Heibron,M.; Chrismpim, S.J.; Alves, R.P.; Simòes, L.S.A. - 1982 - Geologia do Cabo dos Búzios (Estado do R. de Janeiro). Anais da Academia Brasileira de Ciências 54, 553-562.

Heibron, M. - 1984 - Evolução metamórfico-estrutural da área entre Itutinga e Madre de Deus de Minas, MG. Dissertação de Mestrado, IG-UFRJ, Rio de Janeiro, $151 \mathrm{p}$.

Heibron, M; Gonçalves, M.L; Teixeira, T; Trouw, R.A.J; Padilha, A.V.; Kawashita, K.; - 1989Geocronologia da região entre Lavras, São Del Rei, Lima Duarte e Caxambu (MG). An Acad. Bras. Ciênc., 61 (2): 177-200

Hurley,P.M, -1967 - Test of continental drift by comparison of radiometric ages. Science, Washington, $157: 495-500$

Hurley, P. M. - 1968 - Absolute abundance and distribuition of Rb, K, and $\mathrm{Sr}$ in Earth Geoch. Cosm, Acta, V32, p273-283.

Hurley, P.M. and Rand, J.R., 1969. Pre-drift continental nuclei, vl64, No.3885, p1229-1242.

Inda, H.A V. e Barbosa, J.F. - 1978 - Mapa Geológico da Bahia. CPM/SME/CBPM, Salvador - Bahia.

Jacobsen, S.B. e Wasserburg, G.J,.(1984). Sm-Nd isotopic evolution of chondrite, Earth Planetary Sci. Lett. $66: 191-213$.

Janasi, V.A. - 1986 - Geologia e petrologia do maciço monzodiorítico-monzonítico de Piracaia - SP. Dissertação de mestrado, IG - USP, São Paulo, 281p.

Janasi, V.A. \& Vlach, S.R.F. - 1997 - Sr and Nd isotpe systematics of the Capituva and Pedra Branca syenitic massifs (SW Minas Gerais, Brazil): Petrogenesis and interferences on Neoproterozoic lithospheric mantle reservoirs. South - American Symposium on Isotope Geology, June 15-18, Campos de Jordão, SP. p:143-145.

Janasi, V. A.; Haddad, R.C. \& Vlach, S.R.F. - 1997 - Comments on the Sm-Nd isotope systematics of calc-alkaline gronitoids from Pinhal-Ipuiúna batholith (São Paulo and Minas Gerais, Brazil). South American Symposium on Isotope Geology, June 15-18, Campos de Jordão, SP. pl47-149.

Jardim de Sá, E.F. - 1994 - A Faixa Seridó (Provincia Borborema, NE do Brasil) e o seu significado geodinâmico na Cadeia Brasiliana / Pan Africana - Tese de Doutorado, No.3 - Univ. de Brasília. Inst. de Geoc.

Jost, H. e Hartmann, L.A - A Província Mantiqueira: Setor meridional. In: Almeida, F.F.M e Hasui, Y. (eds). Pré-Cambriano do Brasil. Ed. Edgard Blücher Ltda, p345-368

Kaul, P.F.T. - 1980 - O craton de Luis Alves. Congr. Bras. de Geol., 31, Anais ...5, p2677-2683, Camboriú.

Kawashita, K. - 1969 - Um sensivel espectrômetro de massa de fonte sólida e sua aplicação à análise de K, $\mathrm{Rb}$ e Sr. Tese de Mestrado. IG/USP.

Kawashita, K. et.al - 1976 - PROJETO RADAMBRASIL. Folha Jaguaribe/Natal

Kawashita, K.; Sato, K.; Sonoki, I. K. (1984) - Um sistema de aquisção de dados on line em um espectrômetro de massas do Centro de Pesquisas Geocronólogicas. Io, encontro Nacional de espectrometria de massas. RJ.

Kawashita, K.; Sato, K. e Sonoki, I.K. ( 1986) - Análises isotópicas com escectrômetro de massas TH-5 "on line" com micro Aoole e HP. 10. encontro Latino Americano de Espectrometria de Massas. Rio de Janeiro.

Kawashita, K.; Sonoki, I.K.; Sato, K.; Sonoki, H. M. (1990) - Regressões lineares em geocronologia : isócronas, errócronas e pseudo isócronas. Boletin IG-USP. Serie Cient. v21, p53-72.

Kawashita, K.; Sato K.; Diaz, M.e Tassinari, C.C.G., (1991), Metodologia Sm_Nd no IG-USP: Testes e resultados preliminares. $3^{\circ}$. Congresso Brasileiro de Geoquímica - S. Paulo - resumos - $2^{\circ}$ volume, $442-446$.

Kawashita, K.; Mariselma, Z.; Sato, K.; Petronilho, L. e Fernandez, V. V. - 1996 - Rochas carbonáticas da Faixa Paraguai: Idades e inferências com base em ${ }^{87} \mathrm{Sr} /{ }^{86} \mathrm{Sr}$. XXXIX Congr. Bras. Geol., Salvador (BA), V6, p531-533.

Kawashita, K. - 1996 - Rochas Carbonáticas Neoproterozóicas da América do Sul: idades e inferências quimioestratigráficas. Tese de Livre Docência. IG-USP, SP

Kozuch, M.; Van Schmus, W.R.; Brito Neves, B.B. - 1997 - Ages and isotope geochemistry of twobrasiliano magmatic events in the Borborema Province of NE Brazil. South-American Symposium on Isotope Geology. Extend Abstracts, Campos do Jordão. p 157-159.

Ledent, D. and Pasteels, P. - 1968 - Determinations de l'âge de roches post-tectoniques du sud-est du Brésil. Ann. Soc. Géol, Belg., 9l, p.305-309. 
Liew, T.C e MC Culloch, M.T - 1985 - Genesis of granitoid batholiths of Peninsular Malaysia and implications for models of crustal evolution: evidence from a $\mathrm{Nd}-\mathrm{Sr}$ isotopic and $\mathrm{U}-\mathrm{Pb}$ zircon study. Geoch. Cosmoch, Acta, v49, 587-600

Litherland, M e Bloomfield, K. - 1981 - The proterozoic history of Eastern Bolívia. Precambrian Research. 15: 157-179

Litwinski. N. - 1985 - Evolução tectono-termal da região Nordeste de Minas Gerais e Sul da Bahia. Tese de doutoramento. IG/USP. 233 pg.

Lugmair, G.W; Scheirim, N.B.; Marti,K., (1975a). Sm-Nd age of apollo 17 basalt 75075 :evidence for early differentiation of lunar exterior. Proc. Lunar Planet Sci. Conf, 6th, 14 19-1429.

Lugmair G. W.; Sheinim, N.B.; Marti, K., (1975b). Search for extinct ${ }^{146} \mathrm{Sm}$ : The isotopic abundance of $142 \mathrm{Nd}$ in the Juvinas meteorite. Earth Planetary Science Letters. 27: 79-84.

Macambira, M.J.B.; Lafon, J.M.; DallÁgnol, R.; Costi, H.T.; Jorge João, X.S. - 1990 - Geocronologia da Granitogênese da provincia amazônia Central Brasileira, Uma revisão. Rev. Bras. de Geoc. 20 (1-4) p. $258-266$

Macambira, M.J.B e Lafon J.M - 1995 - Geocronologia da Provínicia Mineral de Carajás: síntese dos dados e novos desafios. Bol. do Museu Paraense Emilio Goeldi. Ciências da Terra. V.7, P263-288.

Macedo, M.HF.; Jardim de Sá, E. F.; Sato, K.; Kawashita, K. ( 1990) - Dados isotópicos preliminares de Nd e Sr na região do Seridó (RN-PB) e suas tect.. 360. Congr. Bras. de Geol.. p305-306.

Machado Filho, L.; Ribeiro, M.W.; Gonzales, S.R.; Schemimi, C.A.; Santo Neto, A.; Palmeira, R.C.B.; Pires, J.L.; Teixeira, W. e Castro, H.E. - 1983 - Projeto RADAMBRASIL, Folha Rio de Janeiro/Vitória (SF-23/24), Levantamento de Recursos Naturais. V32, p29-304.

Machado,N; Noce, C.M.; Oliveira, O A A B.; Ladeira - 1989 - Evolução geológica do Quadrilátero Ferrífero no Arqueano e Proterozóico Inferior com base em geocronologia U-Pb, Simp. Geol. Minas Gerais, $1-5$.

Machado, N.; Lindenmayer, Z.; Krogh, T.E and Lindenmayer, D. - 1991 - U-Pb geochronology of Archean magmatism and basement reactivation in the Carajás area, Amazon Shield, Brazil - Precambrian Research, 49, 329-354.

Machado, N.; Noce, C,M; and Carneiro, M.A - 1992 - U-Pb constraints on a major Late Archean event in the Southern S. Francisco craton, Brazilian shield. Joint Annu meet., Nova Scotia, 17:A70 (abstracts).

Machado, N. e Carneiro, M.A - 1992 - A major Archean tectono thermal event in the S. Francisco shield, Brazil: U/Pb evidence from Quadrilátero Ferrifero, Minas Gerais. Can. J. Earth. Sci., 29 (11): 23412346

Machado, N.; Valladares., C.; Heibron, M.; Valeriano, C. - 1996 - U-Pb geochronology of central Ribeira belt (Brazil) and implications for the evolution of the Brazilian Orogeny. Precambrian Research, 79, 347-361

Machado, R. - 1997 - Litogeoquímica e tectônica dos granitóides Neoproterozóicos do Cinturão Paraíba do Sul no Estado do Rio de Janeiro. Tese de Livre Docência. IG/USP. 215pg.

Machiavelli, A. - 1991- Os granitóides deformados da região de Pien (PR): Um provável arco magático do Proterozóico Superior. Dissertação de Mestrado. Inst. de Geociências. USP, 89pg.

Machiavelli, A; Basei, M.A .S. e Siga Jr., O - 1991 - Geocquímica e geocronologia dos granitóides deformados da região de Pien (PR). Provável arco magmático do Proterozóico Superior. Congr. Bras. Geoq. 3, Atas, SP, 1, p249-253

Mantovani, M.S.M. - 1985 - Caracterização isotópica do mamatismo da bacia do Paraná. Sua correlação com a crosta continental subjacente e com a abertura do Atlântico Sul. Tese de Livre Docência IAG-USP.

Mantovani, M.S.M; Hawksworth, C.J.; Basei, M.A.S - 1987 - Nd e Pb isotope studies bearing on the crustal evolution of southeastem Brazil. Ver. Bras. Geoc., 17(3): 263-268.

Marini, O. J.; Dardene, M.A. e Danni,J.C.M. - 1984 - Provincia Tocantins: setores central e sudeste. In: Almeida, F.F.M, de e Hasui. Y. eds. O Pré-Cambriano do Brasil. São Paulo. Ed. Blücherm p.205264.

Marinho, M.M.; Lopes, G.A de c.; Soares, J.V.; Cruz, M.J.M. and Silva, E.F.A. da.,( 1980), Projeto Anage - Caldeirão. Relatório Final, CBPM, Salvador, V. 1. 
Marinho, M.M., (1991), La sequence Volcano Sedimentaire de Contendas-Mirante et la Bordure Occidentale du Bloc de Jequié (Craton du S. Francisco, Brésil): un example de transition archeenproterozoique. Unpublished Doct. Thesis. Univ. Clermont - Ferrand, France.

Marinho, M.M; Vidal, P.; Alibert, C.: Barbosa, J.S.F. and Sabate, P. - 1994 - Geochronology of the Jequié-Itabuna granulitic belt and of Contendas-Mirante Volcano-Sedimentairy belt. Boletim IGUSP. Publ. Especial No. 14, pg73-96.

Marinho, M.M.; Sabate, P. and Barbosa, J.S.F. - 1994 (b) - The Contendas-Mirante Volcano Sedimentairy belt. Boletim IG-USP. Publ. Especial No.17, p73-96

Marini, O . J.; Fuck, R. A ; Dardene, M.A . e Danni, J.C.M. - 1984 - Porvíncia Tocantins. In: O Précambriano do Brasil. Coordenadores: Fernando F.M. de Almeida e Yociteru Hasui. Editora Edgard Blücher Ltda, p 205-264.

Martin, H. - 1987 - Petrogenesis of archaean trondhjemites, tonalites, and granodiorites from eastern Finland: major and trace element Geochemistry. Jour. Petrol. 28:921-953.

Martin, H,; Sabaté, P.; Peucat, J.J; Cunha, J.C. - 1993 - Os processos de geração da crosta continental antiga: exemplo do Maciço Arqueano de Sete Voltas (BA). Anais do Simp. do Cr. S. Francisco. Salvador, p43-47.

Martin, H; Peucat, J.J; Sabaté, P. e Cunha, J.C. - 1996 - Crustal evolution in the Early Archaean of South America: example of the Sete Voltas massif, Bahia State, Brazil. Dados inéditos.

Mascarenhas, J. F.; Cordani, U.G.C. e Sato, K.; (1984 ) - Mapa Geocronológico do Estado da Bahia Resumo. XXXIII Congr. Bras. de Geol. Rio de Janeiro. pl30.

Mascarenhas, J.F. e Garcia, T.W., (1989), Mapa Geocronológico do Estado da Bahia, 1/1.000.000. Texto explicativo, S.G.M-SME, Salvador - Bahia.

McCulloch, M.T.; Wasserburg G.J. - 1978 - Sm-Nd and Rb-Sr chronology of continental crust formation. Science $200:$ p 1003-1011.

Michard, A.; Gurriet, P.; Soundant, M.and Albarede, F. (1985). Nd isotopes in French Phanerozoic shales: external vs. internal aspects of crustal evolution. Geochim. Cosmochim. Acta, 49: 601-610.

Millisenda, C.C.; Liew, T.C.; Hofmann, A.W. and Köhler, H. - 1994 - Nd isotopic mapping of the Sri Lanka basement: update and additional constraints from $\mathrm{Sr}$ isotopes. Precambrian Research, v.66, p95110.

Montalvão, R.M. G. e Tassinari, C.C.G - 1983 -Comentários preliminares sobre o geocronologia das rochas em torno do Greenstone Belt do Cupixi-Amapá. Relatório Interno (CPGeo, IG.-USP). Projeto RADAMBRASIL, F. CUPIXI.

Montalvão, R. M. G. de - 1985 - Evolução Geotectônica dos terrenos granitóide - greeestone belts de Crixás, Guarinos, Pilar de Goiás - Hidrolina (Goiás). Tese de doutorado. Inst. de Geoc. - USP. 372 p.

Montalvão. R.M.G.; Tassinari, C.C.G,; Teixeira, W.; Vasconi A.V. - 1988 - Caracterização geocronológica $\mathrm{Rb}-\mathrm{Sr}$ dos terrenos granodioríticos e trondjhemiticos da região de Rio Maria, Sul da Serra dos Carajás. Anais de XXXV Congr. Bras. de Geol., Belém, Pará. V.3, p1478-1487.

Moorbath, S. e Taylor, P.N, (1981) Isotopic evidence for continental growth in the precambrian plate tectonics. Amsterdã - Elsevier - 491-525

Moraes, N.M.P.; Iyer, S.S.; Sato, K. (1989) - Determination on Rare Earth Elements in geolog. sample, by isotope diluition mass spectrometry. 13o. International Geochemical Exploration Symp. $\mathrm{RJ} /$ Brazil.

Moura, C.A.V e Gaudett, H.E. - 1993 - Zircon ages of the basement orthogneisses of the Araguaia belt, north-central Brazil. Congr. Bras. de Geoq. 4, Brasilia, SBGq, p232-235.

Moura, C. A. V e Gaudette, H., E. - 1994 - Uma discussão sobre a origem dos ortognaisses do embasamento do Cinturão Araguaia com base nos isótopos de Sr e Nd. IV Simpósio de Geologia da Amazônia, SBG, Belém. pg 223-225.

Nakamura, N.; Tatsumoto M.; Nunes,P.D.; Unrush, D.M.; Schw, A.P.; Wildeman, T.R. , (1976). 4by old clast in Boulder 7, Apollo 17: a comprehensive chronological study by $\mathrm{U}-\mathrm{Pb}, \mathrm{Rb}-\mathrm{Sr}$ and $\mathrm{Sm}-\mathrm{Nd}$ methods. Proc. Lunar Planet Sci., Conf. 7th, 2: 2309-2333.

Nakamura, N.; Misawa,K.;(1989) Determination of picogram quantities of Rare-Earth Elements in Meteoritic Materials by Direct-Loading Thermal Ionization Mass Spectrometry. Analytical Chemistry,. 61, No.7, .755-762.

Naumann, M.P.; Hartman, L.A ;; Kappe, J.C. e Chemale Jr., F - 1984 - Sequências supracrustais, gnaisses graníticos e granitos intrusivos da região de Ibaré - Palma, RS. Geologia, aspectos estratigráfícos e considerações geotectônicos. Congr. Bras. Geoc., 33, v5, p2417-2425, Rio de Janeiro. 
Nelson, B. K. and DePaolo. D. J. - 1985 - Rapid production of continental crust 1.7 to 1.9 b.y. ago: Nd isotopic evidence from the basement of the North American mid-continent. Geol. Soc. Am. Bul., v.96, p 746-754.

Noce, C,M. - 1992 - Technical report for research activities on the Phd thesis project. FAPESP / Instituto de Geociências, USP, S. Paulo, Brasil, 30p

Noce, C.M. - 1995 - Geocronologia dos eventos magmáticos, sedimentares e metamórficos na região do Quadrilátero Ferrifero, MG. Tese de doutoramento, IG-USP.

Nunes, A . B. - 1973 - Geologia - Projeto RADAMBRASIL, Folha SB23. Teresina e parte da Folha SB24 - Jaguaribe.

Nutman, A.P. e Cordani, U.G., (1992), SHRIMP U-Pb Zircon Geochronology of Early Archaean gneisses, S. Francisco Craton, Brazil. International Geological Correlation Programme - project 280 - Salvador, Bahia.

Nutman, A .P. Cordani, U.G.; Sabaté, P, - 1994 - SHRIMP U-Pb ages of detrital zircons from the early Proterozoic Contendas-Mirante supracrustal belt, S. Francisco Craton, Bahia, Brazil. Journal of South American Earth Sciences, Vol. 7, No. 2, p 109-114

Olszewski W.J. and Gaudette, H.E. - 1989 Isotopic age results from the shield areas of Wester Brasil. EOS - Transaction, American Geoph Union.V4IA.

Oliveira, M.A.F.; Kawashita, K.; Kilhara, Y.; Delhal, J. - 1986 - Novos dados geocronológicos para rochas charnockiticas da Associação Guaxupé, Complexo Varginha. Rev. Bras. Geoc., 13(3): 301-305.

Padillha, A.V.; Vasconcelos, R.M. e Gomes, R.A.A.D. - 1991 - Evolução Geológica. In: texto explicativo Barbacena, folha SF23XC-III (Viana H.S., org). Programa de Levantamentos Geológicos Básicos do Brasil, escala 1:1000 000, Brasilia, DNPM, Cap. 6: 111-133.

Patchett, P.J - 1992 - Isotopic studies of Proterozoic crustal growth and evolution. In: Proterozoic Crustal Evolution. Editor - K.C. Condie; Elsevier. p. 481-508.

Peucat, J.J.; Vidal P.; Bernard-Griffiths; and Condie, K,C - $1988-\mathrm{Sr}, \mathrm{Nd}$ and $\mathrm{Pb}$ isotopic systematics in the Archaean low - to high grade transition zone of southern India: syn accretion vs. post acrcretion granulites. J. Geol., 97, 537-550.

Picanço, J. L. - 1994 - Aplicação das sistemáticas $\mathrm{Sm} / \mathrm{Nd}$ e $\mathrm{Rb} / \mathrm{Sr}$ no Maciço Itatins (SP). Dissertação de mestrado. IG - USP, 76pg.

Picazzio, Enos - 1997 - Marte no Universo . In: Marte - Novas Descobertas. Diagrama \& Texto / Inst. Astr. e Geofísico - USP. Organizadores: Massambini, O. e Mantovani, MS.M., p. 9-39.

Pimentel, M.M. e Charnley, N., (1991), Intracrustal REE fractionation and implication for Sm-Nd model age calcualtions in late stage granitic rocks.: An example from central Brazil. Chem. Geol. 186: .123138.

Pimentel, M.M. e Fuck, R.A. - 1992 - Neoproterozoic crustal accretion in central Brasil. Geology, V.20, p375-379.

Pimentel, M.M. - 1992 - Reajuste do sistema isotópico Sm-Nd durante o Neopproterozóico em gnaisses do Oeste de Goiás. Rev. Bras. de Geoc. V22(3); p262-268.

Pimentel, M.M; Heaman, L.; Fuck, R,A. - 1992 - Idade do meta-riolito da seqüência Maratá, Grupo Araxá, Goiás: Estudo geocronológico pelos métodos U-Pb em zircão, $\mathrm{Rb}-\mathrm{Sr}$ e Sm-Nd. An. Acad. Bras. Ci. 64 (l), pl9-28.

Pimentel, M.M.; Machado, N.; Lobato, L.; - 1994 - Geocronologia U-Pb de rochas graníticas e gnáissicas da região de Lagoa Real, Bahia, e implicações para a idade da mineralização de Urânio. Congr. Bras. Geoc. Comboriú, p389-39l

Pimentel, M.M. e Machado, N. - 1994 - Geocronologia em terrenos granito - greesntone de Rio MariaPará, $38^{\circ}$. Congr. Bras. Geol., - Balneário de Camboriú-SC, p390-391

Pimentel, M.M.; Fuck, R.A.; Del'Rey Silva, L.J.H - 1996 - Dados Rb-Sr e Sm-Nd da região de Jussara Goiás - Mossâmedes (G0), e o limite entre terrenos antigos de Goiás e o arco magmático de Goiás. Rev. Bras. Geoc. 26(2):61-70.

Pimentel, M.M, Fuck, R.A.; Botelho, N.F. - 1997 - Granites and tectonic evolution of the Neoproterozoic Brazilia belt, Central Brazil. International Symposium on Granites and Associated Mineralizations. Extend Abstracts. p228-230.

Pimentel, M.M. \& Junges, S. - 1997 - Nd isotopic characteristics of metasediments of the Neoproterozoic Mara Rosa Arc, Goiás, Central Brazil. South - American Symposium on Isotope Geology, June 15-18, Campos de Jordão, SP. p.237-239 
Pinese, J.P.P, Teixeira, W. Picciriloo, E.M.; Quemeneur, J.J.G; Bellieni, G. - 1995 - The Precambrian lavas mafics dykes, Southen S.Francisco Craton, Brazil; preliminary geochemical and geochronological results. Physics and chemistry of dykes, Baer e Heimann (eds) Baikema, Hotterdam.

Pires, F.R.M.; Barbosa, M.I.M. - 1993 - O limite Meridional do Craton S. Francisco e o posicionamento de granitos colisionais. Anais de II Simpos. do Cr. S. Francisco, Salvador, p33-38

Ragatky, D. e Tassinari, C.C.G. - 1994 - Caracterização geoquimica e geocronológica dos granitóides da Suite Imibiriçu, SE do Est. de S. Paulo. $38^{\circ}$. Congr. Bras. Geol.- Balneário de Camoboriú, p373375.

Ragatky, D.; Tupinambá,M. e Tassinari, C.C.G. - $1997-\mathrm{Sm} / \mathrm{Nd}$ and $\mathrm{Rb} / \mathrm{Sr}$ studies from a garnet bearing peraluminous granite (Nazaré Paulista) from the Ribeira belt, southeastern Brazil. South- American Symposium on Isotope Geology, Campos de Jordão, June 15-18. p247-249

Ragatky, D. - 1997 - Contribuição à geoquímica e geocronologia do Dominio São Roque e da Nappe de Empurrão Socorro Guaxupe ms região de Igaratá e Piracaia, SP. Tese de doutoramento - IG - USP $118 \mathrm{pg}$.

Reis Neto, J.M. - 1994 - Faixa laiacoca: registro de uma colisão entre dois blocos continetais no neoproterozóico. Tese de mestrado - S.Paulo p253, IG-USP.

Reis Neto, J.M - 1980 - Geocronologia dos granitos da região Centro Oeste. Seminários Gerais. Inst. de Geociências - USP. Separata No.106.

Reis Neto, J.M. - 1994 - Faixa Itaiacoca. Registro de uma colisão entre dois blocos continentais no Neoproterozóico. Tese de doutoramento, IG-USP, S. Paulo, 253 p.

Reymer, A. and Schubert, G., - 1984 - Phanerozoic addition rates to the continental crust and crustal growth. Tectonics, v.3, No.1, p63-77.

Rodrigues.M.F.B - 1976 - Rochas Basálticas do Rio Grande do Norte e Paraiba. Tese de mestrado. IGUSP, 62pg.

Rollinson, H.R. - 1993 - Using Geochemical Data: Evolution, Presentation, Interpretation. Longman Scientifc \& Technical. p215-343.

Rudnick, R.L. - 1995 - Making continental crust. Nature - vol. 378. p571-578.

Sabaté P.; Marinho M.M; Vidal, P. and Vachette, M.C. - 1990 - The 2.0Ga peraluminoso magmatism of Jacobina - Contendas-Mirante belts (Bahia, Brazil): Geologic and isotopic constraints on the sources. Chemical Geol., 83, 325-338.

Safronov, V.S. - 1972 - Acumulation of the Planets. In: On the origem of Solar System. (H.Reeves ed.), 89-1 13, Centre nationale de Recherches, Scientifiques, Paris.

Santos, F.J. dos; Nobrega Coutinho, M.G. da; Ataíde Costa, M.P. de; Ramalho, R. - 1984 - A região de dobramentos Nordeste e a Bacia de Parnaiba, incluindo $\mathrm{Cr}$. S. Luis e bacias marginais. Geologia do Brasil - DNPM - Eds.: Schobbenhaus et. al. 1984, p131-189

Santos, M.V, dos; Tassinari, C.C.G.; Souza Filho, E.E. de; Teixeira, W.; Ribeiro, A.C.O.; Payolla, B.L. e Vasconi, A.V. 1988 - Litoestragrafia das rochas Pré-Cambrianas na Bacia do Médio Xingú - Altamira - PA, Relatório Interno.

Santos, C.A . dos, e Aquino Angelim,L.A . de - 1990 -Programa de levamentos geológicos básicos do Brasil - DNPM - Riacho do Caboclo, Folha SC24V-A-V1.

Santos Pinto, M.; Peucat, I.J.; Martin, H.; Sabaté, P.; - 1984 - A geração dos granitos do Bloco do Gavião: Geocronologia e Química isotópica . $38^{\circ}$. Congr. Bras. Geol., Balneário de Camboriú - SC, p393394.

Sato, K. - 1986 - Síntese geocronológico do Est. da Bahia e evolução crustal, com base no diagrama de evolução do $\mathrm{Sr}$ e razões iniciais $87 \mathrm{Sr} / 86 \mathrm{Sr}$. Master Thesis.(unpublished). Inst. de Geoc. - USP, 214 pg.

Sato, K; Geyh, M.A.; Kawashita, K. (1993). Controle e aquisição de conjugada de dados de espectrômetro beta (-) para radio carbono e trítio do IG-USP. - I Workshop de informática do IG-USP. Boletim IGUSP. publicação especial $\mathrm{n}^{\circ}$. 16, p41-44.

Sato, K. - 1994 - Crustal evolution of the São Francisco craton, Brazil, from Sm-Nd model ages. International symposium on the physiscs and chemistry of the upper mantle, SP, Brazil, Ext. abstracts. p118-120.

Sato, K - 1994 - Evolução crustal do craton de S. Francisco, com base em idades modelo Sm-Nd. Sessão Regular da Academia Brasileira de Ciências. Inst. Astronômico e Geofísico da USP. SP.

Sato, K; Tassinari, C.C.G., Kawashita, K. e Petronilho - 1995 - O método geocronológico Sm -Nd no IGUSP e suas aplicações. An. Acad. Bras. Ci v67(3) p313-336. 
Sato, K . - 1996 - Idades dos principais eventos de diferencição manto-crosta do Craton Amazônico. com base en idade modelo Smm-Nd. V Simpósio de Geologia da Amazônia - Belém / Pa. SBG - Núcleo Norte, p388-390

Sato, K, Cordani, U.G. e Teixeira, W. (1996). Principais eventos de acreção manto-crosta continental do Craton de S. Francisco, com base en idade modelo Sm-Nd. XXXIX Congresso Brasileiro de Geologia, Salvador/Bahia. v6,p525-527.

Sato, K. e Campos Neto, M.C. - 1996 - Idade dos principais eventos de acreção manto-crosta continental no Sudeste Brasileiro, baseado em idade modelo Sm-Nd. XXXIX Congresso Brasileiro de Geologia, Salvador/Bahia. v6, p528-530.

Schobbenhaus Filho, C..; Ribeiro, C. L.; Oliva. A . e Takanohashi, J.T. - 1975 - Texto Explicativo. Folha Tocantins (SC-22). Carta ao Milionésimo, DNPM, Brasilia.

Schobbenhaus, C.; Almeida Campos, D. de; Derze, G. R.; Asmus H.E. - 1984 - Geologia do Brasil - Texto Explicativo do Mapa Geológico do Brazil e Área Oceânica Adjacente incluindo Depósitos Minerais. DNPM.

Schobbenhaus, C.; Hoppe, A ; Baumann, A e Lork, A -- 1994 - Idade U.Pb do vulcanismo Rio Remédios, Chapada Diamantina, Bahia. $38^{\circ}$. Congr. Bras. Geol. - Balneário de Camboriú, SC.

Sengör, A.M.; Natal, B. A. and Burtman, V.S. - 1993 - Evolution of the Altaid tectonic collage and Paleozoic crustal growth in Eurasia. Nature, v364, p299-307.

Siga Jr., O - Geologia da Folha SE24. PROJETO RADAMBRASIL, Rio Doce. Relatório Interno, CPGeo - IG - USP

Siga Jr., O. - 1986 - Reavaliação dos dados Geocronológicos de rochas da área Cupixi. Projeto Itapuru Território Federal de Amapá. Projeto RADAMBRASIL. Relatório inteno.

Siga Jr., O - 1986 - A evolução geológica da porção nordeste de Minas Gerais, com base em interpretações geocronológicas. Tese de Mestrado. 1G/USP. 140pg.

Siga Jr., O. - 1988 - Caracterização geocronológica em parte do setor centro oriental do Craton Amazônico. Projeto Carajás. Núcleo Marabá. Relatório Interno.

Siga Jr. O. - 1995 - Dominios tectônicos do Sudeste do Paraná e Noroeste de Santa Catarina: geocronologia e evolução crustral. Tese de doutorado. IG - USP. 216pg.

Silva , J.M.R.; Lima, M.I.C.; Veronese, V.F.; Ribeiro Jr.. R.N.; Rocha, R.M. e Siga Jr., O - 1987 - Folha SE-24 RioDoce. Levantamento de recursos naturais, geologia. IBGE. Rio de Janeiro 34, 1-172

Soares, A.C.; Noce, C.M.; Vidal,O.; Monteiro, R.L.B. and Leonardos, O.H. - 1992 - Toward a new tectonic model for the Late Proterozoic Araçuai (SE Brazil) - West Congolian (SW Africa) belt. Jour. of South Amer. E. Sci. V6, n1/2, p 33-47.

Soliani Jr, E. - Os dados geocronológicos do Escudo Sul Rio Grandense e suas aplicações de ordem geotectônica. Tese de doutorado, 239p, IG-USP, S. Paulo.

Söllner, F., Lammerer, B. and Weber-Diefenbach, K. - 1991 - Die Krustenentwicklung in der küsternregion nördlich von Rio de Janeiro/ Brasilien. Münchner Geologische Hefte 4, 1-100.

Souza Martins, V.T. - 1997 - Granitos Paleoproterozóicos da porção meridional do Cr. S. Francisco: estudos isotópicos de Sr e Nd. Relatório FAPESP, proc. No. 95/6721-1/ CPGeo IG-USP

Stähle, H.J.; Raith, M; Hoernes, S; Delfs, R., (1987), Element mobility during incipient granulite formation at Kabbaldurga, Southern India; Journ. Petrol., v. 28: 803-834

Tassinari, C.C.G., Teixeira, W. - 1976 - Geocronologia da parte oriental da Folha SC19 - Rio Branco. Projeto RADAMBRASIL - Relatório interno.

Tassinari, C.C.G. - 1980 - Comentários Preliminares sobre a geocronologia da Folha SD 21 - Cuiabá. Projeto RADAMBRASIL 1982 V.26.

Tassinari, C.C.G. - 1980b - Estudo Geocronológico da Folha SC.22, Tocantins, Goiânia, Go. (relatório interno para P.RADAMBRASIL, F. SC22 - TOCANTINS).

Tassinari, C,C,G; Montalvão, R.M - 1980 - Estudo geocronológico do greenstone belt - Crixás. Anais do XXXI Congr. Bras. de Geol.- Baneário de Camboriú, SC, V5, p2752-2759.

Tassinari, C.C.G. - 1981 - Evolução geotectônica da Porvíncia Rio Negro - Juruena na região Amazônica. Tese de mestrado. Inst. de Geociências - USP

Tassinari, C.C.G. - 1981 b - Cometários geocronológicos sobre as rochas da Folha SF21. Rio Apa. Projeto RADAMBRASIL. Reltório interno.

Tassinari, C.C.G.; Siga Jr. O; Teixeira, W. - 1981 - Panorama geocronológico do centro - oeste brasileiro: soluções, problemáticas e sugestões. Ata do I Simp. Geol. Centro-Oeste. Soc. Brs. de Geol. - Goiânia: 93-114 
Tassinari, C.C.G. - 1981- Complexo Goiano - CPGeo - IG-USP, relatório interno. Projeto RADAMBRASIL, Folha SD22, Goiás, V25, p42-46.

Tassinari, C.C.G. - 1982 - Comentários geocronológicos em rochas Pré-Cambrianas da Folha SC23 CPGeo - IG - USP, reltório intemo. Projeto RADAMBRASIL, Folha SC23-Rio S. Francisco.

Tassinari, C.C.G. - 1983 - Estudos geocronlógicos das rochas à Folha ao Milionésimo SE22, Goiânia. CPGeo IG-USP, relatório intemo. PROJETO RADAMBRASIL SE22, V31, GOIÂNIA.

Tassinari, C.C.G. - 1984 - A porção ocidental do Craton Amazônico: evidências isotópicas de acresção continental no Prot. Médio. Simp. Amaz., 2, Manaus, Anais, DNPM, MME, p439-446

Tassinari. C. C. G. - 1988 - As idades das rochas e dos eventos metamóficos da porção Sudeste do Estado de São Paulo e sua evolução crustal. Tese de doutoramento. IG/USP, 257pg.

Tassinari, C.C.G. e Silva, M.E. - 1990 - Evolução crustal da faixa de dobramentos Ribeira e maciço de Joinvile no Est. de S. Paulo. Relatório de Pesquisa. FAPESP, proc. No. 89/1204-8.

Tassinari C.C.G.; Cordani, U.G.; Nutman, A.P.; Van Schmuss, W.R.; Bettencourt, J.S.; Taylor, P.N. 1996 - Geochronological systematics on Basement Rocks from the Rio Negro - Juruena Province (Amazonian craton), and Tectonic Implications. International Geology Review, V. 38, n 2, p. 161-175

Tassinari, C., C., G. e Sato K. -1996 - Idade de formação de crosta continental na parte Sudeste do Estado de São Paulo, com base em dados Sm-Nd. XXXIX Congresso Brasileiro de Geologia, Salvador/Bahia. c6, p489-491

Tassinari, C.C.G. - 1997 - O Mapa Geocronológico do Cráton Amazônico no Brasil: Revisão dos dados isotópicos. Tese de Livre - Docência São Paulo.

Teixeira, W.; Tassinari, C.C.G. - 1977 - Estudos Geocronlógicos da Folha SA 20 Manaus. Relatório Interno, PROJETO RADAMBRASIL.

Teixeira, W.; Tassinari, C.C.G; Siga Jr., O - 1978 - Geologia - Folha Fortaleza - CPGeo - IG-USP, relatório interno. PROJETO RADAMBRASIL, Folha SA24, Fortaleza.

Teixeira, W. - 1981 - Geologia - Folha Jaguaribe / Natal. CPGeo - IG - USP, relatório interno. Projeto RADAMBRASIL Folha SB24/SB25, V23.

Teixeira, W. - 1982 - Geochronology of the southem part of the S. Francisco Craton. Ver. Bras. Geoc., SP, $12(1 / 3)$ p 268-277

Teixeira, W. - 1983 - Geologia da Folhas SF23/24 Rio de Janeiro/ Vitória. CPGeo - IG - USP, relatório interno. Projeto RADAMBRASIL, Folha SF23/24, V32, Rio de Janeiro/Vitória.

Teixeira, W. - 1985 - A evolução geotectônica da porção meridional do Cráton do S. Francisco, com base em interpretações geocronológicas. Tese de doutoramento - IG-USP, São Paulo, 207p.

Teixeira, W.; Jordt Evangelista, H.; Kawashita, K. e Taylor, P.N - 1987 - Complexo granulítico de Acaiaca, M.G: idade, petrogênese e implicações tectônicas. $4^{\circ}$ Simp. Geol. Minas Gerais, Anais, SBGNúcleo-MG, Belo Horizonte, pp.58-71.

Teixeira, W.; Cordani, U.G.; Kawashita, K.; Taylor, P.N.; Van Schmus, R.W. - 1987 - Archean and Early Proterozoic crustal evolution in the southern part of S. Francisco Craton. International Symp. On granites and associated mineralizations, Salvador, BA, Extend abstracts, SGM, p37-40.

Teixeira, W.; Tassinari, C.C,G., Cordani, U.G. and Kawashita K. - 1989 - A review of the geochronology of the Amazonian Craton: Tectonic implications. Precambrian Res., 42 p213-227.

Teixeira, W.; Akimoto, H.; Siga Jr., O.; Sato, K. - 1989 - A evolução geocronológica dos terrenos graníticos-gnaíssicos a Sul da F. Canastra - SO, MG. $5^{\circ}$ Simp. de Geol. Minas Gerais/ $1^{\circ}$ Simp. de Geol. - Brasilia (10) p243-246, SBG MG.

Teixeira, W.; Dossin, I.A.; Dossin, T.M.; Salvador , E.D.; Siga Jr., O.; Sato, K. - 1990 - Interpretação do contexto geotectônico do embasamento na borda leste do Sistema Espinhaço, região de Guanhães e Gouveia, (MG), com base numa interpretação do seu conjunto geocronológico $\mathrm{U} / \mathrm{Pb}, \mathrm{Rb} / \mathrm{Sr}$ e $\mathrm{K} / \mathrm{Ar}$. Congr. Bras. de Geoc., 36, Natal, Anais... Natal, SBG. v6, p2711-2722.

Teixeira, W.; Dossin, T.M.; Salvador, E.D.; Siga Jr., O.; Sato, K. - 1990 - Interpretação do contesto geotec. do embasamento da b. leste do sistema Espinhaço, região de Guanhães e Gouveia - MG com base numa interpretação do seu conjunto geocronológico U-Pb, $\mathrm{Rb}-\mathrm{Sr}$ e K-Ar. $36^{\circ}$ Congr. Bras. de Geol. - Natal/ RN. p309.

Teixeira, W.; Cordani, U. G.; Nutman, A.P. e SATO, K. - 1996 - Polyphase Crustal Evolution in the Late Archean: The case of the Campo Belo Metamorphic Complex, Minas Gerais, Brazil. Simpósio do Arqueano, Brasília. 
Teixeira, W.; Carneiro, M.A.; Noce, C.M.; Machado, N. and Sato, K. - $1996 \mathrm{~Pb}, \mathrm{Sr}$ and $\mathrm{Nd}$ isotope constraints on the Archean evolution of gneiss- granitoid complex in the Southern S.Francisco Craton, Brazil. Precambrian Res. v78, p I5I-I64

Teixeira, W; Cameiro, M.: Noce, C.M.; Machado, N.; Sato. K.: and Taylor, P.N -1996- Pb, Sr and Nd isotope constraints on the Archean evolution of gneissic granitoid complexes in the southern $\mathrm{S}$. Francisco Craton, Brazil - Precambrian Research.

Teixeira, W.; Cordani, U. G.; Nutman, A.P. e Sato, K. - 1996 - Polyphase Crustal Evolution in the Late Archean: The case of the Campo Belo Metamorphic Complex, Minas Gerais, Brazil. Simpósio do Arqueano, Brasília, p63-64.

Trouw, R. e Pankhurst, R. - 1993 - Idades radiometricas ao Sul do cráton de S. Francisco: região da follha Barbacena, Minas Gerais. Anais do Simpósio do Cr. S. Francisco - Salvador, p260-262.

Turpin, L.; Maruejo, P. e Cuney, M. - 1988 - U-Pb, Rb-Sr e Sm-Nd- chronology of basement, hydrotermal albitites and uranium minerazation, Lagoa Real, South Bahia, Brazil. Contribuitions to Mineralogy and Petrology 98(2), p 139-147

Valladres, C - 1996 - Evolução geológica do complexo Paraiba do Sul, no segmento central da Faixa Ribeira, com base em estudos de geoquímica e geocronologia U-Pb. Tese de doutoramento. IG/USP, $147 \mathrm{pg}$.

Valldares, C.; Heibron, M.; Machado, N. e Valeriano, C. - 1997 - Provenance of Central Ribeira Belt metasediments usinh ${ }^{207} \mathrm{~Pb} /{ }^{206} \mathrm{~Pb}$ ages on zircon by laser-ablation. South American Symposium on Isotope Geology. Extended Abstracts, June 15-18, Campos de Jordão. SP. p.323-325.

Van Schumus, W.R.; Brito Neves B.B; Hackspacher, P. and Babinski, M. - $1995-\mathrm{U} / \mathrm{Pb}$ and Sm/Nd geochronologic studies of the estern Borborema Province, Northeastern Brazil: Initial conclusions. Jour. South Amer. Earth Sci. V.8, p267-288.

Van Schmus, W, R.; Dantas E.; Fetter A ;; Brito Neves, B.B.; Hackspacher, P.C.; Babinski, M. - 1996 Neoproterozoic age for Seridó Group, NE Borborema Province, Brazil. XXXIX Congr. Bras. Geol., SBG, V6, p152-155.

Vasconcellos, A.C.B.C.; - 1988 - O Grupo Andrelândia na reigão a norte de Ouro Fino, MG. Dissertação de Mestrado, IG-USP, São Paulo, 199p.

Veizer, J. and Jansen, S.L., - 1979 - Basement and sedimentary recycling and continental evolution. Journal of Geology. v87, 341-370.

Veizer, J. - 1989 - Strontium isotopes in seawater through time. Ann. Rev.Earth Planet. Sci., 17, 141-167.

Vignol, L.M - 1987 - Etudes goechemiques des granulites du Bresil et de la zone d'Ivree: Les elements (K, $\mathrm{Rb}, \mathrm{Sr}, \mathrm{Sm}, \mathrm{Nd})$ et le isotopes radiogeniques $(\mathrm{Sr}, \mathrm{Nd})$. Diplome d'estudes approfondies de geochemie. Université Paris VII, Inst. de Physique du Globe de Paris.

Vlach, S.R.F. - 1985 - Geologia, petrografia e geocronologia das partes meridional e oriental do Complexo Morungaba, SP. Dissertação de Mestrado, IG-USP, São Paulo, 253p.

Vlach, S.R.F. - 1993 - Geologia e petrologia dos granitóides de Marungaba, SP. Tese de doutaramento. Inst. de Geociências-USP (SP).

Wasserburg, G.J.; Jacobsen, S.B.; DePaolo, D. J.; McCulloth, M.T.; Wen, T., (1981), Precise determination of $\mathrm{Sm}-\mathrm{Nd}$ ratios, $\mathrm{Sm}$ and $\mathrm{Nd}$ isotopic abundances in Standard solutions. - Geoch. Cosmoch. Acta. 45: 2311-2323.

Wernick, E.; Fiori, A.P.; Bettencourt, J.S.; choudhuri, A. - 1981 - A tectônica rígida do fím do Ciclo Brasiliano e sua implicação na estruturação da borda sul e sudeste do Cráton do S. Francisco: tentativa de um modelo preliminar. In: Simpósio do Cráton do S. Francisco e Suas Faixas Marginais, Salvador, Bahia, 1978, p 164-168.

White, W. M. and Hofmann A.W. - $1982-\mathrm{Sr}$ and Nd isotope geochemistry of oceanic basalts and mantle evolution. Nature, 296, 821-825

Wilson, $\mathrm{N}$., -1987 -, Combined $\mathrm{Sm}-\mathrm{Nd}, \mathrm{Pb} / \mathrm{Pb}$ and $\mathrm{Rb} / \mathrm{Sr}$ geochronology and isotope geochemistry in polymetamorphic Precambrian terrains, examples from Bahia, Brazil and Channel Island, U.K. Unpublished Master Thesis, Oxford. U.K.

Wilson, N; Moorbath, S.T.; Taylor, P.N and Barbosa, J.S.F. - 1988 - Archean and early Proterozoic crustal evolution in the S. Francisco craton, Bahia, Brazil, Chemical Geology., V70 (1-2), pl46

Zaine, M.F. e Fairchild, T.R. - 1987 - Novas considerações sobre os fósseis da Formação Tamengo, Grupo Corumbá, SW do Brasil. In: Congr. Bras. de Paleontologia, 10, RJ, 1985. Anais SBG p.797-807, RJ.

Zindler, A. and Hart, S. - 1986 - Chemical Geodynamics. Ann. Rev. Earth Planet. Sci., 14:493-571 


\section{APÊNDICES}




\section{APÊNDICE 1}

\section{NOTA EXPLICATIVA DAS TABELAS DE DADOS Sm e Nd, CHAMADAS NO CAP. 5:}

- Coluna 1: SPS/ lit - $N^{\circ}$ de laboratório (SPS) e litologias utilizadas nos trabalhos originais (ver apêndice 2). As litologias simplificadas e utilizadas neste trabalho encontram-se na coluna 4 (ver a legenda na tabela abaixo)

- Coluna 2: coord. $\mathbf{~}^{\prime \prime} \mathrm{m}^{\prime} / \mathrm{g}^{\prime \prime} \mathrm{m}^{\prime}$ Coordenadas geográficas aproximadas com erro até 5 minutos. $\mathrm{O}$ número desta coluna, por ex., $545 / 525$ significa $5^{\circ} 45^{\prime}$ (lat.) $/ 52^{\circ} 5^{\circ}$ (long)

- Coluna 3: N.campo/ região - No de campo / e região aproximada

- Coluna 4: litologias utilizadas neste trabalho (ver tabela baixo)

- Coluna 5: ident - Identicação das amostras chamadas nos textos e nor diagramas.

- Colunas 6, 7 e 8: $\mathbf{T}_{\text {(InIR }}, \mathbf{T}_{\mathrm{DM} 2}, \mathbf{T}_{\mathrm{DMI}}(\mathbf{G a})$ - idades modelo Sm-Nd . T Thur - representa idade modelo relativo ao manto condritico; $\mathrm{T}_{\mathrm{DM}}$ - representa idade modelo $\mathrm{Sm}-\mathrm{Nd}$ relativo ao manto empobrecido "depleted mantle" com evolução isotópica de $\mathrm{Nd}$ no tempo geológico em estágio único baseado na equação 6 e $7 \mathrm{~b}$ (pg. 20); e $\mathrm{T}_{\mathrm{DN} 2}$ - idade modelo Sm-Nd relativo ao manto empobrecido com evolução em dois estágios (equação 13, pg. 25). Obs. Os sobrescritos ${ }^{71} \mathrm{e}^{: 2}=$ representam razões ${ }^{147} \mathrm{Sm} /{ }^{144} \mathrm{Nd}$ respectivamente 0.10 e 0,11 (valores estimados) para o estágio primário (saída do manto até a refusão crustal, ver fig. 4.5).

- Colunas 9 e $10:{ }^{147} \mathrm{Sm} /{ }^{144} \mathrm{Nd}$ e ${ }^{1+43} \mathrm{Nd} /{ }^{1+4} \mathrm{Nd}$ : razão ${ }^{147} \mathrm{Sm} /{ }^{144} \mathrm{Nd}=0.6049[\mathrm{Sm}(\mathrm{ppm}) / \mathrm{Nd}(\mathrm{ppm})]$ e ${ }^{143} \mathrm{Nd} /{ }^{144} \mathrm{Nd}=$ razão isotópica de $\mathrm{Nd}$ com erro fornecido em $2 \sigma$. A razão ${ }^{143} \mathrm{Nd} /{ }^{144} \mathrm{Nd}$ foi normalizada com o valor ${ }^{146} \mathrm{Nd} /{ }^{144} \mathrm{Nd}=0.7219$.

- Colunas 11 e 12: Sm (ppm) e Nd (ppm) - Concentrações de Sm e Nd obtidos pela técnica de diluição isotópica.

- Coluna 13: f - representa o grau de fracionamento na razão ${ }^{147} \mathrm{Sm} /{ }^{144} \mathrm{Nd}$ da rocha crustal em relação ao manto CHUR $-f_{S m / N d}=\left[{ }^{147} \mathrm{Sm} /{ }^{144} \mathrm{Nd}-1\right] / 0.1967$.

- Colunas 14 e $15: \varepsilon_{\mathrm{Nd}}(\mathbf{t}=\mathbf{0})$ e $\varepsilon_{\mathrm{Nd}}(\mathbf{t})$ : corresponde a variação na razão ${ }^{143} \mathrm{Nd} /{ }^{144} \mathrm{Nd}$ da amostra em relação ao CHUR multiplicado por um fator 10000 onde $\varepsilon_{\mathrm{Nd}}(\mathrm{t}=0)$ corresponde o valor de $\varepsilon_{\mathrm{Nd}}$ medido hoje e $\varepsilon_{\mathrm{Nd}}\left(\mathrm{t}=\mathrm{t}_{\text {mètodo }}\right)$ é o valor calculado relativo ao tempo $t$ (formação da rocha) relacionado na coluna $\mathrm{t}_{\text {método }}$

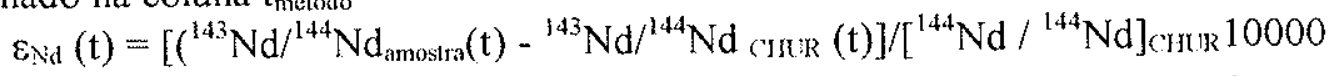

- Coluna 16: $\mathbf{t}_{\text {método }}$ e $\mathbf{R} \mathbf{I}_{(\text {fonte) }}-\mathrm{T}_{\text {mettolo }}$ corresponde as idades de formação das rochas por métodos $\mathrm{Rb} / \mathrm{Sr}$, U-Pb, $\mathrm{Pb}-\mathrm{Pb}$ e K-Ar. $\mathrm{RI}$ (fonte) é a razão inicial ${ }^{87} \mathrm{Sr} /{ }^{86} \mathrm{Sr}$ obtida em diagrama isocrônico $\mathrm{Rb}-\mathrm{Sr}$; (fonte) - referência bibliográfica.

- Coluna 16: $\varepsilon_{\mathrm{sr}}(\mathrm{t})-=\left[\left({ }^{87} \mathrm{Sr} /{ }^{86} \mathrm{Sr}\right)_{\mathrm{RI}} \mathrm{I}^{-a}\right.$ astra -1$\left.] /\left[{ }^{87} \mathrm{Sr}{ }^{86} \mathrm{Sr}\right)_{\mathrm{CHuR}}(\mathrm{t})\right] 10000$ onde $\mathrm{t}$ é a idade isocrônica $\mathrm{Rb}-\mathrm{Sr} \mathrm{e}_{\mathrm{RI}}=$ a razão inicial; ${ }^{87} \mathrm{Sr} /{ }^{86} \mathrm{Sr}_{\mathrm{CHUR}}(\mathrm{t})=0.7045-0.0816\left(\mathrm{e}^{\mathrm{it}}-1\right) \rightarrow$ (Faure 1988).

- Coluna 17: ref. - Referências bibliográficas para os dados Sm-Nd. Todas as idades modelos foram recalculadas neste trabalho segundo modelo de DePaolo 1981 (equações 6 e 7 b citadas no capítulo 3 deste trabalho)

- LITOLOGIAS SIMPLIFICADAS E UTILIZADAS NESTE TRABALHO

\begin{tabular}{|c|c|c|c|}
\hline siglas & litologias & siglas & litologias \\
\hline GTD & GRANITOIDE & MSE & METASSEDIMENTO \\
\hline GNL & GRANULITO & MSQ & METASSEDIMENTO QUÍMICO \\
\hline BAS & BÁSICA & $\mathbf{M x x}$ & MINERAIS onde $x x \rightarrow$ af $=$ anfibólio, \\
\hline UBA & ULTRABÁSICA & & $\mathrm{bi}=$ biotita, $\mathrm{pl}=$ plagioclásio, $\mathrm{pi}=$ \\
\hline VAC & VULCÂNICA ÁCIDA. & & $\begin{array}{l}\text { piroxênio, } \mathrm{gd}=\text { granada, } \mathrm{al}=\text { alanita, } \\
\text { es }=\text { esfeno, } \mathrm{mi}=\text { microclíneo. }\end{array}$ \\
\hline
\end{tabular}




\section{APENDICE 2}

\section{LEGENDA DAS LITOLOGIAS ENCONTRADAS EM TRABALHOS ORIGINAIS}

LEGENDA DAS LITOLGIAS (ROCHA TOTAL)

anf $=$ anfibolito
and =andesito
atx=anatcxito
a_gns=atgen gnaisse
ant /ano=anortosito
bas=basalto
bas.n=batsalto noritico
cal =calcarco
res.c= residu(carbon)
cal.si=calci-silic.
char=charnoquito
chgn=charno-gnaisse
chert=chert
dac=dacito
dia =diabásio
dio=diorito
end=cnderbito
fil=filito
gab=gabro
gnd = granodiorito

gns= gnaisse

gnl= granulito

gtd=granitóide

gtd ${ }_{-}=$gtd (xonolito)

grt=granito

gns_" =gnaisse lélsico

gns_momaisse-migm.

gns ge-gnaisse granit.

gns_t $\mathrm{t}=$ gnaisse tonal.

gni- = $=$ granulito lesisico

gnl m=gramulito mal.

$\mathrm{gtd} / \mathrm{p}=$ granitóide peral

hgrt=hipert.granito

kim $=$ kimberlito

kpe=komotito perid.

lep $=$ leptinito

mig = migmatito

mba $=$ metabásica

m.dia=metadiabásio

m.diometadiorito mdl $r=$ metadolerito

mgrt=metagranito

m_gab-metagabro

mig m=migm-mesos.

mig. $p=$ migm.paleos.

$m k o=$ metakomatiito

m_rio=metariolito

mse=metasedimento

mton=metatonalito

mt. $=$ metatexito

mvu / mvul=metavulc.

mon $=$ monzonito

oanf=ortoanfibolito

ogns=ortognaisse

pgns=paragnaisse

per=peridotito

peg=pegmatito

qmz $z$ =quart.monzon.

sho $=$ shoshonito

sie $=$ sienito
MINERAIS

\begin{tabular}{l|l} 
rio=riolito & bi $=$ biotila
\end{tabular}

$\mathrm{rdc}=$ riodacito $\quad \mathrm{pl}=$ plagioclásio

rmaf=rocha málica $\mathrm{gd}=$ granada

svul=subrulcanica $\quad$ pi $=$ piroxênio

sil=silito

tol=tolcito

ton $=$ tonalito

ton. gn=tonalitom gnass.

trj=trondjhemito

umaf =ultramáfica

vca=vulc.calc.alcal.

vul $=$ vulcânica

vul.fe-vulc.félsica

xis $=$ xisto anf $=$ anfibólio

all = allanita

gnd = granodiorito 


\section{COMPOSIC̄ÕES ISOTÓPICAS / ABUNDÂNCIAS / PESOS ATÔMICOS}

ABUNDÂNCIAS:

$S=R_{1}+R_{2}+R_{3}+\ldots+R_{n} \quad-->S=\sum R_{i}$ onde $R_{i}$ são razões isotópicas

$A_{i}=R_{i} / S$ onde $A_{i}$ são abundâncias relativas

PESO ATÔMICO:

$\mathrm{P}=\mathrm{A}_{1} \mathrm{M}_{1}+\mathrm{A}_{2} \mathrm{M}_{2}+\ldots \mathrm{A}_{\mathrm{n}} \mathrm{M}_{\mathrm{n}} \rightarrow \mathrm{P}=\sum \mathrm{A}_{\mathrm{i}} \mathrm{M}_{\mathrm{i}}$ onde $\mathrm{M}_{\mathrm{i}}$ são massas exatas

MASSAS E RAZÕES ISOTÓPICAS PARA O ELEMENTO Sm:

\begin{tabular}{|c|c|c|c|c|c|}
\hline \multirow{2}{*}{$\begin{array}{l}\text { MASSAS } \\
\text { (m) }\end{array}$} & \multirow[b]{2}{*}{$\begin{array}{l}\text { MASSAS } \\
\text { EXATAS }\end{array}$} & \multicolumn{2}{|c|}{ BCR - 1 / BULK EARTH } & \multicolumn{2}{|l|}{ SPIKE / CPGeo } \\
\hline & & $\begin{array}{l}\text { raz. isotópicas } \\
{ }^{\mathrm{m}} \mathrm{Sm} /{ }^{147} \mathrm{Sm} \\
\text { Wasserburg }\end{array}$ & abundâncias & $\begin{array}{l}\text { raz. isotópicas* } \\
{ }^{{ }^{\mathrm{m}}} \mathrm{Sm} /{ }^{147} \mathrm{Sm}\end{array}$ & $\begin{array}{l}\text { abundân- } \\
\text { cias. }\end{array}$ \\
\hline 144 & 143.91201 & 0.20504 & 0.030747 & 0.06518 & .000783 \\
\hline 147 & 146.91491 & 1.00000 & 0.149957 & 1.00000 & .012087 \\
\hline 148 & 147.91483 & 0.74970 & 0.112423 & 2.30164 & .031625 \\
\hline 149 & 148.91719 & 0.92160 & 0.138200 & 75.3635 & .910855 \\
\hline 150 & 149.91729 & 0.49213 & 0.073798 & 1.75148 & .021168 \\
\hline 152 & 151.91974 & 1.78308 & 0.267385 & 1.35639 & .016395 \\
\hline 154 & 153.92222 & 1.51704 & 0.227491 & 0.58615 & .007086 \\
\hline & & P. ATÔMICC & $=150.3656$ & P.ATÔN & $=148.963$ \\
\hline
\end{tabular}

* = média de 8 determinações.

MASSAS E RAZÕES ISOTÓPICAS PARA O ELEMENTO Sm:

\begin{tabular}{|c|c|c|c|c|c|}
\hline \multirow{3}{*}{$\begin{array}{l}\text { MASSAS } \\
\left({ }^{\mathrm{m}}\right)\end{array}$} & \multirow{3}{*}{$\begin{array}{l}\text { MASSAS } \\
\text { EXATAS }\end{array}$} & \multicolumn{2}{|c|}{ BCR - 1 / BULK EARTH } & \multicolumn{2}{|c|}{ SPIKE / CPGeo } \\
\hline & & raz. isot. ${ }^{*}$ & abundâncias & raz. isot. ${ }^{* *}$ & abundân- \\
\hline & & $\begin{array}{l}{ }^{\mathrm{m}} \mathrm{Nd} /{ }^{144} \mathrm{Nd} \\
\text { Wasserburg }\end{array}$ & & ${ }^{\mathrm{m}} \mathrm{Nd} /{ }^{144} \mathrm{Nd}$ & cias. \\
\hline 142 & 141.90773 & 1.141826 & 0.271685 & 0.82374 & .005524 \\
\hline 143 & 142.90982 & 0.512638 & 0.121977 & 0.44477 & .002982 \\
\hline 144 & 143.91010 & 1.000000 & 0.237939 & 1.00000 & .006706 \\
\hline 145 & 144.91258 & 0.348419 & 0.082902 & 0.42137 & .002826 \\
\hline 146 & 145.91313 & 0.721900 & 0.171767 & 0.91589 & .006141 \\
\hline 148 & 147.91690 & 0.241572 & 0.057481 & 0.61181 & .004103 \\
\hline 150 & 149.92090 & 0.236428 & 0.056251 & 144.902 & .971718 \\
\hline & & P. Atômic & 44.2397 & P. Atômi & 149.7684 \\
\hline
\end{tabular}

$*$ = Normalizadas com ${ }^{146} \mathrm{Nd} /{ }^{144} \mathrm{Nd}=0.7219 ; * *$ = média de 5 determinações.

Para padrão La-Jolla a razão ${ }^{143} \mathrm{Nd} /{ }^{144} \mathrm{Nd}=0,511858$ e P. atômico $=144.2399$ 


\section{AQUISIÇÃO DE DADOS NO MODO DINÂMICO / ESTÁTICO}

CONFIGURAÇÕES DOS COLETORES E DAS MASSAS

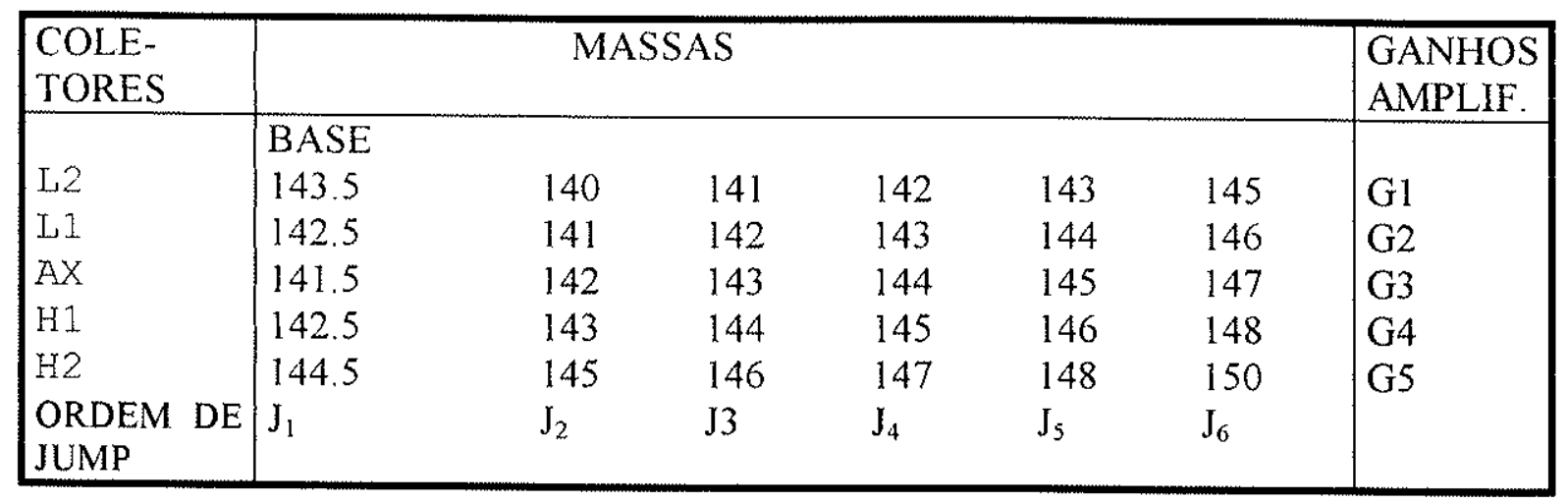

MEDIDAS NO MODO ESTÁTICO/DINÂMICO COMBINADO CONHECENDO-SE A RAZÃO DE NORMALIZAÇÃO ${ }^{146} \mathrm{Nd} /{ }^{144} \mathrm{Nd}=0,7219$ :

$$
\begin{gathered}
\frac{\left({ }^{144} \mathrm{Nd} /{ }^{145} \mathrm{Nd}\right)_{54} \mathrm{G} 3 / \mathrm{G} 4}{\left({ }^{145} \mathrm{Nd} /{ }^{146} \mathrm{Nd}\right)_{55} \mathrm{G} 3 / \mathrm{G} 4}=\frac{\left({ }^{144} \mathrm{Nd} /{ }^{145} \mathrm{Nd}\right)_{\mathrm{N}}}{\left({ }^{145} \mathrm{Nd} /{ }^{146} \mathrm{Nd}\right)_{\mathrm{N}}} \\
\frac{\left({ }^{144} \mathrm{Nd} /{ }^{145} \mathrm{Nd}\right)_{\mathrm{N}}}{\left({ }^{145} \mathrm{Nd} /{ }^{146} \mathrm{Nd}\right)_{\mathrm{N}}}=\frac{\left({ }^{144} \mathrm{Nd} / /^{146} \mathrm{Nd} /{ }^{145} \mathrm{Nd} /{ }_{146} \mathrm{Nd}\right)_{\mathrm{N}}}{\left({ }^{145} \mathrm{Nd} /{ }^{146} \mathrm{Nd}\right)_{\mathrm{N}}} \\
\frac{\left({ }^{345} \mathrm{Nd} /{ }^{146} \mathrm{Nd}\right)_{\mathrm{N}}=\sqrt{\left({ }^{145} \mathrm{Nd} /{ }^{146} \mathrm{Nd}\right)_{55}\left({ }^{144} \mathrm{Nd} /{ }^{146} \mathrm{Nd}\right)_{J_{54}} \mathrm{G}_{2} / \mathrm{G}_{4}}}{\left({ }^{144} \mathrm{Nd} /{ }^{145} \mathrm{Nd}\right)_{54}}=\frac{\left({ }^{143} \mathrm{Nd} / /^{145} \mathrm{Nd}\right)_{\mathrm{N}}}{=}
\end{gathered}
$$$$
\frac{\left({ }^{143} \mathrm{Nd} /{ }^{145} \mathrm{Nd}\right)_{\mathrm{N}}}{\left({ }^{144} \mathrm{Nd} /{ }^{146} \mathrm{Nd}\right)_{\mathrm{N}}}=\frac{\left({ }^{143} \mathrm{Nd} /{ }^{146} \mathrm{Nd} /{ }^{145} \mathrm{Nd} /{ }^{146} \mathrm{Nd}\right)_{\mathrm{N}}}{\left({ }^{144} \mathrm{Nd} /{ }^{146} \mathrm{Nd}\right)_{\mathrm{N}}}
$$

$\frac{{ }^{143} \mathrm{Nd}}{{ }^{146} \mathrm{Nd}}=\frac{\left({ }^{143} \mathrm{Nd} /{ }^{145} \mathrm{Nd}\right)_{34}\left({ }^{145} \mathrm{Nd} / /^{146} \mathrm{Nd}\right)_{\mathrm{N}} 0.7219}{\left({ }^{144} \mathrm{Nd} /{ }^{146} \mathrm{Nd}\right)_{\mathrm{J5}}}$ 
TÉCNICA DE DILUICÃO ISOTÓPICA

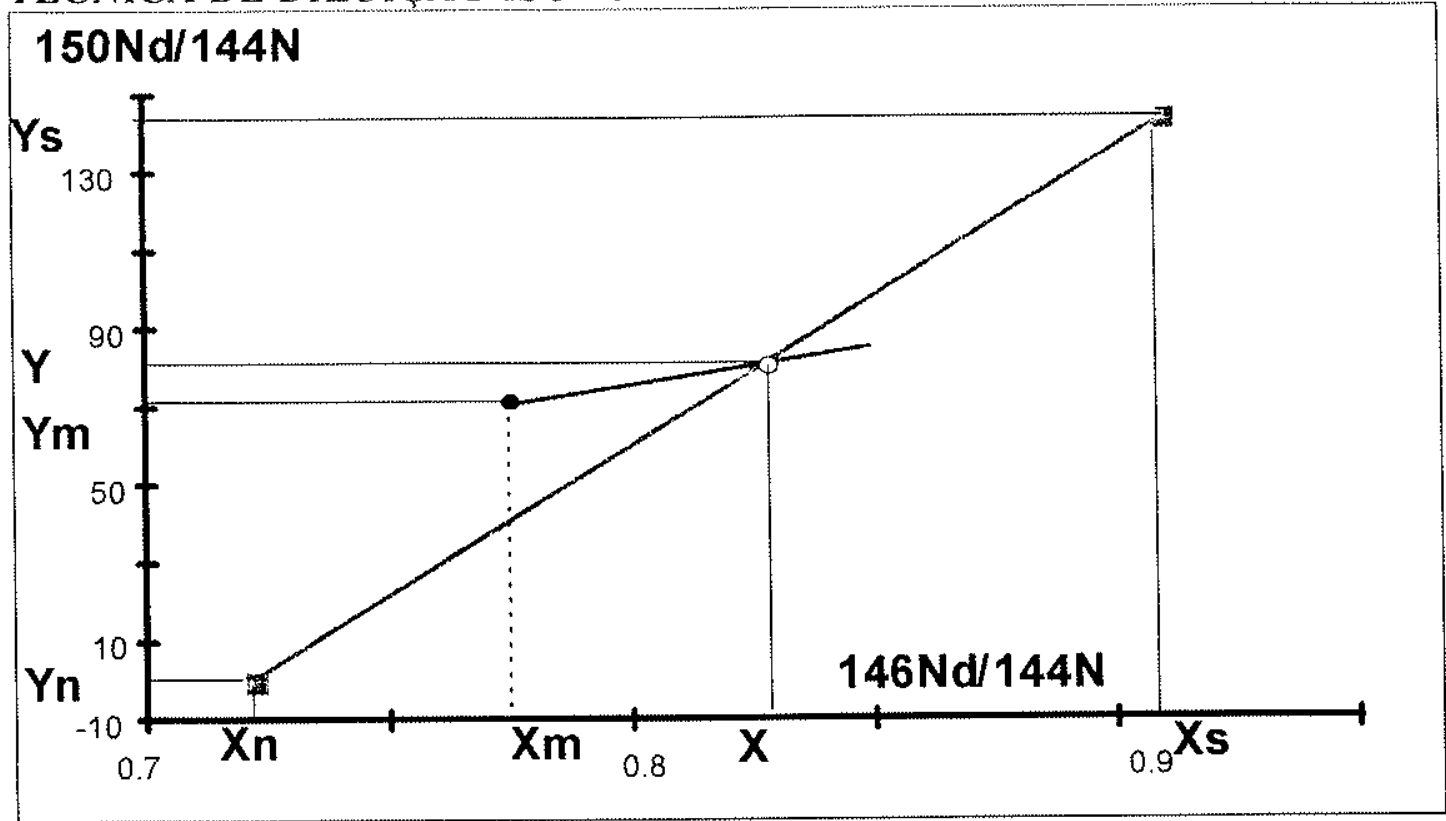

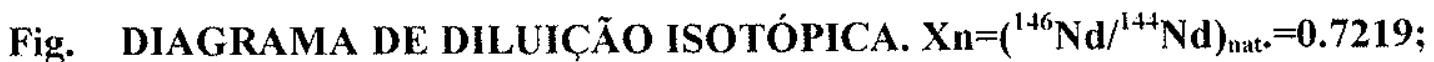

$\mathrm{Yn}=\left({ }^{150} \mathrm{Nd} /{ }^{144} \mathrm{Nd}\right)_{\text {tat. }}=0.236428 ; \mathrm{Xs}=\left({ }^{146} \mathrm{Nd} /{ }^{144} \mathrm{Nd}\right)_{\text {spike }}=.91 ; \mathrm{Ys}=$

$\left({ }^{150} \mathrm{Nd} /{ }^{144} \mathrm{Nd}\right)_{\text {spike }}=144.2 ; \mathrm{s}=$ spike; $\mathrm{n}=$ natural; $\mathrm{m}=$ medida (razão)

Discriminação de Massa:

$\mathrm{Y}=\mathrm{Ym}(1+6 \delta) ; \mathrm{X}=\mathrm{Xm}(1+2 \delta)$

$\delta=(1 / 2)\{(X / X m)-1)\}$

$(\mathrm{Y}-\mathrm{Ym}) /(\mathrm{X}-\mathrm{Xm})=3 \mathrm{Ym} / \mathrm{Xm}=\mathrm{C}$

$\mathrm{Y}=\mathrm{Ym}+\mathrm{C}(\mathrm{X}-\mathrm{Xm})$

$(Y-Y n) /(X-X n)=(Y s-Y n) /(X s-X n)=D$

$\mathrm{Y}=\mathrm{Yn}+\mathrm{D}(\mathrm{X}-\mathrm{Xn})$

$X=(Y m-Y n-C X m+D X n) /(D-C)$

$\left({ }^{143} \mathrm{Nd} /{ }^{144} \mathrm{Nd}\right)_{\mathrm{MN}}=\left({ }^{1+\hat{3}} \mathrm{Nd} /{ }^{144} \mathrm{Nd}\right)_{\mathrm{m}}(1-\delta)$

$\left({ }^{142} \mathrm{Nd} /{ }^{144} \mathrm{Nd}\right)_{\mathrm{MN}}=\left({ }^{1+2} \mathrm{Nd} /{ }^{144} \mathrm{Nd}\right)_{\mathrm{m}}(1-2 \delta)$

$\left({ }^{145} \mathrm{Nd} /{ }^{144} \mathrm{Nd}\right)_{\mathrm{MN}}=\left({ }^{145} \mathrm{Nd} /{ }^{144} \mathrm{Nd}\right)_{\mathrm{m}}(1+\delta)$

$\left({ }^{146} \mathrm{Nd} /{ }^{344} \mathrm{Nd}\right)_{\mathrm{MN}}=\left({ }^{146} \mathrm{Nd} /{ }^{144} \mathrm{Nd}\right)_{\mathrm{m}}(1+2 \delta)$

$\left({ }^{148} \mathrm{Nd} /{ }^{144} \mathrm{Nd}\right)_{\mathrm{MN}}=\left({ }^{148} \mathrm{Nd} /{ }^{144} \mathrm{Nd}\right)_{\mathrm{m}}(1+4 \delta)$

$\left({ }^{150} \mathrm{Nd} /{ }^{144} \mathrm{Nd}\right)_{\mathrm{MN}}=\left({ }^{150} \mathrm{Nd} /{ }^{144} \mathrm{Nd}\right)_{\mathrm{m}}(1+6 \delta)$

Onde o índece ${ }_{M N}$ representa a razão isotópica da Mistura de amostra + spike

Normalizada e $m$ = razão medida no espectômetro. 


$$
\begin{aligned}
& { }^{144} \mathrm{Nd}_{\mathrm{S}} /{ }^{144} \mathrm{Nd}_{\mathrm{N}}=(\mathrm{Y}-\mathrm{Yn}) /(\mathrm{Ys}-\mathrm{Y}) \\
& { }^{144} \mathrm{Nd}_{\mathrm{S}} /{ }^{144} \mathrm{Nd}_{\mathrm{N}}=\frac{\left({ }^{150} \mathrm{Nd} /{ }^{144} \mathrm{Nd} \mathrm{MN}-{ }^{150} \mathrm{Nd} /{ }^{144} \mathrm{Nd} \mathrm{n}_{n}\right)}{\left({ }^{150} \mathrm{Nd} /{ }^{144} \mathrm{Nd}\right)_{\mathrm{s}}-\left({ }^{150} \mathrm{Nd} /{ }^{144} \mathrm{Nd}\right)_{\mathrm{NN}}} \\
& { }^{150} \mathrm{Nd}_{\mathrm{S}} /{ }^{150} \mathrm{Nd}_{\mathrm{N}}=\frac{\left({ }^{144} \mathrm{Nd} /{ }^{150} \mathrm{Nd} \mathrm{MN}-{ }^{144} \mathrm{Nd} /{ }^{150} \mathrm{Nd} \mathrm{n}_{\mathrm{n}}\right)}{\left({ }^{144} \mathrm{Nd} /{ }^{150} \mathrm{Nd}\right)_{\mathrm{s}}-\left({ }^{144} \mathrm{Nd} /{ }^{150} \mathrm{Nd}\right)_{\mathrm{NN}}} \\
& \frac{{ }^{143} \mathrm{Nd}_{\mathrm{n}}}{{ }^{144} \mathrm{Nd}_{\mathrm{n}}}=\frac{{ }^{143} \mathrm{Nd}_{\mathrm{MN}}-{ }^{143} \mathrm{Nd} d_{\mathrm{s}}}{{ }^{144} \mathrm{Nd}_{\mathrm{MN}}{ }^{144} \mathrm{Nd}_{\mathrm{s}}}=\frac{\left({ }^{143} \mathrm{Nd} /{ }^{144} \mathrm{Nd}\right)_{\mathrm{MN}}-\left({ }^{143} \mathrm{Nd} /{ }^{144} \mathrm{Nd}\right) \mathrm{s}^{144} \mathrm{Nds}{ }^{144} \mathrm{Nd} \mathrm{MN}_{\mathrm{N}}}{1-{ }^{144} \mathrm{Nd}_{\mathrm{s}} /{ }^{144} \mathrm{Nd} \mathrm{MN}_{\mathrm{N}}} \\
& \frac{{ }^{143} N d_{n}}{{ }^{144} N d_{n}}=\frac{{ }^{143} N d_{M N}}{{ }^{144} N d_{M N}}+\frac{{ }^{144} N d_{s}}{{ }^{144} N d_{n}}\left(\frac{143}{{ }^{144} N d_{M N}}-\frac{{ }^{143} N d_{s}}{{ }^{144} N d_{s}}\right) \\
& \frac{N d_{n}}{{ }^{144} N d_{n}}=\frac{{ }^{145} N d_{M N}}{{ }^{144} N d_{M N}}+\frac{{ }^{144} N d_{s}}{{ }^{144} N d_{n}}\left(\frac{{ }^{145} N d_{M N}}{{ }^{144} N d_{M N}}-\frac{{ }^{145} N d_{s}}{{ }^{144} N d_{s}}\right) \\
& \frac{{ }^{142} N d_{n}}{{ }^{144} N d_{n}}=\frac{{ }^{142} N d_{M N}}{{ }^{144} N d_{M N}}+\frac{{ }^{144} N d_{s}}{{ }^{144} N d_{n}}\left(\frac{{ }^{142} N d_{M N}}{{ }^{144} N d_{M N}}-\frac{{ }^{142} N d_{s}}{{ }^{144} N d_{s}}\right) \\
& \frac{{ }^{148} N d_{n}}{{ }^{144} N d_{n}}=\frac{{ }^{148} N d_{M N}}{{ }^{144} N d_{M N}}+\frac{{ }^{144} N d_{s}}{{ }^{144} N d_{n}}\left(\frac{{ }^{148} N d_{M N}}{{ }^{144} N d_{M N}}-\frac{{ }^{148} N d_{s}}{{ }^{144} N d_{s}}\right)
\end{aligned}
$$

Obs.: as razões isotópicas do Nd natural e do spike - vide a tabela. 


\section{CORREÇÃO DE FRACIOMENTO ISOTÓPICO}

- LINEAR

- POTENCIA

- EXPONENCIAL

LINEAR:

$$
\begin{aligned}
& \mathrm{R}_{\mathrm{ij}}=\mathrm{R}_{\mathrm{m}, \mathrm{ij}}\left[1+\delta_{\mathrm{uv}} \Delta \mathrm{M}_{\mathrm{ij}}\right] \\
& \delta_{u v}=\left[\left(\mathrm{R}_{\mathrm{N}(\mathrm{uv})} / \mathrm{R}_{\mathrm{m}(\mathrm{uv})}\right)-1\right] / \Delta \mathrm{M}_{\mathrm{uv}} \\
& \text { onde } M=\text { massa; } \Delta M_{u v}=M_{u}-M_{v} \text {; } \\
& \text { indice }_{\mathrm{m}}=\text { medido } \mathrm{e}_{\mathrm{N}}=\text { normalizada } \\
& R_{m(u v)}=\left(M_{u} / M_{v}\right)_{M} ; R_{N(u v)}=\left(M_{u} / M_{v}\right)_{N} \\
& \text { exemplo: } \delta_{146.144}=\left\{\left[\left({ }^{146} \mathrm{Nd} /{ }^{144} \mathrm{Nd}\right)_{\mathrm{m}} / 0.7219\right]-1\right\} /(146-144) \\
& =\{[.7219 / .72401]-1\} /(2)=-0.0014572 \\
& \mathrm{R}_{143 / 144}=\mathrm{R}_{\mathrm{m} 143 / 144}\left[1+\delta_{146,144}(143-144)\right] \\
& =0.51110[1.0014572]=.511845
\end{aligned}
$$

POTÊNCIA:

$\mathrm{R}_{\mathrm{ij} .}=\mathrm{R}_{\mathrm{ij}}\left[1+\delta_{u v}\right]^{\Delta \mathrm{Mij}}$

$\delta_{\mathrm{uv}}=\left[\left(\mathrm{R}_{\mathrm{N}(\mathrm{uv})} / \mathrm{R}_{\mathrm{m}(\mathrm{uv})}\right)\right]^{\mathrm{P}}-1$ onde $\mathrm{P}=1 / \Delta \mathrm{M}_{\mathrm{uv}}$

exemplo: $\delta_{146.144}=\left[0.7219 /\left({ }^{146} \mathrm{Nd} /{ }^{144} \mathrm{Nd}\right)_{\mathrm{m}}\right]^{(1 / 2)}-1$

$$
\begin{aligned}
\delta_{146,144} & =[.7219 / .72401]^{(1 / 2)}-1=-0.0014582 \\
\mathrm{R}_{143 / 144} & =0.51110[1-.0014582]^{(143-144)}=0.511846
\end{aligned}
$$

EXPONENCIAL : VER WASSERBURG ET. AL 1981

GEOCH. C. ACTA V. 45, P2311 - 2311 
DIAGRAMA ESQUEMÁTICO DE UM ESPECTRÔMETRO DE MASSA

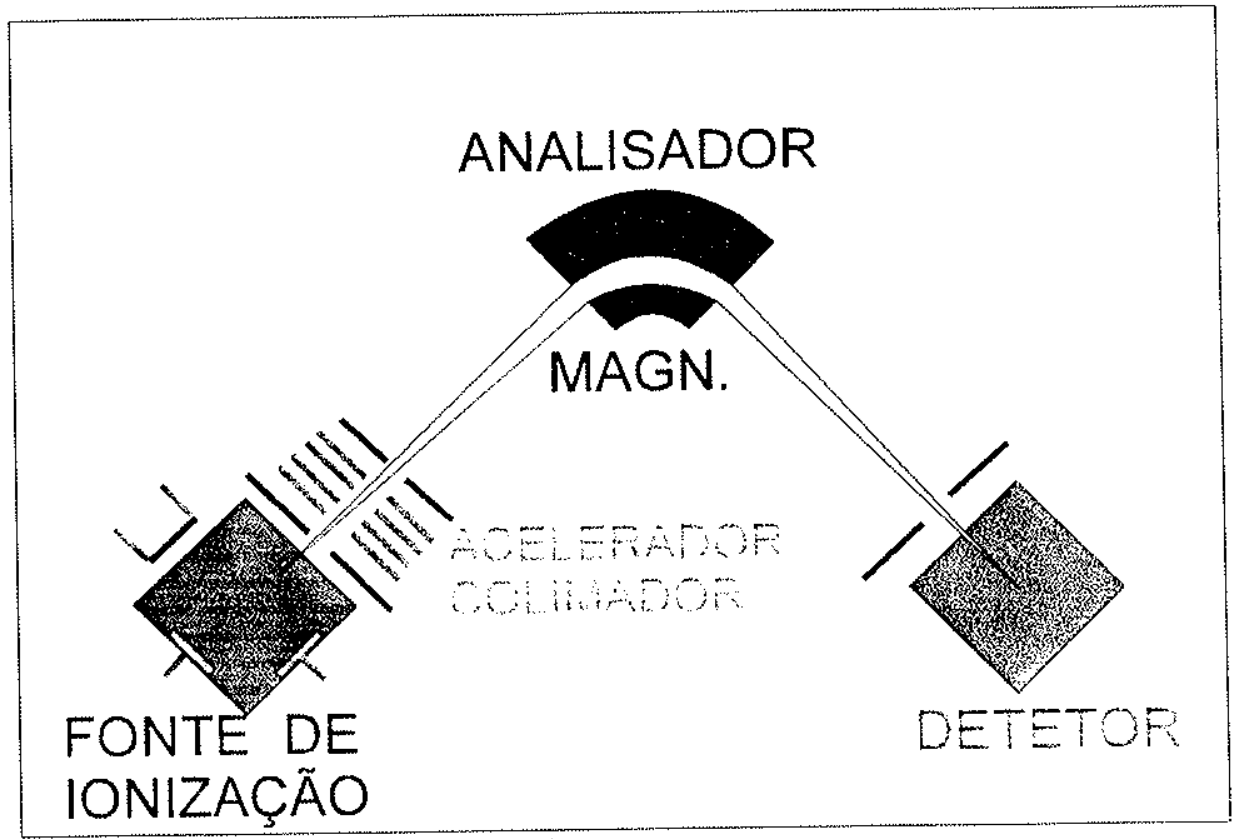

\section{TERMO-IONIZA'ÇÃO - FILAMENTO TRIPLO}

FEIXE DE IONS

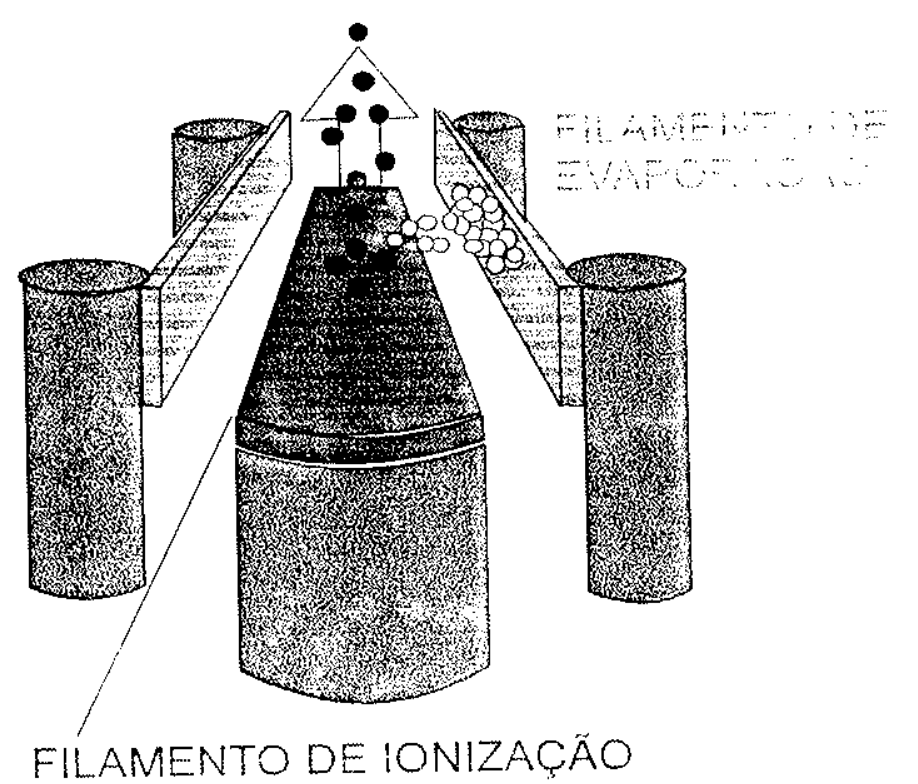


SISTEMA DE DETECÇÃO DE FEIXES DE ÍONS

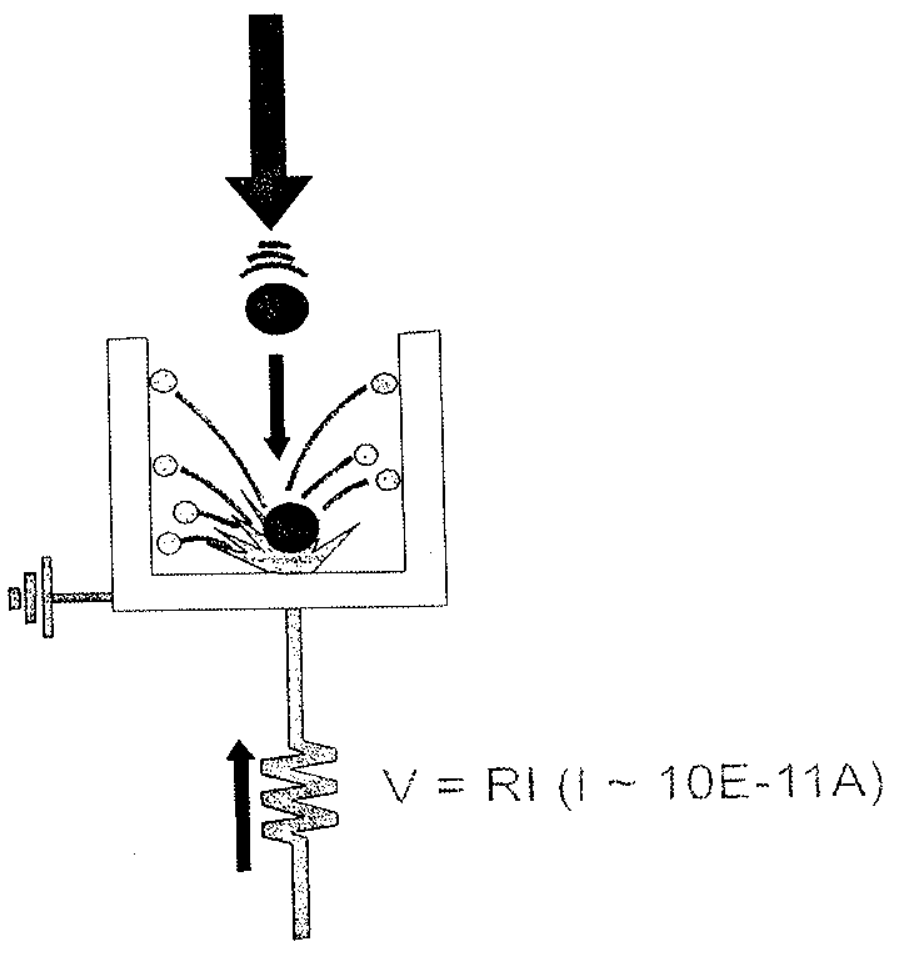

DETETOR DE COPO DE FARADAY

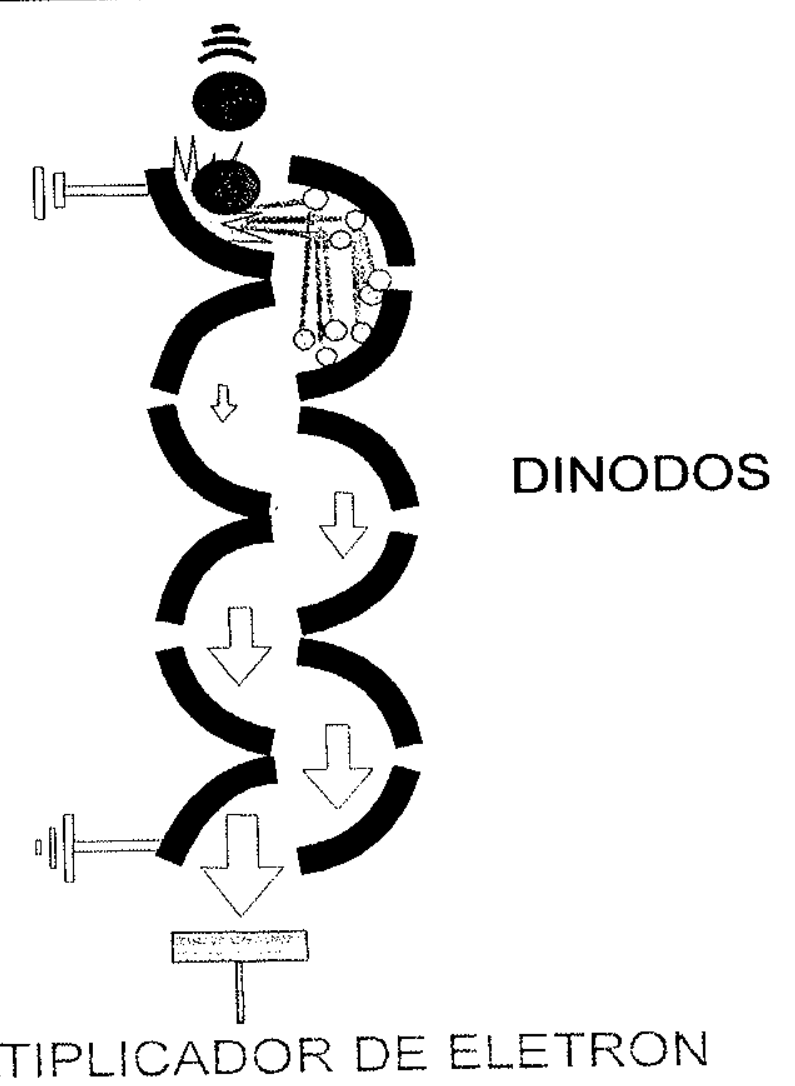

MULTIPLICADOR DE ELETRON 
doAcÁ SegÃo

Pís. Graduacino $17,06,98$ 